NUREG/CR-6042, Rev. 1

SAND93-0971

\title{
Perspectives on Reactor Safety
}

Manuscript Completed: September 1997

Date Published: November 1997

Prepared by

F. E. Haskin

A. L. Camp

S. A. Hodge

Chemical and Nuclear Engineering Department

209 Farris Engineering Center

University of New Mexico

Albuquerque, NM 87131

Sandia National Laboratories, Principal Contractor

Albuquerque, NM 87185-0747

Engineering Technology Division

Oak Ridge National Laboratory

Oak Ridge, TN 37831-8057

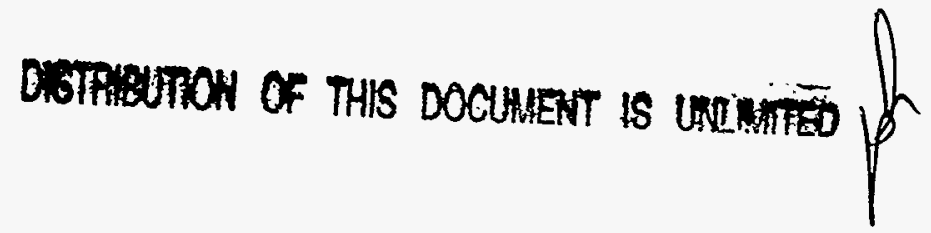

Prepared for

Technical Training Division

Office for Analysis and Evaluation of Operational Data

U.S. Nuclear Regulatory Commission

Washington, DC 20555-0001

NRC Job Code L1914

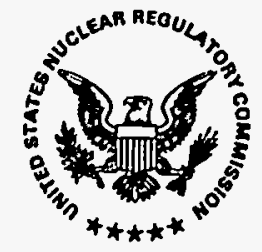




\begin{abstract}
The U.S. Nuclear Regulatory Commission (NRC) maintains a technical training center at Chattanooga, Tennessee to provide appropriate training to both new and experienced NRC employees. This document describes a one-week course in reactor safety concepts. The course consists of five modules: (1) the development of safety concepts; (2) severe accident perspectives; (3) accident progression in the reactor vessel; (4) containment characteristics and design bases; and (5) source terms and offsite consequences. The course text is accompanied by slides and videos during the actual presentation of the course.
\end{abstract}




\section{DISCLAIMER}

This report was prepared as an account of work sponsored by an agency of the United States Government. Neither the United States Government nor any agency thereof, nor any of their employees, makes any wartanty, express or implied, or assumes any legal liability or responsibility for the accuracy, completeness, or usefulness of any information, apparatus, product, or process disclosed, or represents that its use would not infringe privately owned rights. Reference herein to any specific commercial product, process, or service by trade name, trademark, manufacturer, or otherwise does not necessarily constitute or imply its endorsement, recommendation, or favoring by the United States Government or any agency thereof. The views and opinions of authors expressed herein do not necessarily state or reflect those of the United States Government or any agency thereof. 


\section{DISCLAIMER}

Portions of this document may be illegible electronic image products. Images are produced from the best available original document. 


\section{Table of Contents}

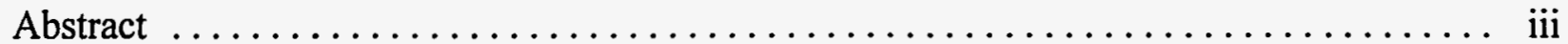

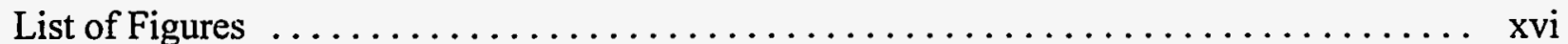

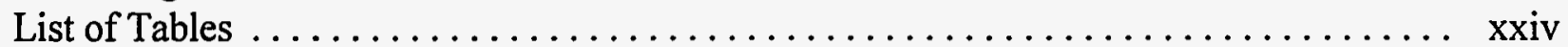

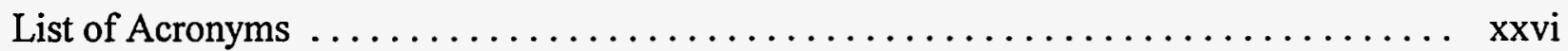

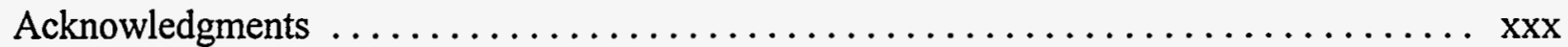

English to Metric Conversion Factors $\ldots \ldots \ldots \ldots \ldots \ldots \ldots \ldots \ldots \ldots \ldots \ldots \ldots \ldots \ldots \ldots \ldots$

1.0 The Development of Safety Concepts, $1946-1975 \ldots \ldots \ldots \ldots \ldots \ldots \ldots \ldots$. $1.0-1$

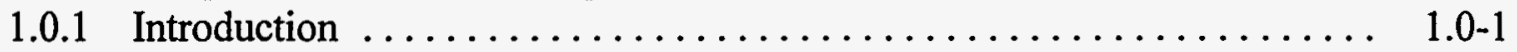

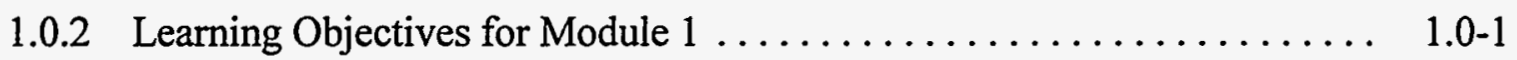

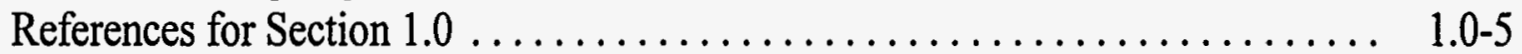

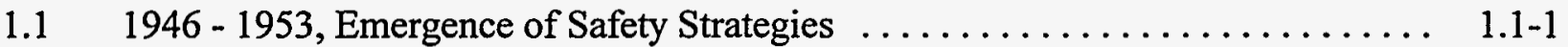

1.1.1 The Atomic Energy Act of $1946 \ldots \ldots \ldots \ldots \ldots \ldots \ldots \ldots \ldots \ldots \ldots \ldots \ldots . .1 .1$

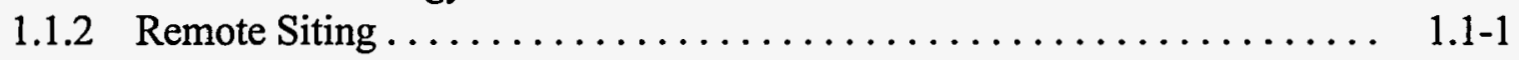

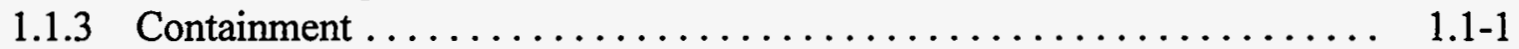

1.1.4 Accident-prevention and Safety Systems $\ldots \ldots \ldots \ldots \ldots \ldots \ldots \ldots, 1.1-2$

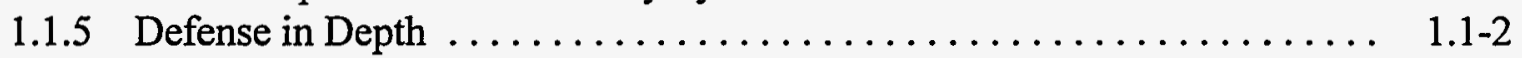

References for Section $1.1 \ldots \ldots \ldots \ldots \ldots \ldots \ldots \ldots \ldots \ldots \ldots \ldots \ldots \ldots \ldots \ldots \ldots, 1.1-6$

1.21954 - 1965 Early Commercial Reactors, Emphasis on Containment .......... 1.2-1

1.2.1 Atomic Energy Act of $1954 \ldots \ldots \ldots \ldots \ldots \ldots \ldots \ldots \ldots \ldots \ldots \ldots .2-1$

1.2.2 Early Siting Precedents $\ldots \ldots \ldots \ldots \ldots \ldots \ldots \ldots \ldots \ldots \ldots \ldots \ldots \ldots \ldots \ldots \ldots \ldots . .2-2$

1.2.3 Power Reactor Development Company Construction Permit Application . 1.2-3

1.2.4 The Price-Anderson Act and WASH-740 . . . . . . . . . . . . . . . . $1.2-4$

1.2.5 The First Intervention ................................ 1.2-5

1.2.6 Reactor Site Criteria, 10 CFR $100 \ldots \ldots \ldots \ldots \ldots \ldots \ldots \ldots \ldots \ldots \ldots \ldots \ldots \ldots . .2-6$

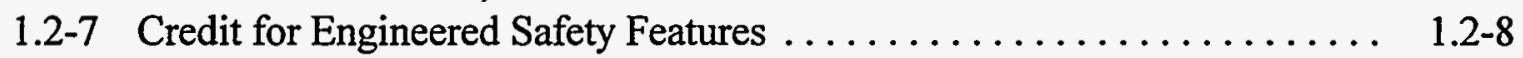

References for Section $1.2 \ldots \ldots \ldots \ldots \ldots \ldots \ldots \ldots \ldots \ldots \ldots \ldots \ldots \ldots \ldots \ldots \ldots \ldots . .2-10$

1.31966 - 1974 Emphasis on Prevention, Public Debate $\ldots \ldots \ldots \ldots \ldots \ldots \ldots \ldots$. $1.3-1$

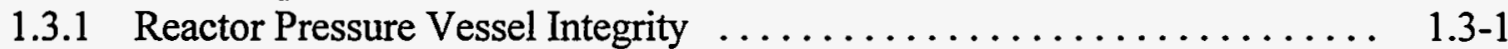

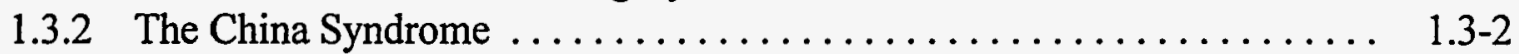

1.3.3 The AEC Core Cooling Task Force (CCTF) ................. 1.3-4

1.3.4 General Design Criteria ............................ 1.3-4

1.3.4.1 Criterion 1-Quality Standards and Records $\ldots \ldots \ldots \ldots \ldots$ 1.3-7

1.3.4.2 Criterion 2-Design Bases for Protection Against Natural

Phenomena ................................ 1.3.8

1.3.4.3 Criterion 3-Fire Protection .................... 1.3-8

1.3.4.4 Criterion 4-Environmental and Dynamic Effects Design Bases .. 1.3-9

1.3.4.5 Criterion 5-Sharing of Structures, Systems, and Components ... 1.3-10

1.3.5 The National Environmental Policy Act (NEPA) $\ldots \ldots \ldots \ldots \ldots \ldots \ldots . . .1 .3-11$

1.3.6 Emergency Core Cooling System Rulemaking $\ldots \ldots \ldots \ldots \ldots \ldots \ldots \ldots \ldots . .1 .3-12$

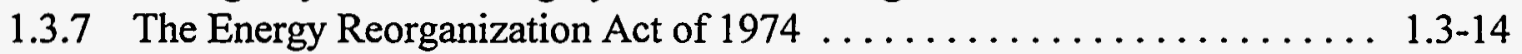




\section{Table of Contents (Cont.)}

References for Section $1.3 \ldots \ldots \ldots \ldots \ldots \ldots \ldots \ldots \ldots \ldots \ldots \ldots \ldots \ldots \ldots \ldots .3-17$

$1.4 \quad$ Design Basis Perspectives $\ldots \ldots \ldots \ldots \ldots \ldots \ldots \ldots \ldots \ldots \ldots \ldots \ldots \ldots \ldots . .4 .1$

1.4.1 Safety Analysis Report Requirements $\ldots \ldots \ldots \ldots \ldots \ldots \ldots \ldots \ldots . .4 .4$

1.4.2 Design-Basis LOCAs . . . . . . . . . . . . . . . . . . . . . . . . . . .

1.4-3 Design-Basis Analysis Conservatisms . . . . . . . . . . . . .

1.4.4 Comparison with Realistic Analyses . . . . . . . . . . . . . . . . . . . .

1.4.5 Seismic Design Basis . . . . . . . . . . . . . . . . . . . . . . . . . . . . . . . 1.4-5

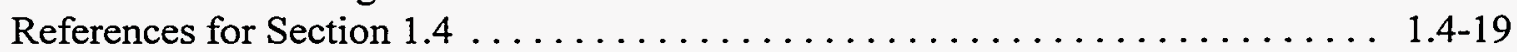

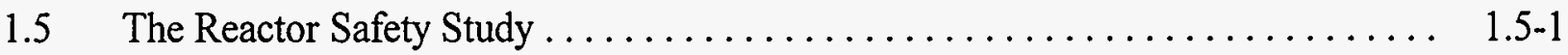

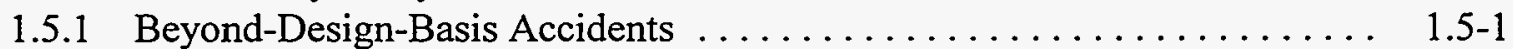

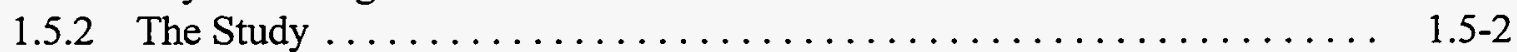

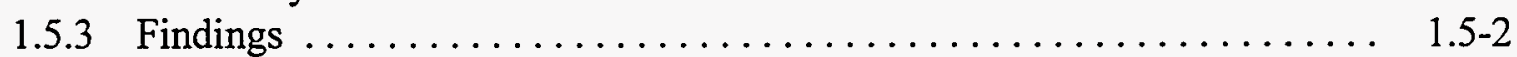

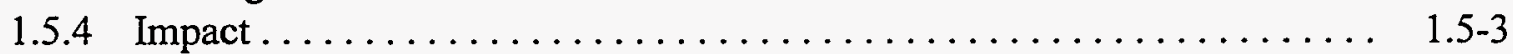

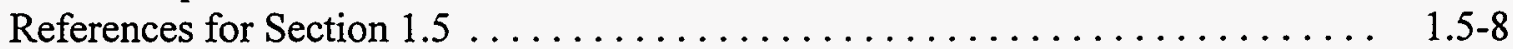

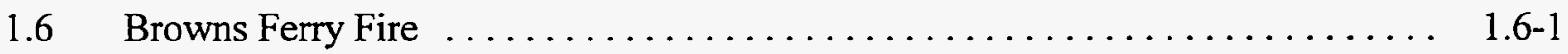

1.6 .1 Initiating Events $\ldots \ldots \ldots \ldots \ldots \ldots \ldots \ldots \ldots \ldots \ldots \ldots \ldots \ldots \ldots \ldots \ldots \ldots \ldots, 1.6-1$

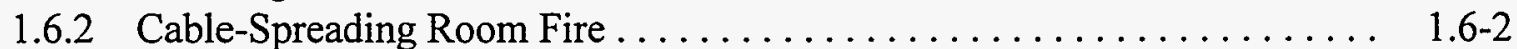

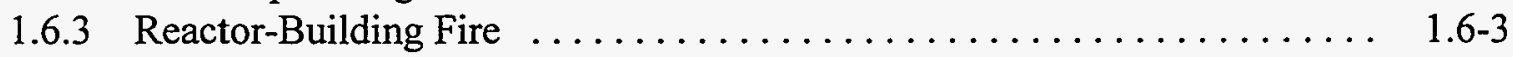

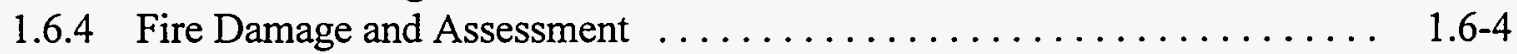

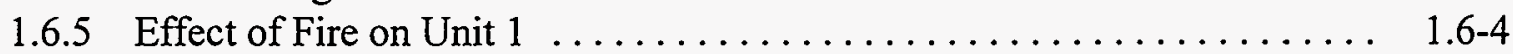

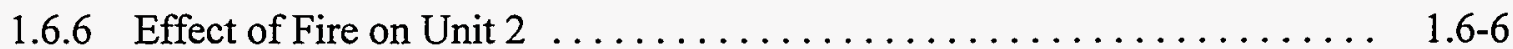

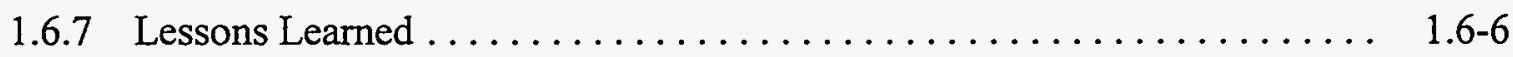

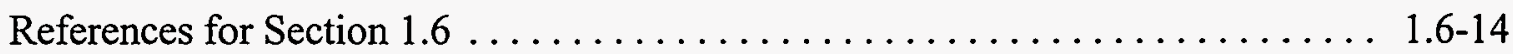

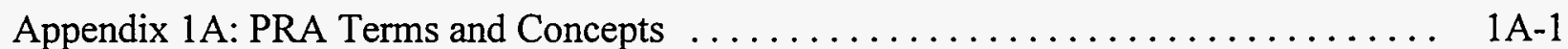

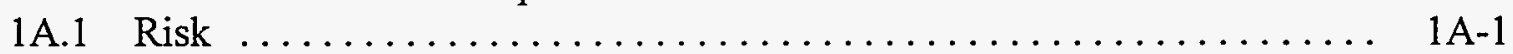

1A.2 The PRA Process $\ldots \ldots \ldots \ldots \ldots \ldots \ldots \ldots \ldots \ldots \ldots \ldots \ldots \ldots \ldots \ldots \ldots \ldots \ldots \ldots \ldots, 1 \mathrm{~A}-2$

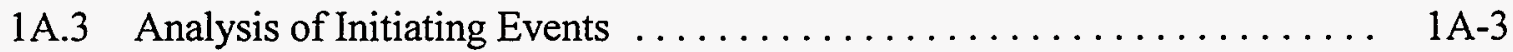

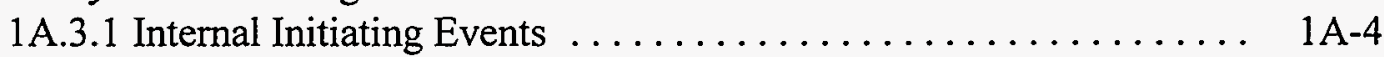

1A.3.2 External Initiating Events . . . . . . . . .

1A.3.2.1 Plant Internal Fires $\ldots \ldots \ldots \ldots \ldots \ldots \ldots \ldots \ldots, 1 \mathrm{~A}-5$

1A.3.2.2 Seismic Events ...................... 1A-5

1A.3.2.3 Weather-Related Events $\ldots \ldots \ldots \ldots \ldots \ldots \ldots \ldots$ 1A-6

1A.3.2.4 Other Naturally Occurring Events $\ldots \ldots \ldots \ldots \ldots \ldots$ 1A-7

1A.3.2.5 Human-Caused External Initiators $\ldots \ldots \ldots \ldots \ldots \ldots$ 1A-7

1A.3.3 Accidents at Low Power and Shutdown $\ldots \ldots \ldots \ldots \ldots \ldots$ 1A-7

1A.3.4 Sabotage Not Treated in PRA $\ldots \ldots \ldots \ldots \ldots \ldots \ldots \ldots \ldots \ldots \ldots \ldots \ldots$

1A-4 Accident Sequence Development $\ldots \ldots \ldots \ldots \ldots \ldots \ldots \ldots \ldots \ldots \ldots \ldots \ldots$

1A.4.1 Multiple Versus Single Failures . . . . . . . . . . . . . . . .

1A.4.2 Use of Event Trees and Fault Trees . . . . . . . . . . . . 1A-10

1A.4.3 Failure Terminology ........................ 1A-11 


\section{Table of Contents (Cont.)}

1A.4.3.1 Independent Versus Dependent Failures .......... 1A-11

1A.4.3.2 Explicitly Dependent Events ................ 1A-12

1A.4.3.3 Common Cause Failures ................. 1A-12

1A.4.3.4 Subtle Failures ..................... 1A-14

1A.4.4 Human Factors, Heroic Acts, Errors of Commission ........ 1A-15

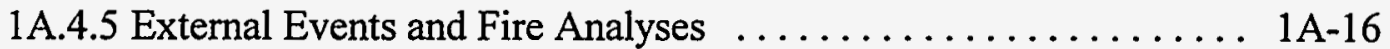

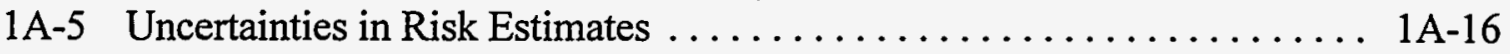

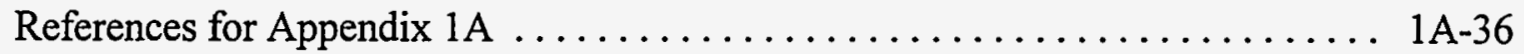

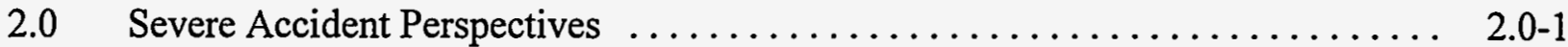

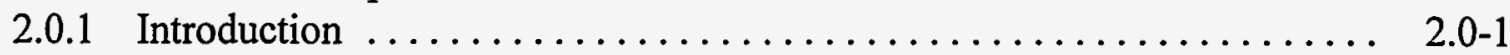

2.0.2 Learning Objectives for Module $2 \ldots \ldots \ldots \ldots \ldots \ldots \ldots \ldots \ldots \ldots \ldots \ldots \ldots \ldots \ldots$

2.1 The TMI-2 Accident $\ldots \ldots \ldots \ldots \ldots \ldots \ldots \ldots \ldots \ldots \ldots \ldots \ldots \ldots \ldots \ldots \ldots \ldots \ldots \ldots \ldots, 1-1$

2.1.1 Introduction $\ldots \ldots \ldots \ldots \ldots \ldots \ldots \ldots \ldots \ldots \ldots \ldots \ldots \ldots \ldots \ldots \ldots, 2.1-1$

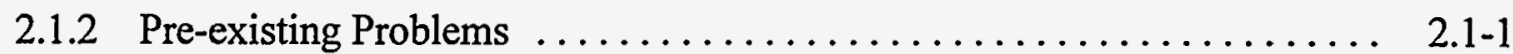

2.1.3 Loss of Feedwater $\ldots \ldots \ldots \ldots \ldots \ldots \ldots \ldots \ldots \ldots \ldots \ldots \ldots \ldots \ldots \ldots \ldots \ldots \ldots, 2.1-2$

2.1.4 Loss of Coolant, Core Cooled $(13 \mathrm{~s}$ to $101 \mathrm{~min}) \ldots \ldots \ldots \ldots \ldots \ldots$. $2.1-2$

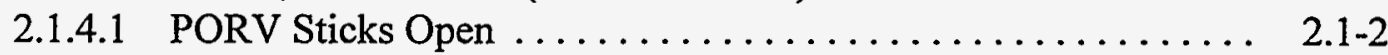

2.1.4.2 Loss of Auxiliary Feedwater $\ldots \ldots \ldots \ldots \ldots \ldots \ldots \ldots .2 .1-3$

2.1.4.3 Throttling of High Pressure Injection $\ldots \ldots \ldots \ldots \ldots \ldots .2 .1-4$

2.1.4.4 Release Pathways .......................... 2.1-5

2.1.4.5 Auxiliary Feedwater Restored .................... 2.1-6

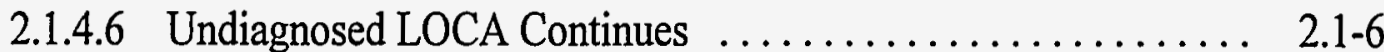

2.1.4.7 Loop B Pumps Turned Off ...................... 2.1-7

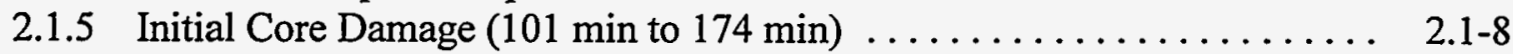

2.1.5.1 Loop A Pumps Off, Core Uncovered $\ldots \ldots \ldots \ldots \ldots \ldots \ldots$ 2.1-8

2.1.5.2 Hydrogen from Zircaloy Oxidation ................. 2.1-9

2.1.5.3 PORV Block Valve Closed. ..................... 2.1-9

2.1.5.4 Initial Melting In Core Region ................... 2.1-10

2.1.6 Quenching and Related Core Damage (174 $\mathrm{min}$ to $375 \mathrm{~min}$ ) ......... 2.1-10

2.1.6.1 Restart of Reactor Coolant Pump 2B ................ 2.1-10

2.1.6.2 Core Region Refllooded. ...................... 2.1-11

2.1.6.3 Pour of Molten Core material ..................... 2.1-12

2.1.6.4 HPI On, Off, Finally Sustained .................... 2.1-12

2.1.7 Recovery Attempts (5 h 15 min to 1 month) ................. 2.1-13

2.1.7.1 Attempt to Collapse Vapor Bubble. ................. 2.1-13

2.1.7.2 Attempt to Use Core Flood Tanks ................. 2.1-13

2.1.7.3 Attempt to Use Decay Heat Removal, Hydrogen Burn ....... 2.1-14

2.1.7.4 Forced Circulation Established ..................... 2.1-15

2.1.7.5 Collapsing the Bubble. ...................... 2.1-15

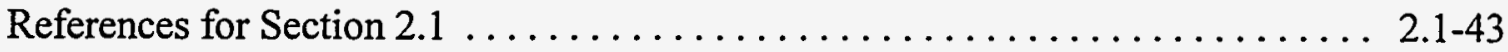


Table of Contents (Cont.)

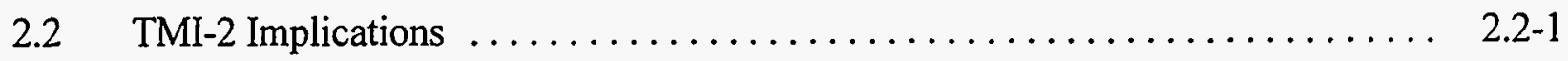

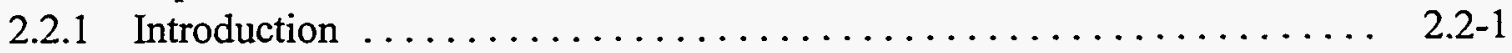

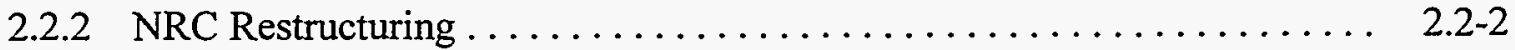

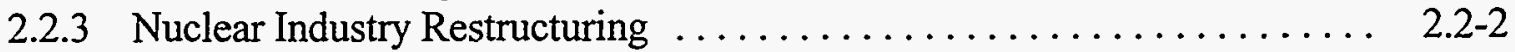

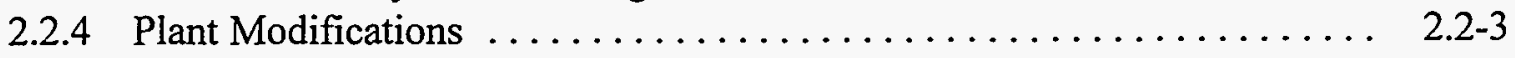

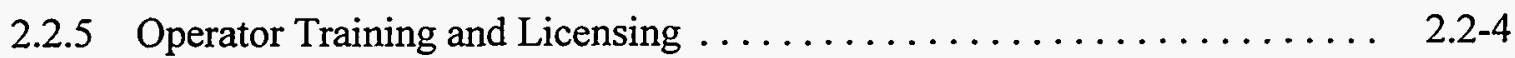

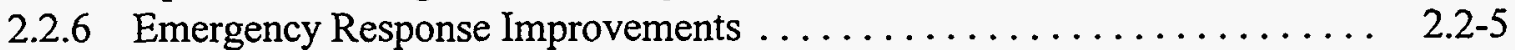

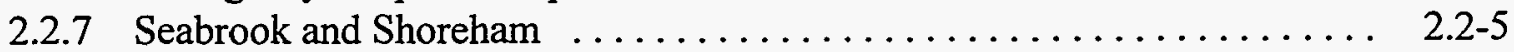

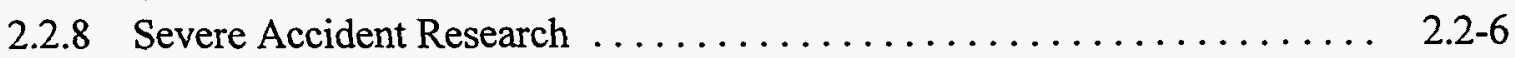

2.2 .9 Severe Accident Policy. . . . . . . . . . . . . . . . . . . . . . . . . . .

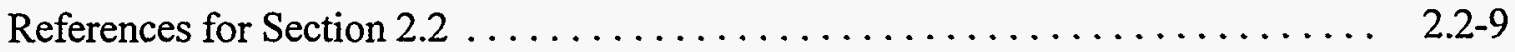

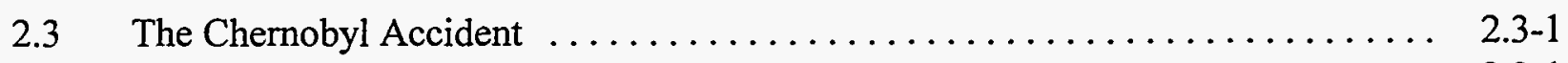

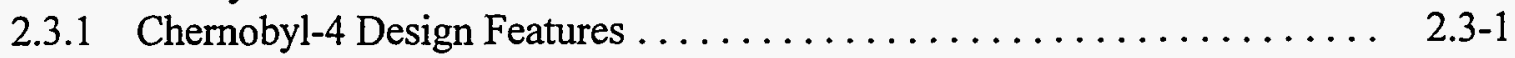

2.3.2 The Chernobyl Experiment $\ldots \ldots \ldots \ldots \ldots \ldots \ldots \ldots \ldots \ldots \ldots \ldots \ldots \ldots \ldots . .3 .2$

2.3.3 The Sequence of Events $\ldots \ldots \ldots \ldots \ldots \ldots \ldots \ldots \ldots \ldots \ldots \ldots \ldots \ldots \ldots \ldots, 2.3-2$

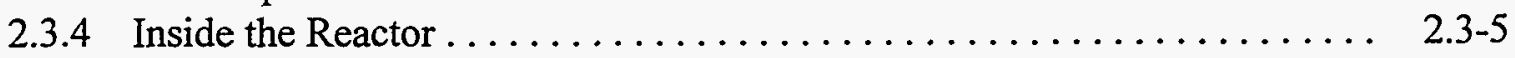

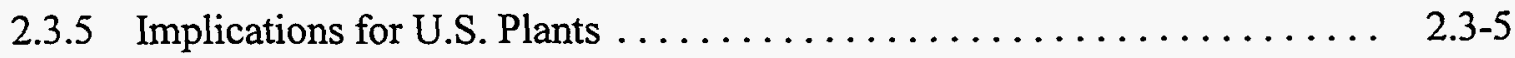

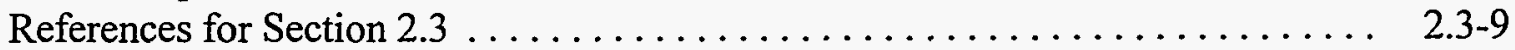

2.4 Risk Influences and the Development of Safety Goals $\ldots \ldots \ldots \ldots \ldots \ldots$ 2.4-1

2.4.1 Past Risk-Influenced Regulatory Practices ................... 2.4-1

2.4.1.1 Anticipated Transients Without Scram ................ 2.4-1

2.4.1.2 Auxiliary Feedwater Reliability $\ldots \ldots \ldots \ldots \ldots \ldots \ldots \ldots .2 .4-5$

2.4.1.3 Station Blackout Rule ........................ 2.4.6

2.4.1.4 Backfit Rule. ............................. 2.4-7

2.4 .2 Safety Goal Policy .............................. 2.4-11

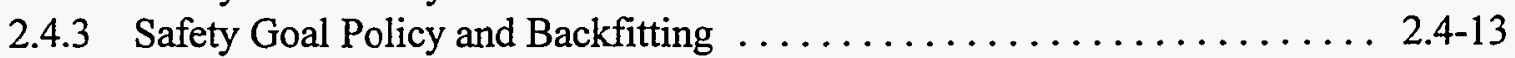

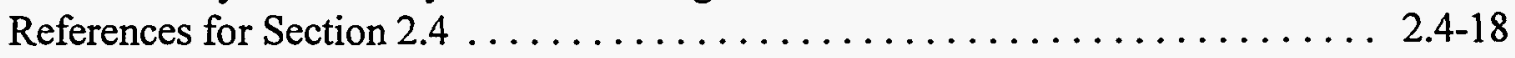

$2.5 \quad$ Risk Assessment and Operational Perspectives .................. 2.5-1

2.5.1 Operating Plant Data $\ldots \ldots \ldots \ldots \ldots \ldots \ldots \ldots \ldots \ldots \ldots \ldots \ldots \ldots \ldots \ldots . . .5 .1$

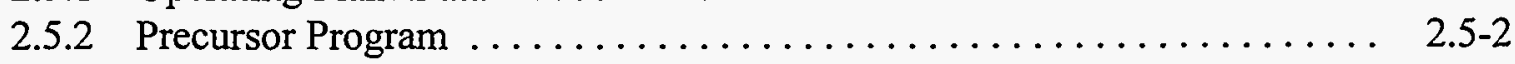

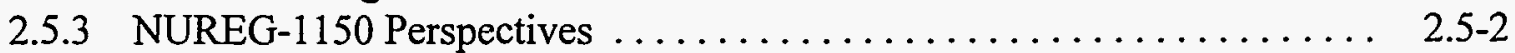

2.5.3.1 Internal Events Results ................... 2.5-3

2.5.3.1.1 NUREG-1150 Boiling Water Reactor Observations. . 2.5-4

2.5.3.1.2 NUREG-1150 Pressurized Water Reactor

Observations ..................... 2.5-6

2.5.3.2 NUREG-1150 Seismic Analysis Observations ........... 2.5.8

2.5.3.2.1 Surry Seismic Analysis ................ 2.5-9

2.5.3.2.2 Peach Bottom Seismic Analysis . . . . . . . . . 2.5. 2.9

2.5.3.3 NUREG-1150 Fire Analysis Observations . ........... 2.5.10

2.5.3.3.1 Surry Fire Analysis ................. 2.5-10

2.5.3.3.2 Peach Bottom Fire Analysis ............ 2.5-10 


\section{Table of Contents (Cont.)}

2.5.3.3.3 General Observations on Fire Analysis. . . . . . . . 2.5-10

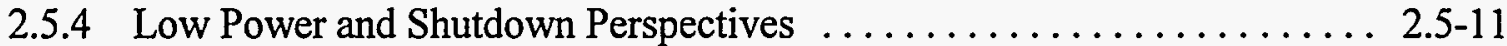

2.5.4.1 Grand Gulf Low Power and Shutdown Observations ........ 2.5-12

2.5.4.2 Surry Low Power and Shutdown Observations $\ldots \ldots \ldots \ldots . . .2 .5-13$

2.5.5 Individual Plant Examinations ........................... 2.5

2.5.5.1 Vulnerabilities and Plant Improvements .............. 2.5-13

2.5.5.2 CDF Perspectives from the IPEs ................... 2.5-14

2.5.6 Station Blackout Sequences. . . . . . . . . . . . . .

2.5.7 Current Understanding of Risk ........................ 2.5-17

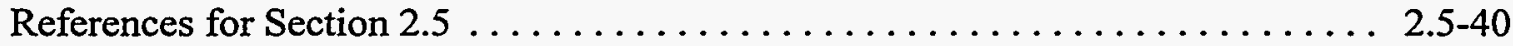

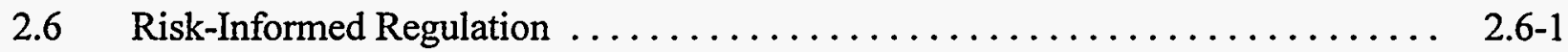

2.6.1 PRA Policy Statement ........................... 2.6-1

2.6.2 Current Issues Concerning the Quantitative Use of PRA . . . . . . . . 2.6-2

2.6.3 An Approach to Risk-Informed Regulation. . . . . . . . . . . . . . . 2.6-4

2.6.3.1 Risk-Informed Philosophy .................... 2.6-4

2.6.3.2 A Four-Element Approach to Integrated Decision Making .... 2.6-5

2.6.4 Current Status of Risk-Informed Regulatory Activities . . . . . . . . . . 2.6-9

References for Section $2.6 \ldots \ldots \ldots \ldots \ldots \ldots \ldots \ldots \ldots \ldots \ldots \ldots \ldots \ldots \ldots .6 .6 .13$

Appendix 2A Davis-Besse Loss Of Feedwater $\ldots \ldots \ldots \ldots \ldots \ldots \ldots \ldots \ldots, 2 \mathrm{~A}-1$

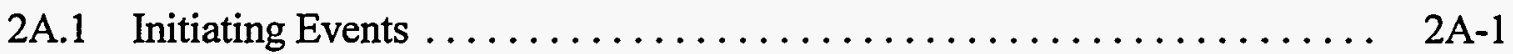

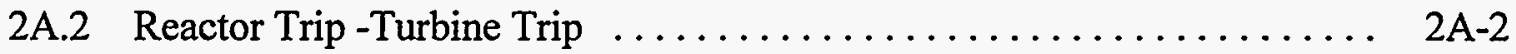

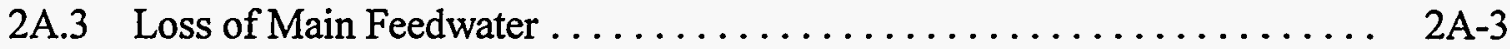

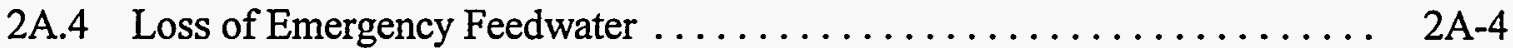

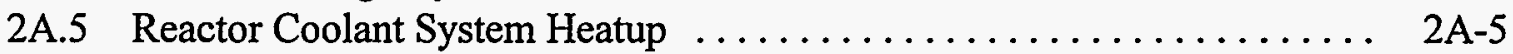

2A.6 Operator Actions $\ldots \ldots \ldots \ldots \ldots \ldots \ldots \ldots \ldots \ldots \ldots \ldots \ldots \ldots \ldots \ldots \ldots \ldots, 2 \mathrm{~A}-6$

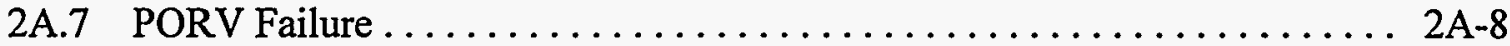

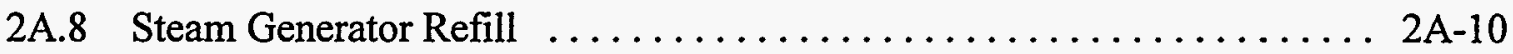

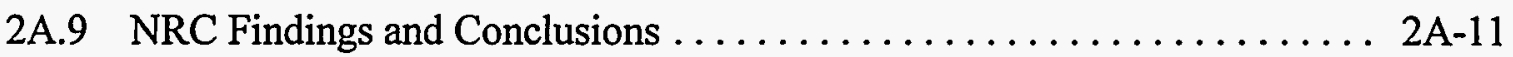

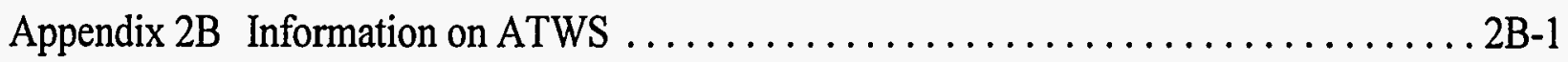

2B.1 Protection Systems Designs and Failure Analyses $\ldots \ldots \ldots \ldots \ldots \ldots .2 \mathrm{~B}-1$

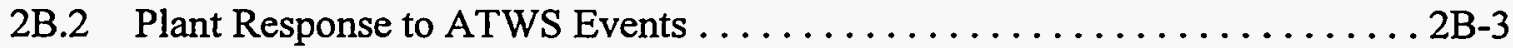

2B.3 Failure of Control Rods to Fully Insert at Browns Ferry $3 \ldots \ldots \ldots \ldots 2$.

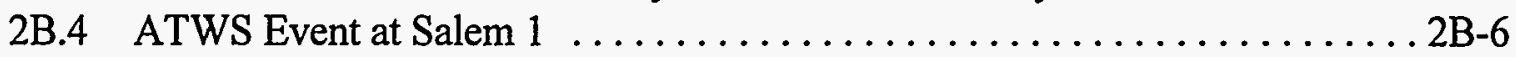

2B.5 10 CFR 50.62, The ATWS Rule ....................... 2B-9

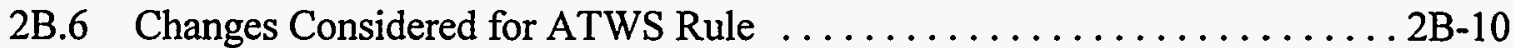

2B.7 BWR ATWS Behavior and Mitigation Measures $\ldots \ldots \ldots \ldots \ldots \ldots \ldots \ldots \ldots \ldots \ldots \ldots \ldots$

2B.7.1 Categories of BWR ATWS . ................... 2 B-12

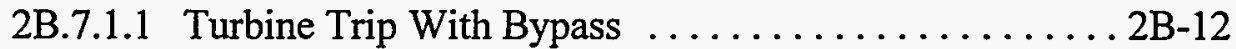

2B.7.1.2 MSIV Closure ...................... 2B-13

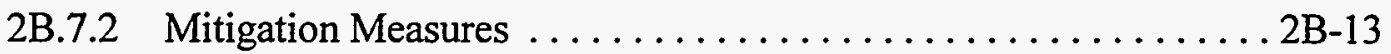

2B.7.2.1 Recirculation Pump Trip ............... 2B-13 


\section{Table of Contents (Cont.)}

2B.7.2.2 Standby Liquid Control System (SLCS) $\ldots \ldots \ldots \ldots 2 \mathrm{~B}-15$

2B.7.2.3 Manual Rod Insertion ................... 2B-15

2B.7.2.4 Control of Vessel Injection . . . . . . . . . . . . . 2B-16

2B.7.3 Application of Emergency Procedure Guidelines ......... 2B-16

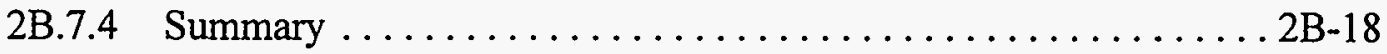

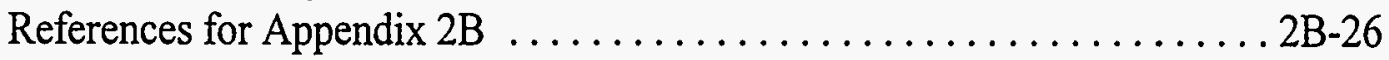

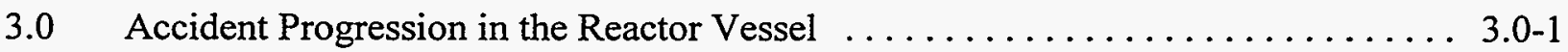

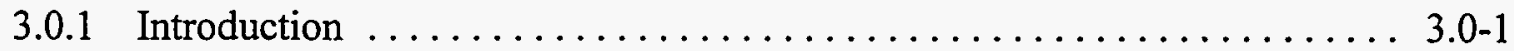

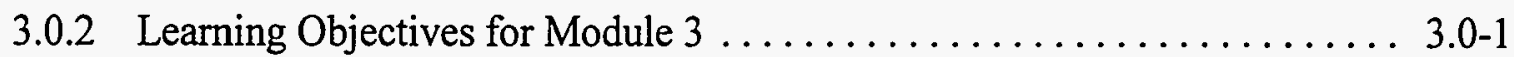

$3.1 \quad$ Severe Accident Stages $\ldots \ldots \ldots \ldots \ldots \ldots \ldots \ldots \ldots \ldots \ldots \ldots \ldots \ldots \ldots \ldots \ldots \ldots .1-1$

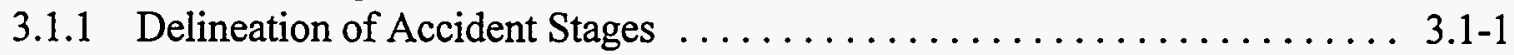

3.1.2 Review of Selected Design Features $\ldots \ldots \ldots \ldots \ldots \ldots \ldots \ldots \ldots . \ldots \ldots . . \ldots \ldots$

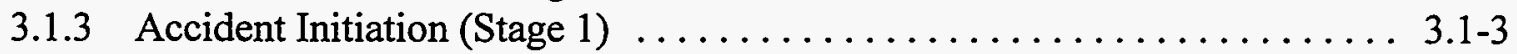

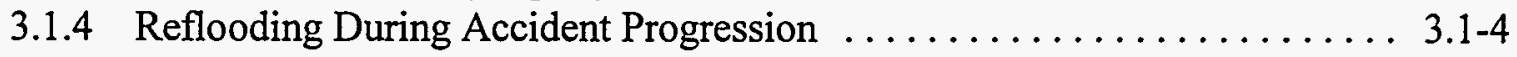

References for Section $3.1 \ldots \ldots \ldots \ldots \ldots \ldots \ldots \ldots \ldots \ldots \ldots \ldots \ldots \ldots \ldots \ldots .1-19$

3.2 Core Uncovering and Heatup $\ldots \ldots \ldots \ldots \ldots \ldots \ldots \ldots \ldots \ldots \ldots \ldots \ldots \ldots \ldots \ldots \ldots \ldots .2-1$

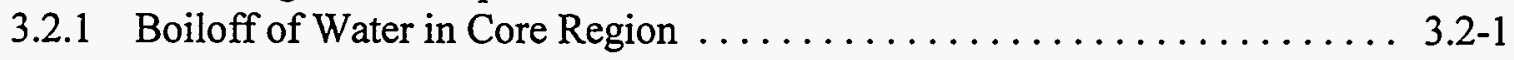

3.2.2 Initial Heatup of Uncovered Fuel $\ldots \ldots \ldots \ldots \ldots \ldots \ldots \ldots \ldots \ldots \ldots \ldots \ldots \ldots \ldots .2-3$

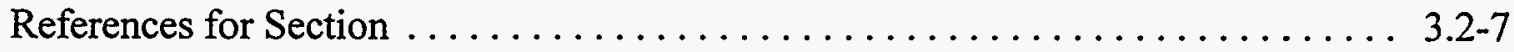

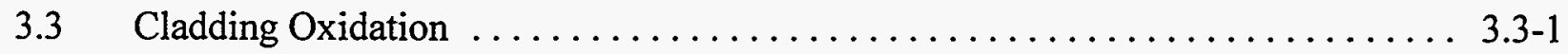

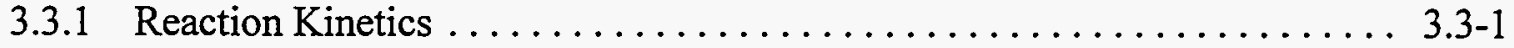

3.3.2 Oxidation Front $\ldots \ldots \ldots \ldots \ldots \ldots \ldots \ldots \ldots \ldots \ldots \ldots \ldots \ldots \ldots \ldots \ldots \ldots .3 .1$

3.3.3 Core Damage Due to Oxidation ............................. 3.3

3.3.4 Reflooding During Stage $3 \ldots \ldots \ldots \ldots \ldots \ldots \ldots \ldots \ldots \ldots \ldots \ldots \ldots \ldots \ldots \ldots \ldots .3 .4$

3.3.5 Natural Circulation During Core Degradation. ................. 3.3-4

References for Section $3.3 \ldots \ldots \ldots \ldots \ldots \ldots \ldots \ldots \ldots \ldots \ldots \ldots \ldots .3-14$

3.4 Melting, Liquefaction, Holdup $\ldots \ldots \ldots \ldots \ldots \ldots \ldots \ldots \ldots \ldots \ldots \ldots \ldots \ldots \ldots \ldots .4 .4$

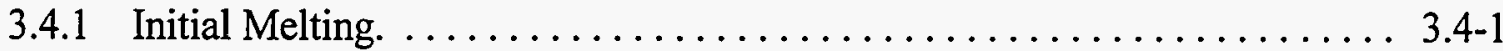

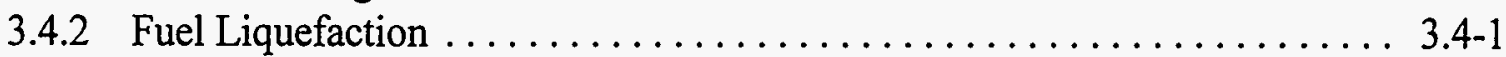

3.4.3 Flow Blockage Versus Streaming ......................... 3.4.2

3.4.4 Reflooding During Stage 4 at TMI $-2 \ldots \ldots \ldots \ldots \ldots \ldots \ldots \ldots \ldots . . .4 .4 .3$

3.4.5 Additional Reflooding Considerations $\ldots \ldots \ldots \ldots \ldots \ldots \ldots \ldots \ldots \ldots .4 .4$

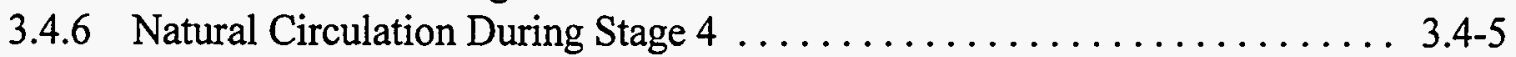

References for Section $3.4 \ldots \ldots \ldots \ldots \ldots \ldots \ldots \ldots \ldots \ldots \ldots \ldots \ldots \ldots \ldots \ldots \ldots \ldots .4 .13$

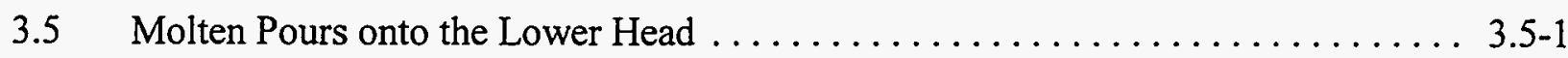

3.5.1 TMI-2 Molten Pour. .............................. 3.5-1

3.5.2 Alternative Melt Flow Scenarios . . . . . . . . . . . . . . . . . . . . . .

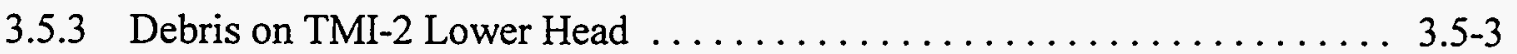




\section{Table of Contents (Cont.)}

3.5.4 Hotspot in TMI-2 Lower Head $\ldots \ldots \ldots \ldots \ldots \ldots \ldots \ldots \ldots \ldots \ldots \ldots . . .5 .4$

3.5.5 Early Views of Lower Head Failure $\ldots \ldots \ldots \ldots \ldots \ldots \ldots \ldots \ldots \ldots \ldots \ldots \ldots . .5 .4$

3.5.6 Lower Head Failure Modes Analyzed for TMI $-2 \ldots \ldots \ldots \ldots \ldots \ldots . .5 .5$

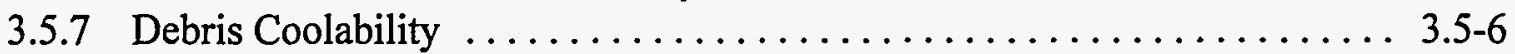

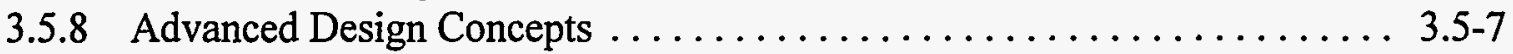

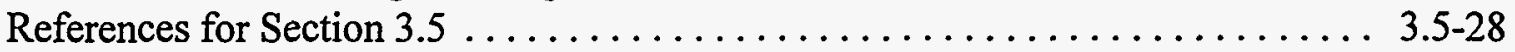

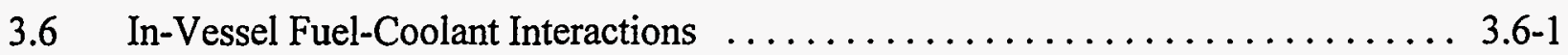

3.6.1 Steam Explosions . . . . . . . . . . . . . . . . . .

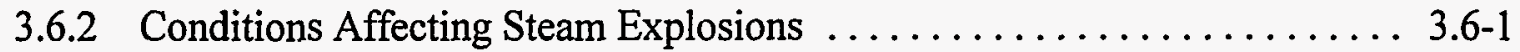

3.6.3 Limitation on In-Vessel FCIs . . . . . . . . . . . . . . . . . . . . . 3.6-2

3.6 .4 In-Vessel FCI Scenarios. . . . . . . . . . . . . .

3.6.5 Alpha Mode Containment Failure $\ldots \ldots \ldots \ldots \ldots \ldots \ldots \ldots \ldots \ldots \ldots .6 .6 .4$

3.6.6 Vessel Breach by an In-Vessel Steam Explosion and Related Issues . . . . . 3.6-5

3.6.7 Impact of Melt Discharge from Vessel $\ldots \ldots \ldots \ldots \ldots \ldots \ldots \ldots . .6 .6 .6$

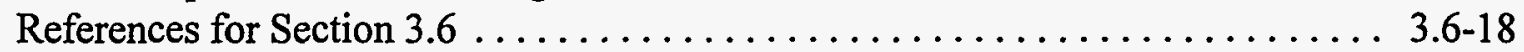

3.7 Special Considerations for BWR Facilities $\ldots \ldots \ldots \ldots \ldots \ldots \ldots \ldots \ldots \ldots \ldots \ldots .7 .1$

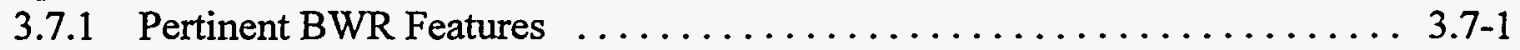

3.7.2 Provisions for Reactor Vessel Depressurization. . . . . . . . . . . . . 3.7-3

3.7.2.1 Why Manual Actuation is Necessary $\ldots \ldots \ldots \ldots \ldots \ldots \ldots . . .7 .7 .3$

3.7.2.2 Rapid Depressurization for Steam Cooling ............. 3.7-4

3.7.2.3 Core Region Dry During Core Degradation ............. 3.7-5

3.7.2.4 Threat of Reactor Vessel Repressurization .............. 3.7-6

3.7.2.5 Notes Concerning SRV Operation $\ldots \ldots \ldots \ldots \ldots \ldots \ldots \ldots \ldots \ldots \ldots \ldots . .7 .7$

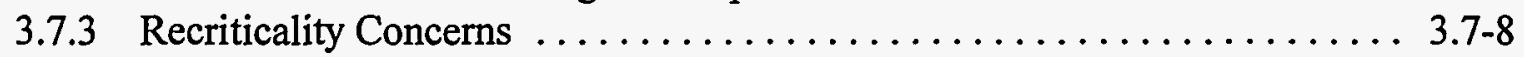

3.7.4 Eutectic Formation and Relocation Sequence for BWR Core Structures .. 3.7-10

3.7.5 Potential Modes for Debris Movement Past the BWR Core Plate ...... 3.7-13

3.7.5.1 Core Plate Structure ....................... 3.7-13

3.7.5.2 Accident Sequence Classification for Core Plate

Considerations ............................. 3.7-14

3.7.5.2.1 Dry Core Plate Accident Sequences ............ 3.7-14

3.7.5.2.2 Wet Core Plate Accident Sequences .......... 3.7-15

3.7.5.3 Status of Experimental Findings ................... 3.7-15

3.7.6 Severe Accident Events in the BWR Lower Plenum ............ 3.7-17

3.7.6.1 Debris Interactions with Lower Plenum Water ........... 3.7-17

3.7.6.2 Events after Lower Plenum Dryout ................. 3.7-18

3.7.7 BWR Bottom Head Failure Modes $\ldots \ldots \ldots \ldots \ldots \ldots \ldots \ldots \ldots . . \ldots . . \ldots \ldots$

3.7.7.1 Failure of the Bottom Head Penetrations ............. 3.7-19

3.7.7.2 Gross Bottom Head Failure .................. 3.7.22

3.7.7.3 Effectiveness of External Water Cooling .............. 3.7-22

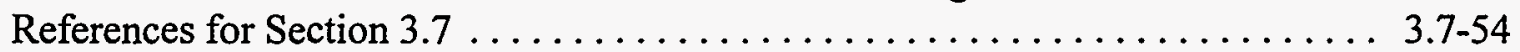




\section{Table of Contents (Cont.)}

4.0 Accident Progression in the Containment $\ldots \ldots \ldots \ldots \ldots \ldots \ldots \ldots \ldots \ldots . . \ldots .6 .1$

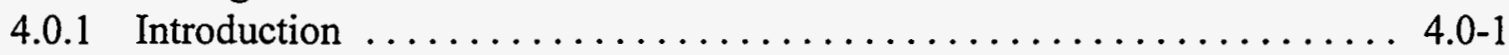

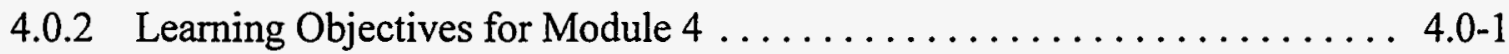

4.1 Containment Characteristics and Design Bases ................... 4.1-1

4.1.1 Containment Types . ............................... 4.1

4.1.1.1 Large Dry Containments ..................... 4.1-1

4.1.1.2 Subatmospheric Containments ................... 4.1-1

4.1.1.3 Ice Condenser Containments $\ldots \ldots \ldots \ldots \ldots \ldots \ldots \ldots \ldots, 4.1-2$

4.1.1.4 BWR Mark I Containments ..................... 4.1-2

4.1.1.5 BWR Mark II Containments .................... 4.1-3

4.1.1.6 BWR Mark III Containments ................... 4.1-3

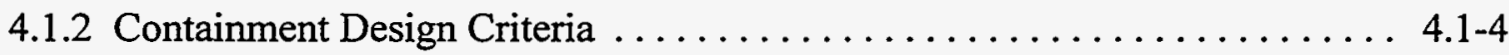

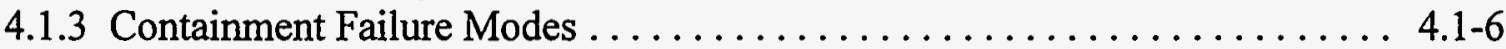

References for Section $4.1 \ldots \ldots \ldots \ldots \ldots \ldots \ldots \ldots \ldots \ldots \ldots \ldots \ldots .1-24$

4.2 Containment Response to Beyond-Design-Basis Accidents $\ldots \ldots \ldots \ldots \ldots \ldots$. $4.2-1$

4.2.1 Containment Challenges and Timing of Events $\ldots \ldots \ldots \ldots \ldots \ldots .4 .2-1$

4.2.2 Implications of Containment Failure . ..................... 4.2-4

4.2.3 Likelihood of Containment Failure During Severe Accidents . . . . . . . . 4.2-4

4.2.4 Containment Venting Strategies $\ldots \ldots \ldots \ldots \ldots \ldots \ldots \ldots \ldots \ldots . .2-6$

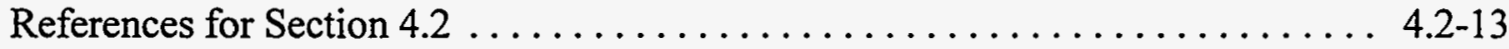

4.3 Ex-Vessel Fuel-Coolant Interactions $\ldots \ldots \ldots \ldots \ldots \ldots \ldots \ldots \ldots \ldots \ldots \ldots \ldots \ldots \ldots .1$

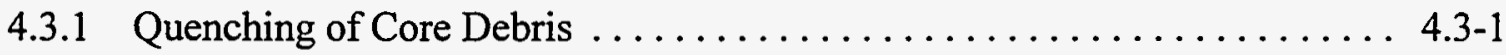

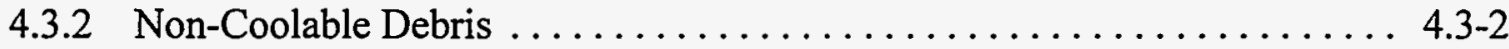

4.3.3 Ex-Vessel Steam Explosions $\ldots \ldots \ldots \ldots \ldots \ldots \ldots \ldots \ldots \ldots \ldots \ldots \ldots . .3 .3$

4.3.4 Containment Design Considerations $\ldots \ldots \ldots \ldots \ldots \ldots \ldots \ldots \ldots \ldots . .3 .4$

References for Section $4.3 \ldots \ldots \ldots \ldots \ldots \ldots \ldots \ldots \ldots \ldots \ldots \ldots \ldots \ldots \ldots \ldots \ldots .3-12$

4.4 Core-Concrete Interactions $\ldots \ldots \ldots \ldots \ldots \ldots \ldots \ldots \ldots \ldots \ldots \ldots \ldots \ldots .4 .1$

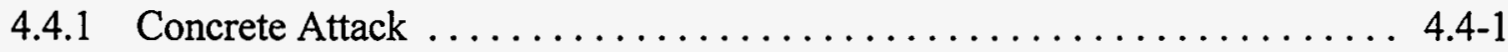

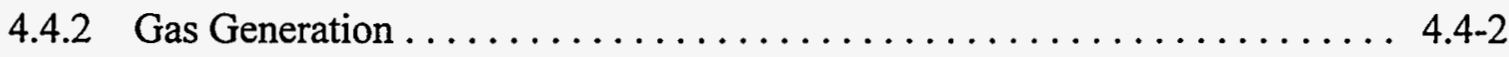

4.4.3 Aerosol Generation $\ldots \ldots \ldots \ldots \ldots \ldots \ldots \ldots \ldots \ldots \ldots \ldots . . .4 .4 .3$

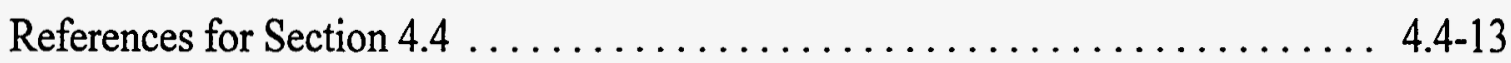

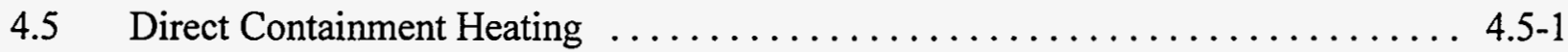

4.5.1 Ejection of Melt from the Vessel ....................... 4.5-1

4.5.2 Interactions in the Reactor Cavity $\ldots \ldots \ldots \ldots \ldots \ldots \ldots \ldots \ldots \ldots \ldots \ldots .5-2$

4.5.3 Energy Deposition and Pressure Rise in Containment ............ 4.5-3

4.5.4 Containment Failure Probabilities for $\mathrm{DCH} \ldots \ldots \ldots \ldots \ldots \ldots \ldots .4 .5-4$

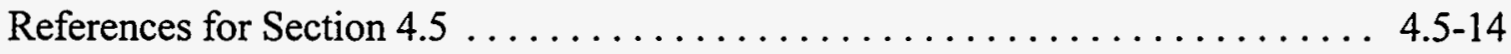




\section{Table of Contents (Cont.)}

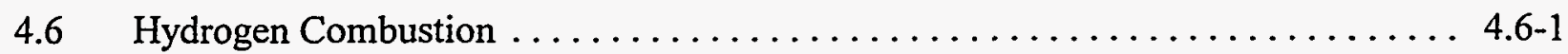

4.6.1 Hydrogen Combustion Reaction ........................ 4.6-1

4.6.2 Conditions Necessary for Combustion $\ldots \ldots \ldots \ldots \ldots \ldots \ldots \ldots .6 .6 .1$

4.6.3 Deflagrations . .................................. $4.6-3$

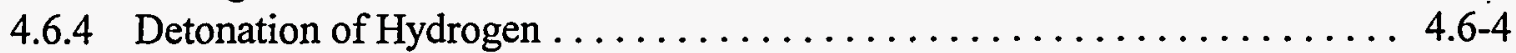

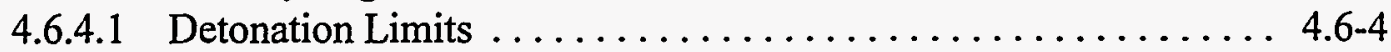

4.6.4.2 Transition to Detonation ........................ 4.6

4.6.4.3 Detonation Pressure and Temperatures ............... 4.6-6

4.6.4.4 Local Detonations ............................. 4.6-6

4.6.4.5 Missile Generation .......................... 4.6-7

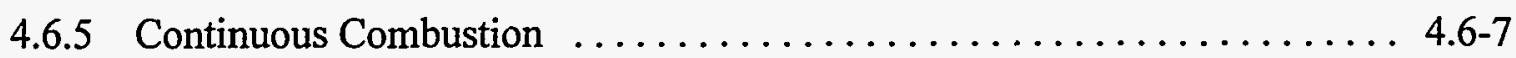

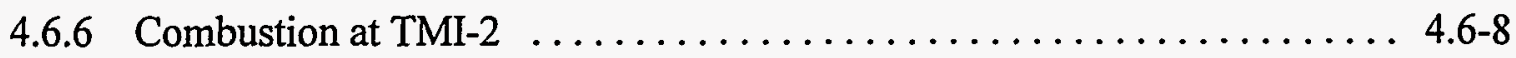

4.6.7 Hydrogen Control Requirements . . . . . . . . . . . . . . . . . . . . .

References for Section $4.6 \ldots \ldots \ldots \ldots \ldots \ldots \ldots \ldots \ldots \ldots \ldots \ldots \ldots .6 .6 .29$

4.7 BWR Mark I Liner Failure By Melt Attack $\ldots \ldots \ldots \ldots \ldots \ldots \ldots \ldots \ldots \ldots \ldots .7 .1$

4.7.1 Pertinent Features of the Mark I Containment Design ............. 4.7-1

4.7.2 Characteristics of Debris Pours From Vessel $\ldots \ldots \ldots \ldots \ldots \ldots \ldots . . \ldots .7 .2$

4.7.2.1 Scenario I: Large Initial Pour of Molten Oxides .......... 4.7-2

4.7.2.2 Scenario II: Metallic Pour Followed by Release of Oxides ..... 4.7-3

4.7.2.3 Accident Scenarios Not Represented ................ 4.7-3

4.7.3 Debris Spreading Across The Drywell Floor ................. 4.7-4

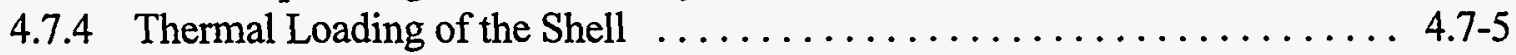

4.7.5 Mitigative Effects of Water ........................... 4.6

4.7.6 Potential for Mark I Containment Failure $\ldots \ldots \ldots \ldots \ldots \ldots \ldots \ldots . .7 .7$

4.7.6.1 Extension to Other BWR Facilities ................. 4.7-7

4.7.6.2 Drywell Flooding Capabilities $\ldots \ldots \ldots \ldots \ldots \ldots \ldots \ldots . . .7 .7-8$

References for Section $4.7 \ldots \ldots \ldots \ldots \ldots \ldots \ldots \ldots \ldots \ldots \ldots \ldots \ldots \ldots \ldots \ldots \ldots \ldots .7 .16$

Appendix 4A Example Calculation of Hydrogen Combustion Pressures and

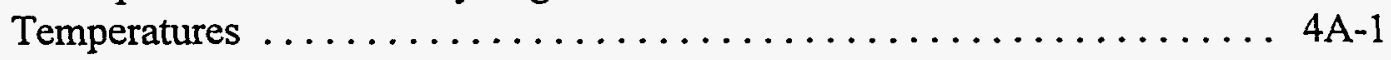

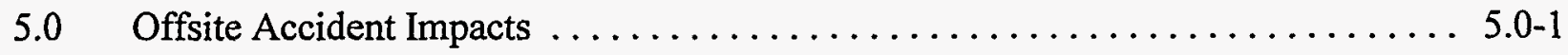

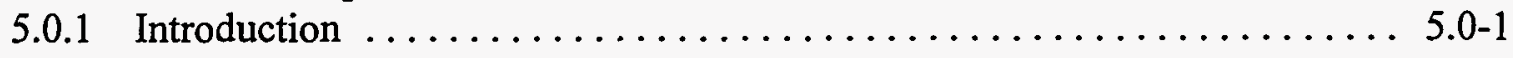

5.0.2 Learning Objectives for Module $5 \ldots \ldots \ldots \ldots \ldots \ldots \ldots \ldots \ldots \ldots \ldots . \ldots \ldots .1$

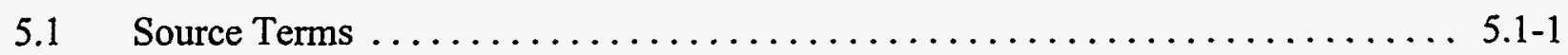

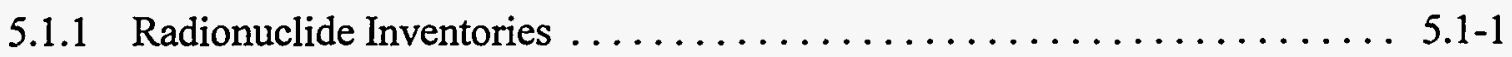

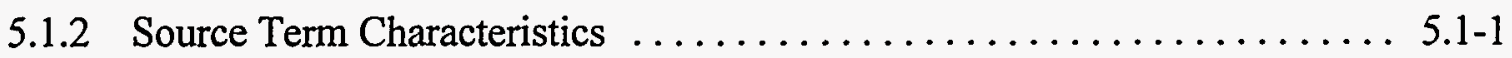

5.1.3 Magnitude of Release Required to Cause Offsite Health Effects ....... 5.1-2

5.1.4 Design Features That Impact Source Terms $\ldots \ldots \ldots \ldots \ldots \ldots \ldots \ldots . \ldots . . \ldots \ldots$

5.1.4.1 Suppression Pools .......................... 5.1-3

5.1.4.2 Drywell-Wetwell Configuration $\ldots \ldots \ldots \ldots \ldots \ldots \ldots \ldots \ldots . . .1-4$

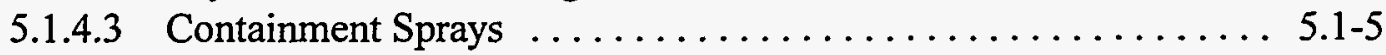




\section{Table of Contents (Cont.)}

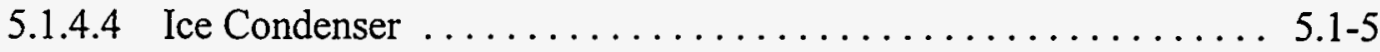

5.1 .4 .5 Reactor Cavity Flooding $\ldots \ldots \ldots \ldots \ldots \ldots \ldots \ldots \ldots . \ldots \ldots .1-5$

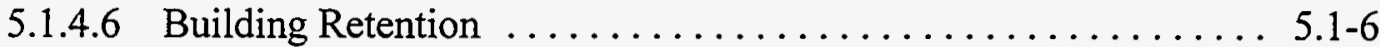

5.1.4.7 BWR Containment Venting $\ldots \ldots \ldots \ldots \ldots \ldots \ldots \ldots \ldots \ldots \ldots .1-6$

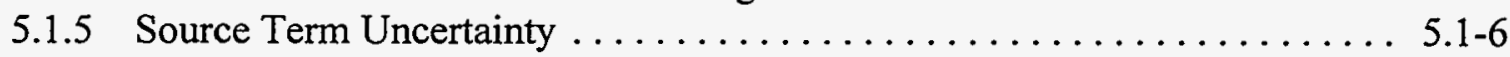

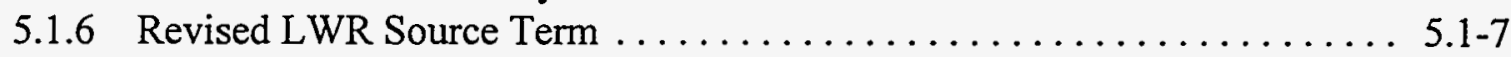

5.1 .7 The Chernobyl Source Term ......................... 5.1-8

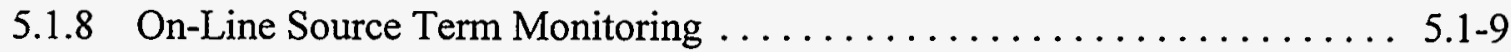

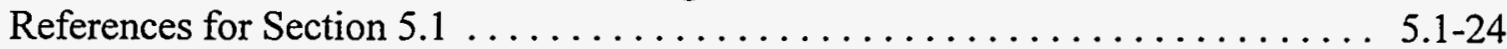

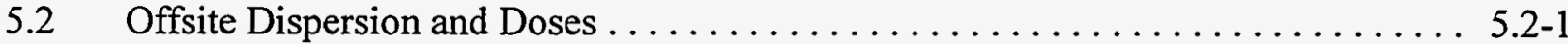

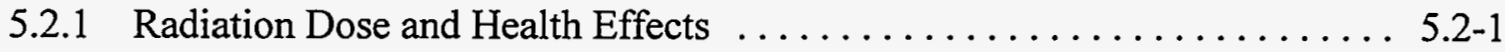

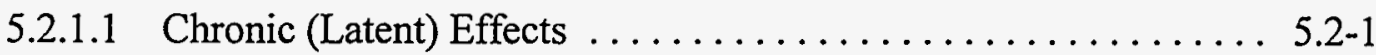

5.2.1.2 Acute Health Effects . . . . . . . . . . . . . . . . . . . . 5.2-1

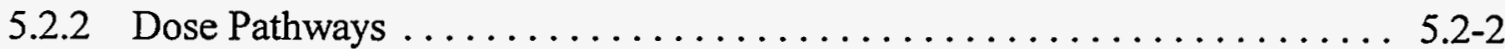

5.2 .3 Meteorology . .................................. 5.2

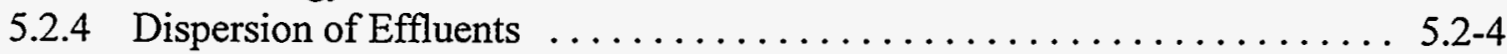

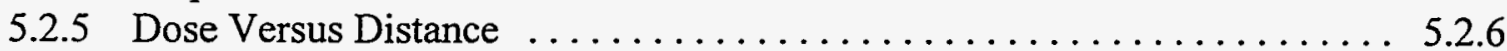

5.2 .6 Uncertainties in Dose Projections . . . . . . . . . . . . . . . . . . . . . 5.2-7

5.2.7 Dispersion of the Chernobyl Release ...................... 5.2-8

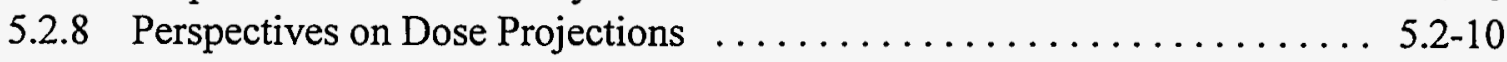

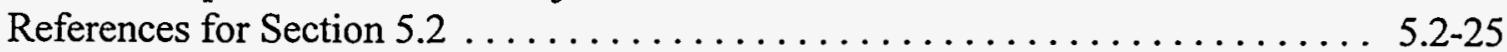

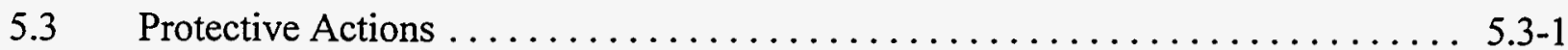

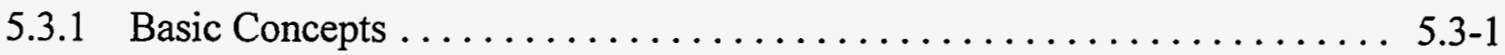

5.3.1.1 Early, Intermediate, and Late Phases $\ldots \ldots \ldots \ldots \ldots \ldots . . \ldots .3-1$

5.3.1.2 Basic Radiation Protection Objectives ............... 5.3-2

5.3.1.3 Early Protective Action Guidance $\ldots \ldots \ldots \ldots \ldots \ldots \ldots . . \ldots .3-2$

5.3.1.4 Timing of Initial Actions ........................ 5.3-2

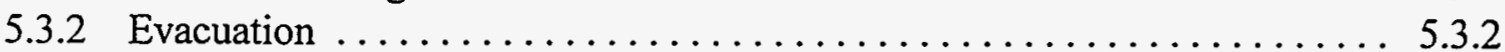

5.3.2.1 Effectiveness of Evacuation $\ldots \ldots \ldots \ldots \ldots \ldots \ldots \ldots \ldots . \ldots \ldots .3 .3$

5.3 .2 .2 Evacuation Risks ............................ 5.3.4

5.3.2.3 Entrapment Scenarios .......................... 5.3.5

5.3.3 Sheltering and Relocation from Hot Spots $\ldots \ldots \ldots \ldots \ldots \ldots \ldots . . \ldots .3 .6$

5.3.4 Improvised Respiratory Protection $\ldots \ldots \ldots \ldots \ldots \ldots \ldots \ldots \ldots \ldots \ldots \ldots \ldots .3 .7$

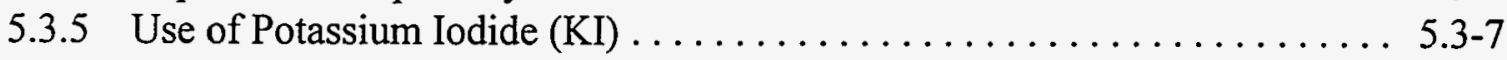

5.3.6 Early Protective Action Decisions During the TMI-2 Accident . . . . . . . 5.3-8

5.3.7 Other Protective Actions . . . . . . . . . . . . . . . . . . . . . . . . . 5.3-9

5.3.8 Protective Actions Following The Chernobyl Accident $\ldots \ldots \ldots \ldots \ldots$. 5.3-9

5.3 .8 .1 Workers ................................ 5.3

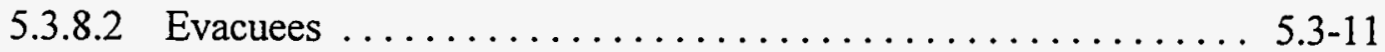

5.3.8.3 Residents of Significantly Contaminated Areas ........... 5.3-11

5.3.8.4 Residents of Less Contaminated Areas ............... 5.3-12 


\section{Table of Contents (Cont.)}

5.3.9 Long-Term Health Effects From the Chernobyl Accident ........... 5.3-13

References for Section $5.3 \ldots \ldots \ldots \ldots \ldots \ldots \ldots \ldots \ldots \ldots \ldots \ldots \ldots \ldots \ldots \ldots . .3-26$

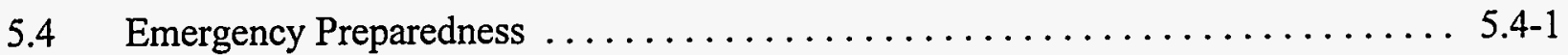

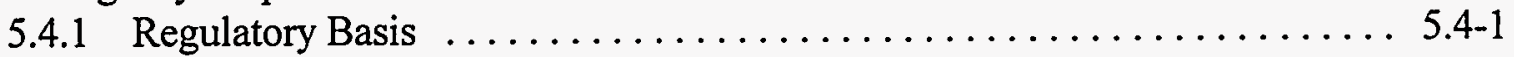

5.4 .2 Roles in an Emergency ................................ 5.4

5.4.2.1 Role of Licensee ......................... 5.4-1

5.4.2.2 Role of State and Local Agencies ................. 5.4-2

5.4 .2 .3 Role of the NRC . . ....................... 5.4-2

5.4.3 Emergency Detection and Classification $\ldots \ldots \ldots \ldots \ldots \ldots \ldots \ldots . .4 .4 .2$

5.4.3.1 Emergency Operating Procedures ................... 5.4-2

5.4.3.2 Emergency Action Levels ..................... 5.4.3

5.4.3.3 Emergency Classification System .................. 5.4-4

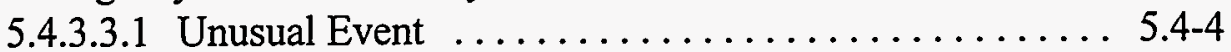

5.4.3.3.2 Alert . . . . . . . .

5.4.3.3.3 Site Area Emergency $\ldots \ldots \ldots \ldots \ldots \ldots \ldots \ldots . . .4 .4$

5.4.3.3.4 General Emergency $\ldots \ldots \ldots \ldots \ldots \ldots \ldots \ldots . .6 .4-5$

5.4.3.3.5 Class Summaries and NUMARC Recognition

Categories ........................ 5.4-5

5.4.3.4 Protective Action Recommendations . ............... 5.4-5

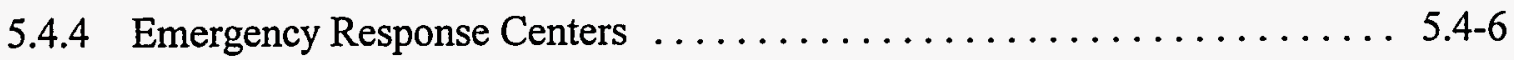

5.4 .4 .1 Control Room ............................ 5.4.6

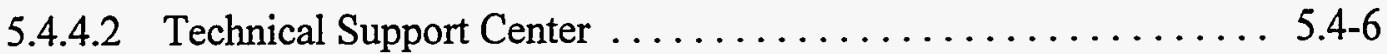

5.4.4.3 Operations Support Center . .................... 5.4-6

5.4.4.4 Emergency Operations Facility .................... 5.4

5.4.4.5 Flow of Authority and Responsibility ............... 5.4-7

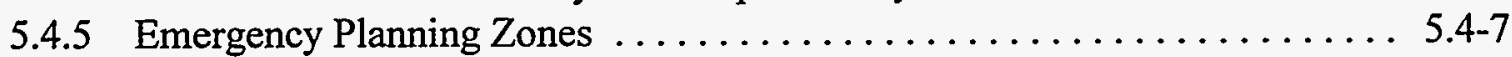

5.4.5.1 Plume Exposure Emergency Planning Zone ............ 5.4-7

5.4.5.2 Ingestion Pathway Emergency Planning Zone ............ 5.4-8

5.4.6 Response of State and Local Organizations . . . . . . . . . . . . . . . . 5.4-9

5.4.6.1 Emergency Response Plans . . . . . . . . . . . . . . . . . . .

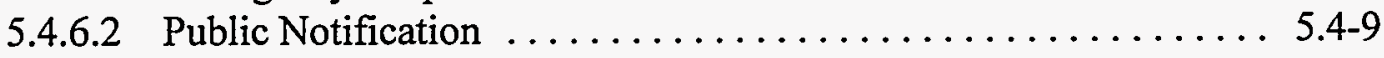

5.4.6.3 Evacuation Time Estimates .................... 5.4-10

5.4.6.4 Dose Projections and Field Monitoring $\ldots \ldots \ldots \ldots \ldots \ldots . . \ldots .4-10$

5.4.6.5 Location of Authority and Responsibility ............. 5.4-10

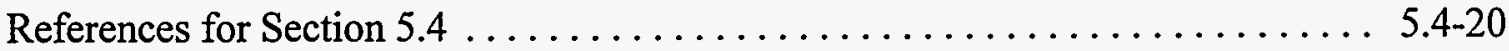

Appendix 5A Protective Action Guides $\ldots \ldots \ldots \ldots \ldots \ldots \ldots \ldots \ldots \ldots \ldots \ldots \ldots \ldots \ldots \ldots \ldots$ 


\section{List of Figures}

1.0-1 Timing of major events and activities relevant to commercial power reactor safety

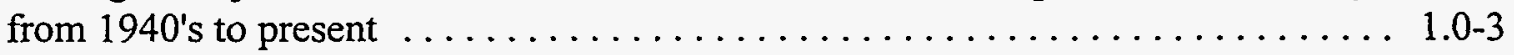

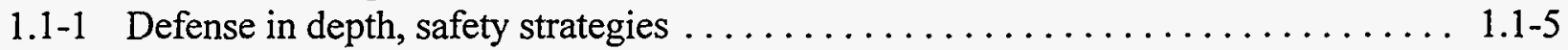

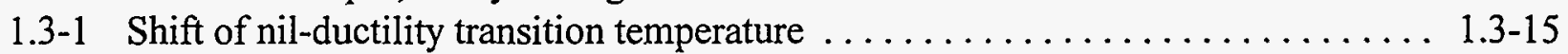

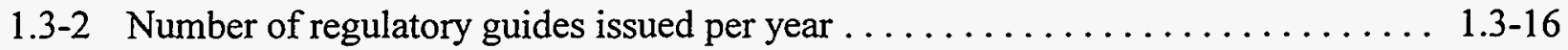

1.4-1 Ratio of power after to power before shutdown for various operation times before

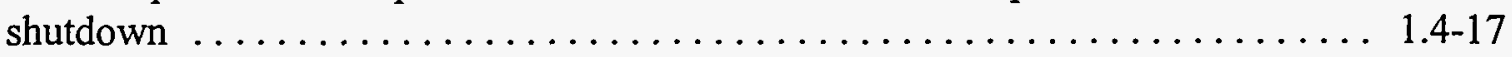

1.4-2 Effect of selected conservatisms on peak cladding temperature $\ldots \ldots \ldots \ldots \ldots 1.4-18$

1.5-1 Breakdown of nuclear power plant accidents by severity $\ldots \ldots \ldots \ldots \ldots \ldots .1 .5-5$

1.5-2 Frequency of man-caused events involving fatalities $\ldots \ldots \ldots \ldots \ldots \ldots \ldots \ldots \ldots .6 \ldots$

1.5-3 Frequency of natural events involving fatalities $\ldots \ldots \ldots \ldots \ldots \ldots \ldots \ldots \ldots \ldots \ldots .5 .7$

1.6-1 Vertical cross section of plant showing reactor building control room and

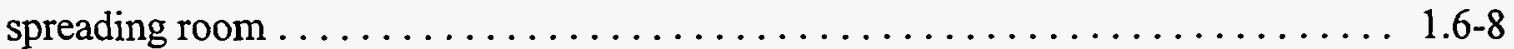

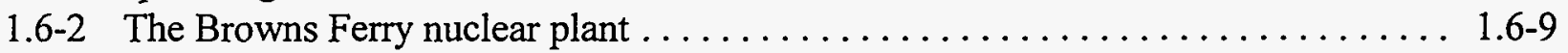

1.6-3 Cable-tray penetration, overall simplified depiction (not to scale) $\ldots \ldots \ldots \ldots 1.6-10$

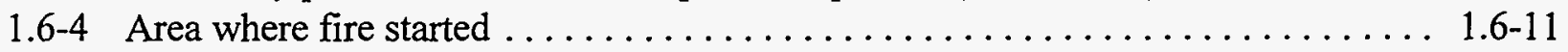

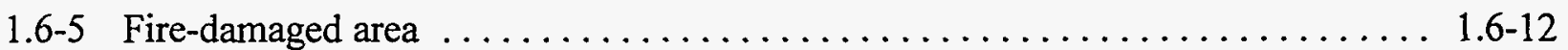

1.6-6 Equipment availability during and immediately following the March 22, 1975

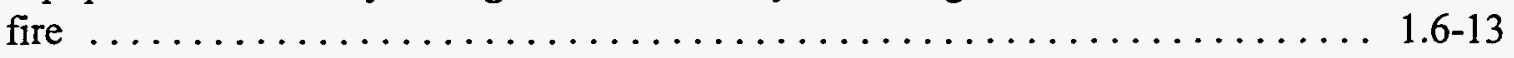

1A-1 Three levels of probabilistic risk assessment $\ldots \ldots \ldots \ldots \ldots \ldots \ldots \ldots \ldots, 1 \mathrm{~A}-28$

1A-2 LLNL hazard curves for Peach Bottom site . . . . . . . . . . . . . . . . 1A-29

1A-3 EPRI hazard curves for Peach Bottom site $\ldots \ldots \ldots \ldots \ldots \ldots \ldots \ldots \ldots \ldots \ldots \ldots \ldots$

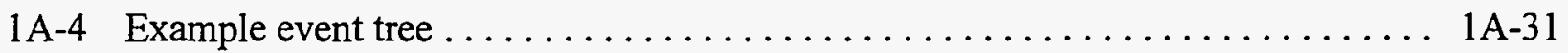

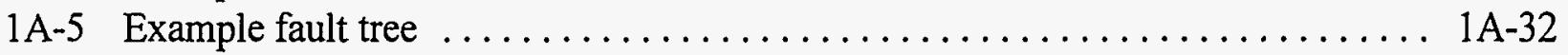

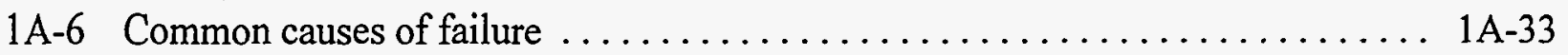

1A-7 Risk assessment procedure for external events $\ldots \ldots \ldots \ldots \ldots \ldots \ldots \ldots$ 1A-34

1A-8 Internal core damage frequency ranges (5th to 95 th percentile) $\ldots \ldots \ldots \ldots$ 1A-35

2.1-1 Arrangement of the primary reactor coolant system and related support system for the Three Mile Island, Unit 2 (TMI-2) Reactor (courtesy of R. Schauss and Construction Systems Associates) $\ldots \ldots \ldots \ldots \ldots \ldots \ldots \ldots \ldots \ldots \ldots \ldots \ldots \ldots \ldots \ldots \ldots .1-24$

2.1-2 TMI-2 scenario: initial condition - standby operation at $97 \%$ power $\ldots \ldots \ldots 2.1-25$

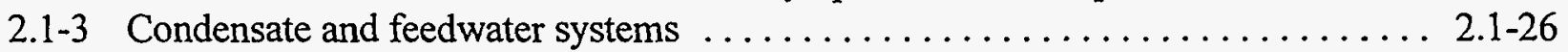

2.1-4 TMI-2 scenario: reactor coolant pressure and pressurizer level vs. time ...... 2.1-27

2.1-5 TMI-2 scenario: system nearly liquid solid, liquid expanding with increasing

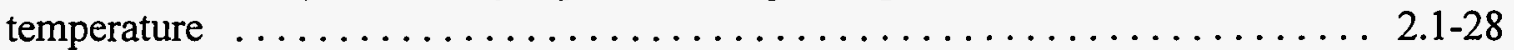

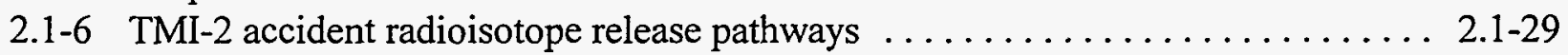

2.1-7 TMI-2 scenario: primary system pressure and temperatures nearly constant following secondary steam condition, primary voids increasing $\ldots \ldots \ldots \ldots .2 .1-30$

2.1-8 TMI-2 scenario: loop A pumps operating, loop B stagnant after shutdown of

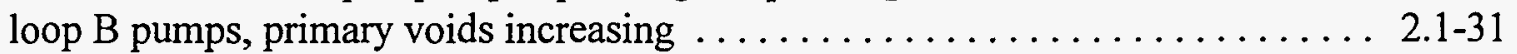

2.1-9 TMI-2 scenario: all pumps off, reactor core drying out and heating up, superheated steam flowing to pressurizer and to one steam generator and condensing . 2 2.1-32

2.1-10 TMI-2 scenario: core dryout and heatup continuing, hydrogen generation by

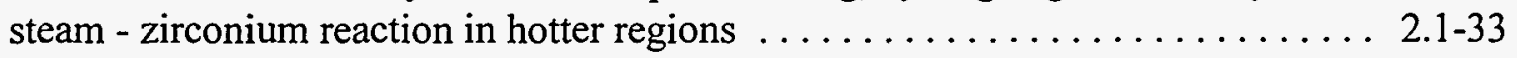




\section{List of Figures (Continued)}

2.1-11 TMI-2 scenario: core partially quenched by fluid during loop B pump start, heatup resumes ..................................... 2.1-34

2.1-12 TMI-2 reactor vessel refilled by manual initiation of safety injection, core

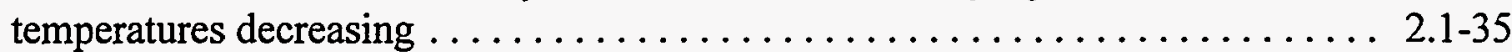

2.1-13 TMI-2 scenario: system pressurized by high-pressure injection system intermittent liquid release through top of pressurizer, heat removal by heatup of injected water, steam generator heat transfer blocked by hydrogen $\ldots \ldots \ldots$ 2.1-36

2.1-14 TMI-2 scenario: primary system depressurizing and releasing hydrogen through the pressurizer into the containment $\ldots \ldots \ldots \ldots \ldots \ldots \ldots \ldots \ldots . \ldots . \ldots .1-37$

2.1-15 TMI-2 containment pressure versus time $\ldots \ldots \ldots \ldots \ldots \ldots \ldots \ldots \ldots \ldots .2 .1-38$

2.1-16 TMI-2 primary system pressure reaches a minimum as pressurizer temperature returns to saturated conditions, liquid in system maintained during depressurization by high-pressure injection and core flood tanks $\ldots \ldots \ldots \ldots \ldots \ldots \ldots \ldots .2 .1-39$

2.1-17 TMI-2 scenario: steam generators blocked by hydrogen, reactor vessel decreasing, primary system pressure increasing, minimal make-up flow . . . . . . . . . 2.1-40

2.1-18 TMI-2 scenario: system repressurized by high-pressure injection, natural circulation to steam generators blocked by hydrogen $\ldots \ldots \ldots \ldots \ldots \ldots \ldots .2 .1-41$

2.1-19 TMI-2 scenario: forced circulation reestablished in loop A with heat removal via

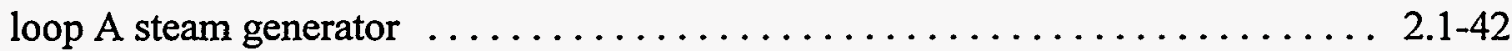

2.3-1 Boiling water pressure tube graphite moderated reactor $\ldots \ldots \ldots \ldots \ldots \ldots \ldots .2 .3-8$

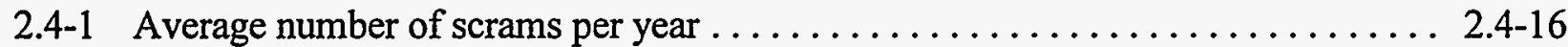

2.4-2 Safety goal implementation guidance $\ldots \ldots \ldots \ldots \ldots \ldots \ldots \ldots \ldots \ldots \ldots \ldots \ldots \ldots . .4 .17$

2.5-1 Internal core damage frequency ranges (5th to 95 th percentiles) $\ldots \ldots \ldots \ldots 2.5-27$

2.5-2 BWR principal contributors to internal core damage frequencies $\ldots \ldots \ldots \ldots \ldots 2.5-28$

2.5-3 PWR principal contributors to internal core damage frequencies $\ldots \ldots \ldots \ldots \ldots 2.5 .29$

2.5-4 Surry internal- and external-event core damage frequency ranges $\ldots \ldots \ldots \ldots .2 .5-30$

2.5-5 Peach Bottom internal- and external-event core damage frequency ranges . . . . . 2.5-31

2.5-6 Surry external-event core damage frequency distributions $\ldots \ldots \ldots \ldots \ldots \ldots .2 .5-32$

2.5-7 Peach Bottom external-event core damage frequency distributions $\ldots \ldots \ldots \ldots 2.5-33$

2.5-8 Principal contributors to seismic core damage frequencies $\ldots \ldots \ldots \ldots \ldots \ldots 2.5-34$

2.5-9 Principal contributors to fire core damage frequencies $\ldots \ldots \ldots \ldots \ldots \ldots .2 .5-35$

2.5-10 Grand Gulf sequence contributions for full-power and POS $5 \ldots \ldots \ldots \ldots .2 .5-36$

2.5-11 Surry sequence contributions for full-power and mid-loop operation $\ldots \ldots \ldots \ldots$ 2.5-37

2.5-12 Reported IPE CDFs for BWRs and PWRs $\ldots \ldots \ldots \ldots \ldots \ldots \ldots \ldots \ldots \ldots \ldots \ldots .2 .5-38$

2.5-13 Reduction in CDF from implementing Station Blackout Rule . . . . . . . . . . 2.5-39

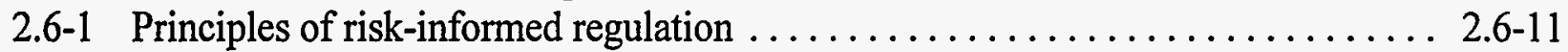

2.6-2 Principal elements of risk-informed, plant-specific decision making $\ldots \ldots \ldots \ldots$ 2.6-12

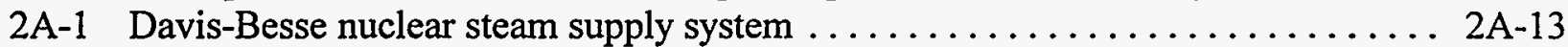

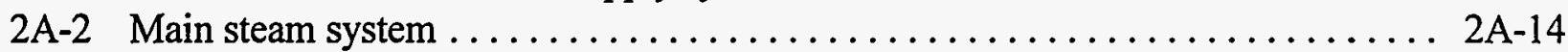

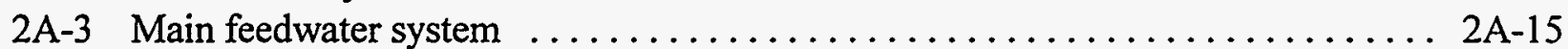

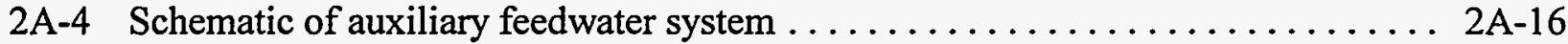

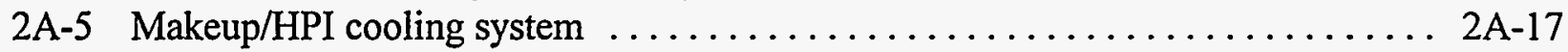

2A-6 Steam feedwater rupture control system (SFRCS) block diagram $\ldots \ldots \ldots \ldots$ 2A-18 


\section{List of Figures (Continued)}

2B-1 BWR operation after failure of scram in the turbine trip-initiated ATWS

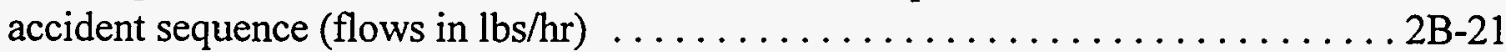

2B-2 BWR operation after failure of scram in the MSIV closure - initiated ATWS

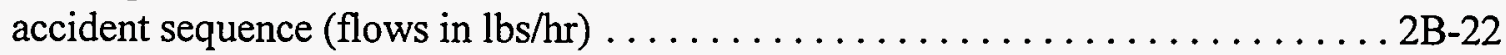

2B-3 The single SLCS injection sparger is located to the side of the control rod guide tubes and injects horizontally into the lower plenum $\ldots \ldots \ldots \ldots \ldots \ldots 2$ B-23

2B-4 Manual rod insertion involves different piping and valves and might be effective

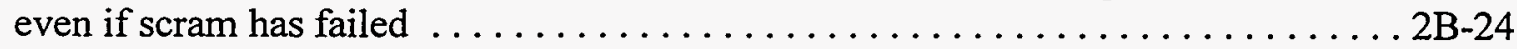

2B-5 The major effect of lowering the reactor vessel water level upon core power occurs when feedwater spargers are uncovered $\ldots \ldots \ldots \ldots \ldots \ldots \ldots \ldots .2 \mathrm{~B}-25$

3.1-1 Approximate temperature and time envelopes for in-vessel severe accident stages assuming no coolant injection during PWR core heatup and degradation . . . . . . 3.1-7

3.1-2 Melting points for metallic elements, reactor metals, and compounds . . . . . . 3.1-8

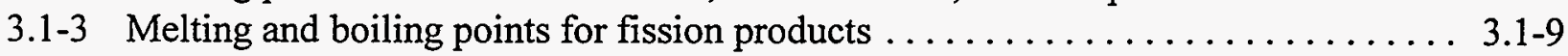

3.1-4 Chemical interactions and formation of liquid phases in an LWR fuel rod bundle with increasing temperature $\ldots \ldots \ldots \ldots \ldots \ldots \ldots \ldots \ldots \ldots \ldots \ldots \ldots \ldots \ldots \ldots \ldots .1-10$

3.1-5 Schematic of BWR reactor vessel internal structure $\ldots \ldots \ldots \ldots \ldots \ldots \ldots \ldots .3 .1-11$

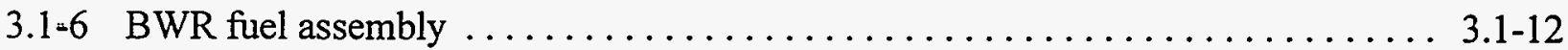

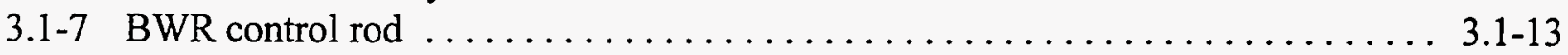

3.1-8 PWR reactor coolant system arrangement $(\mathrm{B} \& W) \ldots \ldots \ldots \ldots \ldots \ldots \ldots \ldots \ldots \ldots . \ldots \ldots .1-14$

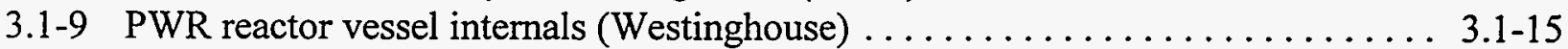

3.1-10 Cutaway view of typical rod cluster control assembly . . . . . . . . . . . . .

3.1-11 Typical PWR arrangement for in-core instrumentation (Westinghouse) . . . . . 3.1-17

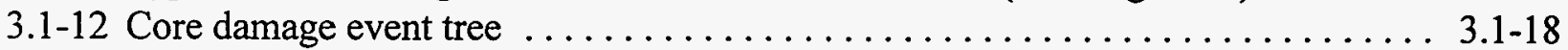

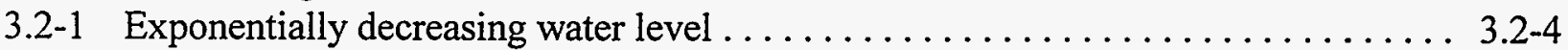

3.2-2 Variation of boiloff time constant with saturation pressure $\ldots \ldots \ldots \ldots \ldots \ldots .2 .2-5$

3.2-3 Approximate calculation of fuel temperature rise (curves) at three different times

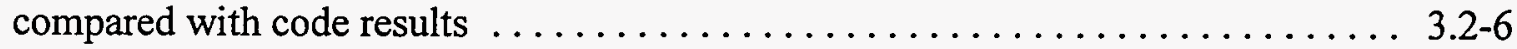

3.3-1 Hydrogen production per unit area from the $\mathrm{Zr}: \mathrm{H}_{2} \mathrm{O}$ reaction $\ldots \ldots \ldots \ldots \ldots$. $3.3-6$

3.3-2 Mass of $\mathrm{Zr}$ oxidized in 5 minutes exposure of 5400 square meters Zircaloy ..... 3.3-7

3.3-3 Calculated axial cladding temperatures at three different times following start of core uncovering for a PWR station blackout $\ldots \ldots \ldots \ldots \ldots \ldots \ldots \ldots \ldots \ldots \ldots \ldots \ldots . .3-8$

3.3-4 Heat balance between uncovered core and residual water . . . . . . . . . . . 3.3-9

3.3-5 Ratio of heat release rate via oxidation to heat transfer rate to residual saturated

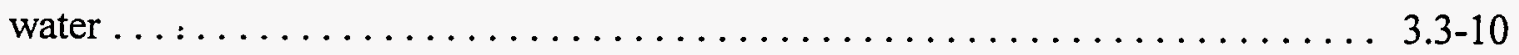

3.3-6 Severe accident natural circulation flows $\ldots \ldots \ldots \ldots \ldots \ldots \ldots \ldots \ldots \ldots .3 .3-11$

3.3-7 Schematic diagram of a BWR with internal circulation $\ldots \ldots \ldots \ldots \ldots \ldots .3 .3-12$

3.3-8 Tensile strength, type 304 stainless steel $\ldots \ldots \ldots \ldots \ldots \ldots \ldots \ldots \ldots \ldots \ldots \ldots . .3 .13$

3.4-1 Distribution of fuel rod rating $(\mathrm{kW} / \mathrm{m})$ in the TMI-2 core $\ldots \ldots \ldots \ldots \ldots \ldots . . .4 .4 .6$

3.4-2 Hypothesized TMI-2 condition between 150 and 160 minutes ............. 3.4-7

3.4-3 Schematic representation of possible mode of initial fuel liquefaction and

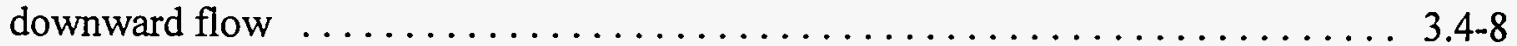

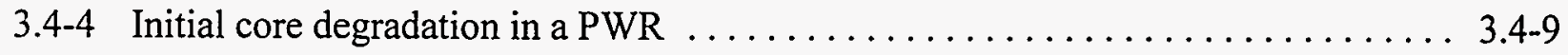

3.4-5 Hypothesized TMI- 2 core at 173 minutes $\ldots \ldots \ldots \ldots \ldots \ldots \ldots \ldots \ldots \ldots .4 .4 .10$ 


\section{List of Figures (Continued)}

3.4-6 Hypothesized TMI-2 core configuration between 174 and 180 minutes ....... 3.4-11

3.4-7 Hypothesized TMI-2 core configuration at 224 minutes (just prior to major core

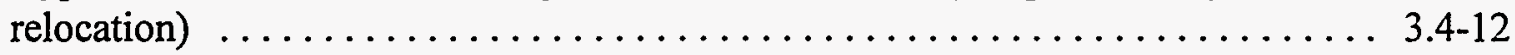

3.5-1 Hypothesized TMI-2 core configuration during relocation $\ldots \ldots \ldots \ldots \ldots \ldots .5 .5-10$

3.5-2 TMI-2 structures surrounding the core $\ldots \ldots \ldots \ldots \ldots \ldots \ldots \ldots \ldots \ldots . .5 .5 .11$

3.5-3 Fuel debris profile inside TMI-2 core barrel assembly (CBA laid flat) . . . . . 3.5-12

$3.5-4$ TMI-2 core support assembly $\ldots \ldots \ldots \ldots \ldots \ldots \ldots \ldots \ldots \ldots \ldots \ldots \ldots \ldots \ldots \ldots \ldots .5 .13$

3.5-5 Locations of solidified materials in TMI-2 core support assembly . . . . . . . 3.5-14

3.5-6 Locations of solidified material TMI-2 elliptical flow distributor . . . . . . . . $3.5-15$

3.5-7 TMI-2 hard layer debris depths in lower head $\ldots \ldots \ldots \ldots \ldots \ldots \ldots \ldots \ldots . .5 .6 \ldots$

3.5-8 TMI-2 lower-head cross section of hard debris, row $7 \ldots \ldots \ldots \ldots \ldots \ldots . .6 .5 .17$

3.5-9 Visualization of the downward progress of a coherent molten mass as the below-

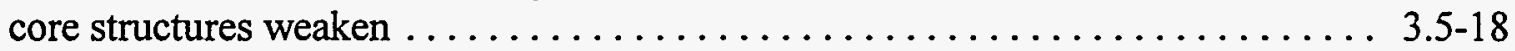

3.5-10 Cross-sectional views of TMI-2 hard layer debris sample $1-11-\mathrm{R} \ldots \ldots \ldots \ldots .3 .5-19$

3.5-11 Scanning electron microscope image of two phase region in TMI-2 hard layer

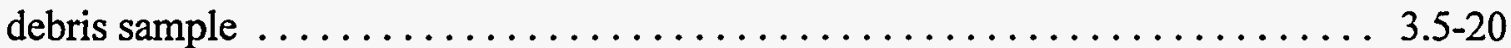

3.5-12 TMI-2 nozzle damage profile $\ldots \ldots \ldots \ldots \ldots \ldots \ldots \ldots \ldots \ldots \ldots \ldots \ldots \ldots \ldots \ldots .5 .21$

3.5-13 Location of lower head steel, nozzle, and guide tube samples $\ldots \ldots \ldots \ldots \ldots .3 .5-22$

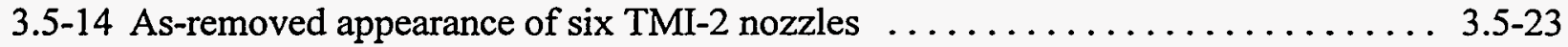

3.5-15 Lower head hot spot and nozzle guide tube locations $\ldots \ldots \ldots \ldots \ldots \ldots \ldots .5 .5-24$

3.5-16 Failure mechanism considered in TMI-2 analyses: (a) tube rupture, (b) weld failure-tube ejection, (c) global vessel failure, and (d) localized vessel failure . . 3.5-25

3.5-17 Typical debris bed dryout experiment $\ldots \ldots \ldots \ldots \ldots \ldots \ldots \ldots \ldots \ldots \ldots \ldots \ldots . .5 .26$

3.5-18 Debris bed dryout heat flux versus particle diameter for water $\ldots \ldots \ldots \ldots \ldots .3 .5-27$

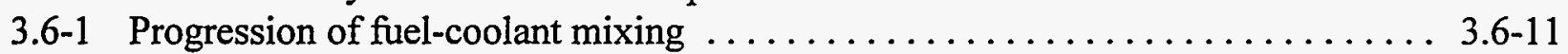

3.6-2 Energy required to vaporize $29 \mathrm{~m}^{3}$ of water versus saturation pressure $\ldots \ldots \ldots 3.6-12$

3.6-3 Melt pour into lower plenum by failure of core plate $\ldots \ldots \ldots \ldots \ldots \ldots .6 .6 .13$

$3.6-4$ Vessel failure from steam explosion $\ldots \ldots \ldots \ldots \ldots \ldots \ldots \ldots \ldots \ldots \ldots \ldots \ldots \ldots .6 \ldots \ldots .6 .14$

3.6-5 High pressure melt release from bottom of reactor vessel . . . . . . . . . . 3.6-15

3.6-6 Low pressure melt release from bottom of reactor vessel $\ldots \ldots \ldots \ldots \ldots \ldots .6 .6-16$

3.6-7 Secondary melt release in a Zion-type PWR reactor cavity . . . . . . . . . . 3.6-17

3.7-1 Definition of radial zones for Browns Ferry unit 1 cycle 6 core $\ldots \ldots \ldots \ldots .3 .7-25$

3.7-2 The progression of severe structural damage in the outer core would significantly lag events in the central core $\ldots \ldots \ldots \ldots \ldots \ldots \ldots \ldots \ldots \ldots \ldots \ldots .7 .26$

3.7-3 If the reactor vessel remains pressurized, relocating core debris falls into water

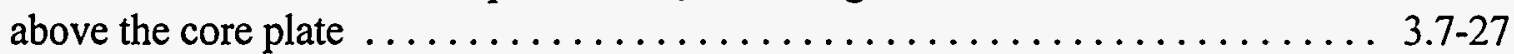

3.7-4 Effects of manual actuation of ADS at about $1 / 3$ core height $\ldots \ldots \ldots \ldots \ldots .7 .7-28$

3.7-5 Vessel depressurization at one-third core height provides steam cooling that temporarily reverses core heatup . . . . . . . . . . . . . . . . . . . . . . .

3.7-6 Vessel depressurization at one-third core height delays hydrogen release $\ldots \ldots$. 3.7-30

3.7-7 Region above the core plate would be dry during structural degradation . . . . . 3.7-31

3.7-8 For the two-stage target rock SRV, control air and system pressure act in concert

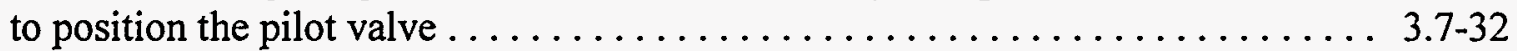

3.7-9 For the Crosby SRV, control air opens main valve $\ldots \ldots \ldots \ldots \ldots \ldots \ldots . . \ldots \ldots .33$ 


\section{List of Figures (Continued)}

3.7-10 Abbreviated schematic of a typical BWR SLCS

3.7-11 The condensate storage tank is an important source of water during accident sequences other than LBLOCA

3.7-12 The condensate storage tank can be drained to the main condenser hotwells, leaving sufficient water volume for the reactor vessel injection $\ldots \ldots \ldots \ldots . . \ldots 3.76$

3.7-13 The BWR control blades are inserted into the interstitial region between fuel assemblies in the core

3.7-14 One-half of the channel box outer surfaces do not see an intervening control blade. .

3.7-15 Relocation of control blades and channel box walls leaves only $\mathrm{UO}_{2}$ pellets encased in thin $\mathrm{ZrO}_{2}$ sheaths

3.7-16 The BWR core plate separates the core region from the reactor vessel lower

plenum but does not support the core

3.7-17 Control blade tip emerging from fuel support structure near core plate edge at

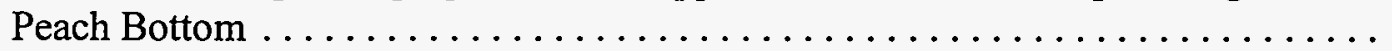

3.7-18 Material relocating from the core region would enter the reactor vessel lower

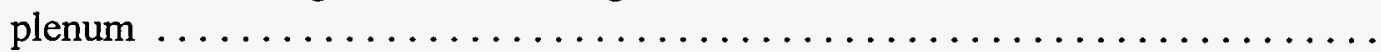

3.7-19 View of core plate with fuel support structures in place at Peach Bottom ......

3.7-20 Two-thirds of the area beneath the BWR core is blocked by the control rod guide tube

3.7-21 Code models specific to the BWR lower plenum and bottom head currently exist $\ldots \ldots \ldots \ldots \ldots \ldots \ldots \ldots \ldots \ldots \ldots \ldots \ldots \ldots \ldots \ldots \ldots \ldots \ldots \ldots \ldots . \ldots \ldots$.

3.7-22 The BWR control rod drive mechanism assemblies are held in place by upper
stub tube welds; the incore instrument tubes are supported by welds at the vesse wall ...

3.7-23 Weld holding control rod drive housing in place within stub tube at Peach Bottom

3.7-24 Instrument guide tube weld location at inner surface of vessel wall at Peach Bottom

3.7-25 Instrument tube failure by creep-rupture of welds and by melt overflow can be

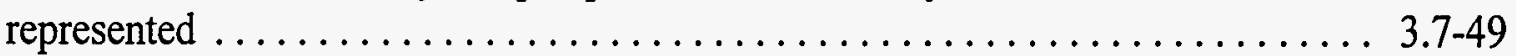

3.7-26 Zirconium oxidation accelerates the initial debris release rate for pressurized accident sequences

3.7-27 Atmospheric trapping within the reactor vessel support skirt could limit water contact with the wall $\ldots \ldots \ldots \ldots \ldots \ldots \ldots \ldots \ldots \ldots \ldots \ldots \ldots \ldots \ldots \ldots \ldots \ldots \ldots \ldots .7 .51$

3.7-28 Delayed wall creep rupture would occur in the vicinity of the gas pocket $\ldots \ldots$ 3.7-52

3.7-29 Cooling of upper vessel wall would be necessary after internal vessel structures have melted

4.1-1 Typical containment volumes and design pressure (psig) .............. 4.1-11

4.1-2 Comparison of design pressure and ultimate failure pressure $\ldots \ldots \ldots \ldots \ldots .4 .1-12$

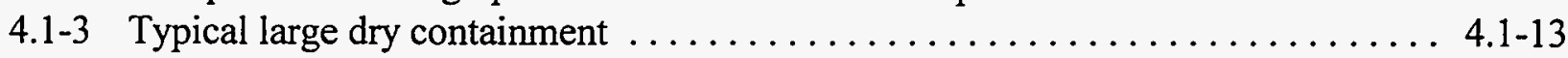

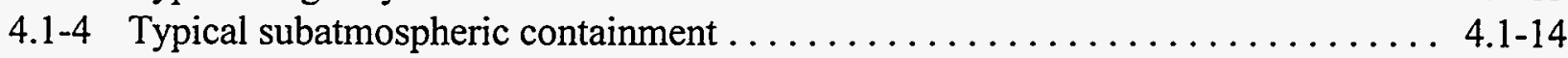

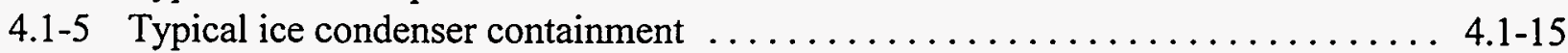

4.1-6 Ice condenser cutaway $\ldots \ldots \ldots \ldots \ldots \ldots \ldots \ldots \ldots \ldots \ldots \ldots \ldots \ldots \ldots \ldots \ldots \ldots \ldots \ldots, 1-16$ 


\section{List of Figures (Continued)}

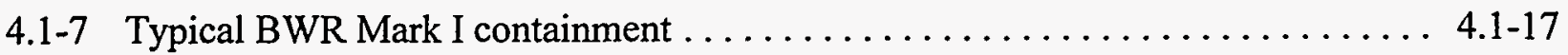

4.1-8 Typical BWR Mark II containment ........................... 4.1-18

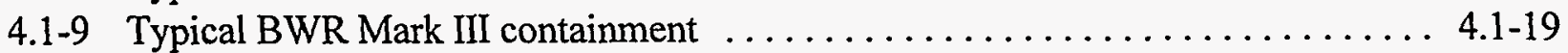

4.1-10 Peak containment pressure for one PWR . ................... 4.1-20

4.1-11 Containment pressure-temperature response for $8.55 \mathrm{ft}^{2}$ pump discharge break . . 4.1-21

4.1-12 Energy changes up to time of peak containment pressures for one PWR ...... 4.1-22

4.1-13 Different bolting arrangements on drywell head closure flange for Browns Ferry

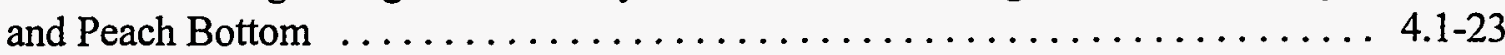

4.2-1 Relative probability of containment failure modes (internal events from

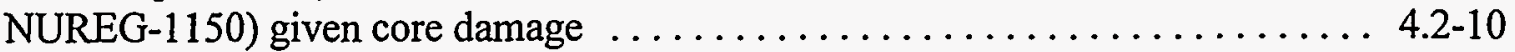

$4.2-2$ Containment failure frequency $\ldots \ldots \ldots \ldots \ldots \ldots \ldots \ldots \ldots \ldots \ldots \ldots \ldots \ldots \ldots \ldots \ldots \ldots \ldots .2-11$

4.2-3 Conditional containment failure probability (internal events) . . . . . . . . . 4.2-12

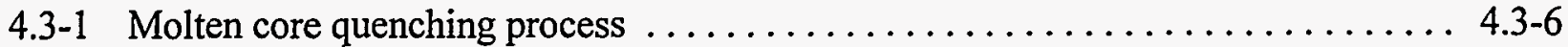

4.3-2 Containment pressure versus time for Zion station blackout sequence ........ 4.3-7

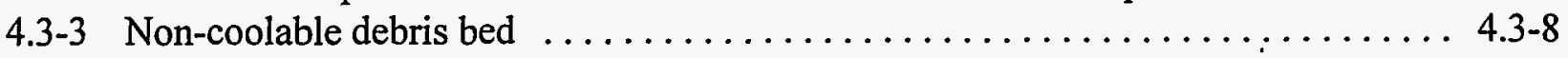

4.3-4 BWR Mark I containment pedestal region . . . . . . . . . . . . . . . . . . 4.3-9

4.3-5 BWR Mark II containment pedestal region $\ldots \ldots \ldots \ldots \ldots \ldots \ldots \ldots \ldots \ldots .4 .3-10$

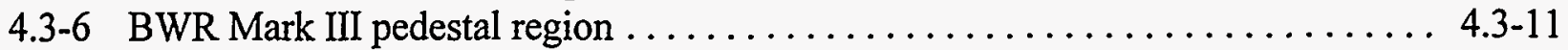

4.4-1 Thermal aspects of core-concrete interactions . . . . . . . . . . . . . . .

4.4-2 Calculations of concrete attack in a BWR Mark II containment during a station blackout sequence $\ldots \ldots \ldots \ldots \ldots \ldots \ldots \ldots \ldots \ldots \ldots \ldots \ldots \ldots \ldots . \ldots \ldots .4 .7$

4.4-3 Combustible gas generation during CCls $\ldots \ldots \ldots \ldots \ldots \ldots \ldots \ldots \ldots . .4 .4-8$

4.4-4 Example amounts of various gases that can be generated during core-concrete interactions ..................................... 4. 4

4.4-5 VANESA calculations of aerosol course rates $\ldots \ldots \ldots \ldots \ldots \ldots \ldots \ldots .4 .4 .10$

4.4-6 Peach Bottom station blackout, fission products released to drywell from coreconcrete interactions $\ldots \ldots \ldots \ldots \ldots \ldots \ldots \ldots \ldots \ldots \ldots \ldots \ldots . \ldots \ldots .4 .11$

4.4-7 Peach Bottom station blackout, masses released to drywell from core-concrete

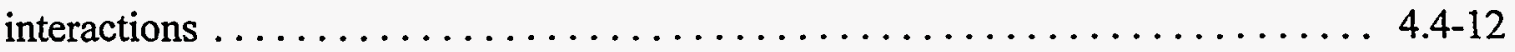

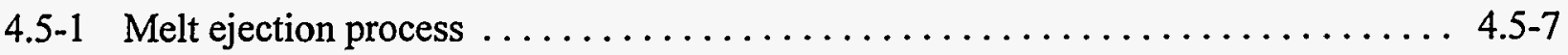

4.5-2 Distribution for fraction of core material ejected, PWR $\ldots \ldots \ldots \ldots \ldots \ldots \ldots$. $4.5-8$

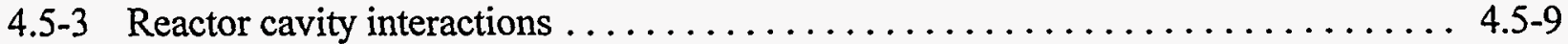

4.5-4 Estimated median particle size versus time $\ldots \ldots \ldots \ldots \ldots \ldots \ldots \ldots \ldots .4 .5-10$

4.5-5 Example distributions for pressure rise at vessel breach, Surry . . . . . . . . . 4.5-11

4.5-6 Surry containment pressure estimates from DCH resolution effort ......... 4.5-12

4.5-7 Large dry and subatmospheric containment results from DCH resolution effort . . 4.5-13

4.6-1 Theoretical adiabatic, constant-volume combustion pressure for hydrogen : air mixtures $\ldots \ldots \ldots \ldots \ldots \ldots \ldots \ldots \ldots \ldots \ldots \ldots \ldots \ldots . \ldots \ldots .6 .12$

4.6-2 Theoretical adiabatic, constant-volume combustion temperature for hydrogen : air mixtures ..................................... 4.

4.6-3 Effect of initial temperature on downward propagating flammability limits in

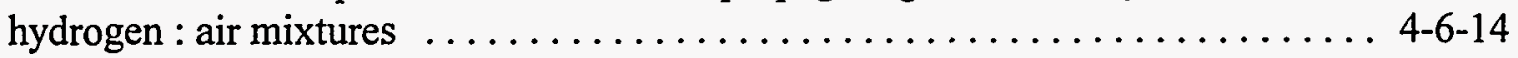

4.6-4 Flammability limits of hydrogen in air diluted with $\mathrm{CO}_{2}$ and $\mathrm{N}_{2} \ldots \ldots \ldots \ldots .64-15$

4.6-5 Flammability limits of hydrogen : air : steam mixtures $\ldots \ldots \ldots \ldots \ldots \ldots .6 .6-16$ 


\section{List of Figures (Continued)}

4.6-6 Spark ignition energies for dry hydrogen : air mixtures $\ldots \ldots \ldots \ldots \ldots \ldots .6 .6-17$

4.6-7 Normalized pressure rise versus hydrogen concentration $\ldots \ldots \ldots \ldots \ldots \ldots$ 4.6-18

4.6-8 Laminar burning velocity of hydrogen : air mixture $\ldots \ldots \ldots \ldots \ldots \ldots \ldots .6 .6-19$

4.6-9 Theoretical detonation velocities for hydrogen : air mixture . . . . . . . . . . 4.6-20

4.6-10 Hydrogen detonation cells . ........................... 4.6-21

4.6-11 Measurement of detonation cell size for hydrogen : air mixtures at atmospheric pressure . . . . . . . . . . . . . . . . . . . . 4.6-22

4.6-12 Dimensions required for detonation propagation in various geometries ...... 4.6-23

4.6-13 Theoretical detonation pressure and normally reflected pressure $\ldots \ldots \ldots \ldots .4 .6-24$

4.6-14 Theoretical detonation temperature and normally reflected detonation temperature $\ldots \ldots \ldots \ldots \ldots \ldots \ldots \ldots \ldots \ldots \ldots \ldots \ldots \ldots . .6 .6 .25$

4.6-15 Flame structures for a range of geometries and flow rates $\ldots \ldots \ldots \ldots \ldots \ldots 4.6-26$

4.6-16 Minimum spontaneous ignition temperatures $\ldots \ldots \ldots \ldots \ldots \ldots \ldots \ldots .6 .6-27$

4.6-17 TMI-2 containment pressure versus time $\ldots \ldots \ldots \ldots \ldots \ldots \ldots \ldots \ldots .6 .6-28$

4.7-1 The BWR Mark I containment design employs a small primary containment with a pressure suppression pool; secondary containment is provided by

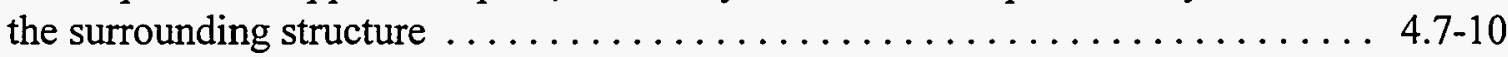

4.7-2 The Mark I drywell floor area is small and the drywell shell is within ten feet of the pedestal doorway $\ldots \ldots \ldots \ldots \ldots \ldots \ldots \ldots \ldots \ldots \ldots \ldots \ldots . . .7 .11$

4.7-3 Core debris released from the reactor vessel would spread over the BWR Mark I drywell floor, including the ex-pedestal region . ............. 4.7-12

4.7-4 Interior of reactor pedestal at Peach Bottom with partial view of doorway . . . . . 4.7-13

4.7-5 Shield over vent pipe entrance at Peach Bottom .................. 4.7-14

4.7-6 Approximately $5700 \mathrm{~m}^{3}\left(1.5 \times 10^{6}\right)$ gallons would be required to cover the reactor vessel bottom head at the largest (1100 Mwe) BWR facilities ........ 4.7-15

4A-1 Theoretical adiabatic, constant-volume combustion pressure for hydrogen :

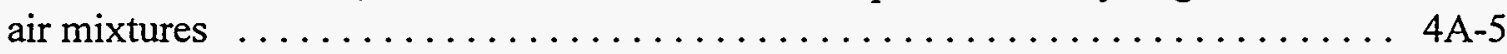

4A-2 Theoretical adiabatic, constant-volume combustion temperature for hydrogen :

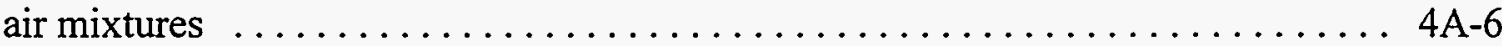

4A-3 Adiabatic, constant-volume combustion pressure for various containment initial conditions . ................................ 4 A 7

4A-4 Adiabatic, constant-volume combustion temperature for various containment

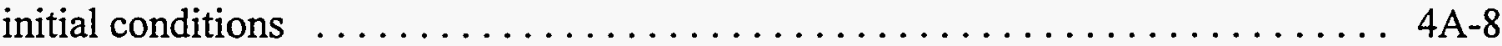

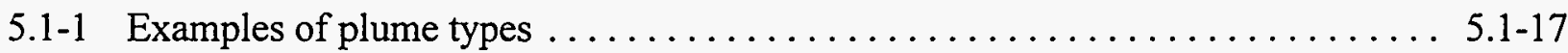

5.1-2 Putting radiation release (curies- $\mathrm{Ci}$ ) in perspective for the public $\ldots \ldots \ldots \ldots \ldots .1-18$

5.1-3 Event tree for severe accident consequences .................... 5.1-19

5.1-4 Comparison of NUREG-1150 source terms with Reactor Safety Study (Surry) bin PWR2 . . . . . . . . . . . . . . . . . . . . . . . . . . . . . . 5.1-20

5.1-5 Comparison of NUREG-1150 source terms with Reactor Safety Study (Peach Bottom) bin BWR4 .............................. 5.1-21

5.1-6 Release of Radionuclides during the active stage of the Chernobyl accident ... 5. 5.1-22

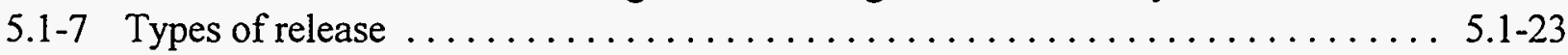

$5.2-1$ Steps in projecting offsite consequences $\ldots \ldots \ldots \ldots \ldots \ldots \ldots \ldots \ldots \ldots .2 .12$

5.2-2 Illustration of person-rems and cancers within 50 and 500 mile radii . ...... 5.2-13 


\section{List of Figures (Continued)}

5.2-3a Putting radiation in perspective for the public (mrem) $\ldots \ldots \ldots \ldots \ldots \ldots . .2-14$

$5.2-3 b$ Putting radiation in perspective for the public (mrem) $\ldots \ldots \ldots \ldots \ldots \ldots \ldots .2-15$

$5.2-4$ Radiation dose pathways $\ldots \ldots \ldots \ldots \ldots \ldots \ldots \ldots \ldots \ldots \ldots \ldots \ldots \ldots \ldots \ldots \ldots \ldots \ldots .2-16$

5.2-5 Examples of low-level temperature distribution in the atmosphere $\ldots \ldots \ldots \ldots$. $5.2-17$

5.2-6 Movement of a parcel of air in (a) a superadiabatic profile and (b) an inversion profile ........................................... 5.28

5.2-7 Various types of smoke plume patterns $\ldots \ldots \ldots \ldots \ldots \ldots \ldots \ldots \ldots \ldots \ldots \ldots \ldots \ldots \ldots .2-19$

5.2-8 Relationship between actual plume and model projections ............. 5.2-20

5.2-9 The quantity $X_{\tau} / Q$ at ground level, for effluents emitted at a height of $30 \mathrm{~m}$, as a function of distance from the source $\ldots \ldots \ldots \ldots \ldots \ldots \ldots \ldots \ldots . \ldots \ldots .2-21$

5.2-10 Radiation hot spots resulting from Chernobyl nuclear power plant accident . . . . 5.2-22

5.2-11a Stomach dose by exposure time: no sheltering, stability class $\mathrm{D}, 2.68 \mathrm{~m} / \mathrm{s}$ wind . . 5.2-23

5.2-11b Plume centerline stomach dose by pathway: no sheltering, 24-hour exposure class $\mathrm{D}, 2.68 \mathrm{~m} / \mathrm{s}$ wind $\ldots \ldots \ldots \ldots \ldots \ldots \ldots \ldots \ldots \ldots \ldots \ldots \ldots \ldots \ldots \ldots \ldots \ldots \ldots \ldots \ldots \ldots .2-23$

5.2-11c Thyroid dose by exposure time: no sheltering, stability class $\mathrm{D}, 2.68 \mathrm{~m} / \mathrm{s}$ wind .. $5.2-23$

5.2-11d Plume centerline thyroid dose by exposure pathway, no sheltering, 24-hour

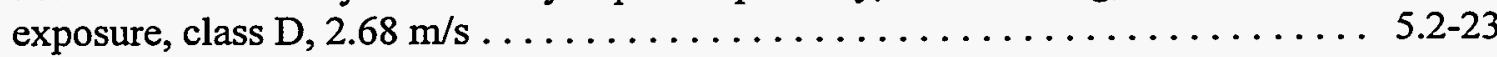

5.2-12 One-hour surface doses predicted by (A) Gaussian plume model, (B) pufftrajectory model, (C) complex numerical model, and (D) doses actually observed $\quad 5.2-24$

5.3-1 Early protective actions for core melt accidents . . . . . . . . . . . . . . . 5.3-19

5.3-2 Protective action flow chart for severe core damage or loss of control facility . . . 5.3-20

5.3-3 Relative effectiveness of early protective actions given early containment failure .................................... 5.3-21

5.3-4 Relative effectiveness of emergency response actions assuming early containment failure with high and low source terms $\ldots \ldots \ldots \ldots \ldots \ldots \ldots \ldots \ldots .3 .3-22$

5.3-5 Number of people within 1 and 5 miles of 111 nuclear power plants, actual or proposed in 1979 ................................... 5.3-23

5.3-6 Percent of thyroid blocking afforded by $100 \mathrm{mg}$ of stable iodine $(130 \mathrm{mg}$ of potassium iodide) as a function of time of administration before or after a $1-\mu \mathrm{Ci}$

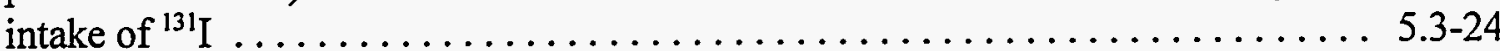

5.3-7 Hourly wind vector at Three Mile Island on March 28, $1979 \ldots \ldots \ldots \ldots \ldots .5 .3-25$

5.4-1 Relative locations of licensee emergency response centers ............. 5.4-16

5.4-2 Example of a plume emergency planning zone with boundaries and evacuation

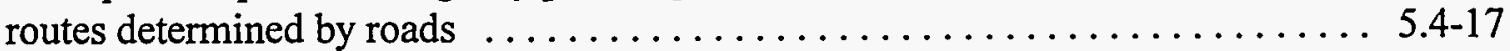

5.4-3 Example of a plume emergency planning zone $\ldots \ldots \ldots \ldots \ldots \ldots \ldots \ldots . .4 .4-18$

5.4-4 Flow chart showing steps from detection of a general emergency event in the control room to public evacuation $\ldots \ldots \ldots \ldots \ldots \ldots \ldots \ldots \ldots \ldots . . .4 .4 .19$ 


\section{List of Tables}

1.1-1 Defense in depth multilayer protection from fission products . . . . . . . . . 1.1-4

1.4-1 Chapter titles from regulatory guide 1.70 revision 3 standard format and content of safety analysis reports for nuclear power plants $\ldots \ldots \ldots \ldots \ldots \ldots \ldots \ldots \ldots .4 .4$

1.4-2 Representative initiating events to be analyzed in Section 15.X.X of the Safety

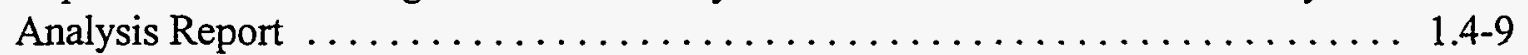

1.4-3 Partial comparison of realistic assumptions with conservative assumptions of

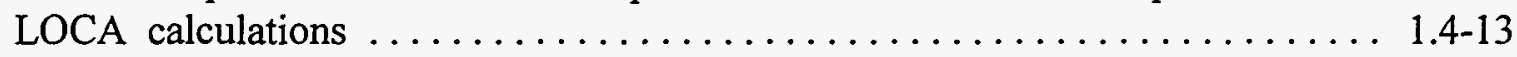

1.4-4 Potential offsite doses due to design-basis accidents (conservative case) . . . . . 1.4-15

1.4-5 Potential offsite doses due to releases at a typical PWR (realistic case) $\ldots \ldots \ldots 1.4-16$

1A-1 Consequence weighted risk . . . . . . . . . . . . . . 1A-19

1A-2 Transient initiating event frequencies $\ldots \ldots \ldots \ldots \ldots \ldots \ldots \ldots \ldots \ldots \ldots \ldots \ldots \ldots \ldots \ldots$

1A-3 Example BWR initiating event frequencies $\ldots \ldots \ldots \ldots \ldots \ldots \ldots \ldots$ A -22

1A-4 Initiating event frequencies for Plant Operating State 5 (cold shutdown) ...... 1A-23

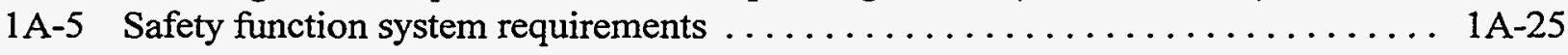

1A-6 Collections and summaries of actual failure events $\ldots \ldots \ldots \ldots \ldots \ldots \ldots \ldots \ldots \ldots \ldots$

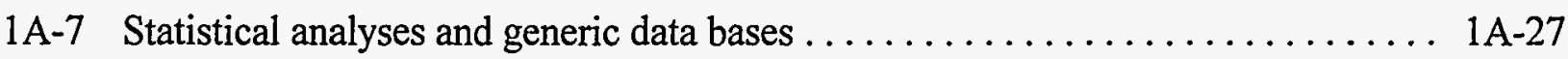

2B-1 The change in vapor specific volumes for a given change in pressure is much greater at low pressure (Table entries based on values taken from steam tables) . . 2B-20

2.1-1 Chronology of Major TMI-2 Accident Events .................. 2.1-17

2.3-1 The most dangerous violations of operating procedures at Chernobyl-4* $\ldots \ldots \ldots$ 2.3-7

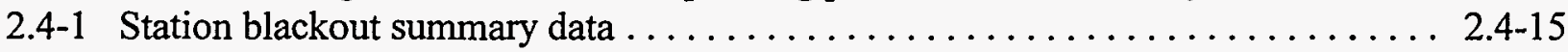

2.5-1 NRC Sources of reactor operational data $\ldots \ldots \ldots \ldots \ldots \ldots \ldots \ldots \ldots \ldots \ldots \ldots \ldots .2 .5-20$

2.5-2 NRC Feedback of nuclear power plant experience $\ldots \ldots \ldots \ldots \ldots \ldots \ldots \ldots .2 .5-21$

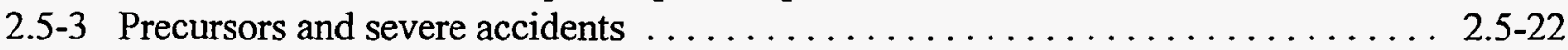

2.5-4 Distributions for Core damage frequency and aggregate risk for POS 5 and

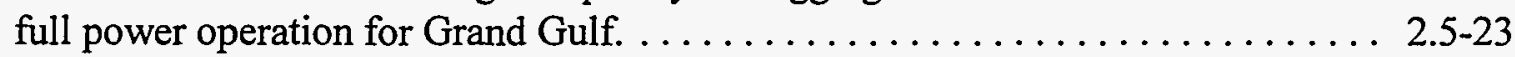

2.5-5 Distributions for Core damage frequency and aggregate risk for mid-loop and full

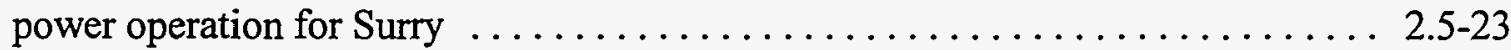

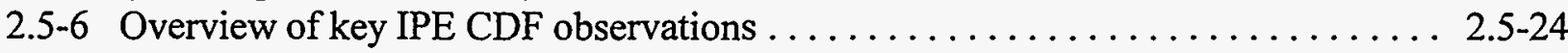

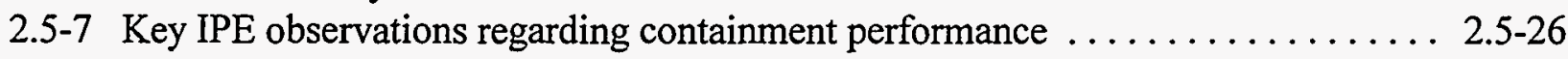

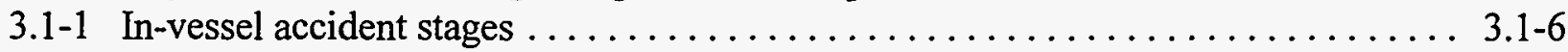

3.1-2 Severe Accident Conditions . . . . . . . . . . . . . . . . . . . . . . . . . .

3.5-1 Average TMI-2 lower head debris composition by quadrant (wt $\%) \ldots \ldots \ldots$. . . . . $5-9$

3.6-1 Fractions of core mixture that can be quenched in below-core for a typical PWR . . 3.6-7

3.6-2 Lower plenum features of a Westinghouse PWR . . . . . . . . . . . 3.6-7

3.6-3 NUREG-1150 alpha mode failure probabilities $\ldots \ldots \ldots \ldots \ldots \ldots \ldots .6 \ldots .6 .8$

3.6-4 Alpha-mode failure probability estimates (given a core melt accident) $\ldots \ldots \ldots \ldots 3.6-9$

3.6-5 Fuel coolant interaction experimental facility characteristics ............ 3.6-10

3.7-1 Vessel depressurization at one-third core height postpones the predicted core

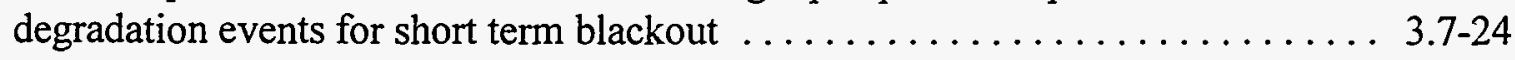

4-1-1 Number of U.S. containments of each type .................... 4.1-9

4.1-2 Examples of design leakage rates (integrated leakage) $\ldots \ldots \ldots \ldots \ldots \ldots . . \ldots .1-9$

4.1-3 10 CFR 50 Appendix $J$ test frequency requirements $\ldots \ldots \ldots \ldots \ldots \ldots \ldots .1 .10$

$4.2-1$ Containment threats according to time regime $\ldots \ldots \ldots \ldots \ldots \ldots \ldots \ldots .2 .9 \ldots \ldots$ 


\section{List of Tables (Continued)}

4.4-1 Typical chemical compositions of concrete (wt. \%) ................ 4.4-4

4.4-2 Core-concrete release for Peach Bottom station blackout sequence $\ldots \ldots \ldots \ldots$. 4.4-5

4.5-1 Scenarios Examined in DCH Resolution Effort ................... 4.5-6

4.6-1 Hydrogen flammability limits in steam-saturated air at room temperature . . . . . 4.6-11

4.7-1 Mark I liner qualitative failure probabilities for various severe accident challenges . .................................. 4.

4A-1 Computation of adiabatic, constant-volume pressure and temperature $\ldots \ldots \ldots .4 \mathrm{~A}-4$

5.1-1 Radioactive materials in a large [3300-MW] light water reactor core grouped by

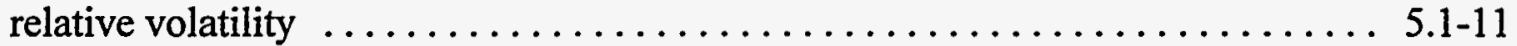

5.1-2 Typical inventories of noble gases and iodine in reactor systems $\ldots \ldots \ldots \ldots . . \ldots 5.1-12$

5.1-3 Illustrative noble gas and halogen releases $\ldots \ldots \ldots \ldots \ldots \ldots \ldots \ldots \ldots . . \ldots \ldots \ldots .1-13$

5.1-4 Decontamination factors associated with various design features $\ldots \ldots \ldots \ldots . . \ldots .1-14$

5.1-5 NUREG-1465 BWR releases into containments . . . . . . . . . . . . . . . . $5.1-15$

5.1-6 NUREG-1465 PWR releases into containments . . . . . . . . . . . . . . . . 5.1-15

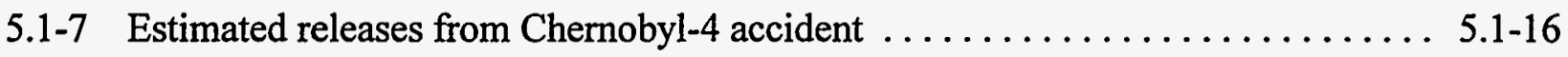

5.2-1 Relationship between Pasquill category and $\Delta T \Delta z$ and $\sigma_{\theta} \ldots \ldots \ldots \ldots \ldots \ldots .2-11$

5.2-2 Characteristic of hot spots resulting from Chernobyl accident $\ldots \ldots \ldots \ldots \ldots$. $5.2-11$

5.3-1 Exposure pathways, nuclear incident phases, and protective actions $\ldots \ldots \ldots \ldots$ 5.3-15

5.3-2 Public response to nuclear-related incidents $\ldots \ldots \ldots \ldots \ldots \ldots \ldots \ldots \ldots .3 .3 .16$

5.3-3 Factors by which radionuclide exposure may be reduced by sheltering for different types of shelters and pathways of exposure $\ldots \ldots \ldots \ldots \ldots \ldots \ldots .3 .3-17$

5.3-4 Respiratory protection provided by common household and personal items

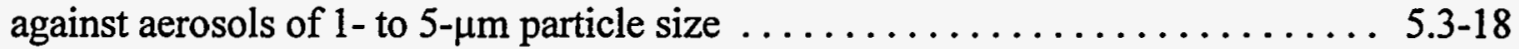

5.4-1 Sample initiating condition and examples of accompanying Emergency Action

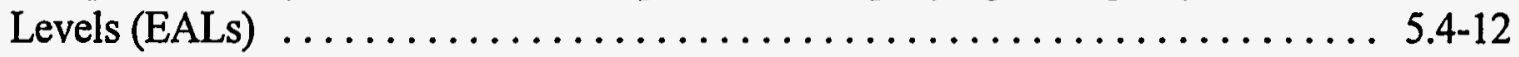

5.4-2 Example of timing for BWR general emergency sequences $\ldots \ldots \ldots \ldots \ldots \ldots .4-12$

5.4-3 Emergency class descriptions $\ldots \ldots \ldots \ldots \ldots \ldots \ldots \ldots \ldots \ldots \ldots \ldots \ldots \ldots \ldots \ldots .4 .13$

5.4-4 Emergency class response $\ldots \ldots \ldots \ldots \ldots \ldots \ldots \ldots \ldots \ldots \ldots \ldots \ldots \ldots \ldots .4 .14$

5.4-5 Emergency Class vs. Recognition Categories ................... 5.4-15

5A-1 Environmental Protection Agency recommended protective actions to reduce whole-body and thyroid dose from exposure to a gaseous plume $\ldots \ldots \ldots \ldots . \ldots \mathrm{A}-2$

5A-2 Environmental Protection Agency recommended protective actions to reduce external gamma dose from plume exposure and committed dose to the thyroid

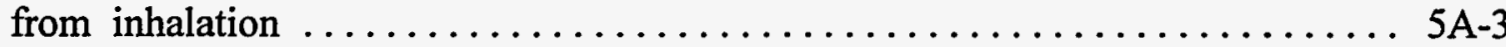

5A-3 Food and Drug Administration (FDA) protective action guides (PAGs) $\ldots \ldots \ldots$ 5A-3 


\section{List of Acronyms}

AC

ACRR

ACRS

ADHRS

ADS

AEC

AEOD

AFL-CIO

AFW

AFWS

ALARA

AOV

APRMs

ARAC

ARI

ASF

ASLAB

ASLB

ASME

ASP

ATOG

ATWS

BAF

BIIT

BNL

$B \& W$

BWR

CCFP

$\mathrm{CCI}$

CCTF

$\mathrm{CDF}$

CFF

CFR

CLB

CR

CRD

CRDHS

CSF

CST

$\mathrm{D}$

$\mathrm{DC}$

DBA

DCH

$\mathrm{DF}$
Alternating Current

Annular Core Research Reactor

Advisory Committee on Reactor Safeguards

Alternate Decay Heat Removal System

Automatic Depressurization System

Atomic Energy Commission

Analysis and Evaluation of Data

American Federation of Labor--Congress of Industrial Organizations

Auxiliary Feed Water

Auxiliary Feed Water System

As Low As Reasonable Achievable

Air Operated Valve

Average Power Range Monitors

Atmospheric Release Advisory Capability

Alternate Rod Injection

Auto Actuation Signal Fails

Atomic Safety and Licensing Appeal Board

Atomic Safety and Licensing Board

American Society of Mechanical Engineers

Accident Sequence Precursor

Abnormal Transients Operational Guide

Anticipated Transients Without Scram

Bottom of Active Fuel

Boron Injection Initiation Temperature

Brookhaven National Laboratory

Babcock and Wilcox

Boiling Water Reactor

Conditional. Containment Failure Probability

Core-Concrete Interactions

Core Cooling Task Force

Core Damage Frequency

Containment Failure Frequency

Code of Federal Regulations

Current Licensing Basis

Control Room

Control Rod Drive

Control Rod Drive Hydraulic System

Critical Safety Functions

Condensate Storage Tank

Dose

Direct Current

Design Basis Accident

Direct Containment Heating

Decontamination Factors 


\section{List of Acronyms (Continued)}

\begin{tabular}{|c|c|}
\hline DG & Diesel Generator \\
\hline DHR & Decay Heat Removal \\
\hline DOD & Department of Defense \\
\hline DOE & Department of Energy \\
\hline EAL & Emergency Action Levels \\
\hline ECCS & Emergency Core Cooling System \\
\hline EDG & Emergency Diesel Generator \\
\hline ENS & Emergency Network System \\
\hline EPA & Environmental Protection Agency \\
\hline EPG & Emergency Procedure Guidelines \\
\hline EPIP & Emergency Plan Implementation Procedures \\
\hline EPRI & Electric Power Research Institute \\
\hline EOF & Emergency Operations Facility \\
\hline $\mathrm{EPZ}$ & Emergency Planning Zone \\
\hline ERDA & Energy Research and Development Administration \\
\hline ERV & Electromatic Relief Valve \\
\hline ESF & Engineered Safety Feature \\
\hline $\mathrm{FCI}$ & Fuel-Coolant Interactions \\
\hline FDA & Food and Drug Administration \\
\hline FSAR & Final Safety Analysis Report \\
\hline FW & Feed Water \\
\hline FEMA & Federal Emergency Management Agency \\
\hline GDC & General Design Criteria \\
\hline GE & General Emergency \\
\hline GL & Generic Letter \\
\hline HCTL & Heat Capacity Temperature Limit \\
\hline HPCI & High Pressure Coolant Injection (HPI) \\
\hline HPCS & High Pressure Core Spray \\
\hline HPI & High Pressure Injection \\
\hline HPME & High Pressure Melt Ejection \\
\hline HPN & Health Physics Network \\
\hline HQ & Head Quarters \\
\hline HSBW & Hot Shutdown Boron Weight \\
\hline IDCOR & Industry Degraded Core Rulemaking \\
\hline INEL & Idaho National Engineering Laboratory \\
\hline INPO & Institute of Nuclear Power Operations \\
\hline IPE & Individual Plant Examination \\
\hline IRC & Incident Response Center \\
\hline IREP & Interim Reliability Evaluation Program \\
\hline JCAE & Joint Committee on Atomic Energy \\
\hline KAPL & Knolls Atomic Power Laboratory \\
\hline LD & Lethal Dose \\
\hline LER & Licensee Event Report \\
\hline LERF & Large Early Release Frequency \\
\hline
\end{tabular}




\section{List of Acronyms (Continued)}

\begin{tabular}{|c|c|}
\hline LLNL & Lawrence Livermore National Laboratory \\
\hline LOCA & Loss of Coolant Accident \\
\hline LOFW & Loss of Feed Water \\
\hline LOSP & Loss of Off-Site Power \\
\hline LPCI & Low Pressure Coolant Injection \\
\hline LPCS & Low Pressure Core Spray \\
\hline LPZ & Low Population Zone \\
\hline LWR & Light Water Reactor \\
\hline $\mathrm{MCA}$ & Maximum Credible Accident \\
\hline MDP & Motor Driven Pump \\
\hline MOV & Motor Operated Valve \\
\hline MSIV & Main Steam Isolation Valve \\
\hline MSLB & Main Steam Line Break \\
\hline MU & Make Up \\
\hline Mwt & Megawatt Thermal \\
\hline Mwe & Megawatt Electric \\
\hline NASA & National Aeronautics and Space Administration \\
\hline NDT & Nil-ductility Transition \\
\hline NEPA & National Environmental Policy Act \\
\hline NPSH & Net Positive Suction Head \\
\hline $\mathrm{NRC}$ & Nuclear Regulatory Commission \\
\hline NRR & Nuclear Reactor Regulation \\
\hline NSAC & Nuclear Safety Analysis Center \\
\hline NUMARC & Nuclear Utilities Management \& Resources Council \\
\hline OBE & Operational Basis Earthquake \\
\hline OFA & Operator Fails to Activate System \\
\hline ORNL & Oak Ridge National Laboratory \\
\hline OSC & Operations Support Center \\
\hline OTSG & Once-Through Steam Generator \\
\hline PAG & Protection Action Guidelines \\
\hline P\&ID & Piping \& Instrument Diagram \\
\hline PCS & Power Conversion System \\
\hline POM & Pump Out for Maintenance \\
\hline PFR & Pump Fails to Run \\
\hline PFS & Pump Fails to Start \\
\hline PORV & Pilot-Operator Relief Valve \\
\hline POS & Plant Operation State \\
\hline PPF & Failure of Power to Pump \\
\hline PRA & Probabilistic Risk Assessment \\
\hline PRDC & Power Reactor Development Company \\
\hline PTS & Pressurized Thermal Shock \\
\hline PWR & Pressurized Water Reactor \\
\hline $\mathrm{QHO}$ & Quantitative Health Objectives \\
\hline $\mathrm{RCIC}$ & Reactor Core Isolation Cooling \\
\hline
\end{tabular}




\section{List of Acronyms (Continued)}

\begin{tabular}{|c|c|}
\hline $\mathrm{RCP}$ & Reactor Coolant Pump \\
\hline RCS & Reactor Coolant/Reactor Containment System \\
\hline RHR & Residual Heat Removal \\
\hline RMIEP/PRUEP & $\begin{array}{l}\text { Risk Methods Integration Program/Phenomenology and Risk Uncertainty } \\
\text { Evaluation Program }\end{array}$ \\
\hline RPS & Reactor Protection System \\
\hline RPT & Recirculation Pump Trip \\
\hline RPV & Reactor Pressure Vessel \\
\hline $\mathrm{RSC}$ & Reactor Safeguards Committee \\
\hline RSCS & Rod Sequence Control System \\
\hline RSS & Reactor Safety Study \\
\hline RSSMAP & Reactor Safety Study Methodology Applications Program \\
\hline RT & Reference Temperature \\
\hline RTM & Response Technical Manual \\
\hline RV & Reactor Vessel \\
\hline RWCU & Reactor Water Clean Up \\
\hline RWM & Rod Worth Minimizer \\
\hline SALP & Systematic Assessment of Licensee Performance \\
\hline SAR & Safety Analysis Report \\
\hline SBO & Station Blackout \\
\hline SDC & Shut Down Cooling \\
\hline SDV & Scram Discharge Volume \\
\hline SERG & Steam Explosion Review Group \\
\hline SFRCS & Steam Feedwater Rupture Control System \\
\hline SGTR & Steam Generator Tube Rupture \\
\hline SLCS & Standby Liquid Control System \\
\hline SPDS & Safety Parameter Display System \\
\hline SRV & Safety Relief Valve \\
\hline SSC & Structures, Systems, and Components \\
\hline SSE & Safe Shutdown Earthquake \\
\hline STA & Shift Technical Advisor \\
\hline SSW & Standby Service Water \\
\hline SUFP & Start Up Feedwater Pump \\
\hline TAF & Top of Active Fuel \\
\hline TAP & Task Action Plan \\
\hline TID & Technical Information Document \\
\hline TMI & Three Mile Island \\
\hline $\mathrm{TSC}$ & Technical Support Center \\
\hline TVA & Tennessee Valley Authority \\
\hline UV & Under Voltage \\
\hline
\end{tabular}




\section{ACKNOWLEDGMENTS}

This course covers an extremely wide range of topics. Developing this material required input from numerous people at the NRC and elsewhere. In particular, we would like to thank Dr. Denwood Ross, whose breadth and depth of knowledge concerning the history of reactor safety was invaluable. Addition information and program guidance was provided by Mark Cunningham and Lee Abramson of the NRC PRA branch. Other key NRC reviewers included Ken Raglin, Len Reidinger, Larry Bell, Erick Beckjord, Warren Minners, Jocelyn Mitchell, Tom McKenna, and Jack Lewis.

At Sandia, information and insights were provided by Walt von Riesemann, Dana Powers, Susan Dingman, and Fred Harper. Dana Powers, Rick Pepping, and Martin Pilch provided valuable review comments. Finally, we wish to acknowledge the support of Kelly Jorgensen, Geoff Courtin, Judy Jones, Darla Tyree, Emily Preston, and Ellen Walroth in the preparation of this document. 


\section{English to Metric \\ Conversion Factors}

$\begin{array}{ll}\text { English } & \text { Metric } \\ 1 \mathrm{Foot} & .3048 \text { meters } \\ 1 \mathrm{Mile} & 1.6093 \text { kilometers } \\ 1 \mathrm{ft}^{2} & .0929 \mathrm{~m}^{2} \\ 1 \mathrm{gallon} & 3.785 \times 10^{-3} \mathrm{~m}^{3} \\ 1 \mathrm{ft}^{3} & .02832 \mathrm{~m}^{3} \\ 1 \mathrm{lbm} & .4536 \mathrm{~kg} . \\ 1 \mathrm{lbf} & 4.44822 \mathrm{Newtons} \\ 1 \mathrm{psi} & 6895 \text { pascals } \\ 1 \mathrm{BTU} & 1055 \mathrm{Joules} \\ 1 \mathrm{Btu} / \mathrm{hr} . & .2931 \text { watts } \\ 1 \mathrm{BTU} / \mathrm{hr}^{3} \mathrm{ft}^{2} & 3.155 \text { watts } / \mathrm{m}^{2}\end{array}$




\subsection{The Development of Safety Concepts, 1946 - 1975}

\subsubsection{Introduction}

Of all modern technologies, the highest potential for catastrophe in the public's mind is probably associated with nuclear power. The awesome destructive power of nuclear weapons provides reason for some to fear all things that utilize nuclear energy or emit radiation. The accidents at Three Mile Island (TMI) and Chernobyl strongly reinforced intuitive public concerns about nuclear power.

In the U.S., the potential hazards of nuclear power were recognized very early, and some features to prevent, contain, and otherwise protect the public from reactor accidents were applied from the outset. U.S. safety strategies evolved with successive generations of larger capacity plants, and many additional safety features were introduced.

It is true that U.S. plants are inherently safer than plants like Chernobyl. It is also true that single accidents in other industries have killed and injured far more people than Chernobyl. However, such arguments are not likely to alter the public perceptions of the hazards of nuclear power. More importantly, no arguments can change the actual hazard--the core inventories of radionuclides.

Whether one's objective is to make nuclear power plants safer or to change public perceptions of their safety, in the long run, the attitude recommended for the nuclear industry by the President's Commission on TMI-2 seems most likely to succeed:
Nuclear power is by its very nature potentially dangerous, and ... one must continually question whether the safeguards already in place are sufficient to prevent major accidents. ${ }^{\prime}$

This course presents both historical and technical information required to support such an attitude.

Figure 1.0-1 depicts the timing of major events and activities relevant to commercial power reactor safety from the 1940 s to the present. To provide a framework for the chapters that follow, a brief history of developments significant to the U.S. regulatory process is presented in Chapters 1 and 2. Trends and events are discussed in roughly the chronological order in which they became significant. Chapter 1 considers the time preceding the accident at Three Mile Island Unit 2 (TMI-2). Chapter 2 discusses the TMI-2 accident and subsequent events. Several references provide additional information regarding the history of nuclear regulation. ${ }^{2,3,4,5,6,7,8,9,10}$

\subsubsection{Learning Objectives for Module 1}

At the end of this module, the student should be able to:

1. Describe the principal elements of the defense-in-depth strategy.

2. Describe the legal basis of NRC's regulatory process including the content and impact of:

a. The Atomic Energy Acts of 1946 and 1954

b. Price-Anderson Act

c. The National Environmental Policy Act of 1969 
d. The Energy Reorganization Act of 1974

3. Describe the content of some key elements of NRC's regulations and regulatory process, including:
a. General Design Criteria (10 CFR 50 Appendix A)
b. Emergency Core Cooling System Acceptance Criteria (10 CFR 50.46 and Appendix K)
c. Siting Criteria (10 CFR 100)

4. Describe three key conservatisms inherent in traditional design-basis accident analyses.
5. Give examples accident initiators and multiple failures that would result in beyond-design-basis accidents. Explain why some beyond-design-basis accidents would not be severe accidents

6. Discuss the reasons why the Browns Ferry fire burned for so long.

7. Describe the level of NRC interest in severe accidents that resulted from the Reactor Safety Study and the Browns Ferry fire. 
Operational Milestones

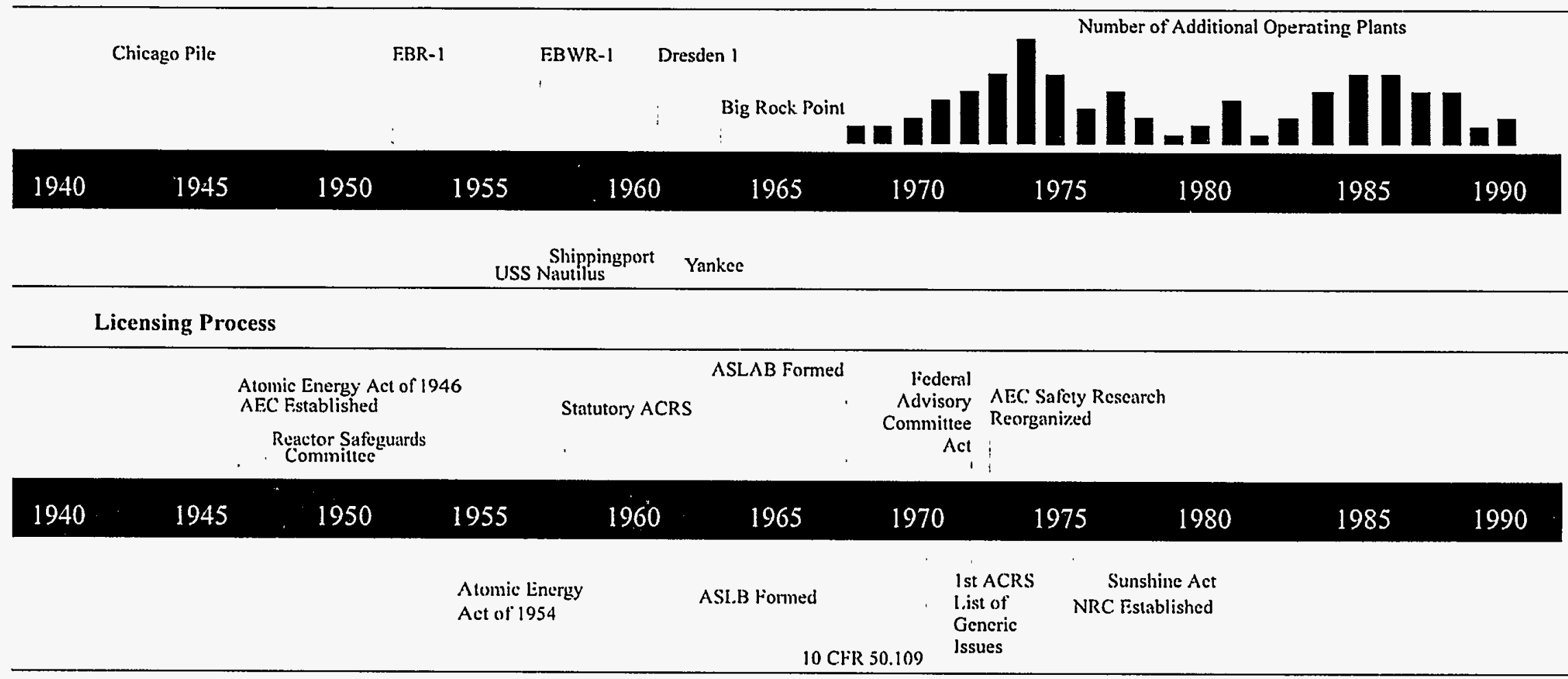

Regulatory Decision \& Criteria

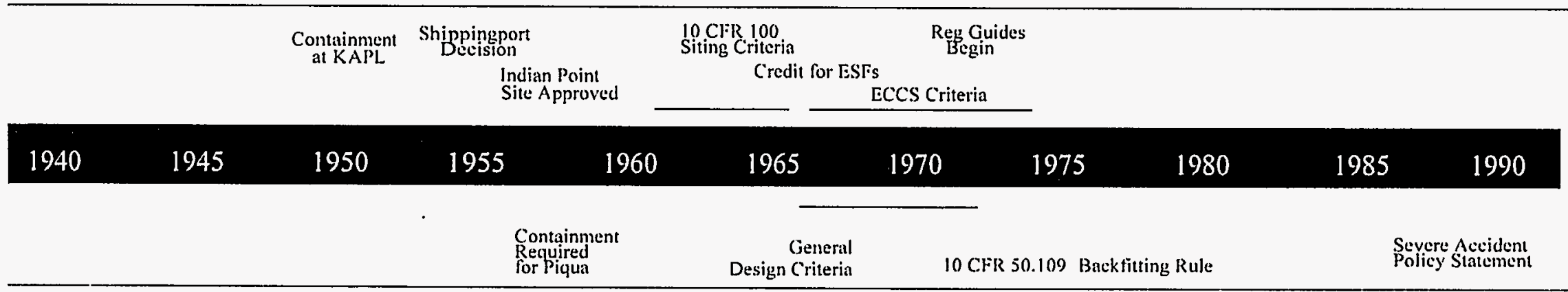

Figure 1.0-1 Timing of major events and activities relevant to commercial power reactor safety from 1940s to present ( 1 of 2 ) 


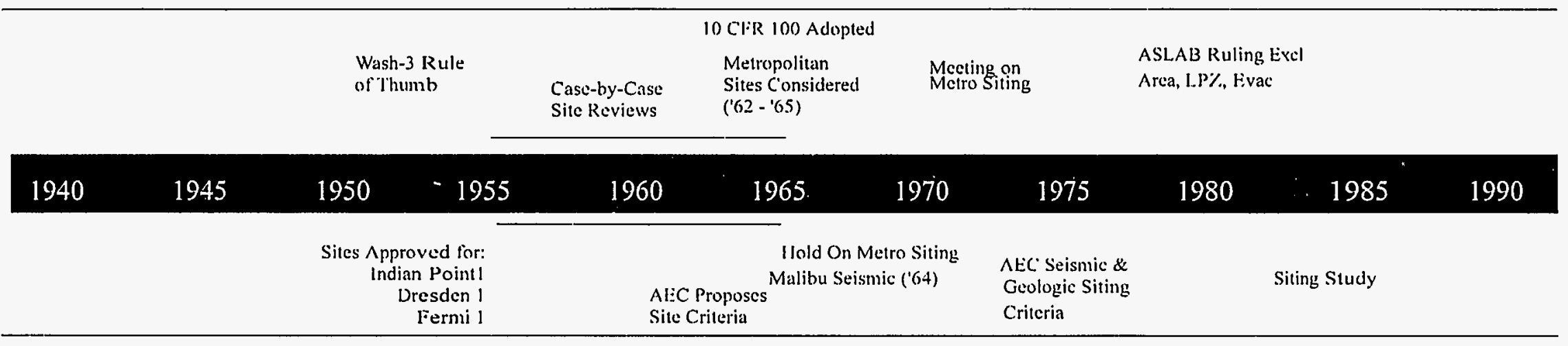

Accidents \& Incidents

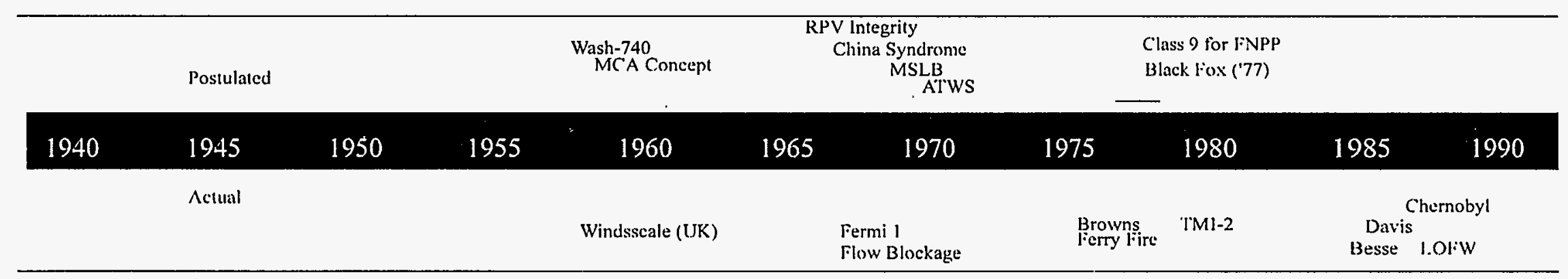

Probabilistic Risk Assessment

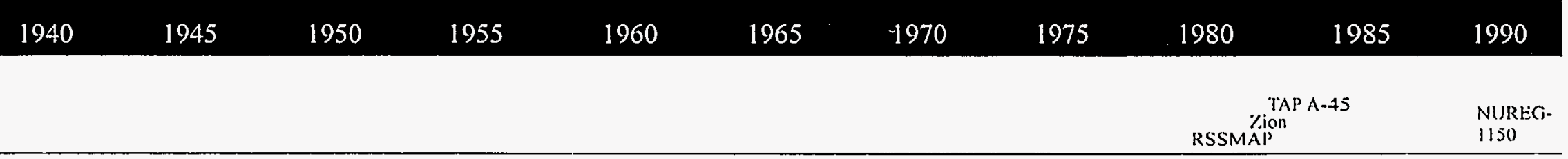

\section{Figure 1.0-1 Timing of major events and activities relevant to commercial power reactor safety from} 1940 s to present $(2$ of 2$)$ 


\section{References for Section 1.0}

1. John G. Kemeny, et al., "Report of the President's Commission on the Accident at Three Mile Island," October 1979.

2. Richard G. Hewlett and Francis Duncan, "Atomic Shield, 1947/1952, Volume II, A History of the United States Atomic Energy Commission," The Pennsylvania State University Press, University Park, Pennsylvania, 1960.

3. C. P. Russel, "Reactor Safeguards," MacMillan, New York, 1962.

4. Richard G. Hewlett and Francis Duncan, "Nuclear Navy 1946-1962", University of Chicago Press, Chicago, Illinois, 1974.

5. George T. Mazuzan and Roger R. Trask, "An Outline History of Nuclear Regulation and Licensing 1946-1979," Historical Office, Office of the Secretary, Nuclear Regulatory Commission, April 1979.

6. David Okrent, "Nuclear Reactor Safety: On the History of the Regulatory Process,"
The University of Wisconsin Press, Madison, Wisconsin, 1981.

7. Alice L. Buck, "A History of the Atomic Energy Commission," DOE/ES-0003/1, U.S. Department of Energy, Assistant Secretary, Management and Administration, Office of the Executive Secretariat, History Division, Washington, DC, July 1983.

8. George T. Mazuzan and Samuel Walker, "Controlling The Atom: The Beginnings of Nuclear Regulation 1946-1962," University of California Press, 1984.

9. J. Samuel Walker, "A Short History of Nuclear Regulation 1946-1990," Historical Office, Office of the Secretary, Nuclear Regulatory Commission, June 1991.

10. American Nuclear Society, "Controlled Nuclear Chain Reaction, The First 50 Years," La Grange Park, Illinois, 1992. 


\subsection{6-1953, Emergence of Safety Strategies}

\subsubsection{The Atomic Energy Act of 1946}

Following the use of the atomic bomb to end World War II, peaceful uses of nuclear energy were rapidly proposed. However, a much higher priority was to maintain control of and advance the weapons-related aspects of the new technology. Consequently, the Atomic Energy Act of 1946, while providing a statutory basis for developing peaceful uses of nuclear energy, stressed the need for secrecy, raw materials, and the production of new weapons. The act did not allow for private commercial applications of nuclear energy; instead, it created a virtual federal government monopoly of the new technology and stressed the minimum regulation necessary under this monopolistic framework. To manage the nation's atomic energy programs, the act established the five-member Atomic Energy Commission (AEC). The Joint Committee on Atomic Energy (JCAE) was created by the act to provide congressional oversight of the AEC.

\subsubsection{Remote Siting}

In 1947 the AEC established a Reactor Safeguards Committee (predecessor to the current Advisory Committee on Reactor Safeguards, ACRS) to determine whether the reactors being planned could be built without endangering public safety. In the first few years after World War II, several low-power (less than $50 \mathrm{MWt}$ ) engineering test reactors were built in the United States to develop peaceful uses of atomic energy. For most of these reactors, the Reactor Safeguards Committee continued the practice established during the Manhattan Project of siting reactors on large government reservations far from populated areas.

A 1950 report, WASH-3,' describes this isolated siting practice. For each reactor, a serious accident was postulated. The accident involved gross overheating or melting of the fuel, rupture of the reactor coolant system, and an uncontrolled release of radionuclides from the relatively conventional building that housed the reactor. Allowing for meteorological effects on the transport and dispersion of radionuclides, the Reactor Safeguards Committee recommended that residents be excluded within a specified distance $R$ of the reactor. The exclusion distance $R$ was related to the reactor thermal power $P$ in kilowatts by the following rule of thumb:

$$
\mathrm{R} \text { (miles) }=0.01 \sqrt{\mathrm{P}(\mathrm{kWt})}
$$

or

$$
\mathrm{R} \text { (kilometers) }=0.016 \sqrt{\mathrm{P}(\mathrm{kWt})} \text {. }
$$

Outside the exclusion area, it was stipulated that the calculated radiation exposure should be less than 300 rem (which is roughly the threshold for a lethal dose), or evacuation should be possible. For a $30 \mathrm{MWt}$ plant, the rule of thumb gives an exclusion distance of 2.24 miles $(3.6 \mathrm{~km})$. For a $3000 \mathrm{MWt}$ plant like many currently used to produce electricity, the rule of thumb would give an exclusion distance of 17.3 miles $(27.8 \mathrm{~km})$.

\subsubsection{Containment}

A significant early exception to government reservation siting was approved in 1952 for the sodium-cooled Submarine Intermediate Reactor Mark A, which was located at Knolls Atomic Power Laboratory (KAPL) 
only 19 miles $(30.6 \mathrm{~km})$ from Schenectady, NY. In response to Reactor Safeguards Committee concerns, the entire reactor facility was enclosed in a gas-tight steel sphere that was designed to withstand "a disruptive core explosion from nuclear energy release, followed by sodium-water and air reactions" ${ }^{2}$ and to contain radionuclides that might otherwise be released in a reactor accident ${ }^{3}$. The AEC accepted this containment strategy; however, containment was not considered a perfect substitute for isolation by distance. The reactor was still built in a sparsely populated area.

In December 1953 the AEC invited private industry to submit proposals for the first "civilian" nuclear power plant. This plant, the Shippingport Atomic Power Station, which was also called the pressurized water reactor (PWR), was owned by the government but was designed and constructed by Westinghouse and operated by Duquesne Light Company under the stringent guidance of the Division of Naval Reactors of the AEC. The PWR would not have met the 1950 rule of thumb criterion. The Shippingport, Pennsylvania site was about 420 acres $\left(1.7 \mathrm{~km}^{2}\right)$ in area and about 20 miles $(32 \mathrm{~km})$ from Pittsburgh. Although remote, the site was in a region with more population than was characteristic of isolated government reservation sites. Therefore a containment building was provided for Shippingport.

\subsubsection{Accident-prevention and Safety Systems}

Nuclear-powered submarines were developed in parallel with commercial nuclear power plants in the early 1950s. The U.S.S. Nautilus, the first nuclear-powered submarine, commenced sea trials in 1955, whereas Shippingport began to produce electrical power in 1957. Since the submarine crew had no avenue of escape while the ship was at sea and major ports were generally large population centers, remote siting could not be relied upon to acceptably limit the consequences of an accident, nor could containment be reasonably engineered for a submarine.

As a result, the Navy relied on an accidentprevention strategy. Stringent procedures were developed for operator training, quality control, and system/component testing. Systems and components were built with considerable design margin to withstand substantially higher than likely temperatures and pressures. Potential equipment malfunctions and failures were postulated anyway, and redundant safety systems were included in the design so that each safety function could be performed by more than one component or system. Prevention and safety-system strategies analogous to those used for submarine reactors evolved in the 1950 s and early 1960s for commercial nuclear reactors on a case-by-case basis.

\subsubsection{Defense In Depth}

Figure 1.1-1 shows the key elements of an overall safety strategy that began to emerge in the early 1950 s and has become known as defense in depth. One key element is accident-prevention. Quality control and assurance are emphasized; plant systems and structures are conservatively designed, procured, and installed; and operators are trained to reduce the likelihood of initiating a serious accident. In spite of these accident-prevention measures, equipment failures and operator errors that could result in serious accidents are postulated, and 
redundant safety systems are installed to prevent the release of radionuclides from the fuel. Notwithstanding these safety systems, radionuclide releases from the reactor coolant system are postulated, and a containment building is provided to prevent these radionuclides from escaping the plant. Plants are now being required to develop accident management programs, which should reduce the likelihood of uncontrolled radionuclide releases during accidents. Further, in siting the reactor, exclusion areas and low population zones (Section 1.2.6) are provided so that potential leakage from the containment can be tolerated without endangering nearby residents. Finally, emergency plans (Sections 2.2.6 and 5.4.5) are developed that include provisions for sheltering and evacuation to further reduce potential doses to the public. Defense in depth can also be described in terms of the multiple barriers or layers of protection against radionuclide releases as indicated in Table 1.1-1.
The preceding description of defense in depth does not address questions of what accident initiators to postulate; what reactor containment radionuclide releases to postulate; how much credit should be given for removing radionuclides using containment sprays, fan coolers, or suppression pools; how strong the containment should be; or what containment leakage to postulate. Of necessity, answers to these questions evolved and continue to evolve as plants are licensed, safety issues are addressed, operating experience is obtained, accidents occur, and safety research is conducted.

As the history discussed in the following sections demonstrates, balance evolved in the defense-in-depth strategy. No single element (e.g., accident-prevention) or barrier (e.g., containment) is emphasized to the exclusion of others. Much of this course describes the current balance and how it was achieved. 
Table 1.1-1 Defense in depth multilayer protection from fission products

\begin{tabular}{|c|c|}
\hline Barrier or Layer & Function \\
\hline 1. Ceramic fuel pellets & $\begin{array}{l}\text { Only a fraction of the gaseous and volatile fission } \\
\text { products is released from the pellets. }\end{array}$ \\
\hline 2. Metal cladding & $\begin{array}{l}\text { The cladding tubes contain the fission products } \\
\text { released from the pellets. During the life of the } \\
\text { fuel, less than } 0.5 \text { percent of the tubes may } \\
\text { develop pinhole sized leaks through which some } \\
\text { fission products escape. }\end{array}$ \\
\hline 3. Reactor vessel and piping & $\begin{array}{l}\text { The } 8-\text { to } 10-\text { in. }(20-\text { to } 25-\mathrm{cm}) \text { thick steel vessel } \\
\text { and } 3-\text { to } 4-\text { in. }(7.6-\text { to } 10.2-\mathrm{cm}) \text { thick steel piping } \\
\text { contain the reactor cooling water. A portion of the } \\
\text { circulating water is continuously passed through } \\
\text { filters to keep the radioactivity low. }\end{array}$ \\
\hline 4. Containment & $\begin{array}{l}\text { The nuclear steam supply system is enclosed in a } \\
\text { containment building strong enough to withstand } \\
\text { the rupture of any pipe in the reactor coolant } \\
\text { system. }\end{array}$ \\
\hline 5. Exclusion area & $\begin{array}{l}\text { A designated area around each plant separates the } \\
\text { plant from the public. Entrance is restricted. }\end{array}$ \\
\hline $\begin{array}{l}\text { 6. Low population zone, } \\
\text { evacuation plan }\end{array}$ & $\begin{array}{l}\text { Residents in the low population zone are protected } \\
\text { by emergency evacuation plans. }\end{array}$ \\
\hline 7. Population center distance & $\begin{array}{l}\text { Plants are located at a distance from population } \\
\text { centers. }\end{array}$ \\
\hline
\end{tabular}




\section{Safety Strategy}

\section{Postulate}

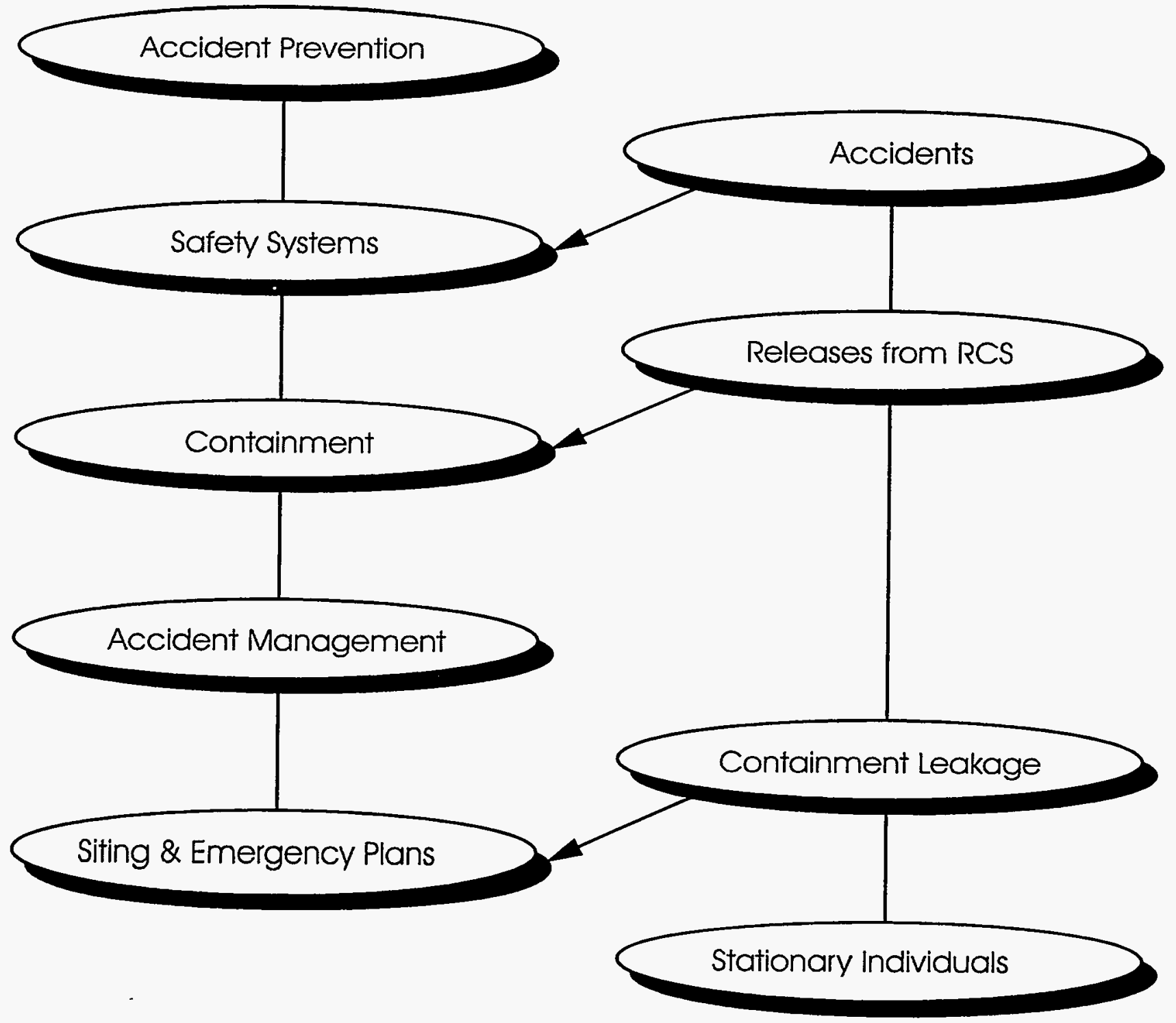

Figure 1.1-1 Defense in depth, safety strategies 


\section{References for Section 1.1}

1. U.S. Atomic Energy Commission, "Summary Report of Reactor Safeguards Committee," WASH-3, 1950.

2. C. P. Russel, "Reactor Safeguards," p. 19, MacMillan, New York, 1962.
3. Richard G.Hewlett and Francis Duncan, "Nuclear Navy 1946-1962," p. 176, University of Chicago Press, Chicago, Illinois, 1974 


\subsection{4-1965 Early Commercial Reactors, Emphasis on Containment}

\subsubsection{Atomic Energy Act of 1954}

In the early $1950 \mathrm{~s}$, there was no immediate need for nuclear power plants in the U.S. The impetus for developing U.S. nuclear power plants came from the fear of falling behind other nations, particularly the Soviet Union. In the midst of the cold war, U.S. government officials argued that countries in need of electrical power would gravitate toward the Soviet Union if it won the nuclear power race. In addition, with the development of the hydrogen bomb by both the U.S. and the Soviet Union, strong desire was expressed by the President and congressional leaders for peaceful uses of nuclear energy. But the development of such peaceful uses was thwarted by the limitations on access to technical information imposed by the Atomic Energy Act of 1946. After considerable debate concerning the merits of public versus private power, the 1946 act was amended by the Atomic Energy Act of 1954. Much of this act survives today under the Nuclear Regulatory Commission.

Among other things, the 1954 act provided for

\section{a program to encourage widespread participation in the development and utilization of atomic energy for peaceful purposes to the maximum extent consistent with the common defense and security and with the health and safety of the public.}

The act largely satisfied industry needs for information, and it allowed private patents for inventions related to non-military applications of nuclear energy. It provided for the federal licensing of medical, research and development, and commercial facilities using nuclear materials. The rights of state or local government to license or regulate the safety (but not economics) of such facilities were preempted. U.S. antitrust laws were applied to licensees.

The act gave the AEC the responsibility for adequately protecting the public health, safety, life, and property. Section 182(a) of the Act requires the Commission to ensure that
the utilization or production of special nuclear material will ... provide adequate protection to the health and safety of the public.

The Congress left it to the AEC to determine what constituted "adequate protection." In its rules and decisions, the Commission refers to this standard as either the "adequate protection" standard or the "no undue risk" standard. The interchangeable use of these two terms has been accepted in legal decisions. $^{1}$

Under the 1954 Act, in addition to continuing its nuclear weapons programs, the AEC was given the responsibility for both encouraging and licensing commercial nuclear power. The Act outlined a two-step procedure for granting licenses. If the AEC found the safety analysis submitted by a utility for a proposed reactor to be acceptable, it would issue a construction permit. After construction was completed and the AEC determined that the facility met the provisions of the act and the rules and regulations of the commission, an operating license could be issued. The act allowed a public hearing "upon the request of any person whose interest may be affected by the proceeding." 
1.2 1954-1965 Early Commercial Reactors, Emphasis on Containment

The AEC's regulatory staff, created soon after the passage of the 1954 Atomic Energy Act, confronted the task of writing regulations and devising licensing procedures rigorous enough to assure safety but flexible enough to allow for new findings and rapid changes in nuclear technology. Within a short time the staff drafted rules on radiation protection, distribution and safeguarding of fissionable materials, and the qualification of reactor operators.

The AEC also established regulations implementing the two-step licensing process. Under the initial licensing regulations, reviews of applications for construction permits were evaluated by the regulatory staff, which next (or concurrently) sent the application to the Advisory Committee on Reactor Safeguards (ACRS) for independent review. The regulatory staff and Advisory Committee on Reactor Safeguards reviewed the information that applicants supplied on the suitability of the proposed site, construction specifications, plan of operations, and safety features. The AEC did not require finalized technical data on the safety of a facility at the construction permit stage. A construction permit could be granted if there was reasonable assurance that the plant could be constructed and operated at the proposed site without undue risk to the health and safety of the public. Permitting construction to proceed without first resolving all potential safety problems was deemed acceptable in light of the existing state of the technology and the commitment to rapid development of nuclear power.

The recommendations of the staff and the Advisory Committee on Reactor Safeguards went to the commissioners, who made the final decision on whether to approve a construction permit or operating license.
(Later, the Commission delegated consideration of regulatory staff and Advisory Committee on Reactor Safeguards judgments to the Atomic Safety and Licensing Boards while retaining final jurisdiction in licensing cases if it chose to review a board ruling.) The commission did not publicly document its findings regarding safety, nor did it make publicly available the reports it received from the Advisory Committee on Reactor Safeguards. Also, public notice of commission action on an application represented a fait accompli.

\subsubsection{Early Siting Precedents}

In 1955 and 1956, the AEC received and approved applications for construction permits for three large, privately owned power reactors. Each was to be in the general vicinity of a large city: Commonwealth Edison proposed the Dresden 1 BWR about 35 miles ( $56 \mathrm{~km}$ ) southwest of Chicago, Illinois; Consolidated Edison proposed the Indian Point 1 PWR 24 miles $(39 \mathrm{~km})$ north of New York City; and Detroit Edison proposed the Enrico Fermi fast reactor 25 miles $(40 \mathrm{~km})$ south of Detroit. Containment buildings were proposed for all three reactors.

The advent of containment was clearly a decisive step in moving large reactors away from highly remote sites to populated areas. The large exclusion distance required by the rule of thumb criterion would have allowed few sites in the United States to qualify for large, uncontained nuclear power plants. The unavailability and/or cost of large blocks of unoccupied land near electrical load centers made isolated siting economically impractical. Furthermore, containment provided a barrier to the release of radionuclides that was highly desirable for 
public safety and for public acceptance of nuclear power.

In response to questions posed in 1956 by a U.S. senator, then AEC Chairman Libby stated:

It is expected that power reactors such as that now under construction at Shippingport, Pennsylvania, will rely more upon the philosophy of containment than isolation as a means of protecting the public against the consequence of an improbable accident, but in each case there will be a reasonable distance between the reactor and major centers of population. ${ }^{2}$

In 1958 , a proposal was made to build a small (48 MWt) organic-cooled commercial reactor without a containment near the town of Piqua, Ohio. This proposal was rejected and a containment building was required for the Piqua plant. ${ }^{3}$ In fact, all the commercial nuclear power plants approved for construction in the U.S. have had containments.

No formal design criteria or site criteria existed in 1955 , and rather little preliminary design information was available in 19551956 when the Dresden 1, Indian Point 1, and Enrico Fermi applications for construction permits were reviewed. Clearly, there was no plant operating experience at the time. In addition there was little consideration of alternative sites or demographic factors. In this light, it is interesting that the early siting decisions, particularly approval of the $585 \mathrm{Mwt}$ Indian Point reactor, set major precedents on power reactor siting. No large power reactor has been built in the United States at a site having a greater surrounding population density than Indian Point.

\subsubsection{Power Reactor Development Company Construction Permit Application}

The January 1956 application for a construction permit to build the Enrico Fermi plant proved particularly contentious. The application was filed by the Power Reactor Development Company (PRDC), a consortium of utilities led by Detroit Edison. The fast breeder reactor that PRDC planned was far more technologically advanced than the light water reactors planned for Dresden 1 and Indian Point 1. The ACRS review of the PRDC application concluded that "there is insufficient information available at this time to give assurance that the PRDC reactor can be operated at this site without public hazard." The ACRS expressed uncertainty that questions regarding the reactor's safety could be resolved within PRDC's proposed schedule for obtaining an operating license. The ACRS urged the AEC to expand its experimental programs on fast breeders to seek more complete data on the issues the PRDC application raised.

Public controversy regarding the PRDC application arose as the result of congressional testimony. In June 1956, AEC Chairman Lewis L. Strauss testified in support of a supplemental appropriation for the civilian nuclear power program before a house appropriations subcommittee. The subcommittee chairman was a strong public power advocate. He chided Strauss about private industry's lack of progress in atomic development and suggested that PRDC had no intention of "building this reactor at any time in the determinable future." 4 Strauss, eager to refute this assertion, replied: "They [PRDC] have already spent eight million 
1.2 1954-1965 Early Commercial Reactors, Emphasis on Containment

dollars of their own money to date on this project. I told you they were breaking ground on August 8. I have been invited to attend the ceremony; I intend to do so." This reply indicated that the AEC chairman was planning to attend the ground breaking ceremony for a reactor whose construction permit had not yet been granted.

During the hearings the next day, AEC Commissioner Thomas Murray, in arguing for additional research and development funds, disclosed the concerns of the ACRS regarding the PRDC application. On the same day, Murray also went to see the chairman of the Joint Committee on Atomic Energy and informed him of the ACRS safety concerns.

The Joint Committee, claiming the AEC had failed to keep them "fully and currently informed" as required by the 1954 Atomic Energy Act, promptly requested a copy of the ACRS report. The AEC reluctantly offered to provide a copy if the Joint Committee would keep it "administratively confidential." The committee refused to accept the document under these conditions. A few months later, the Commissioners discovered that the AEC staff had provided a copy of the document to PRDC. The Commissioners then decided they had no choice but to release the document publicly, an embarrassing change of stance.

On August 2, 1956, based on more optimistic review of the PRDC application by the AEC staff, the commissioners decided to issue PRDC a construction permit by a vote of three to one (Murray was the dissenter). The AEC decision drew an angry response from the Joint Committee and led to the first intervention in nuclear power plant licensing.

\subsubsection{The Price-Anderson Act and WASH- 740}

Angered by the AEC decision to grant the PRDC construction permit, Senator Clinton P. Anderson, Chairman of the Joint Committee on Atomic Energy, introduced legislation which (1) established the ACRS as a statutory body, (2) required it to review all applications for construction permits and operating licenses, (3) required the ACRS to make a public report on each review, and (4) required public hearings on all such applications.

These measures were passed as amendments to the Price-Anderson Act in August 1957. The primary purpose of this act was to establish liability limits and no-fault provisions for insurance on nuclear reactor accidents. Such indemnity legislation was deemed essential by AEC, the emerging nuclear industry, and the Joint Committee on Atomic Energy who recognized that the probability of a severe reactor accident could not be reduced to zero. The original act, which has been periodically amended, had the government underwrite $\$ 500$ million of insurance beyond the $\$ 60$ million available from private companies. The AEC initially opposed setting a specific upper limit, but Anderson wanted to avoid a "blank check" for industry. ${ }^{4} \quad 10$ CFR 140 describes the financial protection required for licensees. ${ }^{5}$

An important technical input to establishing the indemnity provisions of the Price-Anderson Act was the report WASH740 entitled, "Theoretical Possibilities and Consequences of Major Accidents in Large Nuclear Power Plants," which was prepared by Brookhaven National Laboratory and published by the AEC. ${ }^{6}$ Using what would prove to be extremely pessimistic assumptions including a core meltdown with 
the release of fifty percent of the core fission products to the atmosphere, the worst case consequences of a $500 \mathrm{MWt}$ reactor accident were estimated to be 3,400 early fatalities, 43,000 acute injuries, and 7 billion (1957) dollars.

There was a consensus among those involved in the WASH-740 study that the likelihood of a meltdown accident was low, but quantitative probability estimates could not be supported given the lack of operating plant experience. Similarly, the likelihood of containment failure (or bypass) given a meltdown accident was not quantified (or quantifiable, at the time). However, until 1966 , the containment building was treated as an independent barrier, which should remain intact even if the core melted, thereby preventing any large release of radionuclides to the atmosphere. It was recognized that failure of the containment building and melting of the core could occur--for example, as a consequence of gross rupture of the reactor pressure vessel--but such events were not considered credible. Containment failure was not expected to occur just because the core melted.

\subsubsection{The First Intervention}

In the days after the AEC decision to grant the PRDC construction permit, private meetings were held between members of the Joint Committee and labor union representatives. Labor unions had opposed many of the changes in the Atomic Energy Act of 1954, citing fear of industry monopolization by private utilities.

On August 31, 1956 the AEC received three identical intervention petitions from American Federation of Labor--Congress of Industrial Organizations (AFL-CIO) unions.
These were the first intervention petitions ever received by the AEC. They requested suspension of the PRDC construction permit while a hearing was held on the reactor's safety, PRDC's financial qualifications, and the legality of the AEC's conduct in issuing the construction permit. The AEC did not suspend the PRDC construction permit; however, the request for hearings was granted. The hearings began on January 8 , 1957 and ran for more than two years.

On May 26, 1959 the hearings ended with an AEC ruling that the construction permit would stand. The unions appealed this decision, and almost a year later the U.S. Court of Appeals in a two to one opinion upheld the unions by declaring the PRDC construction permit illegal. In a particularly controversial section, the two judge majority took it upon themselves to review the proposed site of the PRDC reactor. Apparently swayed by testimony of unmitigated nuclear accidents like that described in WASH-740 the majority opinion stated:

We think it clear from Congressional
concern for safety that Congress
intended no reactor should, without
compelling reasons, be located where
it will expose so large a population to
the possibility of a nuclear disaster.

The PRDC obtained a stay of the Court of Appeals order while the AEC appealed to the U.S. Supreme Court. On June 12, 1961 the Court announced a seven-to-two vote in favor of the government's position. The decision supported the two-step licensing process holding that the AEC was within its authority to issue the construction permit because a separate positive finding of "adequate protection to the heath and safety of the public" would be required before 
granting an operating license. It was the PRDC case that established that adequate protection and no undue risk were synonymous. Regarding the AEC's authority to license reactors near a large city, the majority decision noted that the issue had been raised by the Court of Appeals, not by the intervenors and concluded that "the position is without merit."

Although the AEC won the PRDC case, its early bungling of the ACRS report, the manner in which it handled the case, and the continuance of the construction permit during the five years of contention fostered the image of an agency more concerned with promoting the development of commercial nuclear power than with regulating its safety.

\subsubsection{Reactor Site Criteria, 10 CFR 100}

In the late 1950 s several smaller reactors, all with containments and all at rural sites, were approved. However, during the same period, a few small power reactors $(60 \mathrm{MWt})$ were proposed for sites within or adjacent to small cities. These were rejected or forced to move to somewhat less populated sites. To avoid wasting future efforts on reactor proposals for sites that would be evaluated unfavorably, the AEC commissioners encouraged the development of written site criteria.

On May 23, 1959 the AEC published in the Federal Register notice of a proposed rule making concerning site criteria. ${ }^{3}$ The notice introduced several concepts that strongly influenced the licensing process for commercial reactors, particularly when site criteria were formally issued as 10 CFR 100 in April 1962.

The maximum credible accident was a concept introduced in the draft to strike a balance between two extremes. If the worst conceivable accident was postulated (e.g., an uncontained meltdown as in WASH-740), only sites isolated from populated areas by hundreds of miles would offer sufficient protection. As noted earlier, this would have effectively precluded the commercialization of nuclear power. On the other hand, if engineered safety features (ESFs) to protect against all possible accidents were included in the facility design, then it could be argued that every site would be satisfactory. Of course, in the latter case no potentially serious accidents could be overlooked and the ESFs would have to be failproof. Such omniscience was not defensible. This led to the idea of designing for what was subjectively assessed to be the maximum credible accident.

When 10 CFR 100 was issued (April 1962), the term maximum credible accident was dropped, but the notion was retained in 100.11 (a) and an associated footnote:

As an aid in evaluating a proposed site, an applicant should assume a fission product release from the core, the expected demonstrable leak rate from the containment and the meteorological conditions pertinent to his site..."

"The fission product release assumed for these calculations should be based upon a major accident, hypothesized for purposes of site analysis or postulated from considerations of possible accidental events, that would result in potential hazards not exceeded by those from any accident considered credible. Such accidents have generally been assumed to result in substantial meltdown of the core 
with subsequent release of appreciable quantities of fission products.

This maximum credible accident has, at various times, also been referred to as the design-basis accident (DBA) or the designbasis loss of coolant accident (LOCA). As discussed in Section 1.4, there is not a single design-basis accident. Plants are designed to withstand a spectrum of accidents. The term siting-basis accident is adopted here to refer to a design-basis accident that is limiting with respect to site evaluation because it has greater predicted offsite doses than other design-basis accidents. The siting-basis accident is generally initiated by a major reactor-coolant system pipe break.

Rather prescriptive and generally conservative guidance for calculating offsite doses evolved from 10 CFR 100 . For example, 10 CFR 100 refers to Technical Information Document (TID) 14844, which postulates that $100 \%$ of the noble gas fission products, $50 \%$ of the volatile (halogen) fission products, and $1 \%$ of the particulates are immediately released to the containment atmosphere following the pipe break. ${ }^{8,9,10}$ The TID-14844 release is based on a postulated core melt accident and the 1962 understanding of fission product behavior. (Section 5.1.6 discusses recent revisions to guidance regarding core melt accident releases.) Containment, which is designed to withstand the peak pressure associated with reactor coolant system blowdown, is assumed to remain intact but to leak radionuclides to the environment at the design leakage rate (the containment leakage rate to be incorporated in the plant technical specifications).

Only very limited metal-water reactions and associated hydrogen production are accounted for in the computational assumptions that evolved after 10 CFR 100 was issued. The reason for this is not clear. The potential importance of metal water reactions during core melt accidents was recognized as early as 1957 (in WASH-740). The fact that stainless steel, which was used for cladding until the mid-1960s, is considerably less reactive than Zircaloy probably had some influence. Design-basis accident assumptions and calculations are discussed further in Section 1.4. The evolution of hydrogen and the burn that occurred at Three Mile Island Unit 2 are discussed in Sections 2.3 and 3.4.

For purposes of site evaluation, 10 CFR 100 requires that doses at two area boundaries be considered. The exclusion area is
that area surrounding the reactor in which the licensee has the authority to determine all activities, including exclusion or removal of personnel and property from the area."

The exclusion area does not have to be owned by the licensee, merely controlled. The low population zone is

the area immediately surrounding the exclusion area, which contains residents, the total number and density of which are such that there is a reasonable probability that appropriate protective measures could be taken in their behalf in the event of a serious accident. ${ }^{12}$

10 CFR 100 stipulates that neither an individual located at any point on the outer boundary of the exclusion area for two hours immediately following onset of the postulated fission product release nor an individual located at any point on the outer 
1.2 1954-1965 Early Commercial Reactors, Emphasis on Containment

boundary of the low population zone for the duration of the accident should receive a total radiation dose in excess of 25 rem to the whole body or 300 rem to the thyroid. ${ }^{13}$ Thus, the design-basis LOCA, whose consequences were not to be exceeded by any other credible accident, became the focus of siting evaluations. 10 CFR 100 also stipulates that the population center distance, which is

the distance from the reactor to the nearest boundary of a densely populated center containing more than 25,000 residents, [should be] at least one and one-third times the distance from the reactor to the outer boundary of the low population zone. $^{14}$

This requirement developed as a result of various considerations. In late 1960 the Advisory Committee on Reactor Safeguards proposed a rather specific criterion--no lethal doses at the population center for the worst conceivable accident (an uncontained meltdown as considered in WASH 740). This philosophy was reflected in the statement of considerations which accompanied the interim version of the site criteria released in March 1961:

Even if a more serious accident (not normally considered credible) should occur, the number of people killed should not be catastrophic. ${ }^{3}$

However, when the AEC published $10 \mathrm{CFR}$ 100 in April 1962 the new statement of considerations discussed the use of a minimum acceptable distance to the nearest population center as a way to limit the cumulative population dose (i.e., the sum of the individual doses received) and to provide for protection against excessive radiation exposure to people in large centers, where effective protective measures might not be feasible. Thus, $10 \mathrm{CFR} 100$ does not require that uncontained meltdown accidents be postulated.

\subsubsection{Credit for Engineered Safety Features}

Although the 10 CFR 100 reactor site criteria notes the

current policy of the Commission of
keeping stationary power and test
reactors away from densely populated
centers ... It should be equally
understood, however, that applicants
are free and indeed encouraged to
demonstrate to the Commission the
applicability and significance of
considerations other than those set
forth in the guides.

The nuclear industry responded to $10 \mathrm{CFR}$ 100 in two ways: (1) by seeking credit for engineered safety features (ESFs, which were called engineered safeguards at the time) and (2) by direct attacks on metropolitan siting restrictions.

Credit for ESFs was sought to allow siting of reactors at locations where, without such features, protection of the public would not be adequate (10 CFR 100 guidelines would be exceeded). Applicants attempted to get maximum credit for reductions in containment pressure and radionuclide concentrations by ESFs during postulated LOCAs. The ESFs for which credit was routinely given were containment, the pressure suppression pool, containment building sprays, containment heat removal systems, and containment air-cleaning systems. 
In approving the San Onofre 1 construction permit application in 1963, credit was even given for emergency core cooling systems (ECCS) so that only $6 \%$ of the core was assumed to melt, thereby reducing the containment fission product inventory to $6 \%$ of that which would otherwise have been postulated for siting.

In November 1964, in response to an AEC request, the Advisory Committee on Reactor Safeguards documented its rationale for accepting certain ESFs as substitutes for distance. ${ }^{15}$ The position of the Advisory Committee on Reactor Safeguards was that credit was appropriate for all of the above listed ESFs except the emergency core cooling system. The emergency core cooling system was deemed essential for accidentprevention, but radionuclide releases postulated for siting were to be consistent with emergency core cooling system failure:

Core spray and safety injection systems ... might not function for several reasons in the event of an accident ... Therefore, reliance cannot be placed on systems such as these as the sole engineered safeguards in the plant. Nevertheless, prevention of core melting after an unlikely loss of primary coolant would greatly reduce the exposure of the public. Thus, the inclusion of a reactor core fission product heat removal system as an engineered safeguard is usually essential.

The San Onofre 1, Connecticut Yankee, Oyster Creek, Nine Mile Point, and Dresden 2 plants were approved for construction from 1963 to 1965 using ESFs to permit relaxing previous requirements on the size of the exclusion area and low population zone. In 1962 an application was submitted for a construction permit to build the two-unit Ravenswood plant essentially in the heart of New York City. ${ }^{3}$ Double containment was proposed for each of the Westinghouse nuclear steam supply systems and for the common spent fuel storage facility. Even so, both the AEC staff and the ACRS expressed concerns regarding the feasibility of building containments with sufficiently small leak rates. AEC staff calculations indicated that even if all engineered safeguards operated, leakage would have to be limited about $10^{-4}$ cubic feet per minute in order to meet 10 CFR 100 siting guidelines. In late 1963, Consolidated Edison withdrew its application for Ravenswood, claiming cheaper power was available from Labrador, 1100 miles away. Metropolitan siting continued to be seriously considered as late as $1970 .^{3}$ 


\section{References for Section $\mathbf{1 . 2}$}

1. Union of Concerned Scientists v. U.S. NRC, Federal Reporter, 824, 2d series, 108, Washington, DC, 1987.

2. Willard F. Libby, then Acting Chairman of the Atomic Energy Commission, letter to Senator Bourke Hickenlooper, March 14, 1956, reproduced in Okrent.

3. David Okrent, "Nuclear Reactor Safety: On the History of the Regulatory Process," The University of Wisconsin Press, Madison, Wisconsin, 1981.

4. U.S. Nuclear Regulatory Commission, "A Short History of Nuclear Regulation 1946-1990," NUREG/BR-1075, January 1993.

5. U.S. Code of Federal Regulations, Title 10, Part 140, January 1, 1991.

6. U.S. Atomic Energy Commission, "Theoretical Possibilities and Consequences of Major Accidents in Large Nuclear Power Plants," WASH740, March 1957.

7. George T. Mazuzan and J. Samuel Walker, "Controlling the Atom: The Beginnings of Nuclear Regulation, 19461962," University of California Press, 1992.

8. J. J. DiNunno, R. E. Baker, F. D. Anderson, and R. L. Waterfield, Calculation of Distance Factors for Power and Test Reactor Sites, TID14844, Division of Licensing and
Regulation, AEC, Washington, D. C. (March 23, 1962). Note: TID-14844 was supplanted by the following two regulatory guides.

9. U.S. Atomic Energy Commission Regulatory Guides 1.3, "Assumptions Used for Evaluating the Potential Radiological Consequences of a Loss of Coolant Accident for Boiling Water Reactors," Revision 2, June 1974.

10. U.S. Atomic Energy Commission Regulatory Guides 1.4, "Assumptions Used for Evaluating the Potential Radiological Consequences of a Loss of Coolant Accident for Pressurized Water Reactors," Revision 2, June 1974.

11. U.S. Code of Federal Regulations Title 10, Part 100.3 (a), April 1962.

12. U.S. Code of Federal Regulations, Title 10, Part 100.3 (b), April 1962.

13. U.S. Code of Federal Regulations, Title 10, Part 100.11 (1)\&(2), April 1962.

14. U.S. Code of Federal Regulations, Title 10, Part 100.3 (d) and 10 CFR 100.11 (a) (3), April 1962.

15. Herbert Kouts, ACRS Chairman, letter to Glenn T. Seaborg, Chairman, U.S. AEC, subject "Report on Engineered Safeguards," November 18, 1964. 


\subsection{6-1974 Emphasis on Prevention, Public Debate}

In 1966, two issues called into question the assumption of containment as an independent barrier. These were the issue of reactor pressure vessel integrity and the so-called China syndrome. The net effect of these issues was to shift the focus of regulatory actions toward a strategy of accident prevention and away from reliance on containment.

\subsubsection{Reactor Pressure Vessel Integrity}

The design and manufacture of early nuclear reactor vessels in the United States conformed to the basic requirements of Section I and/or Section VII of the American Society of Mechanical Engineers Boiler and Pressure Vessel Code. These procedures were also supplemented by nuclear code cases and the Navy Code. ${ }^{1}$ Recognizing the unique nature of nuclear reactors, the American Society of Mechanical Engineers established a special committee to consider reactor pressure vessels in 1955. ${ }^{2}$ In March of 1964, American Society of Mechanical Engineers Section III, "Rules for Construction of Nuclear Vessels," were issued to specify and provide a uniform approach to the design of nuclear pressure vessels. The new rules placed more emphasis on the careful analysis of design details leading to more refined design practices. ${ }^{1}$ Of course plants built to older codes did not benefit from these changes.

This implies that reactor vessels are brittle when cold (below $\mathrm{R}_{\mathrm{NDT}}$ ) but are quite tough at normal operating temperatures. As the temperature of reactor vessel material is raised, the toughness increases, slowly at first but near the reference temperature for nil ductility transition, $\mathrm{RT}_{\mathrm{NDT}}$, toughness begins to increase much more rapidly. This implies that reactor vessels are quite tough at normal operating temperatures. Starting about 1950 information on the effects of neutron radiation on the engineering properties of structural materials began to appear in the literature. Neutron irradiation was found to cause structural materials to embrittle. This can be characterized by a shift in $\mathrm{RT}_{\mathrm{NDT}}$ that occurs over decades of plant operation, as depicted in Figure 1.3-1.

In 1959 an American Society for Testing and Materials task group made recommendations on test procedures for evaluating radiation effects on materials, which led to recommended practices for surveillance tests on structural materials in nuclear reactors. ${ }^{3}$ As part of their safety analysis review, the AEC ensured that each plant conducted a reactor vessel irradiation surveillance program per American Society for Testing and Materials standards to evaluate the shift in $\mathrm{RT}_{\mathrm{NDT}}$ over the plant life, especially in the beltline region opposite the core midplane where the reactor vessel sees the greatest neutron flux.

Because of the stringent design and surveillance practices applied to reactor pressure vessels in the U.S., failure of the reactor pressure vessel has traditionally been considered incredible. Containments for U.S. nuclear power plants are not designed to withstand the loads associated with gross rupture of the reactor pressure vessel.

In 1964 a failure occurred near the nil ductility transition temperature of a large heat exchanger under test by the Foster Wheeler Corporation. As a result of this failure and concerns raised in 1964-1965 by British researchers, the Advisory Committee 
on Reactor Safeguards issued a November 24, 1965 letter. $^{4}$ While acknowledging the low probability of reactor pressure vessel failure, the Advisory Committee on Reactor Safeguards expressed concern for the

increase in number, size, power level, and proximity of nuclear power reactors to large population centers,

and recommended 1) the development of improved design and inspection methods for reactor pressure vessels and 2) the development of means "to ameliorate the consequences of a major pressure vessel rupture." The latter recommendation prompted strong disagreement from both industry and AEC representatives. Nevertheless, more heavily populated sites such as Indian Point and Zion were required to design their reactor vessel cavities to withstand a longitudinal pressure vessel split. Ultimately, pressure on the part of both the Advisory Committee on Reactor Safeguards and AEC staff prompted the development of improved industry standards for the design, fabrication, and inspection of pressure vessels. In addition, major research efforts examining a variety of issues related to reactor pressure vessel integrity were conducted. In 1974, research conducted by the Advisory Committee on Reactor Safeguards concluded that the probability of a reactor vessel failure is less than $10^{-6}$ per vessel-year and that the most likely failures would be within the capability of engineered safety features. ${ }^{5}$

The issue of reactor pressure vessel integrity has remained active since 1974. In particular, the 1979 accident at Three Mile Island Unit 2 (Section 2.3) was responsible for moving the concern of pressurized thermal shock (PTS) to a high level of visibility. A pressurized thermal shock event is a PWR transient that can cause severe overcooling accompanied by vessel pressurization to a high level. The thermal stresses caused by rapid cooling of the reactor vessel inside surface combine with the pressure stresses to increase the potential for fracture if an initiating flaw is present in low toughness material. Additional information on pressurized thermal shock is presented in the references., ${ }^{1,6}$ The regulatory approach that has evolved is aimed at assuring that the probability of reactor pressure vessel failure is exceedingly low. The current rule governing pressure vessel protection against pressurized thermal shock is contained in $10 \mathrm{CFR} 50.61^{7}$

\subsubsection{The China Syndrome}

In preparation for a 1965 extension of PriceAnderson legislation on liability limits and insurance for nuclear reactors, Brookhaven National Laboratory (BNL) reexamined the WASH-740 worst case accident scenario. A loss of coolant accident in a $3,200 \mathrm{MWt}$ reactor was analyzed. No credit was given for engineered safety features. BNL estimated that, several hours following initial primary system blowdown, decay heat from fission products would cause the core to melt through the bottom head of the reactor pressure vessel and potentially through the concrete containment basemat and into the earth until a solid mass with sufficient conductivity to dissipate decay heat was formed. ${ }^{8}$ It was estimated that solidification might occur before basemat meltthrough and would certainly occur before the melt had penetrated more than $100 \mathrm{ft}$. $(30 \mathrm{~m})$ into the ground; however, considering this potentially significant downward penetration, the term China syndrome was introduced. 
If the molten fuel were to penetrate the containment basemat, radionuclides could escape through the soil to the atmosphere. Such soil-filtered releases would probably not cause lethal radiation doses to persons outside the exclusion area. Nevertheless, the China syndrome was significant because it demonstrated a strong correlation between a core meltdown and a possible loss of containment integrity. Phenomena that were not considered in the Brookhaven National Laboratory study were later recognized as potential causes of more serious above ground containment failure modes. Such phenomena had not been considered in reviewing applications for commercial plants despite the fact that the hypothetical sitingbasis accident, which was used to demonstrate compliance with 10 CFR 100 siting criteria (Section 1.2.4), postulated reactor containment system fission product releases corresponding to a full-scale core meltdown.

The concern that core meltdown could threaten containment integrity was raised by the Advisory Committee on Reactor Safeguards in the summer of 1966 for the Dresden 3 BWR and Indian Point 2 PWR applications. Both Westinghouse and General Electric were asked to consider the possibility of providing ESFs that would maintain containment integrity in the presence of large-scale core melt. ${ }^{9}$ General Electric argued that maintaining containment integrity in the face of core meltdown was not feasible for their BWR; they contended that the emergency core cooling system was adequate to prevent core melt in the event of a LOCA. Westinghouse felt that a core catcher below the reactor vessel could be used to maintain PWR containment integrity. Based on information provided by Westinghouse and General Electric, the
Advisory Committee on Reactor Safeguards concluded that it would be very difficult, given the existing state of knowledge, to design safeguards to assure containment integrity given core meltdown. Instead, the Advisory Committee on Reactor Safeguards reports of August 16, 1966 on Dresden 3 and Indian Point 2 recommended major improvements in both primary system integrity to reduce the probability of a LOCA and emergency core cooling to reduce the probability of meltdown given a LOCA. ${ }^{9}$

Thus, the China syndrome led to a shift in emphasis from containment to prevention. As time passed, accident initiators other than the traditional large pipe break were identified as potentially leading to core melt. In particular, scenarios involving anticipated transients without scram, station blackout, other transients, and containment bypass were eventually evaluated, and regulated to reduce the probability of core meltdown. Although the new emphasis on prevention gave rise to a greatly expanded the list of accidents, until the TMI-2 accident in 1979, the focus was on demonstrating the adequacy of emergency core cooling for such accidents not on what to do if core cooling failed.

The Brookhaven reexamination of WASH740 , which gave rise to the China syndrome and to the shift in emphasis from containment to prevention, was never completed or published. An internal AEC summary of the project written in 1969 stated that an important factor in the decision not to produce a complete revision of WASH-740 along the lines proposed by the Brookhaven staff was the public relations considerations. In fact, it was the failure to release a final report of the Brookhaven study that became a public relations concern, because opponents of nuclear power argued 
convincingly that the AEC was covering up the real risk of reactor accidents. ${ }^{10}$

\subsubsection{The AEC Core Cooling Task Force (CCTF)}

In September 1966, Advisory Committee on Reactor Safeguards members expressed their concerns regarding the China syndrome in a meeting with the AEC commissioners. To avoid a letter from the Advisory Committee on Reactor Safeguards, which would have recommended the development and implementation of safety features to protect against LOCAs in which emergency core cooling system did not work, the AEC commissioners established a task force to study and report on questions arising from the China syndrome. ${ }^{9}$ The eleven-man task force, which was known as the AEC Core Cooling Task Force (CCTF), was chaired by William Ergen of Oak Ridge National Laboratory and had six members from industry and five from AEC supported laboratories. The Core Cooling Task Force was asked to consider

1) The degree to which core cooling systems could be augmented to prevent core meltdown,

2) the potential history of large molten masses of fuel,

3) the possible interactions of molten fuel with materials or atmospheres in containments, and

4) the design and development problems associated with systems whose objective is to cope with large molten masses of fuel. ${ }^{9}$
When faced with what little was then known about core meltdown accidents and associated phenomena, it was clear to the Core Cooling Task Force that designing to assure containment integrity after core meltdown would require extensive, protracted, costly research. Such research was far beyond the scope of the Core Cooling Task Force; consequently, the Core Cooling Task Force focused on item 1, preventing core meltdown. ${ }^{\prime \prime}$

The Core Cooling Task Force report entitled "Report of the Advisory Task Force on Power Reactor Emergency Cooling," which became available in late $1967,{ }^{9}$ concluded that augmented emergency core cooling was feasible and beneficial. The report was used for policy decisions by the AEC during the ensuing years, when the AEC emphasized improvements in quality control and emergency core cooling system; however, no significant efforts to address core meltdown accidents arose from the Core Cooling Task Force report. The Core Cooling Task Force correctly pointed out that small LOCAs might have safety significance, ${ }^{11}$ a fact that would be reasserted in the 1975 Reactor Safety Study (Section 1.5) and confirmed by the 1979 accident at Three Mile Island Unit 2 (Section 2.1). In contrast, the task force conclusion that current (1967) technology was sufficient to enable prediction, with reasonable assurance, of the key phenomena associated with the design-basis LOCA, and to provide quantitative understanding of the accident would prove to be incorrect (Section 1.3.6).

\subsubsection{General Design Criteria}

The AEC review of all commercial reactors from Shippingport to Dresden 2 in 1965 was on a case-by-case basis. The list of potential 
hazards expanded as new questions were encountered during individual plant reviews. Tornadoes were first considered for a plant in Arkansas, hurricanes for a plant in Florida, and seismic events for plants in California. Such natural phenomena were then considered in the review of other plants. Unusual operating experiences also resulted in new design requirements. For example, tornadoes once disabled all five offsite power lines feeding the Dresden 1 plant, which had no on-site emergency $A C$ power. Subsequently, first one small onsite diesel, then a larger diesel, then redundant diesels to drive containment related safeguards became the standard. In 1966, redundant on-site power was required to power the emergency core cooling system, requiring still larger diesels.

Until 1965 there were no written criteria against which the various designs could be compared, and there was essentially no review of the detailed design approach, which actually determines the level of safety achieved. As the number of new plant applications grew, there was strong motivation on the part of both industry and the AEC to streamline the licensing review process. In the spring of 1965 , in response to anticipated recommendations of an outside review panel, the AEC staff began drafting what would become the General Design Criteria, Appendix A of 10 CFR 50.

On November 22, 1965 the AEC issued a press release announcing the proposed criteria and requesting public comment. ${ }^{12}$ During the comment period the discussions of reactor pressure vessel failure, the China syndrome, and the Core Cooling Task Force were active. In this light it is interesting to note three significant changes in the revised draft of the general design criteria, which was issued for comment 19 months later (July 10, 1967). ${ }^{13}$ First, the revised draft no longer required the containment be designed to withstand a full meltdown as the original draft had. The revised containment designbasis did contain the vague phrase

including considerable margin for effects from metal-water or other chemical reactions that could occur as a consequence of failure of emergency core cooling systems.

Except for these words, the revised draft made no reference to core melt accidents. Second, the revised draft called for
at least two emergency core cooling systems preferably of different design principles, each with a capability for accomplishing abundant emergency core cooling.

Third, requirements to design against single failures, which had appeared in the November 1965 version in slightly different words, were prominent in the revised draft:

A single failure means an occurrence which results in the loss of capability of a component to perform its intended safety functions. Multiple failures resulting from a single occurrence are considered to be a single failure. Fluid and electrical systems are considered to be designed against an assumed single failure if neither (1) a single failure of any active component (assuming passive components function properly) nor (2) a single failure of a passive component (assuming active components function properly) results 
in a loss of the capability of the system to perform its safety function.

Single failures of passive components in electric systems should be assumed in designing against a single failure. The conditions under which a single failure of a passive component in a fluid system should be considered in designing the system against a single failure are under development.

The proposed criteria of July 10, 1967 provided interim guidance to the regulatory staff and the nuclear industry for several years. On February 19, 1971 the AEC published a revised set of general design criteria, which became Appendix A of 10 CFR $50 .{ }^{14}$ The 1971 criteria reflected the LWR plants that had been reviewed in the previous few years. Two emergency core cooling systems, each capable of providing abundant cooling, were no longer required. The emergency core cooling system criterion now said:

A system to provide abundant emergency core cooling shall be provided,

and the single failure criterion was applied to the emergency core cooling system. None of the criteria related to core melt accidents. The vague phrase of the July 10, 1965 containment design criteria was modified to require consideration of

chemical reactions that may result from degradation, but not total failure, of the emergency core cooling.

The introduction to the 1971 criteria listed several safety considerations for which general design criteria had not yet been (and have not yet been) developed. The list included redundancy issues; common mode failures; systematic, non-random failures; and passive failures.

The general design criteria do not provide quantitative bases for establishing the adequacy of any particular design. The detailed design and its acceptability were deliberately left to the "engineering judgment" of the designer and the regulator, respectively. The development of more detailed regulatory guidance began in the 1967-1968 time frame when the regulatory staff started generating internal documents that specified acceptable detailed design approaches to specific problems. In 1970 the AEC began publishing such regulatory guides. The first published regulatory guide dealt with the concern that an emergency core cooling system should not fail as a result of a loss of containment integrity. ${ }^{15}$ It required that sources of emergency core cooling system water be at sufficiently high pressure (provide sufficient net positive suction head, NPSH) to avoid pump cavitation.

As shown in Figure 1.3-2, the number of regulatory guides issued or revised each year grew rapidly and remained high throughout the 1970s. By 1978, more than 100 different regulatory guides had been issued. ${ }^{9}$ In addition, numerous branch technical positions and standard review plans were issued. None of these had the force of law like the general design criteria; however, utilities usually found it easier to follow a design approach prejudged as acceptable by the regulatory staff than to defend an alternative approach. 
The actual general design criteria address 64 broad issues in 6 major categories:

I. Overall Requirements

II. Protection by Multiple Fission Product Barriers

III. Protection and Reactivity
Control Systems

IV. Fluid Systems

V. Reactor Containment

VI. Fuel and Reactivity Control

Although all of the individual criteria cannot be discussed here, the five criteria forming the overall requirements are worthy of further discussion. These criteria are particularly important and impact many aspects of reactor safety.

\subsubsection{Criterion 1-Quality Standards and Records}

Quality assurance is an important part of maintaining an adequate level of safety at nuclear power plants. A good quality assurance program can assure that a plant is properly designed, that it is built as designed, that proper materials are used in construction, that the design is not inappropriately changed at a later date, and that appropriate maintenance and operational practices are followed.

Criterion 1 states that:

Structures, systems, and components important to safety shall be designed, fabricated, erected, and tested to quality standards commensurate with the importance of the safety functions being performed. ... $A$ quality assurance program shall be established and implemented in order to provide adequate assurance that these structures, systems, and components will satisfactorily perform their safety functions. Appropriate records of design, fabrication, erection, and testing of structures, systems, and components important to safety shall be maintained by or under the control of the nuclear power unit licensee throughout the life of the plant.

The criterion for quality assurance was first proposed in the July 1967 draft of Appendix A. The lack of AEC requirements and criteria for quality assurance was a key issue raised by the Atomic Safety and Licensing Board in the operating license hearings for the Zion plant in 1968. The board ruled that until the licensee presented a program to assure quality and until the AEC developed criteria by which to evaluate such a program, the hearings would be halted. Following the board's ruling and prior to the final issuance of Appendix A, the AEC proposed a new regulation, Appendix B to 10 CFR 50. This new regulation more clearly spelled out requirements for the licensees to develop programs to assure the quality of nuclear power plant design, construction, and operation.

Appendix B contained 18 items that must be part of a quality assurance program for safety-related systems and components. Experience from military, the National Aeronautics and Space Administration, and commercial nuclear projects, as well as the AEC's own nuclear reactor experience was used in developing the 18 items. Appendix 
B clearly places the burden of responsibility for quality assurance on the licensee. Visible quality assurance documentation is required for all activities affecting the quality of safety-related systems. Appendix B was published for comment in April 1969 and implemented in June 1970.

Following establishment of Appendices A and $B$, the AEC and the industry began issuing guidance that provided acceptable ways of meeting the intent and requirements of the specific regulations. In October 1971 The American National Standards Institute issued N45.2, "Quality Assurance Program Requirements for Nuclear Power Plants." 16 This standard was endorsed by the Atomic Energy Commission in Safety Guide 28 (now Regulatory Guide 1.28) in June 1972. Since that time there have been numerous additional guides and other documents on the subject of quality assurance. The Standard Review Plan includes guidance concerning how the NRC staff should review and evaluate proposed quality assurance programs.

\subsubsection{Criterion 2-Design Bases for Protection Against Natural Phenomena}

Criterion 2 recognizes that not all accidents are expected to begin as a result of failures within the plant boundaries. Additionally, natural phenomena may represent a threat to plant safety. Criterion 2 states:

Structures, systems, and components important to safety shall be designed to withstand the effects of natural phenomena such as earthquakes, tornadoes, hurricanes, floods, tsunami, and seiches without loss of capability to perform their safety functions. The design bases for these structures, systems, and components shall reflect: (1) Appropriate consideration of the most severe of the natural phenomena that have been historically reported for the site and surrounding area, with sufficient margin for the limited accuracy, quantity, and period of time in which the historical data have been accumulated, (2) appropriate combinations of the effects of normal and accident conditions with the effects of the natural phenomena and (3) the importance of the safety functions to be performed.

Sections 1.4 and 2.5 describe in more detail the threats from natural phenomena and approaches for dealing with them.

\subsubsection{Criterion 3-Fire Protection}

Fires are a potential hazard at most large industrial facilities, including nuclear power plants. Fires can occur in electrical equipment or a variety of combustible materials that may be present at a plant. Small fires are fairly common occurrences, and to assure that nuclear power plants can adequately deal with fires, Criterion 3 was developed which states:
Structures, systems, and components important to safety shall be designed and located to minimize, consistent with other safety requirements, the probability and effect of fires and explosions. ...

The criterion further specifies the need for using noncombustible materials whenever possible and for providing fire detection and firefighting systems. 
Despite the development of Criterion 3, fires continued to occur at nuclear power plants. On March 22, 1975 the Browns Ferry Nuclear Power Plant experienced a major fire, resulting in the loss of numerous safety systems. The Browns Ferry fire is discussed at length in Section 1.6. Following the fire, the Special Review Group that investigated the fire recommended that NRC should develop additional specific guidance for implementation of Criterion 3. In response to this recommendation, the NRC developed Branch Technical Position 9.5-1, "Guidelines for Fire Protection for Nuclear Power Plants." ${ }^{17}$ This information was later published as Regulatory Guide 1.120: Fire Protection Guidelines for Nuclear Power Plants. ${ }^{18}$

In 1980 the NRC formally proposed Appendix $R$ to 10 CFR 50 to state the minimum acceptable level of fire protection for power plants operating prior to January 1, 1979. Appendix R contains four general requirements to (1) establish a fire protection program, (2) perform a fire hazards analysis, (3) to incorporate fire prevention features, and (4) to provide alternative or dedicated shutdown capability. ${ }^{19}$ Further, a number of specific requirements were included, dealing with

- water supplies for fire suppression

- isolation valves in the fire suppression system

- manual fire suppression

- testing

automatic fire detection

- safe shutdown capability
- fire brigade

- training

- emergency lighting

- administrative controls

- alternative shutdown capability

- fire barriers

- oil collection

Compliance with Appendix $\mathrm{R}$ has led to significant improvements in fire safety at nuclear power plants; however, fires continue to occur and remain an important safety issue.

\subsubsection{Criterion 4-Environmental and Dynamic Effects Design Bases}

Reactor accidents may lead to harsh environmental conditions that may challenge the operation of components and systems or threaten the integrity of structures. Examples of environmental conditions that can occur include:

1. high-temperature steam

2. high pressure

3. radiation

4. missiles

5. pipe whip

For safety systems to function during an accident, they must be designed to withstand the expected environments. Therefore, Criterion 4 states:

Structures, systems, and components important to safety shall be designed to accommodate the effects of and to 
Structures, systems, and components important to safety shall be designed to accommodate the effects of and to be compatible with the environmental conditions associated with normal operation, maintenance, testing, and postulated accidents, including lossof-coolant accidents. ...

Qualification testing is normally used to show that equipment can survive the postulated design-basis accident environments. The beyond-design-basis accidents discussed in later sections can produce environments exceeding the qualification limits.

The design of restraints to preclude pipe whipping has been a complex and controversial process. Criterion 4 allows the licensee an exemption for pipe whipping under certain conditions:

... dynamic effects associated with postulated pipe ruptures in nuclear power units may be excluded from the design basis when analyses reviewed and approved by the Commission demonstrate that the probability of fluid system piping rupture is extremely low under conditions consistent with the design basis for the piping.

Assurance that nuclear power plants meet Criterion 4 is an ongoing process. Testing and documentation required by Criterion 1 are an essential part of the process. However, in certain cases testing may not accurately replicate the environments that will actually be seen during an accident. A classic case involves motor-operated valves. In 1985 an incident at the Davis-Besse plant involved failure of key valves in the auxiliary feedwater system. ${ }^{20}$ The valves had been successfully tested on numerous occasions. However, during the actual incident, the valves were exposed to high differential pressures that were not present during testing, and the torque s'vitches were not set to account for the differential pressure. Continuing vigilance on the part of inspectors and regulators to assure that Criterion 4 is met is an important part of the reactor safety philosophy.

\subsubsection{Criterion 5-Sharing of Structures, Systems, and Components}

Criterion 5 is intended to address features of a multi-unit site that could allow problems to propagate from one unit to another. The criterion states:

Structures, systems, and components important to safety shall not be shared among nuclear power units unless it can be shown that such sharing will not significantly impair their ability to perform their safety functions, including, in the event of an accident at one unit, an orderly shutdown and cooldown of the remaining units.

Prior to the development of Criterion 5, multi-unit sites frequently made use of shared systems and structures. Service water systems, control rooms and other features were often shared. While each unit included enough redundancy to respond to an accident without consideration of the other units, it was possible for an event at one location to affect multiple units at the same time. Plants in multi-unit sites developed after the issuance of the General Design Criteria 
(GDC) generally follow the philosophy of complete separation of units with separate components and structures for all important systems.

Although complete separation of units allows the licensee to easily meet Criterion 5 , there are some important benefits lost in this approach. Probabilistic risk assessment indicate that the ability to properly cross-tie safety systems from one unit to another can significantly reduce the risk of certain types of accidents. For example, cross-tieing diesel generators can reduce the risk of station blackout. Some plants have the ability to cross-tie emergency cooling and heat removal systems. The key is to make sure that the cross-ties are properly designed and implemented so they do not cause undue multi-unit problems.

\subsubsection{The National Environmental Policy Act (NEPA)}

In December 1969 Congress passed the National Environmental Policy Act, which was signed by President Nixon on January 1 , 1970. The Act required federal agencies to consider the environmental impact of their activities. The Act was vague and confusing, and it gave federal agencies broad discretion in deciding how to carry out its mandate.

The AEC initially took a narrow view of its responsibilities under National Environmental Policy Act for several reasons. First was the conviction that the routine operation of nuclear power plants was not a serious threat to the environment, and indeed, was beneficial compared to burning fossil fuel. Second, the major products of nuclear power generation that affected the environment, radiation releases and thermal discharges, were already covered by existing legislation. Finally, the AEC did not want to divert limited human resources from tasks that were more central to its mission. The regulatory staff was inundated by a flood of reactor applications and did not relish the idea of having to spend large amounts of time on environmental reviews. The AEC feared that considering a wider range of environmental issues would cause unwarranted additional licensing delays.

A proposed regulation issued by the AEC in December 1970 added non-radiological issues to the AEC's regulatory jurisdiction, but stated AEC's intent to rely on environmental assessments performed by other federal and state agencies rather than perform its own. The AEC agreed to consider environmental issues in licensing board hearings only if raised by a party to the proceeding. The AEC also postponed a review of National Environmental Policy Act issues in licensing cases until March 1971.

Environmentalists charged that the AEC had failed to fulfill the purposes of the National Environmental Policy Act and took the agency to federal court over the application of the AEC's regulations to the Calvert Cliffs nuclear units, which were then under construction on the Chesapeake Bay in rural Maryland. The July 23, 1971 ruling of the United States Court of Appeals for the District of Columbia was a stunning defeat for the AEC. The court sternly rebuked the AEC saying

\section{We believe that the Commission's crabbed interpretation of National Environmental Policy Act makes a mockery of the Act. ${ }^{21}$}

Recognizing the need to improve the public image of the AEC, the commissioners 
decided not to appeal the Calvert Cliffs court ruling. In effect, the AEC agreed to consider environmental impacts of proposed projects and to develop environmental expertise required to do so. In explaining this decision to industrial groups, James R. Schlesinger, newly appointed AEC Chairman, indicated that although AEC's policy of promoting and protecting the industry had been justified to help nuclear power get started, the industry was "rapidly approaching mature growth," and "should not expect the AEC to fight the industry's political, social, and commercial battles." Rather, he added, the agency's role was "primarily to perform as a referee serving the public interest." 22

In response to requirements of the National Environmental Protection Act (NEPA), the AEC on December 1, 1971 published 10 CFR 51, Licensing and Environmental Policy and Procedures for Environmental Protection. ${ }^{23}$ Originally, Part 51 identified nine classes of accidents. Events ranging from trivial events (Class 1) to major accidents considered in the design basis evaluation required for the safety analysis report (Class 8) were assigned to Classes 1 through 8. Accidents more severe than those postulated in Class 8 , which could lead to core meltdown and radionuclide releases exceeding the dose guidelines of 10 CFR Part 100, were designated Class 9. Although this classification scheme is no longer contained in $10 \mathrm{CFR}$, the term Class 9 is still commonly used to refer to accidents that involve substantial core damage.

\subsubsection{Emergency Core Cooling System Rulemaking}

In May 1971 the AEC released unexpected results of a Pressuiized Water Reactor
(PWR) emergency core cooling system test conducted at the Idaho National Engineering Laboratory (INEL), which indicated the possibility that the emergency core cooling system could fail to provide water to the core. The tests involved a 9-inch diameter pressure vessel with one set of inlet and outlet pipes. A break in an emergency core cooling system inlet pipe was simulated, and an attempt was made to inject water into the pressure vessel to cool the electrically heated rods simulating the core. The water was unable to enter against the residual steam pressure as steam and water were being expelled through the break. This test result prompted the AEC to adopt a set of Interim Acceptance Criteria, ${ }^{24}$ that went into effect until further research on emergency core cooling system could be done. These criteria required additional maintenance and monitoring as well as changes in the emergency core cooling system of some operating reactors.

At the time, generic issues such as emergency core cooling system were being contested at individual licensing hearings greatly delaying the licensing process. In an attempt to streamline the licensing process, the AEC decided to conduct rulemaking hearings on such generic issues. The hearings were adjudicatory in nature, affording the participants the opportunity to testify and to cross-examine other witnesses. Two rulemaking hearings were held in 1972. The first, on radioactive plant effluents, lasted 17 days and was rather easily resolved based on conservative assumptions. The second, on the Interim Acceptance Criteria for emergency core cooling system, began in January 1972 and took 125 days over 23 months. Scientists and engineers representing government, industry, and intervenor organizations were heard and with 
their lawyers, cross-examined one another. Procedural matters often dominated. The hearing record is more than 22,000 pages. From this record and the recommendations of the Hearing Board, the AEC issued "final criteria" on January 4, $1974 . .^{25}$

In 1973, before the "final criteria" were issued, a second series of experiments was completed. These tests were called $1 \frac{1}{2}$ semiscale because a loop simulating the unbroken loops of a reactor was added to the $1 / 2$ (broken) loop. This time water was injected through the unbroken loop, as would occur in the emergency core cooling system of actual power reactors, which have two, three, or four loops. The simulated core was successfully cooled in all tests while the steam escaped through the broken loop as predicted by computer models.

Section 50.46 and Appendix K of 10 CFR 50 defined the final outcome of the rulemaking by specifying that, following postulated LOCAs, emergency core cooling system must assure:

- Peak cladding temperature cannot exceed $2200^{\circ} \mathrm{F}\left(1204^{\circ} \mathrm{C}\right)$,

- oxidation cannot exceed $17 \%$ of the cladding thickness,

- hydrogen generation from hot cladding-steam interaction cannot exceed $1 \%$ of its potential,

- the core geometry must be retained in a coolable condition,

- long-term cooling must be provided.
At the time the "final criteria" were developed, computer codes had limited capabilities for simulating the complex phenomena associated with large LOCAs. To ensure that calculations would be conservative, the rule also provided calculational restraints, some of which are:

- A multiplier of 1.2 on the decay heat rate,

- the assumption that the cladding oxidation rate is not limited by the predicted availability of steam,

- conservative assumptions on emergency core cooling system delivery to the lower plenum.

During the period from 1971 through 1974 the AEC and its successor the NRC reviewed the emergency core cooling system designs of every operating plant. When necessary, retrofitting and upgrading of the emergency core cooling systems were required or the operating power level was reduced to assure compliance with the final criteria. Indian Point 1 was shut down in October 1974 because of an inadequate emergency core cooling system. All new plants and plants under construction were required to meet the final criteria.

The twenty years that followed the semiscale test brought several independent assessments of the emergency core cooling system criteria. NRC sponsored additional experiments to investigate both individual phenomena and system performance, and the development of advanced computer codes that could provide improved simulations of LOCAs. The experimental and computational efforts provided the technical basis for a revised rule for the acceptance of 
emergency core cooling systems. The rule was approved by the NRC in September $1988 .^{26}$ The revised rule retains the acceptance criteria based on peak cladding temperature, cladding oxidation, and hydrogen generation; however, it allows the use of best-estimate computer codes for evaluating those parameters. If best-estimate methods are used, the revised rule requires that the uncertainty of the calculations be quantified and included when comparing calculated results with the acceptance limits provided in $10 \mathrm{CFR} 50$. This allows much more realistic estimates of plant safety margins.

\subsubsection{The Energy Reorganization Act of 1974}

The AEC's efforts under Chairman Schlesinger to narrow the divisions between nuclear proponents and critics and to recover the AEC's regulatory credibility produced, at best, mixed results. The AEC suffered from the general disillusionment with the "establishment" that prevailed by the late 1960 s largely as a result of the Vietnam war. Major differences between the AEC and environmentalists remained regarding emergency core cooling system effectiveness, thermal pollution, and hazards of low-level radiation.

Another issue that undermined confidence in the AEC in the early 1970s was its approach to high-level radioactive waste disposal. In 1970 , in response to increasing expressions of concern about the lack of a policy for high-level waste disposal, the AEC announced that it would develop a permanent repository for nuclear wastes in an abandoned salt mine near Lyons, Kansas. It aired its plans without conducting thorough geologic and hydrologic investigations. The suitability of the site was soon challenged by the state geologist of Kansas and other scientists. The uncertainties about the site generated a bitter dispute between the AEC on the one side and members of Congress and state officials from Kansas on the other. It ended in 1972 in great embarrassment for the AEC. The reservations of those who opposed the Lyons location proved to be well-founded, and numerous well holes were found to have penetrated the salt bed.

In addition to debates over emergency core cooling system and high-level waste disposal, questions over reactor design and safety, quality assurance, the probability of a major reactor accident, and other issues fueled the controversy over nuclear power. The number of contested hearings for plant licenses steadily grew. The AEC came under increasing attacks for its dual responsibilities for developing and regulating the technology. The question of creating separate agencies to promote and to regulate the civilian uses of nuclear energy had arisen within a short time after passage of the 1954 Atomic Energy Act, but in the early stages of nuclear development it had seemed premature and unwarranted. It gained greater support in later years as both the nuclear industry and antinuclear sentiment grew. One of President Nixon's responses to the Arab oil embargo and the energy crisis of 1973-4 was to ask Congress to create a new agency that could focus on, and presumably speed up, the licensing of nuclear plants. After much debate, in 1974 Congress passed the Energy Reorganization Act, which divided the AEC into the Energy Research and Development Administration (ERDA), predecessor to the current Department of Energy, and the Nuclear Regulatory Commission. 


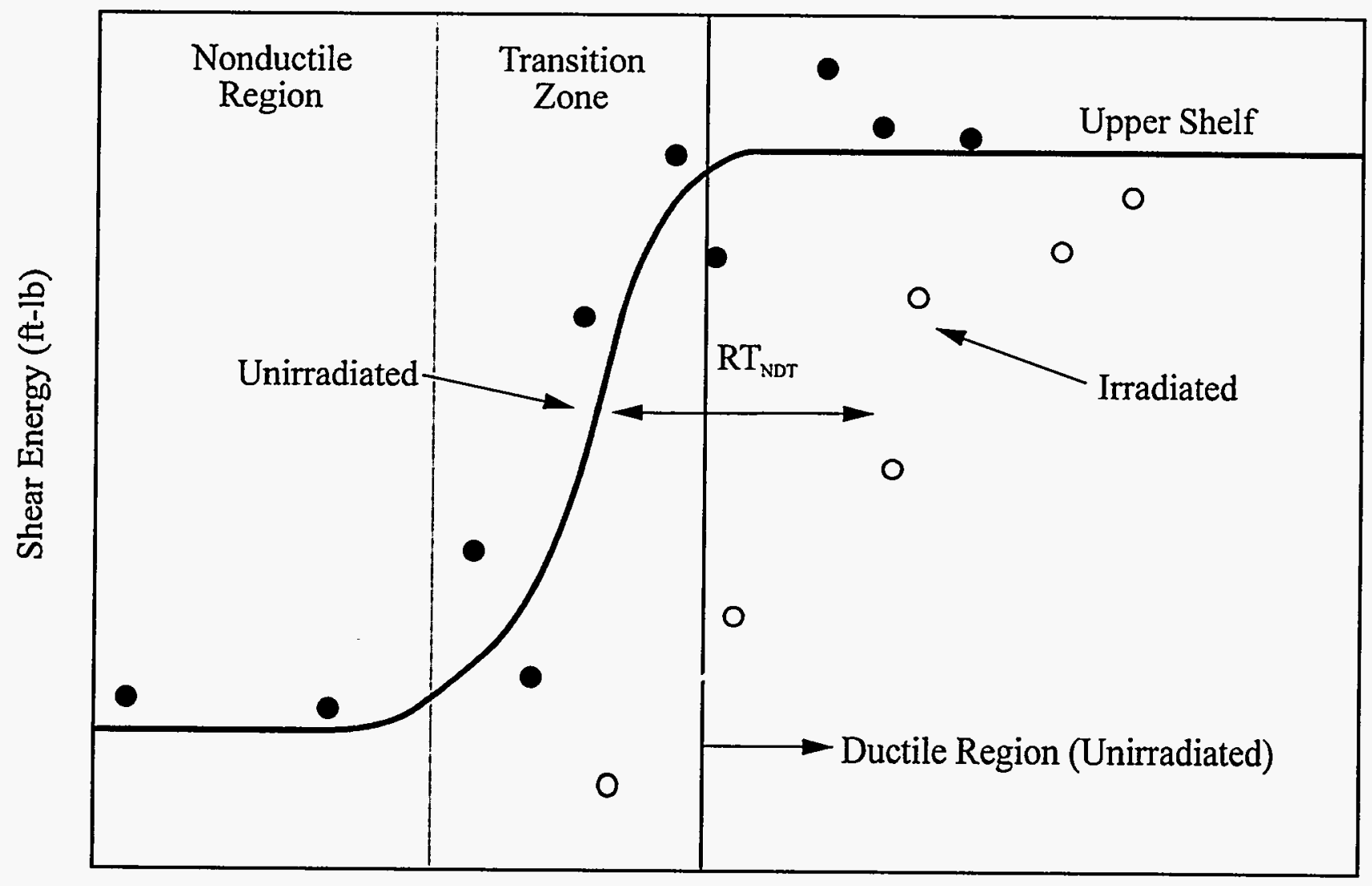

Temperature (F)

Reference nil-ducility transition temperature $\left(\mathrm{RT}_{\mathrm{NDT}}\right)$

Figure 1.3-1 Shift of nil-ductility transition temperature 


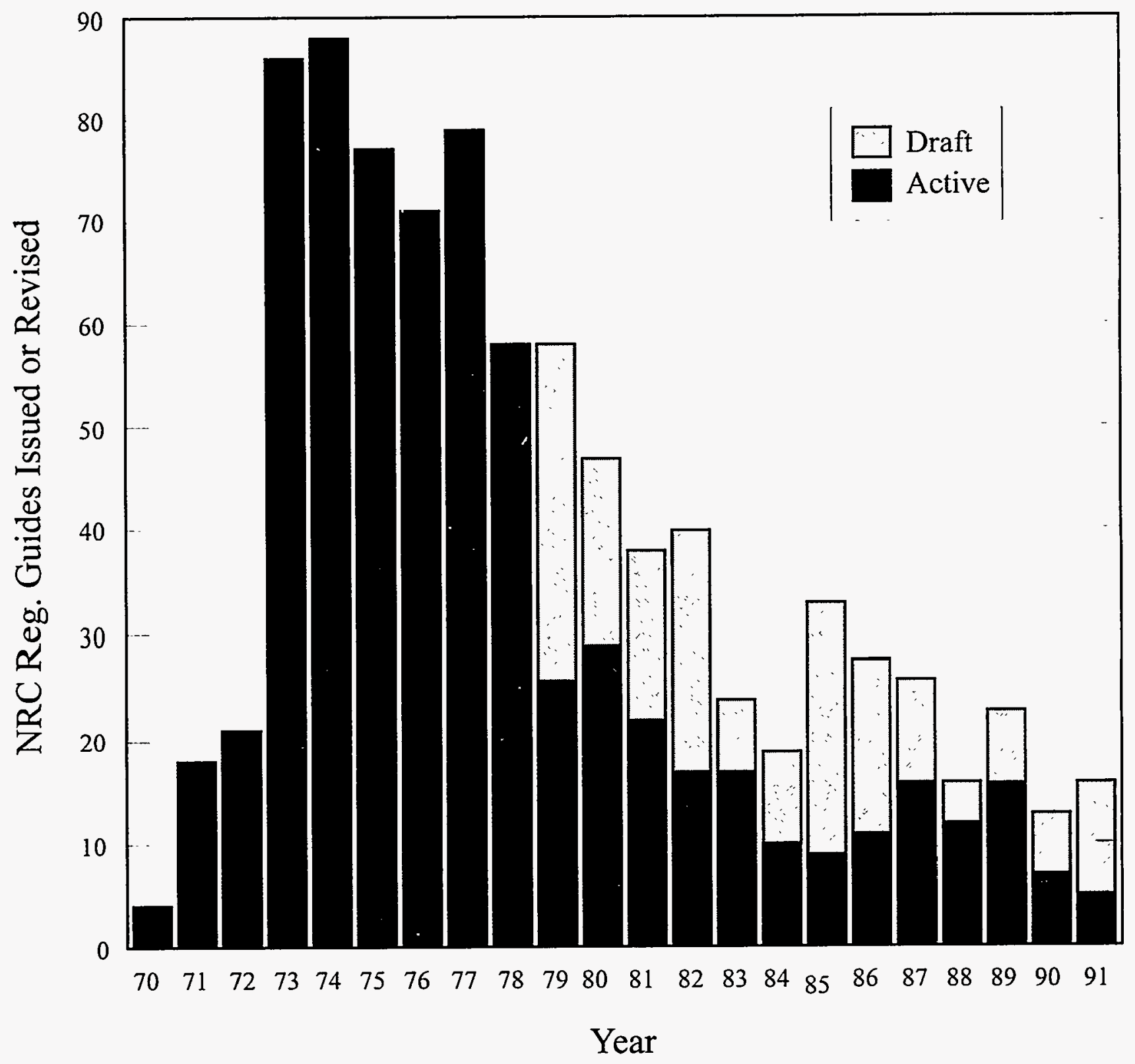

Figure 1.3-2 Number of regulatory guides issued per year 


\section{References for Section 1.3}

1. Theodore A. Meyer, "The Evolution of Reactor Vessel PTS--A Catalyst to the Advancement of Technology," Mechanical Engineering, June 1984, p. 37.

2. George T. Mazuzan and Samuel Walker, "Controlling The Atom: The Beginning of Nuclear Regulation 1946-1962," University of California Press, 1984, p. 217.

3. American Society for Testing and Materials (ASTM) Standards E-23, E-184, E-185, and E-208, Philadelphia, Pennsylvania.

4. Advisory Committee on Reactor Safeguards (ACRS) letter on Reactor Pressure Vessels (November 24, 1965), reproduced in "Nuclear Reactor Safety: On the History of the Regulatory Process", by David Okrent, 1981, pp. 88-89.

5. Advisory Committee on Reactor Safeguards, "Report on the Integrity of Reactor Vessels for Light-Water Power Reactors," WASH-1285, January 1974.

6. U.S. Nuclear Regulatory Commission, Statement of Considerations for Proposed Revision to 10 CFR 50.61, "Fracture Toughness Requirements for Protection Against Pressurized Thermal Shock . Events," May 6, 1991.

7. U.S. Code of Federal Regulations, "Fracture Toughness Requirements for Protection Against Pressurized Thermal Shock Events," Title 10, Part 50.61.

8. Advisory Committee on Reactor Safeguards, Minutes of June 3, 1966 Subcommittee Meeting, reproduced in
"Nuclear Reactor Safety: On the History of the Regulatory Process," by David Okrent, 1981, pp. 99-101.

9. David Okrent, "Nuclear Reactor Safety: On the History of the Regulatory Process," The University of Wisconsin Press, Madison, Wisconsin, 1981, pp. 112-121.

10. John May, "The Greenpeace Book of the Nuclear Age: The Hidden History, The Human Cost," Greenpeace Communications Ltd., London, 1989.

11. Eric S. Beckjord, U.S. Nuclear Regulatory Commission Memorandum, February 28, 1992.

12. U.S. Atomic Energy Commission, "Proposed General Design Criteria for Construction Permits for Nuclear Power Plants," Federal Register, November 22, 1965.

13. U.S. Atomic Energy Commission, "Proposed General Design Criteria for Nuclear Power Plants," Federal Register, July 10, 1967.

14. U. S. Code of Federal Regulations, "General Design Criteria for Nuclear Power Plants," Title 10, Part 50, Appendix A, Federal Register, February 19, 1971.

15. U.S. Atomic Energy Commission, "Net Positive Suction Head for Emergency Core Cooling Containment Heat Removal," Safety Guide 1.1, November 1970.

16. American National Standards Institute, "Quality Assurance Program Requirements for Nuclear Power Plants," ANSI N45.2. 
17. U.S. Nuclear Regulatory Commission, "Guidelines for Fire Protection for Nuclear Power Plants," Auxiliary Power Conversion Systems Branch Technical Position 9.5-1, 1975.

18. U.S. Nuclear Regulatory Commission, "Fire Protection Guidelines for Nuclear Power Plants," Regulatory Guide 1.120, draft for comment, June 1976.

19. U. S. Code of Federal Regulations, "Fire Protection Program for Nuclear Power Plants Operating Prior to January 1, 1979," Title 10, Part 50, Appendix R.

20. U.S. Nuclear Regulatory Commission, "Motor-Operated Valve Common Mode Failures During Plant Transients Due to Improper Switch Settings," Inspection Enforcement (IE) Bulletin No. 85-03, 1985.

21. Judge J. Skelly Wright, Calvert Cliffs decision, US Court of Appeals for the District of Columbia (July 23, 1971), noted in "An Outline History of Nuclear Regulation and Licensing 1946-1979," by George T. Mazuzan and Roger R. Trask, 1979, p. 68.
22. James R. Schlesinger, speech delivered to industry groups in Bal Harbour, Florida, October 20, 1971, cited in "A Short History of the Regulatory Process 19461990," by J. Samuel Walker, 1991, p. 34.

23. U. S. Code of Federal Regulations, "Licensing and Regulatory Policy and Procedures for Environmental Protection," Title 10, Part 51.

24. George T. Mazuzan and Roger R. Trask, "An Outline History of Nuclear Regulation and Licensing 1946-1979," Historical Office, Office of the Secretary, U.S. Nuclear Regulatory Commission, 1979, p. 71.

25. U.S. Code of Federal Regulations, "Acceptance Criteria for Emergency Core Cooling Systems for Light Water Cooled Nuclear Power Reactors," Title 10, Part 51.46 .

26. U.S. Code of Federal Regulations, "Emergency Core Cooling Systems; Revisions to Acceptance Criteria,"Title 10, Part 50.46. 


\subsection{Design Basis Perspectives}

\subsubsection{Safety Analysis Report Requirements}

As discussed in Section 1.2.2, the initial applications to build commercial nuclear power plants were received and reviewed by the AEC in 1955 and 1956. Title 10 Part 50, Domestic Licensing of Production and Utilization Facilities, was added to the Code of Federal Regulations in January 1956. From the outset, the applicants preliminary and final safety analysis reports were the main documents reviewed by the AEC (and later the NRC) in deciding whether to grant construction permits and operating licenses.

Requirements regarding the submittal and content of safety analysis reports were first issued as 10 CFR 50 Section 50.34 in December of $1970 .^{1}$ Additional guidance was later provided in Regulatory Guide 1.70, which is entitled "Standard Format and Content of Safety Analysis Reports for Nuclear Power Plants." ${ }^{2}$ Table 1.4-1, which is based on this Regulatory Guide, indicates the major topics treated in the safety analysis reports. The NRC reviews safety analysis reports to determine whether plants can be built and operated without undue risk to the health and safety of the public. Guidelines for the NRC review are contained in NUREG-0800 entitled "Standard Review Plan for the Review of Safety Analysis Reports for Nuclear Power Plants." ${ }^{13}$ The NRC findings are documented in a separate Safety Evaluation Report.

Chapter 2 of the Safety Analysis Report provides information on the geology, seismology, hydrology, and meteorology of the site and vicinity. It also provides information regarding nearby industry, transportation, and military facilities. Based on this information, design criteria are established for the magnitude of external phenomena such as floods, earthquakes, winds, tornadoes, and tsunami, which the plant must be capable of withstanding. Seismic design bases are discussed further in subsection 1.4.5.

Table $1.4-2$ is a list of potential accidentinitiating events (initiators), which applicants are specifically requested to address in Chapter 15 of the Safety Analysis Report. Regulatory Guide 1.70 asks that the potential causes of each of these initiators be identified, and the estimated frequency of occurrence of each plausible initiator be assigned to one of the following categories:
a. Incidents of moderate frequency (expected to occur several times during the plant lifetime).
b. Infrequent events (may occur during the lifetime of the plant).
c. Limiting faults (not expected to occur but postulated because of the potential for the release of significant amounts of radioactive material).

For each of the eight initiator groups listed in Table 1.4-2, the potential exists for the release of radionuclides from successive barriers (fuel, cladding, reactor coolant pressure boundary, and containment) to the environment. The plant must be designed to limit such releases such that offsite doses would not exceed the guidelines of $10 \mathrm{CFR}$ Part 100 as a result of any accident in a set of design-basis accidents. ${ }^{4}$ Conversely, a design-basis accident (DBA) is a postulated accident that a facility is designed and built to withstand without exceeding the offsite exposure guidelines of the NRC's siting regulation (10 CFR 100). 
The assumptions used to delineate and analyze DBAs are based on NRC regulations and guidelines that evolved as numerous applications for construction permits and operating licenses were reviewed. The subset of DBAs that are analyzed in detail in the Safety Analysis Report is selected in order to (a) bound the offsite doses for DBAs in each of the eight initiation categories of Table 1.4-2, and (b) to demonstrate the adequacy of key engineered safety features, in particular, the emergency core cooling systems and containment. Therefore, each of these analyzed DBAs invariably includes at least one significant failure of a component (or operator) to perform an intended safety function. Generally, equipment failures beyond those consistent with the single failure criterion of 10 CFR 50, Appendix A (see Section 1.3.4) are not postulated for DBAs. An exception arises when anticipated transients without scram (initiating event group 8 in Table 1.42) are treated as DBAs. Anticipated transients without scram are discussed separately in Sections 2.4, 2.5 and Appendix $2 \mathrm{~B}$.

\subsubsection{Design-Basis LOCAs}

For many water cooled reactors the siting-basis accident, which is the DBA that results in the largest potential radiological consequences to the public, begins with an instantaneous break of a large pipe in the reactor coolant system. Such breaks are postulated in spite of the extensive design, construction, testing, inspection, operations, and maintenance measures taken to prevent them. In addition, a coincident loss of offsite power is postulated and the singlefailure criterion is then applied, which usually leads to the assumption that one of the emergency diesel generators fails to start. This implies the loss of one of two or three AC-powered trains in various safety systems.
A spectrum of break locations and sizes is considered, including hypothetical severances of the largest pipes in the system in such a way that reactor coolant would discharge unimpeded from both ends of the severed pipe. This type of break is referred to as a "double-ended guillotine break."

Because the reactor coolant system operates under high pressure, a reactor coolant pipe break would result in rapid expulsion of a large fraction of the reactor coolant into containment. Some of the steam resulting from this expulsion pressurizes the containment; the rest is condensed on structures or by engineered safety features. In PWR containments, cold water sprays and/or ice racks are provided to condense steam blowdown. In BWR containments, steam would be condensed in the water-filled pressure-suppression pool. Condensing the steam limits containment pressure, which is the driving force for outward leakage. At the end of the blowdown (expulsion) period, the primary system would be filled mostly with saturated steam at the same pressure as that in the containment. In fact, a largebreak LOCA or main steam line break usually establishes the peak internal pressure that the containment is designed to accommodate.

In a large-break LOCA, the reactor would immediately go subcritical due to the loss of reactor coolant (neutron moderation). Successful actuation of the reactor protection system would keep the reactor subcritical when reflooded with emergency coolant. However, there would still be considerable thermal energy generated in the fuel from the decay of radioactive fission products. Immediately after shutdown, the generation rate of this "decay heat" is about $7 \%$ of the thermal power during operation. For example, a $1000 \mathrm{MWe}$ nuclear plant generates about $3100 \mathrm{MWt}$ during full power 
operation but still generates about $225 \mathrm{MWt}$ immediately after shutdown. The decay heat generation rate decreases fairly rapidly as indicated in Figure 1.4-1. However, if emergency cooling water were not supplied to remove heat from the core following the pipe break, core temperatures would increase to the point where energetic chemical reactions would occur between hot cladding and residual water-steam in the reactor pressure vessel. Given a prolonged failure to cool the core, large quantities of hydrogen could be generated, portions of the core would melt, and fission products would be released to containment and possibly to the environment. Such severe accident phenomena are discussed in more detail in subsequent chapters.

The emergency core cooling system (ECCS) is provided to limit the consequences of LOCAs. An automatic control system senses the occurrence of a LOCA and coordinates the operation of the different parts of the ECCS as they are needed. The function of the ECCS is to supply water to the core (via spray and/or flooding systems) to cool and limit the temperature increase of the cladding, thus preventing significant core damage and release of radionuclides from the fuel rods.

\subsubsection{Design-Basis Analysis Conservatisms}

In determining the acceptability of a proposed ECCS, the NRC reviews LOCA calculations performed by the applicant, and measures the results against five acceptance criteria specified in 10 CFR 50 , Section 50.46 and Appendix $\mathrm{K}$ (see Section 1.3.6). ${ }^{5}$ None of these criteria, including the principal criterion that the peak cladding temperature not exceed $2200^{\circ} \mathrm{F}\left(1204{ }^{\circ} \mathrm{C}\right)$, represent threshold levels. That is, exceeding the success criteria would not result in an immediate public safety problem.
What the success criteria do represent is "a conservative statement of conditions which, if generally met, will provide a high degree of confidence that public safety is protected even if a highly unlikely LOCA occurs."

The method of analysis and evaluation of design-basis LOCAs that resulted from the ECCS rulemaking invoked many pessimistic assumptions (10 CFR Part 50, Appendix K).

Such assumptions result in a calculated peak cladding temperature well above the value obtained using more realistic assumptions. In addition, the design of the ECCS must be shown to provide the required performance in spite of the loss of one train of AC power. Table 1.4-3 is a partial list of some of the conservative assumptions used in traditional design-basis LOCA calculations, illustrating the multiplicity of Conservatisms. The table also contains a comparison with more realistic assumptions.

A calculation of peak cladding temperature using the Appendix $\mathrm{K}$ conservatisms is provided in Figure 1.4-2. The decay heat generated in this time interval is significant, amounting to almost one third of the energy added to the containment atmosphere. As indicated in Table 1.4-3, decay heat is conservatively assumed to be $20 \%$ above best estimate values in design-basis LOCA calculations. Of course, this is also conservative with respect to the calculated peak clad temperature. As illustrated in the figure, removing a few such Appendix $\mathrm{K}$ conservatisms can reduce the predicted peak clad temperature by several hundred degrees. ${ }^{?}$

In September 1988, 10 CFR 50.46 was modified to allow more realistic calculations to be used in estimating peak cladding temperatures. The new requirements, while less stringent, required that uncertainties in 
the calculations be considered and that the models provide:

"assurance of a high level of probability that the performance criteria of 50.46(b) would not be exceeded."

Traditional offsite dose analyses for design-basis LOCAs postulate releases of radioactive fission products from the reactor fuel to the containment (and thus available for leakage to the environment) that are worse than actually expected given that the ECCS acceptance criteria must be met. NRC Regulatory Guides 1.3 and 1.4 (for BWRs and PWRs respectively) recommend the assumption that $25 \%$ of the radioactive iodine inventory developed from full-power operation of the core be immediately available for leakage from containment. ${ }^{8,9} \mathrm{~A}$ release to containment of this magnitude could only occur if the ECCS failed, thereby permitting significant core melting.

One of the most significant barriers to the release of fission products to the environment from a postulated LOCA accident is the containment building. This structure is designed to have a very low leakage rate when subjected to the maximum of the peak internal pressures predicted for design-basis pipe breaks. The internal pressure following a pipe break inside containment peaks and then begins to decrease rapidly when the rate of energy addition to the containment atmosphere by blowdown falls below the rate of energy absorption by internal structures and removal by containment sprays, fan coolers, ice beds, or suppression pools. For accident calculations, however, the containment is conservatively (as if the pressure did not decrease) assumed to leak at a constant rate called the design-basis leak rate for the first
24 hours and at $50 \%$ of that rate for the remaining duration of the accident.

DBA analyses take into account the reduction in the amount of radioactive material available for leakage to the environment by engineered safety features such as containment sprays and recirculating filtration systems. The amount of cleanup is evaluated for each system using conservative assumptions for parameters such as adsorption and filtration efficiencies.

The potential doses at the exclusion-area and low-population-zone boundaries are calculated assuming that the accident occurs when meteorological conditions are worse (from the standpoint of calculated doses) than those that would be expected to prevail at the site approximately $95 \%$ of the time (Regulatory Guides 1.3 and 1.4). Table 1.44 presents the results from typical calculations of potential offsite doses due to several kinds of DBAs. Even with the considerable number of pessimistic assumption employed, the calculated doses that a person out-of-doors in the vicinity of the plant might receive for the entire course of the accident are usually well below the 10 CFR Part 100 guidelines.

\subsubsection{Comparison with Realistic Analyses}

The conservative assumptions used for DBA analyses in the Safety Analysis Report assure that the calculated consequences will exceed those that would be expected were the accident to actually occur. For example, studies show fuel cladding temperatures in the range from $1200^{\circ} \mathrm{F}$ to $1600{ }^{\circ} \mathrm{F}\left(650^{\circ} \mathrm{C}\right.$ to $870^{\circ} \mathrm{C}$ ) being predicted for more realistic calculations, as compared to $2100{ }^{\circ} \mathrm{F}$ to $2200{ }^{\circ} \mathrm{F}\left(1150{ }^{\circ} \mathrm{C}\right.$ to $\left.1200{ }^{\circ} \mathrm{C}\right)$ for conservative safety analysis report calculations. The radiological consequences that might realistically result from the 
unlikely event of a LOCA have been explored in connection with environmental evaluations. Table 1.4-5 presents some realistic dose estimates obtained for typical PWR events and accidents. Note that the realistic exclusion radius dose for a design-basis LOCA is over two orders of magnitude less than the corresponding conservatively calculated dose estimate in Table 1.4-4. ${ }^{6}$ The most significant difference between the conservative and realistic dose calculations is in the release from fuel that is assumed. Realistically, ECCS would protect the core from melting, even given the postulated partial failure of AC power, and far less than $25 \%$ of the radioactive iodine inventory would escape from the fuel to the reactor containment.

In short, very conservative DBA analyses predict radiation doses to the public that are below 10 CFR Part 100 guidelines, and realistic DBA analyses predict much lower doses. This is not to say that accidents resulting in doses exceeding Part 100 guidelines are impossible; however, such accidents would realistically have to involve both:

a. More severe initiating events or more component failures or operator errors than postulated for DBAs in order for ECCS to fail, core melting to occur, and significant quantities of radionuclides to be released from the fuel, and

b. some significant breach or bypass of containment in order for significant quantities of radionuclides to be released to the environment.

To assess the likelihood and consequences of such severe uncontained accidents, both deterministic and probabilistic analyses are performed (see Sections 1.5 and 2.5).

\subsubsection{Seismic Design Basis}

Design basis events are postulated in each safety analysis report for external events such as earthquakes, tornados, floods, accidents at nearby industrial facilities, etc. The approach to designing against many potential ex-plant (external) accident initiators can be illustrated by considering the seismic design basis.

Seismic safety considerations were largely overlooked for the first several power reactors, which were built east of the Rocky Mountains. Then, in the period 1963-1965, reactors were proposed for sites near Bodega Bay, San Onofre, and Malibu, California. During the AEC and ACRS review of these sites, seismic concerns were raised. ${ }^{10}$ The originally proposed requirements for seismic design were made two or three times more stringent. Even so, the Bodega Bay and Malibu sites were rejected due to seismic concerns.

In 1965, the AEC regulatory staff initiated work with its consultants to develop more specific seismic engineering criteria. In a May 1967 the AEC sent a draft document entitled "Seismic and Geologic Siting Criteria for Nuclear Power Plants" to the ACRS for review and comment. Ultimately this draft evolved into Appendix $A$ to 10 CFR Part 100."

The draft and subsequent revisions reflected the traditional philosophy that nuclear power plants should be designed against two levels of potential seismic events. Nuclear power plants are designed to continue to operate given earthquakes of moderate intensity and to safely withstand the effects of larger earthquakes. The operating basis earthquake $(\mathrm{OBE})$ is the largest earthquake that 
could reasonably be expected to affect the plant site during the operating life of the plant

and for which the plant is designed to continue operating without undue risk to the health and safety of the public. Nuclear power plants have instruments to warn of and measure earthquake motion. At the first indication of an earthquake, the operator is alerted. If the earthquake does not exceed the magnitude of the OBE, the plant can be kept on line to provide needed electrical power, and no inspection or evaluation of the plant would be required after the event. If the earthquake exceeds the magnitude of the OBE, the plant is shut down and could not be restarted until inspections and evaluations confirmed that it would be safe to do so.

The safe shutdown earthquake (SSE) is

based upon an evaluation of the maximum earthquake potential considering the regional and local geology and seismology and specific characteristics of local subsurface material.

An earthquake of this magnitude may never have been experienced (and may never occur) at the site, but it determines the maximum vibratory ground motion for which plant safety features are designed to remain functional. At this level other plant features might be damaged, but the plant could be safely shut down.

Plant features (including foundations and supports) that are designed to remain functional following a SSE are designated Seismic Category I. ${ }^{12}$ These include features that are necessary to assure:

\section{The integrity of the RCS pressure} boundary,

2. The capability to shut down the reactor and maintain it in a safe condition, or

3. The capability to prevent or mitigate the consequences of accidents that could result in potential offsite exposures comparable to the guideline exposures of 10 CFR Part 100."

By a combination of structural analysis and testing during plant design, plant structures and equipment important to safety are built to survive the SSE. Seismic analyses of structures, systems, and components are discussed in Safety Analysis Report Sections 3.7 and 3.8 , and guidance regarding such analyses is provided in the corresponding Standard Review Plan sections and references. In these seismic analyses conservative assumptions permit all vibratory parameters to be determined from the peak value of the horizontal ground acceleration caused by the earthquake such as $0.3 \mathrm{~g} \quad(30 \%$ of the gravitational acceleration). Vibration tests are conducted to confirm key analyses. Such tests are often done on the first models of individual components including piping, fuel elements, pressure vessels, pumps, and valves and on full-scale reactor structures. Whole reactor buildings have been tested using mechanical shakers attached to the structure, and high explosives have been detonated nearby to simulate strong earthquakes.

Several items included in or omitted from the 1967 draft seismic criteria sparked considerable debate. One item, the proposed minimum design basis (or floor) of $0.1 \mathrm{~g}$ for the SSE, was particularly controversial. Not until November 1971, after many major re- 
drafts, did the AEC issue a Notice of Proposed Rule-Making to amend the 10 CFR Part 100 by adding Appendix A: "Seismic and Geologic Siting Criteria for Nuclear Power Plants." 10 The criteria were adopted in 1973 and reflected the practice which had been followed in actual construction permit reviews. Guidance was provided regarding the general extent of the geologic and seismic investigation required; however, no clear method was provided for selecting the SSE based on the results of such investigations.

The limited seismic audit performed on two reactors for the 1975 Reactor Safety Study (see Section 1.3) identified several errors and deviances in seismic design. In 1977 the Nuclear Regulatory Commission initiated a major new research program in seismic safety including the application of probabilistic techniques (see subsection 2.2.2). In 1978 and 1979 , based on new analyses of existing seismic data, the NRC required reevaluation of the seismic design bases for several reactors constructed by the Tennessee Valley Authority. In early 1979, five operating reactors were shut down for an extended period by the NRC in order to permit re-analysis and possible modifications because errors had been made in the seismic design of important piping systems. A large number of other reactors have since reported errors in their seismic design, and the adequacy of detailed seismic design has received considerable NRC attention.

Currently, 10 CFR 100 Appendix A requires that the maximum vibratory ground motion of the OBE be one-half that of the SSE. It further requires a suitable dynamic analysis or qualification test to demonstrate that structures, systems, and components neces- sary for continued safe operation are capable of withstanding the effects of the OBE. In some cases (e.g., piping) this has caused the OBE requirements to have more design significance than the SSE. The NRC has agreed that the OBE should not control the design of safety systems. As a result, the regulation is being amended to permit future applicants for construction permits to set the maximum $\mathrm{OBE}$ vibratory ground motion based on one of two options: ${ }^{13}$

(I) One-third or less of the SSE, where $O B E$ requirements are satisfied without an explicit response or design analyses being performed, or

(ii) a value greater than one-third of the SSE, where analysis and design are required.

In either case, the plant must be shut down for inspection if the OBE is exceeded. In addition to changes in the selection of OBE's the NRC is proposing changes in the definition of SSEs for new plants. ${ }^{14}$ The new approach adds probabilistic considerations to the previous methods and proposes that:

the probability of exceeding the Safe Shutdown Earthquake Ground Motion at a site be lower than the median probability of exceedance computed for the current population of the operating plants.

The changes proposed are intended to assure that future plants are as safe as current plants, while allowing for incorporation of recent findings from earthquake research activities. 
Table 1.4-1 Chapter titles from Regulatory Guide 1.70 Revision 3 standard format and content of Safety Analysis Reports for nuclear power plants

Chapter 1 Introduction and General Description of Plant

Chapter 2 Site Characteristics

Chapter 3 Design of Structures, Components, Equipment, and Systems

Chapter 4 Reactor

Chapter 5 Reactor Coolant System and Connected Systems

Chapter 6 Engineered Safety Features

Chapter 7 Instrumentation and Controls

Chapter $8 \quad$ Electric Power

Chapter 9 Auxiliary Systems

Chapter 10 Steam and Power Conversion System

Chapter 11 Radioactive Waste Management

Chapter 12 Radiation Protection

Chapter 13 Conduct of Operations

Chapter 14 Initial Test Program

Chapter 15 Accident Analysis

Chapter 16 Technical Specifications

Chapter 17 Quality Assurance 
Table 1.4-2 Representative initiating events to be analyzed in Section 15.X.X of the Safety Analysis Report

\section{Increase in Heat Removal by the Secondary System}

1.1 Feedwater system malfunctions that result in a decrease in feedwater temperature.

1.2 Feedwater system malfunctions that result in an increase in feedwater flow.

1.3 Steam pressure regulator malfunction or failure that results in increasing steam flow.

1.4 Inadvertent opening of a steam generator relief or safety valve.

1.5 Spectrum of steam system piping failures inside and outside of containment in a PWR.

2. Decrease in Heat Removal by the Secondary System

2.1 Steam pressures regulator malfunction or failure that results in decreasing steam flow.

2.2 Loss of external electric load.

2.3 Turbine trip (stop valve closure).

2.4 Inadvertent closure of main steam isolation valves.

2.5 Loss of condenser vacuum.

2.6 Coincident loss of onsite and external (offsite) A.C. power to the station.

2.7 Loss of normal feedwater flow.

2.8 Feedwater piping break.

3. Decrease in Reactor Coolant System Flow Rate

3.1 Single and multiple reactor coolant pump trips.

3.2 BWR recirculation loop controller malfunctions that result in decreasing flow rate.

3.3 Reactor coolant pump shaft seizure.

3.4 Reactor coolant pump shaft break. 


\section{Table 1.4-2 Representative initiating events to be analyzed in} Section 15.X.X of the Safety Analysis Report (continued)

\section{Reactivity and Power Distribution Anomalies}

4.1 Uncontrolled control rod assembly withdraws from a subcritical or low power startup condition (assuming the most unfavorable reactivity conditions of the core and reactor coolant system), including control rod or temporary control device removal error during refueling.

4.2 Uncontrolled control rod assembly withdraws at the particular power level (assuming the most unfavorable reactivity conditions of the core and reactor coolant system) that yields the most severe results (low power to full power).

4.3 Control rod maloperation (system malfunction or operator error), including maloperation of part length control rods.

4.4 Startup of an inactive reactor coolant loop or recirculating loop at an incorrect temperature.

4.5 A malfunction or failure of the flow controller in BWR loop that results in an increased reactor coolant flow rate.

4.6 Chemical and volume control system malfunction that results in a decrease in the boron concentration in the reactor coolant of a PWR.

4.7 Inadvertent loading and operation of a fuel assembly in an improper position.

4.8 Spectrum of rod ejection accidents in a PWR.

4.9 Spectrum of rod drop accidents in a BWR.

\section{Increase in Reactor Coolant Inventory}

5.1 Inadvertent operation of ECCS during power operation.

5.2 Chemical and volume control system malfunction (or operator error) that increases reactor coolant inventory.

5.3. A number of BWR transients, including items 2.1 through 2.6 and item 1.2 . 


\section{Table 1.4-2 Representative initiating events to be analyzed in Section 15.X.X of the Safety Analysis Report (continued)}

\section{Decrease in Reactor Coolant Inventory}

6.1 Inadvertent opening of a pressurizer safety or relief valve in a PWR or a safety or relief valve in a BWR.

6.2 Break in instrument line or other lines from reactor coolant pressure boundary that penetrate containment.

6.3 Steam generator tube failure.

6.4 Spectrum of BWR steam system piping failures outside of containment.

6.5 Loss-of-coolant accidents resulting from the spectrum of postulated piping breaks within the reactor coolant pressure boundary, including steam line breaks inside of containment in a BWR.

6.6 A number of BWR transients, including items 2.7, 2.8, and 1.3.

\section{Radioactive Release from a Subsystem or Component}

7.1 Radioactive gas waste system leak or failure.

7.2 Radioactive liquid waste system leak or failure.

7.3 Postulated radioactive releases due to liquid tank failures.

7.4 Design basis fuel handling accidents in the containment and spent fuel storage buildings.

7.5 Spent fuel cask drop accidents. 
Table 1.4-2 Representative initiating events to be analysis in Section 15.X.X of the Safety Analysis Report (continued)

8. Anticipated Transients Without SCRAM.

8.1 Inadvertent control rod withdrawal.

8.2 Loss of feedwater.

8.3 Loss of AC power.

8.4 Loss of electrical load.

8.5 Loss of condenser vacuum.

8.6 Turbine trip.

8.7 Closure of main steam line isolation valves. 


\section{Table 1.4-3 Partial comparison of realistic assumptions with conser- vative assumptions of LOCA calculations}

\section{Accident Initiation}

1. Crack in large pipe, rupture of smaller pipe, or limited break in large pipe resulting in shutdown and repair.

\section{System/Component Reliability}

1. Off site power is available.

2. All components of emergency AC, ECCS, and containment ESFs function properly.

Reactor Power

1. The plant is operated at $100 \%$ power or less.

2. Hottest region of core has expected peaking factor.

3. Decay heat follows best estimate prediction.

\section{ECCS and Containment ESFs}

1. Break occurs in system such that some of water from ECCS reaching broken loop is effective.

2. ECCS pumps deliver at higher than design flow rate.
1. A spectrum of pipe breaks is analyzed including instantaneous double-ended breaks of any reactor coolant, feedwater, or main steam line.

1. Off-site power is lost concurrent with initiating event.

2. The worst single active failure is postulated for each accident analyzed.

1. The plant is operated at $102 \%$ power continuously.

2. Hottest region of core assumed to be at the maximum allowable peaking factor due to abnormal condition.

3. Decay heat is conservatively above best estimate to account for uncertainties in prediction.

1. For postulated PWR cold leg breaks all ECC water directed to the broken loop is diverted to containment until the end of blowdown.

2. ECCS pumps deliver at design flou rate or less. 


\section{Table 1.4-3 Partial comparison of realistic assumptions with conservative assumptions of LOCA calculations (continued)}

\section{ECCS and Containment ESFs (Continued)}

3. Reactor coolant pumps continue to run.

4. Best estimate fluid discharge and heat transfer correlations apply.

5. Fuel rods would have a distribution of temperature.

6. Initial containment temperature and ultimate heat sink temperature would be nominal.
3. Reactor coolant pumps are tripped and coasting down or assumed to have a locked impeller.

4. Conservative fluid discharge and heat transfer correlations are used.

5. ECCS acceptance criteria apply to the hottest single fuel rod.

6. Initial containment temperature and ultimate heat sink temperature would be at upper limits.

\section{Consequence Calculations}

1. At most radionuclides in reactor coolant and gap activities in a few fuel rods would be released to the containment.

2. Containment leakage would be some nominal fraction of the design leak rate even when the containment was at its peak pressure.

3. Best-estimate atmospheric dispersion and transport models apply.

4. Emergency planning would be implemented to protect the surrounding population from any radionuclides that might be released to the environment.
1. $100 \%$ of the noble gasses and $25 \%$ of the core iodine inventory is immediately released to containment. [Reg.Guides 1.3 and 1.4]

2. Containment leaks at the rate incorporated as a technical specification requirement for the first 24 hours and at half this rate for the remaining duration of the accident. [Reg. Guides 1.3 and 1.4]

3. Conservative atmospheric dispersion and transport models are used. [Reg.Guides 1.3 and 1.4]

4. Doses are calculated for a hypothetical person standing outside in the radioactive plume, for 2 hours at the exclusion area boundary and during the entire period of plume passage at the low population zone outer boundary. [10 CFR 100 (d)] 
Table 1.4-4 Potential offsite doses due to design-basis accidents (conservative case)

\begin{tabular}{||l|c|c|c|c||}
\hline & \multicolumn{2}{c|}{$\begin{array}{c}\text { Two Hour } \\
\text { Exclusion Boundary } \\
\text { (3200 feet or 975 meters) }\end{array}$} & \multicolumn{2}{c|}{$\begin{array}{c}\text { Duration of } \\
\text { Accident } \\
\text { Low Population } \\
\text { Zone } \\
\text { (4 miles or 6.4 km) }\end{array}$} \\
\cline { 2 - 5 } & $\begin{array}{c}\text { Thyroid } \\
\text { (Rem) }\end{array}$ & $\begin{array}{c}\text { Whole Body } \\
\text { (Rem) }\end{array}$ & $\begin{array}{c}\text { Thyroid } \\
\text { (Rem) }\end{array}$ & $\begin{array}{c}\text { Whole Body } \\
\text { (Rem) }\end{array}$ \\
\hline Loss of Coolant & 155 & 3 & 81 & 3 \\
\hline Control Rod Ejection & $<1$ & $<1$ & $<1$ & $<1$ \\
\hline Fuel Handling & 2 & 2 & $<1$ & $<1$ \\
\hline Steam Line Break & 16 & 1 & 3 & 1 \\
\hline $\begin{array}{l}10 \text { CFR 100 Dose } \\
\text { Guideline }\end{array}$ & 300 & 25 & 300 & 25 \\
\hline \hline
\end{tabular}


Table 1.4-5 Potential offsite doses due to releases at a typical PWR* (realistic case)

\begin{tabular}{|l|c|c|c|}
\hline \multicolumn{1}{|c|}{ Event/Accident } & $\begin{array}{c}\text { Individual } \\
\text { Dose at } \\
\text { Exclusion } \\
\text { Radius } \\
\text { (rem/event) }\end{array}$ & $\begin{array}{c}\text { Individual } \\
\text { Dose at } \\
\text { miles or } \\
40 \mathrm{~km} \\
\text { (rem/event) }\end{array}$ & $\begin{array}{c}\text { Dose to } \\
\text { Population } \\
\text { Within } \\
50 \text { miles or } \\
80 \mathrm{~km} \\
\text { (rem/event) }\end{array}$ \\
\hline $\begin{array}{l}10 \text { gallons per day continuous leak } \\
\text { rate from sources outside } \\
\text { containment }\end{array}$ & $5 \times 10^{-6}$ & $1 \times 10^{-8}$ & $2 \times 10^{-2}$ \\
\hline $\begin{array}{l}\text { Gases from inadvertent discharge of } \\
\text { part of boric acid condensate tank }\end{array}$ & $5 \times 10^{-9}$ & $1 \times 10^{-11}$ & $2 \times 10^{-5}$ \\
\hline \begin{tabular}{l} 
Loss of load \\
\hline $\begin{array}{l}\text { Fuel handling accident inside } \\
\text { containment (3 days after } \\
\text { shutdown) }\end{array}$
\end{tabular} & $2 \times 10^{-8}$ & $4 \times 10^{-11}$ & $8 \times 10^{-5}$ \\
\hline $\begin{array}{l}\text { Fuel handling accident outside } \\
\text { containment }\end{array}$ & $3 \times 10^{-4}$ & $6 \times 10^{-7}$ & $1 \times 10^{-6}$ \\
\hline \begin{tabular}{l} 
Large-break LoCA \\
\hline
\end{tabular} & $8 \times 10^{-3}$ & $2 \times 10^{-5}$ & $3 \times 10^{1}$ \\
\hline
\end{tabular}

* From WASH-1250. Doses are whole body doses. Natural background dose is approximately $10^{5} \mathrm{man}-\mathrm{rem} / \mathrm{yr}$ for the assumed population within the 50 mile or $80 \mathrm{~km}$ radius of the nuclear plant (i.e., 750,000 to $1,000,000$ people). 


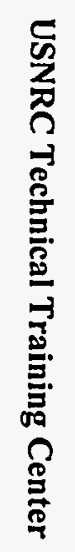

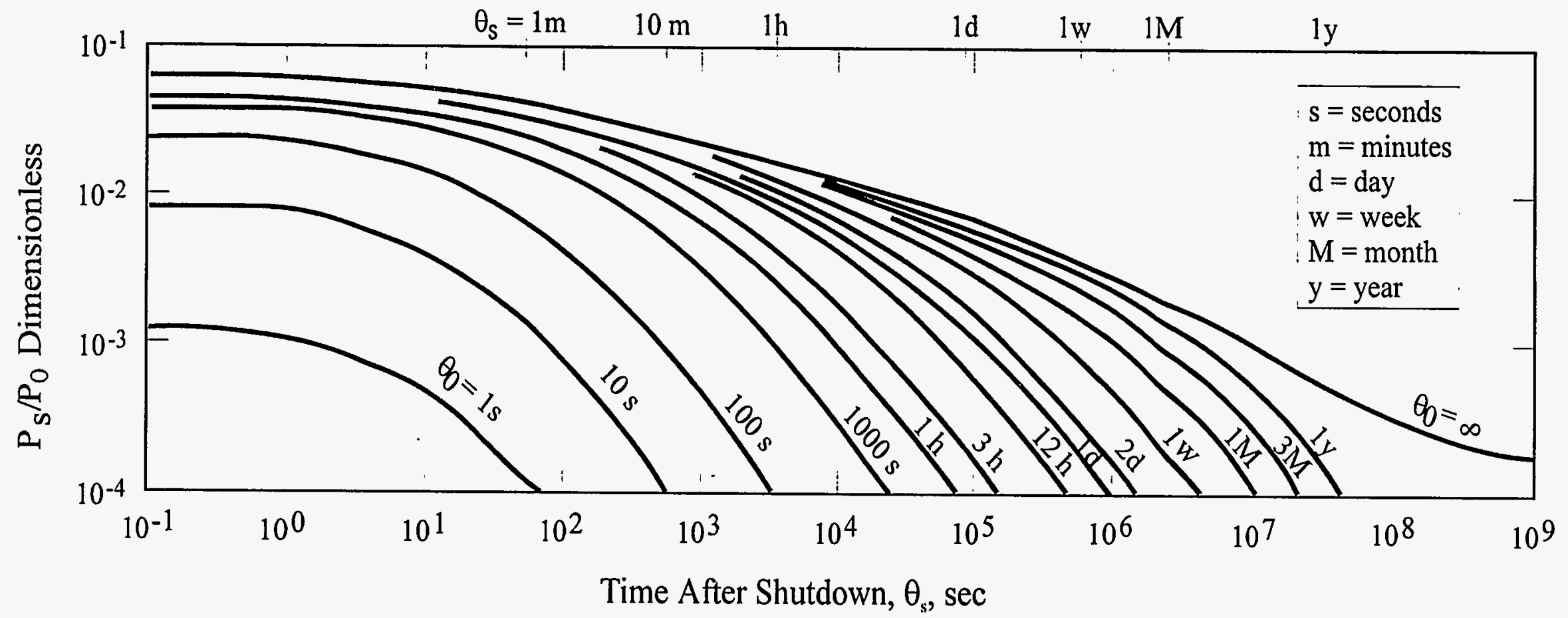




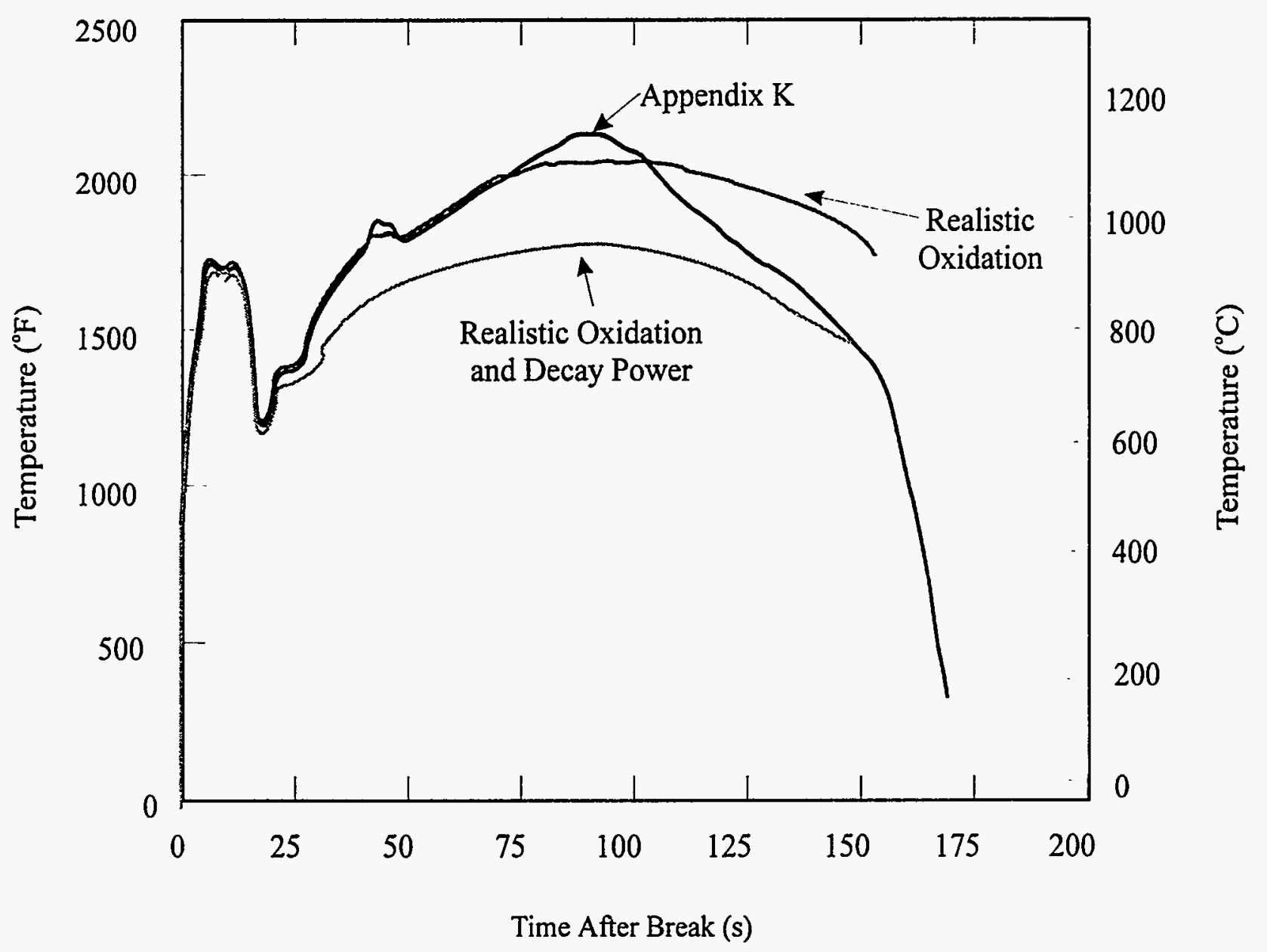

Figure 1.4-2 Effect of selected conservatisms on peak cladding temperature 


\section{References for Section $\mathbf{1 . 4}$}

1. U.S. Code of Federal Regulations, Title 10, Part 50.34, Jan 1, 1991.

2. U.S. Nuclear Regulatory Commission Regulatory Guide 1.70, Rev. 3, "Standard Format and Content of Safety Analysis Reports for Nuclear Power Plants", November 1978.

3. U. S. Nuclear Regulatory Commission, "Standard Review Plan for the Review of Safety Analysis Reports for Nuclear Power Plants," NUREG-0800.

4. U. S. Code of Federal Regulations, Title 10, Part 100.11(a), footnote 1 , see Module 1, page 1.2-6.

5. U. S. Code of Federal Regulations, Title 10, Part 50.46 (b), Jan 1, 1991.

6. U.S. Nuclear Regulatory Commission, "The Safety of Nuclear Power Reactors (Light Water-Cooled) and Related Facilities," WASH-1250, 1973, p. 5-8.

7. R. Steiger, Extended BE/EM Study, Idaho National Engineering Laboratory letter STIG-177-77 (1977), cited in B. E. Boyack, et. al., "Quantifying Reactor Safety Margins," Nuclear Engineering and Design, 1991.

8. U.S. Atomic Energy Commission Regulatory Guide 1.3, "Assumptions Used for Evaluating the Potential
Radiological Consequences of a Loss of Coolant Accident for Boiling Water Reactors," Revision 2, June 1974.

9. U.S. Atomic Energy Commission Regulatory Guide 1.4, "Assumptions Used for Evaluating the Potential Radiological Consequences of a Loss of Coolant Accident for Pressurized Water Reactors," Revision 2, June 1974.

10. David Okrent, "Nuclear Reactor Safety: On the History of the Regulatory Process," The University of Wisconsin Press, Madison, Wisconsin, 1981, Chapter 17.

11. U. S. Code of Federal Regulations, Title 10, Part 100, Appendix A, Jan $1,1990$.

12. U. S. Nuclear Regulatory Commission, Regulatory Guide 1.29, "Seismic Design Classification."

13. U. S. Code of Federal Regulations, Draft Title 10, Part 50, Appendix S, "Earthquake Engineering Criteria for Nuclear Power Plants," 1992.

14. U. S. Code of Federal Regulations, Draft Revision to Title 10, Part 100, Appendix A, 1992. 


\subsection{The Reactor Safety Study}

\subsubsection{Beyond-Design-Basis Accidents}

The Reactor Safety Study was prompted in part by a request from Senator John Pastore for a comprehensive assessment of reactor safety. The AEC's first response to this request was the WASH-1250 report entitled The Reactor Safety Study of Nuclear Power Reactors (Light Water-Cooled) and Related Facilities, which was published in final form in July 1973. ${ }^{1}$ WASH-1250 provided factual information regarding the conservatisims applied in the design of nuclear power plants. It did not, however, address the likelihood or potential consequences of beyond-design-basis accidents, which involve more serious initiating events or more failures following initiation than the accidents analyzed in the Safety Analysis Report. Beyond-design-basis accidents include those initiated by reactor pressure vessel rupture, those initiated by seismic events more severe than the safe shutdown earthquake, and those involving multiple component failures or operator errors after initiation, that is, failures beyond those postulated under the single failure criteria.

Figure 2.5-1 illustrates a breakdown of nuclear power plant accidents according to their severity. Even though they were not specifically designed to do so, given appropriate operator responses, plant systems (including non-safety-grade systems) are capable of handling many beyond-design-basis accidents. However, there are beyond-design-basis accidents, stich as LOCAs in which emergency core cooling systems fail to provide adequate flow, that would lead to core damage. For some core damage accidents, the extent of damage would be minor (e.g., 10 CFR 50 Appendix $\mathrm{K}$ cladding temperature limit exceeded for a brief time period). ${ }^{3}$ However, a subset of core damage accidents (e.g. accidents involving a prolonged failure of core cooling systems) would result in substantial core damage. Such accidents are called severe accidents (or Class 9 accidents) ; ${ }^{3}$ that is, a severe accident is a reactor accident more severe than design-basis accidents in which, as a minimum, substantial damage is done to the reactor core.

As indicated in the Section 1.4, the radionuclide releases from fuel assumed in conservative design-basis LOCA analyses could only be realized if significant core melting occurred. Consequently, for a severe accident in which containment remained functional, the resulting offsite doses would be comparable to those conservatively calculated in the Safety Analysis Report for design-basis LOCAs. Yet the possibility remains of severe accidents in which containment is either bypassed or breached as a result of severe accident phenomena. Depending on the mechanism, location, and timing of containment failure, and the meteorological conditions, offsite doses could be substantially (100 times) worse than conservatively calculated for the design-basis LOCA. That is, the accidents with the greatest potential public consequences are uncontained severe accidents.

In this light, several questions had to be addressed in order to respond to Senator Pastore's request for a comprehensive assessment of reactor safety. What accidents could result in significant core damage and containment breach or bypass? How likely are these accidents? What would be their health and economic consequences? These are fundamental questions that WASH-1250 did not address. Such questions are addressed in probabilistic risk assessments, but, at the time, relevant probabilistic estimates were quite limited in scope and/or 
highly subjective. For example, in a policy paper (dated November 15, 1971) to the commissioners proposing an approach to the preparation of environmental reports, the regulatory staff estimated that the probability of accidents leading to substantial core meltdown was $10^{-8}$ per reactor-yeat. In retrospect, this was a highly optimistic estimate, but it typifies the degree to which meltdown accidents were considered "not credible."

\subsubsection{The Study}

In the summer of 1972 the AEC initiated a major probabilistic study, the Reactor Safety Study (RSS). Professor Norman C. Rasmussen of the Massachusetts Institute of Technology served (half-time) as the study director. Saul Levine of the AEC served as full-time staff director of the AEC employees that performed the study with the aid of many contractors and consultants.

The team attempted to make a realistic estimate of the potential effects of light water reactor accidents on the public health and safety. One BWR, Peach Bottom Unit 2, and one PWR, Surry Unit 1, were analyzed in detail to estimate the likelihood and consequences of potential accidents.

The team adapted methods previously used by the Department of Defense and NASA to predict the effect of failures of small components in large, complex systems. The overall methodology, which is still utilized, is called probabilistic risk assessment (PRA). A tutorial on PRA methods and terminology is included as Appendix 2A.

The team first identified events that could potentially lead to core damage. Event trees were then used to delineate possible sequences of successes or failures of systems provided to prevent core meltdown and/or the release of radionuclides. Fault trees were used to estimate the probabilities of system failures from available data on the reliability of system components. Using these techniques, thousands of possible core melt accident sequences were assessed for their occurrence probabilities. The public health and economic consequences of the identified severe accidents were estimated using computational models that were developed as part of the overall effort.

A draft Reactor Safety Study report, WASH-1400, was issued by the AEC for comment in August 1974. The draft drew extensive comments from government, industry, environmental groups, nuclear critics, and the public. The final report, WASH-1400 (NUREG 75/014), was issued by the NRC in October $1975 .{ }^{5}$

\subsubsection{Findings}

The Reactor Safety Study indicated that risks to the public from potential U.S. nuclear power plant accidents were small compared to other risks encountered in a complex technological society. Other sources of risk that were compared in the study included fires, explosions, toxic chemical releases, dam failures, airplane crashes, earthquakes, tornadoes, and hurricanes. Figures 1.5-2 and 1.5-3 show these risk comparisons. These figures are interpreted in the following manner:

1. Pick a point on one of the curves.

2. The ordinate represents the frequency with which a consequence greater than or equal to the corresponding abscissa value will occur.

For example, in Figure 1.5-2, the probability of a nuclear power plant accident involving 
1000 or more fatalities in any given year is approximately $10^{-6}$.

In these figures, it is assumed that there are 100 power reactors and that they all have risks equal to the average risks for Surry and Peach Bottom. There is no evidence to support this assumption; however, the other 98 reactors would have to be orders of magnitude worse than Surry and Peach Bottom for the general conclusions to be rendered invalid. While the risks from nuclear power appear to be very low, the Reactor Safety Study did indicate that core melt accidents were more likely than previously thought (approximately $5 \times 10^{-5}$ per reactor year for Surry and Peach Bottom), and that light water reactor risks are mainly attributable to core melt accidents. The Reactor Safety Study also demonstrated the wide variety of accident sequences (initiators and ensuing equipment failures and/or operator errors) that have the potential to cause core melt. In particular, the report indicated that, for the plants analyzed, accidents initiated by transients or small LOCAs were more likely to cause core melt than the traditional design-basis LOCAs. Finally, the Reactor Safety Study investigations into containment failure suggested that different containment types (e.g., Mark I BWR versus subatmospheric) may differ in their capability to withstand core melt accidents (for which they were not designed).

\subsubsection{Impact}

The preceding findings have withstood the test of time; however, the Reactor Safety Study received considerable, valid criticism. In June 1977 the NRC appointed a Risk Assessment Review Group (the Lewis Committee, named after Harold Lewis, Chairman of the American Physical Society's Study Group on Light Water Reactors) to review WASH-1400. ${ }^{6}$ The review group's report to the Commission in September 1978 was highly critical:

We have found a number of sources of both conservatism and nonconservatism in the probability calculations in WASH-1400, which are very difficult to balance. Among the former are an inability to quantify human adaptability during the course of an accident, and a pervasive regulatory influence in the choice of uncertain parameters, while among the latter are nagging issues about completeness, and an inadequate treatment of common cause failure. We are unable to define whethe, the overall probability of a core melt given in WASH-1400 is high or low, but we are certain that the error bands are understated. We cannot say by how much. Reasons for this include an inadequate data base, a poor statistical treatment, an inconsistent propagation of uncertainties throughout the calculation, etc.

While the Lewis Committee was critical of the quantitative results of WASH-1400, it provided positive encouragement for future use of the methods. The committee report states,

We do find that the methodology, which was an important advance over earlier methodologies applied to reactor risks, is sound, and should be developed and used more widely under circumstances in which there is an adequate data base or sufficient technical expertise to insert credible subjective probabilities into the calculations. ... Proper application of the methodology can therefore 
provide a tool for the NRC to make the licensing and regulatory process more rational, ...

The NRC commissioners, seeming not to understand these conclusions, issued a January 1979 policy statement that seemed to discredit the entire Reactor Safety Study. The statement a) withdrew any past endorsement of the Executive Summary of the report, b) agreed that the peer review process for WASH-1400 was inadequate and c) accepted the conclusion that WASH-1400's absolute values of risks should not be used uncritically, and d) agreed that the numerical estimate of the overall risk of reactor accidents was unreliable. $^{7}$

In spite of recommendations by the Advisory Committee on Reactor Safeguards and others that severe accident research and Reactor Safety Study methods be applied to improve the safety of reactors in operation and under construction, it was not until after the accident at Three Mile Island that serious efforts to address severe accident issues were undertaken. 


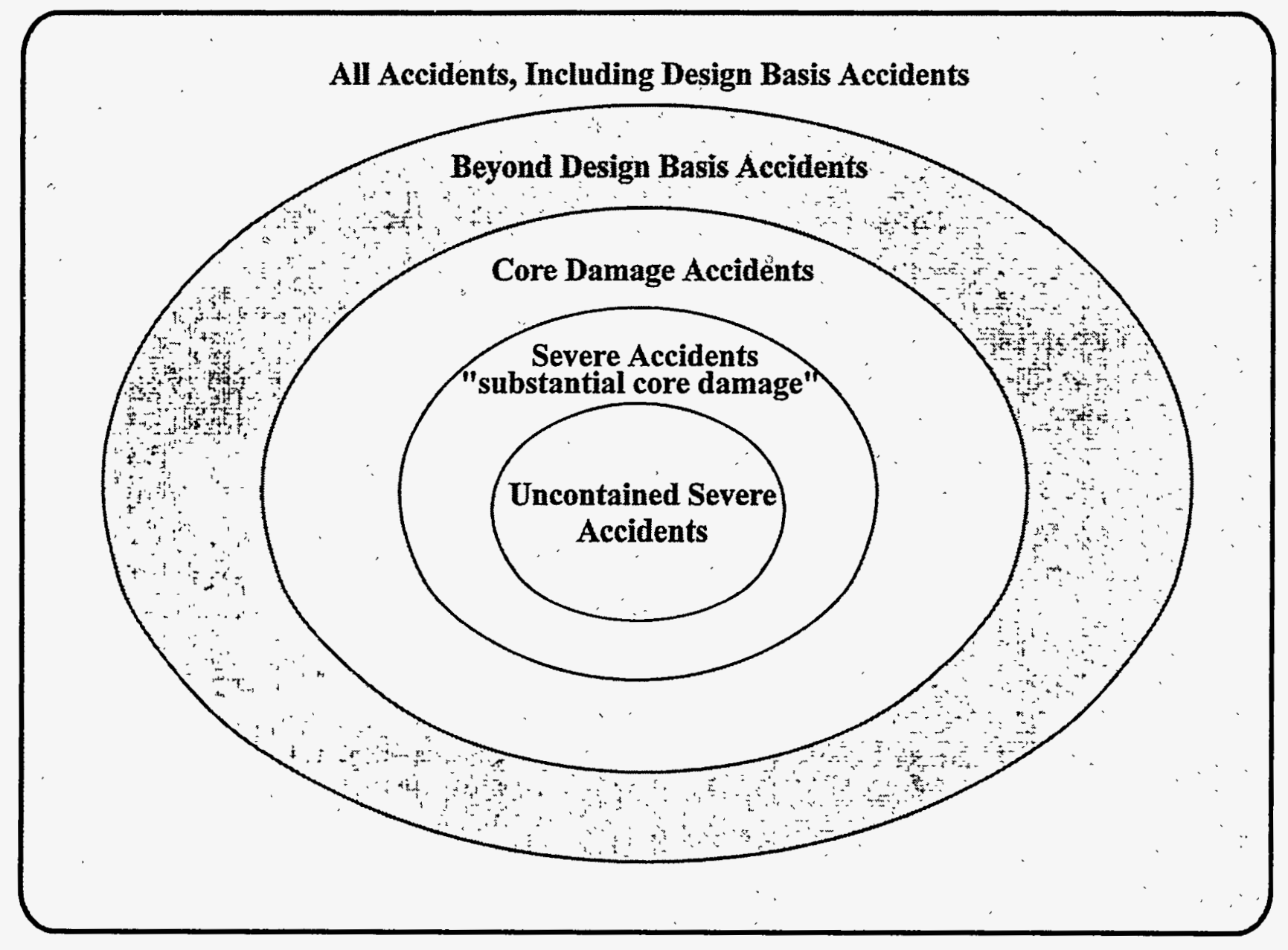

Figure 1.5-1 Breakdown of nuclear power plant accidents by severity 


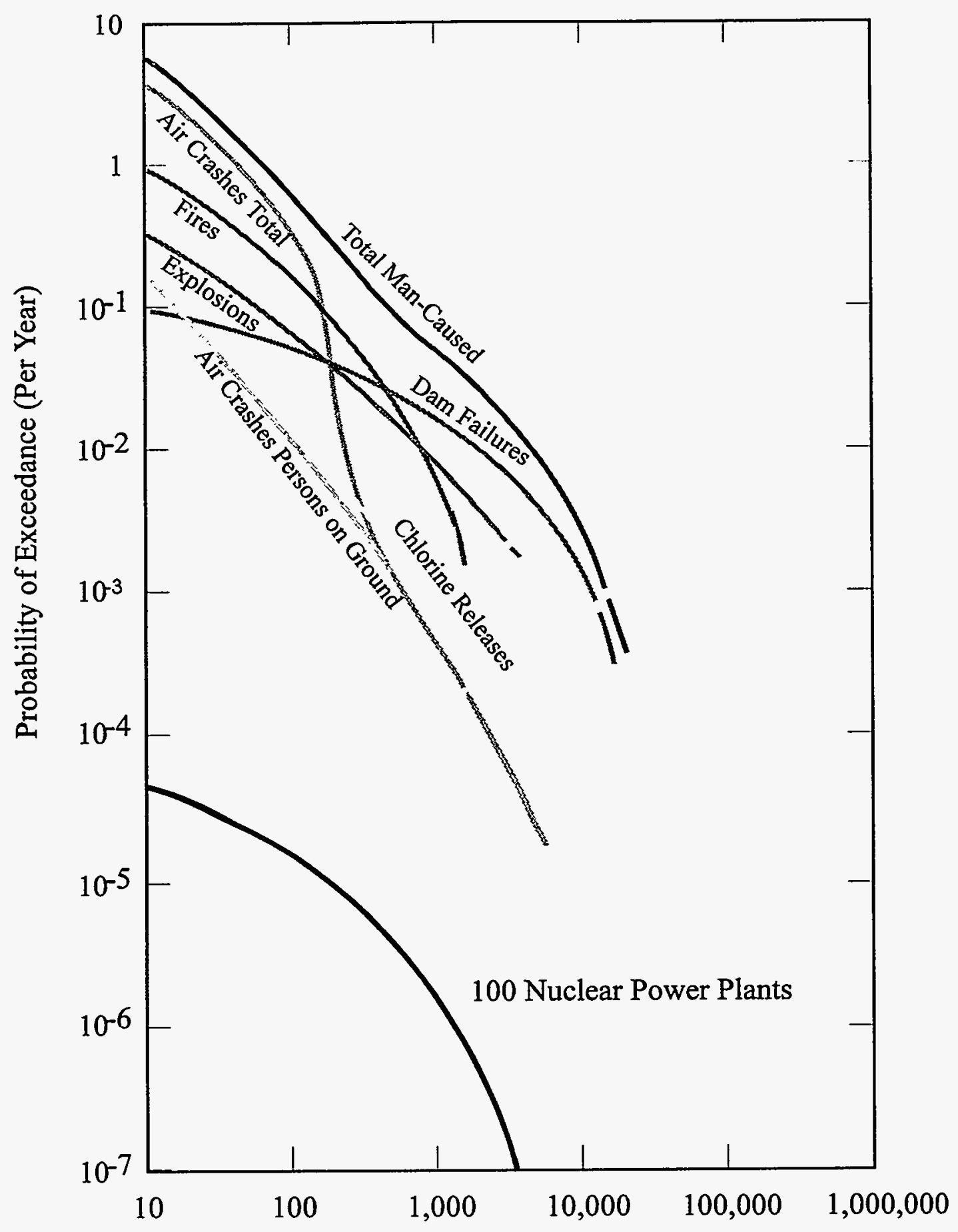

Fatalities (X)

Figure 1.5-2 Frequency of man-caused events involving fatalities 


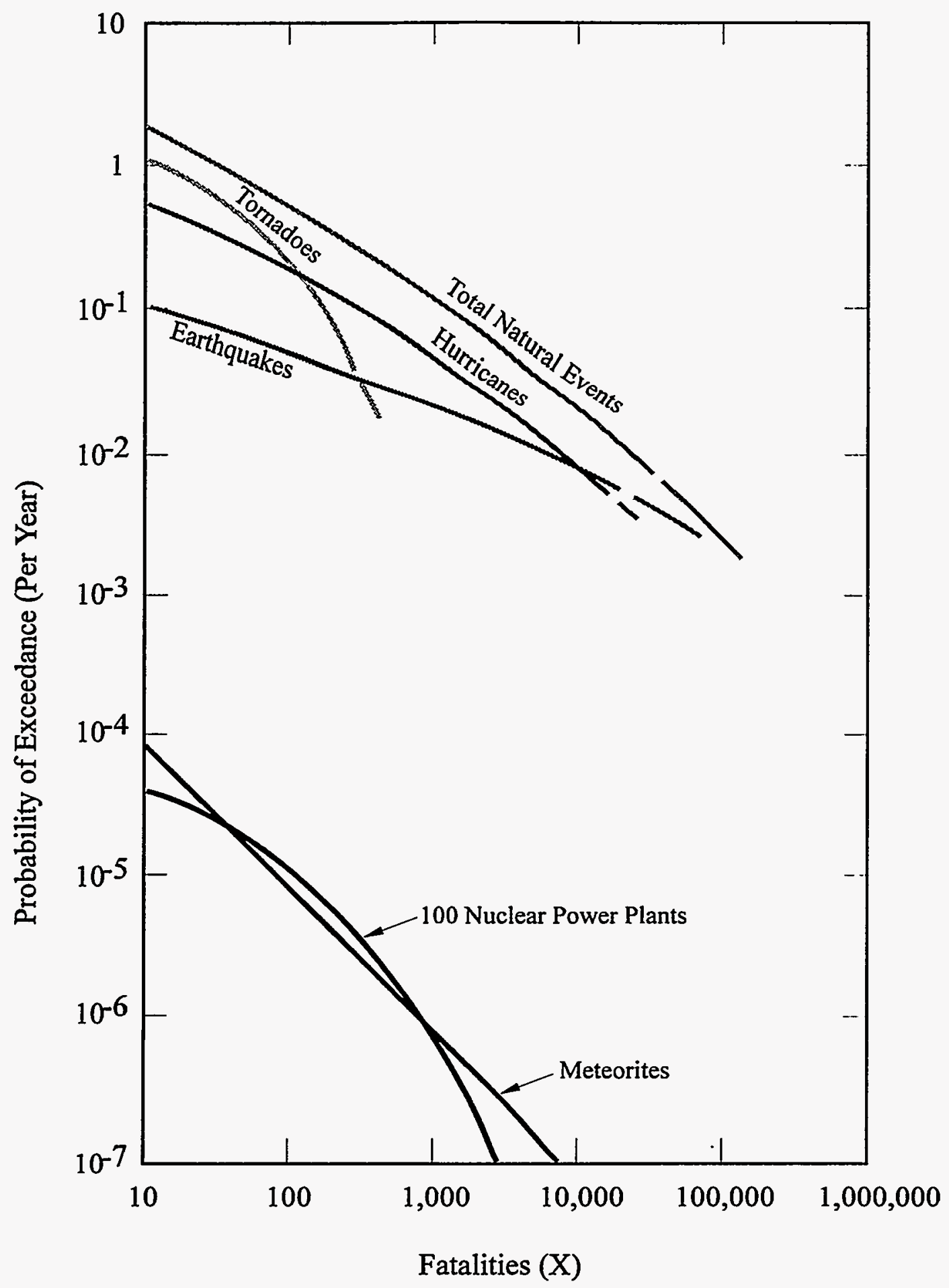

Figure 1.5-3 Frequency of natural events involving fatalities 


\section{References for Section $\mathbf{1 . 5}$}

1. U. S. Nuclear Regulatory Commission, "The Safety of Nuclear Power Reactors (Light Water-Cooled) and related Facilities," WASH-1250.

2. U. S. Code of Federal Regulations, Title 10, Part 50, Appendix K, January 1, 1991.

3. U. S. Nuclear Regulatory Commission, "NRC Policy on Future Reactor Designs, Decisions on Severe Accident Issues in Nuclear Power Plant Regulation," NUREG-1070, July 1985.

4. U. S. Nuclear Regulatory Commission, Regulatory Staff to Commissioners, November 15, 1971, Policy Paper.
5. U. S. Nuclear Regulatory Commission, "Reactor Safety Study: An Assessment of Accident Risks in U.S. Commercial Nuclear Power Plants," WASH-1400, October 1975.

6. H. W. Lewis, et al., "Risk Assessment Review Group Report to the U.S. Nuclear Regulatory Commission," NUREG/CR0400, September 1978.

7. J. Samuel Walker, "A Short History of Nuclear Regulation 1946-1990," Historical Office, Office of the Secretary, Nuclear Regulatory Commission, June $1991, \mathrm{p} 38$. 


\subsection{Browns Ferry Fire}

On March 22, 1975 a major fire occurred at the Browns Ferry nuclear power plant, which is located near Decatur, Alabama. The Browns Ferry plant is owned by the Tennessee Valley Authority (TVA). At the time, it was the largest nuclear power plant in the world, having three units with a maximum design power output of approximately $3195 \mathrm{MWe}$. Units 1 and 2 were operating at a combined level of 1100 MWe. Unit 3 was still under construction.

The Browns Ferry fire was a close call that very nearly led to core damage. In searching for air leaks in an area containing electrical cables that supplied power to the plant's control room and safety systems, a technician started the fire. He used a lighted candle to conduct the search, and the open flame ignited the insulation around the cables. The fire burned for over seven hours and nearly disabled the safety equipment of one of the two affected units.

The fire caused an estimated damage of $\$ 10$ million and resulted in two operating units being incapacitated for over a year. As a result of the shutdown of the two units, additional costs of about $\$ 10$ million were incurred each month for replacement power.

The accident was a blow to the public image of nuclear power and the recently established NRC. It focused new attention on protecting against fires that could threaten plant safety and on the possibility of "common-mode failures," in which a single breakdown could initiate a chain of events that incapacitated even redundant safety features.

The following subsections discuss the initiation and progression of the Browns Ferry fire and the lessons learned. Much of the material is drawn from an article by $R$.
L. Scott that appeared in Nuclear Safety in 1976. ${ }^{1}$

\subsubsection{Initiating Events}

The fire was initiated by a small ( 3 in. to 4 in. or 7 to $10 \mathrm{~cm}$ ) lit candle that was being used to check for air leakage of the reactor containment building (Figure 1.6-1). The flame ignited some polyurethane used to seal leakage paths, and the fire burned for 7 hours before being extinguished (Figure 1.62 ). The reactor building is maintained at a negative pressure with respect to the exterior of the walls in order to ensure that any airflow is always into the reactor building. It was this design feature that aggravated the fire. The purpose of maintaining a negative pressure on the reactor building is to continuously remove the air and pass it through filters to remove any radioactivity that might be present. However, in order for radioactivity to be present in the reactor building, it would first have to escape from the primary containment or piping. Then, any radioactivity that managed to get into the reactor building would be removed by the filters, with no effect or impact on public health and welfare. The cable-tray penetrations through the wall of the reactor building are sealed to minimize inleakage, thus maintaining an adequate negative pressure in the reactor building. The penetrations are filled with a polyurethane foam to form the seal, and then a flameproofing compound is applied 3 to 6 $\mathrm{mm}(\sim 0.1 \mathrm{in}$.) thick over the foam and over the cables on both sides of the penetration for a distance of $30 \mathrm{~cm}$ (12 in.) to form a fire barrier (Figure 1.6-3).

The penetration where the fire originated had been disturbed at some time after the initial installation, because holes had been punched through the flameproofing and sealant to provide openings for additional cables 
through the penetration. The result was that the polyurethane sealant was exposed. Leakage tests had been performed previously on the reactor building, and the results indicated that inleakage should be reduced. An extensive program was therefore under way for resealing penetrations through the wall of the reactor building.

The method used to check the effectiveness of the sealing operation was to hold a lit candle near the penetration opening. If the opening was not fully sealed, the lower pressure in the reactor building would cause air to be pulled through the opening, giving a good visual indication of leakage even where the area was poorly lit. The use of an open flame to test for air leakage in a condenser vacuum was then a commonplace practice for the utility industry.

On March 22, three teams, each consisting of an engineering aide and an electrician, were working in the cable-spreading room testing and sealing penetrations. Work proceeded during the day without incident until about 12:15 p.m., when an engineering aide observed a hole about 50 to $100 \mathrm{~mm} \mathrm{(2}$ to 4 in.) wide in a cable-tray penetration through the wall. The hole was approximately 20 in. or $0.5 \mathrm{~m}$ back into the penetration from the face of the concrete wall, and the entire penetration was congested with cable trays, making the hole difficult to reach (Figure 1.6-4). The engineering aide passed a lit candle by the hole, and the flame blew horizontally into the hole, indicating a significant leakage path into the reactor building. The aide had difficulty reaching into the penetration, but he tried to stuff two pieces of sheet polyurethane foam into the hole. (This sheet of polyurethane was not the same type as that used originally for the sealant; this type is far more flammable.) $\mathrm{He}$ then re-lit the candle and re-checked the penetration. The flame was again pulled horizontally, indicating a large airflow and leakage path, and apparently the foam ignited at this time $-12: 20$ p.m. The aide observed a low red glow and yelled "fire." His attempt to beat the fire out with a flashlight was unsuccessful. He then tried to smother the fire with rags, but this also failed. He then discharged a $\mathrm{CO}_{2}$ fire extinguisher twice, but the $\mathrm{CO}_{2}$ was pulled right through the hole without putting the fire out. Two more drychemical fire extinguishers were discharged into the hole, but each gave "only one good puff" and the fire continued. The electrician then called for someone to notify the reactor operations shift engineer that there was a fire in the cable-spreading room. Meanwhile, the fire had moved deeper into the hole because of the airflow and was now also on the reactor-building side of the wall; thus there were two fires to contend with -one in the cable-spreading room and one in the reactor building.

\subsubsection{Cable-Spreading Room Fire}

About $15 \mathrm{~min}$. after the fire started (at approx. 12:35 p.m.), a siren alarm sounded to warn personnel in the cable-spreading room to evacuate because the permanently installed $\mathrm{CO}_{2}$ Cardox fire-extinguishing system was to be actuated. This system flushes the room with enough $\mathrm{CO}_{2}$ to displace most of the oxygen required for the survival of the personnel. After the room was evacuated, an assistant shift engineer attempted to actuate the Cardox system at the Unit 1 cable-spreading room control station but found that the power had been shut off at the disable switch at the Unit 2 entrance to the room. This isolation procedure was a safety measure taken while men were leak-testing the penetration. The engineer then turned the power on at Unit 2, apparently without success, after which he attempted to use the manual crank system. 
However, he found that a metal plate had been installed under the breakout glass to prevent inadvertent operation of the $\mathrm{CO}_{2}$ system. The actuation at Unit 2 appeared to be unsuccessful because there was a 3-min. delay from the time of actuation due to travel time from central storage, but at about $12: 40$ p.m. the Cardox system began discharging $\mathrm{CO}_{2}$ for the first time.

Between 12:40 p.m. and 3:00 p.m., the Cardox system was actuated two more times as the fire fighting continued under the direction of an assistant shift engineer. At about 1:45 p.m., firemen from the Athens, Alabama, Fire Department arrived and began to assist in the fire-fighting efforts. At about 2:00 p.m., the Fire Chief recommended the use of water on the fire, but the Plant Superintendent decided against this because of the possibility of shorting circuits, which could further degrade conditions such that control of the shutdown and cooling of the reactors would be more difficult. Furthermore, the fire was progressing slowly $(0.8 \mathrm{in}$. to $1.2 \mathrm{in.} / \mathrm{min}$. or 2 to $3 \mathrm{~cm} / \mathrm{min}$.). The use of $\mathrm{CO}_{2}$ and dry chemicals kept the fire suppressed, but, on several occasions when the fire was reported to be out, it flared up again because of the high energy content in the cables. At 3:00 p.m., a shift engineer arrived at the site, proceeded to the cable-spreading room, and assumed charge of the fire fighting. The fire in that room was finally reported to be extinguished at about 4:20 p.m.

\subsubsection{Reactor-Building Fire}

The fire that started on the cable-spreading room side of the penetration spread into the reactor building because of the inward airflow. Two construction workers in the cable-spreading room, on seeing that the fire was spreading into the reactor building, went there to fight the fire. One of the workers notified a TVA Public Safety Officer that there was a fire in the reactor building. The two workers were joined by a third, and all three, equipped with dry-chemical fire extinguishers, proceeded to the fire in the reactor building. The fire was burning in cable trays that were $20 \mathrm{ft}$. or $6.1 \mathrm{~m}$ above the second floor of the reactor building. A worker climbed a ladder placed next to the fire and discharged a dry-chemical extinguisher on the fire, but he was then forced to leave because he could not breathe. This dry-chemical application suppressed the flames but not the temperature, and the fire flared up again.

At about 12:34 p.m. the general fire alarm was actuated. An assistant shift engineer arrived, climbed the ladder, and discharged a dry-chemical extinguisher on the fire, after which he discharged a $\mathrm{CO}_{2}$ extinguisher on the fire. $\mathrm{He}$ also experienced breathing difficulty, and by this time smoke was becoming so dense that a breathing apparatus was requested. Until the apparatus arrived, $\mathrm{CO}_{2}$ was applied to the cable trays from the floor. When the apparatus (air packs) arrived, fire fighting continued until visibility became so poor that the workers could not get near the fire.

The assistant shift engineer left the area and called the Athens Fire Dept. at 1:09 p.m. The fire truck arrived at 1:30 p.m., and, by 1:45 p.m., seven firemen had been admitted to the plant and were prepared to assist in fighting the fire but in support of, and under the direction of, Browns Ferry personnel. It has been stated that there appears to have been no centrally organized direction of the fire-fighting efforts in the reactor building between approximately 1:00 p.m. and 4:20 p.m. However, it should be noted that the ventilation system was lost at 12:45 p.m. and was not reestablished until 4:00 p.m. The consequence was excessive smoke, making 
visibility poor and necessitating air-breathing equipment. Also, lighting was lost in the reactor building at about 1:30 p.m. In addition, there was a shortage of airbreathing equipment, and the available equipment was used by workers who were manually aligning valves in an attempt to get the reactor into a shutdown cooling mode. Once the plant was depressurized and a positive source of water was going into the reactor, attention was focused on the fire in the reactor building. At about 4:30 p.m. the shift engineer who had directed the activities in the cable-spreading room until that fire was extinguished took charge of the firefighting activities in the reactor building. Temporary DC lighting was set up both inside and outside the reactor building, and a routine was established of sending in two or three fire fighters at a time to use dry chemicals on the fire. At about 6:00 p.m. the Athens Fire Chief again recommended the use of water (his first recommendation was at 2:00 p.m.). Water had not been used because of the electrical shock hazard, and the Plant Superintendent had not wanted to de-energize the circuits because he felt some of them were needed for controlling the shutdown of the reactors.

At approximately 7:00 p.m. the Plant Superintendent agreed to the use of water on the fire, contrary to the recommendation of the TVA Public Safety Officer, because the reactors were in a more stable condition. Another shift engineer took the fire hose, climbed the scaffolding to the fire, and sprayed water on the fire, using a water fogtype nozzle. He had difficulty breathing, and so he jammed the nozzle of the hose into the cable tray so that it would continue spraying water on the fire area and then climbed down and left the building. Later, two shift engineers returned and sprayed the area again. At 7:45 p.m. the fire was declared to be out.

\subsubsection{Fire Damage And Assessment}

The fire-damaged areas of the cablespreading room and the reactor building are shown in Figure 1.6-5. As indicated, the damage in the cable-spreading room extended only about $1.5 \mathrm{~m}$ ( $5 \mathrm{ft}$.) north of the wall penetration. Most of the damage occurred in the reactor building, extending up to $11.4 \mathrm{~m}(37 \mathrm{ft}$.) from the wall penetration. A total of 117 conduits, 26 cable trays, and 1611 cables were damaged. In all, about 9300 conductors had to be replaced or spliced. Of the 1611 cables damaged, 628 were safety related.

At 4:00 p.m. on Saturday March 22, the Atlanta Regional Office of the NRC Office of Inspection and Enforcement was notified of the fire, in accordance with requirements. The Atlanta office immediately initiated an investigation that ultimately required 280 man-days of effort. The detailed report was given to TVA and made available to the public on July 28,1975 , along with a Notice of Violation of NRC requirements and a list that identified areas of concern. It should be noted that the Notice of Violation was corrective rather than punitive; that is, the aim was to correct deficiencies.

\subsubsection{Effect of Fire on Unit 1}

Since the control room for the reactor is common to both Units 1 and 2 , activity at one unit could be observed by the operators of both units. About $20 \mathrm{~min}$. after the fire started, the Unit 1 operator noted anomalous behavior of controls and instrumentation for systems designed to provide emergency cooling of the reactor core. For the next several minutes, a mounting number of events occurred, such as the automatic starting of pumps and equipment, which the operator would shut down when he 
determined that they were not needed, only to have them automatically start again.

At 12:51 p.m. the reactor was scrammed, shutting the reactor down. This stopped the chain reaction and eliminated nuclear fission as a direct source of heat; however, heat generation in the core continued as a result of radioactive decay of fission products in the reactor fuel. It was this aspect that was of major concern to the nuclear reactor operators, because continuous cooling of the fuel to remove this decay heat must be provided to prevent damage to the fuel. During the first few hours after shutdown, the decay heat level can be 2 to $3 \%$ of the heat output at full power, decreasing to $1 \%$ after 1 day and declining very slowly thereafter. Therefore the most urgent need for cooling is during the first few hours after the reactor is shut down.

About $4 \mathrm{~min}$. after the reactor was shut down, several electrical boards that supplied control voltages and power to many of the systems used in cooling the reactor after shutdown were lost. Also, many of the instruments and indicating lights were put out. Shortly after 1:00 p.m. the main-steamisolation valves closed automatically, causing several problems. First, the steam generated by the decay heat could not be passed to the condenser, thus eliminating this method of removing the decay heat. Second, the valve closure resulted in the loss of steam that was driving the feedwater pumps, thus eliminating another method of providing high-pressure cooling water to the core. Fire had also disabled the High Pressure Coolant Injection and Reactor Core Isolation Cooling systems. Even though a control-rod-drive (CRD) system pump was supplying flow at around 400 liters/min. (105 gpm), the water level over the fuel began to decrease because of boiling caused by the decay heat. Condensate booster pumps were operable, but these pumps can only inject water into the pressure vessel at pressures of $2.4 \mathrm{MPa}(\sim 350 \mathrm{psi})$ or less. Given these conditions, the operator chose to depressurize the reactor, which was $7.4 \mathrm{MPa}$ $(1070 \mathrm{psi})$ at this time, by remote control of the relief valves to permit the use the lowpressure systems that were still available.

The pressure-relief valves were manually opened from the control room, and the steam was transferred from the pressure vessel to the pressure-suppression pool (still within primary containment) and condensed. By this method the pressure in the vessel was reduced to about $1.8 \mathrm{MPa}(260 \mathrm{psi})$ in 20 min.; the condensate booster pumps were then used to maintain an adequate water level in the reactor vessel. During the depressurization period the water level in the core decreased but did not drop below a

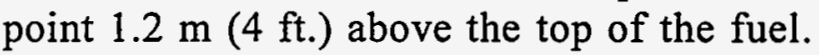
Normal level is $5.08 \mathrm{~m}$ (200 in.), but the 1.2

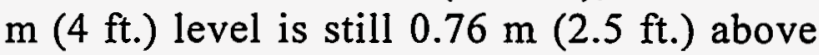
the level at which the core spray and residual-heat-removal systems are actuated. Once the reactor pressure was reduced below $2.4 \mathrm{MPa}$ (350 psi), one condensate booster pump and one condensate pump provided adequate makeup water, and the normal water level above the fuel was attained.

This mode of core cooling was adequate until about 6:00 p.m., when loss of control air prevented further manual control of the remaining (4 out of 11) operable pressurerelief valves. The valves closed, and pressure in the vessel started building up again. As pressure increased above $2.4 \mathrm{MPa}$ (350 psi), the condensate booster pumps could no longer inject water into the vessel and thus only the control-rod-drive-system pump was adding water.

After the fire was declared out at 7:45 p.m., the smoke began to clear, and reliance on 
breathing apparatus decreased so that a more orderly approach to obtaining shutdown cooling could be taken. The actual valve conditions (opened or closed) were determined, and control power to motor operators, pump controls, etc., was established using temporary jumpers.

After about $31 / 2$ hours (at about 9:50 p.m.) control of the relief valves was restored, the reactor was depressurized, and the condensate booster pump again pumped water into the reactor. With low-pressure operation now secured, adequate makeup water could be supplied by one of the condensate pumps. In addition, two additional condensate booster pumps and two additional condensate pumps were available to the operator. Another alternative would have been to use a nonstandard system configuration and manual valve alignment. Two residual-heat-removal-pumps in Unit 2 could have been aligned to the Unit 1 reactor through a crosstie pipe, and, as an additional backup, river water could have been used from either of two available service-water pumps. At 4:10 the next morning, normal shutdown cooling was established.

A chart displaying equipment and system availability is shown in Figure 1.6-6. It should be pointed out that, with the reactor at high pressure, there were other alternatives for obtaining makeup water to the reactor. A few examples of other alternatives are listed below:

1. The Unit 2 CRD pump and a shared spare CRD pump could have been used in addition to the CRD pump on Unit 1.

2. The standby liquid-control pumps could have been made available by performing a manual valve alignment, actuating two valves, and manually restoring power to the pumps.

3. The reactor core-isolation cooling system (RCICS) could have been made available by installing a special short piece of pipe that was stored nearby.

The point is that adequate cooling-water makeup was provided throughout the incident, and additional alternatives could have been used to provide makeup water with the reactor at either high or low pressure.

\subsubsection{Effect of Fire on Unit 2}

The effect of the fire on Unit 2 was less pronounced. A few minutes after Unit 1 was shut down, abnormal events, such as decreasing reactor power, sounding of many alarms, and loss of some indicating lights, began to occur in Unit 2. The operator shut the reactor down at 1:00 p.m. About $3 \mathrm{~min}$. later the main-steam-line isolation valves closed automatically and high-pressure cooling systems were successfully initiated. After depressurization, low-pressure pumps were used to provide cooling. By 6:30 p.m., stable conditions were obtained, and normal means for cooling the core were established by $10: 45$ p.m.

\subsubsection{Lessons Learned}

The extent of damage caused by the fire is attributable to the length of time the fire burned. TVA's rationale for not using water to suppress the fire earlier in the sequence of events was stated as follows: "The Plant Superintendent made the conscious decision not to use water because of the possibility of shorting circuits and further degradation of the plant to a condition that would have been more difficult to control. Reactor safety 
concerns under the circumstances took precedence over extinguishing a localized fire." This position reflected a fairly widespread reluctance on the part of licensees at the time to use water on a fire involving electrical cables. However, the failures caused by the fire as it continued to burn were largely responsible for the difficulties encountered in bringing the plant to a safe-stable state, and the fire was extinguished rather quickly when water was finally applied. Hence the main lesson learned is that, if initial attempts to extinguish a cable fire with nonwater means are unsuccessful, water should be used.

The damage to electrical power and control circuits resulted in the loss of redundant subsystems and equipment. This was surprising in view of the independence and separation criteria that had been applied in the design of the plant. The two principal reasons for the failures were found to be:
(1) failure to recognize potential sources of failure of safety equipment (i.e., the interconnection of safety equipment and nonsafety circuits such as the indicator-light circuits); and (2) contrary to what had been considered good practice, the conduit used to isolate cables from their redundant counterparts did not protect the cables adequately.

Although damage inflicted by the fire resulted in the loss of a number of systems, in particular the emergency core-cooling system, alternatives were available, and adequate cooling was provided throughout the event. In addition, other systems were restored both during and after the fire, and some equipment was restored by manual operation -- especially valves using handwheels. Therefore, loss of the emergency core-cooling systems made the situation more difficult, but not impossible because of the numerous alternatives. 


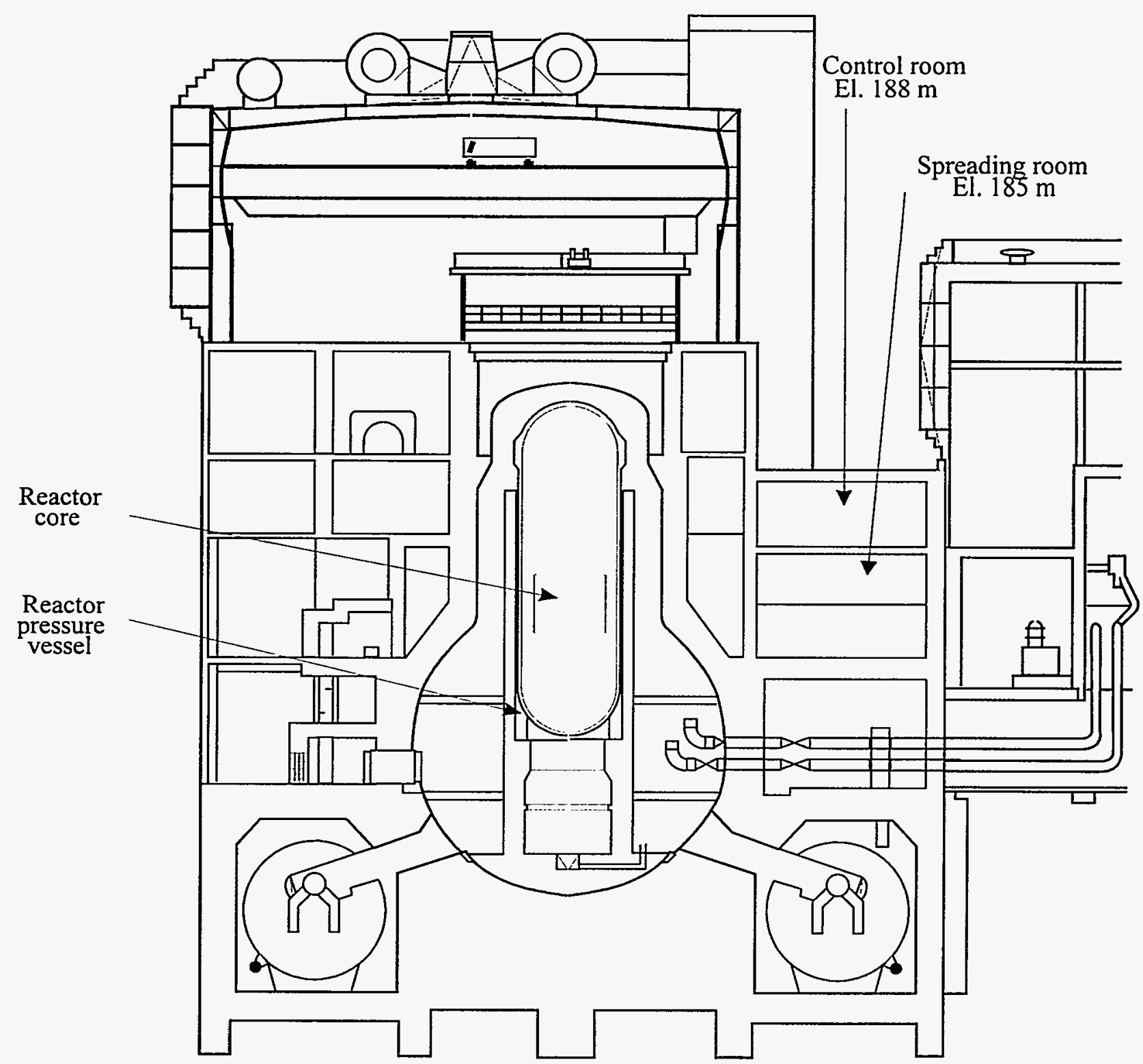

Figure 1.6-1 Vertical cross section of plant showing reactor building control room and spreading room 
Path From Cable-Spreading Room to Reactor-Building

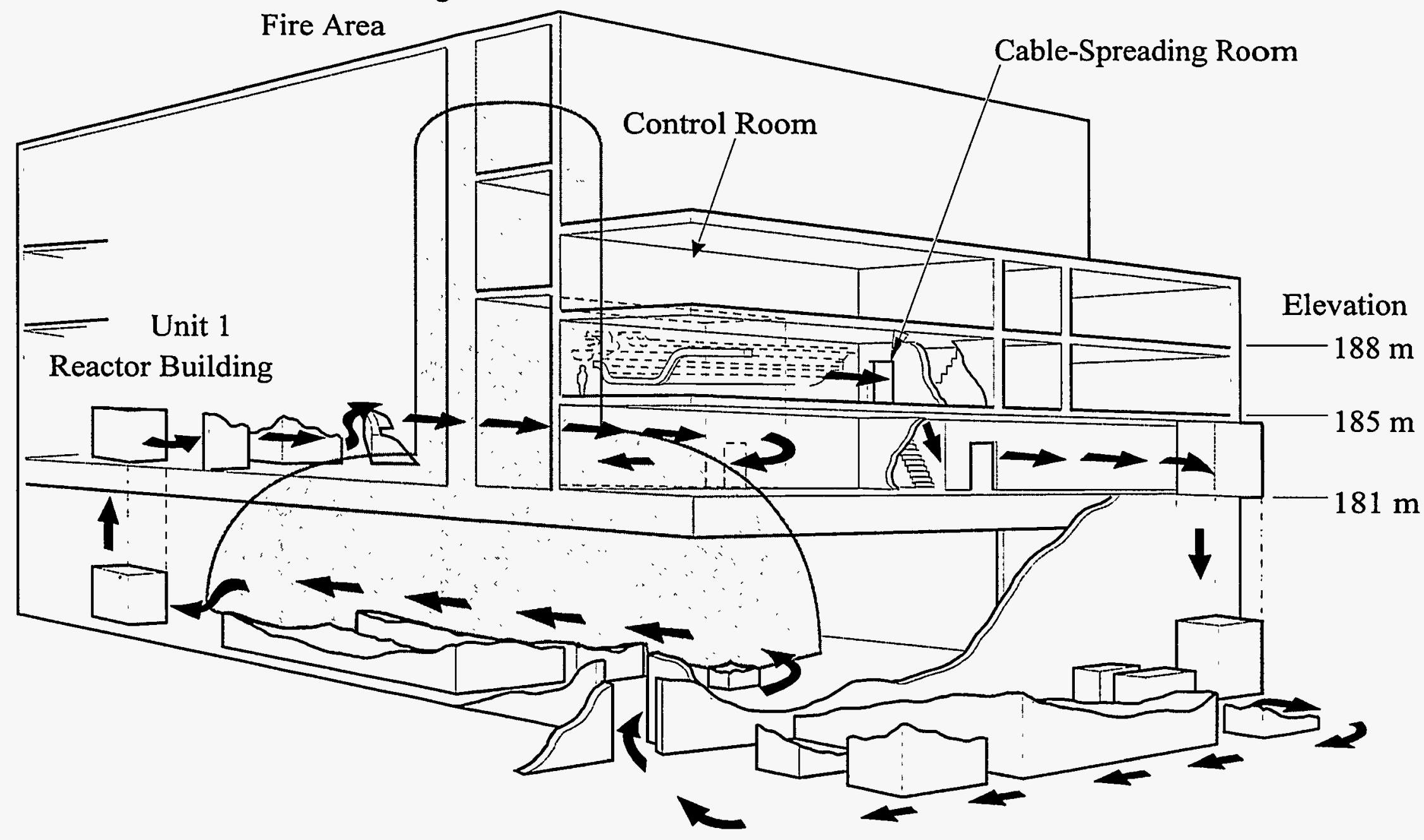

Figure 1.6-2 The Browns Ferry nuclear plant 


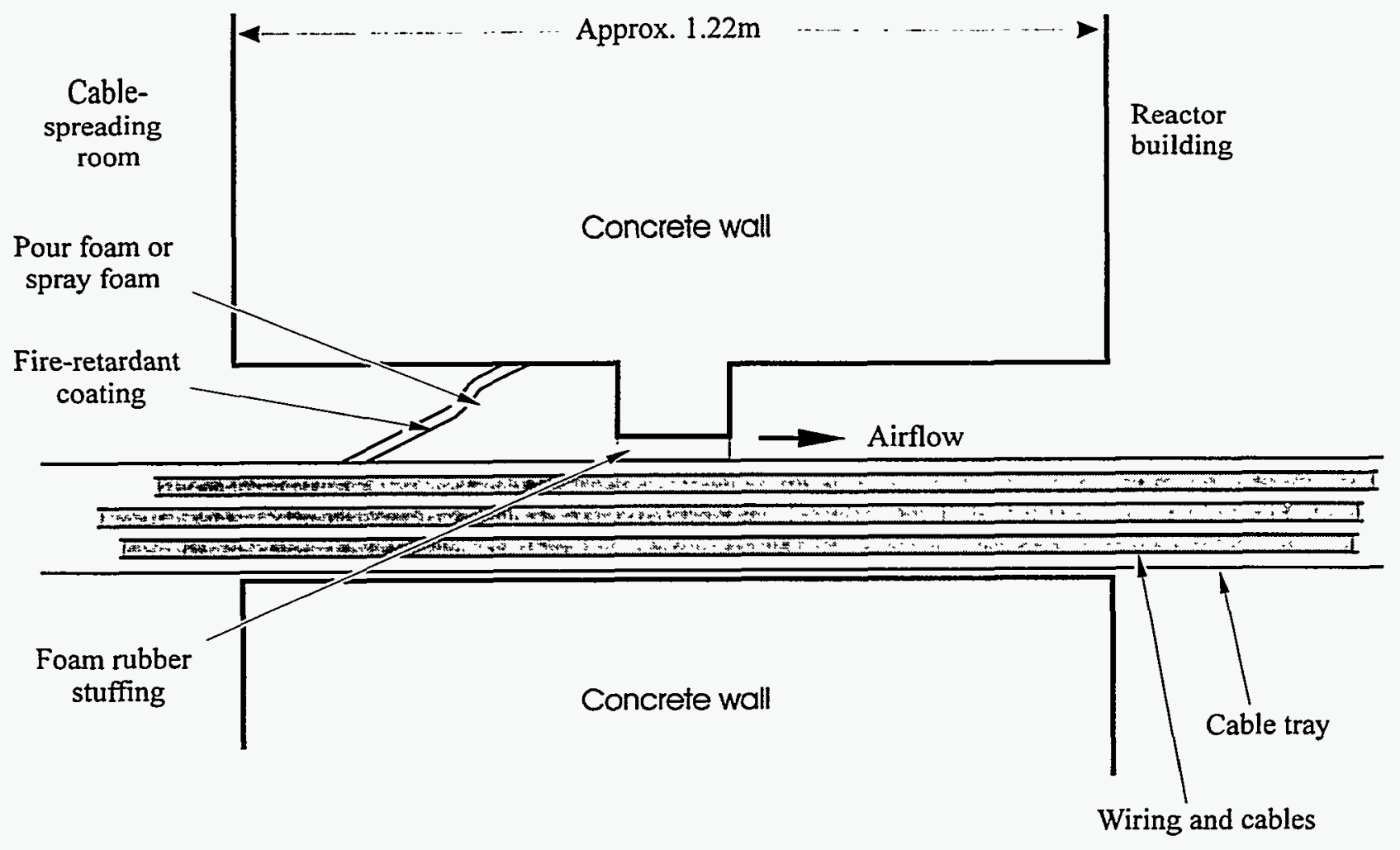

Side view

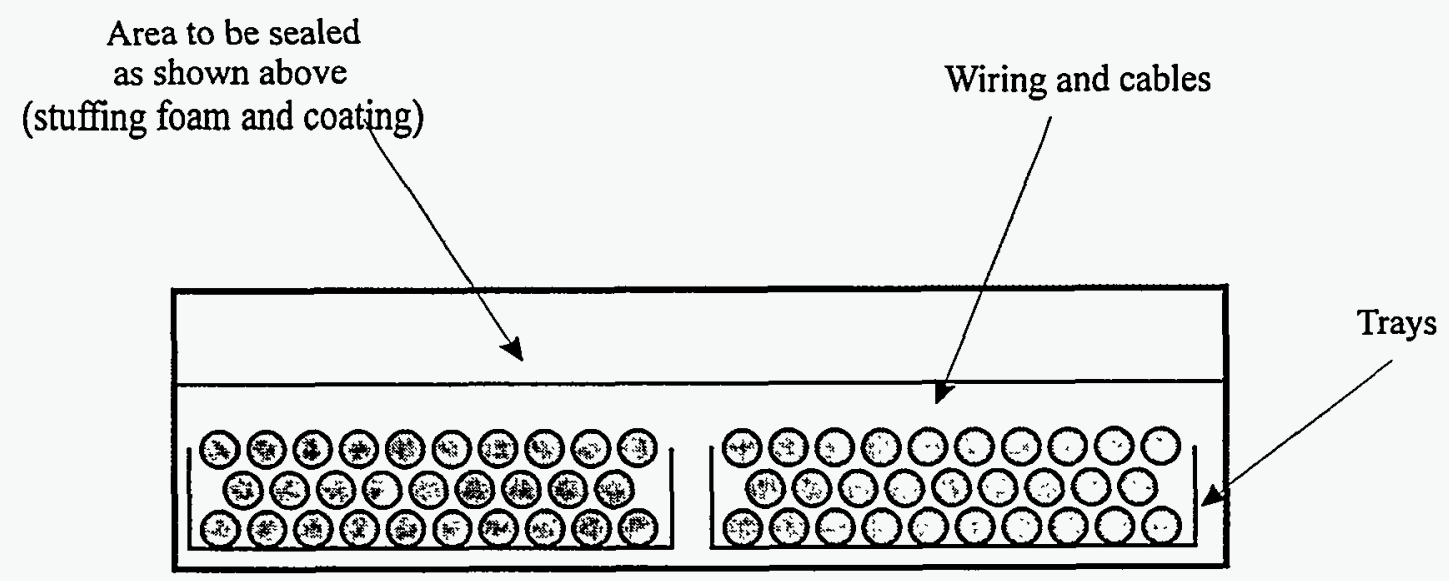

Concrete wall

Front view

Figure 1.6-3 Cable-tray penetration, overall simplified depiction (not to scale) 


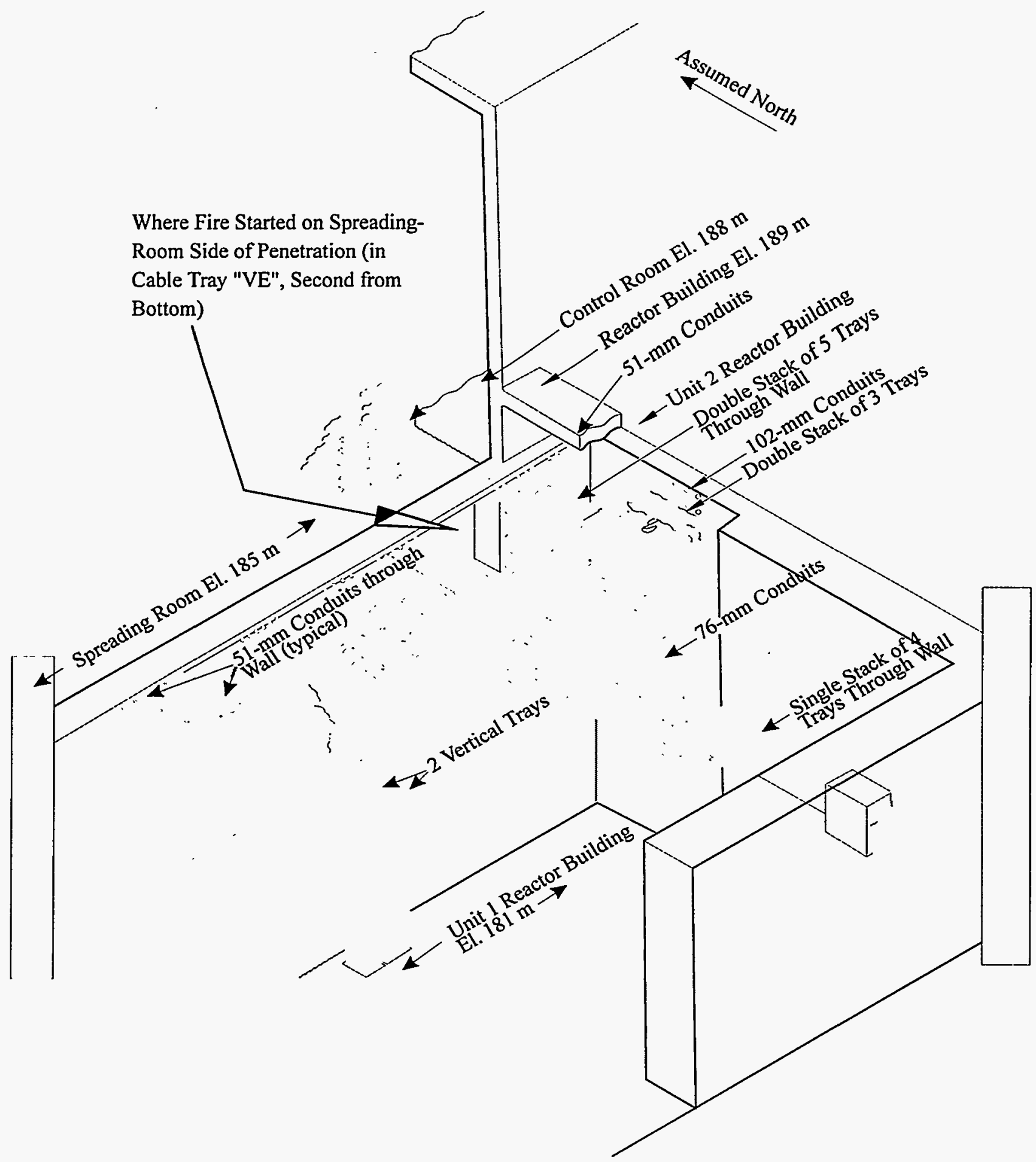

Figure 1.6-4 Area where fire started 


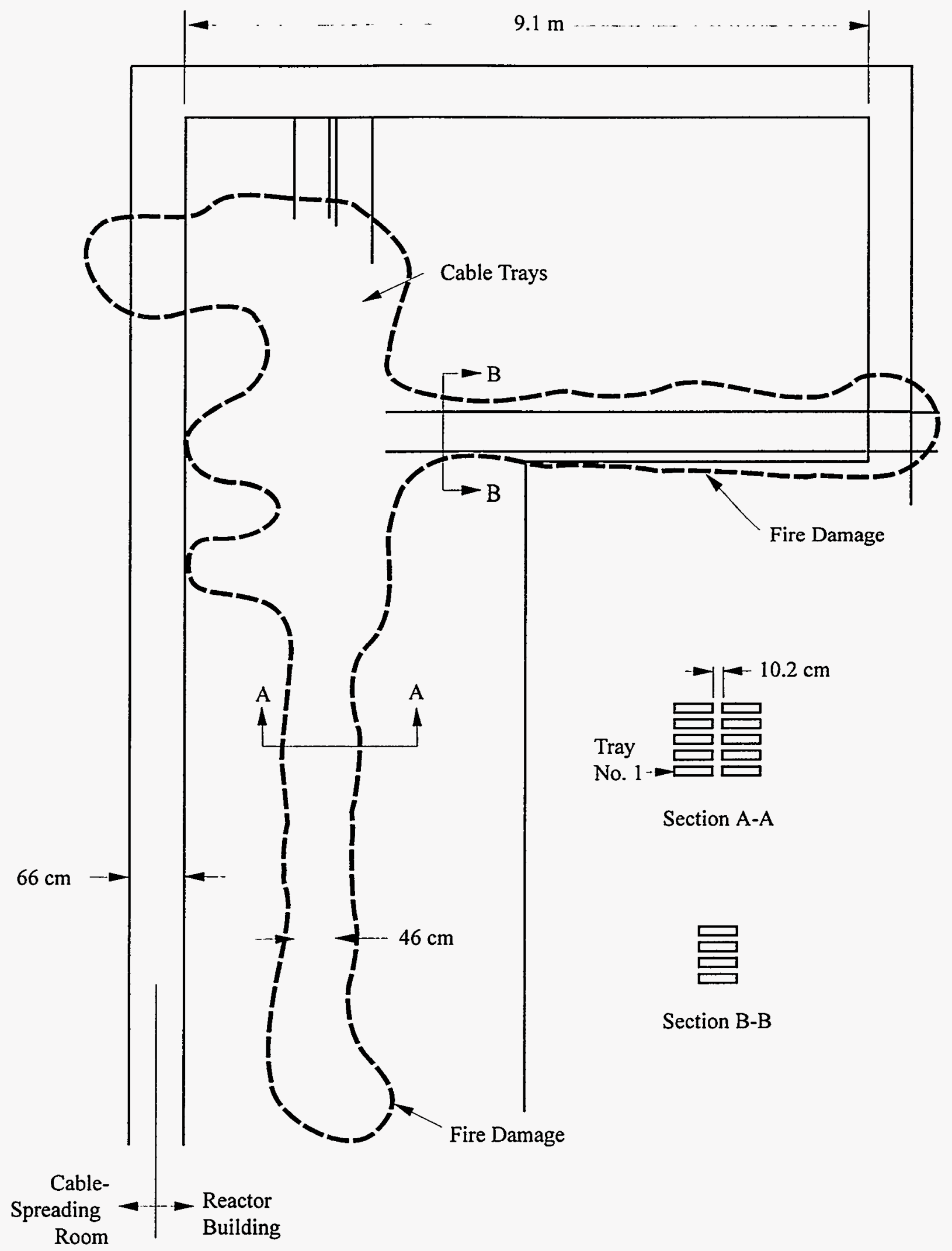

Figure 1.6-5 Fire-damaged area 
High-Pressure Systems

High-Pressure coolant injection

Reactor core-isolation cooling

Reactor feedwater pumps

Control-rod drive

Standby liquid control

Low-Pressure Systems

High-Pressure coolant injection

Core spray

$\dot{i}$

Condensate and condesate booster pumps

Condesate pumps

Standby coolant supply

Residual-heat-removal unite crosstie

Relief Valves

Manual operability for 7 of 11

Manual operability for 4 of 11

Note: 11 relief valves and 2 safety valves were available throughout the fire for the automatic operation on high rector-vessel pressure.
Time
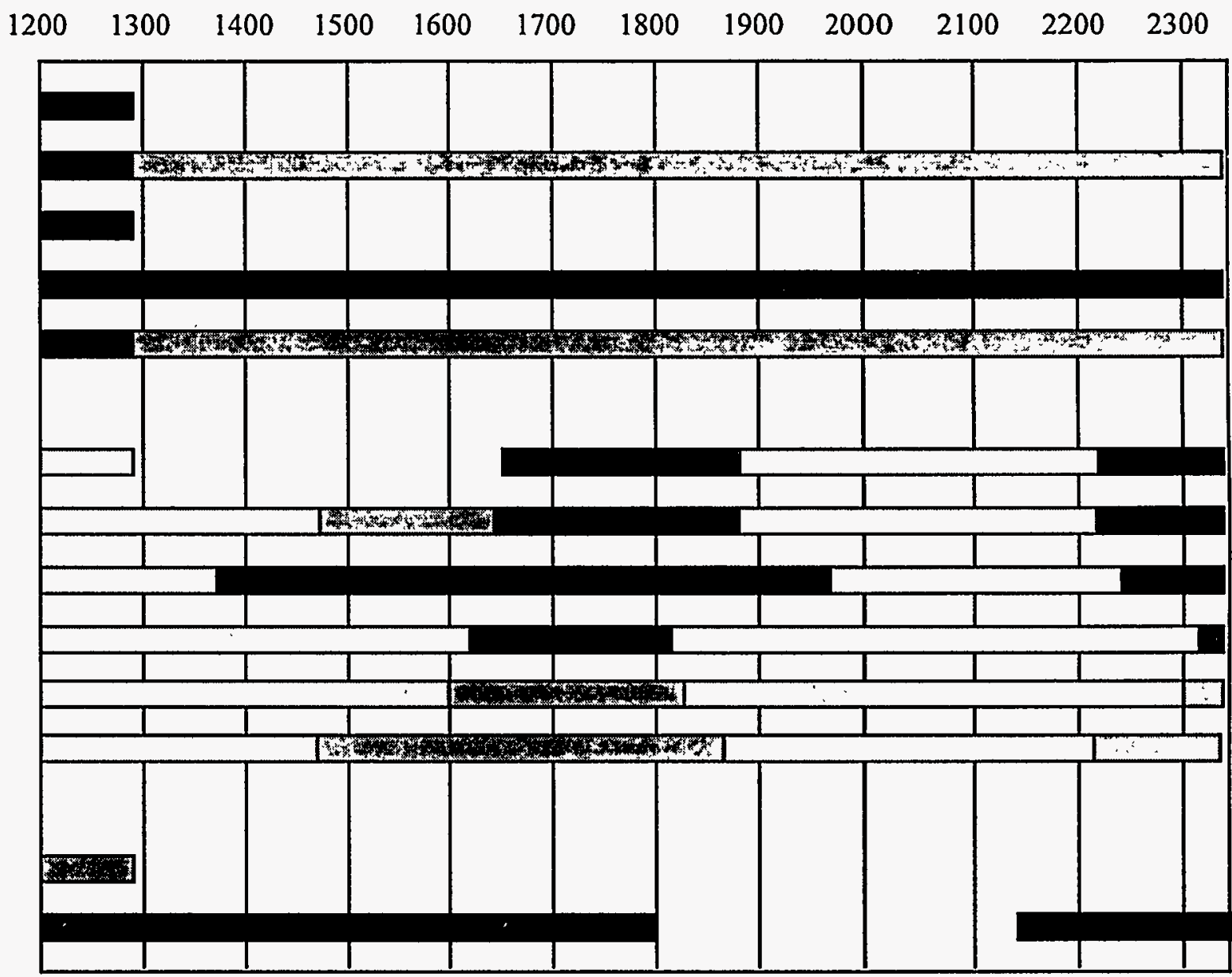

Available

Available using non-standard system operations

$\square$ Inoperable due to high reactor-vessel pressure

Figure 1.6-6 Equipment availability during and immediately following the March 22, 1975 fire 


\section{References for Section 1.6}

1. R. L. Scott, "Browns Ferry Nuclear Power Plant Fire on March 22, 1975" Nuclear News, Volume 17, No. 5, September-October 1976, p. 592. 
Appendix 1A

\section{PRA Terms and Concepts}

This appendix introduces term and concepts employed in probabilistic risk assessments (PRAs). PRA methods are used to identify the particular accidents that are possible and to estimate their likelihoods and consequences. Increasingly, safety issues are being resolved, policies are being set, and decisions are being made based at least partially on estimates of core damage frequency and other risk measures (see Section 2.6). Responsible participation in these processes requires a basic understanding of the estimation methods and their limitations. More in-depth material is available in NRC courses devoted to PRA. ${ }^{1}$

\section{A.1 Risk}

Colloquially, risk is defined as danger, hazard, peril--exposure to death, injury, loss, or some other negative consequence. Thus, risk implies an unrealized potential for harm. If the danger is actually realized, then it is no longer risk but actual death, injury, loss, or other harmful consequence.

To quantify a risk, the likelihood of actually experiencing a given set of consequences must be estimated. While many definitions of risk have been proposed, the following definition is consistent with such estimates:

Risk is the frequency with which a given set of consequences would be expected to occur.

Typically, units of risk are $\mathrm{yr}^{-1}$ reflecting the likelihood of experiencing the given consequence per calendar year. Risk can be estimated for either an individual or a selected population. For example, if the consequence in question is death due to cancer, the total U.S. cancer risk is simply the total number of people per year dying of cancer. The individual risk of cancer death can be estimated by dividing the total number of U.S. cancer deaths recorded last year by the estimated U.S population. The resulting risk to an individual is approximately $2 \times 10^{-3}$ per year; that is, on the average, an individual in the U.S. has a one in 500 chance per year of dying from cancer. Of course, the risk for particular groups of individuals within the overall population is different from this average value.

One measure of the risk of accidents at nuclear power plants is core damage frequency:

The core damage frequency is the probability per year of reactor operation (reactor year) of experiencing a core damage accident.

For this risk, the consequence in question is a core damage accident. Estimates of core damage frequencies for various U.S. nuclear power plants range from approximately $10^{-3}$ to $10^{-6}$ per reactor year.

Potential health and economic consequences of severe nuclear power plant accidents include early fatalities, early injuries, latent cancers, population doses, various health effects, and onsite and offsite costs. For such consequence measures, application of the preceding definition of risk becomes more complicated, because frequencies must be estimated for accidents with varying degrees of severity. For example, the frequency of transportation accidents involving 100 or more early fatalities is substantially lower than the frequency of transportation accidents involving only 1 fatality. In risk assessments, frequencies of accidents with all possible consequence levels are estimated.

It is desirable to combine the risks associated with high, moderate, and low 
consequence accidents into an overall risk measure. For this purpose, the concept of actuarial or consequence-weighted risk is used.

The consequence-weighted risk associated with an accident is the product of the accident's frequency and its consequence.

The total consequence-weighted risk is the sum of the consequence weighted risks of the individual accidents. The process of calculating consequence-weighted risk is illustrated in Table 1A-1 for a hypothetical plant that has only four possible accidents. Consequence-weighted risk is so widely used in probabilistic risk assessments that the modifier consequence-weighted (or actuarial) is usually dropped, and the total consequence-weighted risk is simply called the plant risk.

\section{A.2 The PRA Process}

Probabilistic risk assessment (PRA) is the systematic process of

1. identifying accidents that could endanger the public health and safety,

2. estimating the frequencies of such accidents, and

3. estimating the consequences of such accidents.

In other words, PRA addresses three basic questions:

1. What is possible?

2. How likely is it?

3. What are the consequences?
PRA methods are extremely powerful because they provide a systematic process for identifying vulnerabilities. Most PRAs lead directly to safety improvements by eliminating previously undiscovered vulnerabilities. These safety improvements are often made at the utility's initiative without the need for regulatory action. Therefore, while some of the remaining discussion in this appendix describes the limitations of PRA methods, the reader should note that the overall benefits of the methods far outweigh the limitations.

PRAs can be performed for non-nuclear as well as for nuclear facilities, but the focus here is on the risks of nuclear power plant accidents. Traditionally, nuclear power plant PRAs have been conducted at one of three levels. Figure 1A-1 illustrates the activities and/or products associated with each level. ${ }^{2}$

The Level 1 PRA identifies potential accident initiators and models possible sequences of events that could occur as the plant responds to these initiators. To identify the potential accidents and quantify their frequency of occurrence, event trees and fault trees (see Section 1A.4) are developed and quantified using historical data on initiating event frequencies, component and system failures, and human errors. Accident sequences leading to core damage are identified and their frequencies (together with the total core damage frequency) are estimated. Although the accident sequences of primary interest in a Level 1 PRA lead to core damage, all these accident sequences are not equivalent. Some are more severe than others in terms of potential plant damage and/or public health consequences. Therefore, all the Level 1 accident sequences are classified into plant damage states according to those factors which determine the potential severity of the consequences. 
A plant damage state is a group of accident sequences that has similar characteristics with respect to accident progression and containment engineered safety feature operability.

The plant damage states define the important initial and boundary conditions for the Level 2 accident progression and source term analyses.

The Level 2 PRA analyzes the thermalhydraulic progression of the accident in the reactor coolant system, interfacing systems, the containment, and, where relevant, surrounding buildings. The release of radionuclides from the fuel, the reactor coolant system, containment and surrounding buildings is also modeled. These analyses yield estimates of the frequencies and magnitudes of potential radiological source terms.

A radiological source term defines the radionuclide inventory that is released to the environment and other attributes such as the elevation, energy, and timing of the release that can have an important effect on offsite doses.

The Level 3 PRA estimates the potential health and economic consequences associated with the source terms from the Level 2 PRA. Weather characteristics, plume dispersion, population concentrations, evacuation and sheltering are accounted for in such estimates. From the Level 3 PRA the consequence-weighted risks of early fatalities, latent cancers, and other health and economic consequences are estimated.

\section{A.3 Analysis of Initiating Events}

Accidents are often grouped by their initiating events. The definition of an initiating event depends on whether the plant is producing power or not. For power operation, an initiating event is an event that requires a rapid shutdown or trip of the plant and challenges the safety systems to remove decay heat. For nonpower operation, an initiating event is an event that requires an automatic or manual response to prevent core damage. In either case, if an initiating event is not successfully responded to, core damage may result.

The first step in performing a PRA is to identify possible initiating events and determine their frequencies. Risk assessment methodologies have strengths and limitations that depend on the type of initiator considered. These strengths and limitations should be understood if PRA results are to be properly interpreted and employed in making regulatory or nonregulatory decisions.

Accidents are often classified by their initiators. Important accidents often fall into one of the following categories:

1. Station Blackout (loss of offsite and onsite ac power),

2. Loss of Coolant Accidents (LOCAs),

3. Anticipated Transients Without Scram (ATWS),

4. Transients (other than ATWS),

5. Special initiators.

LOCAs may be further subdivided into large, intermediate, small, and very small depending on the injection systems required to successfully respond to the LOCA. Transient initiators are usually events related to the balance of plant (BOP). Special initiators include failures in plant support systems (AC or DC busses, cooling water, 
service water, instrument air, HVAC, etc.) Special initiators also include failures of components that separate the high pressure reactor coolant from lower pressure regions, for example steam generator tube ruptures or failure of the valves isolating the reactor coolant system from the decay heat removal system. Accidents resulting from the latter initiators are called interfacing systems LOCAs.

Initiating events are typically divided into two broad groups. Internal events include equipment failures and human errors occurring within the plant such as pipe breaks, stuck valves, damaged pumps, instrument failures, and operator errors. External events include natural and humancaused events outside the plant such as earthquakes, tornadoes and other severe weather, floods caused by heavy precipitation or dam failure, aircraft crashes, and volcanic activity. There are sometimes exceptions to the use of the plant boundary to distinguish internal from external events. For example, loss of offsite power is included as an initiator in all analyses of internal events. Fires internal to the plant have traditionally been classified as external events (although many analysts now agree they should be classified as internal events).

\section{A.3.1 Internal Initiating Events}

Internal initiating events usually receive the most attention in PRAs, and their frequencies are generally less difficult to estimate than the frequencies of external initiators. ${ }^{3}$

Table 1A-2 lists transient initiators for BWRs and PWRs. Initiators requiring similar plant responses are grouped together. Note that the listed initiators are often more specific than the design-basis initiators postulated and analyzed in Safety Analysis
Reports (see Section 1.4), although there is considerable overlap. Design-basis initiators can lead to core damage if additional failures occur (a design-basis initiator can lead to a beyond-design-basis accident).

The initiators and generic frequencies listed in Table 1A-2 are based on both historical data and engineering analyses. Such generic frequencies are often used as a starting point, but they are obtained by averaging over groups of plants and, thus, may not be accurate for a particular plant. A set of internal initiating event groups and their frequencies for one of the NUREG1150 plants is shown in Table 1A-3. Initiating events not shown in this table, such as Reactor Vessel Rupture, were screened out of the study, based on low probability. More detail concerning the information in Tables $1 \mathrm{~A}-2$ and $1 \mathrm{~A}-3$ may be found in NUREG/CR-4550, ${ }^{4}$ which is one of the supporting documents for NUREG-1150.

\section{A.3.2 External Initiating Events}

In addition to the internal initiating events discussed above, there are external initiators that can occur with variable magnitudes. Traditionally these have included:

1. Aircraft impacts,

2. Plant-internal and external flooding,

3. Extreme winds and tornadoes (and associated missiles),

4. Plant-internal and external fires,

5. Accidents in nearby industrial or military facilities,

6. Pipeline accidents (gas, etc.), 
7. Release of chemicals stored at the site,

8. Seismic events,

9. Transportation accidents,

10. Turbine-generated missiles.

Note that these initiators include not only naturally occurring phenomena, but also unintentional human-caused events and failures within the reactor site, not directly related to reactor operations.

An external initiating event of sufficient magnitude may have the potential to directly cause multiple component failures and lead to core damage with few, if any, additional independent failures. Plant-internal fires and seismic events are the two most important external initiating events for most plants.

Hazard analyses are performed to assess the likelihood of external events as functions of their magnitudes. Such analyses may indicate that the risk contribution of some initiators is clearly negligible. For example, the frequency of aircraft-impact damage to any one of the vulnerable structures whose failure could lead to core melt is often found to be much lower (e.g., by a factor of 100) than the frequency of other large external events, such as earthquakes. (If the consequences of severe accidents induced by aircraft impact are comparable to those for severe accidents induced by more likely external events, then detailed assessments of aircraft-impact accidents may be unnecessary.) Some unique characteristics of particular initiators are discussed in more detail below.

\section{A.3.2.1 Plant-Internal Fires}

Fire in a nuclear power plant can initiate a serious accident by rendering vital plant equipment inoperable. The term plantinternal fire is used to denote any fire originating within the plant (including outdoor equipment such as high voltage transformers). Causes can include equipment malfunctions and human errors. Initiating event frequencies are based on the historical frequency of occurrence of fires and the locations and quantities of combustible materials. The characteristics of the combustible material determine the rate at which a fire can spread and propagate heat and smoke to undesired locations.

It is important to note that fires can be significant contributors to plant risk despite regulations, such as 10 CFR 50, Appendix $R$. Regulations can significantly reduce risk, but can not eliminate it entirely. Compliance with Appendix $\mathrm{R}$ can not prevent all fires from occurring, nor can it prevent all possible combinations of equipment failures and human errors, given a fire.

\section{A.3.2.2 Seismic Events}

The significance of a seismic event is proportional to the magnitude of the earthquake, in terms of the ground acceleration felt by the plant. If a seismic event results in a ground acceleration slightly above the level allowed for continuous operation (the Operating Basis Earthquake level, see Section 1.4.2), the plant would be shut down for postearthquake examination. Such a shutdown constitutes a transient that could challenge safety-related systems only if compounded by random equipment failures or operator errors. At somewhat higher ground acceleration levels, offsite power may be lost due to failure of the ceramic insulators on high tension electrical transmission lines. Plant equipment that is not Seismic Category I may also fail during such events, since it is not typically designed to withstand the seismic loadings. Finally, for ground 
acceleration levels above the Safe Shutdown Earthquake, safety related equipment can fail as a direct result of the seismic event.

Although the Reactor Safety Study concluded in 1975 that seismic events represented a very minor contributor to accident risk from a nuclear reactor, ensuing developments have led to a strong case that the seismic contributions to risk from LWRs are appreciable. The difficulty in predicting seismic risks lies in predicting the frequency with which seismic events of various magnitudes occur.

The probabilistic expression of the frequency and magnitude of seismic events is known as the seismic hazard curve and is usually expressed in terms of the annual frequency of exceedance (the probability per year of a seismic event at least as large as a stated ground acceleration). Data on the frequencies of small seismic events in seismically active regions are easy to obtain, but data are sparse for very large seismic events. The recorded earthquake history in the Eastern U.S. goes back only about 200 years.

Estimates of ground accelerations for very large earthquakes must be based on observations of existing fault lengths (both active and inactive) and relationships between fault lengths and earthquake magnitudes. This results in significant uncertainty in the frequency of high magnitude (once in 100 to 100,000 years) seismic events. Furthermore, there has been some controversy as to the interpretation of recorded earthquake motions in the eastern U.S. The uncertainties in the hazard curve are represented by developing a family of curves with a probability assigned to each curve such that the summation of probabilities over the family of curves is unity. NUREG-1150 used seismic hazard curves that were part of an NRC-funded
Lawrence Livermore National Laboratory project that resulted in seismic hazard curves for all nuclear power plant sites east of the Rocky Mountains. ${ }^{5}$ For purposes of completeness and comparison, the seismically induced core damage frequencies were also calculated based upon a separate set of seismic hazard curves developed by the Electric Power Research Institute (EPRI). ${ }^{6}$ Figures $1 \mathrm{~A}-2$ and $1 \mathrm{~A}-3$ present the two markedly different families of hazard curves that were used for the Peach Bottom site in NUREG-1150.

\section{A.3.2.3 Weather-Related Events}

Severe weather such as hurricanes, tornadoes, high winds, and floods can cause the loss of offsite power or, if they exceed plant design bases, cause damage to safetyrelated structures and equipment. Frequencies of severe weather initiators are difficult to estimate because it is hard to predict how severe the weather could get at any plant location with a frequency of once in 100 to 100,000 years. In fact, significant climatic changes have occurred during such time spans, so even if one could examine accurate weather data for the past 100,000 years, there would still be significant uncertainty as to whether the probabilities developed from that data would be truly applicable to the next fifty or so years.

Fortunately, the most severe weather is often very localized, so it is possible to examine the worst known storm near the reactor facility and use geometrical arguments to determine an estimate of the probability that the reactor site itself might be affected. Normally, a bounding analysis of that probability is sufficient to screen out most severe weather events from further consideration. The loss of offsite power as a result of severe weather is generally included in the overall loss of offsite power frequency (included in the plant-internal 
events analysis). If any particular severe weather events can not be screened out based on low frequency, then analyses of plant response are performed during the accident sequence development phase of the PRA.

\section{A.3.2.4 Other Naturally Occurring Events}

A number of other naturally occurring phenomena could conceivably cause damage to a nuclear power plant and initiate a core damage accident. These include volcanic activity, lightning, avalanche, landslide, fog, drought, forest fire, sand storm, high tide, seiche, tsunami, low lake or river level, meteor impact, and soil shifting. Most of these events either are not applicable to a particular site, are predictable, develop very slowly (and hence provide much time for corrective actions), or can be analyzed using "worst case" bounding analyses to demonstrate they pose negligible risks. Those that can not be dismissed should be included in the accident sequence analysis.

\section{A.3.2.5 Human-Caused External Initiators}

External events include not only naturally occurring phenomena, but also unintentional human-caused events, such as pipeline and transportation accidents. Like many of the naturally occurring external events, many of these events either are not applicable to a particular site, are predictable, develop very slowly (and, hence, provide much time for corrective actions), or can be analyzed using "worst case" bounding analyses to demonstrate they pose negligible risks. These types of events are inherently better understood than the naturally occurring external events because there is a theoretical upper bound to the magnitude of the humancaused initiating event (e.g., it is difficult to postulate the magnitude of the most severe credible earthquake, but the type and severity of a nearby industrial or transportation accident is limited by the types of industries and transportation facilities that exist near the reactor site). Furthermore, there is a large body of information available about these types of accidents that is directly applicable to the facilities near the reactor site. Those that cannot be handled through bounding analyses should be included in the accident sequence analysis.

\section{A.3.3 Accidents at Low Power and Shutdown}

Traditionally, accidents initiated at low power and shutdown have not been considered to be particularly important. However, efforts initiated in France and now underway in the U.S. indicate that accidents initiated at low power and shutdown may be more significant than previously thought. ${ }^{7,8}$ There are several reasons for this. During low power and shutdown, there are fewer technical specification requirements. Particularly during shutdown, many systems are inoperable because components are out for maintenance. The operators often have a poor concept of the status of plant systems during shutdown because components are being taken in and out of service frequently and not all instrumentation is available. Furthermore, there are more people in the control room and many control room indicator lights are on because so much equipment is out of service. There is complacency, a common perception that the plant is in a safe condition when it is in shutdown.

While it is true that the decay heat generation rate decreases to about $1 \%$ after 1 day, it declines very slowly thereafter. One percent of full power production is sufficient to cause fairly rapid heatup of an uncooled core, given loss of residual heat removal as an initiating event. Further, 
during shutdown the reactor coolant level is lowered close to the top of the active fuel to permit the reactor head to be removed for refueling. LOCAs could be initiated by inadvertent opening of drain lines and the core could be uncovered rapidly. There are seldom any written procedures for dealing with accidents at shutdown. Finally, accidents at shutdown can occur while the containment is open and occupied, thereby increasing the potential for radiological health effects.

Many of the initiating events that can occur at full power can also occur at low power and shutdown. The frequencies of some events, such as earthquakes or loss of offsite power, are not affected by the particular operating mode of the plant. Other events, such as LOCAs, can occur at either full power or shutdown, but at different frequencies due to the different plant state (pipe breaks are less likely at shutdown due to lower reactor coolant pressure). Some full power events, such as a turbine trip, can not occur at shutdown, while other initiating events, such as loss of Residual Heat Removal or some types of maintenance errors, can only occur at shutdown. Overall, there tend to be more categories of initiating events to consider at low power and shutdown than at full power. Table 1A-4 presents initiating event frequencies for the Grand Gulf plant while in Plant Operation State (POS) $5^{9}$, which basically includes the Cold Shutdown Mode of Operation. These frequencies are per year of operation in POS 5.

\section{A.3.4 Sabotage Not Treated in PRA}

Up to this point we have discussed the possibility of severe accidents that result from accidental initiating events. An additional possibility is that someone could intentionally commit acts intended to lead to a severe accident, i.e., commit an act of sabotage. Sabotage is the commission of acts intended to cause harm or damage. For nuclear facilities, acts of sabotage could come from outside of the plant (e.g., an attack on the facility), from within the plant, or both. They could be perpetrated by an outside individual or organization, or by one or more persons who are permitted access to the plant either as workers or as visitors. An act of sabotage could be committed by individuals or groups having diverse motives, such as terrorists seeking to cause a large release of radioactive material or a disgruntled worker seeking revenge on a single individual. Requirements for physical protection of plants and materials are described in 10 CFR Part $73 .{ }^{10}$

Sabotage can involve a wide variety of different types of initiating events, depending upon the particular scenarios followed by the saboteurs. All of these threats, especially insider threats, are wellknown to security analysts. However, because acts of sabotage are related to the human will to cause damage, they are extraordinarily complex to analyze from a probabilistic perspective.

It is generally accepted that the frequency of sabotage threats decreases as their severity increases, but attempts to develop a sabotage "hazard curve" have been unsuccessful. Such a curve would have to account for political conditions both in the U.S. and internationally, interpersonal relationships of plant employees, their families and friends, and other intangible considerations. In short, it is not currently feasible to make useful and defensible estimates of public risks associated with sabotage of nuclear or non-nuclear facilities.

The current methodology for assessing the security of nuclear facilities involves demonstrating that a large set of postulated threats to the facility can be repelled 
reliably. These threats are analyzed without regard to their probabilities, although they are selected based on current knowledge of real threats.

\section{A.4 Accident Sequence Development}

The term accident sequence is used to denote the sequence of events that delineate an accident. These events include the accident initiator (the initiating event) and subsequent successes and failures of plant systems and/or operations.

\section{A.4.1 Multiple Versus Single Failures}

Given an initiating event, core damage can result only if one or more of the following key functions are lost:

\section{1. reactivity control}

\section{2. coolant inventory control}

\section{3. core heat removal}

All reactors have redundant means of performing these functions. Table 1A-5 presents examples of the systems that would perform these functions for a typical BWR and a typical PWR. In many cases, there is redundancy within individual systems. Often in BWRs a single coolant injection system, in combination with appropriate support systems, can perform both the coolant inventory control and core heat removal function. Pump suction alignments determine whether coolant is added to the system from a storage tank or recirculated from the suppression pool. Core heat removal depends upon support system alignments that eventually transfer heat to an ultimate heat sink.

Except for a few unusual initiators, such as pressure vessel rupture or an extremely large earthquake, an initiating event must be followed by multiple, additional failures in order for core damage to occur. An important part of current design requirements for U.S. nuclear power plants is the single failure criterion which is set forth in $10 \mathrm{CFR}$ 50 Appendix A:"

A single failure means an occurrence which results in the loss of capability of a component to perform its intended safety functions. Multiple failures resulting from a single occurrence are considered to be a single failure. Fluid and electrical systems are considered to be designed against an assumed single failure if neither (1) a single failure of any active component (assuming passive components function properly) nor (2) a single failure of a passive component (assuming active components function properly) results in a loss of the capability of the system to perform its safety function.

Single failures of passive components in electric systems should be assumed in designing against a single failure. The conditions under which a single failure of a passive component in a fluid system should be considered in designing the system against a single failure are under development.

For example, consider a plant that must provide a minimum coolant flow rate of say $1000 \mathrm{gpm}\left(0.063 \mathrm{~m}^{3} / \mathrm{s}\right)$ in order to prevent core damage following certain accident initiators. The plant systems will be successful if they provide $1000 \mathrm{gpm}(0.063$ $\mathrm{m}^{3} / \mathrm{s}$ ) on demand. This is the injection success criteria for such accidents. The plant systems will withstand single failures if $1000 \mathrm{gpm}\left(0.063 \mathrm{~m}^{3} / \mathrm{s}\right)$ can be provided in spite of the failure of any single component to perform its intended function. This can be achieved through the use of two systems (or one system with two trains) containing similar components, provided that each system (or train) alone is capable of 
delivering $1000 \mathrm{gpm}\left(0.063 \mathrm{~m}^{3} / \mathrm{s}\right)$ on demand. The two systems (or trains) are said to be redundant if they contain essentially identical components; for example, each train might contain a motor driven pump and several motor operated valves. The trains would be diverse, or partially diverse, if they rely on different energy sources; for example, one train might contain a steam driven pump rather than a motor driven pump.

Assuming a plant can withstand single failures, any accident that leads to core damage must involve multiple failures. For example, in a two train injection system, one of the two pumps might fail to start, and an isolation valve on the other train might fail to open. Terminology used to distinguish various types of multiple failures is discussed in Section 1A.4.3.

\section{A.4.2 Use of Event Trees and Fault Trees}

The identification of accidents leading to core damage is undertaken by the use of event trees. An event tree is developed for each initiating event or group of similar initiating events. The questions asked at the top of an event tree usually concern the success or failure of front line systems that may be used to prevent core damage. The accident initiator and the system success/failure questions are diagramed sequentially in the order that they affect the course of the accident. The tree branc'ses at points where the systems either succeed or fail in their functions.

Actual event trees can be very complex and involve hundreds of possible accident sequences; however, the event tree process can be illustrated by the simple example shown in Figure 1A-4. Consider a LOCA initiated by a small pipe break (event S2).
The front-line systems that should automatically respond to prevent core damage are the reactor protection system (RPS) and the High Pressure Injection (HPI) System. Proper operation of these two systems constitutes a success path through the event tree because core damage would be prevented. There are, of course, other success paths. For example, if the RPS succeeds but HPI fails, core damage can still be prevented if both the Automatic Depressurization System (ADS) and the Low Pressure Injection System (LPS) function. Note that some illogical branches have been eliminated in Figure 1A-4. For example, if high pressure injection and automatic depressurization both fail, then low pressure injection is not possible and does not affect the outcome.

The frequency associated with any particular outcome of the event tree is the product of the initiating event frequency and the successive, often dependent success or failure probabilities at each branch. For example, the risk of core damage due to an accident initiated by a small LOCA (S2) and compounded by failure of both High Pressure Injection (FHPI) and Automatic Depressurization (FADS) is

$$
\mathrm{F}_{\mathrm{S} 2} *\left[1-\mathrm{P}_{\mathrm{fRPS} \mid \mathrm{S} 2}\right] * \mathrm{P}_{\mathrm{FHPIS} 2, \mathrm{RPS}} * \mathrm{P}_{\mathrm{fADS} \mid \mathrm{S} 2, \mathrm{RPS}, \mathrm{fHPI}}
$$

Here $F_{S 2}$ is the frequency of small LOCAs per reactor year, $P_{\text {fRPSIS2 }}$ is the probability RPS fails given an $S 2$ initiator, $P_{\text {fHPISS2,RPS }}$ is the probability HPI fails given an $\mathrm{S} 2$ initiator and RPS success, and $\mathrm{p}_{\mathrm{fADS} \mid \mathrm{S} 2, \mathrm{RPS}, \mathrm{rHPI}}$ is the probability ADS fails given an $\mathrm{S} 2$ initiator, RPS success, and HPI failure.

For nuclear power plants, system failure probabilities are generally small, much smaller than unity; hence, success probabilities like $\left(1-p_{\mathrm{fRPS} \mid \mathrm{S} 2}\right)$ are essentially equal to one. 
The fact that system failure probabilities are small is, of course, desirable; however, it also means that the failure probabilities of such systems cannot be directly quantified based on failure data. Instead, a logical model for each system must be developed to express the system's failure probability as a function of the failure probabilities of its components and supporting systems. Such logical models are developed through the use of fault trees.

For a particular event called the top event (usually a failure of a system to perform some intended function), a fault tree is used to identify the combinations of base events (usually component failures or operator errors) that could lead to the top event. An example is shown in Figure 1A-5, which is a fault tree for a hypothetical, one-pump injection system. The symbols used in fault trees originate from the logical operations OR $(+)$ and AND $\left({ }^{*}\right)$. For the example, insufficient system flow could result from a failure to actuate the injection system $\mathbf{O R}$ from insufficient flow from the pump. The actuation failure requires both that the automatic actuation signal fail AND that the operator fail to actuate the system manually. Insufficient flow from the pump can be caused by any of the failure events listed under the corresponding $\mathbf{O R}$ gate. Note that one of these events, failure of power to the pump, is based on another fault tree for the power system, which is a support system for the injection system.

Figure $1 \mathrm{~A}-5$ is a very simple example. Fault trees for actual nuclear power plant systems commonly involve hundreds of logic gates and hundreds of base events. Nevertheless, Figure $1 \mathrm{~A}-5$ can be used to illustrate the process undertaken to solve fault trees and event trees. The first step is to find the minimal combinations of events that lead to system failure. These are called minimal cut sets for the system. For the example depicted in Figure 1A-5, any of the failure events under the bottom OR gate would result in insufficient flow from the pump and hence system failure. System failure due to auto actuation signal failure (ASF) requires both events under the AND gate on the left hand side. Hence, in Boolean logic notation, the injection system failure (ISF) is given by a sum over 6 cut sets:

$$
\begin{aligned}
\mathrm{ISF}= & \mathrm{ASF} * \mathrm{OFA}+\mathrm{VFO}+\mathrm{POM}+\mathrm{PFS} \\
& +\mathrm{PFR}+\mathrm{PPF}
\end{aligned}
$$

The first five cut sets on the right hand side are minimal cut sets because the base events they contain (taken alone or in combination with other failures) lead to core damage. The single event PPF in the last term on the right hand side, failure of power to the pump (PPF), is not a base event and would have to be expressed in terms of minimal cut sets for the power system. Of course, some of the "base events" in the above expression, in particular event ASF, could have been modeled in more detail. After determining the minimal cut sets for each of the front line systems depicted on an accident event tree, the logical expression for any path through the event tree is simply the logical AND of all system failures along the path. Computer codes are used to perform such logical substitutions. Repeated events and duplicate cut sets are subsumed in this process, and low probability cut sets may be deleted. The results of the solution process are the minimal cut sets associated with each path leading to core damage.

\section{A.4.3 Failure Terminology}

\section{A.4.3.1 Independent Versus Dependent Failures}

Multiple failures may be either independent or dependent. Two events are said to be independent if the occurrence of one does not effect the likelihood of the other, 
otherwise the events are said to be dependent. Most important severe accidents are expected to include events that are at least partially dependent, due to common underlying causes of failure or interactions among systems. Dependent failures defeat the redundancy or diversity of plant systems that provide key functions such as coolant injection. The term system interaction is used to describe dependent failures that involve or affect more than one plant system. Dependent failures can be divided into three categories: explicitly dependent events, common cause failures, and subtle failures. The distinctions between these categories are based on the manner in which the impact of the dependent events are (or are not) treated in risk assessments (Section 2.6). The following subsections describe these three categories of dependent failures in more detail.

\section{A.4.3.2 Explicitly Dependent Events}

Many interactions and dependencies involve the explicit dependence of one system upon another. For example, many emergency core cooling systems are explicitly dependent upon support systems providing electrical power, instrument air, cooling water, etc. Cascading or propagating failures are also important. For example, a pump may fail to start due to the malfunction of a circuit breaker in the pump control circuit. Categories of explicit dependencies include:

Initiating event dependencies Accident initiators can cause the unavailability of more than one system

Support system dependencies Operation of front-line reactor core and containment safety systems can be directly or indirectly dependent on certain support systems (i.e., electrical power, heating, ventilation, cooling, actuation, and isolation).

Shared equipment dependencies Individual components which are shared by more than one system (e.g., the BWR suppression pool, and other components used in various modes of Residual Heat Removal).

Human errors - Operator failure to respond according to procedures can result in the failure or unavailability of more than one component or system.

Propagating failures - Failure of one component due to the failure of another component to which it is directly linked (e.g., failure of a thermostat leads to room overheating and failures of components in the room).

\section{A.4.3.3 Common Cause Failures}

A common cause failure is the simultaneous failure or unavailability of more than one component due to some underlying common cause, such as design errors or environmental factors.

It should be noted that by this definition common cause failures include the explicitly dependent failures discussed in the following section. However, the term common cause is more often used to describe situations in which for some unknown reason redundant components fail with a higher frequency than would be calculated under the assumption that the components failed independently. The term common mode failure is also used to describe this type of failure (and is perhaps more appropriate).

As indicated in Figure 1A-6, potential underlying common causes can be grouped 
under engineering and operations, each with two subcategories: design and construction under 'engineering, procedural and environmental under operations. ${ }^{12}$

A functional design deficiency might result from an unrecognized deficiency in some component (e.g., a sensing instrument that does not provide the required sensitivity), unanticipated changes in plant operating conditions that leave the protection system inadequate for its purpose, or misunderstanding of the behavior of process variables in the design of the protection system. Realization faults include design errors and failures due to a common element unrecognized in the design. Grouped under construction are deficiencies due to improper manufacture, installation, and/or preoperational testing of all components of a similar type.

Common causes arising in plant operations include procedural errors such as incorrect calibration of all of the components of a given type, inadequate testing, mistakes made in maintenance work that might apply to a series of similar components, incorrect or outdated operating or maintenance instructions, and operator errors. The environment to which plant components are subjected can also be a common cause of failures. This includes such things as high temperatures, moisture, vibration, wear, dirt, and various more severe environmental events such as storms, fires, floods, earthquakes, and accident conditions that might act in more or less the same way upon similar components throughout the plant.

Examples of component groups that are susceptible to common cause failures include:

- Safety Relief Valves (SRVs)

- Motor Operated Valves (MOVs)

- Motor Driven Pumps (MDPs)
- Air Operated Valves (AOVs)

- Diesel Generators (DGs)

- Batteries

- Circuit breakers.

Common cause events can be placed directly on fault trees. Engineering judgment is used to determine which common cause events are important enough to include. It is not possible to include all conceivable combinations of common cause events due to the number of components involved. For example, the number of combinations of motor-operated valves in a plant that could fail from a common cause is almost endless. Standard practice is to consider common cause combinations across multiple trains of single systems, but with a few exceptions not across multiple systems.

Plant specific data for common cause phenomena are scarce; therefore, industry wide data and compilations of generic data must be used to quantify common cause failure probabilities. One method of common cause probability estimation involves the use of so-called beta factors that are estimated from industry wide data. A beta factor is the conditional probability of a component failure given that a similar component has failed. Typical values for beta factors range between 0.01 and 0.1 , depending upon the type of component involved.

Consider a simple example involving two identical components in different trains of a two train system. If the independent failure probability of each component is 0.01 , then the probability of both components failing independently is $10^{-4}$. However, if the common cause beta factor for components of this type is 0.1 , then the probability of both components failing due to a common cause is $10^{-3}$, which is an order of magnitude higher than the independent failure probability. Normally, the common cause 
failure rate for multiple components will be significantly higher than the independent failure rate, and common cause failures are usually significant in the final PRA results.

\section{A.4.3.4 Subtle Failures}

Subtle failures are best explained by example. They require detailed knowledge of the design and operation of plant systems and can, therefore, be difficult to uncover. Six examples follow.

\section{Sneak Circuits Following Power Restoration}

A potential problem in the Reactor Core Isolation Cooling (RCIC) system circuitry of a particular BWR was identified. Within this particular RCIC control system, because of the design of the RCIC steam leak detection circuit, it is possible for a sneak circuit to occur and cause an unintended, nonrecoverable isolation of the RCIC pump in conjunction with a station blackout. There are at least three subtle design aspects which lead to the occurrence of this failure mode: (1) the RCIC system contains an isolation circuit, (2) the isolation circuitry is deenergized given a loss of offsite power (i.e., the circuitry is not fed by a noninterruptible, battery-backed vital $\mathrm{AC}$ power supply), and (3) the isolation circuit contains a seal-in circuit.

\section{Pump Room Cooling}

Given the loss of room cooling at a certain plant, the maximum room temperature remains below the temperature for which a pump and its control circuits are qualified. However, a room cooler isolation control circuit exists, and this circuit is set to trip the pump at $200^{\circ} \mathrm{F}\left(93^{\circ} \mathrm{C}\right)$. This temperature would be reached within twenty minutes following loss of room cooling; therefore, room cooling is actually required for the pump.

Room cooler test procedures have been found inadequate at some plants. At one plant, it was determined that cooling of the Engineered Safety Features switchgear room was required. The cooling system was safety-grade and was tested monthly. The cooling system was actuated by a wallmounted thermostat. However, the monthly test required the cooler to be started via a switch which bypassed the thermostat portion of the actuation circuit. The plant has since changed the test procedure so that the availability of the thermostat is verified monthly. The plant now uses a hot air blower to actuate the thermostat.

\section{Air Binding of Cooling Water Systems}

There have been several incidents involving the failure or partial failure of cooling water systems because of air binding caused by leaks in a load being cooled. The plant compressed air systems have both compressor cooling and aftercoolers that are supplied with some form of cooling water. If a leak develops in these coolers, the higher pressure air will enter the cooling system and could result in air binding. This is a problem particularly with closed-cooling systems, but could also be a problem with open systems. Air binding can result in failure of multi-train systems. Depending on the other loads on the cooling system, this potential failure of the air system and the entire cooling system can be important as an initiating event, or as a compounding support system failure.

\section{Passive Component Failures}

At one PWR an important accident sequence involves failure of a manual butterfly valve in the discharge of the nuclear service water system. This valve is in a common line that 
nearly all of the service water loads discharge to before returning to the lake. Failure of this valve in a manner that blocks flow prevents cooling. of most safety loads. This scenario is difficult to diagnose and even more difficult to recover from. Although passive failures (e.g., stem/disc separation) of valves are rare, these events need to be considered, particularly in common support systems. It is also interesting to note that the plant has experienced this failure mode in a service water valve of the same design and size as the common valve. The valve that failed is further upstream and only blocked flow from one RHR heat exchanger.

\section{Normal Operating Configuration}

The normal operating configuration of systems cannot always be inferred from plant piping and instrumentation diagrams (P\&IDs). For example, a P\&ID may show valves as normally closed when, in reality, the plant operates with these valves open. One P\&ID indicated that a room containing three high-pressure injection pumps had two room coolers, each receiving power and cooling water from a different division. Discussions with the plant revealed that, only one of the two room coolers is normally operated. Further discussion revealed that power to the operating cooler fan could be taken from Division 1 while power to supply the cooling water to the cooler heat exchanger was being taken from Division 2 . Because of this operating configuration, several single failures of the three highpressure injection pumps were identified.

\section{Locked Door Dependencies}

The plant configuration is not always obvious during special types of accidents such as a station blackout. During a station blackout, the security system at some plants locks the powered security restrictive and key-locked doors; that is, they do not fail open, thereby potentially restricting accident response actions.

\section{A.4.4 Human Factors, Heroic Acts, Errors of Commission}

Human factors analyses are incorporated into current, state-of-the-art PRA studies to model the failure of operators to follow written procedures under normal operating and accident conditions. These acts can be included in fault trees or incorporated into the cut set results. Probabilities for these events are relatively easy to determine, although there is significant uncertainty. Also, the effects of such failures can be identified by tracing the reactor systems and examining the written procedures. It is infinitely more difficult, however, to model cases where the operators "think for themselves" and/or intentionally violate written procedures by undertaking actions that they believe will aid in achieving a desired plant condition. Such acts may indeed improve the situation (see discussion of Davis Besse loss of feedwater event in Appendix 2A), in which case they are defined in PRAs as heroic acts. Frequently, however, such independent acts initiate or exacerbate accidents, in which case they are called errors of commission. Both the Three Mile Island (Section 2.1) and Chernobyl (Section 2.3) nuclear accidents were exacerbated by such errors of commission. No PRA would have considered the possibility that a licensed reactor operator would actually turn the emergency core cooling system off during a LOCA, yet that occurred at Three Mile Island. Similarly, operators are not expected to disable large numbers of safety related systems in violation of technical specifications, yet this was done at Chernobyl. Thus, human errors of commission may be very significant to actual risks, yet at present there is no comprehensive method by which such 
actions can be examined as part of a probabilistic risk assessment.

\section{A.4.5 External Events and Fire Analyses}

External events and fires require additional steps in both the initiating event and accident sequence analysis portions of a PRA. A key reason for the differences is that the initiating events can have variable magnitude. As indicated in Figure 1A-7, the basic steps in the analysis of risks from variable magnitude initiating event like earthquakes, are (1) hazard analysis, (2) plant-system and structure response analysis, (3) evaluation of the fragility and vulnerability of components (structures, piping, and equipment), (4) accident sequence development, and (5) consequence analysis. Section 1A.3.2.2 discussed the development of hazard curves, and consequence analysis is discussed in Chapter 5. The other steps are discussed briefly below.

In the response analysis, the response of plant systems and structures for a specified hazard input level is calculated. The response of interest is often the structural response at selected structural, piping, and equipment locations. For earthquakes, the response parameters could be spectral acceleration, moment, and deflection. For extreme winds, they could be force or moment on a structural element and deflection. For fires, thermal response and smoke accumulation are of interest.

The fragility of a component is the conditional failure frequency for a given value of a response parameter. The first step in generating fragility curves is a clear definition of what constitutes failure for each componeni. This failure criterion is calculated by an analysis of the parameter of interest, such as a structural or thermal failure threshold. Uncertainties in the component fragility are represented by developing a family of fragility curves for each component. The sum of the probabilities assigned over a family of fragility curves is unity.

The use of event trees and fault trees for accident sequence development was discussed in Section 1A.4.2. The major differences in this step for external events as contrasted with traditional internal events are the addition of external-event-caused failures to the fault trees and the increased likelihood of multiple failures of safety systems due to correlations between component responses and between component capacities.

There are additional considerations when determining core damage frequencies associated with fires. The threat of core damage posed by fire in a particular area of the plant depends on the frequency of ignition in the area, the amount and nature of combustible material in the area, the nature and efficacy of automatic and manual fire-suppression systems in the area, the proximity of vital equipment. Coincident failures of fire protection systems and other systems must be considered. Only a small fraction of the fires that could occur in a nuclear power plant would be expected to lead to core damage. Fires in the control room and emergency switchgear areas are important in view of the potential for simultaneous failure of several systems by fires in these areas. Thus, in the past these areas have received particular attention in fire protection programs. Fire analyses include credit for the fire protection programs required by Appendix $R$ to $10 \mathrm{CFR}$ Part $50 .^{13}$

\section{A.5 Uncertainties in Risk Estimates}

Proper use of PRA results generally requires an understanding of the limitations and uncertainties associated with the results. 
The limitations and uncertainties vary for different types of events and failures. Since the Reactor Safety Study, risk analyses have examined in detail the potential for severe accidents to be initiated by operational failures like those considered for designbasis accidents in SAR Chapter 15 . Consequently, the methodology and databases for treating such accidents are better developed than for initiators requiring hazard analyses. There is substantial agreement within the risk assessment community that PRAs can determine the most likely sequences of equipment failures and operator errors of omission (failures to follow procedures in response to equipment failures) that could lead to core damage.

There is less agreement, however, on the interpretation of the absolute magnitude of the calculated core damage frequencies and other risks obtained from such PRAs. This is due to the fact that, along with statistical uncertainties associated with data collection and analysis, there are scope and methodology limitations inherent in current state of the art PRAs. For example, PRA methods are inadequate for addressing human errors of commission (see subsection 1A.4.3.4), design and construction errors or the influence of plant management. Further, PRA methods are only beginning to be applied to accidents initiated at low power and shutdown. Consequently, PRAs do not (and do not claim to) represent the total public risk from the analyzed plants.

To characterize uncertainty, analysts use a distribution of possible values and discuss each risk measure in terms of the mean, median, and various percentiles of its distribution. For example, the internal-event core damage frequencies from the NRC NUREG-1150 risk assessment of five plants are shown in Figure 1A-8. The lower and upper extremities of the bars represent the 5 th and 95th percentiles of the distributions, with the mean and median of each distribution also shown. Thus, the bars include the central $90 \%$ of the distribution. Figure 1A-8 shows that the range between the 5th and 95 th percentile covers from one to two orders of magnitude for each of the five core damage frequencies.

As a result of the uncertainties inherent in seismic hazard curves (see Section 1A.3.2.2), many risk analysts feel that estimates of seismic risks are less robust than those calculated for internal events. In this regard, the NRC is not requiring the calculation of a seismic core damage frequency as part of its ongoing Individual Plant Examination (IPE) program. Alternatively, an assessment of the margin between the plant design and the plant SSE level may be made. This margin assessment process avoids the need of developing a seismic hazard curve, although specification of the earthquake level at which the margin is to be assessed is determined by agreement between the plant utility and the NRC, and may involve probabilistic considerations. Previous PRA studies have shown the seismic margin to be considerable in that the estimated frequency of seismically induced core damage is often more that a factor of ten lower than the estimated SSE frequency.

Comparing a risk estimated for one plant to that estimated for another plant or to some absolute limit or goal is not simply a matter of comparing two numbers. It is more appropriate to observe how much of the uncertainty distribution lies below a given value, which translates into a measure of the certainty that the core damage frequency is less than the given value. For example, if the 95th percentile of core damage frequency for a given plant was $1.0 \times 10^{-4}$ per reactor year, there would be only a $5 \%$ chance that the plant's true core damage frequency would exceed $1.0 \times 10^{-4}$ per reactor year. Similarly, when comparing risks calculated for two or 
more plants, it is not sufficient to simply compare the mean values of the uncertainty distributions. Instead, entire distributions must be compared. For example, from Figure 1A-8, one can have relatively high confidence that the internal-event core damage frequency for Grand Gulf is lower than that of Sequoyah or Surry. Conversely, differences in core damage frequency between Surry and Sequoyah are not very significant. 
Table 1A-1 Consequence weighted risk

\begin{tabular}{llll}
\hline $\begin{array}{l}\text { Accident } \\
\text { Scenario }\end{array}$ & $\begin{array}{l}\text { Estimated } \\
\text { Frequency } \\
\text { (accid/yr) }\end{array}$ & $\begin{array}{l}\text { Estimated } \\
\text { Consequence } \\
\text { (deaths/accid) }\end{array}$ & $\begin{array}{l}\text { Consequence- } \\
\text { Weighted Risk } \\
\text { (deaths/yr) }\end{array}$ \\
\hline $\mathrm{S}_{1}$ & $2.0 \times 10^{-5}$ & 1 & $2.0 \times 10^{-5}$ \\
$\mathrm{~S}_{2}$ & $0.2 \times 10^{-5}$ & 3 & $0.6 \times 10^{-5}$ \\
$\mathrm{~S}_{3}$ & $0.6 \times 10^{-5}$ & 7 & $4.2 \times 10^{-5}$ \\
$\mathrm{~S}_{4}$ & $0.3 \times 10^{-5}$ & 5 & $1.5 \times 10^{-5}$ \\
& $3.1 \times 10^{-5}$ & & $8.3 \times 10^{-5}$ \\
\hline
\end{tabular}




\section{Table 1A-2 Transient initiating event frequencies}

\begin{tabular}{|c|c|c|}
\hline Reactor/Group & Initiating Event & $\begin{array}{c}\text { Frequency/Reactor } \\
\text { Year }\end{array}$ \\
\hline \multicolumn{3}{|l|}{ BWR Groups } \\
\hline \multirow[t]{3}{*}{ LOSP } & LOSP & 0.08 \\
\hline & Loss of auxiliary power (transformer) & $\underline{0.02}$ \\
\hline & Group Total & 0.10 \\
\hline \multirow[t]{12}{*}{ Loss of PCS } & Electric load rejection with turbine bypass failure & 0.004 \\
\hline & Turbine trip with turbine bypass valve failure & 0.004 \\
\hline & MSIV closure & 0.27 \\
\hline & Inadvertent closure of one MSIV & 0.21 \\
\hline & Partial MSIV closure & 0.06 \\
\hline & Loss of condenser vacuum & 0.41 \\
\hline & Pressure regulator fails open & 0.08 \\
\hline & Pressure regulator fails closed & 0.10 \\
\hline & Turbine bypass fails open & 0.04 \\
\hline & $\begin{array}{l}\text { Turbine bypass or control valves increase } \\
\text { pressure (closed) }\end{array}$ & 0.42 \\
\hline & Cause unknown & $\underline{0.06}$ \\
\hline & Group Total & $\overline{1.66}$ \\
\hline IORV & IORV & 0.14 \\
\hline \multirow[t]{11}{*}{ PCS Available } & Electric load rejection & 0.45 \\
\hline & Turbine trip & 0.87 \\
\hline & Recirculation control failure, increasing flow & 0.18 \\
\hline & Recirculation control failure, decreasing flow & 0.05 \\
\hline & One recirculation pump trip & 0.06 \\
\hline & Recirculation pump trip (all) & 0.03 \\
\hline & Abnormal startup of idle recirculation pump & 0.02 \\
\hline & Recirculation pump seizure & 0.004 \\
\hline & FW--increasing flow at power & 0.14 \\
\hline & Loss of FW heater & 0.02 \\
\hline & Trip of one FW or condensate pump & \\
\hline \multirow{8}{*}{0.20} & Rod withdrawal at power & 0.01 \\
\hline & Inadvertent insertion of rods & 0.06 \\
\hline & Detected fault in RPS & 0.05 \\
\hline & Inadvertent startup of $\mathrm{HPCI} / \mathrm{HPCS}$ & 0.01 \\
\hline & Scram from plant occurrences & 0.58 \\
\hline & Spurious trip via instrumentation, RPS fault & 1.11 \\
\hline & Manual scram, no out-of-tolerance condition & $\underline{0.87}$ \\
\hline & Group Total & $\overline{4.71}$ \\
\hline \multicolumn{3}{|l|}{ FW Lost but } \\
\hline Condenser & Loss of all FW flow & 0.07 \\
\hline \multirow[t]{2}{*}{ Available } & FW, low flow & $\underline{0.49}$ \\
\hline & Group Total & $\overline{0.56}$ \\
\hline
\end{tabular}


Table 1A-2 Transient initiating event frequencies (continued)

\begin{tabular}{|c|c|c|c|}
\hline Reactor/Group & Event & Initiating Event & $\begin{array}{l}\text { ncy/Reactor } \\
\text { Year }\end{array}$ \\
\hline \multicolumn{4}{|l|}{ PWR Groups } \\
\hline LOSP & & Loss of offsite power & 0.15 \\
\hline \multirow[t]{10}{*}{ Loss of PCS } & & Inadvertent safety injection signal & 0.05 \\
\hline & & Total loss of FW flow (all loops) & 0.16 \\
\hline & & Closure of all MSIVs & 0.04 \\
\hline & & Increase in FW flow (all loops) & 0.02 \\
\hline & & FW flow instability--operator error & 0.29 \\
\hline & & FW flow instability--miscellaneous mechanical cause & 0.34 \\
\hline & & Loss of all condensate pumps & 0.01 \\
\hline & ' & Loss of condenser vacuum & 0.14 \\
\hline & & Loss of circulating water & $\underline{0.05}$ \\
\hline & & Group Total & 1.10 \\
\hline \multirow[t]{22}{*}{ PCS Available } & & Loss of RCS flow (one loop) & 0.28 \\
\hline & & Uncontrolled rod withdrawal & 0.01 \\
\hline & & CRD mechanical problems and/or rod drop & 0.50 \\
\hline & & Leakage for control rods & 0.02 \\
\hline & & Leakage in primary system & 0.05 \\
\hline & & Low pressurizer pressure & 0.03 \\
\hline & & Pressurizer leakage & 0.005 \\
\hline & & High pressurizer pressure & 0.03 \\
\hline & & Containment pressure problems & 0.005 \\
\hline & & CVCS malfunction--boron dilution & 0.03 \\
\hline & & Pressure/temperature/power imbalance--rod position error & 0.13 \\
\hline & & Startup of inactive coolant pump & 0.002 \\
\hline & & Total loss of RCS flow & 0.03 \\
\hline & & Loss or reduction in FW flow (one loop) & 1.50 \\
\hline & & Full or partial closure of MSIV (one loop) & 0.17 \\
\hline & & Increase in FW flow (one loop) & 0.44 \\
\hline & & Loss of condensate pumps (one loop) & 0.07 \\
\hline & & Steam generator leakage & 0.03 \\
\hline & & Condensate leakage & 0.04 \\
\hline & & Miscellaneous leakage in secondary system & 0.09 \\
\hline & & Sudden opening of steam relief valves & 0.02 \\
\hline & & Turbine trip, throttle valve closure, EHC problems & \\
\hline - & & Generator trin or generator caused faults & \\
\hline & & Pressurizer spray failure & 0.03 \\
\hline & & Spurious trips--cause unknown & 0.08 \\
\hline & & Auto trip--no transient condition & 1.49 \\
\hline & & Manual trip--no transient condition & $\underline{0.47}$ \\
\hline & & Group Total & $\overline{7.20}$ \\
\hline
\end{tabular}




\section{Table 1A-3 Example BWR initiating event frequencies}

Initiator

Nomenclature
Description
Frequency

(per year)
$\mathrm{T} 1$

$\mathrm{T} 2$

T3A

T3B

T3C

$\mathrm{TAC} / \mathrm{x}$

$\mathrm{TDC} / \mathrm{x}$

Transient caused by loss of safety DC Bus " $x "$

Transient with the Power Conversion System (PCS) unavailable

Transient due to an Inadvertent Open Relief

Valve (IORV) in the primary system
0.079

0.05

2.5

0.06

with the steam side of the PCS initially available

0.19

$5.0 \mathrm{E}-3$

$5.0 \mathrm{E}-3$

$1.0 \mathrm{E}-4$

S1 Intermediate LOCA

$3.0 \mathrm{E}-4$

S2

Small LOCA

S3

Small-small LOCA

$3.0 \mathrm{E}-2$

"V"

$<1 E-8$ 


\section{Table 1A-4 Initiating event frequencies for Plant Operating State 5} (cold shutdown)

\begin{tabular}{|c|c|c|}
\hline $\begin{array}{c}\text { Initiating } \\
\text { Event } \\
\text { Nomenclature }\end{array}$ & Description & $\begin{array}{c}\text { Mean } \\
\text { Frequency } \\
\text { per Year } \\
\text { for POS } 5\end{array}$ \\
\hline $\mathrm{T}_{1}$ & Loss of Offsite Power (LOSP) Transient & 0.13 \\
\hline A & Large LOCA at Low Pressure & $3.62 \mathrm{E}-05$ \\
\hline$A_{H Y}$ & Large LOCA during Hydro Test (High Pressure) & $1.25 \mathrm{E}-04$ \\
\hline $\mathrm{S}_{1}$ & Intermediate LOCA at Low Pressure & $3.62 \mathrm{E}-05$ \\
\hline $\mathbf{S}_{1 \mathrm{H}}$ & $\begin{array}{l}\text { Intermediate LOCA during Hydro Test } \\
\text { (High Pressure) }\end{array}$ & $1.25 \mathrm{E}-04$ \\
\hline $\mathrm{S}_{2}$ & Small LOCA at Low Pressure & $3.62 E-05$ \\
\hline $\mathbf{S}_{2 \mathrm{H}}$ & Small LOCA during Hydro Test (High Pressure) & $1.25 \mathrm{E}-04$ \\
\hline $\mathrm{S}_{3}$ & Small-small LOCA at Low Pressure & $3.62 \mathrm{E}-05$ \\
\hline $\mathrm{S}_{3 \mathrm{H}}$ & $\begin{array}{l}\text { Small-small LOCA during Hydro Test } \\
\text { (High Pressure) }\end{array}$ & $1.25 \mathrm{E}-04$ \\
\hline $\mathrm{H}_{1}$ & Diversion to Suppression Pool via RHR & $6.1 E-02$ \\
\hline $\mathrm{J}_{2}$ & LOCA in connected system (RHR) & $1.56 \mathrm{E}-02$ \\
\hline $\mathrm{E}_{1 \mathrm{~B}}$ & Isolation of SDC loop B only & $5.7 \mathrm{E}-02$ \\
\hline $\mathrm{E}_{\mathrm{IC}}$ & Isolation of RWCU as DHR & $1.57 \mathrm{E}-03$ \\
\hline$E_{\mathrm{ID}}$ & Isolation of ADHRS only & $5.7 \mathrm{E}-02$ \\
\hline $\mathrm{E}_{1 \mathrm{~T}}$ & Isolation of SDC common suction line & 0.356 \\
\hline$E_{1 v}$ & Isolation of common suction line for ADHRS & 0.356 \\
\hline $\mathrm{E}_{2 \mathrm{~B}}$ & Loss of operating RHR shutdown system & $6.5 \mathrm{E}-02$ \\
\hline $\mathrm{E}_{2 \mathrm{C}}$ & Loss of RWCU as DHR & $1.57 \mathrm{E}-03$ \\
\hline$E_{2 D}$ & Loss of ADHRS only & $6.5 \mathrm{E}-02$ \\
\hline $\mathrm{E}_{2 \mathrm{~T}}$ & Loss of SDC common suction line & $3.8 \mathrm{E}-02$ \\
\hline $\mathrm{E}_{2 \mathrm{v}}$ & Loss of common suction line for ADHRS. & $3.8 E-02$ \\
\hline $\mathrm{T}_{5 \mathrm{~A}}$ & Loss of all Standby Service Water (SSW) & $2.4 \mathrm{E}-02$ \\
\hline
\end{tabular}




\section{Table 1A-4 Initiating event frequencies for Plant Operating State 5 (cold shutdown) (continued)}

\begin{tabular}{clc}
$\begin{array}{c}\text { Initiating } \\
\text { Event } \\
\text { Nomenclature }\end{array}$ & \multicolumn{1}{c}{ Description } & $\begin{array}{c}\text { Mean } \\
\text { Frequency } \\
\text { per Year } \\
\text { for POS } 5\end{array}$ \\
\hline$T_{5 C}$ & Loss of all Plant Service Water (includes Radial Well) & $2.4 \mathrm{E}-02$ \\
$\mathrm{~T}_{5 \mathrm{D}}$ & Loss of all Component Cooling Water & $2.4 \mathrm{E}-02$ \\
$\mathrm{~T}_{\mathrm{AB}}$ & Loss of 1E 4160 V AC Bus B & $1.66 \mathrm{E}-03$ \\
$\mathrm{~T}_{\mathrm{DB}}$ & Loss of 1E 125 V DC Bus B & $6 \mathrm{E}-03$ \\
$\mathrm{~T}_{\mathrm{IA}}$ & Loss of Instrument Air & 0.18 \\
$\mathrm{~T}_{\mathrm{ORV}}$ & Inadvertent Open Relief Valve at Shutdown \\
$\mathrm{T}_{\mathrm{IOP}}$ & Inadvertent Overpressurization (makeup greater than & $7.2 \mathrm{E}-02$ \\
& letdown) & $1.57 \mathrm{E}-03$ \\
$\mathrm{~T}_{\mathrm{IHP}}$ & Inadvertent Pressurization via spurious HPCS actuation & $1.4 \mathrm{E}-02$ \\
$\mathrm{~T}_{\mathrm{IOF}}$ & Inadvertent Overfill via LPCS or LPCI & $2.2 \mathrm{E}-02$ \\
$\mathrm{~T}_{\mathrm{RPT}}$ & Loss of Recirculation Pump & $7.2 \mathrm{E}-02$ \\
$\mathrm{~T}_{\mathrm{LM}}$ & Loss of Makeup & $8 \mathrm{E}-03$ \\
\hline
\end{tabular}

* This value was taken from NUREG/CR-3862, EPRI Category 20 -- Feedwater Increasing Flow at Power. Note that for POS 5, inadvertent overpressurization is essentially loss of RWCU.

$\star$ This value was taken from NUREG/CR-3862, EPRI Category 24 -- Feedwater - Low Flow. Note that for POS 5, loss of makeup is essentially loss of CRD.

$\begin{array}{ll}\text { ADHRS } & \text { alternate decay heat removal system } \\ \text { CRD } & \text { control rod drive } \\ \text { DHR } & \text { decay heat removal } \\ \text { EPRI } & \text { electric power research institute } \\ \text { LOCA } & \text { loss of coolant accident } \\ \text { LOSP } & \text { loss of off-site power } \\ \text { LPCI } & \text { low pressure coolant injection } \\ \text { LPCS } & \text { low pressure core spray } \\ \text { RHR } & \text { residual heat removal } \\ \text { RWCU } & \text { reactor water cleanup } \\ \text { SDC } & \text { shut down cooling } \\ \text { SSW } & \text { stand-by service water }\end{array}$


Table 1A-5 Safety function system requirements

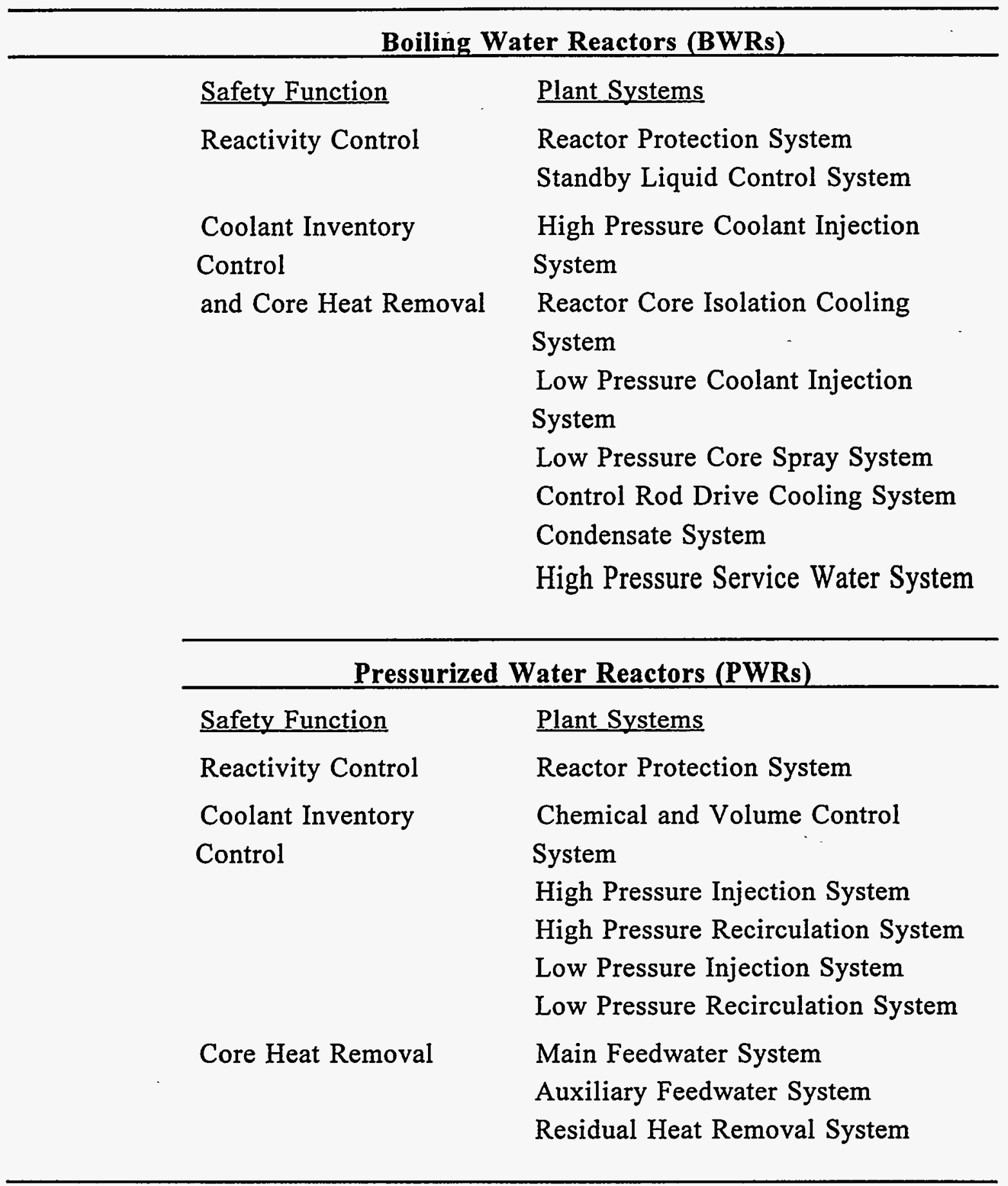


Table 1A-6 Collections and summaries of actual failure events

\begin{tabular}{l} 
Title \\
\hline 1. Licensee Event Reports \\
2. Licensee Event Report Summaries \\
Valves \\
Pumps \\
Electrical Power \\
Circuit Breakers, Protective Relays \\
Initiating Events \\
Selected I\&C Components \\
Control Rods and Drive Mechanisms
\end{tabular}

3. In-Plant Reliability Data Systems

Oak Ridge National Laboratory

Pumps

Source Reference

USNRC

Idaho National

Engineering Laboratory

NUREG/CR-1363

NUREG/CR-1205

NUREG/CR-1362

NUREG/CR-4212

NUREG/CR-3862

NUREG/CR-1740

NUREG/CR-1331

Valves

NUREG/CR-2886

NUREG/CR-3154

Electrical Power Components (Diesels, NUREG/CR-3831

Batteries, Chargers and Inverters)

4. Nuclear Plant Reliability Data System

5. Reactor Safety Study Section III - LER Data for 1972-1973

6. ATWS: A Reappraisal

7. Loss of Offsite Power at Nuclear Power Plants

8. Diesel Generator Reliability at Nuclear Power Plants

9. Classification and Analysis of Reactor Operating Experience Involving Dependent Evènts

10. PORV Failure Reduction Methods

11. Evaluation of Station Blackout Accidents at Nuclear Power Plants: Technical Findings Related to Unresolved Safety Issue A-44:
Institute for Nuclear Power Operations

USNRC

Electric Power

Research Institute

Electric Power

Research Institute

Electric Power

Research Institute

Electric Power

Research Institute

Combustion

Engineering

NRC
Quarterly Reports

WASH-1400

EPRI NP-2230

EPRI NP-2301

NSAC- 103

EPRI NP-2433

EPRI NP-3967

CEN-145

NUREG-1032

Final Report 


\section{Table 1A-7 Statistical analyses and generic data bases}

\begin{tabular}{|c|c|c|}
\hline \multicolumn{3}{|c|}{ Statistical Analyses } \\
\hline Title & Source & Reference \\
\hline $\begin{array}{l}\text { Probabilistic Safety Analysis } \\
\text { of DC Power Requirements for } \\
\text { Nuclear Power Plants }\end{array}$ & USNRC & NUREG-0666 \\
\hline Reliability Data Book & $\begin{array}{l}\text { Swedish Nuclear Power } \\
\text { Inspectorate }\end{array}$ & RSK $85-25$ \\
\hline $\begin{array}{l}\text { Statistical Analysis of Nuclear } \\
\text { Power Plant Pump Failure Rate } \\
\text { Variability-Preliminary Results }\end{array}$ & $\begin{array}{l}\text { Los Alamos National } \\
\text { Laboratory }\end{array}$ & NUREG/CR-3650 \\
\hline \multicolumn{3}{|c|}{$\frac{\text { In addition, items } 2,3,5,7,8,9 \text {, and } 10 \text { of Table } 1 \mathrm{~A}-6 \text { present analyses of repc }}{\text { Generic Failure Rate Data Bases }}$} \\
\hline Title & Source & Reference \\
\hline Reactor Safety Study & USNRC & WASH-1400 \\
\hline $\begin{array}{l}\text { Interim Reliability and } \\
\text { Evaluation Program (IREP) } \\
\text { Procedures Guide }\end{array}$ & Sandia National Laboratories & NUREG/CR-2728 \\
\hline Reliability Data Book & $\begin{array}{l}\text { Swedish Nuclear Power } \\
\text { Inspectorate }\end{array}$ & RKS 85-25 \\
\hline $\begin{array}{l}\text { Station Blackout Accident } \\
\text { Analyses -TAP A-44 }\end{array}$ & USNRC & NUREG/CR-3226 \\
\hline
\end{tabular}




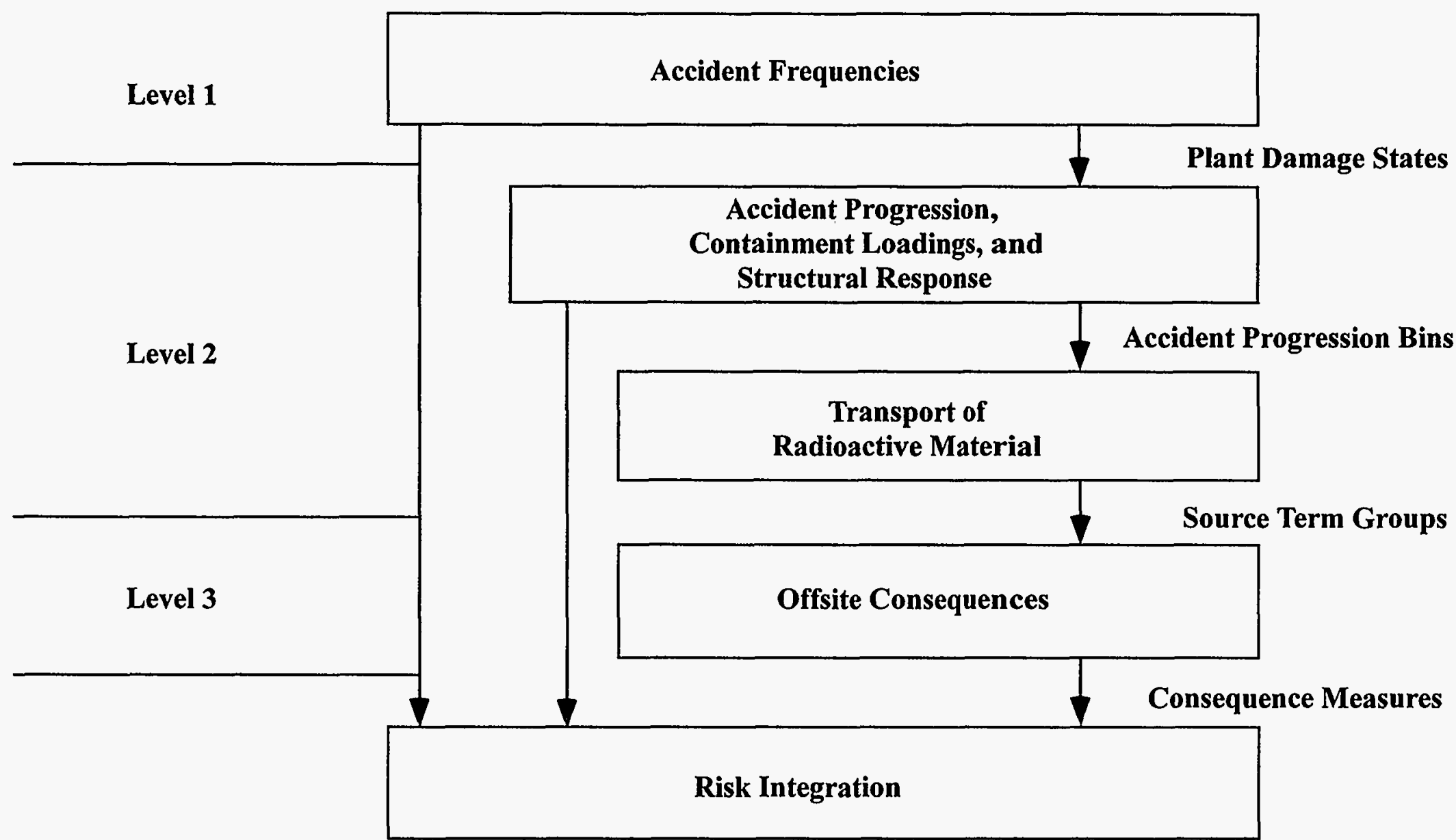

Figure 1A-1 Three levels of probabilistic risk assessment 


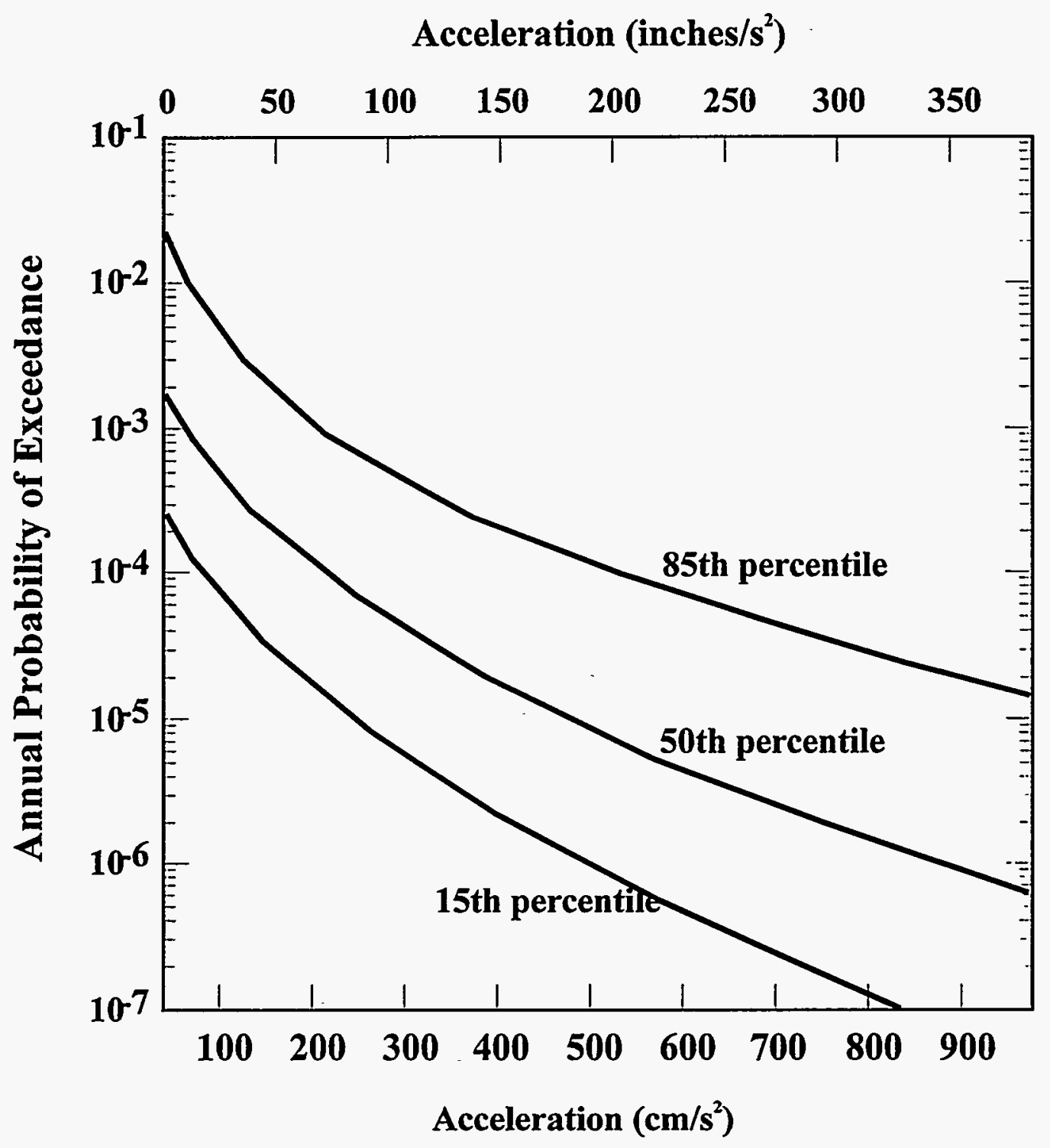

Figure 1A-2 LLNL hazard curves for Peach Bottom site 


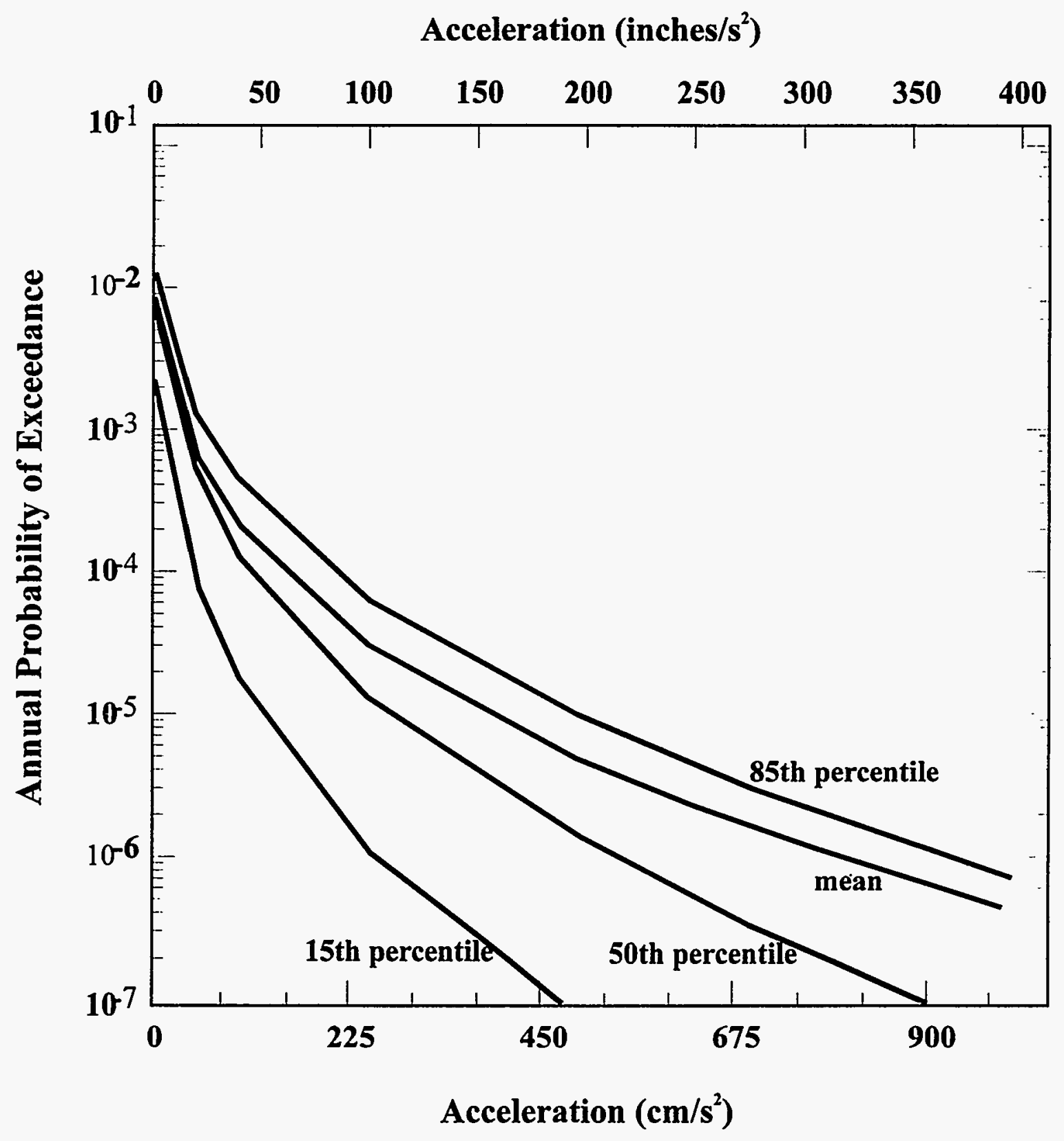

Figure 1A-3 EPRI hazard curves for Peach Bottom site 


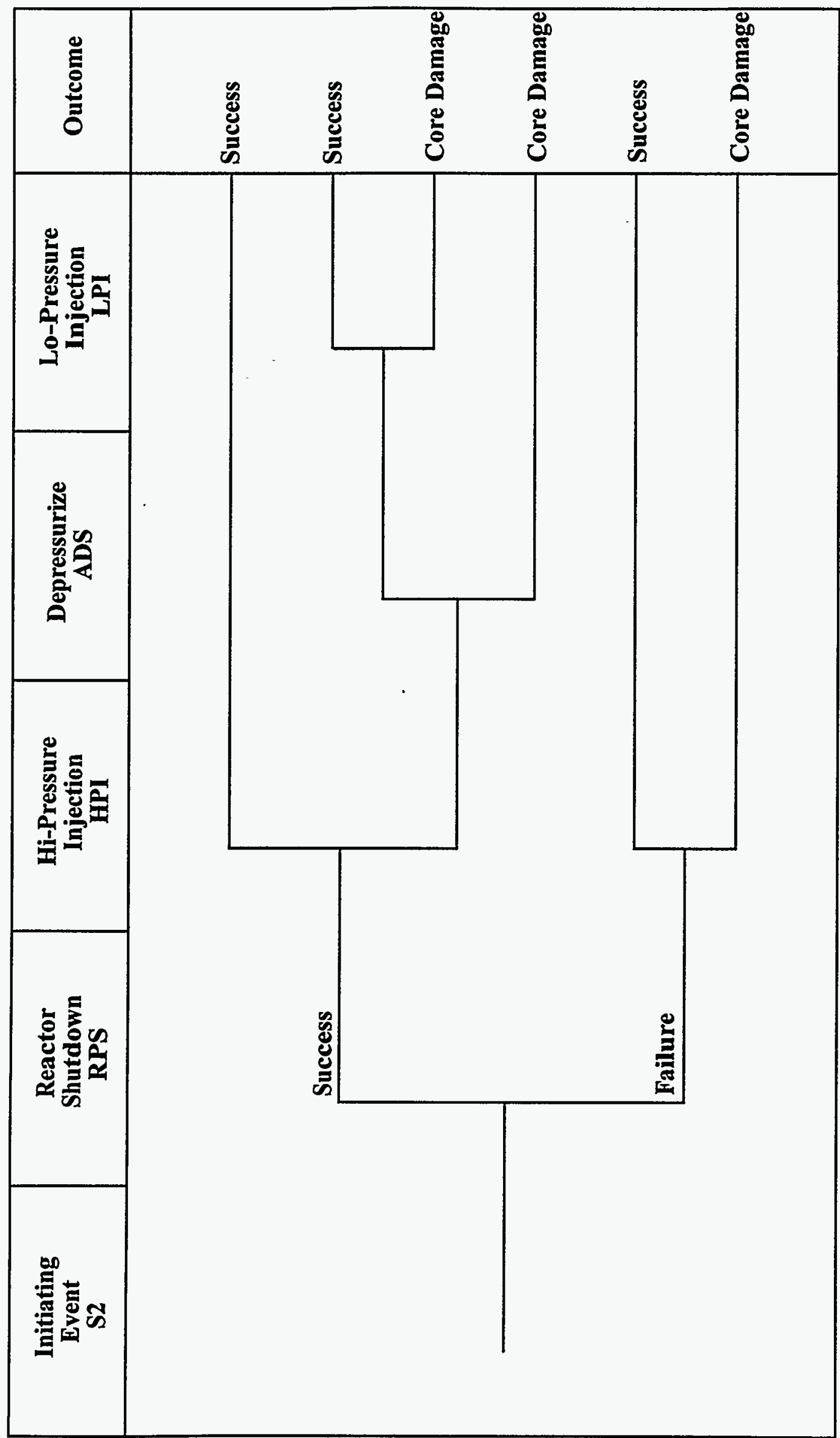

总 

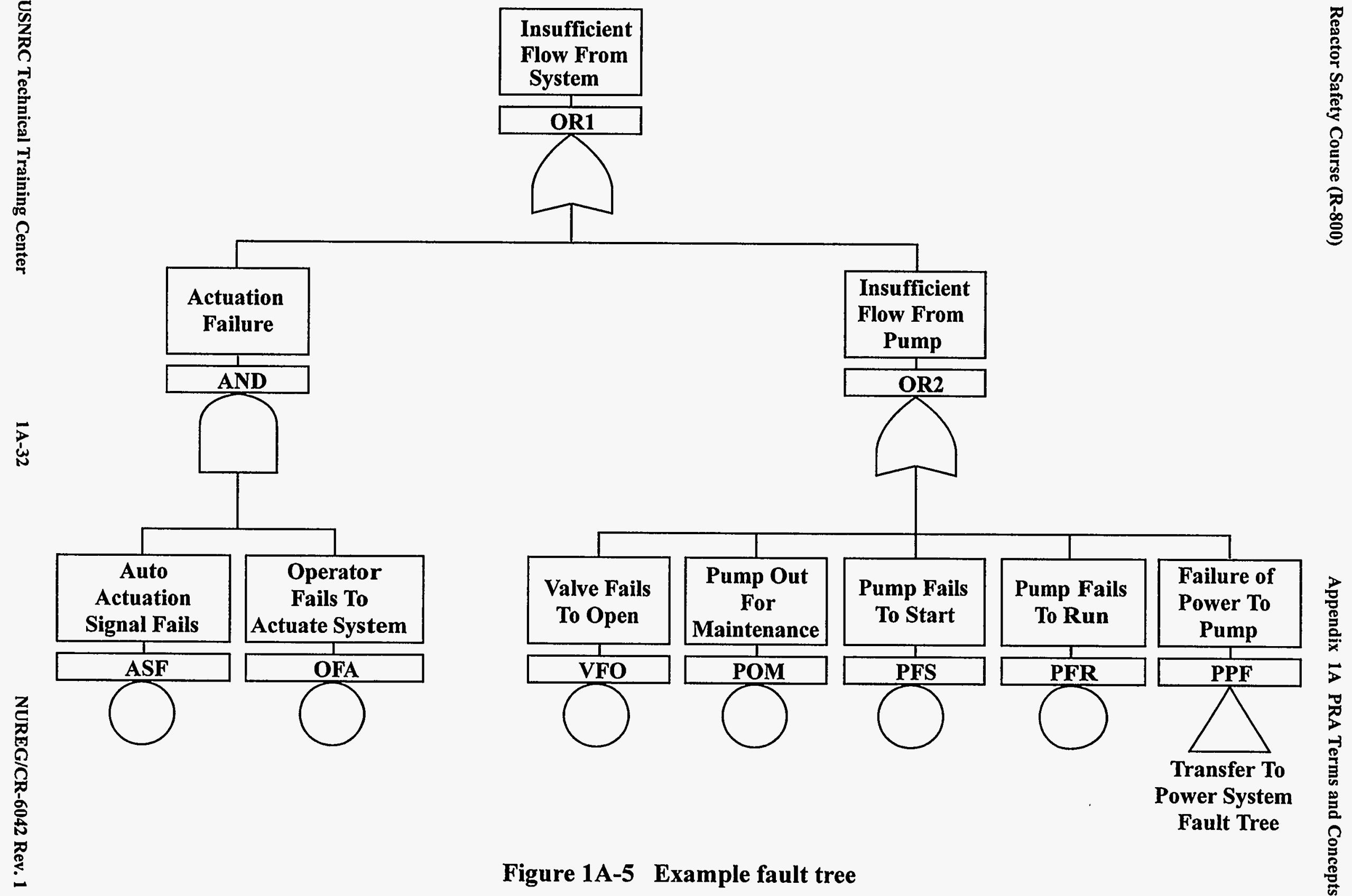

Figure 1A-5 Example fault tree 


\section{Common Causes}

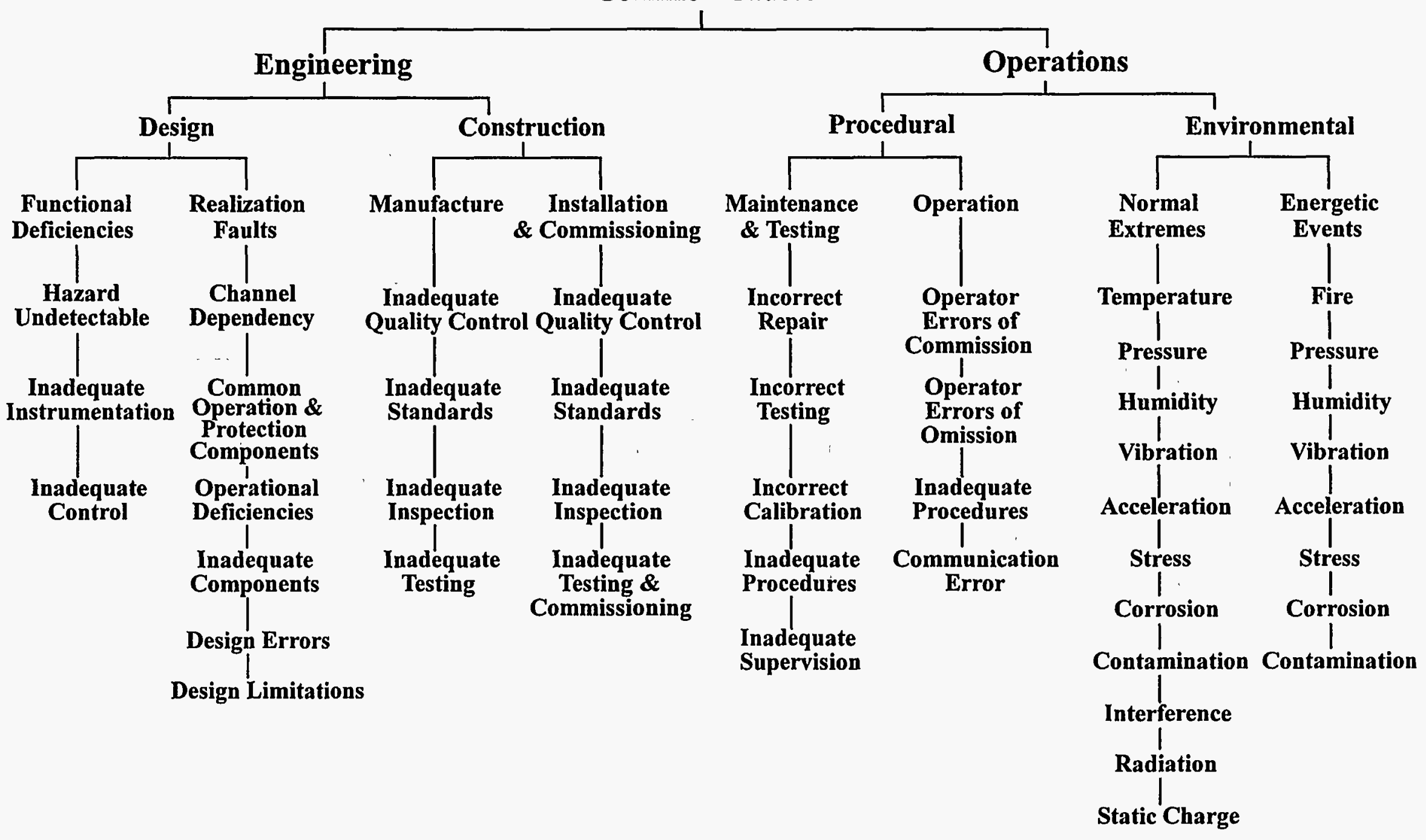

Figure 1A-6 Common causes of failure 


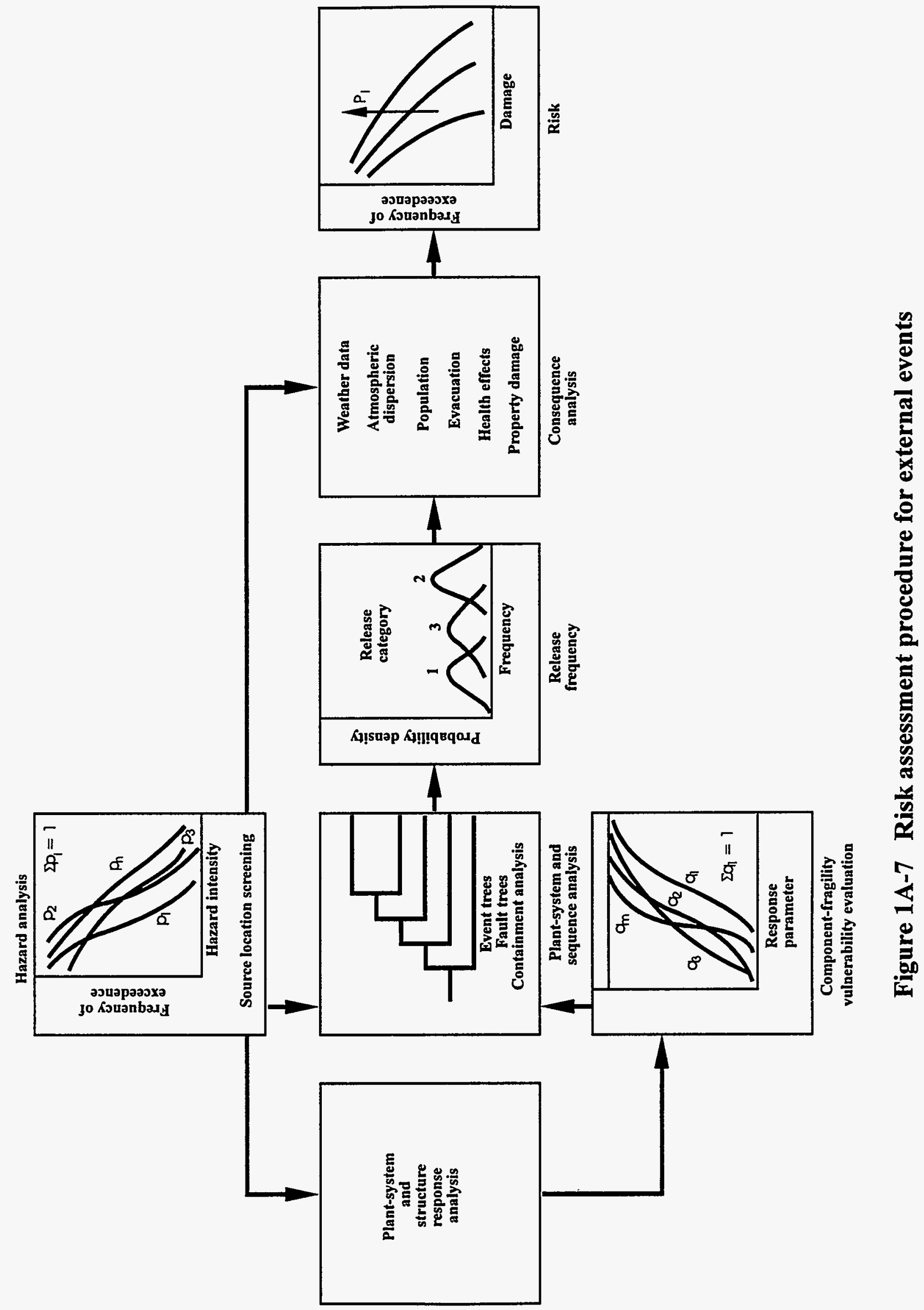




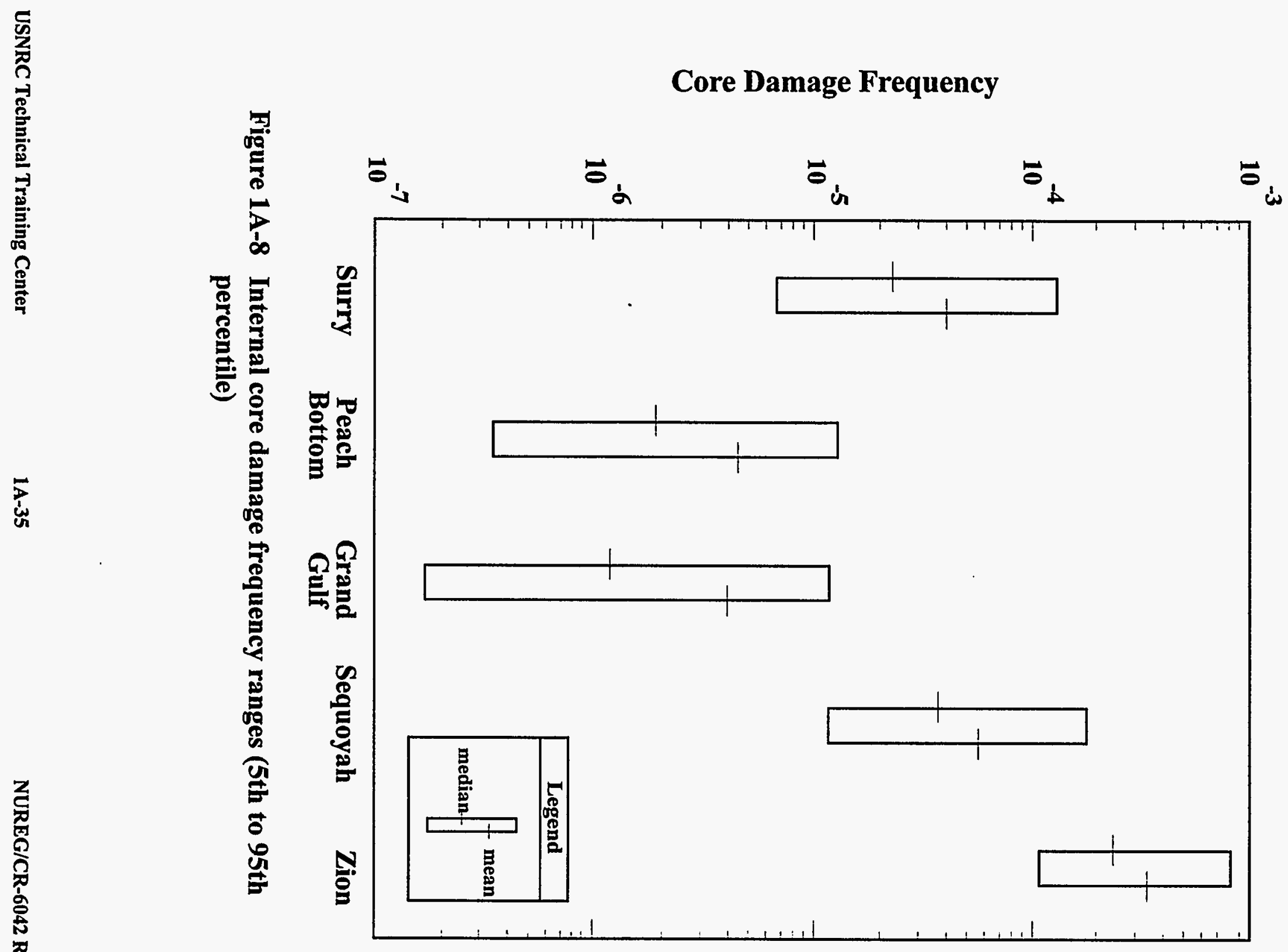




\section{References for Appendix 1 A}

1. U. S. Nuclear Regulatory Commission, "PRA Course," NUREG/CR-4350, SAND 85-1495, Volumes 1 through 7, August 1985.

2. U. S. Nuclear Regulatory Commission, "Severe Accident Risks: An Assessment for Five U.S. Nuclear Power Plants," NUREG-1150, December 1990.

3. U. S. Nuclear Regulatory Commission, NUREG 75/014, October 1975.

4. D. M. Ericson, Jr., et al., "Analysis of Core Damage Frequency: Internal Events Methodology," U. S. Nuclear Regulatory Commission, NUREG/CR-4550, Vol. 1, Rev. 1, January 1990.

5. G. E. Cummings, "Summary Report on the Seismic Safety Margins Research Program," Lawrence Livermore National Laboratories, NUREG/CR4431, UCID-20549, January 1986.

6. Seismicity Owners Group and Electric Power Research Institute, "Seismic Hazard Methodology for the Central and Eastern United States," EPRI NP-4726, July 1986.

7. J. M. Lanore, et al., "A Probabilistic Safety Assessment of the Standard French 900 MWe Pressurized Water Reactor," CEA/IPSN- France, EPS 900, April 1990.

8. D. W. Whitehead, "BWR Low Power and Shutdown Accident Sequence Frequencies Project, Phase 2-Detailed
Analysis of Pos 5," U. S. Nuclear Regulatory Commission, August 31, 1992.

9. D. W. Whitehead, et al., "Evaluation of Potential Severe Accidents During Low Power and Shutdown Operations at Grand Gulf Unit 1: Analysis of Core Damage Frequency From Internal Events for Plant Operational State 5 During a Refueling Outage," U. S. Nuclear Regulatory Commission, NUREG/CR-6143, 1994.

10. U. S. Code of Federal Regulations, Title 10, Part 73, January 1, 1991.

11. U. S. Code of Federal Regulations, Title 10, Part 50, Appendix A, January $1,1991$.

12. Pickard, et al., "Procedures for Treating Common Cause Failures in Safety and Reliability Studies," U. S. Nuclear Regulatory Commission, NUREG/CR4780, EPRI NP-5613, Vol 1., January 1988.

13. U. S. Code of Federal Regulations, Title 10, Part 50, Appendix R, January $1,1991$.

14. U. S. Code of Federal Regulations, Title 10, Part 50.72, January 1, 1991.

15. J. W. Minarick, et al., "Precursors to Potential Severe Core Damage Accidents," Nuclear Regulatory Commission, NUREG/CR-4674, August 1991. 


\subsection{Severe Accident Perspectives}

\subsubsection{Introduction}

The basic safety philosophy followed by both industry and the NRC in promoting the safety of nuclear power plants is defense in depth. As originally conceived (see Section 1.1.5) defense in depth referred primarily to design and siting considerations included to prevent accidents, contain radionuclides should an accident occur, and keep the public away from any radionuclides that might be released anyway. The Browns Ferry fire demonstrated that accidents beyond those specifically addressed during design could occur and be very serious. The Reactor Safety Study indicated that such accidents dominate the risk posed by commercial nuclear power plants. Nevertheless, only after the TMI- 2 accident occurred in 1979 was there significant regulatory interest in so-called beyonddesign-basis accidents.

Events at TMI-2 and Chernobyl forever altered the preexisting mindset that, because plants are designed to be safe, severe accidents are not credible. This chapter discusses the TMI-2 and Chernobyl accidents and their impact commercial reactor regulation. The evolving development and use of information regarding the risks associated with severe accidents is emphasized.

Before proceeding, it is reasonable to ask "Why not design against all possible accidents?" In part, the answer to this question is the basis for defense in depth, namely, the recognition that human beings cannot think of everything. As indicated in the introduction to Chapter 1 ,

one must continually question whether the safeguards already in place are sufficient to prevent major accidents.

Hence, the regulatory approach taken by the NRC continues to evolve to reflect experience with operating plants and other developments that have safety implications.

In addition, however, there is usually a prohibitive cost associated with designing for the exceedingly unlikely (e.g., large meteor impact); and such expenditures may provide at best minimal improvements to plant safety or, in fact, make matters worse by grossly complicating the design. In fact, experience demonstrates that significant safety improvements can often be achieved with relatively simple, inexpensive changes to existing plants. On the other hand, advanced plants are being designed, utilizing the lessons learned from decades of reactor experience, both to prevent and to tolerate a wider spectrum of potential accidents than existing plants.

\subsubsection{Learning Objectives for Module 2}

At the end of this module, the student should be able to:

1. List at least three important contributors to the accident at TMI-2.

2. Describe the changes that occurred after the TMI-2 accident in:
a. the NRC
b. the nuclear industry
c. nuclear power plants
d. operator training
e. emergency response
f. severe accident research.

3. Identify two features of U.S. plants not present at Chernobyl. 
4. Discuss perspectives provided by individual plant examinations and NUREG-1150 with respect to:

a. PWR versus BWR core damage frequencies

b. magnitude of uncertainties in the core damage frequencies

c. relative importance of station blackout, ATWS, external events, and LOCAs at BWRs and PWRs d. magnitude of risks compared to NRC safety goals and other risks.

5. Give three examples of risk-influenced regulations and regulatory guidelines since the TMI- 2 accident.

6. Explain the basis for and key elements of NRC's policies and practices with respect to severe accidents and safety goals. 


\subsection{The TMI-2 Accident}

\subsubsection{Introduction}

The Three Mile Island (TMI) Nuclear Station is operated by the Metropolitan Edison Company, a member of the General Public Utilities Corporation. TMI is located near Middletown, Pennsylvania, about 10 miles southeast of Harrisburg, the state capitol. At the time of the accident, the station had two Babcock \& Wilcox PWRs, Unit 1 rated at $792 \mathrm{MWe}$ and Unit 2 rated at $880 \mathrm{MWe}$. Figure 2.1-1 depicts the nuclear steam supply system including the reactor vessel, two once-through steam generators, four reactor coolant pumps (two per loop), and the pressurizer. The hot-leg piping carries heated coolant from the reactor outlet nozzles to an inlet at the top of each steam generator. Two cold-leg pipes carry reactor coolant from the bottom head of each steam generator to the respective reactor coolant pumps and back to the vessel through inlet nozzles. Other features shown on Figure 2.1-1 include the core flood tank, the reactor coolant drain tank, and the reactor building sump. The entire nuclear steam supply system depicted in Figure 2.1-1 is in a cylindrical steel-lined concrete containment called the reactor building.

The following description of the sequence of events that occurred during the TMI-2 accident is condensed from several sources. ${ }^{1,2,3,4,5,6}$ In particular, the NRC investigation produced a scenario that runs over 100 pages.'

\subsubsection{Pre-existing Problems}

The TMI-2 reactor, the $880 \mathrm{MWe}$ unit, was operating at $97 \%$ of rated power before the accident. Figure 2.1-2 is a simplified drawing that depicts the pre-accident conditions in the reactor coolant system. Figure 2.1-2 indicates a reactor coolant system pressure of $2150 \mathrm{psig}$ $(14.8 \mathrm{MPa})$, flow of subcooled water through both reactor coolant loops, a steam bubble in the pressurizer, and boiling of secondary water in both steam generators. Similar drawings are used to indicate conditions in the reactor coolant system as the accident progresses.

Before the accident began, there had been a persistent leak of reactor coolant from the pressurizer to the reactor coolant drain tank. The leak was known by the operators to be through either the electromagnetic PilotOperated Relief Valve (PORV) or one or both of the pressurizer safety valves. The safety valves and PORV are provided, as their names imply, to relieve abnormally high reactor coolant pressures. The safety valves open automatically on high pressure to prevent rupture of the reactor coolant system. The PORV opens automatically at a lower pressure to prevent inadvertent and unnecessary opening of the safety valves. In spite of the leak, the pressurizer water level and the reactor coolant pressure were being held at normal levels by the operators. Consequently, they were not particularly upset by the leak. (The NRC later concluded that this pre-existing leak exceeded technical specification limits.) The leak played a role in subsequent events in at least one respect. It created high temperature indications in the downstream piping, and these pre-existing indications later disguised a more serious loss of coolant.

Figure 2.1-3 shows the condensate and feedwater system. Steam from the steam generators passes through the turbine and condenses in the condenser. Water from the condenser hotwell is pumped first by the condensate pumps through the condensate polishers, then by the condensate booster pumps through the low pressure feedwater heaters, and finally by the feedwater pumps through the high pressure feedwater heaters to the steam generators. The condensate polishers use ion-exchange resins to purify the feedwater. For roughly 11 hours prior to the accident, shift foremen and 
auxiliary operators had been attempting to transfer spent resins from the condensate polishers to a resin regeneration tank. Under normal circumstances, compressed air is used to "fluff" spent resins, which are then transferred in demineralized water through a transfer line between the tanks. But a resin block developed in the transfer line driving water back through the isolation valve between the demineralizer and the condensate pumps. As a result, water entered an instrument air line through a check valve that had frozen open. This apparently caused the polisher inlet and/or outlet isolation valves to drift toward the closed position. The accident began when all the isolation valves on the condensate polishers closed. This in turn caused one of the two operating condensate pumps and both of the condensate booster pumps to trip initiating the TMI-2 accident at 4:00:36 a.m. on Wednesday, March 28, 1979.

\subsubsection{Loss of Feedwater}

A fairly detailed chronology of the TMI-2 accident is provided in Table 2.1-1. The reader may find it useful to refer to this chronology and the associated Figures frequently. For the most part, times in the following discussion are measure in hours (h), minutes ( $\mathrm{min}$ ), and seconds (s) from turbine trip, which occurred $1 \mathrm{~s}$ after the condensate pump trip. Where clock times are specified, they are denoted with an a.m. or p.m. suffix, as in 4:00:36 a.m.

Within the first second of the accident, condensate pump 1A, the two condensate booster pumps, the two feedwater pumps, and the turbine tripped. The resulting loss of main feedwater to the steam generators drastically reduced the rate of heat removal from the reactor coolant system. During the initial seconds following the loss of main feedwater, the reactor continued to operate, and the reactor coolant began to heat up and expand. This caused the rapid initial increase in reactor coolant pressure and pressurizer level shown in Figure 2.1-4. About $3 \mathrm{~s}$ after turbine trip, the reactor coolant pressure exceeded the PORV setpoint of $2255 \mathrm{psig}(15.55 \mathrm{MPa})$, causing the PORV to open. The reactor coolant pressure continued to rise until, at about $8 \mathrm{~s}$, the reactor automatically scrammed on high reactor coolant pressure. As a result of the reactor trip, the volume of the liquid reactor coolant began to contract, and the reactor coolant pressure began to fall as indicated in Figure 2.1-4.

\subsubsection{Loss of Coolant, Core Cooled (13 s to $101 \mathrm{~min}$ )}

\subsubsection{PORV Sticks Open}

The opening of the PORV and the reactor trip functioned as designed to prevent overpressure in the reactor coolant system. However, trouble developed at $13 \mathrm{~s}$ when the reactor coolant pressure dropped below the 2205 psig (15.21 MPa) setpoint for PORV closure. A mechanical failure caused the PORV to stick open. Because the PORV remained open, steam continued to flow, undetected, through the stuck-open PORV, and reactor coolant pressure continued to fall rapidly as indicated in Figure 2.1-4. A loss-of-coolant accident (LOCA) had been initiated. It went undetected because control room personnel did not realize that the PORV was stuck open. A control board indicating light signaled that the PORV was closed. In fact, this merely indicated that the actuating solenoid was de-energized. No direct reading of actual valve position was available.

Had they recognized the PORV was open, the operators could have closed a block valve manually, thereby mitigating the effect of the stuck-open relief valve and totally preventing subsequent damage to the reactor core. Should the operators have known enough to close the 
block valve in spite of the erroneous indicating light? Certainly a rapid drop in reactor coolant pressure as depicted in Figure 2.1-4 is not a normal response to a loss of feedwater. The operators virtually ignored this symptom, and (as discussed later) focused instead on the pressurizer level behavior depicted in Figure 2.1-4.

Another way of determining the position of the PORV is by reading the temperature in the pipes leading from this valve to the reactor coolant drain tank. An abnormally high temperature indicates the presence of escaping reactor coolant. In fact, such readings were made and high temperatures were noted, but they were thought to be caused by the same valve leakage that the operators were aware of before the accident.

The open PORV could also have been inferred from the reactor coolant drain tank pressure. This pressure began increasing when the PORV first opened $3 \mathrm{~s}$ after turbine trip. At about $3 \mathrm{~min} 12 \mathrm{~s}$, the relief valve on the reactor coolant drain began opening intermittently. At $14 \mathrm{~min} 48 \mathrm{~s}$, the tank's rupture disk blew, as designed, at $192 \mathrm{psig}$. The pressure in the tank then dropped rapidly. Had an operator observed the drain tank pressure meter before the rupture disk blew, the fact that the PORV was open could have been diagnosed. However, the meter was on a panel behind the roughly 7$\mathrm{ft}$-high reactor console on which all critical instruments were placed. The plant's data acquisition computer did contain a time history of the tank pressure. However, data printout lagged significantly during the intense activity associated with the accident.

Clearly, there were reasons for the operators in these early minutes of the accident to have missed the fact that leakage was continuing through the PORV. But there were to be persistent signs of a serious loss of coolant that would be ignored. In short, the operators at Three Mile Island didn't realize they had a loss of coolant through the relief valve until 139 min. By then matters had passed the point of no return.

\subsubsection{Loss of Auxiliary Feedwater}

The auxiliary feedwater system is designed to compensate for a loss of main feedwater and prevent the steam generators from going dry. The three auxiliary feedwater pumps (two electric-driven and one steam-driven) started automatically within $1 \mathrm{~s}$ of the trip of the main feedwater pumps. The automatic auxiliary feedwater isolation valves also opened, as designed, after two conditions had been met: (a) the auxiliary feedwater pumps were delivering their normal discharge pressure (at least 875 psig); and (b) the water level in the steam generators was 30 inches or less. Condition (a) was satisfied $14 \mathrm{~s}$ after turbine trip. Condition (b) was satisfied at about $30 \mathrm{~s}$.

There are also block valves in the auxiliary feedwater lines to the steam generators. These block valves are required to be open while the plant is operating. Records indicated that the valves had been reopened following maintenance completed 2 days earlier; however, they were not open at the time of the accident. It took the operators $8 \mathrm{~min}$ to discover the valves were closed, in part, because tags on the control room panel inadvertently covered the valve position indicator lights. As a result, there was no flow of auxiliary feedwater from the condensate storage tank to the steam generators until an operator opened the block valves at $8 \mathrm{~min} 18 \mathrm{~s}$.

Babcock \& Wilcox claimed that, had there been auxiliary feedwater, the temperature of the reactor coolant might have remained relatively stable until the problem of the condensate pumps was corrected and normal feedwater was reinstated. This view has been contested not only by the NRC but also by the utility- 
sponsored Nuclear Safety Analysis Center, an investigative arm of the Electric Power Research Institute. Their investigations indicate that, except for adding another dimension to the areas of concern within the main control room, the early unavailability of auxiliary feedwater did not significantly affect the progression of the accident, which was dominated by the uncompensated loss of reactor coolant.

\subsubsection{Throttling of High Pressure Injection}

In a normal loss of feedwater scenario, without the stuck open PORV, the reactor coolant continues to contract after reactor trip. Letdown flow is reduced or stopped, and makeup flow is increased to maintain the normal water level in the pressurizer. With this in mind, at $41 \mathrm{~s}$, an operator manually started a second makeup pump (1B) to reverse the downward trend in the pressurizer level shown in Figure 2.1-4.

At about $1 \mathrm{~min}$, the water level in the pressurizer indeed began to increase. But this was not solely due to increased makeup flow. With the stuck-open PORV, the reactor coolant pressure continued to decrease and the NRC contends that as early as $1 \mathrm{~min}$ and continuing thereafter the reactor coolant experienced either a general expansion, as might occur with distributed voids, or the formation of one or more discrete steam vapor voids. As reactor coolant circulating through the core became saturated, it expanded and its pressure increased. The force exerted by this expanding reactor coolant through the pressurizer surge line caused the water level in the pressurizer to increase.

The pressurizer heaters, which would normally be used to keep the coolant in the RV subcooled, had tripped. Even if they had been operational, their energy addition capacity was far exceeded by the rate of energy loss out the stuck open PORV.

About $2 \mathrm{~min}$ after turbine trip, the reactor coolant pressure dropped below 1600 psig as a result of the stuck-open PORV. At this pressure the emergency core cooling system was automatically actuated. Makeup pump 1C started and makeup pump $1 \mathrm{~B}$ tripped leaving pumps $1 \mathrm{~A}$ and $1 \mathrm{C}$ running as high-pressure injection pumps. The makeup valves opened to admit the full, $1000 \mathrm{gpm}$, output of the pumps into the reactor coolant system. The pressurizer water level was increasing rapidly as shown in Figure 2.14. In part this was due to high pressure injection (HPI), but expansion due to vapor formation in the reactor coolant was also contributing to the pressurizer level increase.

The operators had been trained to avoid filling the pressurizer and causing the primary system to go "water solid." With the primary system full of liquid a very small temperature increase could cause the pressure to rise to the point where the safety valves would open. It is not unusual for safety valves to leak after they lift, thereby necessitating costly repairs. Procedures for a turbine trip, which the operators were attempting to follow, require the operators to switch to manual control and reduce makeup flow as soon as the pressurizer regains normal level.

At $3 \mathrm{~min} 13 \mathrm{~s}$, after verifying that all of the emergency core cooling systems had started normally, the operators bypassed the high pressure injection system. Bypassing the system did not shut it down but merely permitted the operators to control high pressure injection flow manually. At 4 min 38 $\mathrm{s}$, to avoid overfilling the pressurizer, the operators shut off makeup pump 1C, severely throttled HPI flow from makeup pump 1A, and initiated letdown flow in excess of $160 \mathrm{gpm}$. After a brief pause, the pressurizer level continued to increase due to thermal expansion 
of the reactor coolant. The coolant supplied by HPI was less than the amount being lost through the PORV. The stage was set for a severe accident unless the loss of coolant was diagnosed and corrected.

Figure 2.1-5 depicts the reactor coolant system condition at $8 \mathrm{~min}$. Reactor coolant pressure had decreased to $1500 \mathrm{psig}$. Saturated reactor coolant was being pumped through both loops by all four reactor coolant pumps. The pressurizer was full, and the steam generators were dry.

\subsubsection{Release Pathways}

Because of the discharge of reactor coolant through the open PORV, the pressure in the reactor coolant drain tank increased rapidly. While the tank was being pressurized, some reactor coolant was forced through the vent line into the vent gas header. This damaged portions of the vent gas system creating paths by which radioactive gases would eventually leak to the auxiliary and fuel handling buildings.

The reactor coolant drain tank relief valve began opening intermittently at $3 \mathrm{~min} 12 \mathrm{~s}$. Reactor coolant then began accumulating in the reactor building sumps. At $7 \mathrm{~min} 29 \mathrm{~s}$, a reactor building sump pump started automatically. A second reactor building sump pump came on at $10 \mathrm{~min} 19 \mathrm{~s}$. The sump pumps' discharge was aligned to the auxiliary building sump tank, which had a blown rupture disk. Water, therefore, spilled onto the auxiliary building floor.

The two reactor building sump pumps were turned off at about $38 \mathrm{~min}$ when an auxiliary operator noticed that they were on and that the reactor building sump level was at its high limit (6 feet). Approximately 8,260 gallons of water were pumped from the reactor building sump to the auxiliary building before the sump pumps were turned off.

Reactor building (containment) isolation would have prevented the transfer of water from the reactor building sump to the auxiliary building. However, the rate of coolant loss associated with the stuck open PORV was not sufficient to cause the 4 psig reactor building pressure required for automatic isolation. When the reactor coolant drain tank rupture disk blew at $14 \min 48 \mathrm{~s}$, there was a 1 psig pressure spike in the reactor building, but the 4 psig set point for reactor building (containment) isolation was not approached until about $60 \mathrm{~min}(1 \mathrm{~h})$.

The pathway for releases from the auxiliary building is depicted in Figure 2.1-6. The water initially pumped to the auxiliary building by the reactor building sump pumps contained low radionuclide concentrations characteristic of reactor coolant during normal operation. As the accident progressed, however, fission products escaped from a damaged core, and some were entrained in letdown flow to the makeup tank. The letdown line was, in fact, the major path for transporting radionuclides from the reactor building. There was some liquid leakage from the makeup and purification system to the auxiliary building floor. But the main pathway for radionuclide releases occurred during venting of the makeup tank to the damaged vent header. This venting began over $24 \mathrm{~h}$ after accident initiation, and resulted in the leakage of volatile radionuclides to the auxiliary and fuel handling buildings. Gases from these buildings are picked up by the ventilation system, passed through filters, and discharged through the stack. The filters remove chemically active species like iodine, but have no effect on inert noble gases. 


\subsubsection{Auxiliary Feedwater Restored}

As discussed earlier, about $30 \mathrm{~s}$ after turbine trip, the conditions required for admission of auxiliary feedwater to the steam generators had been met. But, because the auxiliary feedwater block valves were closed, no water flowed to the steam generators. It appeared to the operators that the automatic valves were opening at an unusually slow rate, causing a delay in feeding the steam generators.

About $8 \mathrm{~min}$ after turbine trip, an operator noticed steam generator level at 10 inches on the startup range. This indicated the steam generators were dry. The fact that the auxiliary feedwater block valves were shut was diagnosed, and these valves were opened resulting in dry steam generators being fed with relatively cool water. Auxiliary feedwater sprayed directly onto the hot tubes evaporated immediately. This caused a rapid increase in steam pressure, which had previously dropped when the steam generators boiled dry. This positive indication of feed flow to generators was confirmed by a decrease in the auxiliary feedwater pump discharge pressure and by hammering and crackling of the vibration and loose-parts monitor speaker, set up to listen to the steam generator. Hot- and cold-leg temperatures dropped as did the reactor coolant pressure. Although evaporation of auxiliary feedwater increased the steam pressure, no water collected in the bottom until the tubes cooled down. There was about a 14 min lag in recovery of steam generator level.

\subsubsection{Undiagnosed LOCA Continues}

At the beginning of the accident, the computer alarm printout was synchronized with real time. The alarm printer could only type one line every $4 \mathrm{~s}$, however, and during the accident, several alarms per second were occurring. Within a few minutes, the alarms being printed were for events that had occurred several minutes earlier.

At about 15 min, reactor coolant pump alarms started going off. This indicated insufficient pressure at the pump inlets. There was also a continual slow reduction in reactor coolant pump flow, and low flow alarms sounded at various times.

Pressure at the reactor coolant pump inlets is required to be significantly above the saturation pressure. This requirement is called the net positive suction head (NPSH) requirement. If this NPSH requirement is not met, the formation of vapor bubbles on the suction side causes pump cavitation. Associated vibration could damage the pump seals or even the attached piping.

Operators ignored the NPSH requirement and let the reactor coolant pumps continue to operate. As long as the reactor coolant pumps provided forced circulation, even of froth, the core was cooled.

At $\sim 20 \mathrm{~min}$, the steam bubbles in the reactor coolant caused the out-of-core source-range neutron detector to read higher than expected. Normally, water in the downcomer annulus, outside the core but inside the reactor vessel, shields these detectors. But, because the water was now frothy, it was not shielding the detectors as well as usual. Not realizing that the apparent increase in neutrons reaching the detectors was caused by steam bubbles in the reactor coolant, the operators feared the possibility of a reactor restart. Although it is now known that their fears were unfounded, at the time they were one more source of distraction.

About $25 \mathrm{~min}$ after turbine trip, the operators received a computer printout that indicated the PORV outlet temperature was high, $285^{\circ} \mathrm{F}$. This indication of an open PORV, however, was not 
interpreted as such by the operators. When the PORV opened in the initial transient, the PORV outlet temperature would have increased even if the PORV had closed as designed. The operators supposed that the abnormally slow cooling of the outlet pipe was caused by the pre-existing PORV or safety valve leak. Evidence of the open PORV now included: (a) the low reactor coolant pressure; (b) the rapid rise in reactor coolant drain tank pressure and temperature; (c) the fact that the rupture disk had blown; (d) the rise in reactor building sump level (with operation of the sump pumps); and (e) the continuing high PORV outlet temperature. Nevertheless, the ongoing LOCA was not diagnosed.

The reactor coolant voids and the low reactor coolant pump flows decreased the efficiency of primary to secondary heat transfer in the steam generators. The rate of boiling on the secondary side was low, and operators found it difficult to keep the secondary water level from creeping up. One auxiliary feedwater pump was shut off at $36 \mathrm{~min}$.

As control room personnel struggled to understand what was happening in the plant, hundreds of alarms went off, signaling such things as unusual conditions in the reactor coolant drain tank, high temperature and pressure in the reactor building, and low reactor coolant pressure. Conditions were beyond those that control room personnel had experienced in their training or in their operation of the plant. The symptoms described in the emergency procedures did not fit the situation and proved to be of little help. The operators were well aware that something was wrong, and, about one hour after turbine trip, they called the on-call operating engineer to the site.

The condition in the reactor coolant system at $60 \mathrm{~min}(1 \mathrm{~h})$ is depicted in Figure 2.1-7. The PORV was still open, and the reactor coolant pressure had decreased to 1050 psig. Unknown to the operators, the reactor coolant was a saturated liquid-steam mixture. A large steam bubble had probably formed in the upper reactor vessel head. Pressurizer level was high and was only barely being held down. The reactor coolant pumps were operating but with decreasing flow and increasing vibration. Heat removal via the steam generators was ineffective. To add to the confusion, the condenser was no longer available, the alarm computer lagged so badly that it was virtually useless, radiation alarms were beginning to come on, and the reactor building pressure and temperature were gradually increasing.

\subsubsection{Loop B Pumps Turned Off}

At $\sim 74 \mathrm{~min}$, the operators shut down reactor coolant pump 1B. A few seconds later reactor coolant pump 2B was shut down. (Pressurizer spray comes from the A loop.) The action to shut down the loop B reactor coolant pumps was taken because reactor coolant pump performance was seriously impaired as indicated by high vibration, low flow ( $60 \%$ of normal), low amperage, and inability to meet NPSH requirements.

Shutting down the two B loop reactor coolant pumps reduced the flow of coolant through the reactor core. There was still enough mass flow in the steam-water mixture being pumped by the two loop A pumps to keep the core from overheating. The open PORV was, however, still reducing the reactor coolant inventory and pressure. The remaining liquid reactor coolant continued to vaporize, and, although this vaporization removed core decay heat, it further impeded forced circulation via the loop-A reactor coolant pumps.

A sample of reactor coolant analyzed a few minutes after the loop-B pumps were shut off indicated a low boron concentration. This finding, coupled with apparently increasing 
neutron levels, increased the operators' fears of a reactor restart. As explained earlier, the source range neutron detector count rate was increasing because steam bubbles in the downcomer allowed more neutrons to reach the detector. There was no actual danger of recriticality. It is now believed the sample was diluted by condensed steam, causing the indication of low boron concentration.

At $80 \mathrm{~min}$, an operator had the computer print out the PORV $\left(283^{\circ} \mathrm{F}\right)$ and pressurizer safety valve $\left(211^{\circ} \mathrm{F}\right.$ and $\left.219^{\circ} \mathrm{F}\right)$ outlet temperatures. Because there had been essentially no change in these temperatures, the operators should have realized that the PORV had not closed. At about the same time, the letdown line radiation monitor indicated a sevenfold increase. The letdown line radiation monitor was notoriously sensitive, but the implications of the reading were not understood by the operators.

At $87 \mathrm{~min}$ ( $1 \mathrm{~h} 27 \mathrm{~min}$ ), steam generator B was isolated. Operators observed increases in reactor building pressure and noted that the secondary pressure in steam generator B was 300 psi lower than in generator A. They believed that secondary steam was leaking from generator $\mathrm{B}$ into the reactor building. In hindsight, the lower pressure in generator $B$ was caused by reduced heat transfer in loop $B$ after reactor coolant pumps $1 \mathrm{~B}$ and $2 \mathrm{~B}$ were shut off.

Figure 2.1-8 depicts the condition in the reactor coolant system at $90 \mathrm{~min}(1 \mathrm{~h} 30 \mathrm{~min})$. The reactor coolant pressure was 1050 psig. The pressurizer was nearly full. The loop-B reactor coolant pumps were off, the $B$ steam generator was isolated, and the steam and liquid phases had separated in loop B. The reactor coolant pumps in loop A were still on, circulating the steam-water mixture through steam generator $\mathrm{A}$.

\subsubsection{Initial Core Damage (101 min to $174 \mathrm{~min}$ )}

\subsubsection{Loop A Pumps Off, Core Uncovered}

Approximately 5 to $10 \mathrm{~min}$ after the loop-B reactor coolant pumps were shut off, the looseparts monitor again indicated increasing pump vibration. In fact, standing in the control room, the operators said they could feel the vibrations. The operators also reported flow instability, as the loop A flow continued to decrease. At $\sim 101 \mathrm{~min}(1 \mathrm{hr} 40 \mathrm{~min} 40 \mathrm{~s}$ ), the loop-A reactor coolant pumps were turned off. This action sealed the fate of TMI-2.

The operators asserted during interviews that they were concerned about a inducing a LOCA by a reactor coolant pump seal failure, and decided to go on natural circulation. To establish natural circulation would have required (among other things) subcooled reactor coolant. The operators assumed that, because the pressurizer level was high, the core must be covered. In actuality, natural circulation was precluded by the steam that had formed in the reactor coolant system. It was the higher pressure of steam bubbles formed in the reactor vessel that kept the water level high in the pressurizer. After shutting off the loop-A pumps, the operators did not see any indications that natural circulation had been established.

After shutdown of the last two reactor coolant pumps, vapor that had previously been mixed with liquid to form a frothy reactor coolant, separated and rose to the higher portions of the reactor vessel and the rest of the reactor coolant system. Water continued to escape from the stuck-open PORV and HPI flow remained throttled. By $103 \mathrm{~min}$ (1 h $42 \mathrm{~min} 30 \mathrm{~s}$ ), the separation of steam and liquid phases in the 
reactor vessel had again reduced the shielding of the source-range neutron detectors, which indicated increasing neutron levels. The operators increased high pressure injection flow to avert a restart by providing emergency boration. Reactor coolant pressure increased, and the neutron count rate dropped significantly.

For at least a few minutes after the loop-A reactor coolant pumps were shut off, it would have been possible to terminate the accident without extensive core damage. If full HPI flow had been initiated, the reactor coolant system could have been refilled. The block valve upstream of the PORV could have been shut to repressurize the system and collapse the vapor bubbles. These actions would have permitted sustained core cooling by forced (reactor coolant pump) or natural circulation, but the actions were not taken.

\subsubsection{Hydrogen from Zircaloy Oxidation}

Figure 2.1-9 depicts the situation at $120 \mathrm{~min}$ $(2 \mathrm{~h})$. The reactor coolant pressure was about 750 psig. The PORV was still open, HPI flow was still throttled, and all reactor coolant pumps were off. There was essentially no flow through the core, and the liquid and vapor in both loops had separated. With this separation, the hot-leg temperature became much higher than the cold-leg temperature. The actual loop A hot-leg temperature was $558^{\circ} \mathrm{F}$. In retrospect, this indicated the presence of superheated steam in the hot leg. For superheated steam to exist in the hot leg, a substantial portion of the upper part of the core must be uncovered.

It is now known that the water level in the core region continued to fall until the top two-thirds of the core uncovered and became very hot. Steam generated by the boiling of water covering the bottom portion of the core flowed upward and oxidized the hot Zircaloy fuel cladding releasing additional energy and large amounts of hydrogen.

As long as the upper part of the reactor coolant system contained only steam, the bubble could have been condensed (collapsed) by refilling (with full HPI) and repressurizing (by closing the PORV block valve) the system. However, with large amounts of noncondensible hydrogen in the system, the bubble could no longer be collapsed.

At about $120 \mathrm{~min}(2 \mathrm{~h})$, a conference phone call began between the control-room technical superintendent and (at their homes) the station superintendent, the vice president of generation, and the Babcock \& Wilcox site representative. The conference call lasted 38 $\mathrm{min}$. Conferees realized that something was abnormal since the reactor coolant pumps were off yet they were unable to get a steam bubble in the pressurizer. The blown-out rupture disk on the reactor coolant drain tank and the water on the reactor building floor did not seem surprising, since this had happened before. The condition of the block valve upstream of the PORV was questioned. It was reported to be shut, but it was not. The conferees decided to restart a reactor coolant pump, and all officials planned to report to the control room.

At $\sim 134 \mathrm{~min}(2 \mathrm{~h} 14 \mathrm{~min}$ ), the reactor building air sample particulate radiation monitor went off scale. This was the first of many radiation alarms that could definitely be attributed to gross fuel damage.

\subsubsection{PORV Block Valve Closed}

At $139 \mathrm{~min}$ ( $2 \mathrm{~h} 19 \mathrm{~min}$ ), a shift supervisor who had just come into the control room isolated the PORV by closing the upstream block valve. Apparently, he did this to see whether it would have an effect on the anomaly of high 
pressurizer level and low steam pressure. Noting that the downstream temperature for the PORV was $35^{\circ} \mathrm{F}$ higher than for the safety valves, it was recognized that a leak had been stopped. The operators also noted an immediate drop in reactor building temperature and pressure. With closure of the block valve, reactor coolant pressure began to increase from a low of 660 psig until it reached 1300 psig about 3 hours later.

Core degradation continued after the PORV block valve was closed because there was still no way to cool the uncovered portion of the core. Although steam generator A contained $50 \%$ cold water, there was no circulation of reactor coolant through the steam generators. In some ways the situation was worse than before the PORV was closed. As the reactor coolant pressure increased, it took less energy to evaporate each pound of residual water covering the bottom portion of the core.

\subsubsection{Initial Melting In Core Region}

Post-accident analyses of plant data and core debris indicate that by $140 \mathrm{~min}(2 \mathrm{~h} 20 \mathrm{~m})$ the core liquid level had dropped to about midcore. The upper regions of the core had heated sufficiently $\left(1500^{\circ} \mathrm{F}\right.$ to $\left.1700^{\circ} \mathrm{F}\right)$ to result in cladding failure and release of gaseous fission products.

At about $149 \mathrm{~min}$ ( $2 \mathrm{~h} 29 \mathrm{~min}$ ), the narrow range hot-leg temperature went offscale high $\left(620^{\circ} \mathrm{F}\right)$. The narrow range cold-leg temperature was already offscale low $\left(520^{\circ} \mathrm{F}\right)$. Wide range temperature measurements were still available, but the operators were in the habit of using the narrow range temperatures, which can be read more precisely. One meter, which indicates the average of the hot-leg and coldleg temperatures, read $570^{\circ} \mathrm{F}$ (the average of the constant readings of $620^{\circ} \mathrm{F}$ and $520^{\circ} \mathrm{F}$ ). This steady average temperature evidently convinced the operators that the situation was static.
Between 150 and $160 \mathrm{~min}$, temperatures got high enough to cause melting and downward relocation of some core materials, which refroze on colder surfaces to begin the formation of a crust that would subsequently act like a crucible holding molten material in the core region.

At $158 \mathrm{~min}(2 \mathrm{~h} 38 \mathrm{~min})$ a letdown cooler radiation monitor went offscale high, reflecting the severe core damage that was occurring.

During the period of core damage, there was virtually no information on conditions in the core. Incore thermocouples, which measure reactor coolant temperature at the exit from the core, could only show temperatures as high as $700^{\circ} \mathrm{F}$ due to limits imposed by the signal conditioning and data logging equipment, not by the thermocouples themselves.

Figure 2.1-10 shows the conditions in the reactor coolant system at $158 \mathrm{~min}$ ( $2 \mathrm{~h} 48 \mathrm{~min}$ ). The PORV block valve was shut, and the reactor coolant pressure had increased to $1200 \mathrm{psig}$. Upper portions of the reactor coolant system were filled with the steam-hydrogen mixture. The Zircaloy oxidation continued, and some melting and relocation of core materials was indicated.

\subsubsection{Quenching and Related Core Damage (174 min to $375 \mathrm{~min}$ )}

\subsubsection{Restart of Reactor Coolant Pump 2B}

At $174 \mathrm{~min}(2 \mathrm{~h} 54 \mathrm{~min})$ the operators restarted reactor coolant pump 2B. Flow was indicated for a few seconds and then dropped to zero. The pump was shut off 19 min later. The core was partially quenched as liquid remaining in the cold leg was pumped into the core. This probably caused some collapse of rubble in the core region. With the block valve closed, the steam generated during the partial quench 
caused the reactor coolant pressure to increase to 2200 psig.

At $176 \mathrm{~min}$ ( $2 \mathrm{~h} 56 \mathrm{~min}$ ), a technician reported that letdown sample lines had an extremely high radiation level $(600 \mathrm{R} / \mathrm{hr})$. A radiation level of $1 \mathrm{R} / \mathrm{hr}$ had previously ( $2 \mathrm{~h} 30 \mathrm{~min}$ ) been reported in the makeup tank area of the auxiliary building. The auxiliary building was evacuated, and a site emergency was declared. The conditions in the reactor coolant system $180 \mathrm{~min}(3 \mathrm{~h})$ into accident, are depicted in Figure 2.1-11. The reactor coolant pressure was at 2050 psig. Reactor coolant pump 2B was on, but no flow was indicated. The pressurizer level was offscale high. Most incore thermocouples were reading off scale. The actual hot-leg temperatures were nearly $800^{\circ} \mathrm{F}$. This indicates that at least the upper part of the core was dry. There were many high radiation alarms, indicating that extensive fuel damage had occurred. Fifty to sixty people were in the control room by this time, attempting to resolve the crisis.

\subsubsection{Core Region Reflooded}

At $192 \mathrm{~min}$ ( $3 \mathrm{~h} 12 \mathrm{~min}$ ) the PORV block valve was reopened in an attempt to control reactor coolant pressure. Opening the valve resulted in an increase in the valve outlet temperature, a limited pressure spike in the reactor coolant drain tank (rupture disk had previously burst at $\sim 15 \mathrm{~min}$ ), an increase in reactor building pressure, and a pathway by which hydrogen and radionuclides from the damaged core could reach the reactor building.

After the PORV block valve was opened, the reactor coolant pressure began dropping rapidly. In response, at $200 \mathrm{~min}(3 \mathrm{~h} 20 \mathrm{~min})$, engineered safeguards were manually initiated. Makeup pump 1C started and the makeup valves fully opened. Reactor coolant temperature dropped rapidly as cold water was injected into the reactor vessel. The out-of-core neutron levels dropped rapidly due to the rapid water level increase in the downcomer. The water added was sufficient to ensure that the core region was recovered.

The sudden injection of cold water onto the hot core materials caused additional releases of volatile radionuclides due to thermal shock. These radionuclides could then flow out letdown line to the auxiliary building or through the open PORV block valve into reactor building. The radiation level in the reactor building dome increased to $8 \mathrm{R} / \mathrm{hr}$. The vent stack alarm also went off at about this time. Many other radiation monitors registered alarms. The control building, except for the control room itself, was evacuated.

At $203 \mathrm{~min}(3 \mathrm{~h} 23 \mathrm{~min} 23 \mathrm{~s}$, 7:24 am), a general emergency was declared on the basis of the many radiation alarms, and the potential for offsite releases of radionuclides. The utility notified State and Federal officials when it declared the site and general emergencies.

At $\sim 209 \mathrm{~min}$ ( $3 \mathrm{~h} 29 \mathrm{~min}$ ) a borated water storage tank alarm was received. Water for high pressure injection is taken from the borated water storage tank. There were still 53 feet of water in this tank. Nevertheless, the fact that the level was falling caused concern that continued high pressure injection would exhaust the borated water storage tank inventory. Highly radioactive water from the reactor building sump would then have to be used for high pressure injection. The makeup pumps and associated pipes and valves in the auxiliary building would then have become contaminated with radionuclides. This could cause grave problems if repairs became necessary. There was, therefore, an inclination to use as little HPI flow as possible. Emergency safeguards were reset, and makeup pump $1 \mathrm{C}$ was stopped. At the same time, the PORV block valve was shut. Closing this valve, with makeup pump 1A still 
running, caused a rapid increase in pressurizer level.

The condition in the reactor coolant system at $210 \mathrm{~min}$ ( $3 \mathrm{~h} 30 \mathrm{~min}$ ) is depicted in Figure 2.112. The opening of the block valve for $17 \mathrm{~min}$ together with the operator-initiated increase in HPI flow had reduced the reactor coolant pressure to $1500 \mathrm{psig}$. The vessel had been refilled and the core recovered. Temperatures in the reactor coolant system were decreasing, but steam and hydrogen gas was trapped in the hot-legs, blocking circulation of water through the system. Most of the damage to the core had been done, and radiation levels in the plant were high.

\subsubsection{Pour of Molten Core Material}

At about $222 \mathrm{~min}$ ( 3 h $42 \mathrm{~min}$ ) the PORV block valve was reopened for the second time. It remained open until $315 \mathrm{~min}(5 \mathrm{~h} 15 \mathrm{~min})$.

At about $224 \mathrm{~min}$ ( $3 \mathrm{~h} 44 \mathrm{~min}$ ), it is now known that approximately 20 metric tonnes $\left(2 \times 10^{4} \mathrm{~kg}\right)$ of molten core material poured from the core region into the reactor vessel lower head. A rapid increase in reactor coolant pressure between 224 and 226 min indicates substantial quenching of relocated material by water in the lower head. The phenomena associated with the formation, holdup, and relocation of molten core materials is discussed in Chapter 3.

\subsubsection{HPI On, Off, Finally Sustained}

At $236 \mathrm{~min}$ ( 3 h $56 \mathrm{~min}$ ), engineered safety features actuated on high (4 psig) reactor building pressure. Makeup pump 1C started.

Both makeup pumps (1A and $1 \mathrm{C}$ ) tripped at $258 \mathrm{~min}$ (4 h $18 \mathrm{~min}$ ). Two unsuccessful attempts were made to restart pump 1A. The control switch was then put in the "pull-to-lock" position. This completely defeated automatic starts of the pump. The pressurizer indicated full, and the operators were concerned about full high pressure injection flow coming on with an apparently solid primary system. Actually, a very large part of the reactor coolant system was filled with steam and hydrogen gas, and the system was far from being water solid. This condition could have been recognized from the fact that the temperatures in the hot legs were consistent with superheated steam.

By $266 \mathrm{~min}$ ( 4 h $26 \mathrm{~min}$ ) high pressure injection was reestablished. From this time on, high pressure injection flow was continuously maintained at varying flow rates after having been shut off altogether for at least $5 \mathrm{~min}$.

Between $4 \mathrm{~h}$ and $4 \mathrm{~h} 30 \mathrm{~min}$, incore thermocouple temperature readings were taken off the computer. Many registered question marks. Shortly after, at the request of the station superintendent, an instrumentation control engineer had several foremen and instrument technicians go to a room below the control room and take readings with a millivoltmeter on the wires from the thermocouples. The first few readings ranged from about $200^{\circ} \mathrm{F}$ to $2300^{\circ} \mathrm{F}$. These were the only readings reported by the instrumentation control engineer to the station superintendent. Both later testified that they discounted or did not believe the accuracy of the high readings because they firmly believed the low readings to be inaccurate. In the meantime, the technicians read the rest of the thermocouples. Their readings, a number of which were above $2000^{\circ} \mathrm{F}$, were entered in a computer book, which was later placed on a control room console. The technicians subsequently left the area when nonessential personnel were evacuated.

Only a small amount of heat could be removed by the unisolated A steam generator because the upper part of the primary system was filled by a mixture of steam and hydrogen gas. The water level on the secondary side was rising because more auxiliary feedwater was coming than was 
leaving as steam. At $4 \mathrm{~h} 42 \mathrm{~min}$, auxiliary feedwater was shut off.

\subsubsection{Recovery Attempts (5 h 15 min to 1 month)}

For the rest of the day, control room personnel struggled to regain stability in the plant. The principal problem was to ensure a reliable flow of water through the core.

\subsubsection{Attempt to Collapse Vapor Bubble}

The operators first tried to repressurize in order to collapse what they believed to be saturated steam bubbles in the reactor coolant system and establish natural circulation.

At $5 \mathrm{~h} 15 \mathrm{~min}$, the PORV block valve was closed to initiate the repressurization. Two makeup pumps were running throughout the repressurization so that a feed and bleed situation existed. By $5 \mathrm{~h} 43 \mathrm{~min}$, the primary system was fully repressurized. The pressure was maintained between 2000 and 2200 psig by cycling the PORV block valve.

Figure 2.1-13 shows the reactor coolant system condition at $6 \mathrm{~h}$. Liquid was being released intermittently through the PORV block valve. Two makeup pumps (HPI pumps) were running, and core heat removal was by heatup of the injected water. Steam generator heat transfer was blocked by hydrogen.

In order to encourage natural circulation, operators raised the water level of steam generator $\mathrm{A}$ to $90 \%$, using the condensate pump for feed. It became clear that even with a full steam generator and high pressure, natural circulation was not being established.

At $6 \mathrm{~h} 10 \mathrm{~min}$, airborne radiation levels in the Unit 2 control room required evacuation of all but essential personnel. At $6 \mathrm{~h} 17 \mathrm{~min}$, Unit 2 personnel put on masks to protect them against possible airborne radionuclides. At $6 \mathrm{~h} 27 \mathrm{~min}$, nonessential personnel began moving to the Unit 1 control room. At $6 \mathrm{~h} 52 \mathrm{~min}$, people leaving the Unit 2 control room failed to close the door properly, possibly compromising the recirculation ventilation system.

By $7 \mathrm{~h}$, communications in the Unit 2 control room were hampered by respirators. Some personnel removed their respirators for short periods.

The operators were reluctant to start a reactor coolant pump for fear of vibration-induced seal failure LOCA. They recognized they had bubbles in both loops. They believed the reactor core was covered and considered the possibility of uncovering it as each option was reviewed. The concern that the PORV should remain closed was reevaluated leading to a decision to use the PORV block valve for pressure reductions.

\subsubsection{Attempt to Use Core Flood Tanks}

With the failure of repressurization to collapse the bubble, concern arose over whether the core was covered and how long the borated water storage tank inventory would last. These uncertainties led to the next strategy, which was to depressurize the primary system sufficiently to inject water from the core flood tanks. Nitrogen gas maintained the pressure on the water in the core flood tanks slightly above 600 psig. Utility personnel reasoned that lower pressure would activate the core flood tanks, which would dump more water onto the core, assuring that it would be covered. Actually, if the reactor coolant pressure drops only slightly below 600 psig (as happened at TMI-2) only a small amount of water is injected before the core flood tank pressure equilibrates with that in the primary system. An amount of water approaching the full volume of the tanks would only be injected into the 
reactor vessel if the reactor coolant pressure dropped far below 600 psig, as in a large break LOCA.

At 11:38 a.m. ( $7 \mathrm{~h} 38 \mathrm{~min}$ ), the PORV block valve was opened, allowing steam and gas once again to escape from the pressurizer. The reactor building pressure increased from $0.2 \mathrm{psig}$ to 2.5 psig during this reactor coolant system depressurization.

Figure 2.1-14 shows the condition in the reactor coolant system at $8 \mathrm{~h}$. The reactor coolant pressure had been reduced to about 1000 psig. During depressurization, hydrogen was released through the PORV into the reactor building.

At $8 \mathrm{~h} 41 \mathrm{~min}$, the reactor coolant pressure reached 600 psig, and the core flood check valves opened. Little water was injected from the core flood tanks into the reactor vessel. Some control room personnel interpreted this to mean the core was covered; others concluded that the core had never been uncovered. At $9 \mathrm{~h}$ 10 min, plant personnel closed the PORV block valve, halting the depressurization.

\subsubsection{Attempt to Use Decay Heat Removal, Hydrogen Burn}

Members of the emergency command team soon decided to depressurize again in the hope of reaching a low enough pressure to permit use of the decay heat removal system.

At 9 h $50 \mathrm{~min}$, operators again opened the PORV block valve. As the block valve was opened, there was an extremely sharp increase in reactor building pressure and temperature. As a result of the pressure spike, which is shown in Figure 2.1-15, the reactor building again isolated, engineered safeguards actuated, and the reactor building sprays came on. Figure 2.1-15 indicates a peak pressure of $28 \mathrm{psig}$, which is the setpoint for the actuation of reactor building sprays.

It is now known that the pressure spike occurred when hydrogen, which had been released while the PORV block valve was open, ignited and burned with oxygen in the reactor building atmosphere. Ignition apparently occurred simultaneously with the opening of the PORV block valve at $9 \mathrm{~h} 50 \mathrm{~min}$. The reactor building sprays quickly brought the pressure and temperatures down. Six minutes after actuation, the sprays were shut off from the control room because there appeared to be no need for them.

Initially, the spike was dismissed as some type of instrument malfunction. Shortly afterward, however, at least some supervisors concluded that for several independent instruments to have been affected in the same way, there must have been a pressure pulse. It was not until late Thursday night, however, that control room personnel became generally aware of the pressure spike's meaning. Its meaning became common knowledge among the management early Friday morning.

Figure 2.1-16 shows the condition in the reactor coolant system at $10 \mathrm{~h} 30 \mathrm{~min}$. Reactor coolant pressure had been reduced to about 400 psig, which was about the minimum achieved, and the pressurizer temperature had reached saturation. Liquid was maintained in the reactor coolant system during depressurization by continuous high pressure injection and some flow from the core flood tanks. The reactor coolant pressure never dropped below 320 psig or $250^{\circ} \mathrm{F}$, the pressure and temperature below which the decay heat removal system would have been allowed to operate. It is probably fortunate that the decay heat removal system could not be used. It was not designed to handle highly radioactive liquids, and failure of seals in the system could have resulted in 
leakage of such liquids directly to the auxiliary building.

At $11 \mathrm{~h} 8 \mathrm{~min}$ operators ended attempts to depressurize. Figure 2.1-17 shows the condition at $13 \mathrm{~h}$. The system pressure was about 600 psig. Very little decay heat was being removed except by makeup water and by occasional opening of the PORV block valve. Gradual heatup was causing the reactor temperature and pressure to rise. Pressure control was being attempted by adjusting makeup flow and cycling the PORV block valve. Steam generator B was isolated. Hydrogen in the upper portions of the system was preventing any significant heat removal by steam generator $\mathrm{A}$.

\subsubsection{Forced Circulation Established}

At 13 h $20 \mathrm{~min}$, utility executives offsite ordered the emergency command team to repressurize the system again. The objective was to collapse enough steam to permit the restart of a loop A reactor coolant pump. This would establish forced circulation through the core and heat removal by steaming in loop $\mathrm{A}$ steam generator.

Figure 2.1-18 depicts the status of the reactor coolant system at $15 \mathrm{~h}(7 \mathrm{pm})$. The reactor coolant was repressurized to 2300 psig. Reactor coolant pumps are off, although steam generator A was steaming to the condenser providing some heat removal. Steam generator $B$ was isolated. Natural circulation of reactor coolant through the steam generator was still blocked by the hydrogen gas at the top of the hot legs (the so-called candy canes).

There was some concern, as to whether a reactor coolant pump would operate under the conditions that existed. With voids in the reactor coolant, sustained running could damage the pump or blow out the seals. Therefore, the control room personnel decided to "bump" one of the pumps (run it for only a few seconds) and to observe current and flow while the pump was running.

The loss of two motor control centers (at the time of the hydrogen burn) meant that the AC oil lift pumps were out of service. It is not possible to start a reactor coolant pump unless the oil lift pump can be started. There is a standby DC oil lift pump, but it was necessary to send people to the auxiliary building to start it.

At $15 \mathrm{~h} 33 \mathrm{~min}$, operators started reactor coolant pump 1A by manually bypassing some of the inhibiting circuitry. The pump was run for $10 \mathrm{~s}$, with normal amperage and flow. Dramatic results were seen immediately. Reactor coolant pressure and temperature instantly dropped, but began to rise again as soon as the pump was stopped. Evidently, there was an immediate transfer of heat to the steam generator when the coolant circulated. There was also a rapid spike in the steam pressure and a drop in steam generator level.

At $15 \mathrm{~h} 50 \mathrm{~min}$, based on their earlier success, the operators managed to start a pump $1 \mathrm{~A}$ and keep it running. This forced water through the core region and steam generator A. By $16 \mathrm{~h}(8$ $\mathrm{pm}$ ) relatively stable conditions were achieved as depicted in Figure 2.1-19. Reactor coolant temperatures were at about $290^{\circ} \mathrm{F}$. Pressurizer level was still full-scale. Reactor coolant pressure was about 1300 psig. Steam generator B was isolated and at about $97 \%$ water level. Makeup was normal. The pressurizer temperature was about $150^{\circ} \mathrm{F}$, and operators were letting down in an attempt to remove the excess hydrogen.

\subsubsection{Collapsing the Bubble}

At $17 \mathrm{~h} 25 \mathrm{~min}(9: 25 \mathrm{pm})$, the utility believed pressure could soon be reduced to a level at which the decay heat removal system could be used. 
Apparently, no one at this time realized that a bubble still existed in the reactor coolant system. Starting the reactor coolant pumps swept the remaining gas in the upper part of the system around with the water as discrete bubbles. The gas bubbles would tend to collect in the most quiescent part of the system -the upper head of the reactor vessel.

It is now known that the gas was largely hydrogen. Hydrogen is slightly soluble in water, and its solubility is greater at high pressure. An attempt to depressurize the system would cause some of the dissolved hydrogen to effervesce out of the water. As the pressure dropped, the bubble would grow in size and interfere with circulation of the reactor coolant.

In addition to growing in size, the bubble and the dissolved gas made it impossible to depressurize the reactor coolant system completely. Ordinarily, reactor coolant pressure is controlled by the size of the steam bubble in the upper part of the pressurizer.
When this bubble contains only steam, spraying cold water into the top the pressurizer shrinks the bubble and reduces the pressure. When the bubble contains a gas like hydrogen, however, spraying does not reduce the size of the bubble as much, so there is less control over the pressure.

A related problem occurred in the letdown system. As explained, hydrogen gas comes out of solution when the pressure is reduced.The gas from the letdown water collected in the bleed tanks and makeup tank, increasing the pressure and making it necessary to vent the tanks often. The vented gas was not pure hydrogen; it contained small amounts of volatile radionuclides as well. There was limited space available for holding the gas released from the letdown flow. These two factors made the reduction of pressure an extremely slow process that took several days to accomplish.

Natural circulation in the reactor coolant system was finally established on April 27, almost a full month after the accident began. 


\section{Table 2.1-1 Chronology of Major TMI-2 Accident Events}

\footnotetext{
Elapsed

Time

Event or Condition

h:min:s

-0:00:01 Condensate pump 1A and condensate booster pumps trip.

0:00:00 Feedwater pumps trip, turbine trips.

0:00:03 PORV opens at 2255 psig.

0:00:08 Reactor trip (control rods dropped) at 2355 psig.

0:00:13 PORV failed to reclose at 2205 psig.

0:00:15 Indicated pressurizer level peaked at 256 inches and began a rapid decrease.

0:00:14 Auxiliary feedwater pumps achieved normal discharge pressure.

0:00:15 Steam generator levels indicate 74 inches (startup range).

0:00:30 PORV and pressurizer safety valve outlet temperatures alarmed high.

0:00:38 Steam generator A water level at 23.8 inches. Auxiliary feedwater valves open as level decreases below 30 inches and give dual indication on panel.

0:00:40 Steam generator B water level at 23.7 inches and decreasing.

0:00:41 Operator manually started one of the three makeup pumps (pump 1B).

0:00:54 Pressurizer level reached lowest level (158 inches) and started to rise.

20:01:00 NRC estimate of onset of steam void formation.

20:01:45 Steam generators $A$ and $B$ boiled dry.

0:02:01 High pressure injection initiated $(1000 \mathrm{gpm})$ when reactor coolant pressure fell below 1600 psig setpoint.

0:03:12 Reactor coolant drain tank relief valve began opening intermittently.

0:03:13 Operators bypassed the high pressure injection system.

0:03:28 Pressurizer high level alarm.

0:04:38 Operator throttled high pressure injection isolation valves and stopped makeup pump $1 \mathrm{C}$.

0:04:52 Second let-down cooler put in service to allow increased letdown.

0:05:00 Pressurizer level reached 377 inches and continued to rise.

0:05:15 An operator restarted condensate pump 1A.
} 


\title{
Table 2.1-1 Chronology of Major TMI-2 Accident Events (continued)
}

\author{
Elapsed \\ Time \\ Event or Condition \\ h:min:s
}

$>0: 05: 15$ Operators tried to restart condensate booster pump 2B but it tripped.

0:05:30 Saturated conditions indicated. Indicated reactor coolant temperature $\left(\mathrm{T}_{\mathrm{h}}=582^{\mathrm{oF}}\right)$ and pressure (1340 psig) reached saturation.

0:06:00 Pressurizer steam bubble lost.

0:07:29 Reactor building sump pump 2A started (140 gpm).

0:08:00 Figure 2.4-5. Expansion/Saturation Due to LOFW/LOCA.

0:08:18 Operator opened auxiliary feedwater block valves.

0:10:19 Second reactor building sump pump (2A) started.

0:10:48 High $(5.65 \mathrm{ft}$ ) reactor building sump level alarm. Sump soon overflowed $(6 \mathrm{ft})$.

0:11:43 Pressurizer level indication came back on scale and dropped rapidly ( 20 inches in $1 \mathrm{~min}$ ) as reactor coolant loop temperatures continued to decrease from the heat being removed by the steam generators.

0:14:48 Reactor coolant drain tank rupture disk blows.

$20: 14: 50$ Reactor coolant pump alarms sound.

0:18:00 Waste exhaust monitors showed a small increases in radioactive iodine. Reactor building exhaust showed a tenfold increase in reading of radioactive emissions.

0:22:00 Abnormal out-of-core source-range neutron flux behavior.

0:24:58 PORV outlet temperature was $285.4^{\circ} \mathrm{F}$. Safety valve outlet temperature was $270^{\circ} \mathrm{F}$.

0:28:00 Operators have been dispatched to the auxiliary building to confirm pressurizer level indication and/or determine source of water that has filled pressurizer.

$>0: 30: 00 \quad$ Emergency diesel generators shut off.

$\sim 0: 36: 00$ Auxiliary feedwater pump 2B turned off.

0:38:10 Reactor building sump pumps turned off.

$\sim 0: 40: 00$ Increasing count rate continued on the source range neutron detector. 


\section{Table 2.1-1 Chronology of Major TMI-2 Accident Events (continued)}

\section{Elapsed}

Time

h:min:s

$0: 46: 23$ Letdown cooler monitor count rate began increasing. It would increase by a factor of 10 within the next 40 minutes.

0:50:00 Operators called on-call operating engineer to the site.

1:00:00 Figure 2.1-7. Reactor Coolant Voids Increasing.

1:11:00 Operators initiate reactor building cooling.

1:13:40 Loop B reactor coolant pumps turned off. Loop A pumps kept on to retain pressurizer spray capability.

$>1: 14: 00$ Sample of reactor coolant indicates low boron concentration (700 ppm).

1:20:00 An operator had the computer print out the PORV $\left(283^{\circ} \mathrm{F}\right)$ and pressurizer safety valve $\left(211^{\circ} \mathrm{F}\right.$ and $\left.219^{\circ} \mathrm{F}\right)$ outlet temperatures.

1:27:00 Operators isolate steam generator B.

1:30:00 Figure 2.1-8. Loop-B Stagnates After Pumps Shut Off.

$\sim 1: 30: 00$ Reactor coolant sample indicated $400-500 \mathrm{ppm}$ boron and $4 \mu \mathrm{Ci} / \mathrm{ml}$.

1:40:40 Loop A reactor coolant pumps turned off.

1:42:30 Excore source-range detectors indicated increasing neutron flux levels. Emergency boration initiated.

1:51:00 Loop A and B hotleg $\left(T_{h}\right)$ temperatures were increasing (eventually went off-scale high $-620^{\circ} \mathrm{F}$ ). Cold leg temperatures were decreasing.

2:00:00 Figure 2.1-9. Further Voiding After Loop-A Pumps Shut Off.

2:00:00 Conference call.

2:14:23 Reactor building air sample particulate radiation monitor went off scale.

2:18:00 Fifteen to twenty people in control room at this time.

2:19:00 PORV block valve closed, loss of coolant halted.

2:20:00 Vessel water level had dropped to about midcore.

2:29:00 Hotleg temperature indications passed the high end of the instrument scale, $620^{\circ} \mathrm{F}$.

2:30:00 $1 \mathrm{R} / \mathrm{h}$ reported in makeup tank area of auxiliary building. 


\title{
Table 2.1-1 Chronology of Major TMI-2 Accident Events (continued)
}

\section{Elapsed}

Time

\author{
Event or Condition
}

h:min:s

2:38:23 Letdown cooler A radiation monitor went offscale high.

2:39:23 Two samples indicated the boron concentration in the reactor coolant was $400 \mathrm{ppm}$. Emergency boration was started to avoid a reactor restart.

2:47:00 Alarm typewriter indication showed self-powered neutron detectors responding to high temperature down to 4 foot level of the core. $90 \%$ of the core exit thermocouples $>700^{\circ} \mathrm{F}$.

2:48:00 Figure 2.1-10. Hydrogen Generation.

2:50:00 Start of melting, downward relocation, and crust formation.

2:54:00 Reactor coolant pump 2B was restarted and operated for $17 \mathrm{~min}$.

2:56:00 Site emergency declared.

2:57:00 Fifty to sixty people are in control room; attempting to resolve the crisis.

3:00:00 Figure 2.1-11. Effects of Loop-B Pump Restart.

3:12:00 PORV block valve opened to control reactor coolant pressure.

3:20:00 Engineered safeguards actuated, makeup pump 1C started, HPI flow increased.

3:21:00 Excore neutron instrumentation indicated a sharp decrease (reflood). Reactor building dome radiation monitor read $8 \mathrm{R} / \mathrm{h}$.

3:23:23 General emergency declared.

3:29:00 PORV block valve reclosed.

3:30:00 Figure 2.1-12 Vessel Refilled.

3:32:00 The makeup tank radiation level was at about $3 \mathrm{R} / \mathrm{h}$, and the auxiliary building basement was reported flooded with airborne radioactivity. Spent-fuel demineralizer monitor read $250-900 \mathrm{mr} / \mathrm{h}$. Source range monitor count rate shows increase by a factor of three.

3:37:00 Operators tripped makeup pump 1C.

3:42:00 PORV block valve again opened.

3:44:00 Molten pour. 


\section{Table 2.1-1 Chronology of Major TMI-2 Accident Events (continued)}

\footnotetext{
Elapsed

Time

Event or Condition

h:min:s

3:55:39 Reactor building automatically isolated on high ( $>4 \mathrm{psig})$ pressure. Makeup pump 1C started automatically.

$>4: 00: 00$ Over the next 90 minutes, core exit thermocouple readings were manually obtained ranging from 217 to $2580^{\circ} \mathrm{F}$.

4:18:00 Makeup pumps $1 \mathrm{~A}$ and $1 \mathrm{C}$ tripped.

Operator attempted to restart pump $1 \mathrm{~A}$.

Switch was then placed in "Pull to Lock."

4:20:00 Reactor building dome radiation monitor records $600 \mathrm{R} / \mathrm{h}$.

4:22:00 Makeup pump 1B was started.

4:26:00 Sustained high pressure injection after this time.

$\sim 4: 30: 00$ Condensate system completely shut down. Problems with the condensate system were continuing. The condenser had been steadily losing vacuum. It was necessary to maintain steam to the main turbine seals in order to operate the condenser at a vacuum. When main steam is not available, seal steam is provided by the oil-fired auxiliary boiler. The auxiliary boiler broke down, so that seal steam could not be maintained. It was, therefore, necessary to shut down the condensate system completely.

4:40:00 Reactor building dome radiation monitor records $1000 \mathrm{R} / \mathrm{h}$.

4:42:00 Auxiliary feedwater was turned off. Only a small amount of heat could be removed by the steam generator because the upper part of the primary system was filled by a mixture of steam and hydrogen gas. The water level on the secondary side was rising because more auxiliary feedwater was coming than was leaving as steam. At 4 hours 42 minutes, auxiliary feedwater was shut off.

$\sim 5: 00: 00$ Reactor building dome radiation monitor reaches $6000 \mathrm{R} / \mathrm{h}$.

5:15:00 Initial repressurization began, PORV block valve shut.

5:29:00 Emergency diesel fuel racks reset.

5:35:00 NRC Region 1 inspector reports no consideration of offsite evacuation, since utility reports no significant leakage, and there has been no significant off-site radioactivity yet.
} 


\title{
Table 2.1-1 Chronology of Major TMI-2 Accident Events (continued)
}

\author{
Elapsed \\ Time \\ $\mathrm{h}: \min : \mathrm{s}$ \\ Event or Condition
}

5:43:00 By cycling the PORV block valve, reactor coolant pressure was maintained in the 1865-2150 psig range during the next 2 hours.

6:00:00 Figure 2.1-13. Repressurized, Attempting to Collapse Vapor Bubble.

6:04:00 Commenced filling steam generator A (to 97\%) using condensate pumps.

6:10:00 Airborne radiation levels in Unit 2 control room require evacuation of all but essential personnel.

6:17:00 Unit 2 personnel put on masks to protect against possible radiation.

6:27:00 Everyone, except essential personnel, started moving to Unit 1 control room.

6:52:00 People leaving the Unit 2 control room fail to close the door properly, possibly compromising the recirculation ventilation system.

7:00:00 Communications in the Unit 2 control room were hampered by respirators. Communications problems led some personnel to remove respirators for short periods.

7:00:00 A tour of the auxiliary building found $10 \mathrm{R} / \mathrm{h}$ at the radiation waste panel, water standing on the floor in areas with floor drains, and the auxiliary building sumps full.

7:08:00 Auxiliary feedwater pump 2A was started. Level in steam generator A reached $100 \%$ (operating range).

7:38:54 Depressurization initiated to actuate core flood system.

7:40:00 Region 1 inspector reports that utility believes there will be no radioactive release to the surrounding area.

8:00:00 Figure 2.1-14. Depressurizing, Releasing $H_{2}$.

8:30:00 The power-operated emergency main steam dump valve was closed at the request of corporate management.

8:41:00 Core flood tanks initiate, little flow.

9:04:00 Makeup pump 1C was shut off (concerned with borated water storage tank inventory).

9:10:00 Initial depressurization halted. 
Table 2.1-1 Chronology of Major TMI-2 Accident Events (continued)

Elapsed

Time

h:min:s

9:50:00 Figure 2.1-15. Second Depressurization Initiated, Hydrogen Burn. High pressure injection actuated.

Reactor building sprays actuated.

9:50:30 Makeup pump 1C was stopped.

9:57:00 Reactor building spray pumps were stopped.

10:26:15 Loop $A T_{h}<620^{\circ} \mathrm{F}$. Stays on scale 10 minutes.

10:30:00 Figure 2.1-16 Reactor Coolant Pressure Near Minimum (400 psig).

11:06:00 Pressurizer level decreased to 180 inches in the next 18 minutes. Loop A temperature was increasing.

11:08:00 Second depressurization attempt ends.

13:00:00 Figure 2.1-17. Steam Generators Blocked By Hydrogen.

213:00:00 About 13 hours after turbine trip, the auxiliary boiler was brought back into operation. Steam for the turbine seals was now available and it was possible to hold a vacuum on the condenser. Two condenser vacuum pumps were started. It was the operator's belief that the main condenser would soon be available.

13:20:00 Repressurization began.

14:35:00 NRC Region 1 inspector reported that there still appeared to be a bubble in loop $\mathrm{B}$.

15:00:00 Figure 2.1-18. Repressurized, Flow Blocked by Hydrogen.

15:33:00 Operator started reactor coolant pump 1A started, ran it for 10 seconds, then tripped it.

15:45:00 The station superintendent directed operators to start a reactor coolant pump.

15:50:00 Operator started reactor coolant pump 1A and let it run continuously.

16:00:00 Figure 2.1-19. Forced Circulation Reestablished. 


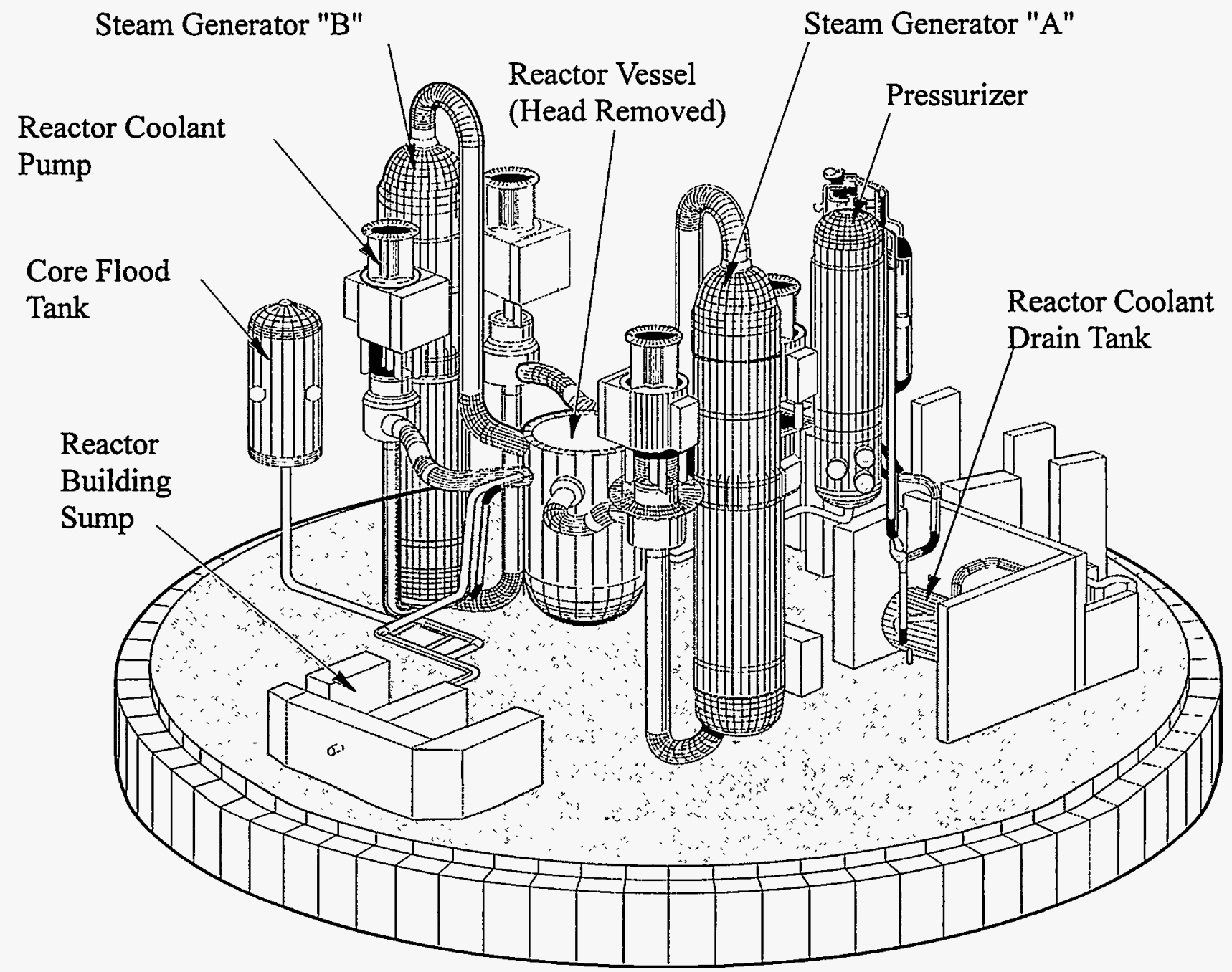

Figure 2.1-1 Arrangement of the primary reactor coolant system and related support system for the Three Mile Island, Unit 2 (TMI-2) Reactor (courtesy of R. Schauss and Construction Systems Associates) 


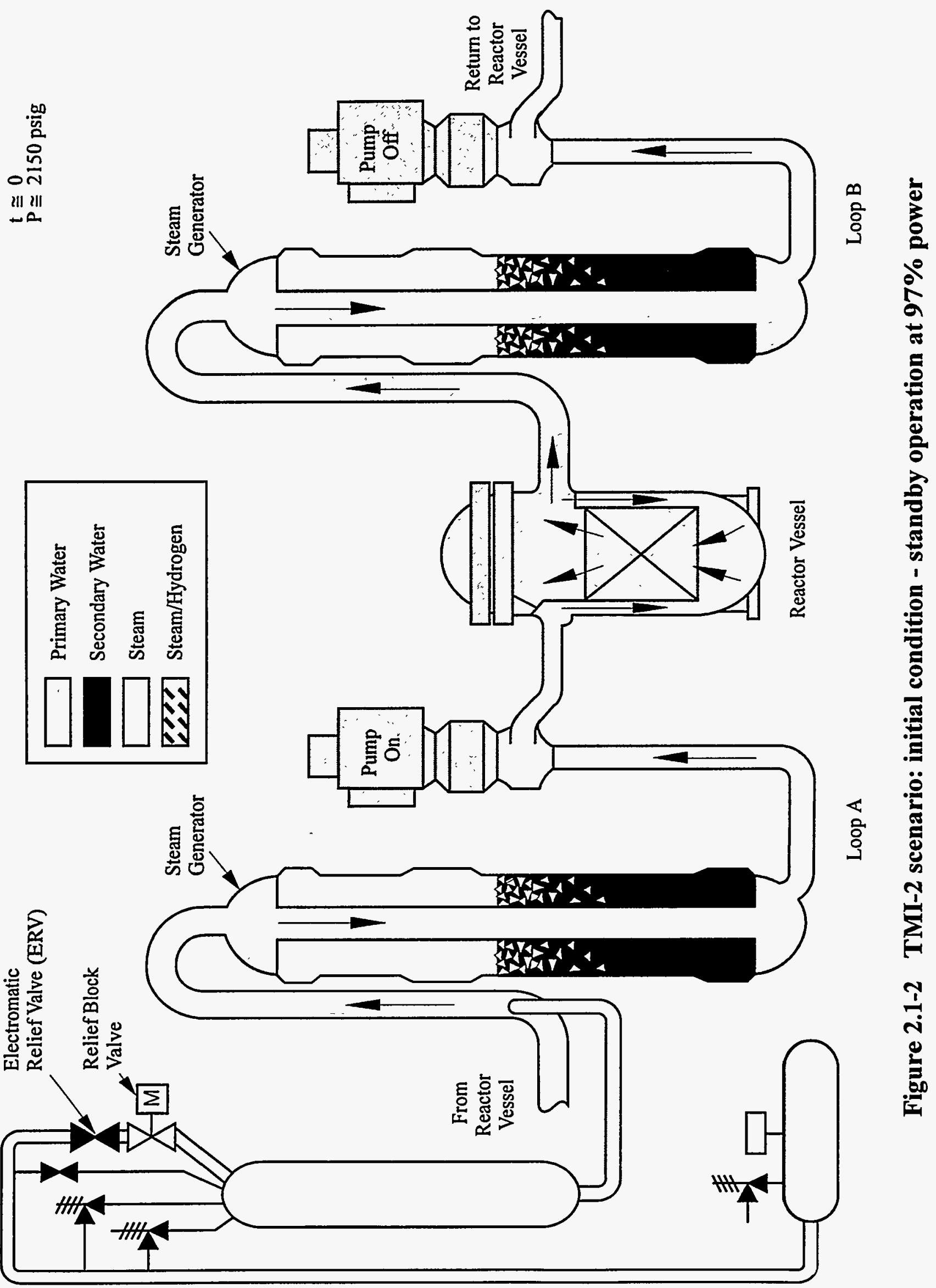




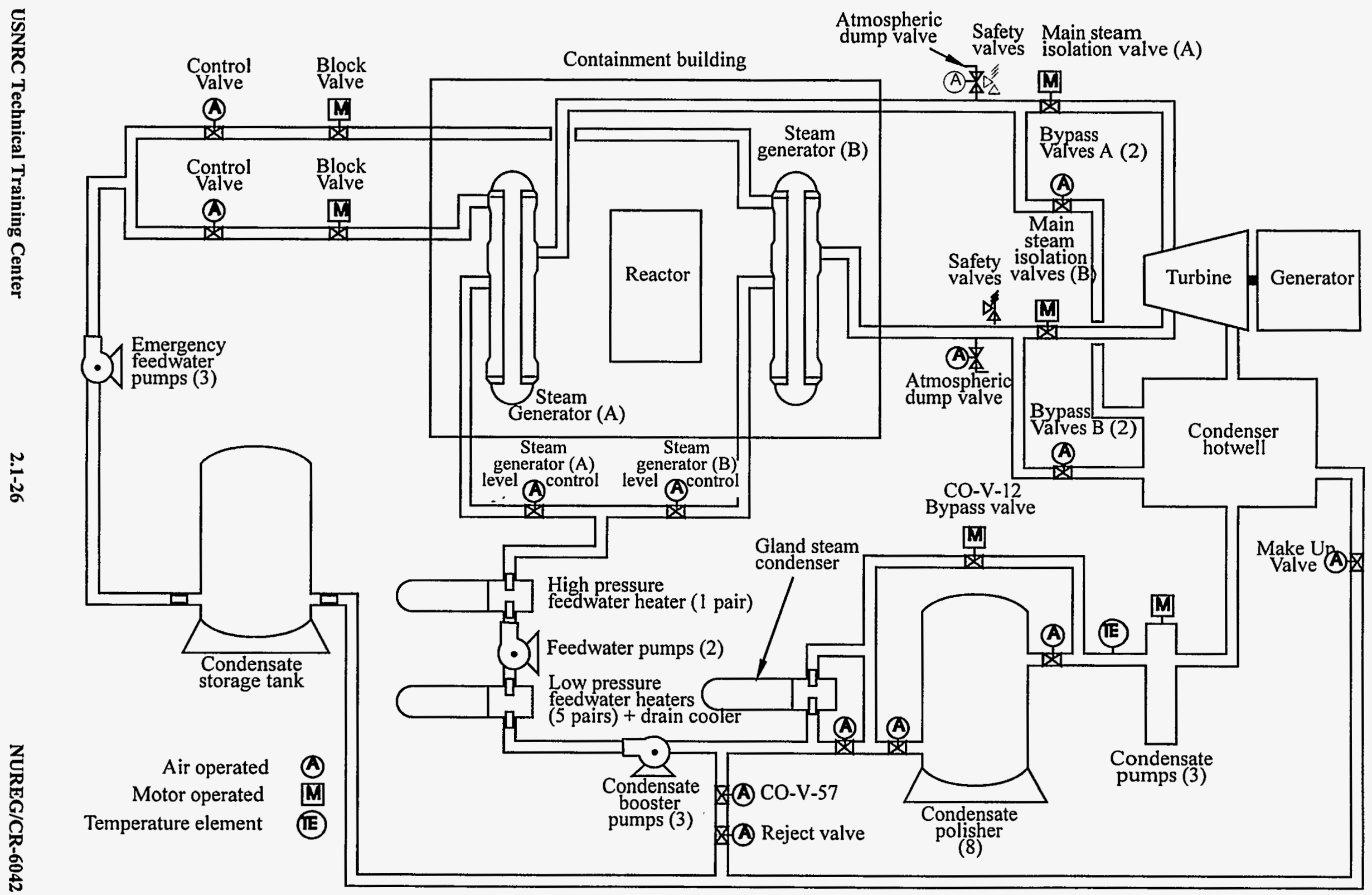

Figure 2.1-3 Condensate and feedwater systems 


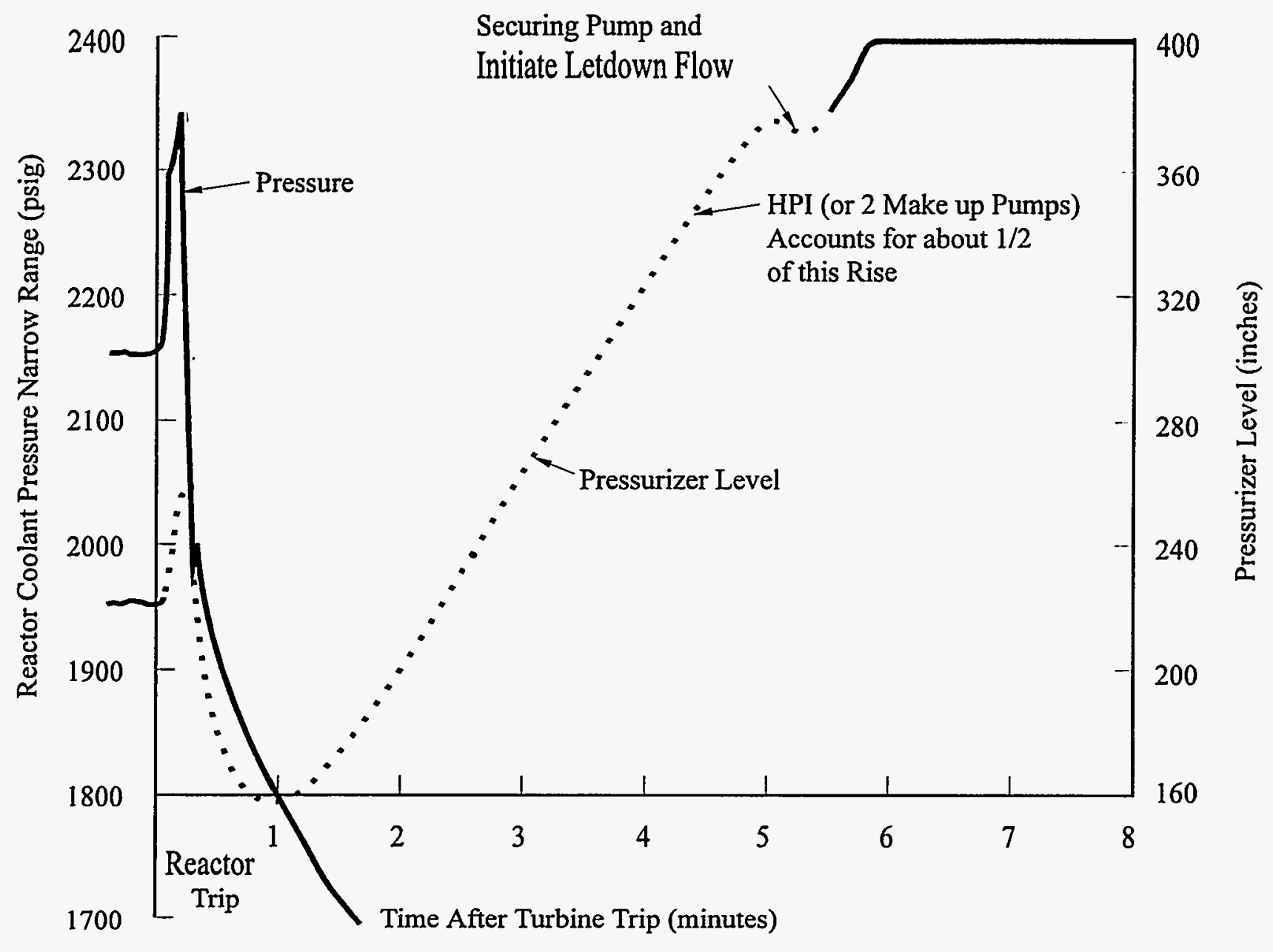

Figure 2.1-4 TMI-2 scenario: reactor coolant pressure and pressurizer level vs. time 


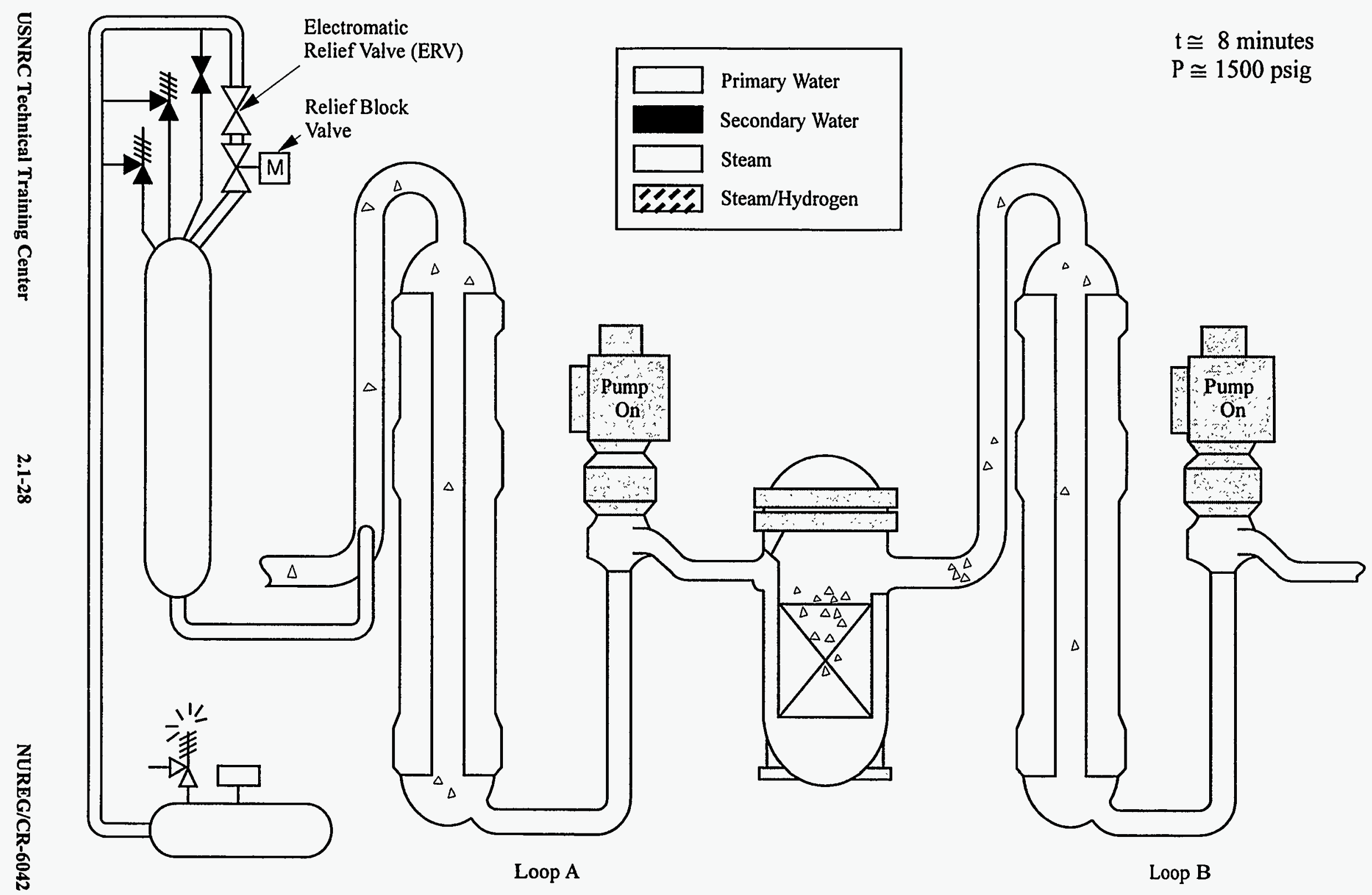

Figure 2.1-5 TMI-2 scenario: system nearly liquid solid, liquid expanding with increasing temperature

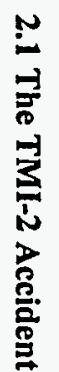




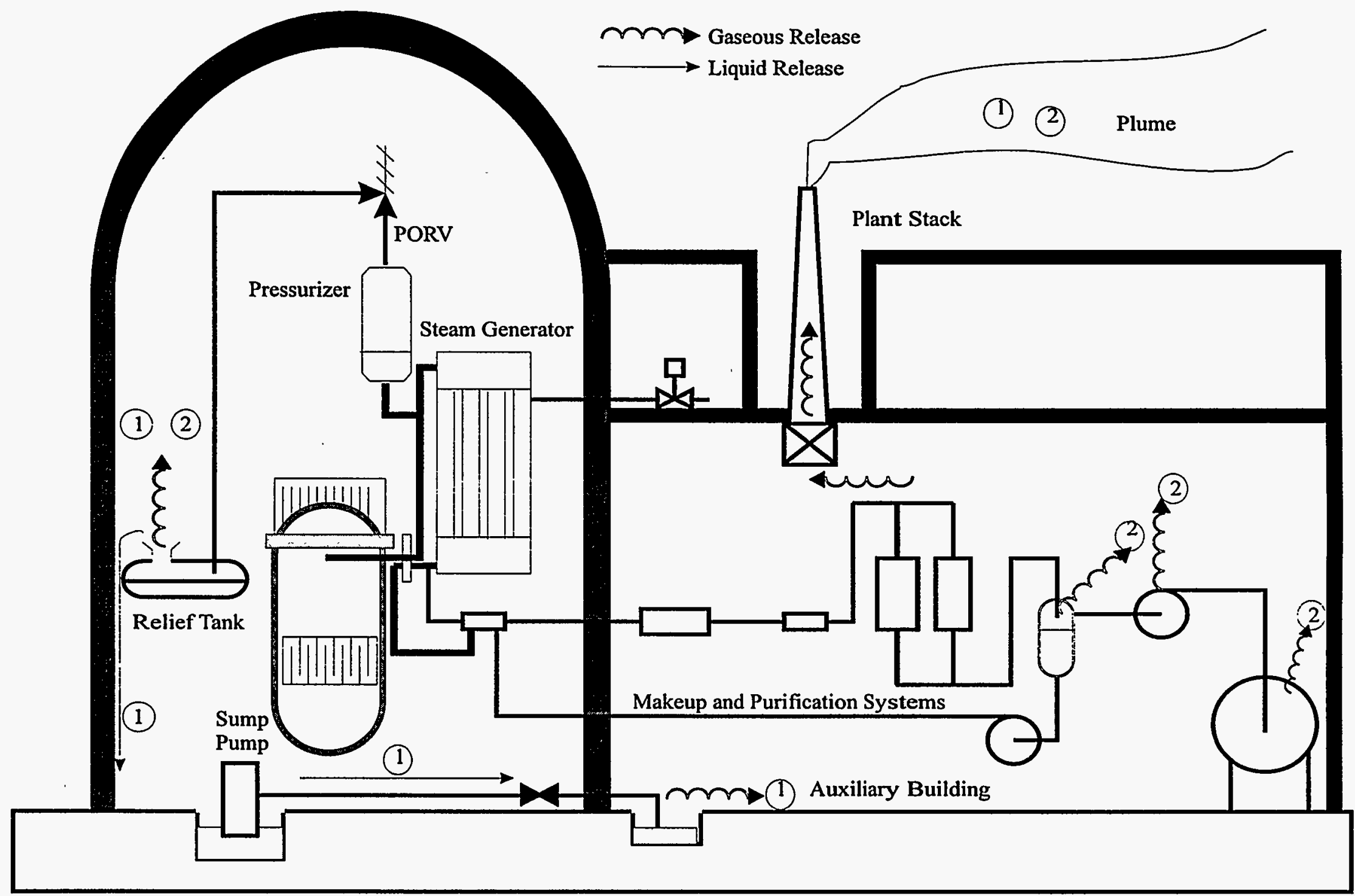

1. Early (first 38 minutes) before core damage, normal coolant only, sump pump operation

2. After core damage, leakage from makeup and purification system was the source of most of the release 


$$
\text { }
$$
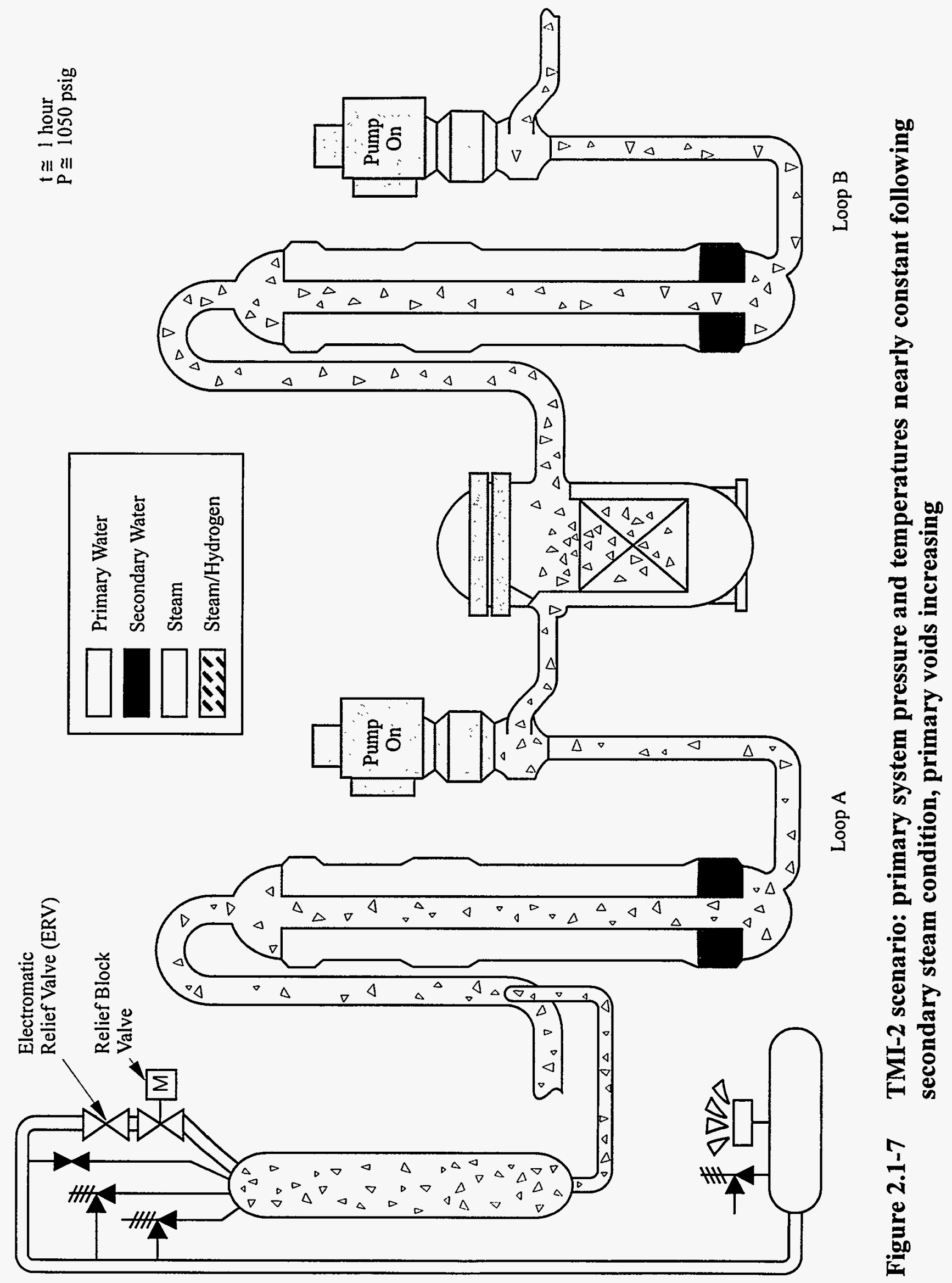

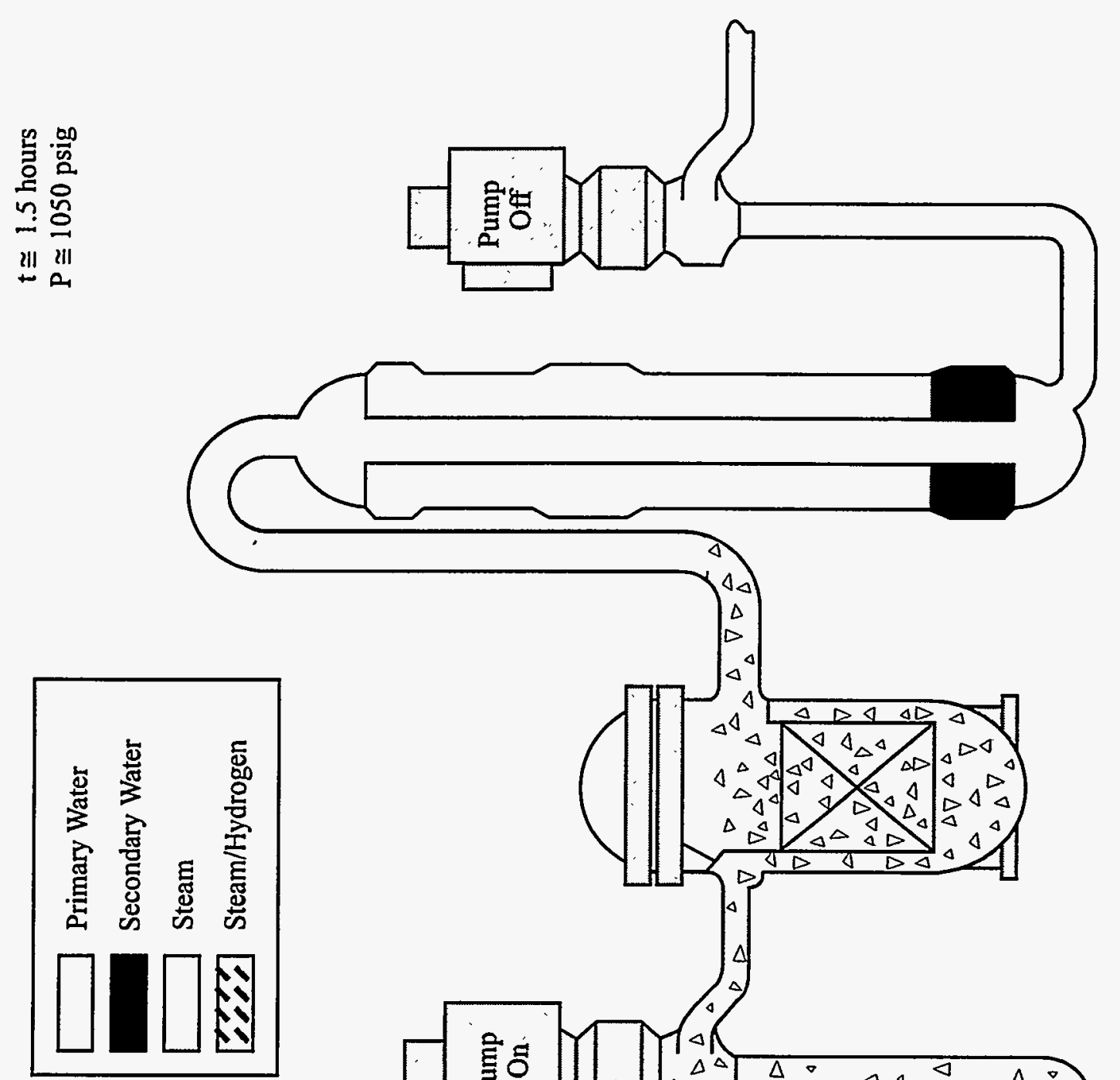


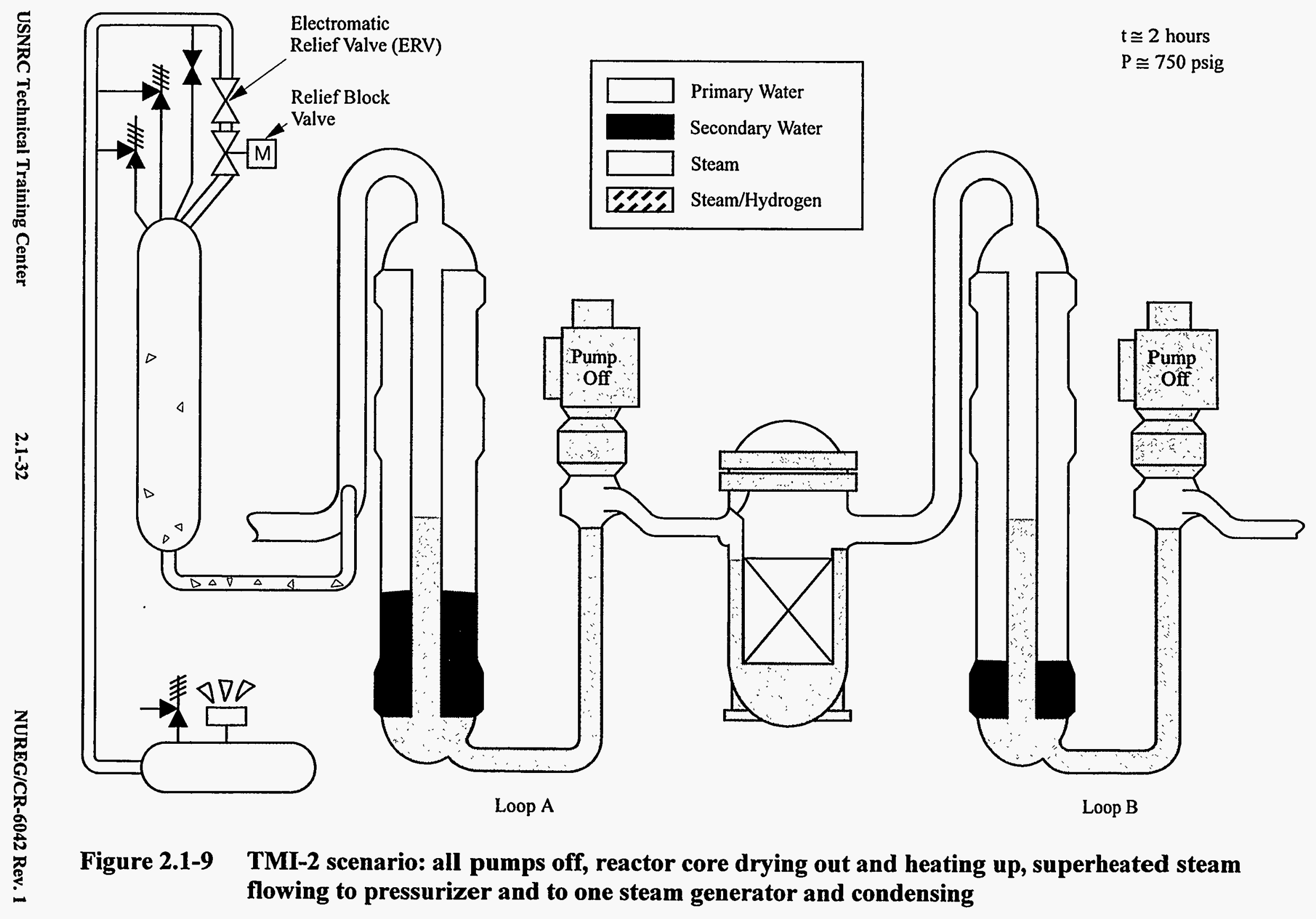



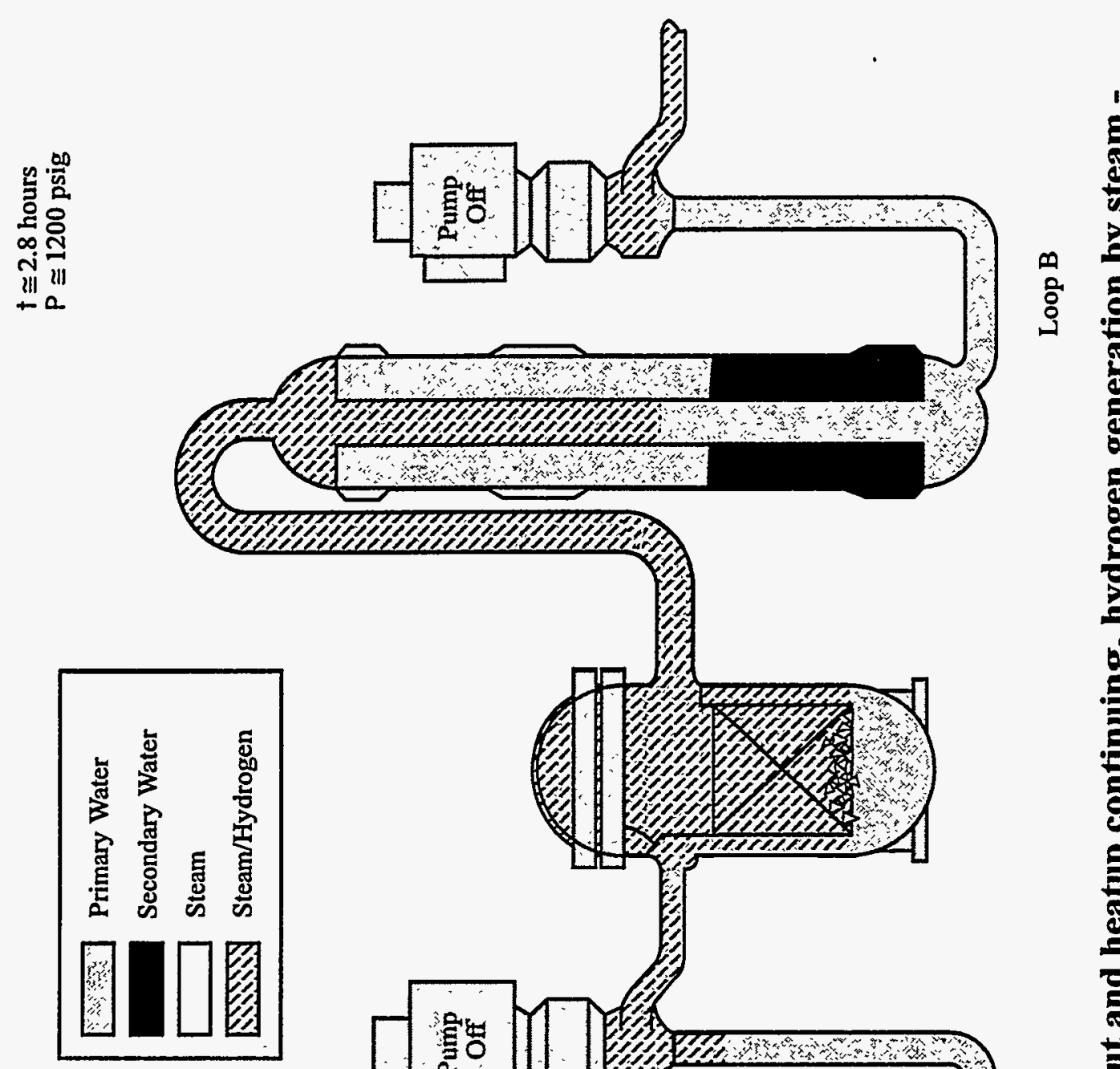

봉

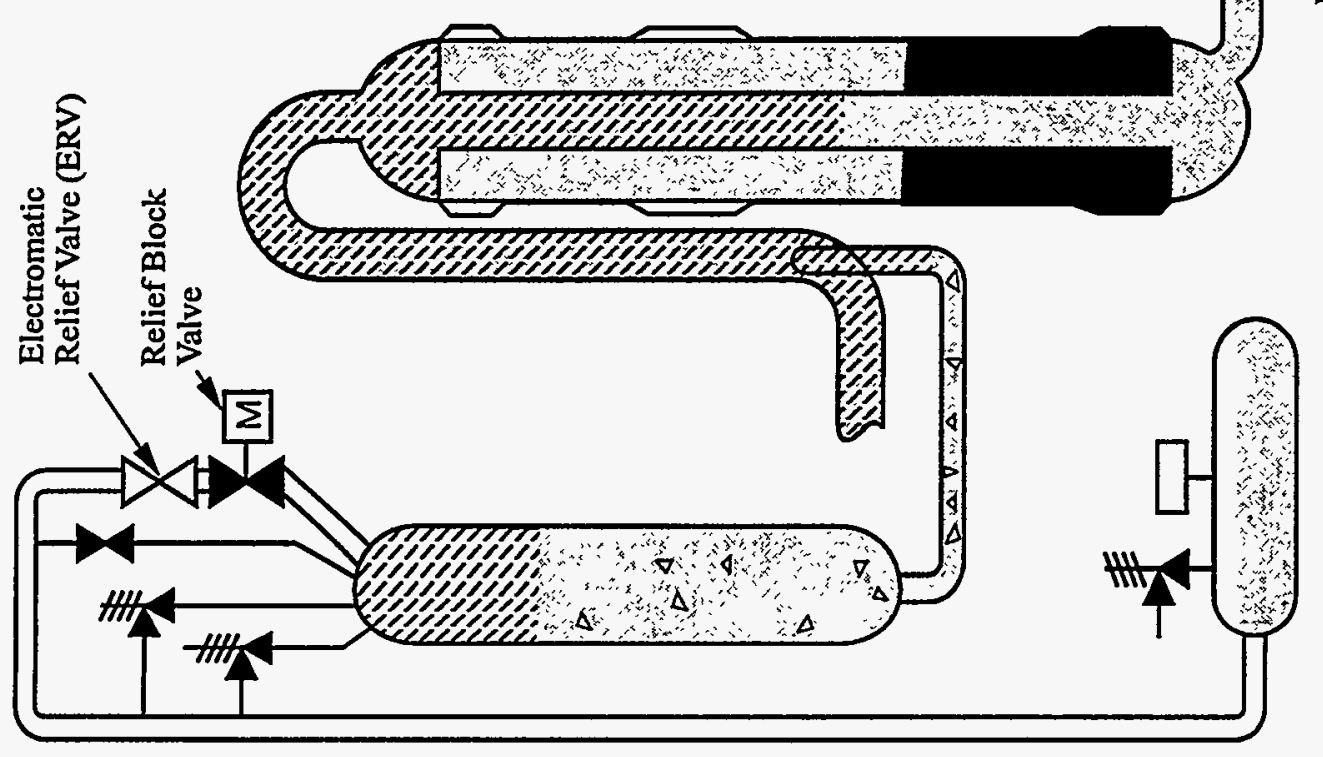




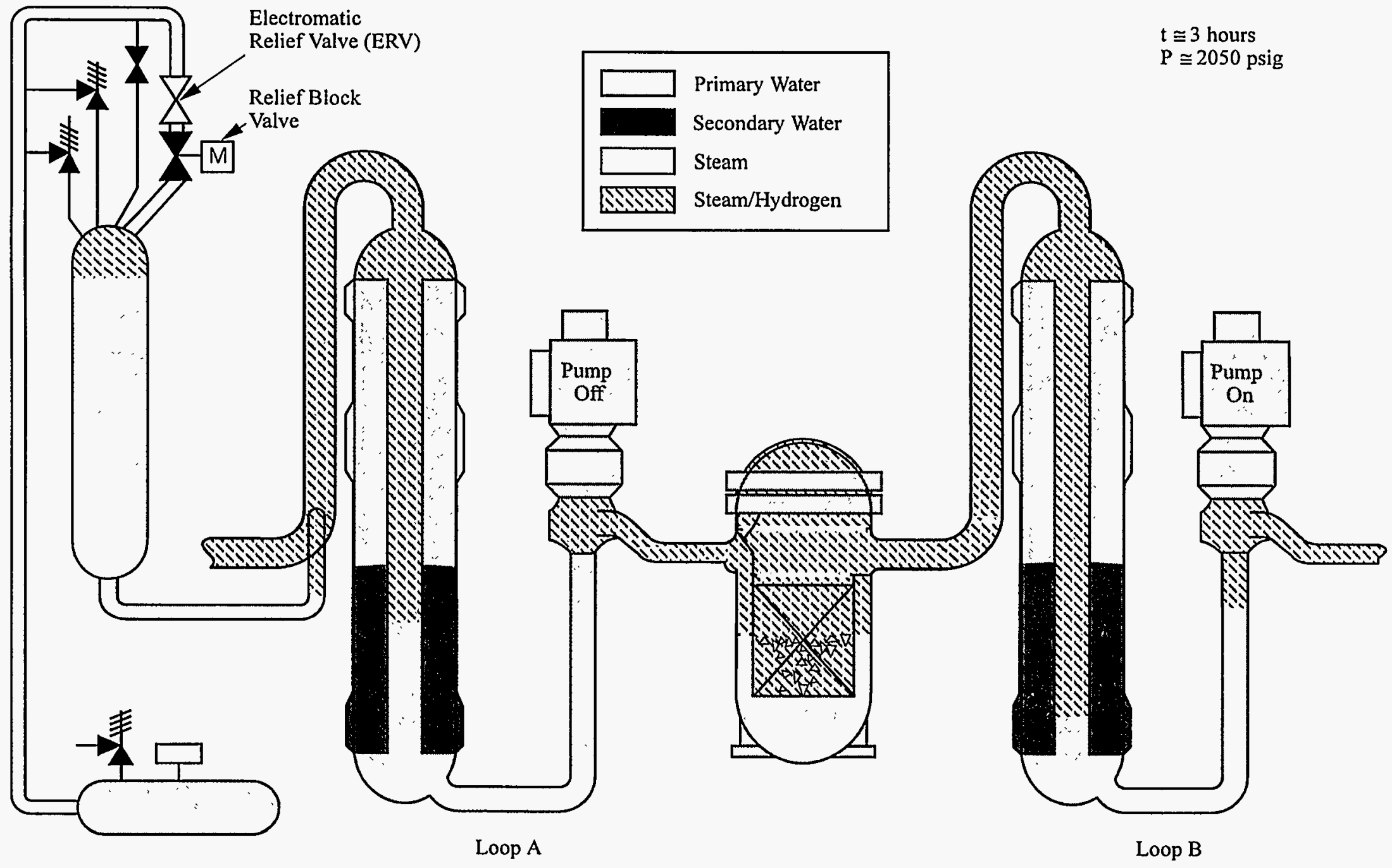

$\stackrel{N}{\dot{\omega}}$

Figure 2.1-11 TMI-2 scenario: core partially quenched by fluid during loop B pump start, heatup resumes 


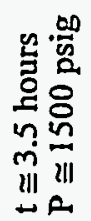
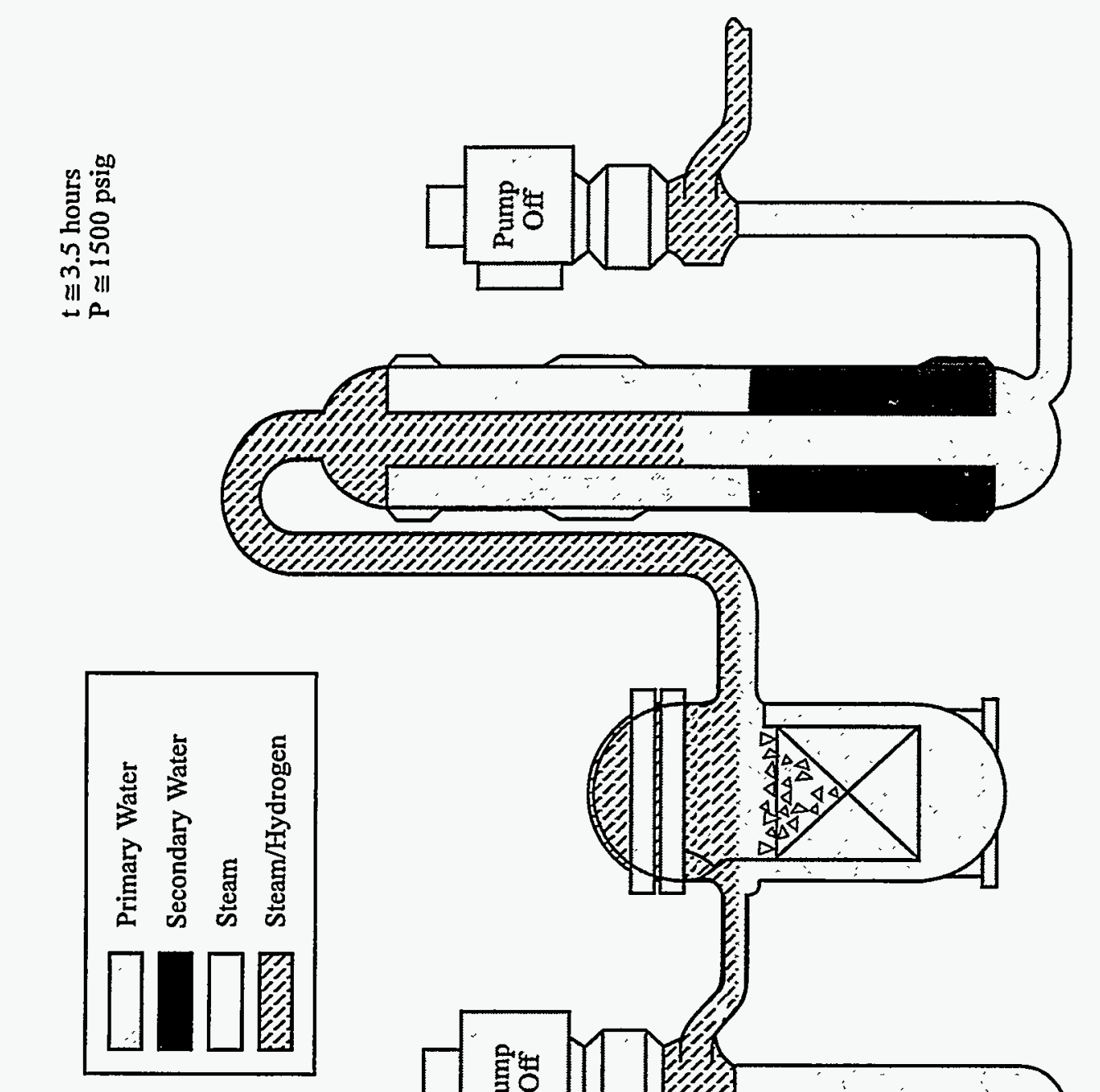

응

ํㅗㄹ

$\frac{1}{0}$
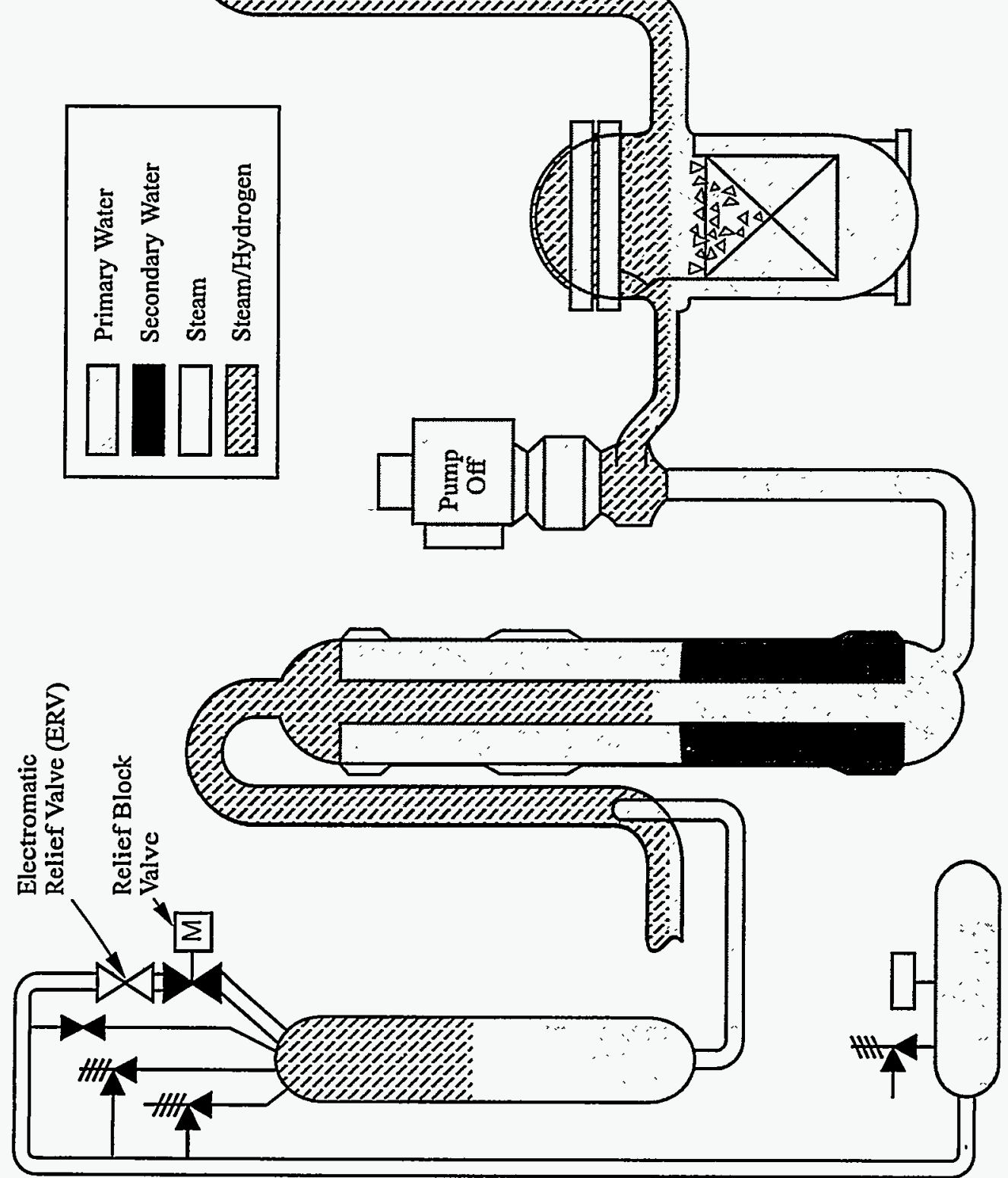

৫্口

 

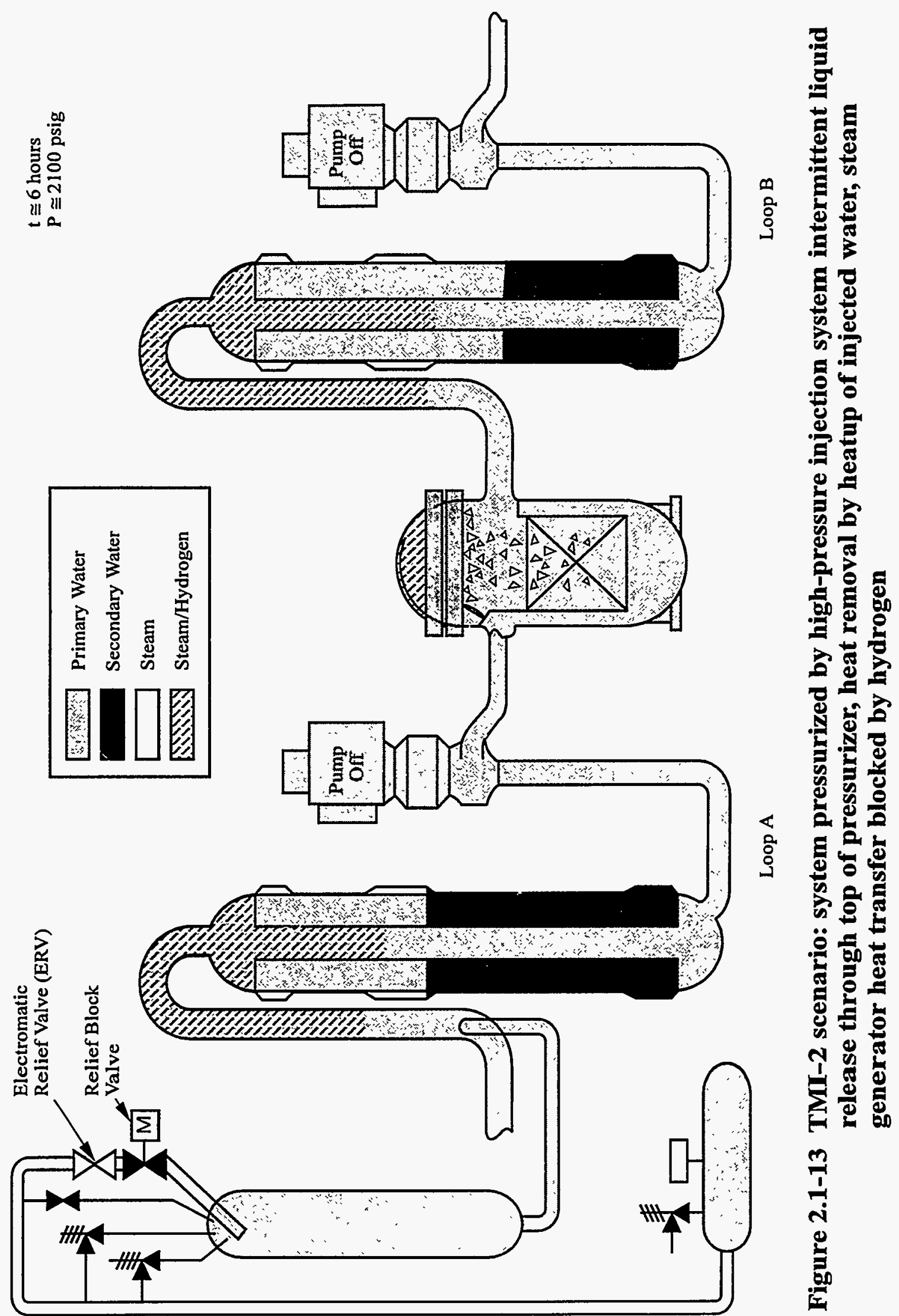


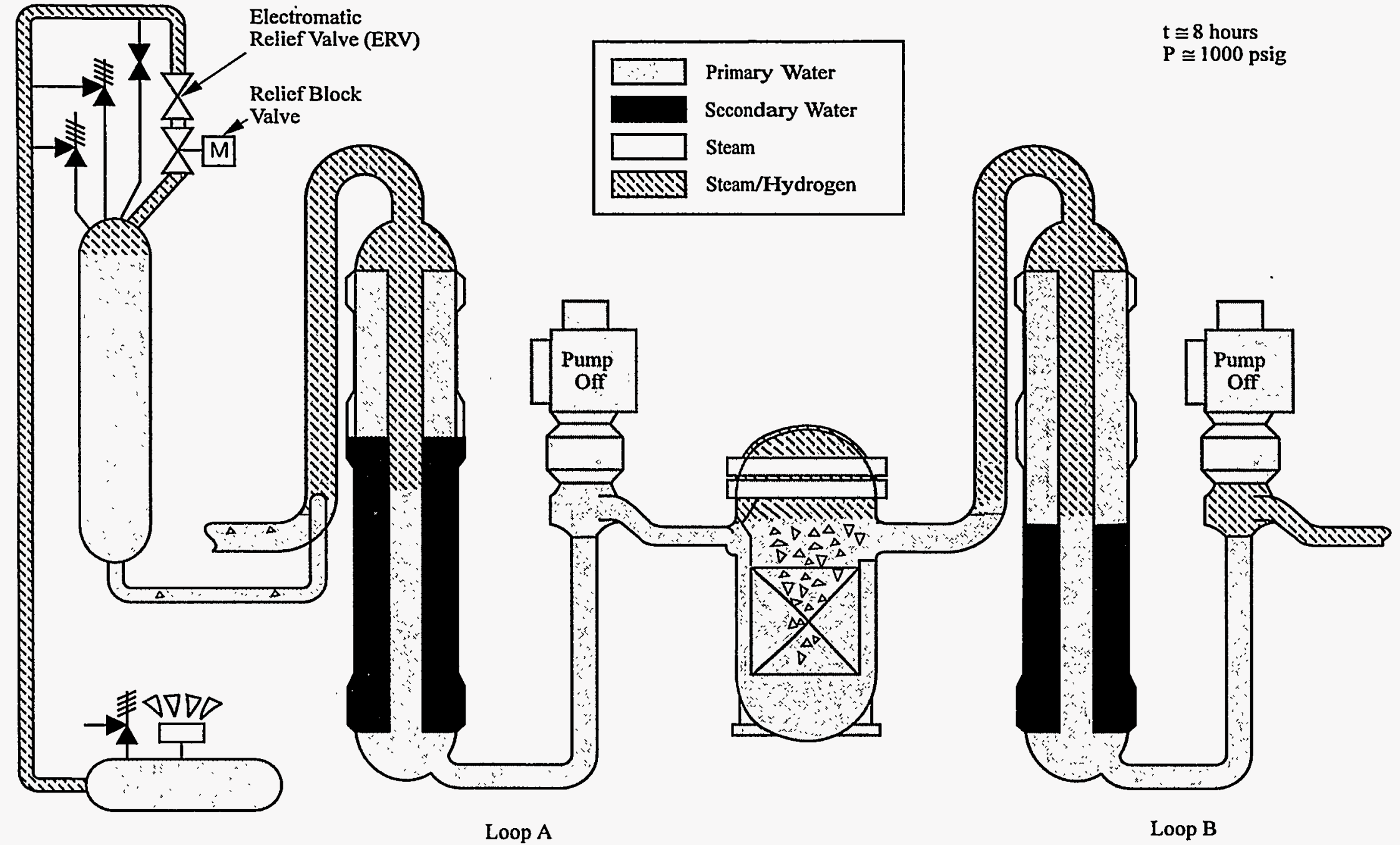

Figure 2.1-14 TMI-2 scenario: primary system depressurizing and releasing hydrogen through the pressurizer into the containment 


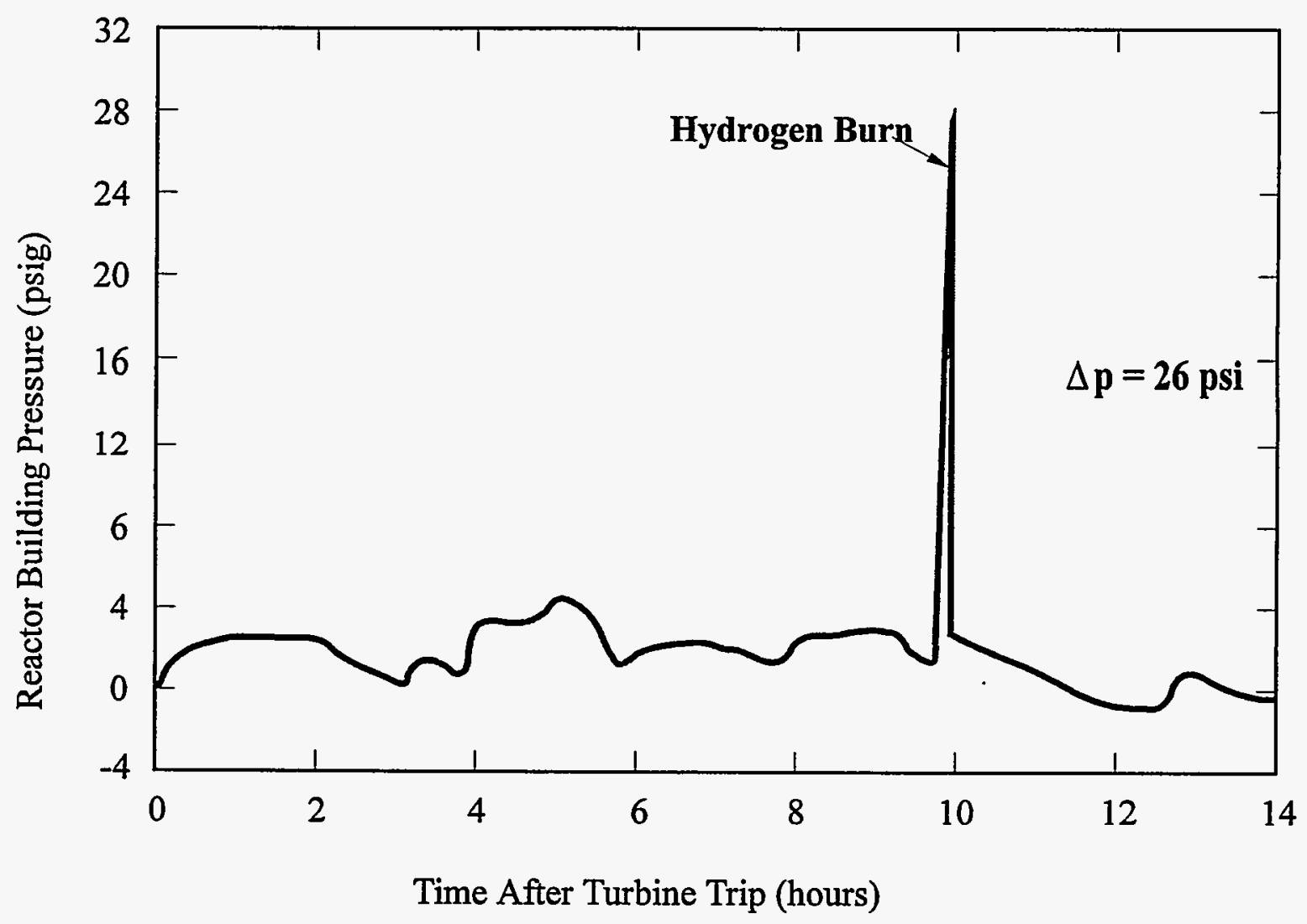

- Figure 2.1-15 TMI-2 containment pressure versus time 

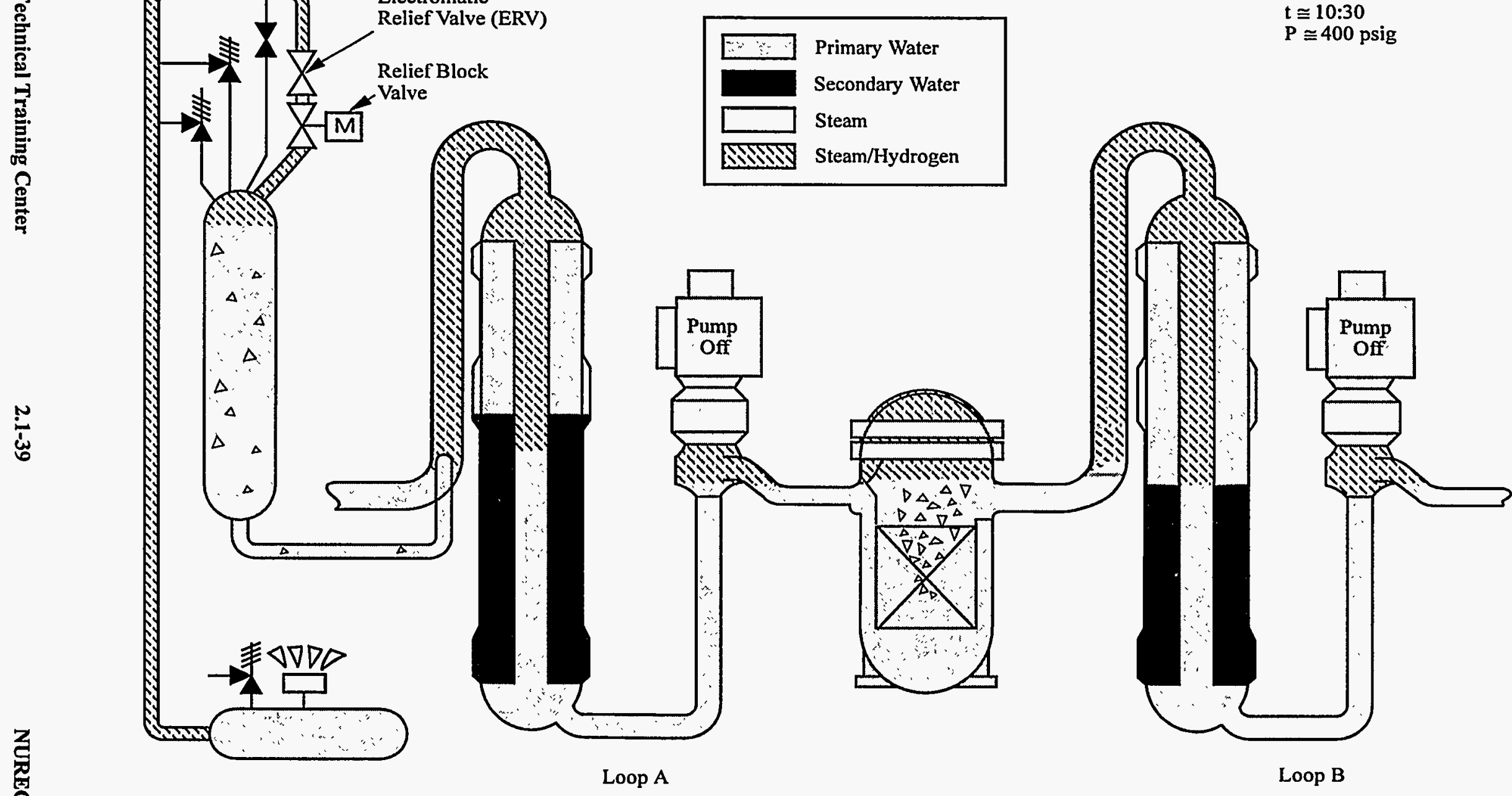

Figure 2.1-16 TMI-2 primary system pressure reaches a minimum as pressurizer temperature returns to saturated conditions, liquid in system maintained during depressurization by high-pressure injection and core flood tanks 


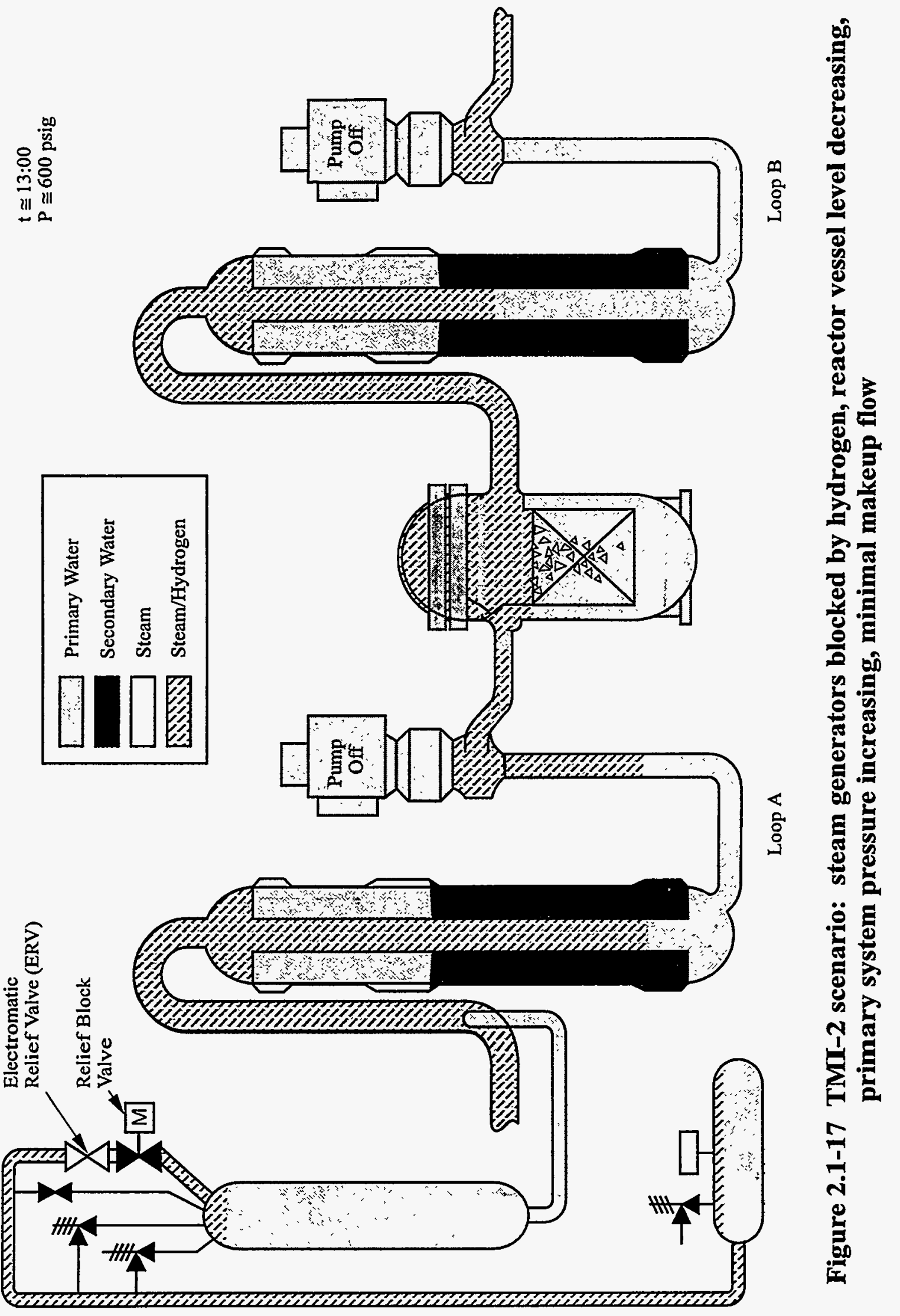




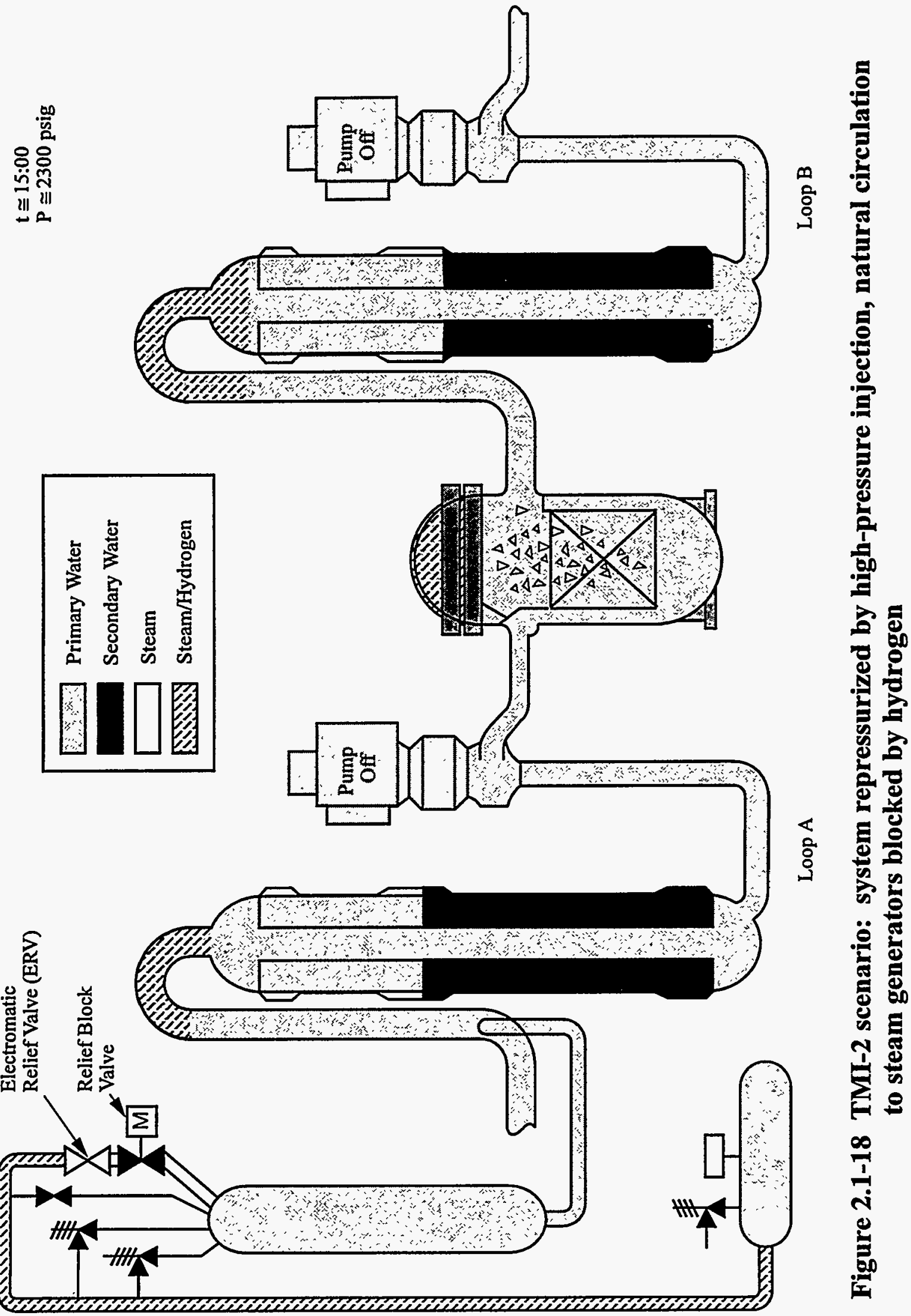




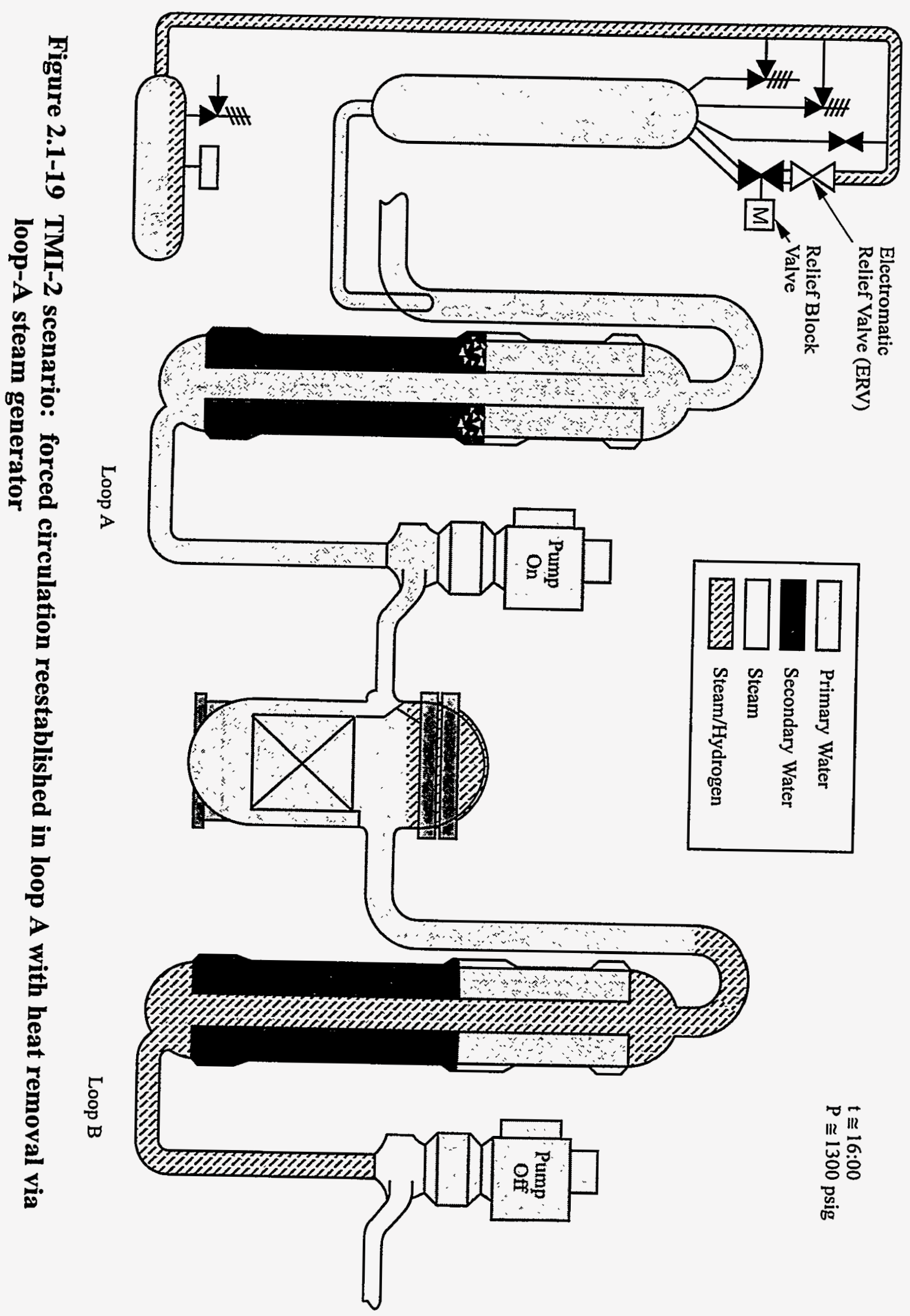




\section{References for Section 2.1}

1. U.S. Nuclear Regulatory Commission, "Investigation Into The March 28, 1979 Three Mile Island Accident by Office of Inspection and Enforcement," NUREG-0600, Investigative Report No. 50-320/79-10, August 1979.

2. E. Rubinstein and J. F. Mason, "An Analysis of Three Mile Island," IEEE Spectrum, November 1979.

3. M. Rogovin, G. T. Frampton, et al., "Three Mile Island, A Report to the Commissioners and to the Public," U. S. Nuclear Regulatory Commission, NUREG/CR-1250, Volume II Part 2, January 1980.
4. U. S. Nuclear Regulatory Commission, "TMI-2 Lessons Learned Task Force" Final Report, NUREG-0585, 1980.

5. U. S. Nuclear Regulatory Commission, "NRC Action Plan Developed as a Result of the TMI-2 Accident," NUREG-0669, May 1980.

6. R. A. Knief, "The Accident at Three Mile Island Unit 2," Chapter 15 of Nuclear Energy Technology - Theory and Practice of Commercial Nuclear Power, Hemisphere Publishing, 1991. 


\subsection{TMI-2 Implications}

\subsubsection{Introduction}

The TMI-2 accident put to rest the notion that severe nuclear power plant accidents were not credible. Failure to diagnose and compensate for loss of coolant from the stuck open PORV led to substantial core damage (oxidation and melting), which is discussed further in Chapter 3. Yet, in spite of the extensive core damage and the combustion of hydrogen in containment, the radionuclide releases to the environment were very low. Of the 66 million curies of radioactive iodine-131 in the reactor at the time of the accident, only 14 or 15 curies escaped to the environment.

Uncertainty about the causes of the accident, confusion about how to deal with it, and contradictory information and appraisals of the level of danger in the days following the accident often made utility and government authorities appear inept, deceptive, or both. Press accounts fed public fears and fostered a deepening perception of a technology that was out of control. Two days after the onset of the accident (long after core cooling was restored), the Governor of Pennsylvania issued a pair of recommendations -- initially for sheltering within 10 miles $(16 \mathrm{~km})$ and later for closing schools and evacuating pregnant women and pre-school children within 5 miles $(8 \mathrm{~km})$. Despite the limited scope of the recommended evacuation, there was a spontaneous evacuation involving some 144,000 persons from 50,000 households. Approximately two-thirds of the households within 5 miles $(8 \mathrm{~km})$ of TMI-2 had at least one person evacuate. After one week the decision was made to re-open the schools, the evacuation order was lifted, and most of the evacuees returned.

Almost immediately after the TMI-2 accident, the government and the nuclear industry sought to identify the causes and began taking steps to reduce the likelihood of future accidents. Extensive corrective actions for U.S plants were required by the NRC's TMI Action Plan' (see Section 2.2.4). The first and most prominent formal investigation of the accident was conducted by the President's Commission on the Accident at Three Mile Island, also known for its chairman, John Kemeny. ${ }^{2}$ Two important NRC-sponsored investigations were by the Special Inquiry Group or Rogovin Committee, which addressed broad accident issues, and the in-house Lessons Learned Task Force (NUREG-0585), which addressed concerns most germane to the NRC's own activities. ${ }^{3,4}$ In their reports, the investigators emphasized many deficiencies for which corrective actions were already in progress. More significantly, the reports strongly criticized the NRC, the utility, the nuclear industry, and the reactor operators. The TMI-2 nuclear steam supply system design was found to have contributed to the accident much less than the human factors and attitudes involved. The investigators also validated that the major health consequence was

on the mental health of the people living in the region, [including] ...immediate short-lived mental distress produced by the accident.

A majority of the President's Commission supported a moratorium on the licensing of new nuclear power plants; however, such a moratorium was not recommended in the Commission's final report due to a lack of consensus on guidelines for lifting the moratorium once it was put into force. A de facto moratorium ensued, however, as the NRC delayed granting reactor licenses pending resolution of relevant issues and lessons learned from TMI-2. 


\subsubsection{NRC Restructuring}

The President's Commission was highly critical of the NRC and found that

the NRC is so preoccupied with the licensing of (new) plants that it has not given primary consideration to overall safety issues.

In response to such criticisms, the NRC reorganized to strengthen accountability and give higher priority to plant safety. The NRC emphasis shifted from licensing new plants to regulating operating plants. This was consistent with the work load resulting from post-accident modifications to existing plants, the de facto moratorium on licensing new plants, and the cancellations and lack of new orders that followed the TMI accident. In addition, over several years, most of the NRC's scattered headquarters offices in the Washington, DC metropolitan area were consolidated into a single building complex placing individuals with safety-related responsibilities (e.g., inspection and enforcement, operating experience, and research) in much closer proximity to each other.

The need for "increased emphasis and improved management" of NRC's inspection and enforcement functions was addressed by developing a strengthened enforcement policy with substantial penalties for "failure to report new 'safety-related' information" and for rule violations, expanding the resident inspector program to station at least two NRC inspectors at each plant site, and regularly conducting team inspections. The inspectors were now more concerned with understanding plant operations and safety than administrative compliance. One comprehensive team inspection is the Systematic Assessment of Licensee Performance (SALP) program which rates plants on a scale of one to three in each of four areas (operations, maintenance, engineering, and plant support). Systematic assessment of licensee performance, together with other NRC activities, were used to enforce higher organizational and management standards for licensees.

The NRC established a new Office for Analysis and Evaluation of Operational Data to systematically review information from the performance of operating plants. This action was in response to the belated recognition that malfunctions similar to those at TMI had occurred at other plants, but the information had not been assimilated or disseminated in a way that could have averted the TMI accident.

In addition to the organizational changes described above, the NRC initiated major changes affecting operator training and licensing, operating plant configurations, emergency response, severe accident research, plant licensing, and regulatory decision making. These initiatives are discussed in later sections.

\subsubsection{Nuclear Industry Restructuring}

The President's Commission concluded that the nuclear industry

must dramatically change its attitudes towards safety and regulations [and] ...must also set and police its own standards of excellence to ensure the effective management and safe operation of nuclear power plants.

The Commission charged that the industry had a mind-set that plants were "sufficiently safe" and emphasized that this attitude

must be changed to one that says nuclear power is by its very nature potentially dangerous, and ... one must continually question whether the 
safeguards already in place are sufficient to prevent major accidents. ${ }^{2}$

The industry response to the accident demonstrated a significant change in attitude. Three key issues were singled out for prompt attention: ineffective reactor safety information exchange, difficult operatormachine interfaces, and inadequate operator training. The U. S. nuclear utilities established several organizations to deal with these issues in the near term and with a broader spectrum of technical and management issues in the longer term.

The utilities established the Nuclear Safety Analysis Center (NSAC) under the Electric Power Research Institute (EPRI) to develop strategies for minimizing the possibility of future reactor accidents and to answer generic reactor safety questions. Nuclear Safety Analysis Center was also charted to recommend changes in safety systems and operator training, to act as a clearing house for technical information, to perform analyses of significant reactor transients, and to participate in performing probabilistic risk assessments.

The utilities also formed the Institute of Nuclear Power Operations (INPO). The Institute has served to establish industrywide qualifications, training requirements, and testing standards first for nuclear-plant operators and subsequently for technicians, engineers, and managers. The INPO plant evaluation program serves an audit and testing function for utility staffs. INPO provides guidance and training for those responsible for training programs, rather than dealing directly with individual operating personnel. Compliance with INPO criteria is judged by the National Nuclear Accrediting Board, an independent organization with expertise that encompasses training, university education, management, and regulation from both inside and outside the nuclear-utility industry. Each U. S. utility becomes a member of the INPO-chartered National Academy of Nuclear Training when accreditation is earned at each of its reactor sites for ten designated training programs. Continuing membership requires reaccreditation every four years.

The industry later established the Nuclear Utility Management and Resources Council (NUMARC) to deal with personnel-related and licensing issues, support self-initiated, self-policed plant performance and safety improvements.

The utilities also established a selfsponsored insurance program that provides coverage for replacement power costs in the event of a prolonged post-accident reactor shutdown. This, of course, is intended to limit the financial consequences of accidents (e.g., in 1980 the cost for the TMI-2 recovery was estimated at $\$ 973$ million, exclusive of replacement power costs) and provide more stability on an industry-wide basis.

\subsubsection{Plant Modifications}

The TMI accident led to a number of investigations of the adequacy of design features, operating procedures, and personnel of nuclear power plants to provide assurance of no undue risk regarding severe reactor accidents. The report "NRC Action Plan Developed as a Result of the TMI-2 Accident" (NUREG-0660, May 1980) describes a comprehensive and integrated plan involving many actions that serve to increase safety when implemented by operating plants and plants under construction. ${ }^{1} \quad$ The items approved for implementation by NRC are identified in the report "Clarification of TMI Action Plan Requirements" (NUREG-0737, November 1980). ${ }^{5}$ The staff issued further criteria on auxiliary feedwater system improvements 
(derived from NUREG-0667), and instrumentation (Regulatory Guide 1.97, Revision 2). ${ }^{6,7}$ The TMI Action Plan led to requirements for over 6,400 separate action items, an average of 90 action items per plant. There were 132 different types of action items approved. Of these, 39 involved equipment backfit items, 31 involved procedural changes, and 62 required analyses and reports.

Many of the action items addressed smallbreak and transient initiated accidents. Their significance had previously been identified by WASH-1400 and its reviews. Traditionally, attention had been on the design-basis large break LOCA. A major shift in emphasis toward small breaks and transients resulted from the TMI-2 accident. Many procedural, software, and hardware modifications were implemented to detect and mitigate such accidents as well as to monitor radiation-releases and other postaccident symptoms.

Considerable emphasis was placed on improving the operator-machine interface. Control rooms were reviewed for adequacy of the operator-machine interface as well as for habitability during accidents. Detailed analysis of operator tasks supported the development of new symptom-based operating procedures and improvements in control-panel hardware arrangements and markings, alarm and annunciator priorities and configurations, and computer-based data collection and display systems. Safety parameter display systems (SPDS) were installed to aid diagnosis and decision making. One example of a safety parameter display system, called a "PT-plot," graphs PWR primary and secondary system pressures and temperatures highlighting regions corresponding to over-cooling transients, under-cooling transients, and LOCAs. Emergency safety feature actuation systems were improved to provide an unambiguous control-room display of the status of all safety systems.

The TMI-2 accident led to increased emphasis on the importance of containment survival during severe accidents. While the changes to containments were not as numerous as the changes to other plant systems, additional hydrogen control measures were implemented for some plants. These changes are discussed in more detail in Chapter 4.

\subsubsection{Operator Training and Licensing}

The TMI-2 accident highlighted the importance of operators in responding to evolving accident conditions. In some countries, a "hands off" approach is taken, where the operators do not take action for a specified time period, so as not to make a situation worse before they understand what is going on. In the U.S., operators are actively involved from the outset, and it is important that the actions taken be positive ones. Following the TMI-2 accident, the NRC developed stringent new requirements for operator training, testing, and licensing, and for shift scheduling and overtime. In cooperation with industry groups, NRC promoted the increased use of reactor simulators. Before the TMI-2 accident, it was common for operators to train for requalification at a "generic" simulator, spending $90 \%$ of their simulator time on normal operations with the remainder emphasizing the design-basis large-break LOCA. Now each plant is required to have a plant-specific simulator, Simulator time is spent primarily on covering the entire spectrum of postulated transients and accidents. The NRC added extensive simulator exercises to the traditional reactoroperator (RO) and senior-reactor-operator (SRO) exams and plant walk-throughs. Annual requalification exams, similar to the initial NRC exams are now administered by 
the utility, subject to NRC approval and validation. In addition, the NRC added requirements for a new Shift Technical Adviser (STA) to provide engineering capability on each control-room shift.

\subsubsection{Emergency Response Improvements}

Given the confusion and uncertainty experienced during the TMI- 2 accident and the subsequent evacuation, the NRC took steps to upgrade emergency preparedness and planning. New rules and guidelines were developed. Emergency response capabilities were expanded with improved plans, equipment, and facilities. Emergency response personnel from industry, the NRC, the Federal Emergency Management Agency (FEMA), and local organizations now receive extensive training and are evaluated by periodic drills. Site plans and procedures address

- accident recognition and classification,

- declaration and initial notification,

- communication networks,

- response readiness.

The NRC now requires dedicated emergency operations facilities (NUREG-0737, Rev. 1) to be constructed, maintained, and tested near each plant. ${ }^{8}$ During any future accident, a joint information center would provide a common location for utility, federal, state, and local representatives to communicate with the media. Public notification and information channels have been established.

\subsubsection{Seabrook and Shoreham}

In the aftermath of the TMI-2 accident, the NRC temporarily suspended the granting of full power operating licenses. This de facto moratorium ended 16 months after the accident (August 1980) when a full-power operating license was işsued to North
Anna-2. (Granting of low power licenses had resumed earlier, starting with Sequoyah.) During the rest of the 1980s, the NRC granted full-power licenses to over forty other reactors, most of which had received construction permits in the mid-1970s. In 1985 it authorized the undamaged Three Mile Island Unit 1, which had been shut down for refueling at the time of the TMI-2 accident, to resume operation.

Although many of the licensing actions aroused little opposition, others triggered major controversies. The two licensing cases that precipitated what were perhaps the most bitter, protracted, and widely publicized debates were Seabrook in New Hampshire and Shoreham on Long Island, New York. The key, though hardly the sole, issue in both cases was emergency planning. The Three Mile Island accident had vividly demonstrated the deficiencies in existing procedures - for coping with an off-site nuclear emergency. The lack of effective preparation had produced confusion, uncertainty, and panic among members of the public faced with the prospect of exposure to radiation releases from the plant. After the accident, the NRC, prodded by Congress to improve emergency planning, adopted a rule that required each nuclear utility to come up with a plan for evacuating the population within a ten mile radius of its plant(s) in the event of a reactor accident. ${ }^{11}$ The rule applied to plants in operation and under construction. It called for plant owners to work with state and local police, fire, and civil defense authorities on emergency plans that would be tested and evaluated by the NRC and the FEMA. The NRC expected cooperation between federal, state and local government officials to upgrade emergency plans and provide better protection for the public should a serious nuclear accident occur. 
The NRC did not, however, anticipate that state and local governments would try to prevent the operation of nuclear plants by refusing to participate in emergency preparations. That was precisely what the states of New York and Massachusetts sought to do in the cases of Shoreham and Seabrook. In New York, Governor Mario M. Cuomo and other state officials claimed that it would be impossible to evacuate Long Island if Shoreham suffered a major accident. Therefore, the state refused to join in emergency planning or drills. The NRC granted Shoreham a low-power operating license, but the state and the utility, Long Island Lighting, eventually reached a settlement in which the company agreed not to operate the plant in return for concessions from the state.

A similar issue arose at Seabrook, though the outcome was different. The plant is located in the state of New Hampshire, but the ten mile emergency planning zone extends across the state line into Massachusetts. By the time that construction of the plant was completed, Massachusetts Governor Michael S. Dukakis, largely as a result of Chernobyl, had decided that he would not cooperate with emergency planning efforts for Seabrook. New Hampshire officials worked with federal agencies to prepare an emergency plan, but Massachusetts, arguing that crowded beaches near the Seabrook plant could not be evacuated in the event of an accident, refused. As a result of the positions of New York regarding Shoreham and Massachusetts regarding Seabrook, in 1988 the NRC adopted a "realism rule," which was grounded on the premise that, in an actual emergency, state and local governments would make every effort to protect public health and safety. ${ }^{12}$ Therefore, in cases in which state and/or local officials declined to participate in emergency planning, the NRC and FEMA would review and evaluate plans developed by the utility. On that basis, the NRC issued an operating license for the Seabrook plant. The arguments that raged over emergency planning and other issues at Shoreham and Seabrook attracted a great deal of attention, spawned heated controversy, and raised anew an old question of the relative authority of federal, state, and local governments in licensing and regulating nuclear plants.

\subsubsection{Severe Accident Research}

Following TMI-2, NRC research was redirected to focus on severe accidents. This research had several objectives, including:

1. to obtain a better understanding of the physical phenomena of severe accidents,

2. to develop models of these phenomena in order to predict the ways that severle accidents might progress,

3. to develop more realistic estimates of the radionuclide releases that could result from severe accidents, and

4. to examine available data sources and existing PRAs to identify the important accident sequences for various classes of reactors.

In order to meet these objectives, major research programs were started at the national laboratories and universities. Eventually the results of these efforts were integrated together in a major PRA for five reference plants (NUREG-1150). ${ }^{13}$ NUREG1150 essentially replaces the Reactor Safety Study in terms of providing current severe accident perspectives and insights. Both the severe accident research and NUREG-1150 are discussed in more detail in later modules. 
The Industry Degraded Core Rulemaking (IDCOR) Program, under the sponsorship of the Atomic Industrial Forum, was conducted in parallel with the NRC research efforts. The IDCOR group concentrated on developing models for assessing the risks of severe accidents. IDCOR models were used to analyze four of the five NUREG-1150 reference plants. This facilitated the identification and resolution of modeling differences.

\subsubsection{Severe Accident Policy}

In August 1985, when the bulk of the actions required by the TMI Action Plan had been completed, the NRC issued a policy statement on severe accidents. ${ }^{14}$ A policy statement is not a regulation in the sense that it does not impose specific requirements, but rather provides the Commission's rationale. and motivation for future regulatory positions. On the basis of available information from the Severe Accident Research Program, the Commission concluded that existing plants pose no undue risk to the public and that no immediate additional regulatory changes were recommended for these plants to address severe accidents, Note that many changes had already occurred, such as changes in operator training and implementation of hydrogen control measures for some containment types. Even with these changes and the stated finding of no undue risk, the NRC recognized that there was still much uncertainty in the phenomena associated with severe accidents, and the Severe Accident Policy included rationale for continuation of the Severe Accident Research Program. If the research uncovers further issues or questions of undue risk, then the Commission can act at that time.

Past research has indicated the plant-specific nature of severe accident vulnerabilities. Therefore, the Severe Accident Policy stated the desirability of performing a systematic examination of each nuclear power plant in order to identify potential plant-specific vulnerabilities to severe accidents. Three years later, the NRC issued a generic letter (88-20) and guidance (NUREG-1335), which called for licensees to perform a systematic Individual Plant Examination (IPE) of each nuclear power plant operating or under construction. ${ }^{15,16}$ The stated purpose of the Individual Plant Examination was to have each utility:

1. develop an appreciation of severe accident behavior;

2. understand the most likely severe accident sequences that could occur at its plant;

3. gain a more quantitative understanding of the overall probabilities of core damage and fission product releases; and

4. if necessary, reduce the overall probabilities of core damage and fission product releases by modifying, where appropriate, hardware and procedures that would help prevent or mitigate severe accidents.

The IPE Generic Letter makes it clear that a major benefit from this activity is the education of the utility staff in the area of severe accidents. The utilities are expected to perform much of the analysis in-house and not rely solely on consultants for performing the analysis.

IPE results were to be reported to the NRC within three years according to guidance provided in NUREG-1335. The results of the IPE have been reviewed by the NRC. Section 2.5 provides a discussion of these results, which will be used, in part, to deal with Unresolved Safety Issues and Generic Safety Issues. The IPE submittals indicate 
whether particular issues apply to the plant and the utility's case for resolution.

The severe accident policy recommends that new plants be shown to be acceptable for severe accidents by meeting specified criteria and procedural requirements, which include completion of a Probabilistic Risk Assessment (PRA) and consideration of the severe accident vulnerabilities that the PRA exposes. 


\section{References for Section $\mathbf{2 . 2}$}

1. U. S. Nuclear Regulatory Commission, "NRC Action Plan Developed as a Result of the TMI-2 Accident," NUREG-0660, May 1980.

2. John G. Kemeny, et al., "Report of the President's Commission on the Accident at Three Mile Island," October 1979.

3. M. Rogovin, et al., "Three Mile Island, A Report to the Commissioners and to the Public," U. S. Nuclear Regulatory Commission, NUREG/CR-1250, January 1980.

4. U. S. Nuclear Regulatory Commission, "TMI-2 Lessons Learned Task Force Final Report," NUREG-0585, October 1979.

5. U. S. Nuclear Regulatory Commission, "Clarification of TMI Action Plan Requirements," NUREG-0737, November 1980.

6. U. S. Nuclear Regulatory Commission, "Transient Response of Babcock \& Wilcox-Designed Reactors," NUREG0667.

7. U.S. Nuclear Regulatory Commission, Regulatory Guide 1.97, "Instrumentation or Light-Water-Cooled Nuclear Power Plants to Assess Plant and Environs Conditions During and Following an Accident," Revision 2, December 1980.

8. U.S. Nuclear Regulatory Commission, "Clarification of TMI Action Plan Requirements," NUREG-0737, Supplement 1, January 1983.

9. Federal Register, Vol. 45, 55,402, August 19, 1980.

10. J. Samuel Walker, "A Short History of Nuclear Regulation 1946-1990," Historical Office, Office of the Secretary, Nuclear Regulatory Commission, June 1991, p.38.

11. U. S. Nuclear Regulatory Commission, "Severe Accident Risks: An Assessment for Five US Nuclear Power Plants," NUREG-1150, December 1990.

12. Federal Register, Vol. 50, 32,138, August 8, 1985.

13. U. S. Code of Federal Regulations, "Individual Plant Examination for Severe Accident Vulnerabilities," Title 10, Part 50.54, (f) Generic Letter 8820, Nov 23, 1988.

14. U. S. Nuclear Regulatory Commission, "Individual Plant Examination: Submittal Guidance," NUREG-1335, August 1989. 


\subsection{The Chernobyl Accident}

The worst nuclear power plant accident occurred on April 26, 1986 at unit 4 of the nuclear power station at Chernobyl in the Ukraine. A violent explosion destroyed the Chernobyl-4 reactor, blew its top off, and spewed large amounts of radioactive material into the environment. The accident occurred during a test in which operators had turned off the plant's safety systems and then lost control of the reactivity in the reactor. The subsequent reactivity excursion led to a massive vapor explosion, followed by hydrogen combustion and a graphite fire that lasted several days. The areas around the plant were highly contaminated and 31 workers died, 28 from acute radiation sickness.

The radioactive plume spread far into other parts of the former Soviet Union and Europe. Although the plume did not pose a threat to the United States, one measure of its intensity was that levels of iodine-131 around Three Mile Island were three times higher after Chernobyl than they were after the TMI-2 accident.'

In many ways, the pre-Chernobyl attitude toward nuclear safety in the former Soviet Union was similar to the pre-TMI attitude in the United States. Influenced by the "it can't happen" mindset, operating personnel who were impatient to conduct a test took actions that violated procedures and began the accident. The accident took on catastrophic proportions as the result of undesirable reactor design features. ${ }^{2}$ This section provides a brief overview of the Chernobyl reactor design, a description of the sequence of events leading to the accident, and a discussion of the relevance of the accident to U.S. plants.

\subsubsection{Chernobyl-4 Design Features}

The Chernobyl-type reactors have undergone many design and operation changes since the accident at Chernobyl-4. The discussion below portrays the design as it existed at the time of the accident and does not reflect the many changes that have since occurred.

The Chernobyl site in located in the Ukraine and contains four RBMK reactors. As shown in Figure 2.3-1, the RBMK design is a graphite-moderated, light water cooled, pressure tube reactor. ${ }^{3}$ The RBMK-1000 design generates approximately $1000 \mathrm{MWe}$. The reactor has 1661 vertical pressure tubes that contain slightly enriched uranium dioxide fuel elements. The fuel tubes are made of a zirconium alloy and contain water at a pressure of about $1000 \mathrm{psig}(7.1 \mathrm{MPa})$. The water acts as a coolant, but unlike U.S. reactors, is not the primary moderator of neutrons.

The graphite moderator is $39 \mathrm{ft}$. (12 m) in diameter and $23 \mathrm{ft} .(7 \mathrm{~m})$ high. The fuel tubes pass up through the moderator assembly. Cooling water flows upward through the core with steam collected and driven through two turbines to generate electricity. Eight pumps return the water to the core. One of the most significant problems of the Chernobyl-4 core design was a positive void coefficient of reactivity. As boiling in the core increased, the power level increased. There were also problems with the reactivity control systems. 180 control rods are inserted from the top to control the reactor. To further exacerbate the reactivity problem, the control rods moved slowly and under some situations the control rods did not immediately introduce negative reactivity in the early phases of insertion. 
RBMKs do not employ a U.S. style containment building; however, they are not totally without containment. The graphite moderator is enclosed in a steel container filled with inert gases to prevent graphite fires. The steel container is further surrounded by a concrete structure on all sides but the top. The Russian design document speaks of compartmentalized containment to limit the spread of radionuclides in the event of a pipe rupture. Much of the primary system piping is contained in small concrete compartments. Each compartment is designed to withstand a double-ended guillotine break of the largest pipe in the compartment. The structure surrounding the reactor was designed to withstand the rupture of 3 pressure tubes.

\subsubsection{The Chernobyl Experiment}

The Chernobyl accident began on April 25 with an experiment. ${ }^{1}$ The experiment was a test designed to demonstrate that, in the event of a turbogenerator disconnection and the loss of offsite power, the inertia of the turbine rotor could be used to help maintain emergency power while the standby diesel generators were started. This in turn could relieve the diesel generators of the rapid startup requirements and associated stresses on the equipment. While such tests are not unknown, the procedures for the test were very poor, there was a desire to complete the tests quickly, and the operators lacked a complete understanding of the hazards involved.

Virtually no additional safety measures were taken during the test. The safety procedures indicated that all switching operations were to have the permission of the plant shift foreman and that during an emergency the staff members were to follow plant instructions. (There were no specific instructions for these conditions.) This situation was in spite of the fact that the experiment called for deactivation of the Emergency Core Cooling System, so that it would not automatically actuate as the circulation pumps ran down.

\subsubsection{The Sequence of Events}

The material in this section was taken primarily from a September 11, 1986 special issue of Nuclear News. ${ }^{3}$ This special issue contains an analysis of the accident by Valery Legasov of the Soviet Union as presented to an International Atomic Energy Agency conference in Vienna. Legasov presented a candid view of the accident, including many side comments. He noted, for example, that there would have been pressure on the operators to complete the tests as they shutdown on this occasion, because the next planned maintenance period was more than a year away. He also said that, in hindsight, it can be seen that technical means could easily have been used to prevent the operators from overriding safety protection systems and otherwise violating procedures. Failure to provide adequate protection for such human error represented "a tremendous psychological mistake" on the part of the designers of the $\mathrm{RBMK}$ reactor.

The run up to the accident started at 1:00 a.m. on April 25, with the reduction of reactor power over the next five minutes from $100 \%$ (3200 MWt) to half that power. Then the unwanted turbogenerator was shut down. The plant systems that had been connected to this turbogenerator, including four of the main circulation pumps and two feedwater pumps, were switched to the grid busbars of the turbogenerator that was still on line. 
At 2:00 pm, the ECCS was isolated to prevent it from kicking in automatically. The start of the test, however, was then postponed at the request of the local electricity dispatcher. As a result, the plant was maintained in the unauthorized state with no ECCS for the next nine hours, although this particular violation did not in actuality play any important part in what followed. Still, the delay may have aggravated operator impatience over the test, and contributed to the "mindset" that led plant personnel to ignore procedures and block safety systems in their effort to get the plant to the proper power level for the test.

At 11:10 pm, the load demand was lifted, and preparation for the test resumed with power reduced to the required level, 700$1000 \mathrm{MWt}$. The automatic control system that operates on groups of control rods in 12 zones of the core, to stabilize power density distribution, was switched off, in keeping with a low-power operation requirement. At higher power levels, these zonal rods also regulate the average power automatically. When the local controllers are switched off, automatic controllers working on a signal of the average power of the whole core come into play, but it appears that the operators did not synchronize this automatic system quickly enough to the required power setpoint. There was an overshoot in the power reduction, and the level fell below 30 MWt.

By 1:00 am on April 26, the operators were able to stabilize the power back at $200 \mathrm{MWt}$, but this was as high as they could get it due to the xenon poison buildup that had started during the excursion to lower power and was still continuing. To drag the reactor up to $200 \mathrm{MWt}$, the operators had pulled far too many of the manual control rods out of the reactor, and the neutron flux distribution in the core was such that the reactivity worth of those rods that would be effective in the first few centimeters of travel back into the core was limited to the equivalent of six to eight fully inserted rods.

According to the rules, the operating margin of reactivity should not be allowed to go below 30 rod equivalents without special authorization from the chief engineer of the power station. Legasov said that if the margin ever falls below 15 rod equivalents, "nobody in the whole world, not even the Prime Minister, can authorize continued operation of the reactor." But the operators were so intent on getting the reactor up to an acceptable power level for the test that they ignored the touchy side of the reactor.

Thus, the operators at Chernobyl- 4 decided to press on, and at 1:03 and 1:07 a.m., they started the sixth and seventh main circulation pumps in immediate preparation for the tests. Since the reactor power, and consequently the hydraulic resistance of the core and the recirculation circuit, were substantially lower than planned, the full eight pumps produced a massive coolant flow through the reactor, 245,000 to 255,000 gpm $\left(56,000\right.$ to $\left.58,000 \mathrm{~m}^{3} / \mathrm{hr}\right)$. At some individual pumps, the flow was up to 35,000 gpm $\left(8000 \mathrm{~m}^{3} / \mathrm{hr}\right)$, compared with a normal operating level of $30,000 \mathrm{gpm}\left(7000 \mathrm{~m}^{3} / \mathrm{hr}\right)$. This was another violation, because of the danger that pump breakdown and vibration could be caused by cavitation at the pumps. But the most serious consequence of the increased flow was the creation of the coolant conditions very close to saturation, with the possibility that a small temperature increase could cause extensive flashing to steam. The steam pressure and the water level in the steam separation drums had also dropped below emergency levels, but, as part of the continuing attempt to keep the reactor running long enough for the test to be started, the operators also blocked the 
resulting signals of the low levels to the emergency protection system.

At 1:19 a.m., the feedwater supply was increased to as much as four times its initial value in an attempt to restore the water level in the steam separation drums. This reduced both the reactor coolant inlet temperature and fuel channel steam production, with consequent negative reactivity effects. Within 30 seconds the automatic control rods had fully withdrawn in response to the negative reactivity, and the operators attempted to withdraw the manual rods as well. But the operators again overcompensated, and the automatic rods began to move back in.

At 1:22 a.m., the reactor parameters were approximately stable, and the decision was made to start the actual turbine test. But in case they wanted to repeat the test again quickly, the operators blocked the emergency protection signals from the turbine stop valve, which they were about to close, so that it would not trip the reactor. Also, just before they shut off the steam to the turbine, they sharply reduced the feedwater flow back to the initial level required for the test conditions. This boosted the coolant inlet temperature, creating a transient situation that could not be addressed because safety systems, were cut off.

At 1:22:30 a.m., the operators obtained a printout from the fast reactivity evaluation program, giving them the position of all the rods and showing that the operating reactivity margin had fallen to a level that required immediate shutdown of the reactor. But they delayed long enough to start the test. There was clearly a failure to appreciate the basic reactor physics of the system, which had rendered the control rods relatively worthless. The neutron flux distribution in the core had been pulled into such a distorted shape that the majority of the rods would have go to well into the core before they would encounter sufficient neutron flux for their absorption to be effective.

At 1:23:04 a.m., the turbine stop valve was closed. With the isolation of the turbine, four of the primary circulation pumps started to run down, another transient situation for which the automatic responses had been cut off.

Shortly after the beginning of the test, the reactor power began to rise sharply. The bulk of the coolant was very close to the saturation point at which it would flash to steam, because the operators had earlier run an excessive level of coolant flow with all eight pumps on during low power reactor operation. The RBMK reactor, with its positive void coefficient, responds to any such formation of steam with an increase in reactivity and power, and further increases in temperature and steam production resulting in a runaway condition.

At 1:23:40 a.m., the scram button, which would drive all control rods into the core, was pushed. Legasov told the Vienna meeting that there seemed to be some ambiguity about the motivation for this action, as unearthed during subsequent questioning by investigators of the fatally ill shift foreman, who had given the order. He may have been belatedly responding to the printout of reactivity margin; he could have been responding to the sharp rise in reactor power; or he may simply have believed that the test had now run long enough to allow him to shut down the reactor.

After a few seconds a number of shocks were felt in the control room, and the operator saw that the control rods had not reached their lower stops. He therefore 
deactivated the rods to let them fall by gravity.

At about 1:24 a.m., observers outside the plant reported two explosions, one after the other; burning lumps of material and sparks shot into the air above the reactor and some fell onto the roof of the turbine hall and started a fire.

In his presentation of Table 2.3-1, which delineates the operator violations, at the Vienna meeting, Legasov said that if any one of the first five violations had not been committed, the accident would not have happened.

\subsubsection{Inside the Reactor}

The mechanism of the accident, particularly in the last few seconds before the explosion that literally blew the top off the reactor, was the subject of intense interest for one of the working groups at the meeting. By the end of the week, the consensus of international experts was that the accident mechanism as described in the Soviet report, a prompt critical reactivity excursion and a steam explosion, was a wholly plausible explanation for what happened. There is still a need for more detailed understanding of the mechanism, and some doubts linger on the cause of a second explosion that was reported to have taken three or four seconds after the first.

The prompt critical excursion took the power first to around $530 \mathrm{MWt}$ at 1:23:40, and only the Doppler effect of the fuel heating up to an estimated $3000^{\circ} \mathrm{C}$ pulled it back down briefly. The continuing reduction of water flow through the fuel channels during the power excursion led to intensive steam production, the destruction of the fuel, a rapid surge of coolant boiling (with the particles of destroyed fuel entering the boiling water), a rapid and destructive increase of pressure in the fuel channels, and finally the explosion that destroyed the reactor.

At precisely the moment of fuel disruption, which was believed to occur when the energy density in the fuel exceeded 540 $\mathrm{Btu} / \mathrm{lb} \mathrm{b}_{\mathrm{m}}(1260 \mathrm{~J} / \mathrm{g})$, there was an abrupt fall of the coolant flow as check valves on the main circulation pumps closed in response to the increased pressure in the core. This loss of flow was also recorded by the datalogging system. The flow from the pumps would have been partially restored after the rupture of the fuel channels, but the water was now directed into a mass of damaged zirconium and hot graphite. The ensuing reaction would have produced large amounts of hydrogen and carbon monoxide, which, upon contact with air above the reactor, could have caused the second explosion.

\subsubsection{Implications for U.S. Plants}

U.S. reactors employ very different designs than Chernobyl-4. First, all U.S. power reactors have negative reactivity coefficients in virtually every situation, and control rods in U.S. plants provide fast negative reactivity insertion. Further, disabling of safety systems in violation of technical specifications is not expected to knowingly occur. The level of safety-related training is much higher than that attained at Chernobyl prior to the event. In addition, as discussed in Chapter 4, all U.S. power reactors employ large strong containment structures. Such a structure might not have been effective against the enormous energy releases of Chernobyl, but would be effective in many postulated severe accidents at U.S. plants.

One U.S. reactor, the N Reactor at Hanford, Washington, was shut down following Chernobyl. The design of the $\mathrm{N}$ Reactor 
included pressure tubes and graphite moderation, but was different from Chernobyl in many other respects. However, the reduced need for the plutonium that it produced coupled with adverse publicity and safety concerns led to the ultimate shutdown and mothballing of the $\mathrm{N}$ Reactor.

Supporters of nuclear power emphasized that a Chernobyl-type accident could not occur in commercial U.S. plants (or other nations), which featured safety systems and containments to prevent the release of radionuclides. But nuclear critics pointed to Chernobyl as the prime example of the hazards of nuclear power. The Chernobyl tragedy was a major setback to the hopes of nuclear proponents to win public support for the technology and to spur orders for new reactors. U. S. utilities had not ordered any new plants since 1978 and the number of cancellations of planned units was growing. The Chernobyl accident added a new source of concern to long-standing controversies over the licensing of U.S. plants.

The Chernobyl accident could not be repeated at a U.S. nuclear power plant due to fundamental differences in reactor design. Nevertheless, risk assessments of U.S. plants have identified possible severe accidents in which containment fails and very large releases of radionuclides occur. Most of these releases would not be accompanied by explosions or fires like those at Chernobyl where the radioactive plume was lofted high into the atmosphere and away from local residents. As discussed in Chapter 5, a large release from U.S. plant could, under unfavorable meteorological conditions, result in more early fatalities than occurred at Chernobyl. While uncontained severe accidents leading to such releases are not considered likely, one should avoid the mindset that "it can't happen here." 


\section{Table 2.3-1 The most dangerous violations of operating procedures at Chernobyl-4*}

Violation

1. Reducing operational reactivity margin below permissible limit

2. Power level below that specified in test program

3. All circulating pumps on with some exceeding authorized discharge

4. Blocking shutdown signal from both turbogenerators

5. Blocking water level and steam pressure trips from drum-separator

6. Switching off emergency core cooling system
Motivation

Attempt to overcome

xenon poisoning

Error in switching

off local auto-control

Meeting test requirements

To be able to repeat tests if necessary

To perform test despite unstable reactor

To avoid spurious triggering of ECCS
Consequence

Emergency protection system was ineffective

Reactor difficult to control

Coolant temperature close to saturation

Loss of automatic shutdown possibility

Protection system based on heat parameters lost

Loss of possibility to reduce scale of accident

*From the Soviet Union summary of its report to the IAEA. 


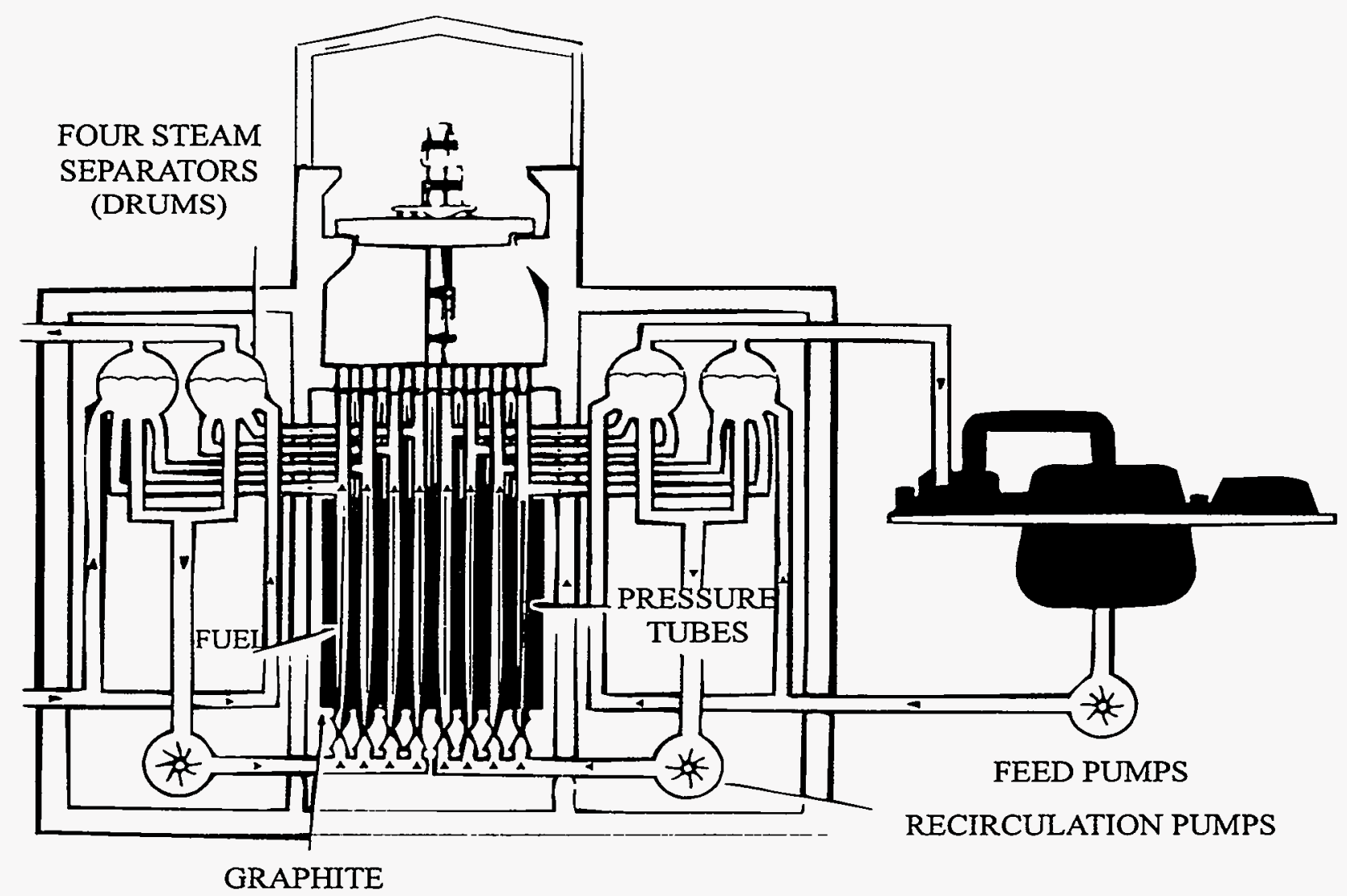

Schematic diagram of the RBMK-1000, a heterogeneous water-graphite channel-type reactor (source: Soviet report to IAEA)*

*Reprinted with special permission from IAEA

Figure 2.3-1 Boiling water pressure tube graphite moderated reactor 


\section{References for Section 2.3}

1. R. A. Knief, "Nuclear Engineering, Accident at Unit 4 of Chernobyl Nuclear Theory and Technology of Commercial Nuclear Power," Second Edition, Hemisphere Publishing, 1992, p. 458.

2. N. A. Shteynberg et al., "On the Causes and Circumstances of the Power Plant on 26 April 1986," Report of USSR GPAN Commission, NRC Translation 2932, 1991.

3. American Nuclear Society, "Special Report," Nuclear News, La Grange Park, Illinois, September 11, 1986. 


\subsection{Risk Influences and the Development of Safety Goals}

As discussed in Section 1.2.1, the Atomic Energy Act of 1954 requires the NRC to ensure that

the utilization or production of special nuclear material will

... provide adequate protection

to the health and safety of the public.

In its rules and decisions, the Commission refers to this standard as either the "adequate protection" standard or the "no undue risk" standard. The interchangeable use of these two terms has been accepted in legal decisions. ${ }^{1,2}$ Congress left it to the AEC/NRC to determine what constituted "no undue risk." Prior to the TMI-2 accident, such determinations were based primarily on the engineering judgment of the NRC staff, the ACRS, and the Commissioners. Following the TMI- 2 accident, the NRC began to deal with risk in a more systematic and quantitative manner through the use of PRA techniques. Quantitative risk limits have not generally been imposed in NRC regulations; however, quantitative risk estimates do provide supporting rationale and impetus for regulatory decisions. As PRA has improved over the years, the weight given to quantitative risk estimates has increased.

The next sections describe the role that quantitative risk estimates played in addressing past important regulatory issues. Then, the development of the backfit rule and safety goals are discussed.

\subsubsection{Past Risk-Influenced Regulatory Practices}

Risk considerations, both qualitative and quantitative, have influenced a number of existing regulations and in fact have always been present in the minds of decision makers.
The remainder of this section will give examples illustrating how the consideration of risk has evolved from an ad hoc approach to a more systematic process.

\subsubsection{Anticipated Transients Without Scram}

An "anticipated transient" is an event that is expected to occur one or more times during the life of a nuclear power plant. There are a number of anticipated transients, some quite trivial and others that are more significant in terms of the demands imposed on plant equipment. Anticipated transients include such events as a loss of electrical load that leads to closing of the turbine stop valves, a load increase such as opening of a condenser bypass valve, a loss of feedwater flow, and a loss of reactor coolant flow.

The reactor protection system (RPS) is designed to monitor key plant variables to detect offnormal plant conditions arising from anticipated transients and automatically initiate whatever safety action is needed. For some anticipated transients, to assure that no damage to the plant occurs, the RPS is designed to automatically "scram" the reactor, that is, to cause the control rods to rapidly move into the core, thereby shutting down the nuclear reaction and reducing the heat generation rate to that associated with radionuclide decay (see Figure 1.4-1). An "anticipated transient without scram" or ATWS event would occur if the RPS failed to scram the reactor given such a transient. Appendix 2B provides more information about the RPS and ATWS.

\section{Origin of the ATWS Issue}

The concern about ATWS originated in discussions of the ACRS, the regulatory staff, and reactor manufacturers about potential interactions between reactor control and protection systems. This concern was based on a classic accident that occurred at the High 
Temperature Reactor Experiment (HTRE-3), an experimental reactor in Idaho. ${ }^{3}$ Both the control system and protection system for this reactor took inputs from the same neutron flux instruments. A design defect in these instruments prevented an increase in current when the reactor power increased. The unchanging current caused the reactor control system to withdraw the control rods and simultaneously blinded the reactor protection system to the resulting power increase. The core was destroyed.

ACRS member S. H. Hanauer began raising the control/protection separation issue in connection with specific plants being reviewed by the ACRS in 1966 and 1967. Reactor instrument designers carried out analyses of various kinds of failures. After considerable discussion, and some design changes, it was determined that separation of control and protection functions was being achieved to a reasonable degree, either by physical separation or by electrical isolation. It became clear that failures caused by equipment wear-out or failures occurring on a random basis in protection systems would not cause appreciable deterioration of reliability because of the redundancy of the systems. It was not so clear, however, that these systems were sufficiently invulnerable to common cause failures (see Appendix 2B).

In a letter to the ACRS dated January 21, 1969, E. P. Epler, an ACRS consultant, pointed out that common cause failures could reduce the reliability of protection systems in such a way that the system might not function properly in the event of an anticipated transient. ${ }^{3}$ Epler argued as follows: (1) Reactor scram was needed to prevent core meltdown and a loss of containment integrity following a routine operating event such as loss of electric load, which might occur about once a year. (2) A scram failure probability smaller than $10^{-4}$ per demand could not be defended because of the possibility of common cause failures.
(3) Therefore, core melt and a major release of radioactivity might occur with a probability larger than $10^{-4}$ per reactor-year.

In a memorandum enclosed with his letter, Epler noted that public figures like Alvin Weinberg, the Director of Oak Ridge National Laboratory (ORNL), and Chauncey Starr, then Dean of Engineering at the University of California, Los Angeles, and formerly President of Atomics International, had publicly indicated that the probability of a serious reactor accident was similar to that of a jet airliner plunging into Yankee Stadium during a World Series game, which Epler estimated as roughly $10^{-7}$ per year. However, because of the lack of measures to cope with the China Syndrome, and because of his own estimate of the probability of scram failure, Epler felt that the actual probability of a serious accident might be a factor of 1,000 higher.

The ATWS issue posed by Epler sparked heated debate and took over 15 years to resolve. Initial efforts to resolve the issue took two general directions. The first involved attempts to evaluate the likelihood of common cause or other failures of reactor protection systems that might lead to ATWS events. Second, in late 1970, analyses of the consequences of postulated ATWS events were requested of reactor designers, and all the designers performed these analyses.

\section{WASH-1270}

In September 1973 the NRC publicly adopted a position on ATWS with the publication of the WASH-1270 report. ${ }^{4}$ Along with providing for important plant design changes, an important aspect of the WASH-1270 report was that it defined an overall safety goal, as well as a quantitative goal for ATWS, for future plants. Specifically, the overall safety goal was that

... the risk to the public from all reactor accidents should be 
very small compared to other risks of life such as disease or natural catastrophes.

Projecting about one thousand nuclear plants in the United States by the year 2000 , it was argued that the safety objective would require

that there be no greater than one chance in one million per year for an individual plant of an accident with potential consequences greater than the Part 100 guidelines.

WASH-1270 further proposed to allocate only one-tenth of their objective to any one accident type; hence, the safety objective for ATWS was that it not lead to an accident with serious offsite consequences more frequently than $10^{-7}$ per reactor-year.

With the issuance of the WASH-1270 report in September 1973, the regulatory staff had taken a position on ATWS and it was seemingly resolved except for implementation. The ACRS moved the ATWS issue into the resolved column on their list of generic issues in February 1974. In the period 1974-1975 all the reactor vendors submitted analyses on ATWS in general response to the requirements set forth in the WASH-1270 report.

Unfortunately, the resolution of ATWS was short lived. In the ensuing years a number of positions were taken by the NRC and the industry. In 1975 the NRC proposed additional design changes. The industry countered by pointing out that the Reactor Safety Study did not show ATWS as a major contributor to risk for LWRs. The industry followed up with a series of reports indicating low risk to the public.

In April 1978 the regulatory staff issued a new report, NUREG-0460, titled "Anticipated Transients Without Scram for Light Water
Reactors." ${ }^{15}$ This report proposed a change in safety objective for an unacceptable ATWS from $10^{-7}$ per reactor-year as set forth in the WASH1270 to $10^{-6}$ per reactor-year. This was apparently based on the overall frequency of core melt predicted in the Reactor Safety Study $\left(5 \times 10^{-5}\right.$ per reactor-year). The staff employed a mixture of deterministic and probabilistic analyses to prescribe the design approaches that would be needed to meet the new safety objective for each LWR vendor. The new staff proposals were again opposed very strongly by the industry, and after many meetings between the NRC staff, the ACRS, and representatives of the nuclear industry, strong differences of opinion still existed.

\section{Failure of Control Rods to Fully Insert at Browns Ferry 3}

On June 28, 1980, Browns Ferry Unit 3, a BWR, reported that 76 of 185 control rods failed to insert fully into the core when a manual scram was initiated by the reactor operator. Fortunately, this occurred during a routine shutdown from about $35 \%$ power, rather than during the kind of reactor transient in which complete and rapid scram of all the rods might have been important.

The problem was determined to be hydraulic in nature rather than electrical or mechanical. The control rod drives (CRDs), which insert and withdraw the attached control rods in a General Electric BWR, are essentially water-driven hydraulic pistons. On a scram, a relatively high water pressure is applied to the bottom side of the piston by opening a scram inlet valve. A scram outlet valve opens to relieve water and pressure above the piston and the rods are rapidly driven up into the reactor core. Water discharged from the 185 individual $\mathrm{CRDs}$ during scram insertion is collected in two separate headers called the scram discharge volumes (SDVs). During normal operation, both SDVs are designed to remain empty. 
Tests, inspections, and analyses conducted after the event led to the conclusion that the east SDV was substantially full of water at the time of the event, leaving insufficient room for the discharge water. Accordingly, upon scram actuation, the CRDs rapidly drove the control rods partially into the core but rod motion prematurely ceased when pressure quickly equalized on each side of the pistons. Following each scram actuation, the scram signal was reset by the operator, allowing more water to drain from the SDV and permitting the rods to insert further. Sufficient water was finally drained from the SDV to allow the rods to insert fully on the fourth scram signal.

A Preliminary Notification was issued promptly and on July 3, 1980 the NRC issued IE Bulletin 80-17 to all BWR licensees. Continuing NRC review of the Browns Ferry event identified other problems, which required tests, inspections, hardware changes, new procedures, and operator training at various BWR plants. These actions are discussed in Appendix 2B. Browns Ferry Unit 3 was authorized to restart on July 13,1980 , following completion of the actions required by IE Bulletin 80-17 and other extensive tests.

\section{ATWS Event at Salem 1}

At 12:21 a.m. on February 25, 1983 a low-low water level condition in one of the four steam generators at Salem 1 initiated a reactor trip signal in the reactor protection system. At the time, the reactor was at $12 \%$ rated thermal power in preparation for power escalation after a recently completed refueling outage. Upon receipt of the valid reactor trip signal, both of the redundant reactor trip breakers failed to open (opening of either reactor trip breaker would have caused the reactor to trip). About 25 seconds later, operators manually initiated a reactor trip from the control room. The reactor trip breakers opened as a result of the manual trip signal and this resulted in insertion of all control rods and shutdown of the reactor. Following the manual trip, the plant was stabilized in the hot standby condition. All other systems functioned as designed. Approximately two hours after the Salem 1 event, the cause of the failure to trip was determined by licensee instrumentation technicians to be failure of the UV trip device in both reactor trip breakers to function as designed. The plant was placed in cold shutdown at the request of the NRC.

On February 26, 1983 NRC investigators discovered that a similar failure had occurred on at Salem 1 on February 22, 1983. Based on a computer printout of February 22 events, it was evident that on that day (as on February 25) the two reactor trip breakers failed to open upon receipt of an automatic trip signal from the reactor protection system. The operators initiated a manual trip even though they were unaware that the automatic trip had failed.

Due to the serious nature of Salem 1 ATWS event, the NRC issued Inspection and Enforcement Bulletin No. $83-01^{6}$ on the same day (February 25, 1983) to all PWR licensees for action and to other nuclear power reactor facilities for information. Subsequent initiatives on the part of NRC and industry identified and corrected potential deficiencies in reactor trip breakers and related maintenance procedures at several other plants as described in Appendix 2B.

Because of previously identified problems at Salem and the licensee's failure to recognize that an ATWS event had occurred on February 22, 1983 the NRC did not permit the Salem plants to restart until both technical and management corrective actions were satisfactorily addressed. On April 26, 1983 the NRC agreed that the plants could be returned to service; however, on May 5, 1983 the NRC forwarded to the Salem licensee a Notice of Violation and Proposed Imposition of Civil Penalties (for $\$ 850,000) .{ }^{7}$ Violations included operation of the reactor even though the reactor protection 
system could not be considered operable, and several significant deficiencies which contributed to the inoperability of the reactor trip breakers. Region I instituted an augmented inspection program at Salem to monitor the licensee's progress towards completion of longer term corrective actions, including independent management consultants' recommendations.

The special NRC task force prepared a twovolume report, NUREG-1000. ${ }^{8}$ The first volume dealt with the generic implications of the Salem events. The second volume documented the NRC actions to be taken based on the work of the task force. The results of the task force were considered in deliberations regarding the ATWS position and rule, which was being developed by the NRC.

\section{CFR 50.62, The ATWS Rule}

On November 24, 1981, 15 months before the Salem 1 ATWS event, the NRC invited comments on three proposed ATWS rules.' In July 1982 a Task Force and Steering Group of NRC personnel from several offices was formed to consider comments received on the three proposals and to develop a final rule on ATWS. Appendix 2B reproduces the final ATWS rule and also discusses the key changes that were considered. ${ }^{10}$

The Commission stressed that ATWS risk reductions can also be achieved by reducing the frequency of transients which call for the reactor protection system to operate. Challenges to the reactor protection system may arise from unreliable components, inadequate post-trip reviews, poor testing, or tolerance of inadequate or degraded control systems. Operating experience in Japan indicated a transient frequency that was substantially less than in the United States. Utilities had categorized transients for over ten years but had not specifically instituted a program to reduce them. While not specifically required by the ATWS rule, the Commission urged licensees to analyze challenges to the plant safety systems, particularly the reactor trip system, and determine how improvements could be made. " Industry response to this challenge has been positive as indicated in Figure 2.4-1.

Interestingly, the final rule says nothing about quantitative risk goals. In this case, risk arguments provided the impetus for the rule but are not present in the final rule.

\subsubsection{Auxiliary Feedwater Reliability}

The auxiliary feedwater system (AFWS) normally operates during startup, hot standby, and shutdown to provide feedwater to PWR steam generators. In conjunction with a Seismic Category I water source, it also functions as an emergency system for the removal of heat from the primary system when the main feedwater system is not available for emergency conditions including small LOCAs. The AFWS operates over a time period sufficient either to hold the plant at hot standby for several hours or to cool down the primary system (at a rate not to exceed limits specified in technical specifications) to temperature and pressure levels at which the low pressure decay heat removal system can operate.

The Reactor Safety Study found the AFWS to be important in preventing certain core damage scenarios, and the loss of auxiliary feedwater at TMI-2 reinforced concerns regarding the reliability of the AFWS. Prior to the accident at TMI-2 there was wide variance in design philosophy for auxiliary feedwater systems. In particular the degree of diversity and redundancy varied widely. Some multi-plant sites had only one auxiliary feedwater pump per plant with interconnections between units. Other plants had two motor driven and one turbine-driven pump.

The NRC reviews information provided on the AFWS in the applicant's Safety Analysis Report following the Standard Review Plan. In July 
1981, Section 10.4.9 of the Standard Review Plan $^{12}$ required that, as part of their review, the NRC assure that an AFWS reliability analysis be performed in accordance with NUREG$0737^{11}$ using the methodology defined in NUREG$0611^{13}$ and NUREG-0635. ${ }^{14}$ Such an analysis provides an estimate the AFWS reliability and indicates major contributors to AFWS failure for various loss of main feedwater transients.

As set forth in Standard Review Plan Section 10.4.9, an acceptable AFWS should have an unreliability in the range of $10^{-4}$ to $10^{-5}$. Compensating factors such as other methods of accomplishing the safety functions of the AFWS or other reliable methods for cooling the reactor core during abnormal conditions may be considered to justify a larger unavailability of the AFWS.

In December 1986, additional regulatory guidance regarding auxiliary feedwater systems was set forth. ${ }^{\text {is }}$ The new guidance called for operating plants to demonstrate a $10^{-4}$ unreliability using plant-specific data. This guidance is an example of the use of quantitative risk estimates, although they apply only to a particular system and not to the risk of a severe accident.

\subsubsection{Station Blackout Rule}

Station blackout is the complete loss of alternating current (AC) electrical power to the essential and nonessential switchgear buses in a nuclear power plant. Many safety systems required for reactor core cooling and containment heat removal depend on $\mathrm{AC}$ power; however, because station blackout requires multiple component failures, U.S. plants were not specifically designed (before the July 21 , 1988 station blackout rule) to withstand station blackout. In 1975 the Reactor Safety Study showed that station blackout could be an important contributor to the total risk from nuclear power plant accidents. ${ }^{16}$ As operating experience accumulated, the concern arose that the reliability of both the onsite and offsite emergency AC power systems might be less than originally anticipated. In 1979 the NRC designated station blackout as an unresolved safety issue. A task action plan for issue resolution (TAP A-44) was issued in July 1980, and work was begun to determine whether additional safety requirements were needed.

Operating plant data and several plant specific probabilistic studies yielded the quantitative information presented in Table 2.4-1 and the following important findings regarding station blackout. ${ }^{17}$

1. The variability of estimated station blackout likelihood is potentially large, ranging from approximately $10^{-5}$ to $10^{-3}$ per reactor-year. A "typical" estimated frequency is on the order of $10^{-4}$ per reactor-year.

2. The capability to restore offsite power in a timely manner (less than 8 hours) can have a significant effect on accident consequences.

3. The redundancy of onsite $A C$ power systems and the reliability of individual power supplies have a large influence on the likelihood of station blackout events.

4. The capability of the decay heat removal system to cope with long duration blackouts (greater than 2 hours) can be a dominant factor influencing the likelihood of core damage or core melt for the accident sequence.

5. The estimated frequency of station blackout events that result in core damage or core melt can range from approximately $10^{-6}$ to greater than $10^{-1}$ per reactor-year. A "typical" core damage frequency estimate is on the order of $10^{-5}$ per reactor-year. 
The station blackout rule 10 CFR $50.63,{ }^{18}$ which became effective on July 21,1988 , was promulgated to reduce the risk of severe accidents resulting from station blackout by: (a) maintaining highly reliable ac electric power systems; and (b) as additional defense in depth, assuring that plants can cope with a station blackout for a specified duration selected on a plant-specific basis. ${ }^{19}$

It should be noted that station blackout was not deemed to constitute an undue risk without the station blackout rule. It was recognized that, even with the rule, station blackout may still remain an important contributor to residual risk. The station blackout rule was developed to enhance safety by accident prevention and thereby reduce the likelihood of a core damage accident being caused by a station blackout. Like the ATWS rule (Section 2.4.1.1) it recognizes and addresses the threat posed by common cause failures.

The station blackout rule identifies the reliability of onsite emergency ac power sources as being one of the main factors contributing to risk of core melt resulting from station blackout. Diesel generator units have been widely used as the power source for the onsite electric power systems. The NRC staff developed Regulatory Guide 1.155 entitled "Station Blackout," which presents guidance on (1) maintaining a high level of reliability for emergency diesel generators, (2) developing procedures and training to restore offsite and onsite emergency ac power should either one or both become unavailable, and (3) selecting a plant-specific acceptable station blackout duration that the plant would be capable of surviving without core damage. Application of the methods in this guide would result in selection of an acceptable station blackout duration (e.g. 2, 4, 8, or 16 hours) that depends on the specific plant design and site-related characteristics.
The station blackout rule allows utilities several design alternatives to ensure that an operating plant can safely shut down in the event that all ac power (offsite and onsite) is lost. The NRC staff prefers demonstrating compliance with 10 CFR 50.63 through the installation of a spare (full capacity) alternate ac power source of diverse design that is consistent with the guidance in Regulatory Guide 1.155 and is capable of powering at least one complete set of normal safe shutdown loads. Although an alternate AC power source is the preferred resolution to this issue in 10 CFR 50.63, NRC imposition would exceed current NRC regulations. For advanced LWRs the NRC staff has recommended that the NRC commissioners approve imposition of an alternate ac power source.

The resolution of the station blackout safety issue established the need for an emergency diesel generator (EDG) reliability program that has the capability to achieve and maintain the emergency diesel generator reliability levels in the range of 0.95 per demand or better to cope with station blackout. Explicit guidance in the areas of diesel-generator preoperational testing, periodic testing, and reporting requirements have been developed for meeting this reliability goal in a revision to Regulatory Guide $1.9{ }^{20}$ which was prepared for the resolution of Generic Safety Issue B-56, "Diesel Reliability."

\subsubsection{Backfit Rule}

Backfitting is defined in some detail in $10 \mathrm{CFR}$ 50.109 , but for purposes of discussion here it means measures which are directed by the Commission or by NRC staff in order to improve the safety of nuclear power reactors, and which reflect a change in a prior Commission or staff position on the safety matter in question. ${ }^{21}$ The current Backfit Rule has evolved in three stages: 
Reactor Safety Course (R-800)

1. the 1970 Backfit Rule which allowed the NRC to take advantage of technological advances in safety,

2. the 1985 Final Backfit Rule which included cost impact in the consideration of backfits, and

3. the 1988 Amended Final Backfit Rule which dealt with legal problems associated with cost considerations.

The NRC promulgated its first rule concerning the "backfitting" or safety-enhancement of nuclear reactors in 1970. In explaining the need for such a rule, the NRC noted that

rapid changes in technology in the field of atomic energy result in the continual development of new or improved features designed to improve the safety of production and utilization facilities. ${ }^{22}$

The rule addressed these technological changes by setting forth a standard governing when the NRC could require a plant previously licensed for construction or operation to incorporate a new safety feature. The rule stated that

the Commission may ... require the backfitting of a facility if it finds that such action will provide substantial, additional protection which is required for the public health and safety or the common defense and security. ${ }^{23}$

The rule excepted from this standard any backfit that was necessary to bring a facility into compliance with its license or a Commission order, rule, or regulation. A backfit of this kind was apparently always required.
2.4 Risk Influences and the Development of Safety Goals

By the end of the 1970s the backfit rule had become the target of widespread criticism. Some charged that the rule allowed the Commission to ignore the need for backfitting outmoded plants. For example, the President's Commission on the TMI- 2 accident ${ }^{24}$ stated that the rule had not forced the NRC to "systematically consider" the "need for improvement of older plants." Others charged that the rule allowed the Commission to indiscriminately impose backfits without regard to their real necessity or cost. For example, NRC's Regulatory Reform Task Force claimed that

The staff's prior backfitting
practices which have cost
consumers billions of dollars
have made nuclear plants more
difficult to operate and
maintain, have injected
uncertainty and paralyzing delay
into the administrative process
and in some instances may have
reduced rather than enhanced
public health and safety. ${ }^{25}$

All commentors appeared to agree that the rule had failed to systematize or rationalize the Commission's backfitting process.

In response to criticism of the 1970 rule, the NRC published an advance notice of proposed rule-making on September 28, 1983. The notice invited public comment on draft backfit rules proposed by the Commission's Regulatory Reform Task Force and the Atomic Industrial Forum, the trade association of the nuclear power industry. Fourteen months later, after having received and reviewed numerous comments the Commission published a proposed version of the final rule. ${ }^{26}$ Parties commented on the rule, focusing especially on the authority of the Commission to consider economic costs when deciding whether to impose backfits. 
On September 20, 1985 the Commission published its final rule, which became effective on October $21,1985 .^{27}$ The heart of the final backfit rule is the standard governing the circumstances in which the Commission will order a backfit. The standard incorporated the 1970 rule's requirement that the backfit substantially increase protection to health and safety, but added an additional requirement that the benefits of the backfit justify its costs. Specifically, the rule provided:

The Commission shall require the backfitting of a facility only when it determines ... that there is a substantial increase in the overall protection of the public health and safety or the common defense and security to be derived from the backfit and that the direct and indirect costs of implementation for that facility are justified in view of this increased protection.

The rule set forth in some detail the way in which the NRC would make the determination of whether a proposed backfit meets the governing standard. The rule requires that the NRC prepare a "systematic and documented analysis" of each proposed backfit, considering available information concerning nine factors:

1. the specific objectives of the proposed backfit;

2. the activity that would be required by the licensee to complete the backfit;

3. the potential change in risk to the public resulting from the backfit;

4. the potential impact of the backfit on the radiological exposure of the facility's employees;
5. the costs of installation and maintenance associated with the backfit, including the cost of facility downtime or construction delay;

6. the potential impact on safety of the changes in plant or operational complexity resulting from the backfit;

7. the estimated resource burden on the NRC associated with imposing the backfit;

8. whether the relevancy and practicality of the particular kind of backfit will vary from facility to facility; and

9. whether the backfit is an interim measure and, if so, the justification for imposing the backfit on an interim basis.

In addition to considering these nine factors, the rule required the NRC to take into account "any other-information relevant and material to the proposed backfit" in preparing the requisite analysis.

The rule also stated that "backfit analysis is not required and the standard does not apply" in three situations. The first exception, similar to the exception in the 1970 rule, is when a backfit is necessary to bring a facility into compliance with a license, the rules or orders of the Commission or written commitments of the licensee. The second exception is when

an immediately effective regulatory action is necessary to ensure that the facility poses no undue risk to the public health and safety.

The rule provides that the imposition of a backfit falling within this exception

shall not relieve the Commission of performing an analysis after 
the fact to document the safety significance and appropriateness of the action taken.

The third exception appears in a footnote appended to the subsection containing the second exception. This footnote states:

For those modifications which are to ensure that the facility poses no undue risk to the public health and safety and which are not deemed to require immediately effective regulatory action, analyses, are required; these analyses, however, should not involve cost considerations except only insofar as cost contributes to selecting the solution among various acceptable alternatives to ensuring no undue risk to public health and safety.

The 1985 backfit rule and a related internal NRC Manual chapter which partially implemented it were challenged by the Union of Concerned Scientists. On August 4, 1987 the U.S. Court of Appeals for the DC Circuit rendered its decision vacating both the rule and the NRC Manual chapter which implemented the rule. ${ }^{28}$ The Court concluded that the rule, when considered along with certain statements in the rule preamble published in the Federal Register, did not speak unambiguously in terms that constrained the NRC from considering economic costs in establishing standards to ensure adequate protection of the public health and safety as dictated by section 182 of the Atomic Energy Act. At the same time, the Court agreed with the Commission that once an adequate level of safety protection had been achieved under section 182, the Commission was fully authorized under section $161 \mathrm{i}$ of the Atomic Energy Act to consider and take economic costs into account in ordering further safety improvements. The Court therefore rejected the position of the Union of Concerned Scientists that economic costs may never be a factor in safety decisions under the Atomic Energy Act.

Because the Court's opinion regarding the circumstances in which costs may be considered in making safety decisions on nuclear power plants was completely in accord with the Commission's own policy views on this important subject, the Commission decided not to appeal the decision. Instead, the Commission decided to amend both the rule and the related NRC Manual chapter (Chapter 0574) so that they conform unambiguously to the Court's opinion.

The final amended backfit rule was published as 10 CFR 50.109 on June $6,1988 .{ }^{25}$ In the rulemaking the Commission has adhered to the following safety principle for all of its backfitting decisions.

\section{The Atomic Energy Act commands the Commission to ensure that nuclear power plant operation provides adequate protection to the health and safety of the public. In defining, redefining or enforcing this statutory standard of adequate protection, the Commission will not consider economic costs. However, ade- quate protection is not absolute protection or zero risk. Hence safety improvements beyond the minimum needed for adequate pro- tection are possible. The Com- mission is empowered under sec- tion 161 of the Act to impose additional safety requirements not needed for adequate protec- tion and to consider economic costs in doing so.}

The 1985 revision of the backfit rule, which was the subject of the Court's decision, required, with certain exceptions, that backfits 
be imposed only upon finding that they provided a substantial increase in the overall protection of the public health and safety or the common defense and security and that the direct and indirect costs of implementation were justified in view of this increased protection. The final rule restates the exceptions to this requirement for a finding, so that the rule will clearly be in accord with the safety principle stated above. In response to the Court's decision, the rule now provides that if the contemplated backfit involves defining or redefining what level of protection to the public health and safety or common defense and security should be regarded as adequate, neither the rule's "substantial increase" standard nor its "costs justified" standard (see $50.109(\mathrm{a})(3)$ ) is to be applied (see 50.109(a)(4)(iii)). Also in response to the Court's decision, (see 824P.2d at 119) the rule now also explicitly says that the Commission shall always require the backfitting of a facility if it determines that such regulatory action is necessary to ensure the health and safety of the public and is in accord with the common defense and security. On instruction from the Commission, the NRC staff amended its Manual Chapter on plant-specific backfitting to ensure consistency with the Court's opinion.

Implementation of the Backfit Rule continues to evolve, due to ambiguity concerning terms like "substantial additional protection." The "cost justified" standard is changing due to revised economic analysis. Previously, the cost benchmark had been $\$ 1000 /$ person-rem. Changes that cost less than this amount were considered cost justified. That benchmark was changed in 1995 to $\$ 2000 /$ person-rem. ${ }^{2930}$. Processes for performing these calculations are also evolving, as PRA technology improves.

\subsubsection{Safety Goal Policy}

Several TMI-2 investigators recommended that the NRC explicitly identify a safety goal -- a level of risk at which reactors would be safe enough. Establishing such a goal, advocates believed, would end the interminable question: When is a nuclear power plant safe enough? The NRC established both qualitative and quantitative safety goals in August 1986, after several years of deliberations. ${ }^{31}$

The qualitative safety goals are as follows:

1. Individual members of the public should be provided a level of protection from the consequences of nuclear power plant operation such that individuals bear no significant additional risk to life and health.

2. Societal risks to life and health from nuclear power plant operation should be comparable to or less than the risks of generating electricity by viable competing technologies and should not be a significant addition to other societal risks.

The corresponding quantitative safety goals are:

1. The risk to an average individual in the vicinity of a nuclear power plant of prompt fatalities that might result from reactor accidents should not exceed one-tenth of one percent of the sum of prompt fatality risks resulting from other accidents to which members of the U.S. population are generally exposed.

2. The risk to the population near a nuclear power plant of cancer fatalities that might result from nuclear power plant operation should not exceed one tenth of one percent of the sum of cancer fatality risks resulting from all other causes.

The average accident fatality rate in the U.S. is approximately $5 \times 10^{-4}$ per individual per year, so the quantitative value for the first goal is 
$5 \times 10^{-7}$ per individual per year. The "vicinity of a nuclear power plant" is defined to be the area within one mile $(1.6 \mathrm{~km})$ of the plant site boundary. The average U.S. cancer fatality rate is approximately $2 \times 10^{-3}$ per year, so the quantitative value for the second goal is $2 \times 10^{-6}$ per average individual per year. The population "near a nuclear power plant" is defined as the population within ten miles $(16 \mathrm{~km})$ of the plant site.

When first proposed in the early 1980s, the second of these quantitative goals set off a flurry of controversy. While a ten mile (16 $\mathrm{km})$ radius around the plant site was selected for evaluation, the choice of a particular radius is arbitrary and somewhat controversial. When considering a 0.1 percent cancer rate within a fifty mile $(80 \mathrm{~km})$ radius, for example, this would amount to an average of three excess cancer fatalities per reactor per year (these would be excess over the expected 3000 cancer fatalities from normal causes). This would be a total of 13,500 excess deaths over the next thirty years in an industry comprised of 150 reactors -- a figure critics argued was too high. The NRC could have responded to this criticism by revising the second goal, perhaps by establishing a more stringent goal for risks to persons outside the ten mile $(16 \mathrm{~km})$ radius (not addressed in the original goal), but this would have triggered criticism from proponents of nuclear power, who would have argued that the goal was too strict compared with other risks that society accepts. Thus, both of the preceding quantitative safety goals remained as originally drafted.

Even when an acceptable safety goal can be agreed on, regulators still have to determine whether the goal actually has been met. The NRC recognized this, and announced that because of "the sizable uncertainties ... and gaps in the data base," the quantitative safety goals would serve as "aiming points or numerical benchmarks." The NRC also indicated that the goals were intended to apply to the industry as
2.4 Risk Influences and the Development of Safety Goals

a whole and not precisely to individual plants. The goals were not

in and of themselves meant to serve as a sole basis for licensing decisions. However, if pursuant to these guidelines, information is developed that is applicable to a specific licensing decision, it may be considered as one factor in the licensing decision.

The safety goal policy makes it clear that the quantitative safety goals are not hard and fast requirements (such as a rule would be) and are intended to apply to the industry as a whole, rather than individual plants. However, an actual safety goal implementation approach is still evolving as discussed in Section 2.6. Since 1986 the NRC has struggled with implementation and the possible inclusion of "subsidiary" safety goals. For example, one topic of particular interest and controversy has been the large release goal contained in the 1986 policy statement:

Consistent with the traditional
defense-in-depth approach and
the accident mitigation philoso-
phy requiring reliable perfor-
mance of containment systems,
the overall mean frequency of a
large release of radioactive
materials to the environment
from a reactor accident should
be less than 1 in $1,000,000$ per
year of reactor operation.

Details concerning the large release goal were left to the staff to develop. Subsequently, the Commission indicated that:

1. The staff may partition the large release guideline and establish quantitative core damage frequency and containment performance objectives. 
2. A core damage probability of less than 1 in 10,000 per reactor year of reactor operation appears to be a very useful subsidiary benchmark in making judgments about regulations directed toward accident prevention.

This guidance has been controversial because:

1. There is not yet an accepted definition of a "large release,"

2. The large release and core damage probability goals are more restrictive (and thus subsume) the health effects goals in most cases,

3. PRA calculations of large release frequencies have large uncertainties, and

4. Many plants would not be expected to meet these subsidiary goals.

The second concern listed above relates to the hierarchical nature of the safety goals, starting with qualitative goals and proceeding through the quantitative health effects goals down to more detailed, subsidiary quantitative goals. The ACRS and others have raised concerns that the proposed goals are not selfconsistent and that each successive layer in the hierarchy tends to subsume the previous layer. ${ }^{32}$ For example, virtually all plants that meet the large release goal would be expected to meet all of the other goals. The question then becomes, "Why have the other goals?" The NRC recognizes this concern, but believes that the current approach is consistent with defense-in-depth (a $10^{-6}$ core damage frequency does not justify the absence of containment) and that an entirely self-consistent approach is not possible. Current views on the subsidiary goals are contained in Section 2.6.

The NRC has not yet attempted to apply the safety goals to an actual plant design during a licensing process. Thus, all the safety goals and their objectives must be viewed as continuing to evolve. For example, the NRC staff has discussed setting the core damage objective for future reactor designs a factor of ten more restrictive than the once per 10,000 years proposed for currently operating reactors, although the NRC Commissioners voted in 1988 not to make this standard a formal policy goal. Rather, the NRC should encourage reactor designers to strive towards this improved core damage frequency.

\subsubsection{Safety Goal Policy and Backfitting}

While risk importance began to be an important consideration in decision making during the 1970 s and early 1980s, the process was largely ad hoc, with no clear guidance concerning what risk levels were acceptable for any particular issue. A quantitative safety goal was first considered in conjunction with the ATWS issue as indicated in Section 2.4.1.1. Subsequently, as noted in Section 2.2, the TMI-2 investigators recommended that the NRC explicitly identify a safety goal -- a level of risk at which reactors would be safe enough. As discussed in the previous sections, the NRC established both qualitative and quantitative safety goals in August 1986 to more clearly delineate acceptable levels of risk. ${ }^{29}$

Despite the concerns noted in the previous section, implementation of the Safety Goal Policy began to take shape in the form of guidance for backfitting. The evolution of the Backfit Rule was discussed in detail in Section 2.4.1.4. In January 1992 the NRC staff presented the Commission with an approach to use PRA results to achieve consistency between the Safety Goal Policy and the Backfit Rule. ${ }^{33}$ The approach is based on comparison of the core damage frequency to $10^{-4}$ per year and the conditional containment failure probability (as a surrogate for large release) to $10^{-6}$ per reactor year. Figure 2.4-2 summarizes the interim implementation guidance. A proposed backfit 
would be evaluated in terms of core damage frequency and conditional containment failure probability. Figure 2.4-2 would be used to determine if the backfit warranted further analysis. Note that this guidance only deals with issues of enhanced protection; it is not necessary to consider the safety goals concerning questions of adequate protection or regulatory compliance.

Once a consistent approach for dealing with safety goals and backfits and other regulatory analyses is established, the NRC will have a means to consider backfits and safety issues in a systematic and consistent manner. The process for selecting backfit options will be clarified, and efforts can be focused on those issues most important to risk. While risk will not become the sole measure of the importance of an issue, it can be used to assure that issues are placed in their proper perspective. If a risk-informed approach to backfitting is to be implemented, risk analyses must be available to the decision-makers, and the validity of those analyses clearly understood. In some cases, NRC-sponsored risk assessments and special studies can provide the needed information; however, another source of information is becoming available. That information source is the Individual Plant Examinations (IPEs) and other plant-specific PRAs, as discussed in Section 2.5. 


\section{Table 2.4-1 Station blackout summary data}

\section{Operational Experience}

Loss of offsite power (occurrences per year)
Average
0.1
Range
0 to 0.4

Time to restore offsite power (hours)

Median

$90 \%$ restored

Emergency diesel generator reliability (per demand)

Average

Range

Emergency Diesel Generator Repair Time (hours)

Median

Analytical Results

Estimated range of unavailability of emergency

$\mathrm{AC}$ power systems (per demand)

Estimated range of frequency of station blackout

(per year)

Estimated range of frequency of core damage as a result of station blackout (per year)
0.6

3.0

0.98

0.9 to 1.0
$10^{-4}$ to $10^{-2}$

$10^{-5}$ to $10^{-3}$

$10^{-6}$ to $10^{-4}$ 


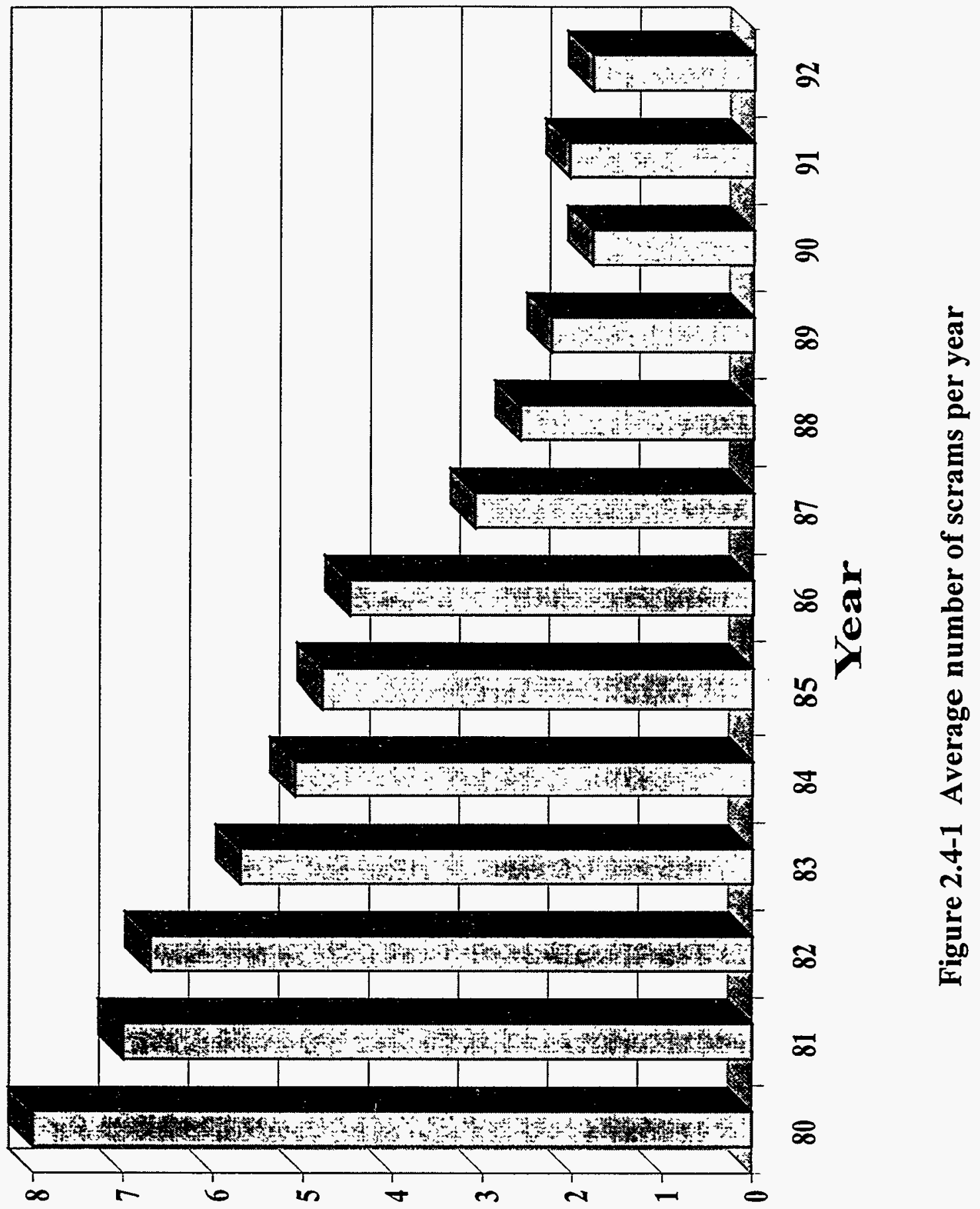

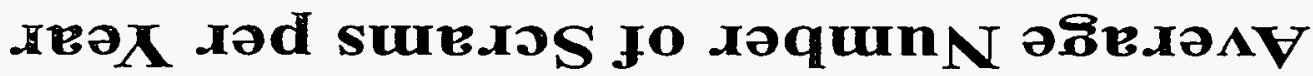




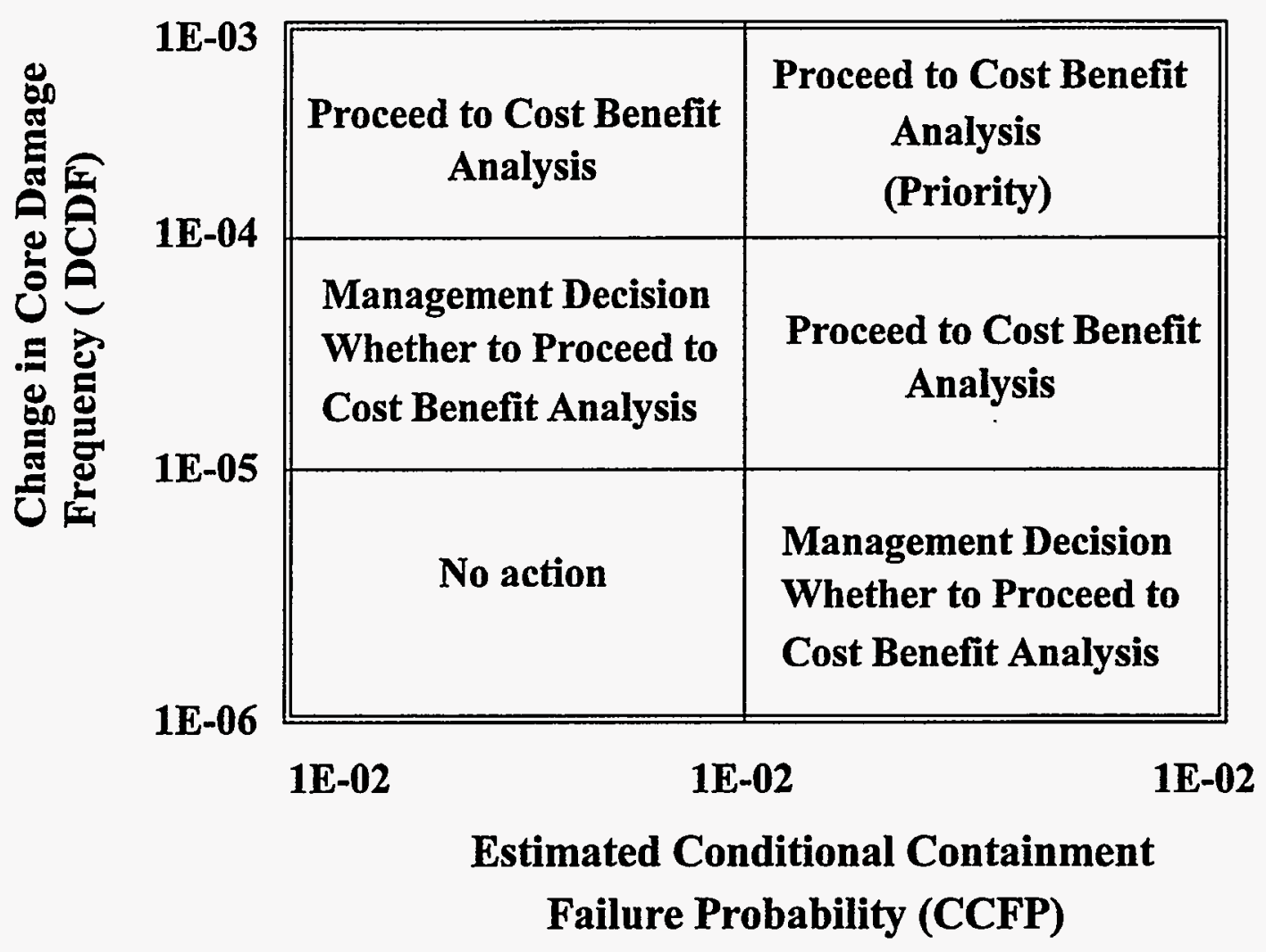

Figure 2.4-2 Safety goal implementation guidance 


\section{References for Section 2.4}

1. Long Island Lighting Company, 18 NRC 445, 464-65 (1983).

2. Union of Concerned Scientists v. U.S. NRC, 824 F.2d 108 (DC Cir 1987).

3. David Okrent, "Nuclear Reactor Safety: On the History of the Regulatory Process," The University of Wisconsin Press, Madison, Wisconsin, 1981, p. 239.

4. U. S. Atomic Energy Commission Regulatory Staff, "Technical Report on Anticipated Transients Without Scram for Water-Cooled Power Reactors," WASH-1270, September 1973.

5. U. S. Nuclear Regulatory Commission Staff Report, "Anticipated Transients Without Scram for Light Water Reactors, NUREG-0460, December, 1978.

6. U. S. Nuclear Regulatory Commission, Inspection and Enforcement Bulletin No. 83-01, "Failure of Reactor Trip Breakers (Westinghouse DB-50) to Open on Automatic Trip Signal," February 25, 1983.

7. Letter from Richard C. DeYoung, Director, NRC Office of Inspection and Enforcement, to Robert Smith, Chairman of the Board, Public Service and Gas Company, transmitting a Notice of Violation and Proposed Imposition of Civil Penalties, Docket Nos. 50-272 and 50-311, May 5, 1983.

8. U. S. Nuclear Regulatory Commission, "Generic Implications of ATWS Events at the Salem Nuclear Power Plant," NUREG-1000, Vol. 1, April 1983.

9. 46 FR 57521, "Proposed ATWS Rule," November $24,1981$.

10. 49 FR 26036, "Statement of Considerations for ATWS Rule," June 26, 1984.
11. U. S. Nuclear Regulatory Commission, "Clarification of TMI Action Plan Requirements," NUREG-0737, November 1980, Item II.E.1.1.

12. U. S. Nuclear Regulatory Commission, "Standard Review Plan," Office of Nuclear Reactor Regulation, NUREG-0800, Section 10.4.9, Rev. 2, July 1981.

13. U. S. Nuclear Regulatory Commission, "Generic Evaluation of Feedwater Transients and Small Break Loss-of-Coolant Accidents in Westinghouse-Designed Operating Plants," NUREG-0611, January 1980, Appendix III and Annex 1 of Appendix X.

14. U. S. Nuclear Regulatory Commission, "Generic Evaluation of Feedwater Transients and Small Break Loss-of-Coolant Accidents in Combustion Engineering Designed Operating Plants," NUREG-0635, January 1980, Appendix III and Annex 1 of Appendix X.

15. U. S. Nuclear Regulatory Commission, "A Prioritization of Generic Safety Issues", NUREG-0933, December 1986.

16. "Reactor Safety Study: An Assessment of Accident Risks in U.S. Commercial Nuclear Power Plants," WASH-1400, October 1975.

17. U. S. Nuclear Regulatory Commission, "Evaluation of Station Blackout Accidents at Nuclear Power Plants, Technical Findings Related to Unresolved Safety Issue A44," NUREG-1032, June 1988, p. 1-1.

18. 10 CFR 50.63, "Loss of All Alternating Current Power," July 21, 1988.

19. 53 FR 23203, "Statement of Considerations for Final Station Blackout Rule," June 21, 1988. 
20. Regulatory Guide 1.9, "Selection, Design, Qualification, Testing, and Reliability of Diesel Generator Units Used as Class 1E Onsite Electric Power Systems at Nuclear Power Plants," Working Draft, November 28, 1989.

21. U. S. Code of Federal Regulations, Title 10, Part 50.109.

22. 35 Federal Register 5,317, March 31, 1970.

23. U. S. Code of Federal Regulations, Title 10, Part 50.109(a), 1971.

24. "President's Commission on the Accident at Three Mile Island," Government Printing Office, Washington, DC, October 1979.

25. 53 Federal Register 20,603, June 6, 1988.

26. 49 Federal Register 47,034, November 30 , 1984.

27. 50 Federal Register 38,097, September 20 , 1985.

28. Union of Concerned Scientists versus U.S. Nuclear Regulatory Commission, 824 F.2d 103, August 24, 1987.
29. U. S. Nuclear Regulatory Commission, "Regulatory Analysis Guidelines of the U.S. Nuclear Regulatory Commission," Final Report, Revision 2, NUREG/BR-0058, November 1995.

30. U. S. Nuclear Regulatory Commission, "Reassessment of NRC's Dollar Per PersonRem Conversion Factor Policy,"NUREG-1530, December 1995.

31. U. S. Code of Federal Regulations, Title 10, "Safety Goals for the Operations of Nuclear Power Plants; Policy Statement, Federal Register, August 4, 1986.

32. Letter from the Advisory Committee on Reactor Safeguards to Lando W. Zech, Jr., "ACRS Comments on an Implementation Plan for the Safety Goal Policy," May 13, 1987.

33. Presentation by the Steering Group on Regulatory Analysis to the Commission, "Interim Guidance on Staff Implementation of the Commission's Safety Goal Policy," January 17, 1992. 


\subsection{Risk Assessment and Operational Perspectives}

Utilities are required to report plant operating data to the NRC under certain circumstances. The NRC uses this information for various safety purposes, ranging from deciding whether a plant may continue to operate after occurrence of an event to assessing long term trends in equipment failures. The range of information that is reported and the NRC's use of the information is described in this section. In addition, as discussed in Section 2.4 and 2.6, estimates of core damage frequency and other risk measures are increasingly being used to resolve safety issues, set policies, and make safety decisions. Because of this, it is important to understand the current estimates of risk for commercial nuclear power plants. This section provides a summary of key risk analyses that have been performed and the current understanding of risk based on these analyses.

\subsubsection{Operating Plant Data}

Each year the NRC receives an extensive amount of information from licensees and other sources regarding nuclear power plant experience. Table 2.5-1 lists some of the sources of information and indicates those that are required by law. Prompt phone notifications and written Licensee Event Reports (required by 10 CFR 50.72 and 10 CFR 50.73) are the predominant sources of information having potential safety implications. ${ }^{1,2}$ The NRC systematically reviews and analyzes the information it receives to identify instances where the margin of safety established through licensing has been degraded. In such cases, the NRC then identifies and implements corrective actions that will restore the originally intended margin of safety. Any proposed improvements in this margin of safety must be separately identified and justified as new licensing actions.

The feedback of operating data or experience is an inherent and important aspect of NRC activities and involves all NRC organizational elements at one time or another. The principal NRC organizations involved are the Office of Nuclear Reactor Regulation (NRR) and the Office for Analysis and Evaluation of Operational Data (AEOD). AEOD was established several months after the TMI-2 accident to identify and feed back significant safety lessons of operational experience to the NRC, its licensees, the nuclear industry as a whole, and the public. Table 2.5-2 lists some of the NRC-originated documents that are used to disseminate relevant nuclear power plant experience. Of particular interest to licensees are Bulletins, Information Notices, and NRR Generic Letters.

Information Notices provide information but do not require specific actions. They are rapid transmittals of information that may not yet have been completely analyzed by the NRC but that licensees should be aware of. Licensees receiving an Information Notice are expected to review the information for applicability to their current and future licensed operations. If the information is applicable to their facility, licensees are expected to take action necessary to avoid repetition of the problem described in the Information Notice.

Bulletins provide information about one or more similar events and require that licensees take specific actions, usually to assure that the intent of an existing rule or requirement is being satisfied. Prompt response by licensees is required and failure to respond will normally result in NRC enforcement action. NRC Bulletins generally require one-time action and are not intended as substitutes for formally issued 
regulations or for imposed license amendments.

NRR Generic Letters can compel licensees to provide information concerning specific safety issues. The licensees may have to perform analyses of the significance of particular issues at their respective plants. The Generic Letter may indicate a resolution process for the issue that is acceptable to the NRC and ask the utilities to respond, either accepting the proposed resolution process or presenting an alternative approach for the NRC to consider.

\subsubsection{Precursor Program}

Given the years of nuclear power plant experience accrued in the U.S., one would expect a large number of accident sequences that could potentially lead to core damage to have been revealed by incidents involving beyond-design-basis initiators and/or sequences of events. Such incidents are commonly referred to as precursors of severe accidents. The NRC collects and evaluates some data for the purpose of identifying these severe accident precursors.

When the NRC determines that a particular event, usually identified in a Licensee Event Report (LER), is worth further investigation, the Accident Sequence Precursor (ASP) Program is used to evaluate the potential core damage frequency importance of the event. The ASP program uses a simplified set of event trees and fault trees for the analysis, in essence performing a mini-PRA. The intent of the program is not a high degree of accuracy, but rather, relative insights and selection of events for further NRC study. In the analysis of an event, the probabilities of failure that actually occurred are set to 1.0 and additional failures that could have led to core damage are quantified to determine how close the particular event came to core damage. This results in an estimate of the core damage frequency that is conditional on the event, and is called the conditional core damage probability. Table 2.5-3 shows the results of ASP analyses of several precursor events. For example, this table indicates that the Browns Ferry Fire came closer to core damage than most other precursors.

The modeling of precursor events has changed significantly over the life of the program, introducing variability into the reported results that prevent meaningful examination of trends in the conditional core damage probabilities. However, it is instructive to examine the mix of contributors found to be important to precursors over the life of the program. For the past several years, more than half of the precursor events have involved electric power-related issues. Events involving the degradation of auxiliary feedwater have generally been found to be the second most common.

Several studies of precursors have been conducted. ${ }^{3}$ Regulatory actions have been taken to reduce the threat from some of the accidents identified in precursor studies. For example, station blackout, loss of feedwater, and Anticipated Transients Without Scram (ATWS) are discussed in Section 2.4.

\subsubsection{NUREG-1150 Perspectives}

NUREG-1150, which was published in December 1990, documents the results of an extensive NRC-sponsored PRA. ${ }^{4}$ The study examined five plants of varying designs to give an understanding of risk for these particular plants. Selected insights regarding classes of plants were also obtained in the study, and these were further developed through the IPE program discussed in Section 2.5.5. The improved PRA methodology used in the NUREG-1150 study significantly enhanced the understanding of 
risk at nuclear power plants, and can be considered as a replacement for the Reactor Safety Study.

The five nuclear power plants analyzed in NUREG-1150 are:

- Unit 1 of the Surry Power Station, a Westinghouse-designed three-loop reactor in a subatmospheric containment building, located near Williamsburg, Virginia;

- Unit 1 of the Zion Nuclear Power Plant, a Westinghouse-designed four-loop reactor in a large, dry containment building, located near Chicago, Illinois;

- Unit 1 of the Sequoyah Nuclear Power Plant, a Westinghouse-designed four-loop reactor in an ice condenser containment building, located near Chattanooga, Tennessee;

- Unit 2 of the Peach Bottom Atomic Power Station, a General Electricdesigned BWR-4 reactor in a Mark I containment building, located near Lancaster, Pennsylvania; and

- Unit 1 of the Grand Gulf Nuclear Station, a General Electric-designed BWR-6 reactor in a Mark III containment building, located near Vicksburg, Mississippi.

A Level 3 PRA for internal events was performed for each of these plants. As we proceed through the remainder of Section 2.5.3, the results and insights of NUREG1150 will be presented within the context of current PRA methods. See Appendix 1A for a summary of these methods.

The frequency of core damage initiated by external events has been analyzed for two of the plants in NUREG-1150, Surry and Peach Bottom. The analysis examined a broad range of external events (e.g., lightning, aircraft impact, tornadoes, and volcanic activity). Most of these events were assessed to be insignificant contributors by means of bounding analyses. However, seismic events and fires were found to be potentially major contributors and thus were analyzed in detail.

The following sections provide a summary of the key results from the NUREG-1150 study. The internal events results are discussed first, followed by the seismic results, and then the fire results.

\subsubsection{Internal Events Results}

The internal-event core damage frequency distributions from NUREG-1150 are included as Figure $2.5-1 .{ }^{44}$ The bars in Figure 2.5-1 show the $90 \%$ uncertainty ranges along with the mean and median values.

Figure 2.5-1 reflects core damage frequencies that are relatively low. Except for a particular sequence involving component cooling water at Zion (plant changes have subsequently been made to address this), there are no serious vulnerabilities that yield unusually high risk. This is due in part to good design and operating procedures. It is also due to the fact that these plants have been studied before and previously identified vulnerabilities have been fixed. A similar result occurred because of the Individual Plant Examination (IPE) program, which is discussed in Section 2.5.5. Through PRAs that were performed for that program, many plant shortcomings were uncovered and then fixed for plants that had not previously been evaluated using PRA. 
The various accident sequences that contribute to the core damage frequency from internal initiators can be grouped by common factors into categories. NUREG1150 uses the accident categories depicted in Figures 2.5-2 and 2.5-3: station blackout, anticipated transients without scram, other transients, reactor coolant pump seal LOCAs, interfacing system LOCAs, and other LOCAs. The selection of such categories is not unique, but merely a convenient way to group the results.

The existence of a highly dominant accident sequence does not of itself imply that a safety problem exists. For example, if a plant has an extremely low estimated core damage frequency, the existence of a single dominant accident sequence would have little significance. Similarly, if a plant was modified to eliminate the dominant accident sequence, another accident sequence or group of accident sequences would become dominant. Nevertheless, the identification of dominant accident sequences and the failures that contribute to those sequences provide understanding of why the core damage frequency is high or low relative to other plants and desired goals. This qualitative understanding of the core damage frequency is necessary to make practical use of the PRA results and improve the plants, if necessary.

The remainder of this section summarizes the internal events results for the BWR and PWR plants examined in NUREG-1150. A somewhat detailed description of results is provided here to give concrete examples of plant-specific and generic factors that can be important to risk. This paves the way to the generic discussion of risk, based on the IPE results, that is included in Section 2.5.5.

\subsection{NUREG-1150 Boiling Water Reactor Observations}

As shown in Figure 2.5-2, the internal-event core damage frequencies for Peach Bottom and Grand Gulf are extremely low. Therefore, even though dominant accident sequences and contributing failure events can be identified, these items should not be considered as safety problems for the two plants. In fact, these dominating factors should not be overemphasized because, for core damage frequencies below $1 \times 10^{-5}$, it is possible that other events outside the scope of these internal-event analyses are the ones that actually dominate. In the cases of these two plants, the real perspectives come not from understanding why particular sequences dominate, but rather why all types of sequences considered in NUREG-1150 have low frequencies for these plants.

LOCA sequences can be expected to have low core damage frequencies at BWRs because of the numerous systems available to provide coolant injection. While low for both plants, the frequency of LOCAs is higher for Peach Bottom than for Grand Gulf. This is primarily because Grand Gulf is a BWR-6 design with a motor-driven high-pressure core spray system, rather than a steam-driven high-pressure coolant injection system as is Peach Bottom. Motordriven systems are typically more reliable than steam-driven systems and, more importantly, can operate over the entire range of pressures experienced in a LOCA sequence.

It is evident from Figure 2.5-1 and 2.5-2 that station blackout plays a major role in the internal-event core damage frequencies for Peach Bottom and Grand Gulf. Each of 
these plants has features that tend to reduce the station blackout frequency, some of which would not be present at other BWRs.

Grand Gulf, like all BWR-6 plants, is equipped with an extra diesel generator dedicated to the high-pressure core spray system. While effectively providing a third train of redundant emergency $\mathrm{AC}$ power for decay heat removal, the extra diesel also provides diversity, based on a different diesel design and plant location relative to the other two diesels. This results in a low probability of common-cause failures affecting all three diesel generators. The net effect is a highly reliable emergency $\mathrm{AC}$ power capability. In those unlikely cases where all three diesel generators fail, Grand Gulf relies on a steam-driven coolant injection system that can function until the station batteries are depleted. At Grand Gulf the batteries are sized to last for many hours prior to depletion so that there is a high probability of recovering $\mathrm{AC}$ power prior to core damage. In addition, there is a dieseldriven firewater system available that can be used to provide coolant injection in some sequences involving the loss of $\mathrm{AC}$ power.

Peach Bottom is an older model BWR that does not have a diverse diesel generator for the high-pressure emergency core coolant system. However, other factors contribute to a low station blackout frequency at Peach Bottom. Peach Bottom is a two-unit site, with four diesel generators available. Any one of the four diesels can provide sufficient capacity to power both units in the event of a loss of offsite power, given that appropriate crossties or load swapping between Units 2 and 3 are used. This high level of redundancy is somewhat offset by a less redundant service water system that provides cooling to the diesel generators. Subtleties in the design are such that if a certain combination of diesel generators fails, the service water system will fail, causing the other diesels to fail. In addition, station DC power is needed to start the diesels. (Some emergency diesel generator systems, such as those at Surry, have a separate dedicated DC power system just for starting purposes.) In spite of these factors, the redundancy in the Peach Bottom emergency $\mathrm{AC}$ power system is considerable.

While there is redundancy in the $\mathrm{AC}$ power system design at Peach Bottom, a more significant factor is a high-quality diesel generator maintenance program. Plantspecific data analysis determined that the diesel generators at Peach Bottom were an order of magnitude more reliable than at an average plant.

Finally, Peach Bottom, like Grand Gulf, has station batteries that are sized to last several hours in the event that the diesel generators do fail. With two steam-driven systems to provide coolant injection and several hours to recover $\mathrm{AC}$ power prior to battery depletion, the station blackout frequency is further reduced.

Unlike most PWRs, the response of containment is often a key in determining the core damage frequency for BWRs. For example, at Peach Bottom, there are a number of ways in which containment conditions can affect coolant injection systems. High pressure in containment can lead to closure of primary system relief valves, thus failing low-pressure injection systems, and can also lead to failure of steam-driven high-pressure injection systems due to high turbine exhaust backpressure. High suppression pool temperatures can also lead to the failure of systems that are recirculating water from the suppression pool to the reactor coolant system. If the containment ultimately fails, certain systems can fail because of the loss of net positive suction head in the suppression pool, and also the reactor building is subjected to a 
harsh steam environment that can lead to failure of equipment located there.

Despite the concerns described in the previous paragraph, the core damage frequency for Peach Bottom is relatively low, compared to the PWRs studied in NUREG-1150. There are two major reasons for this. First, Peach Bottom has the ability to vent the wetwell through a 6-inch diameter steel pipe, thus reducing the containment pressure without subjecting the reactor building to steam. While this vent cannot be used to mitigate ATWS and station blackout sequences, it is valuable in reducing the frequency of many other sequences. The second important feature at Peach Bottom is the presence of the control rod drive hydraulic cooling system, which can provide sufficient coolant to the vessel in some accident sequences, and which is not affected by either high pressure in containment or containment failure. Other plants of the BWR-4 and BWR- 5 designs are potentially vulnerable to containment-related problems. As a result, the NRC has negotiated changes to containment venting for BWR-4 plants. These changes are discussed further in Module 4.

The Grand Gulf design is generally much less susceptible to containment-related problems than Peach Bottom. The containment design and equipment locations are such that containment rupture will not result in discharge of steam into the building containing the safety systems. Further, the high-pressure core spray system is designed to function with a saturated suppression pool so that it is not affected by containment failure. Finally, there are other systems that can provide coolant injection using water sources other than the suppression pool. Thus, containment failure is relatively benign as far as system operation is concerned, and there is no obvious need for containment venting.

\subsection{NUREG-1150 Pressurized Water Reactor Observations}

The three PWRs examined in NUREG- 1150 reflect much more variety in terms of dominant accident sequences than the BWRs. While the sequence frequencies are generally low, it is useful to understand why the variations among the plants occurred.

For LOCA sequences, the frequency is significantly lower at Surry than at the other two PWRs. A major portion of this difference is directly tied to the additional redundancy available in the injection systems. In addition to the normal highpressure injection capability, Surry can crosstie to the other unit at the site for an additional source of high-pressure injection. This reduces the core damage frequency due to LOCAs and also certain groups of transients involving stuck-open relief valves.

In addition, at Sequoyah there is a particularly noteworthy emergency core cooling interaction with containment engineered safety features in LOCAs. In this (ice condenser) containment design, the containment sprays are automatically actuated at a very low pressure setpoint, which would be exceeded for virtually all small LOCA events. This spray actuation, if not terminated by the operator, can lead to a rapid depletion of the refueling water storage tank at Sequoyah. Thus, an early need to switch to recirculation cooling may occur. Portions of this switchover process are manual at Sequoyah and, because of the timing and possible stressful conditions, lead to a significant human error probability. Thus, LOCA-type sequences are the dominant accident sequence type at Sequoyah.

Station blackout-type sequences have relatively similar frequencies at all three PWRs. Station blackout sequences can have 
very different characteristics at PWRs than at BWRs. One of the most important findings of NUREG-1150 is the importance of reactor coolant pump seal failures for the Westinghouse plants that were studied. During station blackout, all cooling to the seals is lost for these plants and there is a significant probability that they will ultimately fail, leading to an induced LOCA and loss of inventory. Because the NUREG1150 PWRs do not have systems capable of providing coolant makeup without $\mathrm{AC}$ power, core damage will result if power is not restored. The seal LOCA reduces the time available to restore power and thus increases the station blackout-induced core damage frequency. New seals have been proposed for Westinghouse PWRs and could reduce the core damage frequency if implemented, although they might also increase the likelihood that any resulting accidents would occur at high pressure, which has implications for the accident progression analysis.

Apart from the generic reactor coolant pump seal question, station blackout frequencies at PWRs are determined by the plant-specific electric power system design and the design of other support systems. Battery depletion times for the three PWRs were projected to be shorter than for the two BWRs. A unique characteristic of the Surry plant is a gravityfed service water system with a canal that may drain during station blackout, thus failing containment heat removal. When power is restored, the canal must be refilled before containment heat removal can be restored.

The dominant accident sequence type at Zion is not a station blackout, but it has many similar characteristics. Component cooling water is needed for operation of the charging pumps and high-pressure safety injection pumps at Zion. Loss of component cooling water (or loss of service water, which will also render component cooling water inoperable) will result in loss of these highpressure systems. This in turn leads to a loss of reactor coolant pump seal injection. Simultaneously, loss of component cooling water will also result in loss of cooling to the thermal barrier heat exchangers for the reactor coolant pump (RCP) seals. Thus, the reactor coolant pump seals will lose both forms of cooling. As with station blackout, loss of component cooling water or service water can both cause a small LOCA (by seal failure) and disable the systems needed to mitigate it. The importance of this scenario is increased further by the fact that the component cooling water system at Zion, although it uses redundant pumps and valves, delivers its flow through a common header. The licensee for the Zion plant has made procedural changes and is also considering both the use of new RCP seal materials and the installation of modifications to the cooling water systems.

ATWS frequencies are generally low at all three of the PWRs. This is due to the assessed reliability of the shutdown systems and the likelihood that only slow-acting, low-power-level events will result. While of low frequency, it is worth noting that interfacing-system LOCA (V) and steam generator tube rupture (SGTR) events do contribute significantly to risk for the PWRs. This is because they involve a direct path for fission products to bypass containment. There are large uncertainties in the analyses of these two accident types, but these events can be important to risk even at frequencies that may be one or two orders of magnitude lower than other sequence types.

Most Westinghouse PWRs have developed procedures for using feed and bleed cooling and secondary system blowdown to cope with loss of all feedwater. These procedures have led to substantial reductions in the frequencies of transient core damage 
sequences involving the loss of main and auxiliary feedwater. Appropriate credit for these actions was given in these analyses. However, there are plant-specific features that will affect the success rate of such actions. For example, the loss of certain power sources (possibly only one bus) or other support systems can fail poweroperated relief valves (PORVs) or atmospheric dump valves or their block valves at some plants, precluding the use of feed and bleed or secondary system blowdown. Plants with PORVs that tend to leak may operate for significant periods of time with the block valves closed, thus making feed and bleed less reliable. On the other hand, if certain power failures are such that open block valves cannot be closed, then they cannot be used to mitigate stuckopen PORVs. Thus, both the system design and plant operating practices can be important to the reliability assessment of actions such as feed and bleed cooling.

\subsubsection{NUREG-1150 Seismic Analysis Observations}

Figures 2.5-4 and 2.5-5 show the results of the core damage frequency analysis for seismic-initiated accidents, as well as internally- and fire-initiated accidents, for Surry and Peach Bottom, respectively. Examination of these figures shows that the core damage frequency distributions of the seismic events are comparable to those of the internal events. It is evident that the seismic events are significant in the total safety profile of these plants. The key features of the seismic results for Surry and Peach Bottom are discussed in the following two sections.

The analysis of the seismically induced core damage frequency begins with the estimation of the seismic hazard, that is, the likelihood of exceeding different earthquake groundmotion levels at the plant site. At the time the NUREG-1150 study was performed, there was not agreement on a model for the seismic hazard. NUREG-1150 used seismic hazard curves for Peach Bottom and Surry that were part of an NRC-funded Lawrence Livermore National Laboratory project that resulted in seismic hazard curves for all nuclear power plant sites east of the Rocky Mountains. ${ }^{5}$ For purposes of completeness and comparison, the seismically induced core damage frequencies were also calculated based upon a separate set of seismic hazard curves developed by the Electric Power Research Institute (EPRI). ${ }^{6}$ Both sets of results are presented in this section. Since the NUREG-1150 study was completed, resolution on the seismic hazard curves has been achieved. ${ }^{7}$

As can be seen in Figures 2.5-6 and 2.5-7, the shapes of the seismically induced core damage frequency distributions are considerably different from those of the internally initiated and fire-initiated events. In particular, the 5 th to 95 th percentile range is much larger for the seismic events. In addition, as can be seen in Figures 2.5-6 and 2.5-7, the wide disparity between the mean and the median and the location of the mean relatively high in the distribution indicate a wide distribution with a tail at the high end but peaked much lower down. This is a result of the uncertainty in the seismic hazard curve.

The difference between the mean and median is an important distinction. The mean is the parameter quoted most often, but the bulk of the distribution is well below the mean. Thus, although the mean is the "center of gravity" of the distribution (when viewed on a linear rather than logarithmic scale), it is not very representative of the distribution as a whole. Instead, it is the lower values that are more probable. The higher values are estimated to have low probability, but, because of their great distance from the bulk 
of the distribution, the mean is "pulled up" to a relatively high value. In a case such as this, it is particularly evident that the entire distribution, not just a single parameter such as the mean or the median, must be considered when discussing the results of the analysis.

\subsection{Surry Seismic Analysis}

The core damage frequency probability distributions, as calculated using the Livermore and EPRI methods, have a large degree of overlap. The differences between the means and medians of the two resulting distributions are not very meaningful because of the large widths of the two distributions.

As shown in Figure 2.5-8, the breakdown of the Surry seismic analysis into principal contributors is reasonably similar to the results of other seismic PRAs for other PWRs. The total core damage frequency is dominated by loss of offsite power transients resulting from seismically induced failures of the ceramic insulators in the switchyard. This dominant contribution of ceramic insulator failures has been found in virtually all seismic PRAs to date.

A site-specific but significant contributor to the core damage frequency at Surry is failure of the anchorage welds of the $4 \mathrm{kV}$ buses. These buses play a vital role in providing emergency AC electrical power since offsite power as well as emergency onsite power passes through these buses. Although these welded anchorages have more than adequate capacity at the safe shutdown earthquake (SSE) level, they do not have sufficient margin to withstand (with high reliability) earthquakes in the range of four times the SSE, which are contributing to the overall seismic core damage frequency results.
Another area of generic interest is the contribution due to vertical flat-bottomed storage tanks (e.g., refueling water storage tanks and condensate storage tanks). Because of the nature of their configuration and field erection practices, such tanks have often been calculated to have relatively smaller margin over the SSE than most components in commercial nuclear power plants. Given that all PWRs in the United States use the refueling water storage tank as the primary source of emergency injection water (and usually the sole source until the recirculation phase of ECCS begins), failure of the refueling water storage tank can be expected to be a substantial contributor to the seismically induced core damage frequency.

\subsection{Peach Bottom Seismic Analysis}

As can be seen in Figure 2.5-8, the dominant contributor in the seismic core damage frequency analysis is a transient sequence brought about by loss of offsite power. The loss of offsite power is due to seismically induced failures of onsite $\mathrm{AC}$ power. Peach Bottom has four emergency diesel generators, all shared between the two units, and four station batteries per unit. Thus, there is a high degree of redundancy. However, all diesels require cooling provided by the emergency service water system, and failure to provide this cooling will result in failure of all four diesels.

There is a variety of seismically induced equipment failures that can fail the emergency service water system and result in a station blackout. These include failure of the emergency cooling tower, failures of the $4 \mathrm{kV}$ buses (in the same manner as was found at Surry), and failures of the emergency service water pumps or the emergency diesel generators themselves. 
The various combinations of these failures result in a large number of potential failure modes and give rise to a relatively high frequency of core damage based on station blackout. None of these equipment failure probabilities is substantially greater than would be implied by the generic fragility data available. However, the high probability of exceedance of larger earthquakes (as prescribed by the hazard curves for this site) results in significant contributions of these components to the seismic risk.

\subsubsection{NUREG-1150 Fire Analysis Observations}

The core damage likelihood due to a fire in any particular area of the plant depends upon the frequency of ignition of a fire in the area, the amount and nature of combustible material in that area, and the nature and efficacy of the fire-suppression systems in that area. In NUREG-1150, fire analyses were performed for the Surry and Peach Bottom plants.

Similarly to the seismic results, Figures 2.5 4 and 2.5-5 show the results of the core damage frequency analysis for fire-initiated accidents are comparable to those of the internal events for Surry and Peach Bottom. It is evident that the fire events are significant in the total safety profile of these plants. The key features of the fire results for Surry and Peach Bottom are discussed below, followed by a summary of common characteristics of fire sequences for the two plants.

\subsection{Surry Fire Analysis}

Figure 2.5-9 shows the dominant contributors to core damage frequency resulting from the Surry fire analysis. The dominant contributor is a transient resulting in a reactor coolant pump seal LOCA, which can lead to core damage. The scenario consists of a fire in the emergency switchgear room that damages control power for the high-pressure injection and component cooling water pumps. Cable trays for the two redundant power trains were run one on top of the other with approximately 8 inches of vertical separation in a number of plant areas, which gives rise to the common vulnerability of these two systems due to fire. In addition, the Halon fire-suppression system in the emergency switchgear room is manually actuated.

The other principal contributor is a spuriously actuated pressurizer PORV. In this scenario, fire-related component damage in the control room includes control power for a number of safety systems.

\subsection{Peach Bottom Fire Analysis}

Figure 2.5-9 shows the mechanisms by which fire leads to core damage in the Peach Bottom analysis. Station blackout accidents are the dominant contributor, with substantial contributions also coming from fire-induced transients and losses of offsite power.

Control room fires are of considerable significance in the fire analysis of this plant. The cable spreading room below the control room is significant but not dominant in the fire analysis. The remaining physical areas of significance are the emergency switchgear rooms.

\subsection{General Observations on Fire Analysis}

Figures $2.5-5$ and $2.5-6$ clearly indicate that fire-initiated core damage sequences are significant in the total probabilistic analysis of the two plants analyzed. These analyses include credit for the fire protection 
programs required by Appendix $\mathrm{R}$ to $10 \mathrm{CFR}$ Part 50.8

Although the two plants are of completely different design, with completely different fire-initiated core damage scenarios, the possibility of fires in the emergency switchgear areas is important in both plants. The importance of the emergency switchgear room at Surry is particularly high because of the reactor coolant pump seal LOCA scenario. Further, the importance of the control room at Surry is comparable to that of the control room at Peach Bottom.

This is not surprising in view of the potential for simultaneous failure of several systems by fires in these areas. Thus, in the past such areas have generally received particular attention in fire protection programs. It should also be noted that the significance of various areas also depends upon the scenario that leads to core damage. For example, the importance of the emergency switchgear room at Surry could be altered (if desired) not only by more fire protection programs but also by changes in the probability of the reactor coolant pump seal failure.

\subsubsection{Low Power and Shutdown Perspectives}

Traditionally, PRAs of severe accidents in nuclear power plants have considered initiating events that could occur only during full-power operation. This focus was based on the judgment that the level of risk associated with accidents that could occur during full-power operation was greater than that for accidents during the other modes of operation, such as low-power and shutdown. The primary justification for this view appeared to be that lower decay heat levels are generally associated with these other modes of operation, so more time is available to recover from adverse situations in these modes.

Some previous screening analyses performed for other than full-power modes of operation have also suggested that risks during these modes of operation are small relative to those occurring during full-power operation. However, there are several factors that could influence the risk associated with accidents initiated during shutdown. These include:

1. The greater need for operator action to prevent core damage (because automatic safety systems are disabled during some of the shutdown modes).

2. The increased unavailability of equipment as a result of planned maintenance. (There is a demand for high equipment availability during power operation, which limits the amount and length of maintenance activities that can be performed while the plant is at power.)

3. The breach of containment integrity caused by the opening of penetrations and hatches. (These openings, which are allowed by technical specifications, in many cases are necessary before the activities planned for shutdown can occur.)

In response to such concerns, the Office of Nuclear Regulatory Research (NRR) undertook a two-phase project to analyze the frequencies, consequences, and risk of accidents during modes of operation other than full-power for two plants, and to compare the results with those from fullpower analyses for the same plants ${ }^{9,10}$. The plants selected were Grand Gulf and Surry. The scope of the program included that of a Level 3 PRA for internal events and a Level 1 PRA for seismically induced and internal 
fire and flood induced core damage sequences.

An initial coarse screening analysis was performed examining accidents initiated by internal events (including internal fires and floods) for all plant operational states. This study found that the core damage frequency during low-power and shutdown appears to be comparable to that at full-power. In addition, it became clear that a large effort would be required to accurately address all conditions of potentially significant risk that could arise during low-power or shutdown modes. Consequently, detailed analyses were performed for only a selected period for the two plants.

For Grand Gulf, a period called Plant Operating State 5 (POS 5) was chosen. POS 5 covers cold shutdown operation (where the reactor vessel is at atmospheric pressure and the bulk water temperature is below $200{ }^{\circ} \mathrm{F}$ ) and the time in the refueling operating condition until the vessel head is detensioned. This period was chosen because of its large contribution to core damage frequency (CDF) in the initial coarse screening and its estimated large contribution to risk.

For Surry, the evaluation was conducted for mid-loop operation, in which the reactor coolant system level is lowered to the midplane of the hot leg. This period was chosen because many incidents have occurred during mid-loop operation throughout the world, and because the screening study indicated that this period could have a risk comparable to full-power.

The results of the Grand Gulf and Surry evaluations are presented below. It is important to note that such results are highly plant specific because of the unique character of each plant's refueling process. Grand Gulf and Surry have features that may not be present at other plants which tend to reduce the risk during low-power and shutdown operations.

\subsubsection{Grand Gulf Low Power and Shutdown Observations}

Figure 2.5-10 presents a comparison of mean core damage frequency percentages for the major classes of accidents from both the NUREG-1150 full-power and the POS 5 analyses for Grand Gulf. In both analyses, the station blackout class is important because station blackouts cut across multiple systems. However, during POS 5, there are additional accidents (e.g., LOCAs) that can cut across multiple systems. There are differences in the accident progression associated with the station blackouts at fullpower and during POS 5. These are (1) almost all the POS 5 station blackout sequences lead to an interfacing system LOCA and the full-power sequences do not; (2) the containment is always open at the start of POS 5 accidents whereas it is isolated at the start of full-power accidents; and (3) the probability of arresting the core damage process in the vessel is higher for full-power accidents than for POS 5. In the full-power analysis the ATWS class is the second most important class, while ATWS is not possible during POS 5 since the plant is already subcritical. The second most important class for POS 5 is LOCAs.

Table 2.5-4 presents a comparison on a calendar-year basis of the core damage frequency, early fatality risk, and total latent fatality risk for POS 5 and for full-power for Grand Gulf. While the POS 5 mean core damage frequency is about a factor of two lower than the full-power value, there is overlap between the two distributions. The mean early fatality risk of POS 5 is only a factor of 1.7 greater than the full-power risk even though the containment is open during most of the accidents in POS 5. The mean 
total latent cancer fatality risk of POS 5 is about a factor of 4 greater than the corresponding full-power risk. One reason for this is that in POS 5, the containment is always open, and in full-power the containment is always isolated at the start of an accident. Also, some of the difference is caused by different versions of the consequence code being used for the two studies. The version used for POS 5 generally results in higher estimates for the total latent cancer fatality risk.

\subsubsection{Surry Low Power and Shutdown Observations}

The contribution to the total core damage frequency from internal events during midloop operation at Surry was found to be lower by an order of magnitude than that at full-power. This is mainly due to the much smaller fraction of time that the plant is at mid-loop. Figure 2.5-11 presents a comparison of mean core damage frequency percentages for the major classes of accidents from both the NUREG-1150 fullpower and the mid-loop analyses for Surry.

Table 2.5-5 presents a comparison on a calendar-year basis of the core damage frequency, early fatality risk, and total latent fatality risk for mid-loop operation and for full-power for Surry. While the mid-loop operation mean core damage frequency is an order of magnitude lower than the full-power value, there is some overlap between the two distributions.

The offsite risk estimates for latent health effects of accidents during mid-loop operation were similar to the risk estimates for full-power operation for Surry. This is due to the lack of mitigative features for a significant fraction of the accidents initiated during mid-loop operation, which causes the releases to the environment to be large. The early health consequences are much lower than the full-power results, despite the unisolated containment, primarily because of the long time after reactor trip when the accidents occur in mid-loop operation (i.e., because of the natural decay of the shortlived isotopes of iodine and tellurium, which are primarily associated with early health effects). The uncertainties in risk for accidents during mid-loop operations are largely due to uncertainties associated with isolating the containment and achieving a pressure retaining capability.

\subsubsection{Individual Plant Examinations}

The NRC issued Generic Letter (GL) 88-20 in November 1988, requesting that all licensees perform an Individual Plant Examination (IPE) "to identify any plantspecific vulnerabilities to severe accidents and report the results to the Commission." The purpose and scope of the IPE effort includes examining internal events occurring at full-power, including those initiated by internal flooding. In response, the staff received 75 IPE submittals covering 108 nuclear power plant units. The staff then examined the IPE submittals to determine what the collective IPE results imply about the safety of U.S. nuclear power plants and how the IPE program has affected reactor safety." A summary of the Level 1 findings is provided in the following sections. Insights related to accident progression are discussed in Module 4.

\subsubsection{Vulnerabilities and Plant Improvements}

The primary goal of the IPE Program was for licensees to "identify plant-specific vulnerabilities to severe accidents that could be fixed with low-cost improvements." However, GL 88-20 did not specifically define what constitutes a vulnerability; hence, the IPEs exhibit considerable diversity in the criteria used to define a 
vulnerability. The wording used in some submittals is such that it is not always clear whether a licensee is identifying a finding as a "vulnerability" or as some other issue worthy of attention. Therefore, a problem considered to be a vulnerability at one plant may not have been specifically identified as a vulnerability at another plant. In fact, only four licensees with boiling water reactor (BWR) plants and 15 licensees with pressurized water reactor (PWR) plants explicitly stated that their plants had vulnerabilities. However, nearly all of the licensees identified other areas warranting investigation for potential improvements.

Over 500 proposed improvements were identified by the licensees to address perceived weaknesses in plant design or operation. Most of these plant improvements are classified as procedural/ operational changes (approximately 45\%), design/hardware changes (approximately $40 \%$ ), or both. Few of the improvements involve maintenance-related changes. Typically, the procedural or design changes indicate revised training in order to properly implement the actual change. Many of these proposed improvements have already been implemented at the plants, and others are still under consideration.

Some improvements are associated with other requirements (primarily the station blackout rule) and utility activities. However, although these improvements were not necessarily identified as a result of the IPE, in some cases, the licensee is using the IPE to prioritize the improvements and to support decisions regarding their implementation. The specific improvements vary from plant to plant. However, numerous improvements that had significant impact on plant safety include changes to $\mathrm{AC}$ and DC power, coolant injection systems, decay heat removal systems, heating, ventilating and air conditioning, and PWR reactor coolant pump seals.

\subsubsection{CDF Perspectives from the IPEs}

The IPE results indicate that the plant core damage frequency (CDF) is often determined by many different sequences (in combination), rather than being dominated by a single sequence or failure mechanism. The largest contributors to plant CDF and the dominant failures contributing to those sequences vary considerably among the plants (e.g., some are dominated by LOCAs, while others are dominated by station blackout [SBO]). However, for most plants, support systems are important to the results because support system failures can result in failures of multiple front-line systems. Further, the support system designs and dependency of front-line systems on support systems vary considerably among the plants. That variation explains much of the variability observed in the IPE results.

Consistent with previous risk studies, the CDFs reported in the IPE submittals are lower, on average, for BWR plants than for PWR plants, as shown in Figure 2.5-12. Although both BWR and PWR results are strongly affected by the support system considerations discussed above, a few key differences between the two types of plants contribute to this tendency for lower BWR CDFs and cause a difference in the relative contributions of the accident sequences to plant CDF. The most significant difference is that BWRs have more injection systems than PWRs and can depressurize more easily to use low-pressure injection systems. This gives BWRs a lower average contribution from LOCAs. However, the results for individual plants can vary from this general trend. As shown in Figure 2.5-12, the CDFs for many BWR plants are actually higher than the CDFs for many PWR plants. The variation in the CDFs is primarily driven by 
a combination of the following factors, which are further detailed in Table 2.5-6:

- plant design differences (primarily in support systems such as cooling water, electrical power, ventilation, and air systems)

- variability in modeling assumptions (including whether the models accounted for alternative accident mitigating systems)

- differences in data values (including human error probabilities) used in quantifying the models.

\subsubsection{Station Blackout Sequences}

Station blackout has consistently been found to be an important contributor to core damage frequency in PRAs, including the Reactor Safety Study, NUREG-1150, and the IPEs. It has not necessarily been the dominant contributor for each plant in the study, but most plants have a significant contribution from station blackout. Because of the general importance of station blackout, a more detailed examination of this particular sequence is provided in this section. A description is first given of the types of station blackout sequences that can occur, followed by an assessment of the impact of the station blackout rule (based on IPE results).

\section{Types of Station Blackout}

Station Blackout sequences are initiated by a loss of offsite power and the associated reactor scram, followed by failure of the station diesels (or gas turbines, if applicable) to start and load. Station blackout sequences are further discriminated into long-term and short-term station blackouts, which are described below for BWRs and PWRs.
For a long-term station blackout sequence in a BWR, water is temporarily injected into the reactor vessel by the steam turbinedriven systems. Most of the U.S. plants (25 of 37) have two independent systems (highpressure coolant injection [HPCI] plus reactor core isolation cooling [RCIC] or isolation condenser [IC]) that can keep the core covered without the availability of AC power. However, BWR-5 and BWR-6 designs have substituted an electric motordriven high pressure core spray (HPCS) system in lieu of HPCI so that these plants have only one turbine-driven injection system (RCIC). Similarly, the BWR-2 and early BWR-3 plants employ an ACdependent feedwater coolant injection system (FWCI) instead of HPCI. Water flow is intermittent as necessary to keep the core covered and continues for as long as DC (battery) power for turbine governor control remains available from the unit batteries (typically about 6 hours).

The short-term designation for BWRs applies to station blackout sequences with early loss of injection. Injection failure might occur in either of two ways. First, there might be direct failure(s) of the steam turbine system(s) during the period in which DC power remains available. Note that for plants with both RCIC and HPCI, this involves independent failures of the two systems. Because these are high-pressure injection systems, success of their function does not depend upon reactor vessel depressurization. The second (and much less probable) way in which the early total loss of injection initiating event for short-term station blackout might occur is by commonmode failure of the DC battery systems. At most BWR facilities, the diesel generators have dedicated starting batteries, but if the diesels are started from the unit batteries, failure of these batteries would, upon loss of offsite power, be a contributing cause of the station blackout. Furthermore, without DC 
power for valve and turbine governor control, the steam turbine-driven injection systems would not be operable. The loss of DC power would also render the safety/relief valves (SRVs) inoperable in the remotemanual mode; thus, the reactor vessel could not be depressurized.

The basic characteristics of the two dominant forms of BWR station blackout sequences can be summarized as follows. DC power remains available during the period of core degradation for short-term station blackout initiated by independent failure of HPCI and RCIC; the decay heat level is relatively high, and the reactor vessel is depressurized during the period after the core becomes uncovered and begins to degrade. For long-term station blackout, the core remains covered for more than 6 hours, so the decay heat level is about 50 percent less during the period of core degradation. However, when injection capability is lost (due to battery failure) the ability to operate the SRVs is also lost. Thus, the reactor vessel repressurizes and remains pressurized during and after the period of core degradation.

For a PWR, injection systems are lost in a station blackout because the systems rely on AC power. However, core cooling is initially available in a long-term station blackout sequence through turbine-driven auxiliary feedwater. Turbine-driven auxiliary feedwater can operate until the batteries deplete, which normally leads to a loss of control. If $\mathrm{AC}$ power is not recovered soon after loss of control, core damage will follow. Some plants might be able to manually control feedwater after battery depletion, but a continuous source of feedwater is still needed to prevent core damage.

For a short-term station blackout sequence in a PWR, the turbine-driven auxiliary feedwater system fails at the beginning of the accident. The most frequent cause is failure to start and run for the required time period. The early loss of heat rejection causes the inventory of the reactor coolant systems to boil off, leading to early core damage.

Station blackout results in loss of cooling for reactor coolant pumps at most PWRs. This introduces the potential for seal failure from high temperatures, particularly for plants using the old seal material in Westinghouse pumps. The associated leakage from the reactor coolant system can accelerate core damage. This concern is most important for long-term sequences because there is an extended period without seal cooling before core damage occurs. For short-term sequences, the time to core damage is much shorter, so seal failures are more likely to occur after core damage.

\section{Station Blackout Rule}

The Station Blackout Rule, discussed in Section 2.4, requires that an analysis be performed for each nuclear power plant to establish a method to cope with station blackout for a specified duration without core damage occurring (coping method). In some instances, licensees implemented plant modifications to improve the plant's ability to endure a station blackout. The goal of the Station Blackout Rule is to limit the average station blackout contribution to CDF to about $1 \times 10^{-5} / \mathrm{ry}$. This goal should be interpreted as an aiming point or numerical benchmark, rather than as a hard and fast requirement. In the IPE Insights Program, the IPE results were used to infer the impact of the Station Blackout Rule on the plant CDS. For licensees that modeled the Station Blackout Rule coping method in their IPEs, the staff compared the average station blackout CDF with the rule's goal to determine how well it was achieved. For 
licensees that did not model the Station Blackout Rule coping method, the staff compared the average station blackout CDF with the rule's goal to provide insight into the margin for improvement in CDF by implementing the Station Blackout Rule.

Ten licensee IPE submittals (covering 15 plant units) reported estimates of the reduction in total CDF that resulted from implementing the Station Blackout Rule. These estimates are shown in Figure 2.5-13. The average reported reduction was $\sim 2 \times 10^{\circ}$ $5 / \mathrm{ry}$, ranging from $\sim 7 \times 10$ to $\sim 6 \times 10 / \mathrm{ry}$. The average reported percent reduction in total CDF was about $20 \%$, ranging from about 10 to $50 \%$. Licensees that met the Station Blackout Rule using existing equipment were not included in the average CDF reduction calculation.

The range of plant $C D S$ and average $C D S$ for IPEs that accounted for the Station Blackout Rule coping method in their modeling were compared to the CDS for those that did not account for the coping method. Both sets of plants exhibited a wide range of station blackout CDS relative to the Station Blackout Rule goal. Some licensees that modeled the Station Blackout Rule coping method reported station blackout CDS about two orders of magnitude lower than the goal, while others reported station blackout CDS about three times higher than the goal. Similarly, some licensees reported station blackout CDS two orders of magnitude lower than the Station Blackout Rule goal without modeling the Station Blackout Rule coping method, while others reported station blackout CDS close to an order of magnitude higher than the goal. For both sets of plants, the average reported percent station blackout contribution was about $20 \%$, and the average station blackout CDS for the two sets of plants were nearly the same.
These comparisons of IPE results indicate that the Station Blackout Rule had a noticeable, but not enormous impact on the plant CDS. For the limited number of plants that directly reported the impact of the Station Blackout Rule, the average reduction was equal to the value anticipated during the development of the Station Blackout Rule.

\subsubsection{Current Understanding of Risk}

An improved understanding of nuclear power plant risk has been gained through analysis of operating experience and using risk assessment techniques. The average core damage frequencies estimated for both BWRs and PWRs are generally low, with specific results affected strongly by plantspecific factors such as those discussed in Section 2.5.3 for the NUREG-1150 plants. In both the NUREG-1150 and IPE results, station blackout, transients, and LOCAs are usually the more important contributors for PWRs. For BWRs, LOCAs and ATWSs are generally less important than station blackout and transients. Similarly, the ASP results show a consistently high fraction of precursors that involve electrical system failures.

The BWRs generally (but not always) have core damage frequencies that are lower than those of the PWRs. The LOCA sequences, which often dominate the PWR core damage frequencies, are normally minor contributors for the BWRs. This is not surprising because BWRs have many more systems than PWRs for injecting water into the reactor coolant system. For many transients, the same argument holds. BWRs have many more systems that can provide decay heat removal and makeup for transients that lead to loss of water inventory due to stuck-open relief valves or primary system leakage. 
Station blackout accidents contribute a high percentage of the core damage frequency for many of the BWRs. However, when viewed on an absolute scale, station blackout has a higher frequency at the PWRs than at the BWRs. To some extent this is due to design differences between BWRs and PWRs. For example, in station blackout accidents, many PWRs are vulnerable to reactor coolant pump seal LOCAs following loss of seal cooling, leading to loss of inventory with no method for providing makeup. BWRs, on the other hand, have at least one injection system that does not require $\mathrm{AC}$ power. While such $B W R$ and PWR design features influence the core damage frequencies associated with station blackout, the electric power system design, which is largely independent of the plant type, is probably more important.

The NUREG-1150 and IPE analyses indicate that for both BWRs and PWRs, other support systems, such as service water, are quite important. Because support systems vary considerably among plants, caution must be exercised when making statements about generic classes of plants, such as PWRs versus BWRs. Once significant plantspecific vulnerabilities are removed, supportsystem-driven sequences will probably dominate the core damage frequencies of both types of plants. Both types of plants have sufficient redundancy and diversity so as to make multiple independent failures unlikely. Support system failures introduce dependencies among the systems and thus can become dominant.

The risk evaluations for external events that were performed for Peach Bottom and Surry for NUREG-1150 indicate that seismic and fire events can be important, but that the results are highly plant-specific. The ongoing IPE for External Events (IPEEE) program will provide further information regarding the risk from such events.
However, many of the IPEEEs use simplified methods, which may limit their usefulness. NRC is currently evaluating the IPEEEs and drawing insights from the results.

The screening evaluations of risk during low-power and shutdown for Grand Gulf and Surry indicated that the risk during these modes can be considerable. However, more in-depth analyses indicated a much reduced threat because of plant-specific features. The plant-specific nature of these results prevents meaningful extrapolation to other plants. Thus, the risk during low-power and shutdown for the remainder of the nuclear power plants is currently not well understood.

Section 2.4 described the safety goals that have been set for commercial nuclear power plants. Information is now available from the IPEs that can be used to infer how operating plants compare with the safety goals. This inference was made as part of the IPE Insights Program. When comparing the IPE results with the safety goals, it is important to note that the scope of the IPE program is limited to accidents initiated by internal events (excluding internal fires) that occur during full-power operation. Therefore, the risk estimates inferred from the IPE results may reflect only a fraction of the total risk of operating the plant. The results of other PRAs that include external events (and internal fires) and other modes of operation (e.g., low-power and shutdown) indicate risk levels comparable with those obtained for internal events during fullpower operation.

The CDS for all BWRs and most PWRs fall below the $1 \times 10^{-4} /$ ry subsidiary objective; however, nine licensees representing 15 PWR units reported CDS above $1 \times 10^{-4} / \mathrm{ry}$. Conditional containment failure probabilities for bypass and early containment failure are below the 0.1 subsidiary objective for most 
of the PWRs. All of the conditional containment failure probabilities for bypass events in BWRs are below 0.1; however, most of the conditional containment failure probabilities for early containment failure are above 0.1. This result is expected because of the nature of BWR pressure suppression containments.

Although offsite consequences were not generally calculated in the IPEs, by extrapolating the NUREG-1150 health effects to the IPEs, an indication of how the IPEs compare to the quantitative health objectives can be obtained. Through this extrapolation, the staff concluded that, with a few exceptions, most of the IPE results are likely to meet the NRC's quantitative health objectives. The IPE results imply risk levels below the individual latent cancer fatality health objective. In addition, with the possible exception of a few plants, the IPE results also suggest risk levels below the individual early fatality health objective. Although relatively more plants exceeded the proposed subsidiary objectives, only a fraction of these are found to have the potential for individual early fatality risk levels that could approach the corresponding quantitative health objective. 


\section{Table 2.5-1 NRC Sources of reactor operational data}

1.

Prompt notification

Required by 10 CFR 50.72

Violations of Plant Technical Specifications

Approximately 2000 per year

2. Licensee Event Reports

Required by LER Rule, 10 CFR 50.73

Violations of Technical Specifications

Focus on Events Significant to Safety

NRC Receives Several Thousand per Year

3. Construction Deficiency Reports

Required by 10 CFR 50.55 (e)

Approximately 200 in FY83

4. Component Deficiencies

Required by 10 CFR 21

Approximately 200 in 1983

$5 . \quad$ Other Sources

Inspection findings

DOE reactor experience

Licensee reports and requests

Industry Groups

Institute of Nuclear Power Operations

Nuclear Plant Reliability Data System

Electric Power Research Institute

Nuclear Safety Analysis Center

Informal Communication

Foreign Event Information 


\section{Table 2.5-2 NRC Feedback of nuclear power plant experience}

Operating Reactors Licensing Actions Summary (NUREG-1272) Vol. 9, No. 1 (AEOD Annual Report)

Bulletins $(2+1$ supplement in 1990) $(1+1$ supplement in 1991)

Information Notices $(82+12$ supplements in 1990) $(78+15$ supplements in 1991)

NRR Generic Letters $(10+18$ supplements in 1990) $(18+1$ supplement in 1991)

AEOD - review licensee event reports (about 2100 per year)

AEOD - published case studies (about one per year)

AEOD - special studies (about 2 per year)

AEOD - published engineering evaluations (10 in 1990)

AEOD - published technical review reports (18 in 1990)

AEOD - published Power Reactor Events Reports (will resume in 1992)

Report to Congress on Abnormal Occurrences, NUREG-0090 (4 per year)

Miscellaneous NUREGs; case-related hearing testimonies, transcripts, etc.

Performance Indicators for Operating Commercial Nuclear Power Plants (Quarterly)

91-02, dated December 28, 1990 was considered to be issued in 1990. 
Table 2.5-3 Precursors and severe accidents

\begin{tabular}{|c|c|c|c|c|}
\hline Date & Type & Event & $\begin{array}{c}\text { Cond. Core } \\
\text { Damage } \\
\text { Probability }\end{array}$ & Reference \\
\hline 24-Mar-71 & LOSP & LaCrosse loss of offsite power & $4 \times 10^{-5}$ & NUREG/CR-2497 \\
\hline 19-Jan-74 & LOSP & $\begin{array}{l}\text { Haddam Neck loss of offsite } \\
\text { power }\end{array}$ & $2 \times 10^{-4}$ & NUREG/CR-2497 \\
\hline 22-Mar-75 & Fire & Browns Ferry Fire & $1.5 \times 10^{-1}$ & NUREG/CR-2497 \\
\hline 31-Aug-77 & LOFW & Cooper loss of feedwater & $1 \times 10^{-3}$ & NUREG/CR-2497 \\
\hline $10-$ Nov-77 & Flooding & Surry 2 valve flooding & $6 \times 10^{-7}$ & NUREG/CR-2497 \\
\hline 20-Mar-78 & Other & $\begin{array}{l}\text { Rancho Seco loss of nonnuclear } \\
\text { instrumentation }\end{array}$ & $1 \times 10^{-1}$ & NUREG/CR-2497 \\
\hline 06-Mar-79 & Service Water & $\begin{array}{l}\text { Brunswick loss of RHR } \\
\text { service water }\end{array}$ & $2 \times 10^{-5}$ & NUREG/CR-2497 \\
\hline 02-May-79 & LOFW & $\begin{array}{l}\text { Oyster Creek loss of feedwater } \\
\text { flow }\end{array}$ & $2 \times 10^{-3}$ & NUREG/CR-2497 \\
\hline 28-Jun-80 & ATWS & $\begin{array}{l}\text { Browns Ferry partial failure to } \\
\text { scram }\end{array}$ & $9.8 \times 10^{-4}$ & NUREG/CR-3591 \\
\hline 02-Nov-81 & LOCA & Sequoyah loss of coolant & $9 \times 10^{-4}$ & NUREG/CR-2497 \\
\hline 09-Jun-85 & LOFW & Davis Besse loss of feedwater & $1.1 \times 10^{-2}$ & NUREG/CR-4674 \\
\hline 20-Mar-90 & $\begin{array}{l}\text { Shutdown } \\
\text { Transient }\end{array}$ & $\begin{array}{l}\text { Vogtle } 1 \text { loss of shutdown } \\
\text { cooling }\end{array}$ & $1 \times 10^{-3}$ & NUREG/CR-4674 \\
\hline 13-Aug-91 & Transient & Nine Mile Point 2 & $1 \times 10^{-5}$ & Not Published \\
\hline 2-Aug-95 & Unavailability & St. Lucie 1 multiple failures & $1.1 \times 10^{-4}$ & NUREG/CR-4674 \\
\hline
\end{tabular}


Table 2.5-4 Distributions for Core damage frequency and aggregate risk for POS 5 and full-power operation for Grand Gulf

\begin{tabular}{|c|c|c|c|c|}
\hline \multirow[t]{2}{*}{ Analysis } & \multicolumn{4}{|c|}{$\begin{array}{c}\text { Descriptive Statistics (All values are per calendar year) } \\
\text { Percentiles }\end{array}$} \\
\hline & 5th & 50th & 95th & Mean \\
\hline & \multicolumn{4}{|c|}{ Core Damage Frequency } \\
\hline POS 5 & $4.1 \times 10^{-7}$ & $1.4 \times 10^{-6}$ & $5.6 \times 10^{-6}$ & $2.1 \times 10^{-6}$ \\
\hline \multirow[t]{2}{*}{ Full Power } & $1.8 \times 10^{-7}$ & $1.1 \times 10^{-6}$ & $1.4 \times 10^{-5}$ & $4.1 \times 10^{-6}$ \\
\hline & \multicolumn{4}{|c|}{ Early Fatality Risk } \\
\hline POS 5 & $3.7 \times 10^{-11}$ & $2.8 \times 10^{-9}$ & $3.9 \times 10^{-8}$ & $1.4 \times 10^{-8}$ \\
\hline \multirow[t]{2}{*}{ Full Power } & $2.5 \times 10^{-12}$ & $6.1 \times 10^{-10}$ & $2.6 \times 10^{-8}$ & $8.2 \times 10^{-9}$ \\
\hline & \multicolumn{4}{|c|}{ Total Latent Cancer Fatality Risk } \\
\hline POS 5 & $4.3 \times 10^{-4}$ & $1.9 \times 10^{-3}$ & $1.2 \times 10^{-2}$ & $3.8 \times 10^{-3}$ \\
\hline Full Power & $1.4 \times 10^{-5}$ & $2.4 \times 10^{-4}$ & $2.3 \times 10^{-3}$ & $9.5 \times 10^{-4}$ \\
\hline
\end{tabular}

Table 2.5-5 Distributions for Core damage frequency and aggregate risk for mid-loop and full-power operation for Surry

\begin{tabular}{c|cccc}
\hline \multirow{2}{*}{ Analysis } & \multicolumn{4}{|c}{$\begin{array}{c}\text { Descriptive Statistics (All values are per calendar year) } \\
\text { Percentiles }\end{array}$} \\
\cline { 2 - 4 } & 5 th & 50th & 95 th & Mean \\
\hline & \multicolumn{4}{c}{ Core Damage Frequency } \\
\hline Mid Loop & $3.2 \times 10^{-7}$ & $2.0 \times 10^{-6}$ & $1.9 \times 10^{-5}$ & $4.2 \times 10^{-6}$ \\
Full Power & $9.8 \times 10^{-6}$ & $2.5 \times 10^{-5}$ & $1.0 \times 10^{-4}$ & $4.1 \times 10^{-5}$ \\
\hline & \multicolumn{4}{c}{ Early Fatality Risk } \\
\hline Mid Loop & $1.3 \times 10^{-10}$ & $3.6 \times 10^{-9}$ & $1.6 \times 10^{-7}$ & $4.9 \times 10^{-8}$ \\
Full Power & $7.6 \times 10^{-10}$ & $7.0 \times 10^{-8}$ & $5.4 \times 10^{-6}$ & $2.0 \times 10^{-6}$ \\
\hline & & Total Latent Cancer Fatality Risk & \\
\hline Mid Loop & $8.0 \times 10^{-4}$ & $5.3 \times 10^{-3}$ & $5.5 \times 10^{-2}$ & $1.6 \times 10^{-2}$ \\
Full Power & $3.1 \times 10^{-4}$ & $2.2 \times 10^{-3}$ & $1.9 \times 10^{-2}$ & $5.2 \times 10^{-3}$ \\
\hline
\end{tabular}




\section{Table 2.5-6 Overview of key IPE CDF observations}

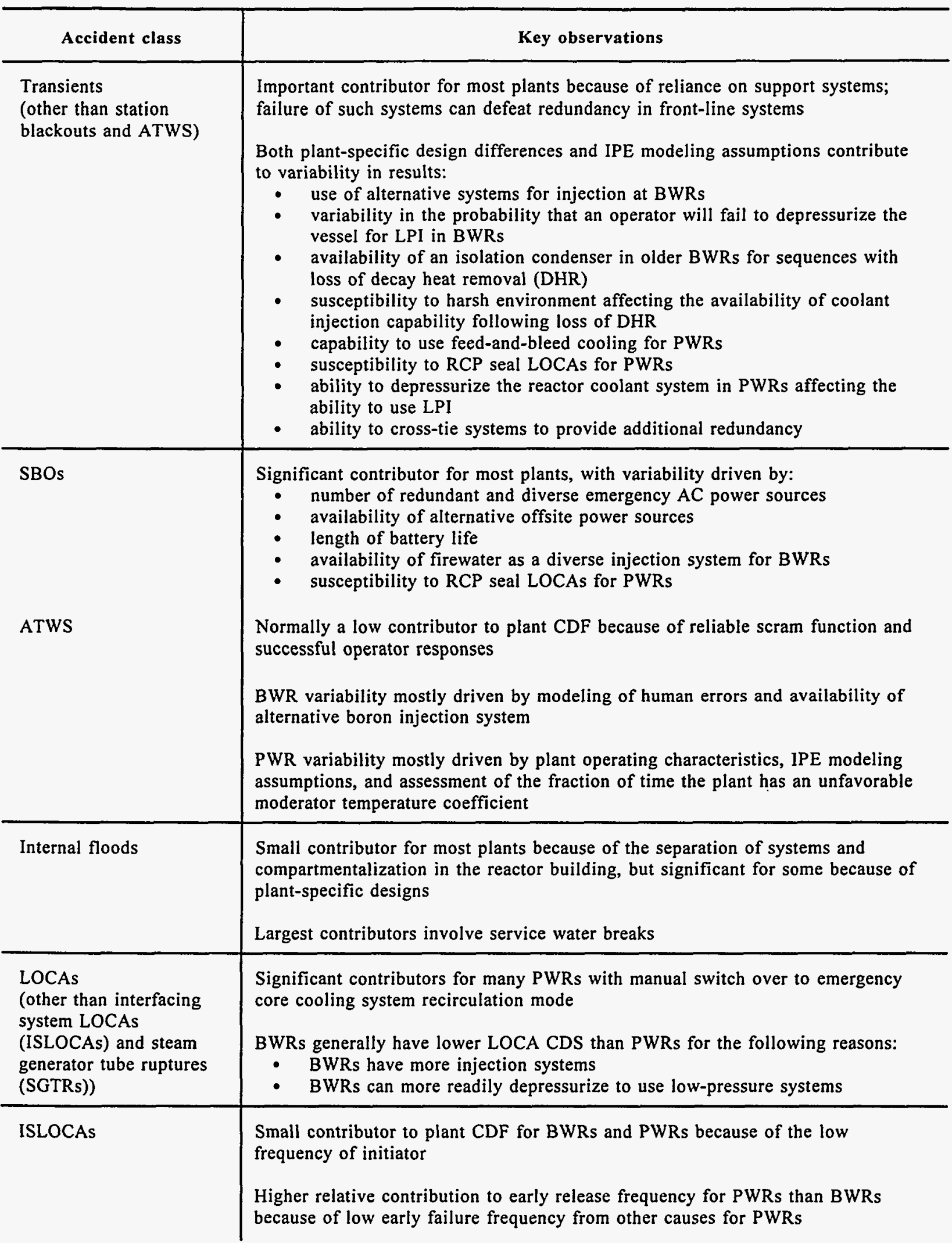




\section{Table 2.5-6 Overview of key IPE CDF observations (continued)}

\begin{tabular}{c|l}
\hline \multicolumn{1}{c|}{ Accident class } & \multicolumn{1}{c}{ Key observations } \\
\hline SGTR & $\begin{array}{l}\text { Normally a small contributor to CDF for PWRs because of opportunities for the } \\
\text { operator to isolate a break and terminate an accident, but important contributor to } \\
\text { early release frequency }\end{array}$ \\
\hline
\end{tabular}




\section{Table 2.5-7 Key IPE observations regarding containment performance}

\begin{tabular}{|c|c|}
\hline $\begin{array}{c}\text { Failure } \\
\text { mode }\end{array}$ & Key observations \\
\hline Early failure & $\begin{array}{l}\text { On average, the large volume containments of PWRs are less likely to have early structural } \\
\text { failures than the smaller BWR pressure suppression containments } \\
\text { Overpressure failures (primarily from ATWS), fuel coolant interaction, and direct } \\
\text { impingement of core debris on the containment boundary are important contributors to early } \\
\text { failure for most BWR containments; hydrogen burns are found important in some Mark III } \\
\text { containments } \\
\text { The higher early structural failures of BWR Mark I containments versus the later BWR } \\
\text { containments are driven to a large extent by drywell shell meltthrough* } \\
\text { In a few BWR analyses, early venting contributes to early releases } \\
\text { Phenomena associated with high-pressure melt ejection are the leading causes of early failure } \\
\text { for PWR containments } \\
\text { Isolation failures are significant in a number of large, dry and subatmospheric containments } \\
\text { The low early failure frequencies for ice condensers relative to the other PWRs appear to be } \\
\text { driven by analysis assumptions rather than plant features } \\
\text { For both BWR and PWR plants, specific design features lead to a number of unique and } \\
\text { significant containment failure modes }\end{array}$ \\
\hline Bypass & $\begin{array}{l}\text { Probability of bypass is generally higher in PWRs, in part, because of the use of steam } \\
\text { generators, and because the greater pressure differential between the primary and secondary } \\
\text { systems may increase the likelihood of an ISLOCA in PWRs } \\
\text { Bypass, especially SGTR, is an important contributor to early release for PWR containment } \\
\text { types } \\
\text { Bypass is generally not important for BWRs }\end{array}$ \\
\hline Late failure & $\begin{array}{l}\text { Overpressurization when containment heat removal is lost is the primary cause of late failure } \\
\text { in most PWR and some BWR containments } \\
\text { High pressure and temperature loads caused by core-concrete interactions are important for } \\
\text { late failure in BWR containments } \\
\text { Containment venting is important for avoiding late uncontrolled failure in some Mark I } \\
\text { containments } \\
\text { The larger volumes of the Mark III containments (relative to Mark I and Mark II } \\
\text { containments) are partly responsible for their lower late failure probabilities in comparison } \\
\text { to the other BWR containments } \\
\text { The likelihood of late failure often depends on the mission times assumed in the analysis }\end{array}$ \\
\hline
\end{tabular}




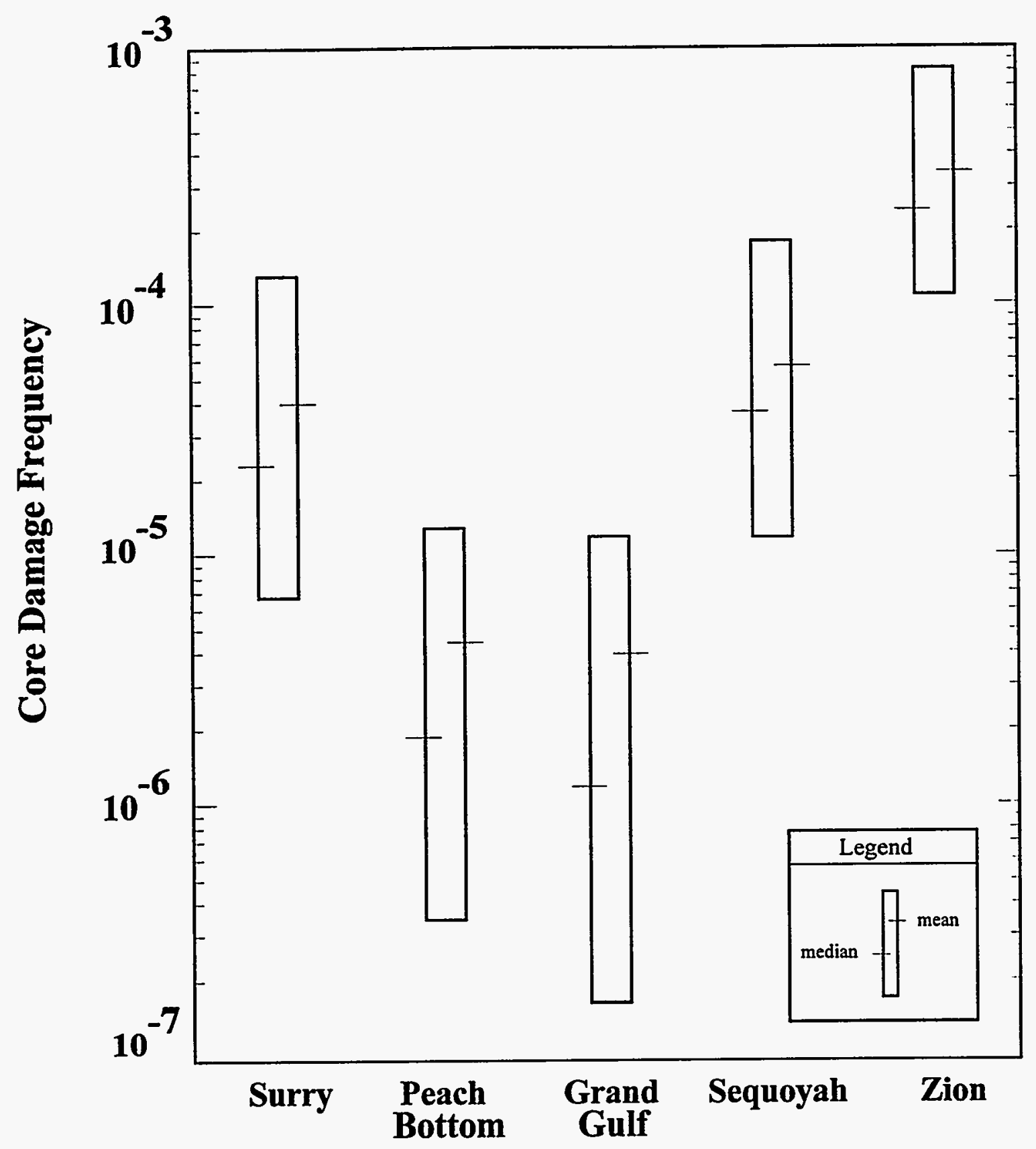

Figure 2.5-1 Internal core damage frequency ranges (5th to 95th percentiles) 


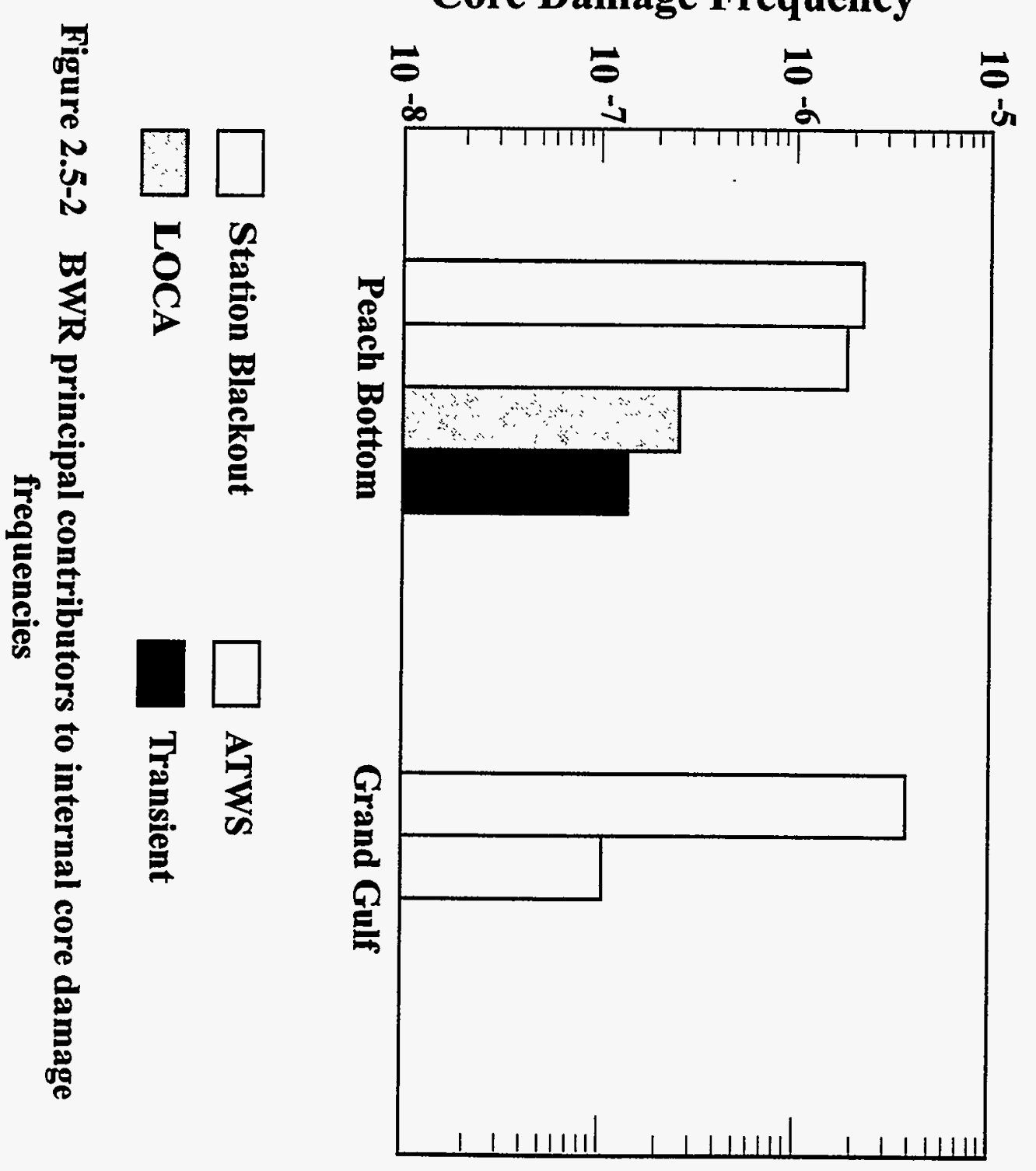

Core Damage Frequency 


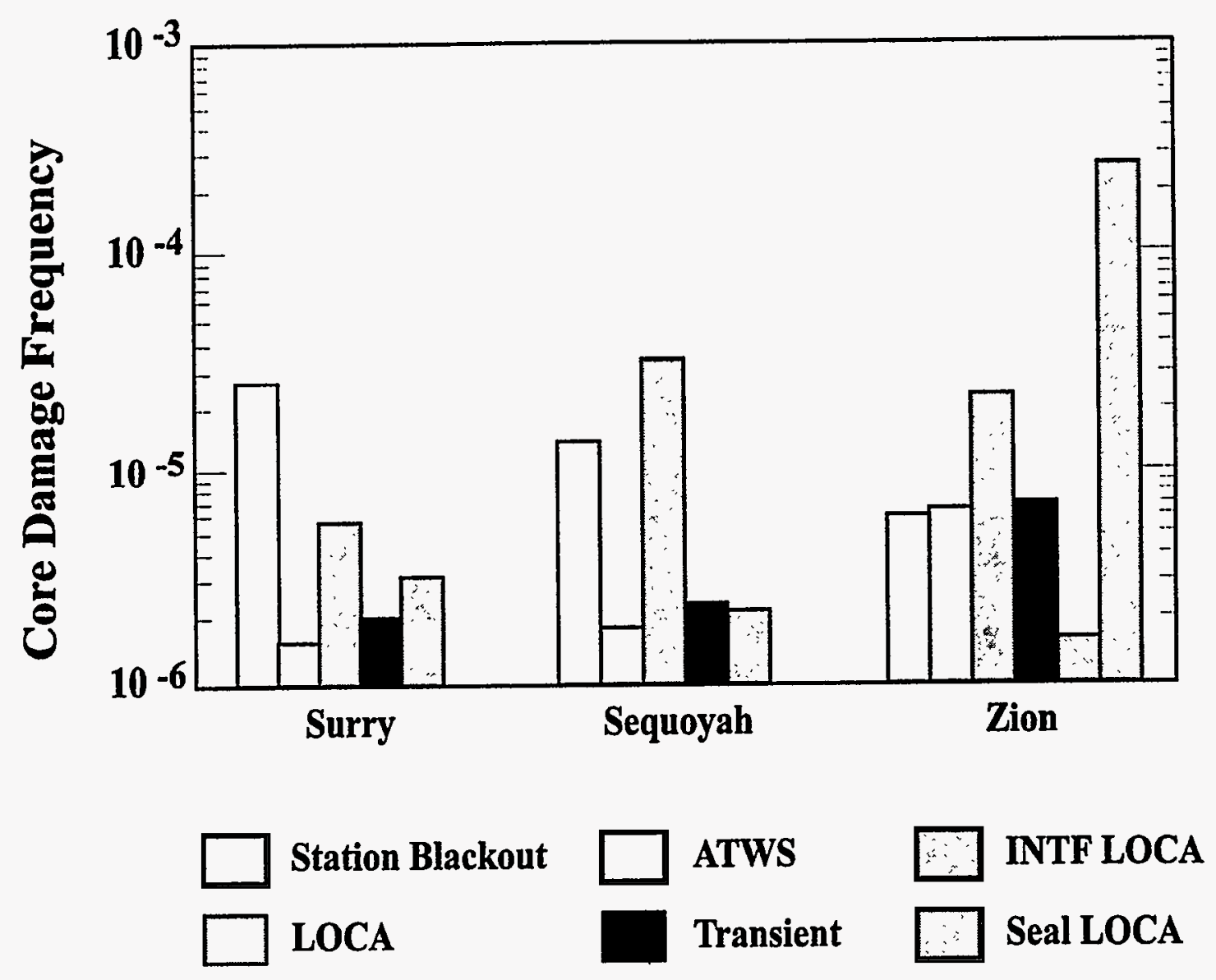

Figure 2.5-3 PWR principal contributors to internal core damage frequencies 


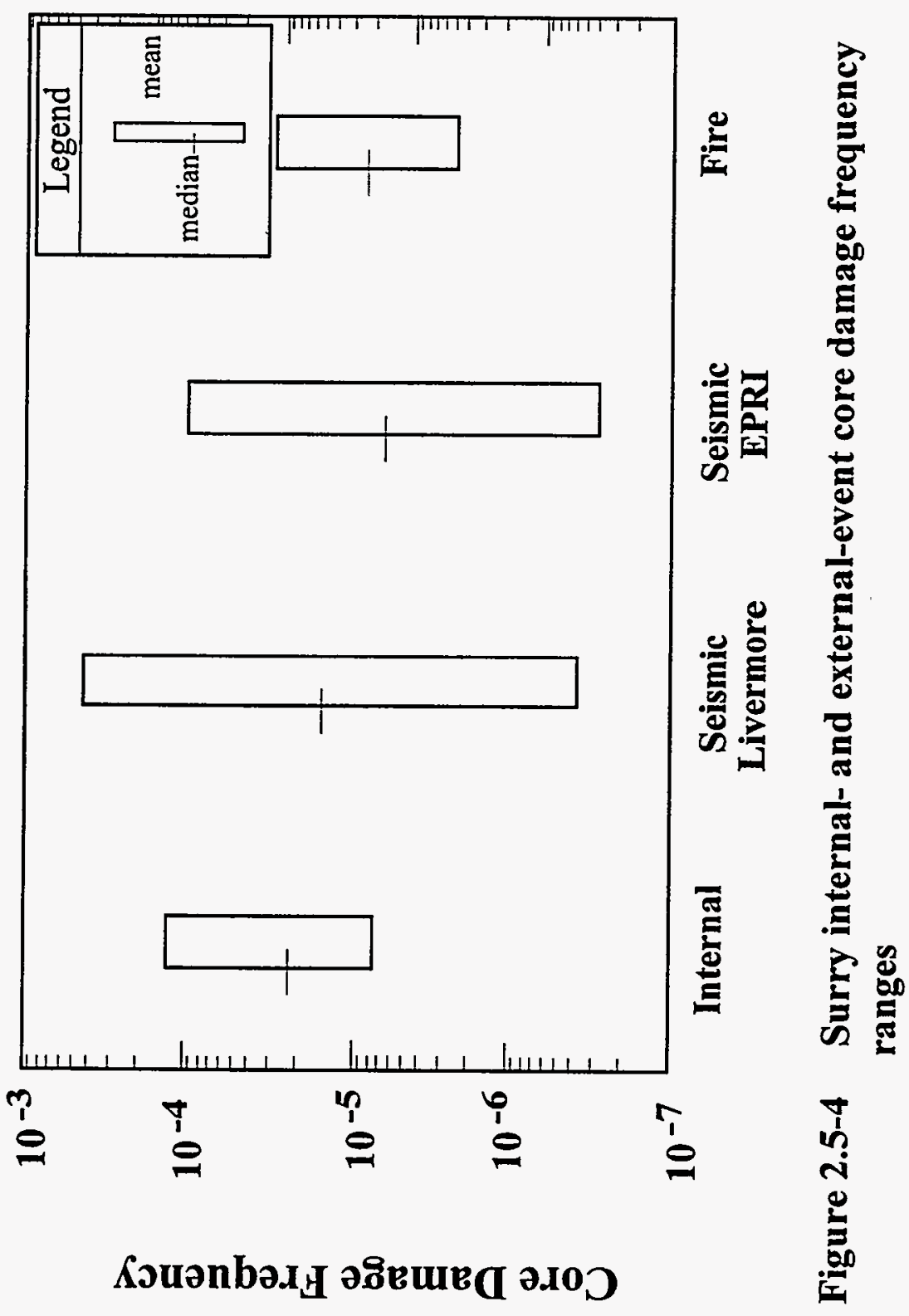




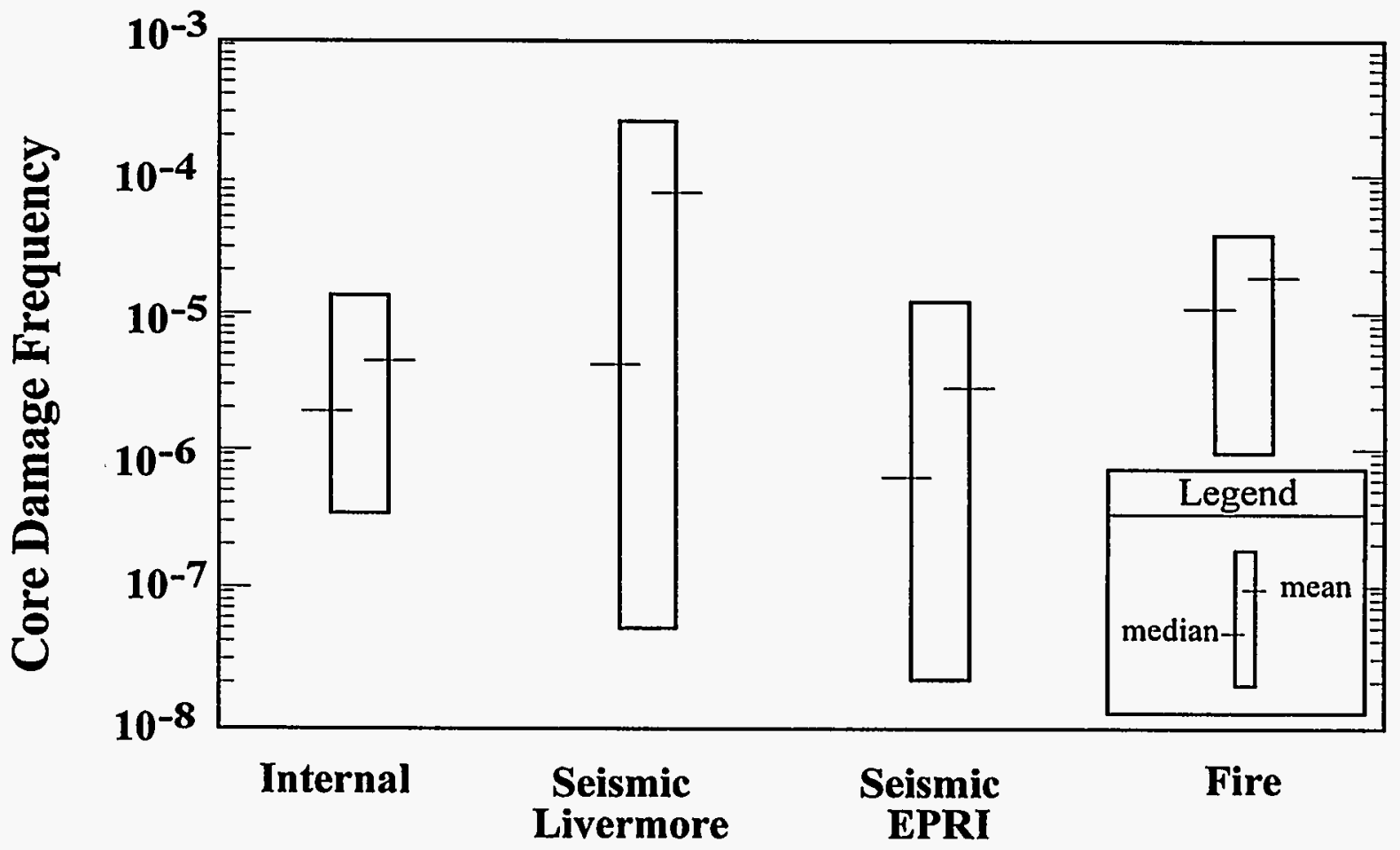

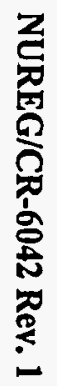

Figure 2.5-5 Peach Bottom internal- and external-event core damage frequency ranges 


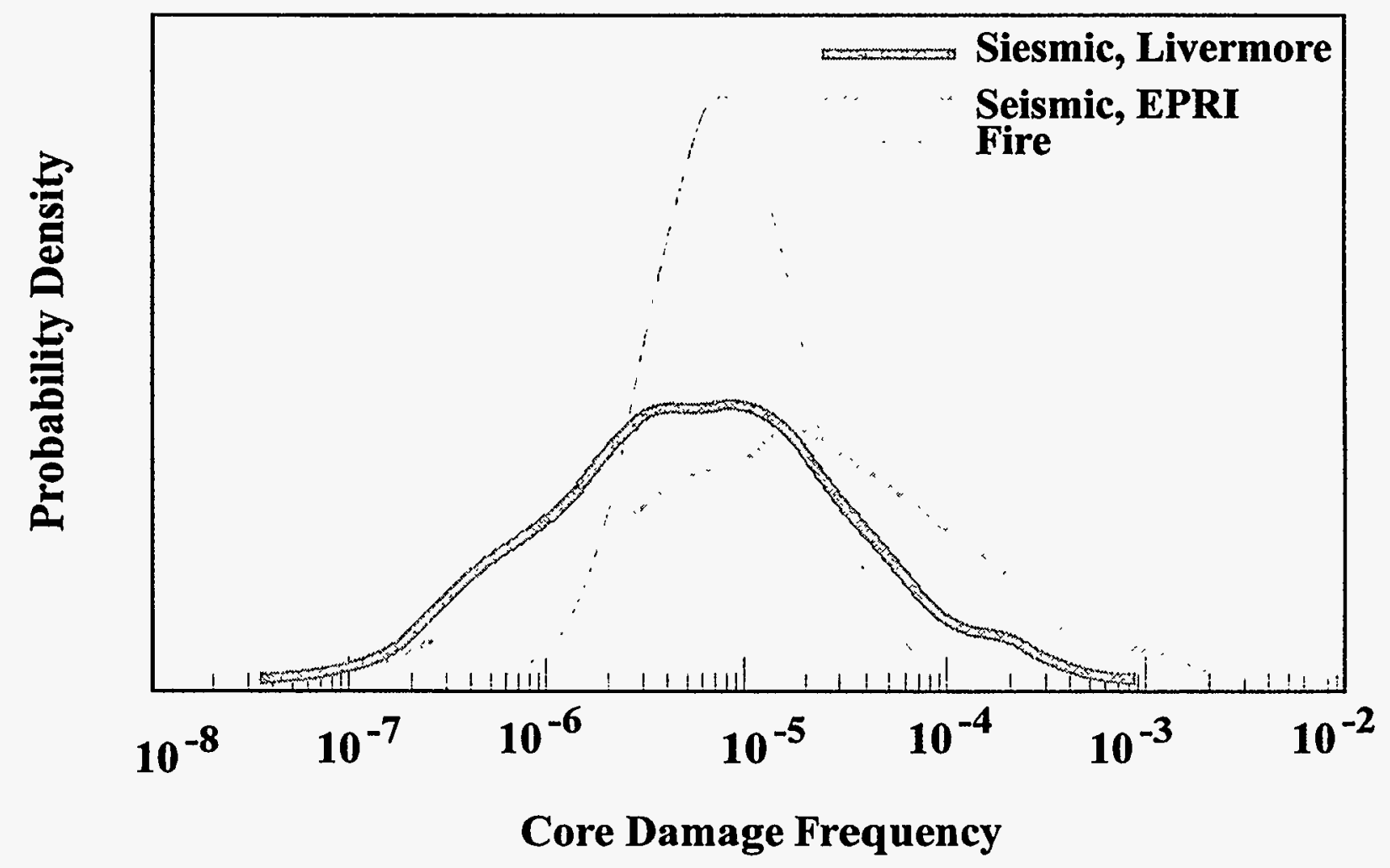




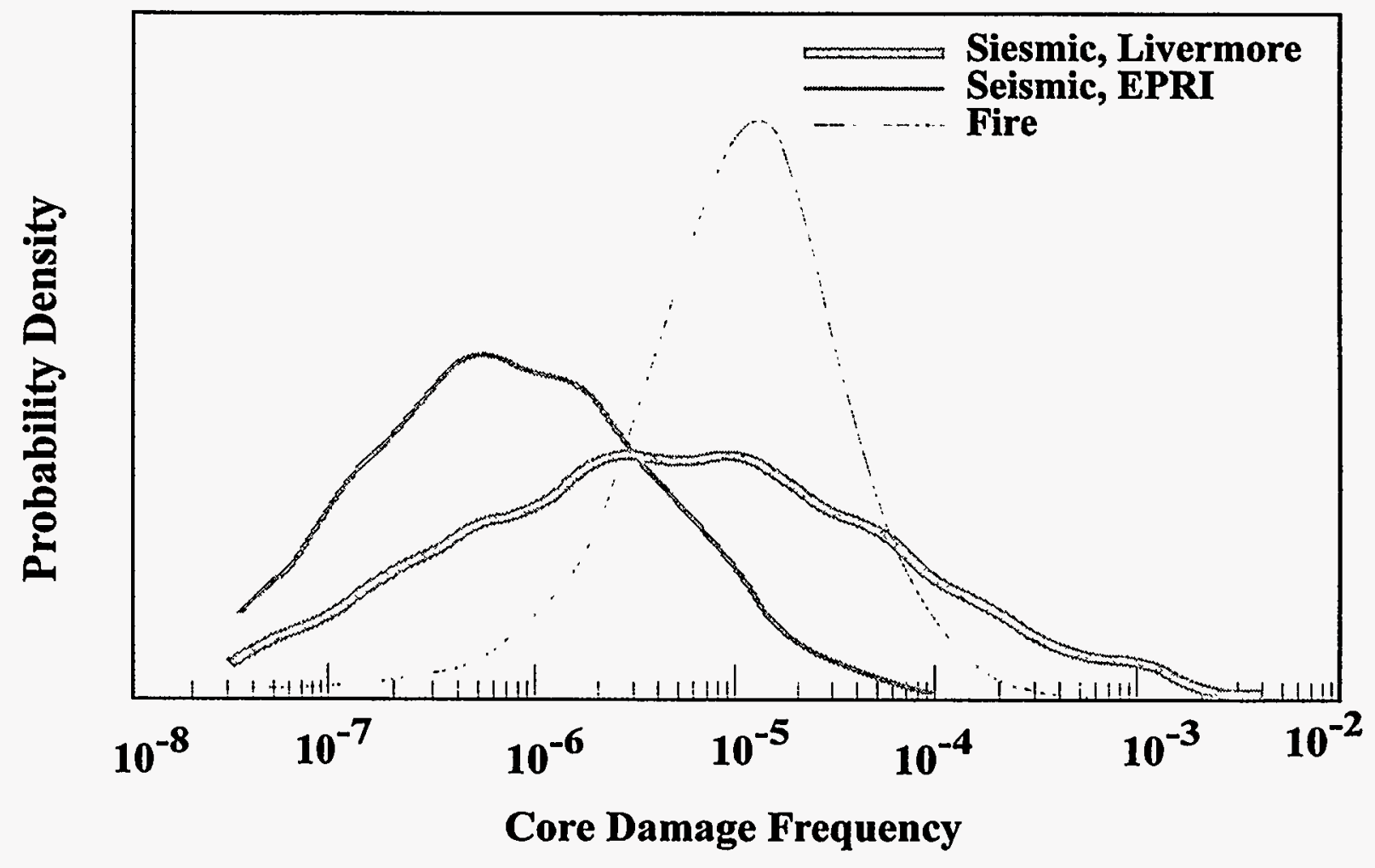

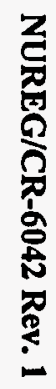

Figure 2.5-7 Peach Bottom external-event core damage frequency distributions 


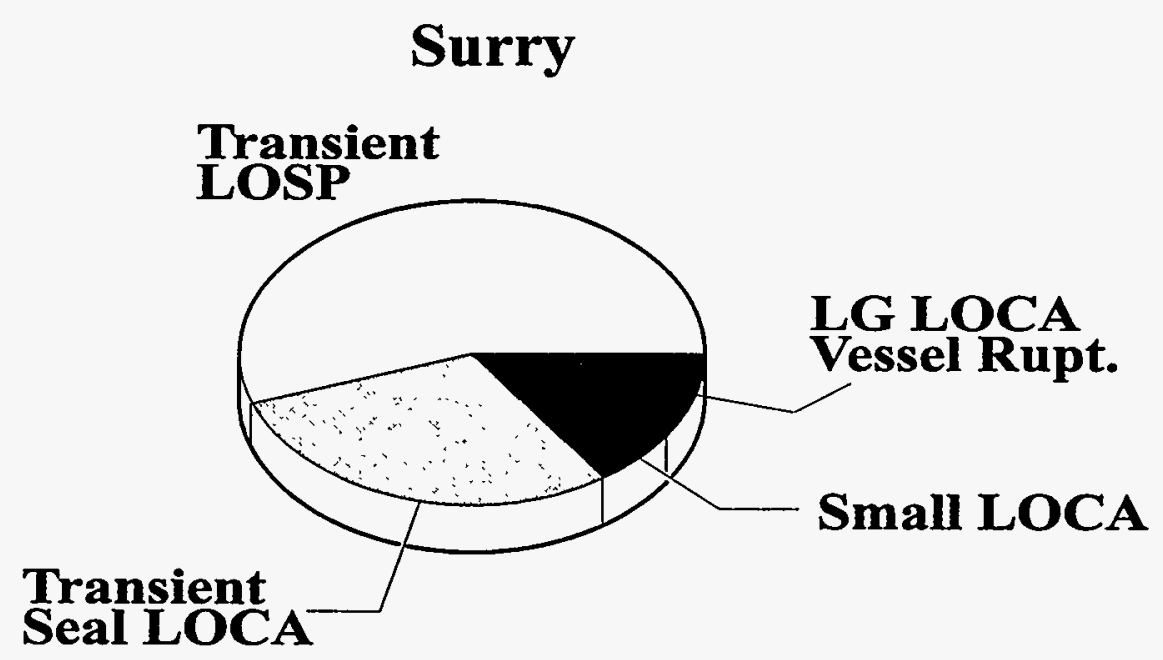

\section{Peach Bottom}

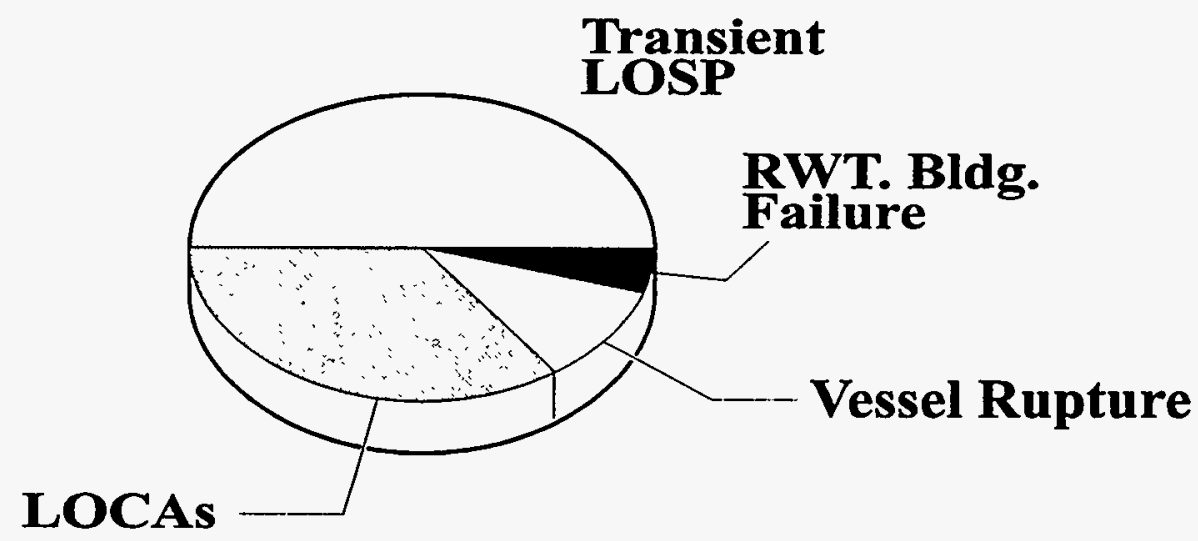

Figure 2.5-8 Principal contributors to seismic core damage frequencies 


\section{Surry}

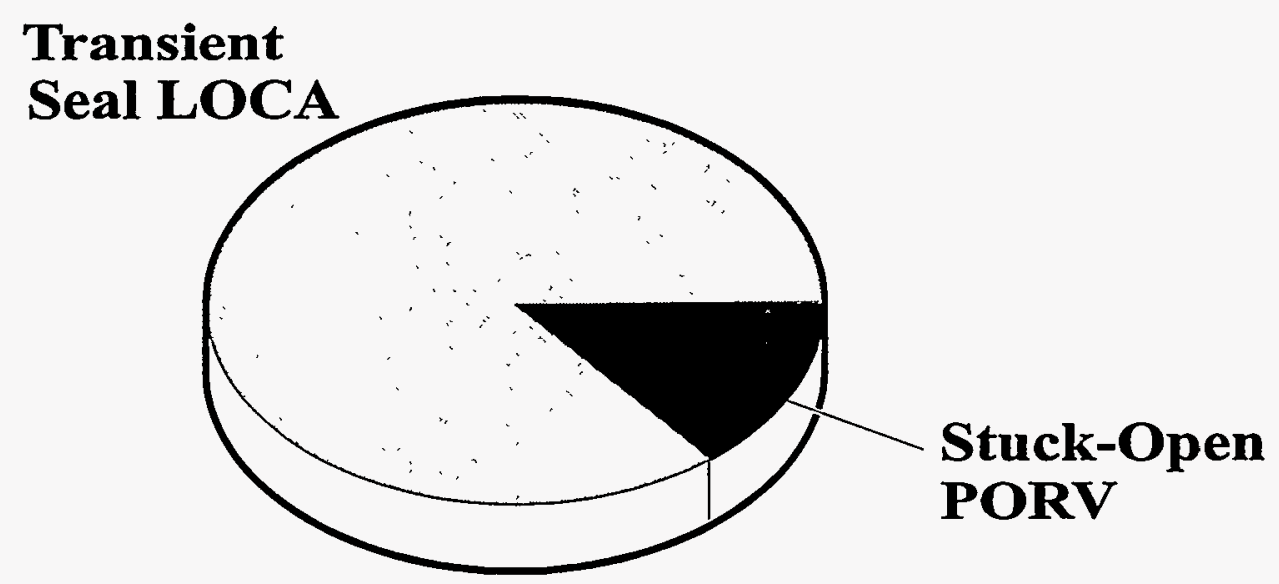

\section{Peach Bottom}

\section{Station Blackout}

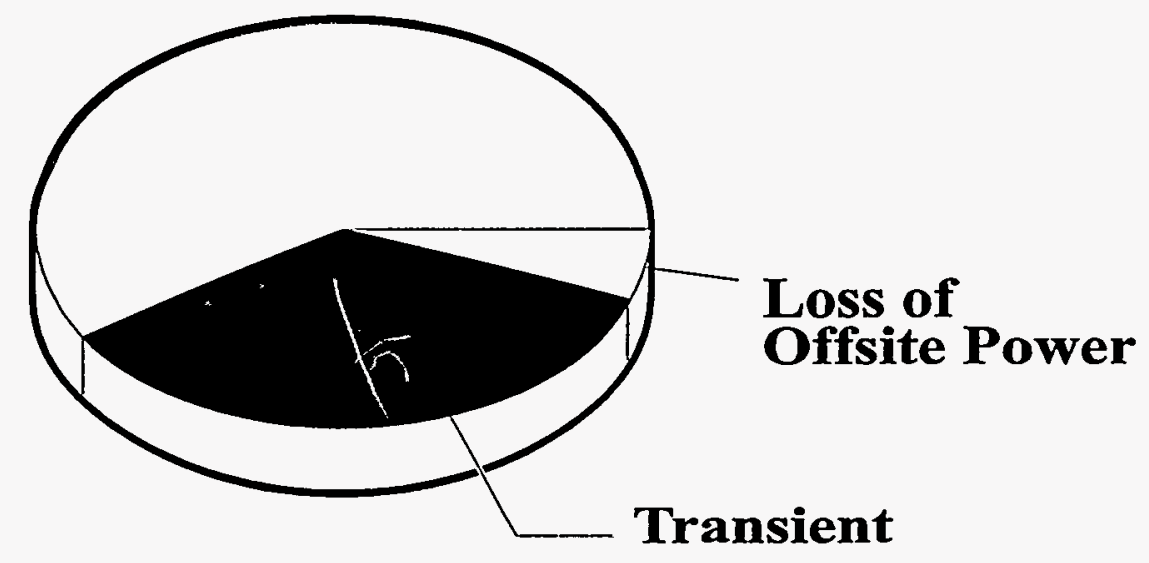

Figure 2.5-9 Principal contributors to fire core damage frequencies 


\section{Full Power}

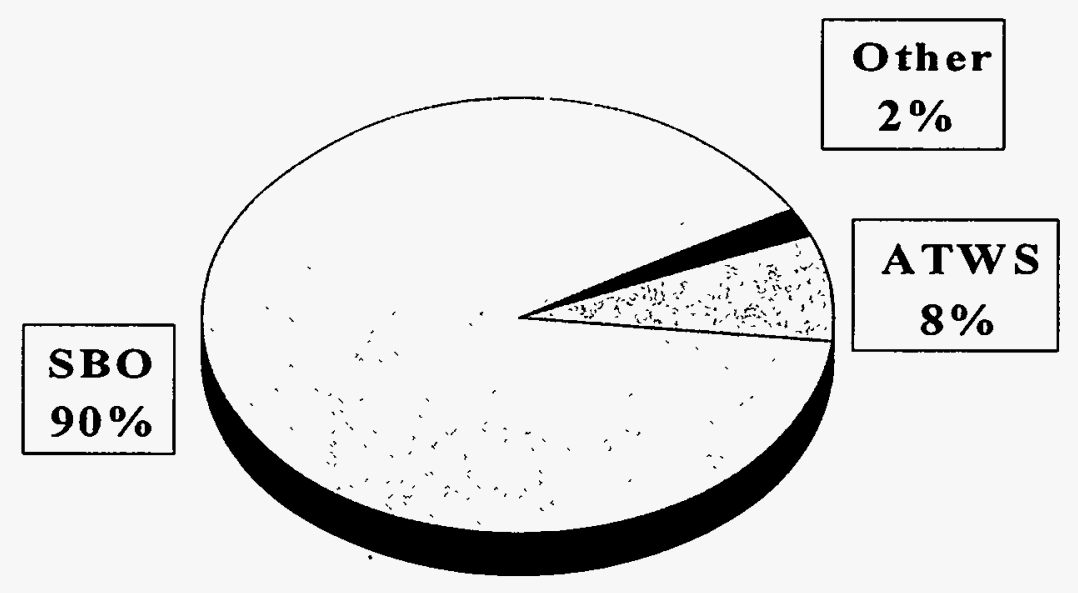

POS 5

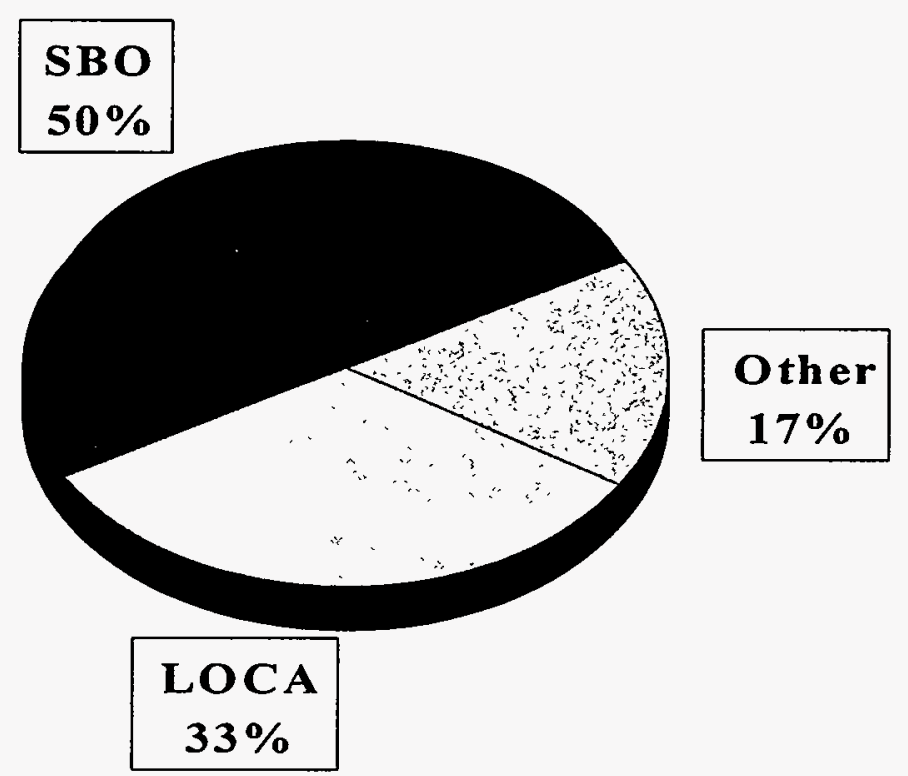

Figure 2.5-10 Grand Gulf sequence contributions for full-power and POS 5 


\section{Full Power}

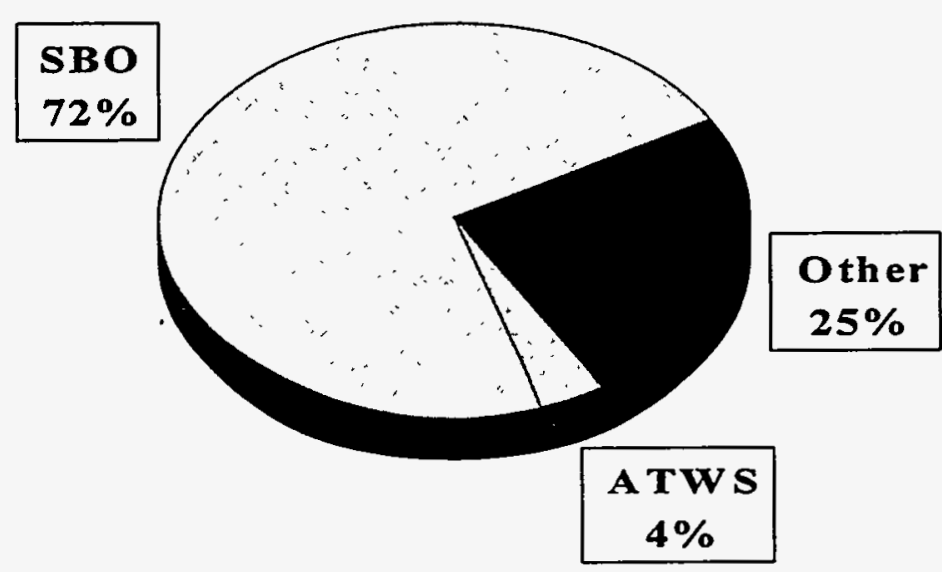

Mid-Loop Operation

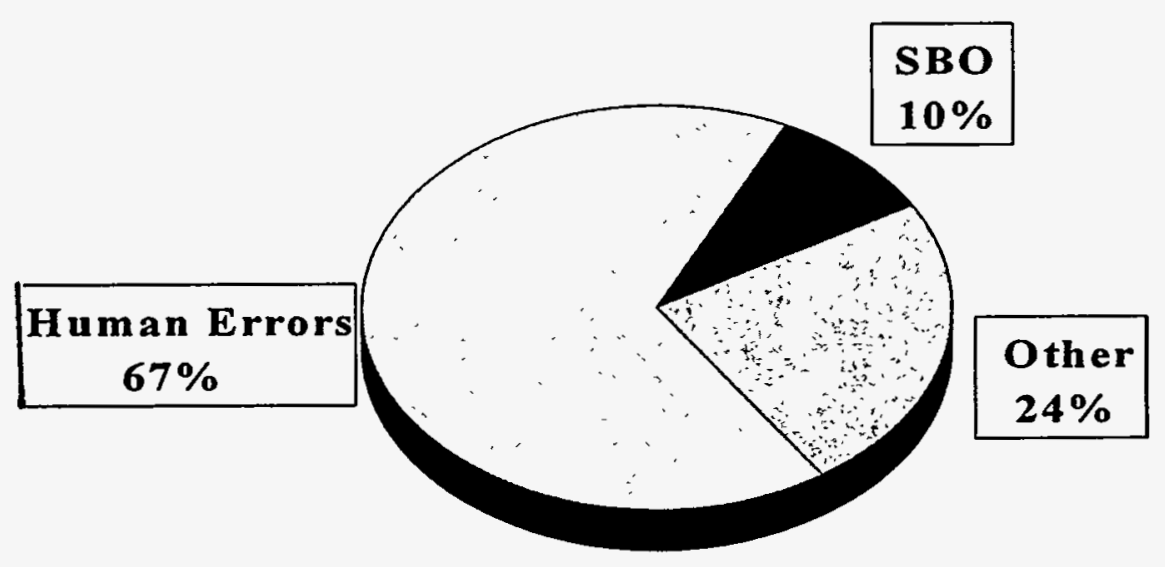

Figure 2.5-11 Surry sequence contributions for full-power and mid-loop operation 


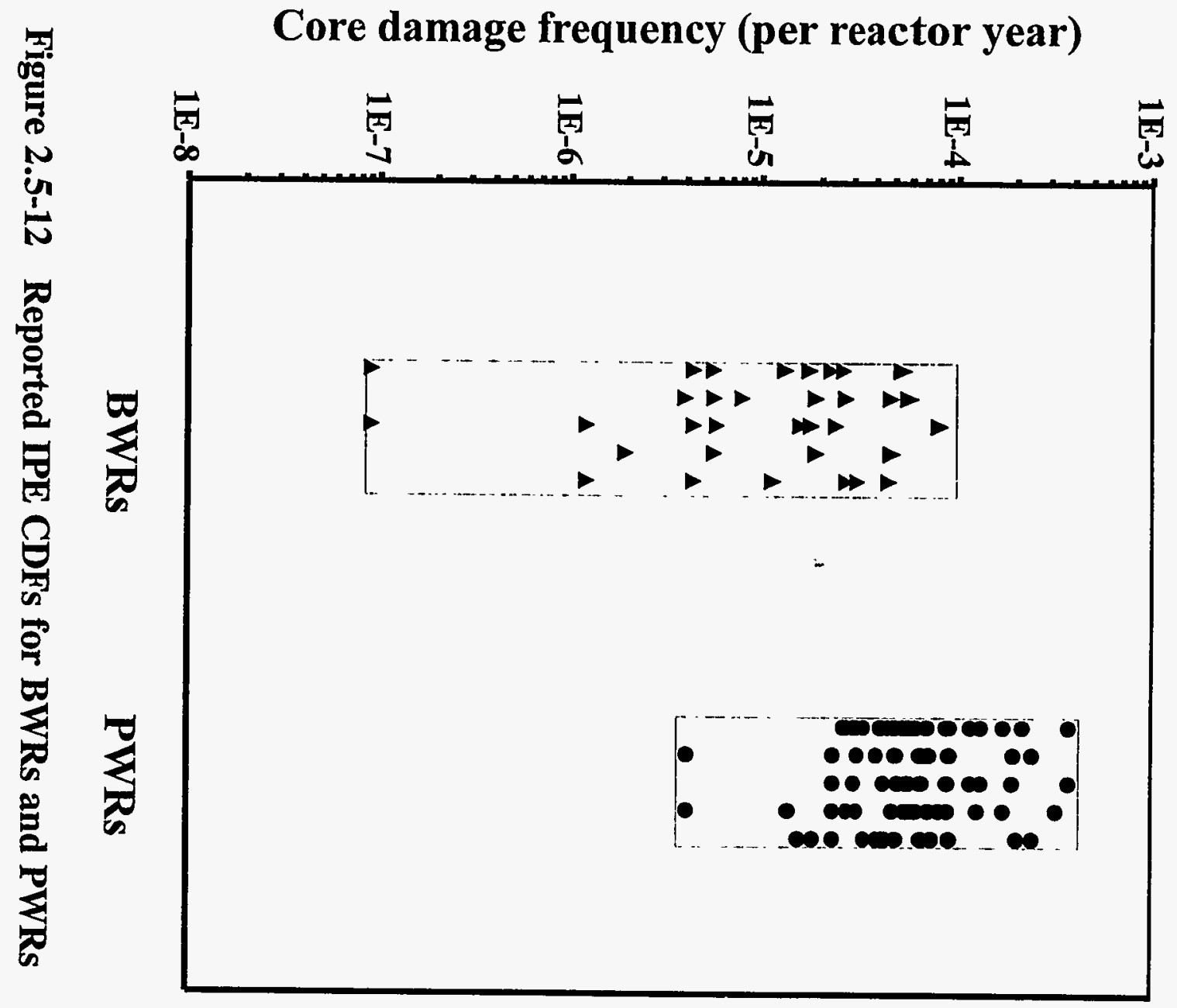




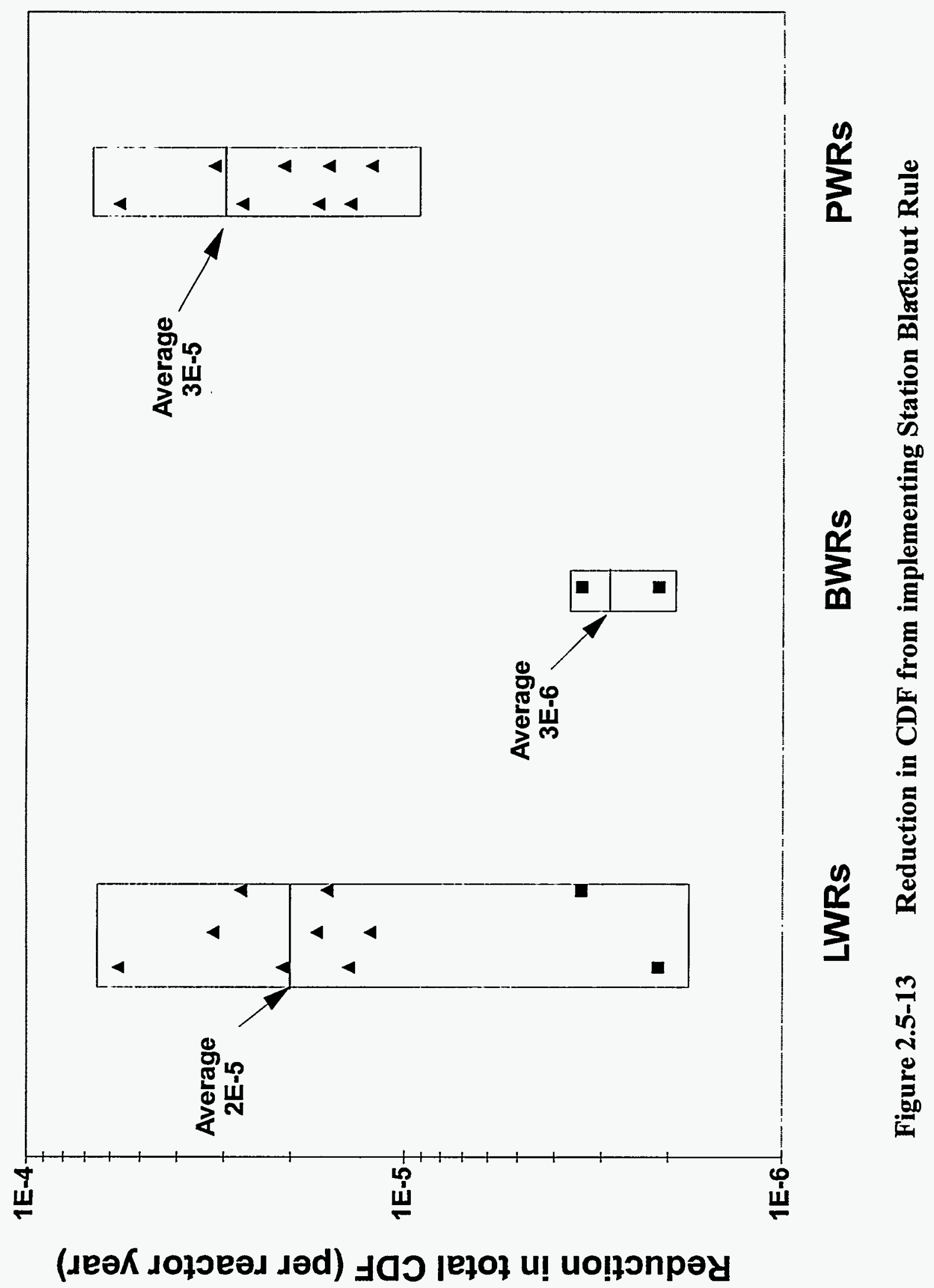




\section{References for Section $\mathbf{2 . 5}$}

1. U.S.Code of Federal Regulations, Title 10, Part 50.72, January 1, 1991.

2. U.S.Code of Federal Regulations, Title 10, Part 50.73, January 1, 1991.

3. J. W. Minarick, et al., "Precursors to Potential Severe Core Damage Accidents," U.S. Nuclear Regulatory Commission, NUREG/CR-4674, August 1991.

4. U.S. Nuclear Regulatory Commission, "Severe Accident Risks: An Assessment for Five U.S. Nuclear Power Plants," NUREG1150, December 1990.

5. G. E. Cummings, "Summary Report on the Seismic Safety Margins Research Program," Lawrence Livermore National Laboratories, NUREG/CR-4431, UCID-20549, January 1986.

6. Seismicity Owners Group and Electric Power Research Institute, "Seismic Hazard Methodology for the Central and Eastern United States," EPRI NP-4726, July 1986.
7. U.S. Nuclear Regulatory Commission, "Recommendations for Probabilistic Seismic Hazard Analysis: Guidance on Uncertainty and Use of Experts," NUREG/CR-6372 Vol. 1 \& 2, April 1997.

8. U.S. Code of Federal Regulations, Title 10, Part 50, Appendix R, January 1, 1991.

9. D. W. Whitehead, et al., "Evaluation of Potential Severe Accidents During Low Power and Shutdown Operations at Grand Gulf Unit 1: Analysis of Core Damage Frequency From Internal Events for Plant Operational State 5 During a Refueling Outage," Sandia National Laboratories, NUREG/CR-6143, June, 1994.

10. T. W. Chu and W. T. Pratt, "Evaluation of Potential Severe Accidents During Low Power Shutdown Operations at Surry, Unit 1," Brookhaven National Laboratory, NUREG/CR-6144, October 1995.

11. U.S. Nuclear Regulatory Commission, "Individual Plant Examination Program: Perspectives on Reactor Safety and Plant Performance," NUREG-1560, Draft for Comment, November 1996. 


\subsection{Risk-Informed Regulation}

\subsubsection{PRA Policy Statement}

Following the NUREG-1150 studies and during the implementation of the IPE program, the NRC debated the future use of PRA within the agency. NUREG- $1489^{1}$ was issued in March 1994 and provided a review of staff uses of PRA at that time. In addition, it provided information about currently available PRA methods and their strengths and weaknesses. At the same time, a commission policy statement on the use of PRA was being developed. That policy statement was issued in August 1995 and stated ${ }^{2}$ :

the commission's intention to encourage the use of PRA and to expand the scope of PRA applications in all nuclear regulatory matters to the extent supported by the state-of-the-art in terms of methods and data. Implementation of the policy statement will improve the regulatory process in three areas: Foremost, through safety decision making enhanced by the use of PRA insights; through more efficient use of agency resources; and through a reduction in unnecessary burdens on licensees.

Therefore, the Commission adopts the following policy statement regarding the expanded NRC use of PRA:

(1) The use of PRA technology should be increased in all regulatory matters to the extent supported by the state-of-the-art in PRA methods and data and in a manner that complements the $N R C$ 's deterministic . approach and supports the NRC's traditional defense-in-depth philosophy.

(2) PRA and associated analyses (e.g., sensitivity studies, uncertainty analyses, and importance measures) should be used in regulatory matters, where practical within the bounds of the state-of-the-art, to reduce unnecessary conservatism associated with current regulatory requirements, regulatory guides, license commitments, and staff practices. Where appropriate, PRA should be used to support the proposal for additional regulatory requirements in accordance with 10 CFR 50.109 (Backfit Rule). Appropriate procedures for including PRA in the process for changing regulatory requirements should be developed and followed. It is, of course, understood that the intent of this policy is that existing rules and regulations shall be complied with unless these rules and regulations are revised.

(3) PRA evaluations in support of regulatory decisions should be as realistic as practicable and appropriate supporting data should be publicly available for review.

(4) The Commission's safety goals for nuclear power plants and subsidiary numerical objectives are to be used with appropriate consideration of uncertainties in making regulatory judgments on the need for proposing and backfitting new generic 
requirements on nuclear power plant licensees.

This policy statement affirms the Commission's belief that PRA methods can be used to derive valuable insights, perspectives, and general conclusions as a result of an integrated and comprehensive examination of the design of nuclear facilities, facility response to initiating events, the expected interactions among facility structures, systems, and components and between the facility and its operating staff.

\subsubsection{Current Issues Concerning the Quantitative Use of PRA}

Even before the issuance of the PRA Policy Statement, the staff had begun to develop approaches for applying PRA more extensively in a regulatory setting. During this process it became clear that there were a number of key issues that needed to be addressed. The debate of these issues has been vigorous and still continues in some areas. The discussion below outlines some of the more important issues.

Do the Safety Goals provide the basis for risk targets?

The safety goals were originally developed to answer the question "how safe is safe enough?" Therefore, it is consistent with that policy to push the plants toward that goal. However, there have been arguments that risk targets should be set that are even more stringent that the quantitative health objectives (QHOs). Making the targets more stringent would account for uncertainty and incompleteness in risk assessments. Further, many in the agency support an ALARA approach toward risk, even though such an approach is not consistent with the
Commission's safety goal policy. Currently, targets are being set based on the subsidiary safety goals (see Section 2.6.3), so that the targets are tied to the QHOs, but are somewhat conservative and also more practical to implement.

Can the Safety Goals be applied on a plantspecific basis?

The safety goal policy clearly states that the safety goals are to be applied to the industry as a whole and not to individual plants. However, when implementing a riskinformed regulatory process, such an approach creates problems because it is difficult to regulate toward an industry average. For example, if we are only interested in the average, then one good plant could make up for one bad plant. Conceivably, plants could actually buy and sell risk credits to each other. Therefore, while the Commission is still interested in the collective industry behavior, implementation in a regulatory sense will be a plant-specific process. That is, if an individual plant proposes a change, decisions will be influenced by the risk at that plant and not so much by the industry average risk.

\section{What risks are to be considered?}

Until recently, many of the PRAs performed for plants included only internal events at full power. However, as discussed in Section 2.5, external events and low power/shutdown events can contribute significantly to risk. The safety goal policy does not clearly describe the risks to be included, but current thinking is that external events and low power/shutdown risks should be accounted for in some fashion. This is an extremely important question because many plants will be near or above the subsidiary safety goals if these risks are included. 
Thus, very little regulatory relief will be available to those plants.

Can plants with low risk be allowed to increase risk up to the Safety Goals?

Some plants are indicating very low risks in their IPE submittals. Assuming that these risk estimates are valid, plants may propose to relax the safety programs to save costs. There has been much debate about this issue among the staff. Given that the Commission has indicated that the safety goals represent a state of "safe enough," increases in risk up to the safety goals would seem to be warranted. However, current thinking is that such increases should be minimized because of uncertainties in PRA numbers and skepticism about very low risk estimates. Further, while risk decisions are likely to be made on a plant-specific basis, if all of the plants with risks below the safety goals increase risk up to the goals, then the industry average will clearly be above the goals. Therefore, the current approach allows for only small increases and encourages good plants to maintain low risk levels. The downside of this approach is that it does not reward the good plants and may, in fact, force them to maintain efforts that may not be in place at the bad plants.

To what extent can regulatory decisions be based on PRA estimates?

If PRAs were perfect, they could be used as the basis for all regulatory decisions. That is, the only requirement for plants would be to keep their risk below a set level. However, PRAs are obviously imperfect and such an approach is not practical with today's technology. Therefore, PRA will be used to some degree to influence decisions, rather than totally define the solutions. The use of PRA, then, leads to tradeoffs among risk estimates, current regulations, and defense-in-depth principles. As an extreme example, risk estimates might indicate that the CDF is so low that a containment is unnecessary to meet the safety goals; however, defense-in-depth principles would still lead to the need for such a structure. As the use of PRA is debated, the degree to which it can be used in a particular decision will continue to be controversial.

\section{How are uncertainties to be considered?}

PRAs, by their nature, produce uncertain results. As shown in Section 2.5, these uncertainties can span orders of magnitude. Further, there is debate within the PRA community as to how uncertainty analyses should be performed. In most cases the Commission and staff have indicated that mean values should be used for comparison purposes when making decisions based on quantitative risk estimates. The safety goal policy indicates that uncertainties should be accounted for, without providing much specific guidance. Various alternatives for treating uncertainties have been proposed, such as setting quantitative limits for the 95th percentile of the risk distribution or performing hypothesis testing on the decision. At this time, such prescriptive criteria for treating uncertainty are generally not being proposed. Rather, it is expected that the use of the somewhat conservative subsidiary safety goals will partially account for uncertainty and that uncertainty estimates will be considered subjectively by the staff in each particular case. The treatment of uncertainty is clearly an area that could use more research and additional guidance in the future.

In considering the answers to the above questions as well as the Commission's guidance in the PRA policy statement, it became clear that regulatory decisions should not be made entirely based on quantitative risk numbers. Other factors needed to be considered. Therefore, the 
decision was made to change the terminology from "risk-based" regulation to "risk-informed" regulation, reflecting the state of the art in PRA and the need to consider other factors, such as defense-indepth. The next section describes the current approach to risk-informed regulation as of the summer of 1997 .

\subsubsection{An Approach to Risk-Informed Regulation}

As this document is being written, regulatory guidance for risk-informed regulation is being developed. A number of regulatory guides and standard review plans have been proposed as drafts for comment., $3,4,6,7,8,9$ The remainder of this section contains information extracted from these draft documents. While the documents are likely to change before final publication, it is expected that the guiding principles will remain the same.

\subsubsection{Risk-Informed Philosophy}

In its approval of the policy statement on the use of PRA methods in nuclear regulatory activities, the Commission stated an expectation that "the use of PRA technology should be increased in all regulatory matters...in a manner that complements the NRC's deterministic approach and supports the NRC's traditional defense-in-depth philosophy." The use of risk insights in licensee submittals requesting Current Licensing Basis (CLB) changes will assist the staff in the disposition of such licensee proposals.

In implementing risk-informed decision making, changes are expected to meet a set of key principles. Some of these principles are written in terms typically used in traditional engineering decisions (e.g., defense-in-depth). These principles are:
1. The proposed change meets the current regulations. This principle applies unless the proposed change is explicitly related to a requested exemption or rule change.

2. Defense-in-depth is maintained.

3. Sufficient safety margins are maintained.

4. Proposed increases in risk, and their cumulative effect, are small and do not cause the NRC Safety Goals to be exceeded.

5. Performance-based implementation and monitoring strategies are proposed that address uncertainties in analysis models and data and provide for timely feedback and corrective action.

Each of these principles should be considered in the risk-informed, integrated decision making process, as illustrated in Figure 2.6-1.

The staff's proposed evaluation approach and acceptance guidelines follow from these principles. In implementing these principles, the staff expects that:

- All safety impacts of the proposed change are evaluated in an integrated manner as part of an overall risk management approach in which the licensee is using risk analysis to improve operational and engineering decisions broadly and not just to eliminate requirements the licensee sees as undesirable. The approach used to identify changes in requirements should be used to identify areas where requirements should be increased, as well as where they could be reduced. 
- The acceptability of proposed changes should be evaluated by the licensee in an integrated fashion that ensures that all principles are met.

- Core damage frequency (CDF) and large early release frequency (LERF) can be used as suitable metrics for making risk-informed regulatory decisions.

- Increases in estimated CDF and LERF resulting from proposed CLB changes will be limited to small increments. (Note that the issue of packaging multiple changes where some involve risk increases and others involve risk decreases has not yet been addressed.)

- The scope and quality of the engineering analyses (including traditional and probabilistic analyses) conducted to justify the proposed CLB change should be appropriate for the nature and scope of the change and should be based on the as-built and asoperated and maintained plant.

$\bullet$ Appropriate consideration of uncertainty is given in analyses and interpretation of findings.

- The plant-specific PRA supporting licensee proposals has been subjected to quality controls such as an independent peer review.

"In this context, LERF is being used as a surrogate for the early fatality QHO. It is defined as the frequency of those accidents leading to significant, unmitigated releases from containment in a time frame prior to effective evacuation of the close-in population such that there is a potential for early health effects. Such accidents genterally include unscrubbed releases associated with early containment failure at or shortly after vessel breach, containment bypass events, and loss of containment isolation. This definition is consistent with accident analysis used in the safety goal screening criteria discussed in the Commission's Regulatory Analysis Guidelines.
Data, methods, and assessment criteria used to support regulatory decision making must be scrutable and available for public review.

\subsubsection{A Four-Element Approach to Integrated Decision Making}

Given the principles of risk-informed decision making discussed above, the staff has identified a four-element approach to evaluating proposed CLB changes. This approach, which is presented graphically in Figure 2.6-2, acceptably supports the-NRC's decision making process. This approach is not sequential in nature; rather it is iterative.

\section{Element 1: Define the Proposed Change}

Element 1 involves three primary activities. First, the licensee should identify those aspects of the plant's licensing bases that may be affected by the proposed change, including, but not limited to, rules and regulations, final safety analysis report (FSAR), technical specifications, licensing conditions, and licensing commitments. Second, the licensee should identify all structures, systems, and components (SSCs), procedures, and activities that are covered by the CLB change under evaluation and consider the original reasons for inclusion of each program requirement. Third, the licensee should identify available engineering studies, methods, codes, applicable plant-specific and industry data and operational experience, PRA findings, and research and analysis results relevant to the proposed CLB change. With particular regard to the plant-specific PRA, the licensee should assess the capability to use, refine, augment, and update system models as needed to support a risk assessment of the proposed CLB change.

The above information should be used collectively to provide a description of the 
CLB change and to outline the method of analysis. The licensee should describe the proposed change and how it meets the objectives of the Commission's PRA Policy Statement, including enhanced decision making, more efficient use of resources, and reduction of unnecessary burden. In addition to improvements in reactor safety, this assessment may consider benefits from the CLB change such as reduced fiscal and personnel resources and radiation exposure. In addition, the licensee should affirm that the proposed CLB change meets the current regulations, unless the proposed change is explicitly related to a proposed exemption or rule change.

\section{Element 2: Perform Engineering Analysis}

As part of the second element, the licensee will evaluate the proposed CLB change with regard to the principles that adequate defense-in-depth is maintained, that sufficient safety margins are maintained, and that proposed increases in risk, and their cumulative effect, are small and do not cause the NRC Safety Goals to be exceeded.

Defense-in-Depth -- The engineering evaluation conducted should evaluate whether the impact of the proposed CLB change (individually and cumulatively) is consistent with the principle that defense-indepth is maintained. Defense-in-depth is maintained if:

- A reasonable balance among prevention of core damage, prevention of containment failure, and consequence mitigation is preserved.

- Over-reliance on programmatic activities to compensate for weaknesses in plant design is avoided.

- System redundancy, independence, and diversity are preserved commensurate with the expected frequency and consequences of challenges to the system (e.g., no risk outliers).

- Defenses against potential common cause failures are preserved and the potential for introduction of new common cause failure mechanisms is assessed.

- Independence of barriers is not degraded.

Defenses against human errors are preserved.

Safety Margins -- The engineering evaluation conducted should assess whether the impact of the proposed CLB change is consistent with the principle that sufficient safety margins are maintained. Here also, the licensee is expected to choose the method of engineering analysis appropriate for evaluating whether sufficient safety margins would be maintained if the proposed CLB change were implemented.

Sufficient safety margins are maintained if:

- Codes and standards or alternatives approved for use by the NRC are met, and

safety analysis acceptance criteria in the current licensing basis (e.g., FSAR, supporting analyses) are met, or proposed revisions provide sufficient margin to account for analysis and data uncertainty.

Evaluation of Risk Impact, Including Treatment of Uncertainties -- As noted earlier, the licensee's risk assessment should be used to address the principle that proposed increases in risk, and their cumulative effect, are small and do not cause the NRC Safety Goals to be exceeded. For 
purposes of implementation, the licensee should assess the expected change in CDF and LERF. The necessary sophistication of the evaluation, including the scope of the PRA (e.g., internal events only, full power only), depends on the contribution the risk assessment makes to the integrated decisionmaking, which depends to some extent on the magnitude of the potential risk impact.

The PRA performed should realistically reflect the actual design, construction, and operational practices. Consequently, the PRA used to support risk-informed decision making is expected to reflect the impact of previous changes made to the CLB.

For the purposes of establishing guidelines for risk-informed decision making, a CDF guideline of $1 \times 10^{-4}$ per reactor year (annual average of $\mathrm{CDF}$ ) has been adopted (with additional management attemtion for the $1 \times 10^{-5}$ to $1 \times 10^{-4}$ range). A LERF of $1 \times 10^{5}$ per reactor year (annual average of LERF) has been adopted as a containment performance guideline (with additional management attention for the $1 \times 10^{-6}$ to $1 \times 10^{-}$ ${ }^{5}$ range). These guidelines are intended for comparison with a full scope PRA (including internal events, external events, full power, low power and shutdown).

The acceptance guidelines have the following elements:

For a plant with a mean CDF at or above $1 \times 10^{-4}$ per reactor year (the Commission's subsidiary CDF objective) or with a mean LERF at or above $1 \times 10^{-5}$ per reactor year, it is expected that applications will result in a net decrease in risk or be risk neutral.

For a plant with a mean CDF of less than $1 \times 10^{-4}$ per reactor year, applications will be considered which, when combined with the LERF guidelines described below:
- result in a net decrease in $\mathrm{CDF}$ or are CDF-neutral;

- result in increases in calculated CDF that are very small (e.g., CDF increase of less than 1E-6 per reactor year); or

- result in an increase in calculated CDF in the range of $1 \times 10^{-6}$ to $1 \times 10^{-5}$ per reactor year, subject to increased NRC technical and management review.,

AND

- For a plant with a mean LERF of between $1 \times 10^{-6}$ and $1 \times 10$ per reactor year:

- result in a net decrease in LERF or are LERF-neutral;

- result in an increase in calculated LERF of up to $1 \times 10^{-6}$ per reactor year, subject to increased NRC OR technical and management review,

- For a plant with a mean LERF of less than $1 \times 10^{-6}$ per reactor year:

- result in a net decrease in LERF or are LERF-neutral;

- result in increases in calculated LERF that are very small (e.g., LERF increase of less than $1 \times 10^{-7}$ per reactor year); or

- result in an increase in calculated LERF of up to $1 \times 10^{-6}$ per reactor year, subject to increased NRC technical and management review.

In the context of decision making, the acceptance guidelines should not be 
interpreted as being overly prescriptive. They are intended to provide an indication, in numerical terms, of what is considered acceptable. As such, the numerical guidelines are approximate values that provide an indication of the changes that are generally acceptable. Furthermore, the uncertainties associated with PRA calculations preclude a definitive decision of acceptability or unacceptability based purely on the numerical results. The intent in making the comparison of the PRA results with the acceptance guidelines is to demonstrate with reasonable assurance that Principle 4 is being met. This decision must be made based on a full understanding of the impacts of the uncertainties, both those that are explicitly accounted for in the results and those that are not. This is a somewhat subjective process, and the reasoning behind the decisions must be well documented.

In the initial comparison of the PRA results to the acceptance guidelines, the appropriate numerical measures to use are mean values. In general, if the change is such that it would result in either the point estimate or mean value of the CDF or LERF or the corresponding increase $(\triangle \mathrm{CDF}$ or $\triangle \mathrm{LERF}$ ) exceeding its guideline, the change will not be approved unless, for example, it is shown that there are unquantified benefits that are not reflected in the quantitative risk results. In addition, if convincing qualitative arguments are made that the analysis is conservative, or compensatory measures are proposed to counter the impact of the major risk contributors, even though the impact of these measures may not be estimated numerically, then such arguments will be considered in the decision process. Finally, changes which result in very small increases in the estimates of CDF or LERF might be allowable even for plants for which the base case approaches the guidelines, but again, only if additional qualitative arguments can be made as discussed above.
If the mean value of a measure were to lie near the corresponding guideline a full parametric, uncertainty analysis will allow an assessment of the confidence with which the guideline is met.

Because of the nature of PRA analyses, it is not reasonable to be so prescriptive about the acceptable level of confidence; changes could still be allowed when lower levels of confidence are calculated when, as discussed above, convincing qualitative arguments that the true values are less than the calculated values can be brought to bear. Such arguments can only be made with a full understanding of the contributors to uncertainty.

When the PRA is not full scope, then it is necessary for the licensee to address the significance of the out-of-scope items. The contribution of the out-of-scope portions of the model to the change in metric may be addressed by bounding analyses, detailed analyses, or by a demonstration that the change has no impact on the unmodeled contributors. In addition, it should also be demonstrated that changes based on a partial PRA do not disproportionally change the risk associated with those accident sequences that arise from the modes of operation not included in the PRA.

\section{Element 3: Define Implementation and Monitoring Program}

Careful consideration should be given to implementation and performance-monitoring strategies. The primary goal for this element is to assess SSC performance under the proposed CLB change by establishing performance-monitoring strategies to confirm the assumptions and analyses that were conducted to justify the CLB change.

The implementation of the regulatory changes should ensure that no unexpected 
adverse safety degradation occurs because of the changes. Based on the findings of the engineering evaluations conducted to examine the impact of the proposed changes, an implementation plan should be developed to ensure that any unexpected problems and deficiencies are cietected and corrected prior to becoming a significant safety problem.

A monitoring program, utilizing appropriate performance-based feedback criteria, is an important element of many risk informed application approaches. This performancebased approach should have the following attributes: there are measurable parameters to monitor plant performance; objective criteria are established to assess performance based on a combination of risk insights, traditional engineering analysis, and performance history; and parameters are selected for monitoring such that, if exceeded, they will provide early indication of problems prior to being a safety concern.

\section{Element 4: Submit Proposed Change}

Requests for proposed change to the plant's CLB typically take the form of requests for license amendments (including changes to or removal of license conditions), technical changes, changes to or withdrawals of orders, and changes to programs.

Licensees are free to decide whether to submit risk information in support of their CLB change request. Where the licensee's proposed change to the CLB is consistent with currently approved staff positions, the staff's determination will be based solely on traditional deterministic engineering analysis without recourse to risk information (although the staff may consider any risk information which is submitted by the licensee). However, where the licensee's proposed change goes beyond currently approved staff positions, the staff will normally consider both information based upon traditional deterministic engineering analysis as well as information based upon risk insights.

\subsubsection{Current Status of Risk-Informed Regulatory Activities}

As this document is being written, efforts are underway to implement risk-informed regulation in a number of areas, including

- technical specifications,

- graded quality assurance,

- in-Service inspection,

- in-Service testing.

For each of these areas, regulatory guides and standard review plans are being prepared. Debate of these documents is expected to be vigorous and the reader is encouraged to obtain the latest versions of these documents as they become available.

Currently, the industry has mixed responses to risk-informed processes that are being proposed. There is no doubt that, in a number of areas, the licensees are burdened with costly activities that contribute little to public safety. Therefore, in principle the licensees support the concept of riskinformed regulation. However, at this time a substantial number of licensees are eliminating or reducing their PRA activities and staff.

There are several reasons that risk-informed regulation has not been an instant success. First, in the industry's mind, the development of the process has been very slow. Second, most licensees intended to use their IPEs as the basis for their riskinformed activities. Reviews of the IPEs have indicated that their quality varies and that they may need substantial enhancement for some applications (note that the IPEs do not include low power/shutdown and most of them have simplified treatments of external 
events). While the IPEs appear to have successfully met their intended purpose, it is extremely unfortunate that the NRC did not provide better guidance to the industry regarding the preparation of the IPEs so that they would be more useful in the context of risk-informed regulation. Third, as indicated in the previous section, risk-informed regulation does not mean that current regulations do not have to be addressed. Therefore, to many it seems as though riskinformed regulation does not replace an old system; it only adds another layer of regulation on top of the old system. For these reasons, many licensees are losing interest in this process.

Despite the concerns that some licensees have with this process, others are still vigorously pursuing these activities and are participating in pilot implementation programs. Over the next year many important decisions regarding the implementation of risk-informed regulation are expected and the reader should stay tuned. In any case it is clear that regulatory thought processes within the NRC have profoundly changed over the last ten years. 


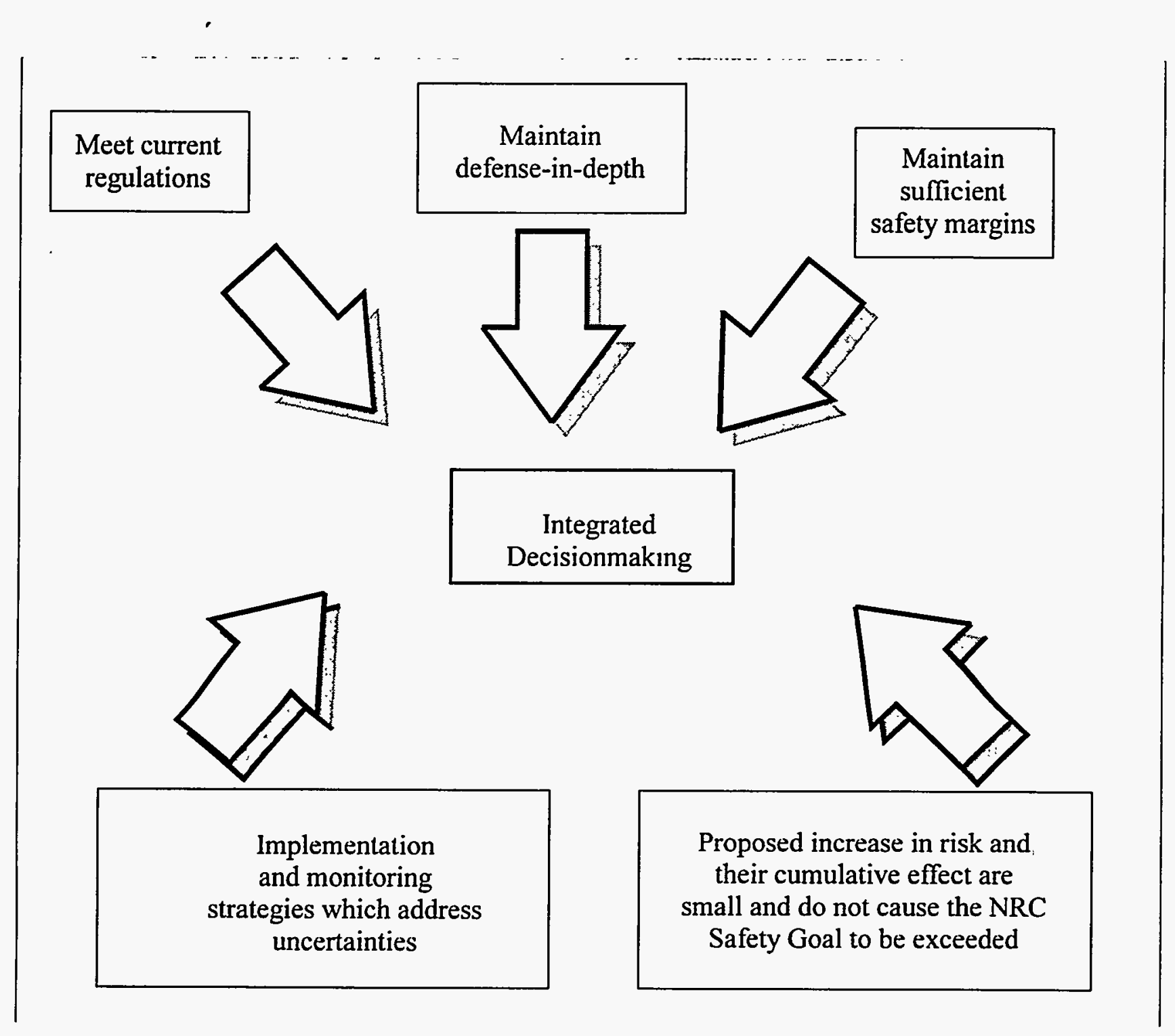

Figure 2.6-1 Principles of risk-informed regulation 


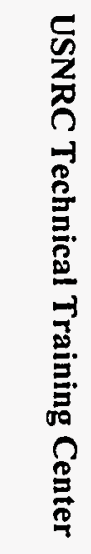

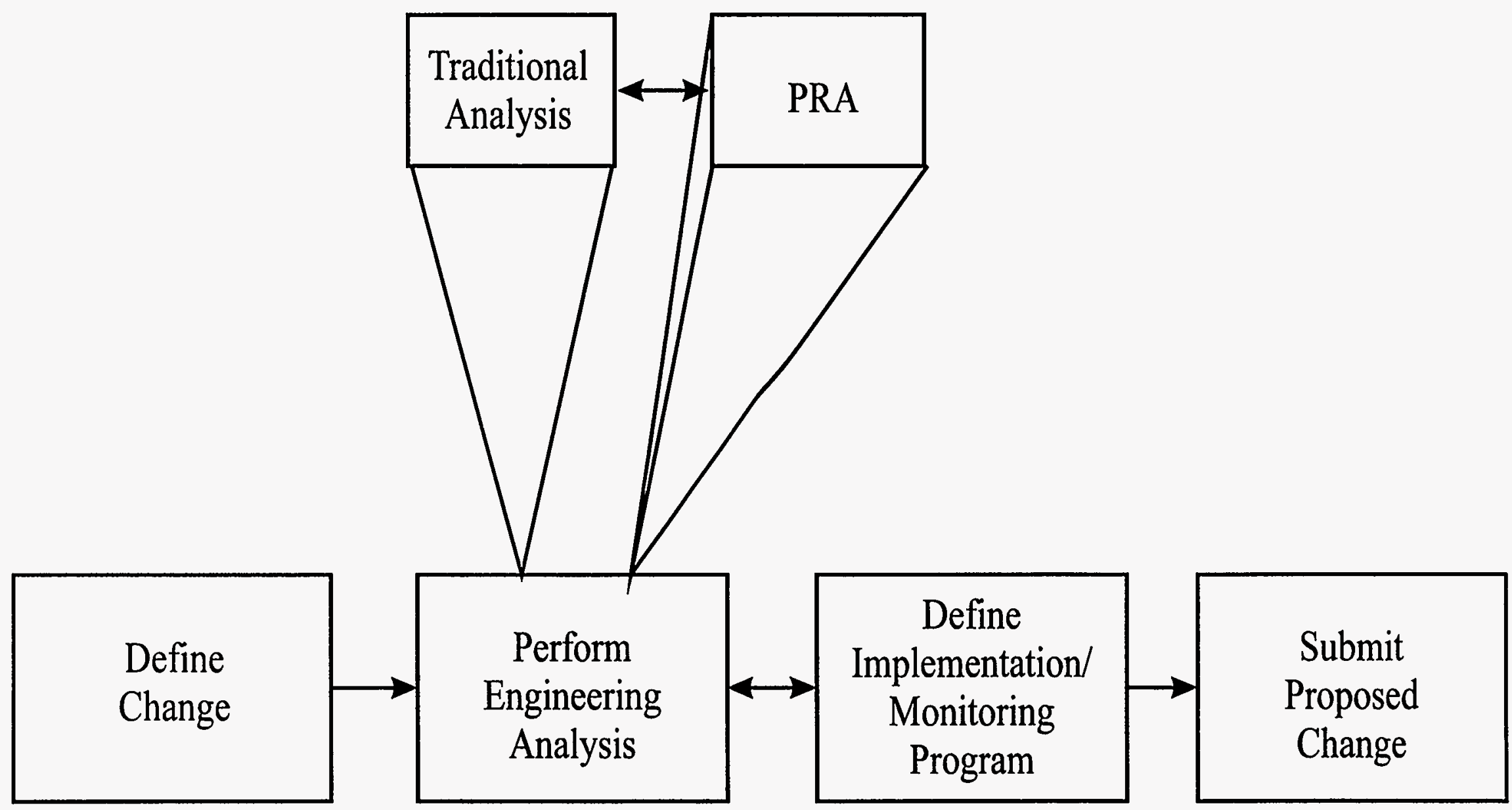

Figure 2.6-2 Principal elements of risk-informed, plant-specific decision making 


\section{References for Section $\mathbf{2 . 6}$}

1. U.S. Nuclear Regulatory Commission, PRA Working Group, "A Review of NRC Staff Uses of Probabilistic Risk Assessment, "NUREG1489, March 1994.

2. U.S. Nuclear Regulatory Commission, "Use of Probabilistic Risk Assessment Methods in Nuclear Regulatory Activities; Final Policy Statement,"Federal Register, 60FR42622, August 16, 1995.

3. U.S. Nuclear Regulatory Commission, "An Approach for Using Probabilistic Risk Assessment in Risk-Informed Decisions on Plant-Specific Changes to the Current Licensing Basis," Draft Regulatory Guide DG-1061, June 1997.

4. U.S. Nuclear Regulatory Commission, "An Approach for Plant-Specific, Risk-Informed, Decisionmaking: Inservice Testing," Draft Regulatory Guide DG-1062, June 1997.

5. U.S. Nuclear Regulatory Commission, "An Approach for Plant-Specific, Risk-Informed,
Decisionmaking: Graded Quality Assurance," Draft Regulatory Guide DG-1064, June 1997.

6. U.S. Nuclear Regulatory Commission, "An Approach for Plant-Specific, Risk-Informed Decisionmaking: Technical Specifications," Draft Regulatory Guide DG-1065, June 1997.

7. U.S. Nuclear Regulatory Commission, "Use of Probabilistic Risk Assessment in PlantSpecific, Risk-Informed Decisionmaking: General Guidance," Standard Review Plan, Rev. L, Chapter 19, March 27, 1997.

8. U.S. Nuclear Regulatory Commission, "RiskInformed Decisionmaking: Technical Specifications," Standard Review Plan, Rev. 13, Chapter 16.1, March 13, 1997.

9. U.S. Nuclear Regulatory Commission, "Standard Review Plan for the Review of Risk-Informed Inservice Testing Applications," Standard Review Plan, Rev. 2C, Chapter 3.9.7, March 13, 1997. 


\section{Appendix 2A Davis-Besse Loss Of Feedwater}

The one-unit Davis-Besse nuclear power plant is located in Oak Harbor, Ohio. The plant is operated by the Toledo Edison Company. The plant consists of one Babcock \& Wilcox PWR designed for a maximum operational power of $874 \mathrm{MWe}$. The Davis-Besse plant has been in operation since July 1978. Key systems of the DavisBesse plant are depicted in Figures 2A-1 through 2A-6.

The following sections describe a loss-offeedwater incident that occurred at the Davis-Besse plant. In view of the importance of the operator actions in this event, the description is a narrative based upon a composite of the operator interviews performed by an NRC review team following the incident (NUREG-1154). The review team decided that this would best convey the effects of stress, training, experience, teamwork, and impediments on operator performance.

The following text is extracted directly from NUREG-1154.

\section{A.1 Initiating Events}

On June 9, 1985, the midnight shift of operators assumed control of the DavisBesse nuclear power plant. The oncoming shift included four licensed operators, four equipment operators, an auxiliary operator, and an administrative assistant. The shift supervisor and the assistant shift supervisor are licensed senior reactor operators and the most experienced members of the operating crew. Both were at the plant before it was issued an operating license in April 1977. The reactor operators, who were responsible for the control room, had decided between themselves who would be responsible for the primary-side and who would take the secondary-side work stations. The secondary-side operator had been a licensed reactor operator for about two years. The primary-side operator was licensed in January 1985; he had previous nuclear Navy experience and was an equipment operator before being licensed. Prior to the morning of June 9, neither reactor operator had been at the controls during a reactor trip at Davis-Besse.

The four equipment operators are a closeknit group, three of whom had been operators in the nuclear Navy. Their experience at the plant ranges from three to nine years, averaging six-and-one-half years per operator. Equipment operators receive directions from the control room operators to manipulate and troubleshoot equipment in the reactor auxiliary building and the turbine building. Generally, equipment operators occupy this position temporarily as they participate in a development program leading to the position of licensed operator. However, two equipment operators did not intend to become licensed operators.

The shift turnover of June 9 was easy, there were no ongoing tests or planned changes to plant status. The plant was operating at $90 \%$ of the full power authorized in the license granted by the NRC in April 1977, to minimize the potential for an inadvertent reactor trip due to noise on primary coolant flow instrumentation. All the major equipment control stations were running on automatic except the No. 2 main feedwater pump. As a result, the integrated control system instruments were monitoring and controlling the balance between the plant's reactor coolant system and the secondary coolant system. 
Since April 1985, there had been control problems with both main feedwater pumps. Troubleshooting had not identified or resolved the problems. In fact, a week earlier, on June 2, 1985, both feedwater pumps tripped unexpectedly after a reactor trip. After some additional troubleshooting, the decision was made to not delay startup any longer, but to put instrumentation on the pumps to help diagnose the cause of a pump trip, if it occurred again. As a precaution, the number two main feedwater pump was operating in manual control to prevent it from tripping and to ensure that all main feedwater would not be lost should the reactor trip. Some operators were uneasy about going up to power with problems in the feedwater pumps, but they complied with the decisions made by their management.

During the first hour of the shift, the operators' attention and thoughts were directed to examining the control panels and alarm panels, and performing instrument checks and routine surveillance associated with shift turnover. Thus, at 1:35 in the morning, the plant generator was providing electricity to the Ohio countryside. The secondary-side operator had gone to the kitchen where he joined an equipment operator for a snack. The other reactor operator was at the operator's desk studying procedures for requalification examinations. The assistant shift supervisor had just left the kitchen on his way back to the control room after a break. The shift supervisor was in his office outside the control room performing administrative duties.

\section{A.2 Reactor Trip - Turbine Trip}

The assistant shift supervisor entered the control room and was examining one of the consoles when he noticed that main feedwater flow was decreasing and that the
No. I main feedwater pump had tripped. Since the No. 2 feedwater pump was in manual control, it could not respond to the integrated control system demand automatically to increase feedwater flow.

The "winding down" sound of the feedwater pump turbine was heard by the reactor operator in the kitchen, and by the administrative assistant and the shift supervisor, both of whom were in their respective offices immediately outside the control room. They headed immediately for the control room -- the event had begun.

The secondary-side reactor operator ran to his station and immediately increased the speed of the No. 2 main feedwater pump to compensate for the decrease of feedwater flow from the No. 1 pump. The primary-side operator had already opened the pressurizer spray valve in an attempt to reduce the pressure surge resulting from the heatup of the reactor coolant system due to a decrease in feedwater flow.

The plant's integrated control system attempted automatically to reduce reactor/turbine power in accordance with the reduced feedwater flow. The control rods were being inserted into the core and reactor power had been reduced to about 80\%. At the same time the primary-side reactor operator held open the pressurizer spray valve in an attempt to keep the reactor coolant pressure below the high pressure reactor trip set point of 2300 psig (normal pressure is 2150 psig). However, the reduction of feedwater and subsequent degradation of heat removal from the primary coolant system caused the reactor to trip on high reactor coolant pressure. The operators had done all they could do to prevent the trip, but the safety systems had 
acted automatically to shut down the nuclear reaction.

The primary-side operator acted in accordance with the immediate post-trip actions specified in the emergency procedure that he had memorized. Among other things, he checked that all control rod bottom lights were on, hit the reactor trip (shutdown) button, isolated letdown from the reactor coolant system, and started a second makeup pump to anticipate a reduced pressurizer inventory after a normal reactor trip. Then he waited, and watched the reactor coolant pressure to see how it behaved.

The secondary-side operator heard the turbine stop valves slamming shut and knew the reactor had tripped. This "thud" was heard by most of the equipment operators who also recognized its meaning and two of them headed for the control room. Almost simultaneously, the secondary-side operator heard the loud roar of main steam safety valves opening, a sound providing further proof that the reactor had tripped. The lifting of safety valves after a high-power reactor trip was normal. Everything was going as expected as he waited and watched the steam generator water levels boil down -each should reach the normal post-trip low level limit of 35 inches on the startup level instrumentation and hold steady.

The shift supervisor joined the operator at the secondary-side control console and watched the rapid decrease of the steam generator levels. The rapid feedwater reduction system (a subsystem of the integrated control system) had closed the startup feedwater valves, but as the level approached the low level limits, the startup valves opened to hold the level steady. The main steam safety valves closed as expected.
The system response was looking "real good" to the shift supervisor.

The assistant shift supervisor in the meantime opened the plant's looseleaf emergency procedure book. (It is about two inches thick, with tabs for quick reference. The operators refer to it as emergency procedure 1202:01; the NRC refers to it as the ATOG procedure -Abnormal Transient Operating Guidelines) As he read aloud the immediate actions specified, the reactor operators were responding in the affirmative. After phoning the shift technical advisor (STA) to come to the control room, the administrative assistant began writing down what the operators were saying, although they were speaking faster than she could write.

The STA was working a 24-hour shift and was asleep when awakened by a telephone call from the shift supervisor, which was followed immediately by the call from the administrative assistant. (The STAs are provided an apartment-type room in the administrative building, which is outside the protected area about one-half mile from the plant. According to procedures, they must be able to get to the control room within 10 minutes of being called.) He had detected a sense of urgency in the telephone calls and so he ran out of the building to his car for the drive to the site. He was anxious himself -- this was his first reactor trip since becoming a shift technical advisor in January 1985.

\section{A.3 Loss of Main Feedwater}

Although the assistant shift supervisor was loudly reading the supplementary actions from the emergency procedure book, the shift supervisor heard the main steam safety valves open again. He knew from experience 
that something was unusual and instinctively surveyed the control console and panel for a clue. He discovered that both main steam isolation valves (MSIVS) had closed -- the first and second of a list of unexpected equipment performances and failures that occurred during the event.

The secondary-side operator was also aware that something was wrong because he noticed that the speed of the only operating main feedwater pump was decreasing. After verifying that the status of the main feedwater pump turbine was normal, he concluded that the turbine was losing steam pressure at about the same time that the shift supervisor shouted that the MSIVs were closed. All eyes then turned up to the annunciators at the top of the back panel. They saw nothing abnormal in the kind or number of annunciators lit after the reactor trip. The operators expected to find an alarm indicating that the Steam Feedwater Rupture Control System (SFRCS, pronounced $S-F A R S E)$ had activated. Based on their knowledge of previous events at the plant, they believed that either a partial or full actuation of the SFRCS had closed the MSIVs. However, the SFRCS annunciator lights were dark. The MSIVs had closed at 1:36 a.m. and they were going to stay closed. It normally takes at least one-half hour to prepare the steam system for reopening the valves.

The No. 2 main feedwater pump turbine, deprived of steam, was slowly winding down. Since the MSIVs were closed and there was limited steam inventory in the moisture separator reheaters, there was inadequate motive power to pump feedwater to the steam generators. At about 1:70 a.m., the discharge pressure of the pump had dropped below the steam pressure which terminated main feedwater flow.

\section{A.4 Loss of Emergency Feedwater}

The secondary-side operator watched the levels in both steam generators boil down; he had also heard the main steam safety valves lifting. Without feedwater, he knew that an SFRCS actuation on low steam generator level was imminent. The SFRCS should actuate the auxiliary feedwater system (AFWS) which in turn should provide emergency feedwater to the steam generators. He was trained to trip manually any system that he felt was going to trip automatically. He requested and received permission from the shift supervisor to trip the SFRCS on low level to conserve steam generator inventory, i.e., the AFWS would be initiated before the steam generator lowlevel setpoint was reached.

He went to the manual initiation switches at the back panel and pushed two buttons to trip the SFRCS. He inadvertently pushed the wrong two buttons and, as a result, both steam generators were isolated from the emergency feedwater supply. He had activated the SFRCS on low pressure for each steam generator instead of on low level. By manually actuating the SFRCS on low pressure, the SFRCS was signaled that both generators had experienced a steamline break or leak and the system responded, as designed, to isolate both steam generators. The operator's anticipatory action defeated the safety function of the auxiliary feedwater system -- a common-mode failure and the third abnormality to occur within 6 minutes after the reactor trip.

The operator returned to the auxiliary feedwater station expecting the AFWS to actuate and provide the much-needed feedwater to the steam generators that were boiling dry. Instead, he first saw the No. I AFW pump, followed by the No. $2 A F W$ 
pump trip on overspeed - a second commonmode failure of the auxiliary feedwater system and abnormalities four and five. He returned to the SFRCS panel to find that he had pushed the wrong two buttons.

The operator knew what he was supposed to do. In fact, most knowledgeable people in the nuclear power industry, even control room designers, know that the once-through steam generators in Babcock \& Wilcoxdesigned plants can boil dry in as little as 5 minutes; consequently, it is vital for an operator to be able to quickly start the AFWS. There could have been a button labeled simply "AFWS--Push to start." But instead, the operator had to do a mental exercise to first identify a signal in the $S F R C S$ that could indirectly start the AFW system, find the correct set of buttons from a selection of five identical sets located knee-high from the floor on the back panel, and then push them without being distracted by the numerous alarms and loud exchanges of information between operators.

The shift supervisor quickly determined that the valves in the AFWS were improperly aligned. He reset the SFRCS, tripped it on low level, and corrected the operator's error about one minute after it occurred. This action commanded the SFRCS to realign itself such that each AFW pump delivered flow to its associated steam generator. Thus, had both systems (the AFWS and $S F R C S)$ operated properly, the operator's mistake would have had no significant consequences on plant safety.

The assistant shift supervisor, meanwhile, continued reading aloud from the emergency procedure. He had reached the point in the supplementary actions that require verification that feedwater flow was available. However, there was no feedwater, not even from the AFWS, a safety system designed to provide feedwater in the situation that existed. (The Davis-Besse emergency plan identifies such a situation as a Site Area Emergency.) Given this condition, the procedure directs the operator to the section entitled, "Lack of Heat Transfer." He opened the procedure at the tab corresponding to this condition, but left the desk and the procedure at this point to diagnose why the AFWS had failed. He performed a valve alignment verification and found that the isolation valve in each $A F W$ train had closed. Both valves (AF-599 and $A F-608)$ had failed to reopen automatically after the shift supervisor had reset the SFRCS. He tried unsuccessfully to open the valves by pressing the buttons on the back panel. He went to the SFRCS cabinets in the back of the control panel to clear any trips in the system and block them so that the isolation valves could open. However, there were no signals keeping the valves closed. He concluded that the torque switches in the valve operators must have tripped. The AFW system had now suffered its third common-mode failure, thus increasing the number of malfunctions to seven within 7 minutes after the reactor trip (1:42 a.m.).

\section{A.5 Reactor Coolant System Heatup}

Meanwhile, about 1:40 a.m., the levels in both steam generators began to decrease below the normal post-reactor-trip limits (about 35 inches on the startup range). The feedwater flow provided by the No. I main feedwater pump had terminated. The flow from the No. 2 main feedwater pump was decreasing because the MSIVs were closed, which isolated the main steam supply to the pump. With decreasing feedwater flow, the effectiveness of the steam generators as a 
heat sink for removing decay (i.e., residual) heat from the reactor coolant system rapidly decreased. As the levels boiled down through the low level setpoints (the auxiliary feedwater should automatically initiate at about 27 inches), the average temperature of the reactor coolant system began to increase, indicating a lack of heat transfer from the primary to the secondary coolant systems. When the operator incorrectly initiated SFRCS on low pressure, all feedwater was isolated to both steam generators. The reactor coolant system began to heat up because heat transfer to the steam generators was essentially lost due to loss of steam generator water level.

The average reactor coolant temperature increased at the rate of about $40 \mathrm{~F} / \mathrm{minute}$ for about 12 minutes. The system pressure also increased steadily until the operator fully opened the pressurizer spray valve (at about 1:42 a.m.). The spray reduced the steam volume in the pressurizer and temporarily interrupted the pressure increase. The pressurizer level increased rapidly but the pressurizer did not completely fill with water. As the indicated level exceeded the normal value of 200 inches, the control valve for makeup flow automatically closed.

At this point, things in the control room were hectic. The plant had lost all feedwater; reactor pressure and temperature were increasing; and a number of unexpected equipment problems had occurred. The seriousness of the situation was fully appreciated.

\section{A.6 Operator Actions}

By 1:tt a.m., the licensed operators had exhausted every option available in the control room to restore feedwater to the steam generators. The main feedwater pumps no longer had a steam supply. Even if the MSIVs could be opened, the steam generators had essentially boiled dry, and sufficient steam for the main feedwater pump turbines would likely not have been available. The turbines for the AFW pumps had tripped on overspeed, and the trip throttle valves could not be reset from the control room. Even if the $A F W$ pumps had been operable, the isolation valves between the pumps and steam generators could not be opened from the control room, which also inhibited the AFWS from performing its safety function. The likelihood of providing emergency feedwater was not certain, even if the AFW pump overspeed trips could be reset and the flow path established. For example there was a question as to whether there was enough steam remaining in the steam generators to start the steam driven pumps. Unknown to the operators, the steam inventory was further decreased because of problems controlling main steam pressure. The number of malfunctions had now reached eight.

Three equipment operators had been in the control room since shortly after the reactor tripped. They had come to the control room to receive directions and to assist the licensed operators as necessary. They were on the sidelines watching their fellow operators trying to gain control of the situation.

The safety-related AFW equipment needed to restore water to the steam generators had failed in a manner that could only be remedied at the equipment location and not from the control room. The affected pumps and valves are located in locked compartments deep in the plant. 
The primary-side reactor operator directed two of the equipment operators to go to the auxiliary feedwater pump room to determine what was wrong -- and to hurry.

The pump room, located three levels below the control room, has only one entrance: a sliding grate hatch that is locked with a safety padlock. One of the operators carried the key ring with the padlock key in his hand as they left the control room. They violated the company's "no running" policy as they raced down the stairs. The first operator was about 10 feet ahead of the other operator who tossed him the keys so as not to delay unlocking the auxiliary feedwater pump room. The operator ran as fast as he could and had unlocked the padlock by the time the other operator arrived to help slide the hatch open.

The operators descended the steep stairs resembling a ladder into the No. $2 A F W$ pump room. They recognized immediately that the trip throttle valve had tripped. One operator started to remove the lock wire on the handwheel while the other operator opened the water-tight door to the No. I AFW pump. He also found the trip throttle valve tripped and began to remove the lock wire from the handwheel.

The shift supervisor had just dispatched a third equipment operator to open $A F W$ isolation valves $A F-599$ and $A F-608$. These are chained and locked valves, and the shift supervisor gave the lock-valve key to the operator before he left the control room. He paged a fourth equipment operator over the plant communications systems and directed him also to open valves $A F-599$ and $A F-608$. Although the operators had to go to different rooms for each valve, they opened both valves in about $31 / 2$ minutes. They were then directed to the AFW pump room.
As operators ran to the equipment, a variety of troubling thoughts ran through their minds. One operator was uncertain if he would be able to carry out the task that he had been directed to do. He knew that the valves he had to open were locked valves, and they could not be operated manually without a key. He did not have a key and that concerned him. As he moved through the turbine building, he knew there were numerous locked doors that he would have to go through to reach the valves. He had a plastic card to get through the card readers, but they had been known to break and fail. He did not have a set of door keys and he would not gain access if his key card broke and that concerned him too.

The assistant shift supervisor came back into the control console area after having cleared the logic for the SFRCS and he tried again, unsuccessfully, to open the AFWS isolation valves. At this point, the assistant shift supervisor made the important decision to attempt to place the startup feedwater pump (SUFP) in service to supply feedwater to the steam generators. He went to the key locker for the key required to perform one of the five operations required to get the pump running.

The SUFP is a motor-driven pump, usually more reliable than a turbine-driven pump, and more importantly, it does not require steam from the steam generators to operate. The SUFP is located in the same compartment as the No. 2 AFW pump. But since the refueling outage in January 1985, the SUFP had been isolated by closing four manual valves and its fuses were removed from the motor control circuit. This isolation was believed necessary because of the consequences of a high energy break of the non-seismic grade piping which passes through the two seismic-qualified AFW pump 
rooms. Prior to January 1985, the SUFP could be initiated from the control room by the operation of a single switch.

The assistant shift supervisor headed for the turbine building where he opened the four valves and placed fuses in the pump electrical switchgear. This equipment is located at four different places; in fact, other operators had walked through the procedure of placing the SUFP in operation and required 15 to 20 minutes to do it. The assistant shift supervisor took about 4 minutes to perform these activities. He then paged the control room form the AFW pump room and instructed the secondary-side operator to start the pump and align it with the No. I steam generator.

The two equipment operators in the $A F W$ pump rooms had been working about 5 minutes to reset the trip throttle valves when the assistant shift supervisor entered the room to check the SUFP. The equipment operators thought that they had latched and opened the valves. However, neither operator was initially successful in getting the pumps operational. Finally, after one equipment operator had tried everything that he knew to get the No. I AFW pump operating, he left it and went to the No. 2 AFW pump where the other operator was having the same problem of getting steam to the turbine. Neither operator had previously performed the task that he was attempting.

The assistant shift supervisor went over to assist the equipment operators and noticed immediately that the trip throttle valves were still closed. Apparently, the equipment operators had only removed the slack in attempting to open the valve. The valve was still closed and the differential pressure on the wedge disk made it difficult to turn the handwheel after the slack was removed, thus necessitating the use of the valve wrench. $A$ third, more experienced operator had entered the pump room and used a valve wrench to open the trip throttle valve on AFW pump No. 2. Without the benefit of such assistance the equipment operators may well have failed to open the trip throttle valves to admit steam to the pump turbines.

The third equipment operator then proceeded to the No. 1 AFW pump trip throttle valve. The valve had not been reset properly and he experienced great difficulty in relatching and opening it because he had to hold the trip mechanism in the latched position and open the valve with the valve wrench. Because the trip mechanism was not reset properly, the valve shut twice before he finally opened the valve and got the pump operating.

\section{A.7 PORV Failure}

Prior to being informed by the assistant shift supervisor that the SUFP was available, the secondary-side operator requested the primary-side operator to reset the isolation signal to the startup feedwater valves in preparation for starting the SUFP. In order to perform this task, the operator left the control console and went to the SFRCS cabinets in back of the control room. As he re-entered the control panel area, he was requested to reset the atmospheric vent valves. As a result of these activities the primary side operator estimated that he was away from his station for 20 to 30 seconds. (In fact, he was away for about two minutes.)

While the operator was away from the primary-side control station, the pressurizer PORV opened and closed twice without his knowledge. The pressure had increased because of the continued heatup of the 
reactor coolant system that resulted when both steam generators had essentially boiled dry.

According to the emergency procedure, a steam generator is considered "dry" when its pressure falls below 960 psig and is decreasing, or when its level is below 8 inches on the startup range (normal post-trip pressure is 1010 psig and post-trip level is 35 inches). The instrumentation in the control room is inadequate for the operator to determine with certainty if these conditions exist in a steam generator. The lack of a trend recorder for steam generator pressure makes it difficult to determine if the steam pressure is 960 psig and decreasing. The range of the steam generator level indicator in the control room is 0-250 inches, a scale which makes determining the 8-inch level difficult. The safety parameter display system (SPDS) was intended to provide the operators with these critical data, but both channels of the SPDS were inoperable prior to and during this event. Thus, the operators did not know that the conditions in the steam generators beginning at about 1:47 a.m. were indicative of a "dry" steam generator, or subsequently, that both steam generators were essentially dry.

When both steam generators are dry, the procedure requires the initiation of makeup/high pressure injection (MU/HPI) cooling, or what is called the "feed-andbleed" method for decay heat removal. Even before conditions in the steam generators met these criteria, the shift supervisor was fully aware that MU/HPI cooling might be necessary. When the hot-leg temperature reached $5910 \mathrm{~F}$ ' (normal post-trip temperature is about 5500F), the secondaryside operator recommended to the shift supervisor that MU/HPI cooling be initiated. At about the same time; the operations superintendent told the shift supervisor in a telephone discussion that if an auxiliary feedwater pump was not providing cooling to one steam generator within one minute, to prepare for MU/HPI cooling. However, the shift supervisor did not initiate $M U / H P I$ cooling. He waited for the equipment operators to recover the auxiliary feedwater system.

The shift supervisor appreciated the economic consequences of initiating $M U / H P I$ cooling. One operator described it as a drastic action. During MU/HPI, the PORV and the high point vents on the reactor coolant system are locked open, which breaches one of the plant's radiological barriers. Consequently, radioactive reactor coolant is released inside the containment building. The plant would have to be shut down for days for cleanup even if $M U / H P I$ cooling was successful. In addition, achieving cold shutdown could be delayed. Despite his delay, the shift supervisor acknowledged having confidence in this mode of core cooling based on his simulator training; he would have initiated MU/HPI cooling if "it comes to that."

The primary-side operator returned to his station and began monitoring the pressure in the pressurizer, which was near the PORV set point of 2425 psig. The PORV then opened and he watched the pressure decrease. The indicator in front of him signaled that there was a closed signal to the PORV and that it should be closed. The acoustic monitor installed after the TMI accident was available to him to verify that the PORV was closed, but he did not look at it. Instead, he looked at the indicated pressurizer level, which appeared steady, and based on simulator training, he concluded that the PORV was closed. In fact, the PORV had not completely closed 
and, as a result, the pressure decreased at a rapid rate for about 30 seconds.

The operator did not know that the PORV had failed. He believed the RCS depressurization was due either to the fully open pressurizer spray valve or to the feedwater flow to the steam generators. He closed the spray valve and the PORV block valve as precautionary measures. But subsequent analyses showed that the failed $P O R V$ was responsible for the rapid $R C S$ depressurization. Two minutes later, the reactor operator opened the PORV block valve to ensure that the PORV was available. Fortunately, the PORV had closed by itself during the time the block valve was closed. The failed PORV was the ninth abnormality that had occurred within 15 minutes after reactor trip.

\section{A.8 Steam Generator Refill}

At about 1:50 a.m. the No. I atmospheric vent valve opened and depressurized the No. 1 steam generator to about 750 psig when the SFRCS signal was reset by the primaryside operator. The vent valve for the No. 2 steam generator had been closed by the secondary-side operator before the SFRCS signal was reset. The indicated No. 1 steam generator level was less than 8 inches. The corresponding pressure and indicated level in No. 2 steam generator were about 928 psig and 10 inches, respectively. The indicated levels continued to decrease until the secondary-side operator started the SUFP after being informed by the assistant shift supervisor that it was available and after the other operator had reset the isolation signal to startup feedwater valves.

Although the flow capacity of the SUFP is somewhat greater, approximately 150 gallons per minute were fed to the steam generators because the startup valves were not fully opened. Essentially all the feedwater from the SUFP was directed to the No. 1 steam generator. At about 1:52 a.m., the pressure in the No. 1 steam generator increased sharply while the indicated water level stopped decreasing and began slowly to increase. Since there was little feedwater sent to the No. 2 steam generator, its condition did not change significantly.

The trip throttle valve for No. 2 AFW pump was opened by the equipment operators at about 1:53 a.m. After the SFRCS was reset and tripped on low level by the shift supervisor, the AFWS aligned itself so that each AFW pump would feed only its associated steam generator, i.e., the No. 2 AFW pump would feed the No. 2 steam generator. Thus, the No. 2 AFW pump refilled the No. 2 steam generator and its pressure increased abruptly to the atmospheric vent valve relief set point. The turbine governor valve was fully open when the trip throttle valve was opened and the pump delivered full flow for about 30 seconds until the operator throttled the flow down.

The No. I trip throttle valve was opened by the equipment operator about 1:55 a.m. and feedwater from the AFWS flowed to the No. 1 steam generator. However, the No. I AFW pump was not controlled from the control room but controlled locally by the equipment operators.

The equipment operators controlled the pump locally using the trip throttle valve. One operator manipulated the valve based on hand signals from the operator who was outside the No. I AFW pump room communicating with the control room operator. For two hours the AFW pump was controlled in this manner by the operators. 
Their task was made more difficult from the time they first entered the AFW pump room by the intermittent failures of the plant communication station in the room.

With feedwater flow to the steam generators, the heatup of the reactor coolant system ended. At about 1:53 a.m. the average reactor coolant temperature peaked at about $592 \circ \mathrm{F}$ and then decreased sharply to $540 \circ \mathrm{F}$ in approximately 6 minutes (normal post-trip average temperature is 550oF). Thus, the reactor coolant system experienced an overcooling transient caused by an excessive $A F W$ flow from the condensate storage tank. The overfill of the steam generators caused the reactor coolant system pressure to decrease towards the safety features actuation system (SFAS) setpoint of 1650 psig. To compensate for the pressure decrease, and to avoid an automatic SFAS actuation, at approximately 1:58 a.m., the primary-side operator aligned one train of the emergency core cooling system (ECCS) in the piggyback configuration. In this configuration the discharge of the low pressure injection pump is aligned to the suction of the high pressure injection pump to increase its shutoff head pressure to about 1830 psig. At about the time the train was actuated, the combination of pressurizer heaters, makeup flow, and reduction of the $A F W$ flow increased the reactor coolant pressure above 1830 psig. As a result, only a limited amount (an estimated 50 gallons) of borated water was injected into the primary system from the ECCS.

At 1:59 a.m., the No. I AFW pump suction transferred spuriously from the condensate storage tank to the service water system (malfunction number 10). This action was not significant, but it had occurred before and had not been corrected. Similarly, a source range nuclear instrument became inoperable after the reactor trip (malfunction number 11) and the operators initiated emergency boration pursuant to procedures. (Note: One channel had been inoperable prior to the event.) The source range instrumentation had malfunctioned previously and apparently had not been properly repaired. Also, the control room ventilation system tripped into its emergency recirculation mode (malfunction number 12), which had also occurred prior to this event.

The steam generator water levels soon exceeded the normal post-trip level and the operator terminated $A F W$ flow to the steam generators. The subcooling margin remained adequate throughout this event. The event ended at about 2 o'clock in the morning, twelve malfunctions and approximately 30 minutes after it began.

\section{A.9 NRC Findings and Conclusions}

The NRC review team concluded that the underlying cause of the Davis-Besse loss-offeedwater incident was the licensee's lack of attention to detail in the care of plant equipment. The licensee had a history of performing troubleshooting, maintenance and testing of equipment, and of evaluating operating experience related to equipment in a superficial manner and, as a result, the root causes of problems were not always found and corrected. Engineering design and analysis effort to address equipment problems had frequently either not been utilized or had not been effective. Furthermore, operator interviews made clear that equipment problems were not aggressively addressed and resolved beyond compliance with NRC regulatory requirements.

In addition to this major conclusion on the underlying cause of the event, the NRC 
Review Team findings and conclusions included:

- The key safety significance of the event is that multiple equipment failures occurred resulting in a transient beyond the design basis of the plant. These failures included several common-mode failures affecting redundant safety-related equipment.

- The operators' understanding of procedures, plant system designs, and specific equipment operation, and operator training all played a crucial role in their success in mitigating the consequences of the event.

- If the manual initiation features of the SFRCS had originally been properly designed with regard to human factors considerations, such as labeling and placement, it is likely that no operator error in auxiliary feedwater initiation would have occurred.

- The post-TMI improvements: Temperature-saturation meters, additional training on transient behavior, and ATOG emergency procedures had a positive contribution to the mitigation of the event. Of these, training on transient behavior was the most important.

- For plant events involving conditions outside the plant design basis, operator training and operator understanding of system and equipment are key to the success of mitigating actions taken by the operators. It is not practical to rely on detailed step-by-step procedures for such events. 


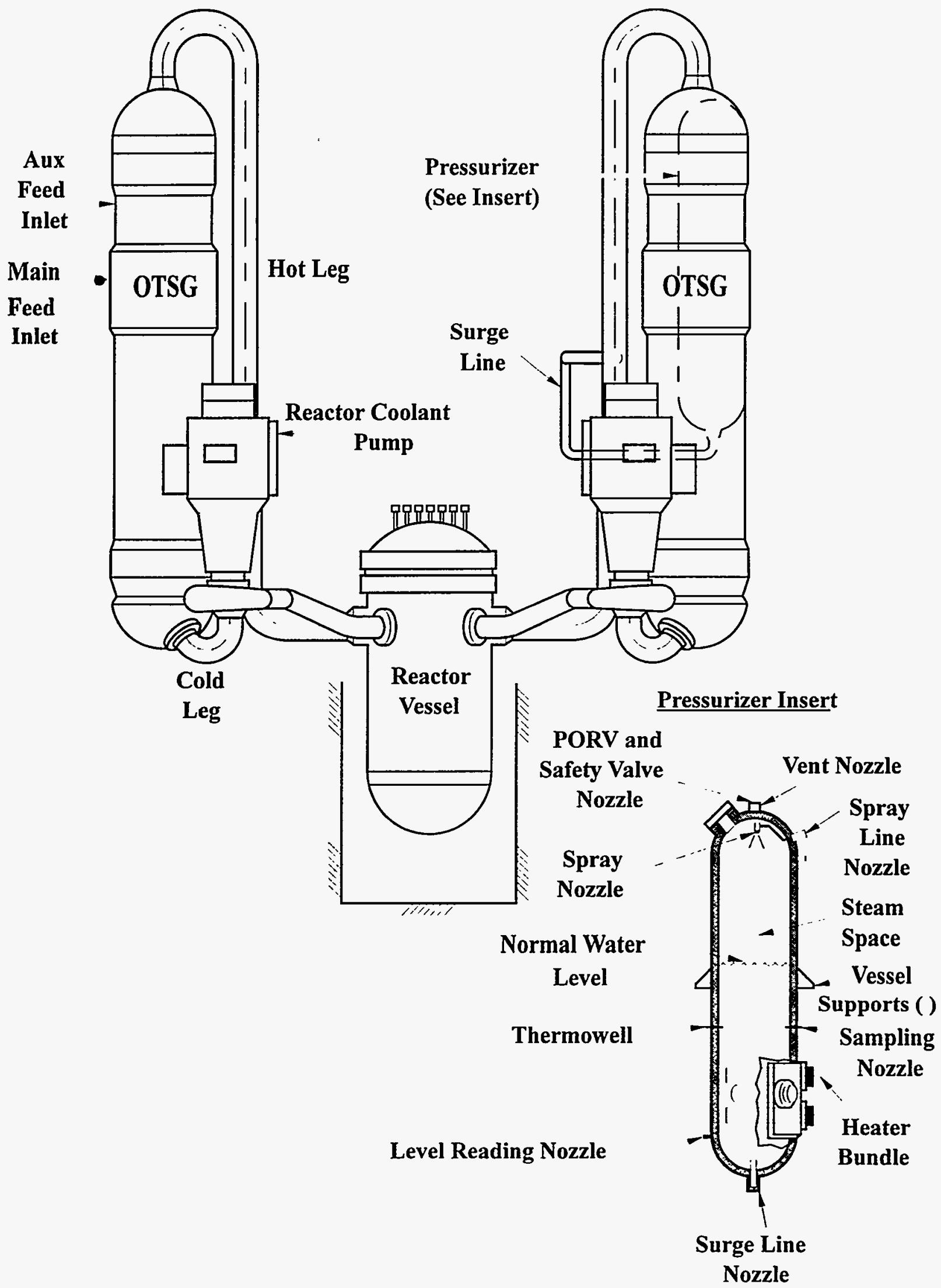

Figure 2A-1 Davis-Besse nuclear steam supply system 


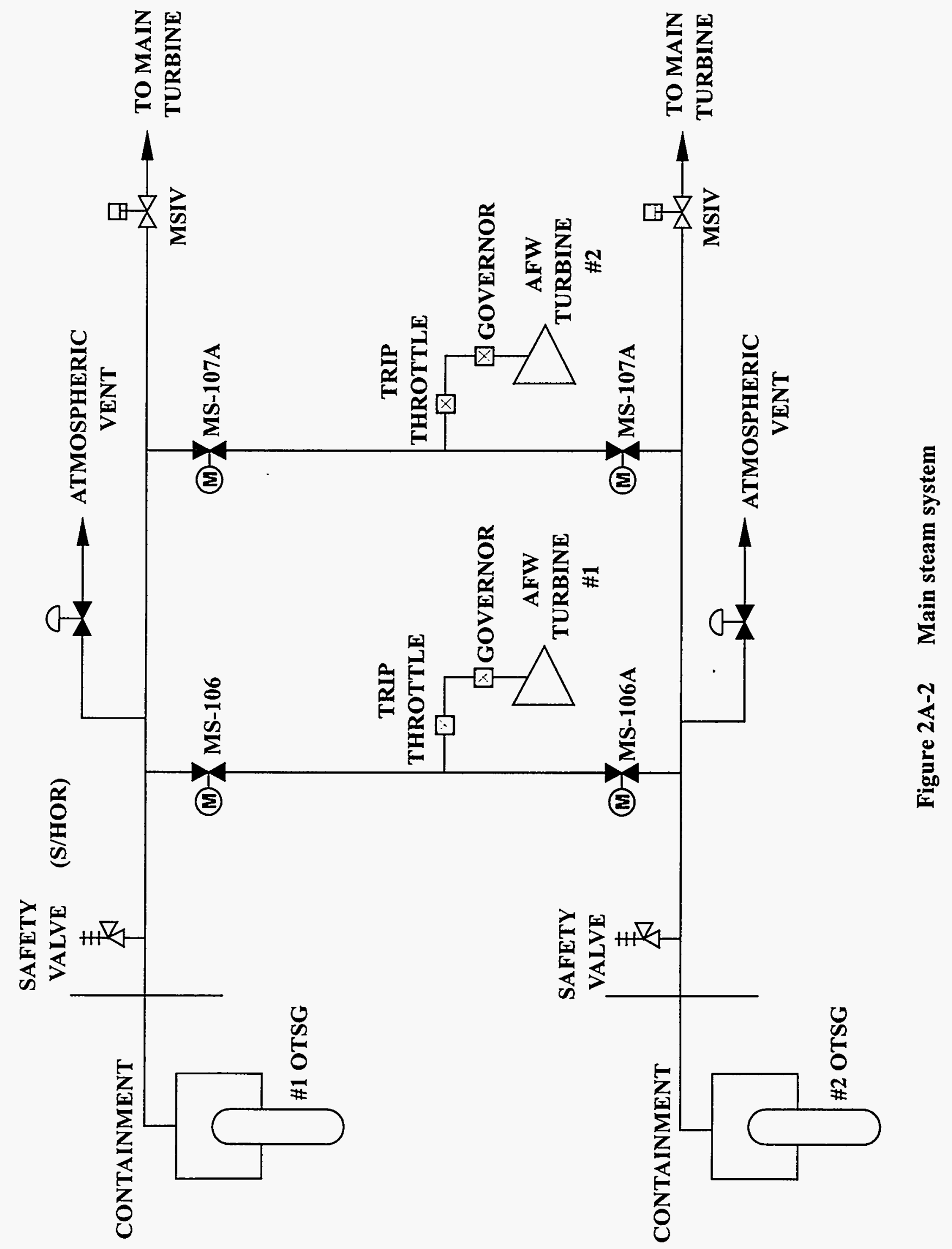




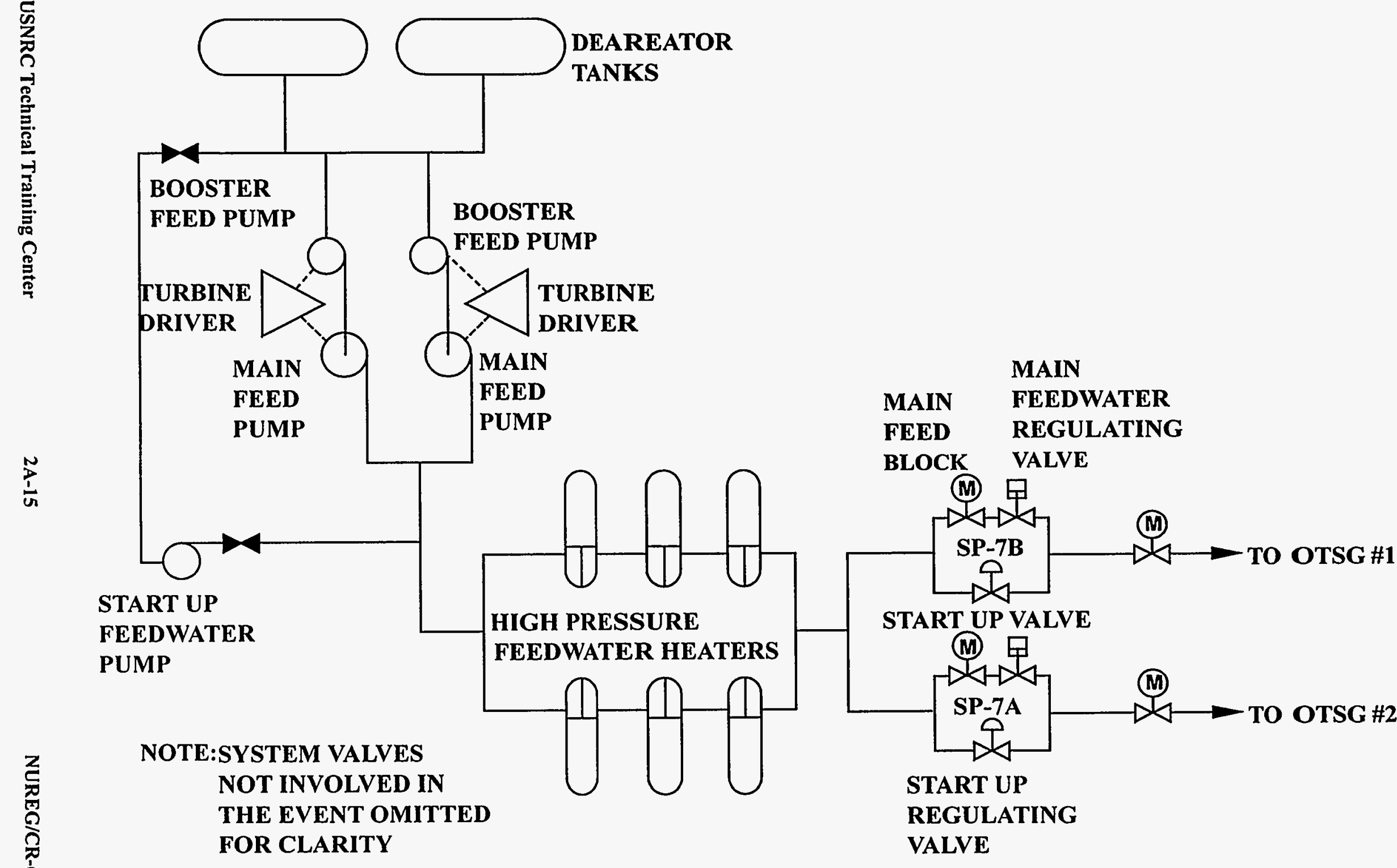

Figure 2A-3 Main feedwater system 


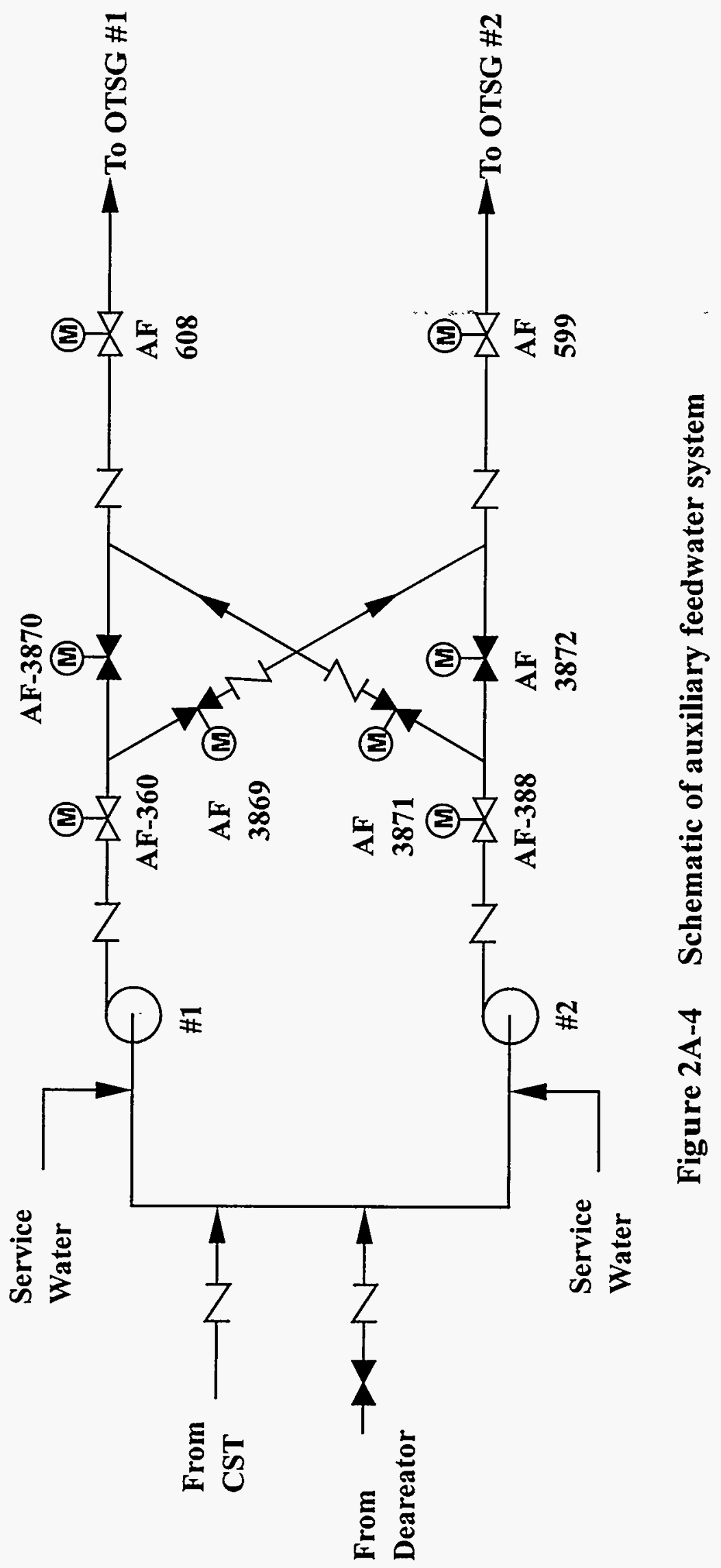




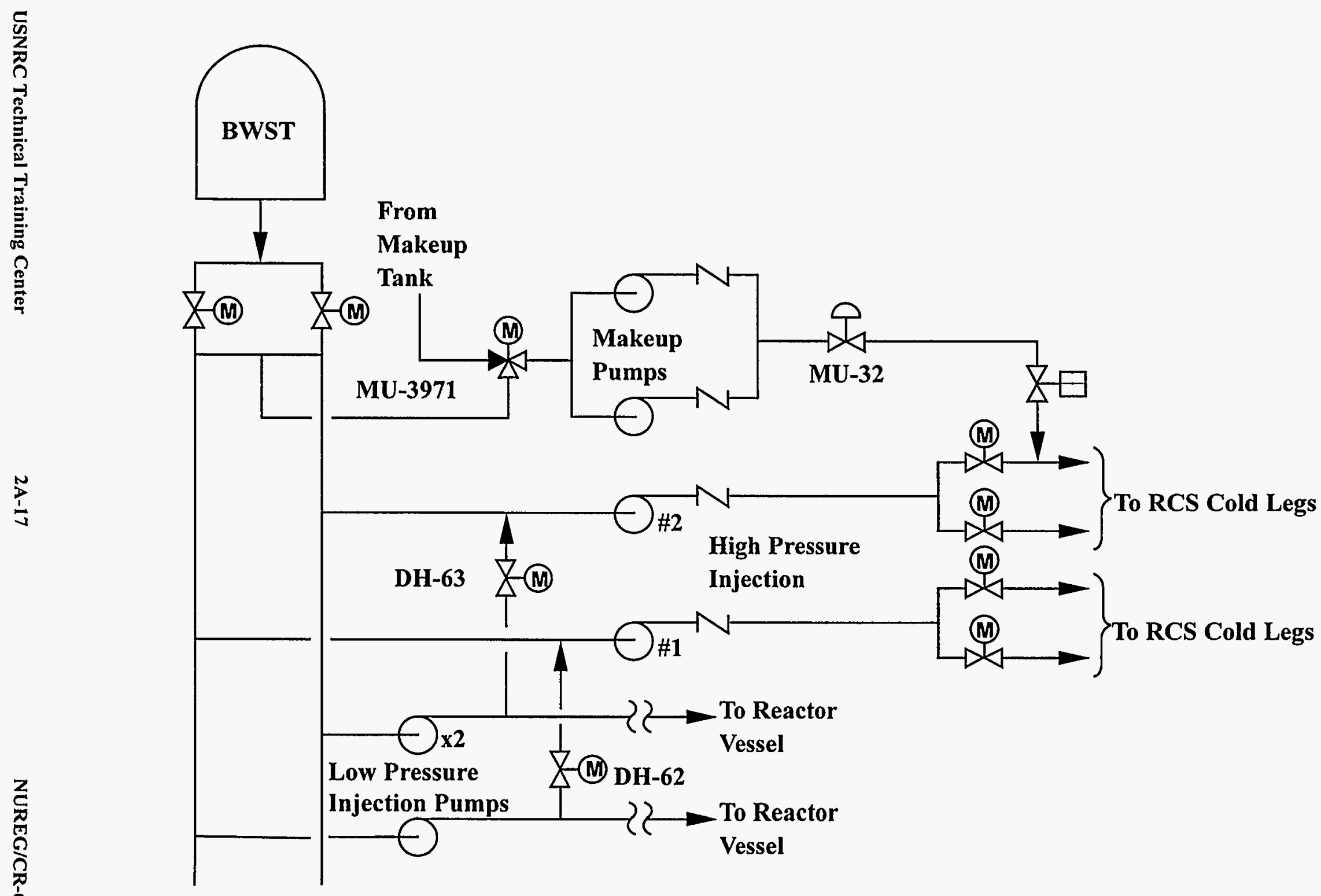

Figure 2A-5 Makeup / HPI cooling system 


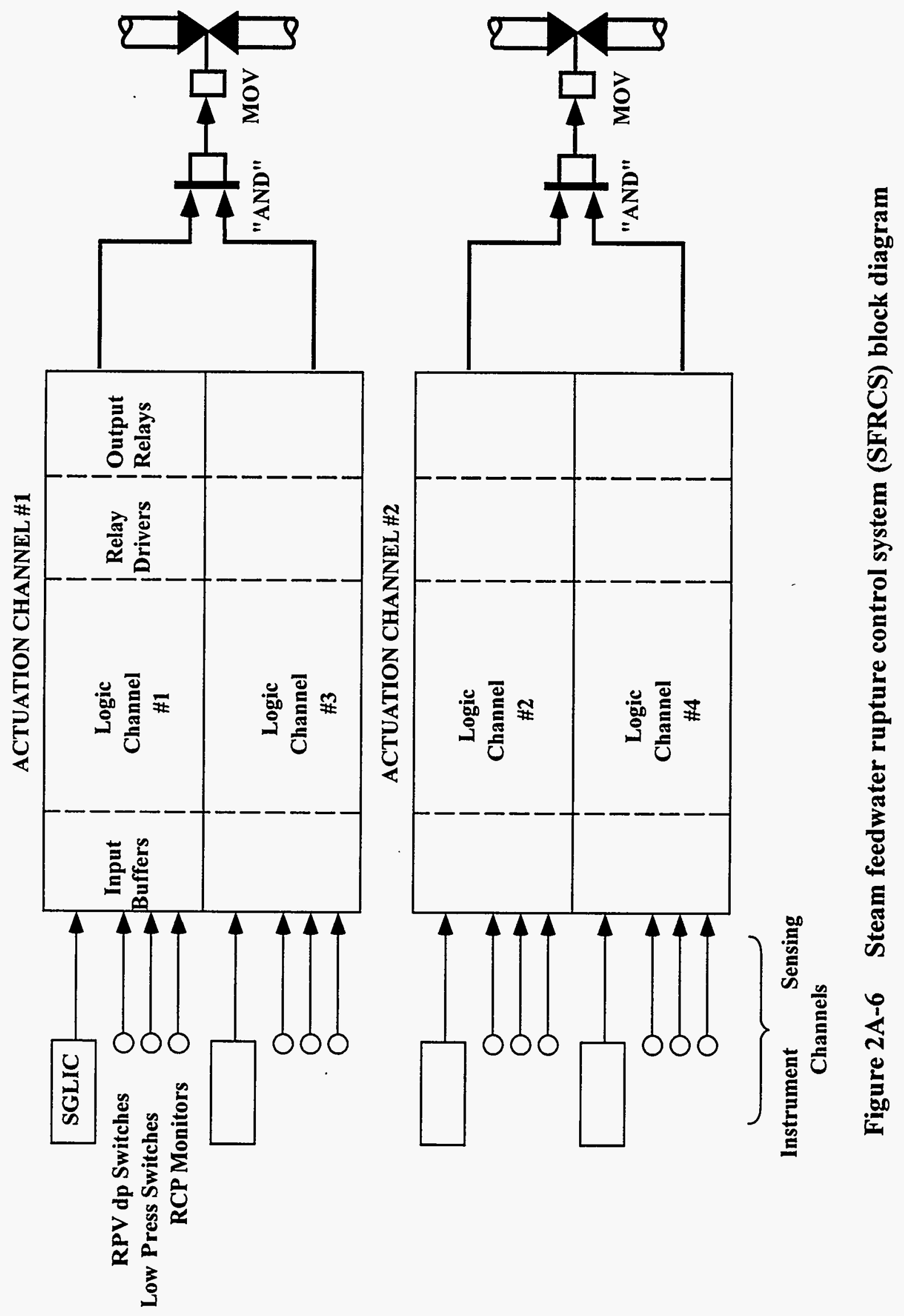




\section{Appendix 2B Information on ATWS}

In September 1973 the regulatory staff issued a report, WASH-1270, called "Technical Report on Anticipated Transients without Scram for Water-Cooled Power Reactors,"' in which they publicly adopted a position on ATWS. Significant WASH-1270 insights regarding reactor protection systems and plant responses to ATWS events are presented in the next two subsections. Subsections 2B.3 and 2B.4 discuss the Browns Ferry partial failure to scram, and the Salem 1 ATWS event respectively. The final ATWS rule is reproduced as Subsection 2B.5, and Subsection 2B.6. These sections discuss the changes considered in formulating the final rule.

\section{B.1 Protection Systems Designs and Failure Analyses}

The reactor protection system (RPS) is a safety-related system that is designed to monitor key operating plant variables; and to cause alarms, control rod insertions, or scram, as the occasion may require when off-normal conditions occur. The reactor trip system (RTS) is part of the RPS and includes those power sources, sensors, initiation circuits, logic matrices, bypasses, interlocks, racks, panels, control boards, actuation devices, and actuated devices, that are required to initiate reactor shutdown. The RTS automatically initiates control rod insertion when required to assure that acceptable fuel design limits are not exceeded. It is designed to fail safe for most internal component failures. The RTS can also be actuated manually by operator action.

The essential RTS design bases are that no single failure can negate a reactor scram when one is needed, and all instrument channels and associated trip logic must be capable of being calibrated, tested, and maintained while the plant operates. These features are implemented in protection system designs by providing for each variable that is to be measured several redundant instrument channels. In most cases, four such redundant channels are provided for each monitored variable. The output responses of the redundant channels are collected and an appropriate alarm, control rod insertion, or scram is initiated when two of the redundant channels agree that action is needed.

Just as the system designer is concerned that no failure in a subsystem should render the protective feature of a group of redundant channels inoperative, he also is concerned that the occurrence of spurious scrams be minimized. This is the reason that two concurrent trip signals are required in the normal protection system arrangement.

The kinds of single failures for which protection systems are designed to be resistant include a wide range of possible occurrences. Component malfunctions and failures are some of the kinds of single failures considered. Both a simple failure to function and an improper function, from whatever cause, are considered on the component, channel, and subsystem levels. Accidental electrical grounds at any point in the system are considered as single failure events, as are short circuits from whatever higher voltage circuits may exist in the vicinity of a given section of the protection system. An additional feature of the single failure design basis is that any damage or other consequence that follows from a hypothesized failure is included in determining the effects of that single failure. Thus, if a hypothesized hot short at some point in a protection system circuit might cause failure of several components, or spurious signals to other channels, then all of these effects are taken into account in determining the vulnerability of the overall system to the single initiating event.

Full scram tests in which the rods are actually driven into the core are carried out during shutdowns for refueling and maintenance, or on 
other occasions when the plant may have been shut down. During operating periods, control rods are moved periodically to adjust reactivity and power distribution in the core. This operation of the rods gives some assurance of operability, although it does not completely guarantee that the rods will scram if called upon to do so. All plants are designed to be shut down safely with the most effective control rod malfunctioning such that it does not enter the core. This "stuck rod" criterion gives assurance of the ability of the system to surmount a limited degree of operational failure.

The results of the designer's failure analyses of protection systems for random independent failures show that the systems are generally resistant to such failures. The probability of scram failure can be demonstrated to be quite low (less than $10^{-7}$ per demand) if only these random failure events are considered. This is due to the highly redundant nature of the protection systems and the testability provided in their designs.

As discussed in Section 2.2.4.4, common cause failures could be a result of: environmental conditions; design, manufacturing, operating or maintenance errors; or functional deficiencies such as an unrecognized deficiency in sensing instrumentation or a misunderstanding of the behavior of process variables in the design of a system. For common cause failures, the analysis of protection systems is more difficult. Techniques to analyze a system for common cause failures are not as well-developed as techniques to analyze a system for random failures. However, the fault tree models used for random failure analysis are helpful in making qualitative judgments as to the effects of common cause failures.

Defenses against common cause failures all involve "diversity" of one kind or another. One form, called equipment diversity, involves use of instruments operating on different principles to measure the same reactor variable. Use of different kinds of components in the amplifying and scram logic systems leading from the sensing instruments is also a form of equipment diversity, as in the use of different kinds of trip breakers and control rod drive mechanisms. A second form is called functional diversity, which involves instrument systems responding to different variables to provide trip action for the same transient or accident. The value of diversity of one sort or another in defending against common cause failures is that with systems of different principle and with different kinds of components, the likelihood of a common failure affecting all the elements that are significant for a given transient or accident is much diminished.

In making analyses of the effects of common cause failures on reactor protection systems, each transient is examined on the assumption that all the instrument channels pertaining to a given reactor variable (e.g., neutron flux) fail in such a way as to not give any protective action signal. All other portions of the protection system are assumed to be operative. In general, the results of these analyses show that protection systems have a reasonable degree of functional diversity in the sensor portions of the systems. If a required protective action signal is not generated by the several redundant channels for a given variable, then, in most cases, another variable is driven off-normal and the necessary signal is generated from that source. The functional diversity of protection system designs, however, often applies mainly to the sensing elements. The transmitters, amplifiers, and circuitry leading into the scram logic matrices for various reactor variables that are monitored, as well as the logic matrix relays and switches or solid-state devices, the scram breakers or pilot valves, control rod drive mechanisms, and control rods often have much less diversity. 


\section{B.2 Plant Response to ATWS Events}

For pressurized water reactor plants the transients with the greatest potential for damage in the event of a failure to scram are the loss of feedwater and certain loss of load transients occurring with the reactor at full power. Loss of feedwater flow could occur as the result of malfunctions of the interlock and supervisory circuitry controlling the feedwater or condensate pumps or valves. The sequence of events for a typical pressurized water reactor plant given a loss of feedwater transient without reactor scram may be summarized as follows:

a. An accidental trip of the feedwater or condensate pumps or valves would cause a rapid reduction of feedwater flow. Low feedwater flow compared to steam flow, in coincidence with low steam generator water level, would initiate a reactor scram signal.

b. This scram signal is ignored in the ATWS analysis, as are three or more subsequent reactor scram signals generated as the transient proceeds. The loss of feedwater flow to the steam generator secondary side would result in a drop in water level in the steam generator.

c. A falling water level in the steam generator results in reduced heat transfer from the primary system. The primary coolant temperature would begin to increase since reactor power would remain high, and this, in turn, would cause the primary pressure to increase.

d. The auxiliary feedwater pumps would be started automatically after the main feedwater pumps or condensate pumps were tripped. However, the auxiliary feedwater pump capacity is not large enough to remove all the heat being generated in the core; e. consequently, the steam generator would boil dry.

f. The primary system temperature and pressure would continue to increase and the primary safety valves in the surge volume of the pressurizer vessel would open and discharge steam.

g. The increasing temperature of the primary coolant would cause expansion of the coolant and the water level would rise in the pressurizer.

h. When the pressurizer vessel became filled completely with water, the safety valves would discharge water instead of steam, but at a rate less than required to keep the primary system pressure from rising sharply.

i. The reactor power would decrease throughout the transient because of the negative reactivity feedback arising from increased water temperature and reduced density. This effect, combined with heat removal by the auxiliary feedwater system and with the discharge of water through the pressurizer safety valves, would reduce the pressure.

j. The pressurizer safety valves would then close and steam would reappear in the pressurizer dome. If the primary system survived the pressure peak, which was estimated in early analyses to reach values between 3000 and 7000 psi, heat generation in the core would be reduced and the heat removal capacity of the auxiliary feedwater system on the secondary side of the plant would cool the core and prevent further pressure increase.

k. Lower pressure in the primary system would allow boron solution injection into the primary system initiated by a safety injection signal generated by low pressure 
in the secondary steam line or by manual actuation.

1. When the boron solution reached the core, enough negative reactivity would be provided to shut the plant down.

A loss of electrical load transient could occur from a generator trip, a turbine trip, or a loss of main condenser vacuum. Generally, the most severe transient would be caused by the loss of condenser vacuum. The main feedwater pumps in many plants are steam turbine-driven and exhaust to the main condenser. Thus, loss of condenser vacuum also could cause a loss of the main feedwater pumps. In this case the sequence of events would be similar to the loss of feedwater transient. The most severe effect of the transient, the peak pressure in the primary system, would be of about the same magnitude as in the loss of feedwater flow transient.

For boiling water reactor plants, the transients having the greatest potential for significant damage are those leading to a reactor coolant system pressure increase. The most severe of these are the loss of condenser vacuum and the closure of all main steam isolation valves. A loss of condenser vacuum causes automatic closure of the turbine stop valves and the turbine bypass valves. The turbine stop valves are fast-acting valves, so there is an abrupt interruption of steam flow from the reactor. The main steam isolation valves are slower in closing, but in this case the large steam line volume is not available to buffer the pressure rise. The result in either case would be an increase in reactor coolant pressure and temperature. The pressure increase would decrease the volume of steam bubbles in the reactor core and this, in turn, would increase the reactivity and cause an increase in reactor power. The power increase would cause a further increase in system temperature and pressure. The other transients that lead to primary system pressure increase are less severe.

Generator or turbine trips are less severe because the turbine bypass valves can be assumed to open and the condenser to be operative. Although the transient proceeds more slowly in these cases, the result still would be a high reactor coolant system pressure. More details about BWR ATWS events are contained in Section 2B.7

\section{B.3 Failure of Control Rods to Fully Insert at Browns Ferry 3}

On June 28, 1980, Browns Ferry Unit 3, a BWR, reported that 76 of 185 control rods failed to insert fully into the core when a manual scram was initiated by the reactor operator. Fortunately, this occurred during a routine shutdown from about $35 \%$ power, rather than during the kind of reactor transient in which complete and rapid scram of all the rods might have been important.

The partially inserted rods were all (with one exception) on the east side of the core where reactor power level was indicated to be $2 \%$ or less. The west side of the core was subcritical. A second manual scram was initiated 6 minutes later and all partially inserted rods were observed to drive inward, but 59 remained partially withdrawn. A third manual scram was initiated 2 minutes later, and 47 rods remained partially withdrawn. Six minutes later, an automatic scram occurred and all the rods inserted fully when the scram discharge level bypass switch was returned from "bypass" to "normal" and there was a high water level in the scram discharge instrument volume. It appears that this was a coincidence in that a manual scram would probably have produced the same result. Core coolant flow, temperature, and pressure remained normal for the existing plant conditions. 
The problem was determined to be hydraulic in nature rather than electrical or mechanical. The control rod drives (CRDs), which insert and withdraw the attached control rods in a General Electric BWR, are essentially water-driven hydraulic pistons. On a scram, a relatively high water pressure is applied to the bottom side of the piston by opening a scram inlet valve. A scram outlet valve opens to relieve water and pressure above the piston and the rods are rapidly driven up into the reactor core. Water discharged from the 185 individual CRDs during scram insertion is collected in two separate headers consisting of a series of interconnected 6-inch-diameter pipes (four on each side of the reactor) called the scram discharge volume (SDV). During normal operation, both SDVs are designed to remain empty by being continuously drained to a separate scram discharge instrument volume (SDIV) tank. The SDVs are therefore normally ready to receive the scram discharge water when a scram occurs. This instrumented tank is monitored for water level and initiates an automatic scram on high level, in anticipation of too much water in the SDV preventing a scram.

The control rod drives at Browns Ferry Unit 3 are grouped in such a manner that the east and west sides of the reactor core are connected to separate SDVs. Later tests, inspections, and analyses resulted in the conclusion that the east SDV was substantially full of water at the time of the event, leaving insufficient room for the discharge water. Accordingly, upon scram actuation, the CRDs rapidly drove the control rods partially into the core but rod motion prematurely ceased when pressure quickly equalized on each side of the pistons. Following each scram actuation, the scram signal was reset by the operator, allowing some -water to drain from the SDV, permitting the rods to insert further with each scram attempt. Sufficient water was finally drained from the SDV to allow the rods to insert fully on the fourth scram signal. It is believed that the east SDV water accumulation problem resulted from improper drainage into the SDIV from the SDV due to inadequate SDV venting, an obstruction in the line between the SDV and SDIV, or a combination of these problems.

The unit remained shut down while a series of tests was performed in an attempt to determine the cause of the water accumulation in the SDV. Ultrasonic probes were installed on the SDVs to continuously monitor the water level in the SDVs. A Preliminary Notification was issued to inform other NRC offices promptly. On July 3 , 1980, IE Bulletin No. 80-17 was issued to all licensees operating BWRs and required them to conduct prompt and periodic inspections of the SDV; perform two reactor scrams within 20 days while monitoring pertinent variables to further confirm operability; review emergency procedures to assure pertinent requirements are included; and conduct additional training to acquaint operating personnel with this type of problem.

On July 18, 1980, Supplement 1 to Bulletin 80-17 was issued to all licensees operating BWRs. This supplement required an analysis of the "as built" SDV; revised procedures on initiation of the standby liquid control system (SLCS); specifying in operating procedures action to be taken if water is found in the SDV; daily monitoring of the SDV until a continuous monitor can be installed; and studying of designs to improve the venting of the SDV. During testing required by IE Bulletin 80-17, additional SDV anomalies were found at seven other BWRs. As a result, Supplement 2 to IE Bulletin 80-17 was issued on July 22, 1980. This required the BWR licensees to provide a vent path from the SDV directly to the building atmosphere without any intervening component except for the vent valve itself. These modifications had to be completed within 48 hours for plants operating or prior to startup for plants shut down. 
Browns Ferry Unit 3 was authorized to restart on July 13, 1980, following completion of the actions required by IE Bulletin 80-17 and other extensive tests.

Continuing NRC review of this event identified a potential for unacceptable interaction between the control rod drive system and the nonessential control air system; therefore, IE Bulletin 80-17 Supplement 3 was issued on August 22, 1980. This Supplement required affected BWR licensees to implement operating procedures within five days, which required an immediate manual scram on low control air pressure, or in the event of multiple rod drift-in alarms, or in the event of a marked change in the number of control rods with high temperature alarms. In addition, the licensees were requested to implement procedures, which require a functional test using water for the instrument volume level alarm, rod block, and scram switches after each scram event.

On October 2, 1980 the NRC issued Confirmatory Orders to the licensees of $16 \mathrm{BWR}$ plants requiring the installation of equipment to continuously monitor water levels in all SDVs and provisions for water level indication and alarm for each SDV in the control room. This equipment permits the reactor operators to take timely action if water accumulates in the SDV. The equipment was required to be operable by December 1980 or prior to restart for those reactors in refueling. In the interim, the licensees were required to increase their surveillance of the SDV water level.

The NRC prepared two detailed reports: "Report on the Browns Ferry 3 Partial Failure to Scram Event on June 28, 1980," dated July 30, 1980, and "Report on the Interim Equipment and Procedures at Browns Ferry to Detect Water in the Scram Discharge Volume," dated September 1980. The various aspects of the BWR scram systems were studied further by the NRC, the BWR licensees, and General Electric.

\section{B.4 ATWS Event at Salem 1}

Salem 1, like other Westinghouse PWRs, uses two redundant reactor trip breakers (RTBs) in series in the RTS. For Salem 1, each RTB includes an under-voltage (UV) trip attachment and a shunt trip attachment to actuate (open) the trip breaker. The UV device initiates a breaker trip when de-energized, while the shunt device initiates a breaker trip when energized. For an automatic trip, only the UV device is actuated; initiation of the UV devices in either or both RTBs will actuate the control rods. A manual trip signal operates both the UV device and the separate shunt device. Either device is designed to cause the RTBs to open. Salem Unit 1 uses Westinghouse DB-50 type RTBs.

At 12:21 a.m. on February 25, 1983 a low-low water level condition in one of the four steam generators at Salem 1 initiated a reactor trip signal in the RPS. At the time, the reactor was at $12 \%$ rated thermal power in preparation for power escalation after a recently completed refueling outage. Upon receipt of the valid reactor trip signal, both of the redundant $R T B s$ failed to open (opening of either RTB would have caused the reactor to trip). About 25 seconds later, operators manually initiated a reactor trip from the control room. The RTBs opened as a result of the manual trip signal and this resulted in insertion of all control rods and shutdown of the reactor. Following the manual trip, the plant was stabilized in the hot standby condition. All other systems functioned as designed. Approximately two hours after the Salem 1 event, the cause of the failure to trip was determined by licensee instrumentation technicians to be failure of the UV trip device in both RTBs to function as designed. The plant was placed in cold shutdown at the request of the NRC.

During investigation of this incident on February 26, 1983 by the NRC, it was found that 
a similar failure had occurred on February 22, 1983 at Salem 1. At 9:55 p.m. on February 22, with the reactor at $20 \%$ power, operators were attempting to transfer the 4160 volt group electrical busses from the station power transformers to the auxiliary power transformers, a routine evolution during power escalation. During the transfer attempt, one of the 4160 busses failed to transfer and deenergized, resulting in the loss of one reactor coolant pump and power for the operating main feed pump control and indication. At 9:56 p.m., a low-low level condition occurred in one steam generator (due to the loss of the main feed pump), initiating a reactor trip signal. Due to the abnormal conditions created by the loss of the 4160 volt bus and in anticipation of loss of steam generator water levels, the operator was directed at about the same time to manually initiate a reactor trip. It was understood by plant personnel and was reported to the NRC that the automatic reactor trip signal due to the low-low level in one steam generator had, in fact, caused the reactor to trip. On February 26,1983 , as a result of NRC queries, the sequence of events computer printout for February 22 was reviewed in detail and it revealed that the RTBs actually opened in response to the operator's manual trip signal. Consequently, it became evident that on February 22 (as on February 25) the two RTBs failed to open upon receipt of an automatic trip signal from the RPS. The operators initiated a manual trip even though they were unaware that the automatic trip had failed.

Since the operators initiated a manual reactor trip shortly after receipt of the automatic trip signals on both February 22 and February 25 , no adverse consequences occurred and the reactor was in a safe condition. However, as the first actual ATWS events, the Salem 1 events were of major safety concern.

With few exceptions, all PWR plants designed by the three nuclear steam system suppliers
(Westinghouse, Babcock \& Wilcox, and Combustion Engineering) use an RTS design requiring circuit breakers to open to trip the reactor. Although the basic designs of the RTSs and the number of RTBs per plant differ considerably among the plant designers, each RTB generally includes a UV trip attachment and a shunt trip attachment to actuate the circuit breaker. Westinghouse designed plants use a Westinghouse breaker (DB type for older plants, DS type for newer plants) while the other two PWR designers use General Electric breakers (AK type).

Other pressurized water reactors (PWRs) have experienced RTB failures, both before and after the February 1983 Salem 1 events. None of them however, involved an ATWS event. The RTB failures prior to the February 1983 events at Salem 1 had been the subject of several actions taken since 1971 by the AECNRC, Westinghouse, and General Electric.

Due to the serious nature of Salem 1 failure of both redundant RTBs on February 25, 1983, the NRC issued Inspection and Enforcement Bulletin No. $83-01^{2}$ on the same day to all pressurized water nuclear power reactor facilities holding an operating license for action and to other nuclear power reactor facilities for information. The Bulletin informed the licensees of the Salem 1 February 25, 1983 event (the similarity of the February 22, 1983 event had not yet been ascertained) and mentioned that failures involving only one of the two breakers had previously occurred at Salem Unit 2, Robinson Unit 2, Connecticut Yankee, and St. Lucie. The Bulletin referenced two previously issued NRC notifications of RTB problems and Westinghouse-issued technical information on their breakers. Action items required of licensees using Westinghouse DB type breakers by Bulletin No. 83-01 included, (a) testing of the DB type breakers, (b) assuring maintenance is in accord with the recommended Westinghouse program, (c) notifying licensed operators of the Salem 1 events, (d) reviewing with the operators the 
procedures to follow in the event of failure of trip, and (e) reporting the results to the NRC.

On February 28, 1983 the NRC Executive Director for Operations (EDO) directed that NRC Region I was to develop a detailed report of the Salem 1 events. This report was subsequently issued as NUREG-0977. ${ }^{3}$ The EDO further directed that a special NRC task force be formed to evaluate the generic implications of the events.

Possible contributors to failures of UV trip devices include: (1) dust and dirt; (2) lack of lubrication; (3) wear; (4) more frequent operation than intended by design; and (5) nicking of latch surfaces caused from repeated operation of the breakers. Based on an independent evaluation of the failed UV trip devices identified by the licensee, the NRC staff concluded that, while the Salem 1 breaker failures occurred as a result of several possible contributors, the predominant cause was excessive wear accelerated by lack of lubrication and improper maintenance.

During the testing required by Bulletin No. 83-01, no further failures of Westinghouse DB type RTBs occurred. However, even though not required to do so by Bulletin No. 83-01, Southern California Edison decided to test the General Electric type AK-2 breakers on their Combustion Engineering designed San Onofre Units 2 and 3. On March 1, 1983, one of eight RTBs in Unit 3 failed to trip on undervoltage. On March 8, 1983, three of eight RTBs in Unit 2 failed to trip on UV. (Note: Contrary to the Salem design in which an automatic trip signal is fed only to the UV trip devices, the signal is fed to both the UV and shunt trip devices for the San Onofre Units 2 and 3 design. The shunt devices were satisfactorily tested; therefore, the RTBs would have tripped from an automatic trip signal during operations.) During the investigations of these events, it was found that previous failures had occurred at these units during 1982 but had not been reported to the NRC.
Accordingly, Inspection and Enforcement Bulletin No. 83-04 $4^{4}$ was issued on March 11, 1983 to all pressurized water nuclear power reactor facilities holding an operating license except those with Westinghouse DB type breakers for action and to other nuclear power reactor facilities for information. The Bulletin described the San Onofre events and mentioned that similar events involving the General Electric AK-2 type breakers had previously occurred at Arkansas Unit 1, Crystal River Unit 3, Oconee Units 1 and 3, Three Mile Island Unit 1 , St. Lucie Unit 1, and Rancho Seco Unit 1. Licensees were to (a) take actions similar to those required by Bulletin No. 83-01, (b) provide a description of all RPS breaker malfunctions not previously reported to the $\mathrm{NRC}$, and (c) verify that procurement, testing, and maintenance activities treat the RTBs and associated UV devices as safety related.

In response to Bulletin No. 83-04, additional cases of past RTB failures were reported to the NRC. In addition, other failures occurred after the testing required by Bulletin Nos. 83-01 and 83-04. In all cases, the NRC closely monitored the corrective actions taken by the licensees to assure that the plants were safe for continued operation.

In parallel with the NRC initiated actions, Westinghouse formed an intercompany task force to conduct an internal review of their procedures for dissemination of technical information to utilities. In addition, they reviewed the testing program for the breakers. Since there were generic implications associated with the Salem 1 ATWS event, Westinghouse worked with the Owners Group (licensees of Westinghouse designed plants) to review operating and emergency procedures, to look for similar failures in other plant systems, and to assure that the owners had current Westinghouse technical information. Westinghouse also identified potential deficiencies with their DS type breakers, which were being used in five operating plants, and 
24 plants under construction. Westinghouse developed updated maintenance procedures for both DB and DS type RTBs. Combustion Engineering and Babcock \& Wilcox made similar reviews, and in cooperation with General Electric, developed updated maintenance procedures for the licensees with $\mathrm{AK}-2$ type breakers.

As noted previously, the Salem 1 licensee failed to recognize on February 22, 1983 that an ATWS event had occurred. This was due to the lack of a thorough and systematic review to achieve the necessary understanding of the event. This, and previously identified problems at Salem, indicated the need for both a number of corrective actions and some significant management improvements. The NRC did not permit the Salem plants to restart until both technical and management corrective actions were satisfactory addressed. On April 26, 1983 the Commission agreed that the plants could be returned to service, after the NRC staff was satisfied with the licensee's commitment to meet certain restart conditions. On May 5, 1983 the NRC forwarded to the Salem licensee a Notice of Violation and Proposed Imposition of Civil Penalties (for $\$ 850,000$ ). ${ }^{5}$ Violations included operation of the reactor even though the RPS could not be considered operable, and several significant deficiencies which contributed to the inoperability of the RTBs. Region I instituted an augmented inspection program at Salem to monitor the licensee's progress towards completion of longer term corrective actions, including independent management consultants' recommendations.

The special NRC task force prepared a twovolume report, NUREG-1000. ${ }^{6}$ The first volume dealt with the generic implications of the Salem events. The second volume documented the NRC actions to be taken based on the work of the task force. The results of the task force were considered in deliberations regarding the ATWS position and rule, which was being developed by the NRC.

\section{B.5 10 CFR 50.62, The ATWS Rule}

50.62 Requirements for reduction of risk from anticipated transients without scram (ATWS) events for light-water-cooled nuclear power plants.

(a) Applicability. The requirements of this section apply to all commercial lightwater-cooled nuclear power plants.

(b) Definition. For purposes of this section, "Anticipated Transient Without Scram" (ATWS) means an anticipated operational occurrence as defined in Appendix A of this part followed by the failure of the reactor trip portion of the protection system specified in General Design Criterion 20 of Appendix A of this part.

\section{(c) Requirements.}

(1) Each pressurized water reactor must have equipment from sensor output to final actuation device, that is diverse from the reactor trip system, to automatically initiate the auxiliary (or emergency) feedwater system and initiate a turbine trip under conditions' indicative of an ATWS. This equipment must be designed to perform its function in a reliable manner and be independent (from sensor output to the final actuation device) from the existing reactor trip system.

(2) Each pressurized water reactor manufactured by Combustion Engineering or by Babcock and Wilcox must have a diverse scram system from the sensor output to interruption of power to the control rods. This scram system must be designed to perform its function in a reliable manner and be independent from the existing 
reactor trip system (from sensor output to interruption of power to the control rods).

(3) Each boiling water reactor must have an alternate rod injection (ARI) system that is diverse (from the reactor trip system) from sensor output to the final actuation device. The ARI system must have redundant scram air header exhaust valves. The ARI must be designed to perform its function in a reliable manner and be independent (from the existing reactor trip system) from sensor output to the final actuation device.

(4) Each boiling water reactor must have a standby liquid control system (SLCS) with a minimum flow capacity and boron content equivalent in control capacity to 86 gallons per minute of 13 weight percent sodium pentaborate solution. The SLCS and its injection location must be designed to perform its function in a reliable manner. The SLCS initiation must be automatic and must be designed to perform its function in a reliable manner for plants granted a construction permit after July 26, 1984 and for plants granted a construction permit prior to July 26,1984 that have already been designed and built to include this feature.

(5) Each boiling water reactor must have equipment to trip the reactor coolant recirculating pumps automatically under conditions indicative of an ATWS. This equipment must be designed to perform its function in a reliable manner.

(6) Information sufficient to demonstrate to the Commission the adequacy of items in paragraphs (c)(1) through (c)(5) of this section shall be submitted to the Commission as specified in 10 CFR 50.4.

(d) Implementation. By 180 days after the issuance of the QA guidance for non-safety related components, each licensee shall develop and submit to the Commission, as specified in 10 CFR 50.4, a proposed schedule for meeting the requirements of paragraphs (c)(1) through (c)(5) of this section. Each shall include an explanation of the schedule along with a justification if the schedule calls for final implementation later than the second refueling outage after July 26,1984 , or the date of issuance of a license authorizing operation above 5 percent of full power. A final schedule shall then be mutually agreed upon by the Commission and licensee.

[49 FR 26044, June 26, 1984; 49 FR 27736, July 6,1984 , as amended at 51 FR 40310, Nov. $6,1986]$

\section{B.6 Changes Considered for ATWS Rule}

10 CFR 50.62 (c)(1)

Diverse and Independent Auxiliary Feedwater Initiation and Turbine Trip for PWRs

This was proposed by the Utility Group on ATWS. It consists of equipment to trip the turbine and initiate auxiliary feedwater independent of the reactor trip system. It has the acronym AMSAC, which stands for Auxiliary (or ATWS) Mitigating Systems Actuation Circuitry. It showed a highly favorable value/impact for Westinghouse plants and a marginally favorable value/impact for $\mathrm{CE}$ and $\mathrm{B} \& W$ plants. It should be designed to minimize the potential for causing a spurious reactor trip.

10 CFR 50.62 (c)(2) and (c)(3)

Diverse Scram System

This was proposed by the Utility Group on ATWS for $C E, B \& W$ and GE plants. The NRC staff analysis showed a favorable value/impact. However, the principal reasons for requiring the feature are to assure emphasis on accident prevention and to obtain the resultant decrease 
in potential common cause failure paths in the RTS. It should be designed to minimize the potential for causing a spurious trip of the reactor. A diverse scram system for Westinghouse plants was not a recommendation of the Utility Group on ATWS and was not a clear requirement of the Staff Rule or the Hendrie Rule. NRC staff analyses indicated a marginally favorable value/impact for Westinghouse plants; however, a diverse scram was ultimately not required for Westinghouse plants.

\section{CFR 50.62 (c)(4)}

Increased Standby Liquid Control System (SLCS) Capacity

The SLCS is a system for injecting borated water into the reactor primary coolant system. The neutron absorption by the boron causes shutdown of the reactor. Addition of this system was proposed by the Utility Group on ATWS for new plants (those receiving an operating license three years after the effective date of the final rule). Because of the vulnerability of BWR containments to ATWS sequences, the NRC determined that increased SLCS capacity was warranted. The preferred location for SLCS injection was into HPCS or HPCI lines, which provides significant improvement in mixing of borated water when compared to SLCS injection into the standpipe at the core inlet plenum. The HPCS/HPCI injection location is also preferred, since it could prevent local power increases and possible power excursions during the recovery phase of an ATWS when cold unborated ECCS water could be added above the core. Some $\mathrm{BWR} / 5$ and $\mathrm{BWR} / 6$ licensees already had this injection location.

\section{CFR 50.62 (c)(4)}

Automatic Initiation of Standby Liquid Control System

One of the alternatives considered by the Task Force was an automatically initiated standby liquid control system with a capacity of greater than $86 \mathrm{gpm}$ (such as 150-200 gpm). This would have resulted in a considerable ATWS risk reduction (about a factor of seven) for operating plants. Unfortunately, the cost to do this (based on information supplied by the Utility Group on ATWS) would have been on the order of $\$ 24$ million per plant. This cost is significantly impacted by the costs of downtime for installation in existing plants and by an allowance for potential downtime from an inadvertent trip that would inject boron into the reactor vessel. The value/impact did not favor this alternate for existing plants. New plants (those receiving construction permits after the effective date of the ATWS rule) are required to have automatic SLCS initiation. The equipment for automatic SLCS actuation should be designed to perform its function in a reliable manner while minimizing the potential for spurious actuation.

10 CFR 50.62 (c)(5)

Automatic Recirculation Pump Trip for BWRs

Recirculation pump trip (RPT) results in a reduction of reactor power from 100 percent to about 30 percent within a minute or so of an ATWS. This requirement had already been implemented on all operational BWRs in response to a show cause order dated February 21, 1980. The BWR owners generally agreed that this was a necessary requirement. It was included in the final rule for completeness.

\section{Adding Extra Safety Valves or Burnable Poisons}

One of the alternatives considered by the NRC Task Force was adding more safety valves to plants manufactured by CE and B\&W. This would reduce the peak pressure in the reactor vessel and yield a higher probability of the plant surviving an ATWS with no core damage. The peak overpressure could also be reduced by modifying the core behavior (the fraction of the time the moderator temperature coefficient is unfavorable) by adding burnable poisons. 
The Utility Group on ATWS estimated that installing larger valve capacity could cost up to $\$ 10$ million per plant. A large fraction of this is the cost of downtime for installation of the valves. The NRC found the value/impact of this option to be unfavorable for existing plants. Thus, the ATWS rule does not cover enhanced pressure relief capacity for new $C E$ and $B \& W$ plants. However, the NRC expects this issue to be addressed during licensing reviews of any specific new or standard plant application.

\section{B.7 BWR ATWS Behavior and Mitiga- tion Measures}

Anticipated Transient Without Scram (ATWS) is the set of accident sequences initiated by a failure of control rod insertion following a transient event for which the plant protection system normally provides a scram. These sequences involve failure of the scram function and, if not successfully brought under control, can lead to a severe accident situation. BWR ATWS has several unique features, particularly with respect to mitigation measures such as reactor vessel water level control. It is characterized by an early threat to containment integrity, because the energy release from the reactor vessel into the pressure suppression pool can greatly exceed the capacity of the pool cooling equipment.

For the ATWS accident sequences, as for all other BWR accident sequences, core degradation can occur only after failure of adequate reactor vessel injection. If sufficient water is injected during ATWS to maintain a lower portion of the core critical, then sufficient steam will be generated to provide adequate steam cooling of the uncovered (subcritical) upper region of the core. Structural degradation and melting would occur in an ATWS severe accident only after reactor vessel injection had been lost, with the subsequent heatup of the uncovered core under the impetus of decay heating.

\section{B.7.1 Categories of BWR ATWS}

This set of accident sequences includes many variations, but the chief distinction lies between ATWS accident sequences where the main steam isolation valves (MSIVs) remain open (but the main turbine is tripped so that steam flow into the main condenser is via the turbine bypass valves) and ATWS sequences with the reactor vessel isolated.

\section{B.7.1.1 Turbine Trip With Bypass}

The ATWS accident sequence for which main turbine trip is the initiating transient is illustrated in Figure 2B-1. The calculated flows shown in this example are based upon the Browns Ferry Nuclear Plant. Here the feedwater pumps continue to function and are automatically adjusted (by the feedwater control system) so as to maintain the reactor vessel water level in its normal operating range. Thus, vessel water level is approximately constant initially and does not play a role in causing variation of core power.

The central assumption for the steady-state balance of flows shown in Figure 2B-1 is that the core power would be $30 \%$ under natural circulation conditions (recirculation pumps tripped), as has been determined by many analyses. ${ }^{78}$ Most of the steam generated within the reactor vessel is passed to the main condensers, but the capacity of the turbine bypass valves is limited, and some must escape via a single cycling safety/relief valve (SRV). Makeup water to the reactor vessel to replace the mass lost by steam relief into the pressure suppression pool is provided by a combination of vacuum drag into the main condenser hotwell from the condensate storage tank (CST) and control rod drive hydraulic system (CRDHS) injection.

Because the core remains covered, the turbine trip-initiated ATWS accident sequence has less severe consequences than does the MSIV closure 
case, discussed in the next Section. Nevertheless, many studies (such as Reference 2) have shown that unstable pressure fluctuations are expected to eventually develop between the reactor vessel and the main turbine bypass valve control system, which in turn would cause large swings of core void collapse and power increase. As these instabilities eventually induce large fluctuations in the vessel water level, the condition for MSIV tripping on low level would be approached.

\section{B.7.1.2 MSIV Closure}

The ATWS initiated by a transient event that causes closure of the MSIVs is the most threatening of this class of accident sequences. An example, based upon the Browns Ferry Nuclear Plant, of the flows associated with the MSIV closure ATWS is provided as Figure 2B-2. With the MSIVs closed, almost all of the steam exiting the reactor vessel would be passed through the SRVs into the pressure suppression pool. (The remainder would be used to drive the high pressure coolant injection (HPCI) or reactor core isolation cooling (RCIC) turbines during their periods of operation and then would enter the pressure suppression pool as turbine exhaust.) Because the rate of energy deposition into the pool can greatly exceed the capacity of the pool cooling equipment, excessive pool temperature leading to primary containment failure by overpressurization is of major concern.

The dominant ATWS sequences identified by the severe accident risk assessment (NUREG-1150') study all include MSIV closure as an initiating event. Specifically, this study identifies two variations of MSIV closure ATWS as among the more probable combinations of failures leading to core damage for Peach Bottom. For Grand Gulf, one MSIV closure case is described as "the most probable combination of failures leading to core damage" within the general class of ATWS sequences. In general, ATWS sequences initiated by MSIV closure are found by probabilistic risk assessments to be second in core melt frequency (behind station blackout) for BWRs. Examples of calculated values are $42 \%$ of the overall calculated risk for Peach Bottom ${ }^{9}, 3 \%$ for Grand Gulf ${ }^{9}, 28 \%$ for Limerick ${ }^{10}$, and $32 \%$ for Susquehanna" .

\section{B.7.2 Mitigation Measures}

The discussions that follow are based upon the assumption of MSIV closure with complete failure of the scram function, so that the control blades remain in the withdrawal pattern that existed before the inception of the transient. Total failure of blade movement constitutes the most severe ATWS case, but is also the most improbable of the possible scram system failures. Where specific setpoints are given, the values appropriate to the Browns Ferry Nuclear Plant ${ }^{12}$ are used for the purpose of illustration.

\section{B.7.2.1 Recirculation Pump Trip}

As in all reactor designs, the criticality of the BWR depends upon a complicated set of factors that simultaneously introduce positive or negative reactivity. Whether power is increasing, constant, or decreasing at a given point in time depends upon the particular reactivity balance at that instant. In BWR studies, it is necessary to recognize the importance of the void coefficient of reactivity. "Voids" are created by the steam bubbles formed by boiling within the core. The moderation or slowing down of neutrons is much less in steam than in liquid water, so increased voiding has the effect of reducing the supply of thermal neutrons. Therefore, an increase in voids introduces negative reactivity and a decrease in voids introduces positive reactivity. Because the BWR operates with the water moderator at saturation condition within the core, negative or positive reactivity insertions caused by the creation or elimination of voids are a natural, important, 
and immediate result of reactor vessel pressure changes.

When successfully inserted, the BWR control blades introduce enough negative reactivity to ensure that the reactor is maintained subcritical even with the moderator at room temperature and with zero voids in the core. (This is true even with as many as five control blades stuck in the fully withdrawn position.) It is easy to imagine that there must be many dangerous situations that might arise during reactor power operation that would require instantaneous shutdown by reactor scram. However, careful review reveals that only one set of initiating conditions might actually require control blade scram as the only means to prevent the occurrence of a severe accident. This is a closure of all MSIVs compounded by failure of recirculation pump trip (RPT), which is an "unanticipated transient," meaning that it is not expected to occur during the lifetime of the plant. Before considering the ramifications of failure of RPT, it is instructive to examine the progression of events without scram but with RPT.

During the 3- to 5-s period while the MSIVs are closing, the reactor vessel is progressively isolated, and, because the reactor is at power, the vessel pressure rapidly increases. The pressure increase causes the collapse of some of the voids in the core, inserting positive reactivity and increasing reactor power, which in turn causes increased steam generation and further increases pressure. This cycle is interrupted when the vessel pressure reaches the level of the SRV setpoints; the SRVs open to reduce the rate of pressure increase and the recirculation pumps are automatically tripped on high pressure. With RPT, the core flow is reduced to about $25 \%$ of its former value as the driving mechanism is shifted from forced to natural circulation. With reduced inlet flow, the temperature of the moderator in the core region is increased, producing additional voids and introducing negative reactivity. The rapid increase of reactor power is terminated, and power then rapidly decreases to about $30 \%$ of that at normal full-power operation.

If failure of the installed automatic protection logic caused the recirculation pumps to continue operation after the reactor vessel pressure had exceeded their trip setpoint (highly improbable), then two possible outcomes must be considered. Because the total relief capacity of the SRVs is about $85 \%$ of normal full-power steam generation, an increasing spiral of reactor power and vessel pressure might continue to the point of overpressure failure of the primary system, inducing a LOCA. On the other hand, with all SRVs open and very little makeup water being added to the vessel, the loss of coolant through these valves could cause uncovering of the core and subcriticality by loss of moderator before the pressure became sufficiently high to cause rupture of the vessel pressure boundary. Calculations with the RAMONA code at Brookhaven National Laboratory have indicated a peak pressure of 1340 psia (9.24 MPa) for ATWS without RPT, which is below the design pressure of the reactor vessel. Thus, these calculations indicate that the loss of coolant from the vessel would effectively terminate the powerpressure spiral.

Assuming that the RPT does function as designed, it is axiomatic that although all transient-initiated accident sequences can most easily and quickly be brought under control and terminated by scram, they can also be controlled and terminated by appropriate other operator-initiated actions. In other words, given properly trained operators and properly functioning equipment, a failure-toscram can be considered to be merely a nuisance requiring more complicated and time-consuming methods of achieving shutdown. The real difficulty for the ATWS accident sequence is that inappropriate actions by the operator might create an unstable and threatening situation. 


\section{B.7.2.2 Standby Liquid Control System (SLCS)}

Injection with the SLCS is the normal means for adding boron to the reactor vessel. Although this system is designed to inject sufficient neutron-absorbing sodium pentaborate solution into the vessel to shut down the reactor from full power (independent of any control blade motion) and to maintain the reactor subcritical during cooldown to ambient conditions, the SLCS is not intended to provide a backup for the rapid shutdown normally achieved by scram. Additional information on the basic design of the SLCS is provided in Module 3, Section 3.7.3.

In most of the current BWR facilities, the sodium pentaborate enters the reactor vessel via a single vertical sparger located at one side of the lower plenum just below the core plate as indicated in Figure 2B-3. (In an effort to improve the mixing and diffusion of the injected solution [which has a specific gravity of about 1.3] throughout the core region, some BWR facilities have been modified to provide a third positive displacement pump and to permit the injected solution to enter the reactor vessel via the core spray line and sparger.) With injection into the lower plenum, upward flow at the core inlet is necessary to sweep the heavier-than-water sodium pentaborate solution into the core.

\section{B.7.2.3 Manual Rod Insertion}

Failure of the automatic scram function requires that the operators manually take the actions necessary to introduce enough negative reactivity into the core to produce shutdown. The operators might do this by manual scram, in case the ATWS was caused by failure of the protective system logic. Otherwise, the operators could manually drive in the control blades, one at a time for plants such as Browns Ferry. As indicated by Figure 2B-4, this procedure, for the most part, involves different piping and valves than are used for scram. Therefore, although relatively slow, manual blade insertion has a significant probability of success as an alternative to scram.

Manual control blade insertion may be essential to avoid containment pressures sufficient to threaten structural integrity in the unlikely event that the liquid neutron poison cannot be injected. However, for the BWR-4 and BWR-5 plants that have these systems, manual insertion requires that the operators bypass the rod worth minimizer (RWM) and the rod sequence control system (RSCS). Typically, the RWM can be quickly overridden from the control room, but the RSCS can only be bypassed by the installation of jumpers in the relay room, an action that can reasonably be expected to take about 15 minutes once the decision to initiate the bypass is made. Because manual blade insertion for these plants is a slow process anyway (one blade at a time, at a speed requiring about one minute for travel from fully withdrawn to fully inserted), the additional time required to effect bypass of the RSCS may be unacceptable from the standpoint of preplanning for effective ATWS management.

The RSCS was originally intended to eliminate the potential for local core damage from a high-worth control rod drop accident at low power. However, a more recent analysis by General Electric has demonstrated that such damage would not occur because local voiding would limit the associated power excursion. The NRC has issued a Safety Evaluation Report ${ }^{13}$ that concludes that it is acceptable to remove the plant Technical Specification requirements for the RSCS. From the standpoint of enhancement of the ability of the operators to successfully respond to ATWS, it is desirable that this system be removed from the affected plants $^{14}$. 


\section{B.7.2.4 Control of Vessel Injection}

While the reactor vessel remains pressurized, makeup flow under the conditions of an MSIV closure ATWS can only be provided by the HPCI, RCIC, and CRDHS. (For purposes of illustration, this discussion is based upon the Browns Ferry/Peach Bottom configuration. Some other plants have different systems available.) The operators can manually reduce reactor power by taking control of these high pressure injection systems and decreasing the injection rate. As illustrated in Figure 2B-2, the HPCI and RCIC systems inject into the reactor vessel through the feedwater lines whereas the relatively small CRDHS flow enters the vessel through the control rod guide tubes.

It is demonstrated in Appendix B of Reference 1 that given an ATWS situation in which the reactor core is capable of unrestricted power operation, the average power depends only on the injection rate. The proof is simple, using only the first law of thermodynamics. Furthermore, if the injection rate to the vessel is specified, then the average power can be determined by a simple hand calculation. Figure 2B-2 illustrates the flows to the reactor vessel provided by operation of $\mathrm{HPCl}$, RCIC, and CRDHS; these total to $2.846 \times 10^{12}$ $\mathrm{lb} / \mathrm{hr}$, which under these conditions is equivalent to $5700 \mathrm{GPM}\left(0.360 \mathrm{~m}^{3} / \mathrm{s}\right)$. Employing the simple method explained in Reference 1 (Appendix B), the average reactor power is $28 \%$, as shown on Figure 2B-2.

As an example of the possible development of ATWS mitigation strategies based on injection control, it is known that about $4 \%$ power can be removed from the pressure suppression pool with all four Residual Heat Removal (RHR) heat exchangers in operation. It is easy to show, using the equations demonstrated in Reference 1 (Appendix B), that injection of about 1100 GPM $\left(0.0694 \mathrm{~m}^{3} / \mathrm{s}\right)$ to the reactor vessel will result in transfer of about four percent power to the pressure suppression pool. However, determination of the resultant reactor vessel water level is not a simple matter. An injection rate of $1100 \mathrm{GPM}$ might well correspond to a substantial portion of the upper core being uncovered while the power (and steam) generation was confined to the lower, covered, region of the core. Steam cooling under these conditions would prevent degradation of the uncovered region.

As discussed in the next Section, the ATWS mitigation procedures recommended by the BWR Owner's Group do not invoke control of vessel injection rate, but rather direct the operators to maintain the reactor vessel water level in the vicinity of the top of active fuel. This seemingly simple shift of the operator control parameter from the injection rate to the indicated vessel water level greatly complicates both the operators role and the calculation of the average core power.

\section{B.7.3 Application of Emergency Procedure Guidelines}

The control room operators would recognize the onset of an ATWS by the unique combination of scram signals, continued indication of reactor power on the average power range monitors (APRMs), and continued indication that multiple control blades remained in their fully withdrawn positions. For a case in which the reactor did not scram automatically in conjunction with an MSIV closure event, entry into the Reactor Vessel Control Guideline of the EPGs would be triggered by vessel pressure above the high pressure scram setpoint and "a condition which requires reactor scram, and reactor power above APRM downscale trip..."15 Either of these triggers is by itself sufficient for entry; only the second, however, is a unique signature of ATWS. The high reactor vessel pressure would also cause tripping of the recirculation pumps.

The Reactor Vessel Control Guideline calls for simultaneous efforts to control reactor vessel 
water level, vessel pressure, and reactor power. Initial measures would be taken to induce reactor shutdown by manual scram. The alternate rod insertion (ARI) system would be initiated, which vents the reactor scram air header and closes the scram discharge volume vent and drain valves. Each of these actions has the potential to induce scram, but for the purposes of this discussion, it is assumed that the ATWS is not terminated.

If the main condenser is available, the EPGs direct action to open the MSIVs and employ the turbine bypass valves to establish the condenser as a heat sink. Since the bypass valves can pass about $25 \%$ of the normal fullpower steam flow from the vessel, this maneuver would greatly reduce the steam flow into the pressure suppression pool and the pool heatup. Implementation of all available pool cooling is directed by the primary containment control guideline of the EPGs.

With the MSIVs closed and the recirculation pumps tripped, several SRVs would be continuously open (the number depending on reactor power), while one valve cycled open and closed. (This is illustrated in Figure 2B-2, where three SRVs continuously open to pass $19.41 \%$ of the normal steam flow and one valve slowly cycles to pass another $0.37 \%$.) In accordance with the EPGs, the operators would attempt to terminate the valve cycling by taking remote-manual control of the SRVs and reducing vessel pressure.

Reduction of reactor vessel pressure by manual SRV actuation under ATWS conditions would be extremely difficult. ${ }^{7}$ If the operator attempted to open a valve that was already open (by automatic actuation), nothing would happen. When the operator opened a previously closed valve, the vessel pressure would drop only slightly, until one of the previously open valves went shut. Thus, there would be only a negligible response to operator SRV control until the operator had manually opened as many valves as had previously been automatically open (three in our example). Upon manual opening of the next valve (the valve previously cycling, now to be held continuously open), the vessel pressure would rapidly decrease because of the power reduction (caused by increasing voids) occurring while several relief valves (four in our example) are held open.

The operator would have to be extremely quick to avert a complete vessel depressurization. However, closing the SRVs with the reactor critical at low pressure causes void collapse with rapid reactivity insertion. The concomitant power increase and steam generation would cause a full vessel repressurization. (The relative intensity of void collapse at low pressure is much greater than at high pressure, as illustrated by Figure 2B-5.) Under these rapidly changing conditions involving power and pressure oscillations, it could not be claimed that the operator had control of either reactor vessel power or pressure.

Initiation of the SLCS to inject sodium pentaborate solution into the reactor vessel is directed by the EPGs "before suppression pool temperature reaches the Boron Injection Initiation Temperature (BIIT)". Simultaneous action to manually drive the control blades into the core is also directed. Several backup methods are specified for each endeavor should the primary means of accomplishment fail.

The BIIT is defined to be the greater of either the pressure suppression pool temperature at which scram is required (by the plant Technical Specifications) or the highest pool temperature at which SLCS initiation would result in reactor (hot) shutdown during ATWS before the Heat Capacity Temperature Limit (HCTL) is exceeded. It is important to recognize that if the HCTL is exceeded, then rapid depressurization of the reactor vessel is required by the EPGs. Clearly the intent here is to avoid imposition of a requirement for rapid depressurization of a critical reactor by 
achieving hot shutdown before the pool temperature reaches the HCTL. In some plants, however, this may not be possible, and the only way to avoid having to attempt a rapid depressurization with the reactor critical is to adopt a higher HCTL during ATWS.

Instructions for control of reactor vessel water level under ATWS conditions are provided by Contingency \#5 "Level/Power Control" of the EPGs. With the reactor remaining at power while sodium pentaborate solution is being injected, this contingency directs that the reactor vessel water level should be lowered to the top of the core. (Operation of the Automatic Depressurization System [ADS] while the water level is reduced is to be manually prevented.) Water level reduction is accomplished by restricting injection to the relatively small amounts provided by the SLCS and the CRDHS.

The effects of reactor vessel water level reduction upon core power are illustrated in Figure 2B-6. It should be noted that the major reduction occurs as the feedwater spargers become uncovered. Prior to this time, the feedwater (much colder than normal since the feedwater heaters are not operating) is injected underwater and passes directly downward through the jet pumps to the core inlet. With the spargers uncovered, however, the feedwater droplets are sprayed into the steam atmosphere within the vessel, where the steam condenses upon and heats the feedwater. In effect, this restores a form of feedwater heating and much warmer water enters the core inlet, which tends to increase the voids in the lower core and thereby reduce reactor power.

The discontinuity in the power vs level curve near the top of the core (at 366 in.) should also be noted on Figure 2B-6. This occurs because the water recirculation loop within the reactor vessel becomes broken as the level falls below the bottom of the steam separators. In effect, the core boiling takes on the characteristics of a swimming pool reactor, with only enough flow at the core inlet to replace the water mass being converted to steam.

Once the reactor vessel water level has been reduced, the EPGs specify that the new level is to be maintained (by control of injection rate) between the top of the core and the Minimum Steam Cooling RPV Water Level, which (employing several very conservative assumptions) is defined so as to ensure adequate steam cooling of the upper regions of a partially uncovered critical core.

When sufficient time has passed since SLCS initiation to inject the Hot Shutdown Boron Weight (HSBW) into the reactor vessel, the EPGs specify that the vessel water level should be restored to the normal range. Raising the water level involves increased flow at the core inlet, which serves to sweep the sodium pentaborate solution that has collected within the lower plenum up into the core region.

\section{B.7.4 Summary}

Automatic recirculation pump trip reduces the reactor power. The operators can act to reduce power further by initiating the injection of liquid neutron poison (some plants have automatic provisions for this) and by manual insertion of control blades. However, these measures require time to produce effects.

The strategy provided by the EPGs for dealing with an MSIV closure ATWS can be summarized as follows: initiate injection of sodium pentaborate solution and lower the reactor vessel water level to the vicinity of the top of the core; when sufficient boron has been injected to achieve hot shutdown, restore the vessel level to the normal range. These actions should terminate the accident sequence before the pressure suppression pool temperature reaches the HCTL and without core damage. The principal challenge that might 
thwart this desired conclusion is that the operator actions taken while attempting to achieve the pressure control directed by the EPGs might unintentionally create an unstable situation.

If, however, all means of injection of sodium pentaborate solution into the reactor vessel fail, then temporary, partial measures to reduce core power such as lowering the reactor vessel water level can only delay the progression of events into a severe accident. Manual control blade insertion can bring about permanent reactor shutdown, but this is a very slow process. Failure of the boron injection systems is a premise of the ATWS accident sequences leading to severe core damage identified by NUREG-1150. (The sole exception involves ATWS combined with early total loss of injection.)
Severe core damage resulting from ATWS can occur only if the reactor vessel injection systems become failed and sufficient water cannot be kept in the core region. Containment events provide the bases for a potential loss of vessel injection systems during BWR ATWS, and the various injection systems might be lost in different ways. Most are low pressure systems, requiring that the reactor vessel be depressurized for performance of function. The $\mathrm{HPCI}$ and RCIC systems are capable of high pressure injection, but are susceptible to elevated pressure suppression pool temperatures when taking suction from this source. In addition, both of these systems have high turbine exhaust pressure trips so that high primary containment pressure can defeat their function. Steam-driven feedwater pumps would be lost at the inception of the accident sequence when MSIV closure cuts off their steam supply. 
Table 2.B-1 The change in vapor specific volumes for a given change in pressure is much greater at low pressure (Table entries based on values taken from steam tables)

\begin{tabular}{cc}
\hline & $\begin{array}{c}\text { Relative Change in Vapor Specific Volume } \\
\text { per Unit Change in Pressure }\end{array}$ \\
Pressure (psia) & 3634.4 \\
15.0 & 92.5 \\
200.0 & 24.7 \\
300.0 & 11.0 \\
400.0 & 6.4 \\
500.0 & 4.2 \\
600.0 & 2.9 \\
700.0 & 2.2 \\
800.0 & 1.7 \\
900.0 & 1.3 \\
1000.0 & 1.1 \\
1050.0 & 1.0 \\
\hline
\end{tabular}




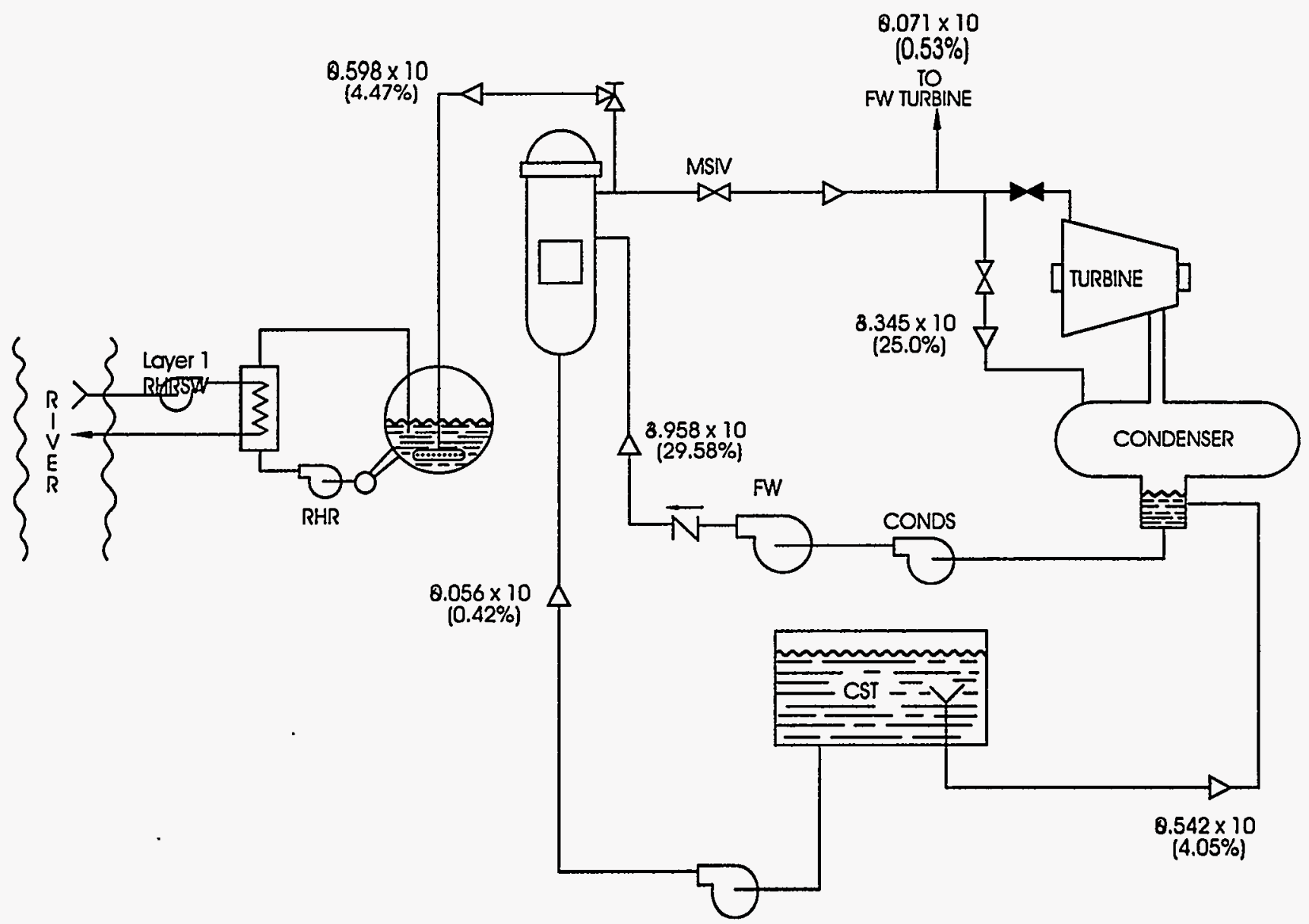

Figure 2B-1 BWR operation after failure of scram in the turbine trip-initiated ATWS accident sequence (flows in lbs/hr) 


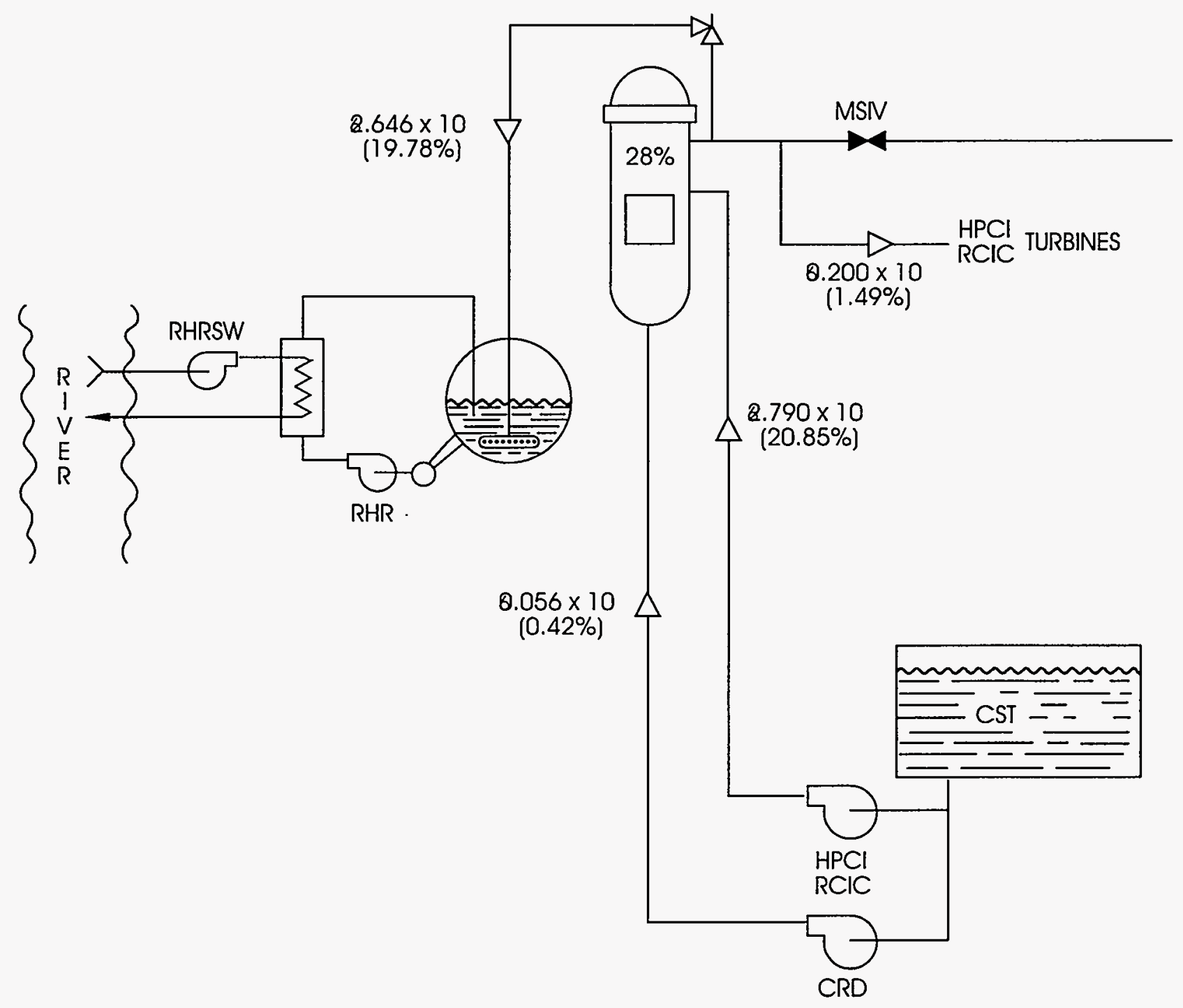

Figure 2B-2 BWR operation after failure to scram in the MSIV closure initiated ATWS accident sequence (flows in lbs/hr) 


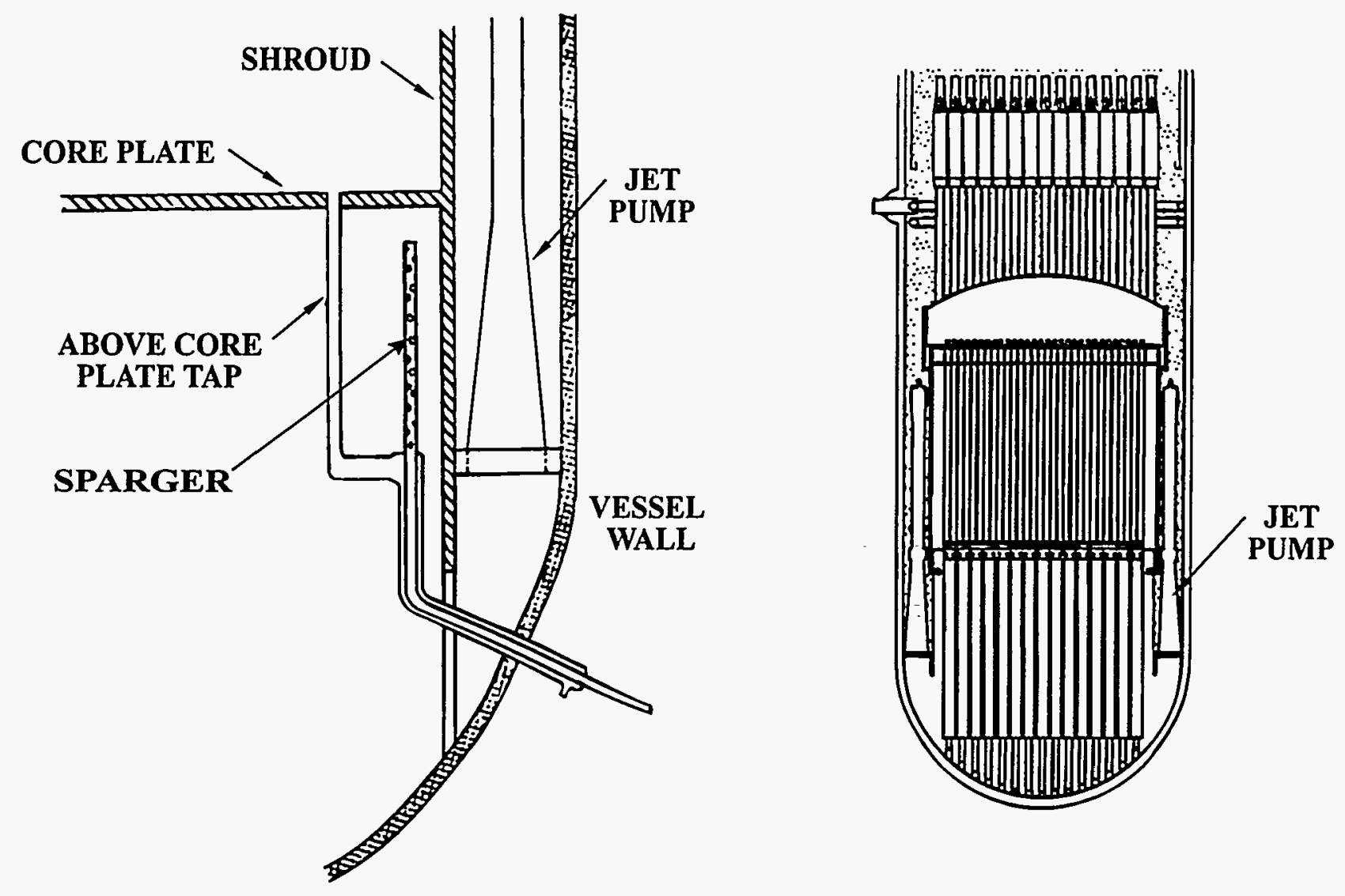

Figure 2B-3 The single SLCS injection sparger is located to the side of the control rod guide tubes and injects horizontally into the lower plenum 


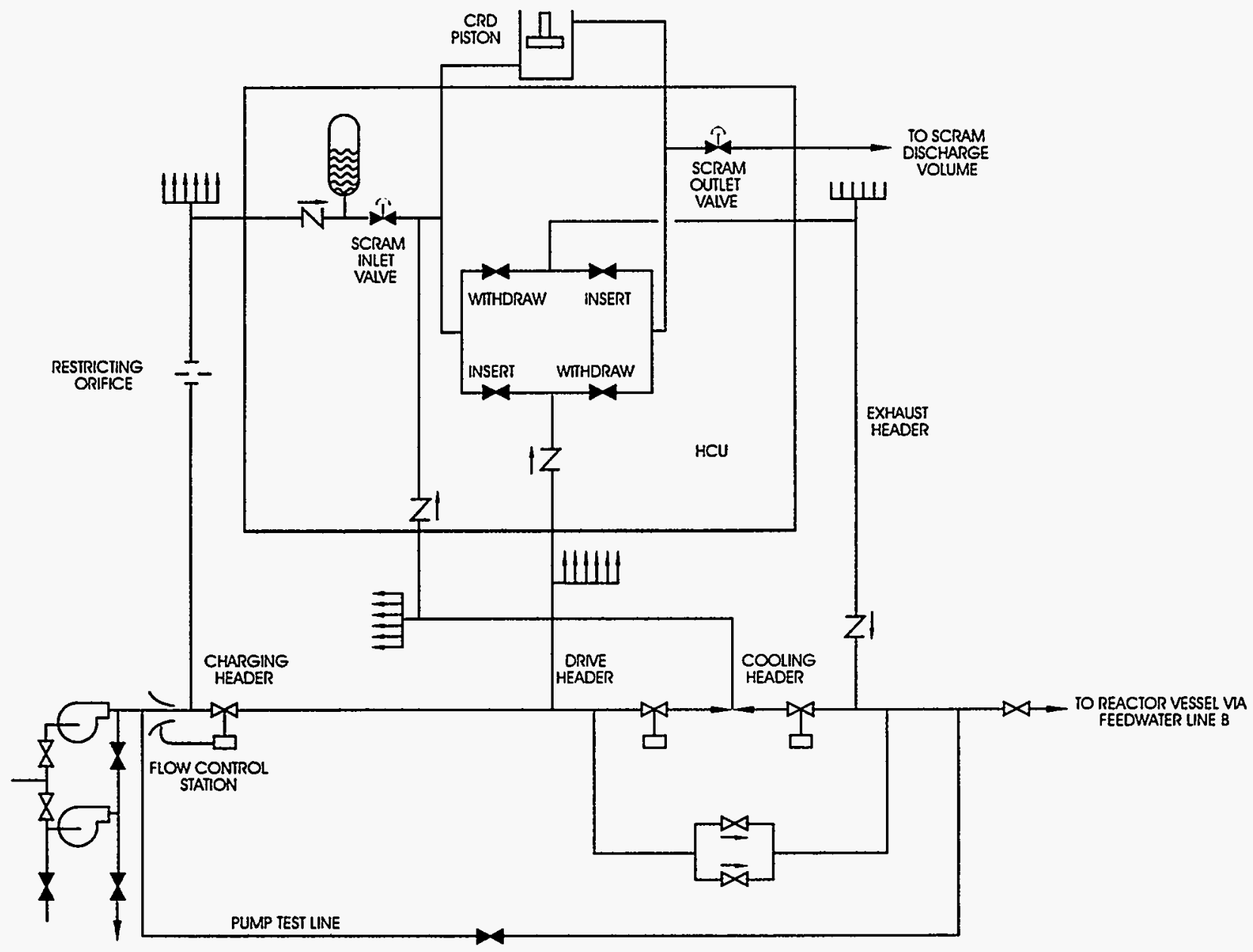

Figure 2B-4 Manual rod insertion involves different piping and valves and might be effective even if scram has failed 

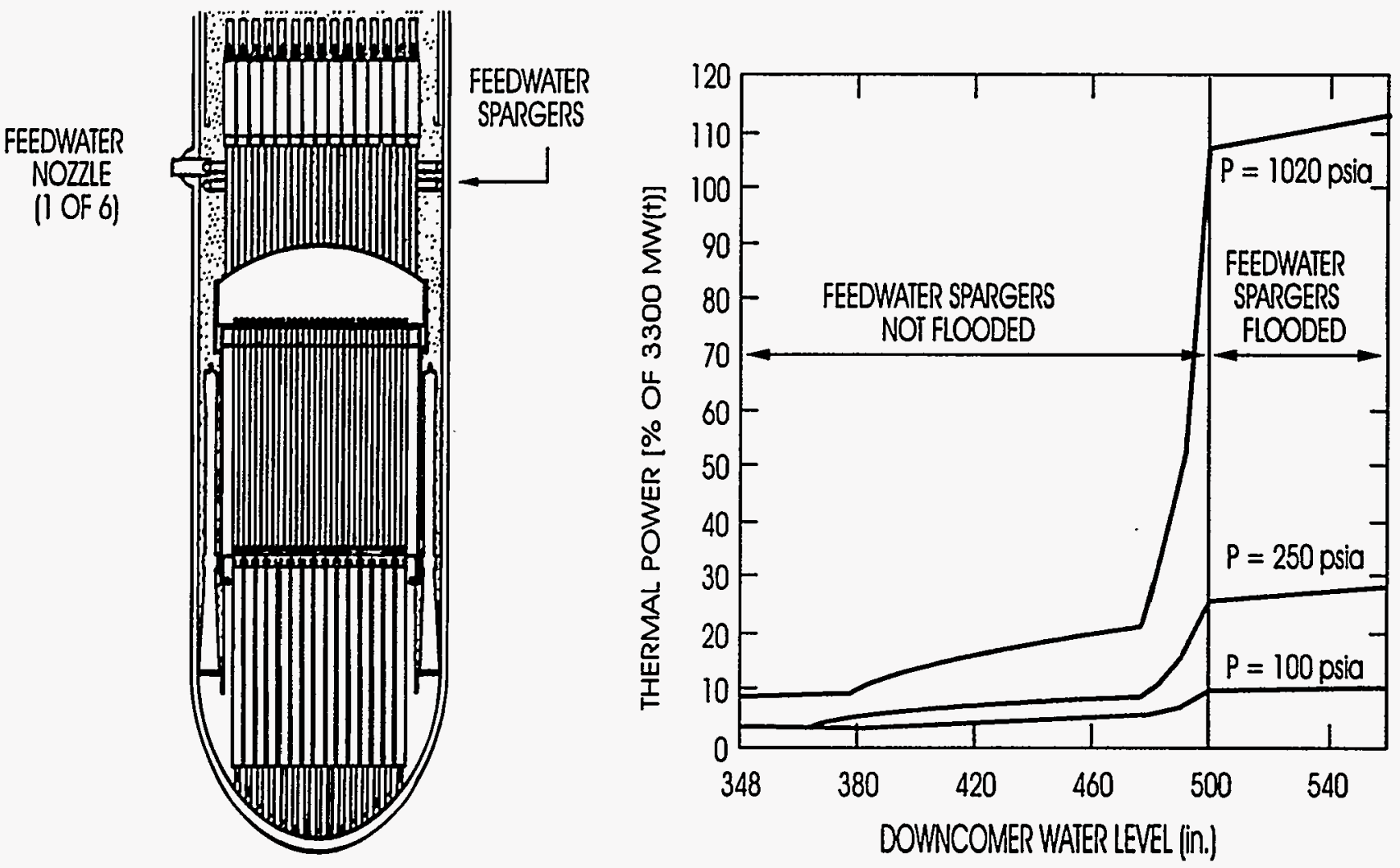

Figure 2B-5 The major effect of lowering the reactor vessel water level upon core power occurs when feedwater spargers are uncovered 


\section{References for Appendix 2B}

1. U. S. Atomic Energy Commission Regulatory Staff, "Technical Report on Anticipated Transients Without Scram for Water-Cooled Power Reactors," WASH-1270, September 1973.

2. U.S. Nuclear Regulatory Commission, Inspection and Enforcement Bulletin No. 83-01, "Failure of Reactor Trip Breakers (Westinghouse DB-50) to Open on Automatic Trip Signal," February 25, 1983.

3. U.S. Nuclear Regulatory Commission, "NRC Fact-Finding Task Force on the ATWS Events at Salem Nuclear Generating Station, Unit 1, on February 22 and 25, 1983," USNRC Report NUREG-0977, March 1983.

4. U.S. Nuclear Regulatory Commission, Inspection and Enforcement Bulletin No. 83-04, "Failure of the Undervoltage Trip Function of Reactor Trip Breakers," March 11, 1983.

5. Letter from Richard C. DeYoung, Director, NRC Office of Inspection and Enforcement, to Robert Smith, Chairman of the Board, Public Service and Gas Company, transmitting a Notice of Violation and Proposed Imposition of Civil Penalties, Docket Nos. 50-272 and 50-311, May 5, 1983.

6. U.S. Nuclear Regulatory Commission, "Generic Implications of ATWS Events at the Salem Nuclear Power Plant," NUREG-1000, Vol. 1, April 1983.

7. R. M. Harrington and S. A. Hodge, "ATWS at Browns Ferry Unit One - Accident Sequence Analysis," Oak Ridge National Laboratory, NUREG/CR-3470, ORNL/TM-8902, July, 1984.
8. General Electric Company, "Assessment of BWR Mitigation of ATWS," Volume II (NUREG-0460 Alternate No. 3), NEDO-24222, February 1981.

9. U. S. Nuclear Regulatory Commission, "Severe Accident Risks: An Assessment for Five U.S. Nuclear Power Plants," NUREG-1150, Vol. 1, Final Summary Report, December 1990.

10. D. L. Kelly et al., "An Assessment of BWR Mark II Containment Challenges, Failure Modes, and Potential Improvements in Performance," EG\&G Idaho, Inc., Idaho National Engineering Laboratory, NUREG/CR-5528 (EGG-2593), July 1990.

11. Pennsylvania Power and Light Company, "Susquehanna Steam Electric Station Probabilistic Risk Assessment Report," NPE 86-003, April 1986.

12. P. Saha, G. C. Slovik, and L. Y. Neymotin, "RAMONA-3B Calculations for Browns Ferry ATWS Study,"NUREG/CR-4739 (BNL-NUREG52021), February 1987.

13. Safety Evaluation by the Office of Nuclear Reactor Regulation Relating to Amendment 17 General Electric Topical Report NEDE-24011-P, "General Electric Standard Application for Reactor Fuel," dated December 27, 1987.

14. S. A. Hodge, J. C. Cleveland, T. S. Kress, and $M$. Petek, "Identification and Assessment of BWR In-Vessel Strategies," Oak Ridge National Laboratory, NUREG/CR5869, ORNL/TM-12080, October 1992.

15. General Electric Company, "BWR Owner's Group Emergency Procedure Guidelines," Revision 4, NEDO-31331, March 1987. 


\subsection{Accident Progression In The Reactor Vessel}

\subsubsection{Introduction}

Given an accident sequence that leads to sustained uncovering of the core, the progression of core damage involves overheating of fuel; exothermic oxidation of the cladding with accompanying production of high temperature hydrogen gas; distortion and breach of the fuel cladding; melting of the cladding; fuel liquefaction; downward relocation of core materials; interactions between molten fuel and residual water in the reactor vessel; and breach of the reactor vessel accompanied by the discharge of molten core materials to the containment.

The temperatures attained by fuel, cladding, and other core materials determine the releases of radionuclides from the fuel. The temperature and flow patterns of hot radioactive gases within the reactor coolant system determine the potential for trapping and retention of radionuclides on surfaces within the reactor coolant system. They also determine the occurrence, timing, location, and size of temperature-induced failures in the reactor coolant system pressure boundary.

The hydrogen gas produced in-vessel can escape to containment, where its combustion can pressurize and heat the containment. Violent in-vessel fuel coolant interactions have the potential to fail the reactor vessel with the accompanying forceful ejection of radionuclides. The melting and downward relocation of core materials in the reactor vessel, if unarrested by the restoration of coolant, can breach the reactor vessel resulting in the discharge of hot core debris, radionuclides, and aerosols into containment, where they may interact with the containment atmosphere, water, and/or concrete. The characteristics of these discharges strongly affect the likelihood and timing of various containment failure modes and the magnitudes of radionuclide releases to the environment should containment fail.

Finally, to a large extent, in-vessel processes determine the likelihood of arresting core degradation and radionuclide releases from the fuel upon restoration of coolant supply.

\subsubsection{Learning Objectives for Module 3}

At the end of this module, the student should be able to:

1. List three energy sources that would be of concern in a severe accident.

2. Identify the three conditions that must be achieved to arrest a severe accident.

3. Characterize the time intervals in which the following events would be expected in severe accidents involving complete failure of cooling water flow to the core.
a. In-vessel molten-core-coolant inter- action
b. Onset of $\mathrm{Zr}$ oxidation
c. Core relocation
d. Melt through of reactor pressure vessel bottom head
e. Core uncovering.

4. Indicate, for each pair of accident types below, the one that would proceed faster and explain why.

a. Large LOCA versus small LOCA

b. PWR transient versus comparable BWR transient
c. Accident initiated at power versus one initiated at shutdown.


5. Explain what is meant by alpha-mode containment failure and indicate the currently perceived likelihood of such an event.

6. List at least one concern regarding the restoration of cooling water when molten core material is present in-vessel.
7. Describe the possible modes of bottom head failure and melt release to containment. 


\subsection{Severe Accident Stages}

\subsubsection{Delineation of Accident Stages}

This module discusses the known in-vessel processes that play important roles in determining the severity and consequences of core-damage accidents. The discussion of in-vessel processes is divided into six parts, corresponding to successive stages of core damage. These stages of core damage are marked by:

1. The initiating event and subsequent failures leading to inadequate core cooling.

2. The onset of sustained core uncovering, which leads to core heatup.

3. The onset of exothermic oxidation of cladding by steam, resulting in hydrogen production, cladding failure, and the release of gaseous fission products from the fuel-cladding gap.

4. The onset of clad melting and fuel liquefaction, which results in more substantial releases of radionuclides from the fuel.

5. Slumping of molten material into the lower plenum of the reactor vessel, which may contain residual reactor coolant.

6. The failure of the reactor vessel bottom head with consequent discharge of molten material into containment.

The significant phenomena occurring during each of these in-vessel stages are discussed in this module.
As indicated in Table 3.1-1, each stage of core damage begins with a particular starting event and terminates with the event that starts the next stage. Although the processes initiated in one stage can continue in subsequent stages, the event that delineates the next stage marks the onset of additional processes that can significantly alter the progression of the accident. The rationale for the starting events and stage durations in Table 3.1-1 is provided in the discussion of each stage. The stage durations are necessarily approximate and incorporate appropriate ranges of values both because the table applies to a range of accidents, and because of uncertainties inherent in predicting accident progression.

Figure 3.1-1 illustrates temperature and time intervals that encompass a wide spectrum of severe accident scenarios and key events and phenomena that would be anticipated to occur as core temperatures increase. The phenomena, events and timing depicted in Figure 3.1-1 are discussed in subsequent sections. However, a few points warrant consideration here. The times measured from the onset of sustained core uncovering in Figure 3.1-1 are based on PWR scenarios in which there is no partial injection of core coolant, and in which the onset of sustained core uncovering begins within a few hours of reactor shutdown. For such accidents, invessel events would proceed to bottom head failure within 3 hours for a PWR as indicated in Figure 3.1-1. The more accelerated accident scenarios are those involving large break LOCAs with immediate failure of emergency core cooling. BWR accident stages tend to progress more slowly due to a number of factors including a smaller core power density and larger masses of water and structural materials 
below the core region. If there is partial injection of core coolant or if the core uncovering is delayed for many hours (allowing decay power to decrease) the accident stages may take longer than depicted in Figure 3.1-1.

Significantly, for non-LOCA accidents, an injection flow of only a few hundred gallons of water per minute is sufficient to keep the core of a $3300 \mathrm{MWt}$ plant covered.' However, once core degradation has begun (stage 2) additional water is required to quench core materials.

Frequently, when students first see Figure 3.1-1 they are bothered by the fact that very rapid steam-Zircaloy reaction is shown to begin at $1832^{\circ} \mathrm{F}\left(1000^{\circ} \mathrm{C}\right)$, which is under the peak cladding temperature of $2200^{\circ} \mathrm{F}$ $\left(1204^{\circ} \mathrm{C}\right.$ ) allowed in the $10 \mathrm{CFR} 50.46$ as a result of the ECCS rulemaking. That is, the $2200^{\circ} \mathrm{F}$ design criterion for ECCS performance appears non-conservative. However, as indicated in Module 1, Section 1.3.6, 10 CFR 50.46 further requires that:

- Peak cladding temperature cannot exceed $2200^{\circ} \mathrm{F}$.

- Oxidation cannot exceed $17 \%$ of the cladding thickness.

- Hydrogen generation from hot cladding-steam interaction cannot exceed $1 \%$ of its potential.

- The core geometry must be maintained in a coolable condition.

- Long-term cooling must be provided.

A fundamental problem in understanding core melt progression is that it is extremely difficult to perform the experiments necessary to fully understand the relevant phenomena. Over the years, computer code calculations of severe accident behavior have been extremely useful for forming and reinforcing engineering judgment. However, care must be taken in using and interpreting severe accident code calculations because such codes can never be fully validated. Even given the years of severe accident research that followed the 1979 TMI-2 accident, no computer code can calculate all major aspects of the TMI-2 accident. Modeling uncertainties tend to increase as the accident progresses, in particular, as significant changes in the core geometry occur. Chemistry plays an important role in determining the sequence of events and the fission product releases associated with core melt accidents. Figures 3.1-2 and 3.1-3 illustrate the wide spectrum of melt and boiling temperatures for elements, alloys, fuel, and fission products. Figure 3.1-4 indicates the chemical interactions and liquid phases that can form in a LWR fuel with increasing temperature. ${ }^{2}$ Considering this diversity, chemistry is usually a significant contributor to uncertainty in core melt accident predictions. In addition, as indicated in Table 3.1-2, a broad spectrum of accident conditions is encountered in core melt accidents. This also makes modeling difficult. Finally differences between BWRs and PWRs, which are described in the next subsection, are important in predicting invessel as well as ex-vessel severe accident progression. Accordingly, rather than display a plethora of code calculations, a general discussion of major in-vessel phenomena and their potential implications is presented.

This module concludes with a discussion of reactor vessel breach and discharge of core materials into the containment. Accident progression in containment is discussed in Module 4. 


\subsubsection{Review of Selected Design Features}

The student is presumed to be familiar with the general design features of both BWRs and PWRs. The purpose of this subsection is to review with the aid of figures a few important design features that can significantly influence the in-vessel progression of severe accidents, particularly features that differ markedly between BWRs (Figures 3.1-5 to 3.1-7) and PWRs (Figures $3.1-8$ to $3.1-11$ ).

As shown in Figure 3.1-5, BWRs have massive steam separators and dryers above the core region. This is not the case for PWRs in which the reactor coolant is subcooled during normal operation and steam is produced in the steam generators, (Figure 3.1-8).

BWR fuel assemblies have outer Zircaloy flow channels (Figure 3.1-6) that prevent coolant flow between assemblies. PWR fuel assemblies, on the other hand, have no surrounding flow channels, so there is coolant mixing between assemblies (Figure 3.1-9).

BWRs have cruciform control blades (Figure 3.1-7) that enter from the bottom (Figure 3.1-5). PWRs have rod cluster control assemblies (Figure 3.1-10) that enter from the top (Figure 3.1-8). As a result, BWRs have a forest of control rod drives and guide tubes in the lower plenums of their reactor vessels, whereas PWRs have only secondary support assemblies (Figure 3.1-9). Westinghouse and Babcock \& Wilcox plants also have bottom-entry in-core instruments and guide tubes (Figure 3.1-11).

In addition, of course, the BWR operates at about 1000 psia whereas the PWRs operate at about 2200 psia. BWRs have larger pressure vessels to accommodate their steam separators and dryers and their lower power densities (51-56 versus 95-105 W/liter). Finally, BWRs cores contain roughly twice the mass of Zircaloy in comparable PWR cores, mainly in the form of the fuel assembly flow channels. Special considerations for BWR facilities under severe accident conditions are discussed in Section 3.7.

\subsubsection{Accident Initiation (Stage 1)}

The extremely wide range of durations for this first stage of accident progression is due to the wide variety of possible accident sequences. In a large-break loss-of-coolant accident (LOCA) reactor coolant blowdown and pressure reduction occur in a matter of seconds. If emergency core cooling systems then fail on demand, Stage 1, accident initiation, has a very short duration. On the other hand, in many accident sequences the loss of coolant and/or the failure of coolant injection may rake many hours. For example, in loss of suppression pool cooling accidents identified for Peach Bottom in the Reactor Safety Study, the core is successfully cooled for almost a day before suppression pool overheating causes overpressurization and failure of containment, which, in turn, results in suppression pool flashing and failure of core cooling systems.

The risk posed by severe LWR accidents is often dominated by transient (including station blackout and ATWS) and small-break LOCA sequences in which the core is uncovered only after a prolonged boiloff of reactor coolant. The discussions presented in this module presume, for the most part, that the reactor vessel is pressurized. However, the potential for temperature-induced failures of the reactor coolant system pressure boundary is addressed. In addition, the discussion 
presumes that reactor shutdown (scram) successfully terminates the fission process, so that decay heat drives the core-damage process. Most of the processes discussed in the context of pressurized, decay-heat driven accidents would exist in unpressurized and/or ATWS sequences as well; although such sequences would differ in timing, rates and extent of core heating and oxidation, thermal-hydraulic conditions including the presence of water in the lower plenum, and other factors.

\subsubsection{Reflooding During Accident Progression}

One element in the consideration of severe core damage is the potential for reintroducing coolant into a damaged core as occurred at TMI-2. Injection into a damaged core is likely under certain circumstances, for example, when lost electrical power is restored. If water is reintroduced early enough, the configuration of the fuel rods differs little from the original geometry, and the temperatures of the fuel and cladding are only slightly above operating levels. Cooling of the core under these conditions is reasonably assured. However, reintroduction of coolant at later times creates conditions under which the resultant outcome is uncertain. Uncertainties regarding core behavior during coolant reintroduction are discussed for Stages 2 through 6 in the sections indicated in Table 3.1-1. Each stage is first discussed under the presumption that adequate cooling is not restored. The potential for terminating core damage during each stage is then discussed.

Core damage can only be terminated when three conditions are satisfied:

1. Water must be continuously available to the core, core debris, or melt in quantities sufficient to quench the material and remove decay heat and heat associated with metal-water reactions.

2. The core, core debris, or melt configuration must be coolable.

3. Means must be available for cooling the water or condensing the steam produced.

Figure $3.1-12$ is a functional event tree which shows the outcomes obtained by meeting all three termination conditions at various stages of core damage either in the reactor vessel or in containment. ${ }^{3}$ Water could be delivered in-vessel by normal or emergency coolant supply systems. Water could be delivered ex-vessel by containment sprays or by normal or emergency coolant supply systems with coolant entering the vessel but flowing out of the opening in the bottom head into the reactor cavity. Possible heat sinks include steam generators, the suppression pool and suppression pool cooling system, residual heat removal systems, and containment heat removal systems (fan coolers or spray recirculation systems).

If adequate coolant injection is reestablished after core uncovering, but early enough to prevent melting, the core geometry would still be coolable and releases would be limited to activity in the fuel-clad gap (Outcome 1). If adequate cooling is re-established later, but in time to prevent extensive meltdown (Outcome 2), the resulting core configuration would be damaged but coolable, perhaps with some coolable debris in the lower head as at TMI2. Coolability of core debris discharged to containment (Outcomes 3 and 6 in Figure 3.1-12) is discussed in Module 4.

If some, but not all, of the necessary termination conditions can be met, the accident progression can be delayed. For 
example, partial coolant injection flow can be used to delay the onset of cladding oxidation. Similarly, if only a limited amount of water can be supplied to a coolable ex-vessel debris configuration, the accident progression may be delayed until the water supply is exhausted (Outcomes 5 and 8 in Figure 3.1-12). 


\section{Table 3.1-1 In-vessel accident stages}

\begin{tabular}{|c|c|c|c|c|}
\hline Stage & Starting Condition & Description & $\begin{array}{l}\text { Approximate } \\
\text { Duration } \\
\end{array}$ & $\begin{array}{c}\text { Where } \\
\text { Discussed }\end{array}$ \\
\hline 1 & Accident Initiator & Initiation & $0-1$ day & Section 3.1 \\
\hline 2 & $\begin{array}{l}\text { Core uncovering } \\
\text { begins }\end{array}$ & $\begin{array}{l}\text { Core uncovering and } \\
\text { heatup }\end{array}$ & $5-35 \mathrm{~min}$ & Section 3.2 \\
\hline 3 & $\begin{array}{l}\text { Hottest cladding } \\
\text { reaches } 1832^{\circ} \mathrm{F} \\
\left(1000^{\circ} \mathrm{C}\right)\end{array}$ & $\begin{array}{l}\text { Cladding oxidation, } \\
\text { melting of some } \\
\text { structural and control } \\
\text { materials }\end{array}$ & $5-10 \mathrm{~min}$ & Section 3.3 \\
\hline 4 & $\begin{array}{l}\text { Hottest cladding } \\
\text { reaches its melt } \\
\text { temperature, } \sim 3200^{\circ} \mathrm{F} \\
\left(1760^{\circ} \mathrm{C}\right)\end{array}$ & $\begin{array}{l}\text { Clad melting, fuel } \\
\text { liquefaction, holdup in } \\
\text { core region }\end{array}$ & $10-30 \mathrm{~min}$ & Section 3.4 \\
\hline 5 & $\begin{array}{l}\text { Core materials first } \\
\text { enter lower plenum }\end{array}$ & $\begin{array}{l}\text { Core slumping, } \\
\text { quenching, reheating }\end{array}$ & $0-80 \mathrm{~min}$ & Section 3.5 \\
\hline 6 & Vessel Breach & $\begin{array}{l}\text { Vessel breach and } \\
\text { materials discharge to } \\
\text { containment }\end{array}$ & -- & Module 4 \\
\hline
\end{tabular}

"Based on PWR scenarios with total failure of coolant injection

Table 3.1-2 Severe Accident Conditions

\begin{tabular}{lcc}
\hline Pressure Range & $15-2500 \mathrm{psia}$ & $(0.1-17 \mathrm{MPa})$ \\
\hline Decay Power Level & $0.5-5 \%$ & \\
Local Heatup Rates & $1.3-18{ }^{\circ} \mathrm{F} / \mathrm{s}$ & $(0.7-10 \mathrm{~K} / \mathrm{s})$ \\
Steam Flow Rates & $0-6,600 \mathrm{lb}_{\mathrm{m}} / \mathrm{ft}^{2} / \mathrm{hr}$ & $\left(0-9 \mathrm{~kg} / \mathrm{m}^{2} / \mathrm{s}\right)$ \\
Maximum Midcore Steam & $>3600^{\circ} \mathrm{F}$ & $\left(>2000^{\circ} \mathrm{C}\right)$ \\
Superheat & $>5180^{\circ} \mathrm{F}$ & $\left(>2860{ }^{\circ} \mathrm{C}=3133 \mathrm{~K}\right)$ \\
Maximum Fuel Temperature &
\end{tabular}


Earliest $\longrightarrow-$ Stage 5 Core slump, Quench, Reheat $\rightarrow-$ Latest Lower

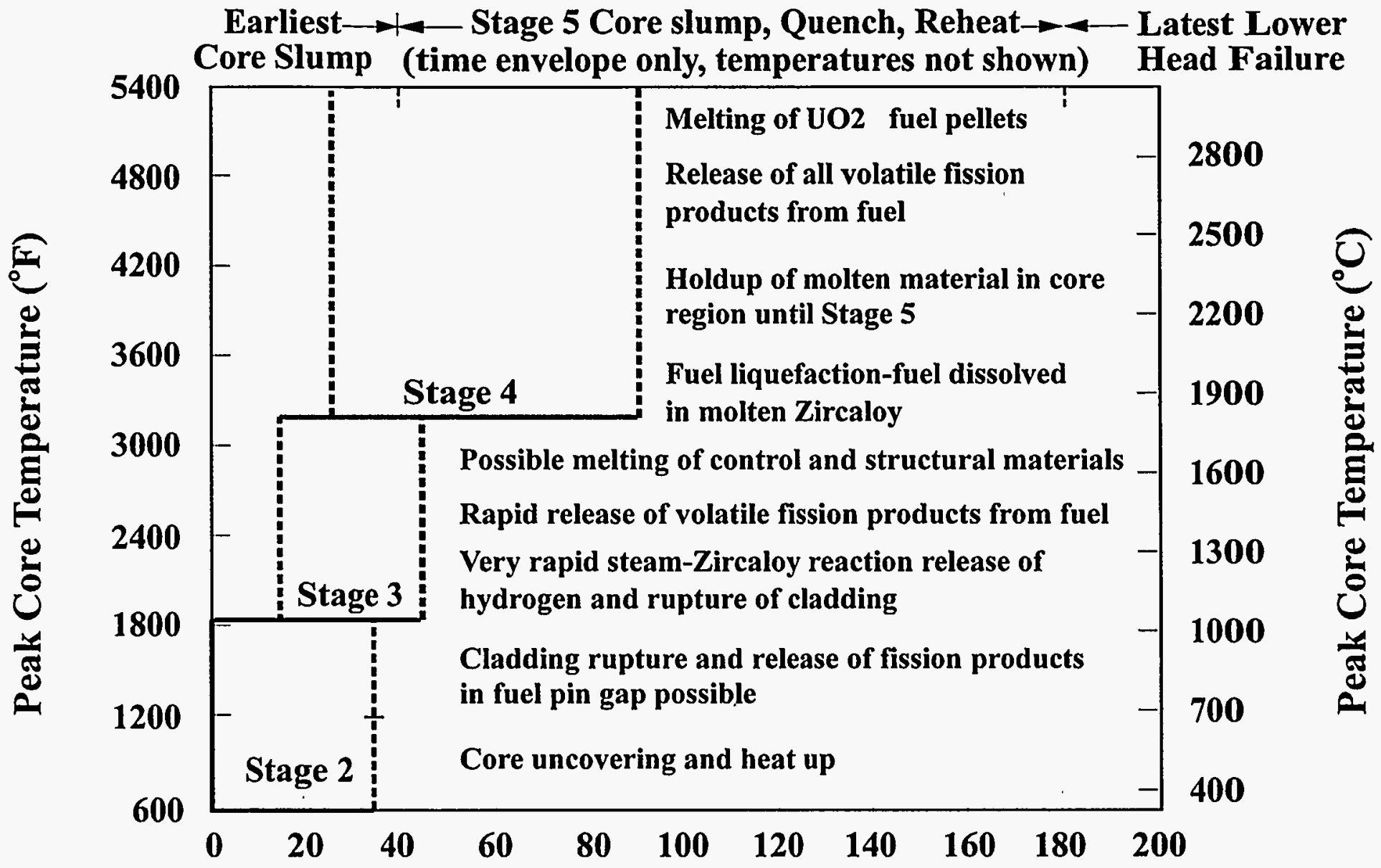

\section{Time After Onset of Core Uncovering (min)}

Figure 3.1-1 Approximate temperature and time envelopes for in-vessel severe accident stages assuming no coolant injection during PWR core heatup and degradation 


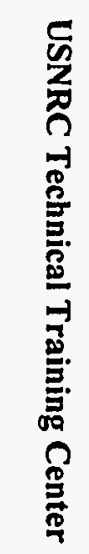

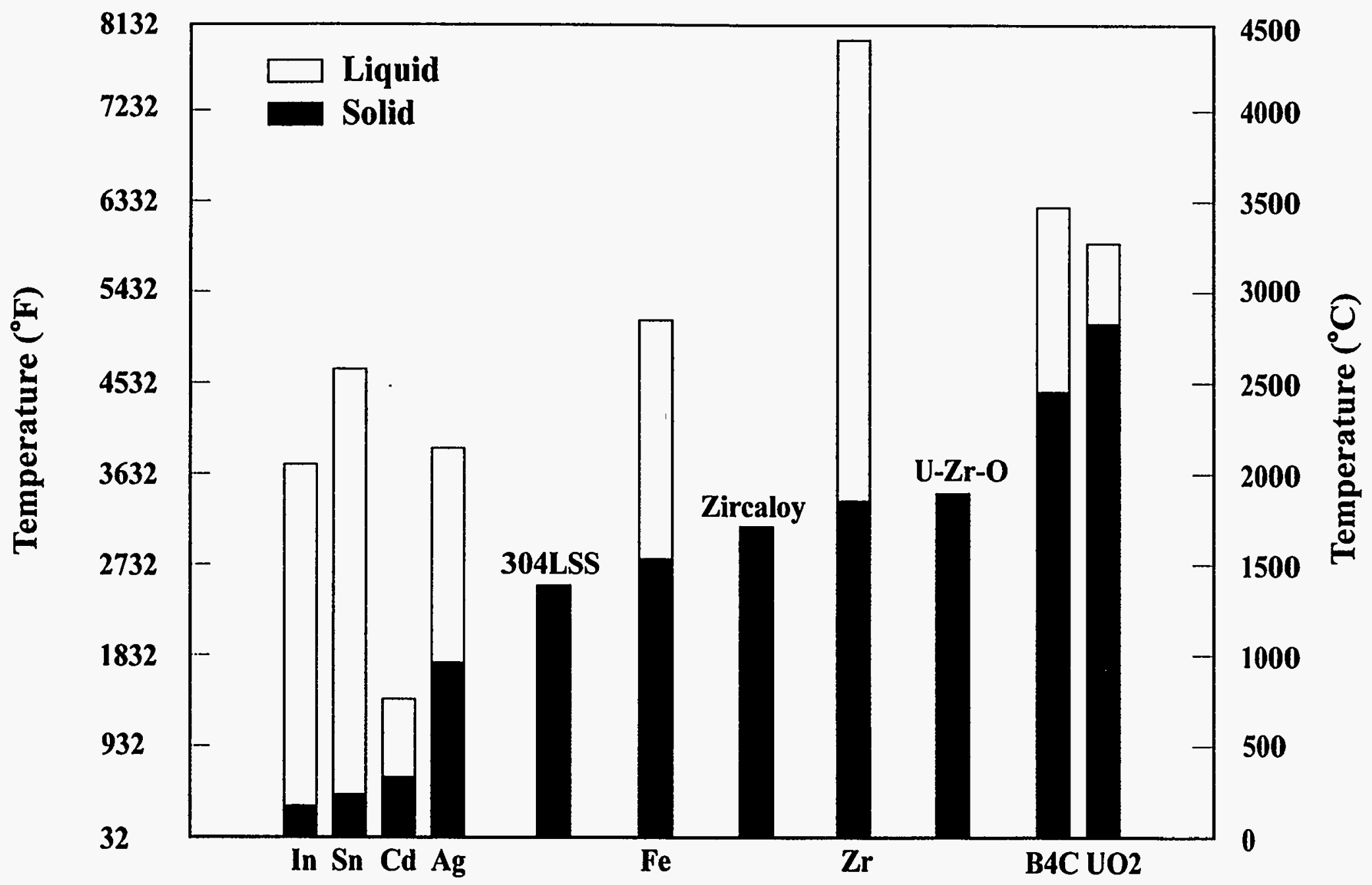

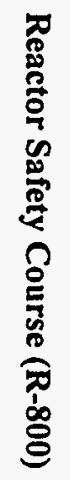

$\stackrel{\omega}{\infty}$

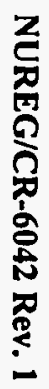

Figure 3.1-2 Melting points for metallic elements, reactor metals, and compounds 


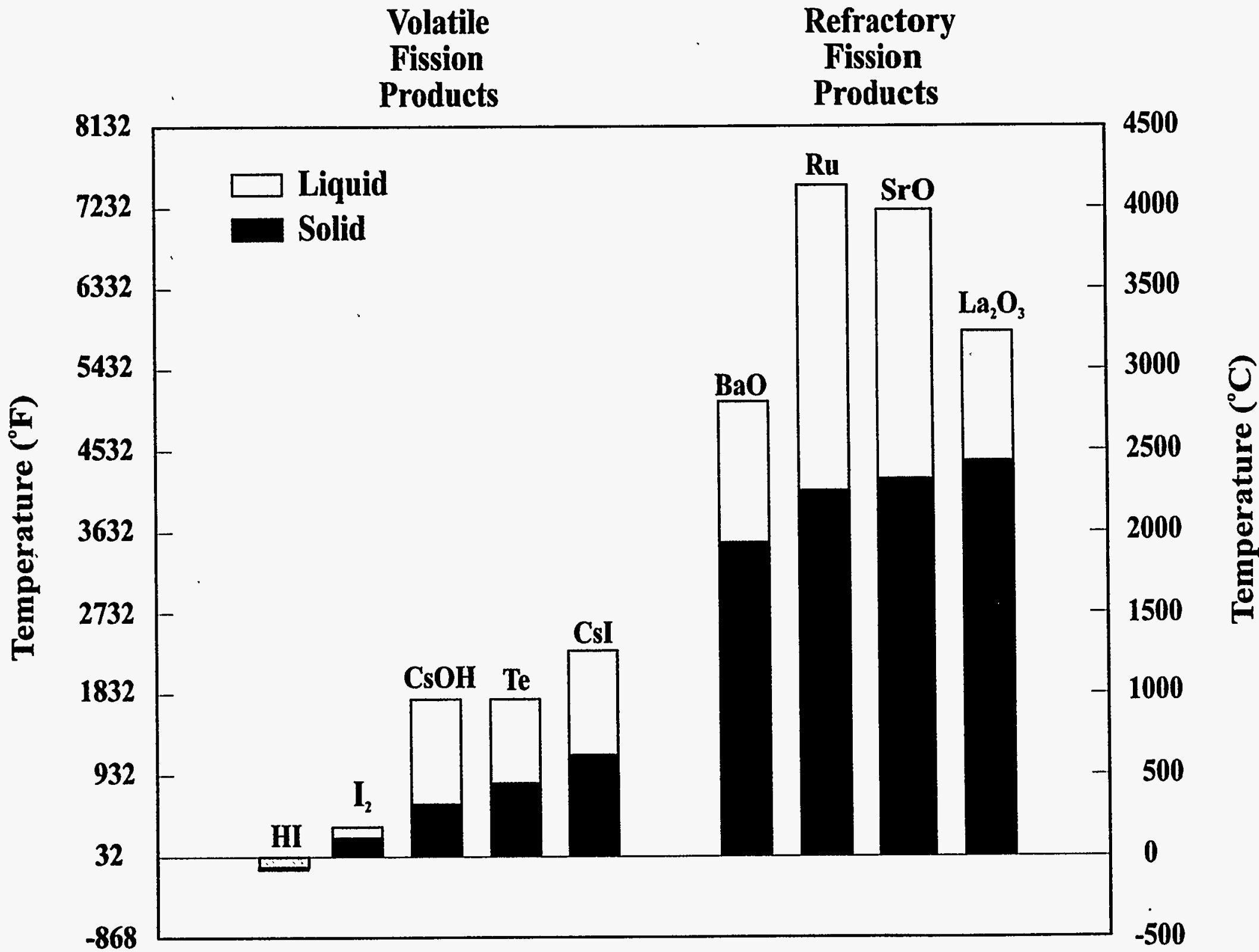

Figure 3.1-3 Melting and boiling points for fission products 


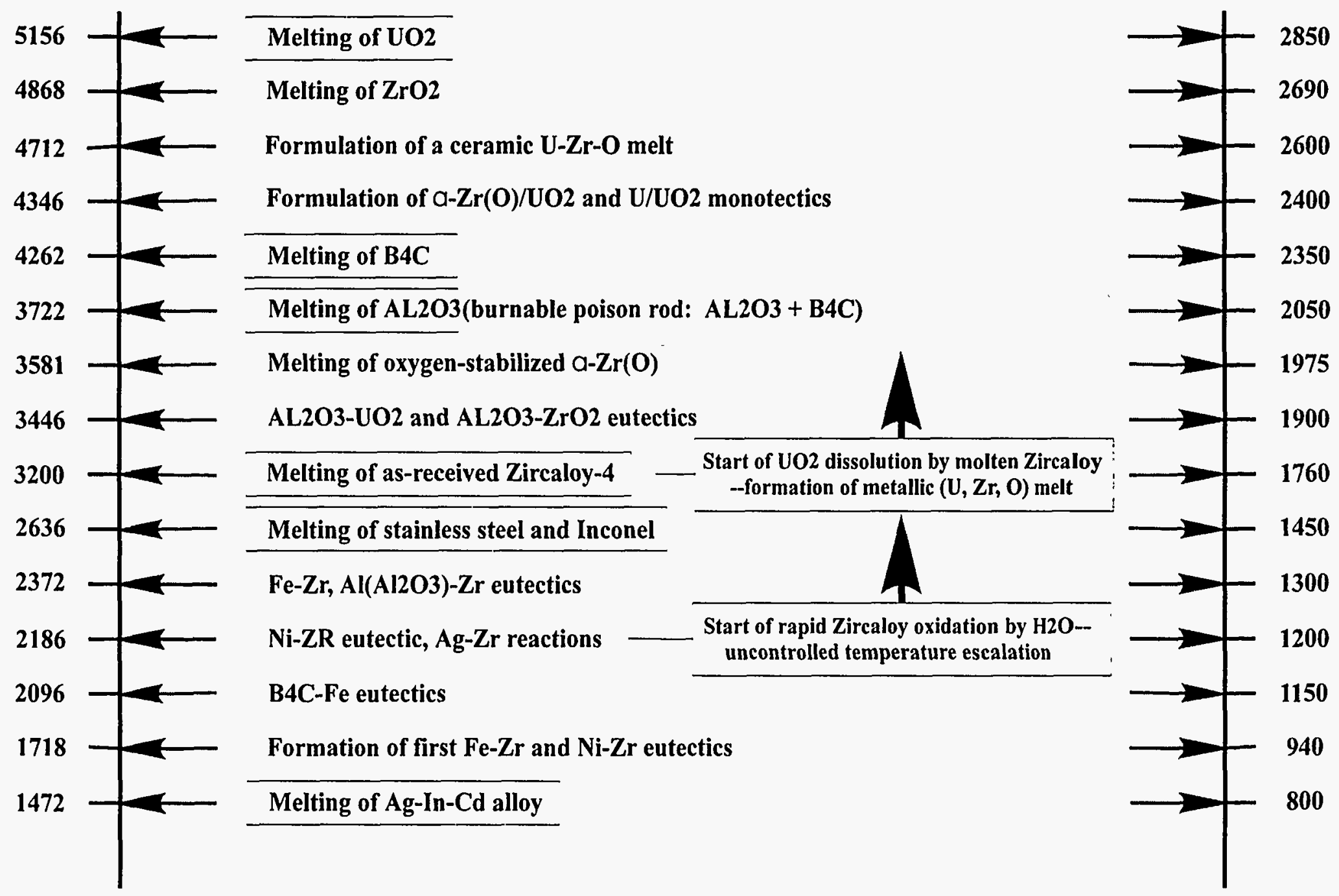

Figure 3.1-4 Chemical interactions and formation of liquid phases in an LWR fuel rod bundle with increasing temperature 


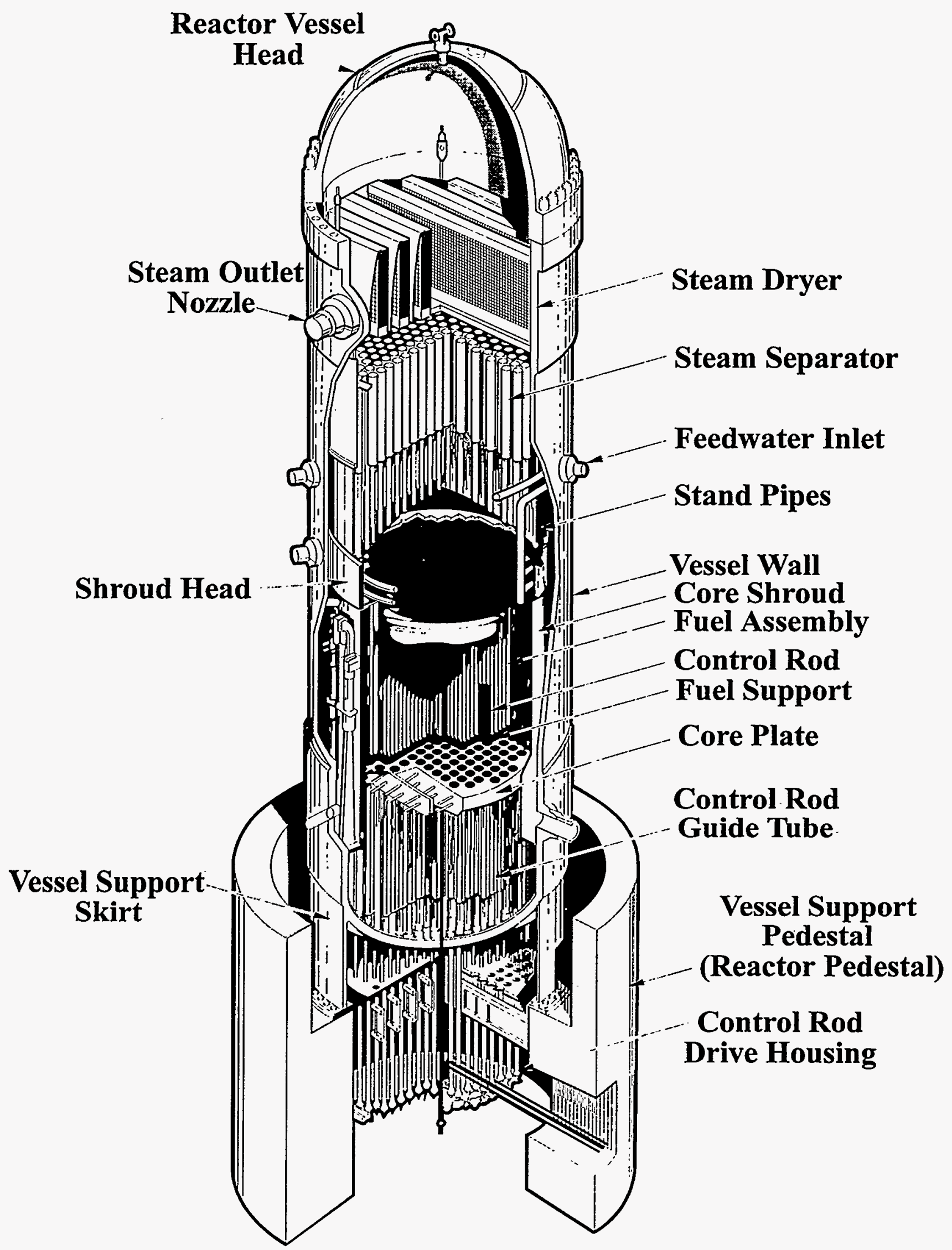

Figure 3.1-5 Schematic of BWR reactor vessel internal structure 


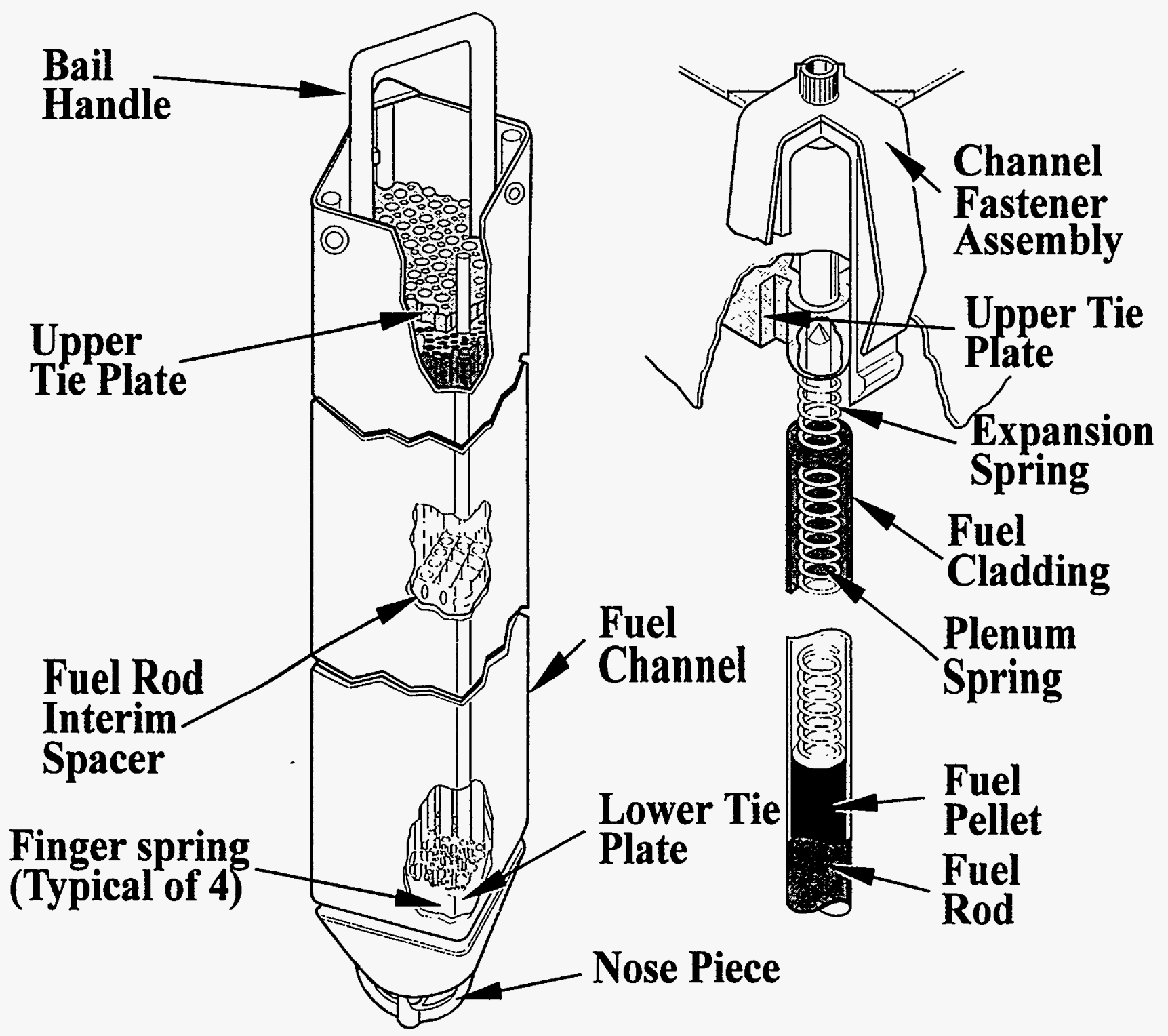

Figure 3.1-6 BWR fuel assembly 


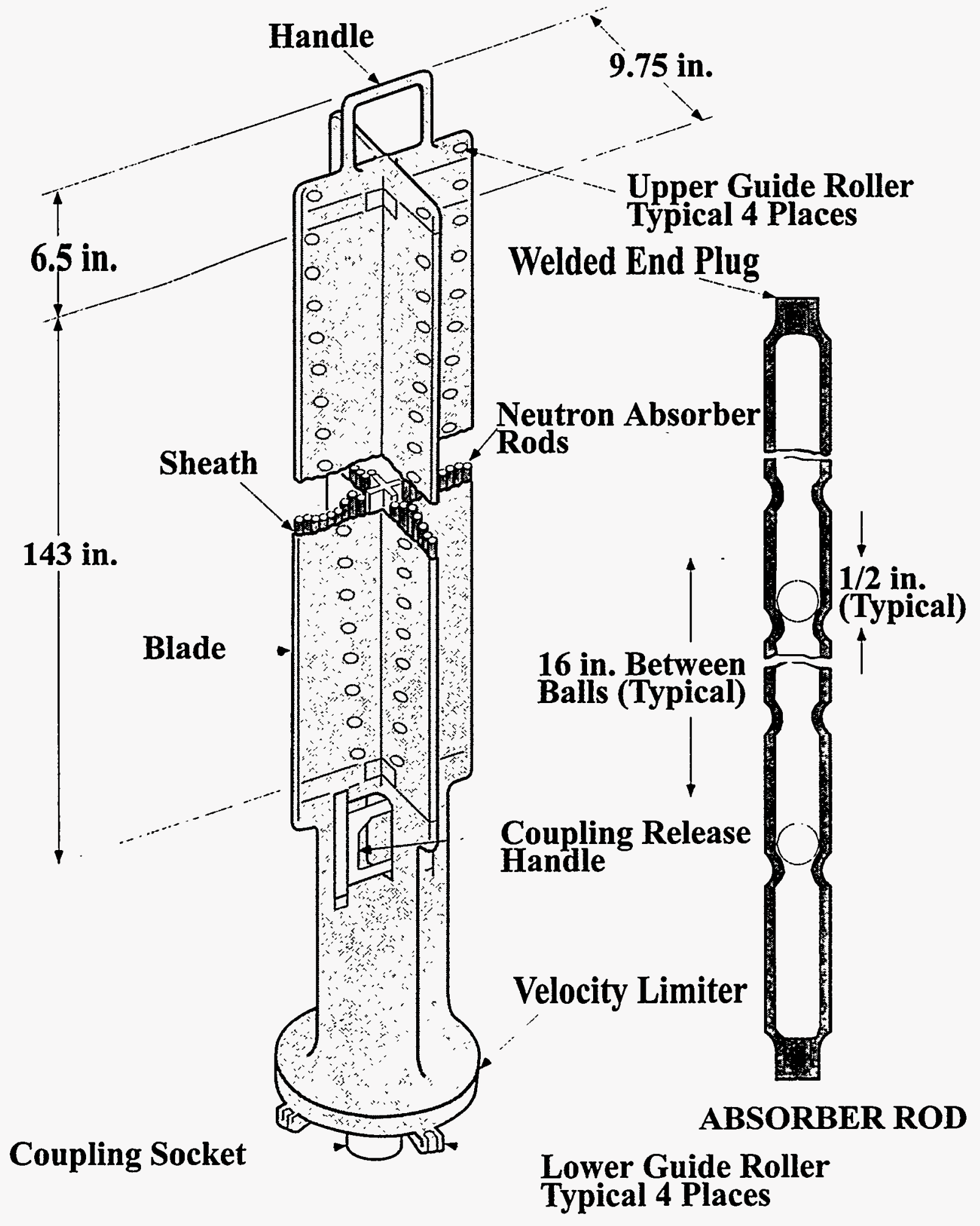

Figure 3.1-7 BWR control rod 


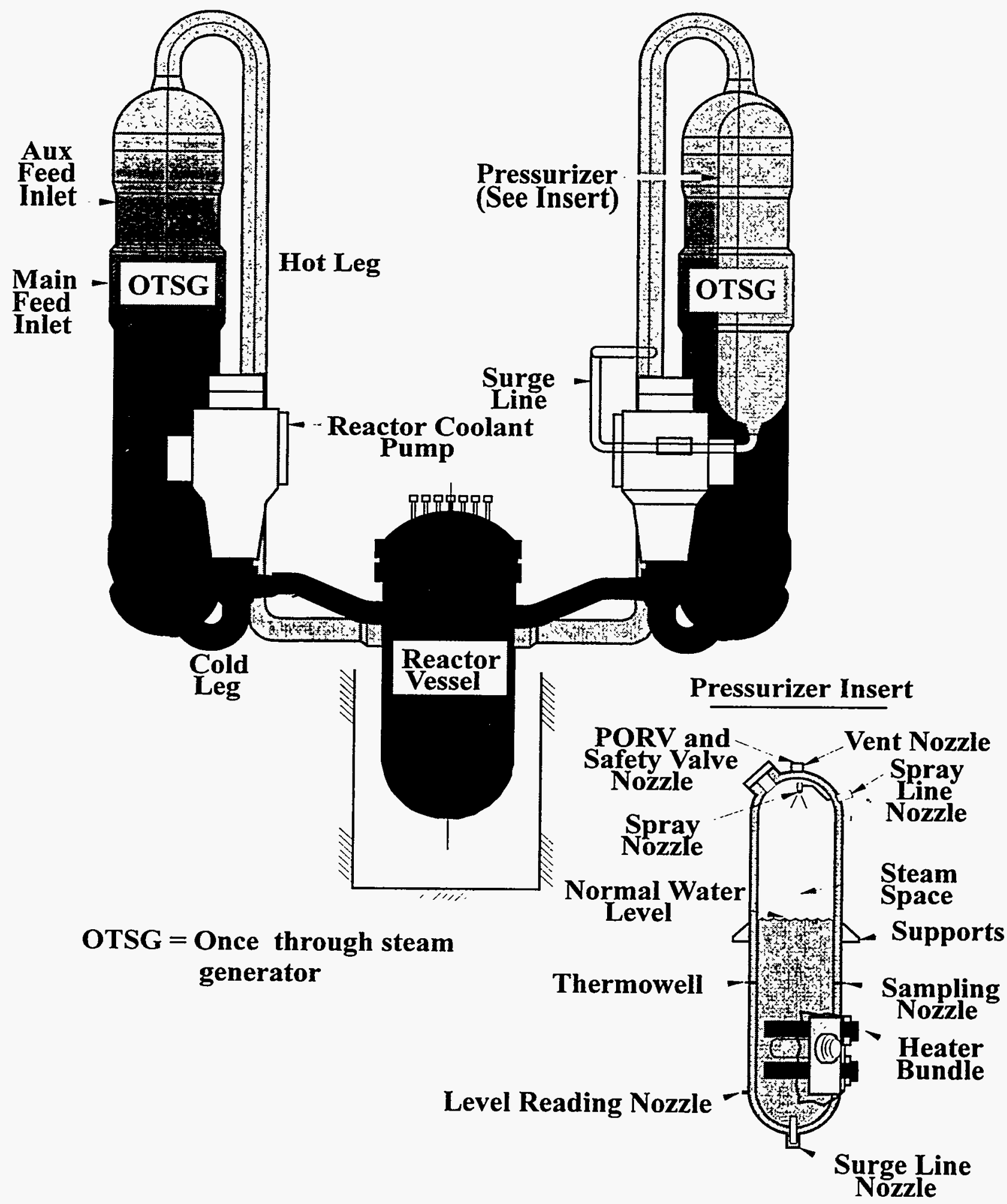

Figure 3.1-8 PWR reactor coolant system arrangement (B\&W) 


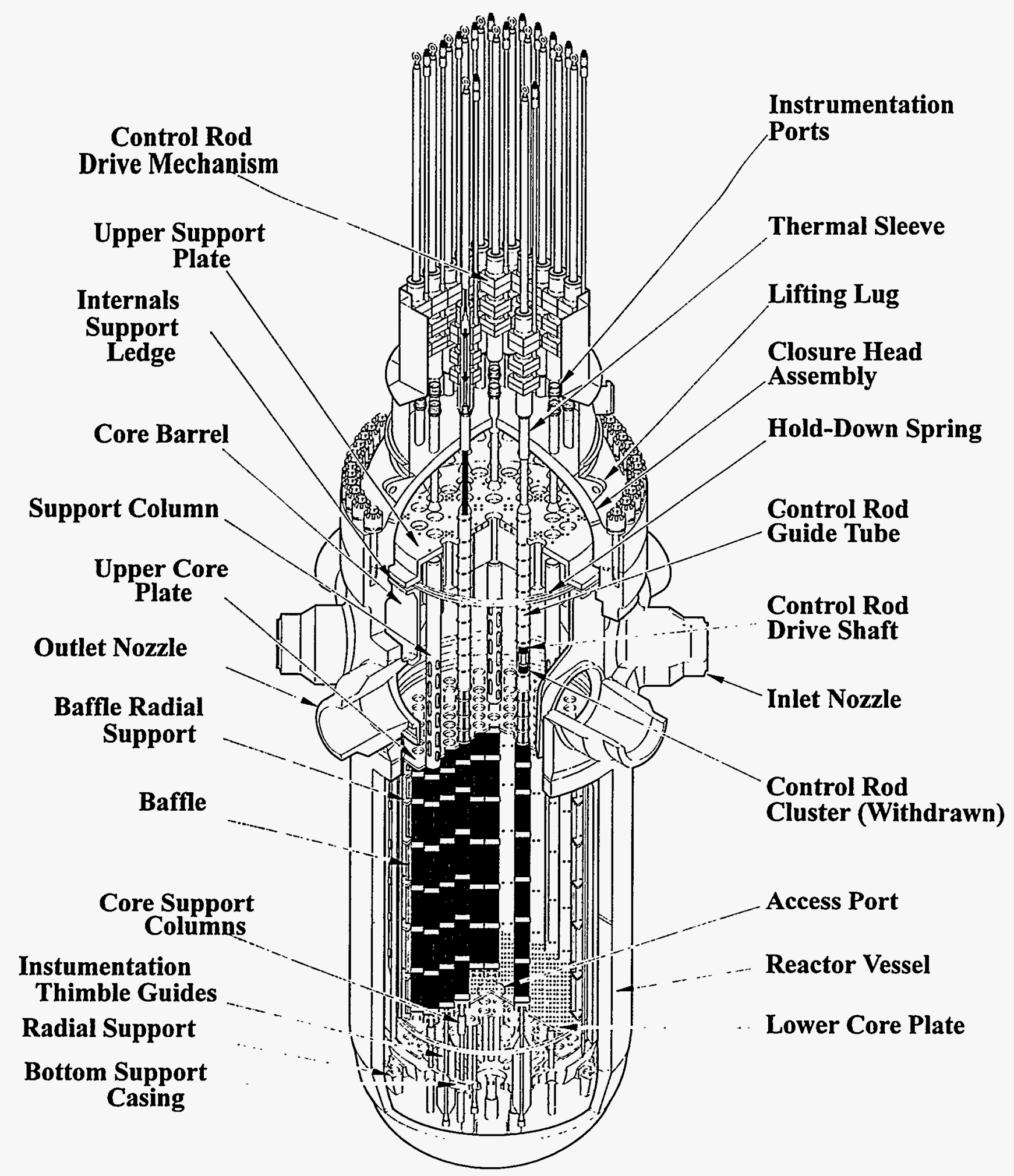

Figure 3.1-9 PWR reactor vessel internals (Westinghouse) 


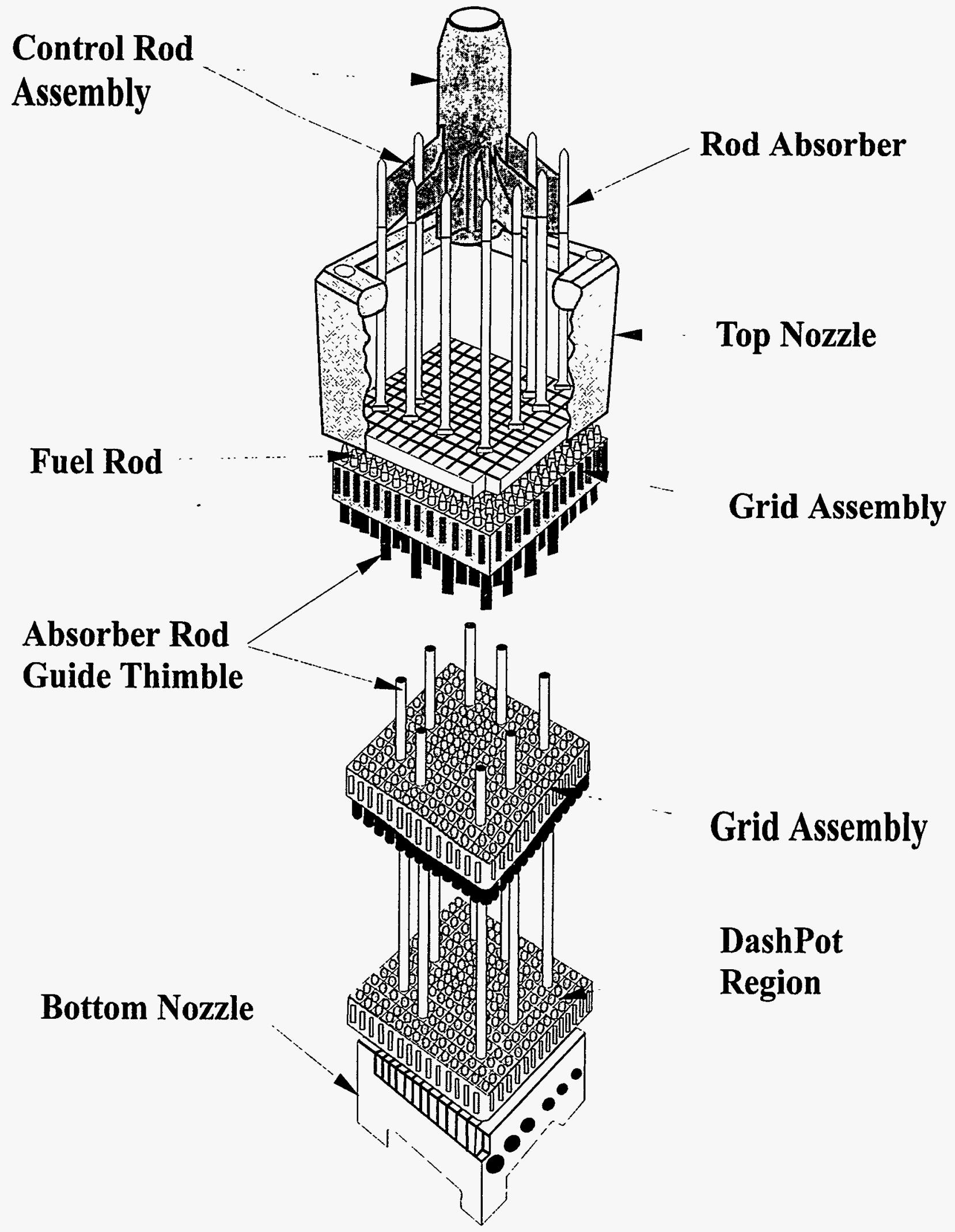

Figure 3.1-10 Cutaway view of typical rod cluster control assembly 
Thermocouple

Conduit Seal and

Disconnect Plug

Port Extension

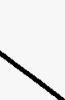

Vessel Head Port

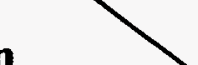

Vesse

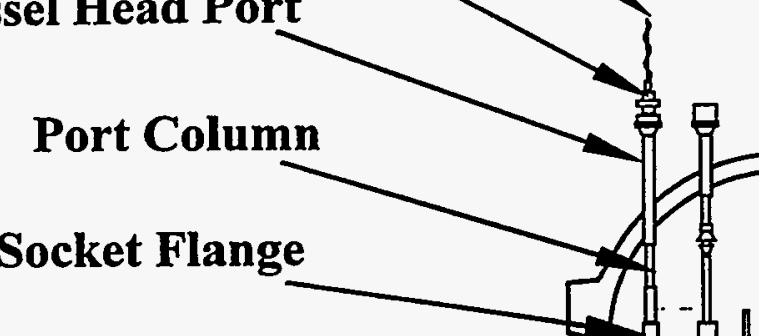

Vessel Seal Line

Support Column

Thermocouple Conduit

$$
\text { at Columns and Mixing }
$$

Top of Active Fuel

Fuel Assembly

Core Support Column

Instrument Thimble Guide

Vessel Penetration Tube

Thimble Guide Tube To Vessel Weld Joint

Thimble Guide

Tube Weld

Figure 3.1-11 Typical PWR arrangement for in-core instrumentation (Westinghouse) 


\begin{tabular}{|c|c|c|c|c|c|c|}
\hline $\begin{array}{l}\text { Core } \\
\text { Damage } \\
\text { Sequence }\end{array}$ & \begin{tabular}{|l|} 
Adequate \\
ECC \\
Established \\
In Time to \\
Prevent \\
Melting
\end{tabular} & $\begin{array}{l}\text { Adequate } \\
\text { In-Vessel } \\
\text { ECC } \\
\text { Established } \\
\text { Later }\end{array}$ & $\begin{array}{l}\text { In-Vessel } \\
\text { Corel } \\
\text { Debris } \\
\text { Geometry } \\
\text { Coolable }\end{array}$ & $\begin{array}{l}\text { Water and } \\
\text { Heat Sink } \\
\text { Available } \\
\text { Ex-Vessel }\end{array}$ & $\begin{array}{l}\text { Ex-Vessel } \\
\text { Debris } \\
\text { Geometry } \\
\text { Coolable }\end{array}$ & Outcomes \\
\hline
\end{tabular}

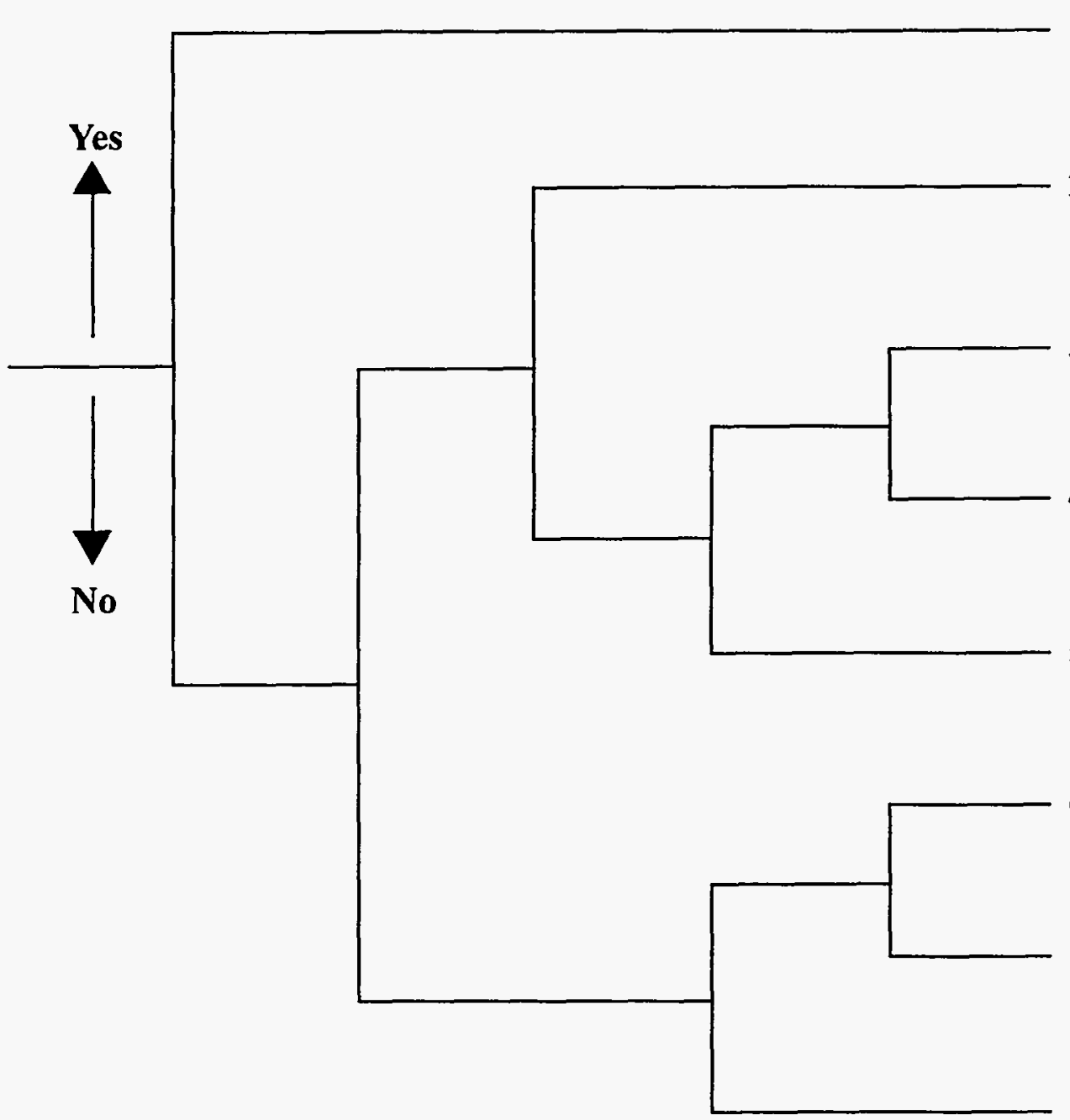

1. Gap Release Possible

2. Melt Release, Debris Contained in Vessel

3. Same as 6, Possible Difference in Timing

4. Same as 7, Possible Difference in Timing

5. Same as 8 , Possible Difference in Timing

6. Melt Release, RPV Failure, No CoreConcrete Interaction

7. Melt Release, RPV Failure, Delayed Core-Concrete Interaction

8. Melt Release, RPV Failure, CoreConcrete Interaction

Figure 3.1-12 Core damage event tree 


\section{References for Section 3.1}

1. R. M. Harrington and L. J. Ott, "The Effect of Small-Capacity, High-Pressure Injection Systems on TQUV Sequences at Browns Ferry Unit One," U.S. Nuclear Regulatory Commission, NUREG/CR-3179, ORNL/TM-8635, September 1983.

2. Hofman, et al., "Reactor Core Materials Interactions," Nuclear Technology, Volume 87, August $1989,147$.

3. F. E. Haskin, J. L. Darby, and W. B. Murfin, "Analysis of Hypothetical Severe Core Damage Accidents for the Zion Pressurized Water Reactor," U.S. Nuclear Regulatory Commission, NUREG/CR-1989, SAND81-0504, October 1982. 


\subsection{Core Uncovering and Heatup}

Core heatup begins when the water level drops below the top of the active fuel as a result of boiloff. Before this time fuel temperatures are close to the system saturation temperature because there is very little heat transfer resistance between the fuel and liquid reactor coolant. So long as fuel remains submerged, it is not expected to be damaged due to high temperature.

\subsubsection{Boiloff of Water in Core Region}

During the uncovering of the core, the fraction of the core decay power that is utilized to vaporize water is reduced as the water level decreases. To a first approximation, all of the decay heat generated in the water covered region results in evaporation, and the water level decreases exponentially with time. ${ }^{1}$ In a PWR, sustained core uncovering begins when the water level reaches the top of the active core, the exponentially decreasing water level depicted in Figure 3.2-1 follows from the equation

$$
L(t)=L(0) e^{-t / \tau}
$$

where

$L(t)=$ water level above bottom of active core region at time $t$ since the onset of core uncovering,

$L(0)=$ water level at the beginning of core uncovering, for a PWR this is the height of the active core region $Z(12$ $\mathrm{ft}$ ),

$t=$ time since onset of core uncovering, and $\tau=$ time constant for boiloff in core region, which is given by the equation

$$
\tau=\frac{\rho A Z h_{f g}}{P_{D}}
$$

with

$\rho=$ liquid density,

$A=$ cross-sectional area of liquid in active core region,

$h_{f g}=$ the energy required to evaporate a unit mass of saturated liquid, that is, the latent heat of vaporization, which decreases with increasing reactor coolant system pressure,

$P_{D}=$ core decay power (approximated as constant during boiloff of water in the core region).

Given the exponentially decreasing water level associated with boiloff in the core region, it takes one time constant for the water level to decrease by a factor of $e$ (from 12 to $4.4 \mathrm{ft}$ ) and another time constant for the water level to decrease by another factor of $e$ (from $4.4 \mathrm{ft}$ to $1.6 \mathrm{ft}$ ). It should be noted that the time constant for boiloff in the core region, $\tau$, varies with the reactor coolant system pressure since both the density $\rho$ and latent heat of vaporization $h_{\mathrm{fg}}$ vary with saturation pressure. Figure 3.2-2 depicts the change in $\tau$ with pressure for the Zion PWR at the decay power (32.5 MW) used in the following example. The total time duration for Stage 2, core uncovering and heatup, is approximately $2 \tau$ or, as noted in Table 3.1-1, 5 to 35 minutes depending on the reactor coolant system pressure. 


\section{Example 3.2-1 - Time Required for Boiloff in Core Region}

In the Zion station blackout accident sequence, steam is discharged from the primary system at the relief valve set point of 2500 psig. $^{2}$ The active core height is $12 \mathrm{ft}$ The area of the core occupied by water is $53.4 \mathrm{ft}^{2}$. The core decay power during boiloff is approximately $32.5 \mathrm{MW}$. Estimate the time required for the water level to decrease from the top of the active core to the core midplane.

\section{Solution:}

Solving Eq. (3.2-1) for $t$ and using Eq. (3.2-2) for $\tau$ gives

$$
t=\frac{\rho A Z h_{f g}}{P_{D}} \ln \left(\frac{L(0)}{L(t)}\right)
$$

From the steam tables, for saturated water at $2515 \mathrm{psia}$,

$$
\begin{aligned}
h_{f g} & =357.0 \mathrm{Btu} / \mathrm{lbm} \\
\rho & =34.83 \mathrm{lbm} / \mathrm{ft}^{3}
\end{aligned}
$$

Substituting:

$$
t=\frac{\left(34.83 \frac{l b m}{f t^{3}}\right)\left(53.4 f^{2}\right)(12 f t)\left(357.0 \frac{B t u}{l b m}\right)}{\left(32.5 \frac{J}{s}\right)\left(\frac{B t u}{1055 J}\right)} \ln \left(\frac{12}{6}\right)
$$

$$
t=258.7 \ln (2) s=179.3 s=2.99 \mathrm{~min}
$$


A detailed treatment of the axial power distribution, local heat transfer, two-phase mixture dynamics, and coupling with the rest of the reactor coolant system requires the use of complex computer models. Figure 3.2-3 compares the predictions based on Eq. 3.2-1 with code calculations for a Zion station blackout scenario compounded by failure of turbine-driven auxiliary feedwater (the so-called TMLB scenario). ${ }^{3}$ As indicated by the comparison, the exponentially decreasing function defined by Equations $3.2-1$ and $3.2-2$ is a reasonable approximation for the water level in the core region during this stage of the accident. This approximation is valid for about two time constants, which corresponds roughly to the onset of the next stage. Beyond this point heat transfer from the uncovered region of the core to the residual water must be considered.

\subsubsection{Initial Heatup of Uncovered Fuel}

Because of low vapor flow rates, the cooling of fuel in the uncovered part of the core by the flow of steam generated during PWR boiloff is relatively ineffective. The temperature rise in the uncovered fuel during the boiloff and initial core heatup stage can, therefore, be approximated as an adiabatic absorption of fission-product decay energy. Using this approximation, the temperature $T(z, t)$ at uncovered elevation $z$ and time $t$ is

$$
T(z, t)=T(z, 0)+\frac{Z P_{l}(z)}{m C_{l}}\left(t-t_{l=2}\right)
$$

where

$Z \quad=$ height of active core region ( $\mathrm{ft}$ ) $m C_{P}=$ heat capacity of entire core, $\mathrm{J} / \mathrm{K}$ $\left(\mathrm{Btu} /{ }^{\circ} \mathrm{F}\right)$,

$P_{D}(\mathrm{z})=$ decay power per unit axial height at $z$ above bottom of active core, $\mathrm{MW} / \mathrm{ft}$

$t_{l, z}=$ time at which the water level in the core region equals $z$, seconds

Figure 3.2-3 compares the results of an adiabatic heatup calculation with code calculated core temperatures. The difference between the fuel temperature and the residual (saturated) water temperature is read on the horizontal axis. The axial position in the core is read on the vertical axis. Curves are shown for three successive times. The times are measured from the point when the water level reaches the top of the active fuel and divided by the characteristic boiloff time constant defined in Equation 3.2-2. The lower intercept of a curve with the vertical axis indicates the water level at that time. The adiabatic heatup approximation appears reasonable based on the comparisons with code calculations. This merely indicates that during this stage the temperature rises in the uncovered regions of the core are determined almost entirely by distribution of decay heat in the core. For a PWR at high pressure the saturation temperature would be about 650 ${ }^{\circ} \mathrm{F}$, and the peak temperature $\left(650+1080=1730^{\circ} \mathrm{F}\right)$ with $t / \tau=1.58$ would be approaching the $1832^{\circ} \mathrm{F}\left(1000^{\circ} \mathrm{C}\right)$ criterion for the onset of the next stage.

The simplifying assumptions used to develop the analytic approximations presented above break down near the start of the next stage, cladding oxidation, which occurs when the peak fuel temperature reaches about $1832^{\circ} \mathrm{F}$ $\left(1000^{\circ} \mathrm{C}\right.$ or $\left.1273 \mathrm{~K}\right)$. 


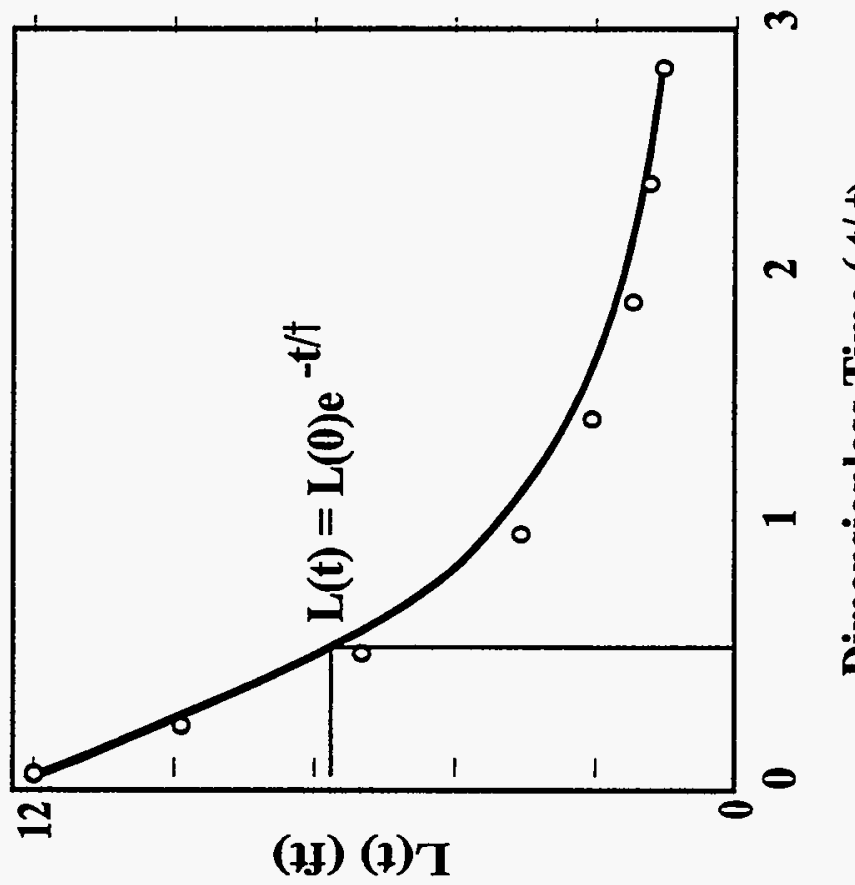

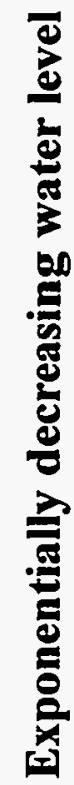

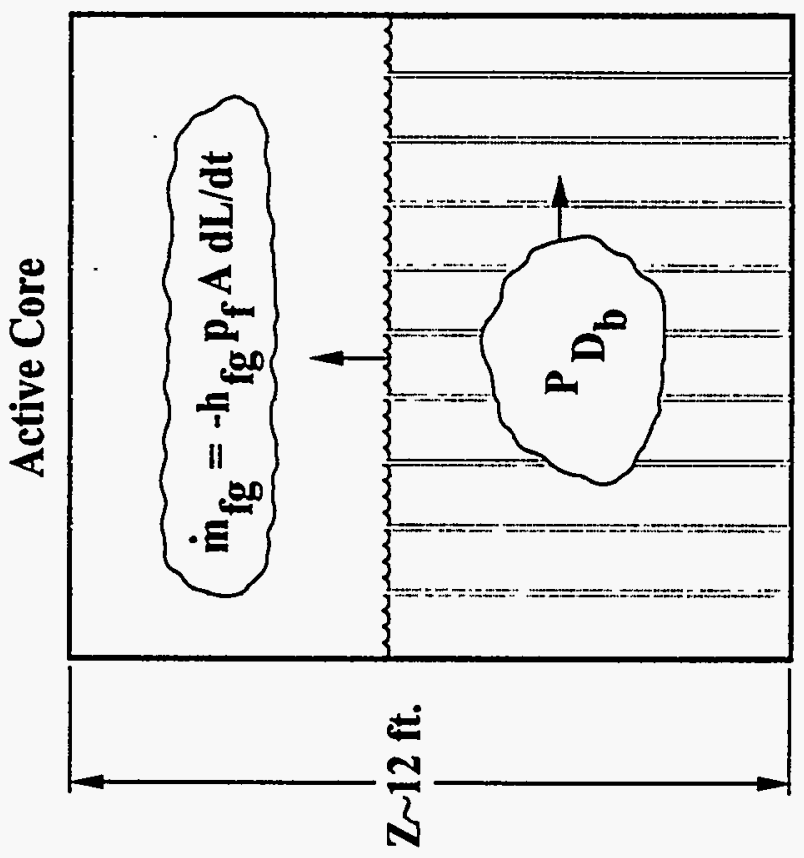

ำ 


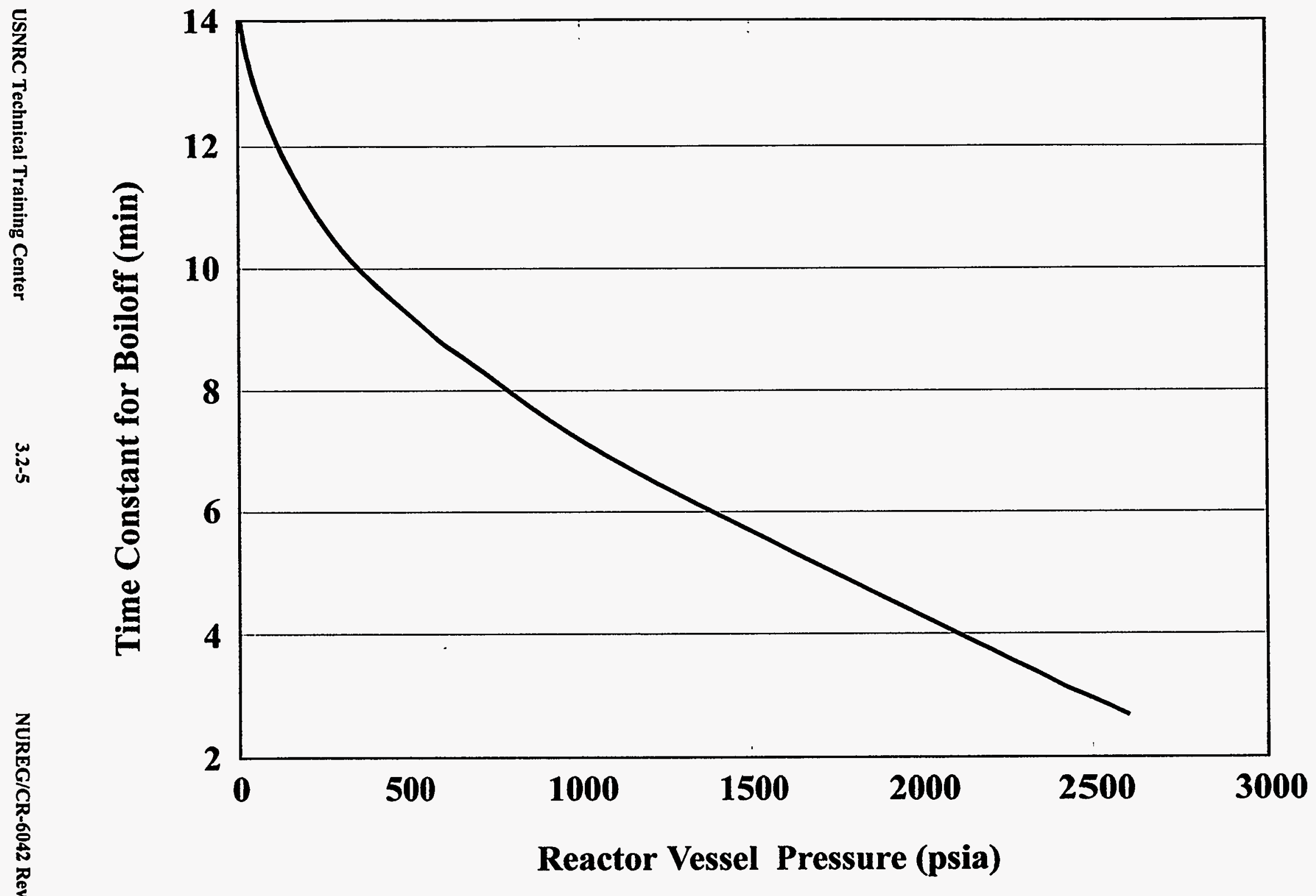

Figure 3.2-2 Variation of boiloff time constant with saturation pressure 


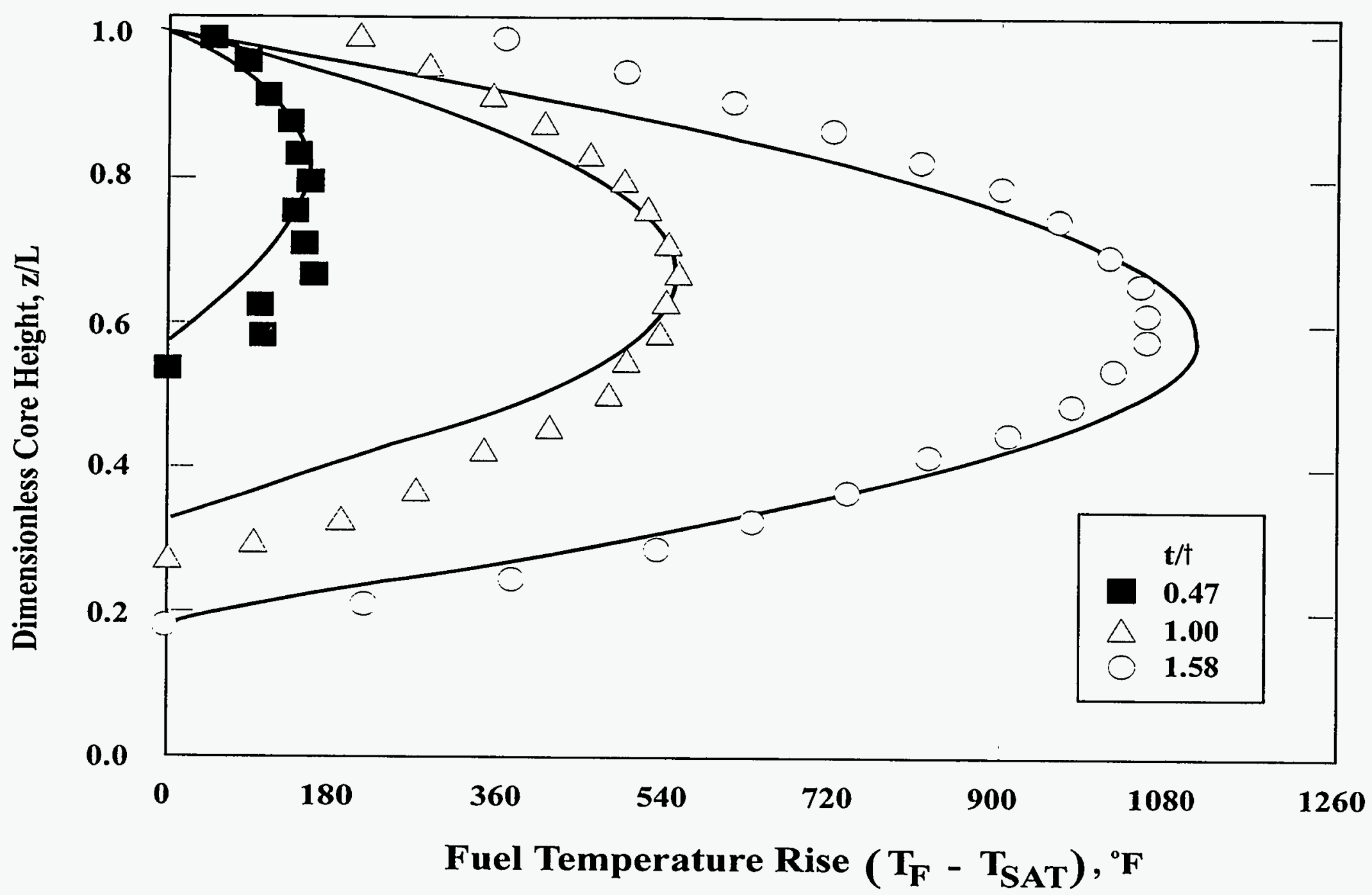

Figure 3.2-3 Approximate calculation of fuel temperature rise (curves) at three different times compared with code results 


\section{References for Section $\mathbf{3 . 2}$}

1. J. B. Rivard and F. E. Haskin, "LWR Meltdown Analyses and Uncertainties," ANS/ENS Topical Meeting on Reactor Safety Aspects of Fuel Behavior, Sun Valley, Idaho, August 2-6, 1981.

2. F. Eric Haskin, Walter B. Murfin, Joseph B. Rivard, and John L. Darby, "Analysis of a Hypothetical Core Meltdown Accident Initiated by Loss of Offsite Power for the Zion 1 Pressurized Water
Reactor," U.S. Nuclear Regulatory Commission, NUREG/CR-1988, SAND81-0503, November 1981.

3. J. B. Rivard, et al., "Interim Technical Assessment of the MARCH Code," U.S. Nuclear Regulatory Commission, NUREG/CR-2285, SAND81-1672, February 1981. 


\subsection{Cladding Oxidation}

The start of Stage 3 (Table 3.1-1) is marked by the initiation of significant cladding oxidation, which occurs when the peak fuel temperature reaches about $1832{ }^{\circ} \mathrm{F}$ (1000 $\left.{ }^{\circ} \mathrm{C}\right) .{ }^{1}$ The chemical reaction is

$$
\mathrm{Zr}+2 \mathrm{H}_{2} \mathrm{O} \rightarrow \mathrm{ZrO}_{2}+2 \mathrm{H}_{2}
$$

This reaction is particularly important because it is highly exothermic (approximately $6.5 \mathrm{MJ} / \mathrm{kg}\left(280 \mathrm{Btu} / \mathrm{lb}_{\mathrm{m}}\right)$ of $\mathrm{Zr}$ reacted), the reaction rate increases strongly with cladding temperature, and the noncondensible gaseous reaction product is hydrogen.

\subsubsection{Reaction Kinetics}

A considerable amount of data on oxidationreaction kinetics exists. If adequate steam is available, it is generally believed that the reaction is limited by oxygen diffusion through the $\mathrm{ZrO}_{2}$ film and the underlying metal. In this case, the reaction rate is governed by parabolic kinetics; that is, $W^{2}=k t$ where $W$ is the weight of metal reacted, $t$ is the time, and $k$ is the rate constant, which increases exponentially with temperature. The following equation can be used to estimate the mass of $\mathrm{Zr}$ oxidized at a particular temperature in a steam environment as a function of time

$$
W_{Z r}=\sqrt{A t e^{-B / R T}}
$$

where,

$\begin{aligned} W_{\mathrm{zr}}= & \text { mass of } \mathrm{Zr} \text { oxidized per unit area } \\ & \text { exposed to steam, } \mathrm{kg}_{\mathrm{Zr}} / \mathrm{m}^{2}\left(\mathrm{lb}_{\mathrm{m}, \mathrm{zr}} / \mathrm{ft}^{2}\right)\end{aligned}$

$t=$ exposure time, $\mathrm{s}$
$T=$ temperature of surface, $\mathrm{K},\left({ }^{\circ} \mathrm{R}\right)$

$R=$ universal gas constant, $8314.29 \mathrm{~J} /(\mathrm{kg}-$ mole $\cdot \mathrm{K})$. (1.98583 Btu/lb-mole/ $\left.{ }^{\circ} \mathrm{R}\right)$

Correlations with experimental data have provided several alternative estimates of the empirical constants $A$ and $B .^{2,3,4}$ The values obtained by Cathcart are

$$
\begin{aligned}
A= & 294 \mathrm{~kg}^{2} /\left(\mathrm{s} \cdot \mathrm{m}^{4}\right)\left(12.3 \mathrm{lb}_{\mathrm{m}}^{2} / \mathrm{ft}^{4} / \mathrm{s}\right) \\
B= & 1.672 \times 10^{8} \mathrm{~J} / \mathrm{kg}-\text { mole }\left(7.195 \times 10^{4}\right. \\
& \text { Btu/lb-mole }) .
\end{aligned}
$$

Figure 3.3-1 shows the mass of hydrogen produced as a function of time for several temperatures. Figure 3.3-2 shows the mass $\mathrm{Zr}$ oxidized in 5 minutes at constant temperature as a function of temperature for surface area of $5400 \mathrm{~m}^{2}(58000 \mathrm{ft})$, corresponding to a PWR core.

\subsubsection{Oxidation Front}

The preceding isothermal example is not realistic because the exothermic energy associated with the oxidation reaction would actually cause the cladding and fuel temperatures to increase rapidly. Reaction energy is removed from the surface by hydrogen and by inward and axial transfer to the metal substrate and then to the fuel. When the reaction zone attains temperatures above about $2420^{\circ} \mathrm{F}\left(1327^{\circ} \mathrm{C}=1600 \mathrm{~K}\right)$, the oxidation rate becomes so large that nearly all the available steam is reacted for typical boiloff sequences. This condition is referred to as steam limiting because the oxidation rate is limited by the amount of steam available to react with the cladding. 


\section{Example 3.3-1: Hydrogen Production Rate}

a. What is the hydrogen production per unit surface area of $\mathrm{Zr}$ after 5 minutes exposure to steam at $2192^{\circ} \mathrm{F}\left(1200^{\circ} \mathrm{C}\right)$ ?

b. If all of the cladding $\left(5400 \mathrm{~m}^{2}, 26,940 \mathrm{lbm}\right)$ in the Zion PWR were exposed to such an environment in a severe accident, how much hydrogen $(\mathrm{kg})$ would be produced?

c. Estimate the total energy release.

\section{Solution:}

a. Substituting into $\mathrm{Eq}(3.3-2)$ gives

$$
\begin{gathered}
W_{Z r}=\sqrt{\frac{294\left(\mathrm{~kg}_{\mathrm{Zr}}\right)^{2}}{\mathrm{~m}^{4} \cdot \mathrm{s}}\left|\frac{5 \mathrm{~min}}{\mathrm{~min}}\right| \frac{60 \mathrm{~s}}{\min } \exp \left(\frac{-1.672 \times 10^{8} \mathrm{~J}}{\mathrm{~kg}-\mathrm{mole}}\left|\frac{\mathrm{kg}-\mathrm{mole} \cdot \mathrm{K}}{8314.29 \mathrm{~J}}\right| \frac{1}{1473.15 \mathrm{~K}}\right)} \\
W_{Z r}=0.322 \mathrm{~kg} / \mathrm{m}^{2}
\end{gathered}
$$

Multiplying $W_{z r}$ by the surface area of $5400 \mathrm{~m}^{2}$ gives the mass of $\mathrm{Zr}$ that could be oxidized according to the parabolic kinetics:

$$
m_{Z r} \leq \frac{0.322 \mathrm{~kg} \mathrm{Zr}}{\mathrm{m}^{2}} \mid \frac{5400 \mathrm{~m}^{2}}{}=1,740 \mathrm{~kg} \mathrm{Zr}=3.83 \times 10^{3} \mathrm{lb}_{\mathrm{m}} \mathrm{Zr}
$$

This is $14.2 \%$ of the $26,940 \mathrm{lbm} \mathrm{Zr}$ present.

b. By Equation (3.3-1), two moles of hydrogen are produced per mole of $\mathrm{Zr}$ reacted; hence, the number of moles of hydrogen released is

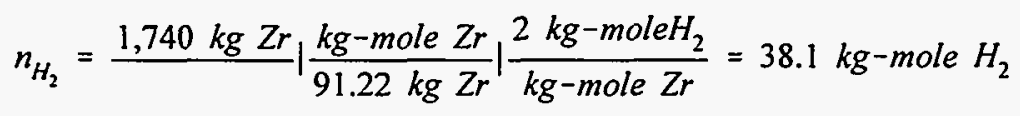

The corresponding mass of hydrogen is

$$
m_{H_{2}}=\frac{38.1 \mathrm{~kg}-\text { mole } \mathrm{H}_{2}}{\mid \frac{2.016 \mathrm{~kg}-\mathrm{H}_{2}}{\mathrm{~kg}-\text { mole } \mathrm{H}_{2}}=76.9 \mathrm{~kg} \mathrm{H}}
$$

c. The total energy released is estimated as the mass of $\mathrm{Zr}$ reacted times $6.5 \mathrm{MJ} / \mathrm{kg}$.

$$
\Delta h_{r n n} \approx \frac{1,740 \mathrm{~kg} \mathrm{Zr}}{\mid}\left|\frac{6.5 \mathrm{MJ}}{\mathrm{kg} \mathrm{Zr}}\right| \frac{\mathrm{GJ}}{10^{3} \mathrm{MJ}}=11.3 \mathrm{GJ}
$$


Figure 3.3-3 illustrates a calculation of the thermal behavior of fuel during the oxidation stage of core degradation. ${ }^{5}$ The calculation is one dimensional, and does not account for the natural-circulation flow discussed later (see 3.3.5). Significant oxidation occurs first near the location of maximum axial power. As oxidation continues, a sharp temperature profile develops, reflecting a distinct oxidation front. Oxidation increases rapidly near the front and then decreases with elevation due to steam depletion. The relatively short 5 minute duration in Table 3.1-1 for Stage 3 is based on calculations that indicate average temperature rise rates in excess of $3.6^{\circ} \mathrm{F} / \mathrm{s}(2 \mathrm{~K} / \mathrm{s})$ in regions undergoing vigorous oxidation. ${ }^{5}$

Figures 3.3-4 and 3.3-5 illustrate the potential contribution of the zirconium oxidation energy to the overall energy release rate in the core region, as a function of oxidation temperature. Decay heat transfer to residual saturated water below the uncovered portion of the core results in a steam production rate that is proportional to the below-water portion of the decay heat power, $P_{D b}$. As indicated in Figure 3.3-5, at sufficiently low peak cladding temperature, the energy release rate due to oxidation is negligible compared to that due to decay power. However, as the cladding temperature in the uncovered core region increases to about $1832{ }^{\circ} \mathrm{F}\left(1000^{\circ} \mathrm{C}=1273\right.$ $\mathrm{K})$, more and more of the vapor generated by evaporation of residual water participates in the zirconium oxidation reaction. At sufficiently high cladding temperatures, virtually all of the resulting vapor could participate in the zirconium oxidation reaction. In this so-called steam limited condition, the energy $h_{f k}$ consumed in evaporating a unit mass of residual water would result in an energy release in the oxidation reaction of $\Delta h_{r x n}$ (normalized to a unit mass of steam). Therefore, the ratio of the energy release rate by the oxidation reaction to the decay power released below the water level, $P_{\text {oxrdatuon }} / P_{D b}$, would at least equal $\Delta h_{r x t} / h_{f k}$. As indicated in Figure 3.3-5, this ratio varies from 6.3 at atmospheric pressure to 19 at 2500 psig. Even if $P_{D b}$ were just $1 / 20$ of the total decay heat power, the oxidation energy could be comparable to the decay heat power during Stage 3 .

The preceding argument ignores energy transfer (including that associated with movement of debris) from the hot, uncovered core region downward to the residual water. As indicated in Figure 3.3-4, each unit of energy that is transferred downward to the saturated residual water results in the production of additional steam to fuel the oxidation reaction. With significant feedback, for example due to radiative heat transfer from the hot reaction zone to the residual water, the energy release rate from oxidation can easily and substantially exceed that from decay heat power. The acceleration of energy release rates from Zircaloy oxidation with temperature, which is illustrated by Figure 3.3-5, has been observed experimentally.

\subsubsection{Core Damage Due to Oxidation}

Clad melting is excluded during Stage 3, which is by definition (Table 3.1-1) limited to temperatures of $3350^{\circ} \mathrm{F}\left(1843^{\circ} \mathrm{C}=1570\right.$ $\mathrm{K})$ or less. Nevertheless, several types of cladding damage can occur during Stage 3. The cladding is simultaneously subjected to thermal transients and, particularly if the reactor coolant system is depressurized, to stresses resulting from increased internal pressure of the initial fill gases and fission gases. At low reactor coolant system pressures, ballooning of the cladding is expected prior to rupture. The temperature and pressure at which ballooned Zircaloy-4 cladding bursts in a steam environment has 
been studied, and it has been found that, even at low (initial) internal pressures, cladding usually bursts at temperatures below $2192^{\circ} \mathrm{F}\left(1200^{\circ} \mathrm{C}=1473 \mathrm{~K}\right)^{6}$

Zirconium-burning tests result in clouds of smoke issuing from the test chamber, indicating that large quantities of aerosols may be generated during the oxidation. ${ }^{7}$ Such aerosols may have a tendency to accelerate the plateout of fission products within the reactor coolant system.

Embrittlement and spallation of $\mathrm{ZrO}_{2}$ from the surface of the cladding as oxidation proceeds may weaken the fuel rods, expose more fresh zirconium metal, and/or produce debris with the potential for blocking coolant flow channels. Increases in the cladding surface area exposed to steam can increase the oxidation rate if the reaction is not already steam starved.

Because low-melting-point silver-indiumcadmium alloys are often employed in PWR control rods, the possibility exists for formation of significant molten quantities of these materials at the temperatures attained during Stage 2. It is uncertain when, and how coherently, such melts might move through the core region, before contacting residual water or core support structures.

For BWRs, special accident management guidelines (procedures) are in place to both delay the onset of rapid zirconium oxidation and limit its extent once initiated. These special measures are discussed in Section 3.7.2.

\subsubsection{Reflooding During Stage 3}

During a normal boiloff, mechanisms for transferring energy from uncovered fuel to residual water are limited principally to radiative heat transfer. On the other hand, if water is reintroduced to the core zone (reflooding) during the oxidation (Stage 3), the core-damage processes may initially be accelerated (and the rate of hydrogen generation increased) due to cladding oxidation by the additional steam generated during the cooling of overheated fuel. Considerable fracturing of cladding embrittled during oxidation is expected during reflood. This may lead to the formation of fairly coarse rubble (fractured cladding, fuel, and control materials) in some regions of the core. Such rubble formation occurred in the upper portion of the TMI-2 core as a result of the temporary restart of reactor coolant pump 2B (see section 3.4.4). It is likely that the rubble beds formed would be coolable and, given a contiuous supply of coolant injection, the accident would be terminated during this stage. (At TMI-2 coolant was not permanently restored until the accident had progressed beyond Stage 3, yet the debris was ultimately cooled in-vessel.) However, cooling of a reflooded core that has undergone severe damage would have to be maintained long-term. Additional aspects of rubble-bed cooling are discussed in Section 3.5.

\subsubsection{Natural Circulation During Core Degradation}

In PWR accidents in which the reactor coolant system is not depressurized as the core heats up, gas movement in the uncovered core and upper head regions begins to be driven by natural convection (buoyancy forces). ${ }^{8}$ Heat and mass transfer from the core to the reactor coolant system structures are dominated by buoyancy-driven components of the flow field. Steam from the boiloff of residual in-vessel water and hydrogen from oxidation of fuel cladding rise from the hot central core region and lose heat and entrained fission products to 
relatively colder structures above the core. As depicted in Figure 3.3-6, the cooled gases recirculate downward through the colder regions of the uncovered core and are reheated again by flowing up through the hot central core region.

In BWRs, the fuel channels which enclose the rods of individual fuel assemblies impede in-core natural circulation. However, if the residual water level falls below the bottom of the BWR downcomer region while fuel is still heating up in the core region, a strong natural convection loop can be established from the core to the steam separators and dryers with return to the core inlet via the downcomers. This is depicted in Figure 3.3-7.

As indicated in Figure 3.3-8, the strength of steel decreases rapidly above $1000^{\circ} \mathrm{F}(538$ $\left.{ }^{\circ} \mathrm{C}\right)$. For some high-pressure PWR accidents, it has been suggested that the natural circulation flows in PWRs could transfer sufficient heat to the reactor coolant system pressure boundary to result in relatively early temperature-induced failures of the reactor coolant system pressure boundary.' The resulting depressurization of the primary system would alter the thermal-hydraulic progression of the accident. In particular, depressurization would preclude the potentially severe ramifications associated with high-pressure ejection of melt into the containment (see Section 3.5). It should be noted, however, that early temperatureinduced failure did not occur at TMI-2. Nevertheless, codes capable of modeling natural circulation are currently being exercised in attempts to investigate the likelihood of such early temperature-induced failures in various PWR severe accident scenarios. 
$\mathrm{H}_{2}$ Production

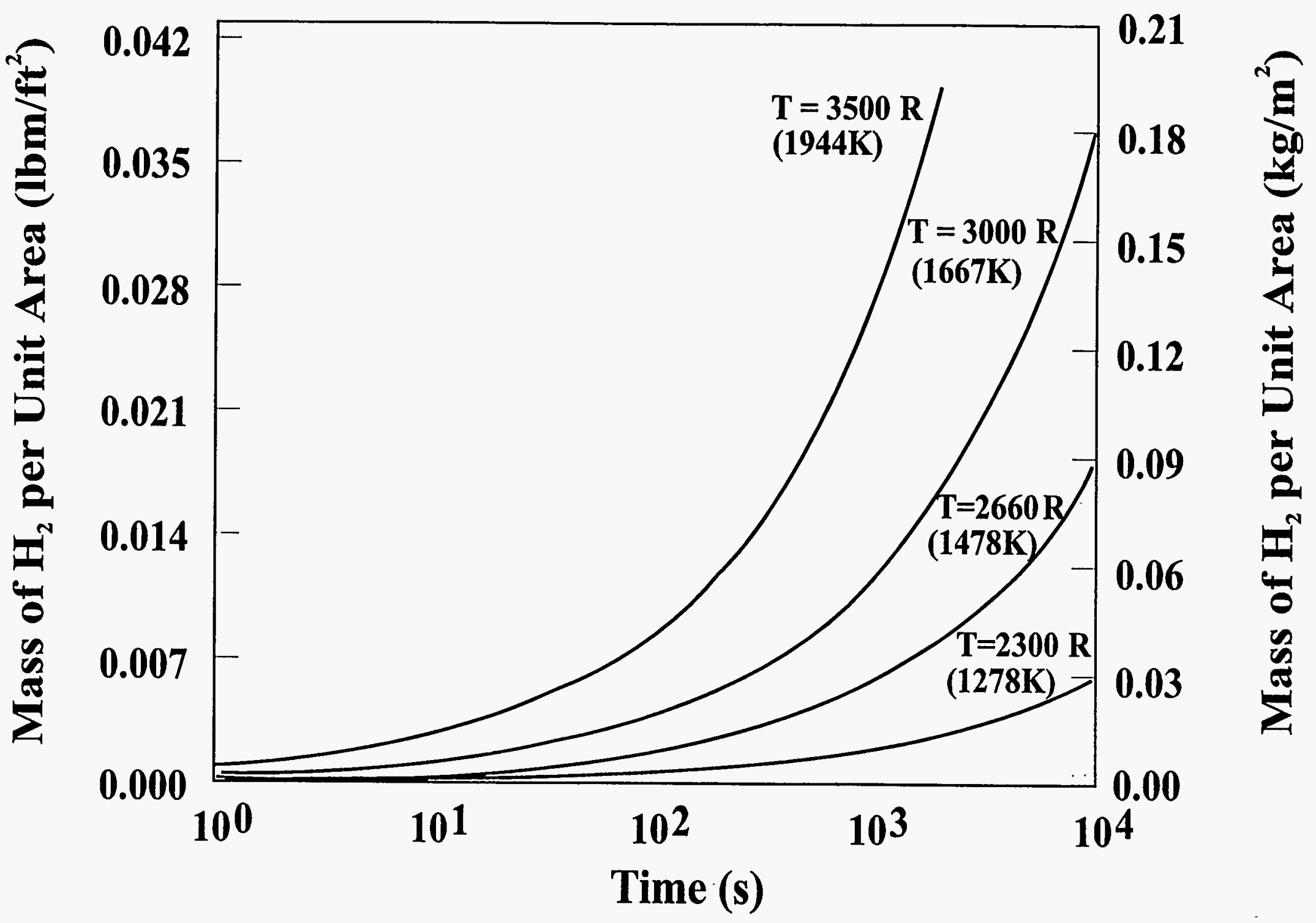

Figure 3.3-1 Hydrogen production per unit area from the $\mathrm{Zr}: \mathrm{H}_{2} \mathrm{O}$ reaction 


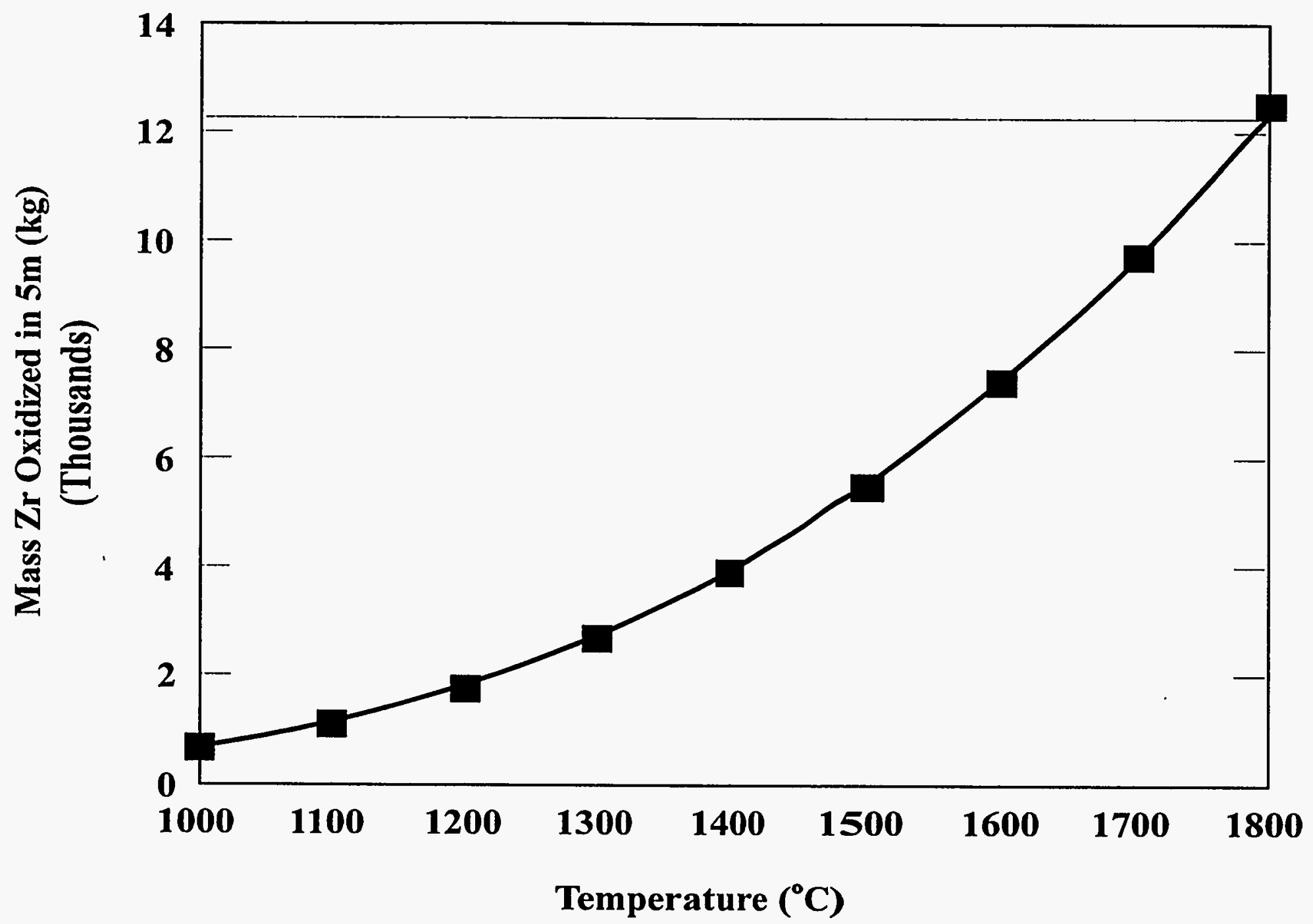

Figure 3.3-2 Mass of Zr oxidized in 5 minutes exposure of 5400 square meters Zircaloy 
Core Height, $\mathrm{z}$ (ft)

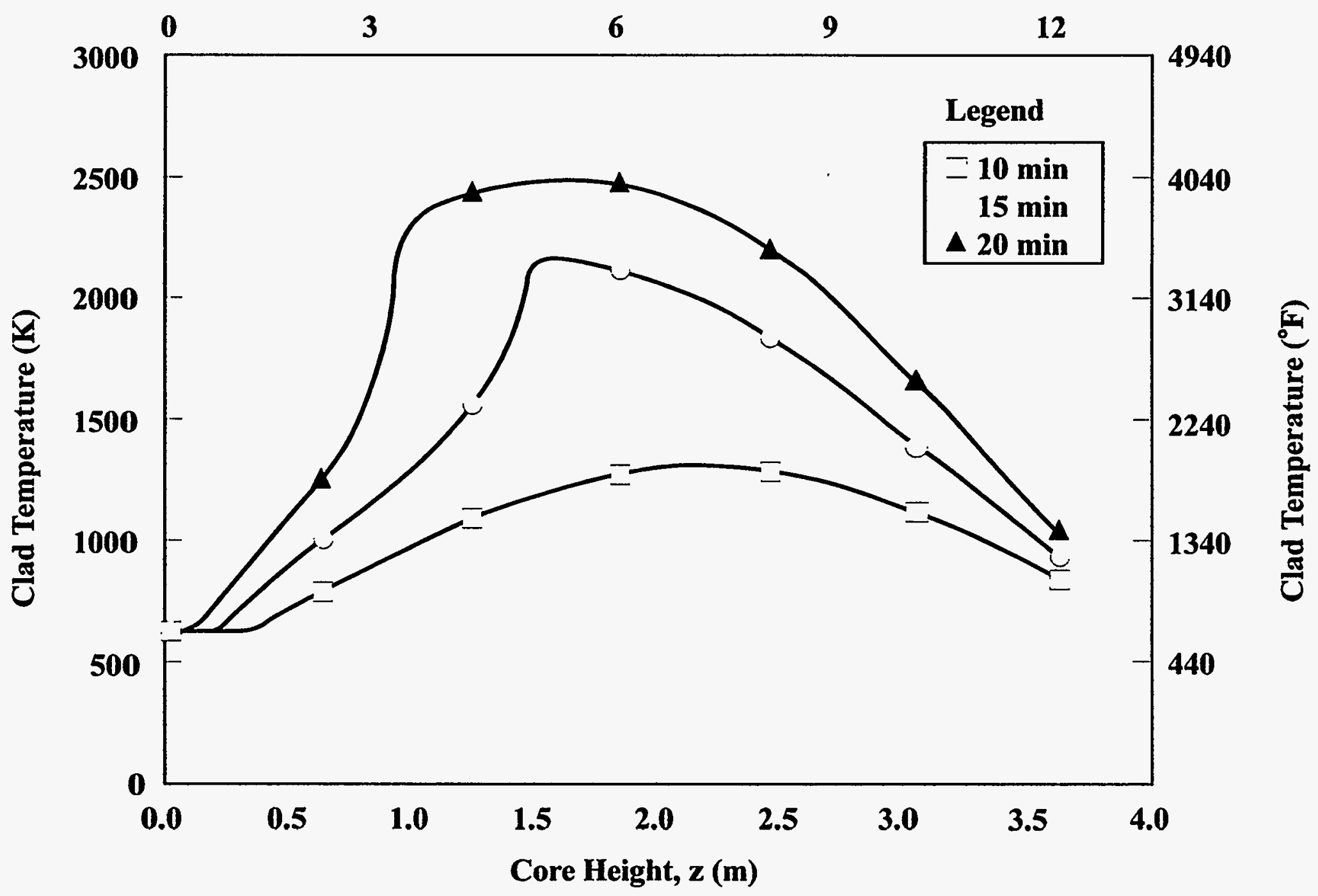

Figure 3.3-3 Calculated axial cladding temperatures at three different times following start of core uncovering for a PWR station blackout 


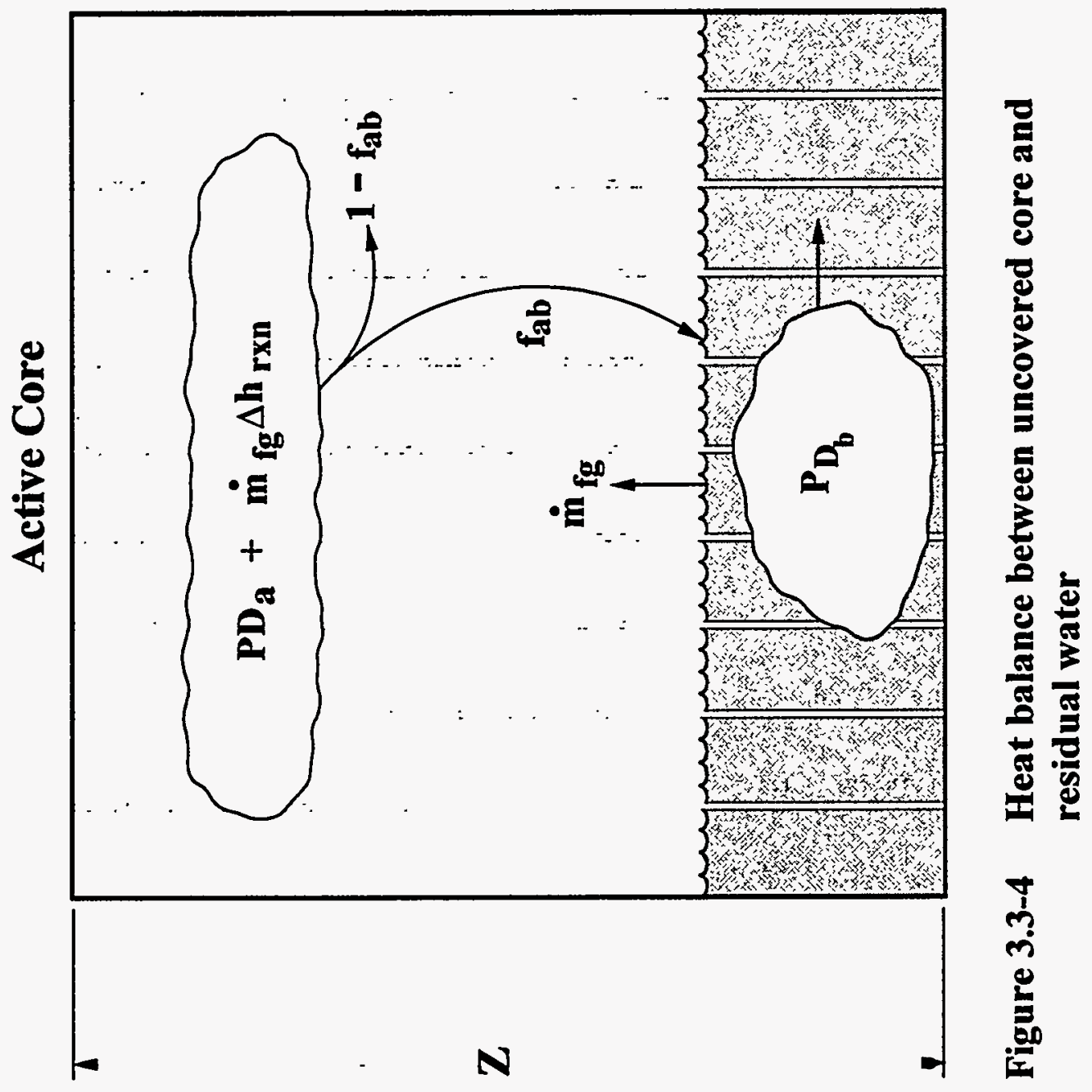




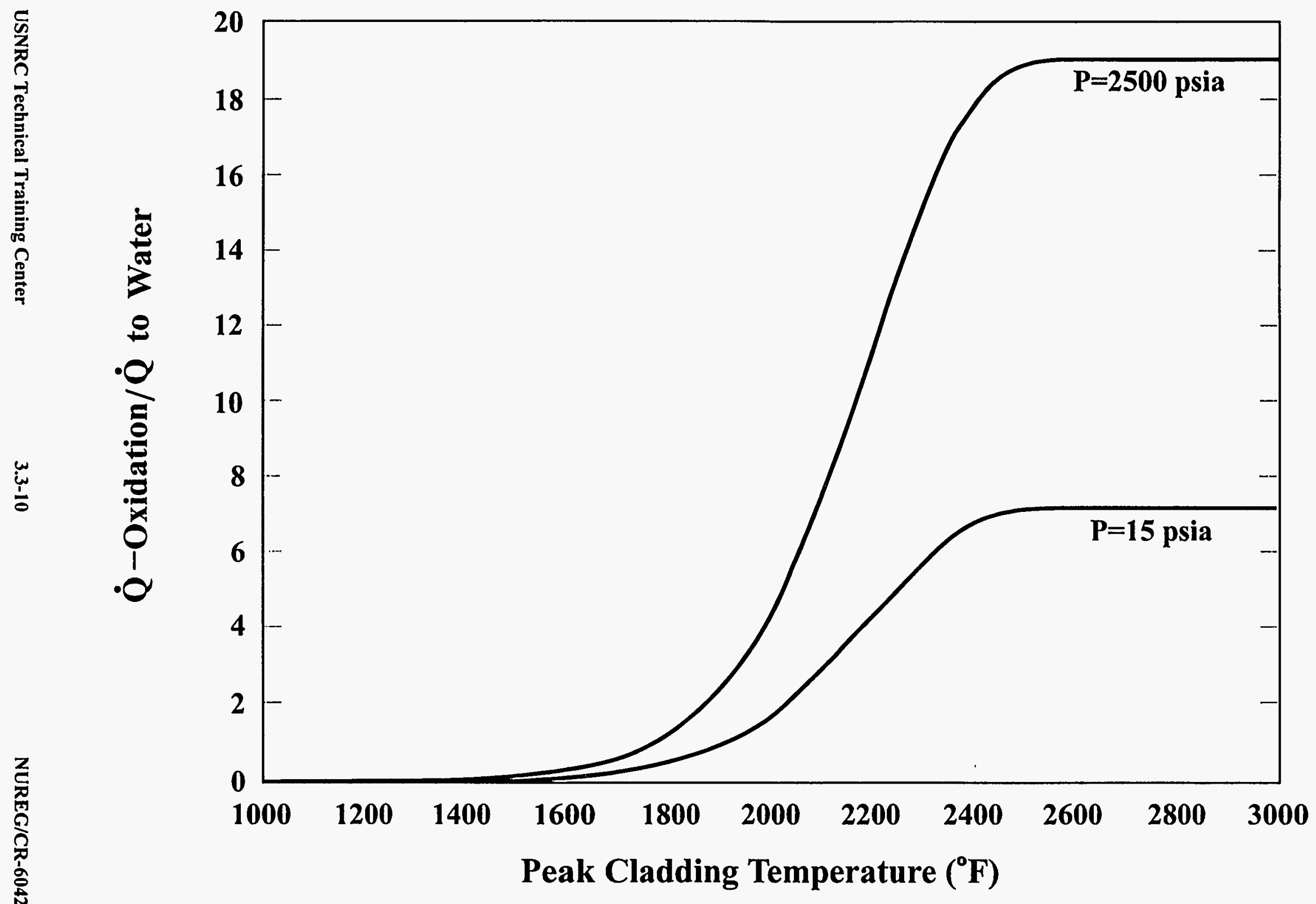

Figure 3.3-5 Ratio of heat release rate via oxidation to heat transfer rate to residual saturated water 


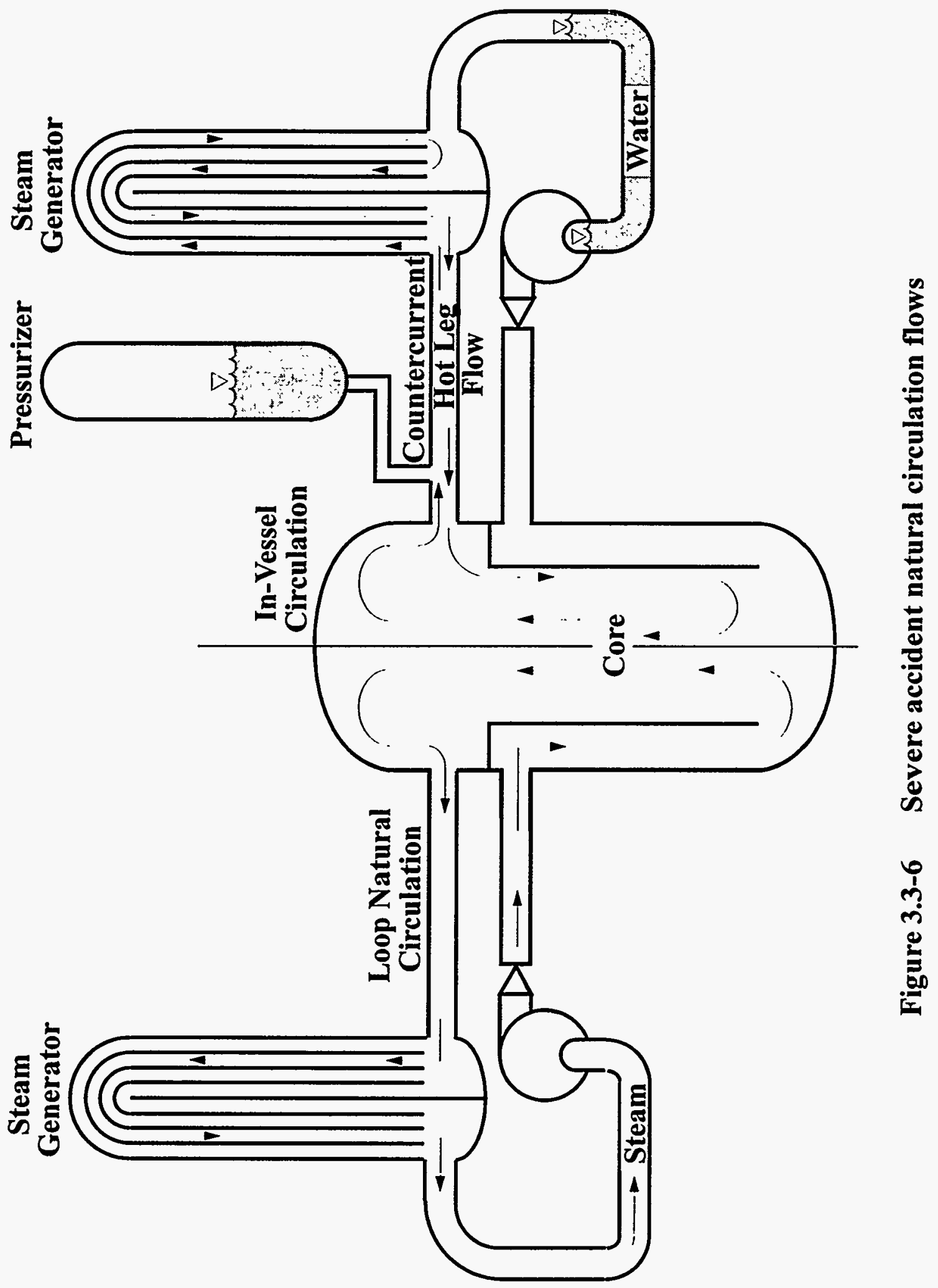




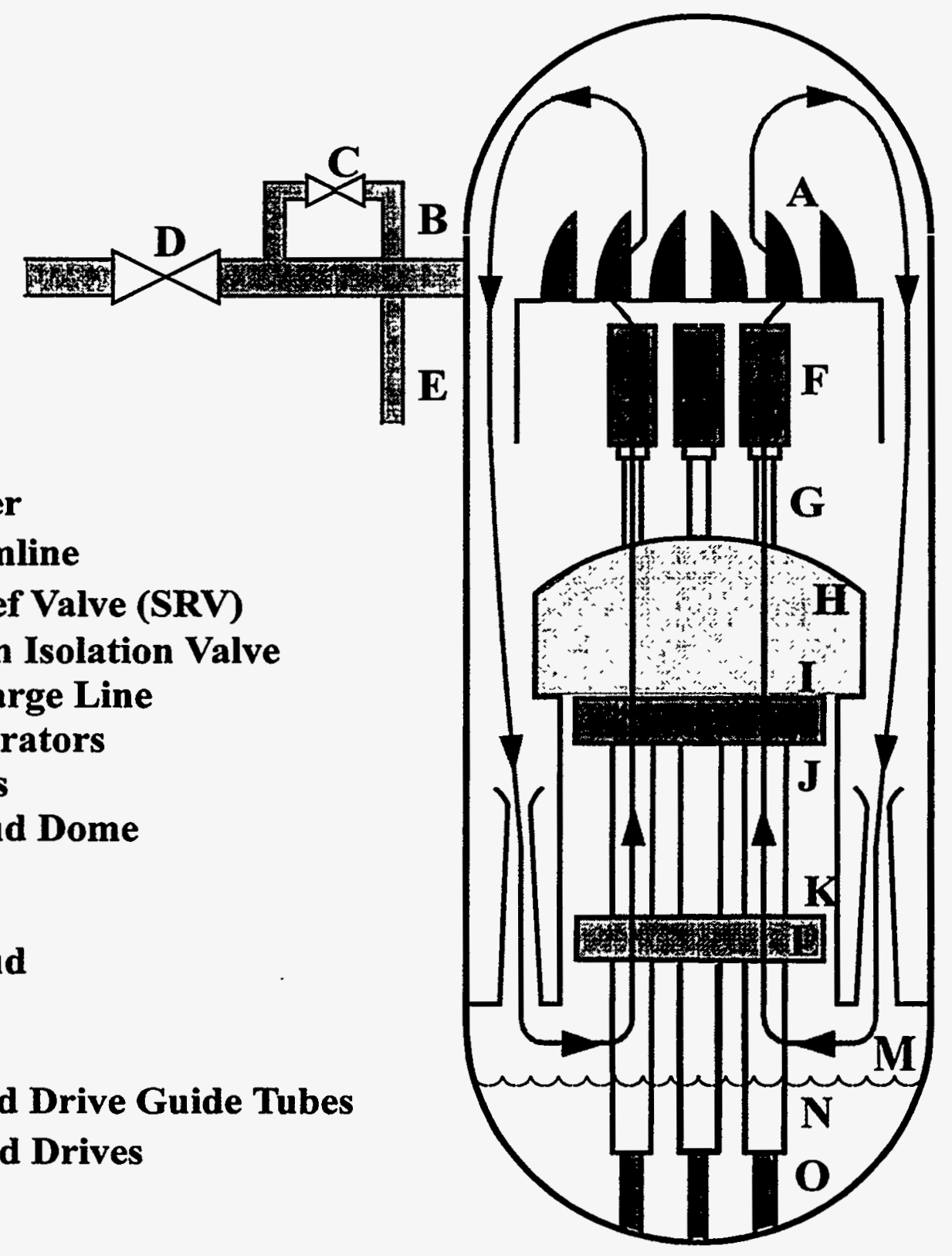

Figure 3.3-7 Schematic diagram of a BWR with internal circulation 


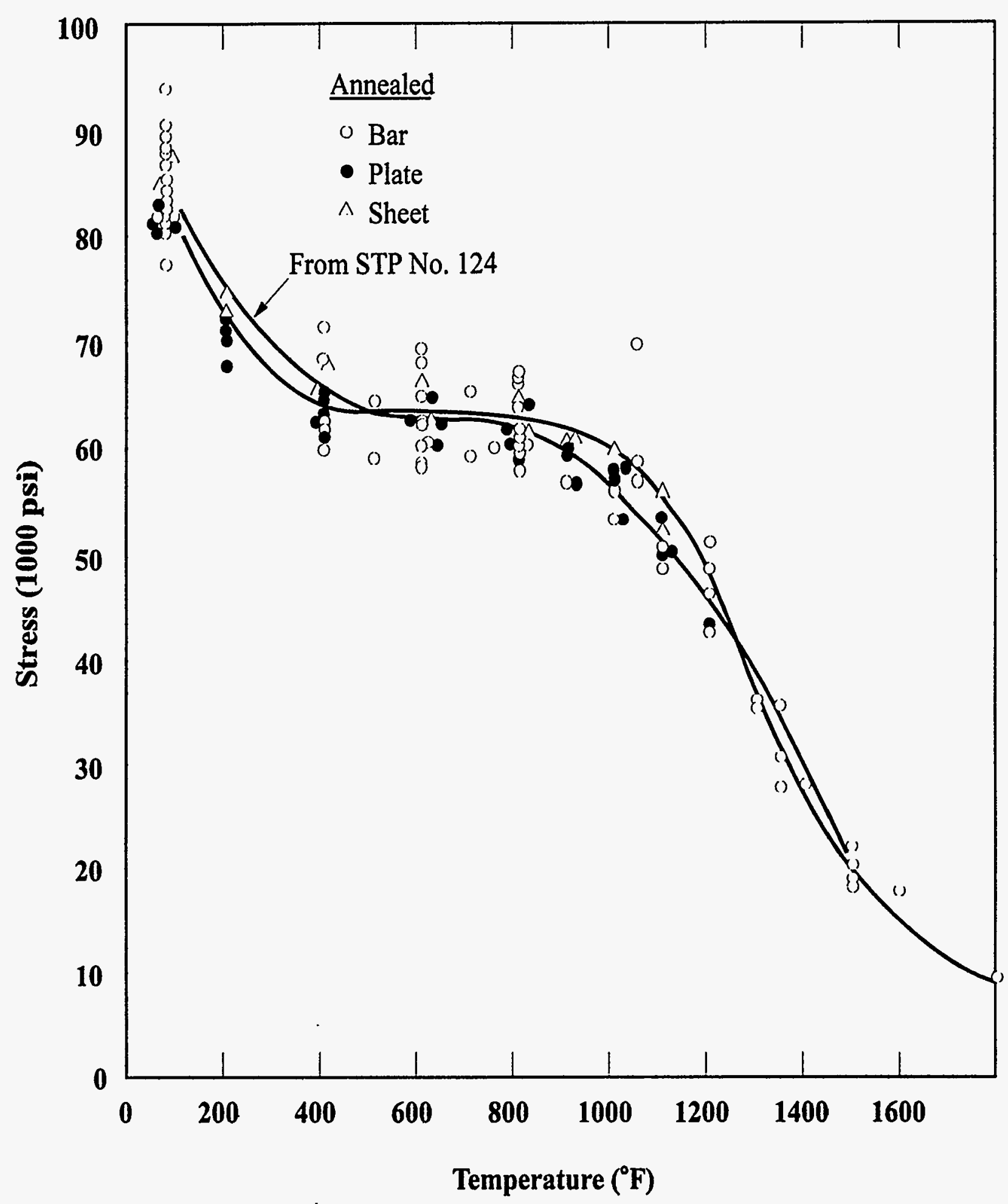

Figure 3.3-8 Tensile strength, type 304 stainless steel 


\section{References for Section 3.3}

1. L. Baker, Jr., and R. O. Ivins, "Analyzing the Effects of a Zirconium-Water Reaction," Nucleonics, 23, 7, p. 70, 1965.

2. L. Baker, Jr. and L. C. Just, "Studies of Metal-Water Reactions at High Temperatures III," ANL-6548, Argonne National Laboratory, Argonne, Illinois, 1962.

3. J. V. Cathcart, et al., "Zirconium MetalWater Oxidation Kinetics IV, Reaction Rate Studies," ORNL/NUREG-17, Oak Ridge National Laboratory, Oak Ridge, Tennessee, August 1977.

4. V. F. Urbanic and T. R. Heidrick, "High Temperature Oxidation of Zircaloy-2 and Zircaloy-4 in Steam," $J$ Nucl Materials, 75(2):251-61, 1978.

5. F. Briscoe, J. B. Rivard, and M. F. Young, "Fuel Rod Temperature Transients During LWR Degraded Core Accidents," Proceedings, International Meeting on Thermal Nuclear Reactor Safety, NUREG/CP-0027, U.S. Nuclear Regulatory Commission Conference Proceeding, Chicago, Illinois, August 29 - September 2, 1982.
6. R. H. Chapman et al., "Zircaloy Cladding Deformation in a Steam Environment with Transient Heating," Zirconium in the Nuclear Industry (Fourth Conference), ASTM STP 681, pp. 393408, American Society for Testing and Materials, Philadelphia, Pennsylvania, 1979.

7. J. B. Rivard et al., "Identification of Severe Accident Uncertainties," NUREG/CR-3440, SAND83-1689, Sandia National Laboratories, Albuquerque, NM, p. 3-8, September 1979.

8. V. E. Denny and B. R. Sehgal, "Analytic Prediction of Core Heatup Liquefaction/Slumping," (Proc. Int. Mtg. on LWR Severe Accident Evaluation, Cambridge, Massachusetts, p. 5.4-1, 1983.

9. F. T. Harper et al., "Evaluation of Severe Accident Risks: Quantification of Major Input Parameters," NUREG/CR-4551, SAND86-1309, Vol. 2, Rev. 1, Part 1, Issue 1, U.S. Nuclear Regulatory Commission, December 1990. 


\subsection{Melting, Liquefaction, Holdup}

Stage 4 begins with the initial downward relocation of molten fuel in the core region. It extends to the time that fuel-bearing melt enters the lower plenum of the reactor vessel. Fuel damage during Stage 4 is extensive. It is driven both by decay power and by oxidation. There is a strong coupling between fuel damage that occurs during this stage and the release, chemistry, and transport of fission products within the reactor coolant system.

\subsubsection{Initial Melting.}

As indicated in Section 3.2, the local decay-heat generation rate determines how rapidly a given uncovered region of the core would heat up. The decay-heat generation rate is proportional to the thermal power during operation. The thermal power distribution can therefore be used to provide a rough idea of the core regions most susceptible to the onset of rapid oxidation and subsequent melting. Figure $3.4-1$ shows the power distribution in the TMI-2 core prior to the 1979 accident. ${ }^{\prime}$ Less than half of the core by volume produces power at 25 $\mathrm{kW} / \mathrm{m}$ or greater. Heat generation rates at the periphery of the core are markedly lower. This suggests that melting would start near the center of the core and might be restricted to the central region of the core. Some of the outermost fuel rods may not attain temperatures resulting in severe damage because of their low power levels and their location adjacent to surrounding structures. The degree of coherency in core damage affects both the course of the accident and the rate of release of fission products from the core.

Zircaloy-4 melts at about $3200{ }^{\circ} \mathrm{F}\left(1760^{\circ} \mathrm{C}\right.$ $=2033 \mathrm{~K}$ ); however, the onset of melting during stage 4 may. occur at lower temperatures if the core contains significant quantities of other metals with low melt temperatures. At TMI-2, a Ni-Zr eutectic was probably the first liquid formed as a result of interactions between the Inconel grid spacers and Zircaloy cladding near the center of the core. The TMI-2 Ag-In-Cd control rod material melts at $1472{ }^{\circ} \mathrm{F}\left(800^{\circ} \mathrm{C}\right.$ $=1073 \mathrm{~K}$ ), and the stainless steel control rod cladding melts at approximately $2636^{\circ} \mathrm{F}$ $\left(1447{ }^{\circ} \mathrm{C}=1720 \mathrm{~K}\right)$. Both of these melt points are well below that of Zircaloy, so molten control rod material also flowed to the liquid steam interface relatively early. Molten silver and iron form relatively lowtemperature eutectics with Zircaloy. Thus, the initial molten mixture contained significant zirconium. Upon reaching the steam/liquid interface the metallic mixture froze to form a lower crust that blocked cọolant channels between fuel rods. Postaccident analyses confirm that the crust was a $\mathrm{Zr}-\mathrm{Ag}-\mathrm{In}-\mathrm{Fe}-\mathrm{Ni}$ metallic mixture surrounding standing columns of fuel pellets. The lowest crust was near the lowest grid spacer and corresponds to the lowest water level in the core during the accident. The ultimate thickness of the crust was 10 to 15 $\mathrm{cm}^{2}$

The postulated condition of the TMI-2 core shortly after the onset of Stage 4 (150 to 160 minutes into the accident) is shown in Figure 3.4-2. ${ }^{3} \quad$ Alternative scenarios in which a blockage does not form in the core region due to a lower water level are discussed in Section 3.4.3.

\subsubsection{Fuel Liquefaction}

Early views of LWR core melt progression reflected in the 1975 Reactor Safety Study held that fuel melting did not occur until the $\mathrm{UO}_{2}$ fuel material attained its melting temperature, $5180^{\circ} \mathrm{F}\left(2860^{\circ} \mathrm{C}=3133 \mathrm{~K}\right)$. Research subsequent to the 1979 TMI-2 
accident has demonstrated that $\mathrm{UO}_{2}$ can be liquefied far below its ceramic phase melting temperature. When the local temperature of the fuel reaches the Zircaloy melting temperature, $3200^{\circ} \mathrm{F}\left(1760^{\circ} \mathrm{C}=2033 \mathrm{~K}\right)$, flow of metallic cladding beneath the oxidized layer can occur. Interactions can then occur between molten Zircaloy and solid $\mathrm{UO}_{2}$ as indicated in Figure 3.4-3. In one series of laboratory experiments, $\mathrm{UO}_{2}$ crucibles holding molten Zircaloy at temperatures between $3272^{\circ} \mathrm{F}\left(1800^{\circ} \mathrm{C}=\right.$ $2073 \mathrm{~K})$ and $3632{ }^{\circ} \mathrm{F}\left(2000{ }^{\circ} \mathrm{C}=2273 \mathrm{~K}\right)$ in an argon atmosphere were rapidly destroyed by the dissolution of solid $\mathrm{UO}_{2}$ in molten Zircaloy. ${ }^{4}$ In another experiment, electrically-heated fuel-rod simulants in steam were massively liquefied and relocated when the oxidation-driven 9-rod-bundle temperature exceeded $3632{ }^{\circ} \mathrm{F}\left(2000{ }^{\circ} \mathrm{C}\right)$. Similar behavior has been reported in several other experiments. ${ }^{5}$

Apparently, zirconium reduces $\mathrm{UO}_{2}$ preferentially along $\mathrm{UO}_{2}$ grain boundaries near the $\mathrm{UO}_{2}$-Zircaloy interface. This produces a homogeneous $\mathrm{U}-\mathrm{Zr}-\mathrm{O}$ melt at low oxygen concentrations or a heterogeneous $\mathrm{U}-\mathrm{Zr}-\mathrm{O}$ melt containing $\mathrm{UO}_{2}$ particles at high oxygen concentrations. In either case, the process is called fuel liquefaction.

In addition to destroying the $\mathrm{UO}_{2}$ matrix, fuel liquefaction accelerates the release of fission products from the fuel. However, minor alloying components or impurities can have large effects on such releases. For instance, tin, which is a $1 \%$ component of Zircaloy, may act as a getter for tellurium, resulting in significant holdup or retention of this fission product. ${ }^{6}$

\subsubsection{Flow Blockage Versus Streaming}

The significant liquefaction of fuel that would occur after the Zircaloy cladding started to melt would result in downward flow of liquid U-Zr-O. Even in the absence of a blockage formed by the refreezing of lower melting temperature eutectics (as occurred at TMI-2), molten U-Zr-O could refreeze on the surfaces of fuel rods or fuel assembly rod spacers in lower regions of the core where temperatures were cooler. Calculations indicate that, without additional oxidation, the liquefied fuel would rapidly freeze producing a significant core blockage. This is true even if freezing requires the transfer of the full $\mathrm{UO}_{2}$ latent heat of fusion $(270 \mathrm{~kJ} / \mathrm{kg})$. A latent heat of fusion more appropriate for the $\mathrm{U}-\mathrm{Zr}-\mathrm{O}$ mixture would require less heat transfer (about $50 \mathrm{~kJ} / \mathrm{kg}$ ) making freezing even more likely.?

On the other hand, the high temperature of the liquefied U-Zr-O would favor high oxidation rates per unit area exposed, and energy addition by oxidation as the liquid flowed downward could preclude its refreezing. If the water level during the meltdown were below the bottom of the active core, the melt could then stream into the lower plenum if not halted by freezing on cooler surfaces below the core region. Quenching of melt that streamed into residual water in the lower plenum could provide the additional steam required to maintain the streaming process. The question of blockage versus streaming is important because it affects the magnitude of resulting fuel coolant interactions and the timing and mode of eventual bottom head failure (Sections 3.5 and 3.6). Most current analyses predict the formation of a blockage in the core region of a PWR even if the residual water level is below the bottom of the active fuel. BWR core melt progression is discussed in Section 3.7.

A central blockage would redirect steam flow outward in an open lattice (PWR) core. This is depicted in Figure 3.4-4. The 
diversion of steam flow to the outer regions of the core could result in two possible alternatives. If the fuel rods have not yet attained temperatures capable of supporting rapid oxidation, they may be cooled by the additional flow, but if the rods are hot enough, they may rapidly oxidize.

Figure 3.4-5 shows the core condition postulated at TMI-2 at $173 \mathrm{~min}$, just prior to the brief restart of reactor coolant pump 2B. ${ }^{4}$ The damage had progressed to the point where the blockage was nearly complete with only the outermost fuel assemblies undamaged. The bowl-like shape of the lower crust or crucible may have been caused by the flow blockage diverting steam flow radially outward. Such flow diversion increases steam flow rates and thus heat transfer at the periphery of the damage zone. This results in freezing the downward relocating melt at elevations above the water level as shown in Figure 3.4-5. A second explanation for the shape of the lower crust is that the onset of melting is primarily controlled by decay heat, and, consequently, the freezing isotherm for the molten metallics increased in elevation as core damage progressed radially outward to regions of lower core power density.

Above the lower crust, a region of at least partially molten material formed as depicted in Figure 3.4-5 for TMI-2. At the time indicated (just prior to the restart of reactor coolant pump 2B), core heatup calculations indicate that peak temperatures within this region of consolidated core materials may have reached $\mathrm{UO}_{2}$ melt temperature $\left(5180^{\circ} \mathrm{F}\right.$ $=2860^{\circ} \mathrm{C}=3133 \mathrm{~K}$ ). The average temperature of the material was probably between $4220^{\circ} \mathrm{F}\left(2873^{\circ} \mathrm{C}=2600 \mathrm{~K}\right)$ and $4580 \mathrm{~F}$ $\left(3073{ }^{\circ} \mathrm{C}=2800 \mathrm{~K}\right) .^{4}$

Undamaged rod stubs were about $2 \mathrm{ft}(60$ $\mathrm{cm}$ ) long near the center of the core, indicating that water did not drop below this level for any significant period of time during the accident. Water covering the bottom of the core kept the lower supporting crust cooled. This helped maintain the structural stability of the crust.

\subsubsection{Reflooding During Stage 4 at TMI-2}

Activation of reactor coolant pump $2 B$ at $\sim 174 \mathrm{~min}$ resulted in the first significant addition of coolant to the TMI-2 reactor vessel following the shutdown of the loop-A reactor coolant pumps at $\sim 100 \mathrm{~min}$. Reactor coolant pump 2B operated for $\sim 19 \mathrm{~min}$; however, significant flow was only measured during the first $15 \mathrm{~s}$. Approximately 1000 $\mathrm{ft}^{3}\left(28 \mathrm{~m}^{3}\right)$ of water was pumped into the reactor vessel from the loop $B$ cold leg.

As discussed in Section 2.4, the reactor coolant pressure increased rapidly when pump 2B was turned on. This pressure increase was caused by steam generated when the water contacted hot surfaces in the core region, and by hydrogen generated by the rapid oxidation of Zircaloy in the top half of the core.

The thermal-mechanical forces resulting from partial quenching of the oxidized fuel rod remnants in the top half of the core fragmented the oxidized cladding and fuel pellets to form a debris bed. The configuration postulated for the core just after the pump 2B restart is shown in Figure 3.4-6. As indicated in the figure, the upper support grid was damaged. Selected areas of the bottom of the upper grid were oxidized, melted, or ablated thermally. There was, however, no damage to the upper plenum structures above the upper core support grid.

The overall upper core debris region was composed of about $27,000 \mathrm{~kg}$ of material. Between 3 and $10 \%$ of this debris was less 
than $1 \mathrm{~mm}$ in diameter, and the control-rod materials (Ag-In-Cd) in this debris were concentrated in particles less than $1 \mathrm{~mm}^{3}$ Particles of this type were found on various horizontal surfaces in the upper plenum. Jets of steam from the $2 B$ pump restart are thought to have led to this transport. Apparently quantities of loose debris also settled to the lower head of the reactor vessel during quiescent periods or were transported there by loop flow during the $2 \mathrm{~B}$ pump transient. This would explain findings of intergranular Ag-In-Cd in the surfaces of several incore instrument nozzles and in the lower head vessel cladding cracks. The alternative that molten control-rod material flowed all the way to the bottom head seems less plausible because of the thick metallic crust formed just above the minimum water level in the core region. Unfortunately, the amount of control-rod material and the depth of the initial debris layer on the lower head could not be determined by examining debris removed from the lower head after the accident.

From $\sim 180 \mathrm{~min}$ to $\sim 200 \mathrm{~min}$, the water level in the TMI-2 core decreased as decay heat from the degraded core boiled liquid from the reactor vessel. The water level at $\sim 200$ min was at its lowest level. ${ }^{4}$ The low thermal diffusivity of the large consolidated region of primarily ceramic core debris above the bottom crust prevented the interior of this region from cooling even when the reactor vessel was subsequently filled with water. Calculations indicate that a pool of molten material formed in the center of the consolidated region and increased in size during this period.

At $200 \mathrm{~min}$. the high pressure injection system was manually actuated and cooling water was injected for the next $17 \mathrm{~min}$. Analyses indicate that the core region was refilled with water by $207 \mathrm{~min}$. As the cooling water filled the reactor vessel, it penetrated the debris bed above the consolidated region. By about $230 \mathrm{~min}$. debris in this upper debris bed was fully quenched.

The consolidated region continued to heat up even though the core region was filled with water. The postulated condition of the core debris at $224 \mathrm{~min}$. is depicted in Figure 3.47. Water covered the core region, and the debris bed above the core region was quenched, but the consolidated region between the upper and lower crusts was predominately molten.

Relocation of approximately 19 tonnes of molten core material into the lower plenum of the reactor vessel occurred between 224 and $226 \mathrm{~min}$. The pour was initiated by a failure of the crust at the periphery of the core region where it contacted the core former plate. The pour is discussed as part of the next stage of in-vessel accident progression in Section 3.5.1. The important point to note here is that reflooding was apparently not a factor in initiating the molten pour.

\subsubsection{Additional Reflooding Considerations}

If water is reintroduced into the core during Stage 4 , it is clear that acceleration of cladding oxidation may occur, because

- the quantity of unoxidized cladding may be relatively large due to the slow rate of steam evolution from boiloff prior to reflooding,

a large fraction of the unoxidized cladding may be at elevated temperatures, 
- quenching of hot fuel upon reflooding the lower part of the core would produce copious amounts of additional steam, and

- there could be relatively uninhibited access of steam to unoxidized cladding.

Acceleration of oxidation associated with reintroduced coolant might, given these assumptions, add tens of GJ of energy to the system in a short time and evolve large quantities of hydrogen. Because the energy required to destroy the entire core geometry at these temperatures may be as little as 6 GJ, ${ }^{7}$ a significant redistribution of core materials in a very short time following the reintroduction of water is possible. ${ }^{7}$ An attendant possibility is one or more steam explosions caused when hot, liquefied fuel falls into the pool of reflooding water. (Steam explosions are discussed in Subsection 3.6.) The actual scenario is quite uncertain, producing significant uncertainty in all subsequent events and processes that are affected.

Nevertheless, barring crust failure, the reintroduction of sufficient water should halt the heatup and result in a cooling of the core. This requires, in addition to the initial quench, either reestablished loop flow (forced or natural convection in the primary system) or local bed convection. Cooling by local convection in the bed, as well as by reestablished loop flow, depends upon the size and characteristics of the rubble and the coolant-volume fraction, and requires that a long-term heat sink be available for the energy removed form the bed. Rubble bed cooling is discussed further in Section 3.5. depleted at the time of core damage, gaseous natural convection between the vessel and the primary side of U-tube steam generators is favored. Because of potential loop seal and downcomer blockage, the convection would most likely be required to traverse the hot leg piping, displacing cooler steam/hydrogen in the generator tubes by warmer steam-hydrogen from the core, Figure 3.3-6. The great height of the steam generator tubes $(18 \mathrm{~m})$ provides a large driving force.

To the extent that the convection is effective, it will provide a sink for fission products. The effectiveness of the steam generators as a heat sink would decrease strongly as the tubes heated up. It has been estimated that halving the temperature difference between hot gases and steam generator tubes reduces the convective heat flux by $40 \% .^{7}$

Thus, given dry steam generators (anticipated for many transient-initiated accidents), effective natural convection would be inhibited when structures acting as a heat sink attained elevated temperatures. On the other hand, as discussed in Section 3.3.5, because the strength of steel decreases rapidly above $1000^{\circ} \mathrm{F}\left(538^{\circ} \mathrm{C}\right)$, reactor coolant system structures such as the hot legs could weaken and fail at sufficiently elevated temperatures. Such temperatureinduced failures would depressurize the reactor coolant system and preclude large containment pressures and temperatures that might otherwise result from high-pressure melt ejection due to reactor vessel bottom head failure (Section 3.5.2.5 and Module 4).

\subsubsection{Natural Circulation During Stage 4}

In PWR accidents, even if the steam generator secondary-side inventory is 


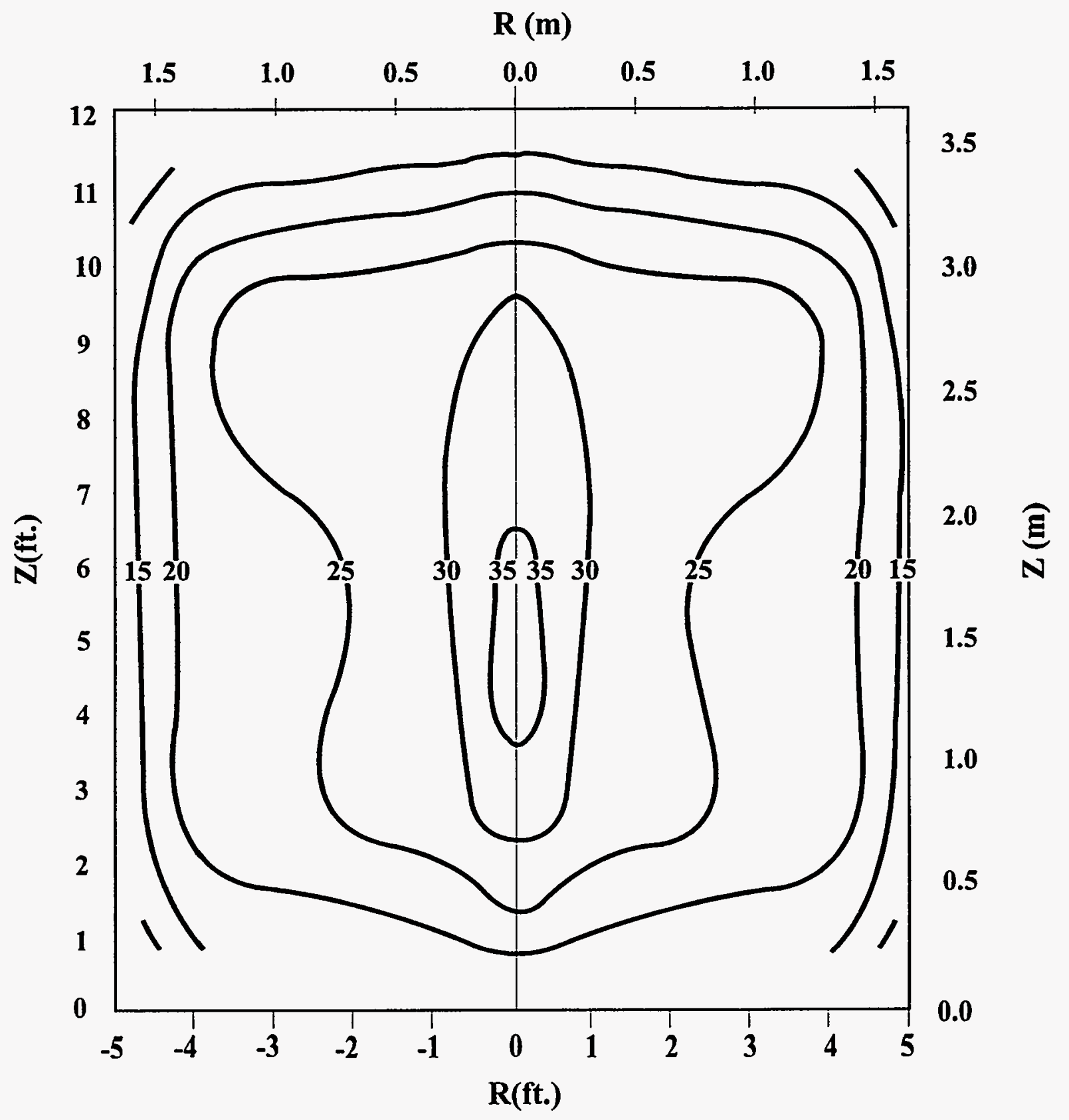

Figure 3.4-1 Distribution of fuel rod rating $(\mathrm{kW} / \mathrm{m})$ in the TMI-2 core 


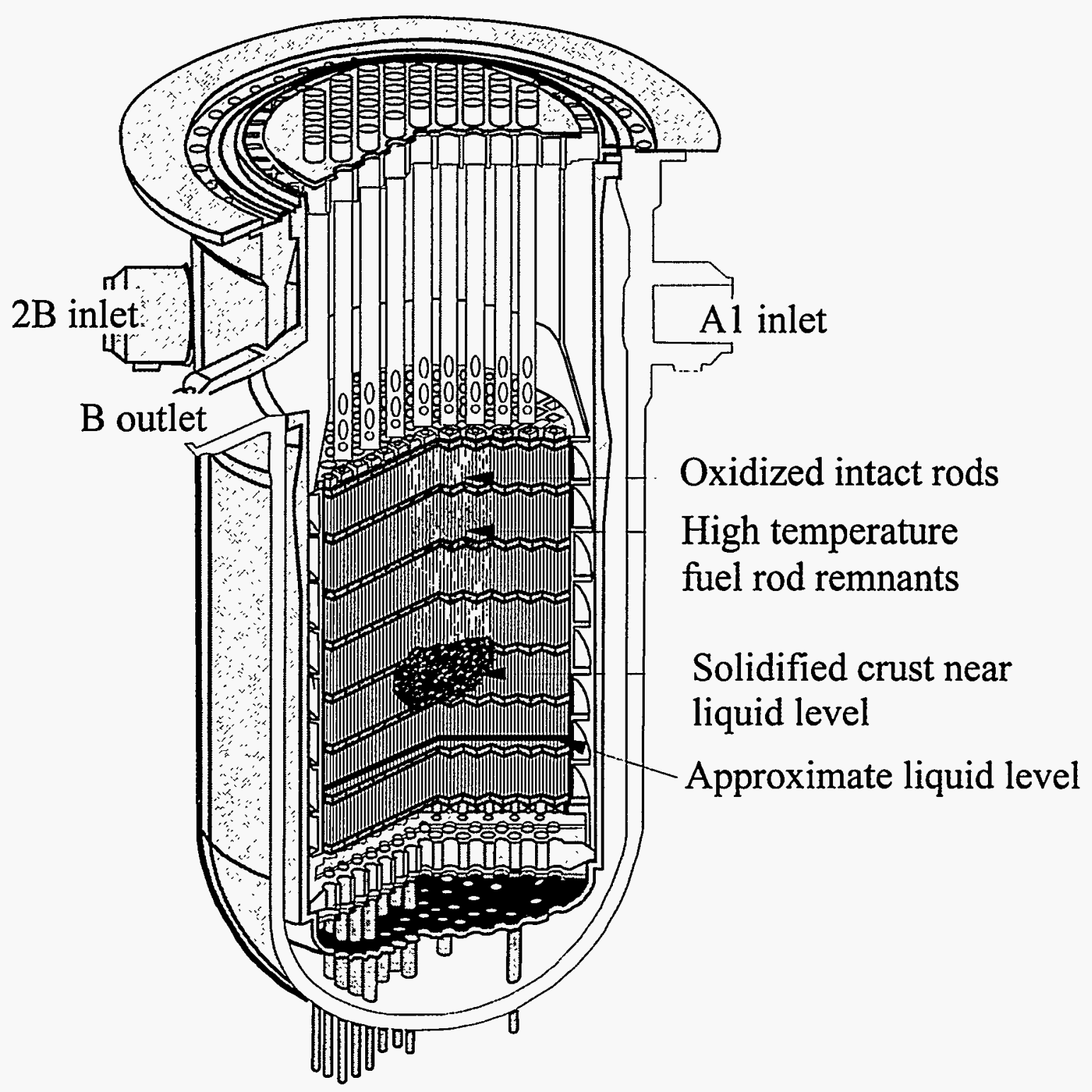

Figure 3.4-2 Hypothesized TMI-2 condition between 150 and 160 minutes 


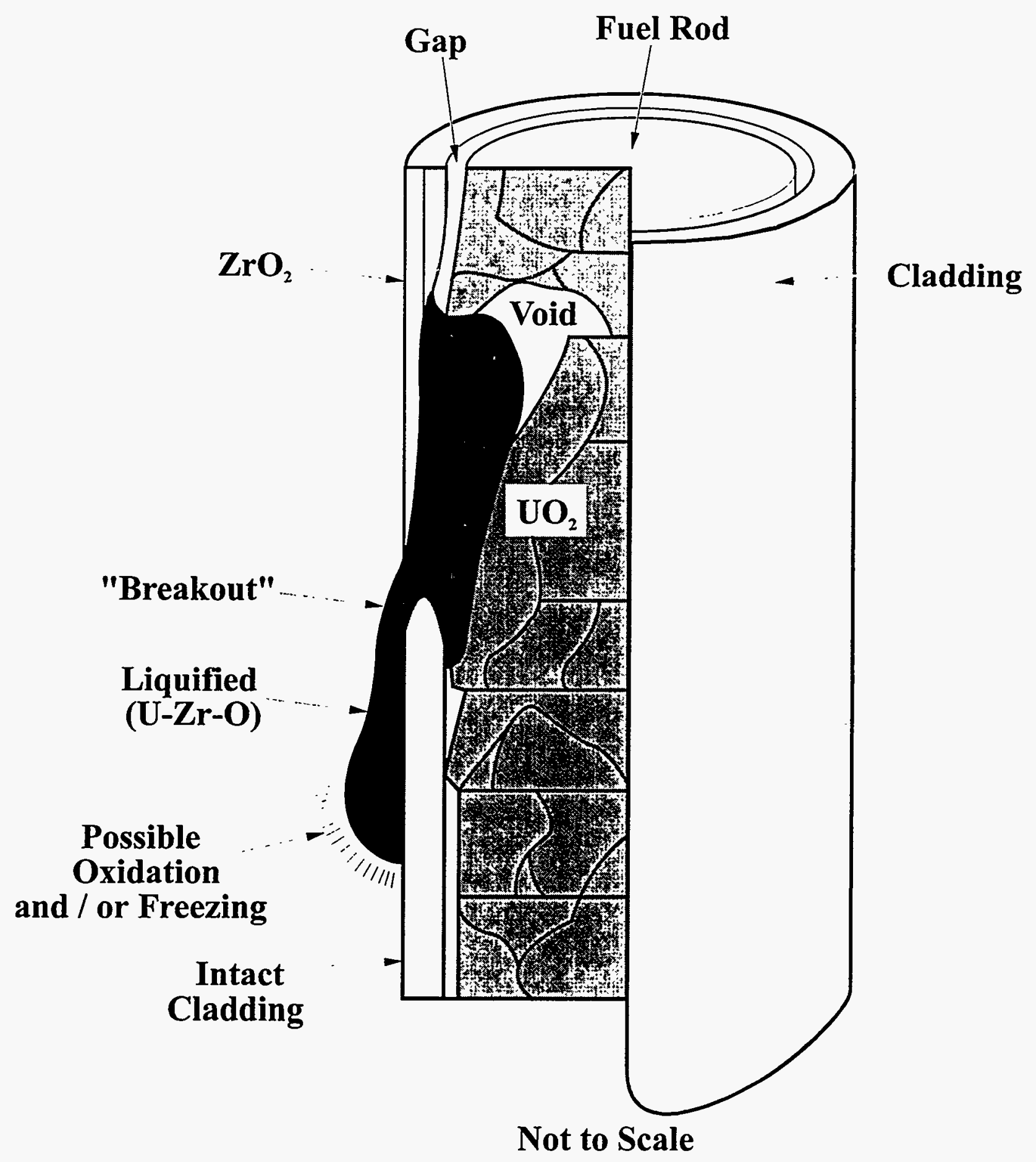

Figure 3.4-3 Schematic representation of possible mode of initial fuel liquefaction and downward flow 


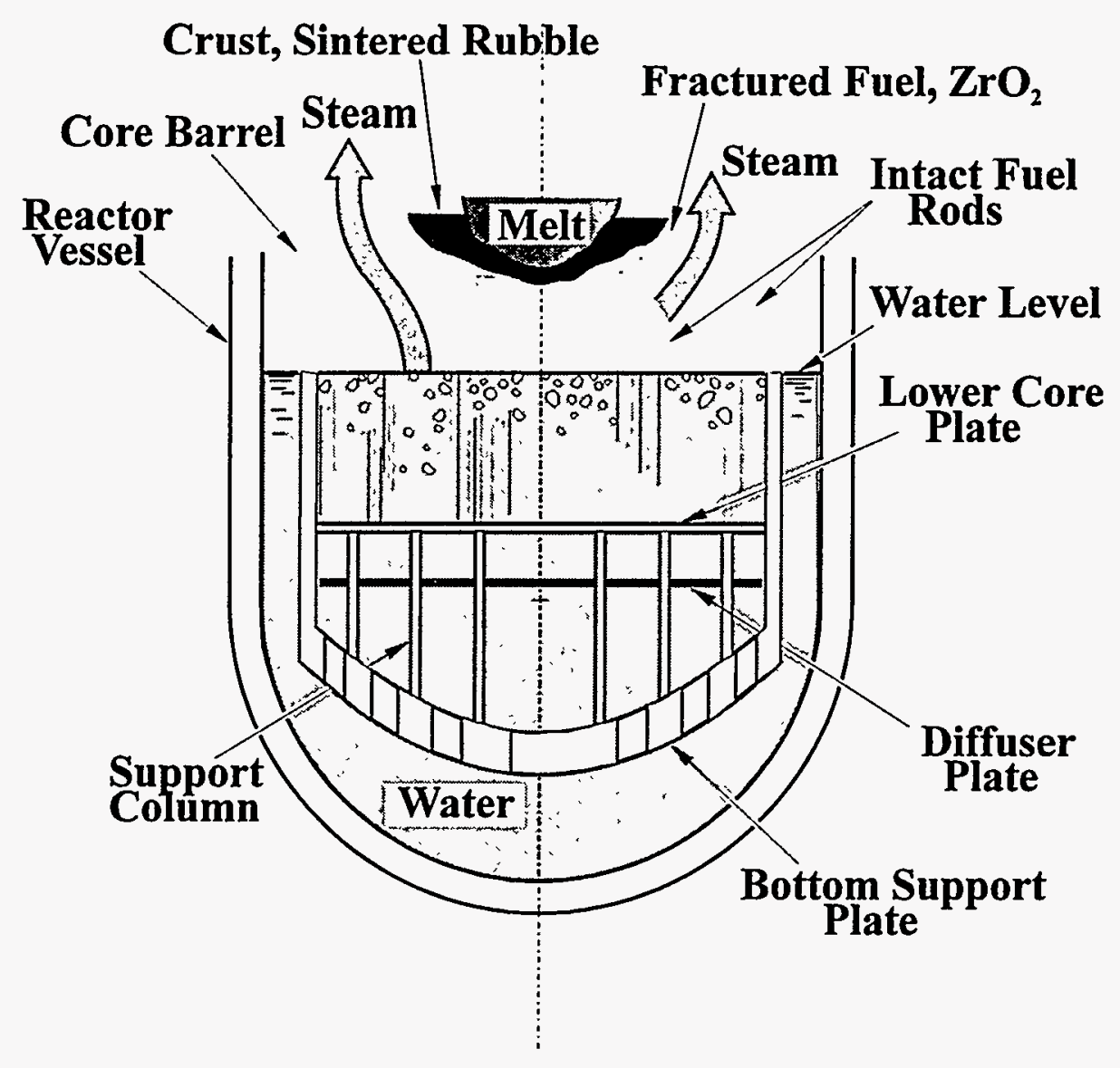

Figure 3.4-4 Initial core degradation in a PWR 


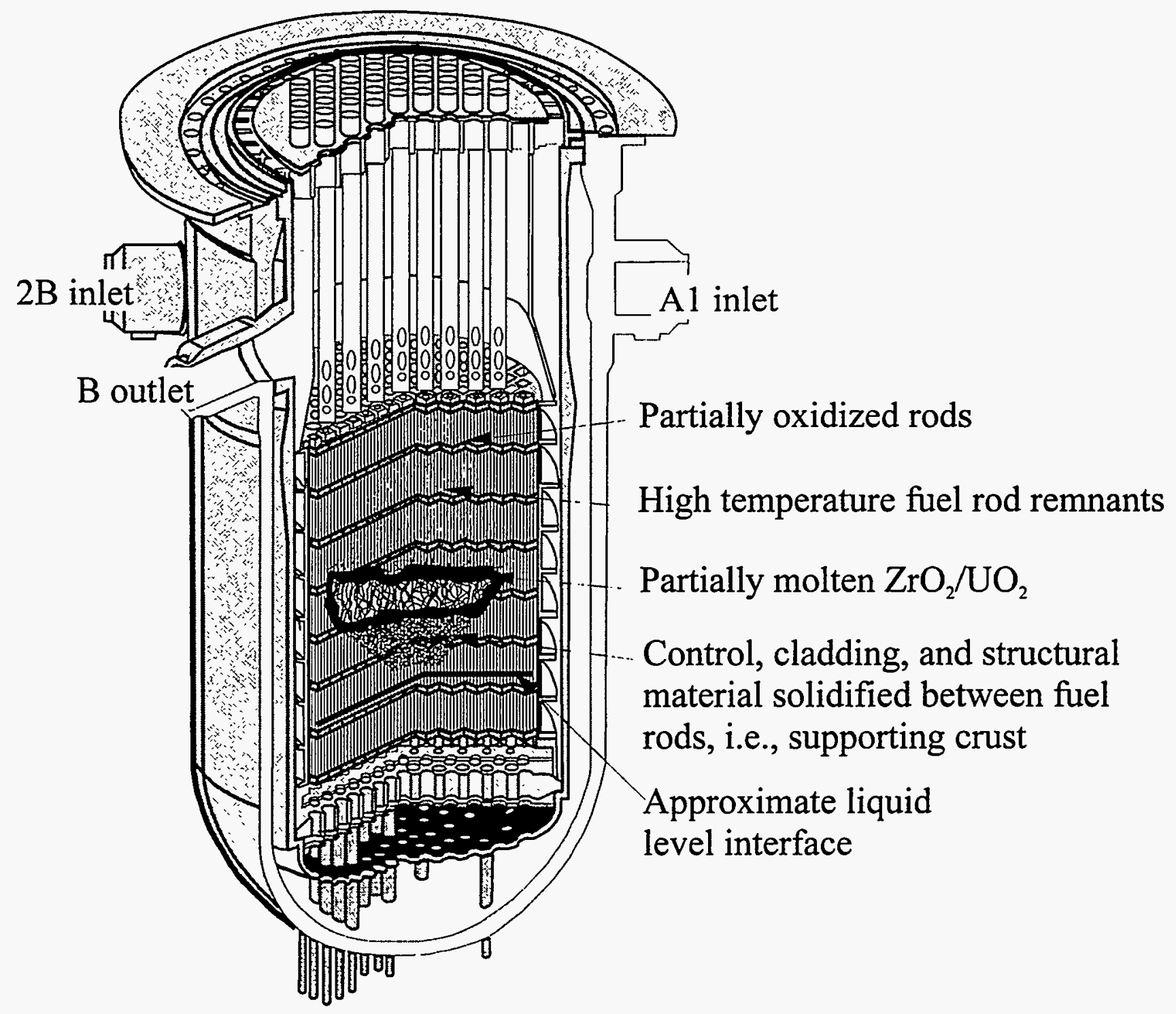

Figure 3.4-5 Hypothesized TMI-2 core at 173 minutes 


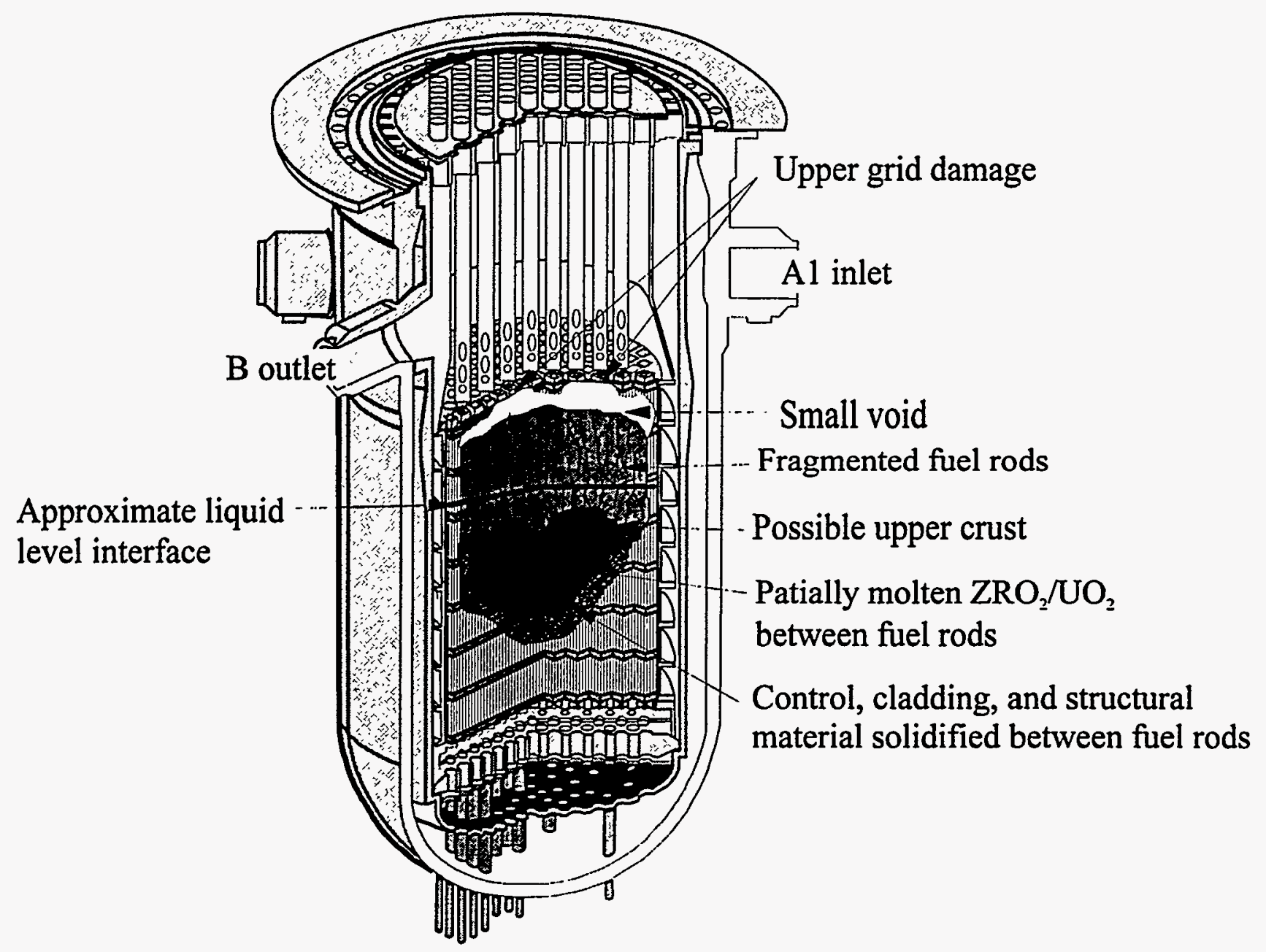

Figure 3.4-6 Hypothesized TMI-2 core configuration between 174 and 180 minutes 


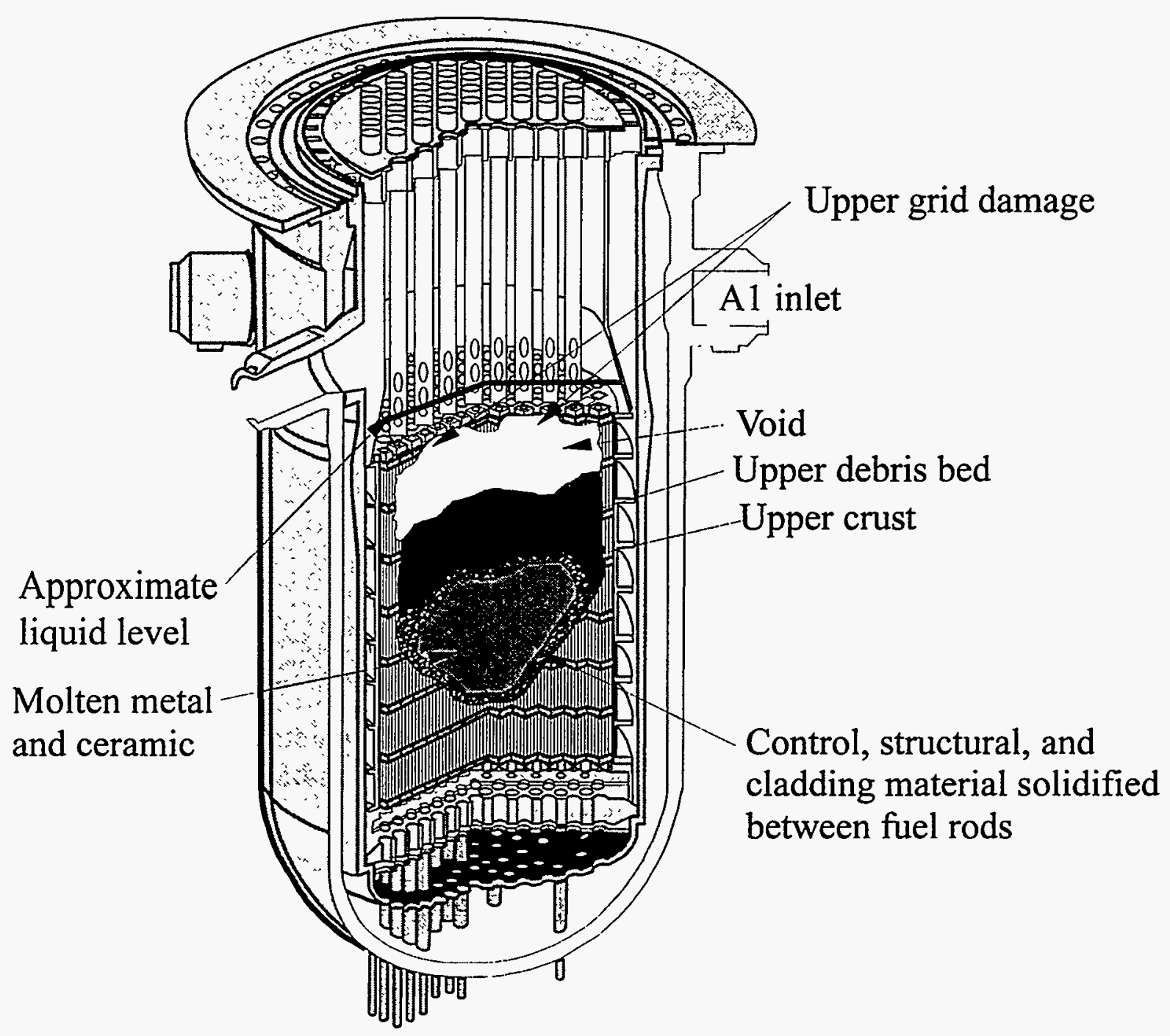

Figure 3.4-7 Hypothesized TMI-2 core configuration at 224 minutes (just prior to major core relocation) 


\section{References for Section 3.4}

1. K. H. Ardron and D. G. Cain, "Core Temperature Transient in the Early Phase of Core Uncovering at TMI-2," Progress in Nuclear Energy, 7:197-228, 1981.

2. J. R. Wolf, D. W. Akers, and L. A. Neimark, "Relocation of Molten Material to the TMI-2 Lower Head, "Nuclear Safety, 87(1):269-279, July-December 1994.

3. J. M. Broughton et al., "A Scenario of the Three Mile Island Unit 2 Accident, Nuclear Technology, 87(1):34-53, August 1989.

4. P. Hofmann, D. Gerwin Peck, and P. Nikolopoulos, "Physical and Chemical Phenomena Associated with the
Dissolution of Solid $\mathrm{UO}_{2}$ by Molten Zircaloy-4," 06.01.06p10c, PNSNR.675/82, Karlsruhe, Federal Republic of Germany: Kernforschungszentrum Karlsruhe, GmbH, 1982.

5. P. Hofmann, S. J. L. Hagen, and G. Schanz, "Reactor Core Materials Interactions at Very High Temperatures," Nuclear Technology, 87(1):146-186, August 1989.

6. J. B. Rivard, et al., "Identification of Severe Accident Uncertainties," NUREG/CR-3440, SAND83-1689, U.S. Nuclear Regulatory Commission, September 1989. 


\subsection{Molten Pours onto the Lower Head}

Stage 5 begins with the movement of molten fuel-bearing debris into the lower plenum of the reactor vessel. It ends with failure of the reactor pressure vessel and the discharge of fuel debris to the containment. Reactor pressure vessel failure could result from weakening of the lower head or its penetrations due to contact with hot debris. Alternatively, vessel failure could result from an energetic interaction of molten fuel with residual water in the lower plenum. This section discusses accident progression scenarios in the absence of energetic fuelcoolant interactions. The implications of energetic fuel-coolant interactions (steam explosions) are discussed in Section 3.6.

\subsubsection{TMI-2 Molten Pour}

Relocation of approximately 20 metric tonnes of molten core material into the lower head of the reactor vessel occurred between 224 and 226 minutes. This was confirmed by several indicators: a primary system pressure increase of 290 psi (2 MPa), increases in out-of-core source-range neutron detector count rates, alarms of in-core selfpowered neutron detectors (SPNDs), alarms of in-core thermocouples, and post-accident measurements of incore thermocouple loop resistances.

The hypothesized configuration during relocation is depicted in Figure 3.5-1. The crust failure appears to have been in the upper half of the consolidated region near the core periphery. Two mechanisms have been postulated for crust failure. First, continued heating of the molten pool could have lead to melting of the supporting crust, which was thinnest on the top (1 cm versus 10 to $15 \mathrm{~cm}$ on the bottom) where heat transfer was greater. Second, at $\sim 220$ minutes the pressurizer block valve was opened resulting in a decrease in the reactor coolant pressure of 70 psi $(0.5 \mathrm{MPa})$ between 220 and $240 \mathrm{~min}$.

Post-accident examinations of the eastern half of the core region and lower vessel internals show that the molten pour started on the eastern side of the core. Figure 3.5-2 shows a cross section of the internal structures surrounding the core region. The primary path from the core region was radially outward through a hole melted in the R6 vertical core baffle plate. The core barrel appears to have experienced local surface ablation in this region as indicated in Figure 3.5-3.'

Examinations of flow holes in the horizontal baffle plates surrounding the core indicate that nearly the whole volume between former plates 6 and 7 filled with molten corium that flowed from the initial meltthrough location around the core, cooling as it flowed. The majority of the molten corium then flowed downward through flow holes in former plate 7 and ultimately into the reactor vessel lower head. Post-accident probings found approximately 4.2 tonnes of solidified fuel debris in the gap between the vertical core former and the core barrel at depths depicted in Figure 3.5-3. Another 5.8 tonnes are estimated to have solidified in the core support assembly region. About 19.2 tonnes relocated onto the lower head of the reactor vessel.

The lower core support assembly consists of a number of plates and a forging as shown in Figure 3.5-4. There were multiple flow paths through the core support assembly to the bottom head. Figure 3.5-5 indicates where solidified material was found in the area between the lower grid and the flow distributor plate, between the flow distributor plate and the grid forging, and in flow holes of the grid forging. ${ }^{2}$ The presence of solidified material indicates that 
molten material flowed through or adjacent to these locations. On this basis, most of the melt flowed down to the elliptical flow distributor on the eastern periphery in the $\mathrm{R} 6 / 7$ and $\mathrm{P} 4 / 5$ areas. Visual examinations indicated that some melt flowed around the perimeter of the core support assembly structures before moving downward.

Figure 3.5-6 indicates the locations in the elliptical flow distributor where solidified material was observed in or above a flow hole. ${ }^{2}$ The flow holes indicated in Figure 3.5-6 agree well with those indicated in Figure 3.5-5. In particular, locations H15, K15, L15 indicate flow on both figures, and flow location $\mathrm{C} 14$ in Figure $3.5-5$ is near locations D-13 and D14 in Figure 3.5-6. The melt appears to have dropped onto the lower head from several different locations around the periphery of the elliptical flow distributor.

As the melt moved downward from the core region, heat was lost to the core baffle and former plates, to the core barrel, to the lower core support assembly, and to water that filled the lower plenum. Minimal damage observed to the elliptical flow distributor suggests that the initial material reaching this plate and subsequently the bottom head was relatively cool. It is possible that the material was mobile at temperatures below the solidus temperature of $(\mathrm{U}, \mathrm{Zr}) \mathrm{O}_{2}$ owing to the presence of phases with higher metal content and lower melting temperatures.

Rapid steam production occurred as a result of heat transfer from the molten core material to water in the bottom head. Nothing in the recorded data or post accident core conditions suggests an energetic steam explosion (see Section 3.6) occurred as the tons of molten core material relocated into the lower plenum with the reactor vessel nearly full of water.

Figures 3.5-7 and 3.5-8 depict the ultimate hard debris layer that formed in the lower head. ${ }^{2}$ The layer depths were established by mechanical probing during defueling operations. The steep cliff-like profile around the periphery of the hard layer indicates rapid freezing of relatively cold debris. A high initial temperature or remelting would have resulted in a flatter profile near the periphery. On the other hand, it is now clear that high temperature melt existed and caused some damage in the more central regions of the lower head (see Section 3.5.4).

\subsubsection{Alternative Melt Flow Scenarios}

In core melt scenarios involving the formation of blockage in the core region, configurations similar to that at TMI-2 are postulated. The formation of a molten pool contained within a crucible-like bottom crust is envisioned with unmelted ceramic $\left(\mathrm{UO}_{2}\right)$ and metallic material either adding to the pool from above or forming a rubble bed above an upper crust as at TMI-2.

The size of the molten region would grow due to continued addition of decay heat (reduced by the loss of volatile fission products during liquefaction). With a total loss of coolant injection, the residual water level could drop below the bottom of the active core and structures supporting the mass of the crust and melt could weaken as depicted in Figure 3.5-9. Given a failure of the core support structures or a breakthrough of suspended melt as occurred at TMI-2, substantial quantities of melt could suddenly plunge into the residual water in the lower plenum. 
On the other hand, a massive, coherent pour of molten material is not the only scenario that can be envisioned. Local crust failure could result in a narrow continuous pour over a fraction of a minute to several minutes. Alternatively, if there were little residual water present, a strong crust might not form in the core region. In this case the discharge of molten material from the core might occur in a narrow discontinuous stream or streams distributed over the duration of the core meltdown.

The rate of formation of liquefied fuel is slow compared to all but the very slowest discharge rates. Thus, if a large fraction of the core is liquefied at the onset of discharge, a larger amount might be discharged. Conversely, if only a small fraction is liquefied at the onset of discharge, much smaller discharge rates would result.

\subsubsection{Debris on TMI-2 Lower Head}

During the TMI-2 defueling, the solidified layer of debris in the lower head was found to be very hard. It had to be broken apart by dropping a $300 \mathrm{lb}(136 \mathrm{~kg})$ hammer from an elevation of $20 \mathrm{ft}(6.1 \mathrm{~m})$. Once the material was broken into pieces, there was virtually no adherence to the lower head itself. Representative samples of the solidified layer were obtained for examination. Because the hard layer had to be broken into pieces, however, information regarding variability in debris properties with depth could not be obtained. Results of physical and radiochemical examinations, which are discussed in detail elsewhere, ${ }^{3}$ are summarized below.

The debris was generally a dull grey ceramic with some areas of yellow (probably hexavalent uranium). The average density of the samples was $8.7 \pm 0.4 \mathrm{~g} / \mathrm{cm}^{3}$. By comparison, the density of $\mathrm{UO}_{2}$ fuel pellets is about $10.8 \mathrm{~g} / \mathrm{cm}^{3}$. The average porosity for all samples was $18 \pm 11 \%$, reflecting a very wide range. As indicated in Table 3.51 , the elemental composition of the debris was found to be very similar to that in the original core, but with slightly more uranium and slightly less zirconium.

Figure 3.5-10 shows cross-sectional views of one sample with apparently connected pores in the longitudinal sections. Such interconnected pores were observed in many of the samples and may have been caused by bubbling of steam or structural material vapors through the melt when it froze. As indicated in Figure 3.5-11, scanning electron microscope examinations revealed a light uranium-rich $(\mathrm{U}, \mathrm{Zr}) \mathrm{O}_{2}$ phase away from the pores. A dark, zirconium-rich $(\mathrm{Zr}, \mathrm{U}) \mathrm{O}_{2}$ phase was often found adjacent to the pores. Based on the time required for such visible phase separation to occur, the debris cooling time was estimated to be from 3 to 72 hours. The lack of complete phase separation implies a cooling time toward the lower end of this range. As discussed later, however, tests of metal samples from the lower head and analyses of potential vessel failure modes imply a much shorter (30 min.) quenching time. This apparent discrepancy has not yet been explained.

Dissolution techniques were used to measure the retention fractions of several key radionuclides in the debris. The analyses indicated that only small fractions of volatile radionuclides like Cs-137 were retained, but most of the low volatility radionuclides were retained. The decay heat generation rate in the debris on the lower head was estimated to be 0.13 watts per gram $(w / g)$ of uranium just after the molten pour. ${ }^{3}$ This compares to $0.18 \mathrm{w} / \mathrm{g}$ of uranium if all radionuclides had been retained. 


\subsubsection{Hotspot in TMI-2 Lower Head}

The condition of the TMI-2 incore instrument nozzles following debris removal from the bottom head is depicted in Figure 3.5-12. As indicated by the section view in Figure 3.5-8, some nozzles had been completely buried in solidified debris but showed absolutely no damage. Other nozzles were partially melted, and 9 nozzles (E-7, E-9, F-7, F-8, G-5, G-6, G-9, H-5, and H-8) were completely melted off. The following explanation accounts for these various degrees of damage.

The portion of the molten pour that initially contacted the lower head is believed to have been substantially cooler than material that reached the lower head later. The initial material lost more specific heat to the core baffle and former plates, the core barrel, the lower core support assembly, and the water that filled the lower plenum. The lower head itself provided an additional heat sink.

The initial cooler material fell to the lower head from several different locations and is believed to have rapidly frozen to form a cup-shaped basal crust structure that protected lower head and nozzles in these areas. Hotter material flowed downward across the top of this insulating crust. Unprotected nozzles in the flow paths of the hotter material were melted off. The height at which a nozzle melted off indicates the depth of the insulating crust that surrounded the nozzle. The protective crust thickness was negligible at location E-9, about $15 \mathrm{~cm}$ at location $\mathrm{H}-5$, and about $25 \mathrm{~cm}$ at locations $\mathrm{M}-9$ and $\mathrm{H}-5$.

In February 1990, 14 nozzles, 2 guide tubes, and 15 vessel steel samples, were removed from the TMI-2 vessel. Figure 3.5-13 shows the locations of these samples. Figure 3.5-14 shows the as-removed appearance of six nozzles. The 15 prism shaped vessel steel samples extended about half way through the 5.4 inch $(13.7 \mathrm{~cm})$ thick vessel. Significant insights regarding potential bottom head failure modes were obtained based on tests and analyses performed on these samples. It was determined that an elliptical hot spot (approximately $1 \times 0.8 \mathrm{~m}$ ) formed where the insulating crust thickness was negligible. This hot spot is depicted in Figure 3.5-15. ${ }^{4}$ Within the hot spot temperatures from $\sim 800$ to $1100{ }^{\circ} \mathrm{C}$ persisted for approximately 30 minutes. Cooling then occurred rapidly (10$100{ }^{\circ} \mathrm{C} / \mathrm{min}$.). ${ }^{5}$ Outside the hot spot, lower head temperatures remained below the 727 ${ }^{\circ} \mathrm{C}$ austenitic to ferritic transition temperature; however, some areas may have been close to this temperature. The temperature gradient through the thickness of the lower head was 20 to $40^{\circ} \mathrm{C} / \mathrm{cm}$.

\subsubsection{Early Views of Lower Head Failure}

As mentioned in Sections 3.3.5 and 3.4.6 and illustrated in Figure 3.3-8, the strength of steel decreases rapidly as its temperature exceeds $1000^{\circ} \mathrm{F}\left(538^{\circ} \mathrm{C}\right)$, which is far less than the steel melting point. Early investigators focused on global weakening accompanied by large plastic deformations of the entire bottom head as the most likely vessel failure mode. If large fractions of the core flow as molten debris to the lower head, estimates of the time required for global failure vary from $22 \mathrm{~min}$. to $40 \mathrm{~min}$., depending on whether the vessel is pressurized or not. ${ }^{6}$ In pressurized accidents, the vessel would contain residual water and the lowest part of the bottom head might be the last location of such water. Without both a permanent supply of water and a coolable debris configuration, failure of the lower head would be imminent. 
The 80 minute maximum duration given in Table 3.3-1 for Stage 5 results from combining the maximum estimated time-to-breach for the reactor vessel (40 minutes) with a scenario in which the core material deposited in the lower plenum is initially quenched (without a vessel-failing steam explosion), and must subsequently reheat to produce vessel failure.

In a 1981 risk assessment of the Zion plant, an alternative mechanism for bottom head failure was identified. ${ }^{7}$ Local meltthrough was postulated to occur at an incore instrument tube penetration. The time to failure identified for this mode was 5 to 7 minutes, independent of relative pressure.

\subsubsection{Lower Head Failure Modes Analyzed for TMI-2}

The TMI-2 lower head did not fail in spite of the hot spot that existed for about half and hour. Structural analyses were performed to investigate what modes of failure might have occurred had the accident proceeded further without efficient cooling of debris in the lower head. As illustrated in Figure 3.5-16, four temperature-related failure modes were analyzed: (1) global vessel failure, (2) localized vessel failure, (3) incore instrument tube rupture, and (4) weld failure-tube ejection.

Global Vessel Failure - Based on the debris composition, it is likely that the molten material reached temperatures greater than $2600{ }^{\circ} \mathrm{C}$ in the central core region before relocation. The temperature of the debris when it reached the lower head is not known; however, material reached the lower head in a molten state, and results of the debris sample examinations suggest slow cooling. The potential for the vessel lower head to withstand prolonged uniform heating from a homogeneous debris bed was examined. Heat transfer from the debris to the lower head was modeled as depicted in Figure 3.5-16c with no allowance for coolant ingress into the debris or between the debris and the lower head. Otherwise optimistic heat transfer assumptions were applied to keep the lower head around the hot spot below the $727^{\circ} \mathrm{C}$ transition temperature from ferritic to austenitic steel. Based on these assumptions, global failure of the lower head due to creep rupture was predicted to occur approximately 2 hours after the molten pour. ${ }^{8}$ Since such a failure did not occur, it follows that debris cooling by water ingress must have occurred within 2 hours of melt relocation.

For accident scenarios in which coolant supply to the vessel is not reestablished, global failure of the lower head by creep rupture is a likely failure mode. Even for scenarios in which coolant is reestablished, if large fractions of the core melt and pour to the lower head, debris cooling in the lower head may be insufficient to preclude global failure by creep rupture.

Local Vessel Failure - Calculations were also performed to assess the margin to failure due to the high temperatures in the hot spot. The effect of the hot spot was approximated by assuming surrounding (background) temperatures consistent with a lower rate of debris to vessel heat transfer as depicted in Figure 3.5-16d. When the hot spot temperatures were imposed on a vessel with cool background temperatures $\left(327^{\circ} \mathrm{C}\right.$ inner surface), the vessel was predicted to survive. When the hot spot temperatures were imposed on a background temperature near the $727^{\circ} \mathrm{C}$ ferritic to austenitic steel transition temperature, lower head failure was predicted to occur 1.5 hours after the molten pour. 
The- latter result, like the predicted global failure within 2 hours, is based on the assumption of no coolant ingress into the debris or between the debris and the lower head. Since the lower head did not fail, the possibility of these cooling mechanisms has been examined further. Cooling by water ingress into the debris is believed necessary to explain why background temperatures were low enough to preclude local failure. Cooling by water ingress into the gap between the debris and the lower head was necessary to explain the rapid cooling rates observed in the metallurgical samples.

A mass-energy balance on the reactor coolant system was performed based on plant data regarding letdown, power-operated relief valve, and makeup flow rates following the molten pour. The results, though not precise, confirm that a decrease in debris internal energy occurred in the 2 hours following the molten pour. This supports the hypothesis that debris cooling occurred at a rate faster than indicated by the physical appearance of the debris samples. ${ }^{8}$

Two other mechanisms for failure of the reactor coolant system pressure boundary were examined based on data obtained from the nozzle samples. These failure mechanisms are depicted in parts (a) and (b) of Figure 3.5-16.

Tube Rupture - The tube rupture mechanism shown in Figure 3.5-16a would result from a combination of high pressure and elevated ex-vessel tube temperatures caused by penetration of hot debris through the tube to ex-vessel locations. Data from some of the TMI-2 instrument nozzles were used to calibrate a melt-penetration model. Model predictions indicate that molten fuel did not penetrate through the instrument tubes to locations below the lower head. Ex-vessel tube rúpture was therefore not a significant threat at TMI-2.

Weld Failure - Tube Ejection - Failure of a penetration tube weld (Figure 3.5-16b) could result from attack and sustained heating by debris surrounding a tube in combination with high reactor coolant system pressure. At TMI-2, metallurgical evidence indicates that the Inconel penetration welds did not melt. ${ }^{9}$ Continuously imposing the peak hot spot temperature of $1100^{\circ} \mathrm{C}$ and full reactor coolant system pressure with other conservative assumptions, failure by this mechanism would be predicted to occur between 4.2 to 16.9 hours after the molten pour. ${ }^{8}$ That is, the localized vessel failure, which was predicted 1.5 hours after the pour in the absence of debris quenching, would have occurred first.

\subsubsection{Debris Coolability}

Debris cooling experiments performed before the TMI-2 reactor pressure vessel investigations did not focus on water cooling of molten debris. Instead, they focused on determining conditions under which water covered beds of internally heated solid particles reach dryout. Dryout occurs when debris to coolant heat transfer rates are high and steam flow rates out of the debris bed prevent sufficient water from reaching the bed interior as illustrated in Figure 3.5-17.

Such experiments and models developed from them indicate some key factors affecting the coolability of debris beds. ${ }^{10}$ These factors include the bed power, the bed configuration, and particle sizes. The higher the power generated in a bed, the more difficult the bed is to cool. The bed power at which some part of a flooded bed drys out is called the dryout power. If flooded from above, deeper debris beds tend to be less coolable than shallow debris beds of the same volume. 
Figure 3.5-18 shows the impact of particle size on the dryout heat flux (dryout power divided by top surface area of the bed) for beds flooded from above." In beds of smaller particles, the surface area for heat transfer is larger, and therefore the vapor generation rates are increased relative to water ingress rates. Many particle sizes are possible during a severe accident, ranging from fractions of millimeters up to centimeter size and larger. There is no one exact particle size that defines a threshold for coolability. However particle sizes of a few millimeters and smaller, which could result from steam explosions (see Section 3.6), are most likely to be noncoolable.

A deep bed, sufficiently small or stratified particle sizes, and/or a small coolant fraction could produce dryout in the bed even after it is initially quenched. ${ }^{12}$ Forced circulation of coolant through some possible configurations of in-vessel debris would be required to prevent dryout. Maintaining forced circulation was considered to be of paramount importance once it was reestablished at TMI-2.

Even with forced circulation, melting in the interior of a large debris bed could occur, and quenched or partially quenched debris could remelt even with forced circulation. Natural processes (such as capillary flow) tend to cause a melting debris bed to crumble. That is, melt flows through the open porosity toward the debris bed boundary where it freezes and forms a crust. If the crust is a poor conductor (e.g., an oxide), then very little of the energy is transferred out of the bed. A molten pool would form and very high temperatures could be attained in the melt. Upward radiative heat transfer could cause melting of vessel upper internal structures, which would fall and increase the metallic content of debris in the lower head. Models have been developed to analyze debris bed heatup, remelting, and lower head response. ${ }^{13}$

Clearly the cooling of lower head debris that occurred at TMI-2 was of crucial importance in preyenting vessel failure. This cooling is believed to have occurred in two ways. First, a slow cooling mode in which channels or cracks in the debris allowed for infusion of water that cooled the debris near the channels but left interior portions hot. Second, a rapid cooling mode in which gaps or channels between the lower debris crust and the vessel allowed relatively high flow rates of coolant between the debris and the vessel.

The analyses of TMI-2 structural failure modes indicate that, even with the benefit of the unanticipated cooling mechanisms that occurred at TMI-2, more debris in the lower head, hotter debris in the lower head, or failure to keep the debris covered by water could have led to global or local temperature-induced failure of the lower head.

\subsubsection{Advanced Design Concepts}

Several studies have been conducted to examine the potential for maintaining core and structural debris within the reactor vessel by flooding the containment to the extent that water covers the outer surface of the lower portion of the reactor vessel..$^{14,15,16}$ In general, experiments have shown that the required wall cooling could be accomplished without departure from nucleate boiling at the outer wall surface. ${ }^{16,17}$ Nevertheless, there are many practical difficulties from the standpoint of providing the volume of water that would be necessary to invoke this strategy in an assured and timely manner because existing plants were not designed to provide such a flooding capability (see also Section 3.7.7). 
Advanced designs such as the Westinghouse AP600 have implemented design features aimed at assuring in-vessel retention of molten debris. First steps have been taken to allow vessel depressurization thereby decreasing the differential pressure loads imposed on the lower head. Second, the lower head has been designed without penetrations so failure mechanisms associated with such penetrations are precluded. Finally, the reactor cavity can be flooded with water, so that heat transfer through the lower head to surrounding water can be used to prevent lower head failure due to creep rupture. ${ }^{17}$ 


\section{Table 3.5-1 Average TMI-2 Lower Head Debris Composition by Quadrant (wt \%)}

\begin{tabular}{l|c|c|c|c}
\hline Element & Southeast & Southwest & Northeast & $\begin{array}{c}\text { Original } \\
\text { TMI-2 Core }\end{array}$ \\
\hline $\mathrm{U}$ & 72.3 & 70.8 & 68.2 & 65.8 \\
$\mathrm{Zr}$ & 14.1 & 15.2 & 15.2 & 18.0 \\
$\mathrm{In}$ & 0.28 & 0.52 & 0.52 & 0.3 \\
$\mathrm{Cr}$ & 0.33 & 0.93 & 0.93 & 1.0 \\
$\mathrm{Fe}$ & 0.74 & 0.28 & 0.028 & 3.0 \\
$\mathrm{Mn}$ & 0.03 & 0.81 & 0.10 & 0.8 \\
$\mathrm{Ni}$ & 0.099 & 84.3 & 85.1 & 0.9 \\
\hline Total & 87.8 & & & 92.14 \\
\hline
\end{tabular}

a Extracted from Reference 1, which cautions that because of the small number of samples examined these data should be used with caution.

b Composition of original TMI-2 core is computed in Reference 1.

c Below analytic detection limit. Elements $\mathrm{Sn}, \mathrm{Ag}, \mathrm{Al}, \mathrm{Mo}$, and $\mathrm{Nb}$ were also below their analytic detection limits. Detection limits vary from element to element; however, a nominal value is approximately $0.1 \mathrm{wt} \%$.

d The total is for measurable constituents. Oxygen was not measured. 


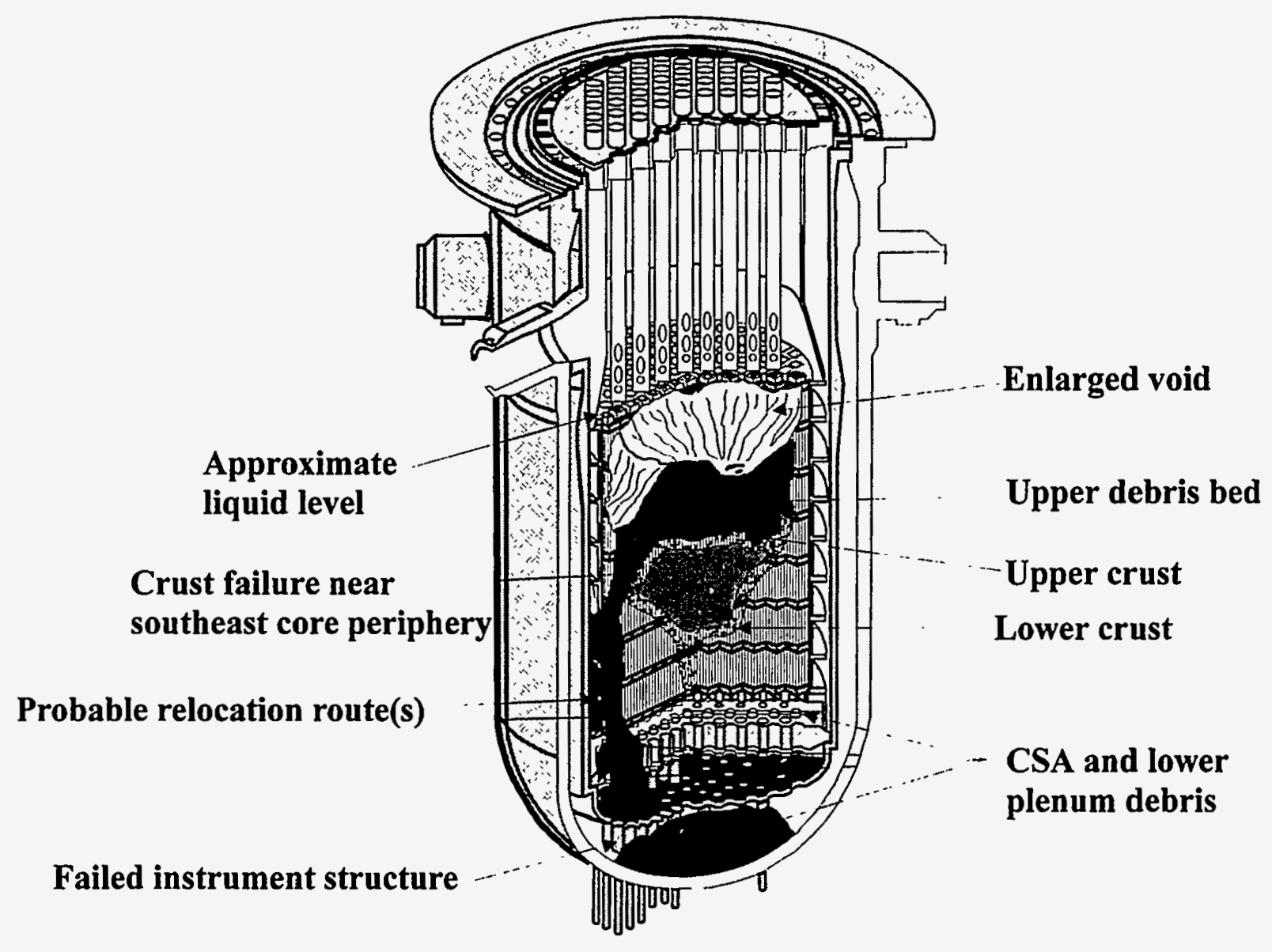

Figure 3.5-1 Hypothesized TMI-2 core configuration during relocation 


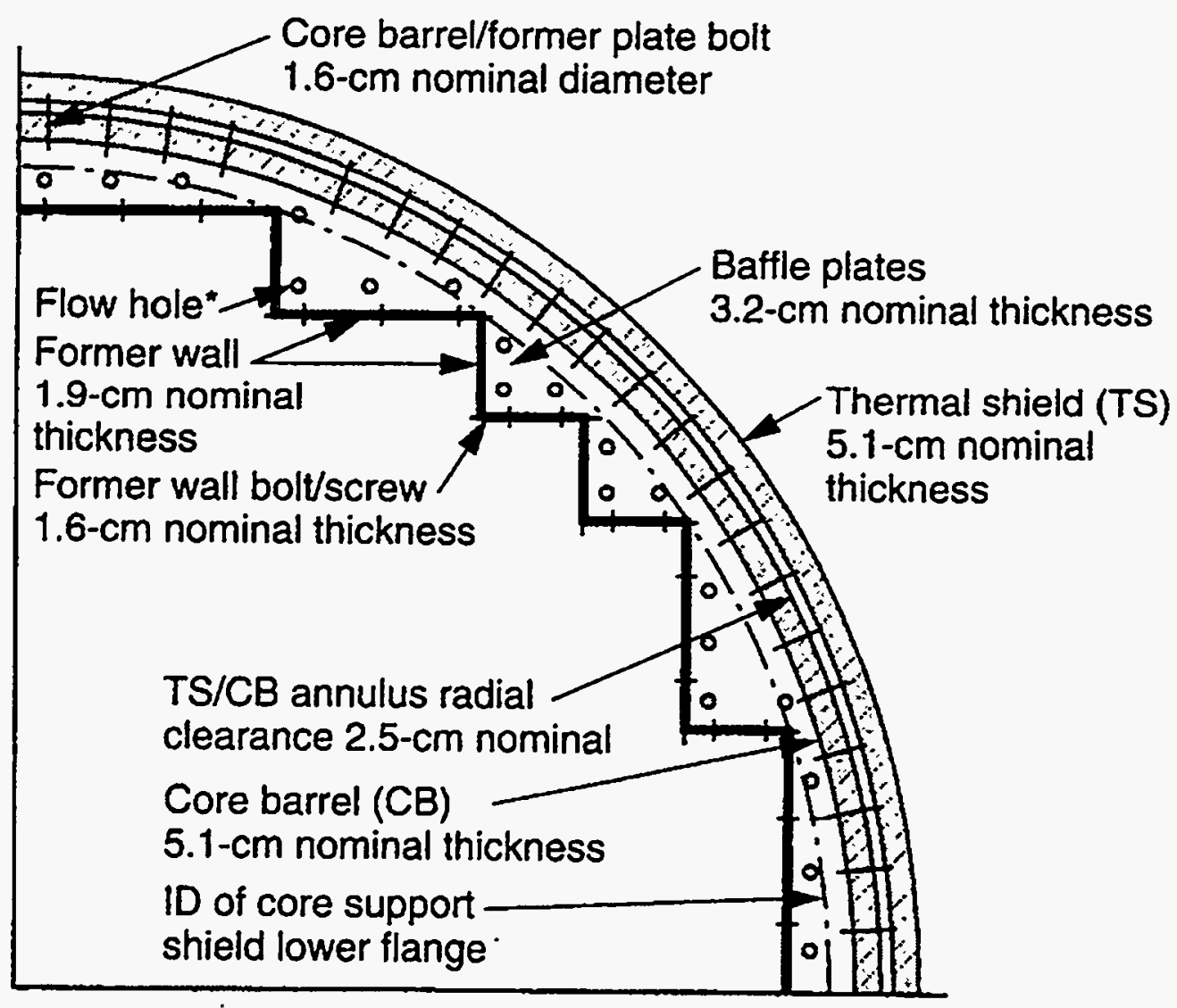

Figure 3.5-2 TMI-2 structurtes surrounding the core 


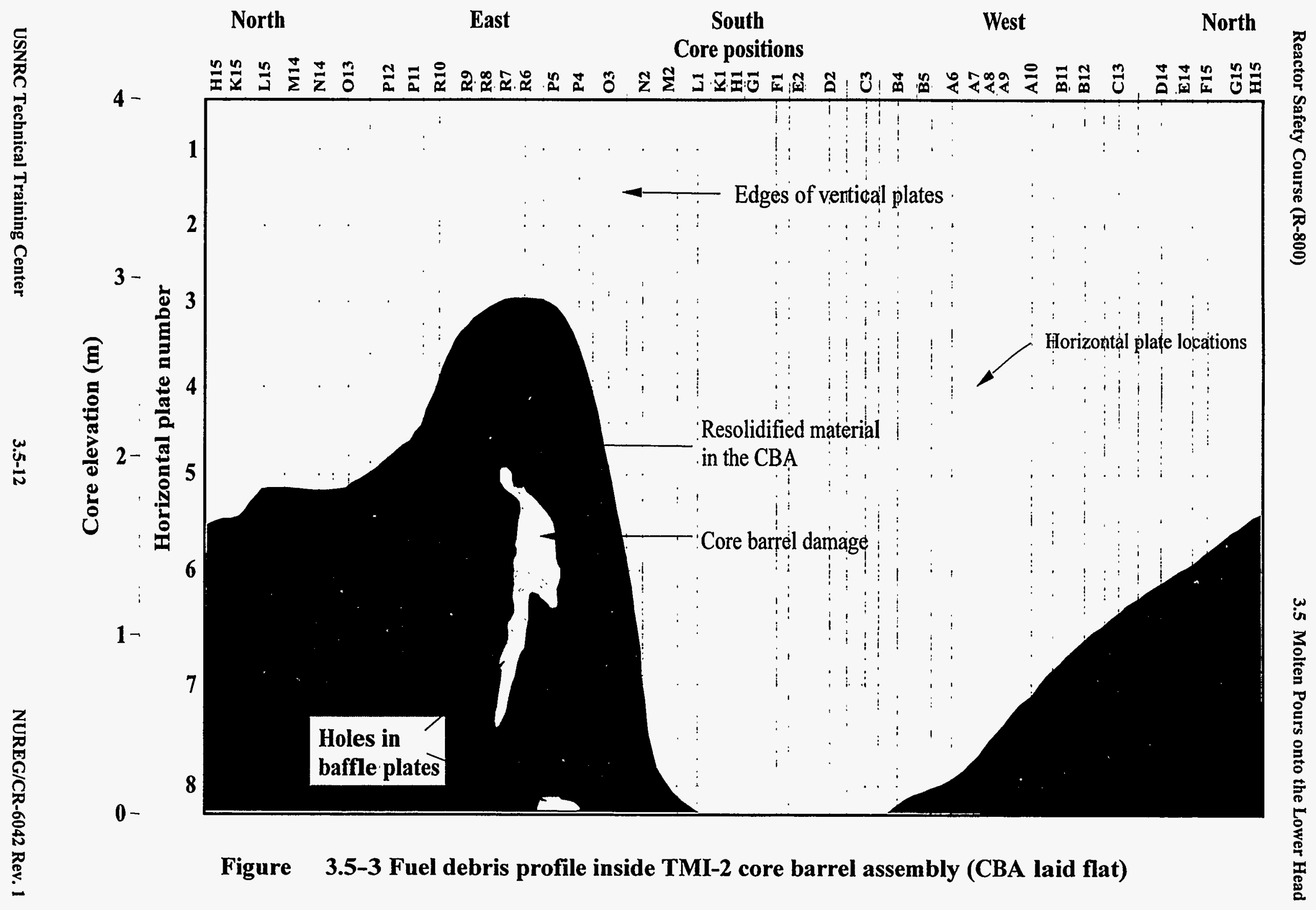


Fuel assembly Instrument support plate

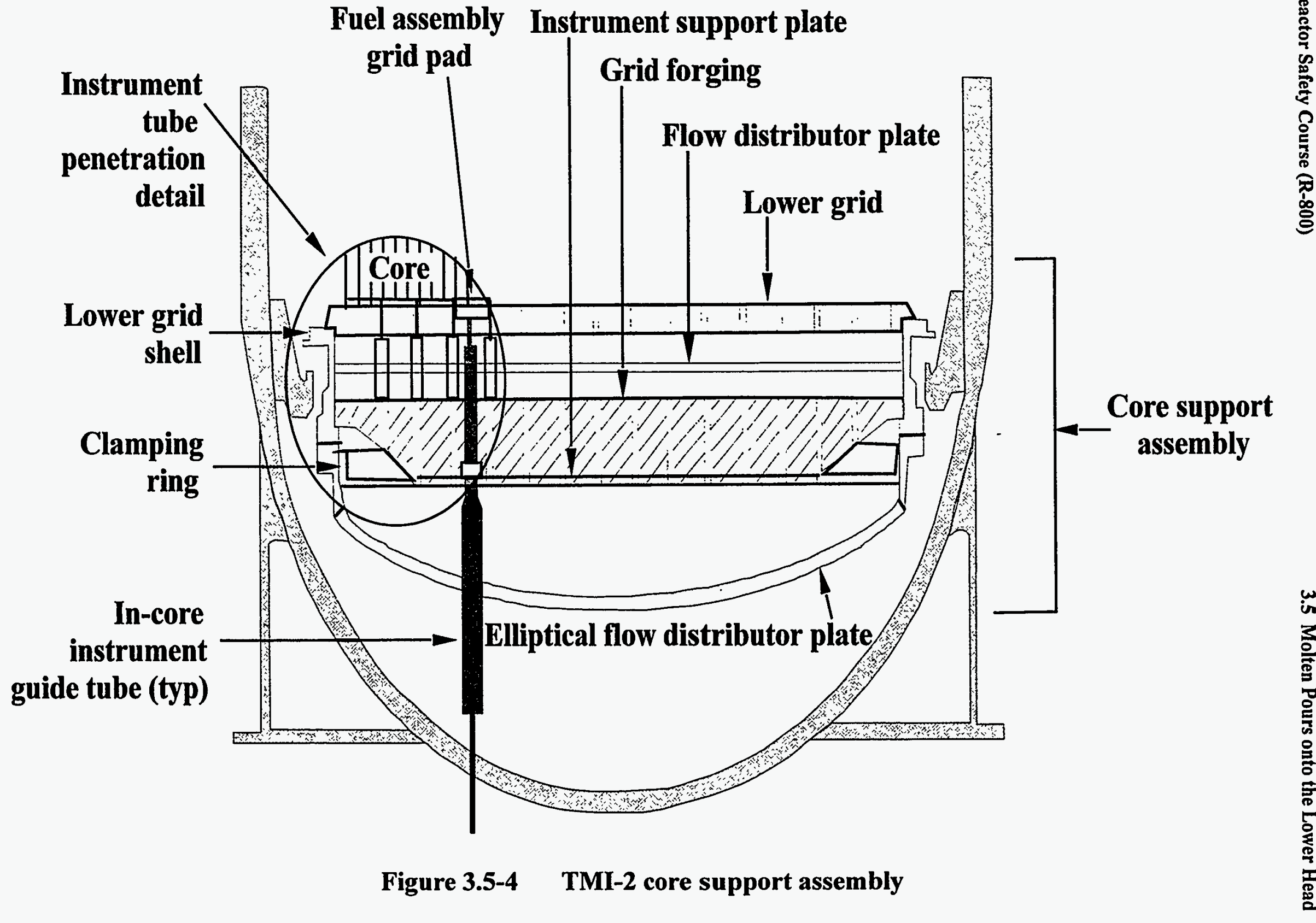

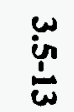

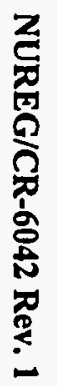

Figure 3.5-4 TMI-2 core support assembly

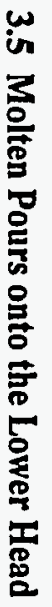




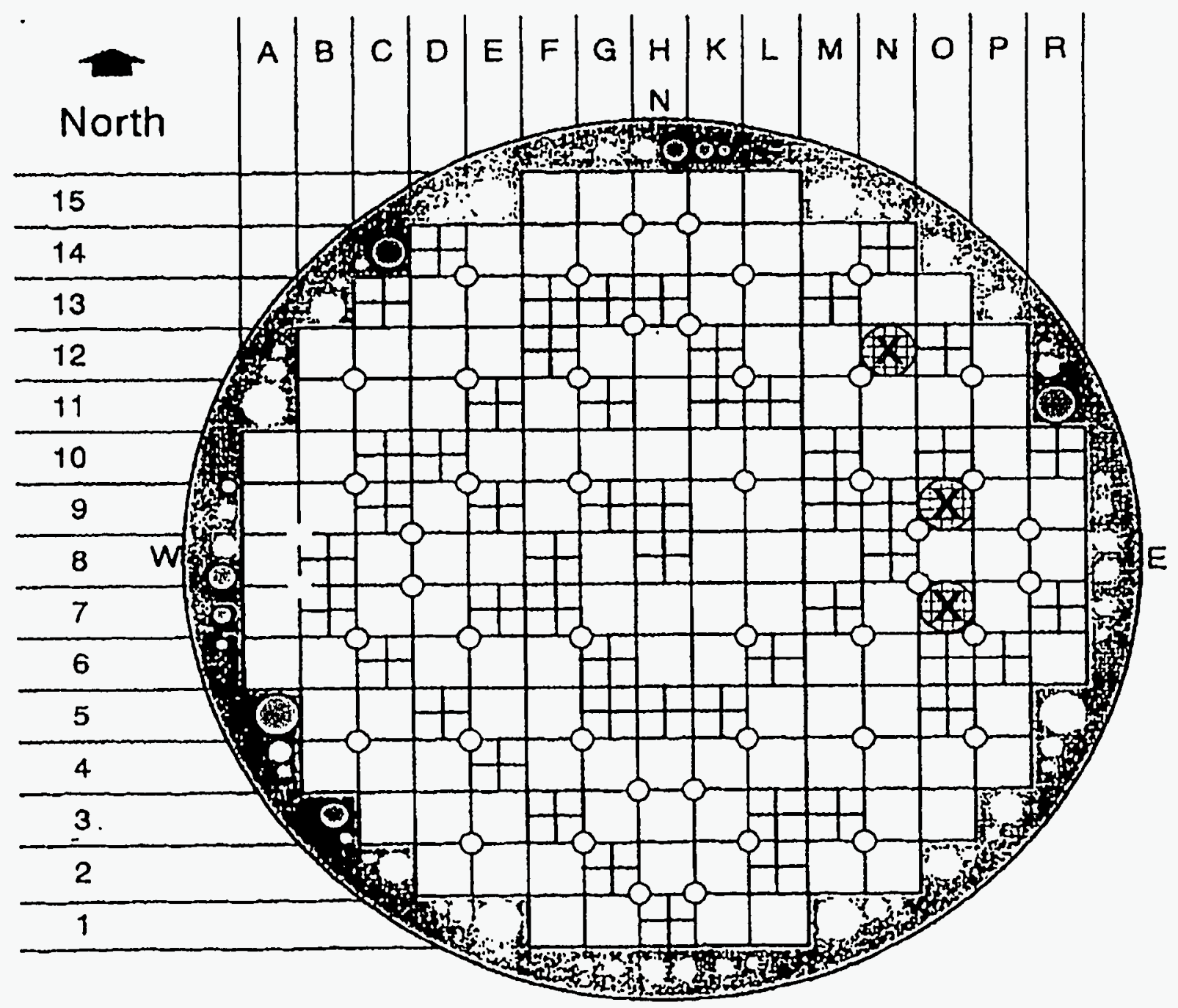

6

Resolidified material flowed through the shaded holes in the grid forging

$X$ Location of resolidified material between the lower grid and the flow distributor plate

$\Leftrightarrow$ Location of resolidified material between distributor plate and the grid forging

Figure 3.5-5 Locations of solidified material in TMI-2 core support assembly 


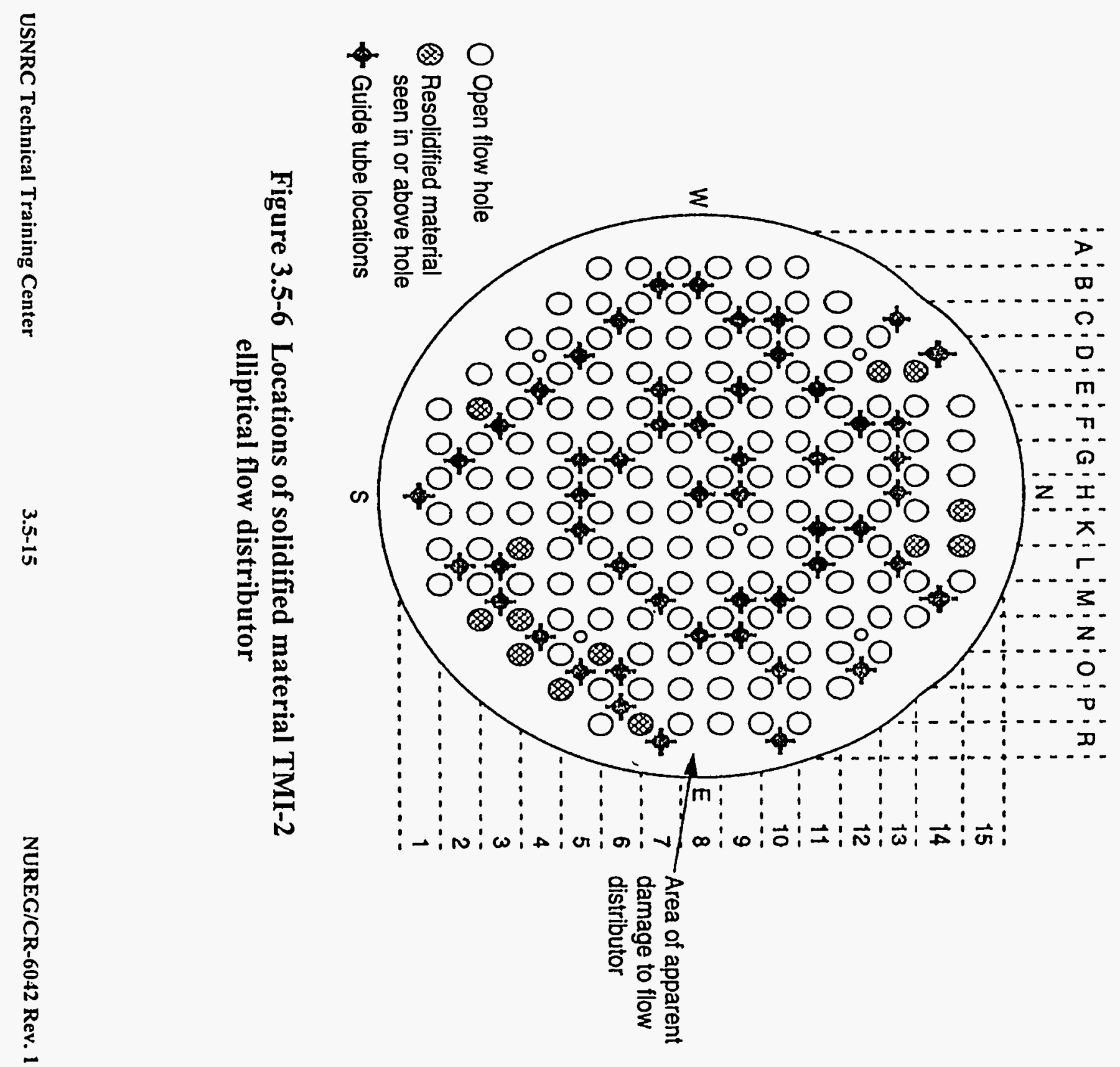




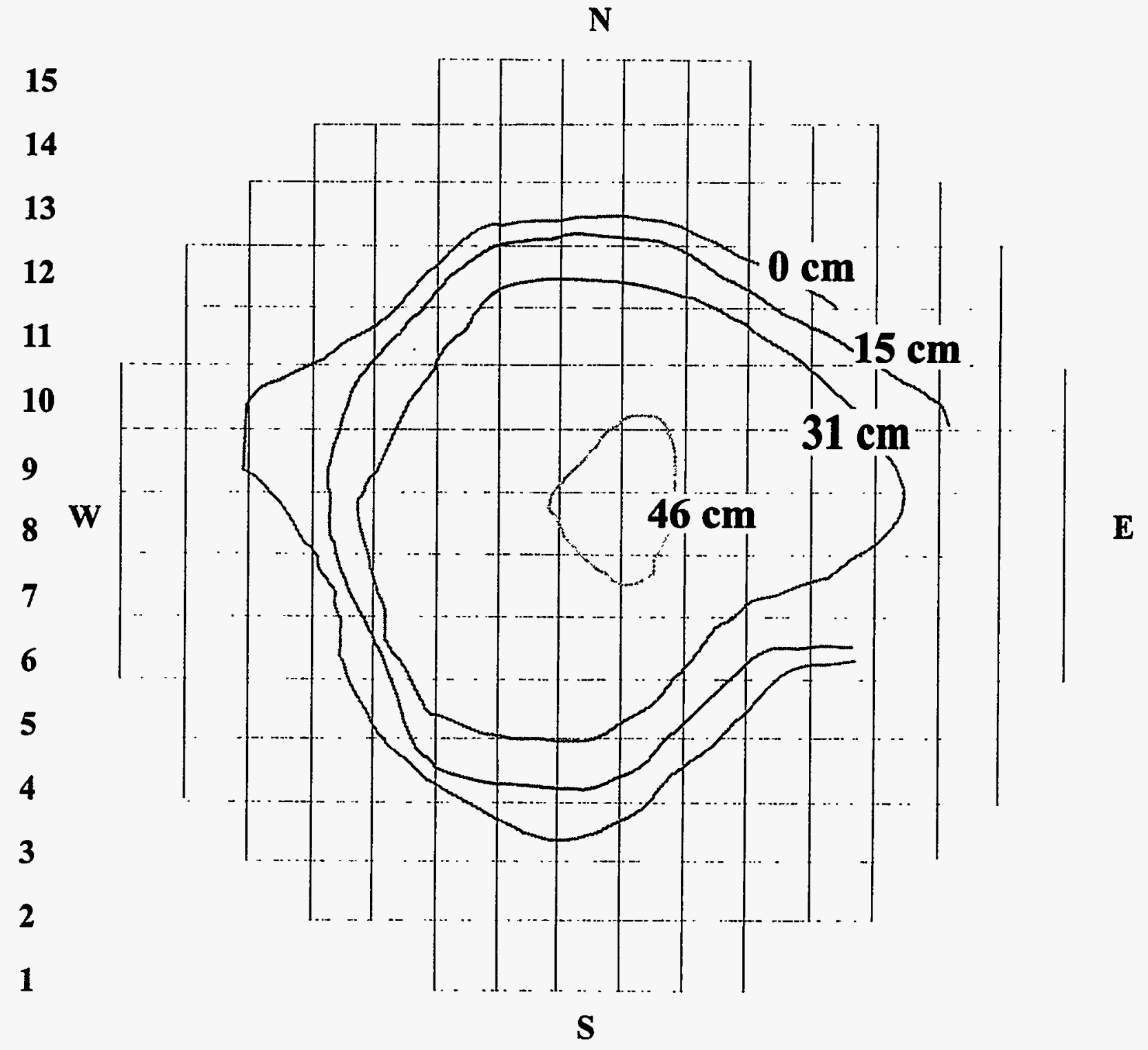

$\begin{array}{lllllllllllllll}\mathbf{A} & \mathbf{B} & \mathbf{C} & \mathbf{D} & \mathbf{E} & \mathbf{F} & \mathbf{G} & \mathbf{H} & \mathbf{K} & \mathbf{L} & \mathbf{M} & \mathbf{N} & \mathbf{O} & \mathbf{P} & \mathbf{R}\end{array}$ Figure 3.5-7 TMI-2 hard layer debris depths in lower head 

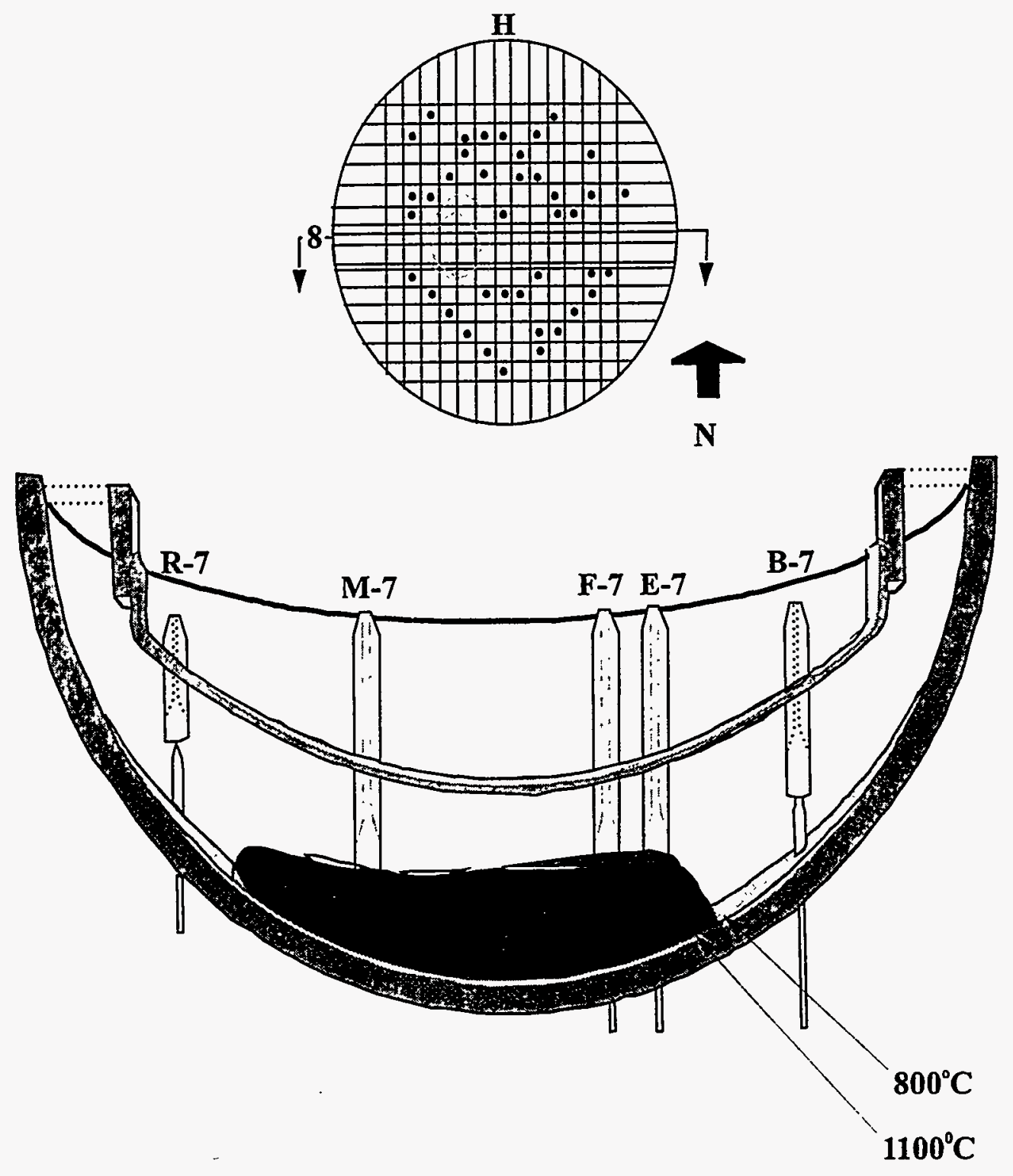

Figure 3.5-8 TMI-2 lower-head cross section of hard debris, row 7 


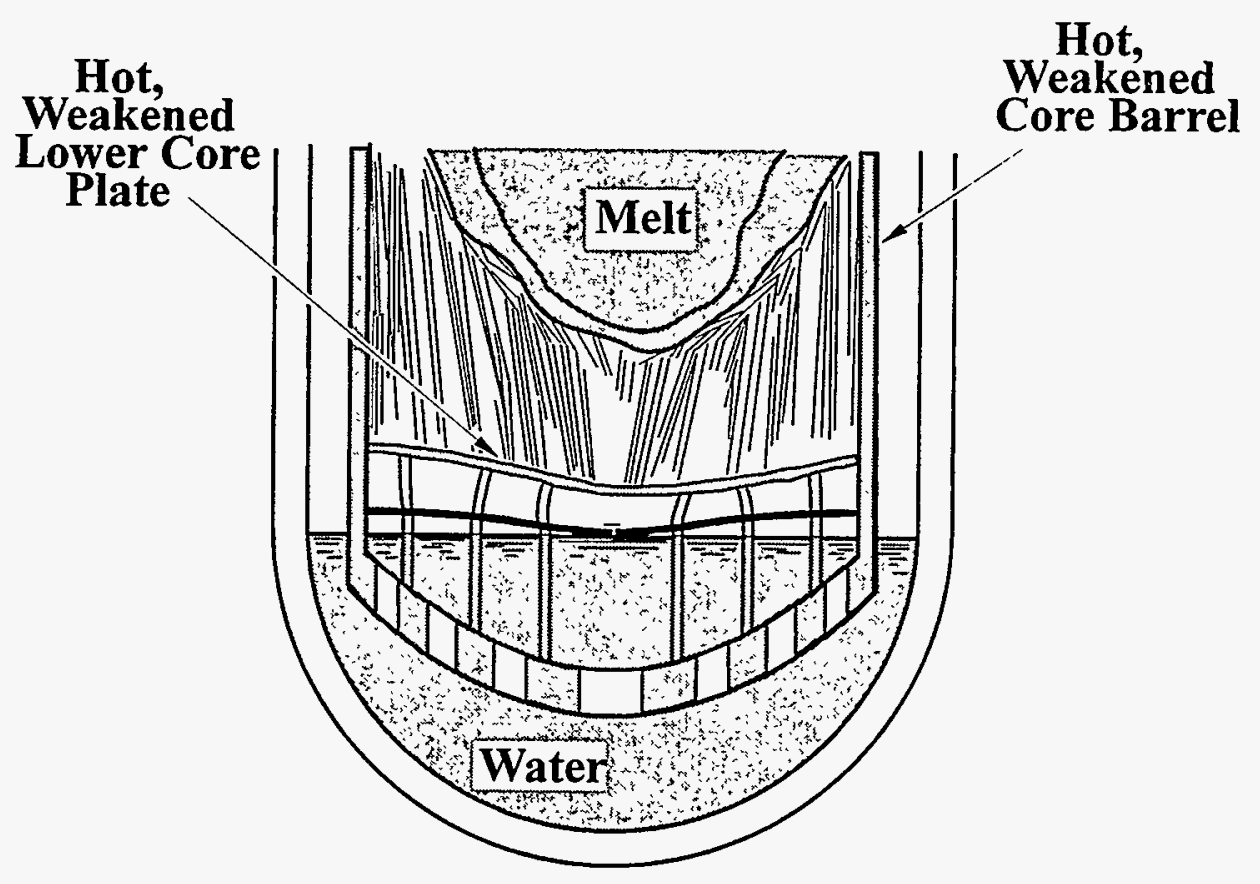

Figure 3.5-9 Visualization of the downward progress of a coherent molten mass as the below-core structures weaken 


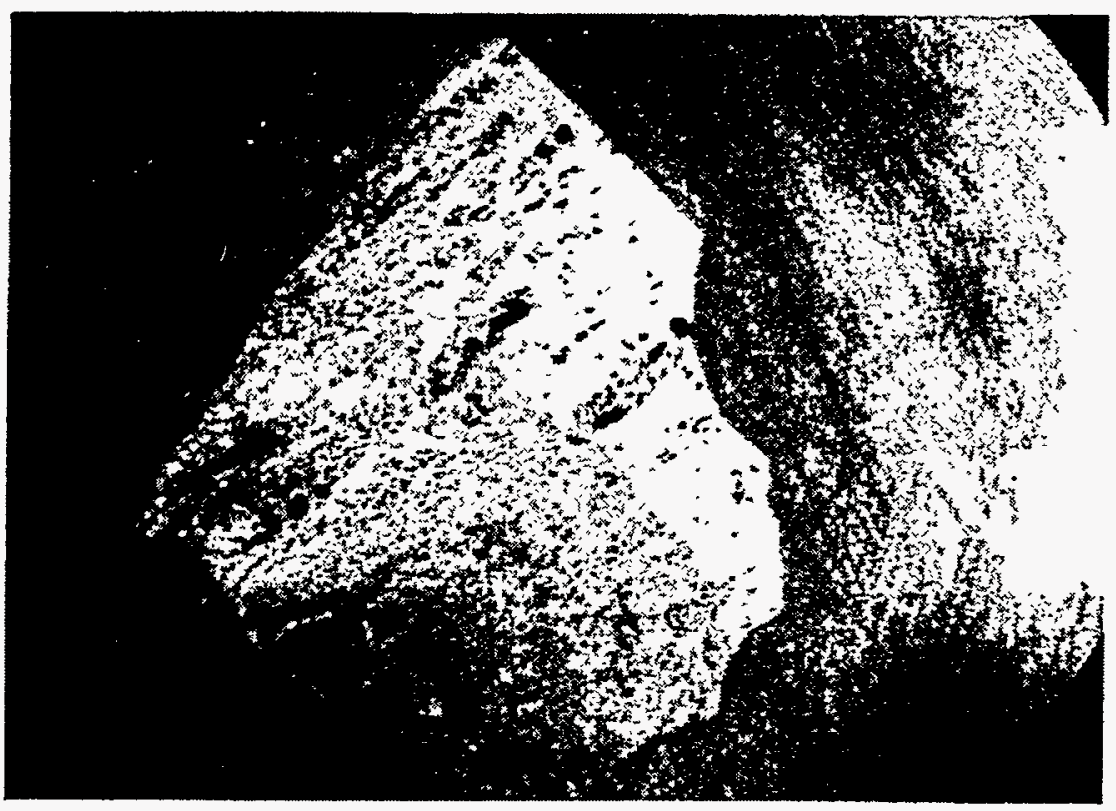

(a)

$90 \mathrm{~m} 141 \times 2.9$

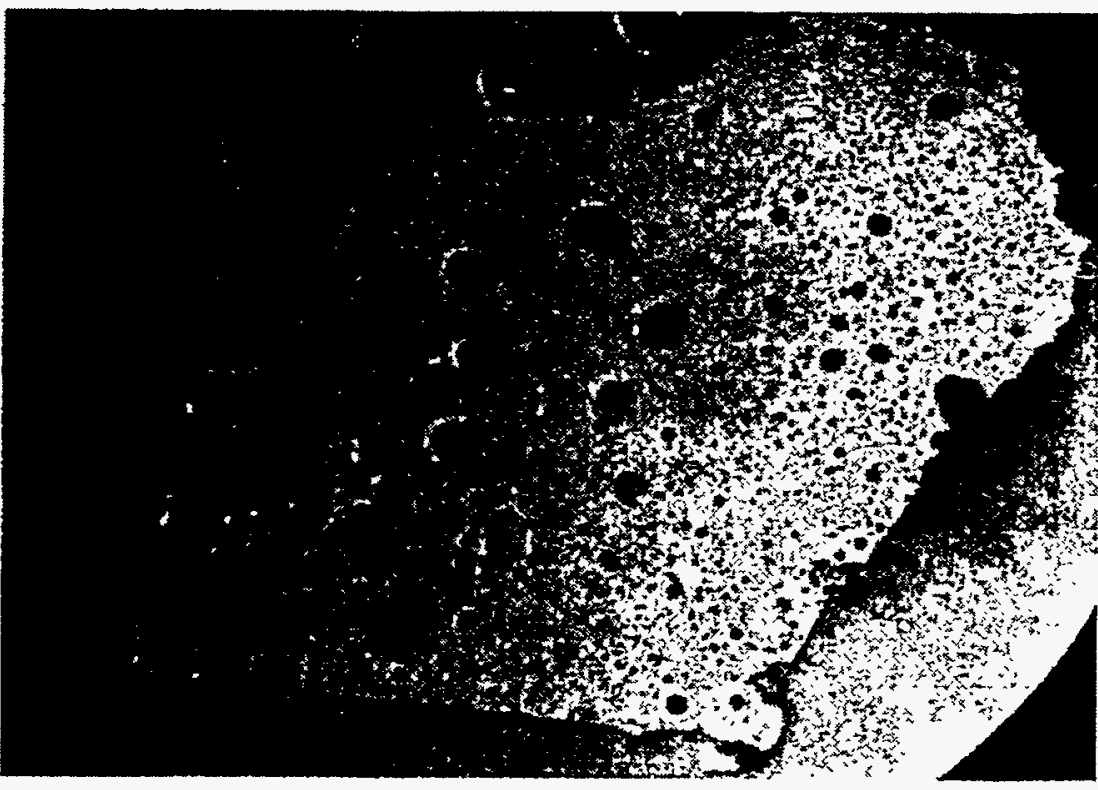

(b)

$90 \mathrm{~m} 142 \times 2.8$

Figure 3.5-10 Cross-sectional views of TMI-2 hard layer debris sample 1-11-R

(a) Longitudinal section

(b) Transverse section 


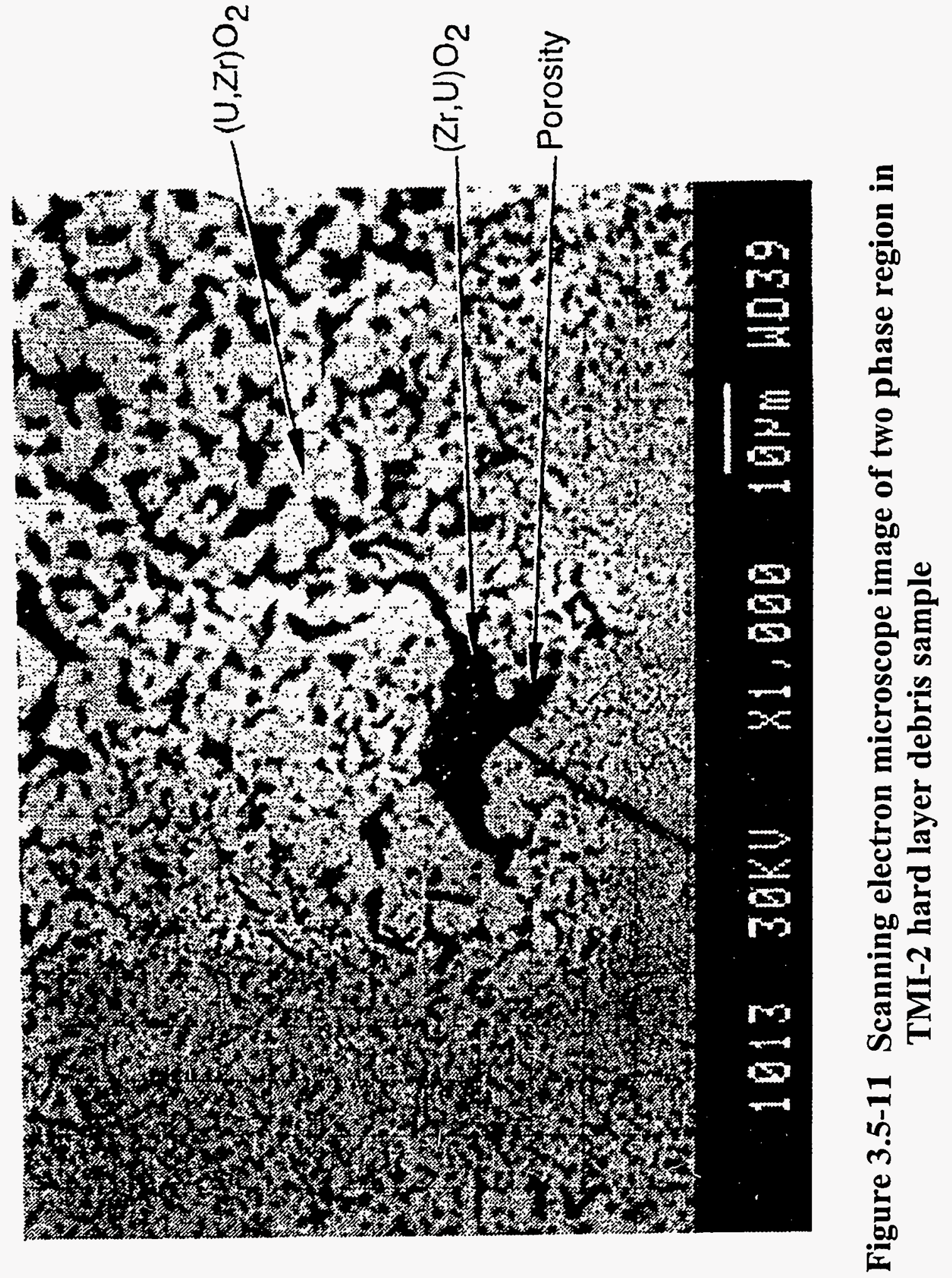




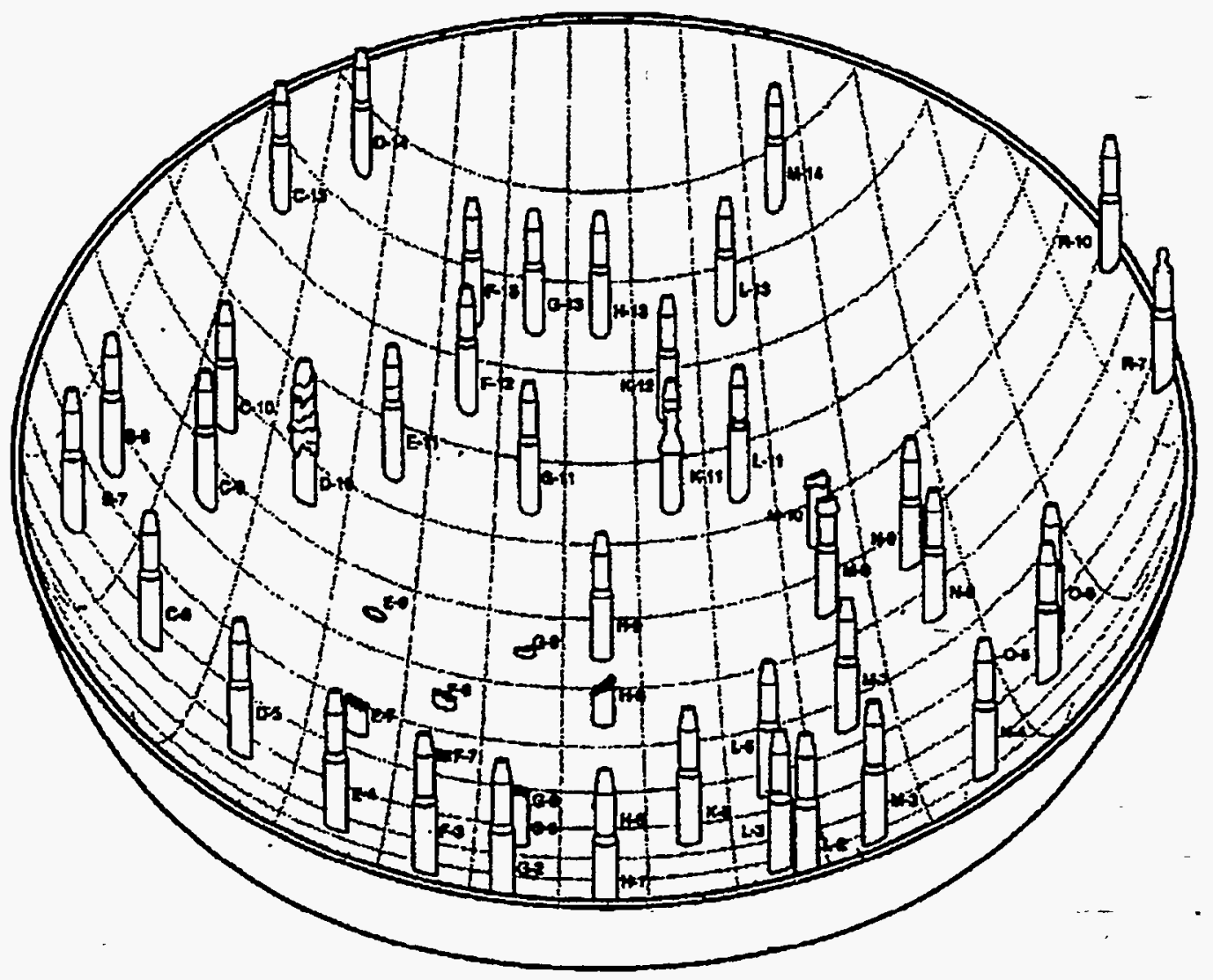

Figure 3.5-12 TMI-2 nozzle damage profile 


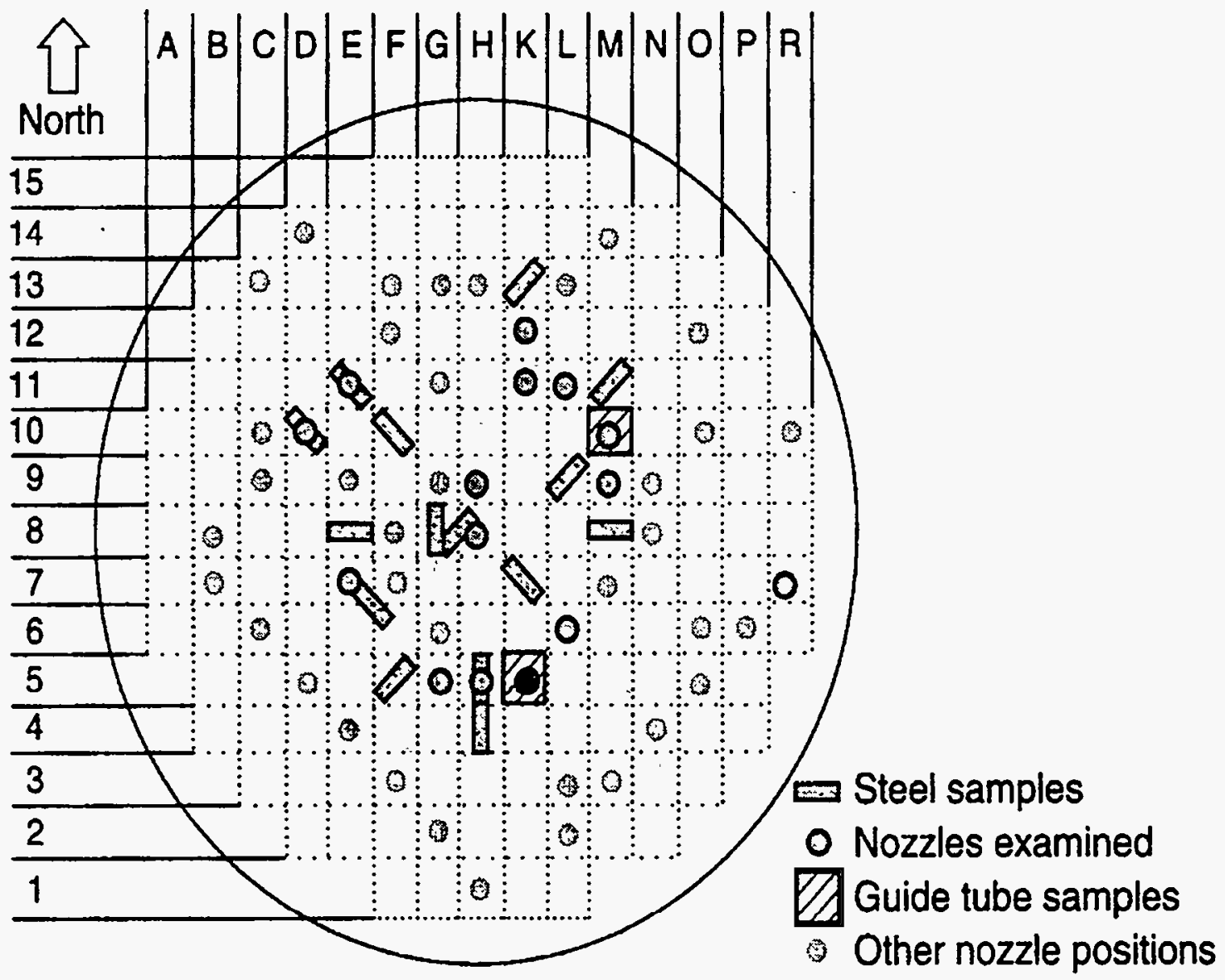

Figure 3.5-13 Location of lower-head steel, nozzle, and guide tube samples 


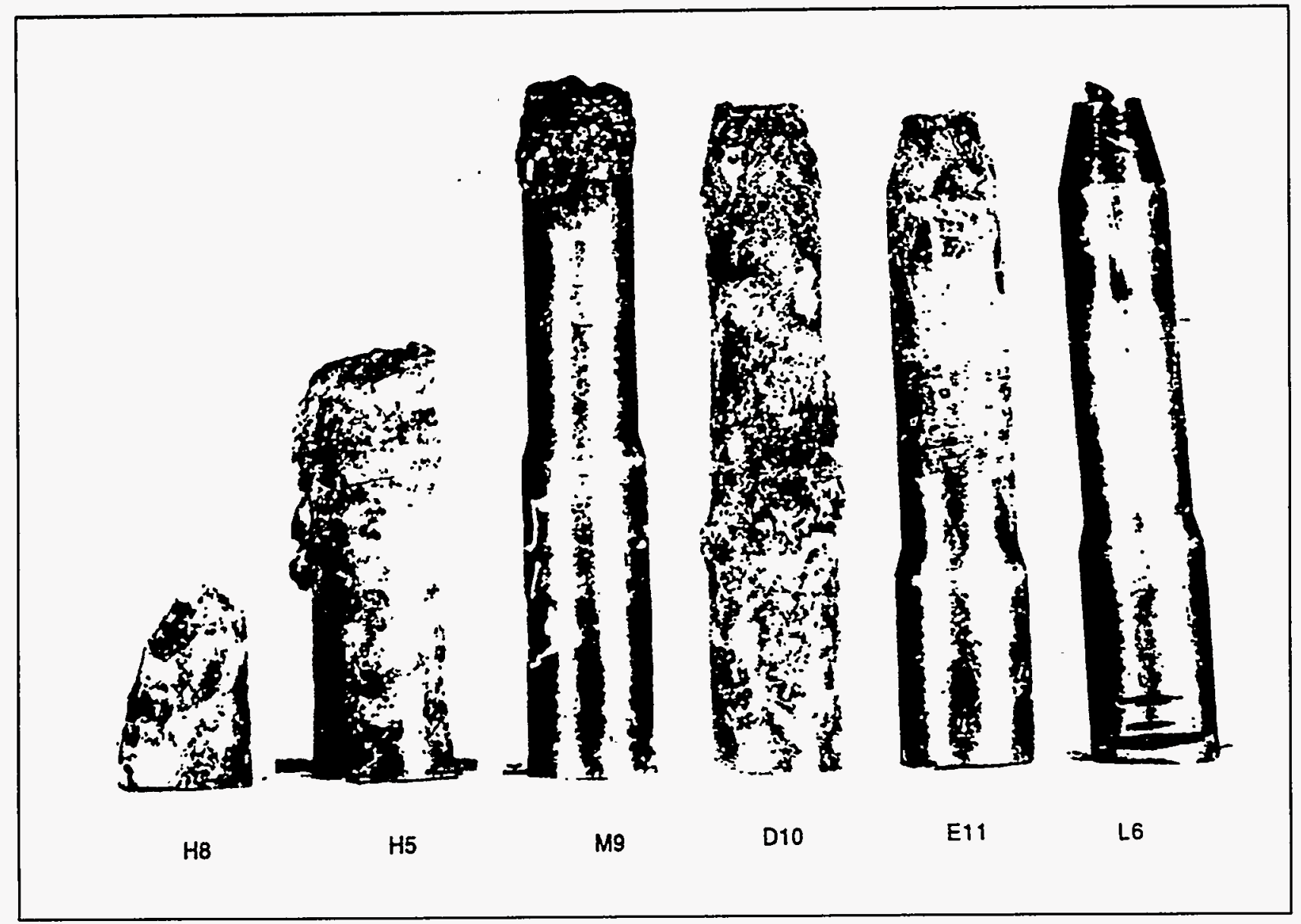

Figure 3.5-14 As-removed appearance of six TMI-2 nozzles 


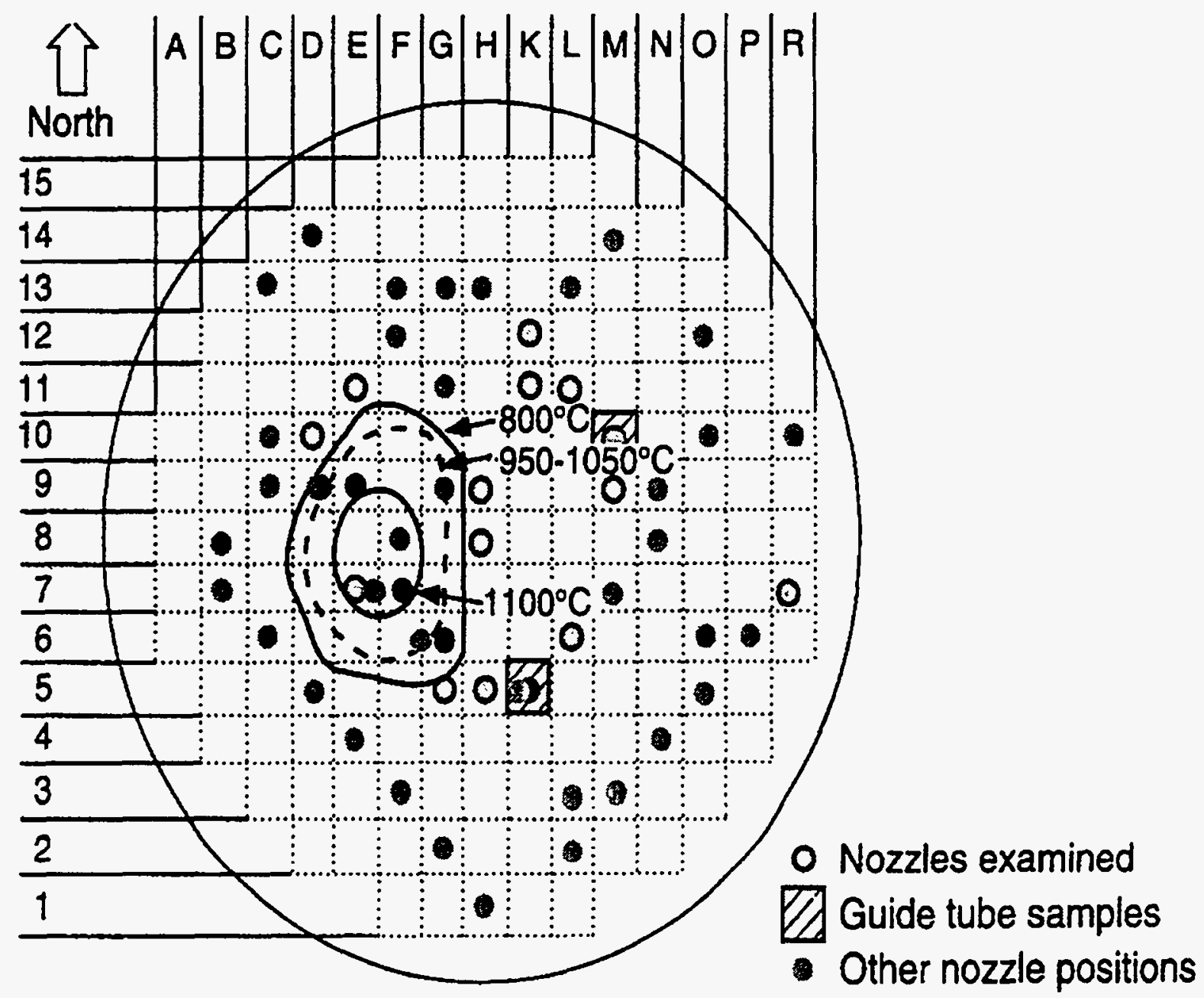

Figure 3.5-15 Lower-head hot spot and nozzle guide tube locations 

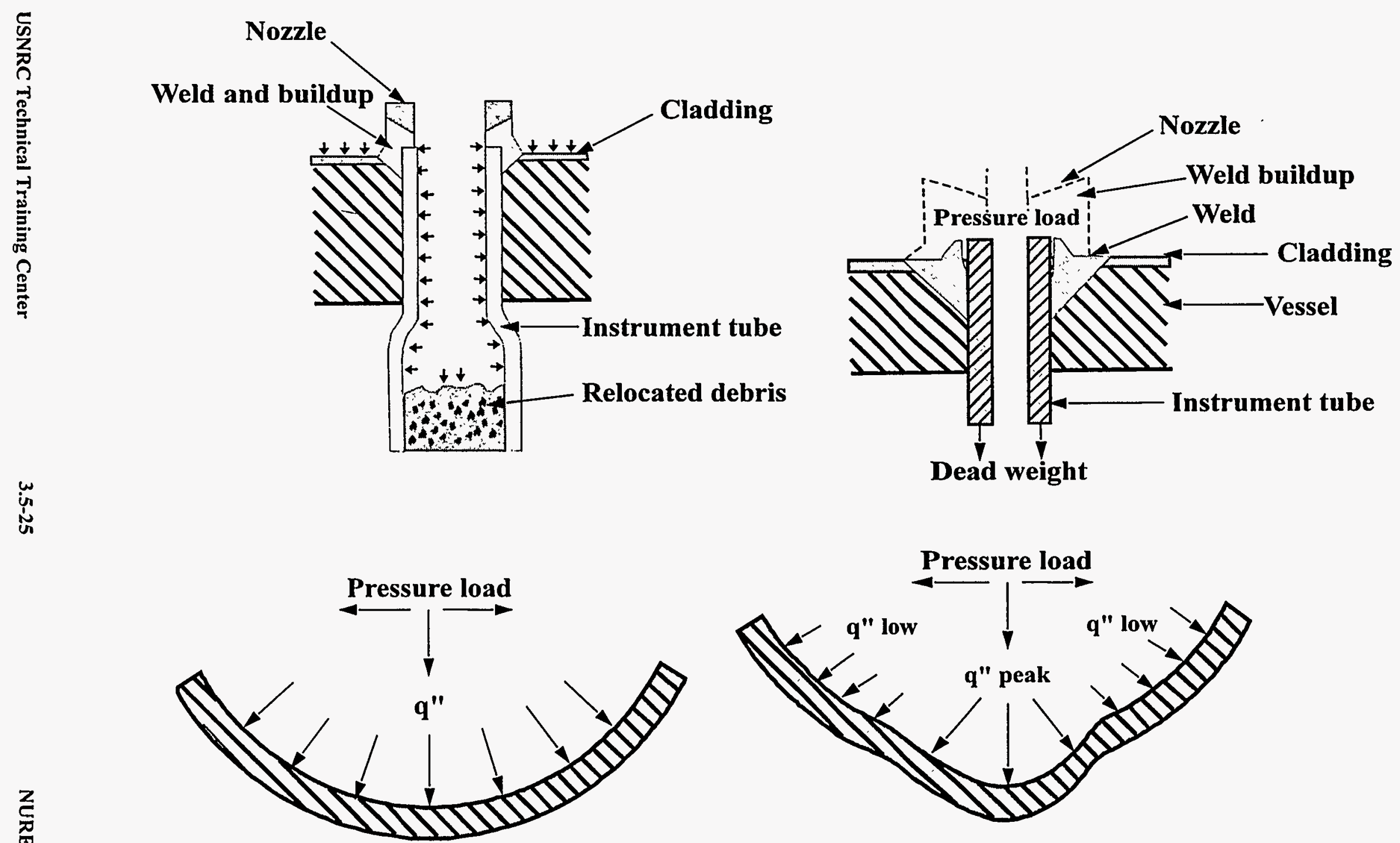

Figure 3.5-16 Failure mechanism considered in TMI-2 analyses: (a) tube rupture,

(b) weld failure--tube ejection, (c) global vessel failure, and

(d) localized vessel failure 


\section{Overlying Water}

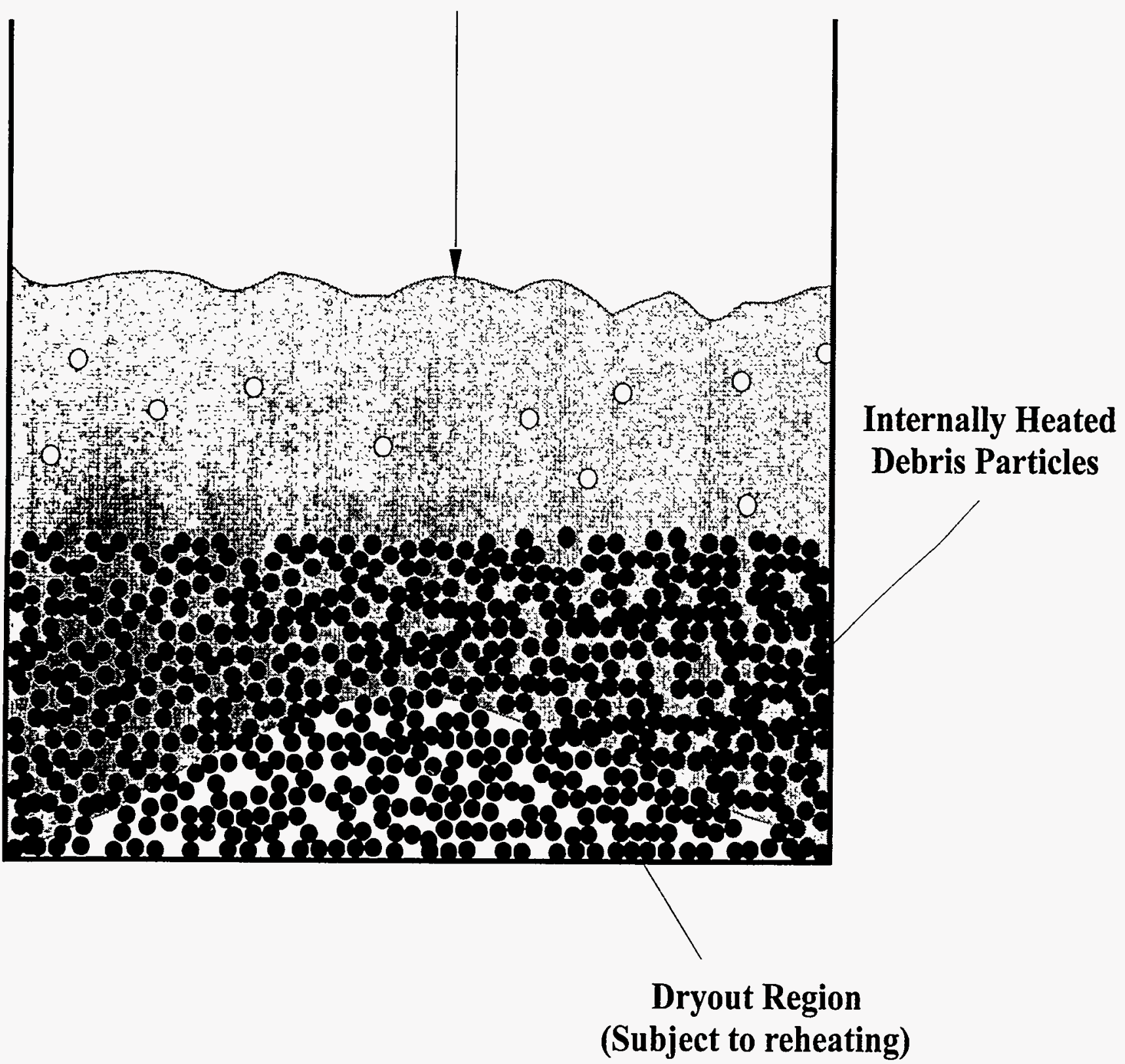

Figure 3.5-17 Typical debris bed dryout experiment 


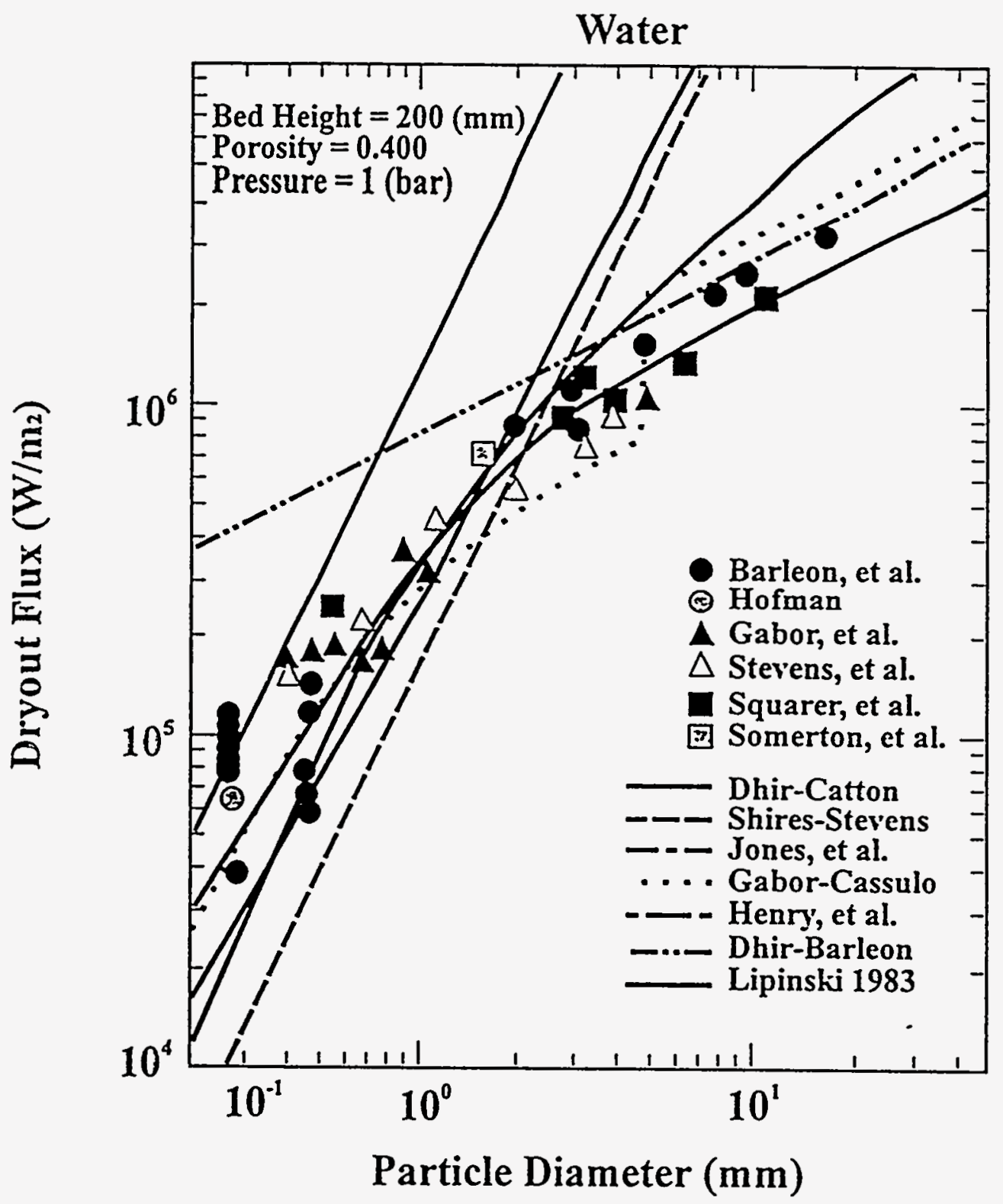

Figure 3.5-18 Debris bed dryout heat flux versus particle diameter for water 


\section{References for Section $\mathbf{3 . 5}$}

1. J. R. Wolf, D. W. Akers, and L. A. Neimark, "Relocation of Molten Material to the TMI-2 Lower Head," Nuclear Safety, Vol. 35(2), 269-279, JulyDecember 1994.

2. V. R. Fricke, "Quick-Look Inspection Results," GPU Technical Report TPO/TMI-026, Rev. 0, December 1982.

3. D. W. Akers and B. X. Schuetz, "Physical and Radiochemical Examinations of Debris from the TMI-2 Lower Head," Nuclear Safety, Vol. 35, No. 2, July-December 1994.

4. G. E. Korth, "Peak Accident Temperatures of the TMI-2 Lower Pressure Vessel Head," Three Mile Island Reactor Pressure Vessel Investigation Project Achievements and Significant Results, Organisation for Economic Cooperation and Development, Paris, France, October 1994.

5. D. R. Diercks and G. E. Korth, "Results of Metallographic Examinations and Mechanical Tests of Pressure Vessel Samples from the TMI-2 Lower Head," Nuclear Safety, Vol. 35, No. 2, 301-312, July-December 1994.

6. F. A. Kulacki, "Estimates of Failure Time for LWR and LMFBR Vessels Following a Core Meltdown Accident," Ohio State University, Department of Mechanical Engineering, USNRC contract AT-(49-24)-0149 Report, February 1976.

7. Commonwealth Edison Company, "Zion Probabilistic Safety Study," Chicago, IL 1981.
8. J. Rempe, L. Stickler, S. Chavez, G. Thinnes, R. Witt, and M. Corradini, "Margin-to-Failure Calculations for the TMI-2 Vessel," Nuclear Safety, Vol. 35, No. 2, July-December 1994.

9. D. R. Diercks and L. A. Neimark, "Results of Mechanical Tests and Supplementary Microstructural Examinations of the TMI-2 Lower Head Samples," NUREG/CR-6187 (ANL94/8) [TMI V(93)AL02], June 1993.

10. R. J. Lipinski, "A Coolability Model for Postaccident Nuclear Reactor Debris," Nuclear Technology, 65, pp. 53-66, 1980.

11. R. Lipinski, "Debris Bed Dryout," Appendix 3.2-B of Thermal-Hydraulic Process Modeling in Risk Analysis: An Assessment of the Relevant Systems, Structures, and Phenomena, NUREG/CR-3986, SAND84-1219, August 1984.

12. K. R. Boldt et al., "SNL-LWR Severe Core-Damage Phenomenology Program, LWR Degraded Core Coolability Program, Vol. 2," NUREG/CR-2725, SAND82-1115.

13. S. A. Hodge, C. R. Hyman, R. L. Sanders "BWR Lower Plenum Debris Bed (BH) Package Reference Manual," MELCOR Computer Code Manuals, NUREG/CR-6119, SAND93-2185, Vol. 2, March 1995.

14. S. A. Hodge, J. C. Cleveland, T. S. Kress, and M. Petek, "Identification and Assessment of BWR In-Vessel Strategies," NUREG/CR-5869, ORNL/TM-12080, October 1992. 
15. R. E. Henry and H. K. Fauske, "External Cooling of a Reactor Vessel Under Severe Accident Conditions," Nuclear Engineering Design, 139, pp. 31-43, 1993.

16. R. E. Henry et al., "Cooling of Core Debris Within the Reactor Vessel
Lower Head," Nuclear Technology, 101, pp.385-399, 1993.

17. T.G. Theofanous and M.L. Corradini, "The containment of Severe Accidents in the Advanced Passive Light Water Reactors," Agenzia Nazionale per la Protezione del'Ambiente, March 1995. 


\subsection{In-Vessel Fuel-Coolant Interactions}

When molten core material (fuel) comes into contact with liquid water (coolant), a variety of different fuel-coolant interactions (FCIs) can occur. The FCIs can range from quiescent boiling to explosive fragmentation of the fuel with rapid steam generation. An explosion caused by the rapid fragmentation of fuel and vaporization of water due to heat transfer from the fragmented fuel is called a steam explosion. If the melt contains unoxidized metals, exothermic metal-water reactions can accompany the fuel coolant interaction, resulting in enhanced energy release and the generation of hydrogen. The nature of the FCI determines the rates of steam and hydrogen production and the potential for damaging the reactor vessel or containment building. Much theoretical and experimental research has been devoted to FCIs over the last three decades. This research is summarized in several review articles. ${ }^{1,2,3,4,5}$

\subsubsection{Steam Explosions}

Steam explosions occur when heat is transferred from the melt to water on a very short time scale (approximately $1 \mathrm{msec}$.). Steam explosions have occurred ever since man began to work with molten metals. The first known written record of such an explosion appears in the Canterbury Tales of the 14 th century. $^{6}$ Destructive steam explosions have occurred in aluminum, steel, and copper foundries; arc-melting facilities; paper mills; granulation plants; and (some believe) Chernobyl. ${ }^{7,8,9,10,11}$

The four major stages of a steam explosion are:

1. Initial coarse mixing of melt and water during which heat transfer is generally characterized by stable film boiling (Figure 3.6-1),

2. a triggering event that causes local destabilization of film boiling and local fragmentation of melt into small drops, on the order of 0.01 to $0.1 \mathrm{~mm}$ in diameter,

3. propagation of the region of rapid heat transfer through the coarse mixture, and

4. explosive expansion driven by steam at high pressure.

In the absence of a triggering event, a nonexplosive FCI would occur. Coarse mixing would result in some quenching of the melt with associated steam and hydrogen production.

\subsubsection{Conditions Affecting Steam Explosions}

The probability and magnitude of steam explosions depend on various initial and boundary conditions, including:

- mass, composition, and temperature of the molten material,

- water mass, depth, and temperature,

- vessel geometry, degree of confinement, and the presence and nature of flow restrictions and other structures,

- fuel-coolant contact mode, in particular, for melts poured into water, the melt entry velocity and pour diameter,

- the ambient pressure, 
- the timing and strength of any external trigger that might be applied (e.g. in an experiment, not a reactor accident).

Intermediate conditions that strongly influence the probability and magnitude of steam explosions include:

- the extent of coarse mixing (drop sizes and surface areas),

- the rate of heat production by the exothermic oxidation of molten metals and partially oxidized materials by the surrounding coolant, and

- the occurrence, timing, and strength of a spontaneous trigger (see below).

During mixing, some of the molten drops may spontaneously fragment into much smaller drops, on the order of 0.01 to 0.1 $\mathrm{mm}$ in diameter. This local fragmentation event is generally called a trigger. It may be produced by natural oscillations in the vapor film about the drop leading to fuel-coolant contact, or it may be induced by shock waves from falling objects, contact of the fuel with the bottom surface, entrance of the fuel into a region of colder water, or by turbulence generated in part of the mixing region. If the fragmentation is rapid enough, local shock waves can be produced, which can cause neighboring drops to fragment. If such a chain reaction escalates, a steam explosion can result.

Steam explosions can occur for a variety of high-temperature molten materials including uranium and its oxides. Spontaneous (no external trigger) steam explosions have been observed for aluminum, iron, tin, and associated oxides in all possible contact modes including melt pours, stratified water over melt, and reflooding. High ambient pressure and low water subcooling have been shown to reduce the probability of spontaneous steam explosions at experimental scales; however, explosions can still occur if the necessary triggers are available.

Experimentally measured conversion ratios (the work done divided by the thermal energy available) range from zero to values approaching the thermodynamic limit. Explosion pressures have been measured over the range of tens of bars to 2 kilobars. Steam explosion computer codes have predicted that pressures of many kilobars are possible for strong steam explosions.

Significant rates of hydrogen production have been observed for both explosive and nonexplosive interactions. Much finer fragments produced in explosive interactions can potentially lead to more rapid production of steam and hydrogen. The actual hydrogen production rate, however, is a result of two competing processes. The large surface-to volume ratio of the molten drop tends to increase the rate of heat transfer from the drop to water, but it also tends to increase the rate of exothermic oxidation, which adds energy to the drop and hot hydrogen gas to the vapor film surrounding the drop. The occurrence of a steam explosion as opposed to a nonexplosive interaction is generally thought to favor increased hydrogen production, especially when the melt is metallic as in foundries.

\subsubsection{Limitations on In-Vessel FCIs}

A rough estimate of the potential for energy release from in-vessel FCIs (excluding $\mathrm{Zr}$ oxidation) can easily be computed by calculating the energy that would have to be transferred to water in order to quench the 
entire core. For example, a typical PWR core might contain $10^{5} \mathrm{~kg}$ of $\mathrm{UO}_{2}$ and $2 \times 10^{4} \mathrm{~kg} \mathrm{Zr}$. Assume that all of this material (plus $10^{4} \mathrm{~kg} \mathrm{Fe}$ to allow for structural material in the melt) is liquefied at $4712{ }^{\circ} \mathrm{F}\left(2600{ }^{\circ} \mathrm{C}=2873 \mathrm{~K}\right)$, below the $\mathrm{UO}_{2}$ melt temperature of $5180^{\circ} \mathrm{F}\left(2860^{\circ} \mathrm{C}\right.$ $=3133 \mathrm{~K}$ ). The decrease in sensible and latent heat required to quench this melt to $212{ }^{\circ} \mathrm{F}\left(100^{\circ} \mathrm{C}=373 \mathrm{~K}\right)$, which is the saturation temperature for water at atmospheric pressure is approximately 170 GJ (a steam explosion of 1 to 1.5 GJ could fail the reactor vessel lower head). A 170 GJ steam explosion would require the evaporation of approximately $75,000 \mathrm{~kg}$ or $75 \mathrm{~m}^{3}$ of saturated water at atmospheric pressure.

In reality, the energy transferred from core materials to residual water would be less than $170 \mathrm{GJ}$ for two reasons:

1. The volume of residual in-vessel water would be limited, in the absence of ECC restoration, and

2. lower melt temperatures and/or higher in-vessel pressures, which would be anticipated in most severe accident scenarios, would reduce the temperature difference between molten core materials and residual in-vessel water.

Figure 3.6-2 illustrates the limited capacity for in-vessel FCI energy releases at various pressures in a PWR if the residual water is limited to $29 \mathrm{~m}^{3}$, which is approximately the volume below the lower core plate of a Westinghouse PWR. Table 3.6-1 shows the corresponding limitations of the mass of core material that could be quenched. ${ }^{12}$ In general, BWR lower plenums are larger and hold more water relative to the mass of the core. Considerations with respect to the potential for debris quenching in a BWR lower plenum are discussed in Section 3.7.6.

Reactor vessel lower plenums, particularly in BWRs, contain significant quantities of structural materials as illustrated in Figures 3.1-5 and 3.1-9. Such structures could restrict the volumes of melt and/or water participating in FCIs at a given time. Table 3.6-2 provides some data on features and geometry that characterize these flow restrictions. ${ }^{13}$

It should be noted that the preceding estimates ignore the potential contribution to FCI energy releases associated with oxidizing metallic $\mathrm{Zr}$ contained in the melt. As noted in Subsection 3.3, quantities of unoxidized zirconium are likely to be involved in the core-liquefaction processes. Mixing of this metallic phase at high temperatures with the water in the lower plenum would promote rapid oxidation of the zirconium, depending primarily upon the degree to which fragmentation of the melt provides large increases in the interfacial surface area. The heat of reaction for $\mathrm{Zr}$ oxidation is approximately $6.5 \mathrm{MJ} / \mathrm{kg}$ of $\mathrm{Zr}$ reacted. If only $1 \%$ of the $\mathrm{Zr}$ typically contained in a PWR core $\left(2 \times 10^{4} \mathrm{~kg}\right)$ were oxidized during in-vessel FCIs, an additional $1.3 \mathrm{GJ}$ would be released. Regardless of the exact outcome, the addition of reaction energy and liberation of a quantity of hydrogen by the oxidation of zirconium during the melt-water interaction phase seems likely.

\subsubsection{In-Vessel FCI Scenarios}

In assessing the impact of in-vessel $\mathrm{FCls}$ on accident progression, three alternative scenarios can be postulated: 
1. No steam explosion but violent boiling, which may partially or totally quench the core debris, depending on the quantity of water available and the agglomeration of the debris.

2. One or more relatively low-yield steam explosions and nonexplosive quenching until the whole of the molten mass of fuel has been fragmented or all of the water evaporates.

3. A large steam explosion involving a significant fraction of the melt, triggered either spontaneously or by a low-yield steam explosion.

Because of the resultant disruption (and possible dispersal) of internal structures and residual core materials, the occurrence of even a relatively low-yield steam explosion could significantly alter the subsequent progression of damage.

\subsubsection{Alpha Mode Containment Failure}

Energetically, it is possible that a large in-vessel steam explosion could cause (a) breach of the reactor vessel, ${ }^{14}$ or (b) breach of the reactor vessel and generation of containment-failing missiles. ${ }^{15}$ Either event would completely alter the course of the accident by causing the immediate ejection of fuel and fission products from the reactor vessel. The second would result in nearly simultaneous venting of the containment. The possibility of these events accounts for the nil minimum duration for Stage 5 given in Table 3.1-1.

The Reactor Safety Study (RSS) first identified the possibility that a large-scale in-vessel steam explosion could result in containment failure. This is commonly referred to as the alpha mode of containment failure. The RSS took the alpha mode failure probability to be 0.01 , although the uncertainty in this probability was acknowledged by also providing a pessimistic estimate of $0.1 .^{12}$

Since the RSS, there has been considerable experimental research performed on fuel-coolant interactions at small to intermediate scales ( $50 \mathrm{mg}$ to $157 \mathrm{~kg}$ ). Early experiments investigated steam explosion efficiencies and various aspects of triggering in geometries that were open to the atmosphere. This early work is summarized in three review papers. ${ }^{2,3,4}$

A 1984 study showed that conversion ratios less than $5.3 \%$ and masses of actively participating molten core less than $5000 \mathrm{~kg}$, as suggested by several mixing models, ${ }^{16,17}$ imply an alpha mode failure probability of 0.0001 or less. However, some argued that the possibility of larger conversion ratios or larger masses actively participating could not be excluded and that the uncertainty in the alpha-mode containment failure probability was therefore large. ${ }^{18}$

In 1985 the first NRC-sponsored Steam Explosion Review Group (SERG-1) assessed the probability of alpha mode failure for NUREG-1150. ${ }^{19}$ The SERG-1 pessimistic failure probability was 0.1 , unchanged from the pessimistic estimate of the RSS. The NUREG-1150 alpha mode failure probabilities are listed in Table 3.6-3.

NRC-funded FCI research after initial SERG-1 workshop sought to enhance the technical basis of the alpha mode failure estimates given by the experts, and reduce uncertainties in the estimates. Numerous experiments were conducted from 1985 through 1995 in both U.S. and European facilities. A review of these experiments is 
provided in a recent paper. ${ }^{5}$ The experiments demonstrate that steam voiding around hot debris particles causes the mixing region to be depleted of water in part as a result of its vaporization due to rapid meltto-coolant heat transfer, and, in part due to displacement of remaining water mass away from the interfacial region. Depletion is even more pronounced in the case of adjacent simultaneous pours as occurred through multiple holes in the elliptical flow distributor at TMI-2.

In June 1995 the NRC convened the SERG-2 workshop to reassess the alpha mode failure issue and to evaluate the current understanding of other FCI issues of potential risk significance. As illustrated in Table 3.6-4, all but two of the 11 SERG-2 experts concluded that the alpha mode failure issue is essentially resolved, meaning that this mode of failure is of very low probability, that it is of little or no significance to the overall risk from nuclear power plants, and that further research not likely to change this conclusion.

The SERG-2 experts based their judgements regarding the likelihood of alpha mode failure largely on experimentally substantiated arguments favoring limits to mixing. There is a consensus among the experts that the triggering process is poorly understood due largely to its inherently random nature. Assumptions regarding triggering under accident conditions tend, therefore, to be conservative. Triggering is postulated at the worst time during premixing, leading to trigger amplification or shock wave propagation.

It should be emphasized, however, that in experiments performed with prototypic reactor melts interacting with saturated to subcooled water at an ambient pressure of nominally $0.1 \mathrm{MPa}$, only one or two cases exhibited weak steam explosions either at high melt-to-coolant volume ratios or at high subcooling, and only when an external trigger was used. In contrast, many more cases using iron-alumina thermite and iron oxide as melt simulants produced strong steam explosions at a wide range of melt-tocoolant volume ratios, much lower subcooling to almost saturated conditions, with or without trigger.

\subsubsection{Vessel Breach by an In-Vessel Steam Explosion and Related Issues}

The steam-explosion energy required to fail the bottom head of a PWR has been estimated to be between $1 \mathrm{GJ}$ and $1.5 \mathrm{GJ}$. That is, a steam explosion need not involve large quantities of melt or water in order to yield such energies. In one study of PWR in-vessel steam explosions, failing the bottom head by an in-vessel steam explosion was found to be much more likely (probability of 0.2 versus 0.0001 ) than alpha mode failure. ${ }^{8}$ Figure 3.6-4 illustrates this mode of vessel breach, which has the potential for driving particulate debris from the reactor cavity, resuspending radioactive aerosols previously plated out within the reactor coolant system, and forming additional aerosols during the explosion.

Steam explosion research is currently under way at several research facilities to address several issues including the possibility of lower head failure due to an in-vessel steam explosion, the potential for significant structural damage due to a steam explosion in the reactor cavity (see Section 4.3), pressure suppression effects on triggering, and effects of melt composition and meltcoolant-confinement geometry on both triggering and energetics of steam explosions. Table 3.6-5 provides summary information on four current steam explosion research facilities. ${ }^{5}$ 
The current level of understanding of the propagation phase of a steam explosion is adequate for estimating the net energy transfer to the coolant and hence, estimating the alpha mode failure probability. Understanding of shock loading of lower head and reactor cavity structures requires more rigorous treatment for which detailed two or even three-dimensional propagation phase models may be required.

\subsubsection{Impact of Melt Discharge from Vessel}

Four modes of discharge of core materials from the vessel can be postulated:

1. Massive failure of the vessel by an in-vessel explosion,

2. a pressure-driven melt jet,

3. gravity-driven pour of a large molten mass,

4. continuous dripping of core materials not involved in the initial release.

These modes of melt discharge are depicted in Figures 3.6-4 through 3.6-7.

The mode of vessel breach can strongly influence the timing and nature of potential loads imposed on containment. In 1984, the NRC sponsored Containment Loads Working Group identified the fact that pressurized dispersal of high-temperature melt into containment at the time of vessel breach (Figure 3.6-5), could result in rapid direct heating and exothermic chemical reactions within the containment atmosphere and pose a severe threat to containment integrity. On the other hand, if the vessel is depressurized, molten material would simply flow into the reactor cavity by gravity (Figure 3.6-6), although if water were present in the reactor cavity significant loads on containment could result from ex-vessel fuel coolant interactions or from the additional hydrogen generated in such interactions. In general, BWR containment drywells are relatively small, and, hence, special procedures are provided to assure that the reactor vessel would be depressurized under severe accident conditions.

The initial geometry and potential for cooling of ex-vessel debris, as well as the nature of interactions between core materials and concrete, are strongly influenced by the mode of vessel breach. The mode of melt discharge into containment also has a strong influence on the resulting concentrations of fission products, particularly in aerosol form, in the containment. Ex-vessel phenomena are discussed in Module 4.

Following either a pressurized ejection or a gravity-driven pour of melt from the vessel, a significant fraction of core materials may remain unmelted in the core region. Without coolant, much of this material may subsequently melt and drop out of the vessel in small amounts over a period of hours. This mode of discharge is illustrated in Figure 3.6-7. If there is water below the vessel, the dripping mass may prolong ex-vessel fuel-coolant or core-concrete interactions. If the hot leg or surge line had failed earlier natural circulation could be established with flow from the reactor cavity up through the reactor vessel and out the failed pipe. The ingress of air from containment following vessel breach could cause additional exothermic oxidation of hot in-vessel debris. This would, in turn, lead to additional releases of radionuclides to containment. All such possibilities would affect the magnitude of the radiological release given late containment failure. 
Table 3.6-1 Fractions of core mixture* that can be quenched in below-core water for a typical PWR**

\begin{tabular}{l|c|c|c|c}
\hline & \multicolumn{4}{|c}{ Saturated Water Pressure } \\
\hline & Atmospheric & $\begin{array}{c}800 \mathrm{psia} \\
(5.5 \mathrm{MPa})\end{array}$ & $\begin{array}{r}1595 \mathrm{psia} \\
(11 \mathrm{MPa})\end{array}$ & $\begin{array}{r}2465 \mathrm{psi} \\
(17 \mathrm{MPa})\end{array}$ \\
$\begin{array}{c}\Delta \mathrm{T}=2700^{\circ} \mathrm{F} \\
\left(1500^{\circ} \mathrm{C}\right) \\
\text { No Freeze }\end{array}$ & 0.79 & 0.44 & 0.31 & 0.17 \\
\hline $\begin{array}{c}\Delta \mathrm{T}=3600^{\circ} \mathrm{F} \\
\left(2000^{\circ} \mathrm{C}\right)\end{array}$ & 0.59 & 0.33 & 0.23 & 0.13 \\
No Freeze & 0.37 & 0.21 & 0.14 & 0.08 \\
$\begin{array}{c}\Delta \mathrm{T}=4500^{\circ} \mathrm{F} \\
\left(2500^{\circ} \mathrm{C}\right)\end{array}$ & & & & \\
\hline \begin{tabular}{c} 
Freeze \\
\hline
\end{tabular}
\end{tabular}

${ }^{*} 10^{5} \mathrm{~kg} \mathrm{UO}_{2}+2 \times 10^{4} \mathrm{~kg} \mathrm{Zr}+10^{4} \mathrm{~kg}$ steel

** in $29 \mathrm{~m}^{3}$ of water

Table 3.6-2 Lower plenum features of a Westinghouse PWR

\begin{tabular}{l|c|c|c}
\hline \multicolumn{1}{c|}{ Feature } & $\begin{array}{c}\text { Approx. } \\
\text { Thickness } \\
(\mathbf{m m})\end{array}$ & $\begin{array}{c}\text { Water Volume } \\
\text { to Next Feature } \\
\left(\mathbf{m}^{\mathbf{3}} \mathbf{)}\right.\end{array}$ & $\begin{array}{c}\text { Energy to } \\
\text { Evaporate Water } \\
(\mathbf{G J})^{* *}\end{array}$ \\
\hline Lower Core Plate & 50 & 6.6 & 4.6 \\
\hline Diffuser Plate & 37 & $14.1^{*}$ & 9.8 \\
\hline Bottom Support Plate & 220 & $7.7^{*}$ & 5.4 \\
\hline Reactor Vessel Bottom & 132 & 0 & -- \\
\hline
\end{tabular}

- Ratio of these two volumes approximate; sum $\left(21.8 \mathrm{~m}^{3}\right)$ is volume of lower hemisphere.

"* Based on a pressure of 2500 psia (17.2 MPa). 
Table 3.6-3 NUREG-1150 alpha mode failure probabilities

\begin{tabular}{l|l|c|c|c|c}
\hline & \multicolumn{1}{|c|}{ Plant } & $\begin{array}{c}\text { System } \\
\text { Pressure }\end{array}$ & $\begin{array}{c}\text { Lower } \\
\text { Bound }\end{array}$ & Mean & $\begin{array}{c}\text { Upper } \\
\text { Bound }\end{array}$ \\
\hline \multirow{2}{*}{ BWRs } & Grand Gulf & High & 0 & $\begin{array}{l}1.0 \times 10^{-3} \\
1.0 \times 10^{-2}\end{array}$ & 0.1 \\
& Low & 0 & 1.0 \\
\cline { 2 - 6 } & Peach & High & $1.0 \times 10^{-8}$ & $1.0 \times 10^{-3}$ & 0.1 \\
& Bottom & Low & $1.0 \times 10^{-7}$ & $1.0 \times 10^{-2}$ & 1.0 \\
\hline \multirow{2}{*}{ PWRs } & Sequoyah & High & 0 & $8.5 \times 10^{-4}$ & 0.1 \\
& & Low & 0 & $8.5 \times 10^{-3}$ & 1.0 \\
\cline { 2 - 6 } & Surry & High & 0 & $9.1 \times 10^{-4}$ & 0.1 \\
& & Low & 0 & $9.1 \times 10^{-3}$ & 1.0 \\
\hline
\end{tabular}


Table 3.6-4 Alpha mode failure probability estimates (given a core melt accident)

\begin{tabular}{l|c|c|c}
\hline Participant & $\begin{array}{c}\text { SERG-1 } \\
(\mathbf{1 9 8 5})\end{array}$ & $\begin{array}{c}\text { SERG-2 } \\
(\mathbf{1 9 9 5 )}\end{array}$ & $\begin{array}{c}\text { View on Status of Alpha Mode } \\
\text { Failure Issue }\end{array}$ \\
\hline Bankoff & $<10^{-4}$ & $<10^{-5}$ & Resolved from risk perspective \\
\hline Berthoud & -- & $<10^{-3}$ & No statement on resolution \\
\hline Cho & $<\mathrm{RSS}^{\mathrm{a}}$ & $<10^{-3}$ & Resolved from risk perspective \\
\hline Corradini & $10^{-4}-10^{-2}$ & $<10^{-4}$ & Resolved from risk perspective \\
\hline Fauske & $\begin{array}{c}\text { Vanishingly } \\
\text { small }\end{array}$ & $\begin{array}{c}\text { Vanishingly } \\
\text { small }\end{array}$ & Resolved from risk perspective \\
\hline Fletcher & -- & $<10^{-4}$ & Resolved from risk perspective \\
\hline Henry & -- & $\begin{array}{c}\text { Vanishingly } \\
\text { small }\end{array}$ & Resolved from risk perspective \\
\hline Jacobs & -- & $\begin{array}{c}\text { Probably low } \\
\text { likelihood }\end{array}$ & Not resolved from risk \\
\hline Sehgal & -- & $<10^{-2}$ & Resolved from risk perspective \\
\hline Theofanous & $<10^{-4}$ & $\begin{array}{c}\text { Physically } \\
\text { unreasonable }\end{array}$ & Resolved from risk perspective \\
\hline Turland & -- & $\begin{array}{r}<10^{-3} \\
\text { Resolved from risk perspective }\end{array}$ \\
\hline
\end{tabular}

${ }^{a}$ Reactor Safety Study (RSS) best estimate $10^{-2}$; NUREG-1150 consensus estimate $10^{-2}$ at low reactor coolant system pressure, $10^{-3}$ at high reactor coolant system pressure. 
Table 3.6-5 Fuel coolant interaction experimental facility characteristics

\begin{tabular}{|c|c|c|c|c|}
\hline Facility & FARO & KROTOS & WFCI & ZREX \\
\hline Location & \multicolumn{2}{|c|}{$\begin{array}{c}\text { Joint Research Center, } \\
\text { Ispra }\end{array}$} & $\begin{array}{c}\text { The University of } \\
\text { Wisconsin }\end{array}$ & $\begin{array}{c}\text { Argonne National } \\
\text { Laboratory }\end{array}$ \\
\hline $\begin{array}{l}\text { Areas of } \\
\text { Interest }\end{array}$ & \multicolumn{2}{|c|}{$\begin{array}{l}\text { Premixing, quenching, } \\
\text { propagation, energetics, } \\
\text { and debris coolability }\end{array}$} & $\begin{array}{c}\text { Conditions } \\
\text { favoring and } \\
\text { suppressing } \\
\text { energetic FCI } \\
\end{array}$ & $\begin{array}{c}\text { Chemical } \\
\text { augmentation of FCI } \\
\text { due to metals in the } \\
\text { melt }\end{array}$ \\
\hline $\begin{array}{l}\text { Test Section } \\
\text { Diameter } \\
(\mathrm{cm})\end{array}$ & $4.7-15$ & $0.95-2.0$ & $0.87-2.0$ & 1.0 \\
\hline $\begin{array}{l}\text { Melt Jet } \\
\text { Diameter } \\
(\mathrm{cm}) \\
\end{array}$ & 1 & $0.3-0.5$ & 0.3 & $0.25-0.5$ \\
\hline $\begin{array}{l}\text { Water Depth } \\
(\mathrm{cm})\end{array}$ & $50-200$ & 1000 & 1000 & 1000 \\
\hline $\begin{array}{l}\text { Pressure } \\
\text { (MPa) }\end{array}$ & $0.1-5.0$ & $0.1-1.0$ & 0.1 & 0.1 \\
\hline Melt & $\begin{array}{c}\mathrm{UO}_{2}-\mathrm{ZrO}_{2} \\
\mathrm{w} / \& \text { w/o } \\
\mathrm{Zr} \text { and } \\
\text { stainless } \\
\text { steel (SS) } \\
\end{array}$ & $\begin{array}{l}\mathrm{UO}_{2}-\mathrm{ZrO}_{2} \\
\text { or } \\
\mathrm{Al}_{2} \mathrm{O}_{3}\end{array}$ & $\begin{array}{c}\mathrm{Sn}, \mathrm{FeO}, \text { or } \\
\mathrm{Fe}_{3} \mathrm{O}_{4}\end{array}$ & $\begin{array}{c}\mathrm{Zr} \\
\mathrm{w} / \text { or w/o } \\
\mathrm{ZrO}_{2}\end{array}$ \\
\hline $\begin{array}{l}\text { Melt Mass } \\
(\mathrm{kg})\end{array}$ & $18-250$ & $1.4-6.0$ & $0.8-4.5$ & $0.2-1.0$ \\
\hline
\end{tabular}



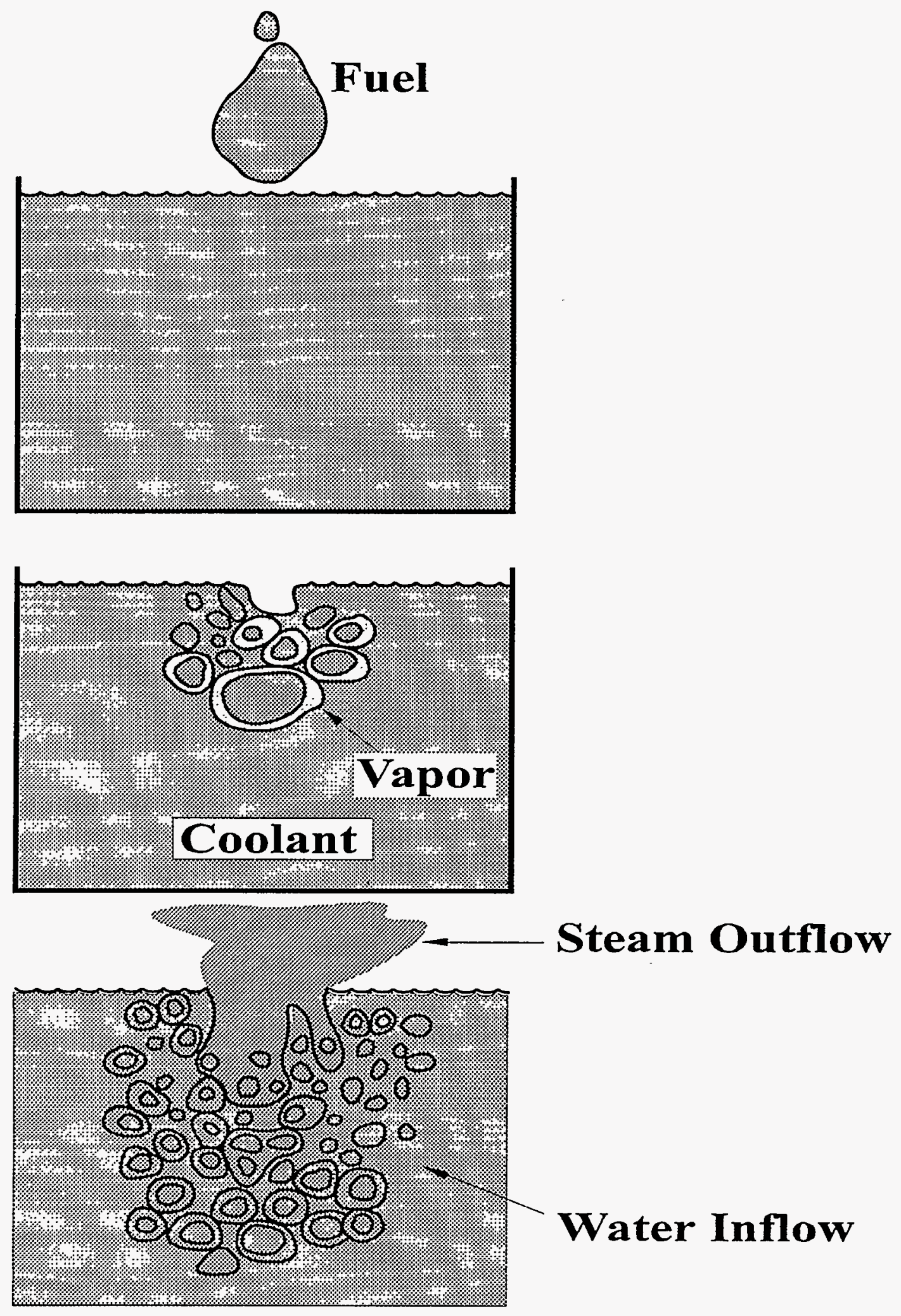

Figure 3.6-1 Progression of fuel-coolant mixing 


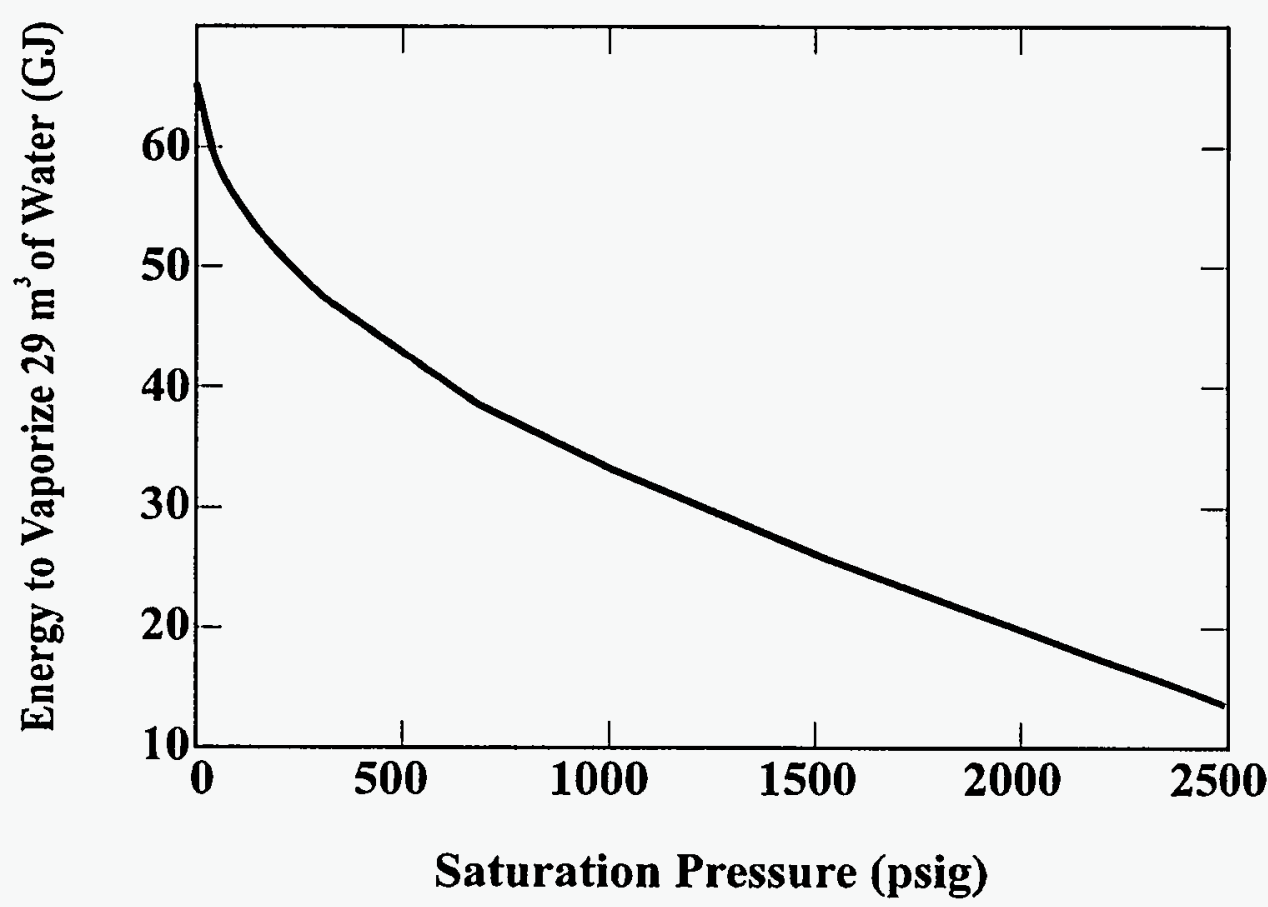

Figure 3.6-2 Energy required to vaporize $29 \mathrm{~m}^{3}$ for water versus saturation pressure 


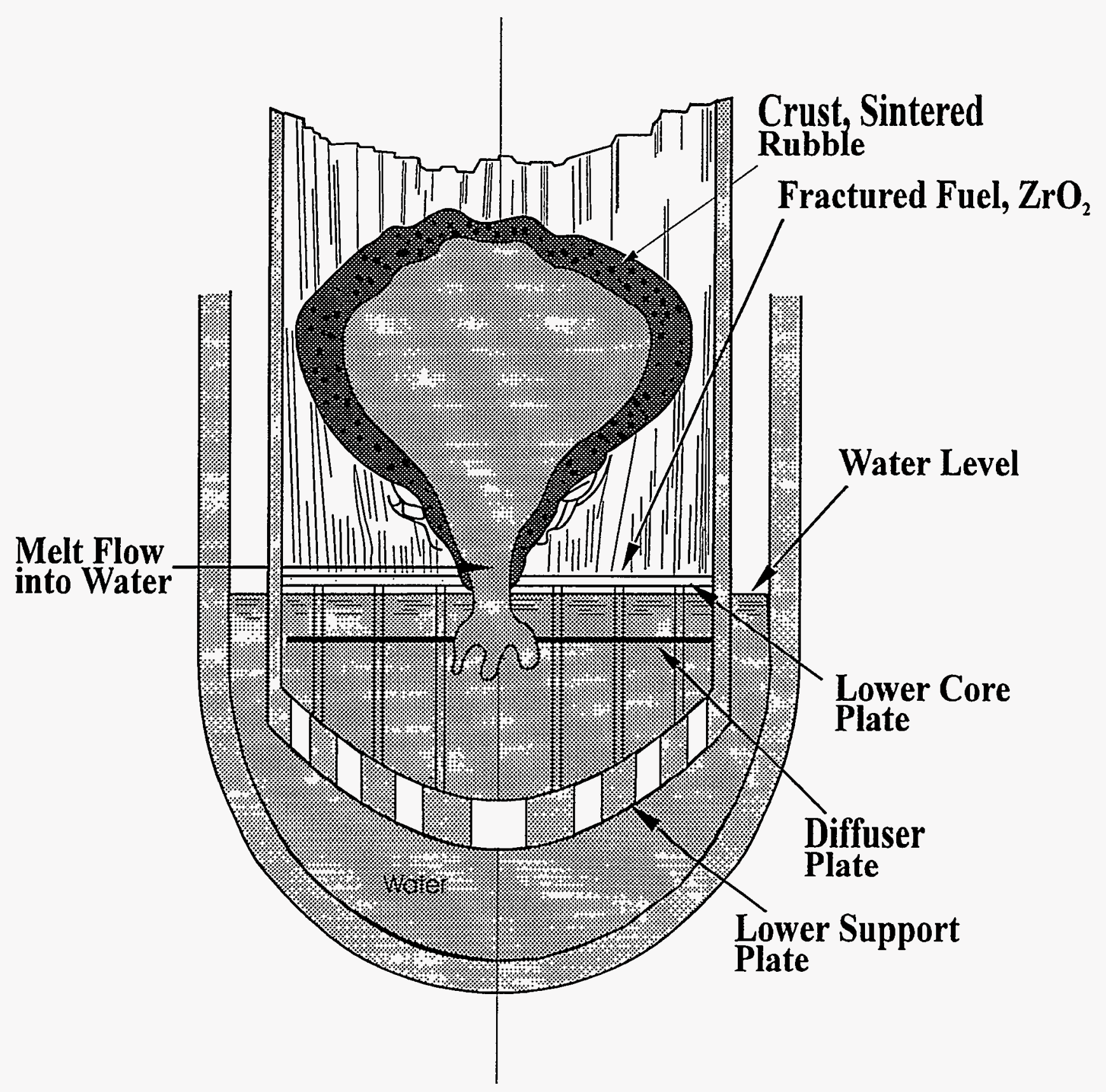

Figure 3.6-3 Melt pour into lower plenum by failure of core plate 


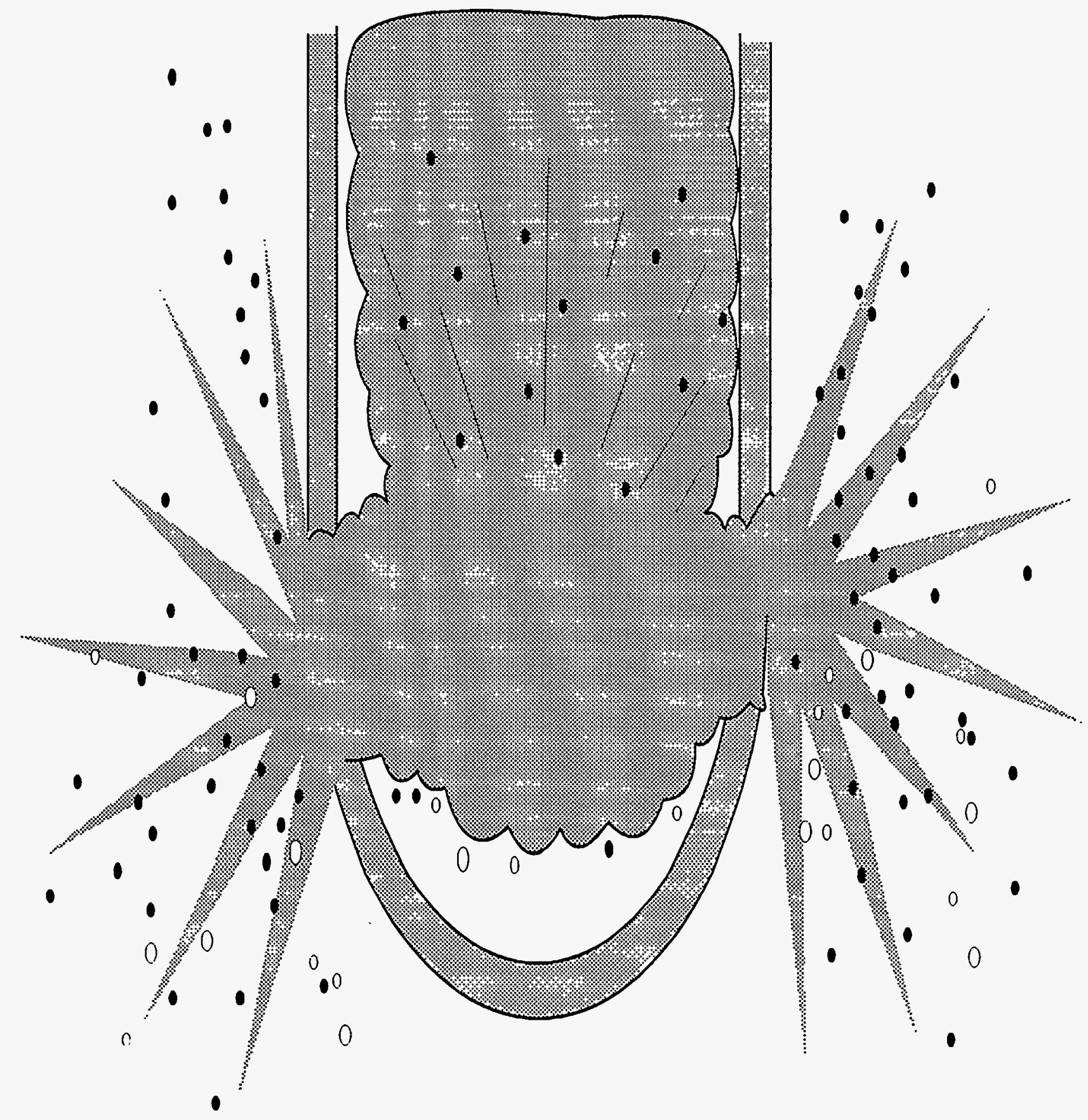

Figure 3.6-4 Vessel failure from steam explosion 


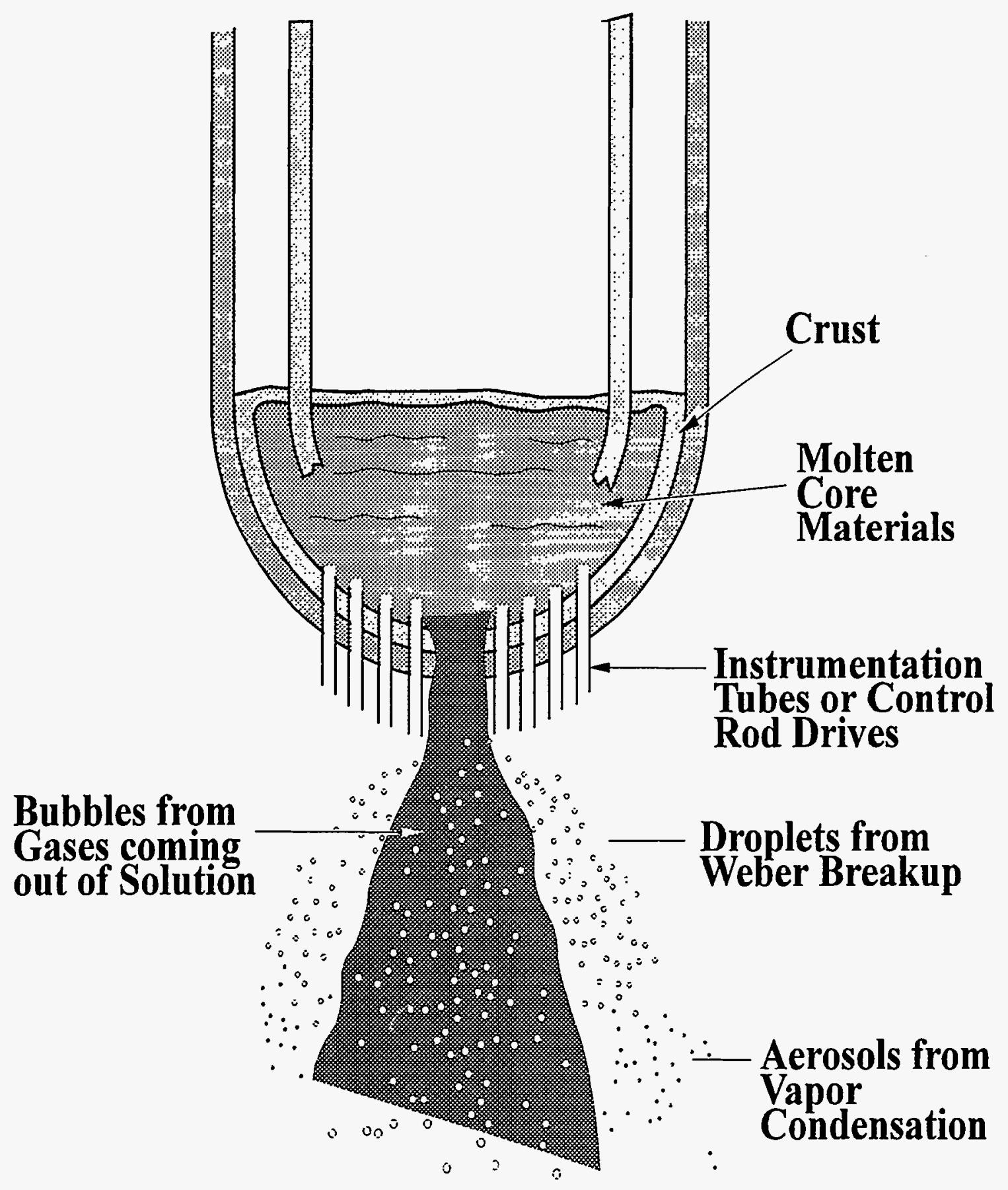

Figure 3.6-5 High pressure melt release from bottom of reactor vessel 


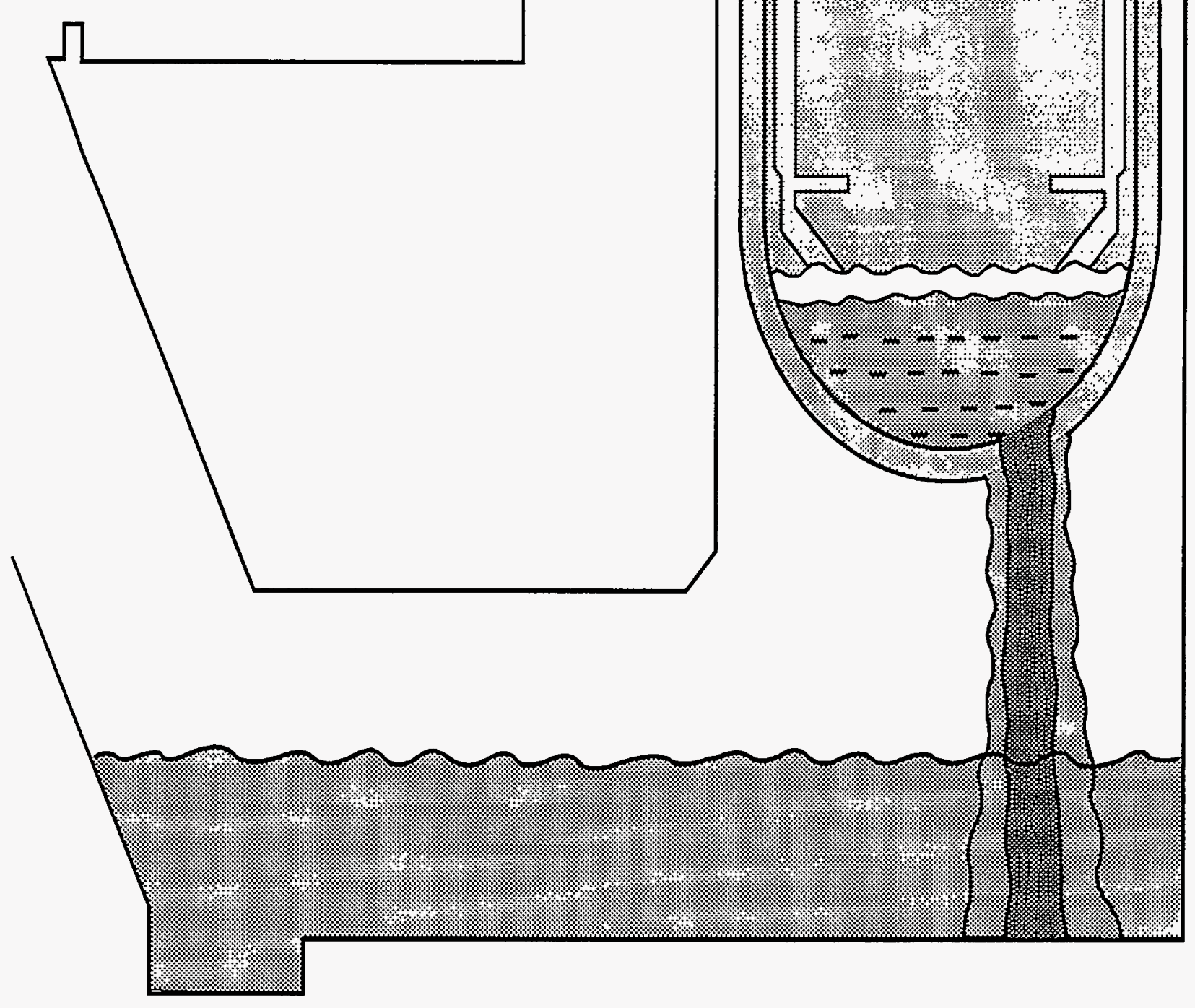

Figure 3.6-6 Low pressure melt release from bottom of reactor vessel 


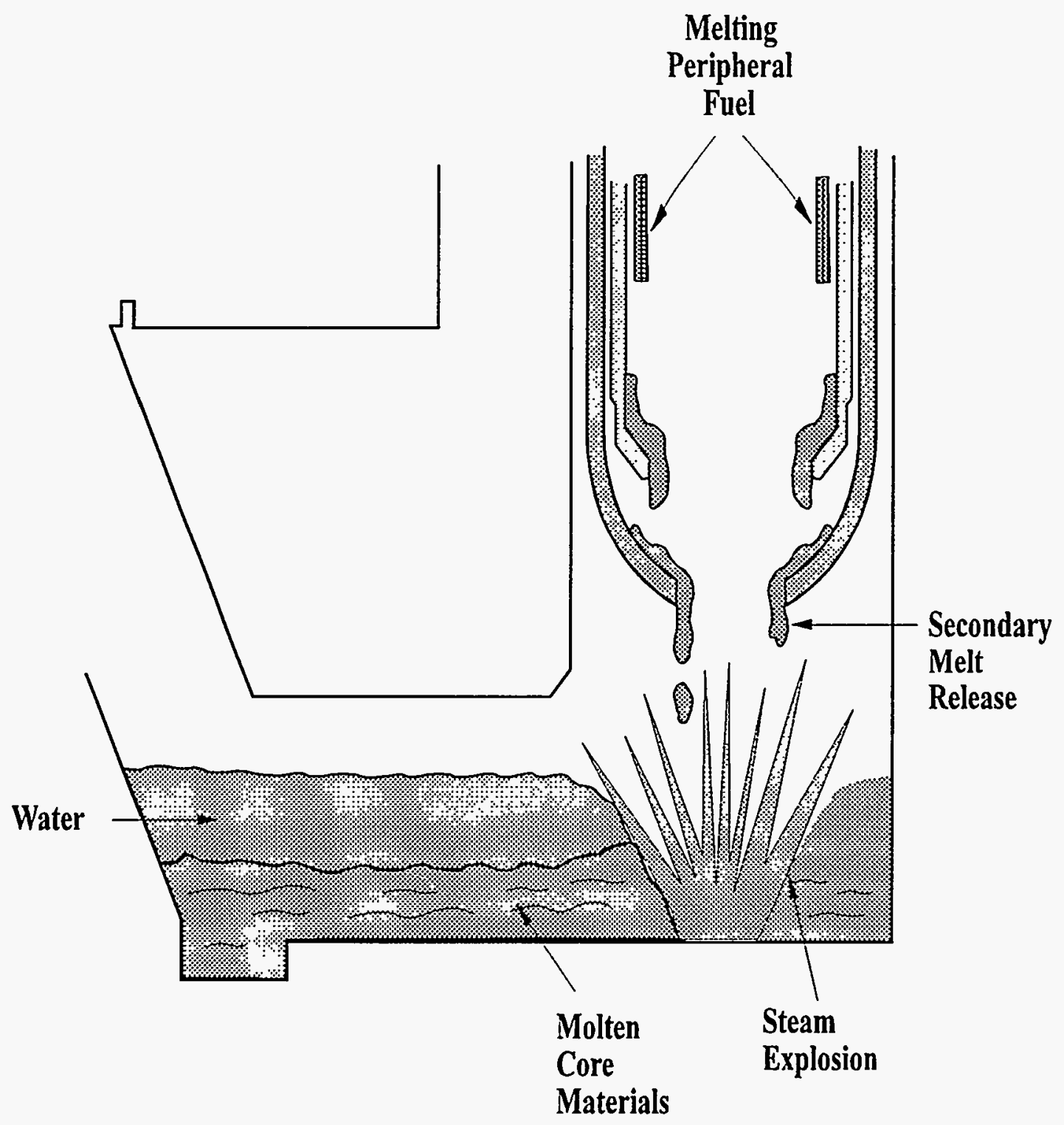

Figure 3.6-7 Secondary melt release in a Zion-type PWR reactor cavity 


\section{References for Section 3.6}

1. R. C. Reid, "Rapid Phase Transitions from Liquid to Vapor," Advances in Chemical Engineering, 12, pp. 105-208, 1983.

2. M. L. Corradini, et al., "Vapor Explosions in Light Water Reactors: A Review Theory and Modeling," Progress in Nuclear Energy, 22(1), pp.1-117, 1988.

3. M. L. Corradini, "Vapor Explosions: A Review of Experiments for Accident Analysis," Nuclear Safety, 32(3), pp. 337-362, 1991.

4. D. F. Fletcher, "A Review of the Available Information on the Triggering Stage of a Steam Explosion," Nuclear Safety, 35(1), pp. 36-57, 1994.

5. S. Basu and T. P. Speis, "An overview of fuel-coolant interactions (FCI) research at NRC," Proceedings of the 23rd Water Reactor Safety Information Meeting, Vol. 2, pp. 187-210, October 23-25, 1995.

6. G. Chaucer, "The Canon's Yeoman's Tale," in Canterbury Tales, Garden City Publishing Company, Inc., Garden City, NewYork, 1934.

7. M. Berman, "Thermodynamic and Fluid-Dynamic Modelling of Two-Phase Propagating Explosions," Workshop on the Causes and Prevention of Melt-Water Interactions, Sandia National Laboratories, Albuquerque, New Mexico, July 29, 1988.

8. M. Berman et al., "Chernobyl: Where Do We Go From Here," Discussions of Steam Explosions at Chernobyl,
Proceedings of the Conference -byComputer, Nuclear Publications, McGraw-Hill, New York, New York, September 29-October 17, 1986.

9. W. Sweet, "Chernobyl, What Really Happened," Technology Review, pp. 4352, July, 1989.

10. F. Reisch, "Chernobyl - the Initiating Event?" Nuclear News, December 1987.

11. A. W. Cronenberg, "Recent Developments in the Understanding of Energetic Molten Fuel-Coolant Interactions," Nuclear Safety, 22(3), pp. 319-337, May-June 1980.

12. J. B. Rivard et al., "Identification of Severe Accident Uncertainties," NUREG/CR-3440, SAND83-1689, September 1984.

13. J. B. Rivard, "Review of In-Vessel Meltdown Models," NUREG/CR-1493, SAND80-0455, July 1980.

14. J. H. Gittus et al., "PWR Degraded Core Analysis," ND-R-610(S), United Kingdom Atomic Energy Authority, Springfields, UK, 1982.

15. U.S. Nuclear Regulatory Commission, "Reactor Safety Study - An Assessment of Accident Risks in U.S. Commercial Nuclear Power Plants," WASH-1400, NUREG-75/014, October 1975.

16. T. G. Theofanous and M. Saito, "An Assessment of Class 9 (Core-Melt) Accidents for PWR Dry Containment Systems," Nuclear Engineering Design, pp. 301-332, 1981 . 
17. M. L. Corradini and G. A. Moses, "A Dynamic Model for Fuel-Coolant Mixing," Proceedings from the International Meeting on LWR Severe Accident Evaluation, Cambridge, Massachusetts, August 1983.

18. M. Berman, "Molten-Core Coolant Interactions Program," Proceedings from the 12th Water Reactor Safety Research Information Meeting, 1984.
19. U.S. Nuclear Regulatory Commission, "A Review of the Current Understanding of the Potential for Containment Failure Arising from In-Vessel Steam Explosions," NUREG-1116, 1985.

20. M. Berman, D. V. Swenson, and A. J. Wickett, "An Uncertainty Study of PWR Steam Explosions," NUREG/CR-3369, SAND83-1438, May 1984. 


\subsection{Special Considerations for BWR Facilities}

Boiling water reactors have unique features that would cause their behavior under severe accident conditions to differ significantly from that expected for the pressurized water reactor design. ${ }^{1,2}$ This section addresses several special considerations affecting BWR severe accident progression and mitigation. In this endeavor, many implications of the phenomena described in Sections 3.1 through 3.6 (such as zirconium oxidation) will be demonstrated by example. First, however, it is necessary to review some of the BWR features pertinent to severe accident considerations.

\subsubsection{Pertinent BWR Features}

An important distinction of the BWR design is that provisions are made for direct operator control of reactor vessel water level and pressure. Reactor vessel pressure control is normally accomplished rather simply by manually induced actuation of the vessel safety/relief valves (SRVs) or by operation of the reactor core isolation cooling (RCIC) system turbine or, for plants so equipped, the isolation condenser or highpressure coolant injection system (HPCI) turbine. Each of these methods relies to some extent, however, upon the availability of DC power or control air, which may not be available under accident conditions. SRV considerations will be described in Section 3.7.2.5.

All BWR facilities except Oyster Creek, Nine Mile Point 1 , and Millstone 1 incorporate either the RCIC or HPCI steam turbine-driven reactor vessel injection system; the later BWR-3 and all BWR-4 plants have both. These systems can be used for reactor vessel pressure control when run continuously in the recirculation mode, pumping water from the condensate storage tank back to the condensate storage tank and periodically diverting a small portion of the flow into the reactor vessel as necessary to maintain the desired water level. The steam taken from the reactor vessel by the turbine is passed to the pressure suppression pool as turbine exhaust, which provides a slower rate of pool temperature increase than if the vessel pressure control were obtained by direct passage of steam from the vessel to the pool via the SRVs. Plants having both HPCI and RCIC systems can employ the HPCI turbine exclusively for pressure control while the RCIC system is used to maintain the reactor vessel water level. The HPCI turbine is larger than the RCIC turbine and, therefore, is more effective for pressure control. These systems require DC power for valve and turbine governor control, but have no requirement for control air.

All BWR-5 and -6 plants are equipped with an electric-motor-driven high-pressure core spray (HPCS) system rather than a turbinedriven HPCI system. The HPCS pump takes suction from the condensate storage tank and delivers flow into a sparger mounted within the core shroud. Spray nozzles mounted on the spargers are directed at the fuel bundles. As in the case of HPCI, the pressure suppression pool is an alternate source of water for the HPCS.

All BWR facilities employ the low-pressure coolant injection (LPCI) mode of the residual heat removal (RHR) system as the dominant operating mode and normal valve lineup configuration; the RHR system will automatically align to the LPCI mode whenever ECCS initiation signals such as low reactor vessel water level or high drywell pressure are sensed. LPCI flow is intended to restore and maintain the reactor vessel coolant inventory during a LOCA after the reactor vessel is depressurized, 
either by the leak itself or by opening of the SRVs.

All BWR facilities also employ a lowpressure core spray (LPCS) system, which takes suction on the pressure suppression pool and sprays water directly onto the upper ends of the fuel assemblies through nozzles mounted in sparger rings located within the shroud just above the reactor core. With the reactor vessel depressurized, the automatically-initiated LPCI and LPCS flows, which begin when the reactor vessel pressure-to-suppression pool pressure differential falls below about $2.00 \mathrm{MPa}(290$ psig), are large. As an example, for a 1065MWe BWR-4 facility such as Browns Ferry or Peach Bottom, the combined flows would be more than $3.16 \mathrm{~m}^{3} / \mathrm{s}(50,000 \mathrm{gal} / \mathrm{min})$, which is sufficient to completely fill an intact reactor vessel in less than four minutes. It should be recalled that the amount of vessel injection necessary to remove decay heat (by boiling) is only about $0.013 \mathrm{~m}^{3} / \mathrm{s}(200 \mathrm{gal} / \mathrm{min})$.

Eight BWR design features have important implications with respect to differences (from PWR behavior) in the expected response of a BWR core under severe accident conditions. These are:

1. There is much more zirconium metal in a BWR core, which under similar conditions would increase the amount of energy released by oxidation and the production of hydrogen. Compared with a PWR of the same design power, a BWR typically contains about one and one-half times the mass of $\mathrm{UO}_{2}$ and three times the mass of zirconium metal (counting both fuel rod cladding and channel box walls).
2. The BWR reactor vessel would be isolated under most severe accident conditions, due to closure of the main steam isolation valves (MSIVs). This tends to make the BWR severe accident sequence thermal hydraulic calculation simpler to perform, since natural circulation pathways through external loops such as hot legs and steam generators need not be considered.

3. Because of the marked reduction in the average radial power factor in the outer regions of the BWR core, degradation events would occur in the central core region long before similar events would take place in the peripheral regions.

4. SRV actuations would cause important pressure and water level fluctuations within the reactor vessel. Operator actions (mandated by emergency procedure guidelines) to depressurize the reactor vessel would lead to early (and total) uncovering of the BWR core.

5. Diversity of core structures (control blades, channel boxes, fuel rods) would lead to progressive downward relocation of different materials from the upper core region to the core plate.

6. With early material accumulation upon its upper surface, the fate of the BWR core plate determines whether the initial debris bed would form within the lower 
portion of the core or in the vessel lower plenum.

7. Because there are many more steel structures in the BWR lower plenum, BWR debris would have a much greater steel content.

8. There is a much larger volume of water (relative to the core structural volume) within the lower plenum beneath a BWR core. If conditions are favorable, debris relocating from the core region can be completely quenched - with sufficient water remaining to remove decay heat (by boiling) for several hours without makeup.

The importance of each of these items will be elucidated in the discussions of Sections 3.7.2 through 3.7.7. Item 3, however, deserves special amplification here. Figure 3.7-1 illustrates a typical division of a BWR core into radial zones for code computation purposes. This example is based upon the Browns Ferry Unit 1 core, which comprises 764 fuel assemblies. Since a symmetric core loading is maintained, the drawing shows just one-fourth (191 assemblies) of the core.

What should be noted from Figure 3.7-1 is that the outer $25.1 \%$ of the core (sum of volume fractions for zones 9 and 10) is characterized by average radial peaking factors of just 0.670 and 0.354 . This dramatic falloff is illustrated by Figure 3.7. 2 , which also indicates the volume-averaged central region power factor (1.199) associated with a four-radial-zone code representation of the core. Because of the associated reductions in decay heating beyond the central region of the core, predicted severe accident events in the central region lead those in the peripheral regions by considerable periods of time. For example, formation and downward relocations of large amounts of debris are calculated for the central region before structural degradation is predicted to begin in the outermost core region.

\subsubsection{Provisions for Reactor Vessel Depressurization}

The BWR Owners Group Emergency Procedure Guidelines (EPGs) ${ }^{3}$ require unequivocally that the operators act to manually depressurize the reactor vessel should the core become partially uncovered under conditions (such as station blackout ) characterized by loss of injection capability. The operators would meet this requirement by use of the Automatic Depressurization System (ADS). The following discussions address why manual actuation of an "automatic" system is necessary, what is expected to be achieved by the rapid depressurization, the status of the core during the subsequent periods of structural degradation (if the accident is not terminated), and the importance of keeping the reactor vessel depressurized during the latter stages of the accident.

\subsubsection{Why Manual Actuation is Necessary}

The most direct means of BWR reactor vessel pressure control is by use of the SRVs, which require no outside energy source for operation as a safety valve but do require both control air and DC power when used as a remotely operated relief valve. This dependence upon the availability of control air and DC power pertains both to remote-manual opening of the valves by the control room operators and to the valveopening logic of the ADS. 
The purpose of the ADS is to rapidly depressurize the reactor vessel so that the low-pressure emergency core cooling systems (ECCS) can inject water to mitigate the consequences of a small or intermediate loss-of-coolant accident should the highpressure systems prove inadequate. The number of ADS-associated SRVs is plantspecific; these valves open automatically if required to provide reactor vessel depressurization because of low reactor vessel water level caused by transients or small breaks. The ADS is initiated by coincidence of low reactor vessel water level and high drywell pressure, provided that at least one of the low-pressure pumps is running. Recently, a bypass timer (typically 265 seconds) has been backfitted to the ADS logic to ensure automatic actuation of ADS on sustained low water level even if the high drywell pressure signal is not present.

There is, however, no timer bypass for the requirement that at least one of the lowpressure ECCS pumps (RHR or Core Spray) be running. (The actual signal is derived by sensing the pump discharge pressure.) This is reasonable, since a great deal of water is lost from the reactor vessel when the ADS is actuated and therefore it is prudent to require that a replacement water source be available. As explained in the next Section, however, it is desirable to actuate the ADS under certain severe accident situations even though there is no operating pump. Without the discharge pressure signal, the ADS must be actuated manually (operator pushbuttons).

(NOTE: Typically, the ADS timer is initiated when the reactor vessel water level is between two and three feet above the top of the core. Current EPGs direct that the operators prevent automatic actuation of the ADS and instead manually initiate this system when the water level reaches the top of active fuel. This intentional delay of
ADS for cases when the low pressure pumps are running is a matter of current controversy, and not all BWR facilities have invoked this provision.)

\subsubsection{Rapid Depressurization for Steam Cooling}

For BWR accident sequences involving partial uncovering of the core, the EPGs provide that the operators must take action to initiate "steam cooling" which, for plants without isolation condensers, is accomplished by manually initiating the ADS. The purpose is to delay fuel heatup by cooling the uncovered upper regions of the core by a rapid flow of steam. Because the source of steam is the remaining inventory of water in the reactor vessel, the steam cooling maneuver can provide only a temporary respite.

In order to illustrate the effects of steam cooling, let us first consider a case in which this maneuver is not used. Figure 3.7-3 shows the calculated reactor vessel water level for a postulated loss of injection (caused by station blackout and failure of RCIC) at Grand Gulf. It should be noted that after falling below the top of active fuel (TAF), the calculated water level follows the curve predicted by Figure 3.2-1 until a downward deviation becomes apparent, near the bottom of active fuel (BAF). This deviation occurs because debris relocating from the upper, uncovered, region of the core is relocating downward into the water remaining in the lower portion of the core, accelerating its boiloff.

Let us now consider the same accident sequence, but with implementation of the steam cooling maneuver. Figure 3.7-4 shows the calculated reactor vessel pressure and water level when the ADS is actuated at about one-third core height (time 75 minutes 
after scram). At this time, there has been no degradation of the upper core. At Grand Gulf, 8 SRVs (of 20 total) are associated with the ADS. The vessel depressurizes quickly and the accompanying water loss due to flashing causes the water level to fall into the lower plenum, well below the BAF and the core plate. Subsequently, the flashing ceases, and the remaining water is significant for debris quenching.

The maximum fuel rod temperature in the central region of the core is plotted versus time in Figure 3.7-5, for both cases. The temperature escalations that occur after time 80 minutes for the case without ADS are caused by the energy releases associated with zirconium oxidation. (The dotted lines on this figure indicate the time at which the temperature increases above $1832^{\circ} \mathrm{F}$ [1273 $\mathrm{K}]$ ). For the case with ADS actuation, the temperature decreases immediately after the valves are opened due to the effects of steam cooling. Subsequently, the temperature again increases, but the time at which the runaway zirconium oxidation temperature is reached has been delayed by about 15 minutes. The differences in hydrogen generation between the two cases during the period plotted are substantial, as can be appreciated by a comparison of the two subplots of Figure 3.7-6.

Table 3.7-1 displays the times associated with the major events of the accident sequence for both cases. When the ADS is actuated, core plate dryout follows immediately thereafter, and debris begins relocating from the upper core region at about time 110 minutes. Without ADS actuation, debris relocation begins about 23 minutes earlier and before core plate dryout, which is delayed until time 102.5 minutes.

It is instructive to consider why the first local core plate failure occurs earlier for the case with ADS actuation. Recall that the core plate is dry when debris relocation begins in this case, so that the hot debris falls directly on the plate surface. When the ADS is not actuated, the initial debris relocations fall into water overlying the core plate. This initial debris is quenched and forms a protective layer over the plate. Later, when water no longer remains over the plate, failure is delayed until the newly relocating debris has heated both the plate and the previously quenched debris.

It is important that the ADS be manually initiated at the proper time. Too soon means that reactor vessel water inventory will be lost without the compensatory benefits afforded by effective steam cooling. Too late means that a steam-rich atmosphere will exist during the onset of runaway metalwater reactions. By procedure, steam cooling is to be placed into effect when the "Minimum Zero-Injection RPV Water Level" is reached. In Revision 4 of the EPGs, this is defined as the lowest vessel level at which the average steam generation rate within the covered portion of the core is sufficient to prevent the maximum clad temperature in the uncovered region of the core from exceeding $1800^{\circ} \mathrm{F}(1255 \mathrm{~K})$. This level is plant-specific; the basis for its determination and procedures for its calculation are described in Appendices to the EPGs.

\subsubsection{Core Region Dry During Core Degradation}

As explained in the previous section, the delay in the onset of core damage gained by use of the steam cooling maneuver is temporary. Nevertheless, staving off the onset of core degradation, which otherwise would begin at about 78 minutes, for an additional 15 minutes can be significant when trying to regain electrical power or implement other means of restoring reactor 
vessel injection capability. Even if such efforts are unsuccessful so that the accident sequence proceeds into core degradation, the steam cooling maneuver provides the benefit of assuring that the core region will be steam-starved when runaway metal-water reaction temperatures are reached.

When considering severe accident progression for BWRs, it is extremely important to recognize that when the specified procedures are followed, the core region would be dry during the period of core degradation. As illustrated in the water level plot included with Figure 3.7-4, execution of the steam cooling maneuver causes the water level to fall below the core plate. This plot represents the results calculated when the ADS valves are opened with the water level at about one-third core height, but the final level will fall below the core plate even if this maneuver is initiated with the water level near the top of the core (although the achieved fuel temperature decrease will be much less).

Figure 3.7-7 shows the water level relative to the core plate immediately after execution of the ADS maneuver. It should be noted that some water is trapped in the downcomer region surrounding the jet pumps. This occurs because the initial temperature of the water in the jet pump region is less than the temperature of the water in the core region. Hence, a lower proportion of the water in the downcomer region is flashed during the rapid vessel depressurization

\subsubsection{Threat of Reactor Vessel Repressurization}

The motivation for keeping the reactor vessel depressurized under severe accident conditions is, first, that the capacity for quenching of the debris relocating from the core region into the lower plenum is enhanced and, second, that relocation of molten debris into the relatively small $B W R$ drywell would then be, should bottom head penetration failures occur, by gravityinduced flow and not by rapid vessel blowdown. If penetration failures do not occur, so that the vessel bottom head ultimately undergoes gross failure by creep rupture, then the time of failure is delayed by several hours if the vessel is depressurized. Keeping the reactor vessel depressurized eliminates direct heating concerns and greatly reduces the initial challenge to the integrity of the primary containment.

The chief threats that the reactor vessel may be pressurized at the time of bottom head failure arise from two considerations, one derived from the potential for equipment failure and the other derived from the possibility of operator error. The question of equipment failure is chiefly associated with the long-term station blackout accident sequence, for which injection capability is maintained until the unit batteries are lost. With loss of the batteries, the ability to operate the SRVs manually is also lost. Because multiple SRVs are installed and operation of any one valve is sufficient for depressurization under severe accident conditions, improved reliability of SRV operation can be attained simply by ensuring that the small amount of DC power and control air necessary for opening will be available (to at least one valve) when required. Several BWR utilities have taken steps toward this end such as provision of a dedicated small DC diesel generator and backup compressed nitrogen supply bottles.

The impact of operator error upon vessel depressurization as typically represented in probabilistic risk assessments is direct. It is postulated that the operators fail to take the required action to manually depressurize the 
reactor vessel. Although the assumed probability for such failure, say 0.001 , may seem low, typical core melt frequencies are much lower - on the order of $10^{-5}$. Accordingly, it is important to recognize that such assumptions concerning operator error, while seeming reasonable and conservative, may lead to the unrealistic conclusions that BWR core melt, should it happen, would always occur in a pressurized vessel and that there is no point in providing equipment upgrades such as a dedicated DC generator since the operators would not use them anyway.

\subsubsection{Notes Concerning SRV Operation}

Any serious attempt to study and comprehend the probable course of an unmitigated severe accident sequence at a BWR facility must include development of a thorough understanding of the operation of the installed SRVs under abnormal conditions of reactor vessel and containment pressure. The pertinent characteristics of the more common SRV designs are described in the following paragraphs. The reader should particularly note that control air pressure sufficient for valve operation under normal conditions may not be adequate if the reactor vessel is depressurized and the containment pressure is elevated.

All SRVs are located between the reactor vessel and the inboard main steam isolation valves (MSIVs) on horizontal runs of the main steam lines within the drywell. The discharge from each valve is piped to the pressure suppression pool, with the line terminating well below the pool surface, so that the steam is subject to condensation in the pool. The number of SRVs varies from plant to plant (e.g., 11 at Limerick; 24 at Nine Mile Point 2), as do the rated relief valve flows.
Some operating BWRs are equipped with three-stage Target Rock valves, which have exhibited a greater tendency to stick open in the past than have other types of valves. Many BWR utilities, however, have replaced the original three-stage valves with the newer two-stage Target Rock valves (Figure 3.7-8). Some operating BWRs are equipped with Dresser electromatic relief valves. BWR-5 and BWR-6 plants are equipped with Crosby and Dikkers dual function SRVs (Figure 3.7-9).

The differences in SRV operation in the automatic and remote-manual or ADS modes can be demonstrated with reference to the two-stage Target Rock design shown in Figure 3.7-8. During normal reactor operation, a small piston orifice serves to equalize the steam pressure above and below the main valve piston, and the main valve disk remains seated. The reactor vessel pressure (valve inlet pressure) is ported via the pilot sensing port to tend to push the pilot valve to the right. When the reactor vessel pressure exceeds the setpoint established by the setpoint adjustment spring, the pilot valve is moved to the right, the stabilizer disk is seated, and the volume above the main valve piston is vented to the valve outlet via the main valve piston vent. The sudden pressure differential causes the main valve piston to lift, opening the valve.

For the remote-manual or ADS modes, the $\mathrm{SRV}$ is opened by control air, which is admitted via a $\mathrm{DC}$ solenoid-operated valve (not shown) to the air inlet at the right of the setpoint adjustment spring. The control air moves the valve actuator to the right (against drywell pressure), which compresses the setpoint adjustment spring and pulls the pilot valve open, seating the stabilizer disk and venting the space above the main valve piston. Because the control air pressure and the reactor vessel pressure work in tandem to 
move the pilot valve to the right, the amount of control air pressure required to open the SRV will depend upon the reactor vessel-todrywell pressure differential. Also, because the control air acts to move the air actuator against drywell pressure, the required control air pressure will increase with drywell pressure.

(It should be noted that the three-stage Target Rock valves behave differently with respect to the effect of the reactor vessel-todrywell pressure differential. A good description of the operation of this older valve design is available in Reference 4.)

The spring-loaded direct-acting SRV shown in Figure 3.7-9 is opened in the spring mode of operation by direct action of the reactor vessel pressure against the disk, which will pop open when the valve inlet pressure exceeds the setpoint value. In the poweractuated mode, a pneumatic piston within the air cylinder moves a mechanical linkage to compress the spring and open the valve. As in the case of the two-stage Target Rock valve, the control air is provided via $D C$ solenoid-operated valves, and the air pressure required for valve opening decreases with reactor vessel pressure and increases with drywell pressure.

All SRVs associated with the ADS are fitted with pneumatic accumulators (located within the drywell) to ensure that these valves can be opened and held open for some (plantspecific) period following failure of the drywell control air system. For severe accident considerations, it is important to recall that remote operation of the SRVS is possible only as long as DC power remains available and the pneumatic supply pressure exceeds the containment pressure by some minimum amount.

\subsubsection{Recriticality Concerns}

The progression of damage and structural relocation of the various components (control blades, channel boxes, fuel rods) of a BWR core during an unmitigated severe accident sequence will be discussed in detail in Section 3.7.4. There it will be shown that the first structures to melt and relocate downward are the control blades. Here we pause to consider severe accident sequences that have the potential for early termination, i.e., accident sequences for which the core structure sustains significant damage but reactor vessel injection capability is restored while the major portion of the fuel remains above the core plate.

If significant control blade melting and relocation were to occur during a period of temporary core uncovering, then criticality would follow restoration of reactor vessel injection capability if the core were rapidly recovered with cold unborated water using the high-capacity low-pressure injection systems. ${ }^{5}$ Obviously, a neutron poison should be introduced into the reactor vessel for reactivity control under these circumstances, but question arises as to how best to do this. The normal means of adding boron to the reactor vessel is by injection with the standby liquid control system (SLCS). Although this system is designed to inject sufficient neutron-absorbing sodium pentaborate solution into the reactor vessel to shut down the reactor from full power (independent of any control rod motion) and to maintain the reactor subcritical during cooldown to ambient conditions, the SLCS is not intended to provide a backup for the rapid shutdown normally achieved by scram.

As indicated in Figure 3.7-10, the basic SLCS comprises a heated storage tank, two $100 \%$ capacity positive displacement pumps, and, as the only barrier to injection into the 
reactor vessel, two explosive squib valves. In most of the current BWR facilities, the sodium pentaborate solution enters the reactor vessel via a single vertical sparger located at one side of the lower plenum just below the core plate. However, so as to improve the mixing and diffusion of the injected solution (which has a specific gravity of about 1.3) throughout the core region, some BWR facilities have been modified to provide a third displacement pump and to permit the injected solution to enter the reactor vessel via the core spray line and sparger.

For the purpose of reducing the time required for reactor shutdown for the ATWS accident sequence, the NRC has issued a Final Rule ${ }^{6}$ requiring that the SLCS injection be at a rate equivalent to $86 \mathrm{gal} / \mathrm{min}(0.0054$ $\mathrm{m}^{3} / \mathrm{s}$ ) of 13 wt.\% sodium pentaborate solution, the boron being in its natural state with 19.8 at.\% of the boron-10 isotope. With this increased injection rate, sufficient boron for hot shutdown can be pumped into the reactor vessel in about 20 minutes, and for cold shutdown in about 48 minutes. It requires approximately an hour to inject the entire contents of the tank.

The operators would have no direct means of knowing whether significant control blade relocation had occurred. Thus, there is a strong potential for surprise should, for example, a station blackout accident sequence suddenly be converted into an uncontrolled criticality upon restoration of electrical power and reactor vessel injection capability. If the SLCS is used to inject sodium pentaborate at a relatively slow rate while the core is rapidly recovered with unborated water using the high-capacity, low-pressure injection systems, then criticality would occur and the core would remain critical until sufficient boron for shutdown (at the prevailing temperature) reached the core region. To avoid the possibility of temporary criticality, it would be desirable to inject effective quantities of boron along with the ECCS flow being used to recover the core. A strategy by which this might be accomplished has been considered recently. ${ }^{\text {? }}$

This example strategy could be implemented using only the existing plant equipment but employing a different chemical form for the boron poison. The only currently available information concerning the poison concentration required is derived from a recent Pacific Northwest Laboratory (PNL) study, ${ }^{5}$ which indicates that much more boron would have to be injected than is available (as a solution of sodium pentaborate) in the SLCS. Furthermore, the dominant loss-of-injection accident sequence is station blackout, and without means for mechanical stirring or heating of the injection source, the ability to form the poison solution under accident conditions becomes of prime importance. Hence the need for the alternate chemical form.

The PNL study ${ }^{5}$ provides the estimate that a boron-10 concentration of between 700 and $1000 \mathrm{ppm}$ would be required within the vessel to preclude criticality once control blade melting had occurred. This is much greater than the concentration (about 225 ppm) attainable by injection of the entire contents of the SLCS tank.

At this point, it should be noted that the conclusions of the PNL study with respect to the boron concentrations required to preclude criticality are acknowledged by the authors of that study to be very conservative. Stated another way, in the many instances where it was necessary to make assumptions during the study, the assumed quantities were selected in a manner that tends to increase reactivity (promote criticality). As an 
example, debris particles are assumed to exist in the form of spheres. As discussed in the following paragraphs, the resulting high boron concentration requirement makes development of a practical coping strategy difficult.

One means to achieve such a high boron concentration would be to mix the powder directly with the water in the condensate storage tank during the blackout period and then, once electrical power is restored, to pump the solution into the reactor vessel in a controlled manner using one of the lowpressure injection system pumps.

The condensate storage tank is an important source of water to the reactor vessel injection systems for each BWR unit. As indicated in Figure 3.7-11 (based upon the Browns Ferry arrangement), it is the normal suction source for the steam turbine-driven HPCI and RCIC systems and the alternate source for the electric motor-driven RHR and core spray pumps.

During normal reactor operation, the condensate storage tank provides makeup flow to the main condenser hotwells via an internal tank standpipe, as indicated on Figure 3.7-12. The purpose of the standpipe is to guarantee a reserve supply of water for the reactor vessel injection systems that take suction from the bottom of the tank. Any practical strategy for direct poisoning of the tank contents must include provision for partial draining to reduce the initial water volume, especially if boron- 10 concentrations on the order of $700 \mathrm{ppm}$ are to be established. The condensate storage tank can be gravity-drained through the standpipe to the main condenser hotwells under station blackout conditions.

Additional information concerning this example of a candidate accident management strategy and the characteristics of the alternate boron poison chemical form is available in Reference 7. It seems desirable that the very conservative estimates of the PNL study should now be replaced by more realistic estimates, which certainly would be expected to lower the target boron concentration from its present value of 700 $\mathrm{ppm}$ and thereby improve the practicality of such a strategy. (For example, Reference 8, which incorporates an assumption that threefourths of the control blade $\mathrm{B}_{4} \mathrm{C}$ remains in the core region, suggests that reflood water boron- 10 concentrations as low as $200 \mathrm{ppm}$ might be sufficient.) In the meantime, many of the BWR facilities have implemented accident management measures, on a voluntary basis, to provide backup capability for the SLCS. These backup strategies invoke such methods as modification of the HPCI or RCIC pump suction piping to permit connection to the SLCS tank, or poisoning of the condensate storage tank.

\subsubsection{Eutectic Formation and Relocation Sequence for BWR Core Structures}

This section addresses the progression of damage and structural relocation of BWR core components that would be expected to occur during an unmitigated severe accident sequence, i.e., an accident sequence for which reactor vessel injection capability is not restored. The BWR core is basically an assembly of unit cells, one of which is shown in the center drawing of Figure 3.713. As indicated, each unit cell comprises four fuel assemblies, each located in one of the four quadrants of a central control blade. Additional details concerning the fuel assembly and control blade internal compositions are shown in Figures 3.1-6 and $3.1-7$, respectively.

As may be confirmed by an inspection of Figure 3.7-14, one-half of the channel box 
outer surfaces do not see an intervening control blade. This arrangement affects the local core heatup rates calculated for conditions in which a shutdown core (all control blades inserted) is postulated to be uncovered. Where the control blades exist, they serve as heat sinks for radiation from the adjacent channel box walls. Where there are no blades, the channel box walls radiate to each other.

Experiments to investigate the phenomena of core melt progression in prototypical BWR core geometries have been carried out in the Annular Core Research Reactor (ACRR) at Sandia National Laboratories (one BWR test) and at the CORA out-of-pile facility ${ }^{9}$ at the Kernforschungszentrum Karlsruhe (KfK) in the Federal Republic of Germany (six BWR tests). The first of these was the DF-4 experiment, ${ }^{10}$ conducted within the ACRR in November 1986. The test apparatus, placed within the cylindrical region surrounded by the ACRR annulus, included a control blade arm, channel box walls, and 14 fresh fuel rods. The apparatus was dry, but the $50-\mathrm{cm}$ (20-inch) long test section was supplied from below with a steam flow representative of BWR boiloff conditions.

When the DF-4 fuel rod cladding was heated beyond the runaway zirconium oxidation temperature, the energy release associated with oxidation accelerated the temperature escalation. Much of the clad melted at $2125 \mathrm{~K}\left(3365^{\circ} \mathrm{F}\right)$ and relocated downward; the remainder was converted to and remained in place as $\mathrm{ZrO}_{2}$, which has a much higher melting point $\left(2978 \mathrm{~K}\left[4900^{\circ} \mathrm{F}\right]\right)$.

The control blade in the DF-4 experiment melted earlier than expected and progressively and rapidly relocated downward. Subsequently, the reactor was shutdown to terminate power generation within the test assembly fuel rods before fuel melting could begin. In a post-test crosssection, the relocated control blade material was found in the form of an ingot at the very bottom of the test section, which was below the bottom of active fuel. Both the control blade and the channel box wall portions of the DF- 4 test section were more than $90 \%$ destroyed due to melting and relocation during the experiment, but the fuel pellet stacks were predominantly still standing. Relocated cladding blocked the base of the fuel rod regions of the experiment.

Figure 3.7-15 illustrates the results of the DF-4 experiment, extrapolated to the same portion of the core that is represented in Figure 3.7-14. (Here the water rods, which were not included in the DF-4 experiment, have been assumed to relocate in the same time frame as the channel box walls.) The ramifications of these standing fuel pellet stacks in the absence of control blades with respect to the potential for criticality if water were to be introduced at this point in an actual accident sequence should be obvious.

The early control blade relocation observed in the DF-4 test was later determined to have been caused by a eutectic interaction between the control blade neutron absorber $\left(\mathrm{B}_{4} \mathrm{C}\right.$ powder) and the surrounding stainless steel of the blade structure. This occurred at a temperature well below the stainless steel melting point $\left(1700 \mathrm{~K}\left[2600^{\circ} \mathrm{F}\right]\right)$. This early $\mathrm{B}_{4} \mathrm{C}$-SS eutectic formation was also observed in the subsequent CORA BWR tests. The reaction proceeds rapidly when the local temperature increases above $1500 \mathrm{~K}(2240$ ${ }^{\circ} \mathrm{F}$ ), and sudden and complete liquefaction has been observed in CORA special-effects tests at $1573 \mathrm{~K}\left(2372{ }^{\circ} \mathrm{F}\right) .{ }^{11}$ Post-test analyses $^{12}$ of the CORA BWR core melt experiments have found that a liquefaction temperature of $1505 \mathrm{~K}\left(2250^{\circ} \mathrm{F}\right)$ for the $\mathrm{B}_{4} \mathrm{C} / \mathrm{SS}$ combination best fits the observed structural failures and melt relocations. 
The CORA experiments also demonstrated the formation of zirconium-based eutectics when the mixture formed from the destruction of the control blades at one axial level flows downward and comes into contact with the adjacent channel box wall at a lower axial level. Typically, this downward relocation of stainless steel and $\mathrm{B}_{4} \mathrm{C}$ occurs in a series of rapidly repeated temporary freeze-remelt steps. Whenever the path of the downward-flowing liquid encounters a temporary blockage, some of the flow is diverted horizontally toward the blade tip and from there into the unbladed portion of the unit cell. In this manner, the liquid steel- $\mathrm{B}_{4} \mathrm{C}$ mixture is spread through much of the lower portion of the unit cell.

When the gap between the control blade and the outer surface of the channel box wall becomes bridged by a semi-permanent blockage (low in the core), the continuously accumulating SS- $\mathrm{B}_{4} \mathrm{C}$ liquid attacks the local channel box wall aggressively. The resulting zirconium-based eutectics are formed at the prevailing temperature of about $1523 \mathrm{~K}$ $\left(2282^{\circ} \mathrm{F}\right)$. Thus, channel box wall failures follow soon (within minutes) after the onset of control blade failures.

To recap, based on the experimental record, structural damage within an uncovered BWR core is expected to be initiated when the temperature of the control blades in the upper regions of the core reaches about 1505 $\mathrm{K}\left(2250^{\circ} \mathrm{F}\right)$. This is about $195 \mathrm{~K}\left(350^{\circ} \mathrm{F}\right)$ below the melting temperature of stainless steel. Within a few minutes thereafter, channel box wall damage would be initiated in the lower regions of the core, at local wall temperatures of about $1523 \mathrm{~K}\left(2282{ }^{\circ} \mathrm{F}\right)$. This is some $600 \mathrm{~K}\left(1080^{\circ} \mathrm{F}\right)$ below the melting temperature of zirconium. (It should be noted, however, that the destruction of the channel wall is not by melting, but rather by the process of dissolution by the liquid steel.) All of this structural damage occurs at temperatures far below the melting temperature $\left(3011 \mathrm{~K}\left[5400^{\circ} \mathrm{F}\right]\right)$ of the $\mathrm{UO}_{2}$ fuel.

As mentioned previously, it is important to note that the fuel rod pellet stacks, encased in thin $\mathrm{ZrO}_{2}$ sheaths, continued to stand at the end of the DF-4 experiment. (CORA results are not germane to this question because these experiments were driven by electrically heated fuel rod simulators.) With the internal fission power heating, melting of the DF-4 cladding was initiated at the inner clad surface. This liquid zirconium then interacted with the outer surfaces of the $\mathrm{UO}_{2}$ pellets to form a paste that, upon subsequent cooling, solidified in a manner that tends to glue the pellets together.

Whether or not the fuel pellet stacks would continue to stand in an actual reactor accident is currently (1996) unknown. The DF-4 experiment employed fresh fuel, which had neither the local cracking nor the internal fission product inventory that would be present in actual fuel after long periods of power operation. Fission product release experiments with high-burnup fuel have demonstrated extensive fuel swelling and foaming. ${ }^{13,14}$

Finally, there remains the question as to the response of the hot fuel pellet stacks, should they remain standing, to the introduction of water. It is well known that hot cladding will shatter when thermally shocked, but the case of standing fuel has not been addressed for BWRs. Fuel collapse did occur in the upper portion of the TMI core when RCP 2B was temporarily restarted. 


\subsubsection{Potential Modes for Debris Move- ment Past the BWR Core Plate}

The BWR core plate is located at the base of the core region within the lower portion of the core shroud, as shown in Figure 3.7-16. Although the core plate does not support the core, it separates the core region from the reactor vessel lower plenum and thus would serve as an impediment to the movement of core and structural debris into the lower plenum under severe accident conditions. In fact, the fate of the core plate is pivotal to the progression of a BWR severe accident; whether the core plate remains in place or fails and relocates will determine whether the debris bed comprising the materials accumulating below the active core forms over the plate surface or within the lower plenum.

\subsubsection{Core Plate Structure}

The core plate is basically a circular stainless steel plate strengthened by an underlying support structure. Figure 3.7-16 indicates the relative arrangement of the fuel assemblies, fuel support piece, control rod guide tube, control rod drive housing, and stub tube for one core unit cell. The primary functions of the BWR core plate are to laterally align the upper portions of the control rod guide tubes and to provide the partition that under normal operating conditions prevents flow from the lower plenum from entering directly into the core region. Instead, the flow enters holes (one for each fuel assembly) in the upper portion of each control rod guide tube and passes through the fuel support pieces into the fuel assemblies; one of these entrance holes is labeled "flow inlet into fuel bundle" on Figure 3.7-16.

To provide an illustrative example of the dimensions of the core plate, the following discussion is based upon the 251-in. ID BWR-4 reactor vessel installed at 1065-MWe facilities such as Peach Bottom or Browns Ferry. Each of the 185 control rod guide tubes supports four fuel assemblies via an orificed fuel support piece such as the one shown in Figure 3.7-17. The support piece rests within the upper portion of the control rod guide tube while the core plate provides an alignment pin to ensure proper placement of both the guide tube and support piece. The upper surface of the core plate is located about $23 \mathrm{~cm}$ (9 in.) below the bottom of active fuel within the fuel assemblies.

The core plate, which is $5 \mathrm{~cm}(2$ in.) thick and weighs $9300 \mathrm{~kg}(20,500 \mathrm{lb})$, provides vertical support to only the 24 outermost fuel assemblies (of the 764 assemblies that make up the core). The support arrangement for one of these 24 peripheral assemblies is shown at the extreme right of Figure 3.7-17. In contrast to the four-lobed fuel support pieces used for the majority of the fuel assemblies, each peripheral fuel support carries only a single fuel assembly and is firmly seated within the core plate itself.

The stainless steel core plate surface resembles a perforated drum membrane, being penetrated by 185 large holes $(28 \mathrm{~cm}$ [11 in.] ID) to accommodate the passage of the control rod guide tubes and 55 smaller holes (5 cm [2 in.] ID) for the in-core instrument guide tubes. The core plate is supported around its outer periphery, which is bolted to a ledge on the core shroud as indicated on Figure 3.7-18. Central support is limited to that provided by the stiffener plates and stiffener rods labeled "core plate support structure" on Figure 3.7-16.

An appreciation for the extent of the core plate, which has a diameter of about $4.9 \mathrm{~m}$ (16 ft.), can be gained from Figure 3.7-19. Under the conditions that would be imposed 
by a severe accident, the peripherally supported core plate is in position to assume the role of providing vertical support for the relocating core and structural debris that would accumulate over its upper surface. This would at least delay any major movement of debris into the lower plenum until local plate structural failures had opened the necessary pathways. Local plate structural failure (creep rupture) would be caused by the combined effects of an increasing weight of debris to be supported and a local loss of structural strength due to elevated plate temperature.

\subsubsection{Accident Sequence Classifica- tion for Core Plate Consid- erations}

The characteristics and rates of debris relocations from the active core region down onto the upper surface of the BWR core plate under severe, accident conditions are accident-sequence dependent. The decay heat level at the onset of debris relocation, for example, depends upon the time at which the core becomes uncovered, which can vary from about 40 minutes (short-term station blackout) to more than 35 hours (loss of decay heat removal) after scram. Nevertheless, from the standpoint of core plate response, BWR severe accident sequences can be broadly divided into two distinct sets: those sequences for which the core plate would be dry when debris relocation begins, and those for which the plate would be covered with water.

\subsection{Dry Core Plate Accident Sequences}

As explained in Section 3.7.2.3, almost all BWR severe accident sequences would involve procedural steps for manual actuation of the ADS when the core became partially uncovered. The attendant flashing of steam and high rate of flow through the open SRVs would cause rapid loss of reactor vessel water inventory and almost immediate core plate dryout. Heatup of the totally uncovered core would then lead to structural relocation of molten control blade (stainless steel/ $\mathrm{B}_{4} \mathrm{C}$ ) and channel box (zirconium) materials. With the core plate dry, plate heatup and the potential for local temperatures conducive to creep rupture would begin immediately after the relocating metallic liquids reached the plate.

As local plate failures occur, overlying debris would fall into the lower plenum, contributing to the establishment of a debris bed there. (See Section 3.7.6.) On the other hand, for regions where the core plate remains intact, the debris bed would form in the region above the plate surface, with the oxides $\left(\mathrm{UO}_{2}\right.$ fuel pellets and $\mathrm{ZrO}_{2}$ from the oxidized portion of the cladding) generally above the metals. This buildup of a debris bed above the plate surface is more likely for the case of the wet core plate, as will be described below.

Before leaving this discussion of the dry case, it is worthwhile to note that the core plate was not designed to constitute an impermeable partition. Leakage through the plate during reactor operation is intended to provide some cooling flow to the core interstitial region, to supplement the control rod drive hydraulic system flow. Because of the numerous original leakage pathways, it would not be necessary to have actual core plate failures in order for much of the metallic liquid reaching the plate surface to flow through, particularly in the vicinity of the incore instrument guide tube penetrations. (These hollow stainless steel tubes would be susceptible to melting long before the core plate itself.) 


\subsection{Wet Core Plate Accident Sequences}

The intent of the BWR Owners Group Emergency Procedure Guidelines (EPGs) ${ }^{3}$ regarding rapid reactor vessel depressurization when the core has been partially uncovered cannot be carried out in some BWR severe accident sequences because either control air or DC power, or both are not available at the time that it becomes necessary to open the SRVs. This is true, for example, for the long-term station blackout accident sequence, which is estimated by the NUREG-1150 study to constitute about $42 \%$ of the overall core damage risk (internal events) at Peach Bottom. For these accident sequences and in sequences involving failure to depressurize due to operator error, molten materials relocating downward from the uncovered upper portion of the core would freeze upon entering the two-phase (steam/water) region above the plate. The associated steam generation would cause a higher degree of metal-water reaction in the upper portion of the core and an accelerated core degradation rate in that vicinity.

For the wet case, much of the relocating metallic liquid would not reach the core plate, but rather would freeze at some elevation above the plate. Subsequent debris bed formation and melting above the plate surface would lead to a period within the accident sequence more like the Three Mile Island (PWR) experience. In other words, retention and buildup of a debris bed above the core plate is more likely for the wet case where core plate dryout, heatup, and structural failure are delayed because the plate is submerged in water during initial material melting and relocation.

Would the presence of water in the BWR core region during the initial stages of debris relocation from the upper core lead to formation of a bowl - like crucible containing oxidic melt as occurred at Three Mile Island? No experiment conducted to date (1996) has addressed this possibility, but it seems very unlikely because of the open spaces between the fuel assemblies in the BWR core configuration and the different frothing heights among adjoining fuel bundles. The difference in frothing heights (due to different power densities) between adjacent bundles in the central region of a typical BWR core would exceed $0.30 \mathrm{~m}$ $1 \mathrm{ft}$.); consequently, any metallic blockages would be discontinuous in the radial direction. (Contrary to first expectations, the freezing level for downward-flowing metallic liquids would be higher in the higher-power fuel assemblies.)

Core plate dryout would, of course, eventually occur for the case without vessel depressurization, when sufficient debris had been quenched to boil away all of the water initially above the plate. By this time, however, the core plate would be covered with a layer of previously quenched metallic material. Subsequent relocation of oxides onto the surface of this mostly metallic layer would induce heating of the plate and the accumulated overlying debris. The temperature increase of the plate would, however, be much slower than for the dry case, where molten metals interact directly with the plate surface.

\subsubsection{Status of Experimental Findings}

The current experimental foundation for understanding downward relocation of core debris under BWR severe accident conditions consists of the DF-4 experiment and the CORA BWR tests. Each of these experiments represents an uncovered length (control blade, channel box, and fuel rods) in 
the upper BWR core with steam flows (from below) typical of a wet core plate accident sequence. However, in each case, the steam flows were fed into the test apparatus from outside and there was no representation of water in the lower portion of the test section or of a core plate. These experiments all demonstrate rapid relocation of metals (control blade and channel box materials) to below the fueled region of the test assembly. These results confirm that relocation of metallic metals would occur first, so that debris initially reaching the core plate surface would consist entirely of metals, but provide no information concerning the core plate response.

An experimental program ${ }^{15}$ to establish the necessary information concerning the severe accident response of the BWR core plate has been recently completed. The XR2 test conducted in December 1995 at Sandia National Laboratories examined the behavior of downward relocating molten metallic materials in the lower portion of a dry BWR core. The material composition and geometry of the XR2 test section was prototypic in both the axial and local radial directions. The simulated portion of the lower core included one-half meter of the fuel assembly, the nose piece, the core plate, the control blade and velocity limiter, and the fuel support structure with the coolant inlet nozzles. The imposed test conditions were calculated beforehand by the NRCsponsored SCDAP/RELAP code, which itself includes models ${ }^{16}$ based upon the results of the previous BWR DF-4 and CORA experiments. Specifically, these calculations provided the bases for the initial thermal state of the test assembly and for the timing and associated rates for the introduction of molten metals onto the test assembly from above.
To simulate downward draining control blade liquids reaching the lower core, control blade material was fed into the upper end of the test section over a period of 1000 seconds. Employing a specially designed wire guide and melter system, this feed material was delivered in a prescribed pattern over the test assembly control blade at a controlled, constant rate. Subsequently, molten Zircaloy was introduced as appropriate to represent the calculated degradation of the upper fuel rod cladding and channel box walls.

The fuel assemblies were severely degraded during the test. The channel box walls were destroyed by the aggressive eutectic-forming action of the molten control blade material, and the fuel rods were stripped of cladding. The $x$-ray imaging system showed the forming of temporary blockages and pools early during the test, but the liquids were able to break free so that large masses of molten materials would drain suddenly to the lower reaches of the test assembly. Thermocouple responses also indicated the effects of large-scale and sudden melt relocations to regions beneath the core plate.

Subsequent to the test, more that half of the feed material and material that melted in the upper portion of the test assembly was found below the core plate elevation. Some of this was located in the inlet nozzle, some had come to rest on the control blade velocity limiter, but most was found in the lower catch basin (which simulates the vessel lower plenum). Thus, the results of the XR-2 experiment demonstrate that the downward flowing metallic liquids do not freeze to form permanent blockages above the core plate, but rather continue to the plate surface and beyond to the lower plenum through existing pathways in the lower core structures and core plate. 
It is important to recognize that the XR2 experiment was not intended to address core plate failure directly, but rather to provide the temperature response of the core plate for use in separate creep rupture calculations. The experiment did not represent the true radial extent of the core plate or the magnitude of the imposed load that would exist at the time that creep rupture would be expected to occur in the actual case. In actuality, the core plate is a perforated disk (with underbracing) that is $4.9 \mathrm{~m}$ (16 ft.) in diameter and is supported around the edge. Ultimately (after the period of initial metals pour addressed by the experiment), the central portion of this disk would be loaded by some $200,000 \mathrm{~kg}$ of fuel debris from the upper central core. This is when core plate failure would be expected to occur, and with the plate temperatures (in excess of $1200 \mathrm{~K}$ [ $\left.1700^{\circ} \mathrm{F}\right]$ ) demonstrated in this experiment, failure seems likely.

\subsubsection{Severe Accident Events in the BWR Lower Plenum}

As explained in the previous section, it is expected that metallic liquids relocating downward through a dry BWR core would to a large extent pass through existing core plate pathways into the reactor vessel lower plenum. Subsequently, following collapse of the central fuel pellet stacks and local failures of the core plate boundary, oxidic debris would enter and begin to accumulate within the lower plenum. While much of this entering oxide would be in the solid phase as $\mathrm{UO}_{2}$ fuel pellet fragments, code predictions indicate that a significant portion would be in the liquid phase in the form of a $\mathrm{UO}_{2}-\mathrm{ZrO}_{2}$ eutectic mixture. At this point, it is important to consider the extent to which the falling debris would interact with the lower plenum water.

\subsubsection{Debris Interactions With Lower Plenum Water}

Fortunately, several experiments ${ }^{17,18}$ have been conducted to examine the behavior of corium streams falling through water. In general, these have been special effects tests employing the actual materials of interest at the temperatures of interest. For example, Reference 17 reports the results of six tests in which a corium composition (by mass) of $60 \% \mathrm{UO}_{2}, 16 \% \mathrm{ZrO}_{2}$, and $24 \%$ stainless steel (SS) at an initial temperature of 3073 $\mathrm{K}\left(5072{ }^{\circ} \mathrm{F}\right)$ was poured at atmospheric pressure into water pools of depth about one meter. No steam explosions occurred, and the fraction of the pour quenched during the fall varied from $55-72 \%$ for subcooled pools to $33-45 \%$ for initially saturated pools. Very little (about 1\%) of the steel dropped into the subcooled pools was oxidized during the fall, but for the saturated pools, up to $35 \%$ of the available steel was oxidized. The corium not quenched during the fall was subsequently quenched while resting at the bottom of the pool, where a debris bed of solidified particles was formed. There was no ablation of the pool floor.

When contemplating the corium pours that might be generated in hypothetical BWR accidents, it is necessary to consider the effects associated with the presence of zirconium metal as a constituent. In spite of the difficulties associated with the handling of liquid zirconium, the experiments conducted to date in the corium pour test series reported in Reference 18 have included one $\mathrm{UO}_{2}-\mathrm{ZrO}_{2}-\mathrm{Zr}$ pour, the results of which may be compared with the results of three similar tests carried out in the same apparatus with $\mathrm{UO}_{2}-\mathrm{ZrO}_{2}$ pours. No steam explosions occurred in these tests, which were carried out at $5.0 \mathrm{MPa}$ (725 psia) with 
saturated water pools varying in depth from 1-2 meters. All of these pours were subject to significant breakup and quenching during the melt fall through the water.

For the Reference 18 tests with $\mathrm{UO}_{2}-\mathrm{ZrO}_{2}$, a portion (from 1/6 to $1 / 3$ ) of the corium mass did not break up during the fall, but rather reached the pool floor while still molten (and subsequently quenched there). For the test with $\mathrm{UO}_{2}-\mathrm{ZrO}_{2}-\mathrm{Zr}$, however, full oxidation of the zirconium and complete breakup of the melt occurred during the fall. Apparently, the energy release associated with the metal oxidation during the fall had the effect of promoting spreading (and quenching) of the accompanying oxide portion of the pour.

Additional corium-water interaction tests are expected to be conducted in the future. In the meantime, the available evidence from the special effects experiments ${ }^{17,18}$ supports a contention that in the actual case, the relocating debris would quench in the lower plenum water.

For BWRs, the argument that the falling masses of hot debris would be quenched in the reactor vessel lower plenum is buttressed by the extent of the stainless steel structures located there and the large surrounding volume of water. For the Browns Ferry/Peach Bottom example, there are 185 control rod guide tubes of $28 \mathrm{~cm}$ (11 in.) outer diameter on a $30.5 \mathrm{~cm}$ (12 in.) pitch in the vessel lower plenum; within each unit cell, any free-falling debris must pass through a $316 \mathrm{~cm}^{2}$ (50 in. ${ }^{2}$ ) opening (see Figure $3.7-20)$ that is $3.7 \mathrm{~m}$ (12 ft.) in length (see Figure 3.7-21). Thus, any rapid passage of large, coherent, molten masses through the lower plenum water is precluded, and a large amount of energy would be transferred from the debris to the relatively cold steel with which it came into contact. These considerations, plus the initial presence of sufficient water in the lower plenum to completely quench more than one entire core, leads to the conclusion that the relocating debris would be quenched. The associated steam generation would be relieved via the SRVs, so that vessel integrity would not be threatened.

\subsubsection{Events After Lower Plenum Dryout}

In accordance with the BWR core material damage and relocation sequence described in Section 3.7.5, it is expected that the composition of the quenched debris bed that accumulated in the lower plenum would vary with height. Lowermost in the bed would be the debris first relocated into the lower plenum. This normally would comprise mostly metallic debris (control blades, channel boxes, candled clad and dissolved fuel) that had either passed through the intact core plate, had accumulated on the plate surface before local plate failure, or had subsequently relocated downward within the same local region before fuel pellet stack collapse.

Higher, within the middle region of the bed would be the collapsed fuel and $\mathrm{ZrO}_{2}$ from the central region of the core. The initial leakages of metallic liquids through the core plate and the subsequent plate structural failures would cause temporary bursts of steaming as the relocating metallic debris was quenched; however, with the collapse of the central core fuel pellet stacks, a constant heat source (the decay heat associated with the pellets) would be introduced to the lower plenum reservoir, initiating a continuous boiloff of the remaining water.

After lower plenum dryout, the debris bed temperature would increase, causing thermal attack and failure of the control rod guide 
tube and instrument tube structures, which the debris would completely surround to a depth of about $3 \mathrm{~m}$ ( $10 \mathrm{ft}$.). Since the control rod drive mechanism assemblies and the control rod guide tubes support the core, the remaining standing outer radial regions of the core would be expected to collapse into the lower plenum when these support columns fail. Thus, the uppermost portion of the completed lower plenum debris bed should primarily consist of the collapsed metallic and fuel materials from the relatively undamaged outer regions of the core. The stainless steel of the control rod guide tubes and mechanism assemblies, the instrument tubes, and other lower plenum structures would be subsumed into the surrounding debris as it became molten.

\subsubsection{BWR Bottom Head Failure Modes}

Given that the lower portion of the debris bed would be comprised almost entirely of metallic materials while $\mathrm{UO}_{2}$ pellets constituted more than half of the central bed, then the central region would heat up much more rapidly after lower plenum dryout, and heat transfer within the bed would be toward the vessel wall. As the temperature of the bed increased, materials in the central region would begin to melt, migrate to cooler regions within the bed, freeze, and subsequently melt again. Eventually, temperatures near the wall would be sufficient to threaten its integrity. Failure of the vessel bottom head wall as a pressure boundary might occur as a result of penetration failures, or by creep-rupture failure of the wall itself. Both of these potential failure modes are discussed below.

\subsubsection{Failure of the Bottom Head Penetrations}

There are more than 200 bottom head penetrations in a BWR reactor vessel of the size employed at Browns Ferry or Peach Bottom, where there are 185 control rod drive (CRD) mechanism assembly penetrations, 55 instrument guide tube penetrations, and a $5.1 \mathrm{~cm}(2$ in.) drain line penetration near the low point of the bottom head. The inner surface of the bottom head is clad with Inconel (thickness $0.32 \mathrm{~cm}$ [0.125 in.]), while the penetrations are stainless steel. Cross-sections of the CRD mechanism assembly and instrument tube penetrations and their weldments are illustrated in Figure 3.7-22. Each CRD mechanism assembly is held in place by an Inconel-to-stainless steel weld located at the upper end of the Inconel stub tube, as shown in Figure 3.7-23. (These are the welds that support the weight of the BWR core.) The location of one of the instrument guide tube welds at the inner surface of the bottom head wall is shown in Figure 3.7-24.

It is important to note that the CRD mechanism assembly welds are located about $10 \mathrm{~cm}$ (4 in.) above the vessel wall and thus would lie within the confines of the lower plenum debris bed. As a consequence, these welds would be expected to reach elevated temperatures before the instrument tube welds at the vessel wall. Failure, if it occurred, would be by creep rupture, which would be promoted at much lower temperatures if the reactor vessel were pressurized.

Although bottom head pressure boundary failures should occur first at the upper stub tube welds, this type of failure is less important from the standpoint of potential for debris release from the reactor vessel than are instrument tube failures. This is true because BWRs are required to have an auxiliary support structure beneath the vessel bottom head that would limit the downward movement of any control rod mechanism assembly to about $3 \mathrm{~cm}$ (1 in.) in the event 
of failure of its stub tube weld. (This requirement does not derive from severe accident considerations, but rather from a need to guard against the sudden expulsion of a control blade from the core during critical operation at very low power.) Since the thickness of the vessel bottom head in the region of the penetrations is $21.4 \mathrm{~cm}$ (8 $7 / 16$ in.), this limited downward movement could not open a significant pathway through the vessel wall even if the CRD mechanism assembly were melted within the debris bed. This is not true for the instrument guide tubes, for which there is no provision to limit their downward movement.

For an unmitigated accident sequence, temperatures at the inner surface of the bottom head wall would eventually become sufficiently high to cause failures of the welds that hold the instrument tubes in place. However, it is probable that a different mode of failure for the instrument guide tubes would occur first. As illustrated in Figure 3.7-25, this potential early failure mode for the instrument guide tubes involves melting of the portions of these guide tubes within the central region of the debris bed. Then, when the sequence of melting, downward movement, and freezing processes for the metals had progressed to the point that molten debris liquids were standing in the central region of the bed, these liquids could spill into the failed instrument tubes and pour through the vessel wall. In order to complete the pathway to the containment, however, it is necessary that the entry of molten debris liquids into the interior of these tubes induce tube wall failures external to the bottom head wall.

Would movement of molten debris liquids through an instrument tube result in tube failure outside the vessel wall? This question has been extensively studied. ${ }^{7,19}$ An important measure of the vulnerability of the tube wall is the ratio of the volume within the tube available for occupation by melt to the volume of the adjacent wall. For BWR instrument guide tubes, this ratio is 1.40 , whereas for PWR guide tubes, this ratio varies from 0.06 to 0.52 . Thus, BWRs are more susceptible to debris release by penetration failures than are PWRs. Analyses ${ }^{19}$ indicate, however, that the BWR instrument guide tube vulnerability is limited to cases where the vessel pressure is greater than $2 \mathrm{MPa}$ (290 psia), and molten oxidic (ceramic) melt enters the tube. (Metallic liquids entering the tube and passing through the vessel wall would be expected to freeze while the tube wall remains intact.) If the reactor vessel is depressurized, then calculations indicate that the only possible penetration failure involves the entrance of ceramic liquids into the vessel drain.

Given the presence of internal debris liquids, then the BWR vessel drain offers the highest potential for the opening of an escape route through the vessel wall, as evidenced by its melt volume-to-wall volume ratio of 1.57 , which is the largest value of this ratio for any type of penetration. However, it is important to recognize that the pathway by which molten debris would enter the vessel drain is different than that for the instrument guide tubes. The vessel drain is located at the bottom of the lower plenum, offset slightly (about $15 \mathrm{~cm}[6 \mathrm{in}$.$] ) from the point$ of vessel zero. Therefore, metallic particles quenched while falling through the lower plenum water during the initial stages of debris movement through the core plate would collect in the drain. After lower plenum dryout, metallic liquids forming within the debris bed and moving downward would enter the remaining voids within the vessel drain. On the other hand, molten material would flow laterally within the bed to enter the failure location of an instrument tube only after the voids in the lower 
portions of the bed had been filled with liquid, to the level of the failure location. The upshot is that the vessel drain would probably be filled earlier by a lower-meltingtemperature metallic mixture; the instrument guide tubes would probably be filled later by a higher-melting-temperature oxidic mixture.

To summarize, BWR penetration failures are unlikely, but the possibility cannot be excluded. If not previously filled by frozen metals, the instrument tubes would be expected to fail ex-vessel if attacked from within by ceramic melt at a pressure of at least $2 \mathrm{MPa}(290 \mathrm{psia})$. While the presence of ceramic melt within the vessel drain could cause failure of the wall with zero pressure differential, it is very probable that the drain would be filled by metallic debris long before molten ceramics became available in the vicinity. Since there are 55 instrument guide tubes and just one drain, it seems that between the two possibilities, opening of an instrument tube pathway is more probable.

If penetration failures did occur, then a leak path from the vessel to the containment atmosphere would be created. Subsequently, the vessel gaseous content would blow down if the reactor vessel were at pressure or, if the vessel were depressurized, would slowly leak out as the gas temperature in the vessel increased and the water in the vessel downcomer region boiled away. The leak path for the steam generated from the water surrounding the jet pumps would be up through the downcomer region, down through the core region, and out through the debris bed. Steam passing through the debris would react with any unoxidized metals in its path, greatly augmenting the local bed heatup rate and promoting local melting.

Figure 3.7-26 illustrates the effect of metals oxidation within the bed in accelerating the release of debris from the reactor vessel. For this calculation, which is based on Peach Bottom, it was assumed that ex-vessel tube wall failures would occur immediately following the introduction of debris liquids from the central portion of the bed. The integrated mass of debris released is plotted as a function of time after initial penetration failure. For the short term station blackout calculation, the vessel is depressurized and the liquids flow from the vessel as they are created by melting within the bed. Stated another way, the rate of release of debris liquids from the vessel is controlled by the rate of debris melting.

For the long term station blackout case, the vessel is pressurized at the time of penetration failure and, as indicated, the initial rate of debris release is much greater. This period of rapid liquid flow from the vessel is a direct result of the accelerated debris melting that is driven by the flow of steam into the bed surface during the period while the vessel is depressurizing through the bed. Once this blowdown period is completed, the release of liquids virtually ceases, until the bed temperature has increased sufficiently (under the impetus of decay heating) that liquids begin to form from debris constituents with higher melting points.

Before leaving Figure 3.7-26, the reader should recall that the long term station blackout accident sequence proceeds much more slowly than the short term version (because the capability to keep the core covered is maintained while battery power remains available). Thus, time zero on this figure represents about 16 hours after scram for long term station blackout, but about 4 hours after scram for short term station blackout. The two integrated release curves intersect at about 140 minutes following penetration failure because the higher decay 
heat rate for the short term case has compensated for the temporary acceleration of debris melting caused by metals oxidation during vessel blowdown in the long term case.

\subsubsection{Gross Bottom Head Failure}

If penetration failures did occur, the downward flow of molten liquids through the instrument tube locations would induce ablation of first the tube wall and then the surrounding solid debris (in lower portions of the bed) and the vessel wall. Wall ablation can significantly increase the size of the effective flow pathways through the wall; however, as discussed in the previous Section, the rate at which liquids are released from the vessel after the initial penetration failure would be controlled by the rate at which the solid debris is melting. Code calculations demonstrate that eventually, wall ablation would lead to gross failure of the wall, such that all remaining debris (comprised primarily of solids) would be released from the vessel.

For cases in which penetration failures did not occur, heat transfer from the central portion of the bed after lower plenum dryout would eventually increase the temperature of the bottom head wall to the point of failure by creep rupture. However, about $95 \%$ of the vessel wall stress under normal operating conditions is due to the internal vessel pressure, and, as described in Section 3.7.2, emergency procedures direct the control room operators to manually depressurize the reactor vessel at an early phase of any severe accident sequence (when the core is partially uncovered). The wall stress after lower plenum dryout with the reactor vessel depressurized and taking into account the weights of both the debris resting on the bottom head and the bottom head itself would be less than $3 \%$ of the normal operating value. ${ }^{7}$ At this low stress level, failure by creep rupture would occur only at wall temperatures approaching the melting temperature of the carbon steel. Calculations based on short term station blackout without penetration failures typically predict that wall temperatures of this magnitude would be reached about six hours after lower plenum dryout.

\subsubsection{Effectiveness of External Water Cooling}

It is important to note that containment flooding to above the level of the core is currently incorporated within the BWR Owners Group EPGs ${ }^{3}$ as an alternative method for providing a water source into the reactor vessel in the event of LOCA (the water would flow into the vessel from the containment through the break). Here we will discuss whether or not containment flooding, if successfully carried out, might be effective in preventing the release of molten materials from the reactor vessel for the risk-dominant non-LOCA accident sequences such as station blackout. The practical difficulties associated with attempting to inject large amounts of water into containment under severe accident conditions will be addressed in Section 4.7.

Heat transfer from the instrument guide tube and vessel drain outer surfaces would be greatly enhanced by the presence of water because the heat transfer mode would be shifted from natural convection of air to nucleate or film boiling of water. HEATING code calculations ${ }^{7}$ have demonstrated that the effectiveness of the water cooling is such that the submerged instrument guide tubes or vessel drain would be expected to survive filling with any possible category of molten debris, even if the vessel remains pressurized.

If the containment were flooded with water, a portion of the drywell atmosphere would 
be trapped within the reactor vessel support skirt, as illustrated in Figure 3.7-27. The fraction of the bottom head surface area beneath the skirt that would be submerged in water could be increased by providing a vent pathway such as by drilling several small holes in the vessel skirt, just below the vessel attachment weld. However, from the standpoint of regulatory requirements, the NUREG-1150 core melt frequency estimates, cost-benefit analysis, and the desire to minimize radiation exposure to personnel, this is clearly not a practical proposal for existing BWR facilities.

Analyses ${ }^{7}$ have shown that the existence of a trapped gas pocket beneath the vessel skirt attachment would ultimately prove fatal to the integrity of the bottom head wall. Figure 3.7-28 illustrates the expected condition of the debris at the time of wall failure. The central portion of the bed is a liquid slurry while a crust (thicker at the bottom) adheres to the wall. Calculations indicate that the presence of water as shown in Figures 3.7-27 and -28 would serve to delay bottom head creep rupture from about 10 hours after scram if the bottom head is dry to about 13 hours after scram.
It is instructive to briefly consider a case in which the bottom head is completely submerged as shown in Figure 3.7-29. Here none of the local bottom head temperatures would ever become high enough to threaten failure by creep rupture. However, upward radiative heat transfer within the vessel from the debris surface would eventually melt all of the upper internal structures; the ensuing stainless steel liquid would be added to the central debris pool. After exhaustion of the stainless steel, the only remaining internal heat sink above the debris surface would be the carbon steel of the vessel wall. All portions of the wall cooled by water on their outer surfaces would remain intact, but unless the water height within the drywell extended well above the surface of the debris pool, upper portions of the vessel wall with exteriors exposed to the drywell atmosphere would ultimately reach failure temperatures. Figure 3.7-29 indicates the minimum water height required to prevent melting of the wall inner surface as determined by an actual calculation ${ }^{7}$ based upon the Peach Bottom or Browns Ferry configuration. 
Table 3.7-1 Vessel depressurization at one-third core height postpones the predicted core degradation events for short term blackout

\begin{tabular}{|l|c|c|}
\hline \multicolumn{1}{|c|}{ Event } & \multicolumn{2}{c|}{ Time (min) } \\
\hline Swollen Water Level Falls Below Top of Core & 40.7 & 40.7 \\
\hline ADS Actuated & - & 75.0 \\
\hline Core Plate Dryout & - & 75.6 \\
\hline Begin Relocation of Core Debris & 87.4 & 110.2 \\
\hline Core Plate Dryout & 102.5 & - \\
\hline First Local Core Plate Failure & 116.7 & 111.6 \\
\hline
\end{tabular}




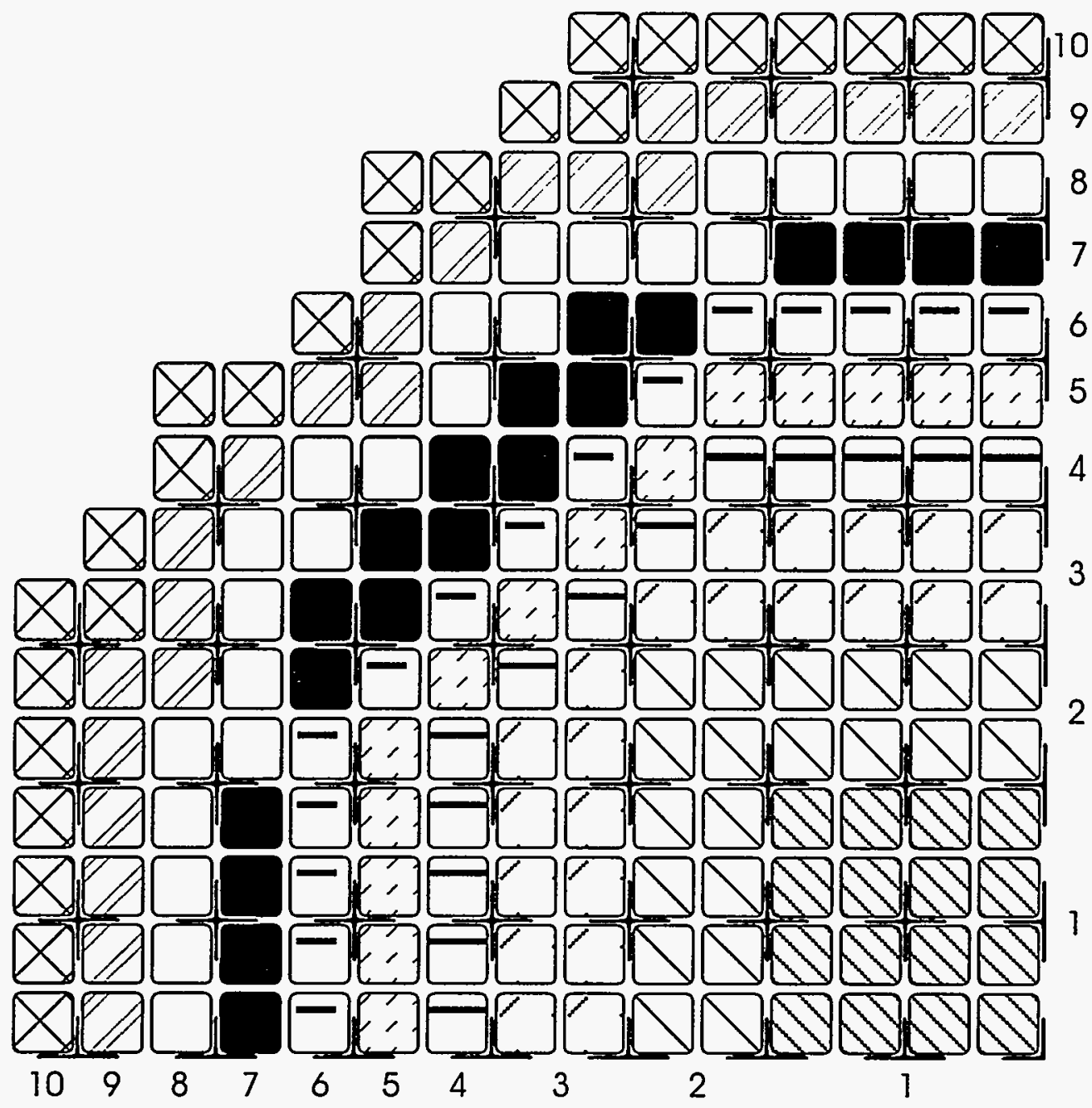

\begin{tabular}{|c|c|c|c|c|}
\hline $\begin{array}{l}\text { RADIAL } \\
\text { ZONE }\end{array}$ & $\begin{array}{l}\text { NO. OF BUNDLES } \\
\text { IN } 1 / 4 \text { CORE }\end{array}$ & $\begin{array}{l}\text { POWER } \\
\text { RANGE }\end{array}$ & $\begin{array}{l}\text { MEAN PEAKING } \\
\text { FACTOR }\end{array}$ & $\begin{array}{l}\text { VOLUME } \\
\text { FRACTION }\end{array}$ \\
\hline 01 & 16 & $0.97-1.27$ & 1.115 & 0.08377 \\
\hline & 20 & $1.06-1.32$ & 1.160 & 0.10471 \\
\hline & 22 & $1.10-1.34$ & 1.233 & 0.11518 \\
\hline & 13 & $1.23-1.36$ & 1.309 & 0.06806 \\
\hline E5 & 14 & $1.10-1.33$ & 1.194 & 0.07330 \\
\hline$\Xi 6$ & 15 & $1.15-1.37$ & 1.258 & 0.07853 \\
\hline 7 & 19 & $1.10-1.23$ & 1.155 & 0.09948 \\
\hline$\square 8$ & 24 & $0.92-1.13$ & 1.000 & 0.12565 \\
\hline 99 & 23 & $0.55-0.85$ & 0.670 & 0.12042 \\
\hline$\nabla_{10}$ & $\frac{25}{191}$ & $0.23-0.47$ & 0.354 & 0.13089 \\
\hline
\end{tabular}

Figure 3.7-1 Definition of radial zones for Browns Ferry unit 1 cycle 6 core 


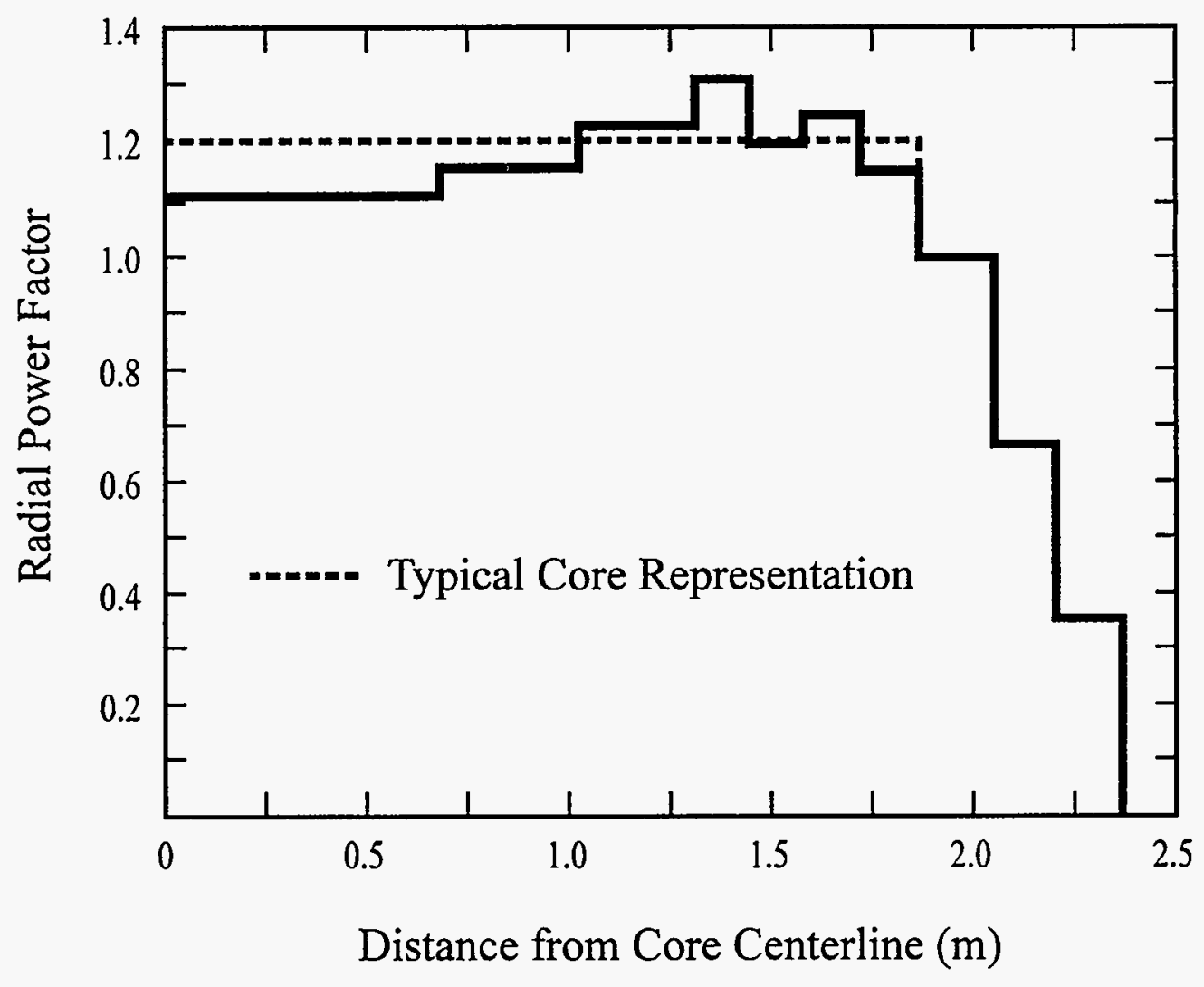

Figure 3.7-2 The progression of severe structural damage in the outer core would significantly lag events in the central core 


\section{GRAND GULF SHORT TERM STATION BLACKOUT WITHOUT ADS ACTUATION}

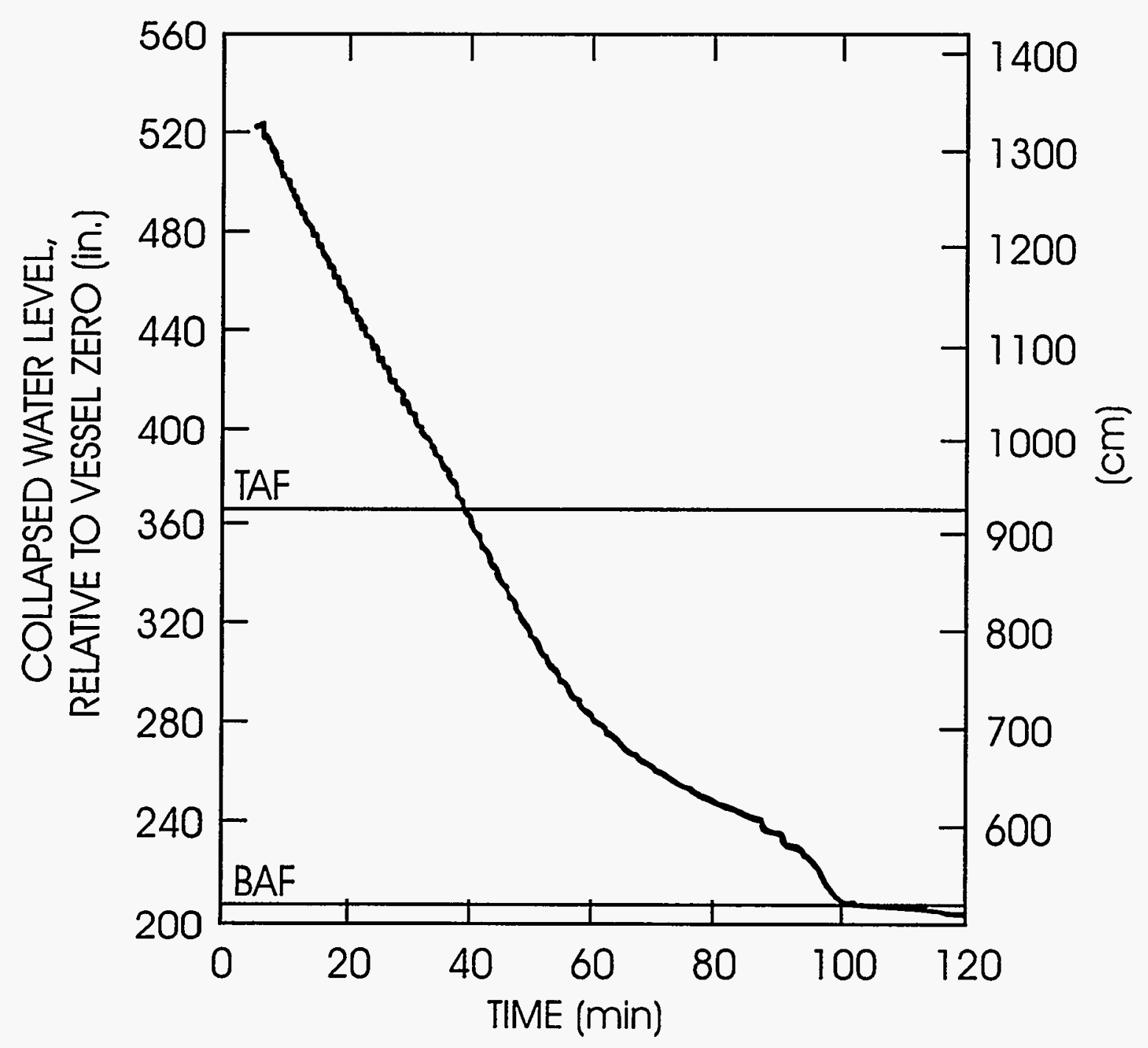

Figure 3.7-3 If the reactor vessel remains pressurized, relocating core debris falls into water above the core plate 
GRAND GULF SHORT TERM STATION BLACKOUT ADS ACTUATION AT $75.0 \mathrm{~min}$.
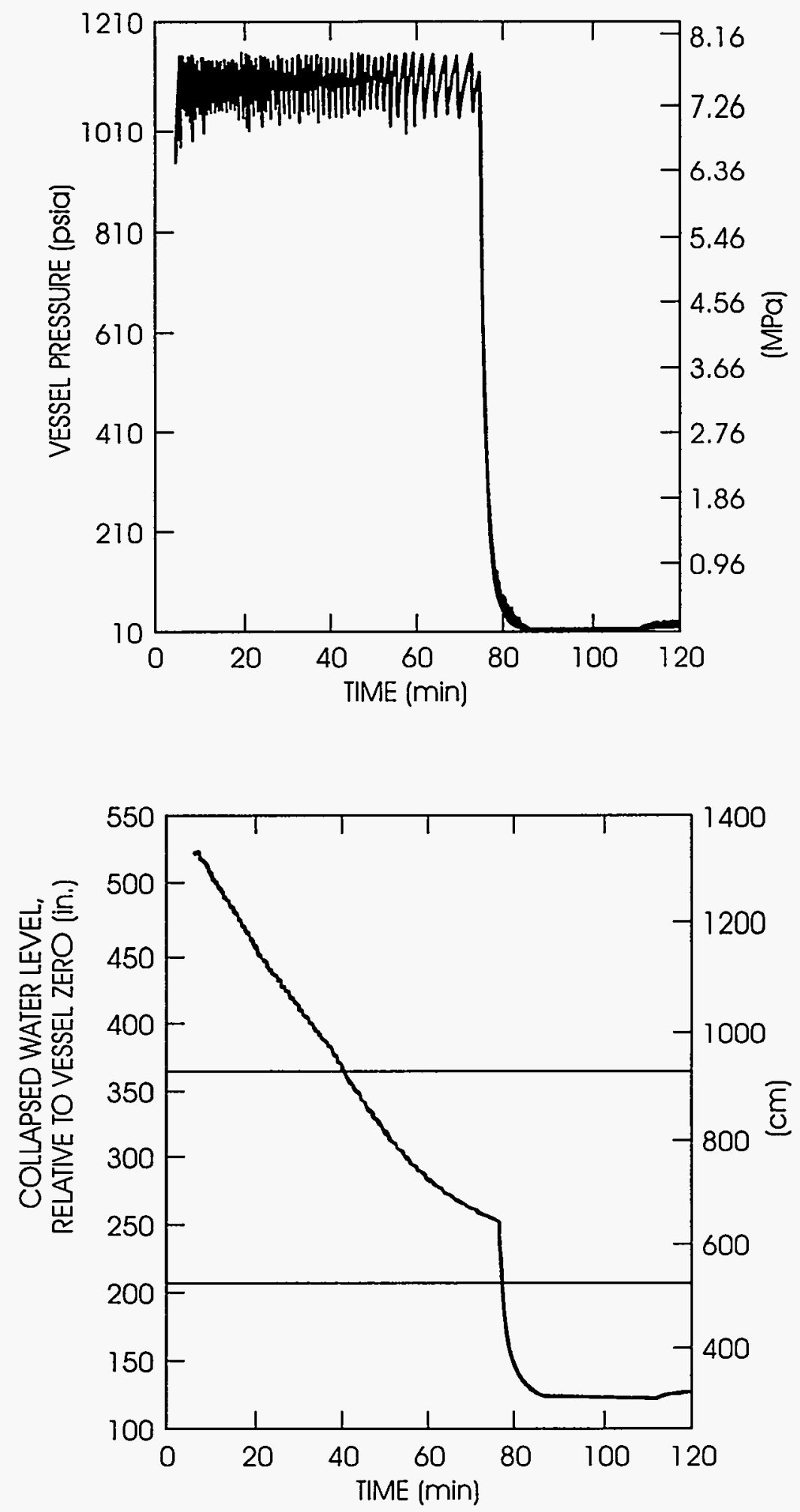

Figure 3.7-4 Effects of manual actuation of ADS at about one-third core height 


\section{GRAND GULF SHORT TERM STATION BLACKOUT}

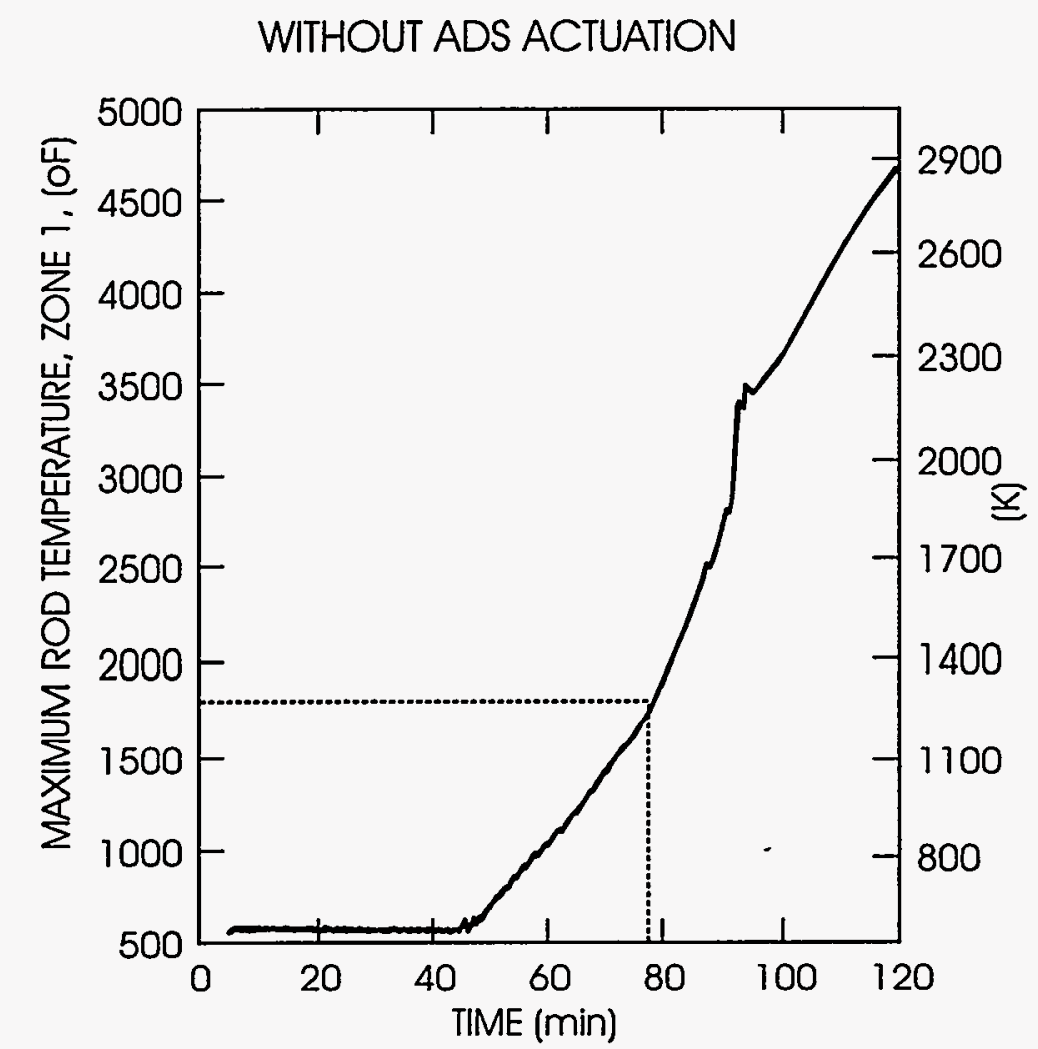

WITH ACTUATION AT $75.0 \mathrm{~min}$.

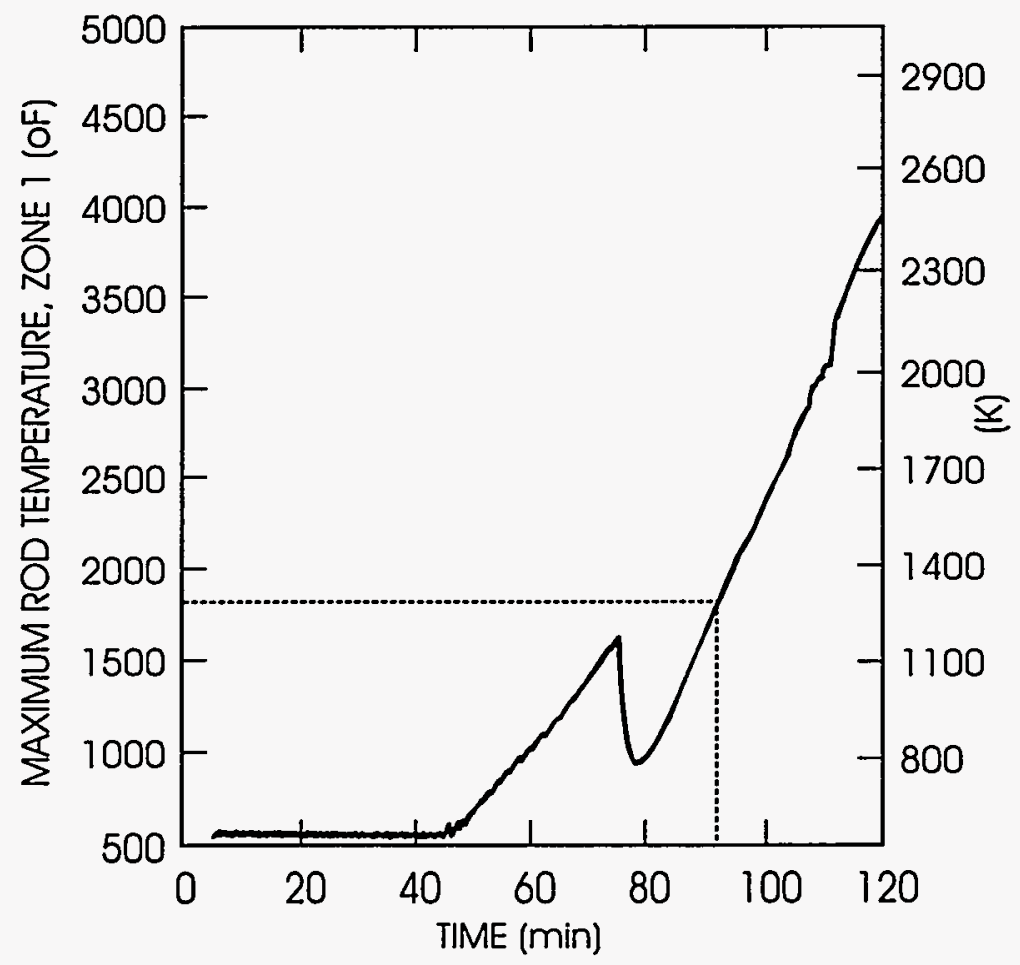

Figure 3.7-5 Vessel depressurization at one-third core height provides steam cooling that temporarily reverses core heatup 
GRAND GULF SHORT TERM STATION BLACKOUT
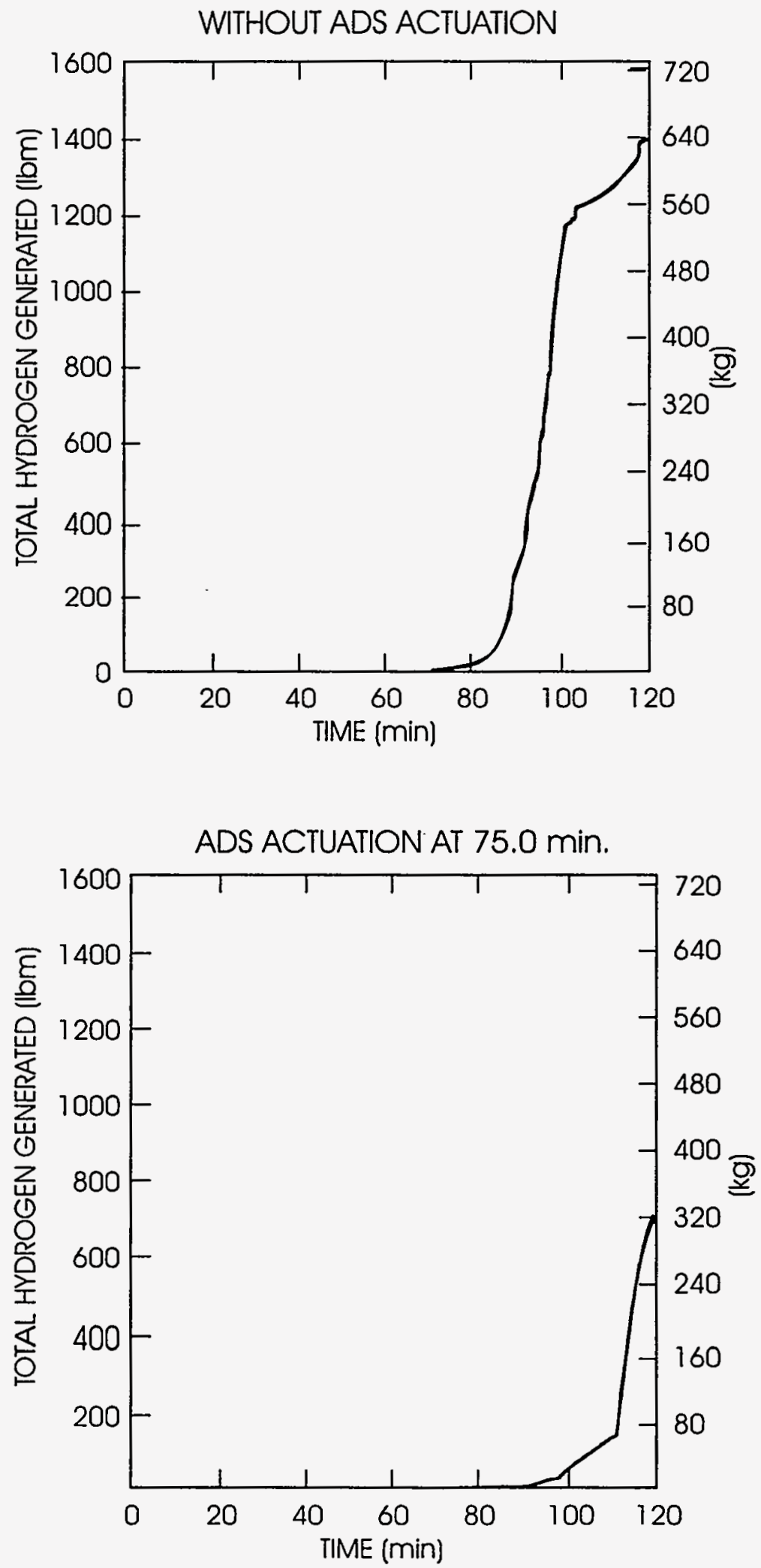

Figure 3.7-6 Vessel depressurization at one-third core height delays hydrogen release 


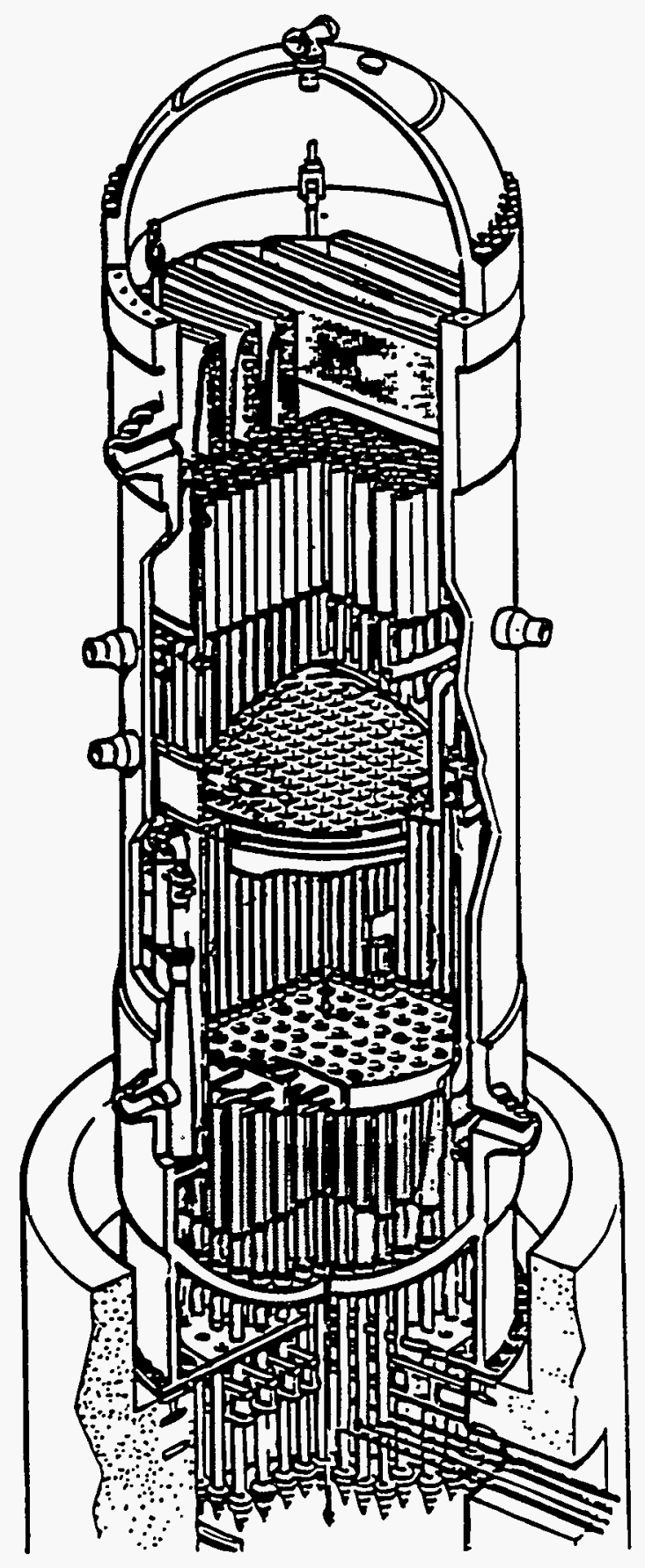

Figure 3.7-7 Regional above core plate would be dry during structural degradation 


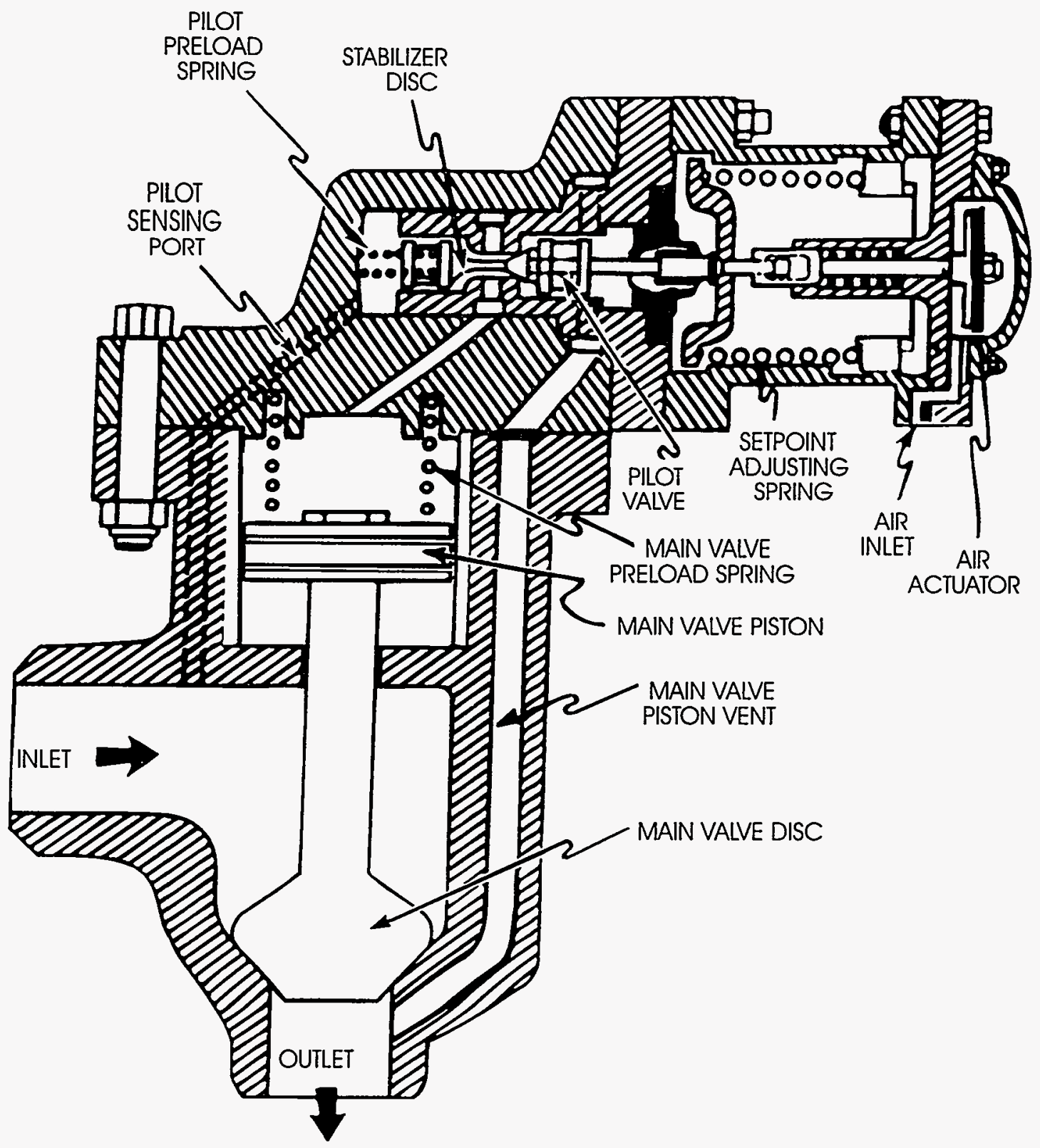

Figure 3.7-8 For the two-stage target rock SRV, control air and system pressure act in concert to position the pilot valve 


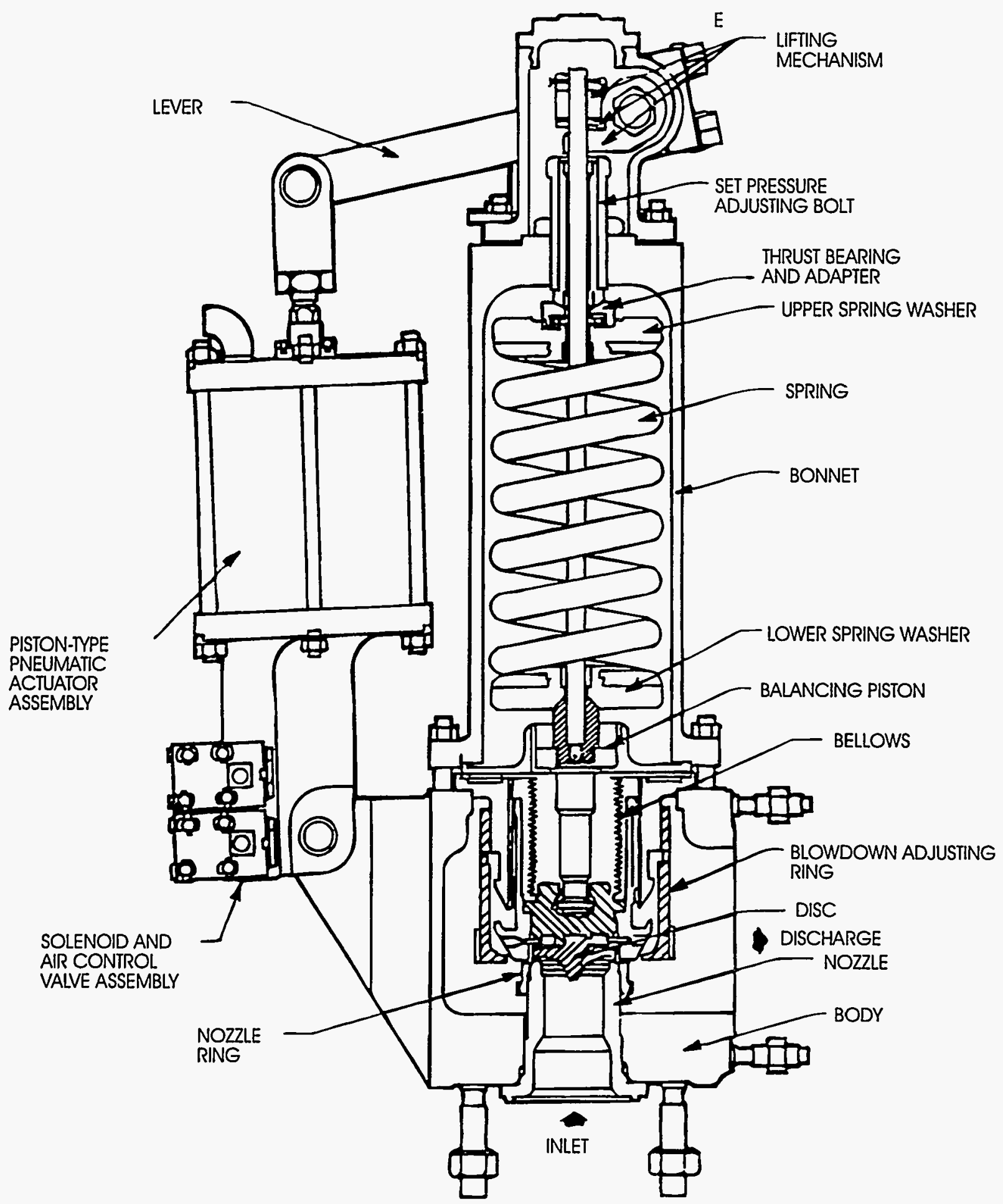

Figure 3.7-9 For the Crosby SRV, control air opens the main valve 


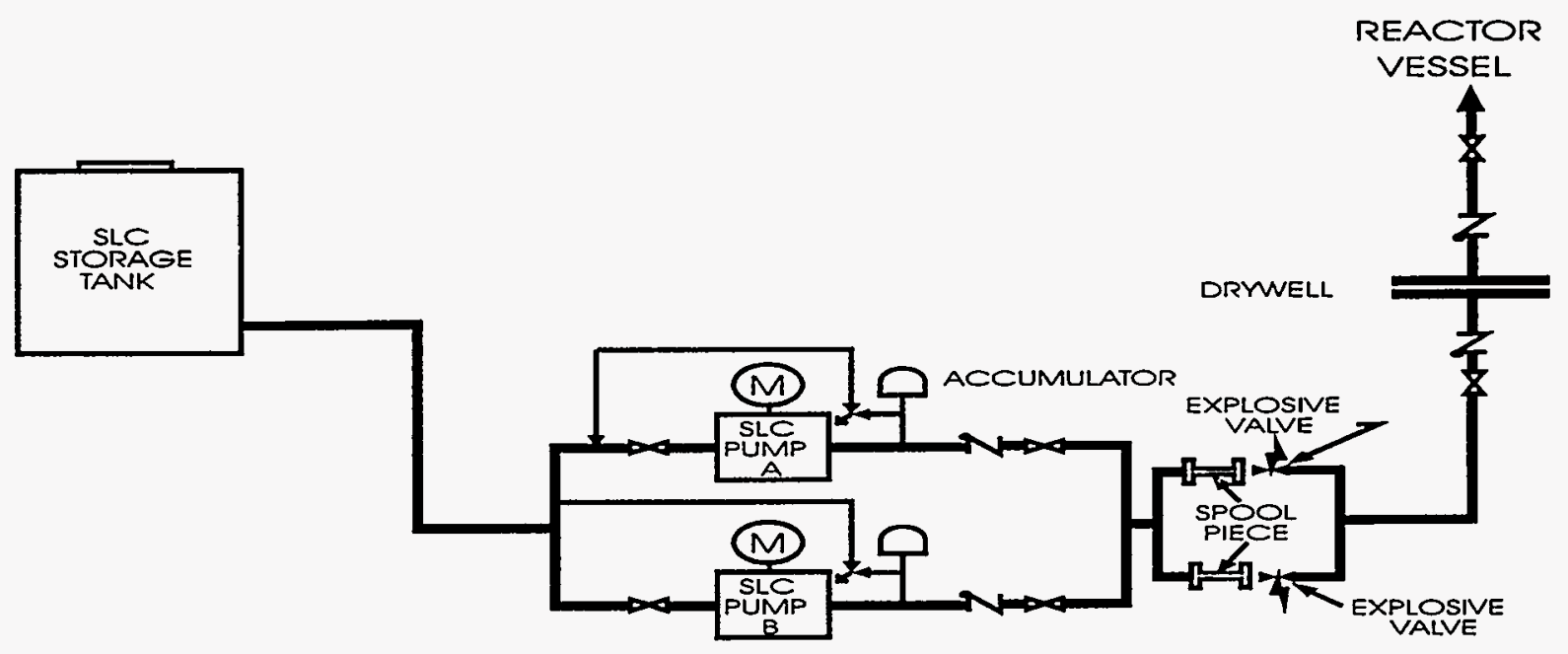

Figure 3.7-10 Abbreviated schematic of a typical BWR SLCS 


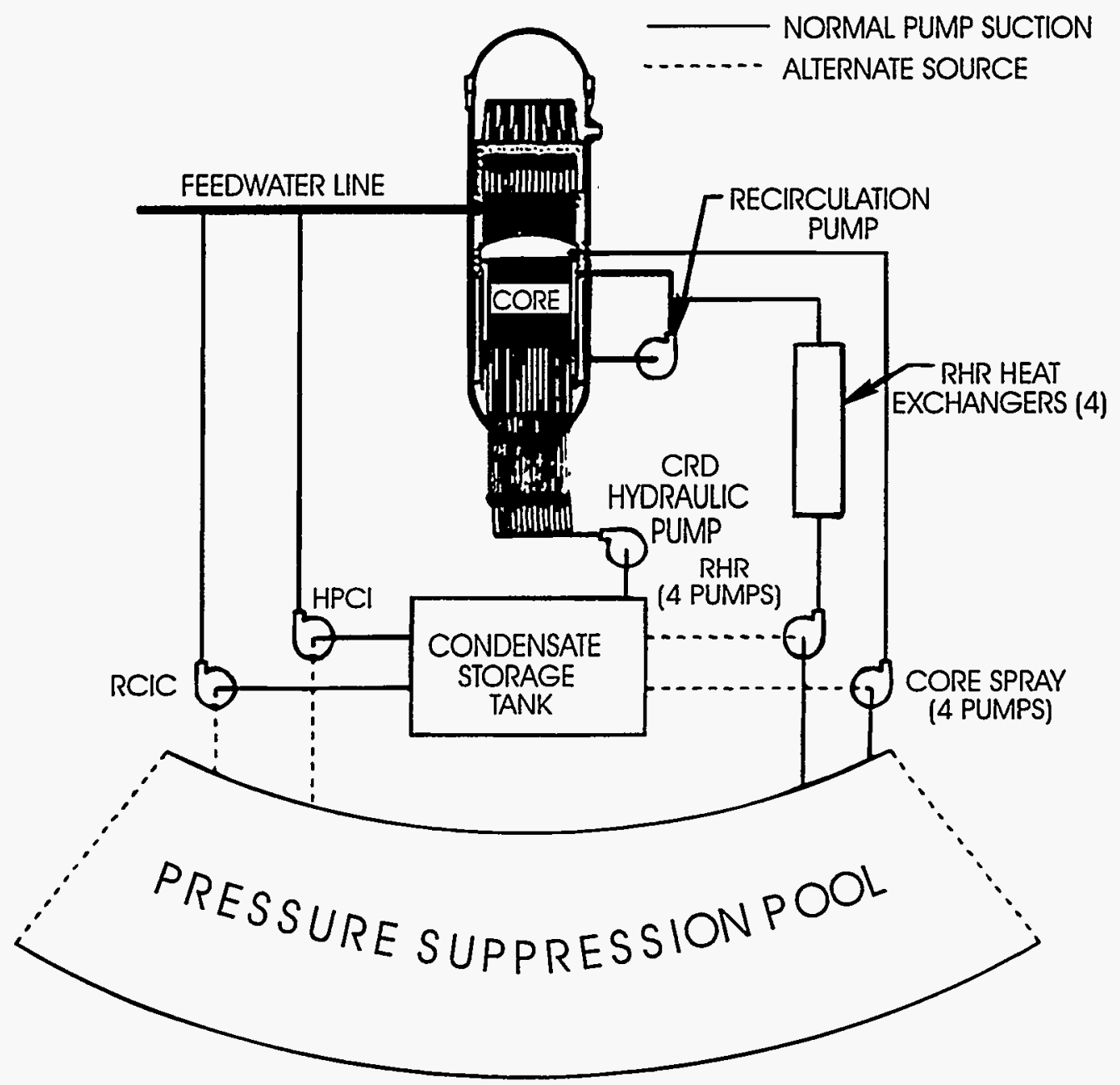

Figure 3.7-11 The condensate storage tank is an important source of water during accident sequences other than LBLOCA 


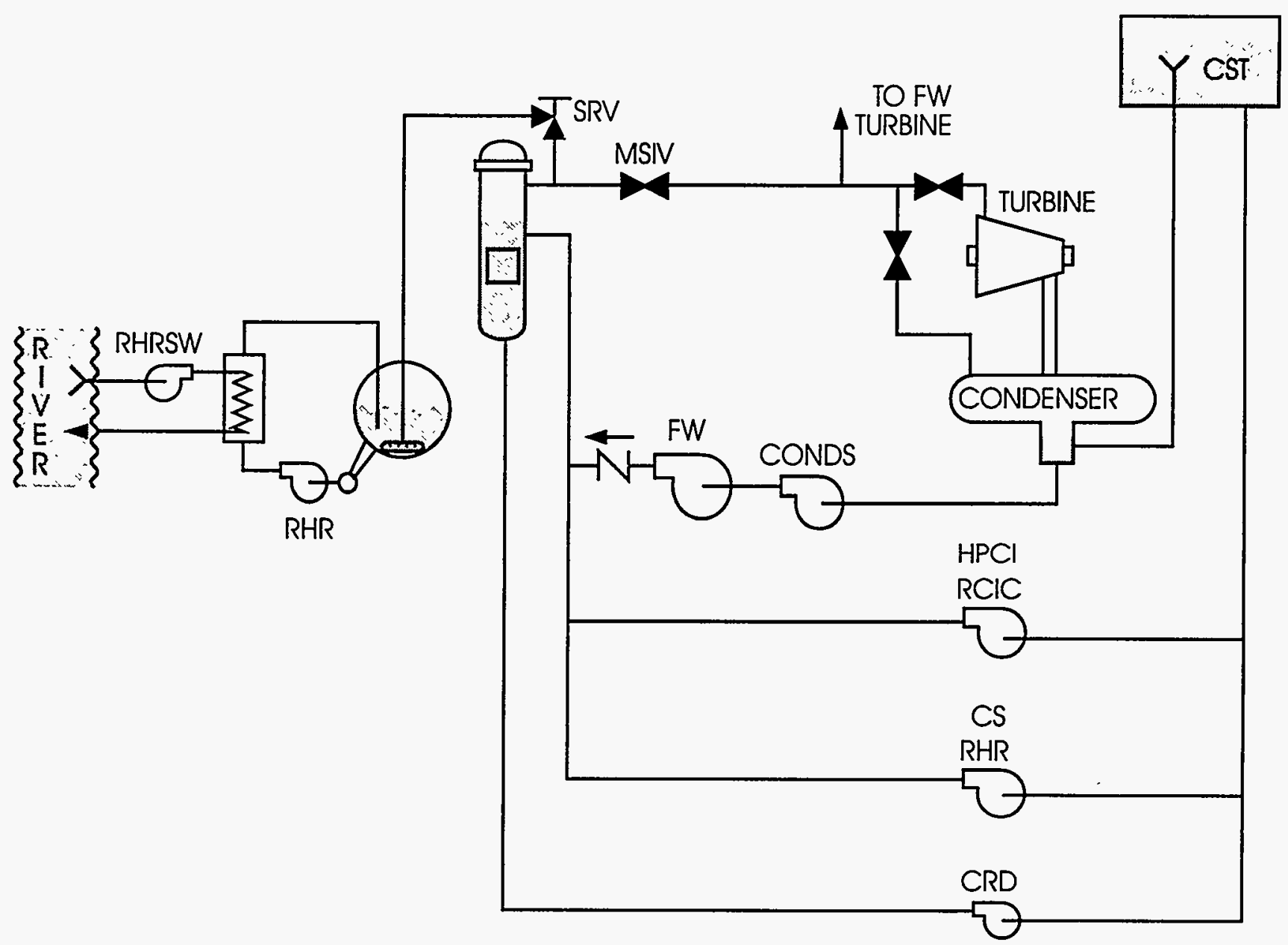

Figure 3.7-12 The condensate storage tank can be drained to the main condenser hotwells, leaving sufficient water volume for the reactor vessel injection 


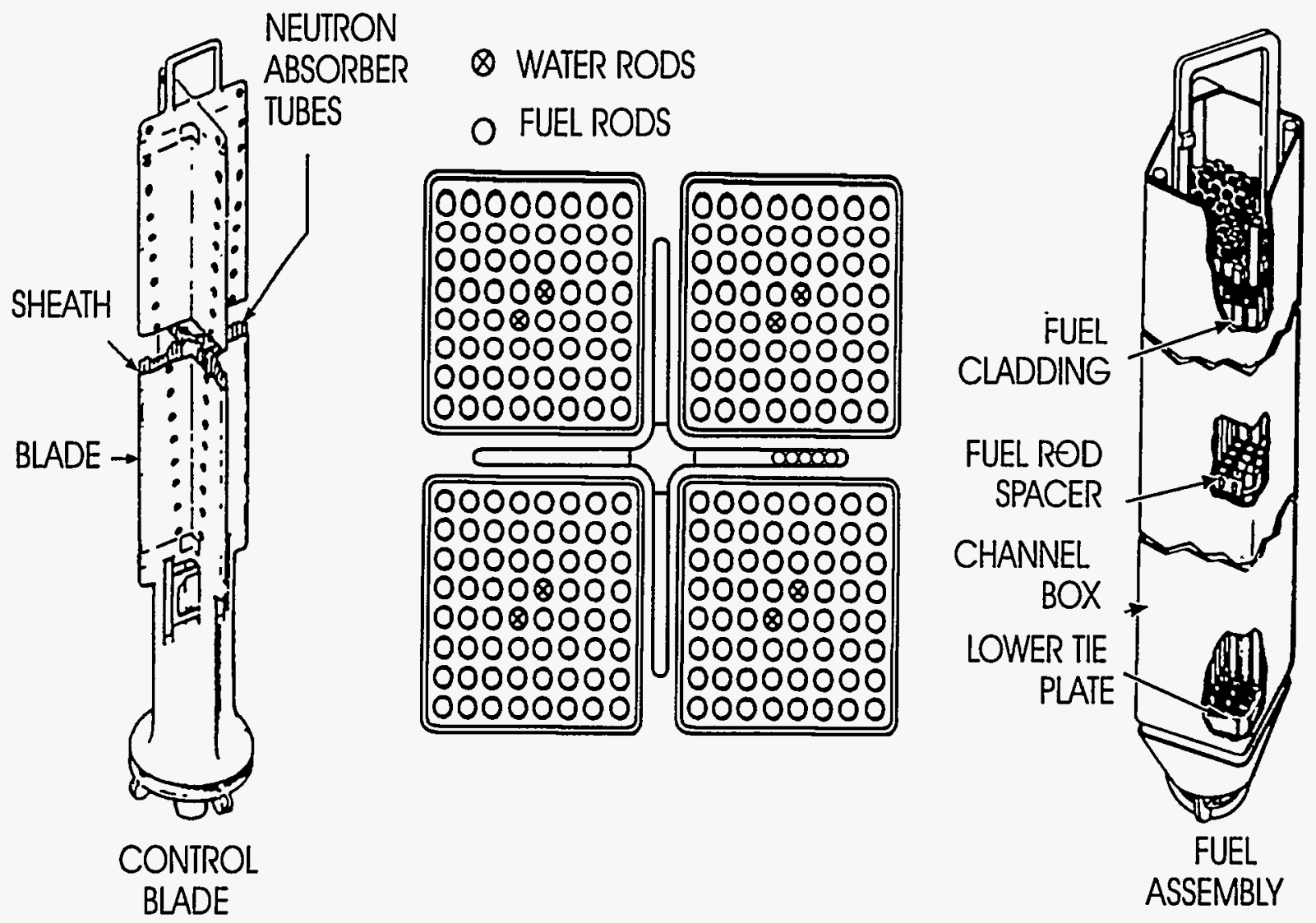

Figure 3.7-13 The BWR control blades are inserted into the interstitial region between fuel assemblies in the core 


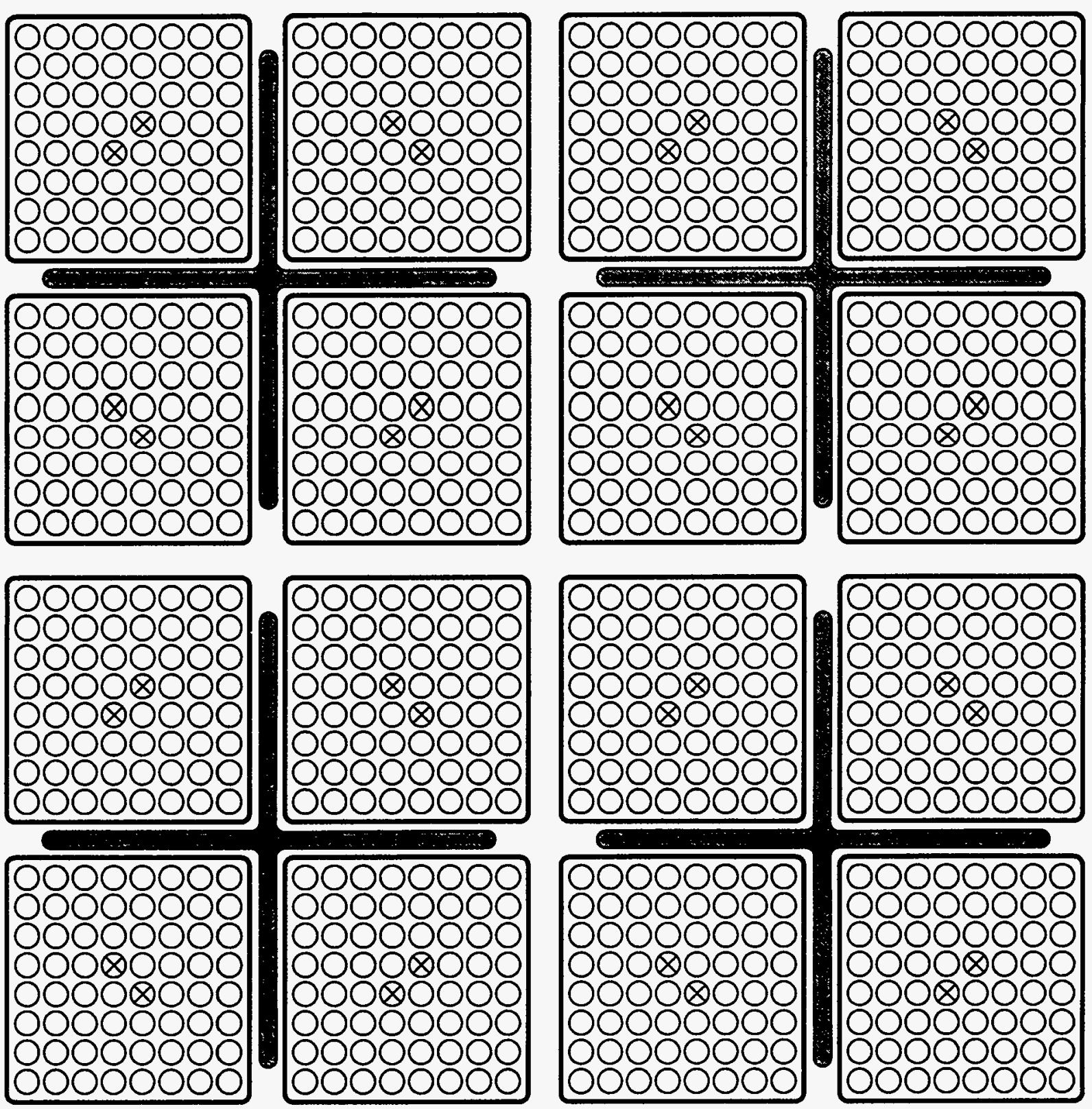

Figure 3.7-14 One-half of the channel box outer surfaces do not see an intervening control blade 


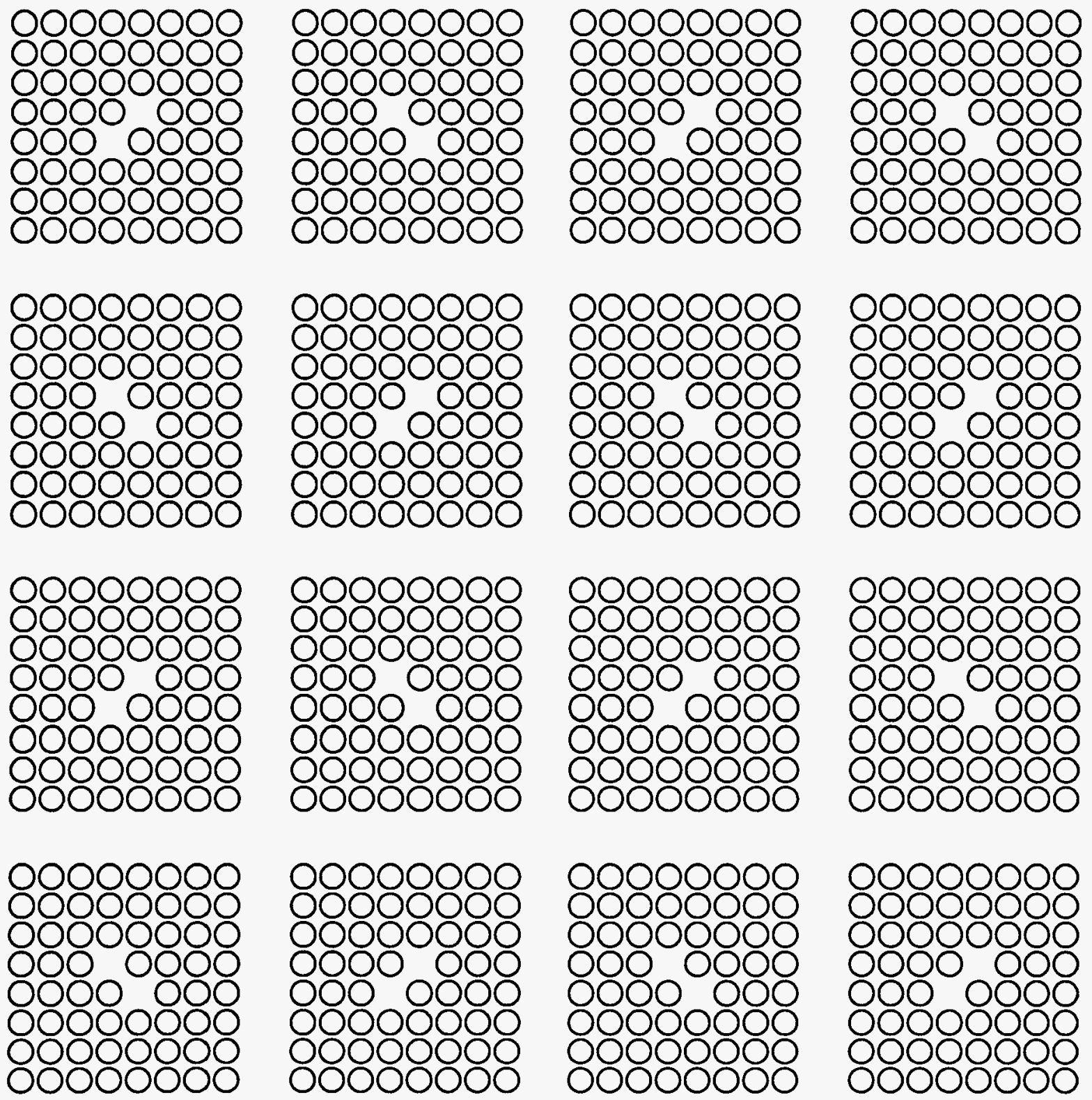

Figure 3.7-15

Relocation of control blades and channel box walls leaves only $\mathrm{UO}_{2}$ pellets encased in thin $\mathrm{ZrO}_{2}$ sheaths 


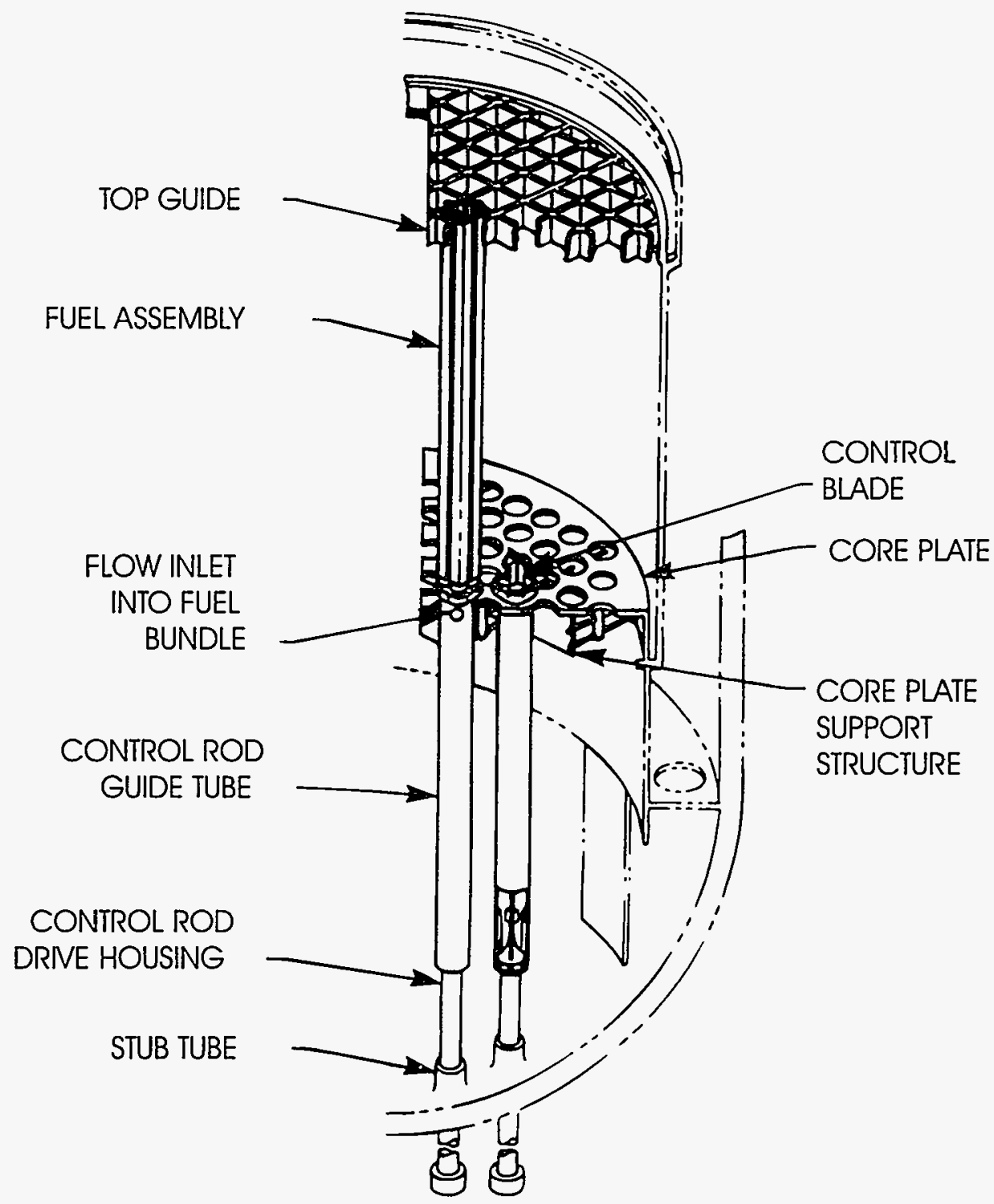

Figure 3.7-16 The BWR core plate separates the core region from the reactor vessel lower plenum but does not support the core 


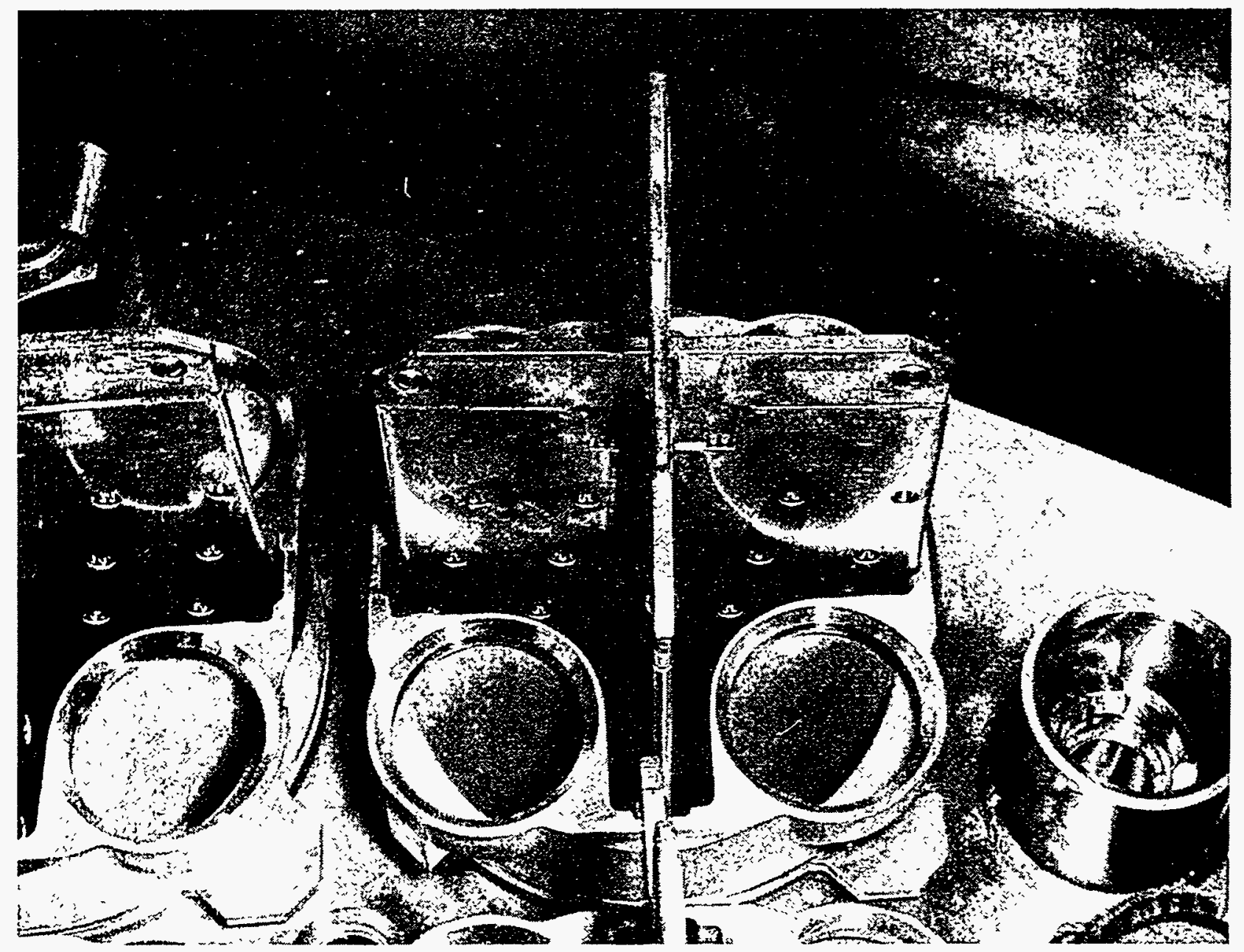

Figure 3.7-17 Control blade tip emerging from fuel support structure near core plate edge at Peach Bottom 


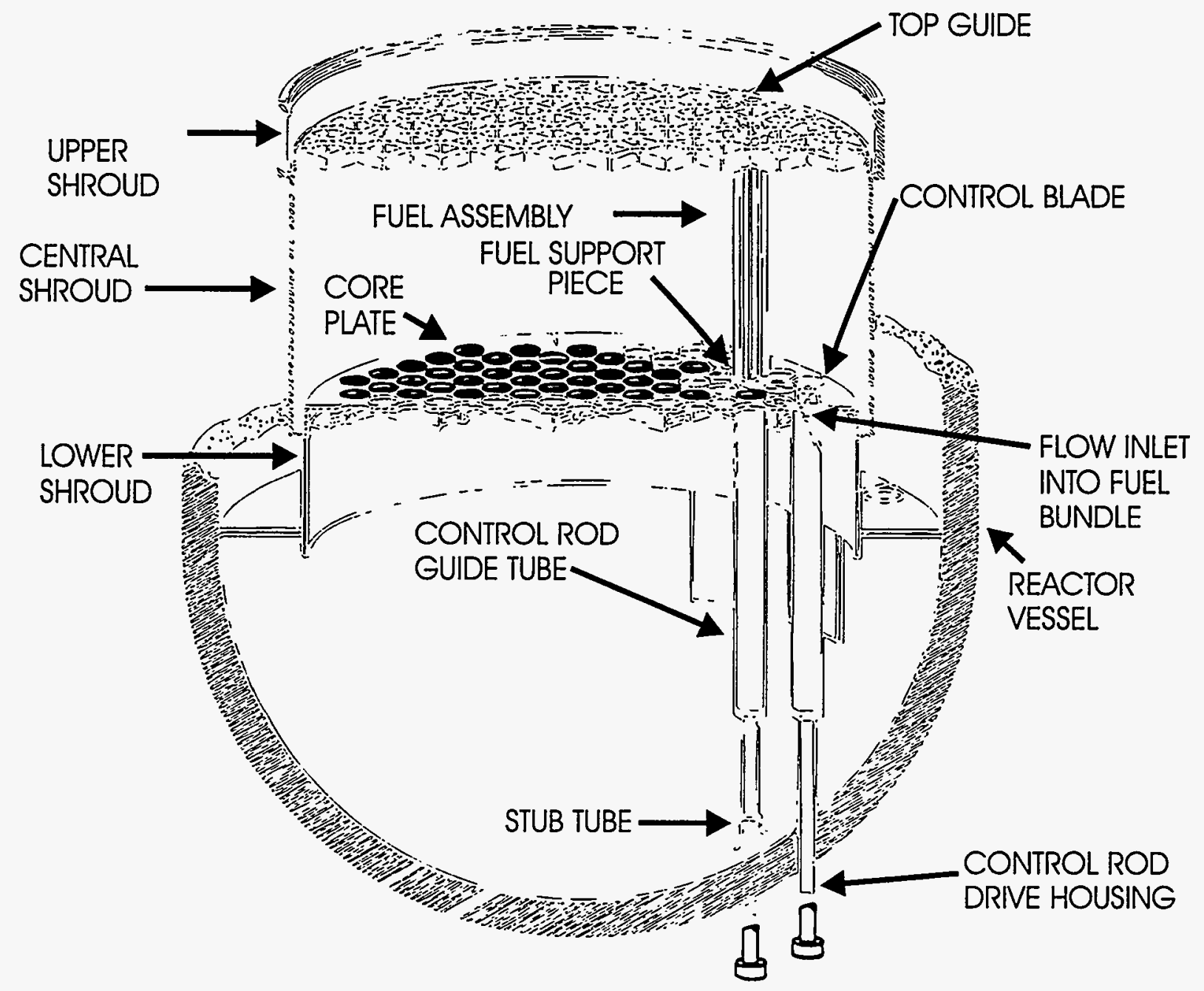

Figure 3.7-18 Material relocating from the core region would enter the reactor vessel lower plenum 




Figure 3.7-19 View of core plate with fuel support structures in place at Peach Bottom 


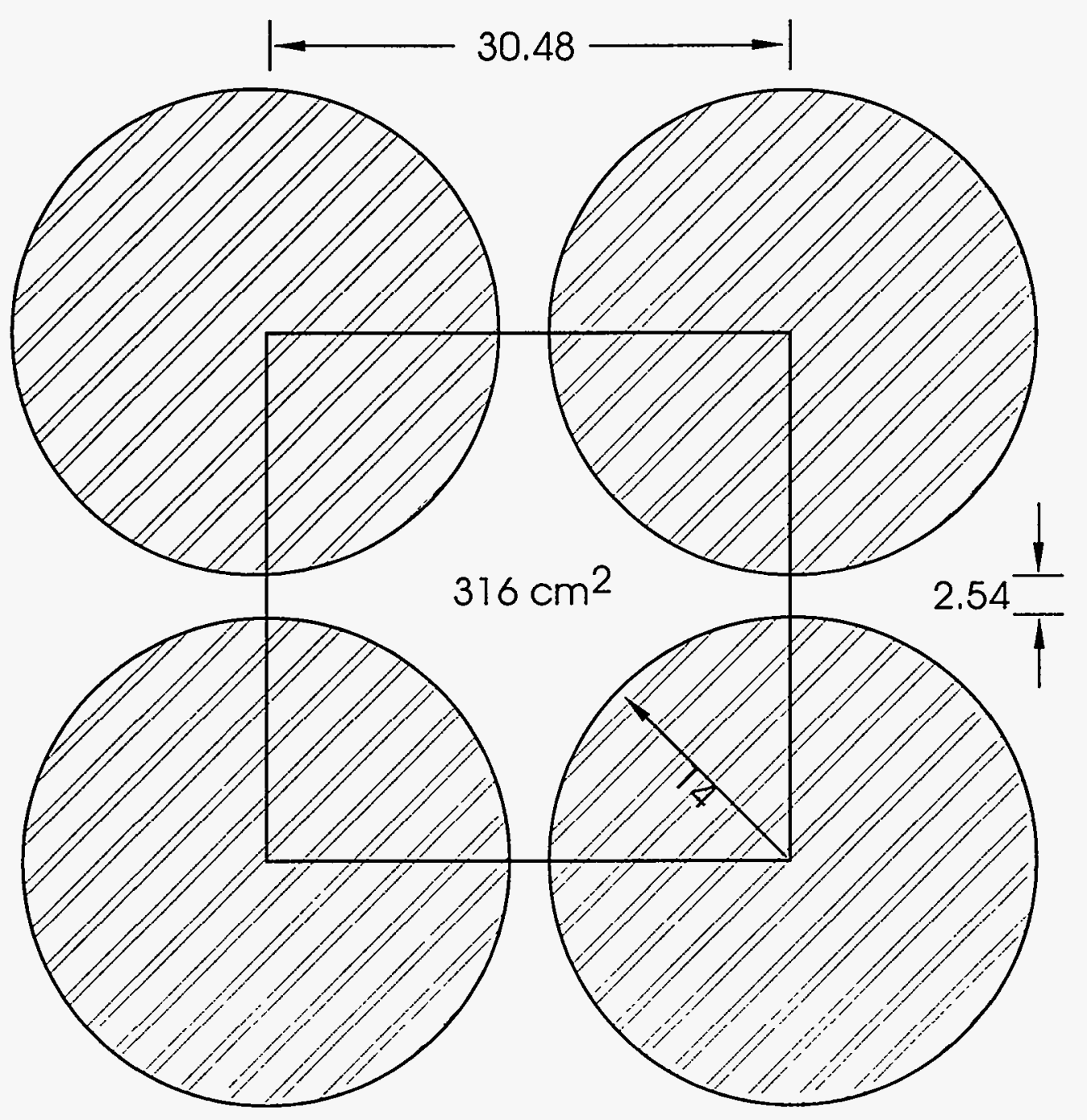

(ALL DIMENSIONS IN cm)

Figure 3.7-20 Two-thirds of the area beneath the BWR core is blocked by the control rod guide tube 


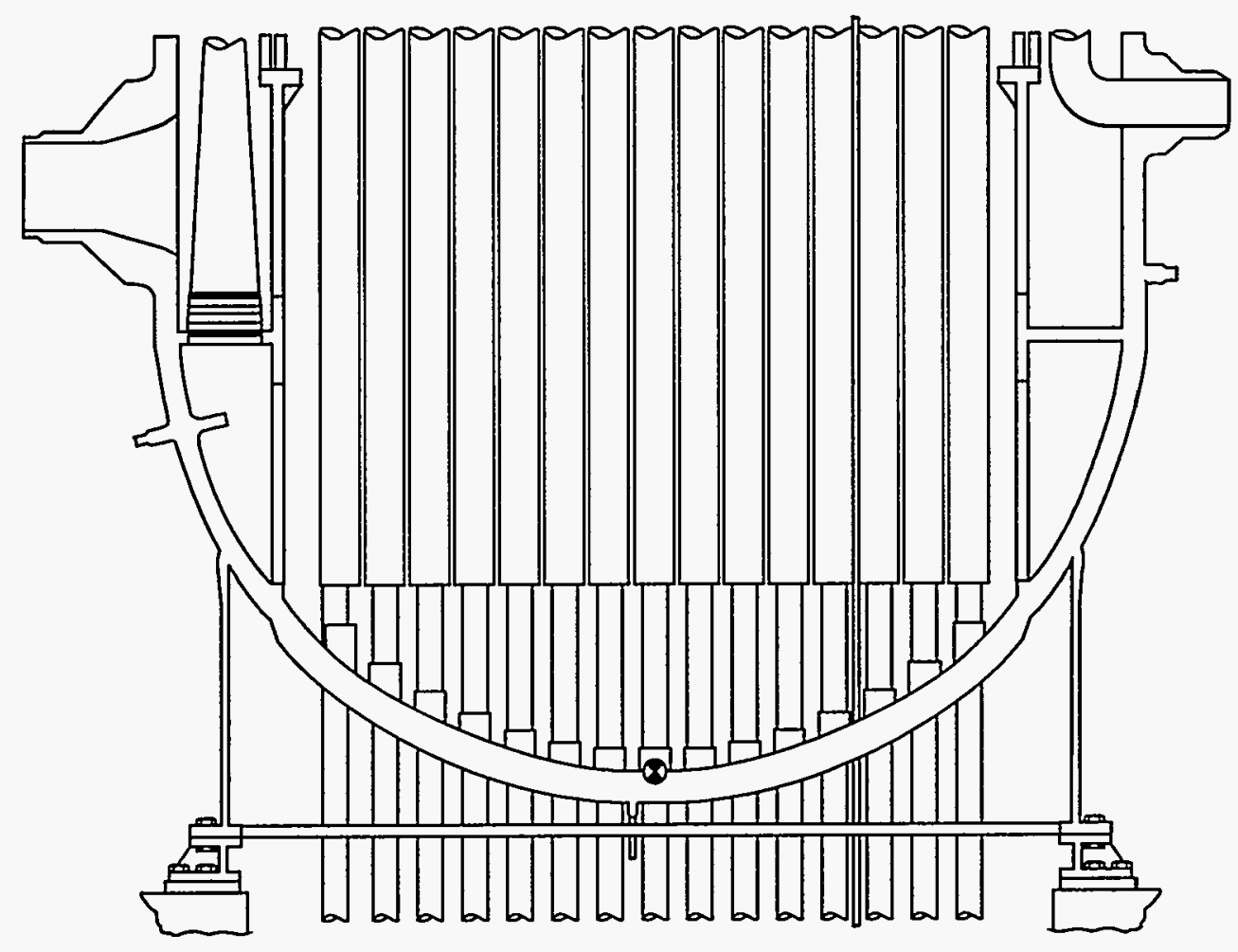

Hemisphere

Stainless steel internal structures

Bottom Head Penetrations

Support Skirt

Figure 3.7-21 Code models specific to the BWR lower plenum and bottom head currently exist 

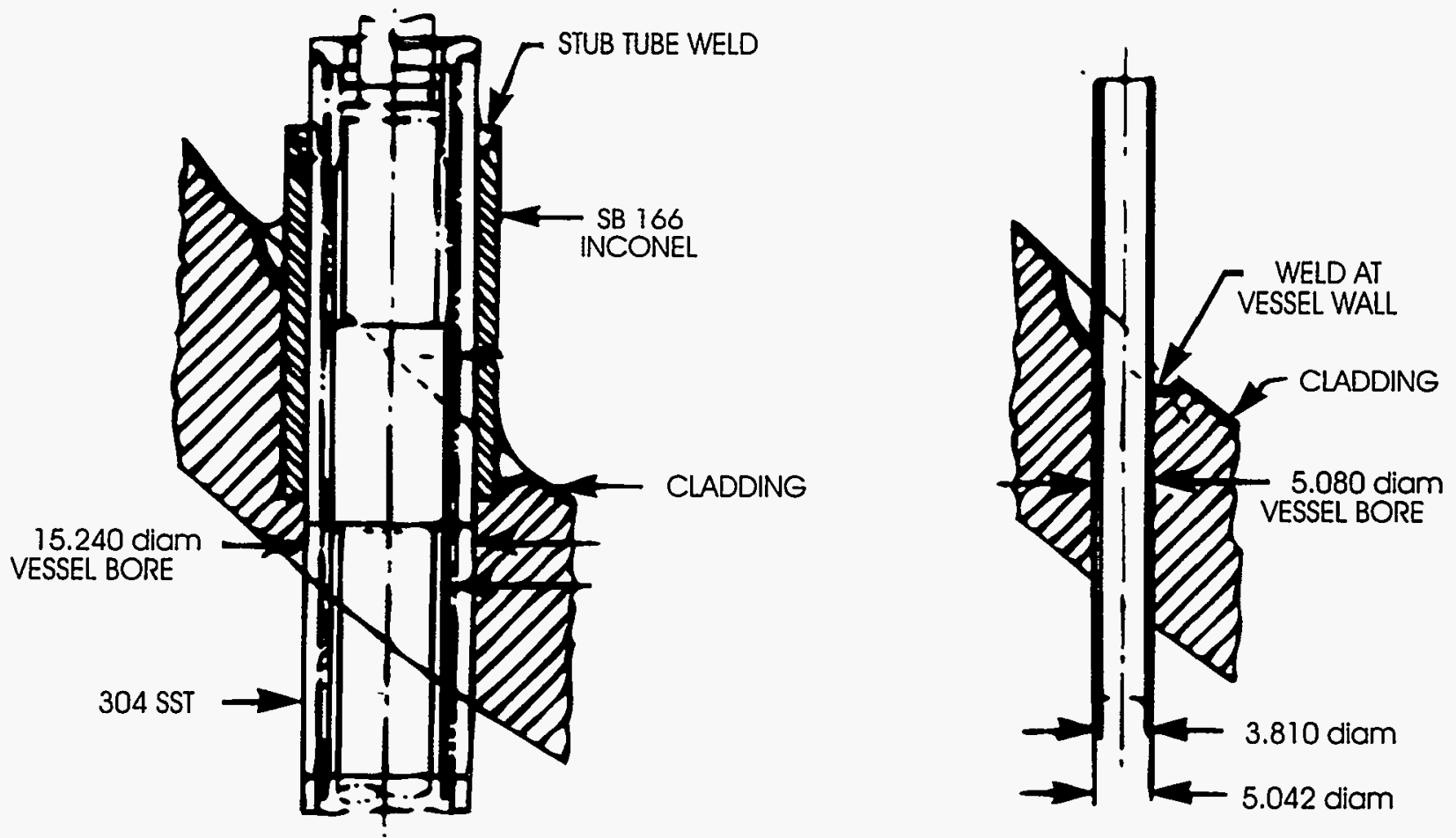

(ALL DIMENSIONS IN cm)

Figure 3.7-22 The BWR control rod drive mechanism assemblies are held in place by upper stub tube welds; the incore instrument tubes are supported by welds at the vessel wall 


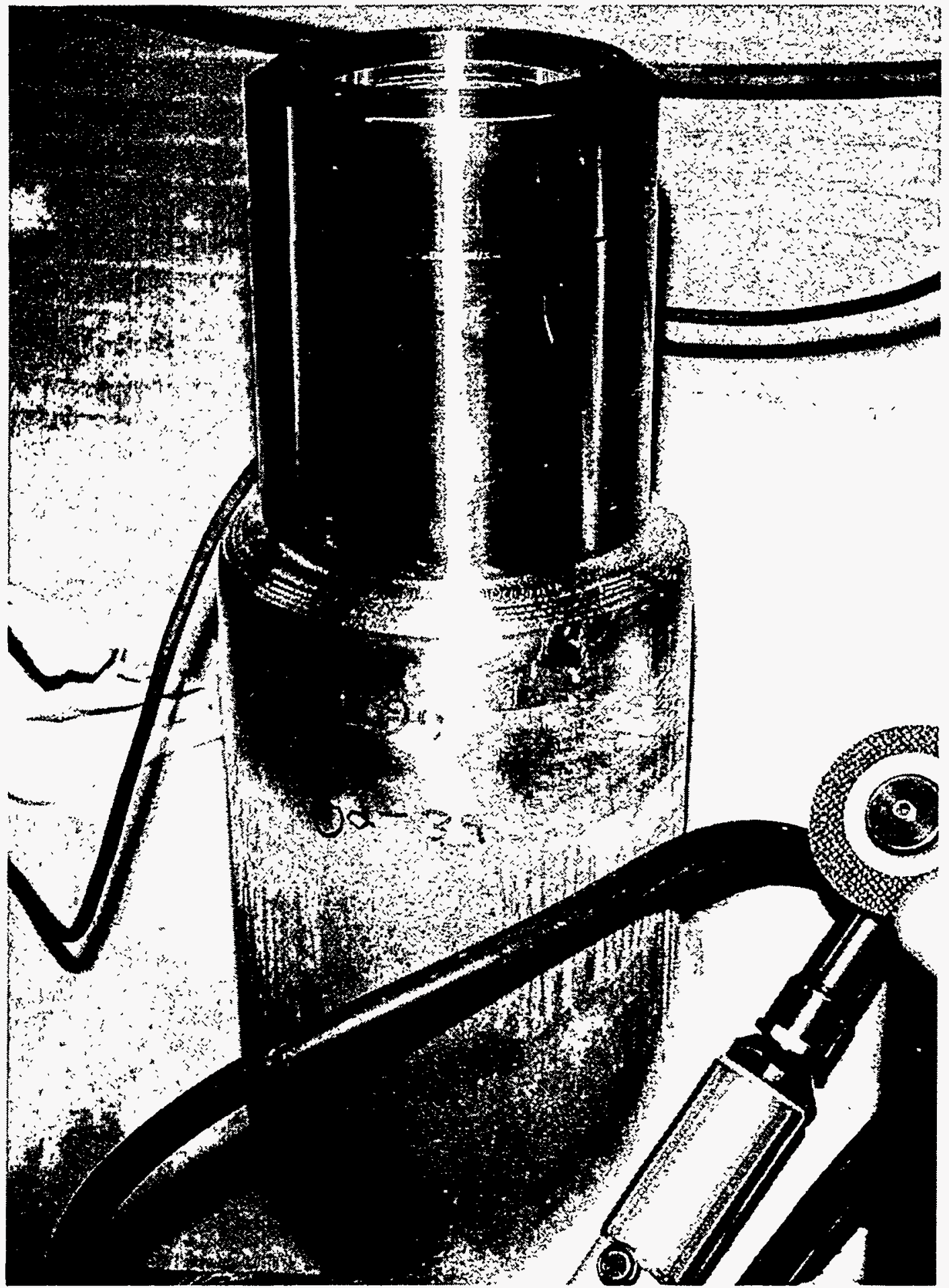

Figure 3.7-23 Weld holding control rod drive housing in place within stub tube at Peach Bottom 


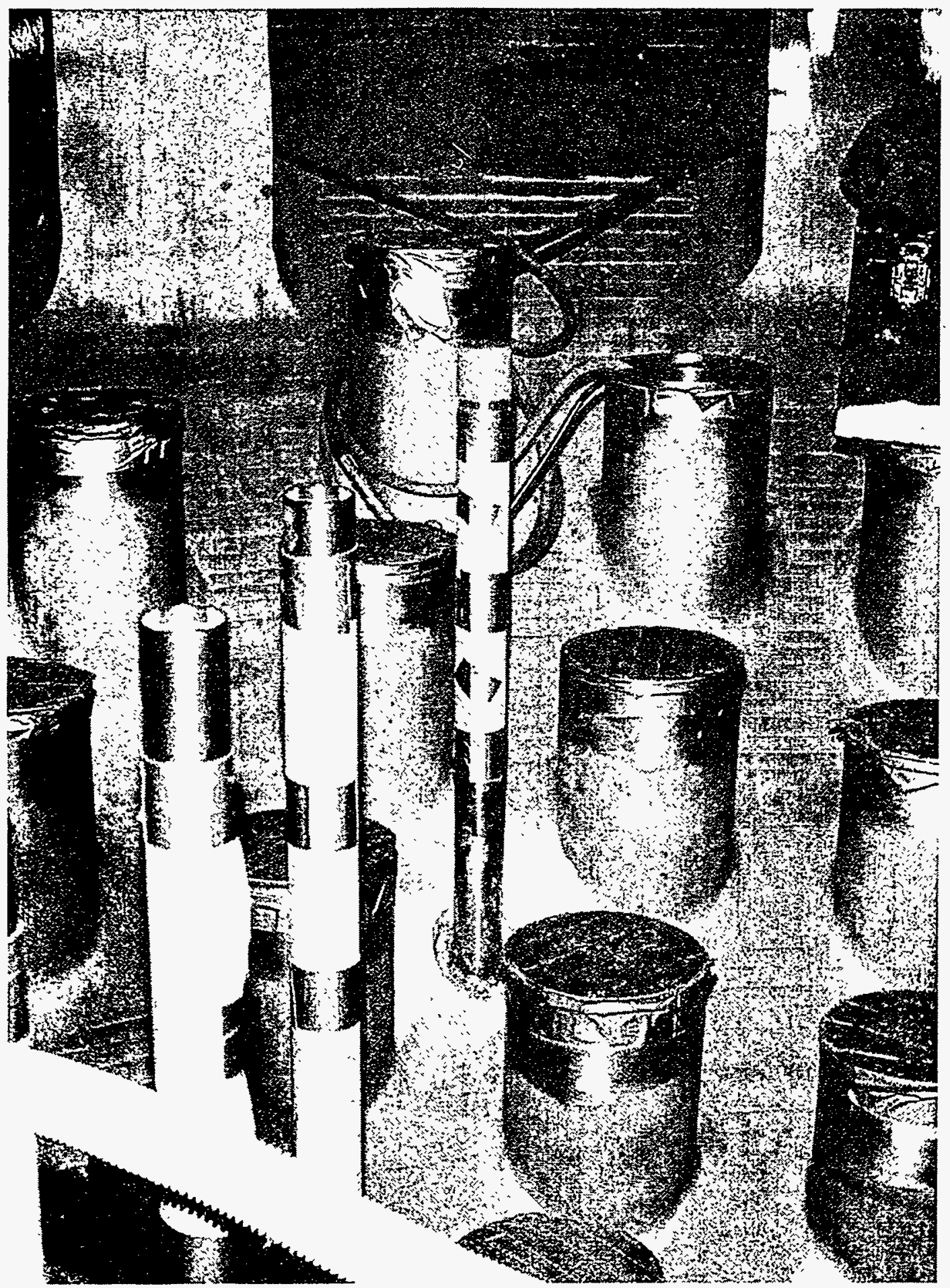

Figure 3.7-24 Instrument guide tube weld location at inner surface of vessel wall at Peach Bottom 


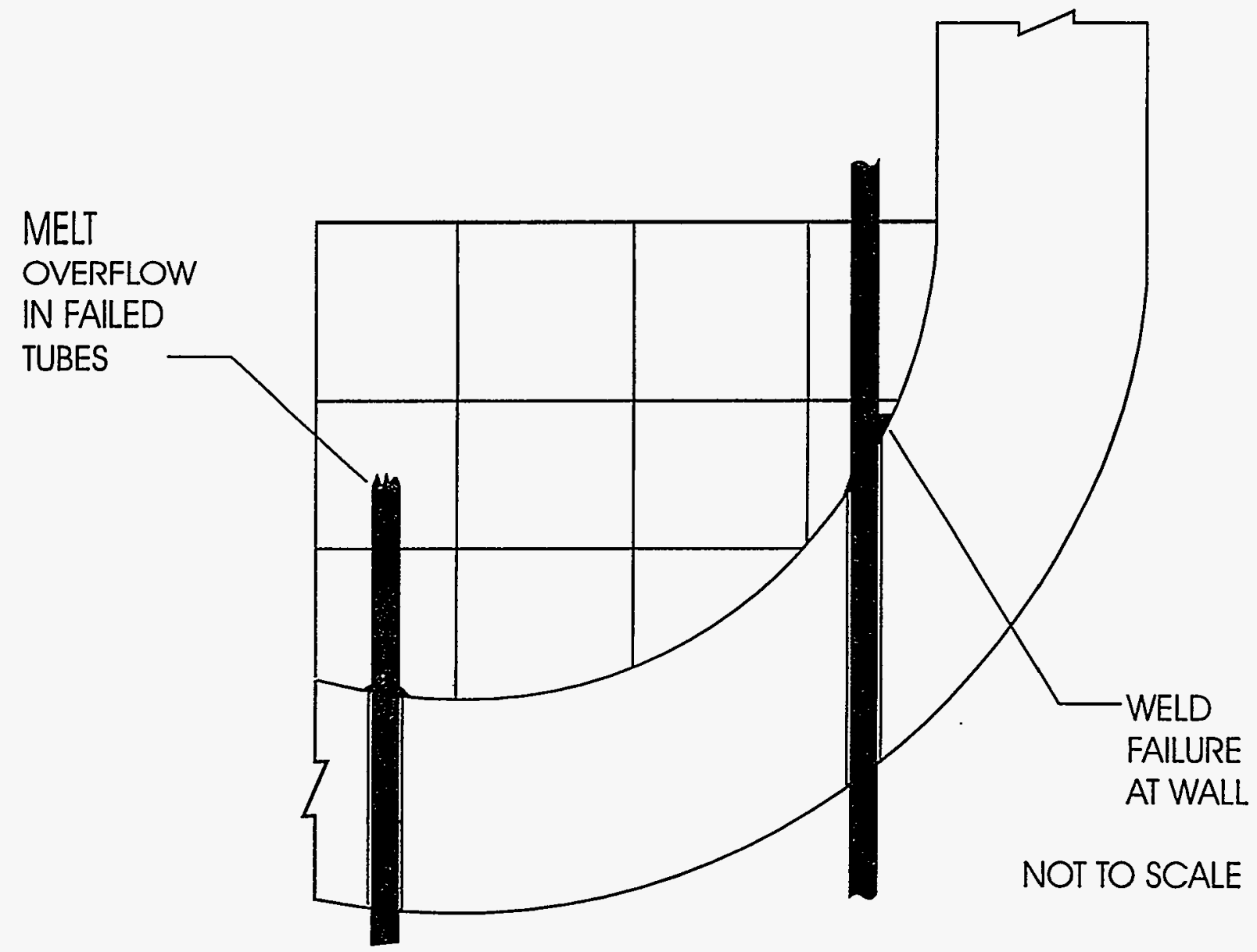

Figure 3.7-25 Instrument tube failure by creep-rupture of welds and by melt overflow can be represented 


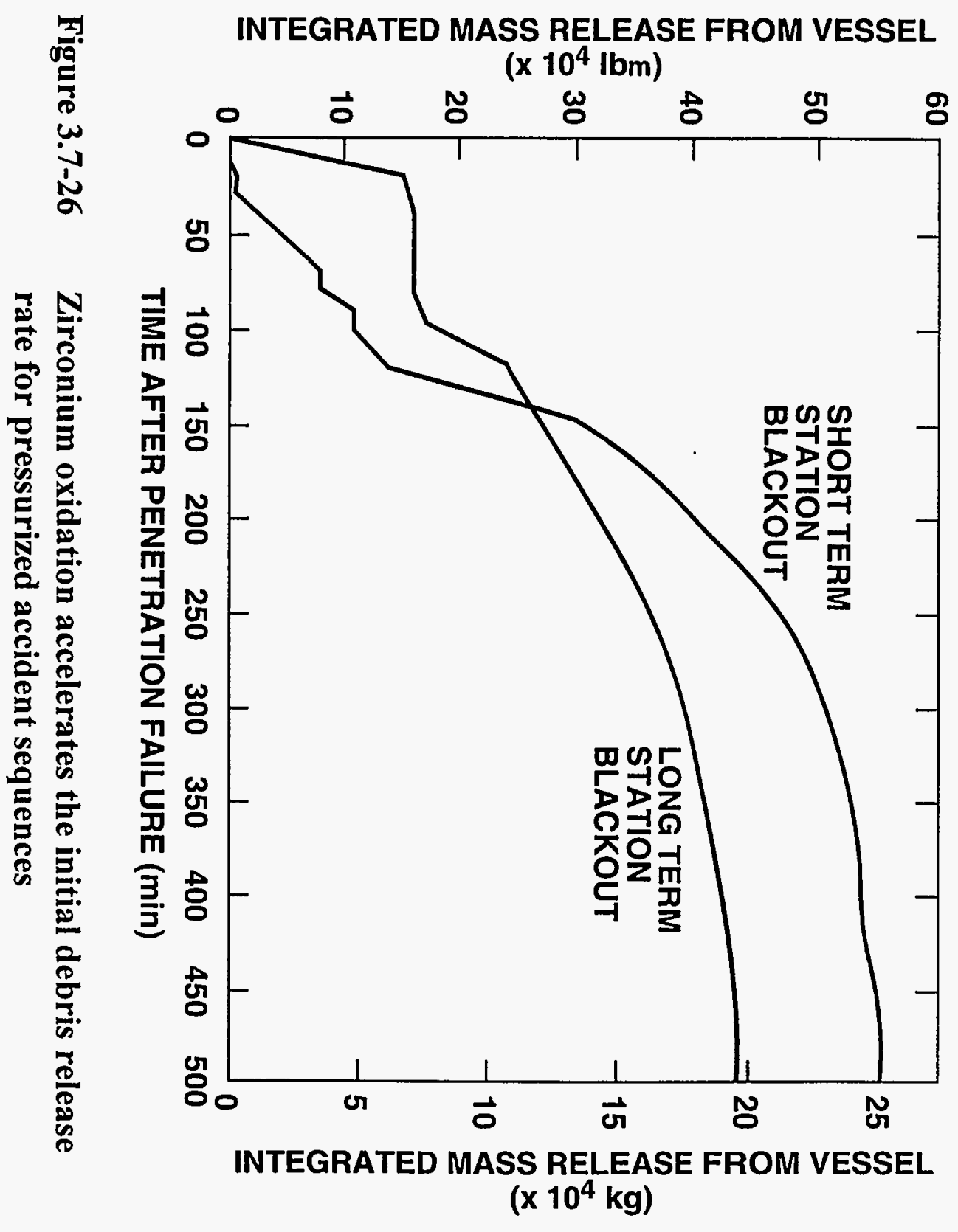




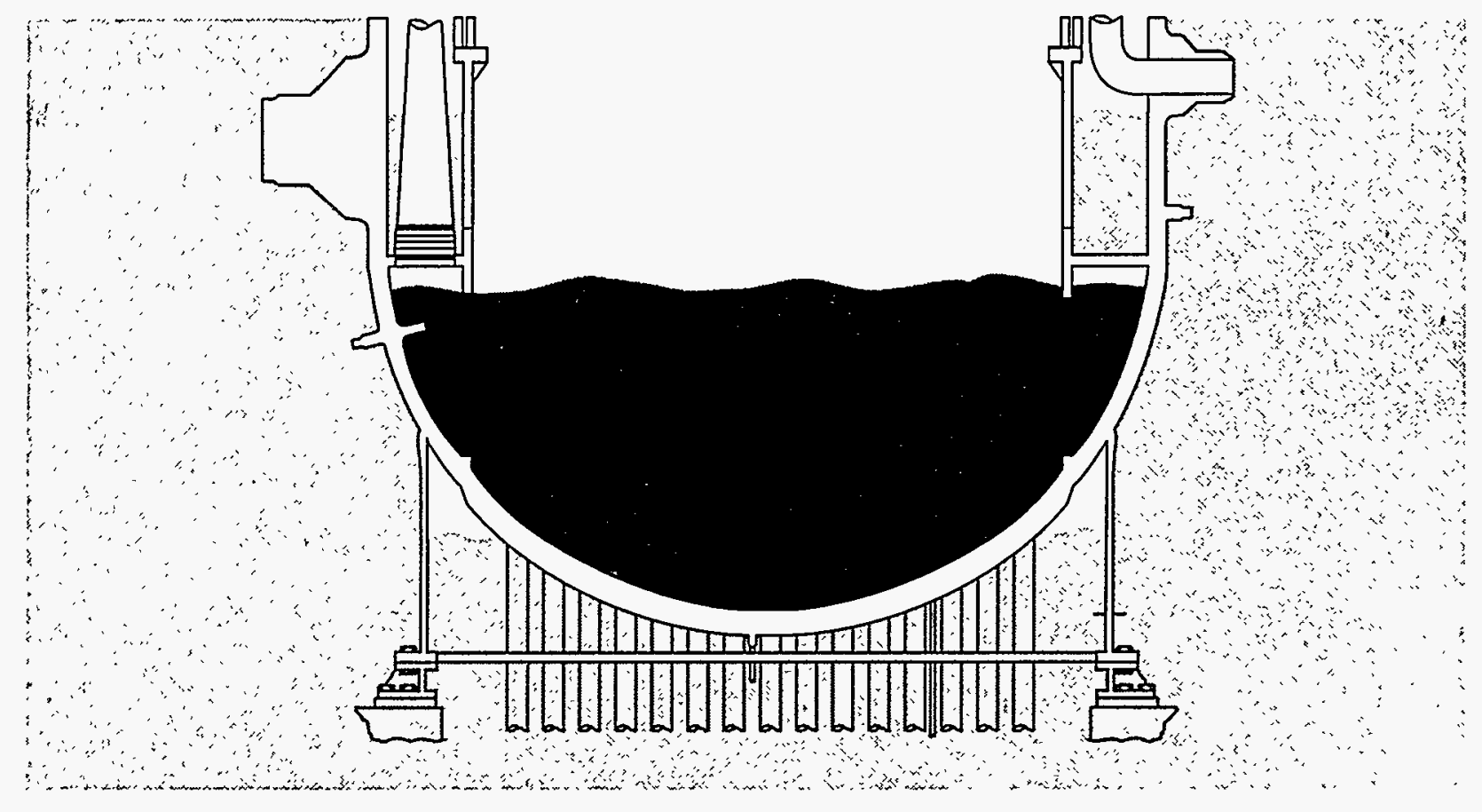

Figure 3.7-27 Atmosphere trapping within the reactor vessel support skirt could limit water contact with the wall 


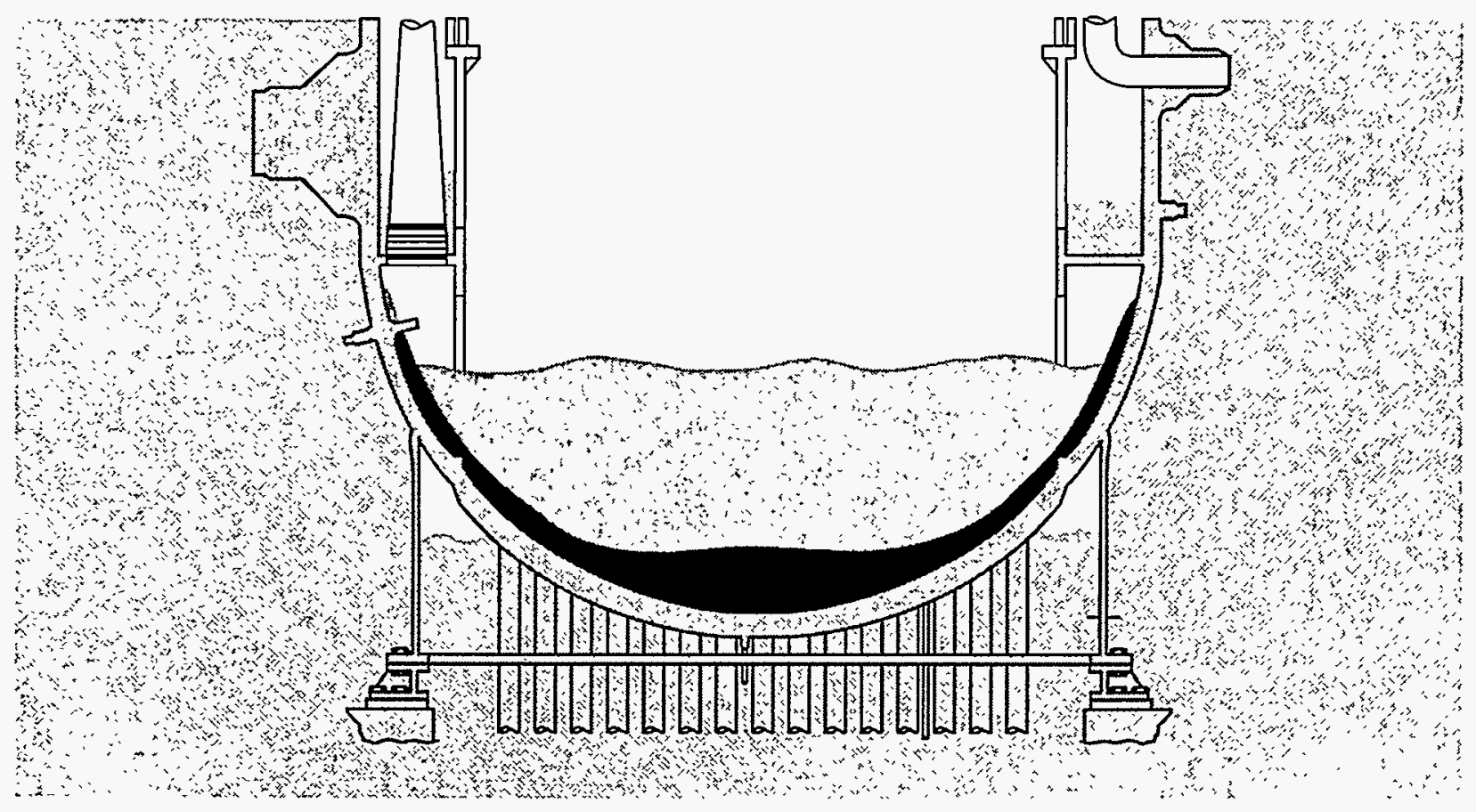

Figure 3.7-28 Delayed wall creep rupture would occur in the vicinity of the gas pocket 


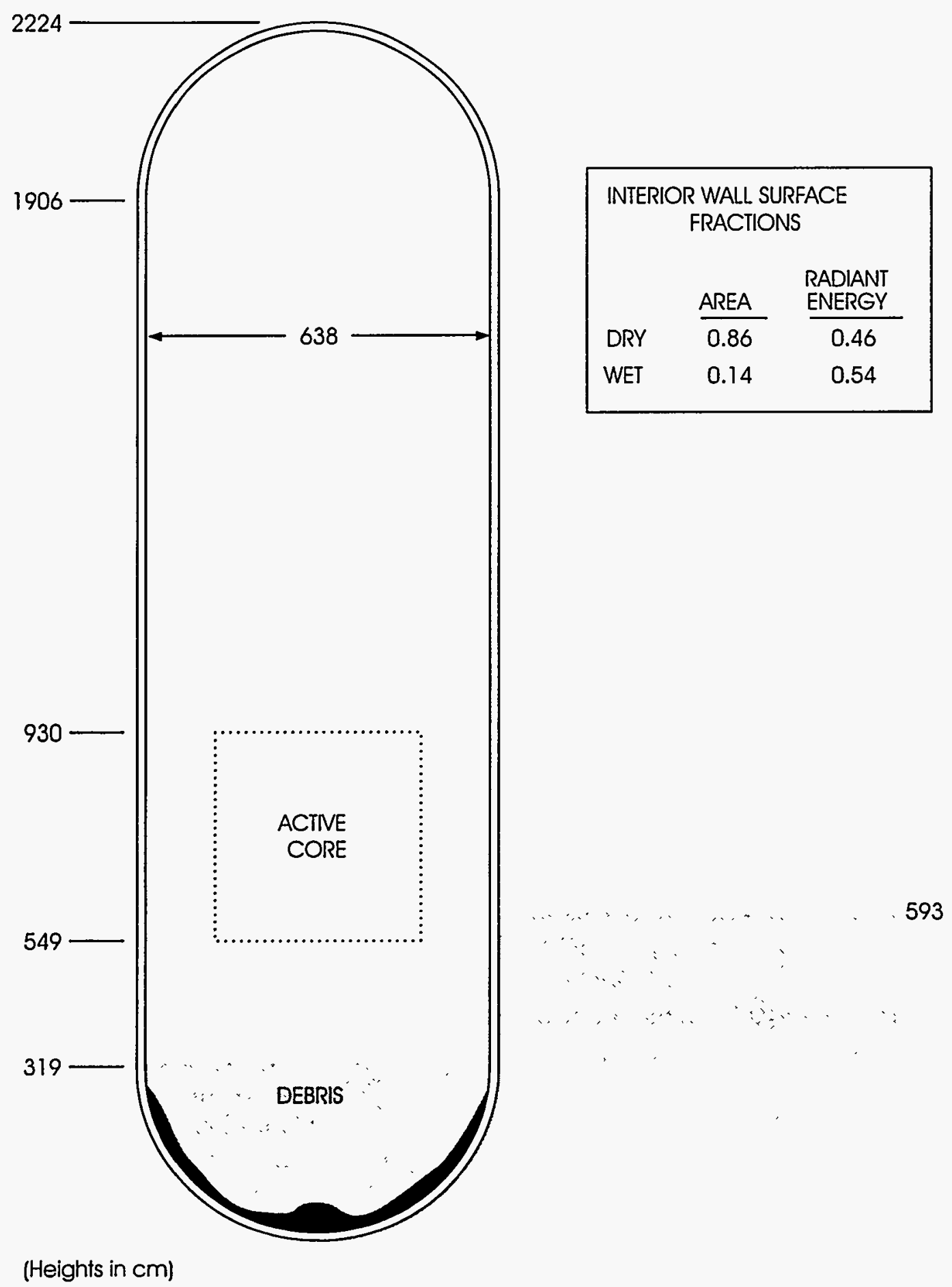

Figure 3.7-29 Cooling of upper vessel wall would be necessary after internal vessel structures have melted 


\section{References for Section 3.7}

1. S. R. Greene, "Realistic Simulation of Severe Accidents in BWRs - Computer Modeling Requirements," NUREG/CR2940, ORNL/TM-8517, Oak Ridge National Laboratory, April 1984.

2. L. J. Ott, "Advanced Severe Accident Models for BWR Applications," Nuclear Engineering Design, 115, pp. 289-303, 1989.

3. General Electric Company, "BWR Owner's Group Emergency Procedure Guidelines," Revision 4, NEDO-31331, March 1987.

4. Tennessee Valley Authority, "Browns Ferry Final Safety Analysis Report," Volume 2, Section 4.4.5.

5. W. B. Scott, et al., "Recriticality in a BWR Following a Core Damage Event," NUREG/CR-5653, PNL-7476, Pacific Northwest Laboratory, December 1990.

6. U.S. Nuclear Regulatory Commission, "Reduction of Risk from Anticipated Transients Without Scram (ATWS) Events for Light-Water-Cooled Nuclear Power Plants, Final Rule," July 1984.

7. S. A. Hodge, J. C. Cleveland, T. S. Kress, and M. Petek, "Identification and Assessment of BWR In-Vessel Strategies," NUREG/CR-5869, ORNL/TM-12080, Oak Ridge National Laboratory, October 1992.

8. B. I. Shamoun and R. J. Witt, "Parametric Study of Recriticality in a Boiling Water Reactor Severe Accident," Nuclear Technology, 107, pp. 227-235, August 1994.
9. S. Hagen and K. Hain, "Out-of-Pile Bundle Experiments on Severe Fuel Damage," CORA Program, KfK 3677 , Forschungszentrum Karlsruhe (FZK), (formerly Kernforschungszentrum Karlsruhe [KfK]), 1986.

10. R. O. Gauntt, R. D. Gasser, and L. J. Ott, "The DF-4 BWR Control Blade/Channel Box Fuel Damage Experiment," NUREG/CR-4671, SAND86-1443, Sandia National Laboratories, November 1989.

11. P. Hofmann, M.Markiewicz, and J. Spino, "Reaction Behaviour of $\mathrm{B}_{4} \mathrm{C}$ Absorber Material with Stainless Steel and Zircaloy in Severe LWR Accidents," KfK 4598, Forschungszentrum Karlsruhe (FZK), (formerly Kernforschungszentrum Karlsruhe [KfK]), July 1989.

12. L. J. Ott, "Posttest Analysis of the CORA-28 Preoxidized BWR Experiment," ORNL/NRC/LTR/-93/26, Letter Report, Oak Ridge National Laboratory, September 1993.

13. M. D. Allen, H. W. Stockman, K. O. Reil, and J. W. Fisk, "Fission Product Release and Fuel Behavior of Irradiated Light Water Reactor Fuel Under Severe Accident Conditions - The ACRR ST-1 Experiment," NUREG/CR-5345, SAND89-0308, Sandia National Laboratories, November 1991.

14. A. J. Grimley, "A Thermodynamic Model of Fuel Disruption in ST-1," NUREG/CR-5312, SAND-3324, Sandia National Laboratories, February 1991.

15. R. O. Gauntt and P. H. Helmick, "Preliminary Results of the XR2-1 
Experiment," Proceedings of the Twenty-Third Water Reactor Safety Information Meeting, NUREG/CP-0149, Vol. 2, pp 263-275, Sandia National Laboratories, 1995.

16. F. P. Griffin, "BWR Control Blade/Channel Box Interaction and Melt Relocation Models for SCDAP," Revision 3, ORNL/NRC/LTR-92/12/R3, Letter Report, Oak Ridge National Laboratory, March 1995.

17. B. W. Spencer, et al., "Fragmentation and Quench Behavior of Corium Melt Streams in Water," NUREG/CR-6133, ANL-93/32, Argonne National Laboratory, February 1994.
18. D. Magallon, et al., "Status of the FARO/KROTOS Melt-Coolant Interactions Tests," Proceedings of the Twenty-Third Water Reactor Safety Information Meeting, NUREG/CP-0149, Vol 2, pp. 157-185, European Commission, Joint Research Centre, Safety Technology Institute, 1995.

19. J. L. Rempe, et al., "Light Water Reactor Lower Head Failure Analysis," NUREG/CR-5642, EGG-2618, Idaho National Engineering Laboratory, October 1993. 


\subsection{Accident Progression In The Containment}

\subsubsection{Introduction}

As discussed in Module 1, containments began to evolve when designers realized that remote siting would not be practical in all cases. The first containments were provided for the Knolls Atomic Power Laboratory and Shippingport experimental reactors in order to allow them to be sited in more populated areas. Containments for large power reactors evolved during the 1960 s, representing a key element of the defense-in-depth strategy. In the event of a design-basis accident, containments are designed to minimize leakage and keep offsite doses well below the 10 CFR 100 limits.

Two basic strategies are used in U.S. containments. The passive pressure suppression approach, used in all General Electric Boiling Water Reactors (BWRs) and Westinghouse Pressurized Water Reactor (PWR) Ice Condenser Containments, involves the use of an energy absorbing medium to absorb most of the energy released during a design-basis loss-of-coolant accident (LOCA). For BWRs the medium is water contained in a suppression pool, and for ice condenser containments, the medium consists of numerous columns of ice. The second approach, used in most PWRs, is simply to design a large, strong volume to receive the energy. All containments also contain active cooling systems, such as sprays and fan coolers, to provide additional cooling and pressure suppression during a design-basis accident. These active systems do not act quickly enough to affect the initial blowdown during a largebreak LOCA, but limit further pressure increases and are also beneficial during slower developing accidents.

Containments are designed to cope with the accidents specified in Chapter 15 of the Safety Analysis Report, as discussed in Section 2.1. Generally, the most limiting design-basis accident leading to the highest pressure rise in the containment is a double-ended guillotine break in a pump discharge line in the reactor coolant system. The design-basis accident leading to the highest containment temperatures is usually a double-ended guillotine break in a main steam line. As described in Section 4.1, containments are designed to survive such accidents with considerable margin.

The China Syndrome and the Reactor Safety Study began to cast doubt on the ability of containments to survive all possible accidents, and it became clear that risk to the public is usually dominated by those accidents in which the containment fails or is bypassed. In a severe accident, there are sources of energy and phenomena that can cause a greater threat to containment than the design-basis LOCA. The hydrogen burn at Three Mile Island highlighted the potential threats from severe accident phenomena, even though the containment survived that particular event. The remainder of this module describes different containment designs and the potential threats to those designs.

\subsubsection{Learning Objectives for Module 4}

At the end of this module, the student should be able to:

1. Describe the six basic containment types and associated engineered safety features.

2. Identify which containment types are less susceptible to isolation failures.

3. Contrast the potential failure mechanisms for steel and concrete containments.

4. Describe the following causes of containment failure. For each cause, indicate when failure could occur. 

a. direct containment heating
b. fuel-coolant interactions
c. liner meltthrough
d. combustion
e. long-term overpressure

5. Describe a BWR accident scenario in which venting of a Mark I or Mark II containment might be appropriate.

6. List at least one concern regarding the containment if $\mathrm{AC}$ power is restored late in a station blackout accident.

7. Explain the different hydrogen control measures used in BWR Mark I, II, and III and PWR ice condenser containment designs.

8. Characterize the usefulness of hydrogen recombiners during severe accidents. 


\subsection{Containment Characteristics and Design Bases}

\subsubsection{Containment Types}

There are six basic containment types used for U.S. Light Water Reactors (LWRs). Four of those designs primarily use the passive pressure suppression concept, and two rely primarily on large, strong volumes. All of these containments are constructed of either steel or concrete with a steel liner for leak tightness. Except for Big Rock Point, BWR designs, which have evolved from the Mark I to the Mark III design, all use a pressure suppression pool. A few Westinghouse PWRs have ice-condenser (pressure suppression) containments, but most PWRs have large dry containments or a subatmospheric variation of the large dry containment. Table 4.1-1 lists the number of containments of each type. ${ }^{1}$ Figure 4.1-1 shows a comparison of the containment volumes and design pressures for typical containments. $^{2}$ The design pressures for containments are based on a very conservative design process. If all isolation features work properly, it is likely that containments will not fail until the design pressures have been greatly exceeded. Figure 4.1-2 compares the design pressures with realistic estimates of ultimate failure pressures for six typical containments.,4

The next six subsections describe the six containment types in more detail. It is important to note that there are plant-specific variations within each containment type, and these discussions do not delineate all of these design differences.

\subsubsection{Large Dry Containments}

A typical large dry containment is shown in Figure 4.1-3. A large dry containment is designed to contain the blowdown mass and energy from a large break LOCA, assuming any single active failure in the containment heat removal systems. These systems may include containment sprays and/or fan coolers, depending on the particular design. Large dry containments can be of either concrete or steel construction. Concrete containments have steel liners to assure leak tightness. Large dry (and all other) containments have a large, thick basemat that provides seismic capability, supports the structures, and may serve to contain molten material during a severe accident.

During an accident, most of the water introduced into containment through a pipe break or relief valves collects in the sump. The water can include the initial reactor coolant inventory plus additional sources injected into the reactor coolant system. Water may enter containment as vapor, liquid, or a two phase mixture. The liquid portion drains quickly into the sump and the vapor portion may condense (on structures or containment spray drops or coolers) and then drain into the sump. Once water storage tanks have been depleted, water in the sump is recirculated to the vessel and/or the containment sprays using recirculation systems to provide long-term heat removal. It is important that the sumps be kept clear of debris that could inhibit this recirculation. Large dry containments are not as susceptible to hydrogen combustion as other, smaller containments. No systems are provided for short term hydrogen control during a severe accident (see Section 4.6). However, hydrogen recombiners are provided to allow long-term hydrogen control.

\subsubsection{Subatmospheric Containments}

Subatmospheric containments are very similar to large dry containments, as shown in Figure 4.1-4. The major difference is that the containment is maintained at a negative pressure $(\sim 5 \mathrm{psi}$ or $35 \mathrm{kPa})$ with respect to the outside atmosphere. This negative 
pressure means that leakage during normal operation is into the containment rather than to the atmosphere. Further, this negative pressure provides some additional margin for response to design basis accidents, and therefore the design pressure and/or volume can be reduced accordingly. Keeping the containment at a subatmospheric pressure also means that any significant containment leaks will be readily detected, when maintaining the negative pressure becomes more difficult.

\subsubsection{Ice Condenser Containments}

Figure 4.1-5 shows the layout of an ice condenser containment and Figure 4.1-6 shows the ice condenser in more detail. Ice condenser containments are constructed of either concrete or steel. Ice condenser containments are the only PWR containments that rely primarily on passive pressure suppression. The containment consists of an upper and a lower compartment connected through an ice bed. In the event of a designbasis LOCA, steam flows from the break, into the lower compartment, and up into the ice beds where most of the steam is condensed. Return air fans maintain a forced circulation from the upper to lower compartments, enhancing flow through the ice beds. One-way doors are present at the entrance and exit of the ice bed region. These doors open upon slight pressure from the lower compartment, but close if air flow occurs in the reverse direction.

The ice beds are more than adequate to limit the peak pressure from a design-basis LOCA. However, in a long-term accident, the ice will eventually melt and containment heat removal will be required. Thus, containment sprays are provided in the upper compartment of the containment. Water from the sprays drains through sump drain lines down into the lower compartment sump, where it can be recirculated for long- term heat removal. It is noteworthy that, because of the melting ice, there will be more water in the lower compartment during many accidents than would be present in a large dry containment. The effect of this additional water upon severe accident phenomena will be discussed in later sections.

Because of their smaller volume, ice condenser containments are more susceptible to combustion events than large dry containments. In fact, a combustion event involving the same quantity of hydrogen that was burned at TMI-2 might have led to containment failure in an ice condenser containment. Therefore, specific hydrogen control requirements have been placed on ice condenser containments. These requirements are examined in Section 4.6.

\subsubsection{BWR Mark I Containments}

Mark I containments are provided for most of the older BWR plants, 24 in number. The Mark I is a pressure suppression containment, which allows the containment to be smaller in volume. The basic design is shown in Figure 4.1-7. The containment is divided into the drywell containing the reactor vessel and the wetwell (torus) containing the suppression pool. The containment may be constructed of either concrete or steel. The water in the suppression pool acts as an energy absorbing medium in the event of an accident. If a LOCA occurs, steam flows from the drywell through a set of vent lines and downcomers into the suppression pool, where the steam is condensed. Steam can also be released from the reactor vessel through the safety relief valves and associated piping directly into the suppression pool. In the event that the pressure in the wetwell exceeds the pressure in the drywell, vacuum breakers are provided that equalize the pressure. 
The water in the suppression pool can be recycled through the core cooling systems, much the same as sump water is recycled in a PWR. Long-term containment heat removal can be provided by sprays or suppression pool cooling systems either of which can be aligned with appropriate heat exchangers. In addition, Mark I containments are equipped with lines connected to the wetwell that can be used to vent the containment if the pressure becomes too high. As will be discussed later, the particular venting strategy chosen can significantly impact the course of an accident.

Because of the small volume of the Mark I containment, hydrogen control measures are required. In this case, the drywell is inerted with nitrogen during most of the operating cycle to preclude the possibility of combustion. More details on hydrogen concerns for Mark I BWRs are contained in Section 4.6.

\subsubsection{BWR Mark II Containments}

Mark II containments are similar in concept to Mark I containments. Figure 4.1-8 shows a Mark II containment. The suppression pool design is simplified, and the entire containment structure is more unified. Instead of the complicated torus design included in the Mark I containment, the suppression pool simply sits in the wetwell region below the drywell. Containment heat removal systems (sprays and suppression pool cooling) and nitrogen inerting strategies are the same as for the Mark I containments. Containment venting can also be performed in a similar fashion to the Mark I containments.

\subsubsection{BWR Mark III Containments}

While the Mark II design represented an evolution of the Mark I design, the Mark III design introduced major changes. A typical Mark III containment is shown in Figure 4.19. Mark III containments can be freestanding steel or steel-lined concrete. These containments have a drywell that functions much as the older designs, but have a larger surrounding containment that includes the wetwell. In the Mark III design, the suppression pool is located in an annular region outside the drywell.

The suppression pool function is essentially the same as in the older designs. In this case, if there is a LOCA in the drywell, then steam will flow through horizontal vents to the suppression pool where the steam will be condensed. It is possible for the blowdown to cause the suppression pool to slosh over the weir wall and partially fill the drywell. In order to assure that adequate water is available in the suppression pool, allowing for recirculation, evaporation, and sloshing, water can be added to the suppression pool from the upper pool above the drywell.

If the pressure in the outer containment exceeds the pressure in the drywell, then vacuum breakers open to equalize the pressure. Long-term containment heat removal can be accomplished with suppression pool cooling or by containment sprays (with appropriate circulation of the water through heat exchangers) in the outer containment.

An important asset of the Mark III design is construction of the outer containment around the drywell, effectively providing a double layer of protection. If containment failure were to occur, in many cases the outer containment would fail first, leaving the drywell and suppression pool intact. Any subsequent fission product releases would still be scrubbed as they passed through the suppression pool, greatly reducing the source term. Thus, the only accidents (other than bypass sequences) likely to produce large 
source terms must involve failure of the outer containment plus either loss of the suppression pool or failure of the drywell. Further, the containment sprays can be used to remove fission products and reduce the source term.

The Mark III design is an intermediate-sized containment, much like the ice condenser containment. It is large enough that inerting is not required for hydrogen control, but still small enough that some hydrogen control measures are needed. Those measures are discussed in later sections.

\subsubsection{Containment Design Criteria}

Section 2.1 provided a discussion of designbasis accidents, as included in Chapter 15 of the Safety Analysis Report (SAR). For containments, the design must preclude exceeding of the 10 CFR 100 dose guidelines, given the most limiting accident evaluated in Chapter 15. Specifically, the requirements of $10 \mathrm{CFR} 50$, Appendix $\mathrm{A}$, General Design Criterion 50 state:

The reactor containment structure,
including access openings,
penetrations, and the containment
heat removal system shall be designed
so that the containment structure and
its internal compartments can
accommodate, without exceeding the
design leakage rate and with
sufficient margin, the calculated
pressure and temperature conditions
resulting from any loss-off-coolant
accident.

It is interesting to note that, while the criterion indicates any loss-of-coolant accident, only those LOCAs considered in Chapter 15 of the SAR are actually considered. For example, the containments are not specifically designed for Reactor Vessel Rupture or Steam Generator Rupture.
Generally, one of the most limiting Chapter 15 accidents is the large break LOCA. The large break LOCA tends to produce both higher pressures and more fission products in containment than the other Chapter 15 accidents. Main Steam Line Breaks tend to produce the highest temperatures in containment and determine the temperature design limits.

Section 2.1 discusses the calculations involved in analyzing a Chapter 15 accident, including the significant conservatisms. Figures 4.1-10, 4.1-11, and 4.1-12 depict containment pressure, temperature and energy balance results for PWR design-basis LOCAs in a large dry containment. Figure 4.1-10 shows the calculated containment pressures resulting from a spectrum of postulated reactor coolant system pipe breaks. For this set of calculations the maximum containment pressure of 50.21 psig (346 kPa) occurs for an $8 \mathrm{ft}^{2}\left(0.74 \mathrm{~m}^{2}\right)$ reactor coolant pump discharge line break. Figures 4.1-11 and 4.1-12 provide more detail for this particular accident. In this accident, the blowdown takes approximately $25 \mathrm{sec}$. Despite the fact that the blowdown occurs with no containment cooling systems operating, the peak pressure does not occur during this period. The reflooding of the core, which includes core flood tank injection at $15.3 \mathrm{sec}$. and emergency core cooling at $26 \mathrm{sec}$, generates additional steam which continues to pressurize containment until about 918 sec., when the peak pressure is reached. In this calculation, which can vary for other plants, a containment cooler is started at $43 \mathrm{sec}$. and the sprays are started at $67 \mathrm{sec}$., providing some positive reduction in the peak pressure. After $918 \mathrm{sec}$, the pressure declines, and recirculation cooling from the sump is established at $3500 \mathrm{sec}$.

While the large break LOCA presents the most significant design-basis accident pressure challenge for containment 
designers, there are other types of loads that must be considered in the design. ${ }^{6}$ These loads include:

1. temperature transients and gradients

2. safe shutdown earthquake loads

3. internal and external missiles

4. mechanical loads from pipe rupture

5. external pressures

6. winds and tornadoes.

Section 2.1.4 described the design basis for seismic and other external events. Thermal transients and gradients could conceivably lead to stresses and cracks or tears in the containment. Missiles can come from many sources, including control rod ejection, shrapnel from a failed pipe, or aircraft impact. When a pipe ruptures, the resulting forces on the piping could cause failure at the point where the piping penetrates the containment. External pressures (and buoyant forces) can result due to external increases in barometric pressure or internal drops in pressure resulting from internal cooling or inadvertent spray operation.

In practice, it is impossible to design and construct a perfect containment, that is, one that has zero leakage over the range of postulated accident conditions. Therefore, nonzero design leakage rates are established that are intended to be as low as can be reasonably achieved and that will keep the offsite exposures below the dose guidelines established in $10 \mathrm{CFR} 100 .^{7}$ These design leakage rates can be site- and plant-specific because the offsite doses are affected by the site geometry and the local meteorology, as well as the reactor type. However, some plants simply use standard technical specifications that are more stringent than a site-specific analysis would allow.

Leakage from a containment structure can occur due to failure of the containment structure, failure of penetrations through the structure, and failure of isolation valves. Penetrations through the containment structures include piping penetrations, electrical penetrations, hatches and airlocks. Isolation valves are provided on all pipes and ducts that penetrate the containment. Normally, two isolation valves are provided for each line, with the isolation valves consisting of locked closed or automatic isolation valves. Requirements for these isolation valves are contained in 10 CFR 50, Appendix A, General Design Criteria 54 through $57 .^{8}$

Containment leakage rates are determined in the SAR and Technical Specifications. Criteria for testing containment leakage are set forth in 10 CFR 50, Appendix J. ${ }^{9}$ This appendix became effective in 1973. Its purpose is to implement, in part, 10 CFR 50, Appendix A, General Design Criteria 16 which mandates "an essentially leak-tight barrier against the uncontrolled release of radioactivity to the environment ..." for postulated accidents. Until 1995 this appendix specified prescriptive containment leakage-testing requirements, including the types of tests required, how they should be conducted, and the reporting requirements. Effective October 26, 1995, an amendment to Appendix $\mathrm{J}$ was issued which added an alternative method, based on performance and risk, for meeting the containment leakage rate test requirements. ${ }^{10}$ This method is designated as Option B; the original Appendix $\mathrm{J}$ method is referred to as Option A. Guidance for the implementation of Option B is provided in NRC Regulatory Guide 1.163." With either option, three types of tests are generally performed to assure leakage remains within design limits:

1. Type A tests - tests of the overall integrated leakage rate,

2. Type B tests - tests to detect local leaks around containment penetrations, and 
3. Type $\mathrm{C}$ tests - tests to measure containment isolation valve leakage rates.

Table 4.1-2 provides examples of design leakage rates that correspond to Option $\mathrm{A}$ of Appendix J. The higher allowed leakage rates for the pressure suppression containments is a result of their smaller volumes. Although the criteria are somewhat different, the allowable leakage permitted under Option B of Appendix $\mathrm{J}$ is 1.0 wt.\%/day. This reflects the NRC conclusion that a small additional leakage would have no significant impact on safety.

Assuring that the design leakage rates are met is a complex process involving a variety of tests, some of which are difficult to perform. Based on an analysis of past containment tests, Option B of Appendix $J$ was developed to simplify the testing process, primarily by allowing the testing frequency to be reduced if the results of past tests demonstrate high containment performance and therefore low risk of significant leakage. Table 4.1-3 provides a comparison of the test frequency requirements for the two Appendix $\mathrm{J}$ options. This table illustrates the advantage that Option B provides if the containment leakage requirements are consistently met. However, in recognition of the costs and effort required to implement a new testing process, licensees can continue to test under Option A; conversion to Option B is voluntary.

The amount of leakage from a containment is a function of the length of time that the containment remains pressurized. Further, there are some postulated accidents in which energy may be added to containment for many hours of even days. Therefore, the NRC has established requirements for containment heat removal. These requirements are contained in 10 CFR 50, Appendix A, Criterion 38.'2 Containment heat removal systems may involve sprays, fan coolers, suppression pool cooling, or emergency core cooling recirculation cooling and must meet the single failure criterion.

\subsubsection{Containment Failure Modes}

In the event that a containment does fail, the manner in which it fails can have a significant impact on offsite releases. If a containment leaks slowly, then large fractions of the radionuclides may still be retained inside the containment or surrounding buildings, depending on where the leak occurs. Retention can result from gravitational settling of radioactive aerosols inside the containment or surrounding buildings or from sprays or other systems removing the radionuclides from the containment atmosphere. The effectiveness of these processes depends upon the residence time of the radionuclides in containment. Conversely, a large rupture of the containment can lead to rapid transport of radionuclides to the environment with minimal retention.

The containment failure mode that occurs depends upon the containment design and the particular phenomena that cause the failure. Particular severe accident phenomena (including those beyond the design-basis) will be discussed in later sections; however, the challenges that they produce include:

1. overpressure

2. dynamic pressures (shock waves)

3. internal missiles

4. external missiles

5. meltthrough

6. bypass.

Overpressure can theoretically lead to either leakage or large rupture in any type of containment. Overpressure can result from several different causes, as discussed in later 
sections. However, it is important to recognize that pressure transients following reactor vessel blowdown under severe accident conditions can be more severe than those normally considered in the analyses of design-basis accidents. This is true because of the initial containment pressure increases caused by hydrogen generation and containment heating during the early phases (prior to reactor vessel failure) of a severe accident. As a containment is pressurized, it begins to deform. High temperatures exacerbate the problem. These deformities can lead to leakage around penetrations in the containment or to tearing of the steel liner (in concrete containments). Based on recent studies, leakage is considered the more likely outcome for concrete containments. ${ }^{13}$ The concrete structure is unlikely to rupture as a result of pressure challenges (even if the steel liner tears), but rather is more likely to crack. Steel containments are susceptible to rupture in the event that the penetrations do not leak and the containment continues to pressurize. Given sufficient pressure, a crack in a steel containment can propagate catastrophically. Generally, assuming that early penetration leakage does not occur, steel containments have a larger margin between the design and ultimate failure pressures than concrete containments.

Shock waves and missiles can potentially cause large holes in the containment. However, the containments are designed for the most credible external missiles, such as tornado-driven missiles, and some types of internal missiles, such as control rod ejections. Missiles or shock waves resulting from hydrogen detonations or steam explosions are a possible threat that will be discussed in more detail later.

There are two basic types of meltthrough to consider. First is the possibility of basemat meltthrough (the China Syndrome). In this case, following vessel failure the molten material melts through the basemat over a period of hours or days and vents the containment through the surrounding soil and can release substantial amounts of contaminated water. This failure mode is not generally catastrophic, because of the long time available for emergency response actions and the possibility of some retention in the soil. The second type of meltthrough is most applicable to Mark I BWR containments. In this case, molten material can exit the area beneath the reactor and flow across the floor, directly contacting the steel liner and causing it to fail. This type of failure, which is addressed in more detail in Section 4.7, can happen much more quickly than basemat meltthrough and can lead to more serious consequences. A similar scenario may be possible for PWR ice condenser containments, if debris is blown out of the reactor cavity near the seal table.

There are two other types of containment failure that can lead to severe consequences: (1) containment bypass and (2) isolation failure. Containment bypass involves failure of the reactor coolant system boundary in such a manner that a path is created to the outside without going through containment.

Bypass involves failures in the reactor coolant pressure boundary separating high pressure and low pressure systems. Normally, this involves the failure of at least two valves. For example, the valves separating the primary system from the Residual Heat Removal (RHR) system may fail, thus putting high pressure into the RHR system. Because the RHR system is normally constructed with low pressure piping and components, it may fail outside containment, providing a direct path from the core to the outside. Such sequences are usually referred to as interfacing systems LOCAs. In PWRs, steam generator tube 
ruptures provide an additional possibility of containment bypass. Primary system pressure will lift the relief valves on the secondary side, with the potential for stuckopen valves to provide the path to the atmosphere.

Containment isolation failure involves failure of the containment isolation function as a result of containment isolation valve failures or other openings in the containment boundary external to the reactor coolant system. These failures may be the result of preexisting leaks or the failure of isolation valves to close upon demand. The failures are more related to system and procedural malfunctions, rather than severe accident phenomena. In this case, the containment has no chance to function and fission products have a direct path outside to the atmosphere. Isolation failures are less likely in Mark I and II BWRs because of their inerted containments that make large leaks easily detected. Similarly, isolation failures are unlikely in PWR subatmospheric containments.
It should be recognized that plant-specific containment design differences abound, many with important ramifications with respect to plant response under severe accident conditions. This is true even for supposedly "sister" plants such as the Browns Ferry and Peach Bottom plants with Mark I containments. A good example is provided by Figure 4.1-13, which affords a subjective comparison of the bolting arrangements used at these two plants for the respective drywell head closure flanges. In this case, the Browns Ferry arrangement is less prone to flange separation by bolt elongation at elevated temperatures. This difference may be important for severe accident sequences involving high drywell temperatures (see Section 4.2), since the integrity of the silicon seals has been demonstrated ${ }^{14}$ to degrade significantly at temperatures in excess of about $600 \mathrm{~K}$ $\left(620^{\circ} \mathrm{F}\right)$. The point here is that the failure pressure can vary with temperature and can be affected by seemingly unimportant design differences. 
Table 4.1-1 Number of U.S. containments of each type

\begin{tabular}{c|c}
\hline Containment Type & Number \\
\hline PWR Large Dry & $59^{*}$ \\
\hline PWR Subatmospheric & 7 \\
\hline PWR Ice Condenser & 9 \\
\hline BWR Mark I & 24 \\
\hline BWR Mark II & 8 \\
\hline BWR Mark III & 4 \\
\hline
\end{tabular}

*Includes Big Rock Point, which is a BWR I.

\section{Table 4.1-2 Examples of design leakage rates (integrated leakage)*}

\begin{tabular}{c|c|cc|c}
\hline Plant & Containment & \multicolumn{2}{c|}{$\begin{array}{c}\text { Peak Design- } \\
\text { Basis Accident } \\
\text { Type }\end{array}$} & \multicolumn{2}{c}{$\begin{array}{c}\text { Maximum } \\
\text { psig }\end{array}$} & $\begin{array}{c}\text { Mllowable } \\
\text { (kP) }\end{array}$ & $\begin{array}{c}\text { Leakage } \\
\text { (wt.\%/day) }\end{array}$ \\
\hline Peach Bottom & BWR Mark I & 49.1 & $(339)$ & 0.5 \\
LaSalle & BWR Mark II & 39.6 & $(273)$ & 0.635 \\
Grand Gulf & BWR Mark III & 11.5 & $(79)$ & 0.437 \\
Sequoyah & PWR Ice & 12 & $(83)$ & 0.25 \\
Surry & Condenser & & & 0.1 \\
Zion & Subatmospheric & 45 & $(310)$ & 0.1 \\
\hline
\end{tabular}

*data taken from the following reports:

Integrated Leak Rate Test Report for Peach Bottom Unit 3, March 18, 1992. Integrated Leak Rate Test Report for LaSalle Unit 1, March 12, 1992. Integrated Leak Rate Test Report for Grand Gulf Unit 1, August 4, 1989. Integrated Leak Rate Test Report for Sequoyah Unit 2, February 19, 1985. Integrated Leak Rate Test Report for Surry Unit 2, September 3, 1991. Integrated Leak Rate Test Report for Zion Unit 1, July 5, 1988. 


\section{Table 4.1-3 10 CFR 50 Appendix $J$ test frequency requirements}

\begin{tabular}{|c|c|c|}
\hline $\begin{array}{l}\text { Test } \\
\text { Type }\end{array}$ & Option A & Option B \\
\hline A & $\begin{array}{l}\text { 1. Preoperational leakage rate test. } \\
\text { 2. Three tests during each } 10 \text { year service } \\
\text { period, at approximately equal intervals. } \\
\text { 3. If any periodic test fails, the schedule for } \\
\text { subsequent tests will be reviewed and } \\
\text { approved by the Commission. A summary } \\
\text { report must be provided to the NRC. } \\
\text { 4. If two consecutive tests fail, a test is } \\
\text { required at each refueling or every } 18 \\
\text { months, whichever comes first. } 2 \text {. Applies } \\
\text { after two consecutive successful tests. }\end{array}$ & $\begin{array}{l}\text { 1. Preoperational leakage rate test. } \\
\text { 2. Test within } 48 \text { months and then at } \\
\text { periodic interval (maximum of } 10 \text { years) } \\
\text { based on past leakage performance of } \\
\text { containment. } \\
\text { 3. If test fails, successful test required } \\
\text { within } 48 \text { months before returning to } \\
\text { extended test interval. } \\
\text { 4. Visual inspection of containment interior } \\
\text { and exterior required prior to each test. } \\
\text { Perform two additional inspections at } \\
\text { refueling outages prior to the next test if } \\
\text { the interval has been extended to } 10 \\
\text { years. } \\
\text { 5. Test results which exceed performance } \\
\text { criteria may require reporting to NRC } \\
\text { (e.g., License Event Report [LER]). }\end{array}$ \\
\hline B & 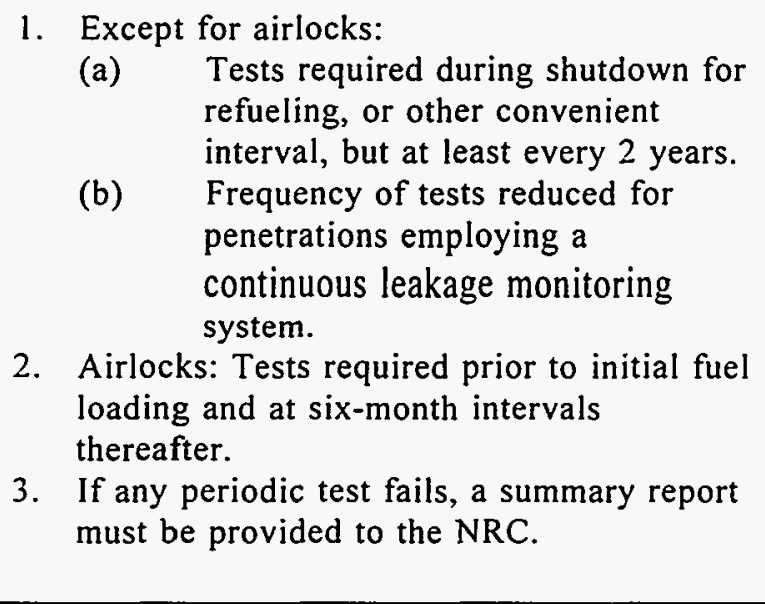 & $\begin{array}{l}\text { 1. Test prior to initial criticality. } \\
\text { 2. Test within } 30 \text { months and then at } \\
\text { periodic interval based on safety } \\
\text { significance and past performance of } \\
\text { each non-airlock boundary. } \\
\text { 3. If test fails, successful test required } \\
\text { within } 30 \text { months before returning to } \\
\text { extended test interval. } \\
\text { 4. Tests required at least every } 10 \text { years. } \\
\text { The maximum interval for airlocks is } 30 \\
\text { months. } \\
\text { 5. Test results which exceed performance } \\
\text { criteria may require reporting to NRC } \\
\text { (e.g., LER). }\end{array}$ \\
\hline $\mathrm{C}$ & $\begin{array}{l}\text { 1. Tests required during shutdown for } \\
\text { refueling, but at least every } 2 \text { years. } \\
\text { 2. If any periodic test fails, a summary report } \\
\text { must be provided to the NRC. }\end{array}$ & $\begin{array}{l}\text { 1. Test prior to initial criticality } \\
\text { 2. Test within } 30 \text { months and then at } \\
\text { periodic interval based on safety } \\
\text { significance and past performance of } \\
\text { each isolation valve. } \\
\text { 3. If test fails, successful test required } \\
\text { within } 30 \text { months before returning to } \\
\text { extended test interval. } \\
\text { 4. Tests required at least every } 60 \text { months. } \\
\text { The maximum interval for certain valves } \\
\text { (e.g., main steam valve in BWRs) is } 30 \\
\text { months. } \\
\text { 5. Test results which exceed performance } \\
\text { criteria may require reporting to NRC } \\
\text { (e.g., LER). }\end{array}$ \\
\hline
\end{tabular}




\section{Containment Net Free Volume $\times 10^{-6}\left(\mathrm{ft}^{3}\right)$}
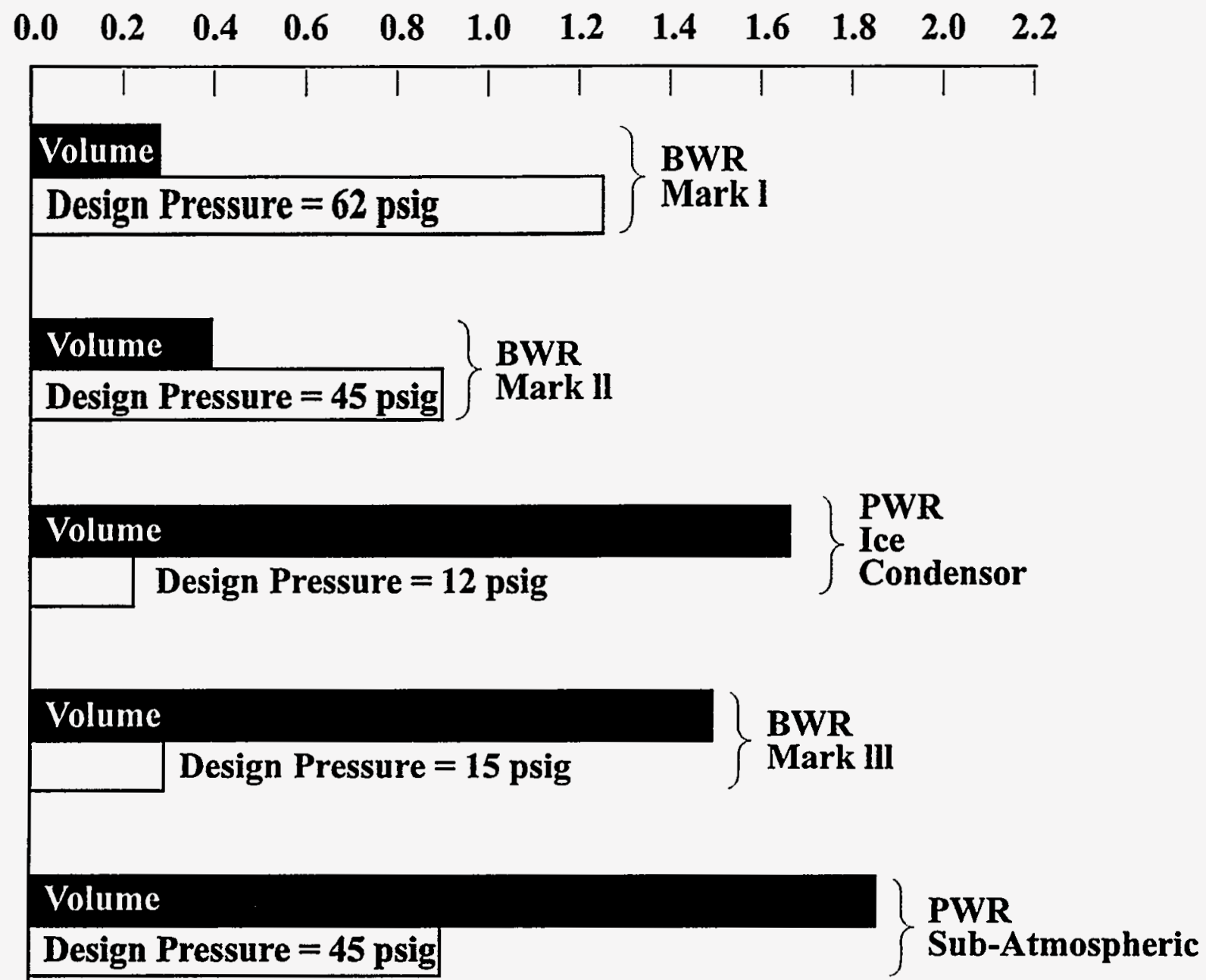

Figure 4.1-1 Typical containment volumes and design pressure (psig) 

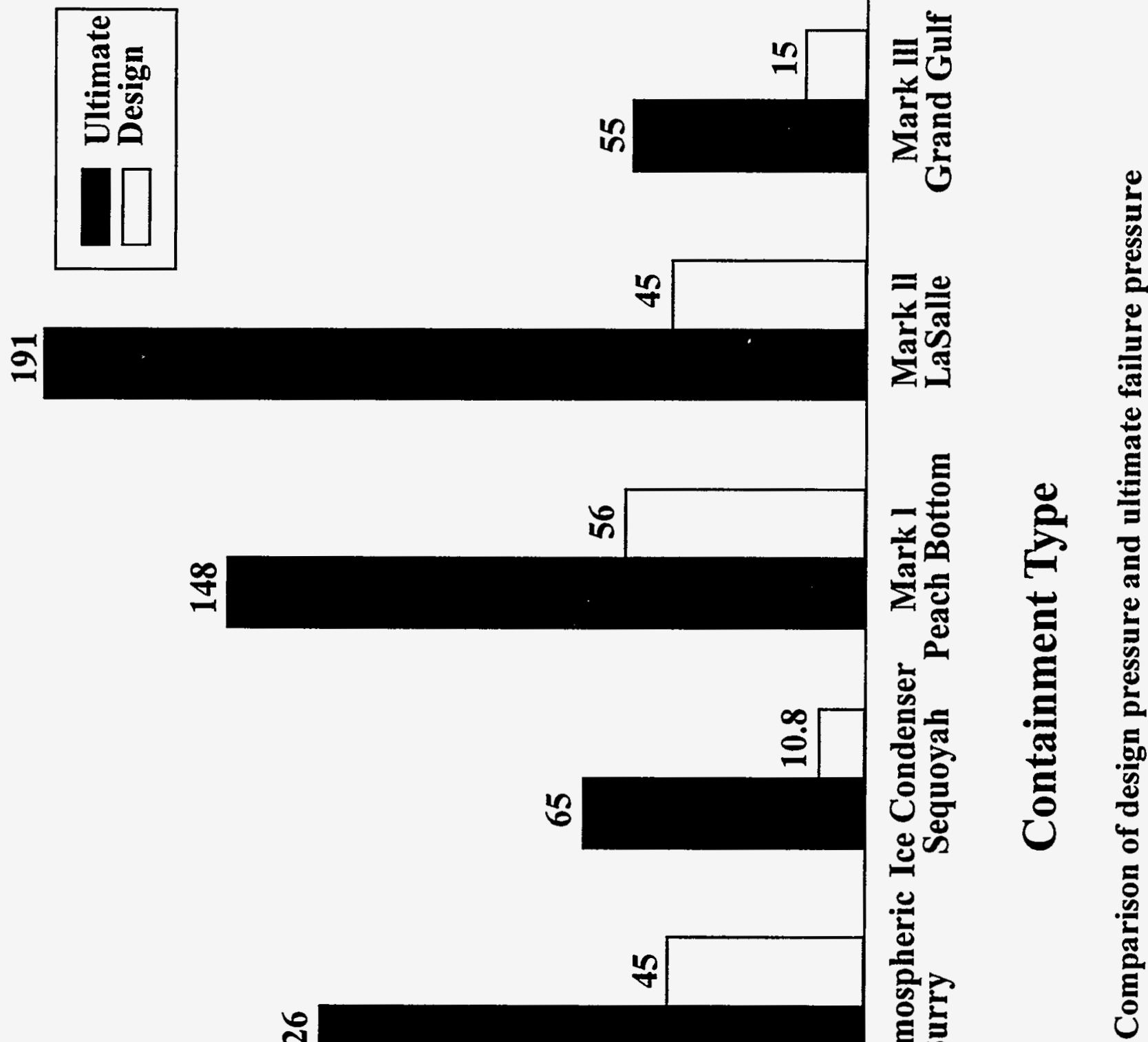

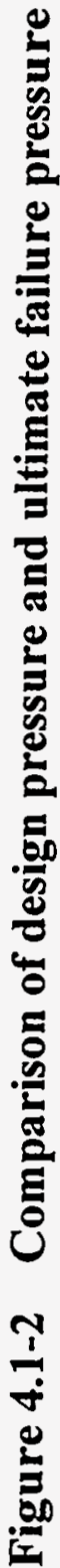

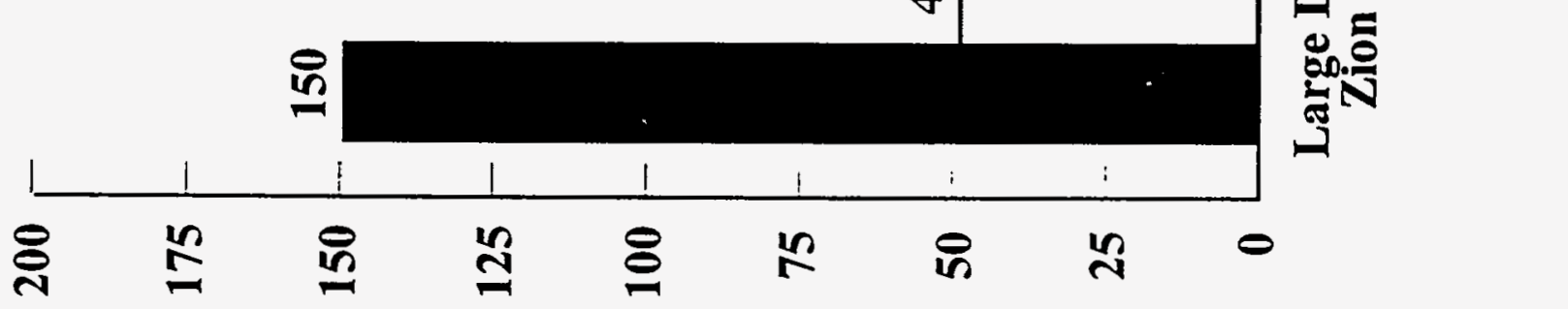

(ô!̣d) ว.xnssəxd 


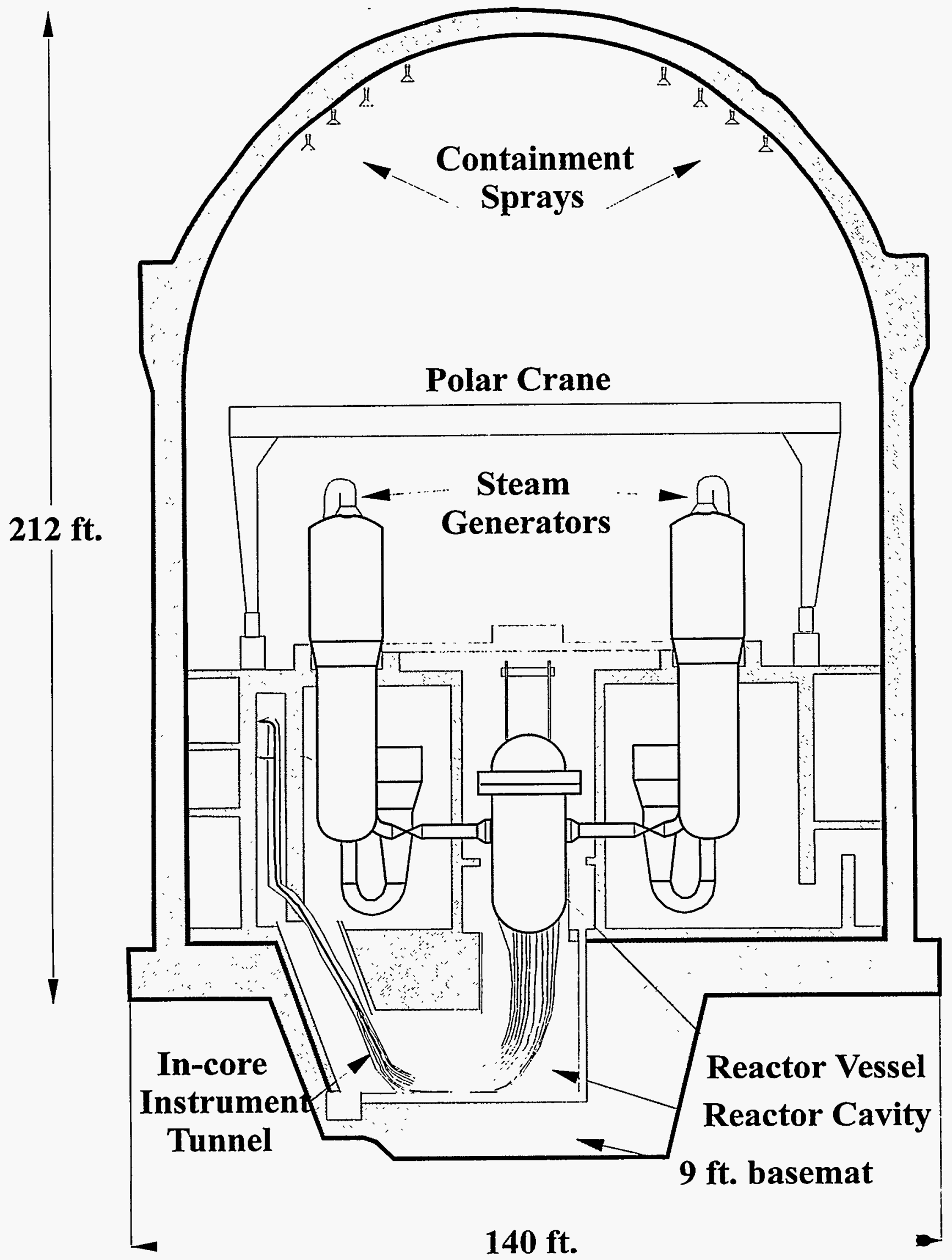

Figure 4.1-3 Typical large dry containment 


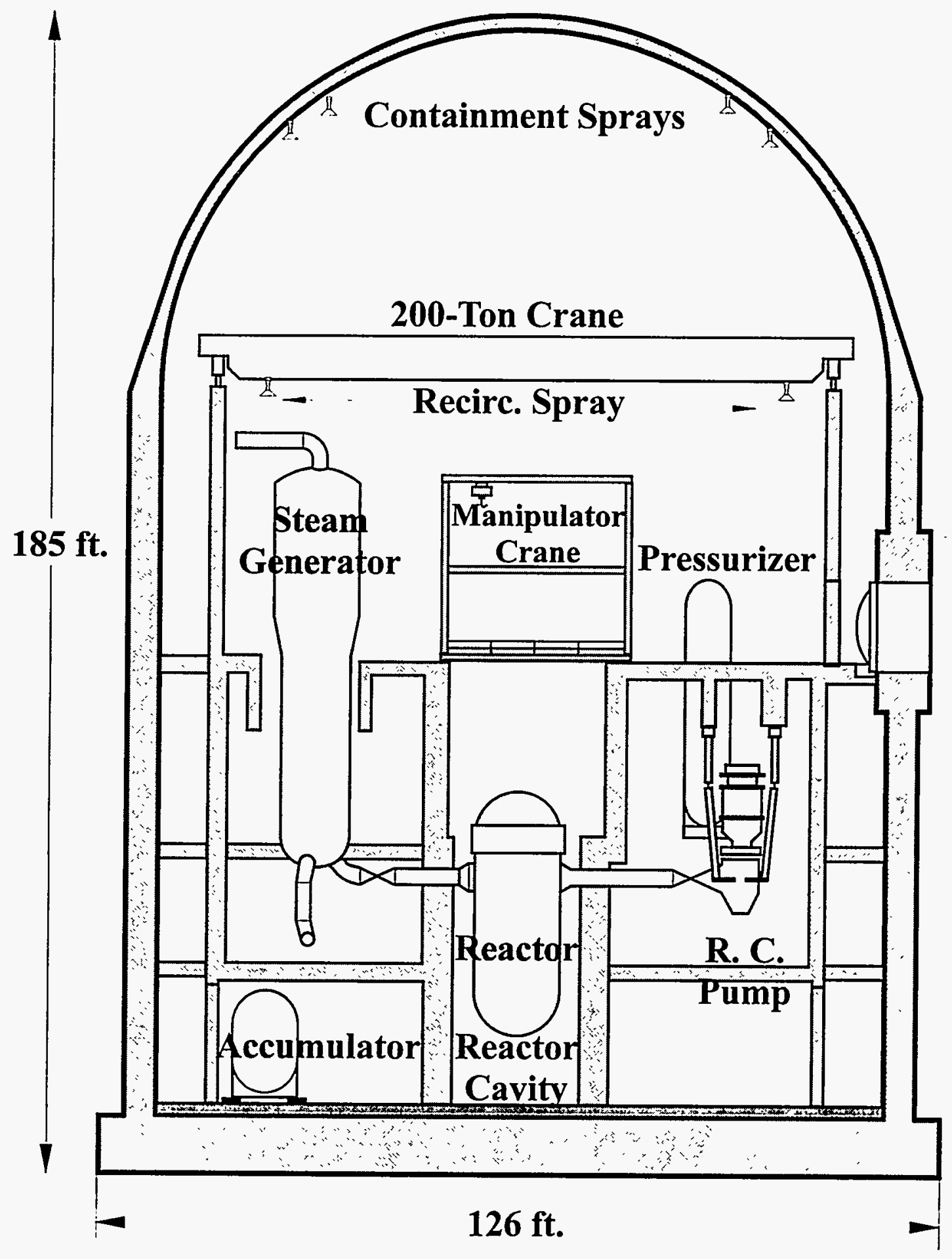

Figure 4.1-4 Typical subatmospheric containment 


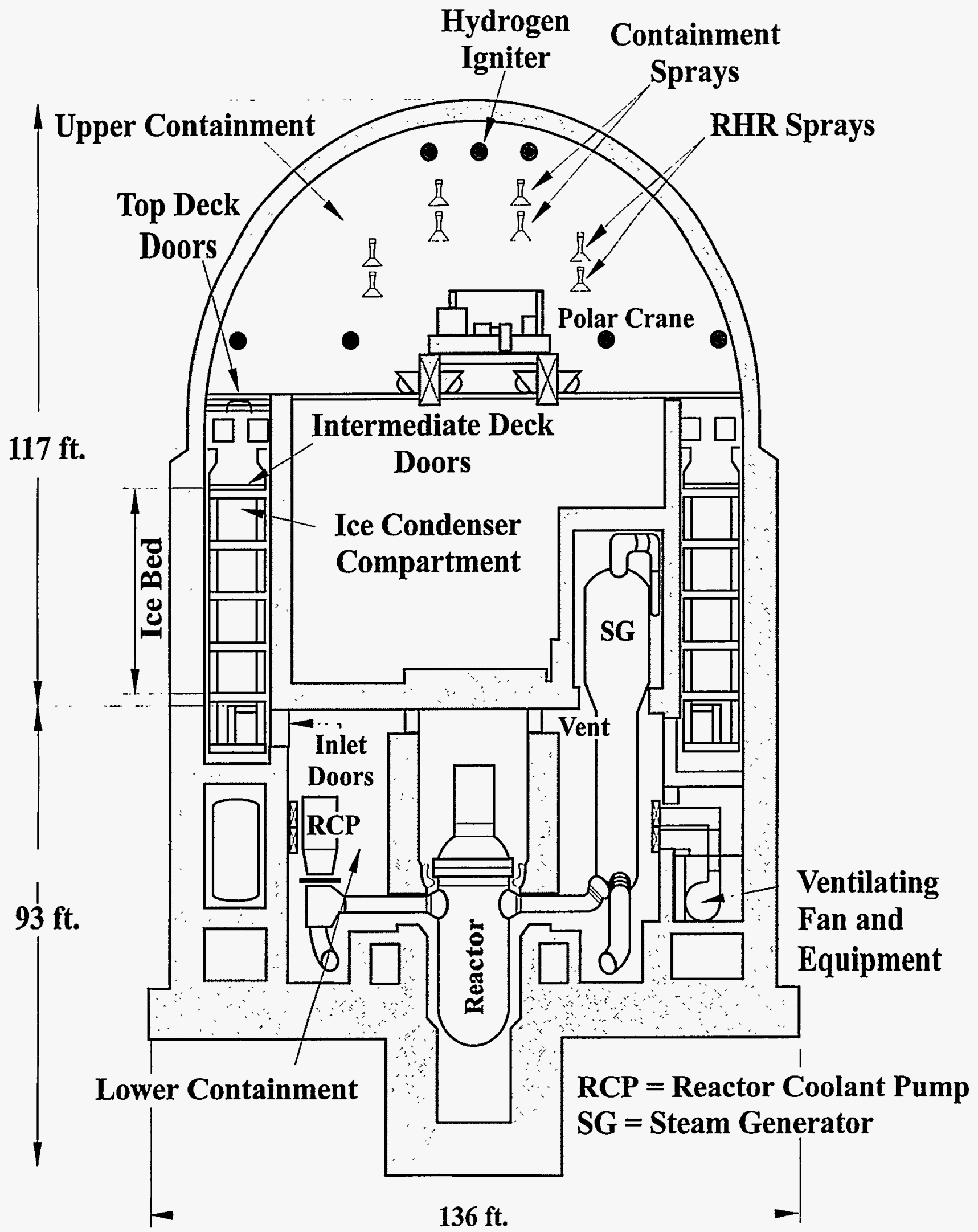

Figure 4.1-5 Typical ice condenser containment 


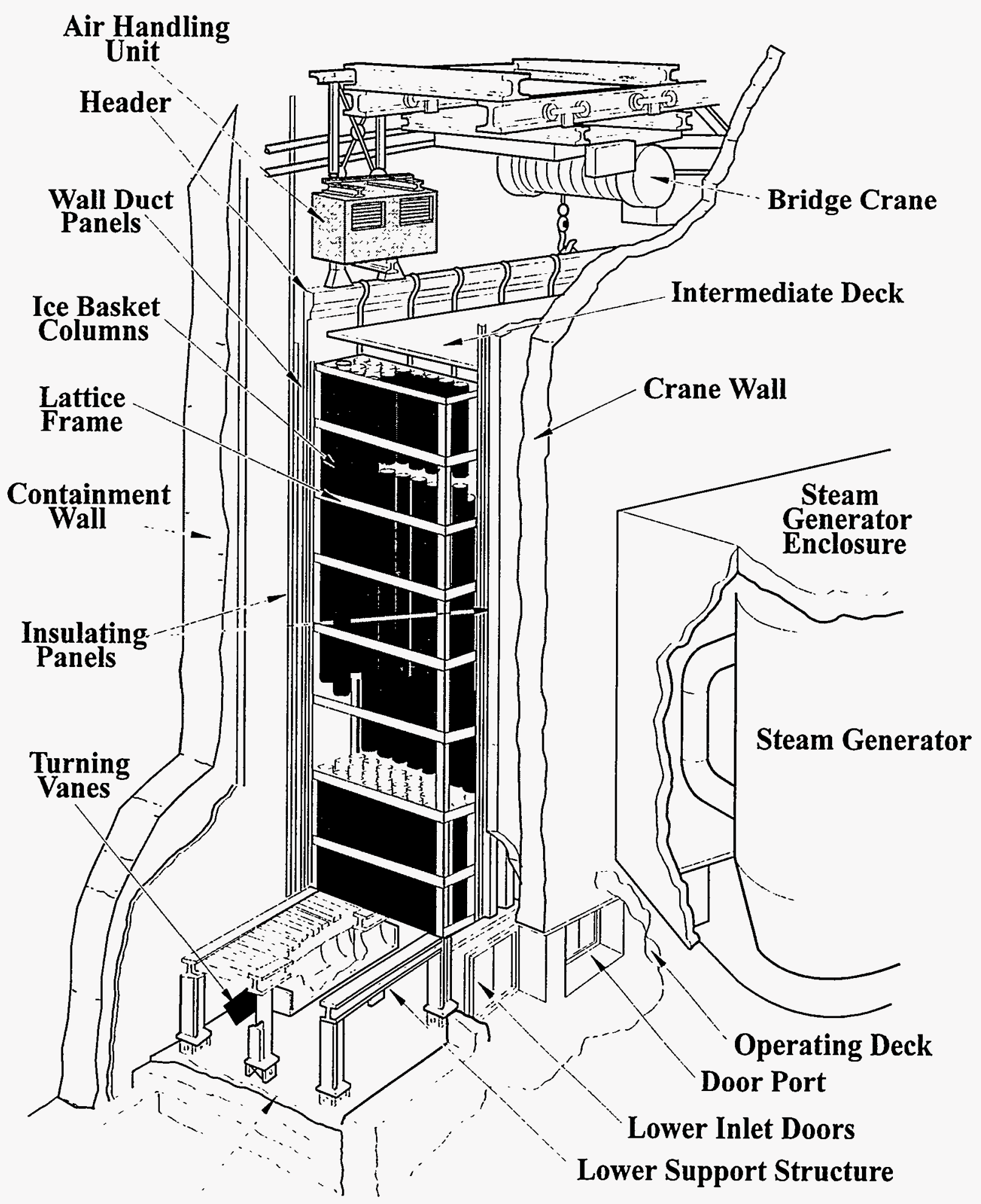

Wear Slab

Figure 4.1-6 Ice condenser cutaway 


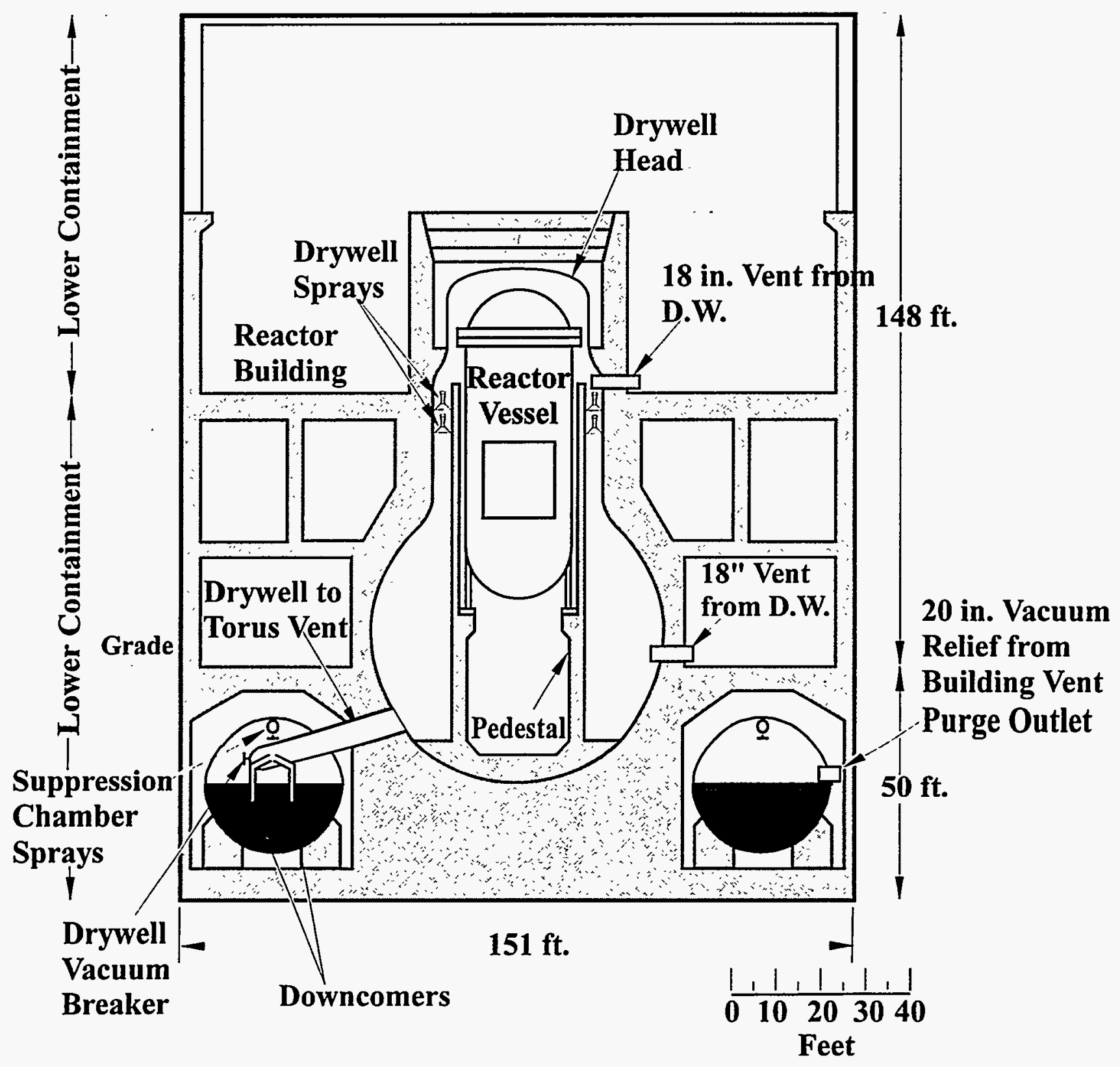

Figure 4.1-7 Typical BWR Mark I containment 


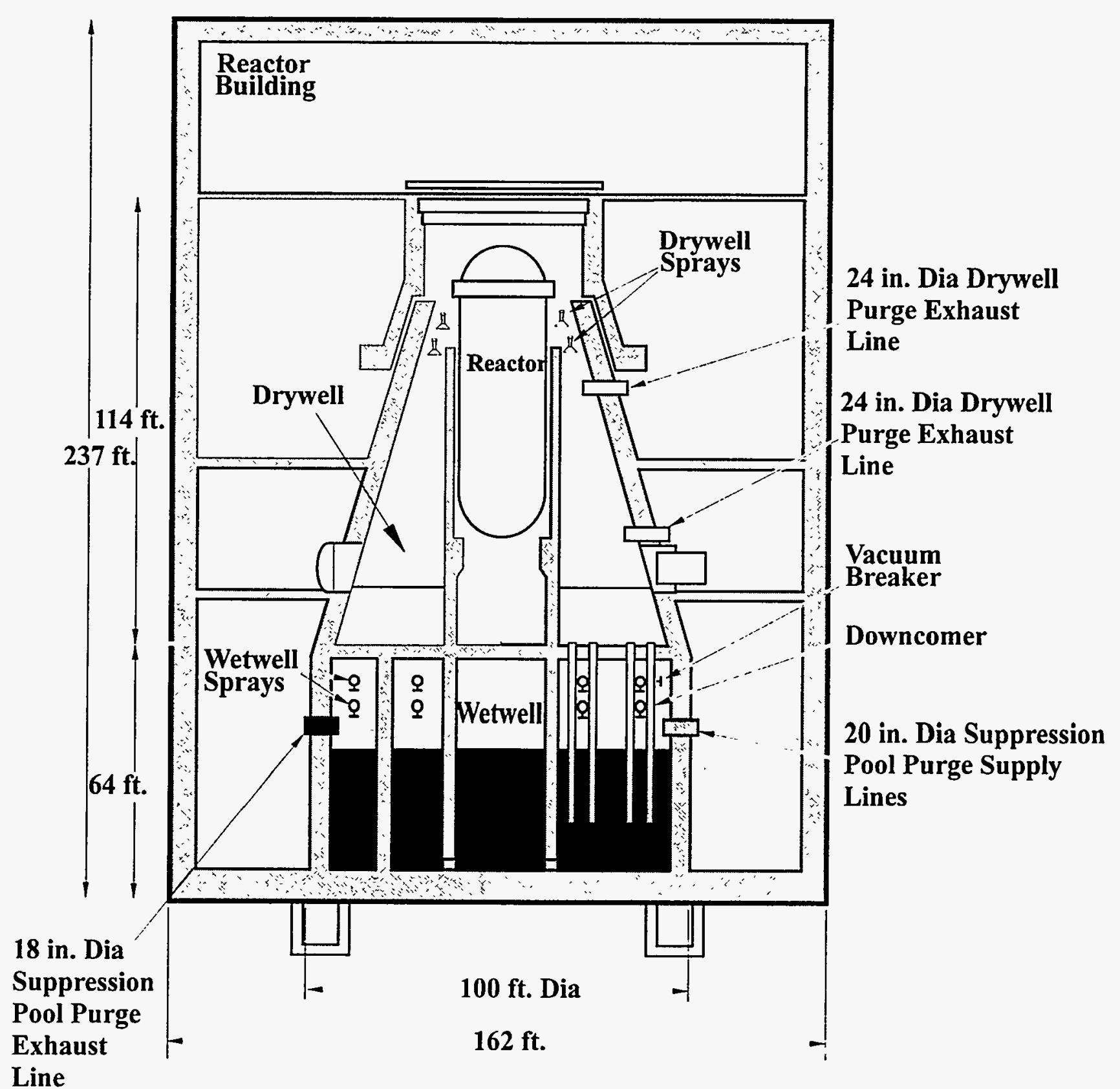

Figure 4.1-8 Typical BWR Mark II containment 


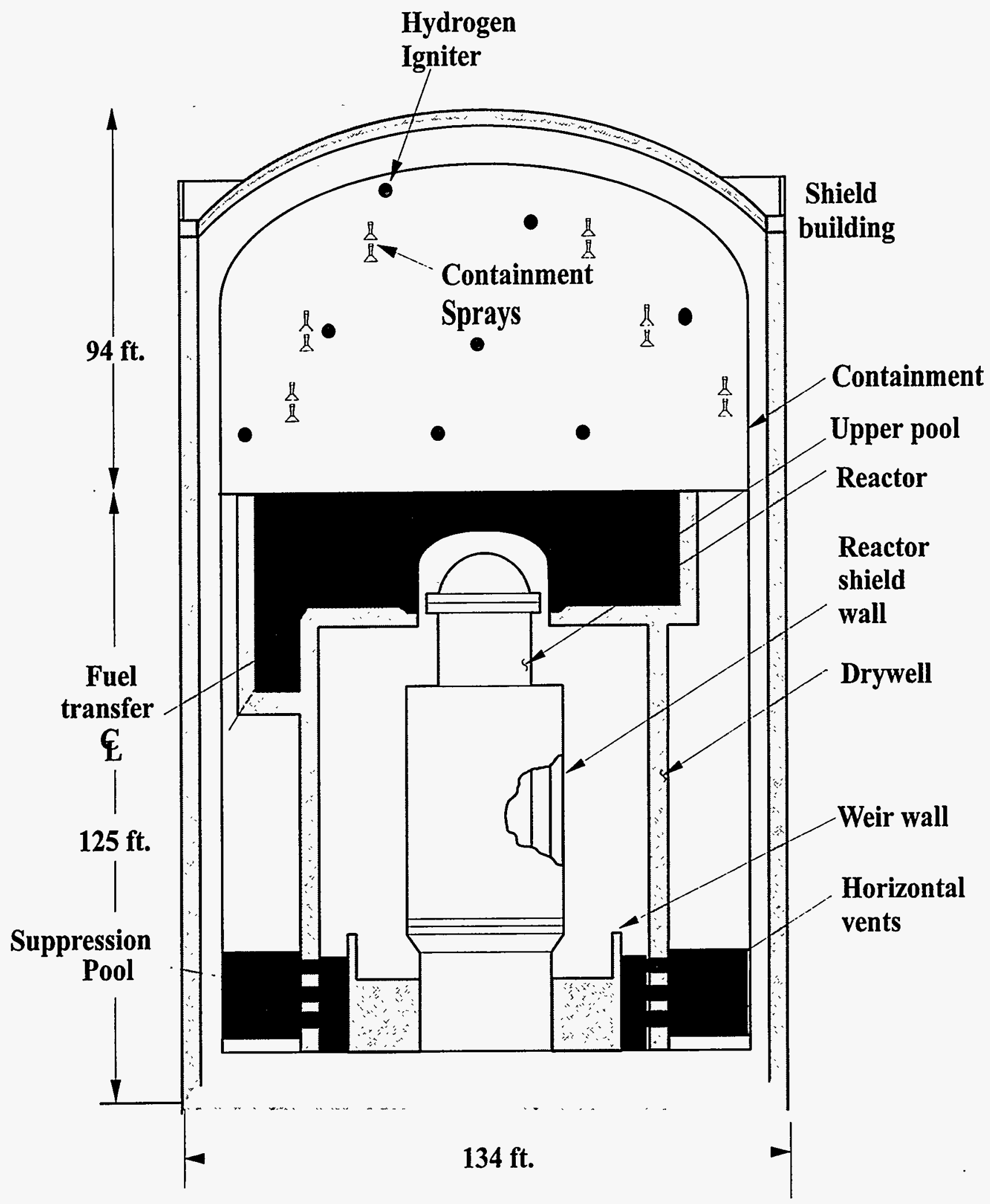

Figure 4.1-9 Typical BWR Mark III containment 


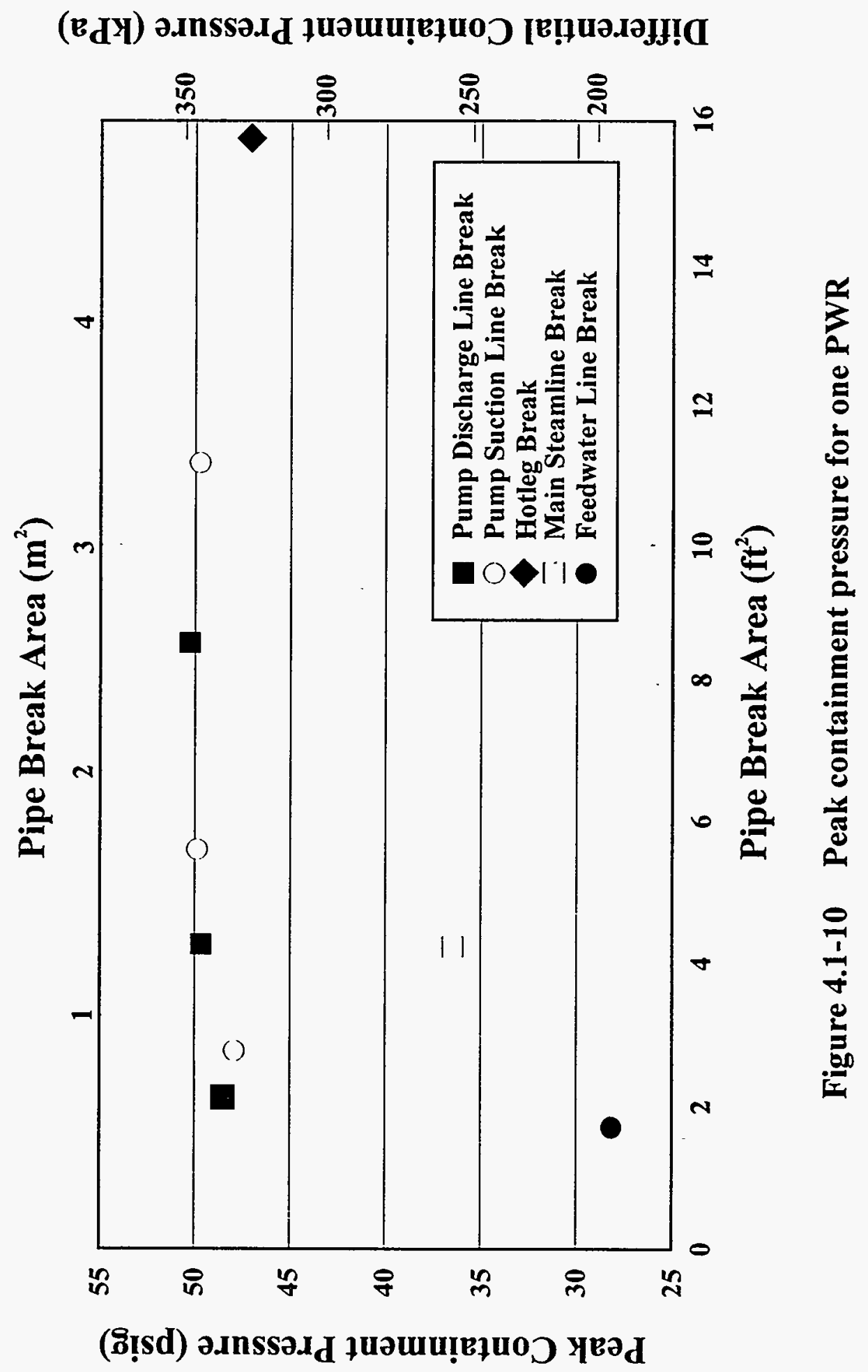




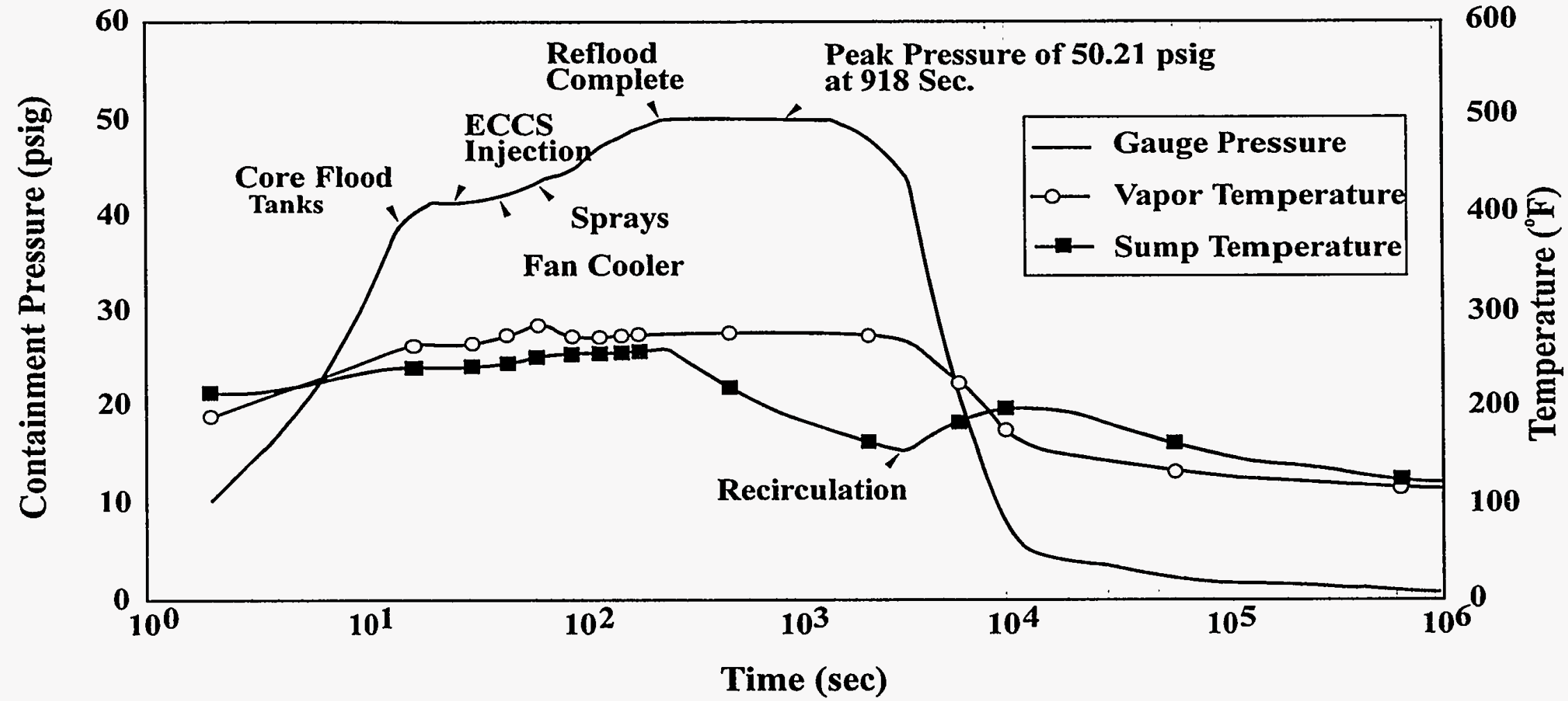

Time (sec) 
Sinks

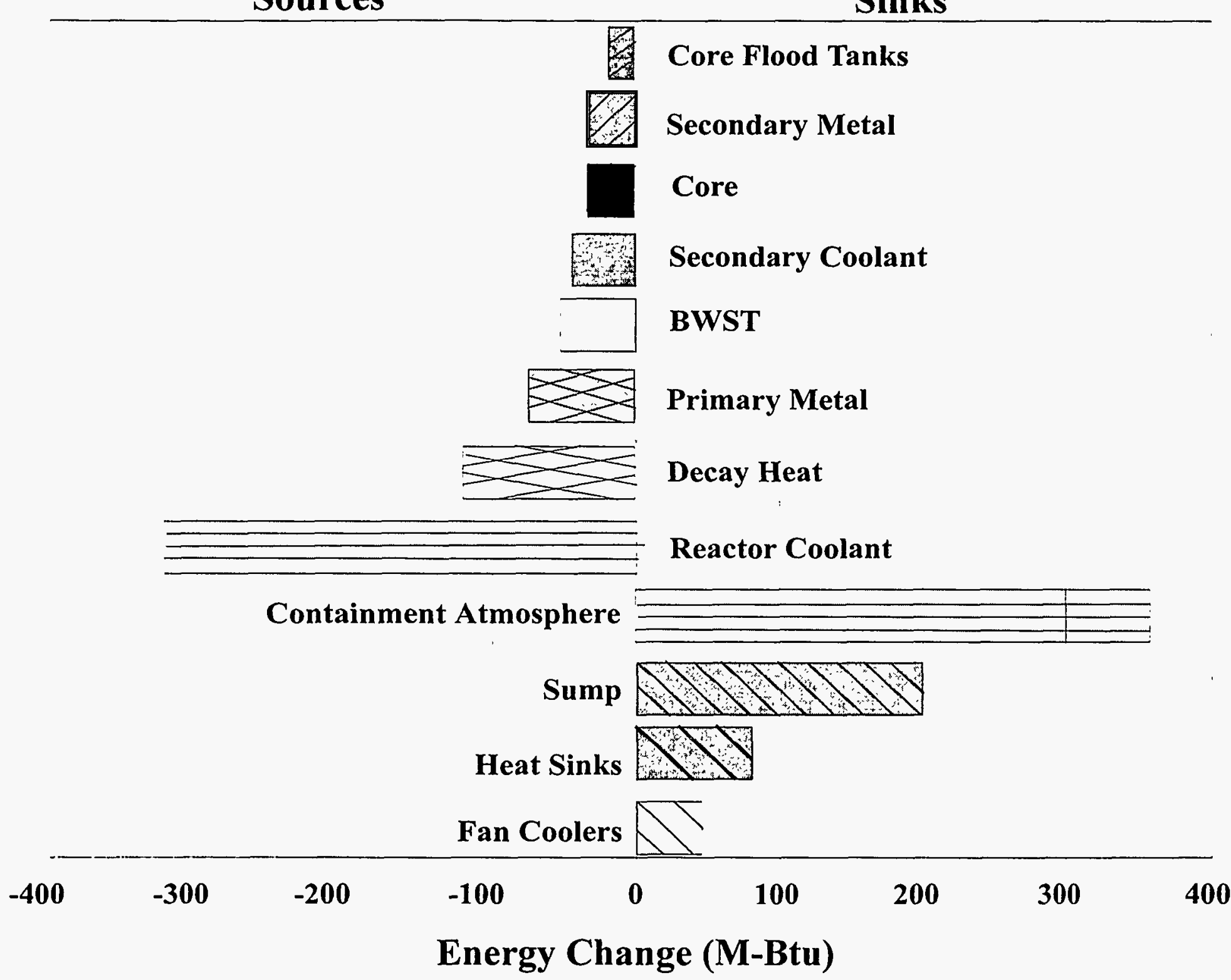

Figure 4.1-12 Energy changes up to time of peak containment pressures for one PWR 

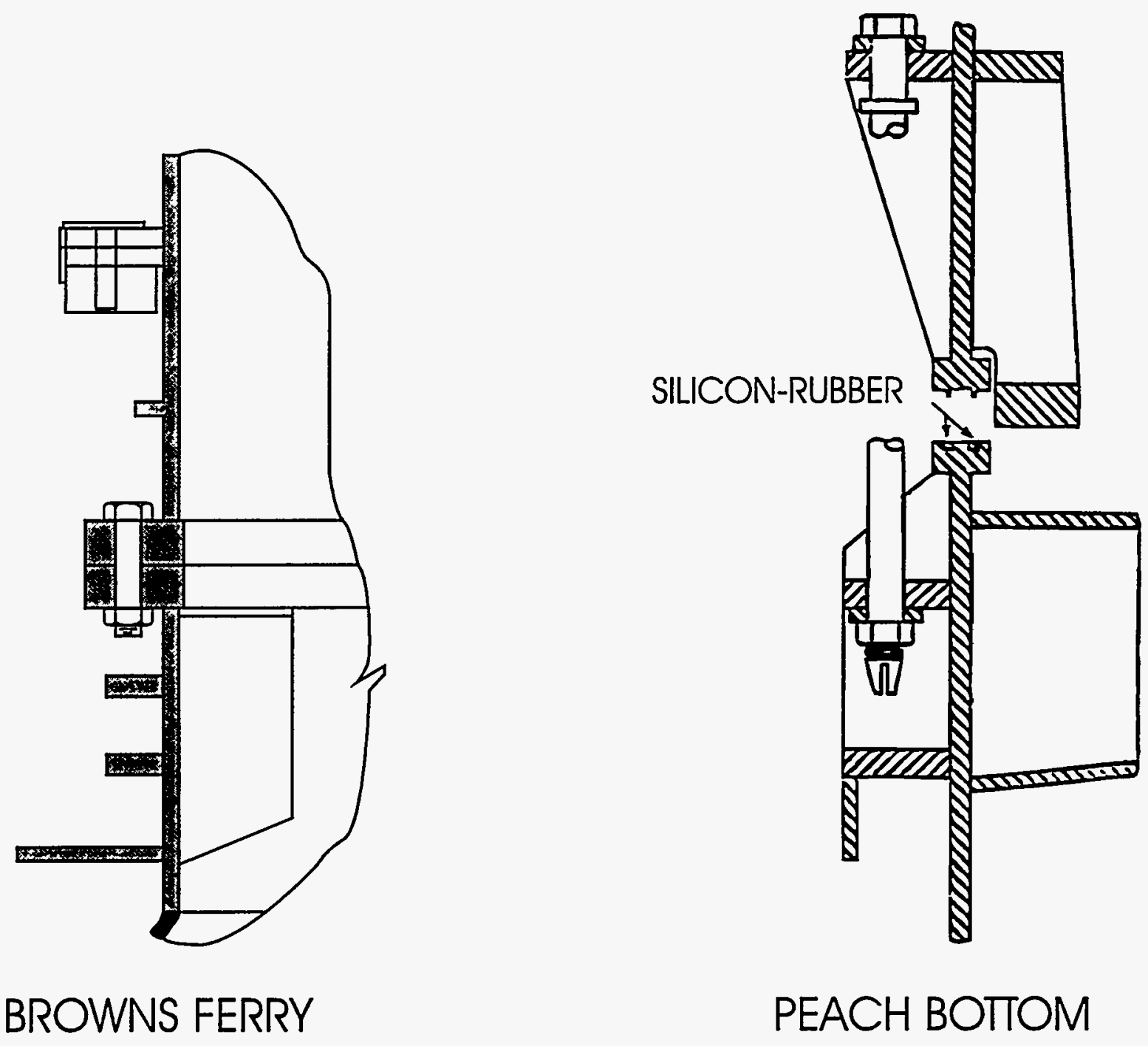

Figure 4.1-13 Different bolting arrangements on drywell head closure flange for Browns Ferry and Peach Bottom 


\section{References for Section 4.1}

1. U.S. Nuclear Regulatory Commission, World Wide Web Site, http://www.nrc.gov, May 10, 1996.

2. A. L. Camp, et al., "Light Water Reactor Hydrogen Manual," NUREG/CR-2726, SAND82-1137, Sandia National Laboratories, August 1983.

3. U. S. Nuclear Regulatory Commission, "Severe Accident Risks: An Assessment for Five U.S. Nuclear Power Plants," NUREG-1150, December 1990.

4. T. D. Brown, et al., "Integrated Risk Assessment for the LaSalle Unit 2 Nuclear Power Plant: Phenomenology and Risk Uncertainty Evaluation Program (PRUEP)," NUREG/CR-5305, SAND90-2765, Sandia National Laboratories, 1992.

5. U.S.Code of Federal Regulations, Title 10, Part 50, Appendix A, General Design Criterion 50, U.S. Government Printing Office, January 1, 1991.

6. Kenneth C. Lish, "Nuclear Power Plant Systems and Equipment," Industrial Press Inc., 200 Madison Avenue, New York, New York, 1972.

7. U.S. Code of Federal Regulations, Title 10, Part 100, U.S. Government Printing Office, January 1, 1991.
8. U.S. Code of Federal Regulations, Title 10, Part 50, Appendix A, U.S. Government Printing Office, January 1, 1991.

9. U.S. Code of Federal Regulations, Title 10, Part 50, Appendix J, U.S. Government Printing Office, January 1, 1991.

10. U.S. Code of Federal Regulations, Title 10, Part 50, Appendix A, General Design Criterion 38, U.S. Government Printing Office, January 1, 1991.

11. U.S. Nuclear Regulatory Commission, "Performance-Based Containment LeakTest Program," NRC Regulatory Guide 1.163, September 1995.

12. U.S. Code of Federal Regulations, Title 10, Part 50, Appendix A, General Design Criterion 38, U.S. Government Printing Office, January 1, 1991.

13. R. J. Breeding, et al., "Evaluation of Severe Accident Risks: Quantification of Major Input Parameters," NUREG/CR-4551, Vol. 2.

14. D. A. Brinson and G. H. Graves, "Evaluation of Seals for Mechanical Penetrations of Containment Buildings," NUREG/CR-5096, SAND88-7016, Sandia National Laboratories, August 1988. 


\subsection{Containment Response to Beyond- Design-Basis Accidents}

As discussed in Section 4.1, containments are not likely to fail from the loads resulting from design-basis accidents. In fact, there are very large margins between the pressures resulting from design-basis accidents and predicted ultimate failure pressures. However, the China Syndrome and the Reactor Safety Study made it clear that more severe challenges to containment were possible. ${ }^{1,2}$ In fact, it appeared that public risk was probably dominated by accidents in which substantial core damage occurred and the containment failed or was bypassed. The TMI-2 accident further emphasized the importance of phenomena, such as hydrogen combustion, that could accompany severe accidents. This section provides some general perspectives on the vulnerabilities of containments to severe accident phenomena. Later sections will describe key severe accident phenomena in more detail.

\subsubsection{Containment Challenges and Timing of Events}

Challenges to containments can occur during four time regimes:

1. at the start of the accident,

2. prior to reactor vessel failure,

3. at or soon after reactor vessel failure, or

4. long after reactor vessel failure.

Table 4.2-1 summarizes the time regimes and their associated containment challenges. Isolation failures and bypass occurring at the start of the accident were addressed in Section 4.1. The three other time regimes are discussed below.

Prior to vessel failure, there are three types of containment pressure loads that can occur. The first type of load includes the pressure loads that result from the initial reactor coolant system blowdown and subsequent steam and hydrogen releases due to reflooding. For design-basis accidents, these loads are not a threat; however, containments are not designed to withstand the loads that may occur during some severe accidents resulting from the rupture of a reactor vessel or steam generator. As of early 1996, there have been no definitive studies concerning the likelihood of containment failure from such events; fortunately, the frequency of such events is estimated to be very small.

As a related matter, it should be noted that the occurrence of high containment pressure signals does not necessarily mean that a LOCA has occurred. Loss of drywell coolers and the concomitant increase in drywell temperature will cause the drywell pressure in the relatively small Mark I and Mark II containments to exceed the alarm setpoints (about $1.7 \mathrm{psig}$ or $12 \mathrm{kPa}$ ) within a few minutes. Although this temperature-induced pressure increase has no implications with respect to the integrity of the drywell boundary, its effect in generating one of the LOCA accident signatures illustrates a potential for operator confusion under conditions such as those accompanying Station Blackout.

A second type of load that can occur prior to vessel breach involves the failure of containment heat removal systems to cope with the ongoing mass and energy additions to the containment even though core cooling is successful. This problem can occur in many ATWS sequences or in LOCAs or transients in which containment heat removal systems fail. In the latter cases, the design pressure may be exceeded early, but the ultimate failure pressure would not be reached for many hours or even days. In fact, some containments may not fail at all, if the heat losses through the structure can 
eventually match the decreasing decay heat load. If the containment does fail, then there is the potential for the loss of core cooling as a result of several phenomena, including:

1. loss of net positive suction head (NPSH) to pumps that are recirculating water from a heated sump or suppression pool,

2. failure of piping as a result of the containment failure, or

3. failure of core cooling system components located in the reactor building of a Mark I or Mark II BWR when steam enters the surrounding reactor building following containment failure.

If core damage results from one of these phenomena, then the accident will proceed in a containment that is already failed.

The third phenomena that can cause failure prior to vessel breach is hydrogen combustion. Hydrogen will be generated during the core heatup and meltdown phase due to zirconium-steam reactions. If a significant amount of this hydrogen is released through relief valves (as at TMI-2) or through a pipe break, then combustion prior to vessel breach can threaten the containment. Hydrogen combustion is discussed in more detail later in this module.

The second time phase of interest, and the one that is often most threatening to containment, is the phase that occurs at or soon after vessel breach. When vessel breach occurs, there are several phenomena that can ensue, sometimes acting simultaneously. Those phenomena include:

1. steam spike,

2. steam explosion,

3. direct containment heating,
4. hydrogen combustion,

5. containment shell melthrough,

6. downcomer failure (Mark II BWR).

Steam spikes or explosions can occur if there is water in the reactor cavity or pedestal region below the reactor vessel. Invessel steam explosions and alpha mode failures were addressed in Module 3. Water may be present below the vessel as a result of leakage from the reactor coolant system, the operation of containment sprays, or melted ice in an ice condenser containment. By themselves, steam spikes are unlikely to threaten containment, unless the containment is already substantially pressurized. The amount of mass and energy added to the containment atmosphere is determined by the amount of water converted to steam as the melt is quenched in the water. If a steam explosion occurs, then shock waves may cause damage to the containment structure or the vessel supports. If the vessel supports fail and the vessel moves significantly, then containment failure may result around the piping penetrations. In some BWRs, steam explosions could lead to suppression pool bypass, possibly resulting in eventual overpressurization of the containment. Steam explosions are discussed more in Section 4.3 .

Direct Containment Heating (DCH) involves the ejection of the melt from the vessel at high pressure, thus spraying the molten material into containment. With the melt broken up into small particles, rapid heat transfer to the containment atmosphere can occur, most likely accompanied by the chemical energy associated with oxidation of metals in the melt. This "direct heating" has the potential to transfer more energy to the containment atmosphere than a steam spike and provides a more significant threat to containment. DCH is discussed more in Section 4.5 . 
When the reactor vessel fails, any hydrogen contained in the reactor coolant system will be released to containment, and additional hydrogen may be generated as a result of chemical reactions accompanying steam spikes, steam explosions, or direct containment heating. This hydrogen may burn immediately if sufficient oxygen is present, particularly if the molten material provides an ignition source or the hydrogen is already at very high temperatures. Hydrogen combustion at vessel breach may directly threaten containment or may threaten containment in combination with one or more of the other phenomena that can occur.

A phenomenon of importance primarily for Mark I BWRs is shell (liner) meltthrough. At vessel breach, the molten material may flow out of the pedestal region, across the drywell floor and then directly contact the steel liner, causing failure. The likelihood of this event and potential means for its mitigation are discussed in more detail in Section 4.7.

A phenomenon of importance for Mark II BWRs is downcomer failure. While Mark II designs vary significantly, there is often the potential for molten material to flow across the floor and into the downcomers. This molten material may directly fail the downcomer or, possibly, lead to a steam explosion that fails the downcomer. Downcomer failure does not lead to immediate containment failure; however, the suppression pool is bypassed, thus negating its heat removal and fission product scrubbing capabilities.

The third time phase of interest is the late phase, hours or more after vessel failure. The late phase threats consist primarily of high temperature, overpressure, basemat meltthrough, and hydrogen burns. High temperature and long term overpressure can result if containment heat removal systems are inoperative. In a BWR, high drywell temperatures can result even if the suppression pool cooling systems are working. With most of the core materials now present in the containment, the decay heat must be removed somehow to prevent temperature and pressure buildup. High temperatures can result in weakened structures that may leak more than expected or fail at pressures lower than the expected ultimate failure pressure. The problem is exacerbated by noncondensible gases that can be generated by core-concrete interactions. These noncondensible gases contribute to the overall pressure.

Basemat meltthrough is a long term result of core-concrete interactions. These interactions can generate hydrogen and other noncondensible gases, generate copious amounts of radioactive and nonradioactive aerosols, and eventually fail the basemat. Coreconcrete interactions will be discussed in more detail in Section 4.4.

Hydrogen burns can also occur during the late phase. In some cases this may involve hydrogen that was present previously, but did not burn due to the lack of an ignition source or an excess of steam in the atmosphere. If steam is removed late in an accident, for example, due to recovery of sprays, a gaseous mixture that was inert may become flammable. Another factor affecting hydrogen burns is the amount of flammable gases (hydrogen and carbon monoxide) being generated from core-concrete interactions. These additional gases can lead to burning late in an accident.

Section 4.2.1 has summarized the time phases of an accident and the phenomena that occur during those phases. Section 4.2.2 will now discuss estimates of 
containment failure probabilities as a result of those particular phenomena.

\subsubsection{Implications of Containment Failure}

The significance of containment failure depends upon the particular accident sequence, the mode of containment failure and the timing of radioactive releases. Module 5 will address the importance of the timing of releases relative to warning times and evacuation speeds. The importance of accident sequence type and containment failure mechanisms are discussed briefly below.

Containment failure can only represent a significant concern if radionuclides are released from the fuel and the reactor coolant system. If fuel melting does not occur and only the activity in the reactor coolant and the radioactive gases in the fuel pins (gap release) are released, then the consequences will be minimal even if containment failure occurs.

If fuel melting does occur and a significant amount of radionuclides is released to containment, then the timing and mode of containment failure are critical factors in determining the offsite consequences. Generally, the most severe failure modes are ones that occur early in time (before or during reactor vessel failure) so that there is little settling or other retention of radionuclides in the containment. Radionuclides can be retained in containment in a number of ways:

1. scrubbing in suppression pools,

2. scrubbing by containment sprays,

3. retention in an ice condenser,
4. gravitational settling and other natural processes,

5. trapping along tortuous release paths.

Most of these retention mechanisms are affected by the time available for the mechanism to work. Small containment leaks allow more time for settling and scrubbing by sprays. Therefore, ruptures are more likely to lead to severe consequences than leaks. If the radionuclides can be mostly retained until after evacuation occurs, then many of the health effects can be substantially reduced. Also, failures that lead into surrounding buildings allow further opportunities for retention.

Module 5 will discuss the offsite consequences of particular accident types in more detail. However, the importance of containment failure can be summarized by stating that the worst failures are failures (or bypasses) that occur early and allow rapid, unscrubbed transit of radionuclides out of the containment.

\subsubsection{Likelihood of Containment Failure During Severe Accidents}

The most comprehensive study of containment failure probabilities is contained in the NUREG-1150 documents. ${ }^{3}$ In addition, the industry has performed individual plant examinations (IPEs) assessing the performance of containments in severe accidents. Seventy-five IPE submittals covering 108 units are included in the discussions below. ${ }^{4}$ Despite the fact that severe accidents provide challenges beyond the design-basis, NUREG-1150 (and the IPE studies) show that containments have the capacity to withstand many of these accidents. This capability is a result of the very conservative design process that 
provides substantial margin with respect to less severe design-basis accidents.

The likelihood of actual containment failure is usually considered according to one of two measures: conditional containment failure probability (CCFP) and containment failure frequency (CFF). Both of these measures depend upon several factors, including the particular containment design and accident sequence. The conditional containment failure probability is the probability of containment failure given an accident. The containment failure frequency is the frequency per reactor year of accidents involving containment failure. These quantities are determined from:

$$
\begin{aligned}
& C C F P=\sum_{i=1}^{n} \frac{S_{i}}{C D F} C_{i} \\
& C F F=\sum_{i=1}^{n} S_{i} C_{i}
\end{aligned}
$$

where

CCFP is the conditional containment failure probability,

CFF is the containment failure frequency,

$\mathrm{CDF}$ is the total core damage frequency,

$S_{1}$ is the frequency of accident sequence $i$,

$C_{t}$ is the conditional probability of containment failure given accident sequence $i$,

and $n$ is the total number of accident sequences.

Because $S_{i}$ and $C_{i}$ depend on the particular accident sequences (which vary considerably among the plants), both CCFP and CFF can be significantly different for two plants with identical containments.

Most of the time, values for CCFP and CFF are calculated for early failures and bypass events. Failures happening many hours after core damage normally contribute much less to public risk. Figure 4.2-1 shows the relative probability of different containment failure modes (CCFP), given a core damage accident, for the five plants evaluated in NUREG-1150. In this figure, early failures include failures that occur before, at, or soon after vessel breach. Note that many of the outcomes at Grand Gulf, which has a Mark III containment, involve failure of the outer containment with the drywell and suppression pool remaining intact. Therefore, the containment failures for Grand Gulf do not all lead to significant radiological releases.

With the caveat noted above for Grand Gulf, the failures that most impact public risk are the early failures and the bypass events. Figure 4.2-2 shows the CFFs of such events for the five NUREG-1150 plants and the IPEs. Figure 4.2-3 shows the CCFP for the same plants. These figures, which consider only internally initiated accidents (the IPEs include internal flooding), account for the variation in accident frequency and type. As noted in Module 2, Grand Gulf has a substantially lower core damage frequency than Sequoyah, and this is reflected in a lower containment failure frequency, even though Grand Gulf has a higher probability of early failure given an accident (CCFP). 
Because of the risk importance of early releases, the phenomena, mechanism, and accident scenarios that can lead to such releases are of particular interest. These involve early structural failure of the containment, containment bypass, containment isolation failures and, for some BWR plants, deliberate venting of the containment.

As a group, the large dry PWR containments analyzed in NUREG-1150 and the IPEs have significantly smaller conditional probabilities of early structural failure (given core melt) than the BWR pressure suppression containments analyzed. Nonetheless, containment bypass and isolation failures are generally more significant for the PWR containments. As seen in Figure 4.2-2, however, these general trends are often not true. for individual IPEs because of the considerable range in the results. For instance, conditional probabilities for both early and late containment failure for a number of large dry PWR containments were higher than those reported for some of the BWR pressure suppression containments.

The results for BWRs, grouped by containment type, follow expected trends and indicate that, in general, Mark I containments are more likely to fail during a severe accident than the later Mark II and Mark III designs. However, the ranges of predicted failure probabilities are quite high for all BWR containment designs and there is significant overlap of the results, given core damage. A large variability also exists in the contributions of the different failure modes for each BWR containment group. However, plants in all three BWR containment groups found a significant probability of early or late structural failure, given core damage.
The commission has previously considered a subsidiary safety goal involving the frequency of containment failures that are accompanied by large releases of radioactivity. The goal was tentatively set at $10^{-6}$ per reactor year. However, the commission abandoned this goal due to difficulties in achieving consensus on an appropriate definition of a large release. An alternate subsidiary safety goal of an average CCFP of 0.1 is still being considered. It is not clear whether the CCFP goal should include all containment failures or only early failures and bypass. Figure 4.2-3 shows that few plants meet this goal if all failures are considered, and most of the BWRs do not meet the goal even for early failures and bypass. No new specific actions to deal with BWR containments, based on IPE findings, are being planned as of mid 1997. Low core-damage frequencies for BWRs provide partial justification for a lack of action.

More recently, the staff has been considering a return to a large release goal. As discussed in Section 2.6, a large early release frequency of $10^{-5}$ per year has been proposed as part of the risk-informed regulation initiative. Note that, if this approach is implemented, there will not be a direct measure of containment performance as part of the decision criteria. That is, a plant could meet the numerical goal with a low core-damage frequency and a poor containment. However, qualitative consideration of defense-in-depth is intended to assure that containment performance is not neglected entirely.

\subsubsection{Containment Venting Strategies}

Containments are somewhat unusual in that they are pressure vessels without safety relief valves. Thus, if containment heat removal is lost, there is no designed-in feature to prevent structural failure. Most 
containments have penetrations that could conceivably be used to vent the containment and relieve pressure. These penetrations include the lines used for leak rate testing, among others. However, most plants do not have procedures for venting during an accident. There are several reasons for this, including the belief that it is unnecessary, the requirements for $\mathrm{AC}$ power for valves, the desire to avoid guaranteed release of radioactive materials, and the potential hazards to personnel involved in the venting process.

Recently, utilities with BWR Mark I and II containments have included venting in their emergency procedures. Venting can be particularly valuable for accident sequences involving the long-term loss of containment heat removal in Mark I and II BWRs. In these sequences, often referred to as TW sequences, core cooling is initially successful. However, the loss of containment heat removal leads ultimately to containment failure. After containment failure, the core cooling systems may fail as a result of the loss of net positive suction head or from the harsh environments due to steam in the reactor building. In some cases, core cooling may fail even before the containment fails. For some BWR plants, high containment pressure can cause the Automatic Depressurization System (ADS) valves to close, leading to the loss of low pressure injection systems. In others, the reactor core isolation cooling system will fail due to high turbine exhaust backpressure. Venting can prevent these problems.

The particular venting procedures vary widely from plant to plant, but include use of leak rate testing lines and lines to the standby gas treatment systems. These plants generally have several possible lines that can be used, ranging in size from two inches to two feet in diameter. Generally, the venting is effective only for long-term loss of containment heat removal sequences. Venting can not occur fast enough to relieve pressure rises from energetic events, such as steam explosions or hydrogen burns. Venting is generally not possible during station blackout, due to the requirements for $\mathrm{AC}$ power to open the vents and is not adequate to handle the steaming rate from an Anticipated Transients Without Scram (ATWS) event.

As discussed in Section 4.1, vent lines from the containment are available in Mark I and II BWRs. Venting is possible from either the wetwell or drywell; however, venting from the wetwell is advantageous, because any radionuclide releases can still be scrubbed through the suppression pool. Thus, such venting is more attractive for BWRs than for other designs. A possible negative effect is that venting may lead to a saturated suppression pool, causing loss of net positive suction head to some pumps. At some plants, the procedures call for cycling the vent valves to prevent this loss of net positive suction head.

At some plants venting occurs through strong piping. However, in others the venting may involve ductwork and relatively weak gas flow paths. If venting occurs at high containment pressure, this ductwork will fail, releasing steam and possibly hydrogen and noble gases into the reactor building. These gases may lead to failure of safety equipment in the reactor building and exacerbate the accident. As a result of these concerns, the NRC has reached agreement with owners of Mark I containments to develop procedures for venting only through hardened piping to alleviate this concern. ${ }^{5}$

A final note concerns venting as it relates to emergency response. Current procedures for 
venting do not attempt to coordinate venting strategies with orders to evacuate. Venting at the wrong time, particularly from the drywell, could conceivably lead to significant releases at the time when the public is moving out onto the roads and is most vulnerable. However, when appropriately used, venting can be an effective measure to release gases from containment via the most desirable pathway if releases are inevitable. Stated another way, early releases of steam, hydrogen, and heated atmosphere and perhaps fission product noble gases may very well preclude a later uncontrolled and high pressure-driven release of atmosphere charged with radioactive aerosols.

The remaining sections in Module 4 discuss some of the specific phenomena that can challenge containments during a severe accident. 


\section{Table 4.2-1 Containment threats according to time regime}

\begin{tabular}{c|c}
\hline Time Regime & Challenge \\
\hline Start of the Accident & $\begin{array}{c}\text { Pre-existing Leak } \\
\text { Containment Isolation Failure } \\
\text { Containment Bypass }\end{array}$ \\
\hline Prior to Vessel Breach & $\begin{array}{c}\text { Reactor Coolant System Blowdown } \\
\text { Insufficient Containment Heat } \\
\text { Removal } \\
\text { Hydrogen Combustion } \\
\text { Lt or Soon After Vessel Breach }\end{array}$ \\
& Steam Spiks \\
\hline Late $>2$ Hours After Vessel Breach) & Combustion \\
& Direct Containment Heating \\
& Debris Contact with Containment \\
\hline & Non-condensible gas generation \\
& Basemat Meltthrough \\
\hline
\end{tabular}



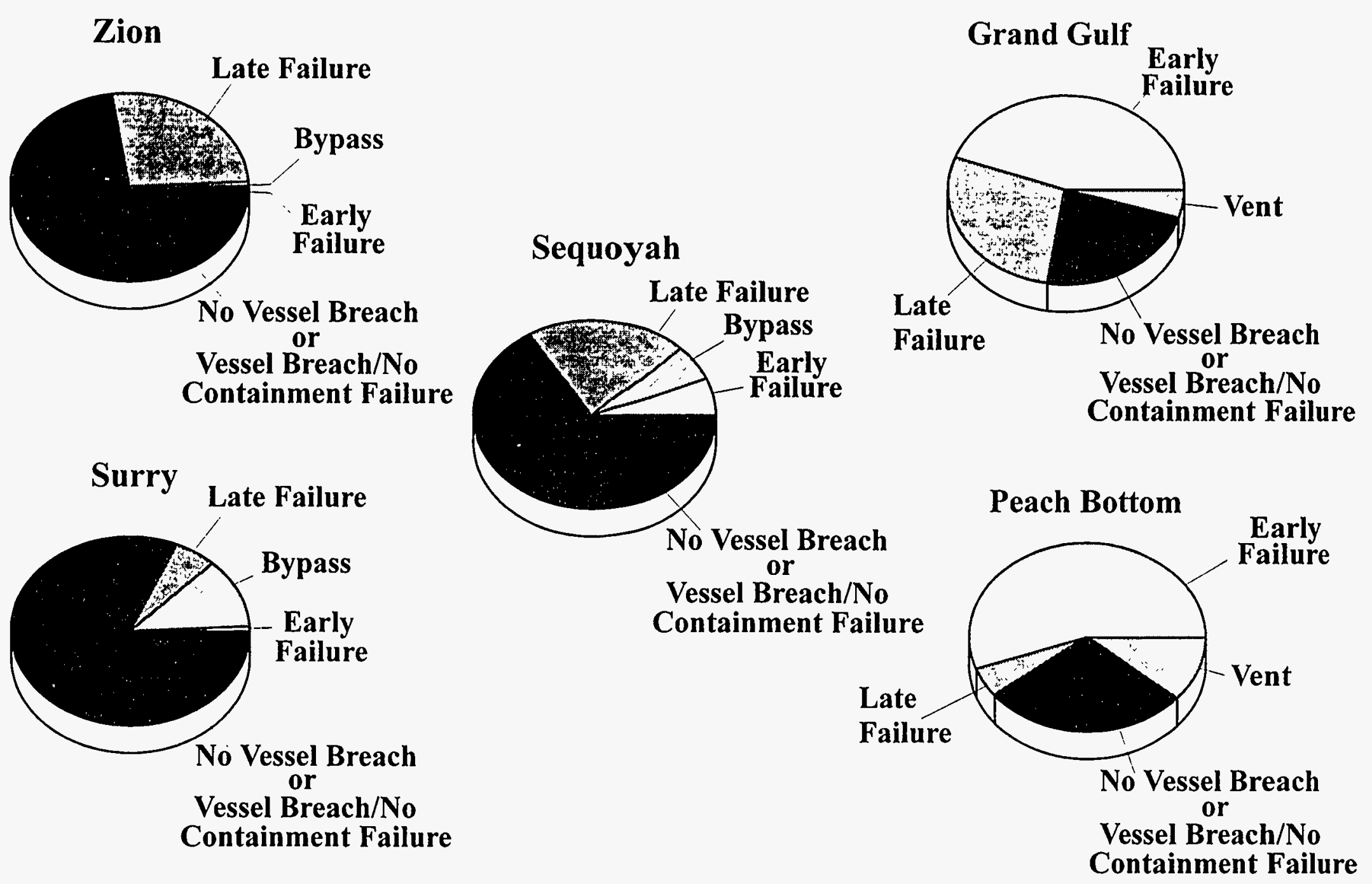

Figure 4.2-1 Relative probability of containment failure modes (internal events from NUREG-1150) given core damage 


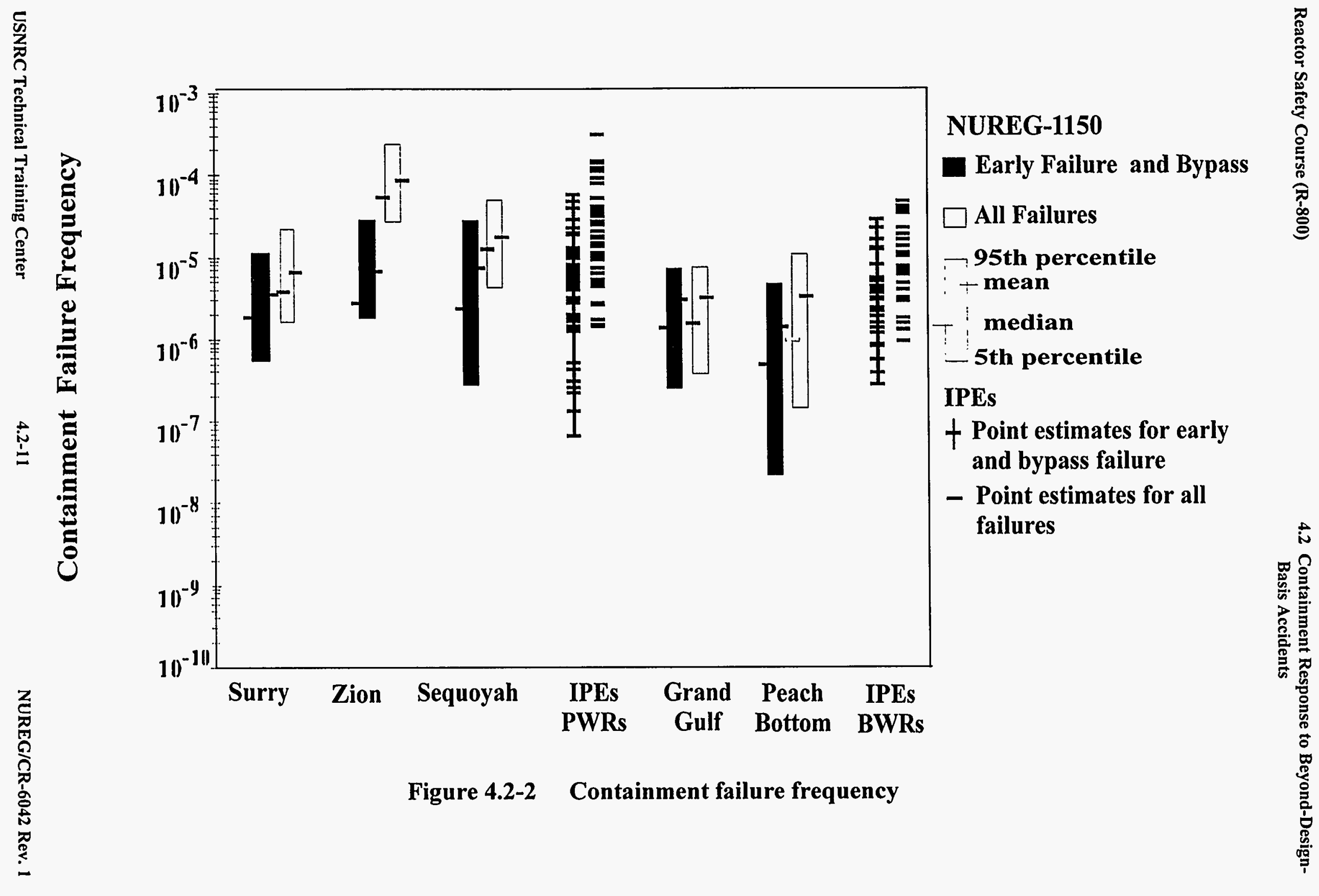




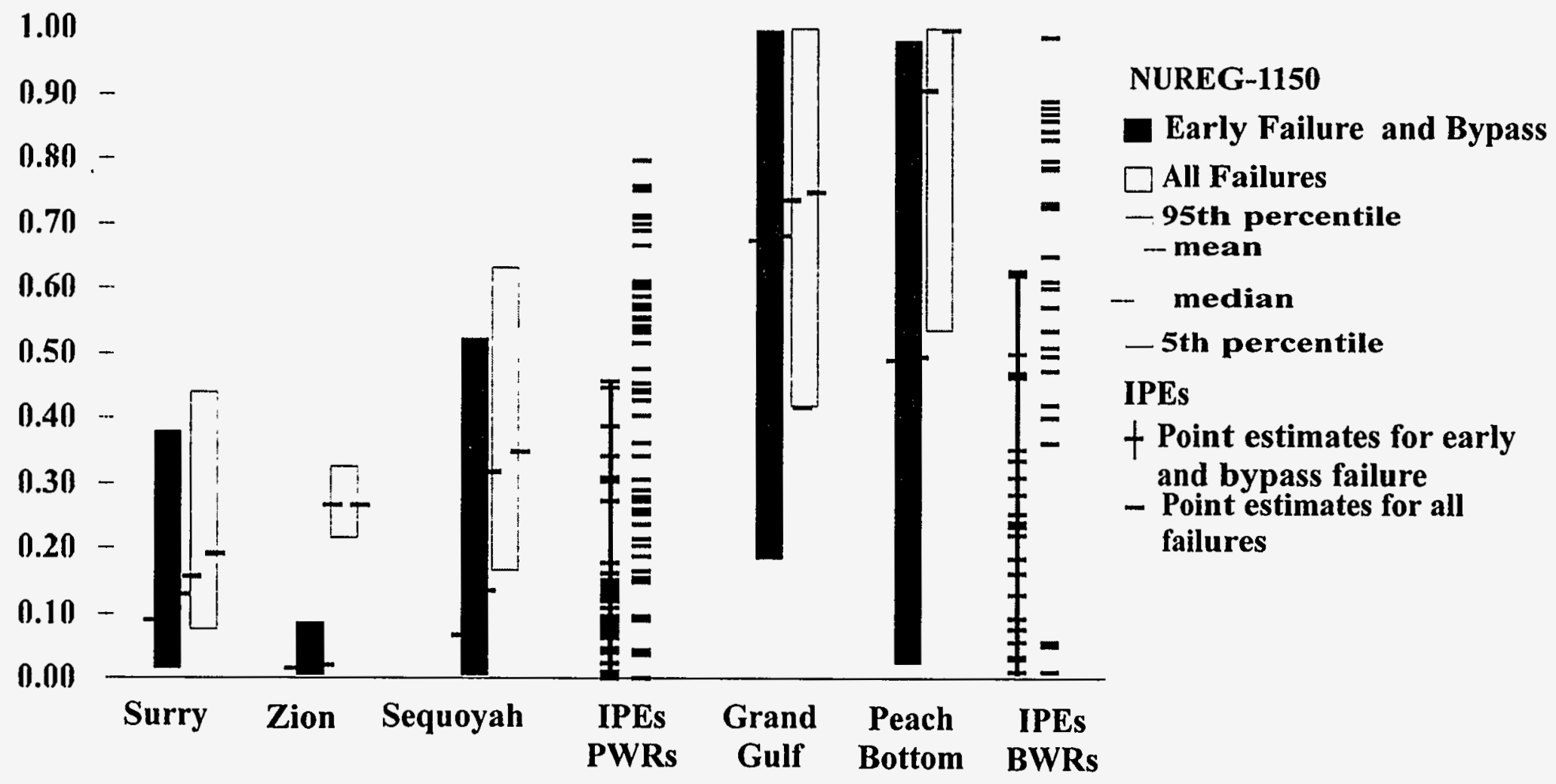

Figure 4.2-3 Conditional containment failure probability (internal events) 


\section{References for Section 4.2}

1. David Okrent, "Nuclear Reactor Safety: On the History of the Regulatory Process," The University of Wisconsin Press, Madison, Wisconsin, pp. 99-101, 1981.

2. U.S. Nuclear Regulatory Commission, "Reactor Safety Study: An Assessment of Accident Risks in U.S. Commercial Nuclear Power Plants," WASH-1400, October 1975.

3. U.S. Nuclear Regulatory Commission, "Severe Accident Risks: An Assessment for Five U.S. Nuclear Power Plants," NUREG-1150, December 1990.

4. U.S. Nuclear Regulatory Commission, "Individual Plant Examination Program: Perspectives on Reactor Safety and Plant Performance," NUREG-1560, Part 1, Volume 1, Draft for Comment.

5. Generic letter 89-16, Installation of a Hardened Wetwell Vent, September 1, 1989. 


\subsection{Ex-Vessel Fuel-Coolant Interactions}

For some plants and particular accident situations, water will be present underneath the reactor vessel when the molten material exits the vessel at the time of failure. In other cases, water may be added on top of the molten material subsequent to vessel failure. It is generally considered axiomatic that water addition is always a good thing in a reactor accident. While current guidance to operators is always to add water, it is important to note that there are several different possible outcomes when molten core debris contacts water, and only some of these outcomes are desirable:

1. The water may act to cool and quench (refreeze) the molten core debris, and may limit the spread of molten core across the containment floor.

2. The debris may form a molten pool under the water, probably with an overlying crust layer, and remain molten.

3. An energetic fuel-coolant interaction may occur.

Each of these possibilities is discussed in more detail below.

\subsubsection{Quenching of Core Debris}

Quenching and continued cooling of the core debris is generally the most desirable outcome. When the debris is solidified, the release of radioactive materials from the debris is effectively terminated. The most significant detrimental effect of quenching is the generation of large quantities of steam, which causes a pressure spike in the containment atmosphere. For the most part, a steam spike will not directly be a threat to the containment unless other phenomena occur simultaneously or the containment is already pressurized significantly prior to the steam spike.

Figure 4.3-1 depicts the quenching process for a PWR. The process involves energy transfer from the molten core debris to liquid water. The molten debris gives up latent heat of fusion plus sensible heat in cooling down to a near-equilibrium temperature. Oxidation energy will be involved if there are unoxidized metals present in the melt. The energy transferred to the water will heat the water to saturation and produce boiling sufficient to the available energy. The steam generated will then enter the containment atmosphere, causing a pressure increase. The speed of the quenching process depends upon how well the molten core mixes with water, the debris particle sizes, and the geometry of the mixture. The quenching process may be very rapid or take many minutes, depending upon these factors.

A calculation was performed for a station blackout sequence in the Zion large dry containment, considering the complete and rapid quenching of an entire molten core, along with $30 \%$ oxidation of the available metals. ${ }^{1}$ This quenching process would yield approximately 268 Million Btu $(283,000 \mathrm{MJ})$ of energy, and would produce a pressure spike of about 35 psig $(240 \mathrm{kPa})$. Figure 4.3-2 shows the pressure in the Zion containment that could result from this accident sequence, assuming that the entire core is dropped into a reactor cavity full of water at about 14,000 seconds. The total containment pressure approaches 90 psig $(620 \mathrm{kPa})$ as a result of the combined effects of prepressurization prior to vessel breach, vessel blowdown at vessel breach, and the 35 psi $(241 \mathrm{kPa})$ pressure rise resulting from the quenching in the reactor cavity. Two different quenching times are shown in Figure 4.3-2, corresponding to one minute and one hour. Without operating containment heat removal systems, the two 
different times produce similar containment pressure rises. The longer time available for heat transfer to structures is somewhat offset by the continued addition of decay heat.

In reality, quenching the debris will usually result in pressures much less than those indicated in Figure 4.3-2. First, it is extremely unlikely that all of the core debris will be involved in one large steam spike. Most models of accident progression indicate that a significant fraction of the core will remain in the vessel and be released slowly over a long time period. Second, there must be sufficient water available to participate in the quenching process. In the example shown, there was a completely full reactor cavity. Even if sufficient water is initially present, some of the water may be blown out of the reactor cavity before it can contact the core debris, possibly resulting in debris that is not quenched.

Subatmospheric containments will respond to steam spikes in much the same manner as large dry containments. There is general agreement that other containment types are even less susceptible to steam spikes due to their pressure suppression design. ${ }^{1}$ While not designed specifically for steam spikes at vessel breach, suppression pools and ice condensers can readily handle such loads, provided that the water or ice has not been depleted prior to the event. Note that, after the debris quenches, a continuing water supply and long-term heat removal are still necessary in most cases to remove the decay heat that can gradually pressurize the containment.

\subsubsection{Non-Coolable Debris}

There are some cases in which core debris may not quench or, if quenched, may subsequently form a rubble bed that is noncoolable. Cooling of core debris requires that the debris remain in contact with water, to allow boiling heat transfer to carry away the decay heat. Two mechanisms that can prevent this contact are debris bed dryout and crust formation. As discussed in Module 3, the vapor that flows up out of the debris bed can provide resistance to overlying and surrounding water that is needed to permeate the debris bed. If the resistance to water is sufficient, parts of the bed may dry out, leading to continued melting and possible core-concrete attack. Figure 4.3-3 depicts the mechanisms contributing to debris bed dryout.

As discussed in Module 3, the key factors affecting debris bed dryout are the particle sizes and the geometry (porosity) of the debris bed. Mixed particle sizes, particularly with smaller particles and deeper debris beds, tend to be less coolable than shallow debris beds composed of large particles. With smaller particles, the surface area for heat transfer is larger, and therefore, the vapor generation rates are increased relative to water ingress rates. Many particle sizes are possible during a severe accident, ranging from 0.01 inches $(0.025 \mathrm{~cm})$ or less up to inch size and larger. There is no one exact particle size that provides a threshold for coolability. However, particle sizes of a tenth of an inch $(0.25 \mathrm{~cm})$ and smaller are the ones most likely to be non-coolable. Such small particles can form during energetic melt ejection from the vessel or as a result of energetic fuel-coolant interactions (discussed in the next subsection).

In addition to debris bed dryout, there is a second possibility for non-coolable core debris. If a molten pool is contacted by an overlying water pool, a crust may form, preventing the further contact of water with the melt. In this case, core-concrete attack may continue unabated, as discussed in Section 4.4. 
With non-coolable core debris, any boiling that does occur will not rapidly affect the containment pressure, and can generally be neglected, unless a sequence involves loss of all containment heat removal for many hours or even days. Because some of the decay heat goes into the core-concrete attack as opposed to the containment atmosphere, this case actually produces less of a long-term overpressure threat from steaming than the case where the debris is quenched. The threats from core-concrete attack and combustible (and other non-condensible) gas generation may more than offset the benefits of reduced steaming and are discussed in more detail in later sections.

\subsubsection{Ex-Vessel Steam Explosions}

The largest threat to containment resulting from the ex-vessel interaction of molten core debris and water is an energetic ex-vessel fuel-coolant interaction (steam explosion). An ex-vessel steam explosion is simply an extreme case of a steam spike where the quenching occurs explosively and produces dynamic as well as static pressures. An exvessel steam explosion can threaten the containment in several different ways, including:

1. generation of dynamic pressure loads (shock waves) that can fail the containment structure,

2. generation of pressures and shock waves that can fail vessel support structures, leading to movement of the vessel and failure of containment piping penetrations,

3. generation of energetic missiles that can be thrown into the containment, or

4. generation of pressures and shock waves that can fail the drywell floor of a BWR
Mark II containment or the drywell wall of a Mark III containment.

Generally, the second and fourth threats above are the ones of most concern, and generally more so for BWRs (and a few PWRs) because of the confined pedestal region and the impact of pedestal failure on the containment. Section 4.3.4 discusses the design-specific aspects of ex-vessel steam explosions in more detail. As with in-vessel steam explosions, there are many factors that contribute to the magnitude of any ex-vessel steam explosion. These include:

1. the amount of water available to participate,

2. the composition of the melt, including the amount of unoxidized metals that may react during the explosion,

3. cavity or pedestal region geometry, insofar as it may lead to confinement of the explosion or focusing of shock waves,

4. transmission of shock waves through a water pool,

5. pouring rate and contact mode, i.e., water on corium, corium on water, or jet ejection into water, and

6. fraction of the core participating.

The physical processes involved in steam explosions were described in Module 3. Those processes are similar for ex-vessel steam explosions, except that some of the initial conditions are different. The exvessel case will always be at low pressure, no higher than the containment failure pressure. Steam explosions tend to be more likely at low pressure. Second, the geometry is different, involving varying degrees of confinement. Third, there are three contact 
modes to consider. The corium may pour from the vessel into a water pool or water may be added on top of corium, not unlike some in-vessel scenarios, or the corium may be ejected from the vessel as a high pressure jet into a water pool.

The latter case is unique to ex-vessel conditions and results when the vessel fails at high pressure. Experiments indicate that some steam explosions are likely under these conditions, but the magnitude is largely unknown. If the initial mass exiting the vessel reacts, it may blow the water out of the cavity or pedestal region, resulting in less reaction of the later material. Because the jet is not all released instantaneously, it is likely that a fairly small fraction of the core will participate. However, significant challenges to containment and vessel supports are still possible, particularly if oxidation accompanies the explosion.

One potential benefit of an ex-vessel steam explosion is that the core debris may be dispersed in the containment, reducing the concerns of core-concrete attack, and possibly making the debris more coolable. On the other hand, the benefit of such an event depends on exactly where the debris ends up and the continuing availability of long-term containment heat removal, and the impact on fission product releases.

As noted in Module 3, rapid quenching of core debris, explosively or otherwise, can result in significant oxidation of any metals contained in the core debris. Hydrogen generated as a result of this oxidation can present a significant threat that will be discussed in later sections.

\subsubsection{Containment Design Considerations}

As noted above, there are many features that can impact the importance of ex-vessel fuelcoolant interactions. First and foremost, the presence of water is necessary for a fuelcoolant interaction to occur. In some scenarios, particularly for large dry PWR containments, the reactor cavity will be dry or nearly so. Generally, for large quantities of water to be present in the reactor cavity, the containment sprays must have operated or large quantities of water have been pumped out through a break in the reactor coolant system. Then, if the sump and floor design allows, some of this water will overflow into the reactor cavity. Ice condenser containments are more likely to contain water in the reactor cavity due to the melting of ice combined with other sources. In fact, ice condenser containments can be deeply flooded in the lower compartment, mitigating fission product releases, but also providing a transmission medium for shock waves.

In BWR containments, water is likely to be present under the vessel for most LOCAs. Transient sequences may have a relatively dry pedestal region if the drywell sprays have not been used, and there has not been significant prior leakage. Mark III containments are the most likely to have large amounts of water under the vessel as a result of water spilling over the weir wall from the suppression pool. However, all three BWR containment types are susceptible to failure of the vessel supports, with relatively small amounts of water present.

Figures 4.3-4, 4.3-5, and 4.3-6 depict typical pedestal regions for BWRs and point out some of the important vulnerabilities. As noted earlier, the Mark II containments are also susceptible to failure of the floor separating the drywell from the wetwell. Another factor for Mark II containments, resulting from the considerable design variation among the Mark II containments, is the possibility of corium flowing down the downcomers into the suppression pool, failing the downcomers with a steam explosion or as a result of meltthrough, thus 
leading to suppression pool bypass. One Mark II containment has downcomers located directly below the vessel, guaranteeing some flow into the downcomers.

For both BWRs and PWRs, if water is not present prior to vessel failure, then water may be pumped into the reactor coolant system at a later time and flow through the failed vessel onto the melt.

The relative containment failure probabilities from ex-vessel fuel-coolant interactions were assessed for the six containment types in the NUREG-1150 and LaSalle studies. ${ }^{2,3}$ These studies indicate that containment failure is very unlikely for the three PWRs examined. For the three BWRs, drywell failures from steam explosions contribute noticeably to the overall containment failure probabilities, particularly for the Mark I and Mark II designs. In contrast, most of the individual plant examinations (IPEs) performed by the utilities found ex-vessel fuel-coolant interactions to be unimportant contributors to the likelihood of containment failure. A few of the IPEs used NUREG-1150 as the basis for their analysis and produced similar results. 


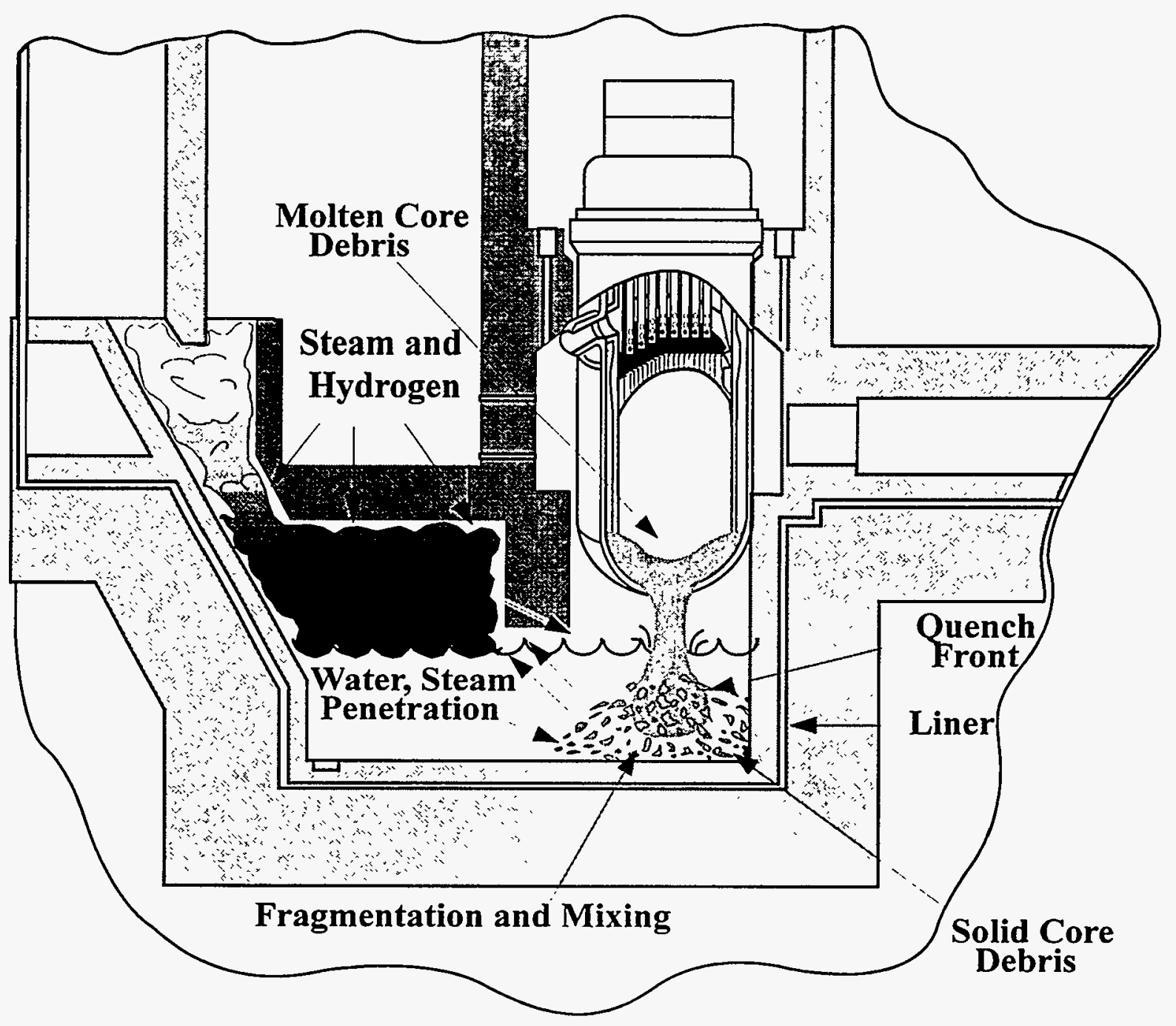

Figure 4.3-1 Molten core quenching process 


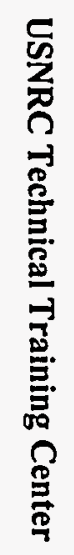

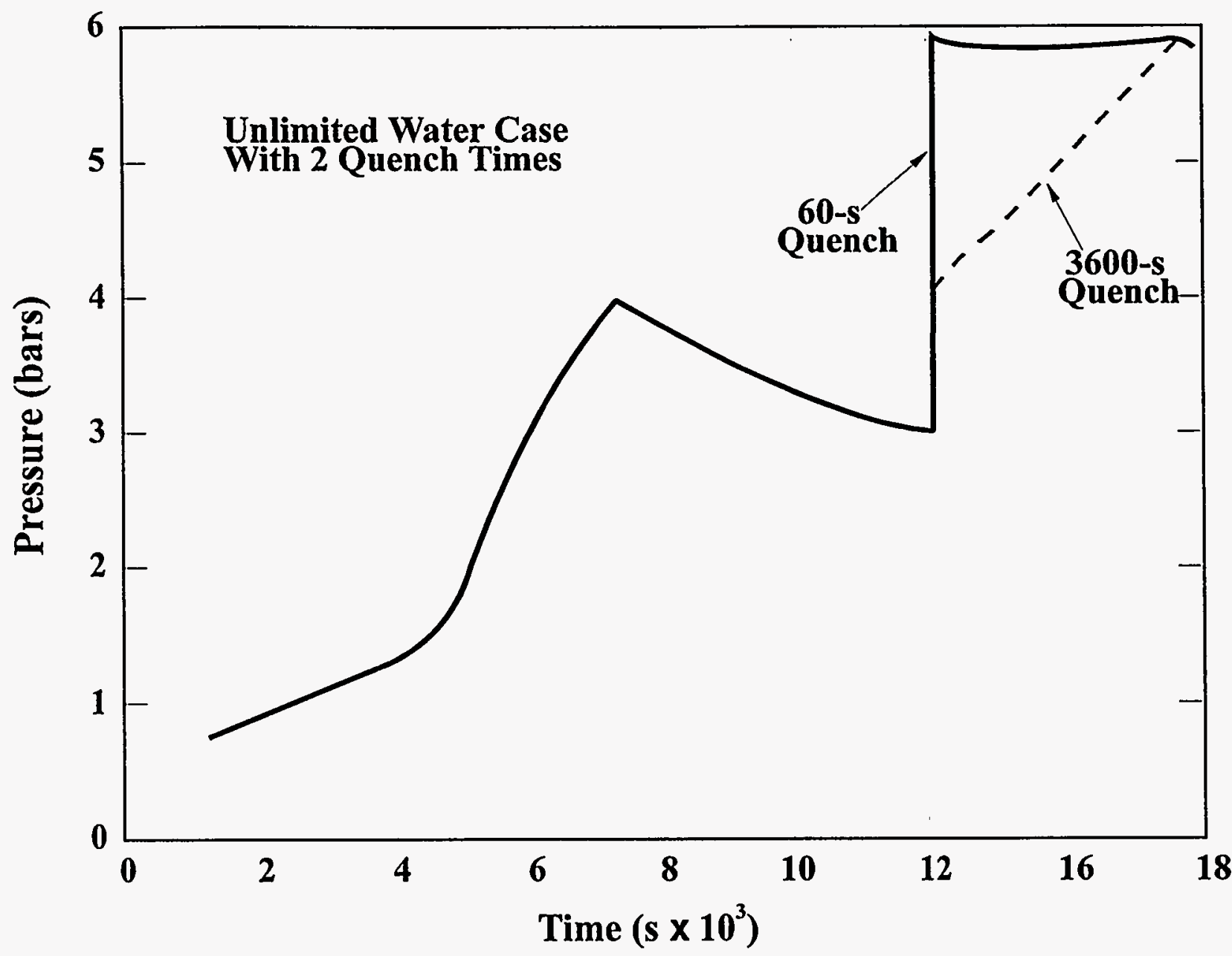

Figure 4.3-2 Containment pressure versus time for Zion station blackout sequence 


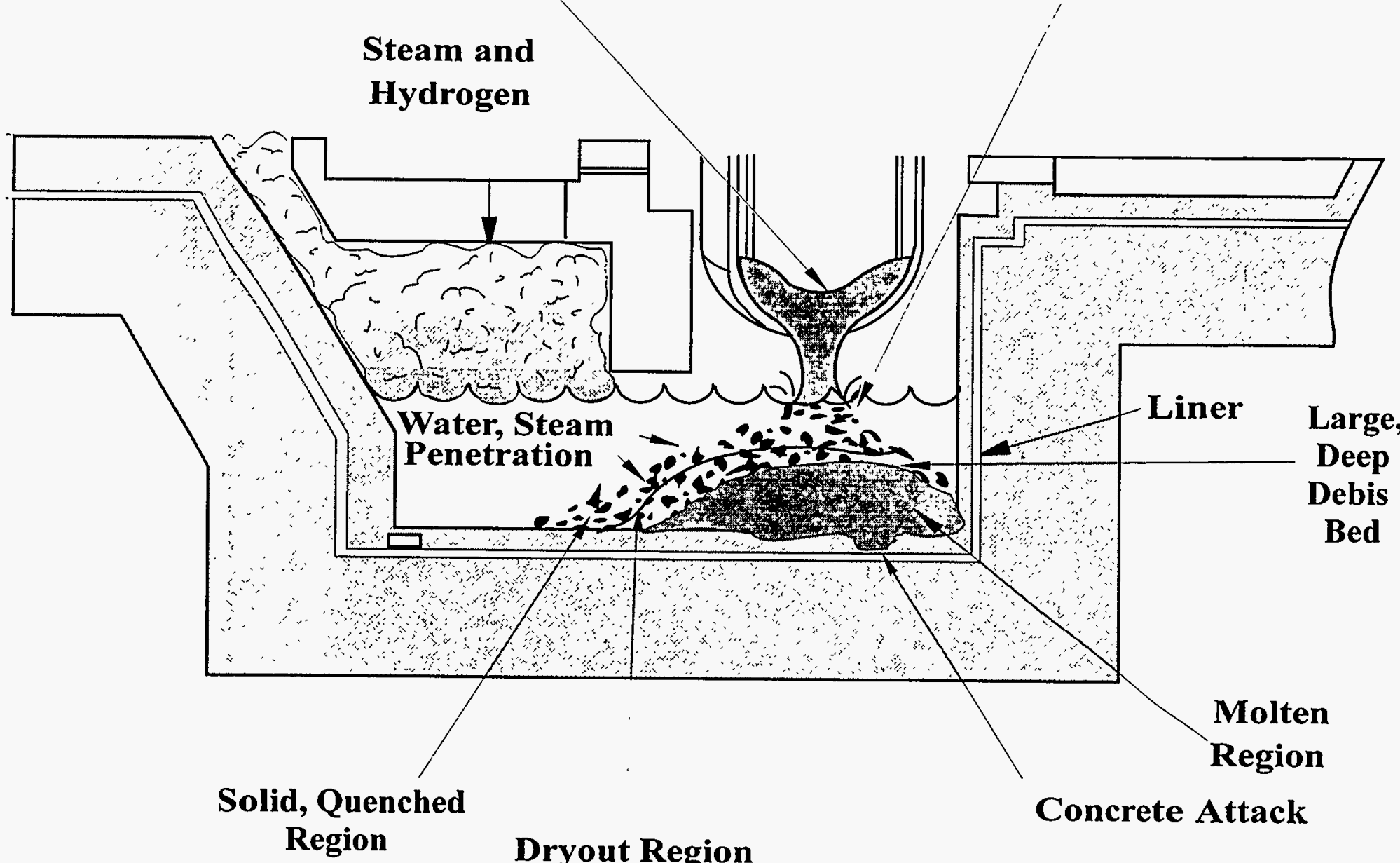

Figure 4.3-3 Non-coolable debris bed 


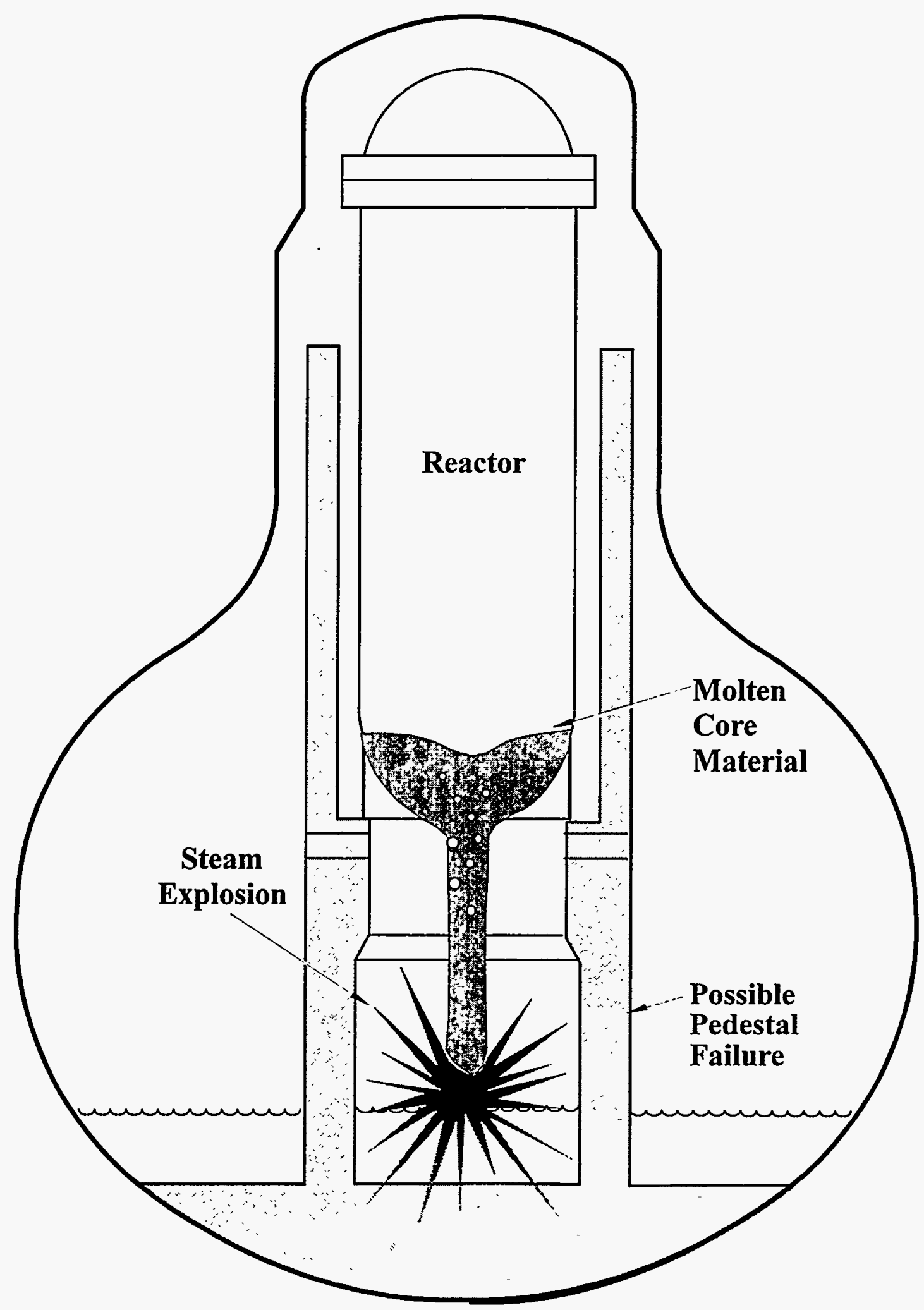

Figure 4.3-4 BWR Mark I containment pedestal region 


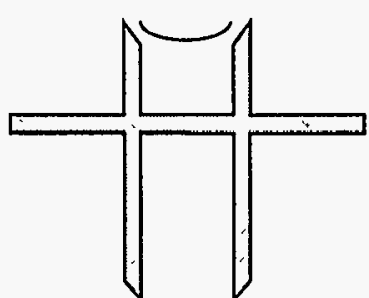

Limerick 1 \& 2

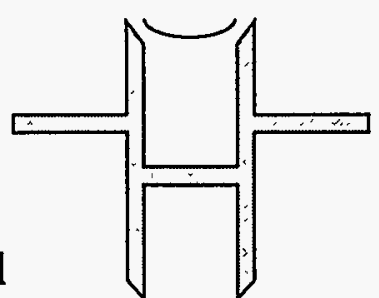

LaSalle $1 \& 2$

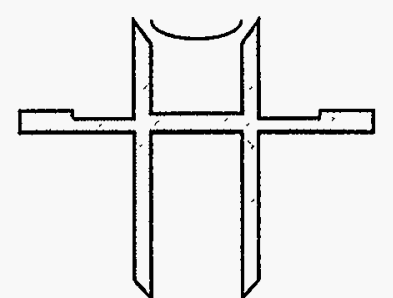

Susquehanna $1 \& 2$

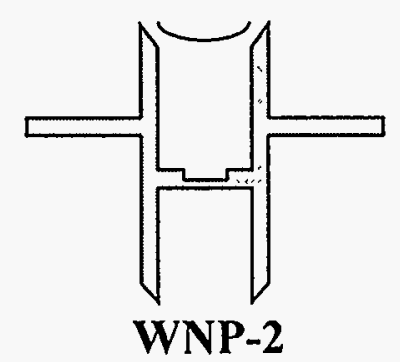

20

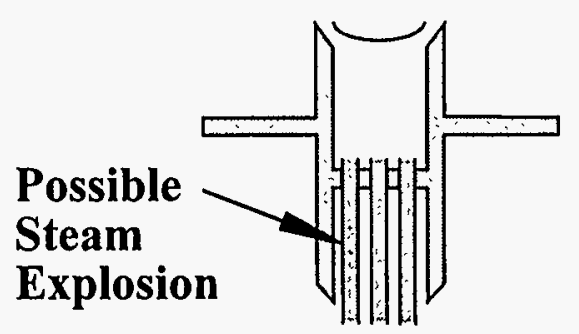

Nine Mile Point

Mark II Containment

Mark II Cavity Variations

Figure 4.3-5 BWR Mark II containment pedestal region 


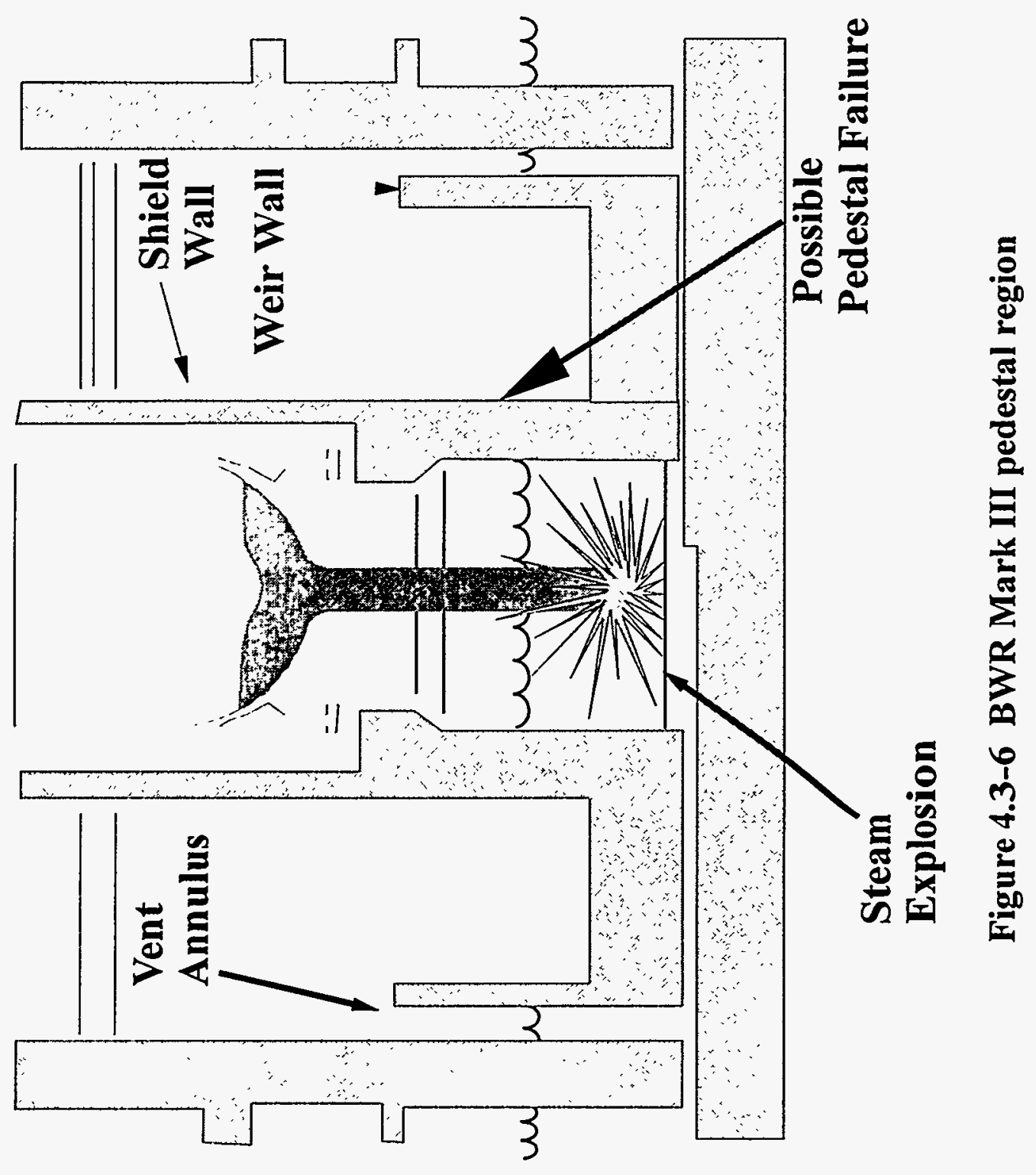




\section{References for Section 4.3}

1. U.S. Nuclear Regulatory Commission, "Estimates of Early Containment Loads from Core Melt Accidents," NUREG1079, Draft Report for Comment, December 1985.

2. U.S. Nuclear Regulatory Commission, "Severe Accident Risks: An Assessment for Five U.S. Nuclear Power Plants," NUREG-1150, December 1990.
3. T. D. Brown, et al., "Integrated Risk Assessment for the LaSalle Unit 2 Nuclear Power Plant: Phenomenology and Risk Uncertainty Evaluation Program (PRUEP)," NUREG/CR-5305, SAND902765, Sandia National Laboratories, 1992. 


\subsection{Core-Concrete Interactions}

If molten core material falls into the reactor cavity or pedestal region and is not blown out due to high pressure melt ejection or exvessel steam explosions, then Core-Concrete Interactions (CCIs) are possible. The possibility of CCIs leading to basemat meltthrough and containment failure was proposed by Brookhaven National Laboratory in reference to the China Syndrome. ${ }^{1}$ Numerous studies and experimental programs have since verified that basemat meltthrough is possible, although there are still significant uncertainties. Research has indicated that $\mathrm{CCIs}$ can also have other important effects in accidents, even when the basemat remains intact. In particular, combustible gas generation can occur and large quantities of aerosols can be generated, thus affecting the source term if the containment fails. In the subsections below, these topics are discussed in more detail. ${ }^{2}$

\subsubsection{Concrete Attack}

The most obvious concern about CCIs is the compromising of the containment structure. In addition to basemat meltthrough, CCIs can lead to failure of vessel supports and other local structures that can indirectly lead to containment failure. The ensuing discussions of concrete attack are intended to include all of these possibilities.

Most concrete used in reactor applications is either limestone, basaltic or a combination of limestone and common sand. Table 4.4-1 gives typical compositions for these three types of concrete. ${ }^{3}$ As shown in Figure 4.41 , the attack of concrete by corium is driven largely by thermal processes. Decay heat and some heat from chemical reactions (which may dominate for short periods of time) are generated in the molten pool and may be transferred to the top surface of the pool or to the surrounding concrete. Under most circumstances, the heat flux to the concrete is sufficient to decompose it, releasing gases and melting the residual materials which are primarily oxides and metal reinforcing bars. The melted materials are added to the molten pool, thus diluting it, increasing its surface area, and reducing the volumetric heat generation rate. In time, heat transfer out the top of the molten pool and through the surrounding concrete may be sufficient to remove the generated heat and the temperature will decline to the point at which the CCI is terminated. Typical CCIs can penetrate concrete at the rate of several inches (tens of $\mathrm{cm}$ ) per hour. Whether or not the CCI is terminated prior to basemat meltthrough is determined by many factors, including:

1. type of concrete and aggregate used in the structure,

2. basemat thickness,

3. cavity size and geometry,

4. melt mass in the cavity,

5. melt composition, and

6. presence of overlying water.

As noted in Section 4.3, the presence of an overlying water pool does not guarantee that the debris will be coolable. A crust may form over the melt, and heat transfer may be insufficient to remove all the decay heat from the melt. A number of experiments have shown minimal effect of water on concrete ablation rates. ${ }^{4}$ However, an overlying water can reduce fission product releases even if it does not cool the debris.

As its temperature increases, concrete begins to fail (lose its structural integrity) even 
before gross melting of its constituents occurs. The loss of structural integrity accompanies the release of water and carbon dioxide from the concrete in three phases: ${ }^{5}$

1. release of molecular and physically entrapped water between 86 and $446^{\circ} \mathrm{F}$ $\left(30\right.$ and $\left.230^{\circ} \mathrm{C}\right)$,

2. release of water chemically constituted as hydroxides between 662 and $932^{\circ} \mathrm{F}(350$ and $500^{\circ} \mathrm{C}$ ), and

3. release of carbon dioxide from the aggregate and the cementitious phases between 1112 and $1832^{\circ} \mathrm{F}$ (600 and 1000 ${ }^{\circ} \mathrm{C}$ ).

The point at which concrete loses its integrity varies with the type of concrete, but generally occurs as hydraulic bonds are eliminated and well before the carbon dioxide is released. Typical concrete contains about 4 to $9 \mathrm{wt} . \%$ water and 0 to 45 wt.\% carbon dioxide. Loss of structural integrity is particularly important when considering the possible impact of CCIs upon vessel supports in BWRs.

Figure 4.4-2 is an example calculation of concrete attack in the LaSalle BWR Mark II containment. ${ }^{6}$ The concrete at LaSalle is a mixture of limestone and common sand. In general, limestone concrete will ablate more rapidly than basaltic concrete. An important aspect of containment failure due to concrete attack is that, even if it occurs, one would expect that many hours would be available to initiate emergency response plans, including evacuation and sheltering, so that offsite health effects can be minimized.

\subsubsection{Gas Generation}

CCls result in the generation of large amounts of gases, some of which are combustible. Combustible gases are generated indirectly in a CCI. As shown in Figure 4.4-3, water and carbon dioxide are released from the concrete. When these gases rise through the melt they can react with unoxidized metals to produce metal oxides and the combustible gases hydrogen and carbon monoxide. As a result of complex reactions within the melt, the actual concentrations of hydrogen and carbon monoxide in the gases exiting the melt can vary significantly. It is likely that the flow of gases up through the melt will be nonuniform and that the melt itself will consist of layers of varying metallic content.

The total amount of combustible gas that can be formed as a result of CCIs is limited primarily by the amount of metallic constituents present in the melt, although some other reactions are possible that can slightly increase this quantity. The molten pool in the reactor cavity may contain large amounts of steel from the reactor vessel, below vessel structures, containment liner plate, concrete reinforcing bars, and other structures. As a result, the total quantity of combustible gas released from core concrete interactions can exceed that produced by $100 \%$ oxidation of all available zirconium, which is normally the limit for in-vessel hydrogen production.

Figure 4.4-4 shows examples of amounts of various gases that can be generated during core-concrete interactions ${ }^{4}$. Note that much more gas (primarily $\mathrm{CO}$ and $\mathrm{CO}_{2}$ ) is produced by limestone concrete than basaltic concrete. In any case, it is not inconceivable that a few thousand pounds (or kilograms) of combustible gases could be generated from CCIs. ${ }^{5}$

As the combustible gas exits the top of the melt, there are several possibilities. First, if there is an overlying water pool, the gases 
will cool before they pass into the containment atmosphere. Second, if there is no overlying water pool, the gases may spontaneously ignite above the molten corium. This spontaneous ignition requires high temperatures (supplied by the molten pool) and the presence of oxygen. Oxygen in the cavity will be rapidly depleted unless flow paths exist to circulate oxygen from the rest of containment. Spontaneous ignition can not occur in Mark I and II BWRs, which have inert containments. Combustion effects will be discussed in more detail in Section 4.6.

For Mark I and II containments, despite their inerted condition, gases from CCIs can still represent a concern. Because these gases are noncondensible, they can lead to significant pressure buildup that can not be removed using sprays or suppression pool cooling. This is why venting may ultimately be required to prevent long-term overpressure from these gases.

\subsubsection{Aerosol Generation}

In the absence of an overlying water layer, core- concrete interactions produce dense clouds of aerosols. Two processes produce such aerosols. First, volatile and semivolatile chemicals species including many fission products can be present in hot gases that bubble up through the melt. As these species emerge into and mix with the cooler atmosphere above the melt, they condense and become aerosol particles. Second, when gas bubbles emerge and burst at the surface of the melt, aerosols containing less volatile species are formed and entrained in the flowing gases. An overlying water pool can effectively remove most of the aerosols generated in CCIs, particularly the less volatile species.
In a severe accident, the radioactive and nonradioactive aerosols released from CCIs can significantly impact the concentrations of radionuclides in the containment atmosphere and, given containment failure, the quantities of radionuclides released to the environment. In general, generation of radioactive aerosols will increase the releases to the environment. In fact, the largest release fractions postulated in risk assessments are generally for accident scenarios involving core-concrete interactions with no overlying water pool in the reactor cavity. However, the generation of large quantities of non-radioactive aerosols can accelerate the agglomeration and gravitational settling of radioactive aerosols in the containment. Thus, if containment failure is delayed long enough, aerosol generation can actually reduce releases to the environment. Large quantities of aerosols, radioactive or not, have the potential to plug air filters that are not designed for such loadings.

Figure 4.4-5 shows example VANESA calculations of aerosol generation rates as a result of CCIs at three plants and for three different accident scenarios. ${ }^{7}$ The wide variations result from differences in melt composition and concrete type. These calculations do not account for any overlying water pools. This figure indicates the tremendous mass of material that can be suspended in the containment in the form of aerosols. Table 4.4-2 and Figures 4.4-6 and 4.4-7 indicate the types of materials that can be contained in the aerosols. Most of the mass is made up of concrete materials, such as $\mathrm{CaO}$ and $\mathrm{SiO}_{2}$. However, Table 4.4-2 and Figure 4.4-6 also show that significant fractions of fission products are released during CCIs. 
Table 4.4-1 Typical chemical compositions of concrete (wt.\%)

\begin{tabular}{cccc}
\hline Oxide & $\begin{array}{c}\text { Basaltic } \\
\text { Concrete }\end{array}$ & $\begin{array}{c}\text { Limestone } \\
\text { Concrete }\end{array}$ & $\begin{array}{c}\text { Limestone/ } \\
\text { Common Sand } \\
\text { Concrete }\end{array}$ \\
\hline $\mathrm{SiO}_{2}$ & 54.73 & 3.60 & 35.70 \\
$\mathrm{CaO}$ & 8.80 & 45.40 & 31.20 \\
$\mathrm{Al}_{2} \mathrm{O}_{3}$ & 8.30 & 1.60 & 3.60 \\
$\mathrm{MgO}^{2}$ & 6.20 & 5.67 & 0.48 \\
$\mathrm{Fe}_{2} \mathrm{O}_{3}$ & 6.25 & 1.20 & 1.44 \\
$\mathrm{~K}_{2} \mathrm{O}$ & 5.38 & 0.68 & 1.22 \\
$\mathrm{TiO}_{2}$ & 1.05 & 0.12 & 0.18 \\
$\mathrm{Na}_{2} \mathrm{O}$ & 1.80 & 0.08 & 0.82 \\
$\mathrm{MnO}$ & - & 0.01 & 0.03 \\
$\mathrm{Cr}_{2} \mathrm{O}_{3}$ & - & 0.004 & 0.014 \\
$\mathrm{H}_{2} \mathrm{O}$ & 5.00 & 4.10 & 4.80 \\
$\mathrm{CO}_{2}$ & 1.50 & 35.70 & 22.00 \\
\hline
\end{tabular}




\section{Table 4.4-2 Core-concrete release for Peach Bottom station blackout sequence}

\begin{tabular}{ccc}
\hline Species & $\begin{array}{c}\text { Released Mass }(\mathrm{kg}) \\
(1 \mathrm{~kg}=2.2 \mathrm{lb} .)\end{array}$ & Release Fraction \\
\hline Fission Products & 1.8 & 1.0 \\
\hline $\mathrm{I}+\mathrm{Br}$ & 27 & 1.0 \\
$\mathrm{Cs}+\mathrm{Rb}$ & 14 & 0.64 \\
$\mathrm{Te}+\mathrm{Sb}$ & 53 & 0.84 \\
$\mathrm{Sr}$ & $5.0 \times 10^{-4}$ & $2.0 \times 10^{-6}$ \\
$\mathrm{Mo}$ & $3.0 \times 10^{-4}$ & $9.0 \times 10^{-7}$ \\
$\mathrm{Ru}$ & 33 & $3.9 \times 10^{-2}$ \\
$\mathrm{La}^{(3)}$ & 4.3 & $1.0^{(4)}$ \\
$\mathrm{Nb}$ & 90 & $9.0 \times 10^{-2}$ \\
$\mathrm{Ce}+\mathrm{Np}+\mathrm{Pu}$ & 64 & 0.62 \\
$\mathrm{Ba}$ &
\end{tabular}

$\underline{\text { Steel }}$

$\begin{array}{lcl}\mathrm{Fe}^{(5)} & 1234 & 1.3 \times 10^{-2(6)} \\ \mathrm{Cr} & 6.6 \times 10^{-2} & 8.10^{-6} \\ \mathrm{Ni} & 29 & 6.2 \times 10^{-3} \\ \mathrm{Mn} & 89 & 0.50\end{array}$

Zircaloy

$\mathrm{Zr}^{(7)}$

0.55

$8.0 \times 10^{-6}$

$\mathrm{Sn}$

46

$5.0 \times 10^{-2}$

Control Material

Gd

17

$5.8 \times 10^{-2}$

Fuel

U

$2.0 \times 10^{-4}$

Concrete ${ }^{(6)}$

$\mathrm{CaO}$

$\mathrm{Al}_{2} 0^{3}$

1988

$\mathrm{Na}_{2} \mathrm{O}$

339

$2.9 \times 10^{-2}$

$\mathrm{K}_{2} \mathrm{O}$

82

0.14

0.74

$\mathrm{SiO}_{2}$

656

0.64

1124

0.21

(1) Based on melt inventory at start of core-concrete interaction.

(2) Includes $\mathrm{Tc}, \mathrm{Rh}$, and $\mathrm{Pd}$.

(3) Includes $\mathrm{Y}, \mathrm{Zr}$ (fp), $\mathrm{Pr}, \mathrm{Nd}, \mathrm{Pm}, \mathrm{Eu}$, and $\mathrm{Sm}$.

(4) Quantitative release is calculated because of the assumed oxide chemical form, which is under review.

(5) Includes $\mathrm{Fe}$ from concrete and reinforcing bars.

(6) Release fraction based on the amount of concrete and reinforcing bars incorporated into the molten pool.

(7) Structural $\mathrm{Zr}$ only. 


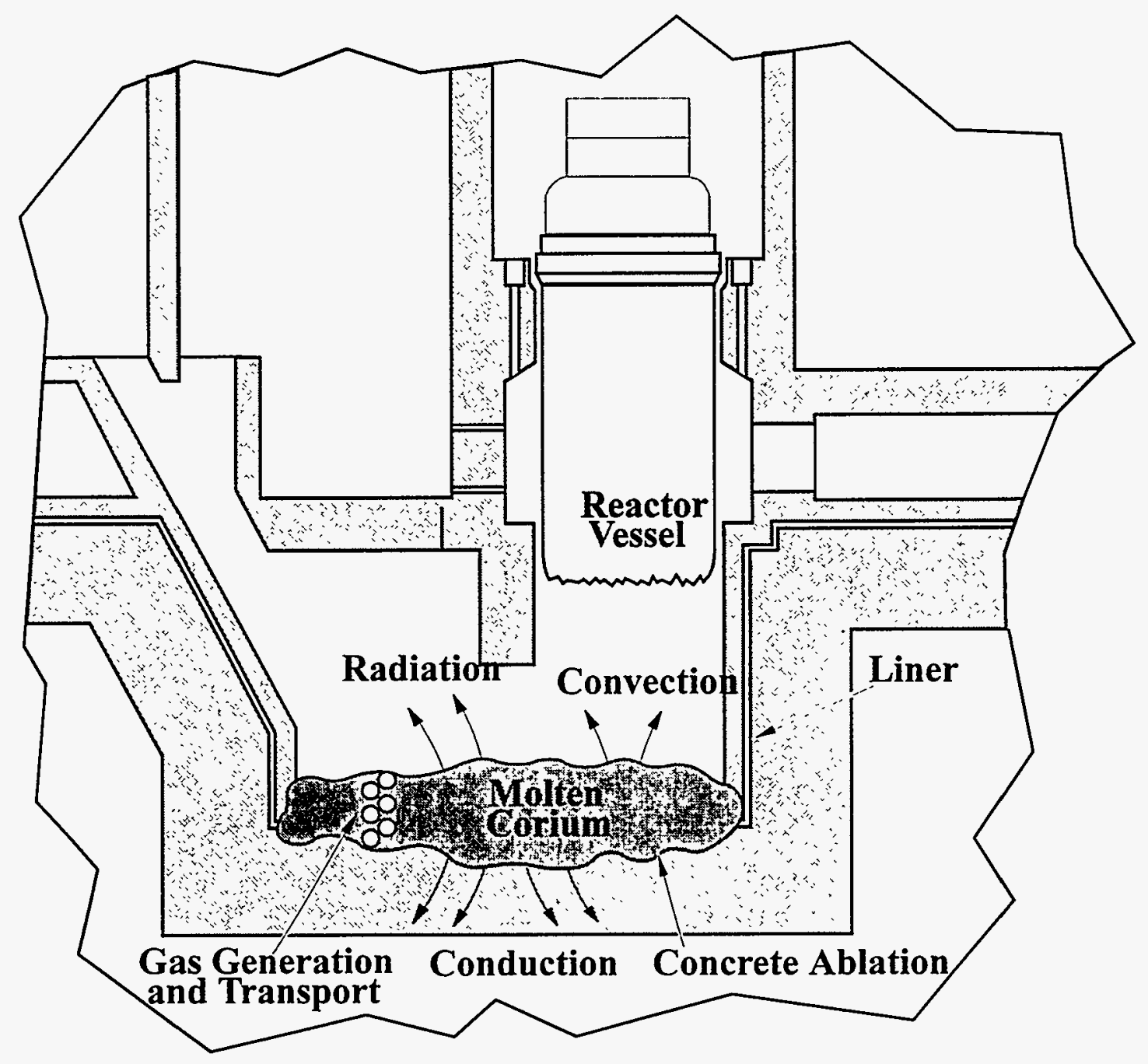

Figure 4.4-1 Thermal aspects of core-concrete interactions 


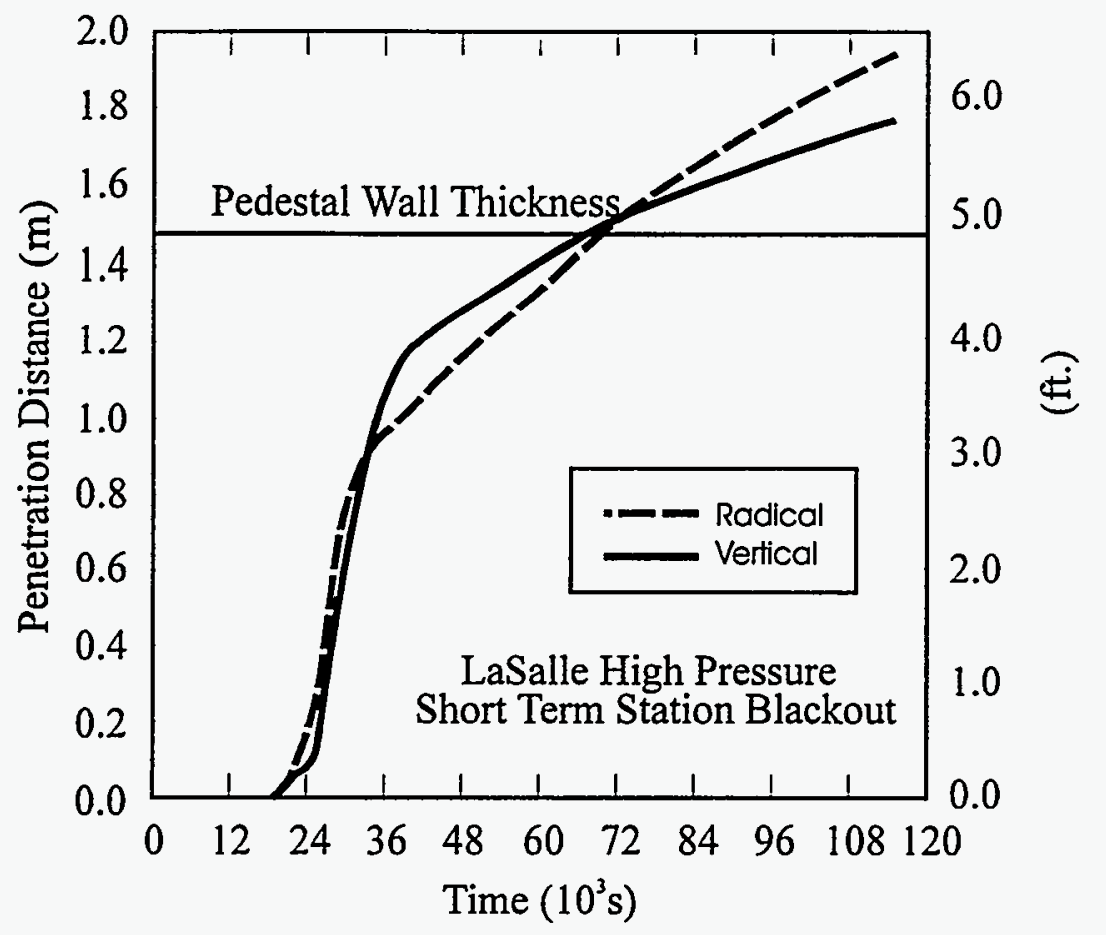

(ft.)

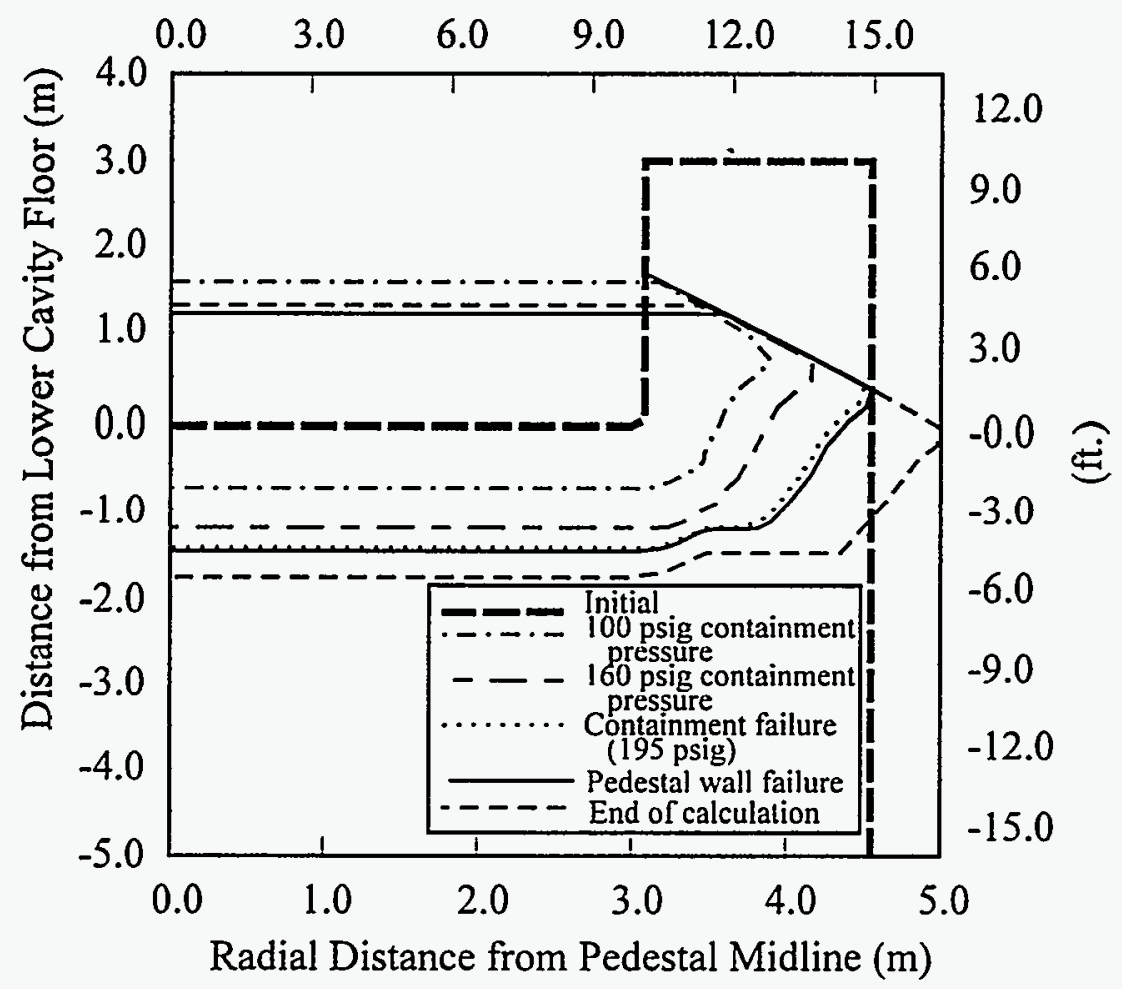

Figure 4.4-2 Calculations of concrete attack in a BWR Mark II containment during a station blackout sequence 


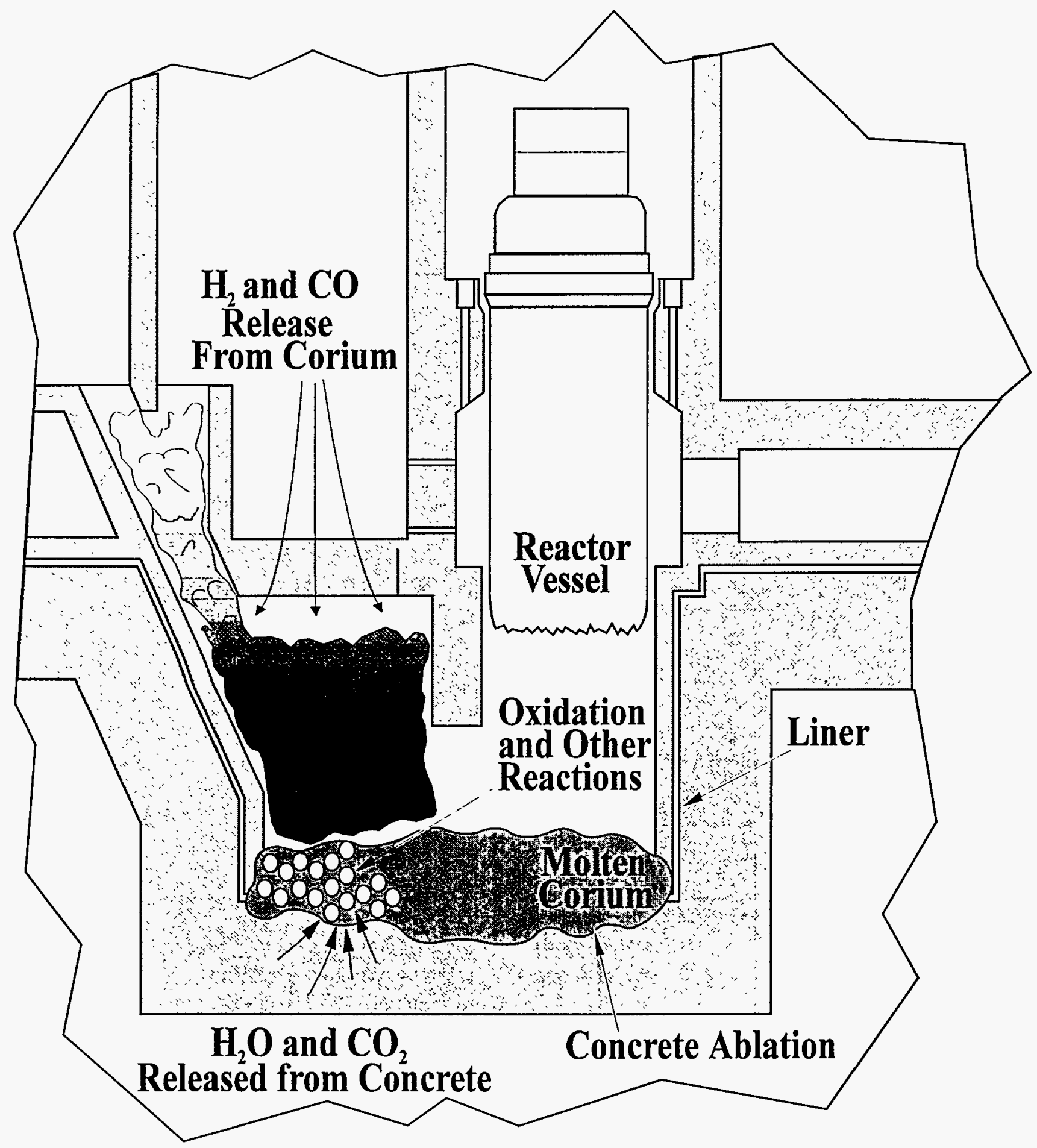

Figure 4.4-3 Combustible gas generation during CCIs 

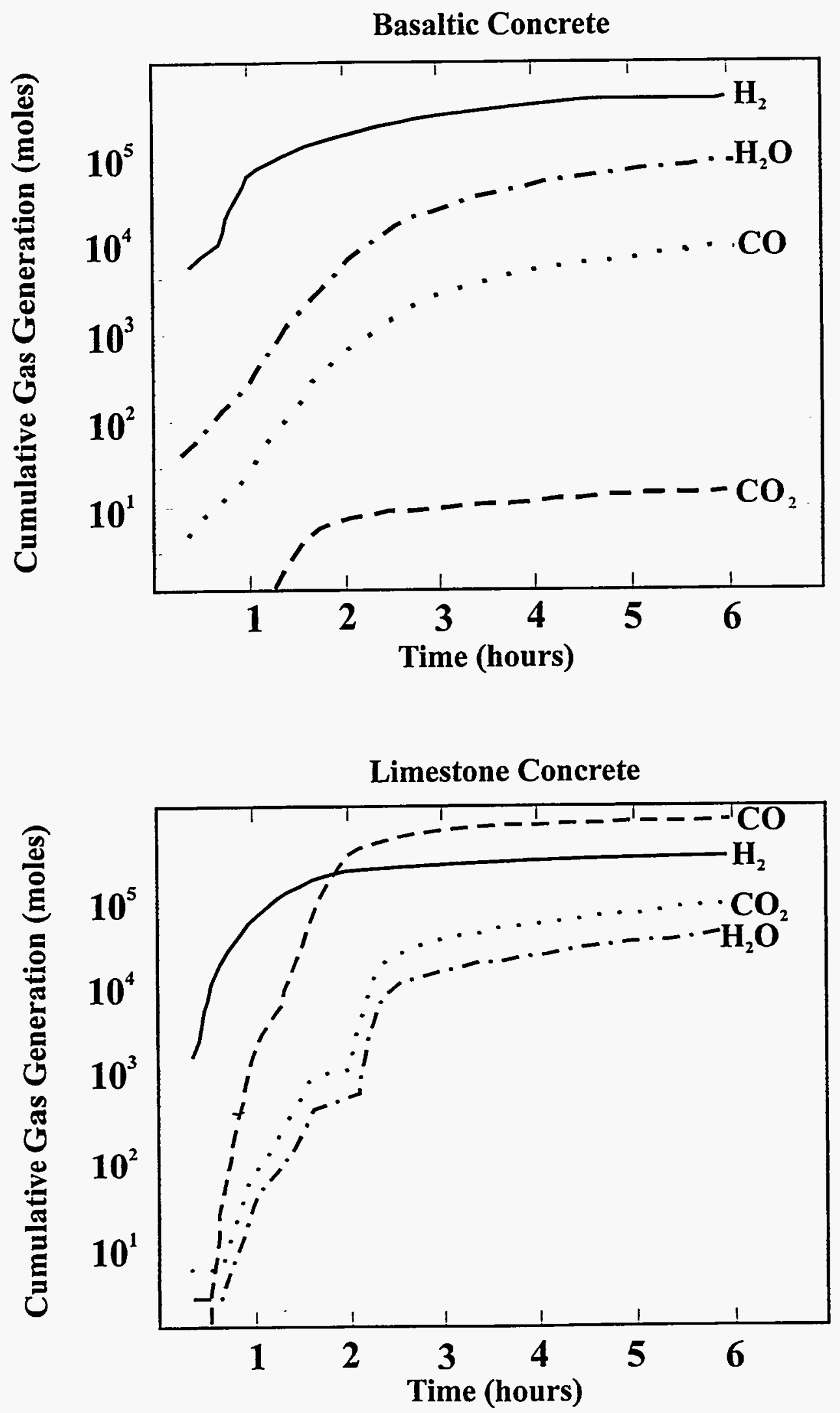

Figure 4.4-4 Example amounts of various gases that can be generated during core-concrete interactions 


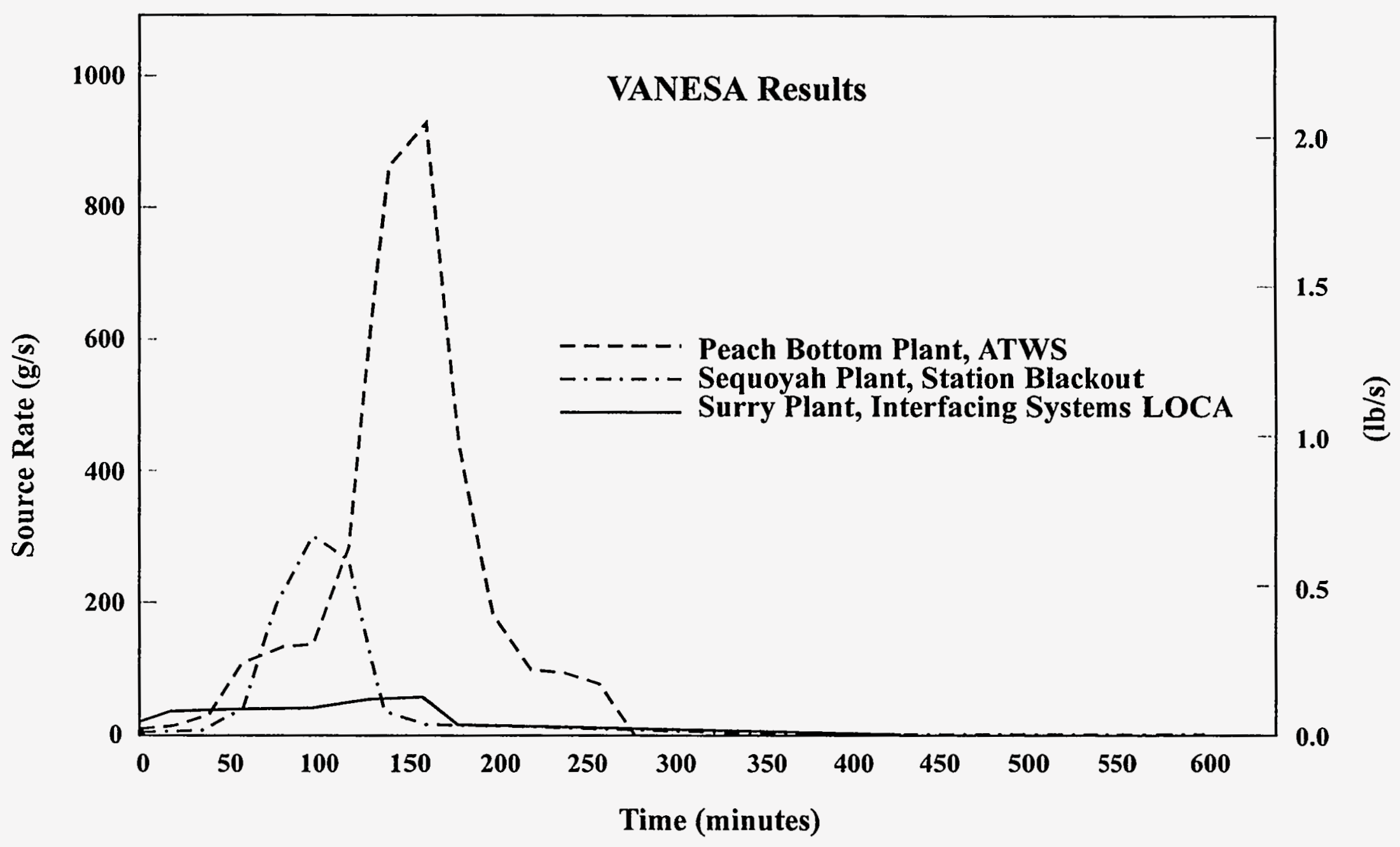

Figure 4.4-5 VANESA calculations of aerosol course rates 


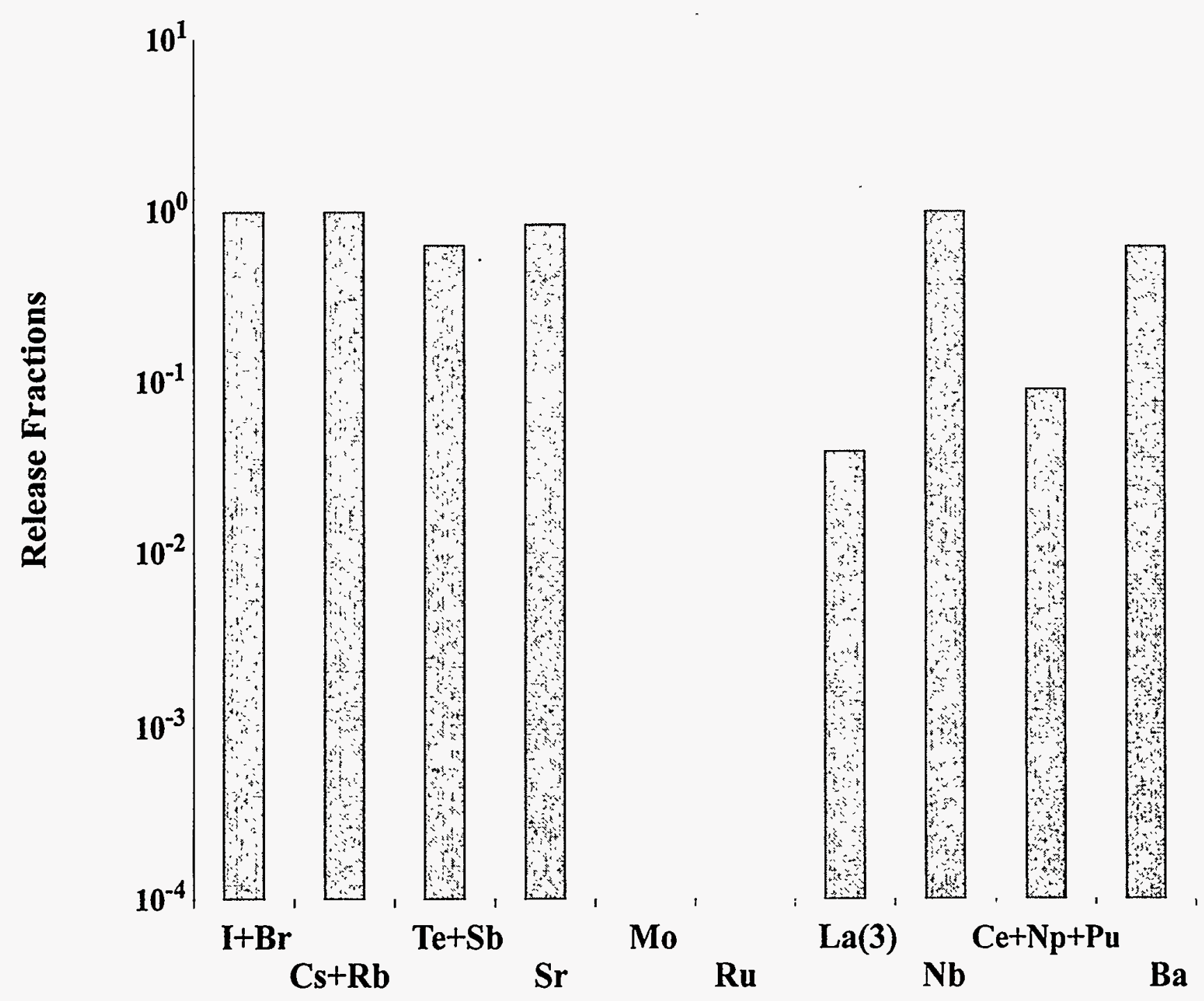

Figure 4.4-6 Peach Bottom station blackout, fission products released to drywell from core-concrete interactions 


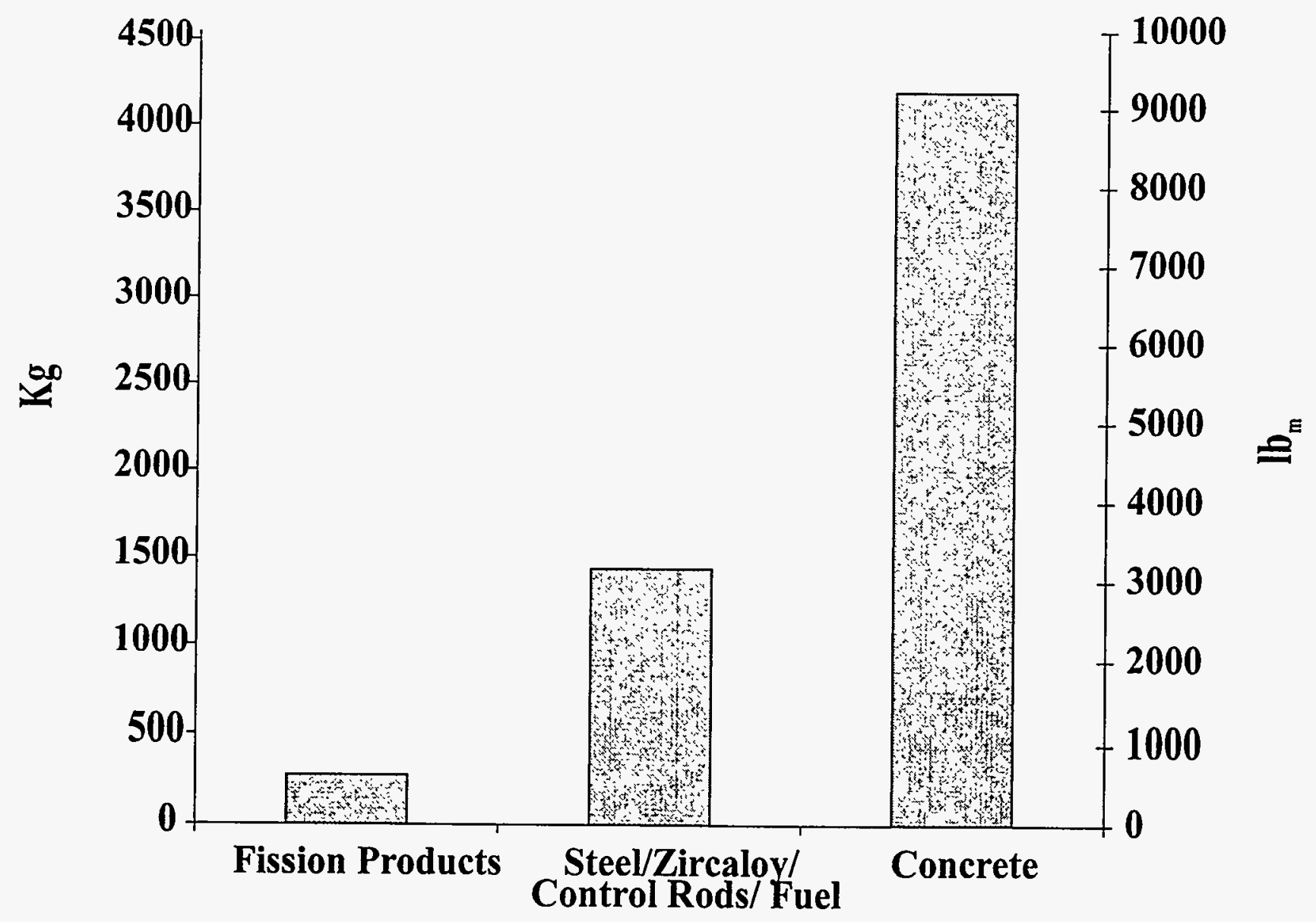

Figure 4.4-7 Peach Bottom station blackout, masses released to drywell from core-concrete interactions 


\section{References for Section 4.4}

1. ACRS Subcommittee Meeting.Minutes, June 3, 1966, reproduced in Okrent, pp. 99-101.

2. R. K. Cole, Jr., D. P. Kelly, and M. A. Ellis, "CORCON-Mod2: A Computer Program for Analysis of Molten-Core Concrete Interactions," NUREG/CR3920, SAND84-1246, Sandia National Laboratories, Albuquerque, NM, August 1984.

3. E. R. Copus and D. R. Bradley, "Interaction of Hot Solid Core Debris with Concrete," NUREG/CR-4558, SAND85-1739, Sandia National Laboratories, June 1986.

4. Reactor Safety Research Semiannual Report, July-December 1986, Volume 36, NUREG/CR-4805, SAND86-2752, Sandia National Laboratories, November 1987. (Note: an error was found on the first graph of the original figure. The labels for the $\mathrm{CO}$ and $\mathrm{Co}_{\mathrm{s}}$ plots were reversed.)

5. A. L. Camp, et al., "Light Water Reactor Hydrogen Manual," NUREG/CR-2726, SAND82-1137, Sandia National Laboratories, Albuquerque, New Mexico, August 1983.

6. C. J. Shaffer, L. A. Miller, and A. C. Payne, Jr. "Integrated Risk Assessment for the LaSalle Unit 2 Nuclear Power Plant: Phenomenology and risk Uncertainty Evaluation Program (PRUEP)," Volume 3: MELCOR Code Calculations, NUREG/CR-5305, 3 of 3, SAND90-2765, Sandia National Laboratories, Albuquerque, New Mexico, July 1992.

7. M. Silberberg, et al., "Reassessment of the Technical Bases for Estimating Source Terms," NUREG-0956, July 1986. 



\subsection{Direct Containment Heating}

A severe accident may progress with either high or low pressure in the reactor coolant system up to the point of vessel breach. Modules 2 and 3 discussed some of the accident scenarios that could involve high pressure at the time of vessel breach. When vessel failure occurs at a pressure of a few hundred psi (several hundred $\mathrm{kPa}$ ) or more, the melt will be ejected as a jet into the reactor cavity. What happens next depends upon the reactor vessel pressure, the cavity and containment design, the presence of water in the cavity, the amount of melt ejected and other factors. One possibility, discussed earlier, is that a steam explosion will result in the reactor cavity, if sufficient water is available. Another possibility is that some of the melt will be fragmented by jet breakup and swept out of the cavity into the containment where it will heat the atmosphere (direct containment heating [DCH]). The latter process can lead to very rapid and efficient heat transfer to the atmosphere, possibly accompanied by oxidation reactions and hydrogen burning that further enhance the energy transfer. The important phenomena are discussed in more detail below.

\subsubsection{Ejection of Melt from the Vessel}

The melt ejection process is depicted in Figure 4.5-1. When the vessel first fails, molten material will be ejected as a liquid stream (melt ejection phase). As the liquid corium level in the vessel drops, gas blowthrough will begin to occur, resulting in a two-phase mixture blowing down from the vessel. The noncoherence of the steam blowdown and melt ejection is predicted to have a large impact on the DCH loads, as discussed in Section 4.5.3. The high velocity expanding gas flow provides the motive force for entraining corium and ejecting it from the reactor cavity (gas blowdown phase).

Vessel failure may occur at a small opening, such as an instrument tube, or as a result of a larger rupture. The particular failure mode does not have a large impact during the melt ejection phase, but can be important for ex-vessel steam explosions or for the gas blowdown phase interactions discussed in Sections 4.5.2 and 4.5.3. The amount of material participating in an ex-vessel steam explosion and the nature of the explosion will be affected by the ejection rate (which depends on the opening size). Small amounts of molten material may result in small explosions that sweep water out of the cavity and preclude larger explosions. For Westinghouse PWR vessels, it has been estimated that the initial hole size could be approximately $1.3 \mathrm{ft}$. $(0.4 \mathrm{~m})$ in diameter for a thermally-induced rupture or about an inch $(0.03 \mathrm{~m})$ for ejection of an incore instrument tube. ${ }^{1}$ However, for the latter case the hole is expected to rapidly ablate to about the size of a thermally-induced rupture, so that the overall effect of the small initial opening size is minimal.

Along with the hole size, the amount and composition of molten material in the lower plenum of the vessel is an important factor. In some scenarios, vessel failure may occur early, when only part of the core is molten. Core material that has not relocated to the lower plenum will not contribute significantly to the direct heating process. Figure 4.5-2 shows an example estimate of the amount of material that may be ejected for given core melt scenarios in PWRs. ${ }^{2}$ The melt composition is also important. Melts rich in metal will tend to result in higher DCH loads because of the energy released when the metal is oxidized, and because of the energy released by combustion of any hydrogen produced by the reaction of steam with the metal. 
As part of the $\mathrm{DCH}$ resolution program, best estimate SCDAP/RELAP5 calculations were performed for representative reactors of all nuclear steam supply systems (PWRs) in the United States $3,4{ }^{*}$ : Zion (Westinghouse 4loop), Surry (Westinghouse 3-loop), Calvert Cliffs (Combustion Engineering), ANO-2 (Combustion Engineering), Oconee (Babcock $\&$ Wilcox lowered loop) and Davis-Besse (Babcock \& Wilcox raised loop). In all of these calculations, the melt composition was predicted to be predominantly oxidic at the time of vessel breach. This is consistent with observations from the TMI accident.

\subsubsection{Interactions in the Reactor Cavity}

When molten material is ejected into the reactor cavity at high pressure, there are a number of phenomena that are important to consider. The possibility of an ex-vessel steam explosion has already been identified. Additional phenomena that lead to fragmented debris that can be dispersed from the cavity are also important. These phenomena, depicted in Figure 4.5-3, include molten jet breakup, gas evolution and chemical reactions, and trapping of a portion of the jet before it can escape the cavity.

The presence of water in the reactor cavity could result in some quenched debris, thus partially mitigating the $\mathrm{DCH}$ threat.

However, experimental evidence indicates that the presence of water in the reactor cavity can be very detrimental, and a molten jet of material entering a pool of water will often appear to result in a steam explosion." With small levels of water, the experiments

-Resolution of the Direct Containment Heating Issue for all Combustion Engineering Plants and Babcock \& Wilcox Plants, NUREG/CR-6475, In Preparation.

"Memo from Richard Griffith to R. G. Gido, Sandia National Laboratories, May 11, 1992. show that the initial contact with molten debris produces a steam explosion that blows the remaining water out of the cavity, ending immediate debris-water interactions. Experiments with water-locked cavities have produced drastic steam explosions of sufficient magnitude to destroy the cavity itself. In addition to potential steam explosions, water can also provide an additional source of hydrogen by chemically reacting with unoxidized metals in the molten debris.

The particle sizes resulting from jet breakup affect the heat transfer and chemical reaction rates (by determining the available surface area), as well as particle transport within containment. At high RCS pressures, the dispersed melt is highly fragmented $(\sim 1 \mathrm{~mm})$ with a broad distribution of particle sizes. Extensive (thermal and chemical) interactions (near equilibrium) of melt with blowdown steam can be expected during dispersal. Figure 4.5-4 shows some estimated particle sizes that can result for given conditions.

Gas evolution from the melt can result in changes in the jet breakup, and can also significantly affect fission product releases.

The melt breakup process is likely to release most of the volatile materials and also allow formation of numerous radioactive aerosols, although these processes are not well understood. As the jet encounters water or steam (either from the blowthrough or as a result of water in the cavity), oxidation of any metals can occur, leading to rapid hydrogen production. Some experiments indicate that the gases exiting the reactor cavity can contain as much as $50 \%$ hydrogen during some phases of the blowdown."

As the high-temperature jet passes through the cavity, melt is entrained and swept out into the containment. The debris dispersal is noncoherent with the RCS blowdown; i.e., 
the melt is fully dispersed from the vessel and cavity long before blowdown is complete. Gases exiting the reactor cavity may have velocities of several hundred feet per second (hundreds of $\mathrm{m} / \mathrm{s}$ ) according to some estimates. ${ }^{3}$ As the melt is swept along, some of it impinges upon the cavity floor or walls. Significant erosion of concrete is not expected to occur because the melt will mostly splash off. Additional metal may enter the $\mathrm{DCH}$ process through two processes: incore instrument tubes, which pass through many cavities, may be ablated and dispersed from the cavity with the melt; and RPV insulation in the annulus around the RPV may be ablated and dispersed with the melt.

As the jet passes through the cavity, corium will bounce off of the walls, perhaps multiple times, as it is carried along by the gases. Ultimately, depending on the driving pressure, some fraction of the melt will be retained in the cavity and not enter the main containment. Particles may be trapped under a seal table or any other obstruction in the path of the jet, as long as the jet does not cut through the obstruction. Locations where the flow sharply changes direction may also collect debris. However, for all PWR reactor cavities examined to date, experiments have shown nearly complete dispersal of the debris at RCS pressures of interest. At low pressures, some cavity designs retain debris, but with the low RCS pressures, the availability of steam is more limiting to $\mathrm{DCH}$ loads ${ }^{1}$. Note that any trapped material may result in subsequent $\mathrm{CCI}$ within the reactor cavity.

Most reactor cavities can withstand the loads accompanying high pressure melt ejection (HPME). However, weaker cavities might be vulnerable to overpressure damage resulting from initial melt/water interactions (explosive or nonexplosive) or from high cavity pressures resulting from the dispersal process itself.

\subsubsection{Energy Deposition and Pressure Rise in Containment}

As core debris is swept out of the reactor cavity, it is transported throughout the containment. The degree to which the debris can be transported to the top of the containment affects the resulting pressure rise. In the lower regions of most PWR containments, the containment is highly subcompartmentalized. It is expected that significant quantities of the core debris will be trapped in these subcompartments before it can reach the upper regions of containment. This trapping may significantly reduce the predicted containment pressure rise. Some containments have a fairly open path around the reactor vessel to the upper containment. Melt can be dispersed upwards from the cavity through the annulus around the RPV into the refueling canal and upper dome. This is the dominant dispersal path in some Combustion Engineering plants. These containments will not benefit as much from the effects of subcompartments.

Suspended debris particles can rapidly transfer their energy to the containment atmosphere. Because of the small particle sizes, the total surface area for heat transfer is enormous. The amount of thermal energy available in a molten core was discussed previously in Module 3. This thermal energy can be transferred to the containment atmosphere through radiative and convective heat transfer. This heat transfer will be very rapid, with much of it occurring in a matter of seconds.

In addition to heat transfer, energy may be imparted to the containment atmosphere as a result of exothermic oxidation reactions involving metallic constituents in the core 
debris and either air or steam. The noncoherence of the steam blowdown and melt ejection limits the extent of these reactions, thereby reducing containment loads. The metal-steam reactions will result in the production of additional hydrogen. Hydrogen from these reactions plus hydrogen previously injected into containment may then burn, resulting in additional pressurization. The hot debris particles and the high temperatures of the exiting gases may lead to some hydrogen combustion even for mixtures outside the normal flammability limits (see Section 4.6).

Figure 4.5-5 shows examples from the NUREG-1150 study of the range of pressures considered possible for a DCH event in the Surry subatmospheric containment. ${ }^{3}$ In that study, now believed to be conservative, the important factors were considered to be the vessel pressure, the presence of water in the cavity, the vessel hole size, the core fraction ejected, the amount of zirconium oxidation, and the operation of containment sprays.

In Figure 4.5-5, the dry cavity case (Case 1) results in higher pressures than the equivalent wet cavity case (Case 2 ). In these estimates, steam explosions resulting in dynamic pressures damaging the cavity or other parts of the containment were not considered. Without steam explosion damage, water was predicted to be beneficial, with the heat absorption outweighing any detrimental effects of hydrogen production.

Figure 4.5-6 shows recent results from the $\mathrm{DCH}$ resolution effort, with descriptions of the scenarios given in Table 4.5-1. Note that the pressures in these more recent calculations are substantially lower than those estimated for NUREG-1150. This is primarily due to two factors. First. in the $\mathrm{DCH}$ resolution effort it was concluded that high pressure boiloff scenarios are not likely to occur. The expectation is that induced reactor coolant system (RCS) failures (pump seal leaks or hot leg/surge line failure) would occur during such scenarios, and would substantially reduce the RCS pressure prior to vessel breach. The second key factor leading to reduced containment pressures in the $\mathrm{DCH}$ resolution effort is the use of melt conditions, based on SCDAP/RELAP5 calculations, that are considerably less severe than those used in previous analyses (i.e., less metallic and smaller melt mass).

\subsubsection{Containment Failure Probabilities for $\mathrm{DCH}$}

While DCH is possible, it is averted in many core melt accidents because they do not proceed to vessel breach at high pressure. First, many accident scenarios are arrested in-vessel, prior to melt ejection. Second, many accident scenarios involve vessel failure at low pressure, without the necessary driving force for DCH. BWRs may be depressurized as a result of a LOCA or relief valve operation. PWRs may be depressurized at vessel breach as a result of a LOCA or because of previous temperatureinduced failure of the reactor coolant system (other than the bottom of the vessel), as discussed in Module 3.

The estimates and underlying assumptions from the NUREG-1150 studies have formed the basis for many of the estimates in the Individual Plant Examination. These estimates include noticeable contributions to early containment failures from $\mathrm{DCH}$ in large dry containments.

Current studies for Westinghouse large dry and subatmospheric PWR containments indicate that they would survive most expected DCH events. ${ }^{4}$ The conditional probability (given a DCH event) of containment failure from $\mathrm{DCH}$ (neglecting 
steam explosions), given core damage is estimated to be less than 0.01 for all plants in this group. The ratio of the 99th percentile of the peak containment pressure from $\mathrm{DCH}$ loading to the 1 st percentile of the containment fragility is plotted in Figure 4.5-7 for each of the large dry and subatmospheric plants in the DCH resolution effort. The relatively low value of this ratio for this group of plants indicates that there is considerable margin relative to the conclusion of minimal DCH threat. Large dry containments are still being examined for vulnerability to $\mathrm{DCH}$ at Babcock and Wilcox and Combustion Engineering plants. These plants may be more susceptible to $\mathrm{DCH}$ in those cases where direct venting from the cavity to the upper containment (blowby around the vessel) is possible.

The NRC has previously considered plant changes to deal with the DCH issue. The Accident Management Program has examined the effectiveness of providing intentional depressurization capability for some types of PWRs. Thus far, no specific regulatory actions have resulted from this work. When evaluated from a risk perspective, intentional depressurization to preclude $\mathrm{DCH}$ has the possible detrimental effects of reducing the time for in-vessel recovery (for early depressurization involving a more rapid loss of coolant inventory) and increasing the possibility of in-vessel steam explosions. ${ }^{* *}$ The tradeoffs between the positive and negative aspects of intentional depressurization are not precisely quantifiable, and there is a possibility that temperature induced failures of the reactor coolant system may render the question moot. Further, the DCH threat for most large dry and subatmospheric containments is less than previously thought.

There has been little research directed toward DCH in ice condenser and BWR containments. Ex-vessel steam explosions may be very important in deeply flooded ice condenser containment reactor cavities. In BWRs, the Individual Plant Examinations indicate that the vessel will be pressurized for many accidents. If high pressure melt ejection occurs, the pedestal region is sufficiently confined that high local pressures are possible, that is, the gases can not be vented fast enough to relieve pressure. Further, drywell pressurization leading to drywell failure can be very important. While code calculations have been performed for some of these cases, there is virtually no experimental data available to support evaluations of the effects of high pressure melt ejection for these containment types.

\footnotetext{
"-Susan Dingman, Risk Sensitivity Evaluations for the Intentional Depressurization Strategy, Letter Report to the NRC, Sandia National Laboratories, Albuquerque, NM, March 1991.
} 
Table 4.5-1 Scenarios Examined in DCH Resolution Effort

\begin{tabular}{|c|c|}
\hline Scenario V & Scenario VI \\
\hline TMI-Like Scenario & Intermediate RCS Pressure (8 MPa) \\
Operator Action to Restore ECCS & Water in Lower Plenum at Vessel \\
Breach \\
RCS Repressurizes (16 MPa) & Oxidic Melt \\
RPV Reflooded at Vessel Breach & Limited Zr/Steel in Ejected Debris \\
Oxidic Melt & Rupture of Lower Head \\
Limited Zr/Steel in Ejected Debris & \\
Rupture of Lower Head & \\
\hline
\end{tabular}




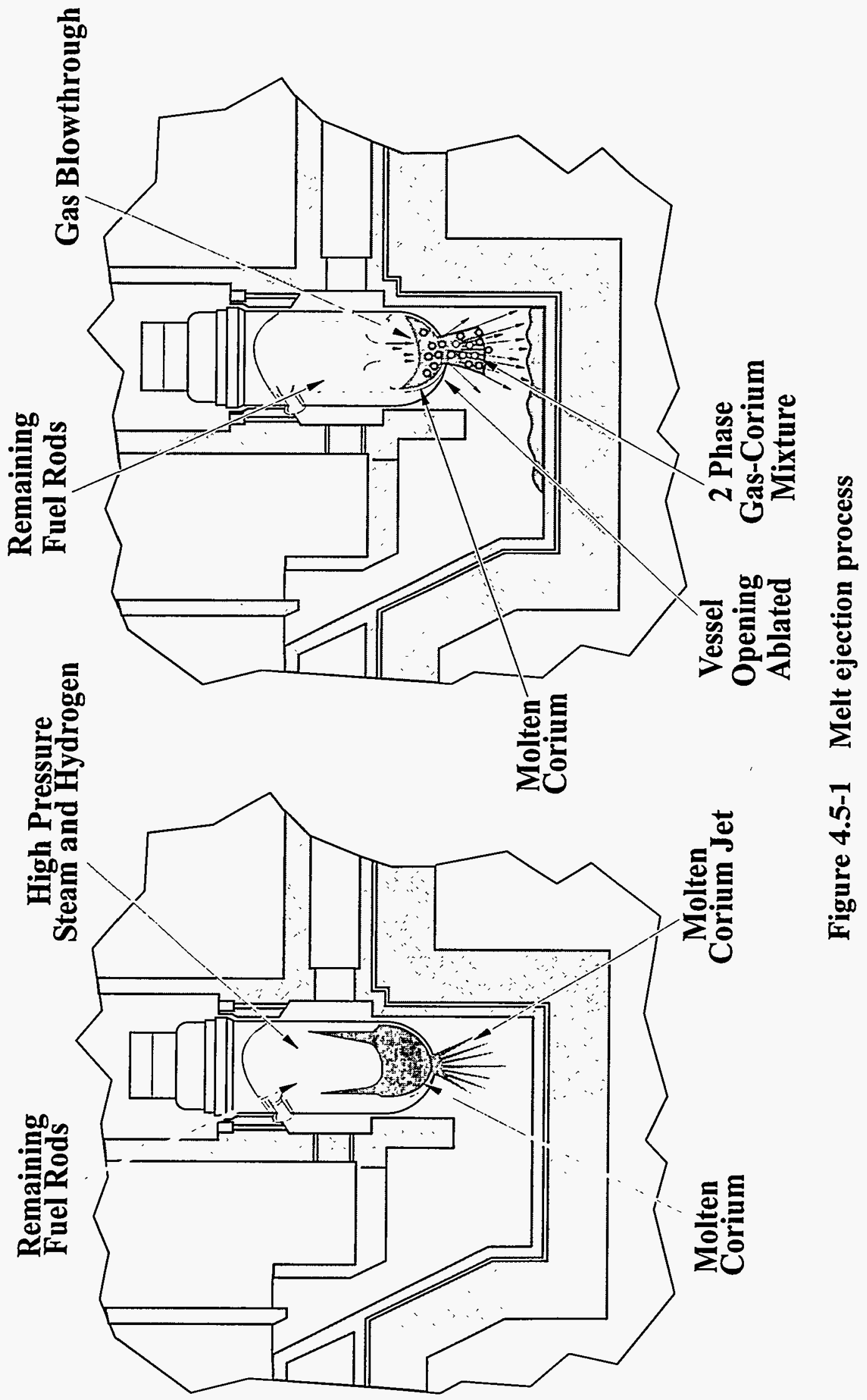




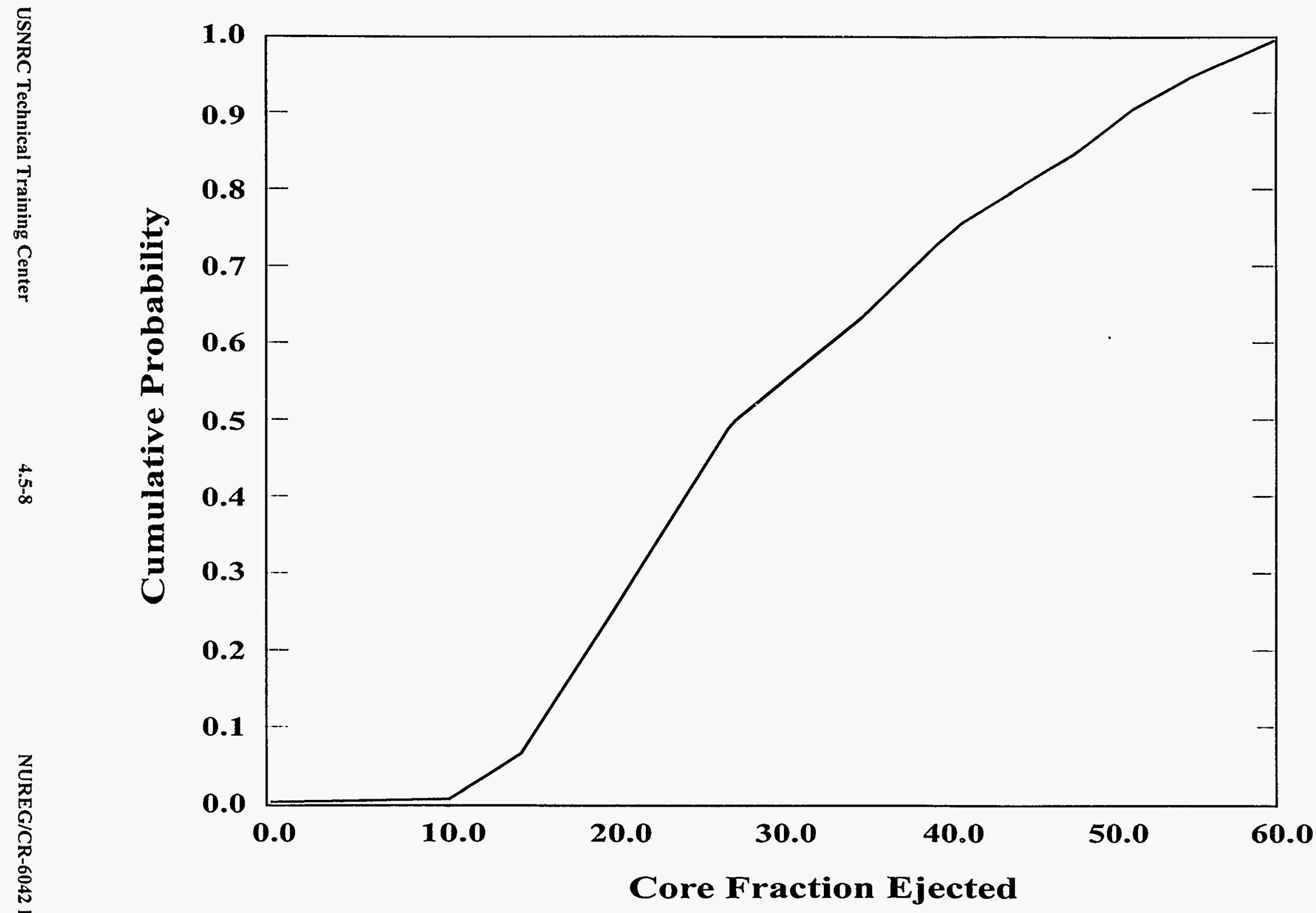

Figure 4.5-2 Distribution for fraction of core material ejected, PWR 


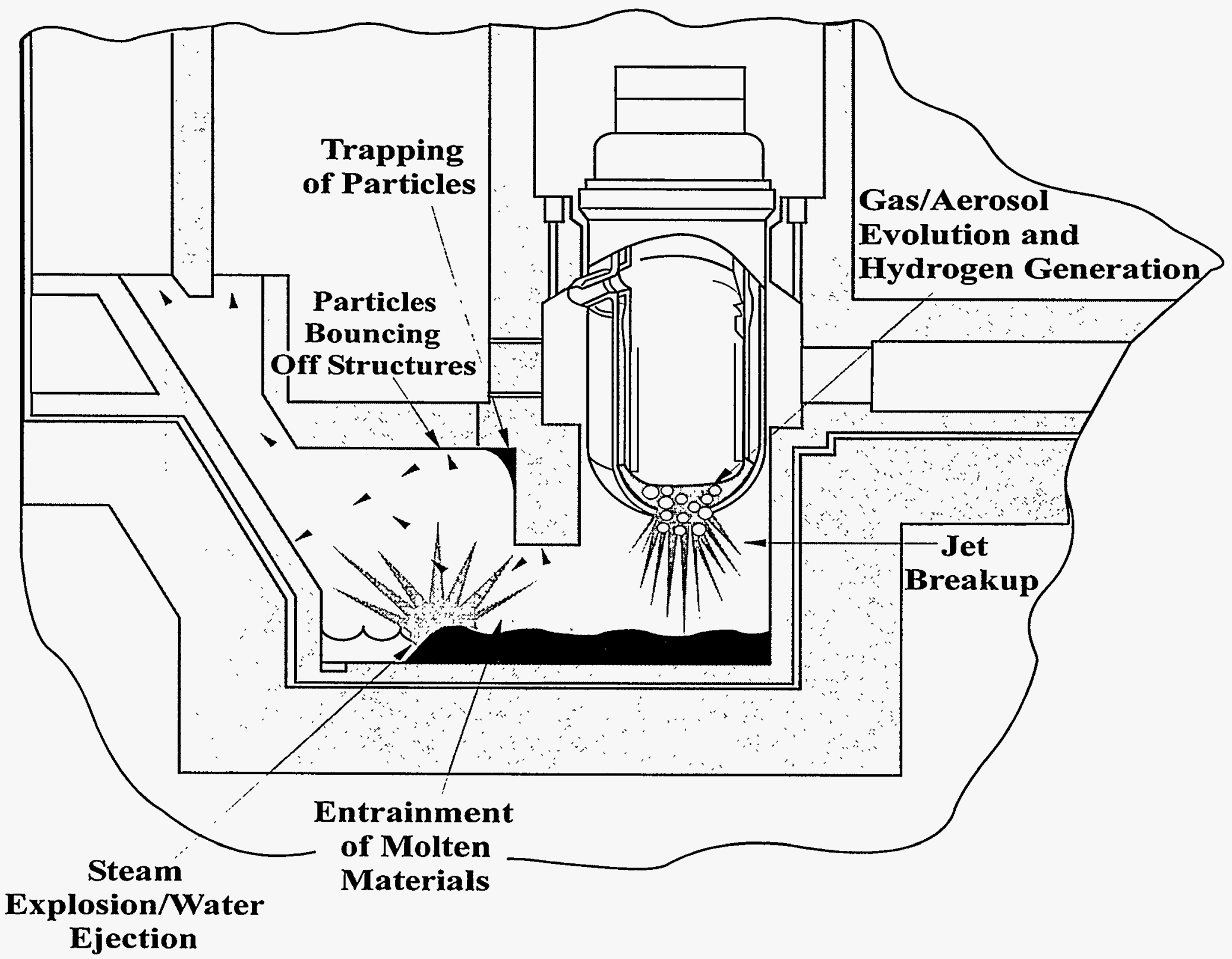

Figure 4.5-3 Reactor cavity interactions 


\section{(ui) səz!s do.I}

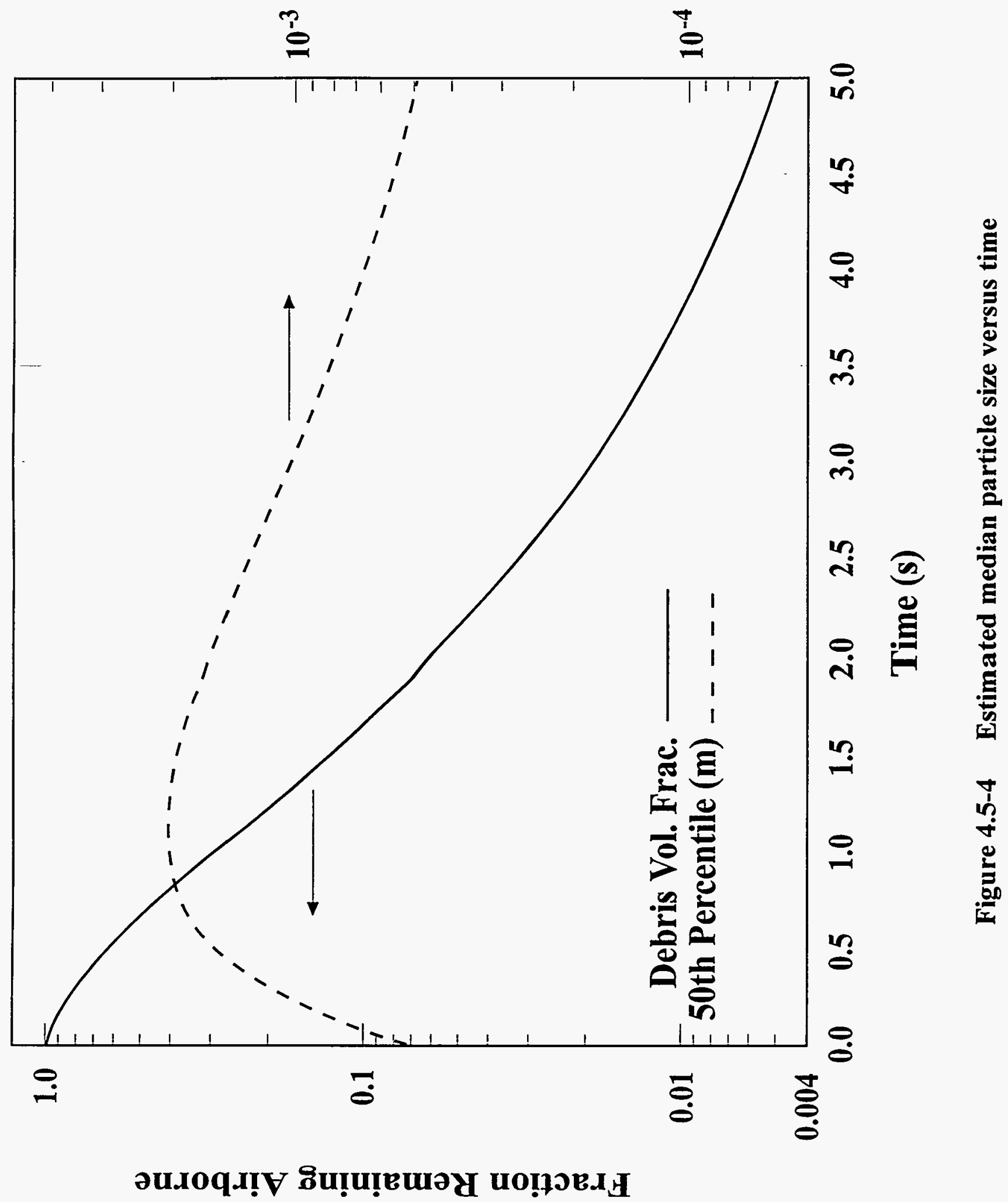




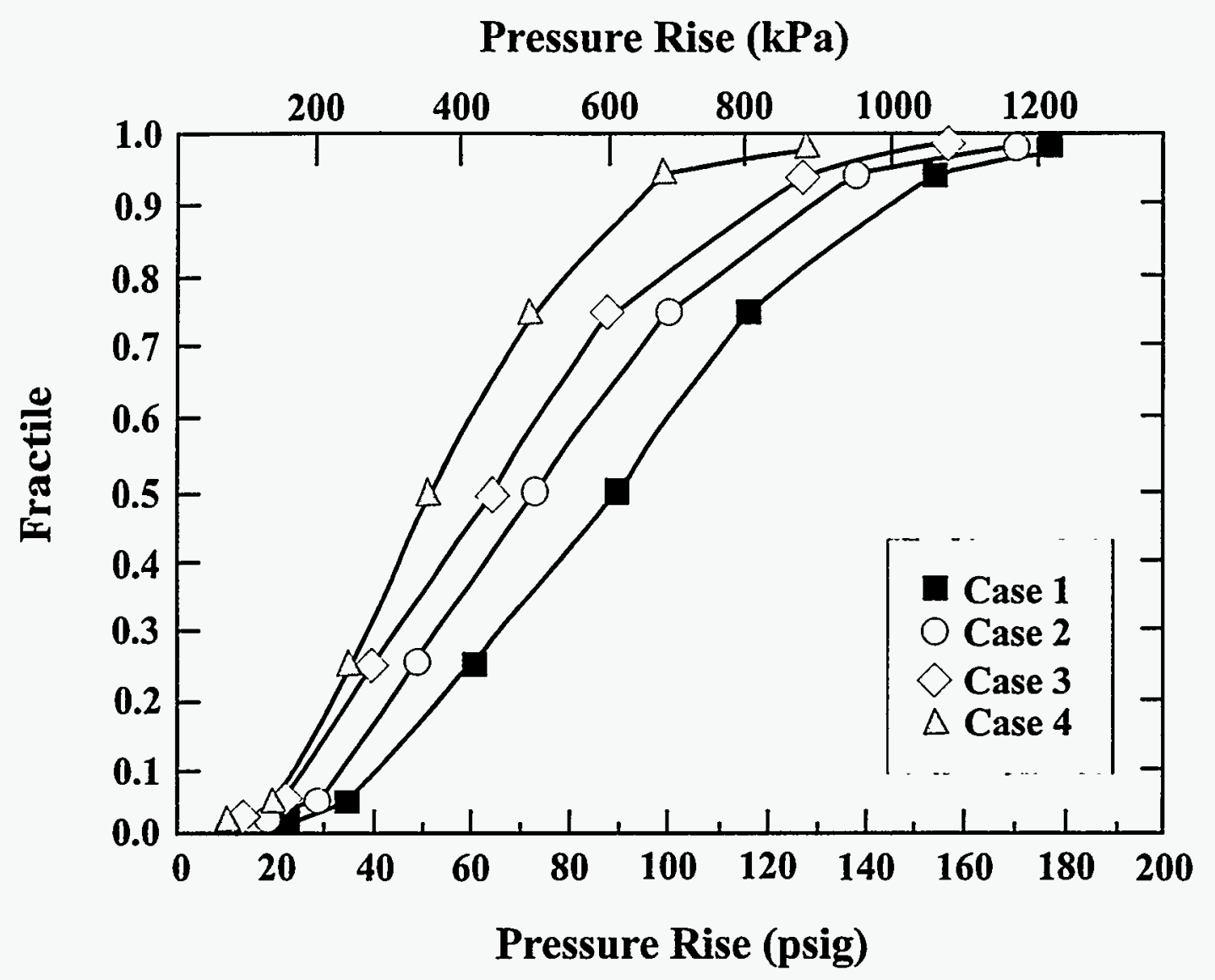

\begin{tabular}{|l|c|c|c|c|} 
& $\begin{array}{c}\text { RCS } \\
\text { Pressure } \\
\text { Casi }(\mathrm{MPa})\end{array}$ & $\begin{array}{c}\text { Vessel } \\
\text { Hole Size } \\
\mathrm{ft}^{2}\left(\mathrm{~m}^{2}\right)\end{array}$ & $\begin{array}{c}\text { Core } \\
\text { Cavity }\end{array}$ & $\begin{array}{c}\text { Fraction } \\
\text { Ejected }\end{array}$ \\
Case 2 & $2000-2500(13.8-17.2)$ & $21.5(2)$ & Dry & $40-60 \%$ \\
Case 3 & $500-2500(13.8-17.2)$ & $21.5(2)$ & Wet & $40-60 \%$ \\
Case 4 & $500-1000(3.4-6.9)$ & $21.5(2)$ & Wet & $40-60 \%$ \\
& & $1.1(0.1)$ & Dry & $20-40 \%$
\end{tabular}

Figure 4.5-5 Example distributions for pressure rise at vessel breach, Surry 


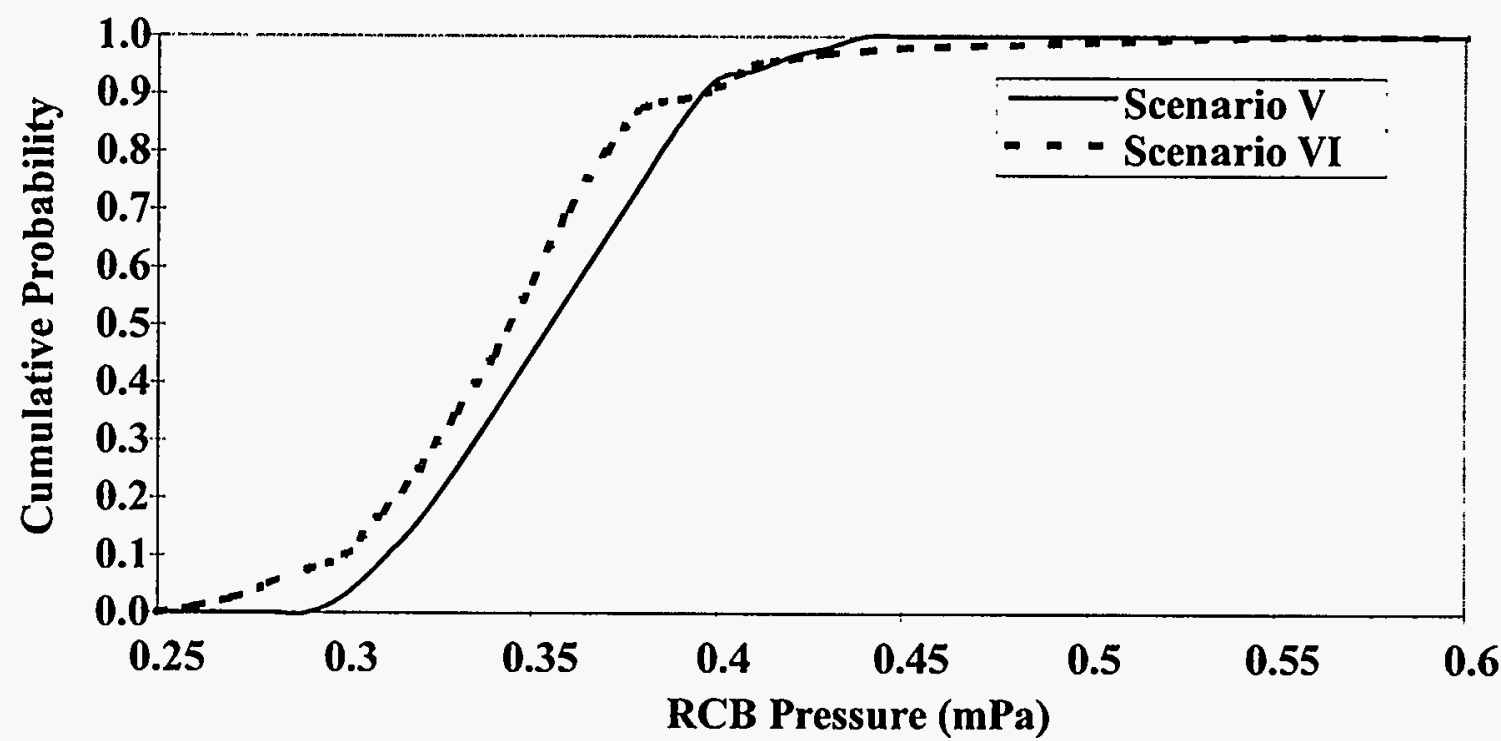

Figure 4.5-6 Surry containment pressure estimates from DCH resolution effort 

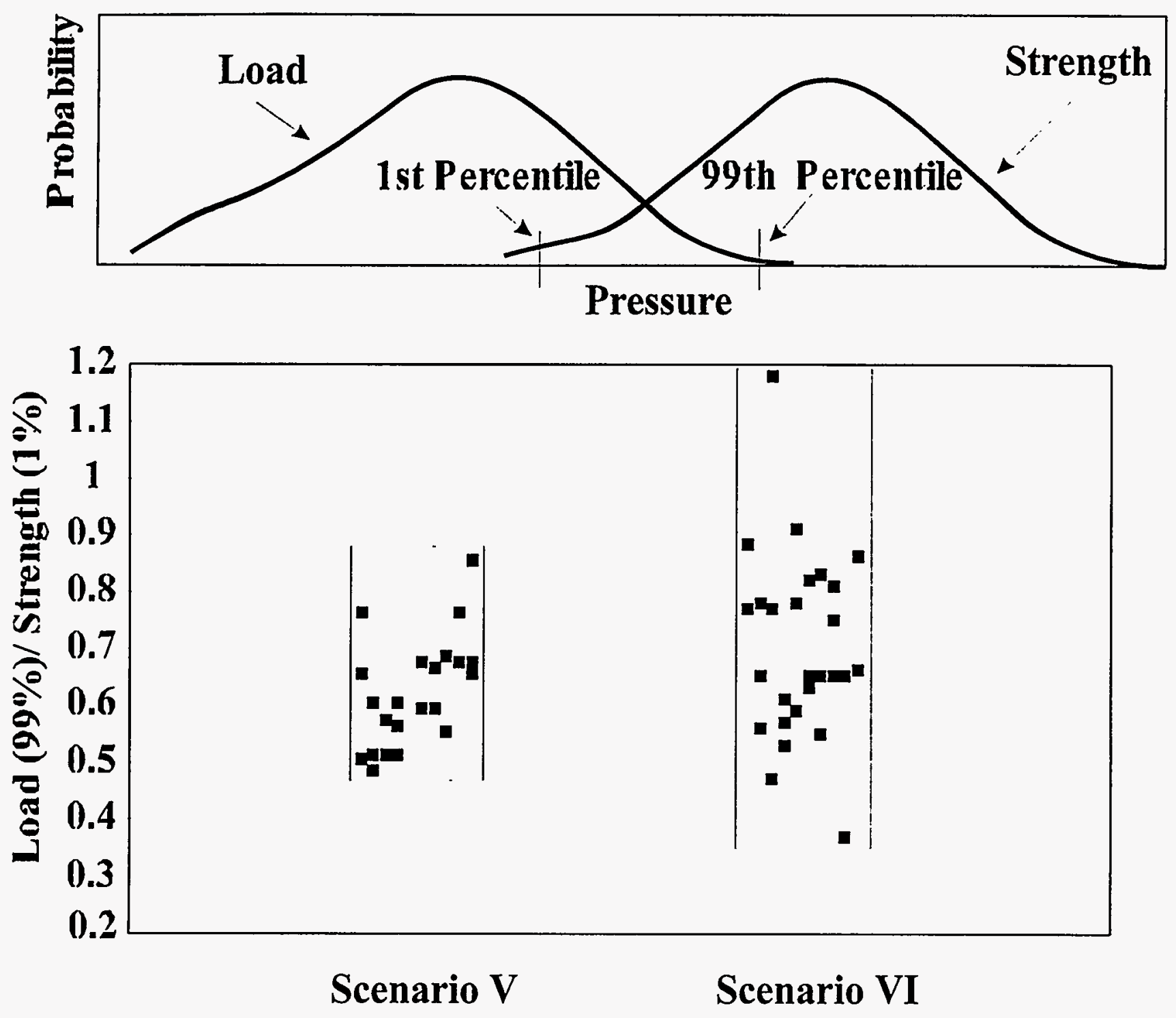

Figure 4.5-7 Large dry and subatmospheric containment results from DCH resolution effort 


\section{References for Section 4.5}

1. M. M. Pilch, Michael D. Allen, and David C. Williams, "Heat Transfer During Direct Containment Heating," Academic Press, 1996.

2. F. T. Harper, et al., "Evaluation of Severe Accident Risks: Quantification of Major Input Parameters," NUREG/CR4551, SAND86-1309, Vol. 2, Rev. 1, Part 1, Sandia National Laboratories, December 1990.
3. F. T. Harper, et al., Evaluation of Severe Accident Risks: Quantification of Major Input Parameters," NUREGICR-4551, SAND86-1309, Vol. 2, Rev. 1, Part 2, Sandia National Laboratories, April 1991.

4. M. M. Pilch, et al., "Resolution of the Direct Containment Heating Issue for all Westinghouse Plants with Large Dry Containments or Subatmospheric Containments," NUREG/CR-6338, SAND95-2381, Sandia National Laboratories, February 1996. 


\subsection{Hydrogen Combustion}

During the TMI-2 accident, hydrogen generated from in-vessel zirconium oxidation was released to the containment through the pressurizer relief valve. This hydrogen eventually ignited, resulting in a $28 \mathrm{psig}$ $(193 \mathrm{kPa})$ peak pressure in the containment. While this particular event did not threaten the TMI-2 containment, it raised awareness of the potential threats that might arise for other scenarios and for other containment types. The main concern over hydrogen combustion in nuclear reactor containments is that the high pressure generated might cause a breach of containment and a release of radioactivity. A second concern is that the resultant high temperature or pressure might damage important safety-related equipment. This section describes the physical mechanisms important to hydrogen combustion events, discusses the TMI-2 event in more detail, and describes the subsequent regulatory activities that have been taken to reduce the potential combustion threats. Much of the material in this section is excerpted from the Light Water Reactor Hydrogen Manual. ${ }^{1}$

\subsubsection{Hydrogen Combustion Reaction}

Combustion of hydrogen according to the reaction:

$$
2 \mathrm{H}_{2}+\mathrm{O}_{2}-->2 \mathrm{H}_{2} \mathrm{O}+\text { energy (heat) }
$$

results in the release of about $5.2 \times 10^{4}$ Btu/lb-mol of hydrogen burned (57.8 $\mathrm{kcal} / \mathrm{gm}$-mole). Combustion waves are usually classified either as deflagrations or detonations. The term "explosion" usually refers to a detonation, but is somewhat ambiguous and should be avoided. Deflagrations are combustion waves in which unburned gases are heated by thermal conduction to temperatures high enough for chemical reaction to occur. Deflagrations normally travel subsonically and result in quasi-static (nearly steady state) loads on containment. Detonations are combustion waves in which heating of the unburned gases is due to compression from shock waves. Detonation waves travel supersonically and produce dynamic or impulsive loads on containment in addition to quasi-static loads. The pressure and temperature obtained from the complete combustion of hydrogen in air, adiabatically (without heat loss) and at constant volume, are shown in Figures 4.6-1 and 4.6-2. These figures show the ratio of initial to final pressures and final temperatures that could be expected for gas mixtures with low steam concentrations. Appendix A shows examples of pressure and temperature calculations for the types of air-steam-hydrogen mixtures that might occur in a reactor containment. In the following sections, the conditions necessary for combustion and the different combustion modes are discussed in detail.

\subsubsection{Conditions Necessary for Combustion}

Normally, for substantial combustion of hydrogen to take place, the gaseous mixture must be flammable, and an ignition source must be present. The special case of high temperature combustion is discussed later. For a flammable gas mixture, the flammability limits are defined as the limiting concentrations of fuel, at a given temperature and pressure, in which a flame can be propagated indefinitely. Limits for upward propagation of flames are wider than those for downward propagation. Limits for horizontal propagation are between those for upward and downward propagation.

The lower flammability limit is the minimum concentration of hydrogen required to propagate a flame, while the upper limit is the maximum concentration. At the lower limit, the hydrogen is in short supply and the 
oxygen is present in excess. At the upper limit of flammability for hydrogen in air, the oxygen is in short supply, about $5 \%$ oxygen by volume. The behavior of the upper limit of flammability of hydrogen with various mixtures such as air:steam is more easily understood if one considers it as the lower flammability limit of oxygen.

In large PWR containments we are usually interested in the lower limit of flammability, there being large amounts of oxygen present. In the much smaller BWR containments, particularly the inerted containments, we may be interested in the upper flammability limit.

For hydrogen:air mixtures, the flammability limits of Coward and Jones are still accepted. ${ }^{2}$ Values for hydrogen flammability in air saturated with water vapor at room temperature and pressure are given in Table 4.6-1. These limits may vary slightly during accident conditions. There may be scale effects due to the large size of reactor containments as well as variations in flammability due to the ignition source strength.

In reactor accidents the conditions inside containment prior to hydrogen combustion may include elevated temperature, elevated pressure, and the presence of steam. The flammability limits widen with increasing temperature. For example, at $212^{\circ} \mathrm{F}\left(100^{\circ} \mathrm{C}\right)$ the lower limit for downward propagation is approximately $8.8 \%$ (see Figure 4.6-3).

If the containment atmosphere is altered by the addition of carbon dioxide, steam, nitrogen, or other diluent, the lower flammability limit will increase slowly with additional diluent, while the upper flammability limit will drop more rapidly. With continued increase in diluent con- centration, the two limits approach one another until they meet and the atmosphere is inerted. A flame cannot be propagated a significant distance for any fuel:air ratio in an inerted atmosphere. The addition of diluents has been proposed as a hydrogen mitigation strategy. Figure $4.6-4$ shows the flammability limits with the addition of excess nitrogen or carbon dioxide. Note that for $75 \%$ additional nitrogen, the atmosphere is inert. ${ }^{3,4}$ This corresponds to $5 \%$ oxygen at the limit of the flammable region, a value very close to that of the upper limit for hydrogen:air combustion. For carbon dioxide, the atmosphere is inerted when the carbon dioxide concentration is $60 \%$ or above, corresponding to $8 \%$ oxygen or less. The larger specific heat of carbon dioxide reduces the flame temperature and flame velocity; hence carbon dioxide suppresses flammability more than nitrogen. It requires about $60 \%$ steam to inert hydrogen:air:steam mixtures. The triangular diagram of Shapiro and Moffette indicates regions of flammability of hydrogen:air:steam mixtures. ${ }^{4}$ It has been widely reproduced and appears as Figure 4.6-5.

Ignition of dry hydrogen:air mixtures, particularly when the mixtures are well within the flammability limits, can occur with a very small input of energy. ${ }^{4}$ Common sources of ignition are sparks from electrical equipment and from the discharge of small static electric charges. The minimum energy required from a spark for ignition of a quiescent hydrogen:air mixture is of the order of $10^{-7} \mathrm{Btu}\left(10^{-4} \mathrm{~J}\right)$ (a very weak spark). The ignition energy required as a function of hydrogen concentration is shown in Figure 4.6-6.5 For a flammable mixture, the required ignition energy increases as the hydrogen concentration approaches the flammability limits. The addition of a diluent, such as steam, will increase the 
required ignition energy substantially. As mentioned previously, high energy ignition sources can cause mixtures outside the flammability limits to burn for some distance.

\subsubsection{Deflagrations}

Deflagrations are flames that generally travel at subsonic speeds relative to the unburned gas. Deflagrations propagate mainly by thermal conduction from the hot burned gas into the unburned gas, raising its temperature high enough for a rapid exothermic chemical reaction to take place. The propagation of a deflagration can be understood by examining the flammability limits discussed in the previous section. Consider a quiescent mixture of hydrogen:air. For hydrogen concentrations below about $4.1 \%$ there will be no significant propagation away from an ignition source. For hydrogen concentrations between 4.1 and $6.0 \%$, there will be upward propagation from the ignition source. Hydrogen concentrations between 6.0 and $9.0 \%$ will produce both upward and horizontal propagation, and hydrogen concentrations above $9.0 \%$ will produce propagation in all directions, although the upward propagation may be faster than the downward propagation. Exact values for propagation limits will, of course, vary with temperature, pressure, and the presence of diluents. The degree of turbulence is also very important with turbulence tending to enhance combustion as long as the turbulence is not violent enough to "blow out" the flame.

It has been found in laboratory experiments that when hydrogen:air mixtures with hydrogen concentrations in the range $4-8 \%$ were ignited with a spark, some of the hydrogen was not burned. ${ }^{6,7,8,9,10}$ The resultant pressure rise was below that predicted for complete combustion, as shown in Figure 4.6-7. Experimental results with a spark ignition source indicate that the completeness of combustion in quiescent mixtures increases with increasing hydrogen concentration, and is nearly complete at about $8-10 \%$ hydrogen. The range of incomplete combustion corresponds to the range in which the mixture is above the flammability limit for upward propagation, but below the flammability limit for downward propagation. As shown in Figure 4.6-7 for the "fans on" cases, turbulence and mixing of the gases can significantly increase the completeness of combustion. The additional variations in Figure 4.6-7 for mixtures below $8 \%$ tend to result from variations in the geometry and scale of the experiments.

Another important parameter when studying deflagrations is the flame speed. The flame speed determines how much time is available for heat transfer during a burn. Heat transfer results in pressures and temperatures below those predicted in Figures 4.6-1 and 4.6-2. The dominant heat transfer mechanisms are evaporation of containment sprays, radiation, and convection. Some plants also contain fan coolers. Normally, if the sprays are on, they will dominate the heat transfer process. Radiation heat transfer can also be important due to the high gas temperatures expected during a hydrogen burn. Convection may be less significant over the short time of a burn. One note is that the presence of sprays may significantly increase the flame speed due to the increased turbulence induced by the sprays. Typically, pressure rises above $80 \%$ of the adiabatic pressure rises are predicted for reasonable values of the flame speed, assuming complete combustion.

As shown in Figure 4.6-8, laminar burning velocities are quite slow. The laminar burning velocity (in a Lagrangian sense) denotes the speed of gases at a steady burner. Propagating laminar flames have flame speeds (in an Eulerian sense) which 
are 5-7 times faster due to volumetric expansion of the burned gases. The maximum laminar burning velocity of hydrogen:air mixtures is about $9.8 \mathrm{fps}(3$ $\mathrm{m} / \mathrm{s}$ ) near a concentration of about $42 \%$ hydrogen. The burning velocity becomes much smaller as the flammability limits are approached.

In a reactor containment, it is likely that a laminar deflagration will become turbulent. Turbulent flames can have average burning velocities 2 to 5 times the laminar burning velocity. Therefore, a hydrogen combustion event can occur in a containment in a matter of seconds, as opposed to the long times predicted by the laminar burning velocities. If the turbulent flame speed (laboratory system) becomes greater than about onetenth of the sound speed (the sound speed is approximately 1150 fps $(350 \mathrm{~m} / \mathrm{s})$ in containment air), shock waves will be formed ahead of the flame front. In that case dynamic loads, in addition to static loads, will be imposed on the containment structure. The mechanisms leading to flame acceleration and detonation will be discussed in the next section.

\subsubsection{Detonation of Hydrogen}

A detonation is a combustion wave that travels at supersonic speeds relative to the unburned gas in front of it. For hydrogen:air mixtures near stoichiometric this speed is about $6600 \mathrm{fps}(2000 \mathrm{~m} / \mathrm{s})$ (see Figure 4.69). The compression of the unburned gas by shock waves in the detonation raises the gas temperature high enough to initiate rapid combustion.

We will attempt to answer as well as possible the following three questions:

1. Under what conditions is a hydrogen:air or hydrogen:air:steam detonation possible in containment?
2. If a detonation is possible, what is the likelihood that it will occur?

3. What pressure loads could a detonation cause?

We can answer the first question fairly well (at least with regard to hydrogen:air mixtures) and also the third question. The second question concerns the transition from deflagration to detonation and is still not completely understood after more than 50 years of investigation. We can say that, in most postulated reactor accident scenarios, deflagrations are much more likely than detonations.

\subsubsection{Detonation Limits}

Hydrogen:air mixtures near stoichiometric (about 29\% hydrogen, two parts $\mathrm{H}_{2}$ to one part $\mathrm{O}_{2}$ ) are known to be detonable. Mixtures departing from stoichiometric, either in the hydrogen-lean or hydrogen-rich direction are increasingly more difficult to detonate. It has been observed that "detonation limits" are functions of geometry and scale, and not universal values at given mixture concentrations, temperatures and pressures. ${ }^{11,12,13}$

Our understanding of the possibility of sustaining a detonation in hydrogen:air mixtures, as well as other gas mixtures, has greatly increased within the last fifteen years. It has been found that a detonation wave is composed of unsteady oblique shock waves moving in an everchanging cellular structure (characterized by its transverse dimension), a "foamy" detonation front. Figure 4.6-10 shows the effect when a detonation passes by a smoked foil. The interacting shock waves form roughly diamond shape detonation "cells."

The farther a mixture is from stoichiometric, and hence the less energetic the chemical 
reaction, the larger is the detonation cell size, $\lambda$. The cell width for hydrogen:air has been accurately measured over an extensive range of hydrogen:air ratios (see Figure 4.611). ${ }^{13}$

The knowledge of hydrogen:air cell size is valuable for evaluating detonation concerns in particular geometries. It is known that if a detonation is to propagate in a given geometry, there is a minimum size for which the detonation will propagate, related to the cell size. For smaller geometries, the detonation will fail. Figure 4.6-12 shows the relationship between various geometries and cell size. For example, at $16 \%$ hydrogen, the cell size is about 9.6 in. $(24.5 \mathrm{~cm})$. This means that a $16 \%$ hydrogen mixture detonation should be able to propagate down a tube 3.2 in. $(8.2 \mathrm{~cm})$ in diameter. The larger the tube diameter, the wider is the range of detonable hydrogen concentrations.

The detonability of a mixture is increased (cell size is decreased) with increasing temperature. For example, in a 17 in. (43 $\mathrm{cm})$ tube at $68^{\circ} \mathrm{F}\left(20^{\circ} \mathrm{C}\right)$, a detonation can be propagated in a mixture with $11.7 \%$ hydrogen. At $212^{\circ} \mathrm{F}\left(100^{\circ} \mathrm{C}\right)$, the detonability limit changes to $9.5 \%$ hydrogen. ${ }^{14}$

The information provided above helps to answer the first question, "Under what conditions is a hydrogen:air detonation possible in containment?" The detonation limits are not fixed, but depend on the geometry and are wider for larger sizes and higher temperatures. The curve of cell size versus hydrogen fraction rises steeply on the hydrogen-lean side. For the large geometrical scales in containments, detonations may propagate in leaner mixtures than has been demonstrated in small and medium scale experiments.

\subsubsection{Transition to Detonation}

A detonable mixture may only deflagrate (burn) and not detonate. Detonations can start directly by the use of a vigorous shock wave coming from a high explosive, strong spark, or laser. Approximately 0.035 oz. (1 $\mathrm{gm})$ of tetryl explosive will initiate a spherical detonation of a stoichiometric hydrogen:air mixture. The increase in explosive charge required as the mixture departs from stoichiometric is roughly proportional to the increase in detonation cell size. Detonations can also start from deflagrations that accelerate to high speeds pushing shock waves ahead of the burn front until at some point shock heating is sufficient to initiate the detonation. Sources of such highly accelerated flames are high speed jets coming from semiconfined regions and flames passing through fields of obstacles.

Many obstacles that might potentially cause flame acceleration, such as pipes and pressure vessels, are present in the lower sections of most containments. Very fast burns may also occur due to the presence of a very intense ignition source, such as a jet of hot combustion products formed subsequent to ignition in some adjoining semi-confined volume.

Deflagration-to-detonation transition is probably the least understood aspect of detonation theory at this time. Measurements have been made of the distance required to have transition to detonation in smooth tubes. Distances many times the tube diameter have been required. If obstacles are inserted into the tube, the required distance to detonation is greatly reduced. The motion of the expanding gases around the obstacles leads to greatly 
increased flame front area, rapid flame acceleration and rapid transition to detonation. Confinement greatly promotes transition, but one cannot rule out transition to detonation in a containment if a detonable mixture of sufficient size is present. The second question, "If a detonation is possible, what is the likelihood that it will occur?" therefore cannot be answered with certainty at present.

\subsubsection{Detonation Pressures and Temperatures}

For the purpose of studying the pressures and temperatures caused by a detonation, it is sufficient to ignore the detonation wave structure and consider it as a thin surface, a discontinuity. Chapman and Jouguet assumed that the detonation traveled at a speed that was sonic relative to the unburned gas. With this assumption one can compute a unique detonation speed for each hydrogen:air mixture, and find the corresponding temperature and pressure behind the detonation wave. The results are shown in Figures 4.6-13 and 4.6-14. It is an experimental fact that the measured speeds of detonations are approximately equal to the calculated Chapman-Jouguet values.

The burned gases behind a detonation are moving in the direction of the detonation. When a detonation hits a rigid wall, the gases must be brought to rest. This is accomplished by a reflected shock wave. We will consider only the case of a detonation wave striking a wall at normal incidence. The reflected shock wave further compresses the burned gas, increasing the detonation pressure by a factor of about 2.3 . The pressures and temperatures predicted behind the normally reflected shock wave are also shown in Figures 4.6-13 and 4.6-14. In a containment one expects wave reflections from walls and obstacles to give rise to complex shock wave patterns. Wave interactions may lead to dissipation or, possibly, to wave focusing which can give rise to very high local peak pressures.

\subsubsection{Local Detonations}

In all the previous sections on detonations it has been assumed that the detonation is taking place in a homogeneous combustible mixture. Such detonations are global, traveling throughout the containment. With the exception of the strongest containments, containments will probably not be able to withstand the quasi-static pressure (adiabatic isochoric pressures) generated after the detonation, even without the additional dynamic loads due to detonation. It is therefore more appropriate to consider the effect of detonations when only a local portion of the containment atmosphere is detonable.

Consider a detonable cloud of hydrogen:air surrounded by air. As the detonation wave leaves the cloud, it will change into an expanding decaying shock wave. The shock wave intensity drops fairly rapidly if the shock wave expands spherically. Within a distance equal to 3 cloud radii, the shock wave pressure will drop to a value low enough to no longer threaten the containment structure. However, it has been found in detailed computer calculations that, because of the containment geometry, the shock waves may be focused in local regions, such as the top center of the containment dome, giving rise to large local peak pressures and impulses. ${ }^{15,16}$ Local detonations may be dangerous in and near the detonable cloud, and may be dangerous at locations farther away if shock focusing effects are significant. 
There are several locations to consider where high hydrogen concentrations are possible. These include:

1. near the hydrogen release point,

2. under ceilings or in the dome due to the rise and stratification of a low density plume, or

3. near steam removal locations such as ice condensers, suppression pools, and fan coolers.

A detonable mixture requires adequate hydrogen and oxygen, but not too much steam. Regions of stratification tend to be difficult to establish and maintain in a turbulent containment environment. Steam removal locations are generally a more significant concern for local detonations.

\subsubsection{Missile Generation}

Missiles may be generated when combustion (deflagration or detonation) occurs in a confined region or when a propagating combustion front produces dynamic pressure loads on equipment. Such missiles may pose a threat to the containment structure itself, as well as representing a potential threat to safety and control equipment. For instance, electrical cables may not be expected to withstand the impact of a door or metal box. The actual risk to plant safety posed by missiles generated from hydrogen combustion depends upon a number of independent factors and is very difficult to predict.

\subsubsection{Continuous Combustion}

The preceding discussions have dealt with the discrete combustion events associated with hydrogen:air:steam mixtures in containment. There are also mechanisms for continuous combustion that are possible in some containments and for certain accident scenarios. Hydrogen may enter the containment as part of a turbulent jet from a pipe break or relief valve or may enter as part of a buoyant plume from the top of a suppression pool or from core-concrete interactions. The hydrogen may be accompanied by large quantities of steam or, in the case of core-concrete interactions, carbon monoxide which is also flammable. The primary threat to nuclear power plants from continuous combustion is the temperature rise and the possible effect on equipment and structures. Pressure increases from continuous combustion will not generally threaten the containment.

Hydrogen that enters the containment may start to burn as a turbulent diffusion flame. A diffusion flame is one in which the burning rate is controlled by the rate of mixing of oxygen and fuel. The nature of the flame is determined by the Froude Number, which is the ratio of the momentum forces to the buoyant forces in the jet or plume. Figure 4.6-15 shows the types of flames that can occur for different source diameters and flow rates. For the hydrogen to burn, it is necessary that at some location the hydrogen:air:steam mixture be within flammability limits.

Combustion can begin either because of an outside ignition source, or because the mixture temperature is above the spontaneous ignition temperature. Shapiro and Moffette in 1952 presented experimental results on the spontaneous ignition temperature of hydrogen:air:steam mixtures (see Figure 4.6-16). ${ }^{17}$ The spontaneous ignition temperature is in the range of 959$1076^{\circ} \mathrm{F}\left(515-580^{\circ} \mathrm{C}\right)$. Above this temperature, combustion can occur without external ignition sources such as electrical sparks. For example, continuous combustion may occur in a reactor cavity above $\mathrm{CCI}$ in a dry cavity. In this case, the combustion will be 
limited by the availability of oxygen. However, if any oxygen is present, hydrogen and carbon monoxide can react even if the mixture is not within normal flammability limits.

Turbulent jets, such as from a pipe break, tend to autoignite at higher temperatures than buoyant plumes. Experiments have shown that such jets can autoignite at temperatures above 1166 to $1346^{\circ} \mathrm{F}$ (630$\left.730^{\circ} \mathrm{C}\right) .^{18}$ A stable flame will occur at a distance from the orifice such that the turbulent burning velocity is equal to the gas flow velocity. There is evidence to suggest that for a particular set of conditions (temperature, pressure, and composition), there is a minimum orifice diameter for flame stability. ${ }^{19}$ This minimum diameter is typically on the order of a few hundredths of an inch (millimeters) or less, and therefore, all practical sized orifices will support a stable hydrogen flame. Turbulent jets of hydrogen can also accompany direct containment heating. Hydrogen may already be present in containment, with additional hydrogen coming from in-vessel and from oxidation reactions during the melt ejection process. The hot particles and high temperature gases will serve to ignite the hydrogen, resulting in an additional energy contribution to the direct containment heating process. As noted in Section 4.5, very rich mixtures of hydrogen may be found at the exit of a reactor cavity, raising the possibility of a detonation. However, in this latter case the mixture may be steam rich and oxygen starved near the release point.

\subsubsection{Combustion at TMI-2}

The TMI-2 accident was discussed at some length in Module 2. During the core heatup and degradation process, hydrogen was generated and released to containment through the pressurizer relief valve and the quench tank. Estimates of the total amount of hydrogen generated range from 594 to 814 $1 b_{m}(270-370 \mathrm{~kg}){ }^{20}$ This amount of hydrogen corresponds to oxidation of about $40 \%$ of the zirconium in the core. Approximately 9 hours and $50 \mathrm{~min}$. into the accident, a hydrogen deflagration occurred, resulting in a 28 psig peak pressure in containment (see Figure 4.6-17). The ignition source is not known, but could have been an electrical spark from a variety of sources.

The pressure rise observed at TMI-2 is consistent with the estimates of the generation and relatively complete combustion of between 7 and $8.2 \%$ hydrogen. The TMI-2 containment has a volume in excess of $2 \times 10^{6} \mathrm{ft}^{3}\left(5.7 \times 10^{4} \mathrm{~m}^{3}\right)$ and a failure pressure far in excess of 28 psig (193 kPa). However, BWR containments and PWR ice condenser containments are much smaller than TMI-2, and the same quantity of hydrogen could have resulted in a detonable mixture in those containments. The realization that hydrogen combustion could cause containment failure in smaller containments led to regulatory actions, as discussed in the following section.

\subsubsection{Hydrogen Control Requirements}

In general, there are very few regulations and guidelines dealing with beyond-designbasis accident phenomena in reactor containments. For example, there are no specific rules dealing with CCIs, ex-vessel steam explosions, or direct containment heating. Hydrogen control has been an exception to this approach, with significant regulations passed following the TMI-2 accident.

Limited hydrogen control was provided prior to TMI-2 in the form of hydrogen recombiners that could remove the small amounts of hydrogen that might be generated during a design-basis LOCA. However, 
these recombiners have virtually no value for the large quantities of hydrogen that could be generated during a severe accident. Therefore, the NRC took additional steps to protect the reactors considered most vulnerable to hydrogen combustion.

The hydrogen rule is contained in $10 \mathrm{CFR}$ $50.44 .^{21}$ In 1981, the NRC ordered that all BWRs with Mark I and Mark II containments be inerted during normal operation to preclude the possibility of combustion. These containments are small enough that relatively low levels of zirconium oxidation could produce detonable mixtures in containment. Although inerting will prevent combustion within the containment, hydrogen can enter the surrounding reactor building of a Mark I or II containment if the containment fails or is vented through structurally inadequate flow paths. This hydrogen can burn, presenting a thermal hazard for safety equipment located in those buildings.

BWR Mark III containments and PWR ice condenser containments were the object of long and controversial examination. A variety of hydrogen control measures were considered by both the industry and the NRC. These measures included inerting, partial inerting, water fogs and foams, and deliberate ignition systems. Because of the need to enter containment for various operational activities and risks to personnel, the utilities opposed inerting approaches. Some other approaches, such as water fogs and foams, were not successfully demonstrated as practical prior to the decisions that were reached. Ultimately, the industry and NRC agreed on the deliberate ignition approach, even though other options are allowed under 10 CFR 50.44. The deliberate ignition approach is discussed in more detail below.
The acceptance of deliberate ignition as a viable strategy is based in part on a couple of controversial assumptions in the hydrogen rule. The TMI-2 accident did not result in vessel breach, and only about half of the available zirconium was oxidized. Therefore, the hydrogen rule was set up to address only degraded core accidents and not full scale melting and vessel breach. Consistent with the assumption that vessel breach does not occur, the limit of zirconium oxidation was set to $75 \%$ of the fuel cladding, not including channel boxes in BWRs. Greater amounts of hydrogen were not expected to be consistent with an accident in which most of the core did not melt or the vessel was not breached. Further, because the vessel is not breached, the release of hydrogen to containment was expected to occur over time periods of at least many minutes, if not longer. The large puff release that might accompany vessel breach or ex-vessel steam explosions does not need to be considered in meeting the hydrogen rule. It is also interesting to note that, while the fuel damage is assumed to be arrested at some point, the reflooding process is assumed to not produce oxidation in excess of $75 \%$ and to not result in a large burst of hydrogen. Therefore, only a select subset of beyond-design-basis accidents is actually addressed.

Deliberate ignition is based on the premise that hydrogen can be burned off in small quantities as it enters the containment. Either numerous small deflagrations or continuous combustion may occur, resulting in minimal pressure rise in containment, although the temperature effects must be considered. If the containment is not steaminerted, then lean mixtures will be combusted until either the hydrogen or oxygen is depleted. As shown in Figures 4.1-5 and 4.1-9, igniters are located through- 
out containment to assure that locally high concentrations of hydrogen are avoided. These igniters are typically glow plugs, requiring $\mathrm{AC}$ power to function.

There are some limitations and concerns associated with igniters. First, they require $A C$ power and will not function during station blackout. Further, if the containment is filled with hydrogen and power is later restored, they could provide a distributed ignition source if the operators do not think to keep them turned off.

Second, there are two regions where higher than average hydrogen concentrations are possible. One is within an ice condenser and the other is above a Mark III suppression pool. In both cases, a steamrich mixture may enter the condensing region, and the gas may emerge very hydrogen-rich. This is particularly true for rapid releases of hydrogen. A third concern relates to accidents more severe than degraded core accidents and to reflooding. Very rapid releases of hydrogen, such as associated with vessel breach or late reflooding, may overwhelm the igniters so that the effect is the same as for a large deflagration. A fourth possibility concerns sequences in which the containment sprays do not function and the containment becomes steam inert. If the hydrogen accumulates in the inert atmosphere, and the sprays are later recovered, a large burn may occur when the containment deinerts.

Despite the concerns raised above, hydrogen igniters are expected to have a positive benefit in many accidents. However, persons responsible for managing accidents need to be aware of the possibilities and use the igniters appropriately.

No additional hydrogen controls have been required for large dry or subatmospheric containments. These containments are large enough and strong enough that deflagrations are not expected to threaten them, except in conjunction with other phenomena. Local detonations are possible, but not considered likely for many accidents. ${ }^{22}$ Detonable mixtures involving most of the containment can not be achieved without complete oxidation of all zirconium, plus additional hydrogen generation from steel oxidation or core-concrete interactions. A large detonation would require all of this hydrogen to be generated, that none of it burn previously, and that the burn undergoes a transition to a detonation. This combination of events is considered unlikely. 
Table 4.6-1 Hydrogen flammability limits in steam-saturated air at room temperature

\begin{tabular}{ccc}
\hline & $\begin{array}{c}\text { Lower Limit } \\
\text { Vol. \% of } \\
\text { Hydrogen }\end{array}$ & $\begin{array}{c}\text { Upper Limit } \\
\text { Vol. \% of } \\
\text { Hydrogen }\end{array}$ \\
\hline Upward Propagation & 4.1 & 74 \\
Horizontal Propagation & 6.0 & 74 \\
Downward Propagation & 9.0 & 74 \\
\hline
\end{tabular}




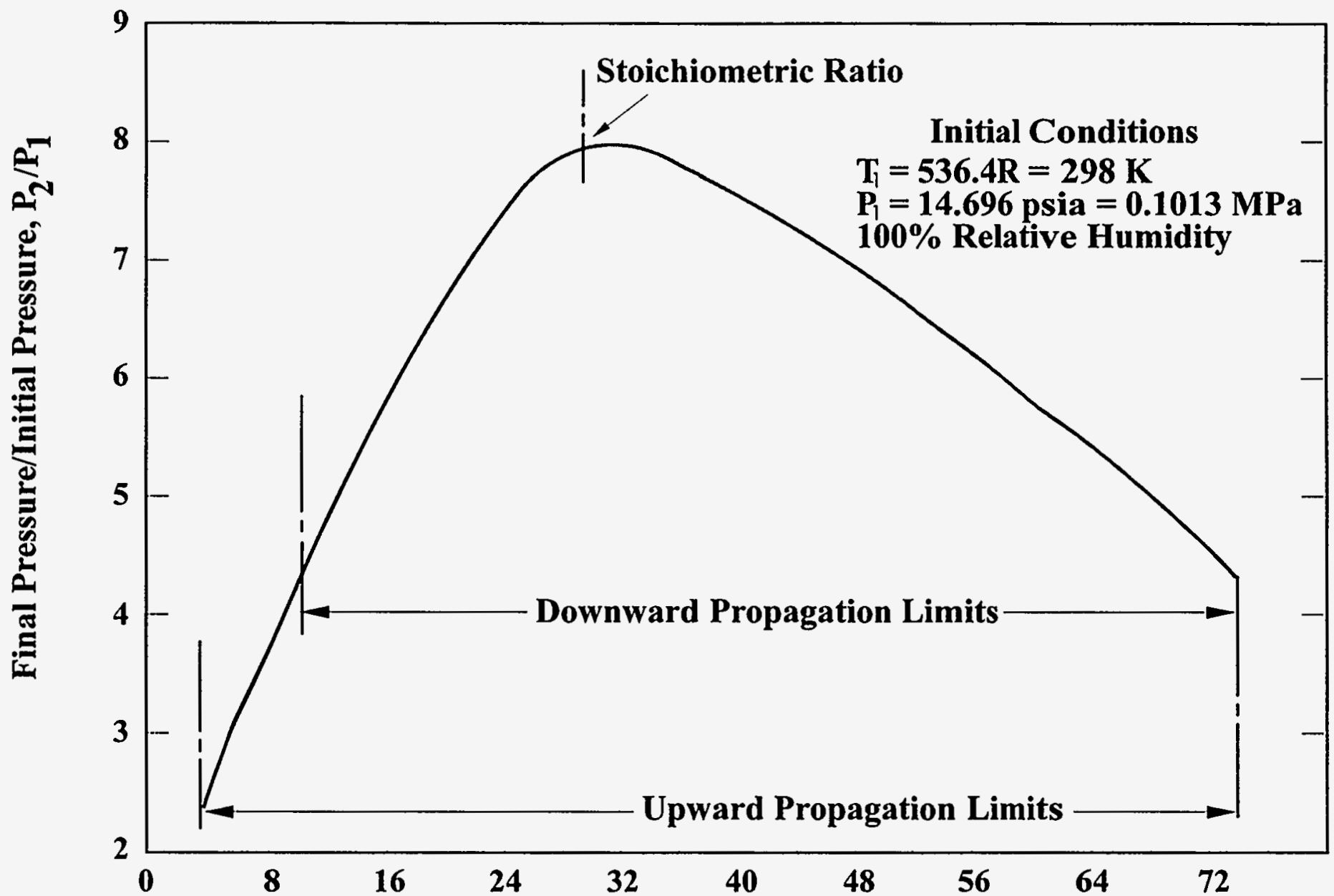

\section{Initial Hydrogen Concentration (vol. \%)}

Figure 4.6-1 Theoretical adiabatic, constant-volume combustion pressure for hydrogen : air mixtures 


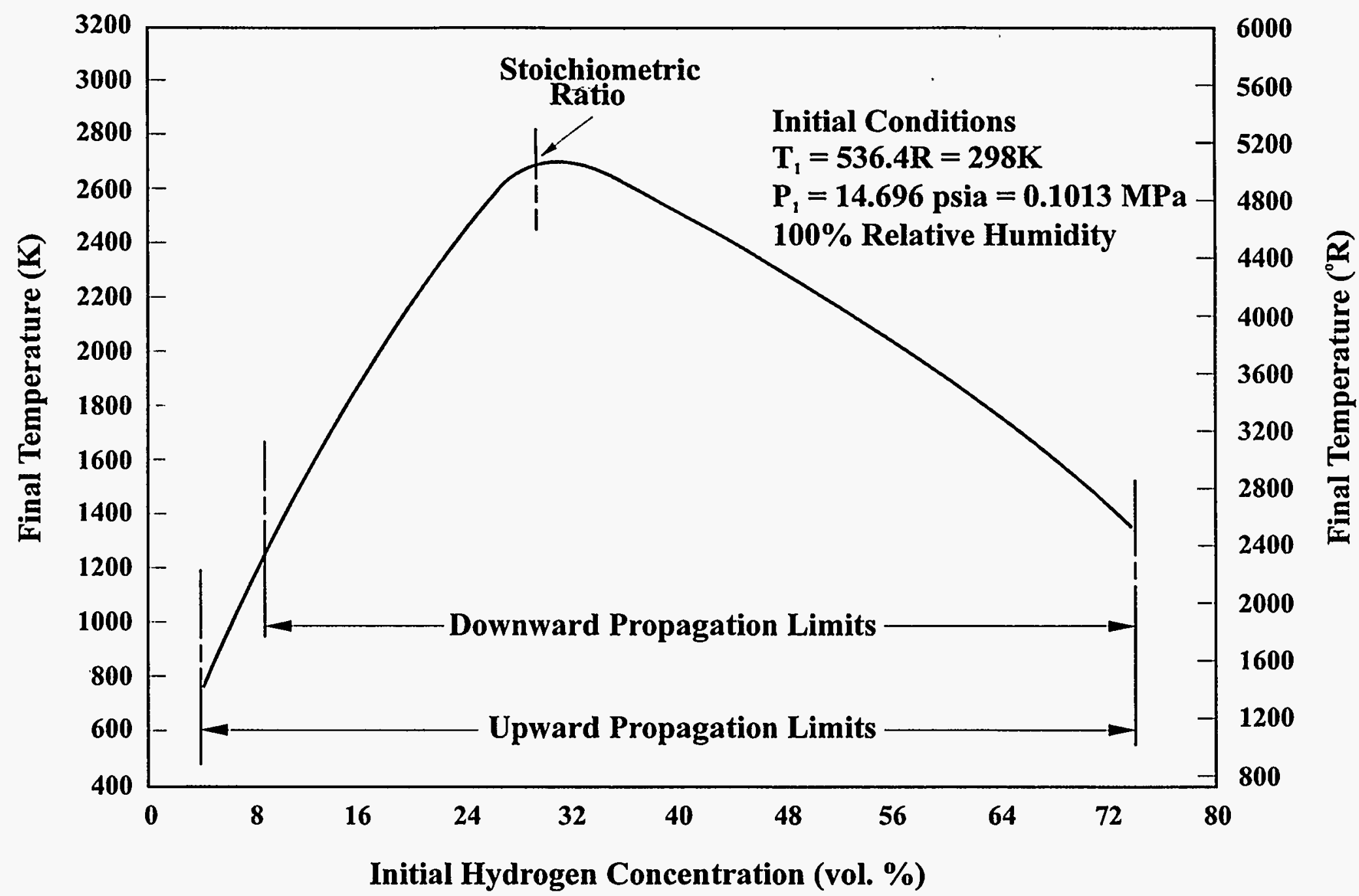

Figure 4.6-2 Theoretical adiabatic, constant-volume combustion temperature for hydrogen : air mixtures 


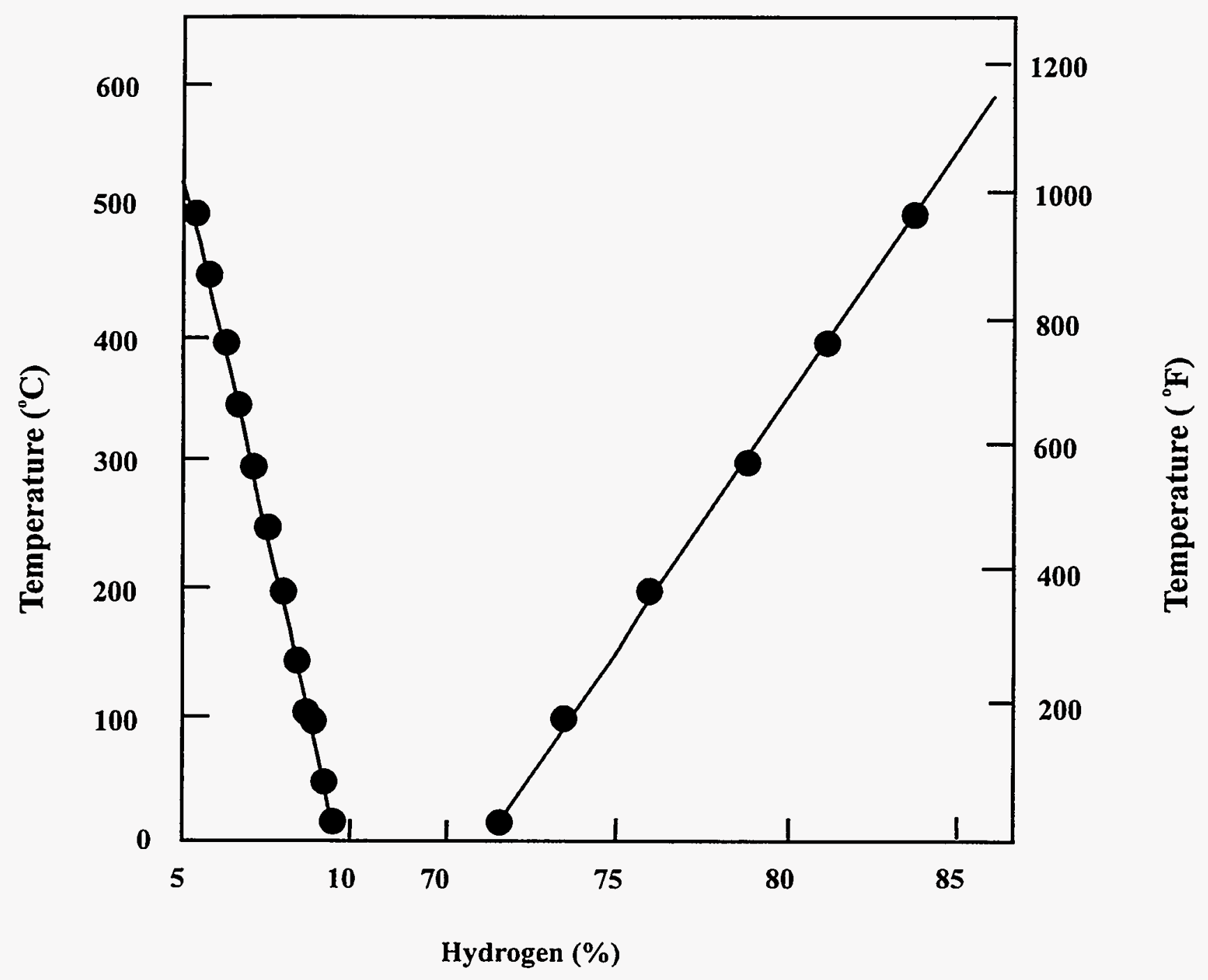

Figure 4.6-3 Effect of initial temperature on downward propagating flammability limits in hydrogen : air mixtures 


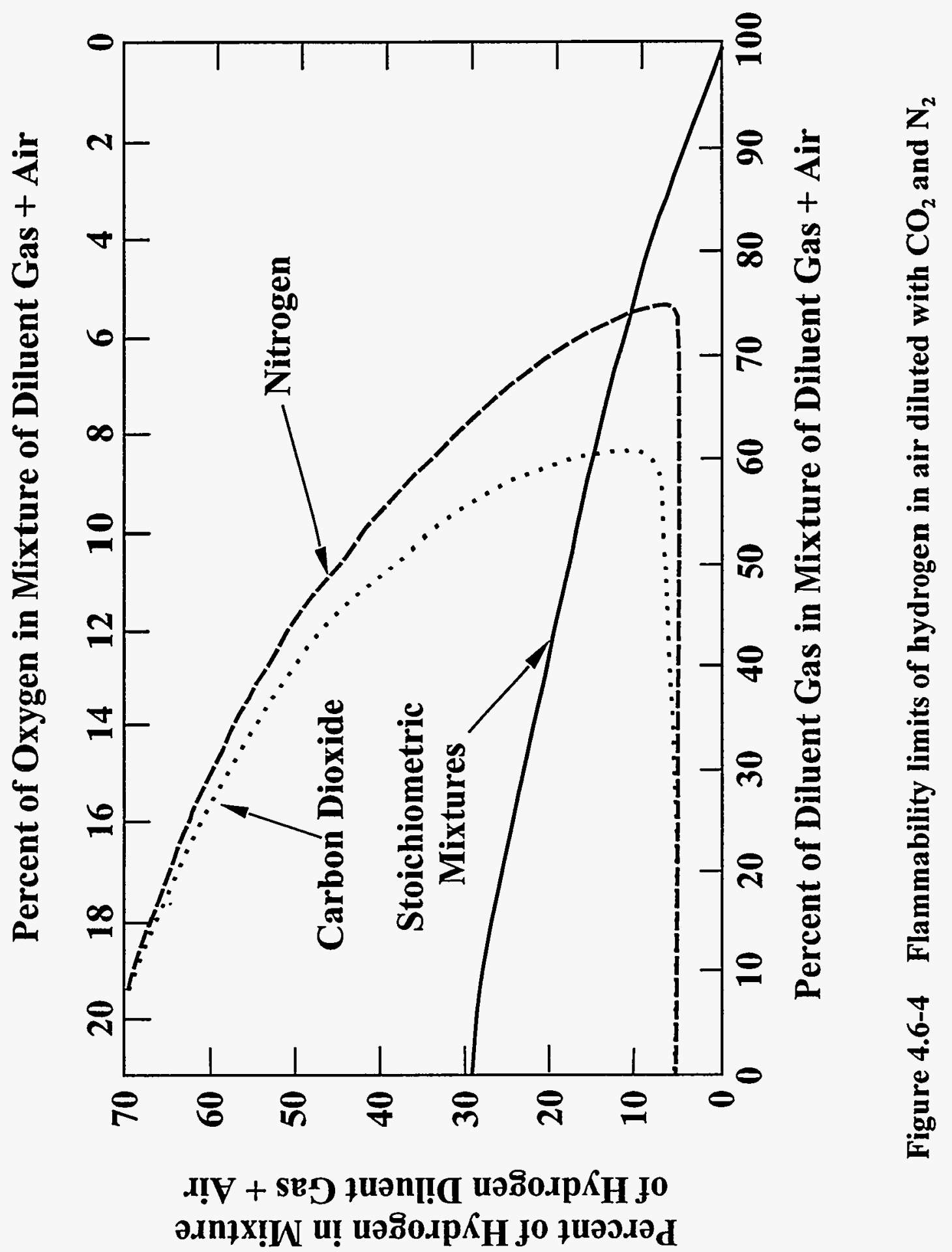




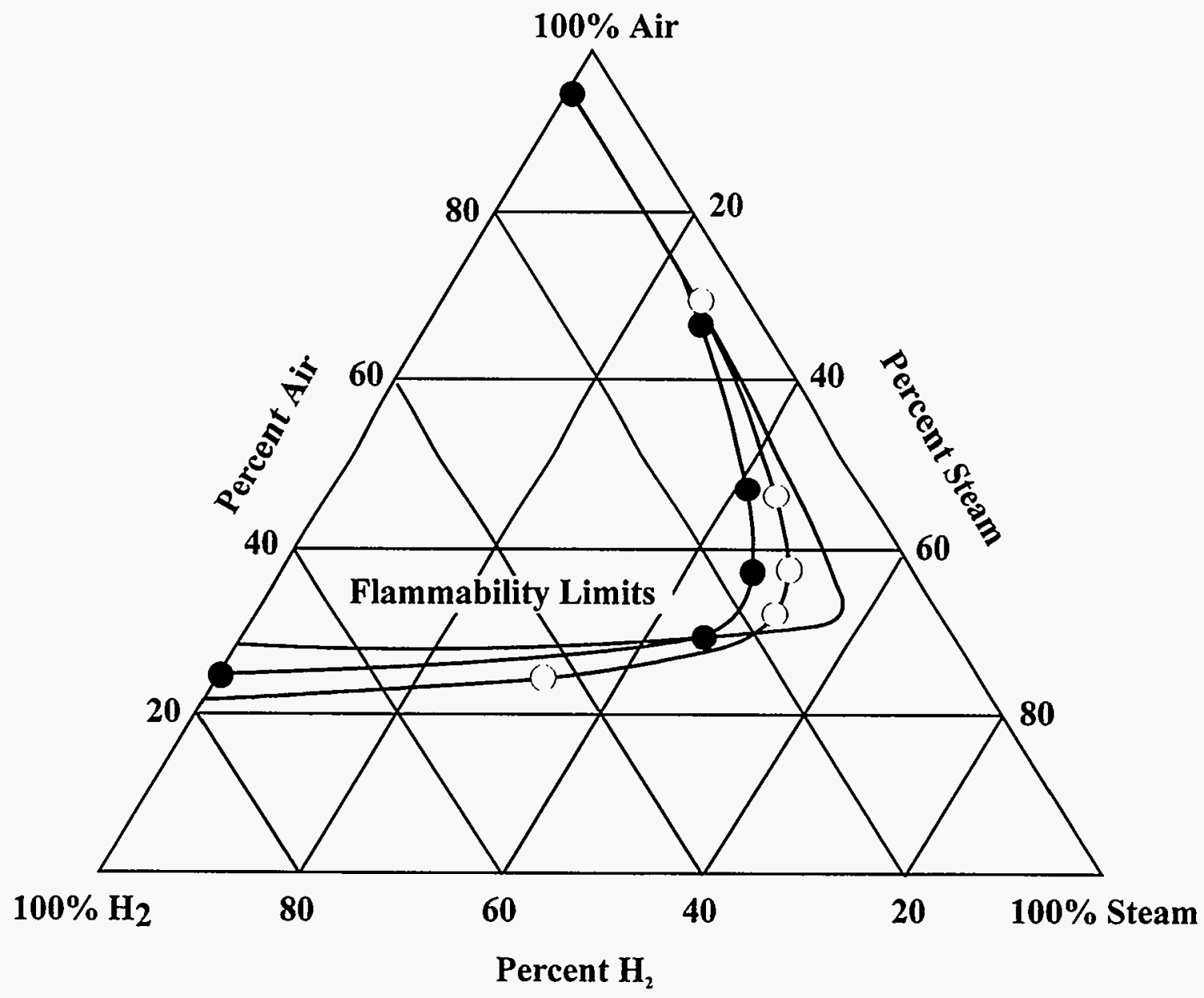

Flammability Limits

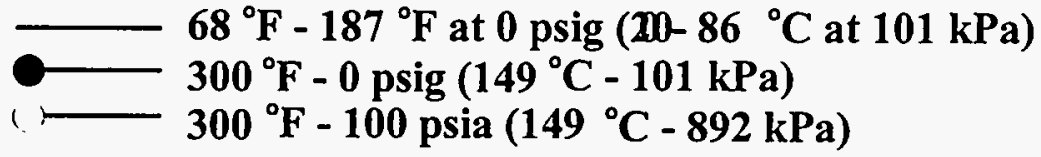

Figure 4.6-5 Flammability limits of hydrogen : air : steam mixtures 


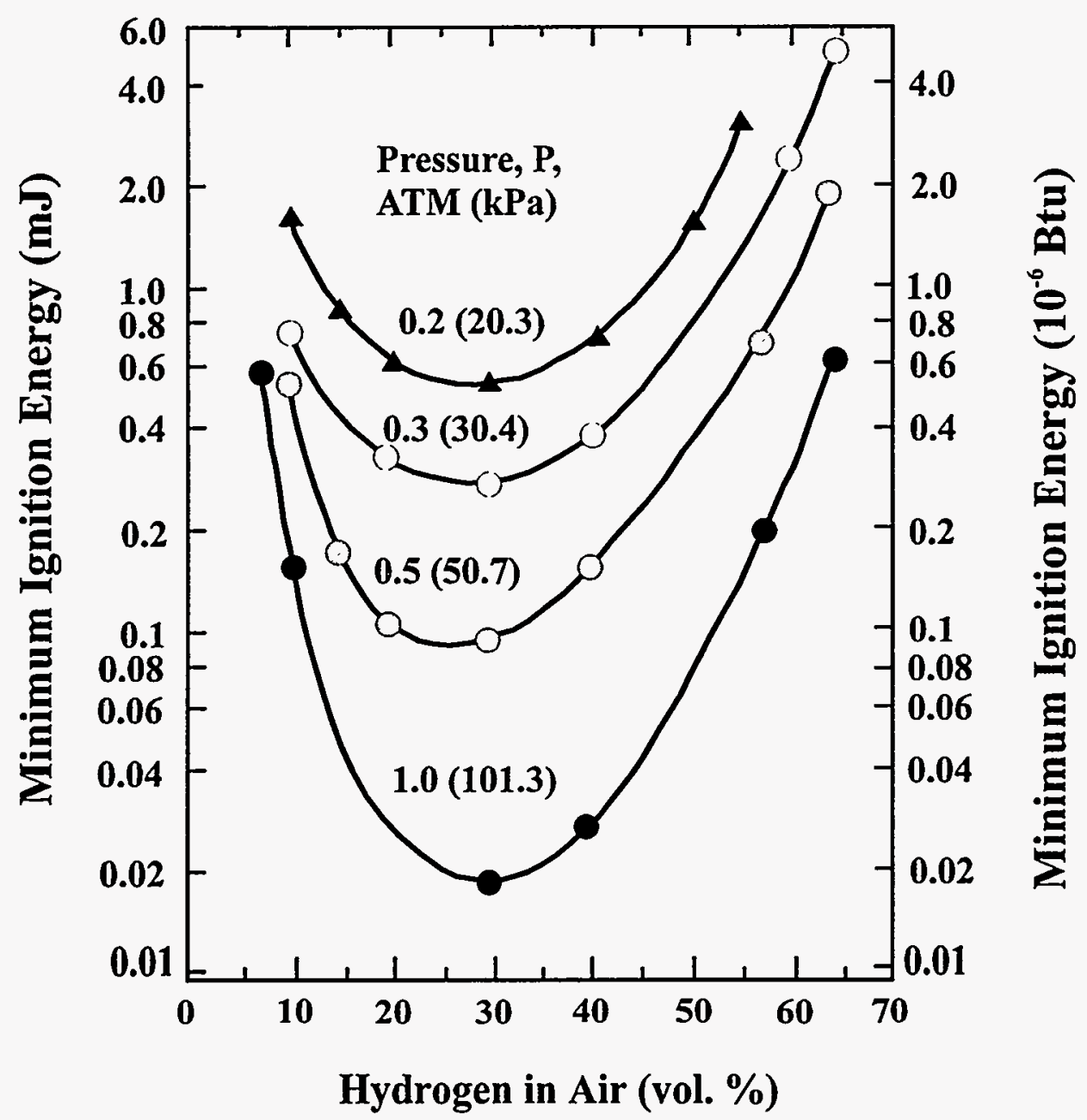

Figure 4.6-6 Spark ignition energies for dry hydrogen : air mixtures 


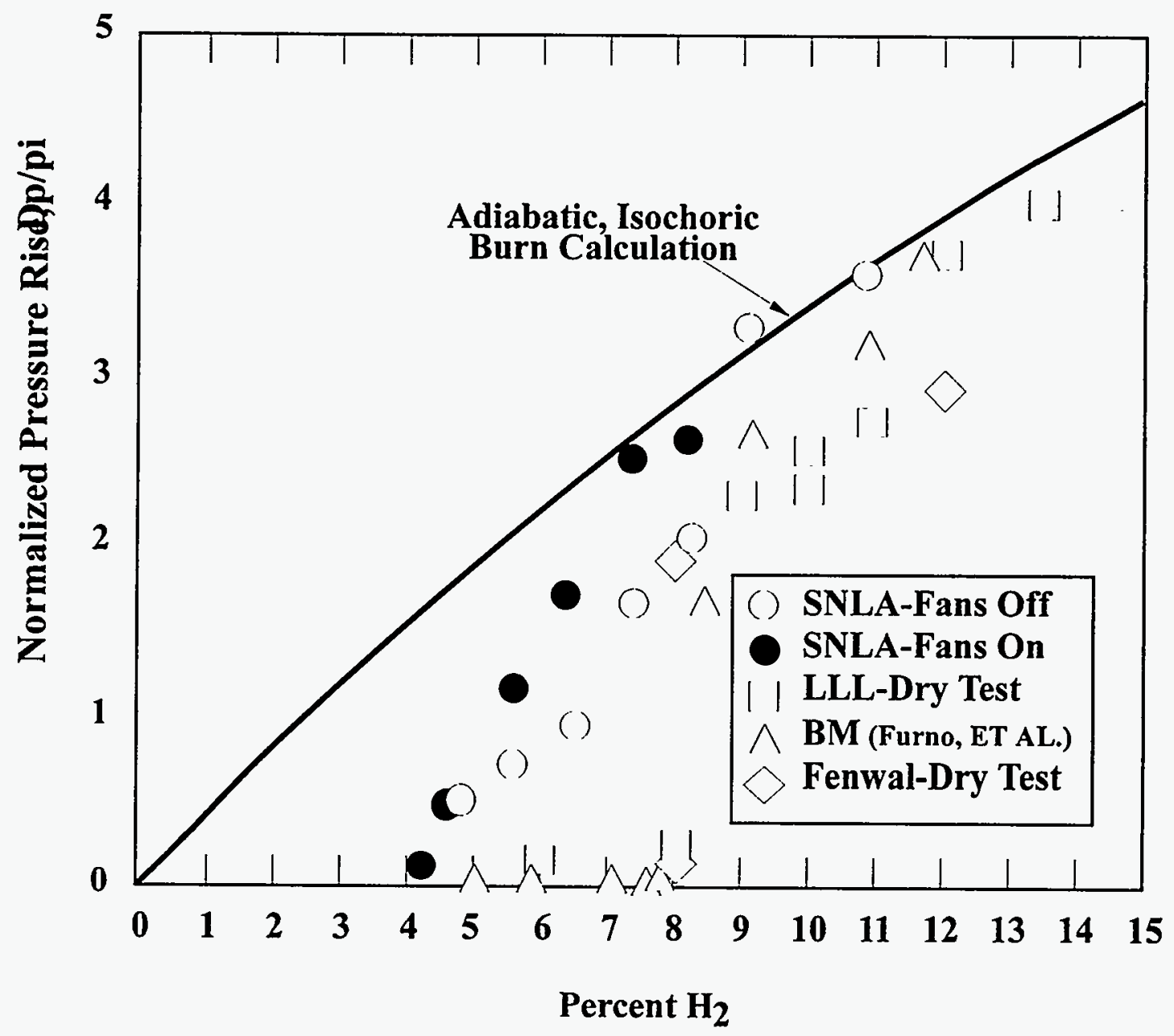

Figure 4.6-7 Normalized pressure rise versus hydrogen concentration 


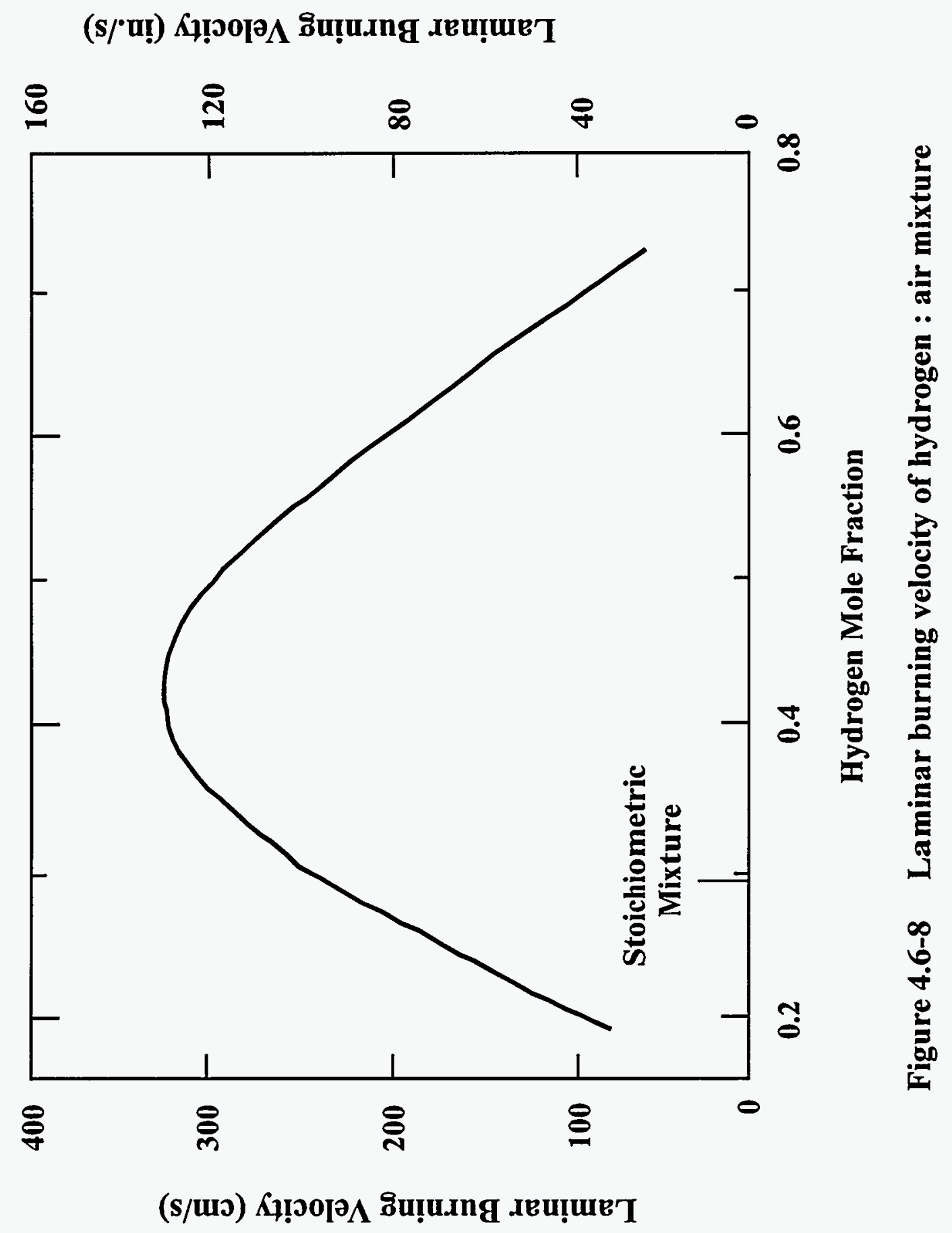




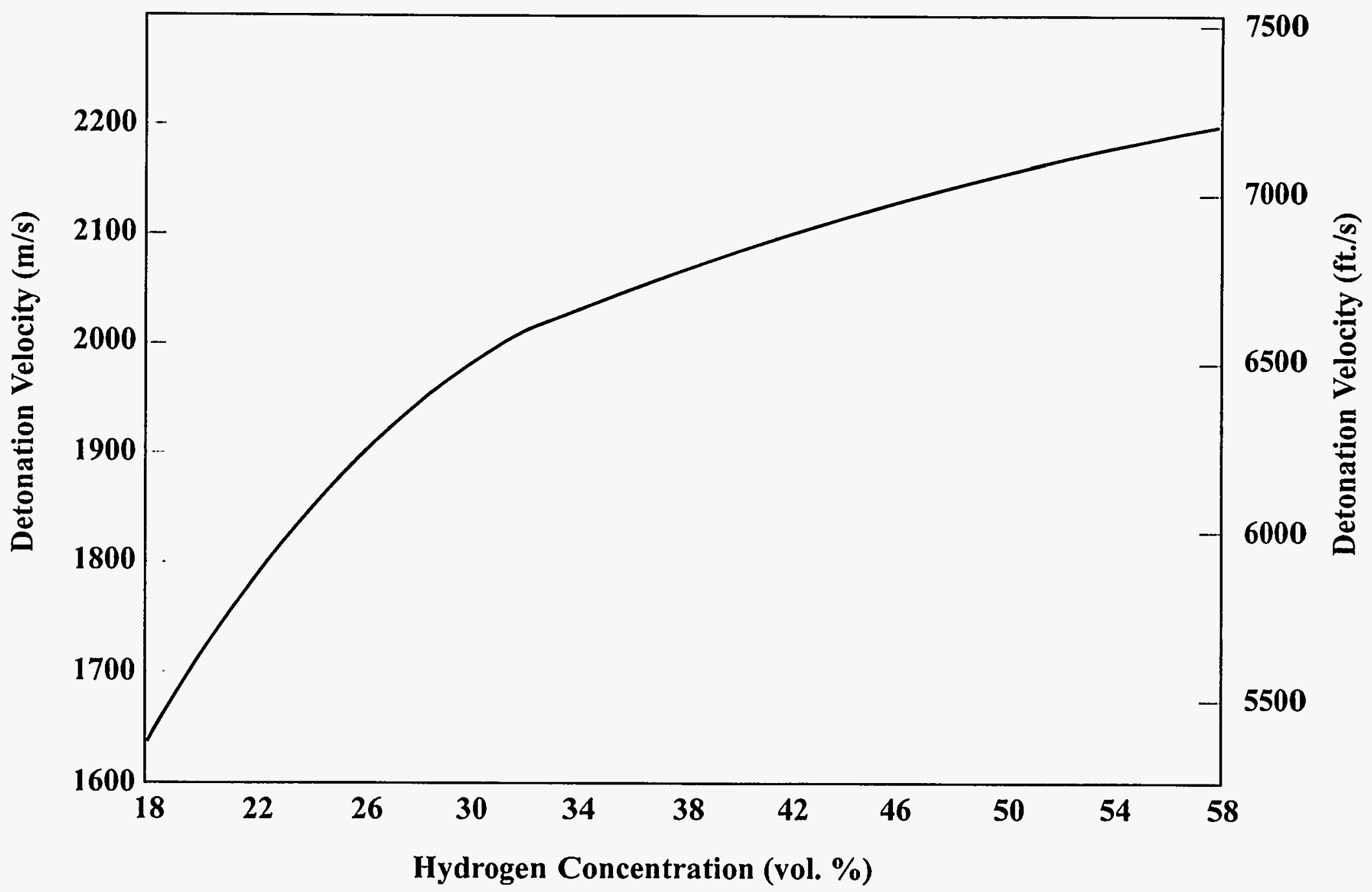

Figure 4.6-9 Theoretical detonation velocities for hydrogen : air mixture 


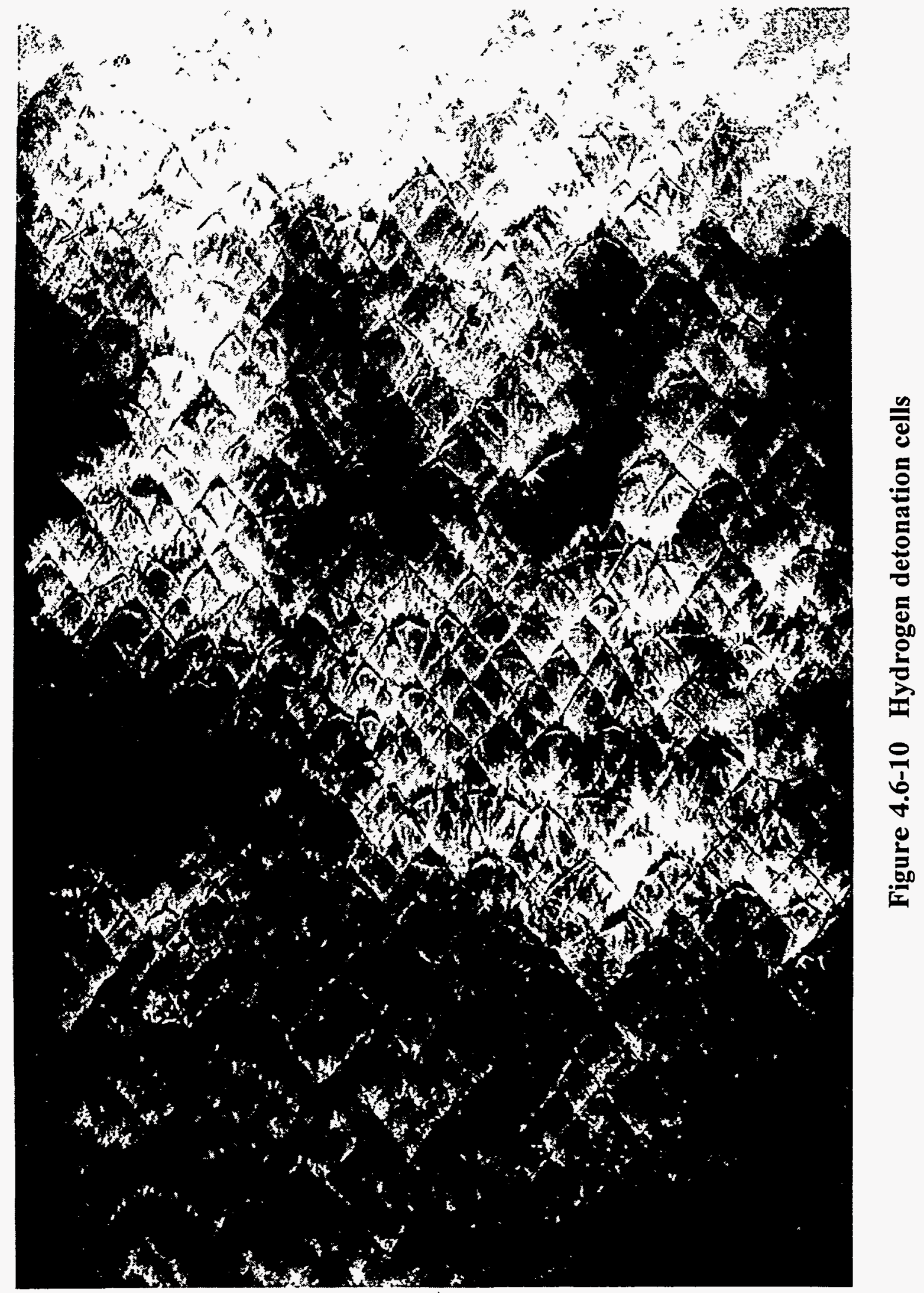




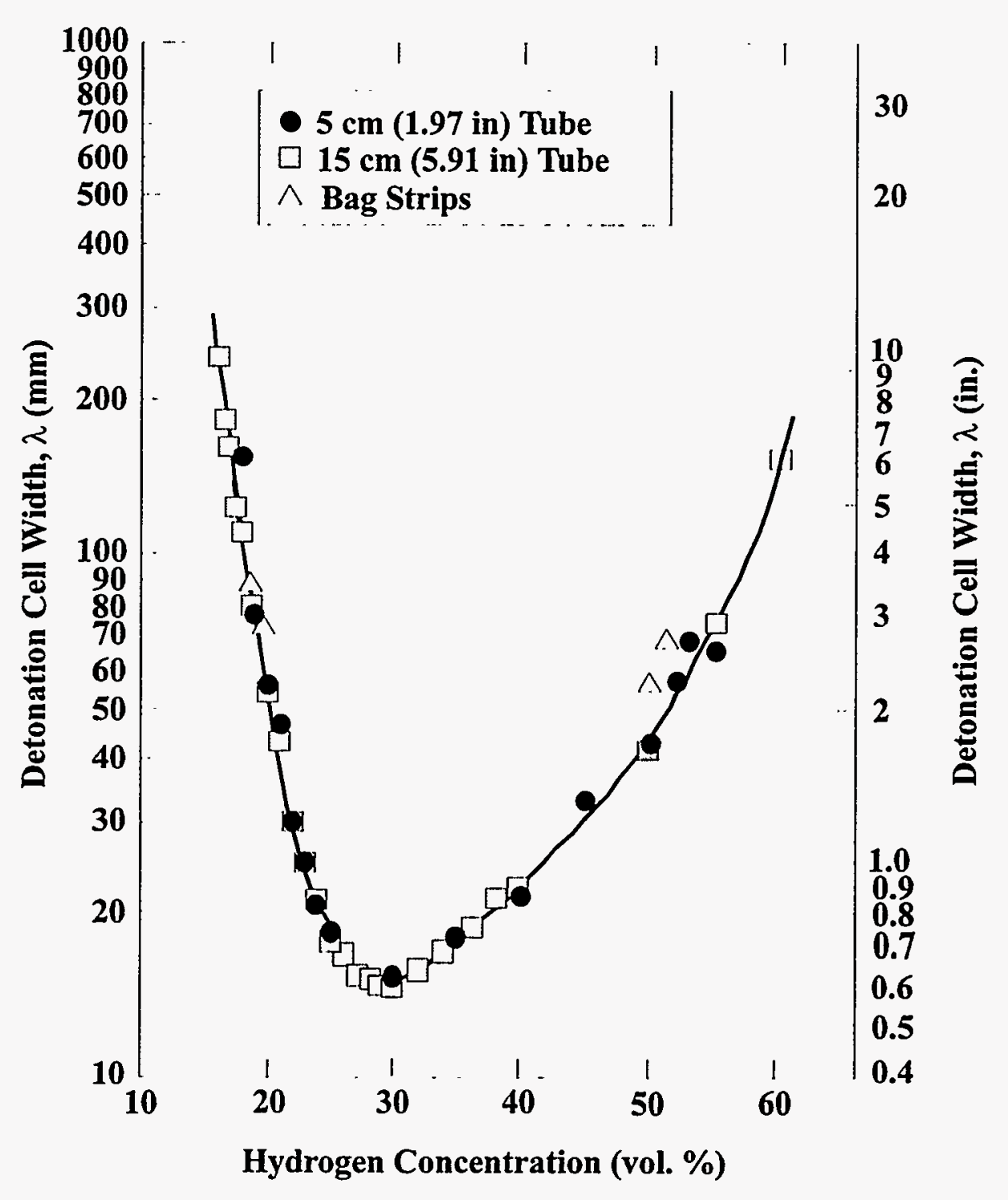

Figure 4.6-11 Measurement of detonation cell size for hydrogen : air mixtures at atmospheric pressure 


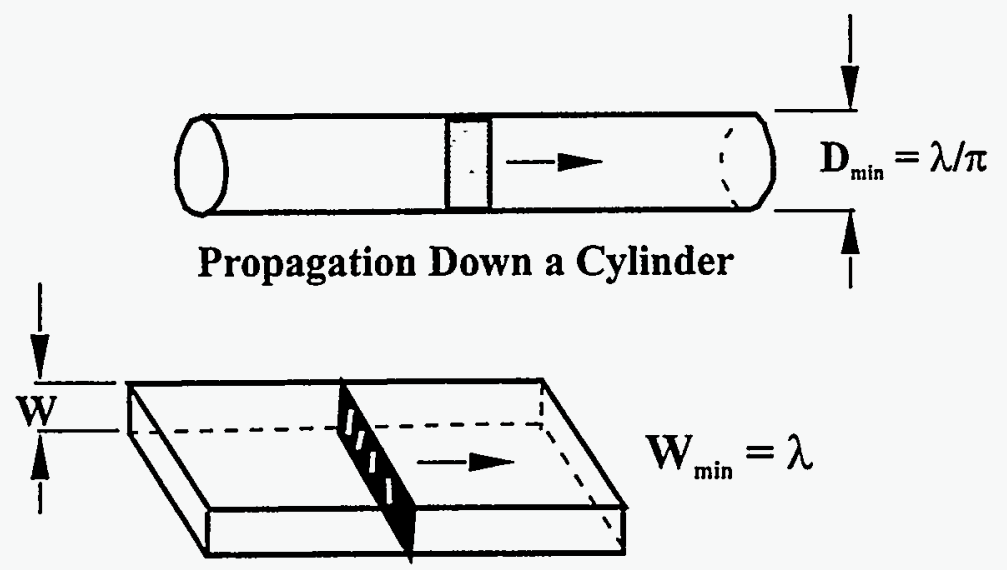

Propagation Down Two - Dimensional Channels

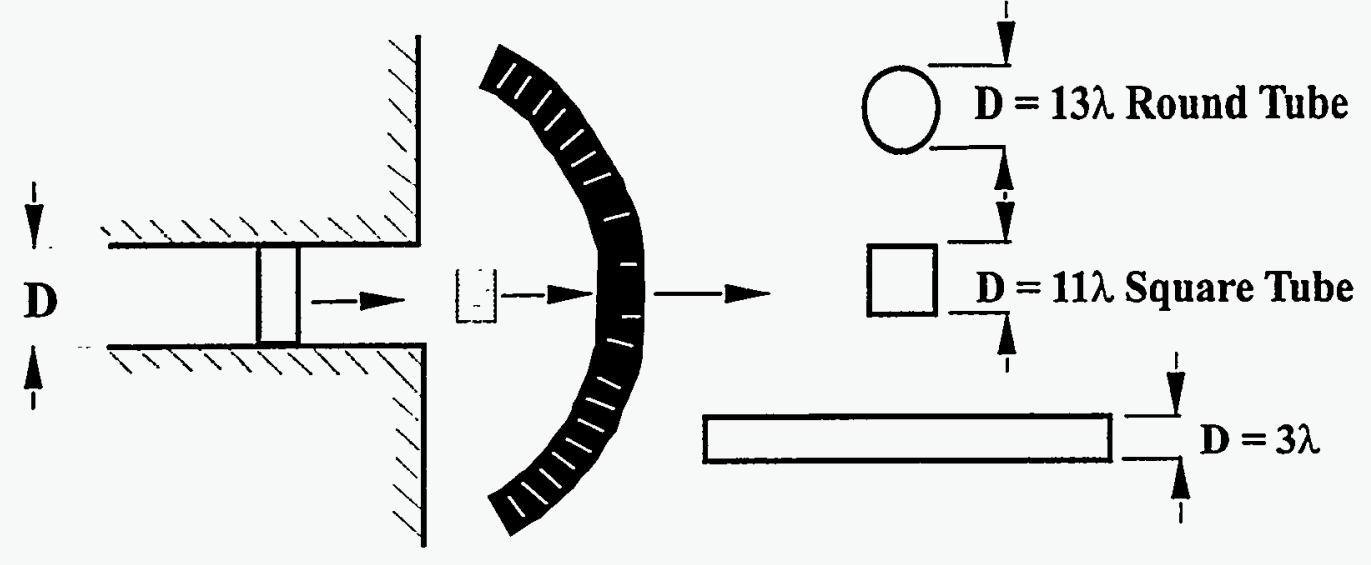

Propagation From a Tube into a Large Open Space

"Critical Tube Diameter"

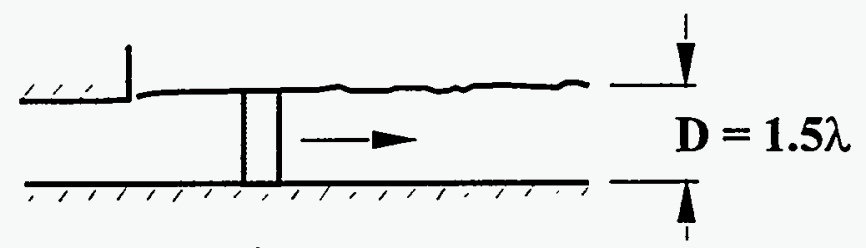

Minimum Cloud Thickness for Propagation

Confined on an One Side

Figure 4.6-12 Dimensions required for detonation propagation in various geometries 


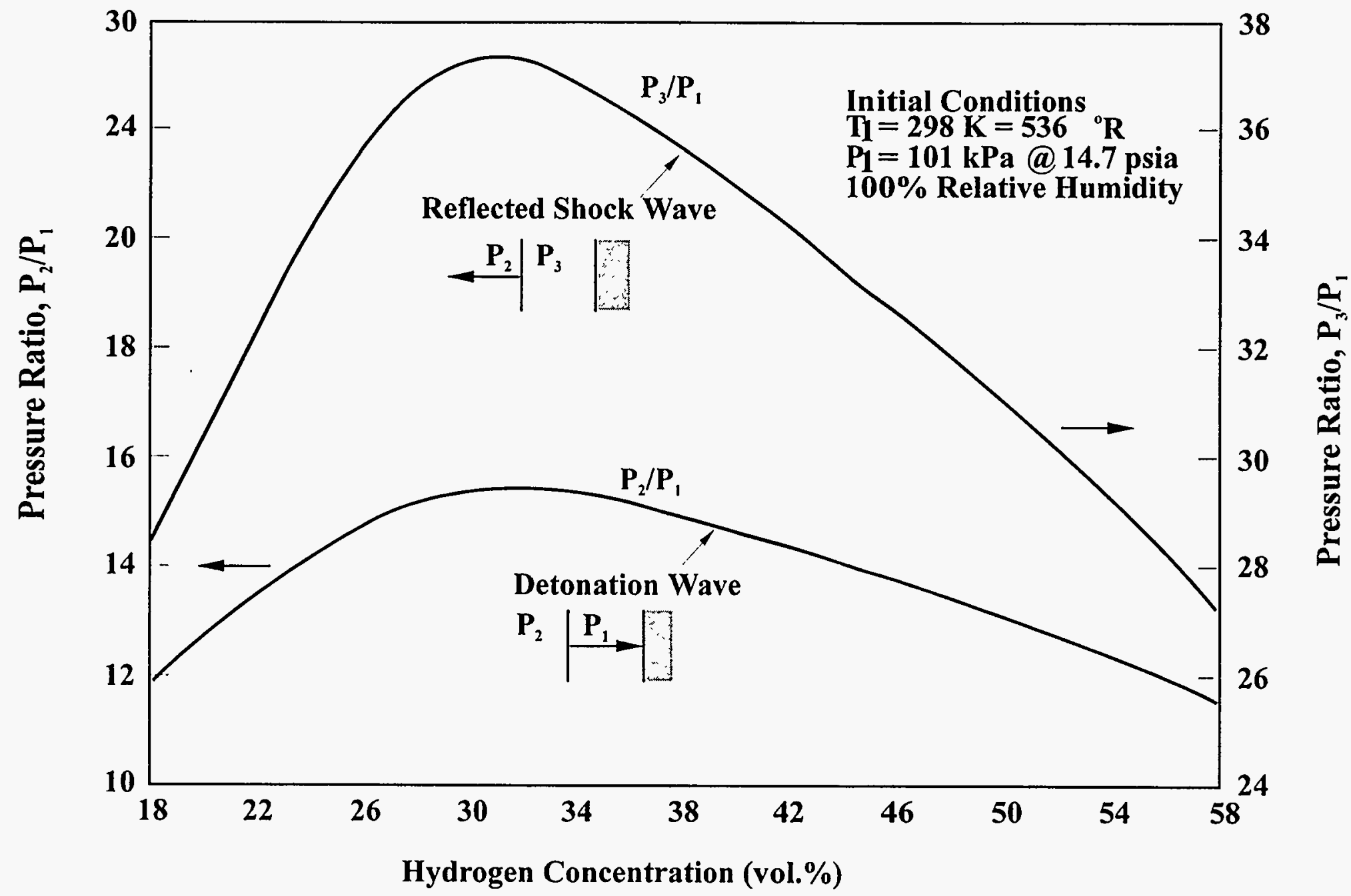

Figure 4.6-13 Theoretical detonation pressure and normally reflected pressure 


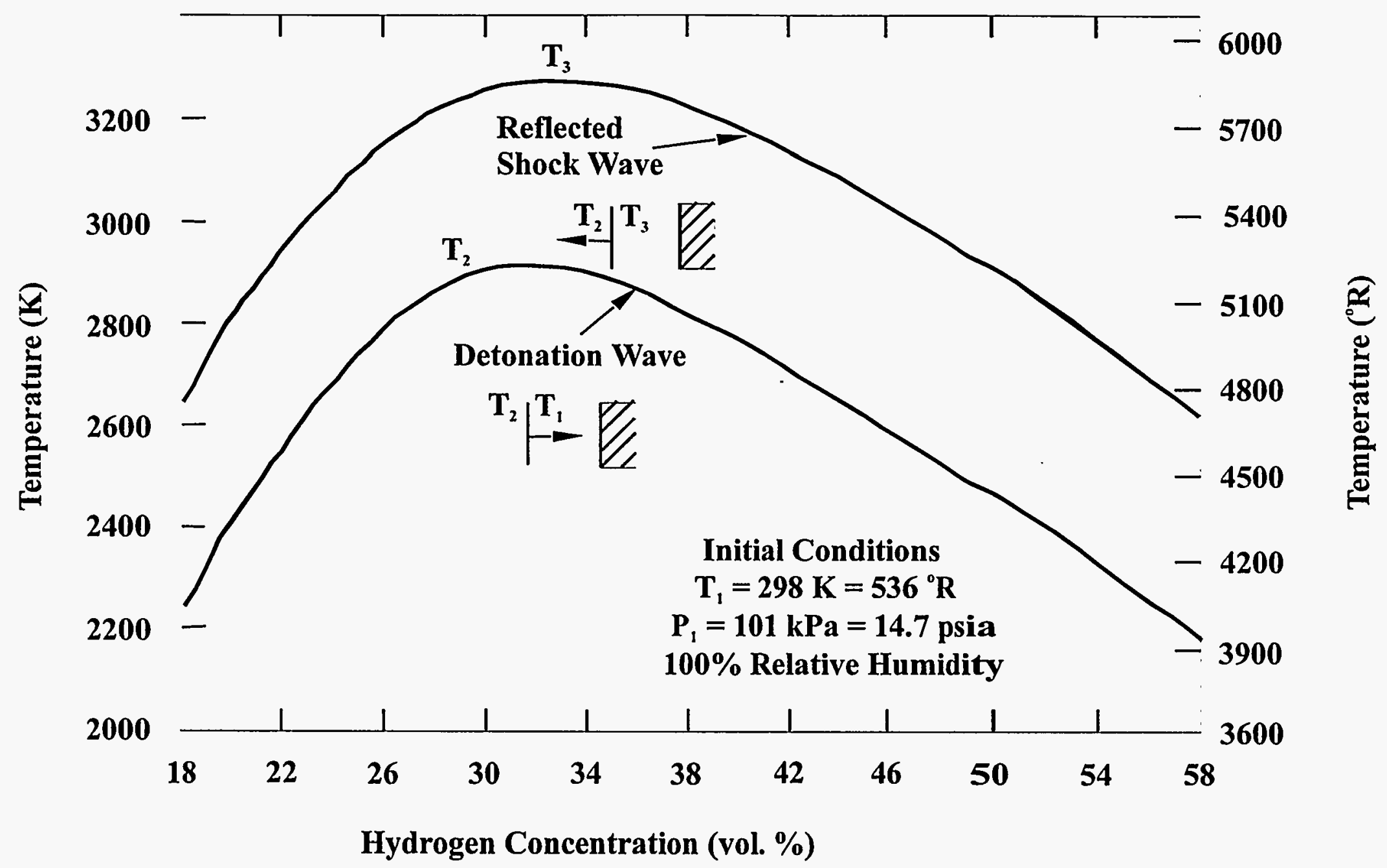

Figure 4.6-14 Theoretical detonation temperature and normally reflected detonation temperature 


\section{Flame Scaling}

Structure Determined by Source Froude Number, F

$$
\mathbf{F}=\rho \mathbf{U}^{2} / g \Delta \rho \mathbf{D}
$$

- $F>1$ Jet-Like Flames

- $\mathbf{F}<1$ Plume-Like Flames

Flow Rate $\left(\mathrm{lb}_{\mathrm{m}} / \mathrm{s}\right)$

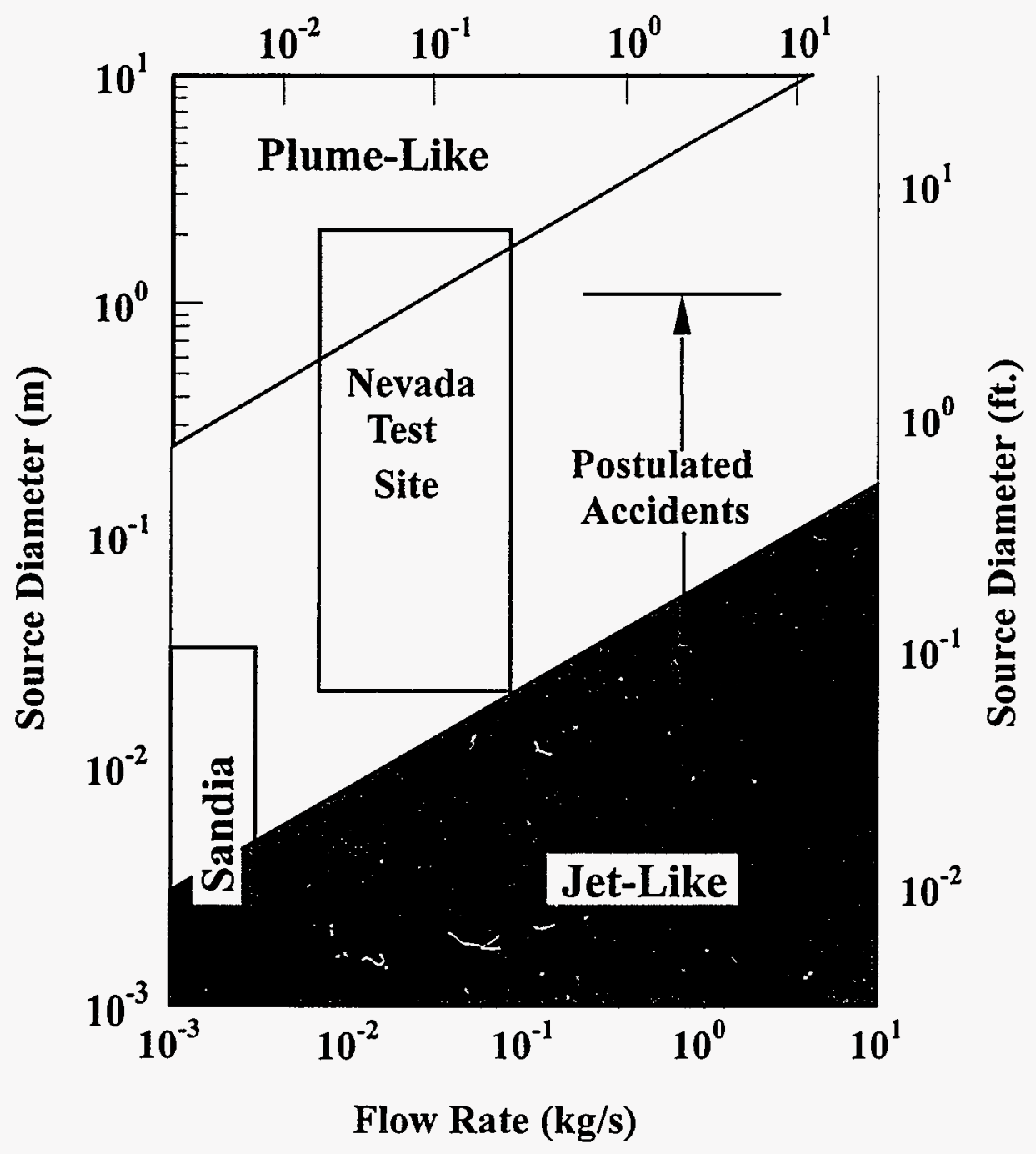

Figure 4.6-15 Flame structures for a range of geometries and flow rates 


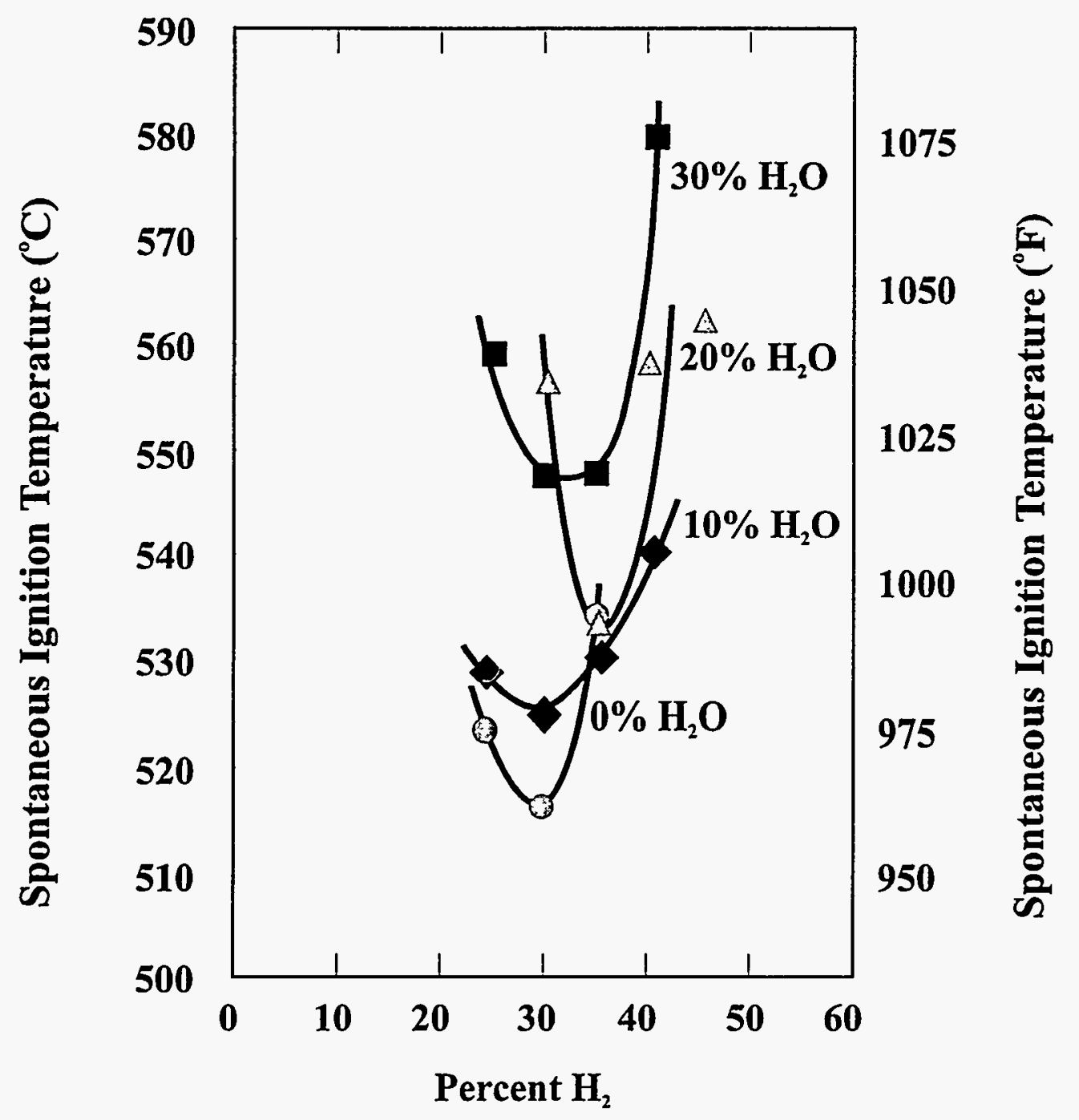

Figure 4.6-16 Minimum spontaneous ignition temperatures 


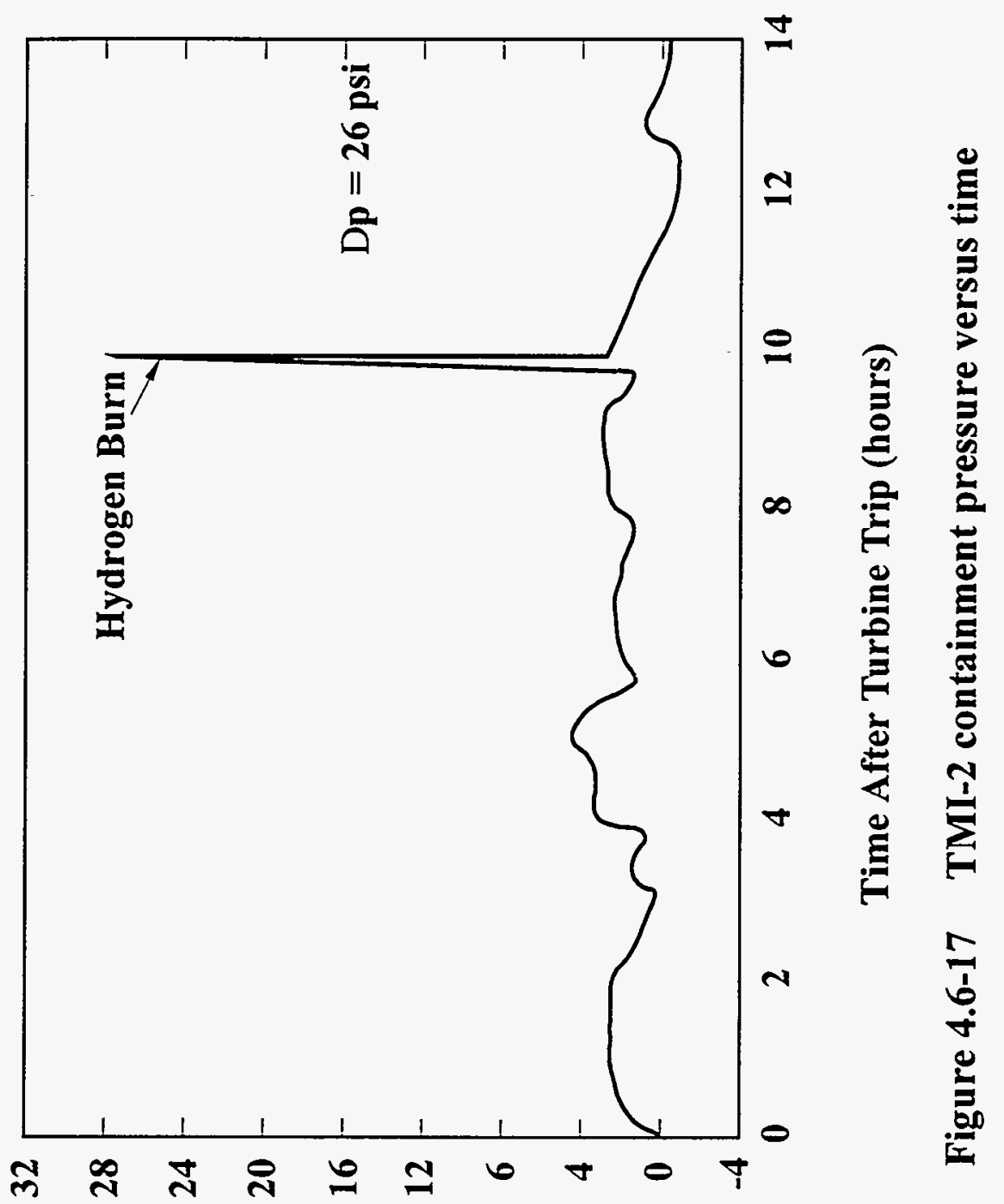

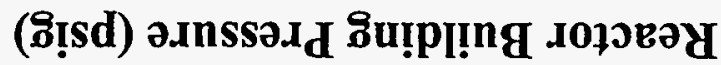




\section{References for Section $\mathbf{4 . 6}$}

1. A. L. Camp, et al., "Light Water Reactor Hydrogen Manual," NUREG/CR-2726, SAND82-1137, Sandia National Laboratories, August 1983.

2. E. P. Coward and G. W. Jones, "Limits of Flammability of Gases and Vapors," Bulletin 503, Bureau of Mines, U. S. Department of Interior, 1952.

3. B. Bregeon, et al., "Near-Limit Downward Propagation of Hydrogen and Methane Flames in Oxygen-Nitrogen Mixtures," Combustion \& Flame, 33:33$45,1978$.

4. Z. M. Shapiro and T. R. Moffette, "Hydrogen Flammability Data and Application to PWR Loss-of-Coolant Accident," WAPD-SC-545, Bettis Plant, September 1957.

5. I. L. Drell and F. E. Belles, "Survey of Hydrogen Combustion Properties," $N A C A \quad R \quad 1383$, National Advisory Committee for Aeronautics, 1958.

6. A. L. Furno, E. B. Cook, J. M. Kuchta and D. S. Burgess, "Some Observations on Near-Limit Flames," 13 Symposium on Combustion, Pittsburgh Combustion Institute, 593-599, 1971.

7. B. C. Slifer and T. G. Peterson, "Hydrogen Flammability and Burning Characteristic in BWR Containments," NEDO-10812, 73NED49, General Electric, April 1973.

8. M. P. Paulson and J. O. Bradfute, "Pressure and Temperature Transients Resulting from Postulated Hydrogen Fires in Mark III Containments," EI 75 4, Energy Inc., 1981.
9. M. Berman, "Light Water Reactor Safety Research Program Quarterly Report," January-March, 1981, NUREG/CR2163,1 of 4 , SAND81-1216,1 of 4, Sandia National Laboratories, Albuquerque, New Mexico, July 1981.

10. W. E. Lowry, et al., "Final Results of the Hydrogen Igniter Experimental Program," NUREG/CR-2486, UCRL53036, Lawrence Livermore National Laboratory, February 1982.

11. M. Berman, "Light Water Reactor Safety Research Program Semiannual Report," April-September 1981, NUREG/CR2481, SAND82-0006, Sandia National Laboratories, Albuquerque, New Mexico, February 1982.

12. Yu. M. Annushkin and E. D. Sverdlov, "Stability of Submerged Diffusion Flames in Subsonic and Underexpanded Supersonic Gas-Fuel Streams," Translation, Combustion, Explosions, and Shock Waves, 14, 5, 1978.

13. C. M. Guirao, R. Knystautas, J. H. Lee, W. Benedick, and M. Berman, "Hydrogen-Air Detonations," presented at the 1982 Combustion (International) Symposium, Haifa, Israel, 1982.

14. D. W. Stamps and M. Berman, "A Critical Review of High-Temperature Hydrogen Combustion in Reactor Safety Applications," SAND88-0680C, International Conference on Thermal Reactor Safety, Avignon, France, October 1988.

15. R. K. Byers, "CSQ Calculations of $\mathrm{H}_{2}$ Detonations in the Zion and Sequoyah Nuclear Plants," NUREG/CR-2385, SAND81-2216, Sandia National 
Laboratories, Albuquerque, New Mexico, July 1982.

16. M. A. Delichatsios, M. B. Genadry, and M. N. Fardis, "Calculations of Hydrogen Detonations in Nuclear Containments by the Random Choice Method," M.I.T., R81-30, December 1981.

17. Z. M. Shapiro and T. R. Moffette, "Hydrogen Flammability Data and Application to PWR Loss-of-Coolant Accident," September 1957.

18. J. E. Shepherd, "Hydrogen-Steam JetFlame Facility and Experiments," NUREG/CR-3638, SAND84-0060, Sandia National Laboratories, February 1985.
19. M. Berman, Light Water Reactor Safety Research Program Semiannual Report, April-September 1981, February 1982.

20. "Technical Aspects of Hydrogen Control and Combustion in Severe Light-Water Reactor Accidents," National Academy Press, Washington, D.C., 1987.

21. Title 10, Code of Federal Regulations, Part 50.44, U.S. Government Printing Office, January 1, 1991.

22. M. P. Sherman and M. Berman, "The Possibility of Local Detonations During Degraded-Core Accidents in the Bellefonte Nuclear Power Plant," NUREG/CR-4803, SAND86-1180, Sandia National Laboratories, January 1987. 


\subsection{BWR Mark I Liner Failure By Melt Attack}

Because of its relatively small enclosed volume and drywell floor area, the BWR Mark I containment structural boundary is particularly vulnerable to failure by overpressure or by direct contact attack should molten core and structural debris leave the reactor vessel. Numerous analyses of the potential for early failure of the containment pressure boundary due to direct interaction with corium have been published, beginning with Reference 1 . According to NUREG-1150 (Section 12.4, Perspectives), "At Peach Bottom, drywell meltthrough is the most important mode of containment failure."

In 1988, the NRC Office of Research began a dedicated major effort toward resolution of the Mark I liner failure issue. The approach involved an initial decomposition of the overall issue into considerations of melt release from the reactor vessel, melt. spreading over the containment floor, and thermal loading of the drywell shell. The results of this effort, which is purported to be a "mechanistic treatment of the sequence of physical phenomena that lead to liner contact by corium debris, and their coupling through a probabilistic framework that allows representation of uncertainties,",2 are documented in References 2 and 3.

The following subsections address the prospects for spreading of debris liquids to the steel drywell shell in a manner that would induce failure of that boundary, and the mitigative measures that might be taken. Following a description of the specific features of the Mark I containment that are relevant to this issue, the decomposition categories of melt release, melt spreading, and thermal attack are each discussed. Finally, an assessment of the mitigative effects of water and a summary of the current status of this issue are provided in Subsections 4.7.5 and 4.7.6, respectively.

\subsubsection{Pertinent Features of the Mark I Containment Design}

The typical BWR Mark I primary and secondary containment configuration is shown in Figure 4.7-1. With the sole exception of the two Brunswick units, which employ steel-lined reinforced concrete structures, all Mark I primary containments incorporate free standing steel structures. Thus, while "liner failure" is correct for identification of the direct corium attack issue with respect to the Brunswick units, it is a misnomer for the other 22 Mark I units, where "shell failure" would be more appropriate. Nevertheless, by historical repetition, "liner failure" has become the general appellation for this issue at all BWR facilities.

It should be recognized that plant-specific containment design differences abound, many with important ramifications with respect to plant response under severe accident conditions. This is true even for supposedly "sister" plants such as Browns Ferry and Peach Bottom.

With respect to the potential for emergent corium to come into contact with the carbon steel drywell shell at the level of the floor, it is important to first note that here also, any detailed analysis must take plant-specific differences into consideration. This discussion is based on the Peach Bottom/Browns Ferry configuration. Figure 4.7-2 provides a plan view of the intersection of the base of the reactor pedestal with the concrete floor. As indicated, there is a single doorway to direct any flow from the inpedestal region toward the opposite portion of the drywell wall. The distance from the point directly underneath the reactor vessel centerline to 
the closest point of the drywall wall is only about $7 \mathrm{~m}(22.85 \mathrm{ft}$.).

Figure 4.7-3 shows the placement of all reactor pedestal penetrations at Browns Ferry, and confirms that the doorway provides the only opening extending to the level of the floor. The location of the drywell sumps within the pedestal region is also shown in this figure.

The pedestal doorway and door at Peach Bottom are shown at the left side of Figure 4.7-4. This photograph also shows a portion of the carbon steel sump cover, which occupies a central rectangular section of the pedestal region floor. The existence of the sumps is a factor with respect to the potential for debris spreading since erosion of the thin sump cover would permit a significant fraction of the emergent debris to be retained in the sumps. The sump volume is about $5.7 \mathrm{~m}^{3}\left(200 \mathrm{ft}^{3}\right.$. $)$ at both Browns Ferry and Peach Bottom.

Another pertinent plant-specific difference involves the entrances to the vent pipes, which lead to the pressure suppression pool as illustrated in Figure 4.7-1. As shown in Figure 4.7-5, the lower lip of the vent pipe shielded opening is located on the sloping drywell wall a short distance (about $0.61 \mathrm{~m}$ [2 ft.]) above the floor. At Peach Bottom, one of these vent pipes lies directly opposite the pedestal doorway. This is not the case at Browns Ferry, where this doorway faces a portion of the drywell wall midway between two of the vent pipe entrances.

\subsubsection{Characteristics of Debris Pours From Vessel}

Before undertaking to address debris flow through the pedestal doorway and spreading in the expedestal region, it is necessary to first select appropriate representative debris releases (rates, quantities, compositions, and temperatures) from the reactor vessel. Since the ultimate purpose of this selection process is for use in exploring means for mitigation, it is reasonable to exclude accident scenarios involving high-pressure melt ejection, for which failure of the shell integrity is virtually certain by means of $\mathrm{DCH}$, liner melt, or overpressurization. (It is of course a goal of BWR accident management that high pressure severe accident sequences not occur. These have not been analyzed; see discussion in Section 3.7.2.)

The Mark I liner failure study ${ }^{2,3}$ recognizes the existence of major uncertainties in the calculation of in-vessel core melt progression and therefore considers two debris pours, each associated with the predictions of a different severe accident code. It is important to recognize that this study is focused upon low-pressure accident sequences and the potential for "early" containment failure, that is, failure in conjunction with the initial release from the reactor vessel, before the aerosols have had time to settle. The two selected pours, which are described below, are intended to bound the spectrum of debris compositions that might reasonably be expected to be encountered within the realm of interest.

\subsubsection{Scenario I: Large Initial Pour of Molten Oxides}

The pour represented as Scenario I derives from calculations performed by the industrysponsored MAAP code ${ }^{6}$. In-vessel melt progression resembles the TMI event and is characterized by holdup of debris in the core region in the form of a large pool of molten oxides mixed with superheated metallic zirconium within a crucible-shaped metallic supporting crust. Eventually, a large portion of the molten pool breaks through the metallic crust, and enters the lower plenum while pushing the water away. There is little interaction between the flowing oxides 
and the water, or with the lower plenum stainless steel structures, except to cause immediate penetration failures. The liquid zirconium-oxide mixture then drains into the containment over a period of about five minutes.

The Mark I liner failure study ${ }^{2}$ employs probability density functions for the pour. characteristics, but it is appropriate to think of Scenario $I$ as an initial rapid release of $12.5 \mathrm{~m}^{3}\left(441 \mathrm{ft}^{3}\right)$ of $20 \%$ zirconium metal in a $\mathrm{UO}_{2}-\mathrm{ZrO}_{2}$ ceramic mixture with negligible $\left(50 \mathrm{~K}\left[90^{\circ} \mathrm{F}\right]\right)$ superheat. All water then drains from the vessel, and the subsequent debris release is relatively very slow, corresponding to the rate at which the debris remaining within the vessel melts. Specifically, the study considers an additional $7.5 \mathrm{~m}^{3}$ (265 $\mathrm{ft}^{3}$ ) of the same debris composition to be released into the containment over the next 150 minutes.

\subsubsection{Scenario II: Metallic Pour Followed by Release of Oxides}

The Scenario II pour derives from the results of the BWRSAR code ${ }^{7}$, which was sponsored at the time by the NRC. (Subsequently, many of the BWRSAR models have been made operational within MELCOR.) Here the core melt progression is that described in Sections 3.7.5 and 3.7.6 for the dry case. Basically, debris relocating into the lower plenum is quenched by the water there. The remaining water is boiled away under the impetus of decay heating and the lower plenum steel structures are subsumed into the surrounding debris. Penetration failures occur at a time when only liquid metals are present as the debris temperature increases after lower plenum dryout. Oxide melting (and release) follows the initial release of metals.

For the Mark I liner failure study, ${ }^{2}$ the Scenario II probability density functions are such that the initial pour can be approximated as $14 \mathrm{~m}^{3}\left(494 \mathrm{ft}^{3}\right.$ ) of a mixture of stainless steel with $30 \%$ zirconium metal at $100 \mathrm{~K}\left(180 \quad{ }^{\circ} \mathrm{F}\right)$ superheat. This initial pour, which occurs over a period of 20 minutes, is followed by a relatively slow release of $15 \mathrm{~m}^{3}\left(530 \mathrm{ft}^{3}\right)$ of oxides (mixed with $15 \%$ zirconium metal) over a period of 100 minutes.

\subsubsection{Accident Scenarios Not Represented}

As mentioned previously, the Mark I liner failure study does not consider high-pressure accident sequences. Neither does it directly address accident sequences in which penetration failures are assumed not to occur.

Completion of the Mark I liner failure study involved a process by which a preliminary analysis was performed and subjected to extensive peer review. This first step is documented in Reference 2. Additional analyses were then performed to address the concerns identified by the peer review. This second round of analyses and the final conclusions of the study are documented in Reference 3.

One of the concerns addressed in the second round of analyses has to do with the amount of metals that might be mixed with the oxides in the Scenario I release. This is an important question because the magnitude of the material superheat that is carried with the spreading debris is paramount to the fate of the wall after contact. (Debris liquids have a higher effective conductivity for heat transfer into the wall surface.) Specifically, it was proposed that upward radiation from the molten pool held in the core region might induce melting of the upper reactor vessel internal structures so that the molten liquids, when released into the lower plenum, would include a large quantity of 
stainless steel. Dedicated calculations with. the APRIL code, ${ }^{8}$ however, showed that the composition of the Scenario I melt as originally conceived was indeed bounding for that scenario.

The accident sequence without penetration failure would, however, produce a much larger included metals superheat than is represented by the Scenario I release. With the reactor vessel depressurized, creep rupture of the vessel wall would not occur until the wall was heated to near the carbon steel melting temperature. At this time, much of the central region of the lower plenum debris bed would be occupied by a slurry of solid oxides and superheated metals. But, if penetration failures did not occur and the bottom head failed by creep rupture, how would the contents of the lower plenum be released to the drywell?

It is, of course, unknown how the separation of the portion of the bottom head below the support skirt from the remainder of the vessel would progress. Would there be a complete break, or would one side of the bottom head sag? As shown in the lower part of Figure 3.7-7, there is a control rod drive housing support structure about $1 \mathrm{~m}(3$ $\mathrm{ft}$.) beneath the vessel that might interrupt the downward movement of the dislocated portion of the vessel bottom head. It is pointed out in Reference 2 that much of the lower plenum content could still be contained within the bottom head after its initial rupture, and that "Pending quantification of the merits of this new type of scenario, quantification of it is left for future study." As noted in Section 3.7, more recent analysis have indicated that penetration failures are less likely than previously believed. ${ }^{15}$

\subsubsection{Debris Spreading Across The Drywell Floor}

As described in the previous section, distinction between the two considered scenarios is that Scenario I involves a mostly oxidic melt with a high initial release rate whereas Scenario II involves an initially metallic melt with a relatively low release rate. The total release quantity for Scenario II is about twice that for Scenario I.

As considered in Reference 2, debris falling from the reactor vessel would first fill the drywell sumps, then would spill over the pedestal region floor. As sufficient height is accumulated over the floor, flow would begin through the pedestal doorway. Initial spreading as the flow enters the expedestal region would be slight, but after contact with the drywell wall, the flow would separate into two branches, each flowing along the wall in a nearly one-dimensional fashion. These two branches then meet at a position diametrically opposite to the doorway.

During the spreading process, the flowing debris radiates to the overlying atmosphere (or water) and transfers heat to and ablates the underlying concrete. Gases released from the concrete promote oxidation of the metals carried with the debris, and the associated energy release serves to increase the debris temperature. The purpose of the spreading calculations described in Reference 2 was to determine the parameters important to the question of survivability of the drywell wall. These are the depth of the debris immediately adjacent to the wall, the initial superheat of this debris, and the length of time that superheat is maintained.

For the second round of analysis, the peer review process recommended that the 
adequacy of the approach employed in the preparation of Reference 2 be checked by the application of other available analytical tools, specifically the MELTSPREAD ${ }^{9}$ and CORCON ${ }^{10}$ codes. The MELTSPREAD code provides a mechanistic treatment of the basic processes involved in the spreading of debris over a steel or concrete substrate, including gravity-driven flow, melt freezing, immobilization and heatup, concrete decomposition and gas release, chemical oxidation of melt metallic constituents, enhancement of heat transfer by any overlying water, and spreading of new melt release over previously spread material. The CORCON code, which provides detailed modeling of core-concrete interaction phenomena, was invoked specifically to confirm the duration of superheat in the debris.

As described in Reference 3, the results of the independent MELTSPREAD and CORCON analyses support the contention that for the pours considered in Reference 2, the depth of debris at the wall, the initial superheat, and the duration of superheat employed for the shell failure analysis are appropriately conservative. In other words, the values used in considerations of heat transfer to the shell (discussed in the next section) are higher than those that would be produced in a best-estimate analysis.

\subsubsection{Thermal Loading of the Shell}

For the initial phase of the Mark I liner failure study, as documented in Reference 2, it was assumed that wall failure would occur if the local temperature reached $1773 \mathrm{~K}$ $\left(2732^{\circ} \mathrm{F}\right)$, which is tantamount to failure by melting. During the subsequent peer review, it was recognized that the drywell shell as installed at Peach Bottom and most other BWR Mark I facilities is susceptible to failure by creep rupture, which would occur at a much lower temperature.
The Peach Bottom drywell shell is encased in concrete below the level of the drywell floor. Above the floor, there is a $5.1 \mathrm{~cm} \mathrm{(2}$ in.) air gap between the outer surface of the shell and the surrounding concrete. Between these two regions, there is a sand-filled transition zone, which is intended to transmit any seismic loads from the primary containment evenly into the supporting concrete foundation. The arrangement of the shell, surrounding concrete, and sand-filled transition zone at the level of the floor is plant specific. At Peach Bottom, the shell is $3.2 \mathrm{~cm}$ ( 1.250 in.) thick and the top of the sand transition zone is at the level of the floor. (At Browns Ferry, the shell thickness is $2.9 \mathrm{~cm}$ [1.125 in.], and the sand-filled transition zone extends more than $10 \mathrm{~cm} \mathrm{[4}$ in.] above the floor level.)

The surface of the transition zone constrains the portion of the spherical shell just above it from moving radially outward against the surrounding concrete. Thus, the shell is subject to temperature-induced creep rupture at the locations where it would be heated by adjoining debris.

In response to the concern identified by the peer review in regard to the assumed shell failure criteria, the ANATECH Research Corporation was assigned to carry out a three-dimensional, finite element, structural analysis of the Mark I shell in localized contact with debris, the results of which are documented in Part $\mathrm{V}$ of Reference 3. The debris, which is of composition (oxidic) and depth $(20 \mathrm{~cm}$ [8 in.]) corresponding to Scenario I, was assumed to be covered with water. Containment pressure was represented as remaining constant at 0.2 $\mathrm{MPa}$ (29 psia). Creep rupture was predicted to fail the shell at $1533 \mathrm{~K}\left(2300^{\circ} \mathrm{F}\right)$, which is about $240 \mathrm{~K}\left(430^{\circ} \mathrm{F}\right)$ lower than the carbon steel melting temperature. This temperature of $1533 \mathrm{~K}\left(2300^{\circ} \mathrm{F}\right)$ was then adopted by the Mark I failure study for use 
as the best-estimate failure temperature for the drywell shell.

\subsubsection{Mitigative Effects of Water}

As described in Section 4.7.3, the most important parameters determining the amount of energy that would be transferred to the shell from the adjacent debris are the debris depth, the initial debris superheat, and the time duration that the debris remained superheated. If a significant quantity of water overlies the drywell floor at the time of initial debris release, then all three of these parameters would be affected favorably, from the standpoint of promoting the survival of the shell.

The depth of debris adjacent to the wall would be reduced, because more of the debris would freeze within the pedestal region, and less would reach the shell.

The largest beneficial effect would be in reducing the amount of superheat carried to the wall. Although the effectiveness of overlying water in cooling crusted debris is not well understood, insulating crusts would develop only after the superheat is lost. Since heat loss mechanisms to water from a superheated corium melt are straightforward and the associated heat transfer is large, it is pointed out in Reference 3 that the effectiveness of water in reducing superheat is not a matter of controversy.

With respect to the duration of superheat in the debris at the wall, the overlying water would play an important role by removing heat from the wetted shell just above the debris. In effect, the portion of the shell that is in contact with water above the debris acts as an efficient cooling fin. A cooling pathway is established from the debris into the shell and up through the fin to the overlying water. This accelerates the elimination of the debris superheat.
One cannot selectively consider only the benefits of the presence of water, however. Before recommending that provision be made to supply water to the Mark I drywell floor under severe accident conditions, it is first necessary to consider the potential for and effects of steam explosions. For the Mark I liner failure study, this consideration is given in Appendix $A$ "The Occurrence and Role of Steam Explosions in a Mark-I Containment" to Part I of Reference 3. There it is argued that integrity-threatening steam explosions over the surface or at the leading edge of the spreading debris can be ruled out, and that in fact, small-scale steam explosions (fuel-coolant interactions) at these locations would be beneficial from the standpoint of promoting quenching. On the other hand, it is noted that there is a concern with respect to the potential for energetic steam explosions induced by the debris pouring within the pedestal region.

Appendix A to Reference 3 Part I also notes that the occurrence of an energetic steam explosion within the pedestal region would offer much more of a threat to the reactor pedestal than to the drywell shell. However, the argument is made that with a limited depth of water (about $30 \mathrm{~cm}$ [1 ft.]), an impulse to the pedestal of the magnitude necessary to cause failure cannot be delivered. (Note that the actual depth can vary from plant to plant.)

It seems that final resolution as to whether or not it is worth risking the destructive potential of steam explosions in order to reap the beneficial aspects of water must await completion of the ongoing (1996) series of experiments (discussed in Section 3.7.6.1) exploring the phenomena associated with the introduction of corium into water. At this point it seems that at the very least, it will be concluded that energetic explosions with the oxidic components of core debris are very hard to generate. 


\subsubsection{Potential for Mark I Containment Failure}

The Mark I liner failure study has considered the case of debris release via penetration failures from a depressurized Peach Bottom reactor vessel. The study concludes that there is a "virtual certainty" of shell failure if the containment floor is dry at the time of initial release, but that early shell failure is "physically unreasonable" if the drywell is flooded with water to the lower lip of the vent pipe openings, a depth of about 61 cm (2 ft.).

For its consideration of this issue, the Advisory Committee on Reactor Safeguards (ACRS) has stated that "Results of the severe accident research have shown that there is no threat of prompt containment failure posed by ... Mark I liner meltthrough. Research should continue to: ... determine the impact of ex-vessel steam explosions on the BWR containments."11

Apparently this statement is intended to include only cases with water overlying the drywell floor. What about the high-pressure case? The ACRS goes on to state "Additional assessment of $\mathrm{DCH}$ is needed for ... BWRs." Thus, it seems that the concern with respect to shell failure that might be caused by high-pressure melt ejection is effectively subsumed into the larger direct containment heating issue.

The reason that the presence of water to the level of the vent openings is considered to reliably preclude only "early" or "prompt" failure of the shell has to do with the formation of solid-base islands of quenched metallic debris in conjunction with the initial release. These could then serve as underwater causeways for transport of subsequent molten releases from the reactor. vessel toward the drywell shell. If debris liquids can reach the shell at locations above the water surface, then the situation reverts to the dry case, for which shell failure is probable.

The current situation with respect to the Mark I liner failure analyses based on the Peach Bottom facility is summarized in Table 4.7-1. As indicated, high pressure cases and accident sequences involving creep rupture of the reactor vessel bottom head have not been analyzed. For the cases that have been studied, extension of the existing results to other Mark I facilities is discussed in the remainder of this section.

\subsubsection{Extension to Other BWR Facilities}

As is the case for all other aspects of severe accident research, plant-specific design features play an important role and must be taken into consideration when considering extrapolation of the Mark I study results, based on Peach Bottom, to other BWR facilities. To provide a feel for the extent of the design variations, there are seven different sizes of reactor vessels in U.S. Mark I containments, ranging from Duane Arnold (183 in. ID) to Peach Bottom (251 in. ID). At Duane Arnold, the radius to the shell at the level of the drywell floor is 6.34 $\mathrm{m}$ (20.8 ft.), as compared to $6.96 \mathrm{~m} \mathrm{(22.85}$ $\mathrm{ft}$.) at Peach Bottom. On the other hand, the potential debris source is smaller at Duane Arnold, where the core comprises just 368 fuel assemblies, as opposed to the 764 assemblies at Peach Bottom.

One of the most important geometric parameters with respect to the shell failure issue is the height of the vent line entrance above the drywell floor. This height determines the maximum depth of water over the floor and, should debris enter a vent pipe, local failure would be virtually certain. As discussed in Part I of Reference 3, the location of the vent line openings is plant 
specific, but in general the shorter heights are associated with the facilities that have the smaller cores and hence the smaller potential debris pours.

Review by the NRC and its contractors ${ }^{12,13}$ of the Individual Plant Examinations (IPEs) submitted by the various BWR facilities has confirmed the importance of the Mark I shell failure issue as previously identified in NUREG-1150. In fact, "Liner meltthrough was found to be the most important contributor to early containment failure for Mark I containments." 12 The IPEs also reveal, however, that in some Mark I containments, the sump and floor configuration is such as to automatically preclude shell failure. Specifically, the sumps at Monticello are large enough to contain all of the debris release from the vessel. At Oyster Creek, a concrete curb serves to prevent the debris from reaching the drywell shell. ${ }^{12}$

\subsubsection{Drywell Flooding Capabilities}

If the drywell floor is to be reliably flooded under severe accident conditions, then the necessary water would have to be capable of delivery into the containment in case of station blackout. The general concept is to vent the containment to permit use of lowpressure pumps and to inject the water via the existing drywell spray headers. To address station blackout concerns, it would be necessary to invoke new or upgraded independently powered pumping systems.

Going one step further, relatively minor modifications beyond the need for an independently powered dedicated pumping system might be employed to permit rapid filling of the wetwell, flooding of the vent pipes, and increase of the water level within the drywell to a height sufficient to cover the reactor vessel bottom head. If drywell flooding to this level could be achieved quickly enough, then the water in the drywell could provide two lines of defense against containment failure: first by serving to keep the debris within the reactor vessel as described in Section 3.7.7.3, and second by extending upward the protection of the drywell shell.

Provision of the necessary volume of water would require the availability of an independent containment flooding system of sufficient capacity to cover the reactor vessel bottom head before lower plenum dryout and the associated threat of penetration failures. This would in general require equipment modifications to existing plants, but similar modifications are required for flooding to protect the shell. In both cases, the drywell would have to be vented during the flooding process and beyond. The only additional requirement for the independently powered pumping systems necessary to deal with station blackout would be to increase their capacity. For two feet of water, $86 \mathrm{~m}^{3}$ (22,800 gal.) would be required. Making allowance for the trapping of a portion of the containment atmosphere in the upper wetwell as indicated in Figure 4.7-6, about $5700 \mathrm{~m}^{3}(1,500,000$ gal.) would have to be added to the Peach Bottom containment in order to submerge the reactor vessel bottom head.

Detailed information concerning the prospects for a containment flooding strategy intended to maintaining the core debris within the reactor vessel is available in Reference 14 . The BWR severe accident sequence leading most rapidly to the formation of a reactor vessel lower plenum debris bed is short-term station blackout, for which the vessel bottom head would have to be submerged in no more than $150 \mathrm{~min}$. (2.5 hours) after the onset of core degradation. For Peach Bottom, this is equivalent to a required pumping capacity of $0.63 \mathrm{~m}^{3} / \mathrm{s}$ (10,000 gal./min.). 
Table 4.7-1 Mark I liner qualitative failure probabilities for various severe accident challenges

\begin{tabular}{|c|c|c|c|c|}
\hline $\begin{array}{l}\text { Reactor vessel } \\
\text { depressurized? }\end{array}$ & $\begin{array}{l}\text { Water covers } \\
\text { drywell floor? }\end{array}$ & $\begin{array}{l}\text { Bottom head } \\
\text { failure mode? }\end{array}$ & Case analyzed? & $\begin{array}{c}\text { Estimated } \\
\text { probability of } \\
\text { prompt liner } \\
\text { failure }\end{array}$ \\
\hline No & Either Way & Any & No & High \\
\hline \multirow{4}{*}{ Yes } & \multirow[b]{2}{*}{ No } & Penetrations & Yes & High \\
\hline & & Creep Rupture & No & Medium - High \\
\hline & \multirow{2}{*}{ Yes } & Penetrations & Yes & Low \\
\hline & & Creep Rupture & No & Low-Medium \\
\hline
\end{tabular}




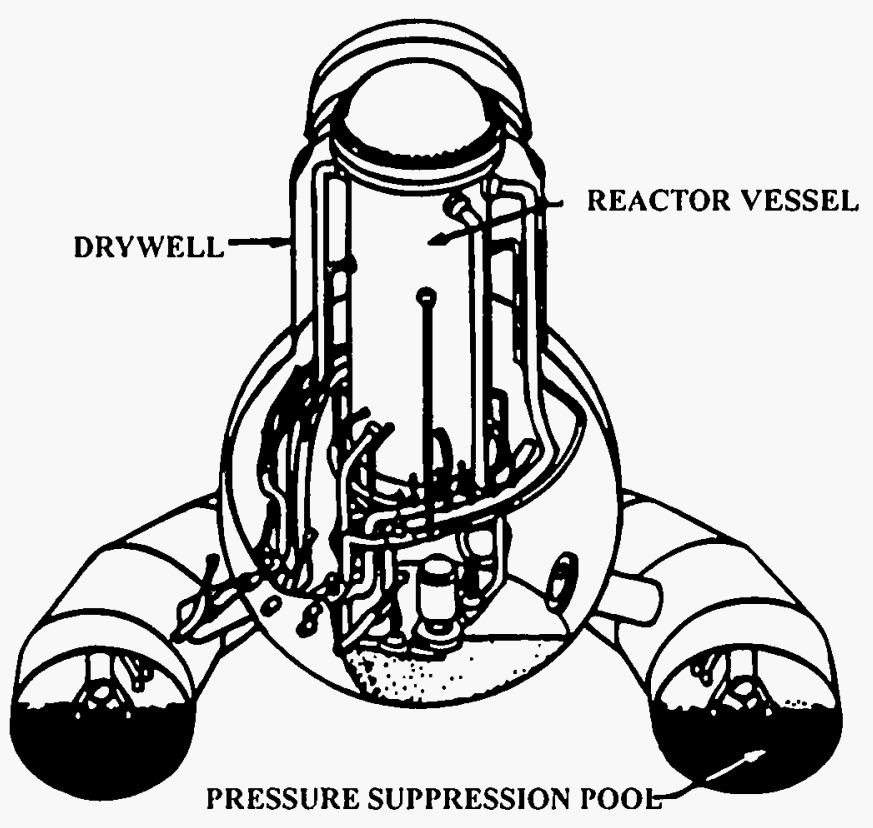

PRIMARY CONTAINMENT
(DRYWELL AND WETWELL)

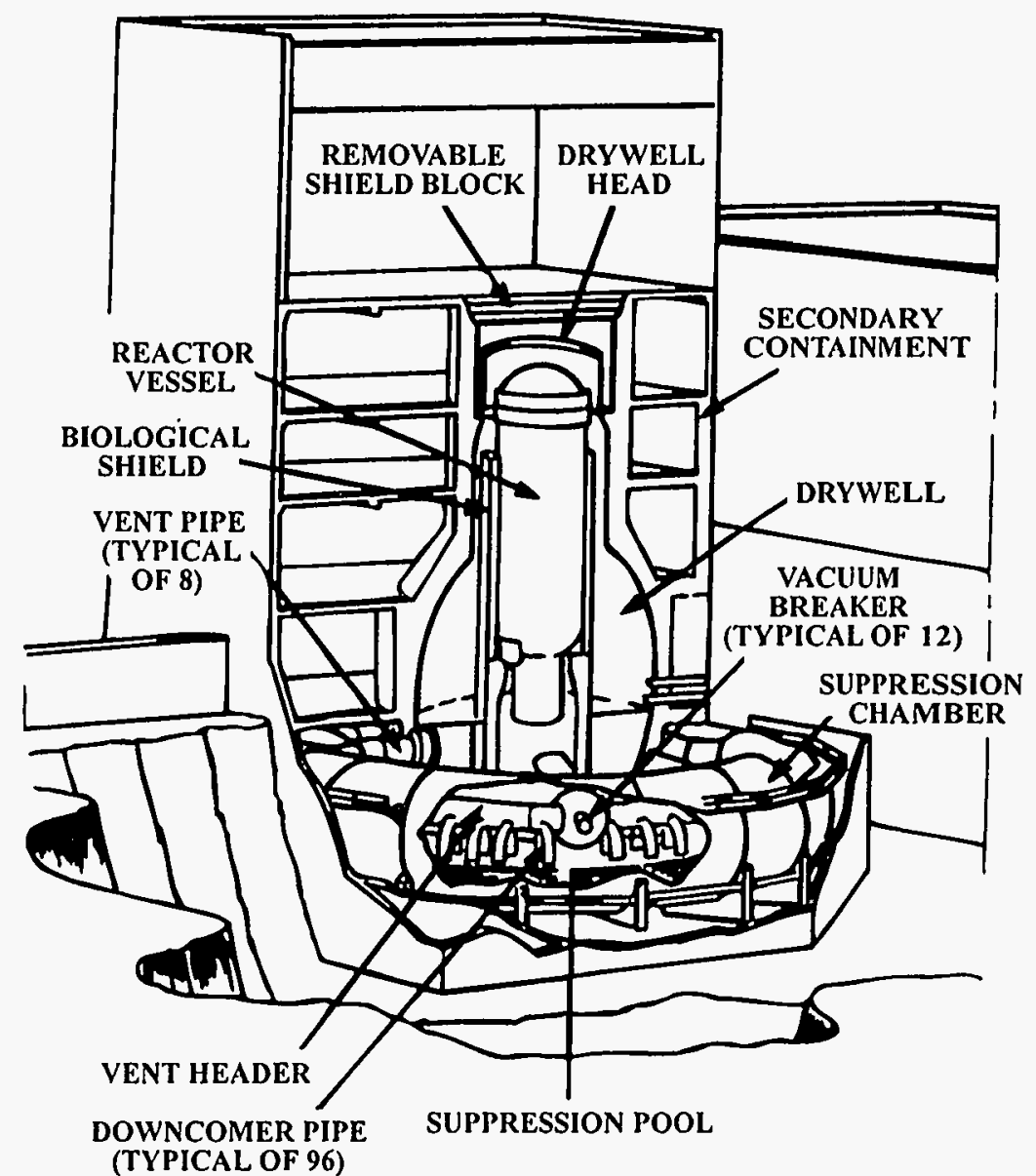

SECONDARY CONTAINMENT

Figure 4.7-1 The BWR Mark I containment design employs a small primary containment with a pressure suppression pool; secondary containment is provided by the surrounding structure 


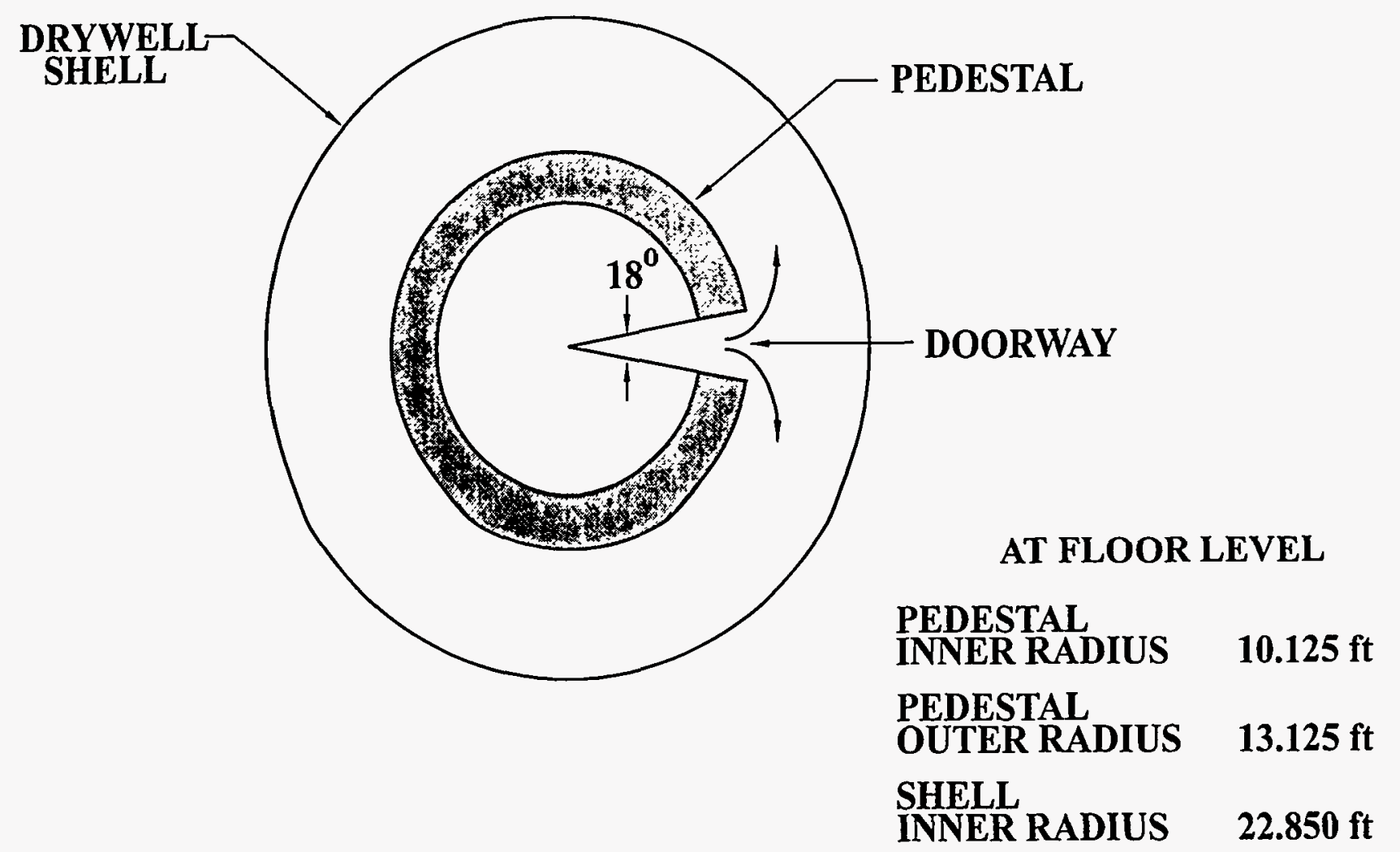

Figure 4.7-2 The Mark I drywell floor area is small and the drywell shell is within ten feet of the pedestal doorway 

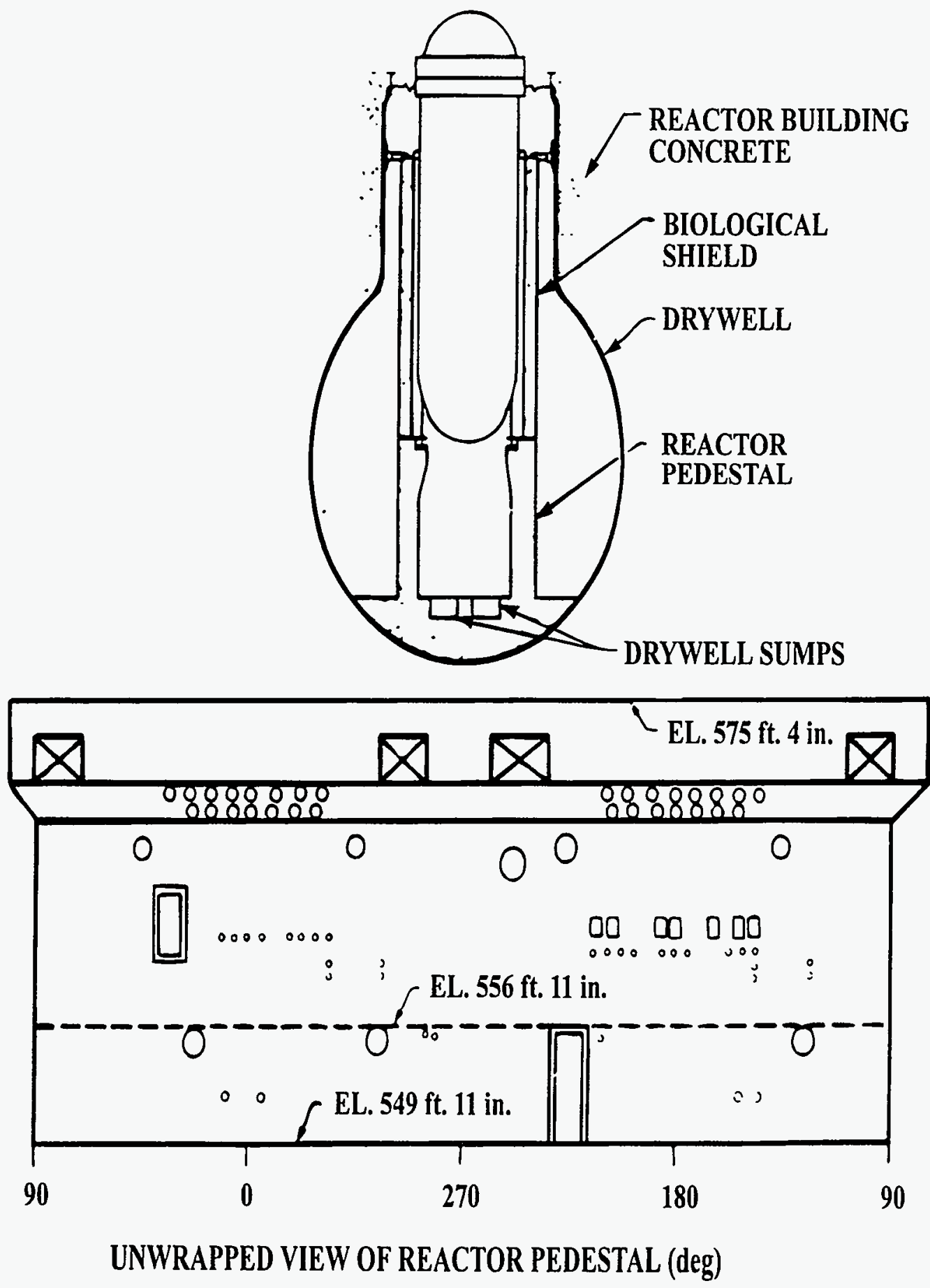

Figure 4.7-3 Core debris released from the reactor vessel would spread over the BWR Mark I drywell floor, including the ex-pedestal region 


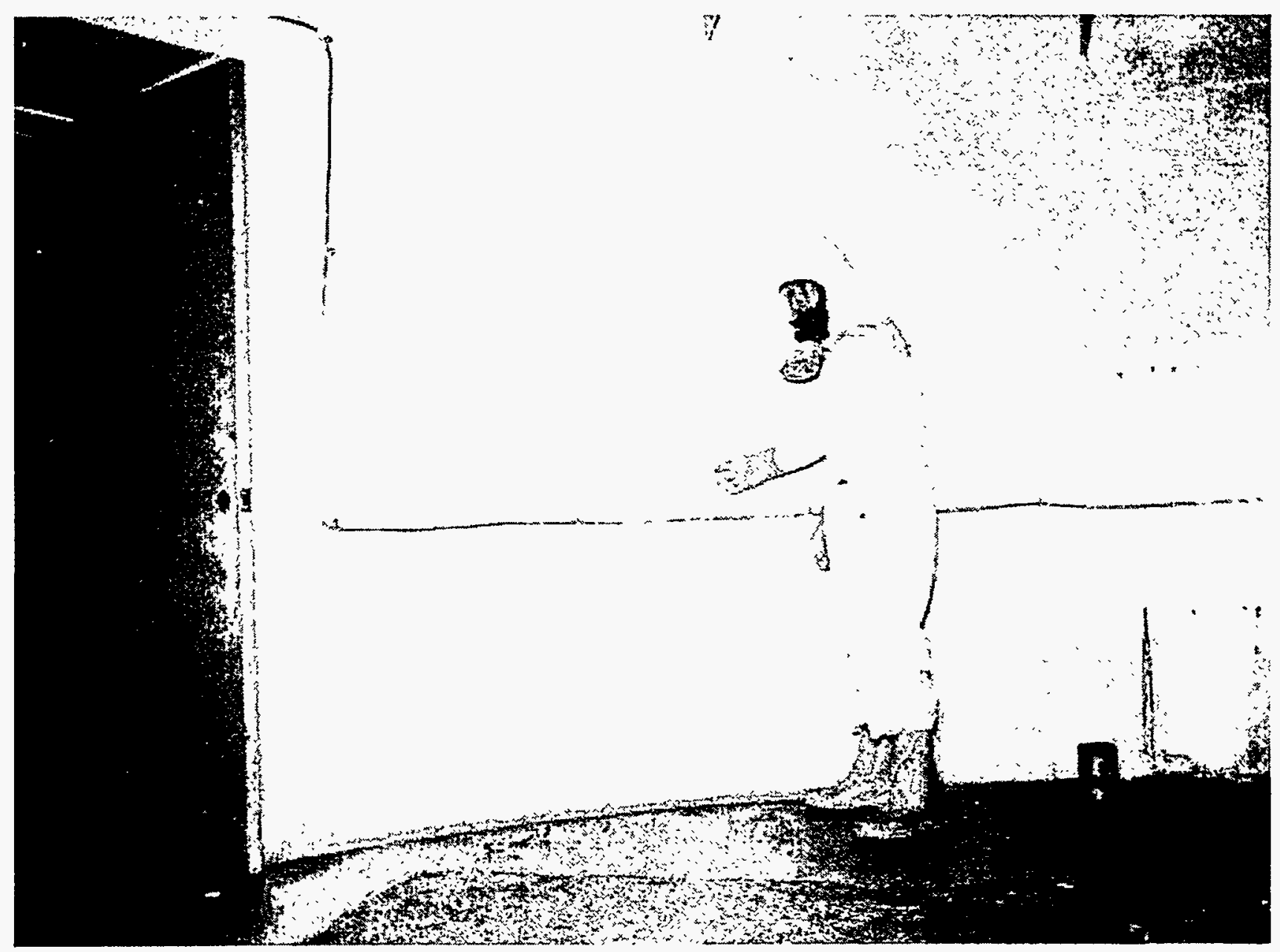

Figure 4.7-4 Interior of reactor pedestal at Peach Bottom with partial view of doorway 


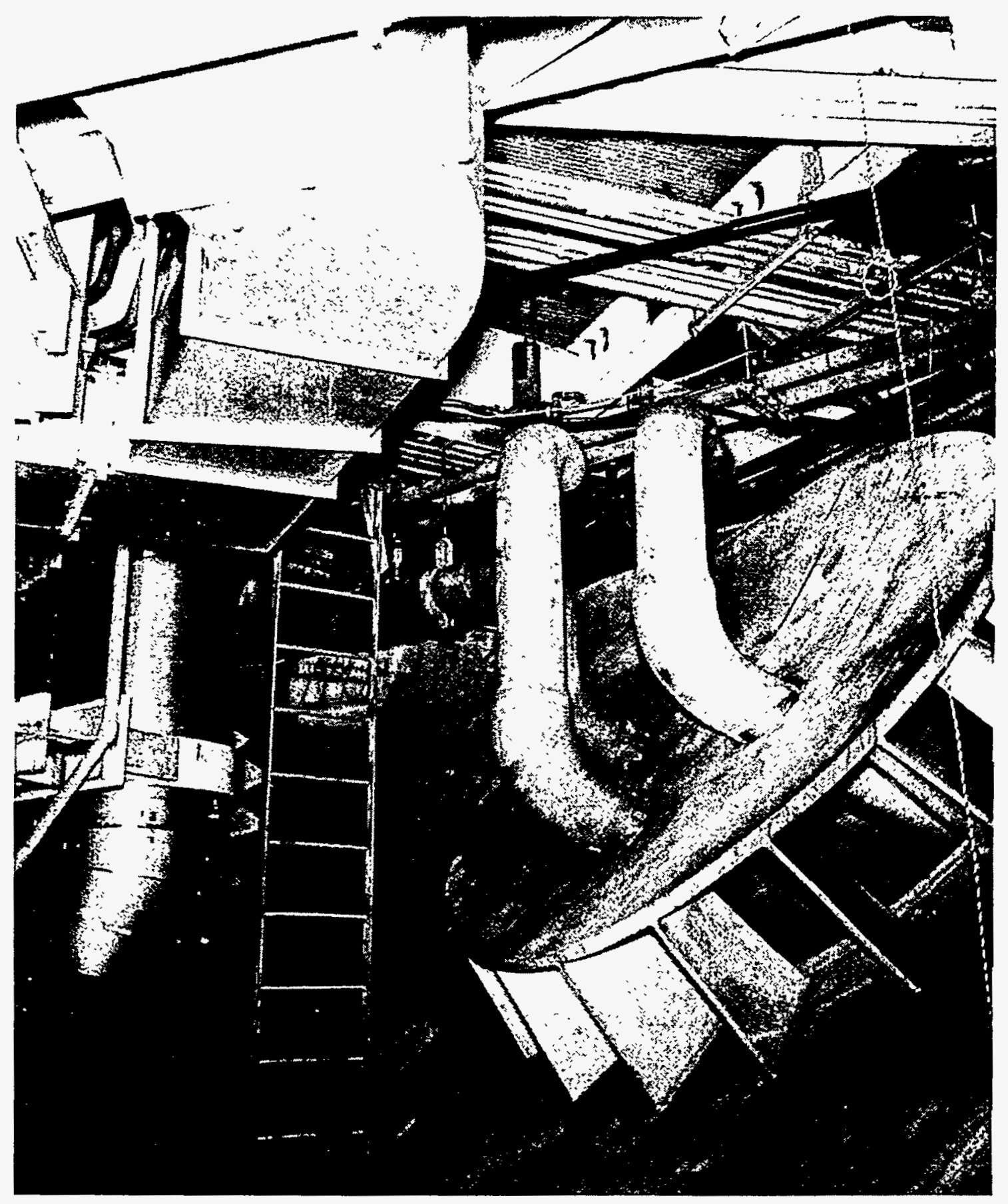

Figure 4.7-5 Shield over vent pipe entrance at Peach Bottom 


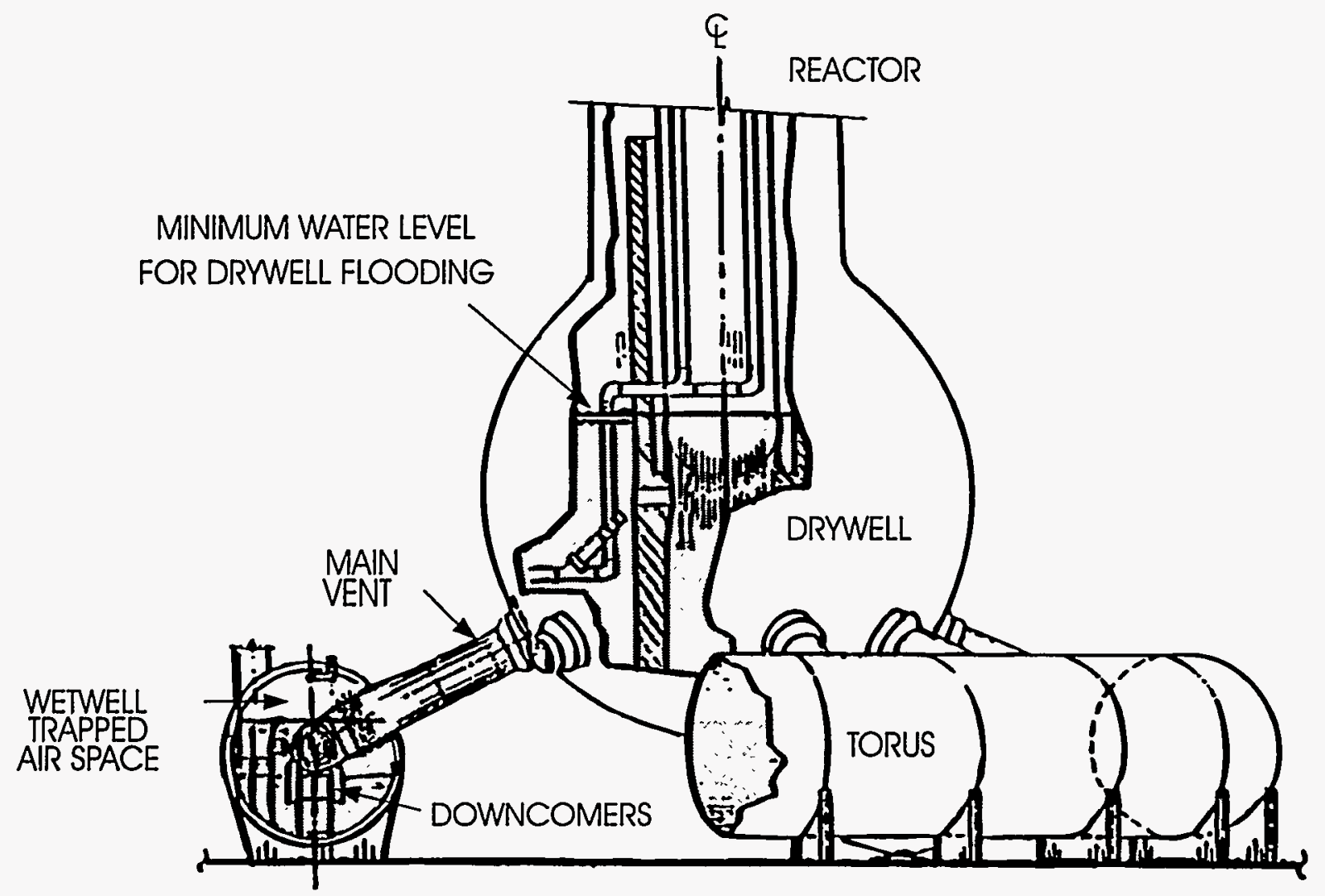

Figure 4.7-6 Approximately $5700 \mathrm{~m}^{3}\left(1.5 \times 10^{6}\right)$ gallons would be required to cover the reactor vessel bottom head at the largest (1100MWe) BWR facilities 


\section{References for Section 4.7}

1. G. A. Greene, K. R. Perkins, and S. A. Hodge, "Mark I Containment Dry": Impact of Core/Concrete Interactions on Containment Integrity and Failure of the Drywell Liner," Source Term Evaluation for Accident Conditions, paper IAEA, Vienna, Austria, October 1985.

2. T. G. Theofanous et al., "The Probability of Liner Failure in a Mark-I Containment,' NUREG/CR-5423, Center for Risk Studies and Safety, University of California, August 1991.

3. T. G. Theofanous, et al., "The Probability of Mark-I Containment Failure by Melt-Attack of the Liner," NUREG/CR-6025, University of California, Rensselaer Polytechnic Institute, Sandia National Laboratories, Argonne National Laboratory, ANATEC, Inc., November 1993.

4. D. A. Brinson and G. H. Graves, "Evaluation of Seals for Mechanical Penetrations of Containment Buildings," NUREG/CR-5096, SAND88-7016, Sandia National Laboratories, August 1988.

5. General Electric Company, "BWR Owner's Group Emergency Procedure Guidelines," Revision 4, NEDO-31331, March 1987.

6. R. E. Henry, et al., "Experiments Relating to Drywell Shell-Core Debris Interactions," Proceedings of the Sixteenth Water Reactor Safety Information Meeting, NUREG/CP-0097, Vol. 5, pp. 317-339, Fauske and Associates, October 1988.

7. S. A. Hodge and L. J. Ott, "BWRSAR Calculations of Reactor Vessel Debris Pours for Peach Bottom Short-Term Station Blackout," Proceedings of the Sixteenth
Water Reactor Safety Information Meeting, NUREG/CP-0097, Vol. 5, pp. 377-401, Oak Ridge National Laboratory, October 1988.

8. S. H. Kim, et al., "The Development of APRIL.MOD2 - A Computer Code for Core Meltdown Accident Analysis of Boiling Water Nuclear Reactors,"NUREG/CR-5157, Rensselaer Polytechnic Institute, 1988.

9. M. T. Farmer, J. J. Sienicki, and B. W. Spencer, "The MELTSPREAD-1 Computer Code for the Analysis of Transient Spreading in Containments," Sixth Proceedings of Nuclear Thermal Hydraulics, 1990 ANS Winter Meeting, November, 1990, p. 21, Argonne National Laboratory, 1990.

10. J. F. Muir et al., "CORCON-MOD 1: An Improved Model for Molten-Core/Concrete Interactions,"NUREG/CR-2142, SAND802415, Sandia National Laboratories, July 1981.

11. Letter from the Advisory Committee on Reactor Safeguards to The Honorable Shirley Ann Jackson, Chairman, U. S. Nuclear Regulatory Commission, "Severe Accident Research," June 28, 1996.

12. C. C. Lin, J. R. Lehner, W. T. Pratt, and M. Drouin, "Severe Accident Progression Perspectives for Mark I Containments Based on the IPE Results," Proceedings of the Twenty-Third Water Reactor Safety Information Meeting, NUREG/CP-0149, Vol. 2, pp. 463-472, Brookhaven National Laboratory and U.S. Nuclear Regulatory Commission, October 1995.

13. W. T. Pratt, John Lehner, A. Camp, and E. Chow, "IPE Results as Compared with NUREG-1150," Proceedings of the TwentyThird Water Reactor Safety Information 
Meeting, NUREG/CP-0149, Vol. 2, pp. 485504, Brookhaven National Laboratory, Sandia National Laboratories, and U.S. Nuclear Regulatory Commission, October 1995.

14. S. A. Hodge, J. C. Cleveland, T. S. Kress, and M. Petek, "Identification and Assessment of BWR In-Vessel Strategies,"
NUREG/CR-5869, ORNL/M-12080, OakRidge

National Laboratory, October 1992.

15. J. L. Rempe et al., "Light Water Reactor Lower Head Failure Analysis." NUREG/CR5642, EGG-2618, Idaho National Engineering Laboratory, October 1993. 


\section{Appendix 4A Example Calculation of Hydrogen Combustion Pressures and Temp- eratures}

This appendix provides an approximate method for estimating hydrogen burn pressures and temperatures. The example is taken from Reference 1 . With the aid of Figures $4 \mathrm{~A}-1$ and $4 \mathrm{~A}-2$, or $4 \mathrm{~A}-3$ and $4 \mathrm{~A}-4$, the pressure and temperature that would be caused by an adiabatic, constant-volume, complete combustion of a homogeneous hydrogen:air:steam mixture can be estimated. Figures $4 A-1$ and $4 A-2$ can be used for cases in which the steam mole fraction before the burn is small. This might be the case in the wetwell (or outer containment) of a Mark III BWR or the upper compartment of an ice condenser containment. Figures $4 \mathrm{~A}-3$ and $4 \mathrm{~A}-4$ are to be used when the conditions before the combustion are steam saturated. For initial temperatures not far above normal room temperature, the steam mole fraction is small even in a saturated atmosphere. In that case either set of figures could be used.

We will describe the procedure to be used in the computations in the next paragraph. For all the calculations absolute pressures and temperatures should be used.

Absolute Pressure $=$ Gauge Pressure + Atmosphere Pressure

$(4 \mathrm{~A}-1)$

Typically, for normal atmosphere pressure,

Pressure $(\mathrm{psia})=$ Pressure $(\mathrm{psig})+14.7$

or

Pressure $(\mathrm{MPaa})=$ Pressure $(\mathrm{MPag})+0.101$
For temperature,

Temperature (Rankine) $=$ Temperature (Fahrenheit) +460

Temperature (Kelvin) $=$ Temperature (Celsius) +273

The subscripts $A, S$ and $\mathrm{H}_{2}$ refer to air, steam, and hydrogen. The analysis considers three times: $t_{0}$, the time at the start of the accident; $t_{1}$, the time just before the combustion; and $t_{2}$ the time just after the combustion. The object of the calculation is to determine $P\left(t_{2}\right)$ and $T\left(t_{2}\right)$, the pressure and temperature just after combustion. We will assume that conditions at time $t_{0}$ are known, and that sufficient information about conditions at time $t_{1}$ is known so that the unknown gas conditions at the time can be computed.

Consider the example when the conditions at the start of the accident are:

$\mathrm{P}\left(\mathrm{t}_{0}\right)=14.7$ psia $(0.101 \mathrm{MPa})$

$\mathrm{T}\left(\mathrm{t}_{0}\right)=560^{\circ} \mathrm{R}(311 \mathrm{~K})$

Relative Humidity $=50 \%$

Just before the combustion the temperature is $590^{\circ} \mathrm{R}(328 \mathrm{~K})$, the air is saturated and a hydrogen detector measures 10 volume percent (mole fraction) hydrogen (see Table 4A-1).

For all three time periods, the total pressure is the sum of the partial pressures of air, hydrogen and steam,

$$
P=P_{A}+P_{S}+P_{H_{2}}
$$


Initially, there is no hydrogen, $P_{H_{2}}\left(\mathrm{t}_{0}\right)=0$. The saturation steam pressures are determined from "Steam Tables" found in thermodynamics textbooks or engineering handbooks. We have

$\mathrm{P}_{\mathrm{SAT}}\left(\mathrm{T}_{0}\right)=\mathrm{P}_{\mathrm{SAT}}\left(560^{\circ} \mathrm{R}(311 \mathrm{~K})\right)=0.95 \mathrm{psia}$ (0.0065 $\mathrm{MPa})$

$\mathrm{P}_{\mathrm{S}}\left(\mathrm{t}_{0}\right)=$ relative humidity $* \mathrm{P}_{\mathrm{SAT}}\left(\mathrm{T}_{0}\right)=0.48$ psia (0.0033 MPa)

Therefore, the initial air partial pressure is

$\mathrm{P}_{\mathrm{A}}\left(\mathrm{t}_{0}\right)=14.7-0.5=14.2 \mathrm{psia}(0.098 \mathrm{MPa})$

From steam tables we obtain, at $t_{1}$,

$\mathrm{P}_{\mathrm{S}}\left(\mathrm{t}_{1}\right)=\mathrm{P}_{\mathrm{SAT}}\left(\mathrm{T}_{1}\right)=2.2 \operatorname{psia}(0.015 \mathrm{MPa})$

The air partial pressure at $t_{1}$ is

$\left.\mathrm{P}_{\mathrm{A}}\left(\mathrm{t}_{1}\right)=\left(\mathrm{T}_{1} / \mathrm{T}_{0}\right) \mathrm{P}_{\mathrm{A}}\left(\mathrm{t}_{0}\right)=590 / 560\right) * 14.2=$ 15.0 psia $(0.103 \mathrm{MPa})$

the hydrogen mole fraction is

$X_{H_{2}}=P_{H_{2}} / P$

which leads to

$P_{H_{2}}=\left(P_{A}+P_{S}\right) * X_{H_{2}} /\left(1.0-X_{H_{2}}\right)$

Hence

$P_{H_{2}}\left(t_{1}\right)=17.2 * 0.1 / 0.9=1.9$ psia $(0.013 \mathrm{MPa}$.
$P_{1}=17.2+1.9=19.1$ psia $(0.131 \mathrm{MPa})$

We now estimate the postburn conditions using Figures 4A-1 and 4A-2. Figure 4A-1 gives the final/initial pressure ratio for burns with a given set of initial conditions. However, the pressure ratio is insensitive to the initial pressure, and insensitive to small changes in initial temperature. The influence of initial steam mole fraction can be greater. The figures were computed using a humidity corresponding to a steam mole fraction of $3 \%$. At $590^{\circ} \mathrm{R}(328 \mathrm{~K})$ the steam mole fraction for $100 \%$ relative humidity will be higher, but will still be small enough to use Figures $4 A-1$ and $4 A-2$. From Figure $4 \mathrm{~A}-1$, we determine that $\mathrm{P}\left(\mathrm{t}_{2}\right) / \mathrm{P}\left(\mathrm{t}_{1}\right)=4.2$, hence $P\left(t_{2}\right)=4.2 * 19.1=80.2$ psia $(0.55$ $\mathrm{MPa})$. An approximate final temperature can be estimated from Figure $4 \mathrm{~A}-2$ by adding to the temperature found from the figure the difference between $T\left(t_{1}\right)$ and $536^{\circ} R(298 \mathrm{~K})$.

$\mathrm{T}\left(\mathrm{t}_{2}\right) \approx 1230+30=1260 \mathrm{~K}\left(2270^{\circ} \mathrm{R}\right)$

When applicable, the use of Figures $4 \mathrm{~A}-3$ and $4 \mathrm{~A}-4$ is simpler than using Figures $4 \mathrm{~A}-1$ and 4A-2. These figures are applicable when the conditions at the start of the accident are near $\mathrm{P}\left(\mathrm{t}_{0}\right)=1$ atm $(0.101 \mathrm{MPa})$, $\mathrm{T}\left(\mathrm{t}_{0}\right)=540^{\circ} \mathrm{R}(300 \mathrm{~K})$ and the conditions just before the combustion are steam saturated. It should be noted that the curves for constant $T\left(t_{1}\right)$ in the two figures correspond to varying pressure, $P\left(t_{1}\right)$, and varying steam mole fraction. At all points on the curves, the composition has been adjusted to saturation conditions. Much of the work in describing the conditions at time $t_{1}$ is not needed here because that information has been incorporated into the figures. For a temperature of $590{ }^{\circ} \mathrm{R}(328$ $\mathrm{K}$ ), we determine that $\mathrm{P}\left(\mathrm{t}_{2}\right)=4.9 \mathrm{~atm}=72.0$ psia $(0.50 \mathrm{MPa})$, and $T\left(\mathrm{t}_{2}\right)=2340^{\circ} \mathrm{R}(1300$ $\mathrm{K})$. 
The results of thermochemical calculations in a computer give values $\mathrm{P}\left(\mathrm{t}_{2}\right)=74.4 \mathrm{psia}$ $(0.51 \mathrm{MPa}), \mathrm{T}\left(\mathrm{t}_{2}\right)=2401{ }^{\circ} \mathrm{R}(1334 \mathrm{~K})$. The difference between the results (summarized in Table 4A-1) gives an indication of the accuracy to be expected from the simple graphical methods.

If the pressure and temperature before the combustion are accurately measured and the hydrogen mole fraction measurement is absent or less accurate, the hydrogen mole fraction can be estimated (assuming saturation) from the relations,

$$
\begin{aligned}
& P_{H_{2}}=P-P_{A}-P_{S} \\
& X_{H_{2}}=P_{H_{2}} / P
\end{aligned}
$$

Some hydrogen detectors may remove the water vapor content of the hydrogen:air:steam mixture. In this case the measured hydrogen mole fraction (of the dry hydrogen:air mixture) will be larger than the value in the original mixture. The correction required to recover the original value is

$$
X_{H_{2}}=\left(1-X_{S}\right) X_{H_{2}}
$$

where $X_{H}$ is the hydrogen mole fraction in the dry hydrogen:air mixture and $X_{S}$ is the steam mole fraction in the original hydrogen:air:steam mixture

$$
X_{S}=P_{S} / P
$$


Table 4A-1 Computation of adiabatic, constant-volume pressure and temperature

\begin{tabular}{|c|c|c|c|c|}
\hline & $\begin{array}{c}\text { Time } \\
\text { Before } \\
\text { Accident } \\
\quad\left(t_{0}\right)\end{array}$ & $\begin{array}{c}\text { Time } \\
\text { Before } \\
\text { Combustion } \\
\left(t_{1}\right)\end{array}$ & $\begin{array}{l}\text { Time After } \\
\text { Combustion } \\
\quad\left(t_{2}\right) \\
\text { Using Figures } \\
\text { 4A-1 \& 4A-2 }\end{array}$ & $\begin{array}{c}\text { Time After } \\
\text { Combustion } \\
\left(\mathrm{t}_{2}\right) \\
\text { Using Figures } \\
\text { 4A-3 \& 4A-4 }\end{array}$ \\
\hline Pressure - psia (MPa) & $\begin{array}{c}14.7 \\
(0.101)^{*}\end{array}$ & $\begin{array}{c}19.1 \\
(0.131)\end{array}$ & $\begin{array}{l}80.2 \\
(0.55)\end{array}$ & $\begin{array}{l}72.0 \\
(0.50)\end{array}$ \\
\hline Temperature $-{ }^{\circ} \mathrm{R}(\mathrm{K})$ & $\begin{array}{c}560 \\
(311)^{*}\end{array}$ & $\begin{array}{c}590 \\
(328)^{*}\end{array}$ & $\begin{array}{l}2270 \\
(1260)\end{array}$ & $\begin{array}{l}2340 \\
(1300)\end{array}$ \\
\hline $\begin{array}{l}\text { Hydrogen Mole } \\
\text { Fraction }\end{array}$ & $0.0^{*}$ & $0.1 *$ & & \\
\hline $\begin{array}{l}\text { Air Partial Pressure - } \\
\text { psia (MPa) }\end{array}$ & $\begin{array}{l}14.2 \\
(0.098)\end{array}$ & $\begin{array}{c}15.0 \\
(0.103)\end{array}$ & & \\
\hline $\begin{array}{l}\text { Steam Partial Pressure } \\
\text { - psia (MPa) }\end{array}$ & $\begin{array}{c}0.48 \\
(0.0033)\end{array}$ & $\begin{array}{c}2.2 \\
(0.015)\end{array}$ & & \\
\hline $\begin{array}{l}\text { Hydrogen Partial } \\
\text { Pressure - psia (MPa) }\end{array}$ & $\begin{array}{c}0.0 \\
(0.0)\end{array}$ & $\begin{array}{c}1.90 \\
(0.013)\end{array}$ & & \\
\hline
\end{tabular}

* Data directly from measured initial conditions 


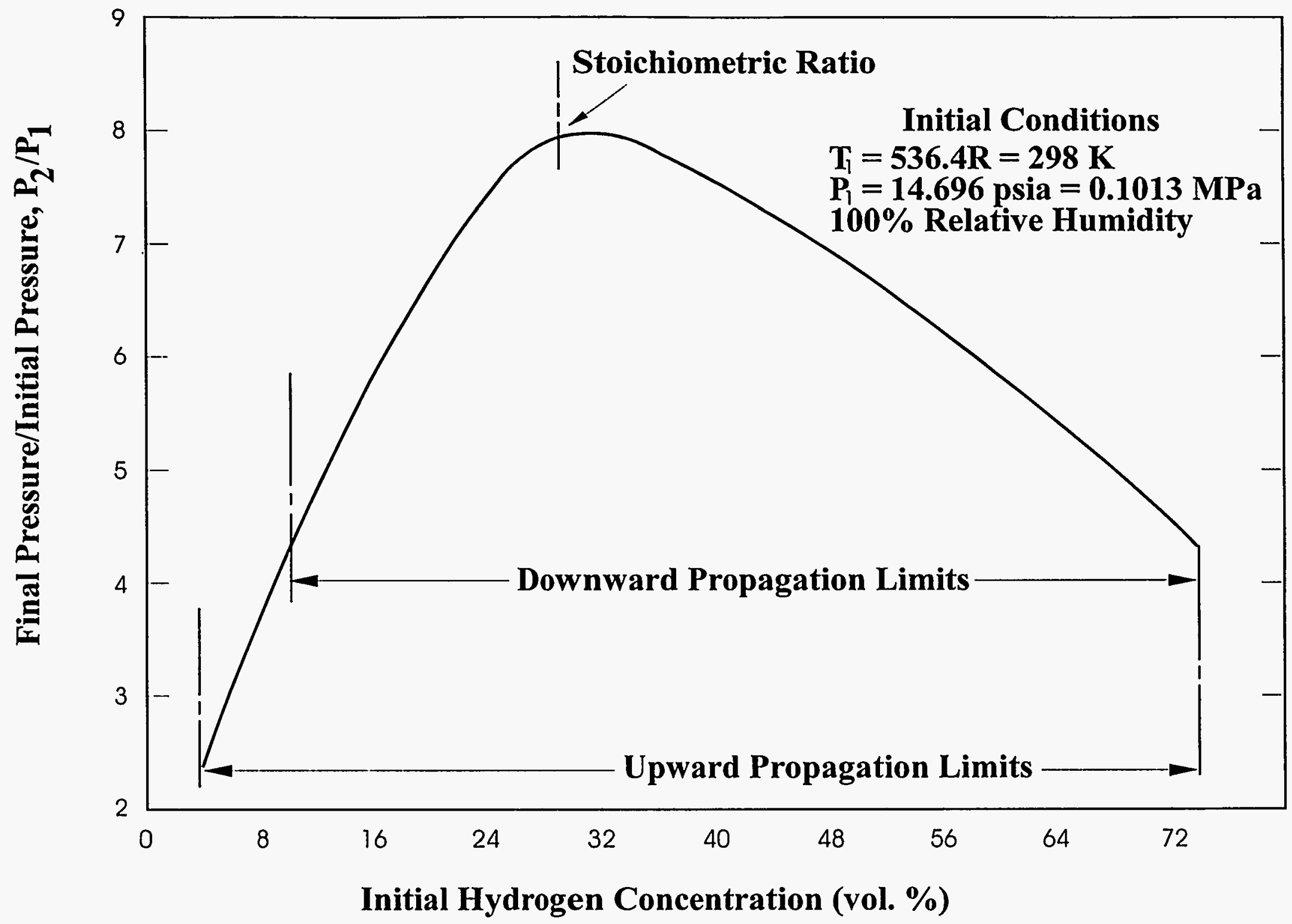

Figure 4A-1 Theoretical adiabatic, constant-volume combustion pressure for hydrogen: air mixtures 


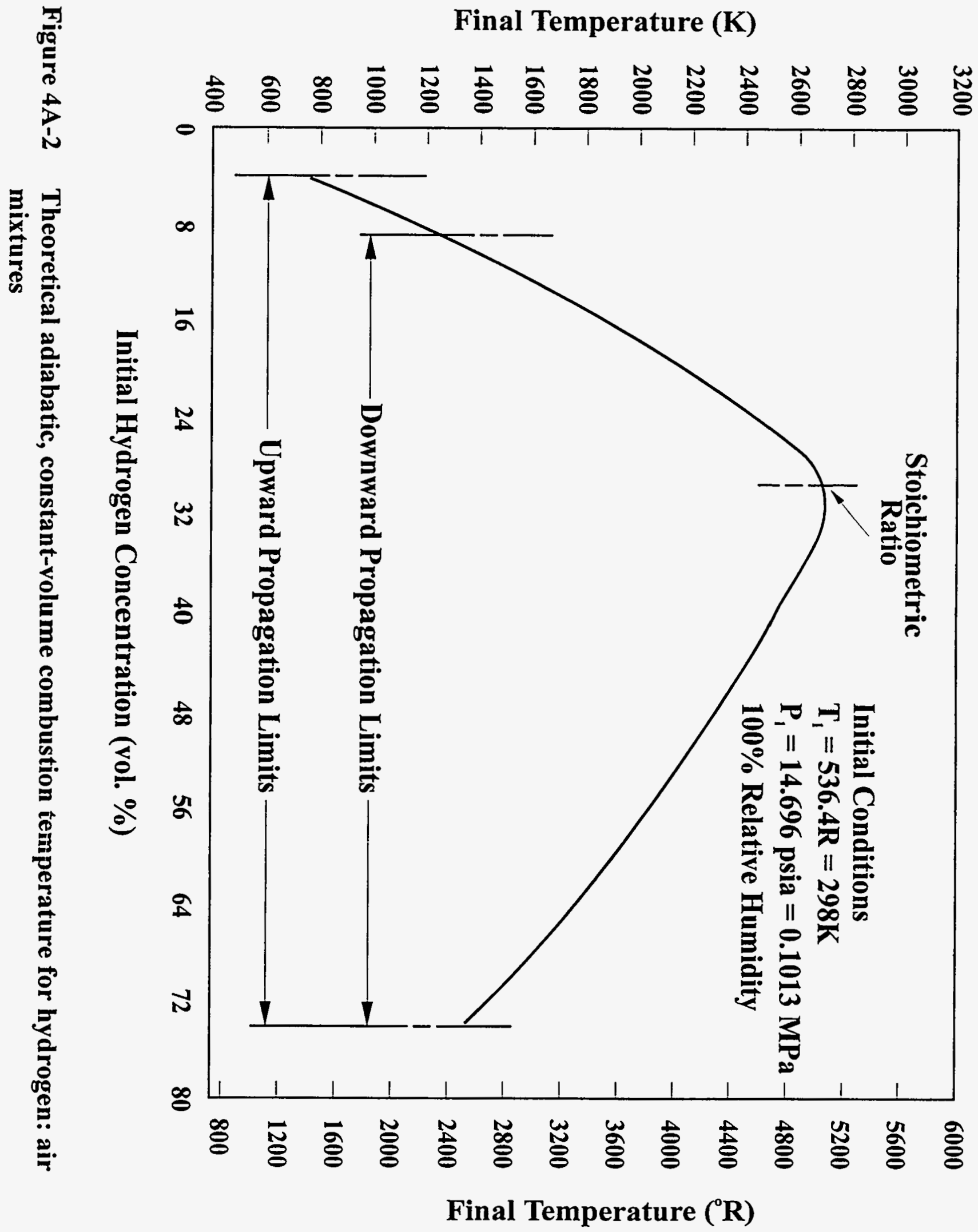




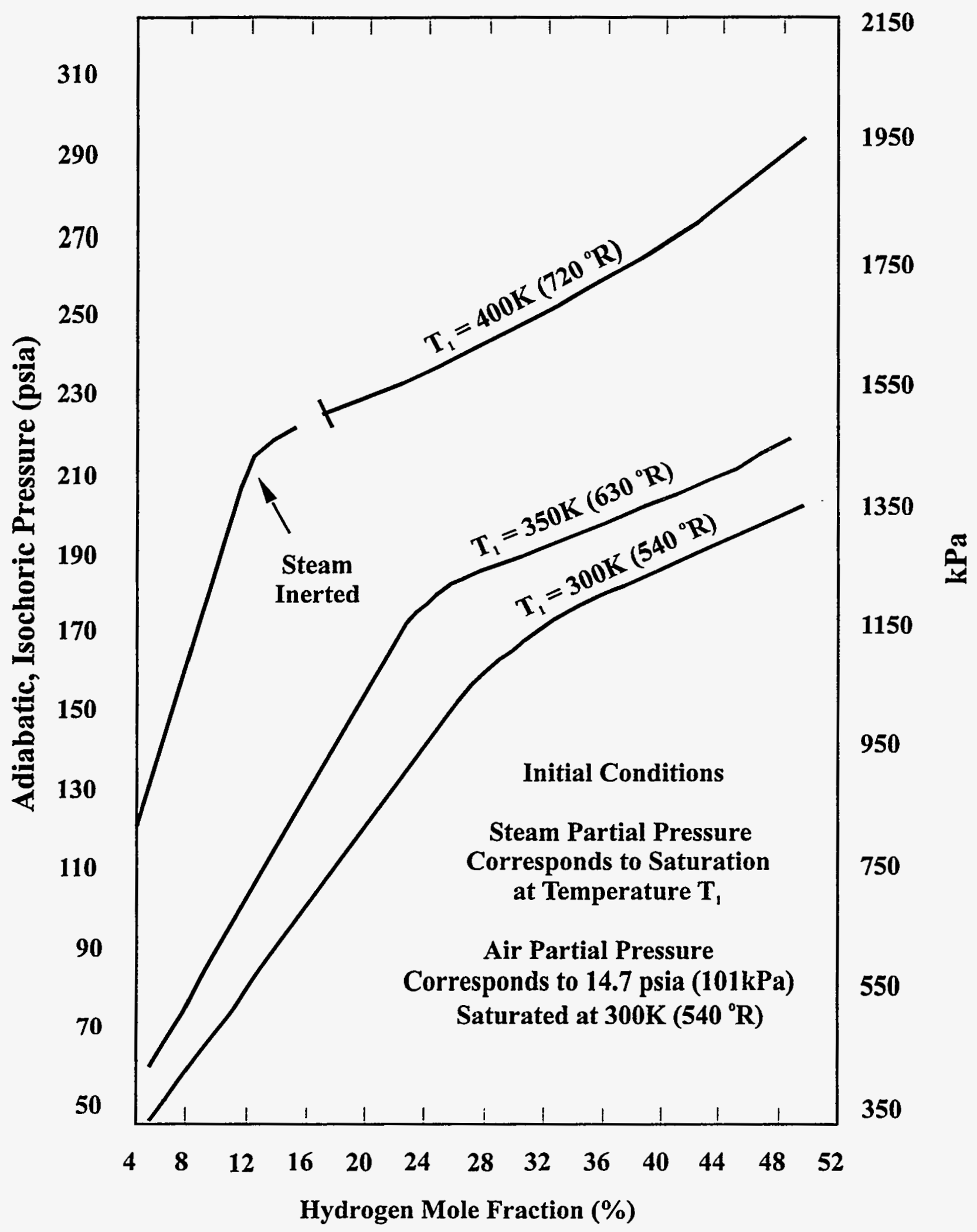

Figure 4A-3 Adiabatic, constant-volume combustion pressure for various containment initial conditions 


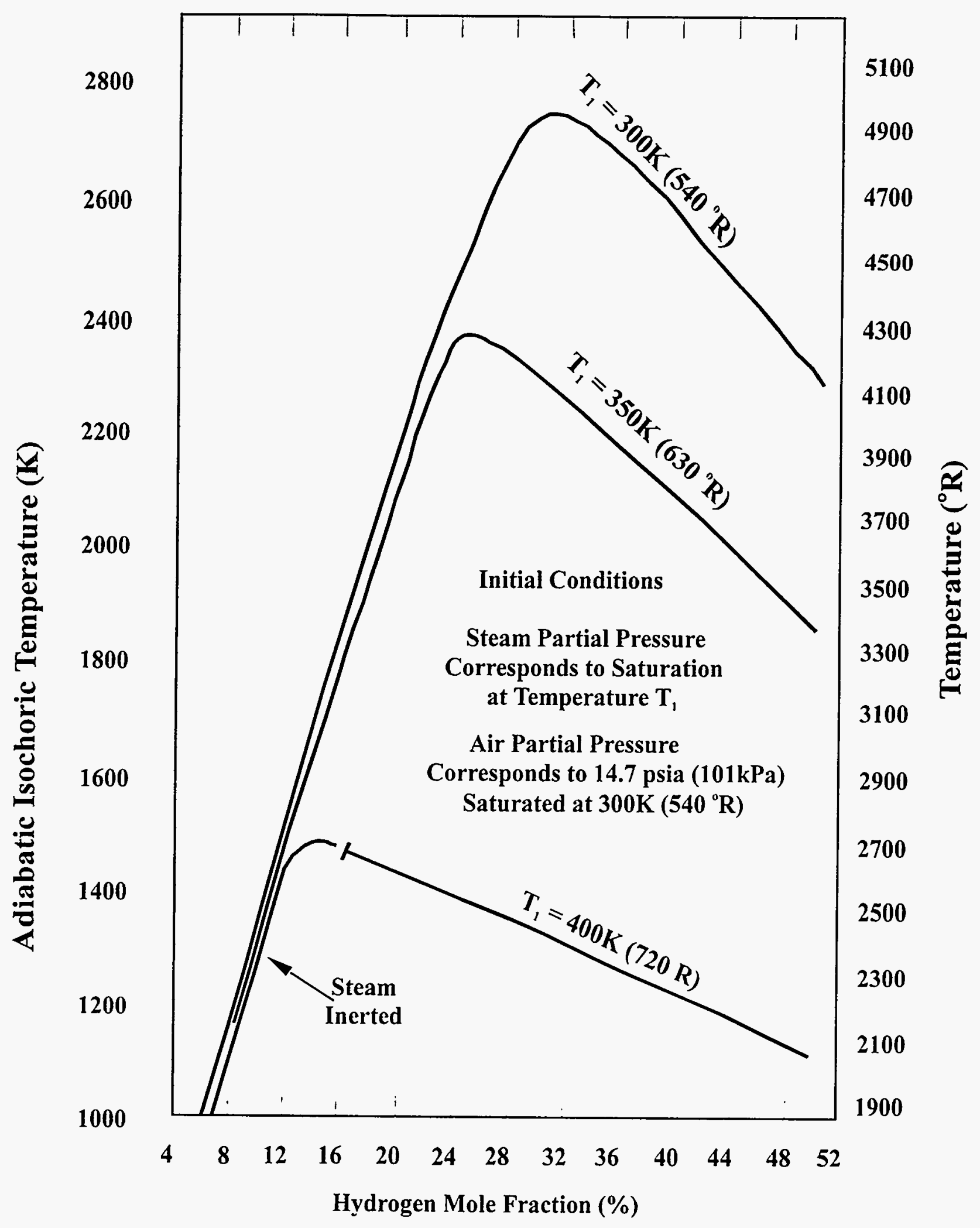

Figure 4A-4 Adiabatic, constant-volume combustion temperature for various containment initial conditions 


\subsection{Offsite Accident Impacts}

\subsubsection{Introduction}

Modules 1 through 4 emphasize the importance of the defense-in-depth philosophy for preventing severe accidents or containing radionuclide releases given such accidents. This module carries the defense-in-depth philosophy one step further. It discusses radionuclide releases that, however unlikely, could occur; the radiation doses and associated health effects that could result; actions that can be taken to protect the public; and the U.S. emergency planning process for implementing such protective actions.

\subsubsection{Learning Objectives for Module 5}

After completing this module, the student should be able to:

1. Describe the location in the plant of radioactive material that could potentially cause offsite injuries or fatalities and the extent of plant damage required for its release.

2. Describe the characteristics of the radioactive source term that have an important effect on offsite doses and the plant design features that could have a major impact on such characteristics.

3. Explain the impact of wind speed, stability class, radioactive decay, ground deposition, and rainfall on the rate of decrease in offsite dose versus distance.
4. Characterize our current ability to accurately project source term characteristics and offsite doses that could result from a severe core-damage accident.

5. Describe the roles and efficacy of evacuation, sheltering, ad hoc respiratory protection, and administration of stable iodine in protecting the public from potential nuclear power plant releases of radioactive materials.

6. Describe the Chernobyl source term and the actions taken to protect the public from this source term. Compare these with the current LWR source terms and NRC guidance on protective actions.

7. Indicate the primary responsibilities of the licensee, state and local agencies, and the NRC during a nuclear power plant emergency.

8. Describe plume exposure Emergency Planning Zone and the ingestion pathway Emergency Planning Zone.

9. Explain what Emergency Action Levels (EALs) are.

10. List the four classes of emergencies in order of increasing severity and indicate which require official notification and which require offsite protective actions.

11. Describe the functions of the Technical Support Center (TSC) and the Emergency Operations Facility (EOF) during a nuclear power plant emergency. 


\section{$5.1 \quad$ Source Terms}

As indicated in Modules 3 and 4, if the energy contained in the core of a nuclear power plant is not controlled, considerable damage can be done to the fuel, cladding, reactor vessel, and even the containment--the plant barriers that normally contain the core radionuclides. Even if the reactor is shut down, the substantial energy generated by the decay of fission products (decay heat) can lead to damage to these barriers. If sufficient quantities of radionuclides are released to the environment as a result of such damage, various offsite health effects may result. This subsection discusses the quantities and characteristics of radionuclide releases to the environment (source terms). Transport of the released radionuclides in the environment and associated offsite doses and health effects are discussed in Section 5.2 .

\subsubsection{Radionuclide Inventories}

The conventional unit that is used to quantify the radioactivity of a material is the curie $(\mathrm{Ci})$. One curie of material undergoes radioactive decay at the rate of $3.7 \times 10^{10}$ nuclear disintegrations per second, which is the radioactivity of one gram of pure radium. The corresponding Standard International (SI) unit of radioactivity is the becquerel (Bq). One becquerel is one nuclear disintegration per second, so $1 \mathrm{Ci}=3.7 \times 10^{10}$ Bq.

Table 5.1-1 shows the principal components of the 5 billion or so curies of radioactive materials in the core of a $3300 \mathrm{MWt}$ light water reactor $30 \mathrm{~min}$ after shutdown according to their relative volatilities. ${ }^{1,2}$ Of the groups listed, radionuclides of the noble gases krypton $(\mathrm{Kr})$ and xenon $(\mathrm{Xe})$ are the most volatile and, consequently, the most likely to be released from the plant to the environment during an accident. $U p$ to
$100 \%$ of the noble gases could be released in severe accidents involving containment failure or bypass. Radioactive iodine and cesium, which rank second in volatility, could also be released in substantial quantities during a severe accident. Radioiodine can concentrate in the thyroid. As a result, small quantities of radioiodine can cause damage to the thyroid gland. Long-lived radioactive cesium is a potential source of long-term offsite dose (e.g. from Chernobyl).

Table 5.1-2 shows radionuclide inventories of the volatile noble gases and iodine in various plant systems. ${ }^{2}$ Note that the vast majority of this volatile radioactive material is contained in the core. All other reactor systems contain less than one-half of $1 \%$ of the xenon, krypton, and iodine activity in the core. Because radioactive cesium is longlived, the spent fuel pool can contain more than the core; however, the driving force (decay heat) for release is much larger in the core.

\subsubsection{Source Term Characteristics}

Radionuclides would be released to the environment as gases $\left(\mathrm{Kr}, \mathrm{Xe}, \mathrm{I}_{2}\right)$ or aerosol particles of water soluble substances such as cesium iodide (CsI) and strontium hydroxide $\left(\mathrm{Sr}(\mathrm{OH})_{2}\right)$ or cesium hydroxide $(\mathrm{CsOH})$ and strontium hydroxide $\left(\mathrm{Sr}(\mathrm{OH})_{2}\right)$, or slightly soluble oxides of tellurium, ruthenium, and lanthanum. Generally, a major release (source term) from a nuclear power plant can be viewed as a cloud (called the plume) of radioactive gases, aerosol particles, and water vapor (mist). As indicated in Figure 5.1-1, the plume could be released continuously over a long time period, or it could be released as a very short puff. It could be released at ground level or higher.

Source terms are characterized by the fractions of the core inventory of 
radionuclides that are released to the environment and other attributes that can have an important effect on offsite doses and the numbers and types of offsite health effects. Such attributes include the start time and duration of the release, the size distribution of the aerosols released, the elevation of the release, and the energy released with the radioactive material. For example, if the plume is hot, rise due to buoyancy may loft the plume over people living near the plant thereby limiting the doses they receive. Also, if the release is slow (takes a long time), shifts in wind direction may cause more people to be exposed but may also cause the exposure to any stationary group to be reduced. Such effects are discussed further in Section 5.2.

The isotopic composition of a source term is important because it determines decay rates and thus radiation exposure rates. Rapidly decaying (halflives under a minute) nuclides deliver most of their dose quickly at short distances from their release point. Conversely, slowly decaying nuclides may deliver dose over many years out to great distances from their release point. The chemical and physical form of the released radioactive materials also influences offsite doses. For example, if only noble gases are released, deposition on the ground and incorporation into the food chain does not take place thereby eliminating several important long-term exposure pathways. Conversely, if the released radioactive material is all in the form of water insoluble particles too large to be respirable, lung exposure due to inhalation does not occur.

\subsubsection{Magnitude of Release Required to Cause Offsite Health Effects}

It is not obvious from examining the values of a source term's characteristics what the potential health impact would be to the public. It is, however, easy to demonstrate that the release of only a relatively small fraction of the core inventory to the environment could be significant. Table 5.13 shows that, under poor meteorological conditions, a prompt release of only $10^{6} \mathrm{Ci}$ of noble gases or $600 \mathrm{Ci}$ of halogens could, based on current federal guidelines (discussed in Appendix 5A), result in doses sufficient to warrant taking actions to protect persons within a mile of the plant. Doses at least ten times higher than federal protective action guides would be required to induce early injuries or fatalities. For example, under the same poor meteorological conditions assumed above, Table 5.1-3 indicates that a release of $10^{7} \mathrm{Ci}$ of noble gases or $2.4 \times 10^{4} \mathrm{Ci}$ of halogens could result in doses exceeding the thresholds for acute, radiation-induced injuries.

As indicated in Section 5.1.1, only the core, the spent-fuel storage pool, and the reactor coolant contain more than $10^{6} \mathrm{Ci}$ of noble gases or $6 \times 10^{2} \mathrm{Ci}$ of halogens. Accidents not involving one of these three regions (e.g., gas-decay tank rupture) would not, therefore, result in doses requiring offsite protective actions. It should be emphasized, however, that one cannot project offsite doses and health effects based solely on the Curies of radionuclides released. For example, as indicated in Table 5.1-3, the average annual release of noble gases for a LWR is $1000 \mathrm{Ci}$, but this release occurs gradually during all kinds of weather conditions. It therefore results in less than 5 mrems indicated for a person one mile downwind of a prompt $10^{6} \mathrm{Ci}$ noble gas release under poor meteorological conditions.

Figure 5.1-2 compares the average annual releases of noble gases and iodine from U.S. plants to the estimated releases that occurred as a result of the TMI-2 and Chernobyl accidents. Clearly the Chernobyl release, an uncontained release discussed in Section 
5.1.7, was large by any measure. The TMI-2 release, much of which occurred during controlled venting of the containment, was very modest in comparison. Nevertheless, as discussed in Sections 5.3.7 and 5.4, current guidelines would call for a precautionary evacuation for an accident like that at TMI2.

Only the reactor core contains sufficient radioactive material and energy (e.g., decay heat) to result in source terms capable of causing offsite injuries and/or fatalities. In addition to core damage, an accident resulting in offsite injuries and/or fatalities would require a direct pathway to the atmosphere and a driving force (e.g., steam). In essence, all three fission product barriers (cladding, reactor coolant system, and containment) would be breached or bypassed. The radioactive material released from the core would have to move through the reactor coolant system (second barrier) and containment (third barrier) without being significantly filtered or removed by other methods such as containment sprays, ice condensers, fan coolers, or suppression pools. Even if such engineered safety features failed, over time natural removal processes (e.g., gravitational settling) would remove most particulate fission products from the atmosphere of an intact containment. Therefore, if the containment holds for several hours and the containment sprays or other removal systems work, early injuries or fatalities would be unlikely.

Figure 5.1-3 uses an event tree to display the potential public health consequences due to core-damage accidents. Moving from left to right in the figure, yes/no answers to questions at the top result in a series of branches, possibly to offsite consequences. For example, if only the radioactive material contained in the fuel pins (gaps) is released with late containment failure, the offsite consequences would be small (branch 7). If all answers are yes, extremely severe offsite consequences are possible (branch 1). As Figure 5.1-3 indicates, offsite health effects are likely only if core melting and containment failure (or bypass) occur. The implications of this observation in deciding when to initiate offsite protective actions are discussed in Section 5.3.7 and 5.4.

\subsubsection{Design Features That Impact Source Terms}

In Module 4, performance of the containment was described with respect to the timing of containment failure and the magnitude of resulting leakage to the environment. Environmental source terms are, however, affected by more than just the mode and timing of containment failure. The following paragraphs describe the effect of different safety systems and plant features on the magnitude of source terms. A common measure of the capability of a system or feature to remove radioactive aerosols or vapors in the decontamination factor (DF, ratio of inlet to outlet concentration), which is the ratio of the inlet concentration to the outlet concentrations. Table 5.1-4 provides a summary of the more significant DFs associated with the features that are discussed.

\subsubsection{Suppression Pools}

BWR suppression pools can be very effective in scrubbing (removing) radionuclides that accompany steam and noncondensible gases bubbling up through the pool. The pool water retains soluble vapors and aerosols but provides little attenuation of noble gas fission products. Although Regulatory Guide 1.3 suggests not allowing credit for fission product scrubbing by BWR suppression pools, ${ }^{3}$ Standard Review Plan Section 6.5.5 was revised to allow such credit. ${ }^{4}$ The Reactor Safety Study assumed a DF of 100 for sub-cooled 
pools and 1.0 for saturated pools. ${ }^{5}$ NUREG1150 calculations based on more sophisticated models indicate decontamination factors ranging from 1.2 to 4000 with a median value of about $80 .^{6}$

Some of the most important radionuclides, such as isotopes of iodine and cesium, and tellurium, are primarily released from fuel while it is still in the reactor vessel. Risk-dominant accident sequences in BWRs are typically initiated by transients rather than pipe breaks. In transients, the in-vessel release is directed to the suppression pool rather than being released to the drywell. As a result, the in-vessel release is subjected to scrubbing in the suppression pool, even if containment failure has already occurred. Because the early health effects are often caused by early releases of volatile radioactive materials, the suppression pool is one of the reasons the likelihood of early fatalities is low for the BWR designs analyzed in NUREG-1150.

If not bypassed, the suppression pools can also be effective in scrubbing ex-vessel releases. Suppression pool bypass places an upper limit on the suppression pool decontamination factor. For example, if as little as $1 \%$ of the flow bypasses the suppression pool, the effective DF factor must be less than 100 .

Experiments have shown that solution $\mathrm{pH}$ is a major factor in determining the amount of molecular iodine $\left(\mathrm{I}_{2}\right)$ and organic iodine found in solution. Unless chemical additives are introduced to control it, the $\mathrm{pH}$ tends to be reduced by long-term radiolysis. This favors the recombination of $\mathrm{I}^{-}$ions to form $\mathrm{I}_{2}$. Increasing pool temperatures and especially pool boiling can, in turn, cause $\mathrm{I}_{2}$ to move from the liquid to the vapor phase. ${ }^{7}$ Hence, it is possible that suppression pools would scrub substantial amounts of iodine in the early phases of an accident, only to re-evolve it later as $\mathrm{I}_{2}$. In NUREG-1150, such re-evolution of iodine was judged to be important in accident sequences where the containment failed and the suppression pool eventually boiled.

There is presently no requirement for $\mathrm{pH}$ control in BWR suppression pools. It may well be that additional materials likely to be in the suppression pool as a result of a severe accident (such as cesium borate, cesium hydroxide, and core-concrete decomposition products) would counteract any reduction in $\mathrm{pH}$ from radiolysis and would ensure that the $\mathrm{pH}$ level remained sufficiently high to preclude re-evolution of iodine. If credit is to be given for long-term retention of iodine in the suppression pool, maintenance of the $\mathrm{pH}$ at or above a level of 7 must be demonstrated. ${ }^{8}$

\subsubsection{Drywell-Wetwell Configuration}

Depending on the timing and location of containment failure, the suppression pool may also be effective in scrubbing the release occurring during core-concrete attack or re-evolved from the reactor coolant system after vessel failure. In the NUREG1150 analyses for Peach Bottom (Mark I containment), containment failure was found likely to occur in the drywell early in the accident. Thus, in many scenarios the suppression pool was not effective in mitigating the delayed release of radioactive material.

The Mark III design has the advantage, relative to the Mark I and Mark II designs, that the wetwell boundary completely encloses the drywell, in effect providing a double barrier to radioactive material release. As long as the drywell remains intact, any release of radioactive material from the fuel is subject to decontamination by the suppression pool. With the Mark III drywell intact, the environmental source 
terms is reduced to a level at which early fatalities would not be expected to occur, even for early failure of the outer containment. However, for Grand Gulf (Mark III containment), drywell failure accompanies approximately one-half of the early containment failures in NUREG-1150, and the suppression pool is ineffective in mitigating ex-vessel releases for such scenarios.

\subsubsection{Containment Sprays}

Containment sprays can be effective in reducing airborne concentrations of radioactive aerosols and vapors. In the Surry (subatmospheric) and Zion (large dry) designs, approximately $20 \%$ of the NUREG1150 core meltdown sequences were predicted to eventually result in delayed containment failure or basemat meltthrough. The effect of sprays, in those scenarios in which they are operational for an extended time, is to reduce the concentration of radioactive aerosols airborne in the containment to negligible levels in comparison with non-aerosol radionuclides (e.g., noble gases). Qualified sprays can reduce airborne aerosol activities by an order of magnitude in 15 to 20 minutes. For shorter periods of operation, sprays would be less effective but could still have a substantial mitigative effect on the release. Without sprays, an order of magnitude reduction in airborne aerosol activities would typically take about 10 hours.

The Sequoyah (ice condenser) design has containment sprays for the purpose of condensing steam that might bypass the ice bed, as well as for use after the ice has melted. The effects of the sprays and ice beds in removing radioactive material are not completely independent since they both tend to preferentially remove larger aerosols.

\subsubsection{Ice Condenser}

The ice beds in an ice condenser containment remove radioactive material from the air by processes that are very similar to those in the BWR pressuresuppression pools. The decontamination factor is very sensitive to the volume fraction of steam in the flowing gas, which in turn depends on whether the air-return fans are operational. For a typical case when the air-return fans are on, the magnitude of the decontamination factors was assessed to be in the range from 1.2 to 20 , with a median value of 3 . Thus, the effectiveness of the ice bed in mitigating the release of radioactive material is likely to be substantially less than for a BWR suppression pool.

\subsubsection{Reactor Cavity Flooding}

The configuration of a PWR reactor cavity or BWR pedestal region affects the likelihood of water accumulation and water depth below the reactor vessel. The Surry reactor cavity is not connected by a flowpath to the containment floor. If the spray system is not operating, the cavity will be dry at vessel failure. In the Peach Bottom (Mark I) design, there is a maximum water depth of approximately 2 feet on the pedestal and drywell floor before water would overflow into the suppression pool via the downcomer. Other designs investigated such as Sequoyah and Zion have substantially greater potential for water accumulation in the pedestal or cavity region. In the Sequoyah design, the water depth could be as much as 40 feet.

If a coolable debris bed is formed in the cavity or pedestal, and makeup water is continuously supplied, core-concrete release of radioactive material would be avoided. 
Even if molten core-concrete interaction occurs, a continuous overlaying pool of water can substantially reduce the release of radioactive material to the containment in the same way suppression pools mitigate releases.

\subsubsection{Building Retention}

In NUREG-1150, radionuclide retention was evaluated for the Peach Bottom reactor building. (An evaluation was not made for the portion of the reactor building that surrounds the Grand Gulf containment, which was assessed to have little potential for retention.) The range of aerosol decontamination factors for the Peach Bottom reactor building subsequent to drywell rupture was 1.1 to 80 , with a median value of 2.6. The location of drywell failure affects the potential for reactor building decontamination. Leakage past the drywell head to the refueling building was assumed to result in very little decontamination. Failure of the drywell by meltthrough resulted in a release that was subjected to a decontamination factor of 1.3 to 90 with a median value of 4 .

In the NUREG-1150 analyses of PWR interfacing LOCA sequences, some retention of radionuclides was assumed in the auxiliary building (in addition to water pool decontamination for submerged releases). In the Sequoyah analyses, retention was enhanced by the actuation of the fire spray system.

\subsubsection{BWR Containment Venting}

In the Peach Bottom and Grand Gulf designs, procedures have been implemented to intentionally vent the containment to avoid overpressure failure. By venting from the wetwell air space (in Peach Bottom) and from the containment (in Grand Gulf) assurance is provided that, subsequent to core damage, the release of radionuclides through the vent line will have been subjected to decontamination by the suppression pool.

As discussed in Module 4, containment venting to the outside can substantially improve the likelihood of recovery from a loss of decay heat removal and, as a result, reduce the frequency of severe accidents. The results of NUREG-1150 indicate, however, only limited benefits in consequence mitigation for the existing venting procedures and hardware. Uncertainties regarding the decontamination factor for the suppression pool and the re-evolution of iodine from the suppression pool are quite broad. As a result, the consequences of a vented release are not necessarily minor. Furthermore, the effectiveness of venting may, for some plants, be limited by the high likelihood of early containment failure mechanisms that would bypass the vent.

\subsubsection{Source Term Uncertainty}

Clearly, the magnitude of the source term varies depending on whether or not containment fails, when it fails, where and how it fails, and the effectiveness of engineered safety features in mitigating the release. However, even if details regarding the nature of containment failure and engineered safety feature performance are known, the uncertainty in predicting severe accident phenomena is still large.

A major shortcoming of the 1975 Reactor Safety Study was its limited treatment of the uncertainties in severe accident source terms. In the intervening years, particularly subsequent to the Three Mile Island accident, major experimental and code development efforts have broadly explored severe accident behavior. In the comprehensive NUREG-1150 study, which 
was published in 1989, care was taken to assess and display the uncertainties associated with the analysis of accident source terms. Many of the severe accident issues that are now recognized as the greatest sources of uncertainty were completely unknown to the earlier Reactor Safety Study analysts.

In the 1975 Reactor Safety Study, source terms were developed for nine release categories ("PWR1" to "PWR9") for the Surry plant and five release categories for the Peach Bottom plant ("BWR1" to "BWR5"). In NUREG-1150, source terms were developed for a much larger number of accident progression bins. For each accident progression bin, an estimate of the uncertainty in the release fractions for each of the elemental groups was obtained.

Figure 5.1-4 provides a comparison of an important large release category (PWR2) from the Reactor Safety Study with a comparable aggregation of accident progression bins (early containment failure, high reactor coolant system pressure) from the NUREG-1150. The Reactor Safety Study results in this case are clearly conservative when compared to the NUREG-1150 results. Figure 5.1-5 compares results for an isolation failure in the wetwell region from the Reactor Safety Study, release category BWR4, with the venting accident progression bin from NUREG-1150. The Reactor Safety Study results are very similar to the mean release terms for the venting bin, with the exception of the iodine group, which is higher because of the late release mechanisms (re-evolution from the suppression pool and the reactor vessel) considered in the NUREG-1150 study. Overall, the comparisons indicate that the source terms in the Reactor Safety Study are in some instances higher and in other instances lower than those in NUREG- 1150. However, for the early containment failure scenarios that have the greatest impact on risk, the Reactor Safety Study source terms are larger than the mean values of the NUREG-1150 study and are typically at the upper bound of the uncertainty range.

\subsubsection{Revised LWR Source Term}

In 1962, (see Sections 1.2.6 and 2.1.2) the Atomic Energy Commission issued Technical information document TID-14844, ${ }^{9}$ which postulated a release of fission products from the reactor vessel into containment to be used for calculating offsite doses in accordance with the reactor siting criteria of 10 CFR Part 100. The TID-14844 release was based on a postulated core melt accident and the 1962 understanding of fission product behavior. In addition to evaluations of site suitability and plant mitigation features such as containment sprays and filtration systems, the TID-14844 release has influenced post-accident radiation environments for which safety-related components are qualified, post-accident habitability requirements for the control room, post-accident sampling systems, and post-accident accessibility considerations.

For currently licensed plants, the characteristics of the fission product release from the core into the containment were derived from TID-14844 as set forth in Regulatory Guides 1.3 and 1.4..$^{3,10}$ The release consists of $100 \%$ of the core inventory of noble gases and $50 \%$ of the iodines (half of which are assumed to deposit on interior surfaces very rapidly). These values were based largely on experiments performed in the late 1950s involving heated irradiated $\mathrm{UO}_{2}$ pellets. TID-14844 also include $1 \%$ of the remaining solid fission products, but these were dropped from consideration in Regulatory Guides 1.3 and 1.4 . The $1 \%$ of the solid fission products are considered in certain areas such as equipment qualification. 
In Regulatory Guides 1.3 and 1.4, the release to containment is assumed to occur instantaneously (with the initial blowdown of the reactor vessel in a LOCA). Further, the iodine chemical form is assumed to be $91 \%$ in elemental $\left(\mathrm{I}_{2}\right)$ form, $5 \%$ in particulate form, and $4 \%$ in organic form. Organic iodine is not readily removed by containment sprays or filter systems. These assumptions have significantly affected the design of engineering safety features, particularly containment isolation valve closure times

Recently, the NRC developed revised accident source terms based on careful evaluation of NUREG-1150 accident scenarios and associated source term estimates. This evaluation is documented in NUREG/CR-5747, ${ }^{11}$ and the resulting revised source terms are published in NUREG-1465. ${ }^{8}$ NUREG-1465 source terms were developed for regulatory application to future LWRs but may also be used to evaluate changes to regulatory requirements for existing plants.

Tables 5.1-5 and 5.1-6 present the NUREG1465 release fractions, which are intended to be representative or typical (rather than conservative or bounding) values, except for the initial appearance of fission products from the failed fuel. This so-called gap release is set by the design basis initiator that leads to earliest cladding failure.

In contrast to the instantaneous releases postulated in Regulatory Guides 1.3 and 1.4, the NUREG-1465 releases are distributed in time to reflect the degree of fuel melting and relocation, reactor pressure vessel integrity, and, as applicable, attack upon concrete below the reactor cavity by molten core materials. The timing aspects are typical of a low pressure core-melt scenario, except that the onset of the release of gap activity is based upon the earliest calculated time of fuel rod failure under accident conditions.
NUREG-1465 also considers the chemical form of iodine in the containment and concludes that no more than $3 \%$ of the airborne iodine would be converted to organic form. When $\mathrm{pH}$ is controlled at values of 7 or greater within the containment, elemental iodine is assumed to comprise no more than $5 \%$ of the total iodine released to containment, and organic iodine no more than 0.15 percent ( 3 percent of 5 percent).

\subsubsection{The Chernobyl Source Term}

The initial release of radioactive materials from Chernobyl 4 reactor resulted from the explosions that destroyed the reactor core on April 26, 1986. Releases continued over a relatively long period of time and occurred in several stages, each of which differed in radionuclide composition and intensity. Figure 5.1-6 shows the estimated timedependance of the release for the first 10 days following the accident when a stream of hot air carried particulates, noble gases and volatile radionuclides from the destroyed reactor up to the atmosphere ${ }^{12}$.

From April 26 until May 1 the release rate decreased, perhaps under the influence of the measures undertaken to extinguish the burning graphite and cover the core, although there is no concensus on this point. During this stage the release consisted of finely dispersed fuel particles entrained by the escaping hot air and graphite combustion products. The radionuclide composition during this stage was similar to that of the fuel.

From May 1 through May 5, there was a rapid increase in the release rate, at first dominated by volatile radionuclides (especially iodine isotopes), after which the composition again became similar to that of the fuel. The release during this stage was attributed to heating of the fuel to over 
$2000^{\circ} \mathrm{C}$ from the residual heat. The released radionuclides were associated with aerosols of fuel and graphite combustion products.

On May 6, there was an abrupt decrease in the release rate perhaps due to chemical interactions of the radionuclides with the materials introduced into the core. A complete explanation of the sudden decrease is not available. Measurable releases of activity continued during the remainder of May. For example, there was a significant peak 20 to 21 days after the beginning of the accident, and a less pronounced peak in the 25- to 30 -day period. ${ }^{13}$

Table 5.1-7 summarizes the quantitative estimates of the magnitude of the releases from the Chernobyl-4 reactor. Based on various data, including measurements of Cs-137 in fuel masses inside the reactor sarcophagus and in the global fallout, the total core cesium released to the environment is estimated to be $33 \% \pm 10 \%$, or $2.3 \pm 0.7 \mathrm{MCi}^{14}$ The relative constancy of the ratio of I-131 and Cs-137 activities in fallout observed in the majority of European countries indicates that $50 \%$ to $60 \%$ of the initial I-131 inventory or 40 to $50 \mathrm{MCi}$ of I-131 was released. Accounting for radioactive decay in the reactor in the period of the release, this corresponds to a total activity of 30 to $35 \mathrm{MCi}$ released into the atmosphere. Iodine-131 released as gases and as aerosols was in the ratio of approximately $3: 7$ over the first two weeks after the accident, but, by the third week, the ratio changed to approximately $10: 1 .^{13}$

Comparing the Chernobyl release fractions in Table 5.1-7 with the revised LWR source terms in Tables 5.1-5 and 5.1-6 shows the volatile release fractions (noble gases, iodine, and cesium) are similar in magnitude. On the other hand, releases of nonvolatile species at Chernobyl resulted from the initial explosions and the ensuing fires. The amount of fuel released is estimated to be $3.5 \% \pm 0.5 \%$ of the fuel inventory in the core. ${ }^{12,14}$ This by far exceeds the NUREG1465 release fractions for nonvolatile species. It should also be emphasized that the NUREG-1465 releases are to the containment, not directly to the atmosphere as occurred at Chernobyl.

\subsubsection{On-Line Source Term Monitoring}

As indicated in Section 5.1.5, it is not possible to predict with certainty the source term that would result from a given plant damage state. What, then, is the feasibility of on-line monitoring to measure source term characteristics during an accident?

For accidents where the total release is through a monitored pathway (e.g., the stack), it may be possible to adequately characterize the release. As part of the upgrades that followed the TMI-2 accident, on-line radiation monitors capable of measuring the noble gases released through plant vents were installed. Noble gases are not considered as great a threat to the public as the halogens and other chemical groups listed in Table 5.1-1. The presence of halogens and other chemical groups must, in general, be determined through analysis of samples taken during the release. Unfortunately, this can require several hours. Nevertheless, at a minimum, the magnitude of a stack release can generally be estimated if the monitors stay on scale.

By their very nature, however, releases resulting in offsite dose high enough to cause early health effects most likely could not be characterized by existing effluent monitors. A release resulting in early offsite health effects (death and injuries) would have to be fast, direct, and unfiltered. Most important are potential releases due to major containment failure. As illustrated in Figure $5.1-7$, such a release would be through an 
unmonitored path to the atmosphere. stacks) would not be able to assess the Effluent-monitoring systems located in extent and the characteristics of such a routinely monitored release paths (e.g., release. 
Table 5.1-1 Radioactive materials in a large [3300-MWt] light water reactor core grouped by relative volatility

\begin{tabular}{|c|c|c|c|c|}
\hline Group & Isotope & Half-life & Core Inventory (Ci) & Group Total (Ci) \\
\hline & $\mathrm{Kr}-85$ & $10.72 y$ & $6.69 \mathrm{E}+05$ & \\
\hline \multirow[t]{5}{*}{ Noble Gases } & $\mathrm{Kr}-85 \mathrm{~m}$ & $4.48 \mathrm{~h}$ & $3.13 E+07$ & $3.84 \mathrm{E}+08$ \\
\hline & $\mathrm{Kr}-87$ & $1.27 \mathrm{~h}$ & $5.72 E+07$ & \\
\hline & $\mathrm{Kr}-88$ & $2.54 \mathrm{~h}$ & $7.74 \mathrm{E}+07$ & \\
\hline & Xe-133 & $5.245 \mathrm{~d}$ & $1.83 E+08$ & \\
\hline & $\mathrm{Xe}-135$ & $9.09 \mathrm{~h}$ & $3.44 \mathrm{E}+07$ & \\
\hline \multirow{5}{*}{ Halogens } & $1-131$ & $8.04 \mathrm{~d}$ & $8.66 E+07$ & \\
\hline & $\mathrm{I}-132$ & $2.30 \mathrm{~h}$ & $1.28 \mathrm{E}+08$ & $7.71 E+08$ \\
\hline & I-133 & $20.8 \mathrm{~h}$ & $1.83 \mathrm{E}+08$ & \\
\hline & I-134 & $52.6 \mathrm{~m}$ & $2.01 \mathrm{E}+08$ & \\
\hline & I-135 & $6.61 \mathrm{~h}$ & $1.73 E+08$ & \\
\hline \multirow{4}{*}{ Alkali Metals } & Cs-134 & $2.062 \mathrm{y}$ & $1.17 \mathrm{E}+07$ & \\
\hline & Cs-136 & $13.16 \mathrm{~d}$ & $3.56 \mathrm{E}+06$ & $2.18 E+07$ \\
\hline & Cs- 137 & $30.17 \mathrm{y}$ & $6.53 E+06$ & \\
\hline & $\mathrm{Rb}-86$ & $18.66 \mathrm{~d}$ & $5.10 \mathrm{E}+04$ & \\
\hline \multirow{8}{*}{ Tellerium Group } & $S b-127$ & $3.85 \mathrm{~d}$ & $7.53 \mathrm{E}+06$ & \\
\hline & Sb- 129 & $4.40 \mathrm{~h}$ & $2.67 E+07$ & $2.13 \mathrm{E}+08$ \\
\hline & Te-127 & $9.35 \mathrm{~h}$ & $7.28 \mathrm{E}+06$ & \\
\hline & Te-127m & $109 \mathrm{~d}$ & $9.63 E+05$ & \\
\hline & Te-129 & $1.16 \mathrm{~h}$ & $2.50 \mathrm{E}+07$ & \\
\hline & $\mathrm{Te}-129 \mathrm{~m}$ & $33.6 \mathrm{~d}$ & $6.60 \mathrm{E}+06$ & \\
\hline & Te-131m & $30 \mathrm{~h}$ & $1.26 \mathrm{E}+07$ & \\
\hline & Te-132 & $3.26 \mathrm{~d}$ & $\frac{1.26 \mathrm{E}+08}{1.70 \mathrm{E}+08}$ & \\
\hline \multirow{5}{*}{ Barium, Strontium } & Ba-139 & $\begin{array}{l}1.396 \mathrm{~h} \\
12746 \mathrm{~d}\end{array}$ & $\begin{array}{l}1.70 E+08 \\
1.68 E+08\end{array}$ & $6.95 \mathrm{E}+08$ \\
\hline & $\begin{array}{l}\text { Ba-140 } \\
\text { Sr-89 }\end{array}$ & $\begin{array}{l}12.746 \mathrm{~d} \\
50.52 \mathrm{~d}\end{array}$ & $9.70 \mathrm{E}+07$ & $0.95 E T$ TO \\
\hline & $\mathrm{Sr}-90$ & 29.1 y & $5.24 \mathrm{E}+06$ & \\
\hline & Sr-9l & $9.5 \mathrm{~h}^{\circ}$ & $1.25 \mathrm{E}+08$ & \\
\hline & $\mathrm{Sr}-92$ & $2.71 \mathrm{~h}$ & $1.30 \mathrm{E}+08$ & \\
\hline \multirow{8}{*}{ Noble Metals } & Co-58 & $70.88 \mathrm{~d}$ & $8.71 \mathrm{E}+05$ & \\
\hline & Co-60 & $5.271 \mathrm{~d}$ & $6.66 \mathrm{E}+05$ & $5.94 E+08$ \\
\hline & Mo-99 & $2.7476 \mathrm{~d}$ & $1.65 E+08$ & \\
\hline & $\mathrm{Rh}-105$ & $35.4 \mathrm{~h}$ & $5.53 E+07$ & \\
\hline & Ru-103 & $39.27 d$ & $1.23 \mathrm{E}+08$ & \\
\hline & Ru-105 & $4.44 \mathrm{~h}$ & $7.98 \mathrm{E}+07$ & \\
\hline & Ru-106 & $1.02 \mathrm{y}$ & $2.79 \mathrm{E}+07$ & \\
\hline & Tc- $99 \mathrm{~m}$ & $6.01 \mathrm{~h}$ & $1.42 \mathrm{E}+08$ & \\
\hline \multirow{15}{*}{ Lanthanides } & $\mathrm{Am}-241$ & $432.7 y$ & $3.13 \mathrm{E}+03$ & \\
\hline & $\mathrm{Cm}-242$ & $162.8 \mathrm{~d}$ & $1.20 \mathrm{E}+06$ & $1.54 E+09$ \\
\hline & $\mathrm{Cm}-244$ & $18.1 \mathrm{y}$ & $7.02 E+04$ & \\
\hline & $\mathrm{La}-140$ & $1.678 \mathrm{~d}$ & $1.72 \mathrm{E}+08$ & \\
\hline & La-141 & $3.90 \mathrm{~h}$ & $1.57 \mathrm{E}+08$ & \\
\hline & La-142 & $1.54 \mathrm{~h}$ & $1.52 \mathrm{E}+08$ & \\
\hline & $\mathrm{Nb}-95$ & $34.97 \mathrm{~d}$ & $1.41 E+08$ & \\
\hline & $\mathrm{Nd}-147$ & $10.98 \mathrm{~d}$ & $6.52 \mathrm{E}+07$ & \\
\hline & $\operatorname{Pr}-143$ & $13.57 \mathrm{~d}$ & $1.46 \mathrm{E}+08$ & \\
\hline & $Y-90$ & $2.67 \mathrm{~d}$ & $5.62 \mathrm{E}+06$ & \\
\hline & $Y-91$ & $58.5 \mathrm{~d}$ & $1.18 \mathrm{E}+08$ & \\
\hline & $Y-92$ & $3.54 \mathrm{~d}$ & $1.30 \mathrm{E}+08$ & \\
\hline & $Y-93$ & $10.2 \mathrm{~h}$ & $1.47 E+08$ & \\
\hline & $\mathrm{Zr}-95$ & $64.02 \mathrm{~d}$ & $1.49 E+08$ & \\
\hline & $\mathrm{Zr}-97$ & $16.8 \mathrm{~h}$ & $1.56 \mathrm{E}+08$ & \\
\hline \multirow{8}{*}{ Cerium Group } & Ce-141 & $32.50 \mathrm{~d}$ & $1.53 \mathrm{E}+08$ & \\
\hline & $\mathrm{Ce}-143$ & $1.38 \mathrm{~d}$ & $1.48 E+08$ & $2.15 \mathrm{E}+09$ \\
\hline & Ce-144 & $284.6 \mathrm{~d}$ & $9.20 \mathrm{E}+07$ & \\
\hline & $\mathrm{Np}-239$ & $2.355 \mathrm{~d}$ & $1.75 E+09$ & \\
\hline & Pu-238 & $87.7 \mathrm{y}$ & $9.90 E+04$ & \\
\hline & Pu-239 & $24100 \mathrm{y}$ & $2.23 \mathrm{E}+04$ & \\
\hline & Pu-240 & $6560 \mathrm{y}$ & $2.82 \mathrm{E}+04$ & \\
\hline & Pu-241 & $14.4 \mathrm{y}$ & $4.74 \mathrm{E}+06$ & \\
\hline
\end{tabular}


Table 5.1-2 Typical inventories of noble gases and iodine in reactor systems

\begin{tabular}{|c|c|c|}
\hline \multirow{2}{*}{ Location } & \multicolumn{2}{|c|}{ Inventory (Ci) } \\
\hline & $\begin{array}{c}\text { Noble gases (Xe, } \\
\mathrm{Kr})\end{array}$ & Iodine (I) \\
\hline Reactor core total & $4.0 \mathrm{E}+8$ & $7.5 \mathrm{E}+8$ \\
\hline Reactor core gap ${ }^{a}$ & $3.0 \mathrm{E}+7$ & $1.4 \mathrm{E}+7$ \\
\hline Spent fuel storage pool & $1.0 \mathrm{E}+6$ & $5.0 \mathrm{E}+5^{\mathrm{b}}$ \\
\hline Primary coolant $^{c}$ & $1.0 \mathrm{E}+4$ & $6.0 E+2^{c}$ \\
\hline \multicolumn{3}{|l|}{$\begin{array}{l}\text { Pressurized Water Reactor--other } \\
\text { systems }\end{array}$} \\
\hline Waste gas storage tank & $1.0 \mathrm{E}+5$ & 1 \\
\hline $\begin{array}{l}\text { Boiling Water Reactor--other syste } \\
\text { Steam line } \\
\text { Waste gas treatment system }\end{array}$ & $\begin{array}{l}1.0 \mathrm{E}+4^{\mathrm{d}} \\
5.0 \mathrm{E}+3 \\
\end{array}$ & $\begin{array}{r}25^{d} \\
0.25 \\
\end{array}$ \\
\hline Shipping cask & $1.0 \mathrm{E}+4$ & 1 \\
\hline
\end{tabular}

${ }^{2} \mathrm{Gap}$ between $\mathrm{UO}_{2}$ fuel and Zircaloy cladding.

'One-third of the core is 30 days old; the rest is 1 year old.

'Nominal value, iodine levels can much higher or lower (factor of 10) depending on fuel leakage.

${ }^{\mathrm{d}} \mathrm{Ci} / \mathrm{hr}$ (circulating). 


\section{Table 5.1-3 Illustrative noble gas and halogen releases}

\begin{tabular}{|c|c|c|}
\hline & $\begin{array}{l}\text { Activity } \\
\text { Released } \\
\text { (Ci) } \\
\end{array}$ & $\begin{array}{c}\text { Fraction of } \\
3000 \mathrm{MWt} \text { Core } \\
\text { Inventory }^{\mathrm{a}}\end{array}$ \\
\hline \multicolumn{3}{|l|}{ Noble Gases (Krypton and Xenon) } \\
\hline Average annual release for a $L W R^{b}$ & $1 \times 10^{3}$ & $3 \times 10^{-6}$ \\
\hline $\begin{array}{l}\text { Prompt release resulting in } 5 \text { rem } \\
\text { committed stomach dose equivalent }{ }^{\mathfrak{c}} \text { to } \\
\text { unprotected individual one mile } \\
\text { downwind under poor meteorological } \\
\text { conditions }^{d}\end{array}$ & $1 \times 10^{6}$ & $3 \times 10^{-2}$ \\
\hline $\begin{array}{l}\text { Prompt release resulting in } 50 \text { rem } \\
\text { acute stomach dose } e^{e} \text { to unprotected } \\
\text { individual one mile downwind under } \\
\text { poor meteorological conditions. }\end{array}$ & $1 \times 10^{7}$ & $3 \times 10^{-2}$ \\
\hline \multicolumn{3}{|l|}{ Halogens (Iodine) } \\
\hline Average annual release for a $L W R^{b}$ & 0.1 & $1 \times 10^{-10}$ \\
\hline $\begin{array}{l}\text { Prompt release resulting in } 5 \text { rem acute } \\
\text { thyroid dose }{ }^{c} \text { to unprotected infant one } \\
\text { mile downwind under poor } \\
\text { meteorological conditions }{ }^{d}\end{array}$ & $6 \times 10^{2}$ & $1 \times 10^{-6}$ \\
\hline $\begin{array}{l}\text { Prompt release resulting in } 200 \text { rem } \\
\text { thyroid dose } \text { fo unprotected infant one }^{\text {to }} \text { mile downwind under poor } \\
\text { meteorological conditions }\end{array}$ & $2.4 \times 10^{4}$ & $3 \times 10^{-5}$ \\
\hline
\end{tabular}

${ }^{\text {SSee Table 5.1-1 }}$

${ }^{b}$ Predominately 1.131

'The smallest dose for which evacuation would be considered based of Environmental Protection Agency protective action guides discussed in Appendix 5A

${ }^{\mathrm{d}}$ Ground level, non-buoyant release, stability class $\mathrm{F}, 1 \mathrm{~m} / \mathrm{s}$ wind speed, calculations using USNRC MACCS 1.5 .11 .1 computer code

'Threshold for radiation-induced prodromal vomiting

'Threshold for radiation-induced thyroiditis 
Table 5.1-4 Decontamination factors associated with various design features

\section{Design Feature}

Containment Sprays

Ice Condensers

Reactor building surrounding a BWR

Mark I containment

Suppression pools and overlying water layers

\section{Decontamination Factor}

$\sim 10$ for aerosols in 10-20 minutes versus

$\sim 10$ for aerosols in 10 hours without sprays

1.2 to 20 while ice is present

1.1 to 80

2 to 4000 before re-evolution 
Table 5.1-5 NUREG-1465 BWR releases into containments*

\begin{tabular}{|c|c|c|c|c|}
\hline & Gap $^{* *}$ & $\begin{array}{l}\text { Early In- } \\
\text { Vessel }\end{array}$ & Ex-Vessel & $\begin{array}{l}\text { Late In- } \\
\text { Vessel } \\
\end{array}$ \\
\hline Duration (Hours) & 0.5 & 1.5 & 3.0 & 10.0 \\
\hline Noble Gases: Xe, Kr & 0.05 & 0.95 & 0 & 0 \\
\hline Halogens: $\mathrm{I}, \mathrm{Br}$ & 0.05 & 0.25 & 0.30 & 0.01 \\
\hline Alkali Metals: Cs, Rb & 0.05 & 0.20 & 0.35 & 0.01 \\
\hline Tellurium group: $\mathrm{Te}, \mathrm{Sb}, \mathrm{Se}$ & 0 & 0.05 & 0.25 & 0.005 \\
\hline Barium, strontium: $\mathrm{Ba}, \mathrm{Sr}$ & 0 & 0.02 & 0.1 & 0 \\
\hline $\begin{array}{l}\text { Noble Metals: } \\
\text { Ru, Rh, Pd, Mo, Tc, Co }\end{array}$ & 0 & 0.0025 & 0.0025 & 0 \\
\hline $\begin{array}{l}\text { Lanthanides: La, } \mathrm{Zr}, \mathrm{Nd}, \mathrm{Eu}, \mathrm{N} \\
\text { b, Pm, Pr, Sm, Y, Cm, Am }\end{array}$ & 0 & 0.0002 & 0.005 & 0 \\
\hline Cerium Group: $\mathrm{Ce}, \mathrm{Pu}, \mathrm{Np}$ & 0 & 0.0005 & 0.005 & 0 \\
\hline
\end{tabular}

- Values shown are fractions of core inventory.

** Gap release is 3 percent if long-term fuel cooling is maintained.

Table 5.1-6 NUREG-1465 PWR releases into containments*

\begin{tabular}{|c|c|c|c|c|}
\hline & Gap** & $\begin{array}{l}\text { Early In- } \\
\text { Vessel }\end{array}$ & Ex-Vessel & $\begin{array}{l}\text { Late In- } \\
\text { Vessel } \\
\end{array}$ \\
\hline Duration (Hours) & 0.5 & 1.3 & 2.0 & 10.0 \\
\hline Noble Gases: Xe, $\mathrm{Kr}$ & 0.05 & 0.95 & 0 & 0 \\
\hline Halogens: I, Br & 0.05 & 0.35 & 0.25 & 0.01 \\
\hline Alkali Metals: Cs, Rb & 0.05 & 0.25 & 0.35 & 0.01 \\
\hline Tellurium group: $\mathrm{Te}, \mathrm{Sb}, \mathrm{Se}$ & 0 & 0.05 & 0.25 & 0.005 \\
\hline Barium, strontium: $\mathrm{Ba}, \mathrm{Sr}$ & 0 & 0.02 & 0.1 & 0 \\
\hline $\begin{array}{l}\text { Noble Metals: } \\
\text { Ru, Rh, Pd, Mo, Tc, Co }\end{array}$ & 0 & 0.0025 & 0.0025 & 0 \\
\hline $\begin{array}{l}\text { Lanthanides: La, Zr, Nd, Eu,N } \\
\text { b, Pm, Pr, Sm, Y, Cm, Am }\end{array}$ & 0 & 0.0002 & 0.005 & 0 \\
\hline Cerium Group: $\mathrm{Ce}, \mathrm{Pu}, \mathrm{Np}$ & 0 & 0.0005 & 0.005 & 0 \\
\hline
\end{tabular}


Table 5.1-7 Estimated releases from Chernobyl-4 accident ${ }^{14}$

\begin{tabular}{cccc}
\hline Noble Gases & $100 \%$ & $190 \pm 20$ & $\mathrm{MCi}$ \\
\hline${ }^{131} \mathrm{I}$ & $55 \pm 5 \%$ & $45 \pm 5$ & $\mathrm{MCi}$ \\
${ }^{137} \mathrm{Cs}$ & $33 \% \pm 10 \%$ & $2.3 \pm 0.7$ & $\mathrm{MCi}$ \\
${ }^{90} \mathrm{Sr},{ }^{90} \mathrm{Y}$ & $4 \%$ & $2.8 \pm 0.8$ & $\mathrm{MCi}$ \\
Fuel & $3.5 \pm 0.5 \%$ & & \\
\hline
\end{tabular}




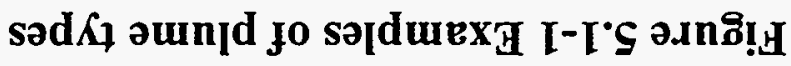

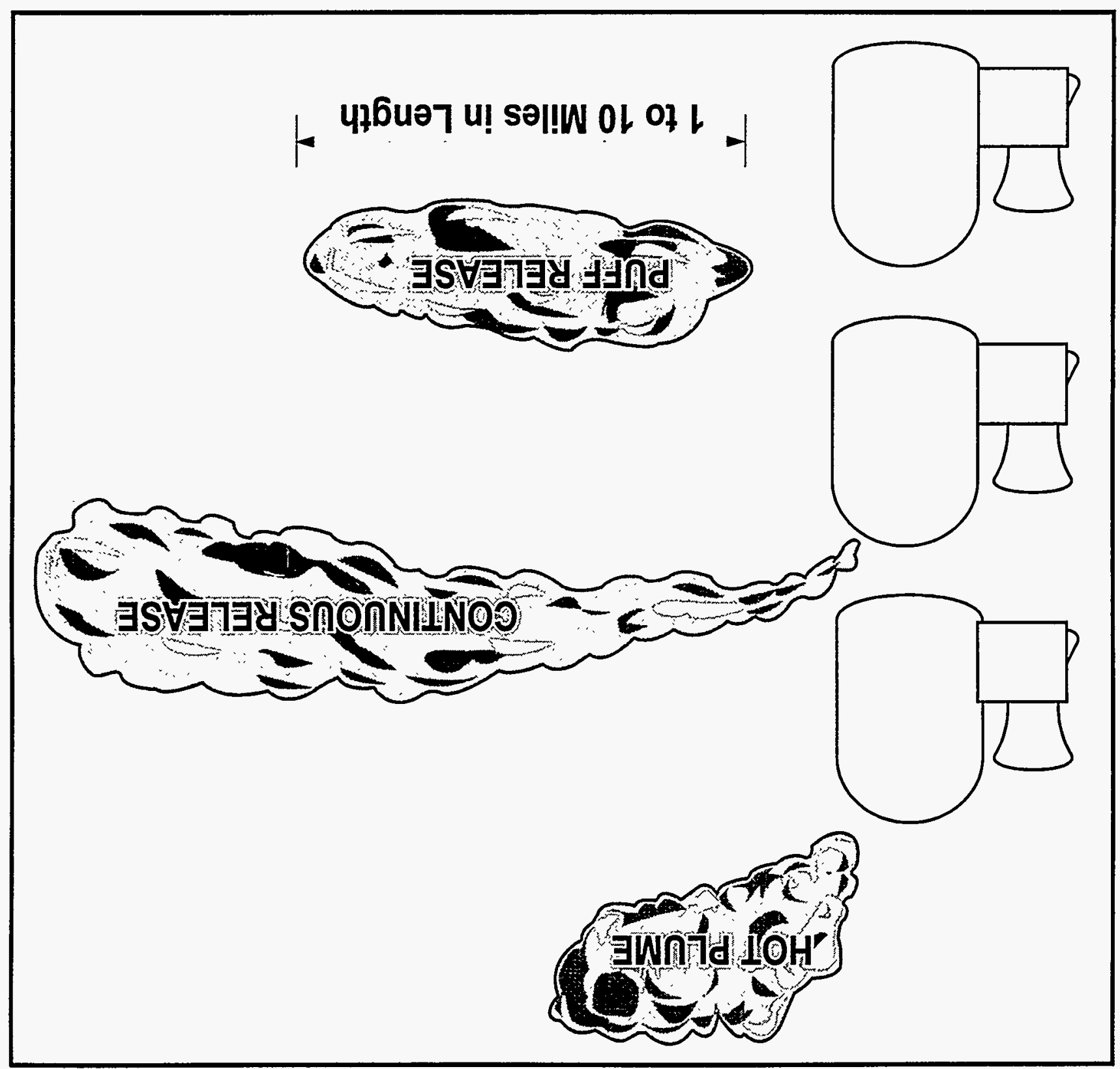




\section{(1)}

Average Annual

Reactor Release

$(1975$ - 1979)

Noble Gas $\quad 1,000 \mathrm{Ci}$

lodine $\quad .13 \mathrm{Ci}$
(2)

TMI Accident Release US March 1979

Noble Gas $\quad 2,500,000 \mathrm{Ci}$

Iodine

$15 \mathrm{Ci}$

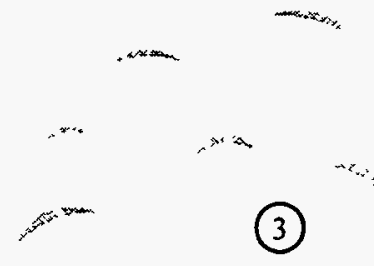

CHERNOBYL Accident USSR April 1986

Noble Gas $\quad 190,000,000 \mathrm{Ci}$

Iodine $\quad 45,000,000 \mathrm{Ci}$

Particulate $\quad 60,000,000 \mathrm{Ci}$
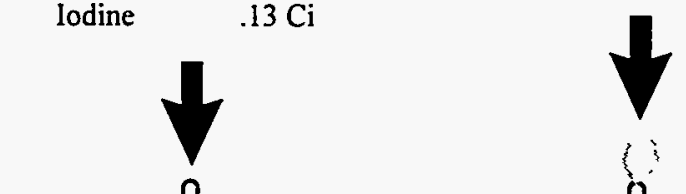

Note: Iodine and particulate releases pose a much greater risk to the public than noble gas releases.

References and notes are found on the following page.

Figure 5.1-2 Putting radiation releases (curies-Ci) in perspective for the public 


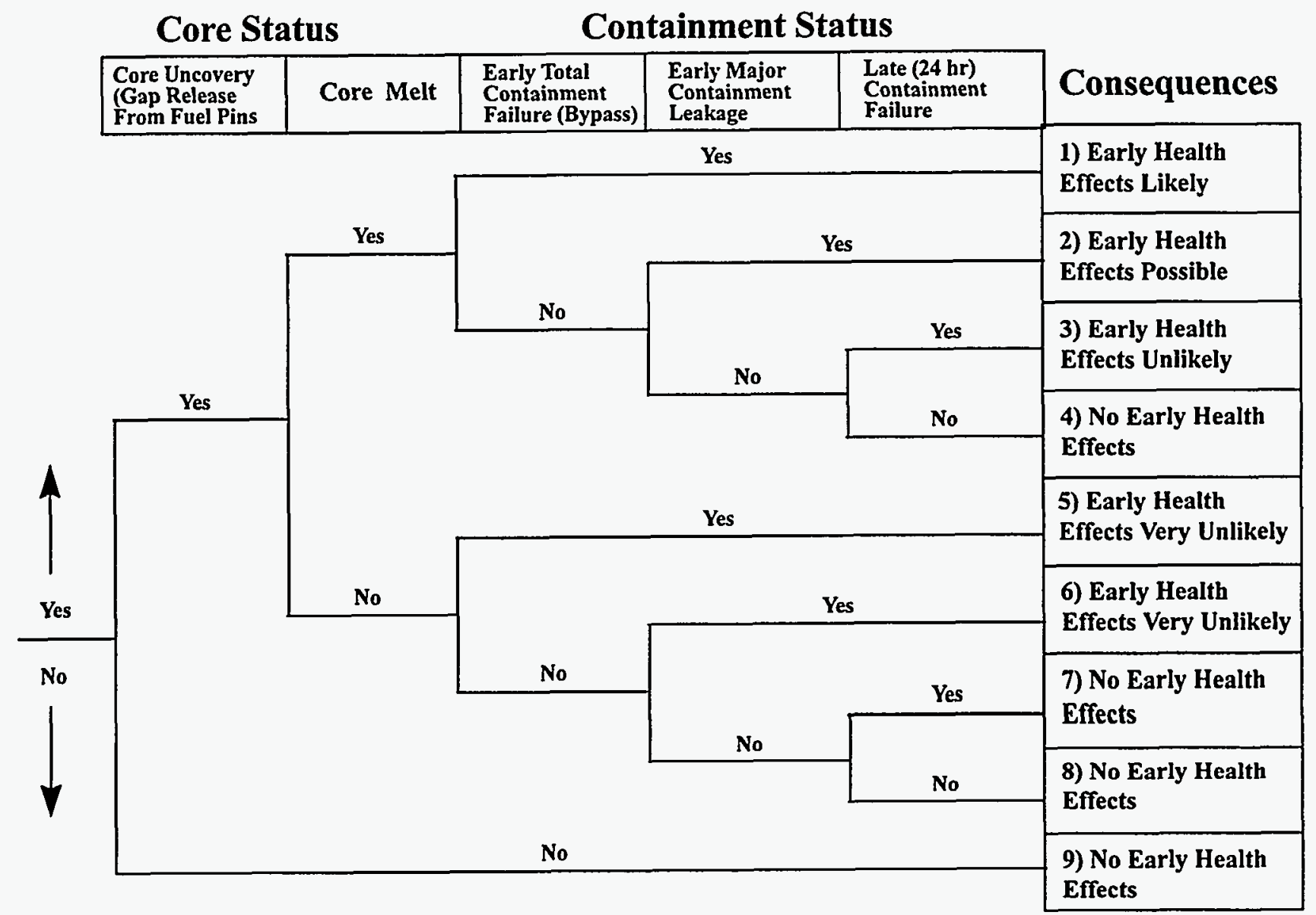

Figure 5.1-3 Event tree for severe accident consequences 


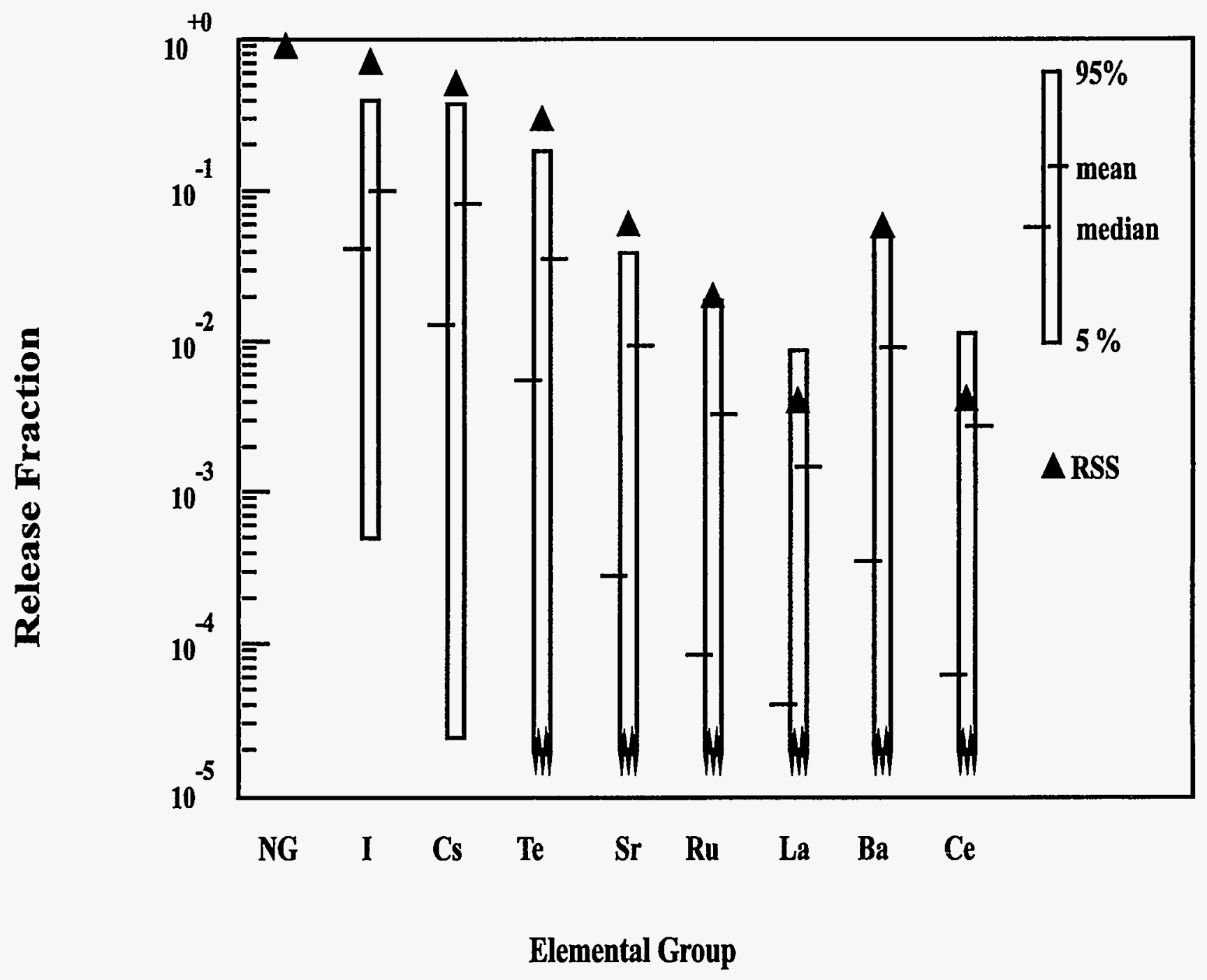

Figure 5.1-4 Comparison of NUREG-1150 source terms with Reactor Safety Study (Surry) bin PWR2 


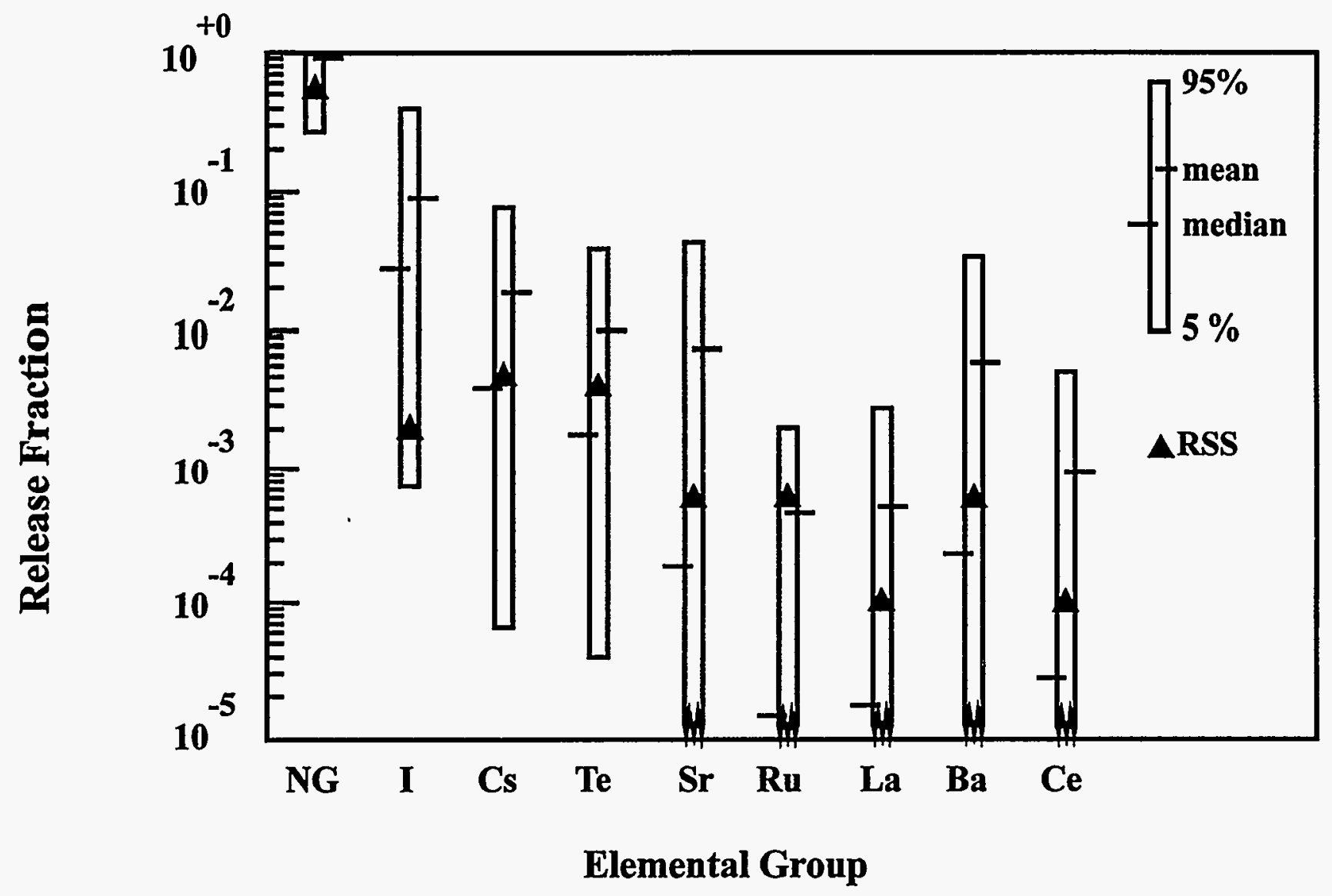

Figure 5.1-5 Comparison of NUREG-1150 source terms with Reactor Safety Study (Peach Bottom) bin BWR4 


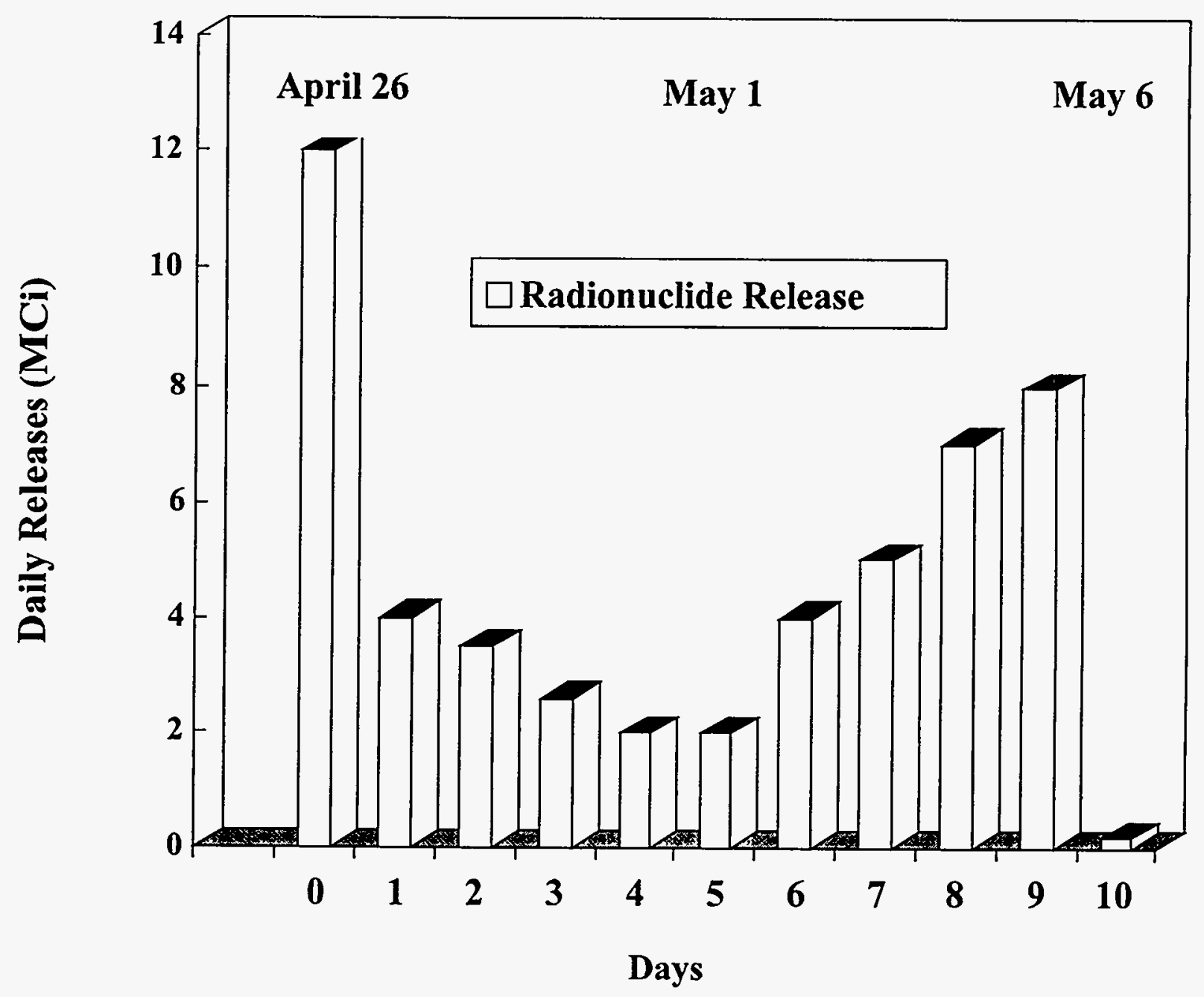

Figure 5.1-6 Release of radionuclides during the active stage of the Chernobyl accident ${ }^{1}$ 


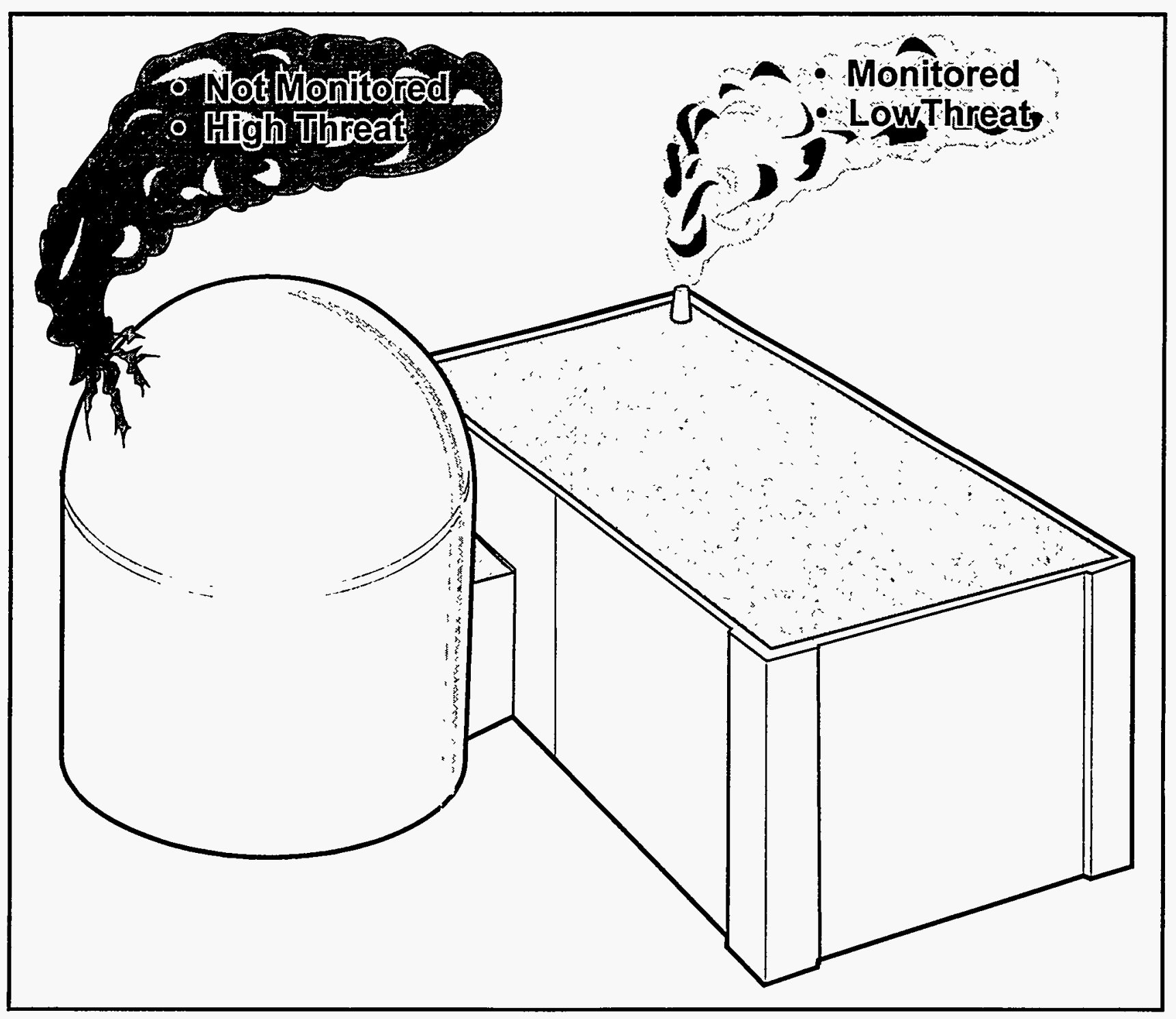

Figure 5.1-7 Types of release 


\section{References for Section 5.1}

1. D. J. Alpert, et al., "Relative Importance of Individual Elements to Reactor Accident Consequences Assuming Equal Release Fractions," NUREG/CR-4467, SAND85-2575, March 1986.

2. T. J. McKenna, et al., "Pilot Program: NRC Severe Reactor Accident Incident Response Training Manual, Vol. 2, Severe Reactor Accident Overview," NUREG-1210, February 1987.

3. U.S. Nuclear Regulatory Commission, "Assumptions Used for Evaluating the Potential Radiological Consequences of a Loss of Coolant Accident for Boiling Water Reactors," Regulatory Guide 1.3, Revision 2, June 1974.

4. U.S. Nuclear Regulatory Commission, "Pressure Suppression Pool as a Fission Product Cleanup System," Standard Review Plan, Section 6.5.5, NUREG0800, December 1988.

5. U.S. Nuclear Regulatory Commission, "Reactor Safety Study: An Assessment of Accident Risks in U.S. Commercial Nuclear Power Plants," WASH-1400, NUREG-75/014, December 1975.

6. U.S. Nuclear Regulatory Commission, "Severe Accident Risks: An Assessment for Five U.S. Nuclear Power Plants," NUREG-1150, December 1990.

7. E.C. Beahm, C.F. Weber, and T.S. Kress, "Iodine Chemical Forms in LWR Severe Accidents," NUREG/CR-5732, ORNL/TM-11861, prepared for NRC by Oak Ridge National Laboratory, April 1992.
8. L. Soffer, S. B. Burson, C. M. Ferrell, R. Y. Lee, and J. N. Ridgely, "Accident Source Terms for Light-Water Nuclear Power Plants," NUREG-1465, February 1995.

9. J. J. DiNunno, et al., "Calculation of Distance Factors for Power and Test Reactor Sites," Technical Information Document (TID)-14844, U.S. Atomic Energy Commission, 1962.

10. U.S Nuclear Regulatory Commission, "Assumptions Used for Evaluating the Potential Radiological Consequences of a Loss of Coolant Accident for Pressurized Water Reactors," Regulatory Guide 1.4, Revision 2, June 1974.

11. H. P. Nourbakhsh, "Estimates of Radionuclide Release Characteristics into Containment Under Severe Accidents," NUREG/CR-5747 (BNLNUREG-52289, Brookhaven National Laboratory, November 1993.

12. USSR State Committee on the Utilization of Atomic Energy. The accident at Chernobyl and its consequences. Summary report on the post-accident review meeting on the Chernobyl accident. Vienna: International Atomic Energy Agency, IAEA Safety Series N 75-INSAG-1; 1986.

13. Yu. P. Buzulukov and Yu. L. Dobrynin, "Release of Radionuclides During the Chernobyl Accident," in The Chernobyl Papers, Volume I, Doses to the Soviet Population and Early Health Effects Studies, Steven 
E. Merwin and Michail I. Balonav editors, Research Enterprises, Richland Washington, 1993.

14. S. T. Belyaev, A. A. Borovoy, and V. F. Demin, et al., "The Chernobyl Source Term, In: Proceedings of a seminar on comparative assessment of the environmental impact of radionuclides released during three major nuclear accidents, Kyshtym, Windscale, Chernobyl. Luxembourg: EUR; Report EUR 13574; 1991: 7191. 


\subsection{Offsite Dispersion and Doses}

In order to assess the consequences of a severe accident, one must (1) estimate the source term, (2) characterize the transport of radionuclides in the environment, and (3) estimate the resulting doses to the public (accounting for protective actions that may be taken). This process is depicted in Figure 5.2-1. Source term estimates are treated in Section 5.1. This section discusses the transport of radionuclides in the environment and the doses that could potentially result from such transport. Offsite protective actions that could be taken to reduce doses to the public are discussed in section 5.3.

\subsubsection{Radiation Dose and Health Effects}

Radiation exposures can affect the health of exposed individuals. The type of effect, its severity, and the length of time until the effect appears are determined by the total dose received, the rate of exposure, the exposed organs, and the degree of medical treatment received.

Although the curie is an appropriate unit for quantifying amounts of radioactive materials (e.g., curies in the core), it is not an appropriate unit for quantifying the potential health effects that may result from the release of radioactive materials to the environment. The number of curies required to induce various health effects can vary considerably, depending on the types of radiation emitted by the decaying nuclei and how the radiation enters the body (i.e., the pathway). The term dose refers to radiation absorbed by a human body. A unit of dose is the rad. One rad corresponds to 100 ergs of energy deposited in a gram of material. The corresponding SI unit is the Grey (Gy), and $1 \mathrm{~Gy}=100 \mathrm{rads}(1 \mathrm{~J} / \mathrm{kg})$. A closely related unit, the rem, is a measure of dose equivalent in humans. The corresponding SI unit is the Sievert $(\mathrm{Sv})$, and $1 \mathrm{~Sv}=100$ rems. The dose to the whole body or to a particular organ is a measure of potential biological damage induced by exposure of the body or organ to radiation.

\subsubsection{Chronic (Latent) Effects}

Small doses or moderately large doses received at low dose rates (e.g., long term exposure to low levels of ground contamination) can cause health effects such as cancer, which appear later in time and are not directly observable following the exposure. Such effects are called chronic effects.

Traditionally, the risk of cancer has been assumed to be proportional to dose, no matter how small. That is, computer models assume that a collective dose of about 2,000 person-rem ( $1 \mathrm{rem}$ to 2,000 people, $0.1 \mathrm{rem}$ to 20,000 people, etc.) will result in one radiation-induced cancer in the affected population.' This linear, no-threshold hypothesis is the subject of considerable debate, with some contending it is too conservative. Under this hypothesis, because the release is spread over a larger area and therefore over a larger population the farther it moves from the plant, a sizable fraction of the predicted radiation-induced cancers can result from very small exposures beyond 50 miles from the plant. This is illustrated in Figure 5.2-2. ${ }^{2}$

\subsubsection{Acute Health Effects}

Large doses received over short time periods threaten both the short- and long-term health of exposed individuals. If exposures are sufficiently intense, exposed organs are damaged causing radiation sickness or death within days or months. As a class, such early health effects are called acute. Radiation sickness includes vomiting, diarrhea, loss of hair, nausea, hemorrhaging, fever, loss of appetite, and general malaise. 
Deaths can be caused by failures of the lungs, small intestine, or blood-forming bone marrow. Barring death or complications, recovery from radiation sickness occurs in a few weeks to a year depending on the dose received. Exposed individuals who survive radiation sickness are still subject to increased risk of latent effects such as cancers.

Because damage sufficient to impair organ functioning does not occur if exposures are small, short-term health effects usually have dose thresholds. That is, the effect does not appear until the dose received is greater than the threshold dose $\left(D_{t h}\right)$. Once the threshold dose has been exceeded, the fraction of the exposed population in which the health effect occurs (the health effect's incidence) rises rapidly with increasing dose until the effect appears in all of the exposed individuals. The dose at which a health effect is induced in half of the exposed population is called the $D_{50}$ dose $\left(L_{50}\right.$ if the dose is lethal).

Figure 5.2-3 depicts the average dose equivalents in millirems received from natural background, common medical procedures, and frequent human activities. ${ }^{3}$ As indicated in the figure, early injuries generally would appear at doses above 50 to 100 rem to the whole body, and early deaths would be expected at much higher doses (e.g., 250 to $600 \mathrm{rem}$ ). It has been estimated that, with only minimal medical treatment, about $50 \%$ of the people who receive a whole-body dose $\left(\mathrm{LD}_{50}\right)$ of 300 rem would die within 60 days. $L_{50}$ has been estimated to increase to 450 rem with supportive medical treatment. ${ }^{4}$

\subsubsection{Dose Pathways}

As indicated in Figure 5.2-4, a person can receive a radiation dose from a plume in several ways, usually called pathways. First, dose can be received externally from the radiation given off by the passing plume or the ground contamination. Such doses are called cloud shine and ground shine, respectively. The dose due to radioactive particles that settle directly onto the skin or clothing of persons immersed in the cloud is called the skin dose. Dose can also be received by inhaling the radioactive material in the plume; this is called inhalation dose. Some of the inhaled material may concentrate in particular organs such as the lungs or thyroid and thus become a special threat to those organs. Cloud shine, ground shine, and inhalation are collectively considered parts of the plume exposure pathway.

Dose can also be received from the ingestion pathway, that is, from eating or drinking contaminated food or water. As in the case of inhaled material, ingested material can concentrate in various organs. Ingestion of milk receives special attention because radioiodine from a plume can contaminate grass eaten by dairy herds. This radioiodine, which can be greatly concentrated in the milk, can then concentrate in the drinker's thyroid gland.

The actual doses received by individuals offsite as a result of an accidental release would depend primarily on three factors:

1. The release (source term) characteristics,

2. the weather during and after the release, which would determine the concentrations of airborne radionuclides and ground contamination offsite, and

3. the protective actions taken by individuals located offsite. 
Source terms are discussed in Section 5.1. The impact of weather on offsite consequences is discussed in the following subsections. The impact of protective actions on offsite-site health effects is discussed in Section 5.3. In considering offsite protective actions against releases from nuclear power plant accidents, both acute dose to the bone marrow and thyroid doses are important. Dose to the bone marrow (mostly from shine) is a dominant cause of early deaths for reactor accidents. Thyroid dose is important because inhalation or ingestion of small amounts of radioiodine can result in damage or destruction of the thyroid. However, unlike bone marrow dose, dose to the thyroid will not be fatal in the short term in most cases. There would, of course, be increased risk of death due to thyroid cancer.

\subsubsection{Meteorology}

In the absence of significant heat transfer with the ground or between adjacent layers of air, the temperature in a well-mixed atmosphere decreases linearly with altitude at a rate of about $5.4^{\circ} \mathrm{F} / 1000 \mathrm{ft}\left(1^{\circ} \mathrm{C} / 100 \mathrm{~m}\right)$. This is called the adiabatic lapse rate (or adiabatic temperature distribution) because it is derived by treating the expansion of air with altitude as an adiabatic expansion. ${ }^{5}$ As indicated in Figure 5.2-5, other temperature distributions such as isothermal, superadiabatic, and inversions may exist over particular ranges of altitudes. The actual temperature profile at any time is determined by a number of factors including heating and cooling of the earth's surface, the movements of large air masses (highs and lows), the existence of cloud cover, and the presence of large topographical obstacles. For example, on clear days with light winds, superadiabatic conditions may exist in the first few hundred meters of the atmosphere due to the heat transferred to the air from the hot surface of the earth.
Conversely, on a cloudless night, when the earth radiates energy most easily, the earth's surface may cool down faster than the air immediately above it, and the result is a radiation inversion.

The degree to which pollutants are dispersed in the atmosphere depends to a large extent on the atmospheric temperature profile. Consider the case of dispersion in a superadiabatic atmosphere. If a small parcel of polluted air is released at some altitude $h$ and the same temperature $T$ as the atmosphere, as indicated in Figure 5.2-6a, the parcel will remain in equilibrium at that point if not disturbed. Suppose, however, that a fluctuation in the atmosphere moves the parcel upward. The parcel will cool adiabatically as it rises; that is, the temperature of the parcel will follow the adiabatic curve shown by the dashed lines in Figure 5.2-6a. Because the surrounding superadiabatic atmosphere cools more rapidly, the parcel becomes increasingly hotter than the atmosphere. This means the parcel becomes increasingly buoyant, causing it to move more rapidly upward. On the other hand, if the parcel is pushed downward, its temperature will fall more rapidly and it will become increasingly more dense than the surrounding superadiabatic air. This will accelerate the downward motion at the parcel. Clearly, the superadiabatic atmospheric conditions are inherently unstable and are highly favorable for dispersing pollutants.

In contrast, if the parcel is released into an isothermal or inversion profile, as indicated in Figure 5.2-6b, a fluctuation upward will make it cooler and hence more dense than the surrounding atmosphere, tending to return the parcel to its original position. Similarly, a downward fluctuation will make the parcel hotter and more buoyant than the surrounding air. This will also tend to return the parcel to its equilibrium point. 
Atmospheres characterized by isothermal or inversion profiles are therefore said to be stable. This is undesirable for pollutant dispersal.

Frequently, the parcel is hotter than its surroundings when released, and it will initially rise due to its greater buoyancy. Various types of dispersal patterns can be observed depending on the conditions in the surrounding atmosphere, as illustrated in Figure 5.2-7. Plumes emitted into an inversion layer (stable atmosphere) disperse horizontally much more rapidly than they disperse vertically (vertical dispersion is inhibited in an inversion layer). Therefore, the plume spreads out horizontally but not vertically, which produces a fan shape when viewed from below (fanning). If a hot plume is emitted into an unstable atmosphere that is capped by an inversion layer, the plume rises to the inversion layer and then spreads rapidly downward, fumigating the ground below (fumigation). Plumes emitted into an uncapped unstable atmosphere tend to breakup because vertical displacements of plume parcels are enhanced (looping). Plumes emitted into a neutral atmosphere (lapse rate equal to the adiabatic lapse rate) are dispersed smoothly both vertically and horizontally, and therefore have a conical profile in the crosswind direction (coning). Plumes emitted into a neutral layer that overlies an inversion layer can spread upward but not downward (lofting).

It is possible to estimate the stability conditions in the lower atmosphere by simply measuring the temperature at two or more heights on a meteorological tower. The slope of the temperature profile can then be compared by dividing the temperature difference $\Delta T$ by the difference in height $\Delta z$ of the measurements. Alternatively, stability can be estimated by monitoring fluctuations (standard deviation $\sigma_{\Theta}$ ) in the angle of a wind vane. Based on experimental data on atmospheric dispersion, stability regions are often divided into the seven stability classes listed in Table $5.2-1^{6}$ depending on the indicated ranges of $\Delta T / \Delta z$ or $\sigma_{\Theta}$.

Other meteorological conditions that can have a strong impact on atmospheric dispersion or ground contamination include wind speed, precipitation and humidity. Data on these factors are also measured on the meteorological tower. The significance of such factors is discussed in the following section.

\subsubsection{Dispersion of Effluents}

Plumes disperse as they are transported downwind, which means that concentrations of released radionuclides would decrease with plume travel distance. Because dispersion causes plume materials (droplets, particles, gas molecules) to move away from the plume centerline in a random series of steps, plume concentrations tend to assume normal (Gaussian) distributions in both the vertical and horizontal directions. The rate of spreading depends on atmospheric stability and is usually not the same in the vertical and horizontal directions.

Models of atmospheric dispersion range in complexity from simple to sophisticated. Perhaps the simplest model is the straightline Gaussian plume model. As illustrated in Figure 5.2-8, this model assumes a constant wind direction and a Gaussianshaped spreading of the plume with distance. It also assumes a constant wind speed, and it does not account for the effects of local topography. According to this model, the released plume (or puff for a short duration release) moves downwind at the wind speed $u$. The plume spreads in all directions due to turbulent diffusions as it moves. This spreading is characterized by empirically determined standard deviations in vertical and cross wind pollutant concentrations. 
These standard deviations increase with downwind distance and atmospheric instability.

The inhalation and immersion doses that would be received by an individual standing in the path of the plume increase with the magnitude of $\chi_{T}$, the time-integrated concentration at the point in question. According to the straight-line Gaussian plume model

$$
\chi_{T} \propto Q \frac{\Phi}{u}
$$

where

$$
\begin{aligned}
& \chi_{T}=\begin{array}{l}
\text { integrated radionuclide } \\
\text { concentration at point in } \\
\text { question }\left(\mathrm{Ci} \cdot \mathrm{s} / \mathrm{m}^{3}\right)
\end{array} \\
& Q=\begin{array}{l}
\text { quantity of radionuclide } \\
\text { released }(\mathrm{Ci})
\end{array} \\
& u=\text { wind speed }(\mathrm{m} / \mathrm{s}) \\
& \Phi=\begin{array}{l}
\text { Gaussian shape function, } \\
\text { which depends on the location, } \\
\text { the stability class, and the } \\
\text { release height }\left(\mathrm{m}^{-2}\right)
\end{array}
\end{aligned}
$$

Figure 5.2-9 shows the quantity $\chi_{T} / Q$ along the plume centerline for effluent released at a height of $100 \mathrm{ft}$ under Pasquill stability classes B, C, and D for a 6 mile/hr wind. $\chi_{T} / Q$ is also shown for a $2 \mathrm{mile} / \mathrm{hr}$ wind speed for stability class $D$. It will be observed that, at reasonable distances from the plant, $\chi_{T} / Q$ decreases more or less exponentially. With the more unstable conditions (B), the maximum of $\chi_{T} / Q$ occurs nearer the release point (within a few hundred meters), then drops rapidly to very low values. On the other hand, under more stable conditions (D), the peak of $\chi_{T} / Q$ is located much further from the source.
Concentrations in populated offsite locations are therefore usually greater under stable than under unstable conditions and stable conditions are often assumed in calculations of the atmospheric dispersion of releases from nuclear power plants.

The preceding discussion ignored the effects of radioactive decay and ground deposition on plume concentrations. Radioactive decay and deposition, both wet and dry, are each first order processes (i.e., their rates are proportional to the local concentration). Both processes cause atmospheric concentrations to decrease more rapidly with distance.

Changes in wind speed and atmospheric stability cause the rate at which plume concentrations decrease with distance to change but do not cause the preceding generalizations to be seriously violated. However, wind stagnation or rainfall can cause high local air or ground concentrations. Wind stagnation causes cloudshine, inhalation, and skin doses at the stagnation distance to increase because the exposure times for these doses all increase. In addition, prolonged stagnation can produce a hot spot on the ground at the stagnation distance because of the greatly increased time period during which deposition occurs at that distance. Rain can have a major impact on accident consequences. Rain decreases plume concentrations and associated cloudshine, inhalation, and skin doses, but rain can result in very high local ground concentrations (hot spots) distributed in very complex patterns as seen at Chernobyl (Figure 5.2-10). ${ }^{7}$

Wind stagnation causes cloudshine, inhalation, and skin doses at the stagnation distance to increase because the exposure times for these doses all increase. In addition, prolonged stagnation can produce 
a hot spot on the ground at the stagnation distance because of the greatly increased time period during which deposition occurs at that distance.

\subsubsection{Dose Versus Distance}

As indicated in Section 5.1.3, releases to the atmosphere from a very severe reactor accident involving both core melting and containment failure could result in offsitesite injuries or fatalities. This section presents dose versus distance calculations based on the straight-line Gaussian plume model for such a release, one resulting from a Surry (PWR) accident scenario in which containment fails early (2.5 hours after scram). The release duration is taken to be 0.5 hour. The release fractions are set at the median values depicted within the NUREG1150 uncertainty ranges of Figure 5.1-4.

Two radiation-induced injuries with relatively low thresholds are prodromal vomiting (threshold stomach dose of $\sim 50$ rem) and hypothyroidism (threshold thyroid dose of $\sim 200 \mathrm{rem}$ ). Figure 5.2-11 provides information regarding the stomach and thyroid doses versus distance for the postulated release under typical meteorological conditions (stability class $\mathrm{D}$, $6 \mathrm{~m} / \mathrm{s}$ wind speed).

It is evident from Figure 5.1-4 that the postulated release fractions are neither optimistic nor pessimistic. Nor are the postulated meteorological conditions particularly extreme. Doses resulting from an actual accident involving both core melting and containment failure could therefore be much higher or much lower depending on the actual source term characteristics and the weather at the time of the release.

In calculating the doses presented in Figure 5.2-11, evacuation, sheltering, and other possible offsite-site protective actions are not considered, and dose reduction factors representative of normal indoor activities are not applied. That is, the doses shown are for hypothetical persons on the plume centerline who remain outside during plume passage for the indicated time intervals measured from plume arrival.

The top left plot in Figure 5.2-11 shows the integrated stomach dose at 4 hours, 24-hours, and 7 days following initial exposure. It is evident that the stomach dose continues to increase after plume passage. This is due to continued exposure to radionuclides deposited on the ground and from inhalation of resuspended radionuclides. The top right plot shows the relative contribution of various pathways to the 24-hour stomach dose as a function of distance. The cloudshine and groundshine pathways contribute roughly equally, whereas the inhalation pathway is insignificant. The 4-hour stomach dose exceeds the $\sim 50$ rem threshold for radiation-induced injury to a distance of $\sim 2.5$ miles.

From the bottom figures, it can be seen that projected thyroid doses are dominated by inhalation doses. The ground and cloud shine contributions increase the thyroid dose only marginally within $24 \mathrm{hr}$. The 4-hr thyroid dose exceeds the $\sim 200$ rem threshold for radiation-induced hypothyroidism within about 5.25 miles.

The dose versus distance results clearly indicate that people close to the plant would have to take protective actions before or shortly after the start of the release to avoid injuries and fatalities. Actions taken after plume passage would be effective only in reducing additional dose from ground contamination. Beyond a certain radius, the direct dose from the plume (cloudshine and inhalation) is not sufficient to result in early 
injuries; but if people remain on contaminated ground, their dose can clearly increase to the point where injuries or fatalities become likely. Obviously, after a major release, areas of substantial ground contamination must be identified, and the population must be relocated.

For most LWR release scenarios, the greatest effluent concentrations occur within the first 2 to 3 miles. Therefore, independent of the size of the release, the greatest need for protective actions most likely will be within 2 to 3 miles of the plant. For large releases, these actions are taken to prevent early injuries and fatalities. For lesser releases, they are taken to keep doses below Environmental Protection Agency protective action guides, which are discussed in Appendix 5A.

Another point to be made from Figure 5.2-11 involves the plume exposure emergency planning zone, which is normally within a 10 mile radius of the plant (see Section 5.4.5.1). Many think that the public risk stops at the boundary of the emergency planning zone. But, it is clear that the postulated release could result in doses in excess of the Environmental Protection Agency whole body (1 to $5 \mathrm{rem}$ ) and thyroid (5 to $25 \mathrm{rem}$ ) protective action guides beyond 10 miles. At these levels, protective actions could be appropriate beyond the plume emergency planning zone.

\subsubsection{Uncertainties in Dose Projections}

In a 1981 study conducted at the Idaho National Engineering Laboratory, a nonradioactive tracer $\left(\mathrm{SF}_{6}\right)$ was released and the resulting air concentrations were compared with predictions made by various models to evaluate their potential use in emergency response situations. Figure 5.212 shows the actual air concentration (plume) pattern observed for one of the tests and the plume pattern predicted by three of the models tested under this program: (a) a simple, straight-line Gaussian plume model of the type used by many emergency response organizations, (b) a Gaussian-puff trajectory model, which accounts for wind shifts, and (c) a more sophisticated wind field and topographic model used in the DOE's Atmospheric Release Advisory Capability (ARAC) program. Even the most complicated ARAC model could not reproduce what actually occurred.

This result points out two concerns. First, only one meteorological tower is typically in the site vicinity. The initial transport of radioactive material from a site after it is released to the atmosphere will be dominated by local conditions (e.g., hills, valleys, lakes, and precipitation). This single source of weather and wind information cannot give a definitive indication of winds away from the plant. Nuclear power plants are typically located in very complex areas (e.g., in river valleys or on the coast), where wind direction and flows can vary considerably within a short distance of the plant. As an example, a $180^{\circ}$ difference in wind direction could result from sea breeze effects at a coastal site. This is the basis for taking protective actions in all directions near (within 2 or 3 miles) of the plant. The events that occurred early in the TMI-2 incident (as discussed in Section 5.3.7), further illustrate the problems inherent in taking protective actions only in the downwind direction.

Second, differences should be expected in the estimates produced by various analysts. Various response organizations may be performing analyses based on different assumptions. For example, the NRC may be concentrating on dose projections based on possible additional plant failures, while the state is making dose projections based on estimates of actual releases. As Figure 5.2- 
12 indicates, even if the same input conditions (e.g., source terms and meteorology) are used, dose estimates may differ.

Unanticipated catastrophic containment failure is an example of a case where source term could be underestimated by a factor of 100,000. For lesser accidents (non-core damage) where the total release is through a monitored pathway and consists mostly of noble gases, the source term uncertainty can be reduced. However, the transport and dose uncertainties would remain. Overall, the best that should be expected in the early time frame is that projected dose estimates may be within a factor of 10 of the true dose value; more likely, they will be even less accurate.

It is clear that one should not expect close agreement when comparing various dose projections with each other or with early field monitoring data. Dose projections should be viewed only as rough estimates.

What may be more important than relying on a dose model in estimating plume movement is a knowledge of local meteorological conditions and trends (e.g., the winds shift every morning at about 9:00 a.m.).

The basic point here is that the analyst needs to understand the problem, the models, and the results. Indiscriminate use of technical aids such as dose projection models without access to staff who understand the unpredictability of local conditions can provide misleading input to protective action decision making.

\subsubsection{Dispersion of the Chernobyl Release}

As shown in Figure 5.2-10, the Chernobyl nuclear power plant is located between $51^{\circ}$ and $52^{\circ}$ north latitudes in the Ukraine in the
$\mathrm{Kiev}$ region and is only $15 \mathrm{~km}$ from the south border of the Gomel region of Belarus. The western part of the Bryansk region of Russia is $150 \mathrm{~km}$ from the plant. The region is relatively flat, and elevations do not exceed $200 \mathrm{~m}$. The climate is moderate, with warm summers, mild winters, and an average precipitation of 20 to 24 inches (500 to $650 \mathrm{~mm}$ ).

From the time the accident began on April 26, 1986, a stream of hot air carried radioactive materials from the destroyed reactor into the atmosphere. Volatile iodine and cesium radioisotopes were discovered at heights up to 6 to $9 \mathrm{~km}$. The exposure rate in the stream at a distance of 5 to $10 \mathrm{~km}$ and a height of $200 \mathrm{~m}$ was approximately $1 \mathrm{rad} / \mathrm{h}$ on April 27 and $0.5 \mathrm{rad} / \mathrm{h}$ on April $28 .^{8}$

When the plume of radioactive material first rose on April 26, the winds carried it northwest into Latvia and across the Baltic Sea into Scandinavia, Lithuania, and Northern Poland. On the second day, the winds changed, blowing to the west and southwest and passing over Southern Poland, Switzerland, Italy, Austria, Southern Germany, and France. On the fifth day the wind changed back to the northwest and the cloud moved into Central Germany, the Netherlands, and Great Britain. Eventually, the winds blew northeast spreading the fallout into Central Russia. Some radioactive material road the jet-stream over the United States and other countries. Trace levels of I-131 were measured in Japan and the United States by May 5.9

In all, more than 20 countries received fallout from Chernobyl, exposing nearly 400 million people. Deposition patterns were complex and diverse. They depended on both particle densities and the weather. The largest particles, which were primarily fuel particles, were deposited within $100 \mathrm{~km}$ of the reactor. Both in this near zone and 
across the former Soviet Union and Europe, levels of contamination depended on whether it was raining when the cloud passed over. Outside the former Soviet Union, the Lap people of northern Sweden were perhaps hardest hit. Their reindeer herds were so contaminated they were unfit for human consumption.

Ukraine, Belarus, and Russia were subjected to the most intense radioactive contamination (see Figure 5.2-10). ${ }^{10,11}$ The three main regions of contamination have been designated the Central, Bryansk-Belarus and Kaluga-Tula-Orel hot spots. The following information regarding these hot spots and other contamination is taken from Reference 12 and summarized in Table 5.2-2.

The central hot spot was formed during the initial active stage of the release, predominantly to the west and northwest. Cs-137 soil surface activities in excess of $1.0 \mu \mathrm{Ci} / \mathrm{m}^{2}$ covered large areas of the territory of the Kiev, Zhitomir, Cherrnigov, Rovno, and Lutsk regions of the Ukraine; as well as the Gomel and Brest regions of Belarus. The most highly contaminated area was the $30-\mathrm{km}$ radius surrounding the reactor, where Cs-137 surface activities generally exceeded $40 \mu \mathrm{Ci} / \mathrm{m}^{2}$. Outside the $30-\mathrm{km}$ zone, such areas were also present to the west and northwest of the reactor in the Gomel, Kiev, and Zhitomir regions. The initial gamma dose rate $(1 \mathrm{~m}$ above the ground) from deposited radionuclides ranged from 1 to $200 \mathrm{mrad} / \mathrm{h}$. By 1991, these dose rates had decreased to 0.005 to $1 \mathrm{mrad} / \mathrm{h}$.

The Bryansk-Belarus hot spot, centered 200 $\mathrm{km}$ to the north-northeast of Chernobyl, was formed on April 28-29, 1986 as a result of rainfall at the interface of the Bryansk region of Russia and the Gomel and Mogilev regions of Belarus. The soil surface activities of Cs-137 in the most highly contaminated areas in this hot spot were comparable to the levels in the central hot spot and exceeded $130 \mu \mathrm{Ci} / \mathrm{m}^{2}$ in some villages of the Mogilev region and 110 $\mu \mathrm{Ci} / \mathrm{m}^{2}$ in the village Zaborye of the Bryansk region. The initial dose rates in air ranged form $0.3 \mathrm{mrad} / \mathrm{hr}$ to $30 \mathrm{mrad} / \mathrm{hr}$. By 1991 , these dose rates had fallen to 0.005 to 0.5 $\mathrm{mrad} / \mathrm{hr}$. The Bryansk-Belarus spot was called a "cesium hot spot" because of the predominance of long-lived Cs-137.

The Kaluga-Tula-Orel spot in Russia, centered approximately $500 \mathrm{~km}$ northeast of the reactor, was also a "cesium hot spot." It was formed from the same radioactive cloud that produced the Bryansk-Belarus spot, as a result of rainfall on April 28-29. However, Cs-137 contamination levels were lower, less than $0.16 \mu \mathrm{Ci} / \mathrm{m}^{2}$. The initial dose rates over this hot spot ranged from 0.3 to 3.0 $\mathrm{mrad} / \mathrm{hr}$. By 1991 these dose rates had fallen to 0.005 to $0.05 \mathrm{mrem} / \mathrm{hr}$.

Outside the three main hot spots in the greater part of the European territory of the former Soviet Union, there were many areas of radioactive contamination with $\mathrm{Cs}-137$ levels mainly in the range 1 to $5 \mu \mathrm{Ci} / \mathrm{m}^{2}$. Overall, the contaminated land areas of the former Soviet Union included approximately $3,100 \mathrm{~km}^{2}$ with $>40 \mu \mathrm{Ci} / \mathrm{m}^{2} \quad \mathrm{Cs}-137$, $7,200 \mathrm{~km}^{2}$ with 16 to $40 \mu \mathrm{Ci} / \mathrm{m}^{2} \mathrm{Cs}-137$, $17,600 \mathrm{~km}^{2}$ with 5 to $16 \mu \mathrm{Ci} / \mathrm{m}^{2} \mathrm{Cs}-137$, $103,000 \mathrm{~km}^{2}$ with 1 to $5 \mu \mathrm{Ci} / \mathrm{m}^{2} \mathrm{Cs}-137^{11}$

The total Cs-137 activity in areas where Cs-137 levels exceeded $1 \mu \mathrm{Ci} / \mathrm{m}^{2}$ is estimated to be approximately $1.0 \mathrm{MCi}$, including $0.3 \mathrm{MCi}$ within a radius of $40 \mathrm{~km}$ around the reactor. ${ }^{10,11}$ Accounting for the large area with Cs- 137 contamination levels less than $1.0 \mu \mathrm{Ci} / \mathrm{m}^{2}$, the total $\mathrm{Cs}-137$ deposition in the former Soviet Union is estimated to be $1.3 \mathrm{MCi}, 95 \%$ of which was deposited in the European part and 5\% 
outside this part (east of the Ural mountain range).

Most of the Sr-90 released was deposited in the near zone of the accident. In fact, areas with $\mathrm{Sr}-90$ surface activity levels on the soil exceeding $3.0 \mu \mathrm{Ci} / \mathrm{m}^{2}$ were almost entirely within the $30-\mathrm{km}$ zone. Areas with Sr-90 levels exceeding $1.0 \mu \mathrm{Ci} / \mathrm{m}^{2}$ were almost entirely within the $100-\mathrm{km}$ zone. Only a few separate sites with $\mathrm{Sr}-90$ levels in the range 1.0 to $3.0 \mu \mathrm{Ci} / \mathrm{m}^{2}$ were found in the Bryansk-Belarus hot spot.

Information on areas contaminated with plutonium isotopes is not extensive because of the difficulty in detecting these isotopes. The only hot spot with plutonium (Pu-239 and $\mathrm{Pu}-240$ ) surface activity on the soil exceeding $0.1 \mu \mathrm{Ci} / \mathrm{m}^{2}$ was located completely within the $30-\mathrm{km}$ zone. In the regions of the Bryansk-Belarus and KalugaTula-Orel hot spots, plutonium activity levels ranged from 0.002 to $0.02 \mu \mathrm{Ci} / \mathrm{m}^{2}$ and 0.002 to $0.008 \mu \mathrm{Ci} / \mathrm{m}^{2}$, respectively. Although Cs-137 and Sr-90 levels were well correlated in these regions, there was no apparent correlation between plutonium and Cs-137 or Sr-90 levels.

\subsubsection{Perspective on Dose Projections}

In the past, considerable attention has been given to the use of real-time dose projections as the primary basis for initiating offsite protective actions. Section 5.1 highlights the difficulty of predicting the source term with sufficient accuracy to justify this use of real-time dose projections during a severe accident. This section explains why significant uncertainties would still be associated with projecting offsite doses, even if one could accurately predict the timing, energetics, composition, and amount of radioactive material that may be or is being released from a plant during a severe accident. As a result, decisions regarding early protective actions should be based on plant conditions, which demonstrate the potential for a large release, not on dose projections for some assumed source term and weather. Nevertheless, both precalculated and real-time dose projections in conjunction with early field monitoring would play a useful role in responding to a severe accident.

Precalculated dose projections may be useful in comparing the consequences of various plant response options (e.g., venting the containment versus allowing later containment failure). During the initial phase of a severe core damage accident, precalculated and real-time dose projections would be helpful in establishing priorities for the use of limited resources in the implementation of offsite actions such as deployment of field-monitoring teams. In an actual uncontrolled release of radioactive material to the environment, it would be imperative to obtain offsite monitoring team data as quickly as possible.

After implementation of protective actions near the plant (based on an assessment of plant conditions), dose projections may assist in determining whether these actions should be extended. The model projections may indicate the maximum distance from the plant where further actions are required. Another role of dose projections is to provide feedback regarding the magnitude and composition of a release based on the analysis of offsite samples and field monitoring results. 


\section{Table 5.2-1 Relationship between Pasquill category and $\Delta T / \Delta z$ and $\sigma_{\theta}{ }^{*}$}

\begin{tabular}{lcc}
\hline Pasquill category & $\Delta T / \Delta z\left({ }^{\circ} \mathrm{C} / 100 \mathrm{~m}\right)$ & $\sigma_{\theta}$ (degrees) \\
\hline A - Extremely unstable & $\Delta T / \Delta z \leq-1.9$ & $\sigma_{\theta} \geq 22.5$ \\
B - Moderately & $-1.9<\Delta T / \Delta z \leq-1.7$ & $22.5>\sigma_{\theta} \geq 17.5$ \\
$\quad$ unstable & $-1.7<\Delta T / \Delta z \leq-1.5$ & \\
C - Slightly unstable & $-1.5<\Delta T / \Delta z \leq-0.5$ & $17.5>\sigma_{\theta} \geq 12.5$ \\
D - neutral & $-0.5<\Delta T / \Delta z \leq 1.5$ & $12.5>\sigma_{\theta} \geq 7.5$ \\
E - Slightly stable & $1.5<\Delta T / \Delta z \leq 4.0$ & $7.5>\sigma_{\theta} \geq 3.8$ \\
F - Moderately stable & $4.0<\Delta T / \Delta z$ & $3.8>\sigma_{\theta} \geq 2.1$ \\
G - Extremely stable & & $2.1>\sigma_{\theta}$ \\
\hline
\end{tabular}

•From Regulatory Guide 1.23, U.S. Nuclear Regulatory Commission, 1980.

Table 5.2-2 Characteristic of hot spots resulting from Chernobyl accident*

\begin{tabular}{lcccc}
\hline Hot Spot & Direction & $\begin{array}{c}\text { Cs-137 Soil } \\
\text { Surface Activity } \\
\left(\mu \mathrm{Ci} / \mathrm{m}^{2}\right)\end{array}$ & $\begin{array}{c}\text { Initial } \\
\text { Dose Rate } \\
(\mathrm{mrad} / \mathrm{hr})\end{array}$ & $\begin{array}{c}1991 \text { (5 yr) } \\
\text { Dose Rate } \\
(\mathrm{mrad} / \mathrm{hr})\end{array}$ \\
\hline Central & W-NW & to $>40$ & 1 to 200 & 0.005 to 1 \\
Byransk-Belarus & $\begin{array}{c}\text { Centered } \\
\sim 200 \mathrm{~km} \mathrm{~N}-\mathrm{NE}\end{array}$ & to $>130$ & 0.3 to 30 & 0.0005 to 0.5 \\
Kaluga-Tula-Orel & $\begin{array}{c}\text { Centered } \\
\sim 500 \mathrm{~km} \mathrm{NE}\end{array}$ & $<0.16$ & 0.3 to 3 & 0.0005 to 0.05 \\
\hline
\end{tabular}

- From Reference 12. 


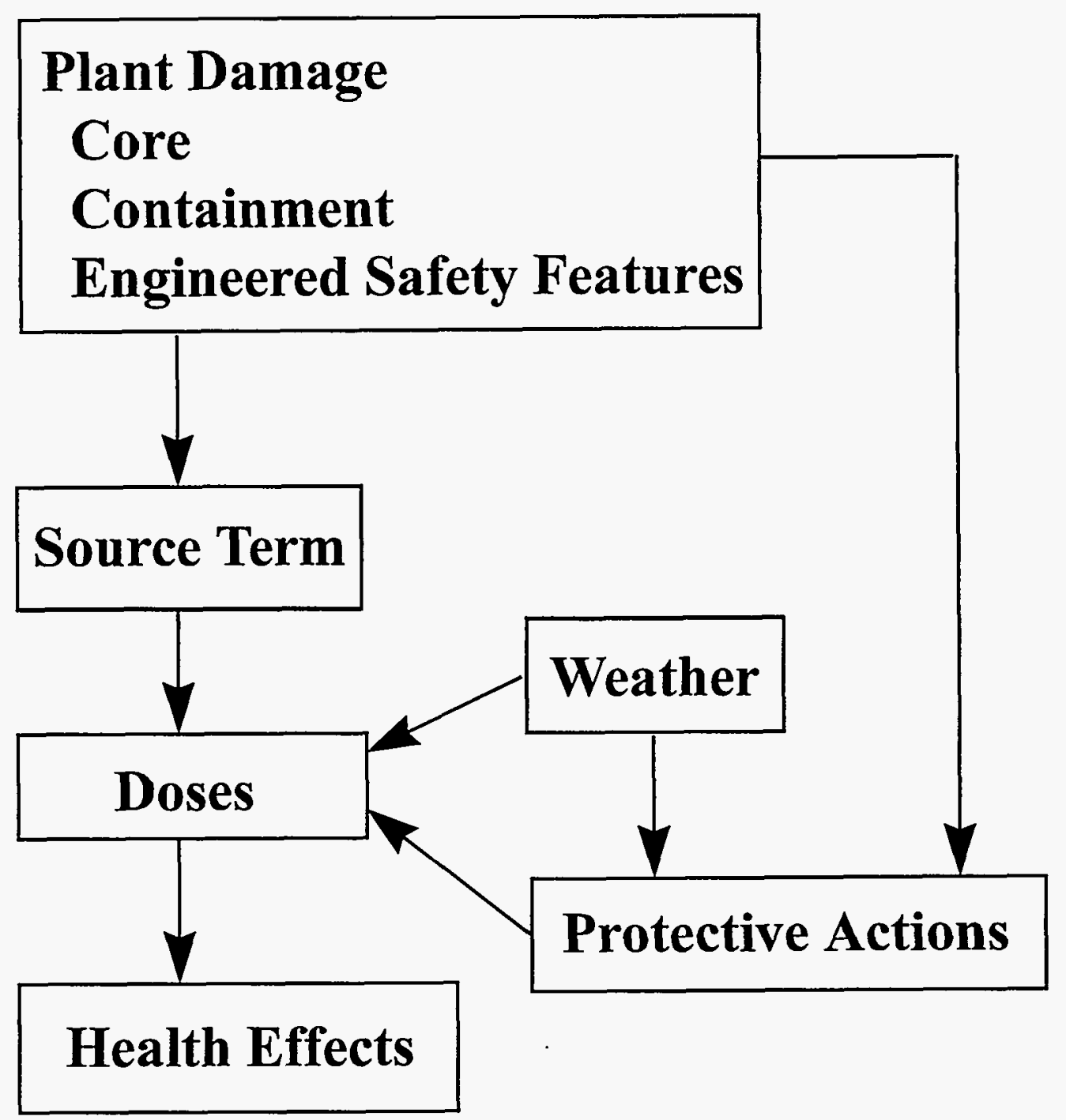

Figure 5.2-1 Steps in projecting offsite consequences 


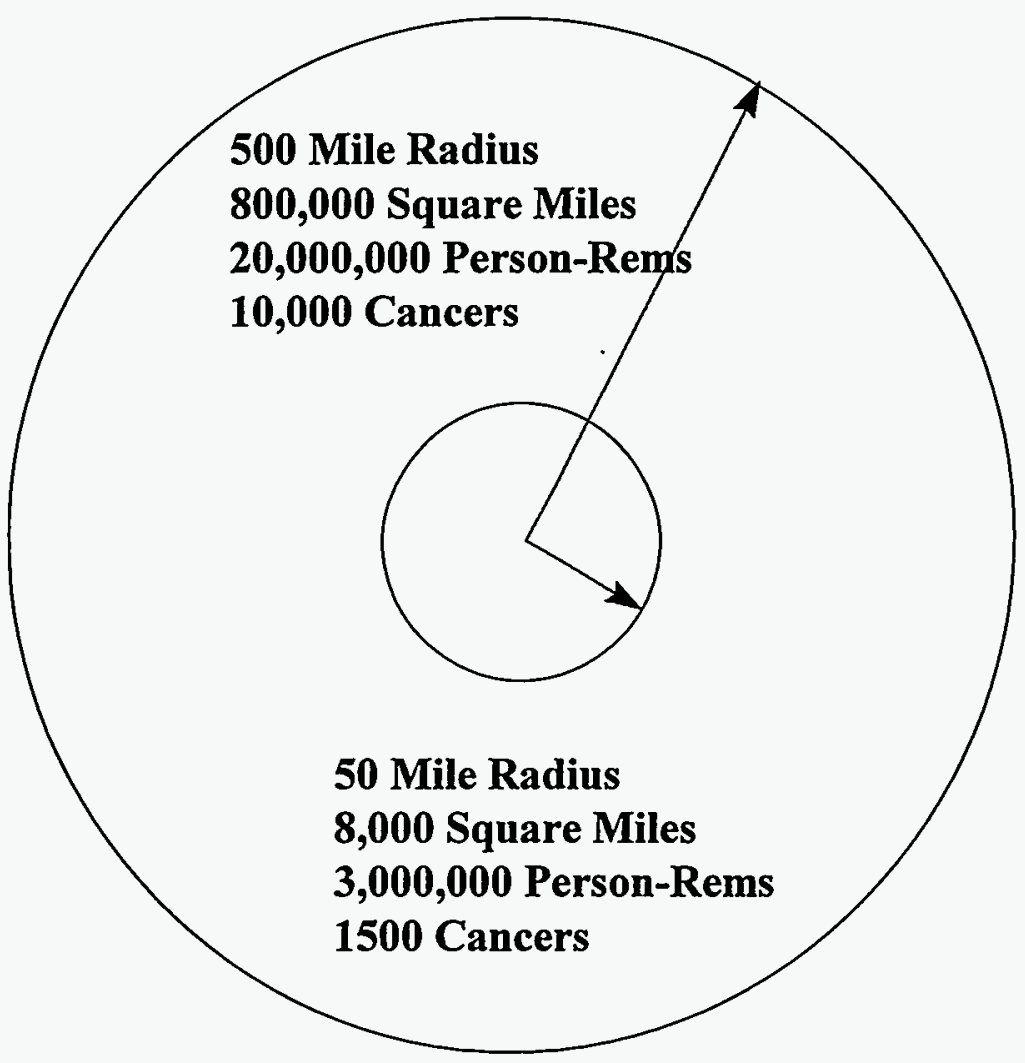

Figure 5.2-2 Illustration of person-rems and cancers within 50 and 500 mile radii 
This chart displays effective dose equivalents for $1 \mathrm{mrem}$ to $800,000 \mathrm{mrem}$ ( $800 \mathrm{rem}$ ). Average dose equivalents from natural background, selected medical procedures, and human activities are shown. The onset of possible radiation effects from acute doses are indicated on the higher charts.

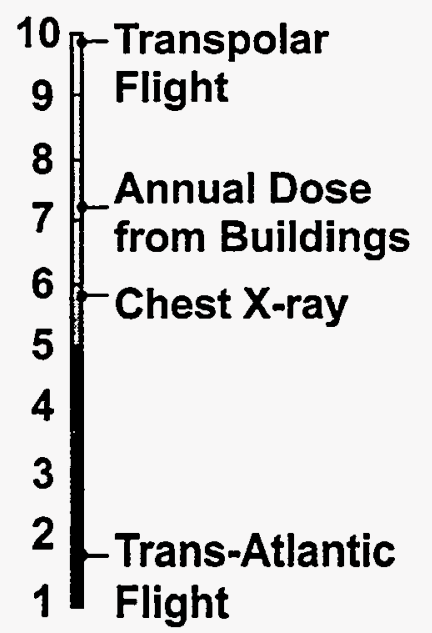

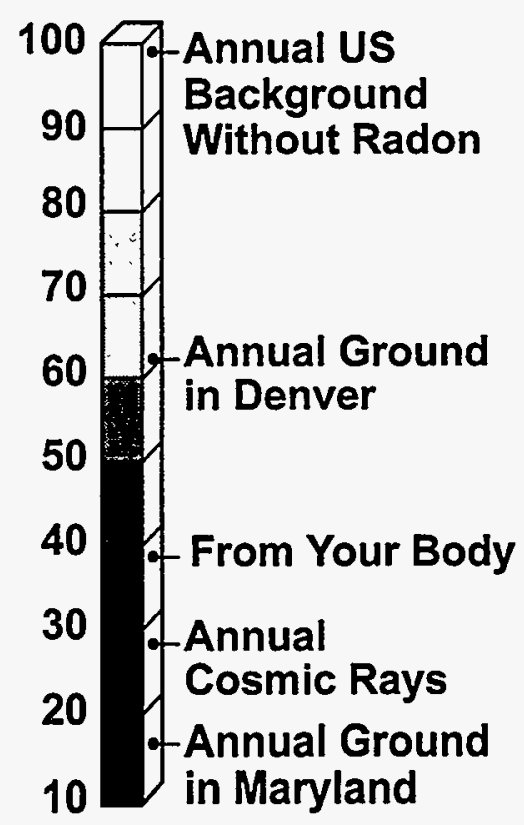

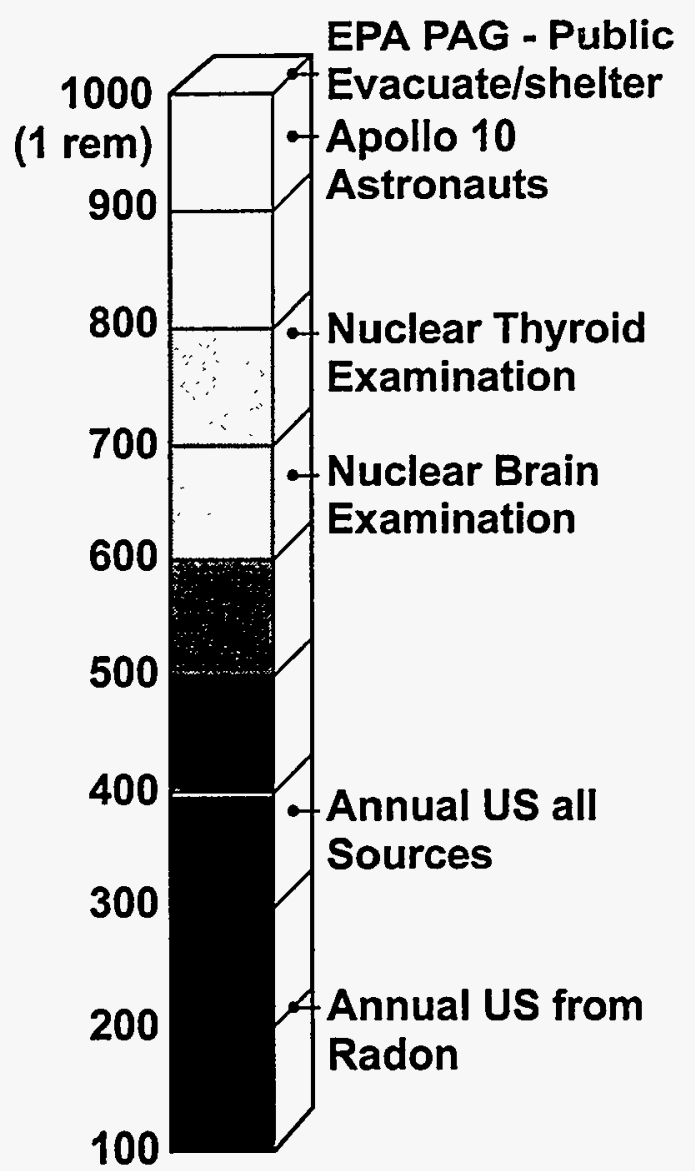

Figure 5.2-3a Putting radiation in perspective for the public (mrem) 

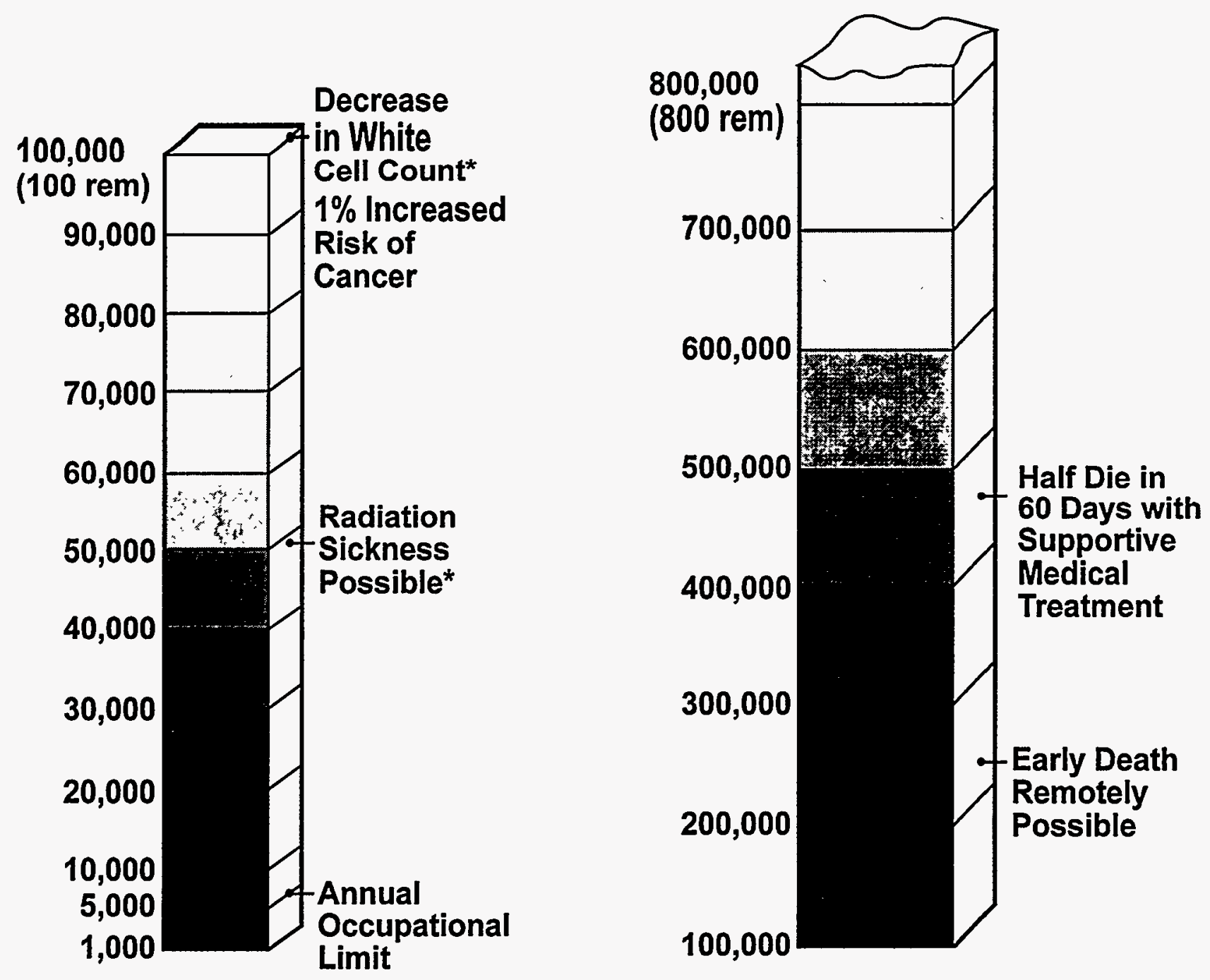

Figure 5.2-3b Putting radiation in perspective for the public (mrem) 


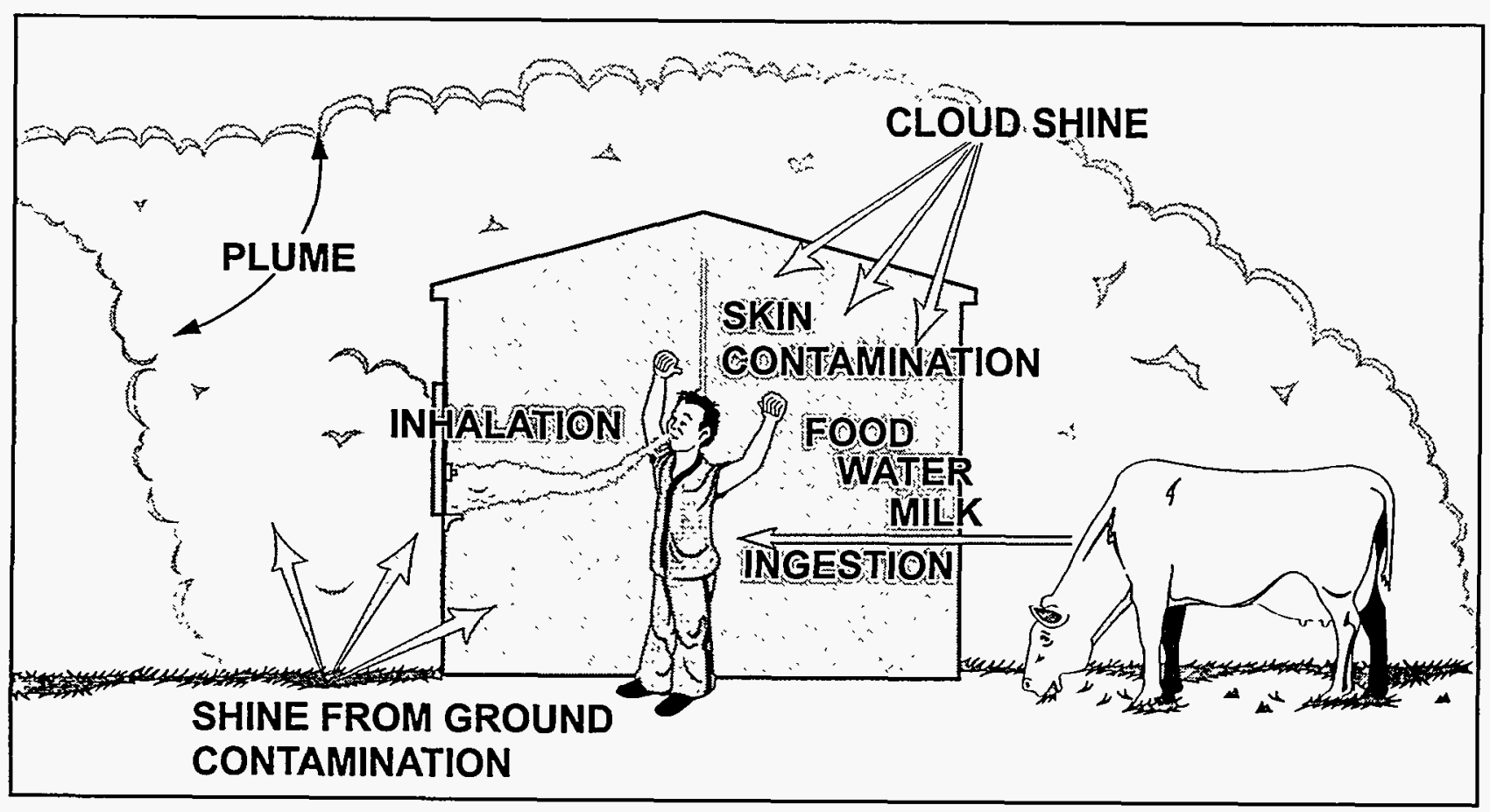

Figure 5.2-4 Radiation dose pathways 


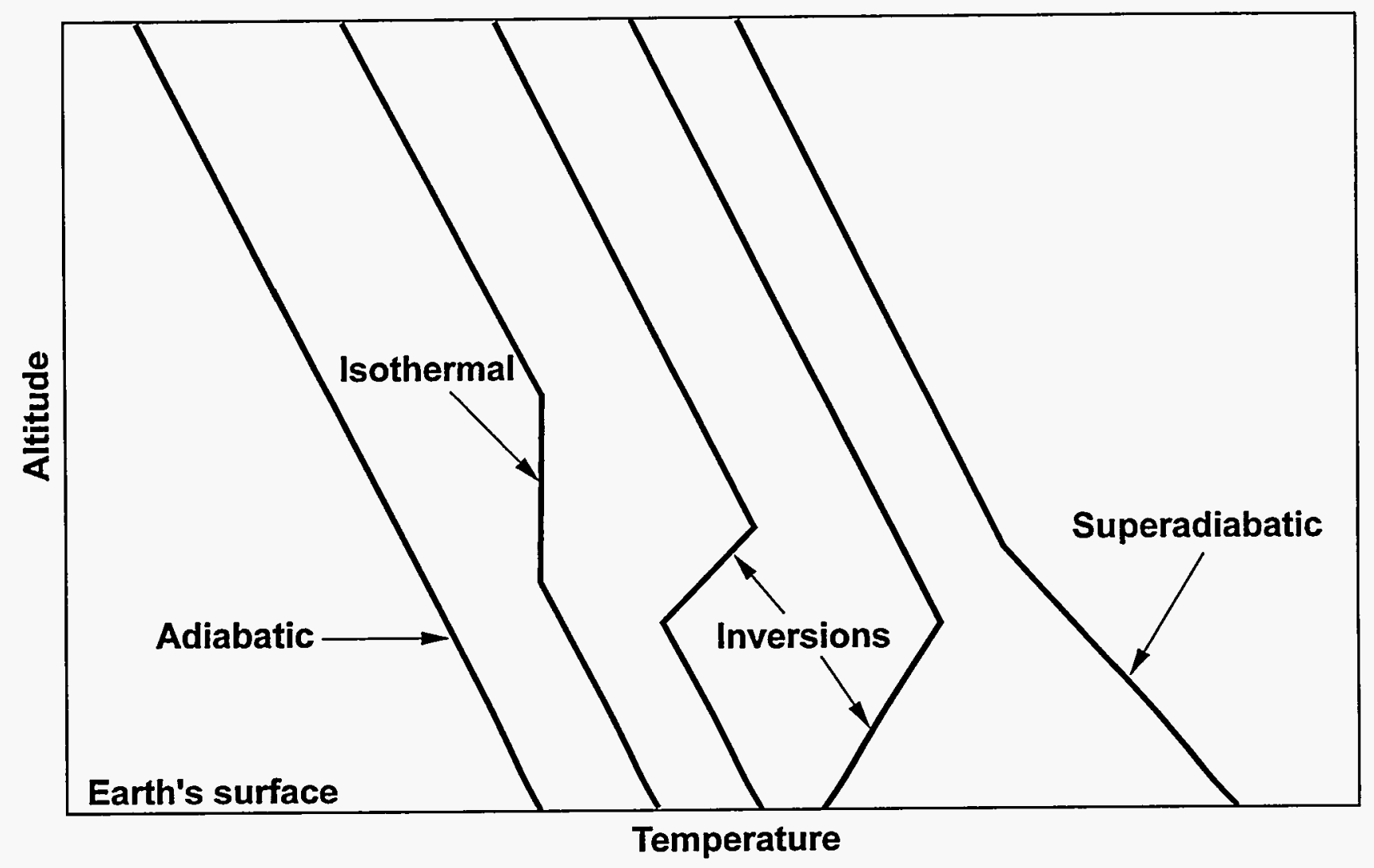

Figure 5.2-5 Examples of low-level temperature distribution in the atmosphere 


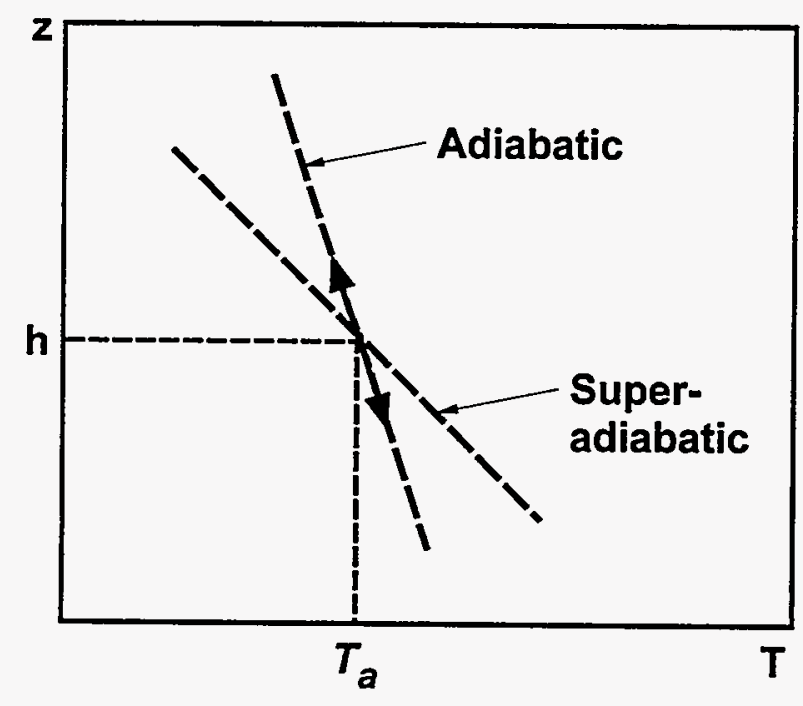

(a)

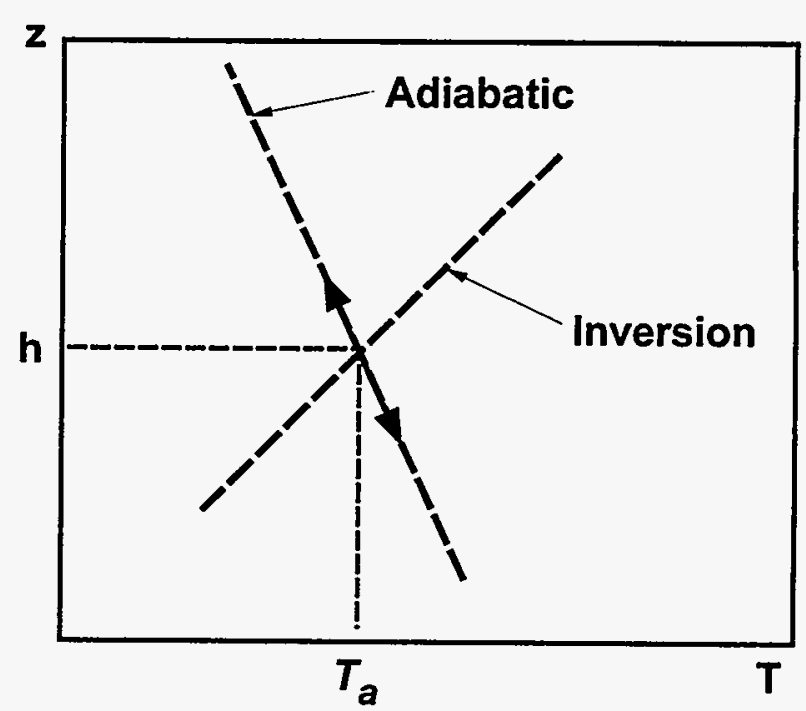

(b)

Figure 5.2-6 Movement of a parcel of air in (a) a superadiabatic profile and (b) an inversion profile 


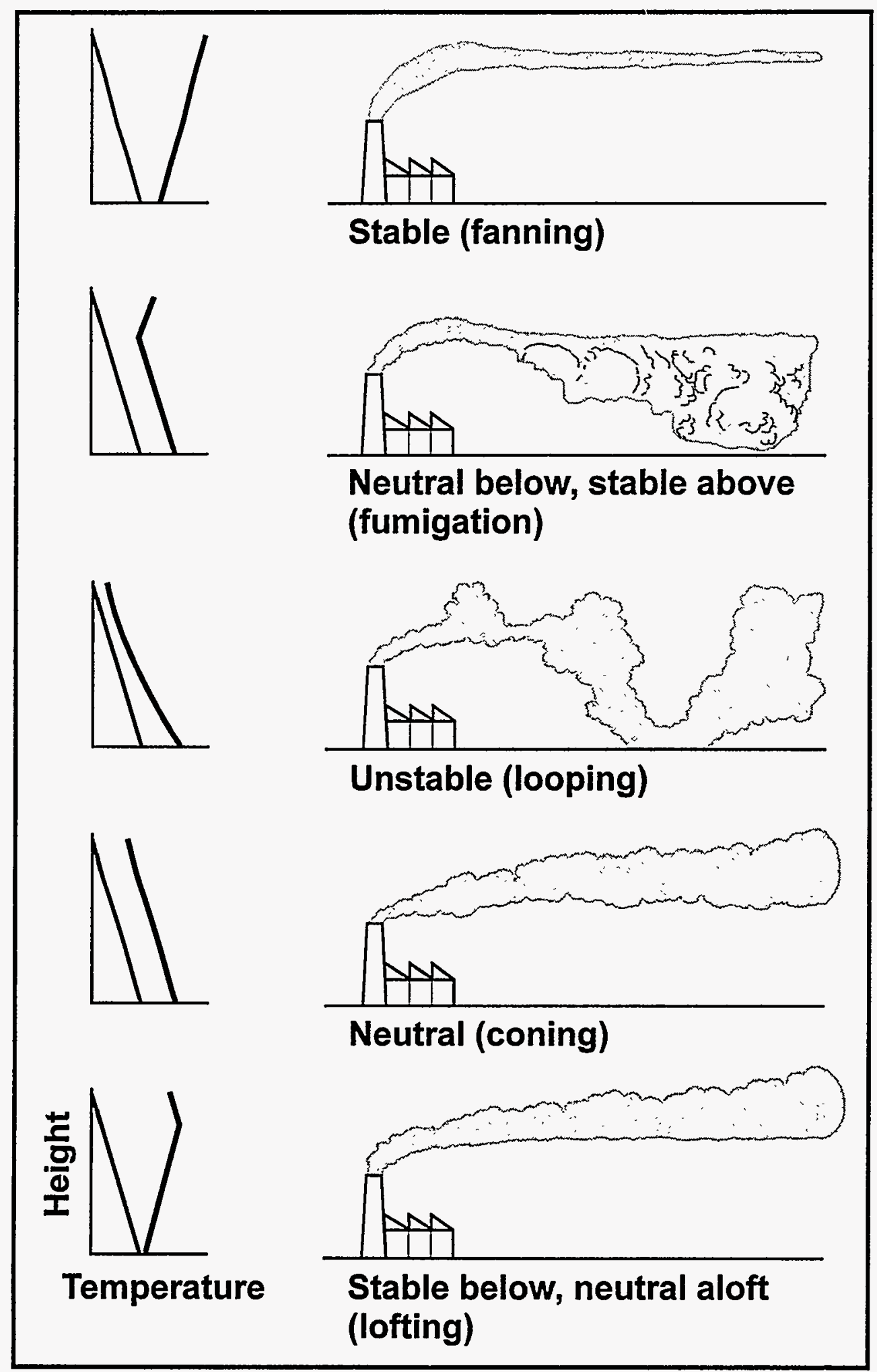

Figure 5.2-7 Various types of smoke plume patterns 


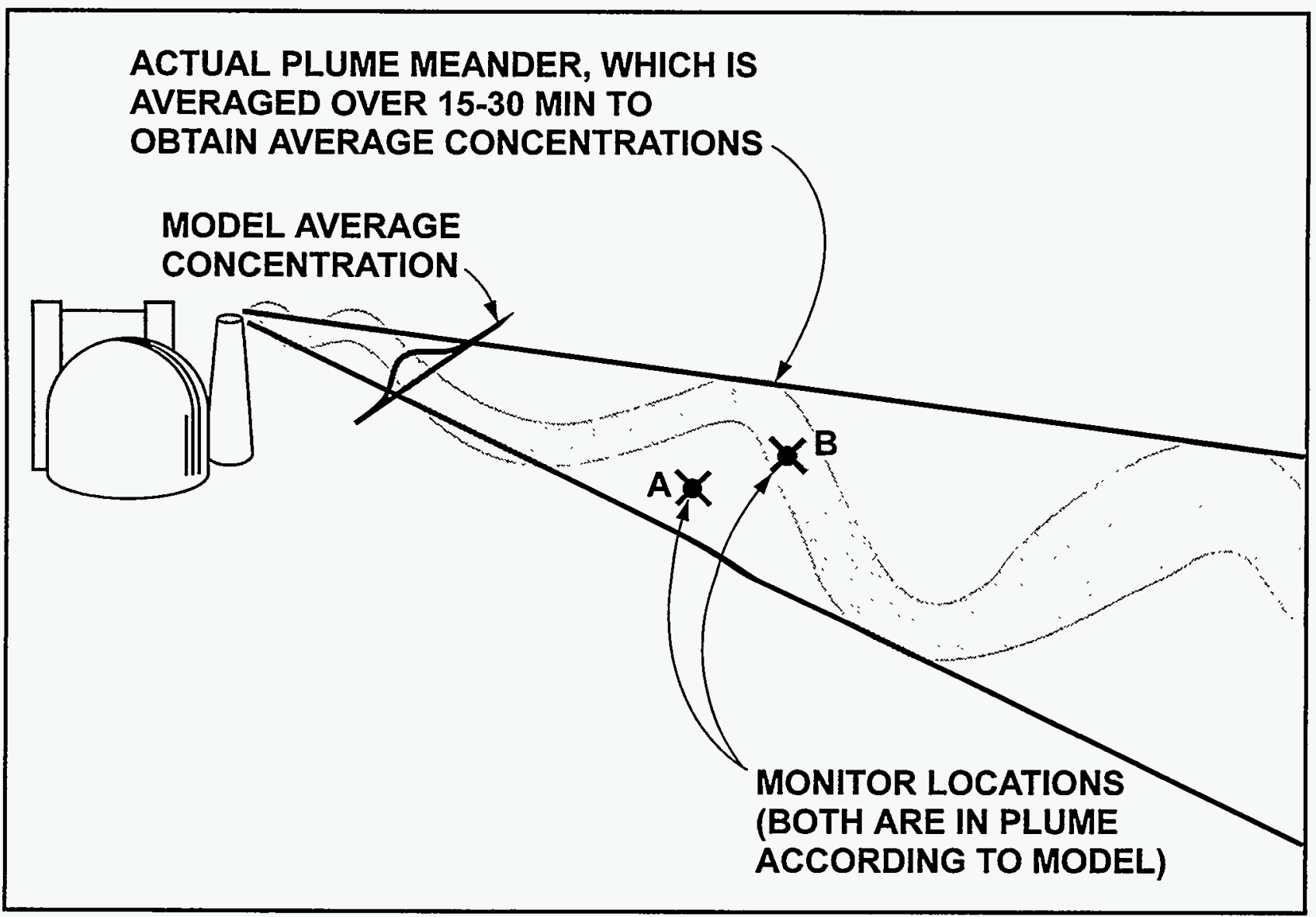

Figure 5.2-8 Relationship between actual plume and model projections 


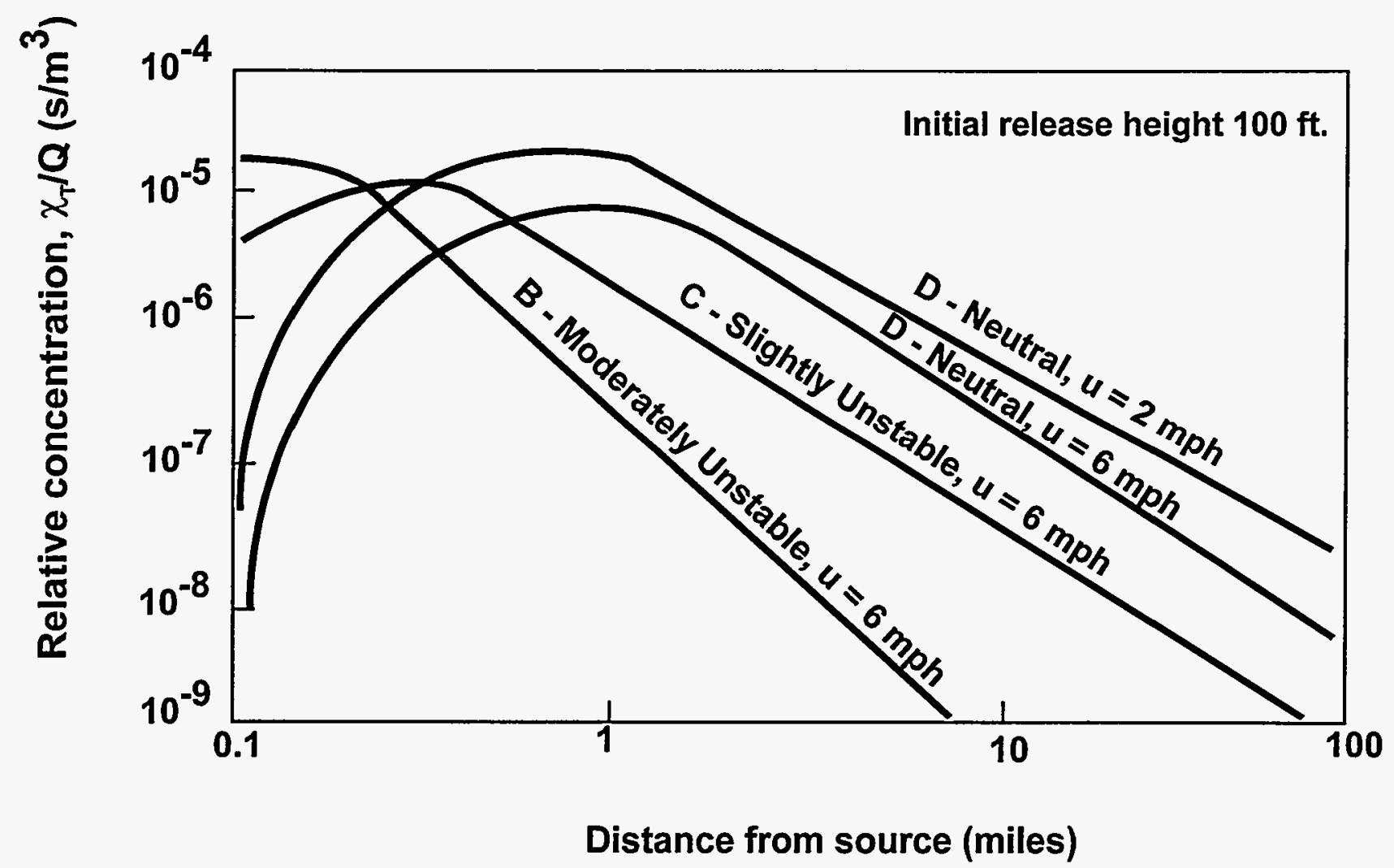

Figure 5.2-9 The quantity $\chi_{\mathrm{T}} / \mathrm{Q}$ at ground level for effluents emmitted at a height of $\mathbf{3 0} \mathbf{~ m}$, as a function of distance from the source 


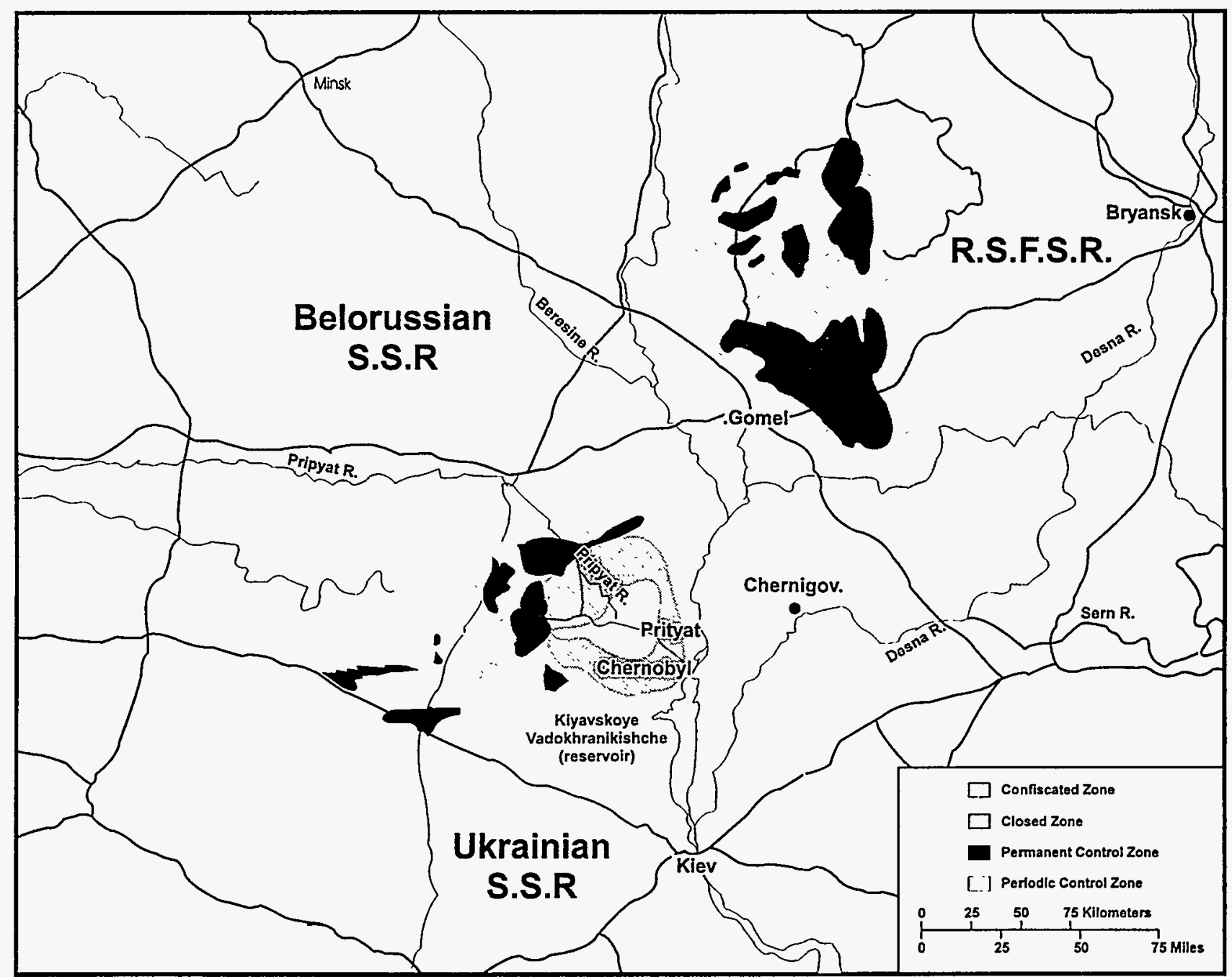

Figure 5.2-10 Radiation hot spots resulting from Chernobyl nuclear power plant accident 


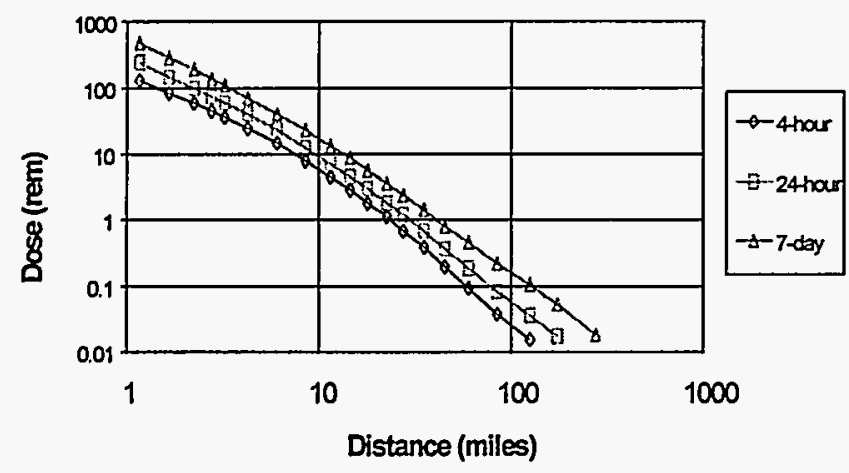

Figure 5.2-11a Stomach dose by exposure time: no sheltering stability class $\mathrm{D}, 2.68 \mathrm{~m} / \mathrm{s}$ wind

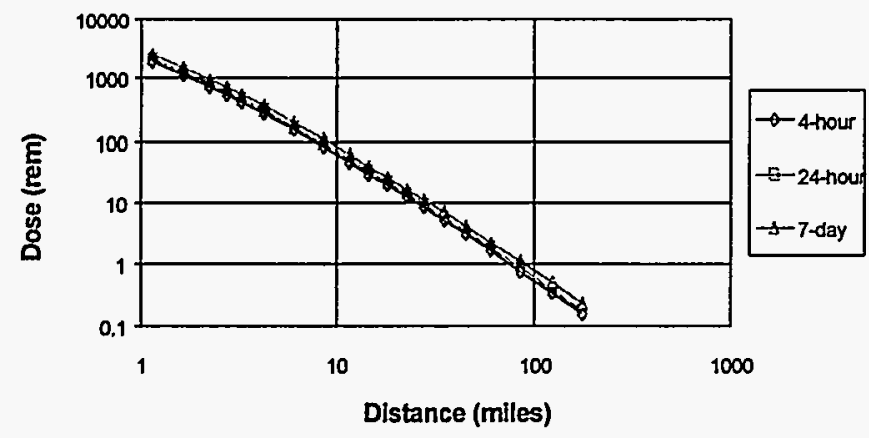

Figure 5.2-11c Thyroid dose by exposure time: no sheltering, stability class $D, 2.68 \mathrm{~m} / \mathrm{s}$ wind

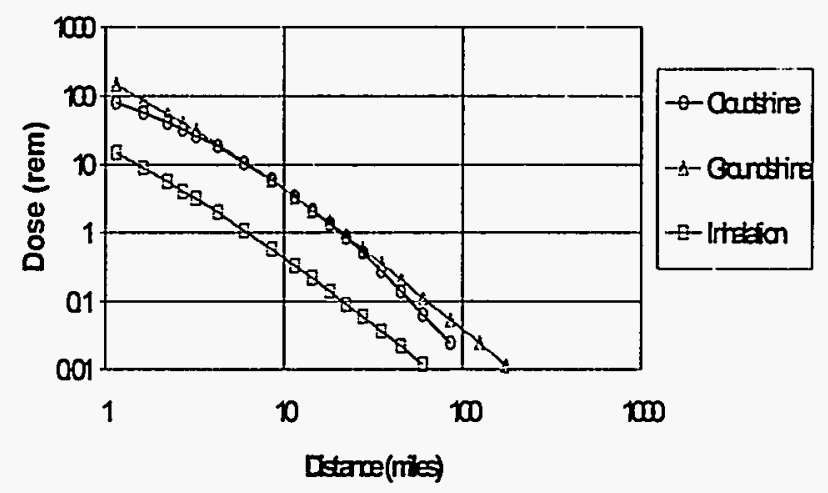

Figure 5.2-11b Plume centerline stomach dose by pathuay: no sheltering 24 hour exposure, dass D, 268 m/s uind

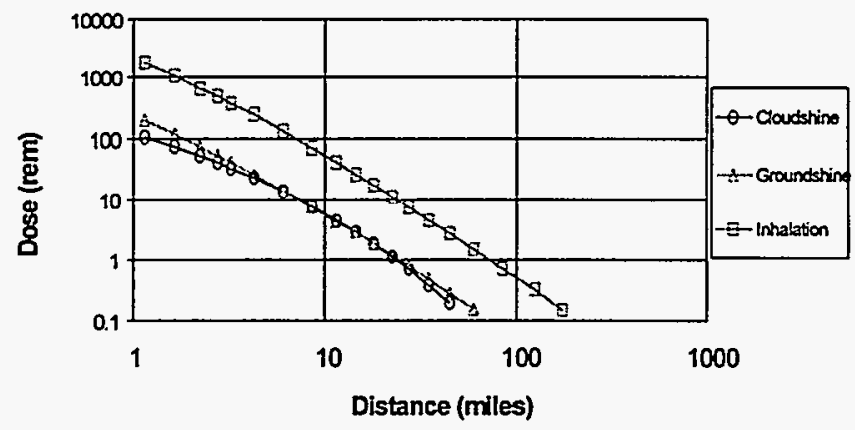

Figure 5.2-11d Plume centerline thyroid dose by exposure pathway, no sheltering, 24-hour exposure, class D, $2.68 \mathrm{~m} / \mathrm{s}$ 


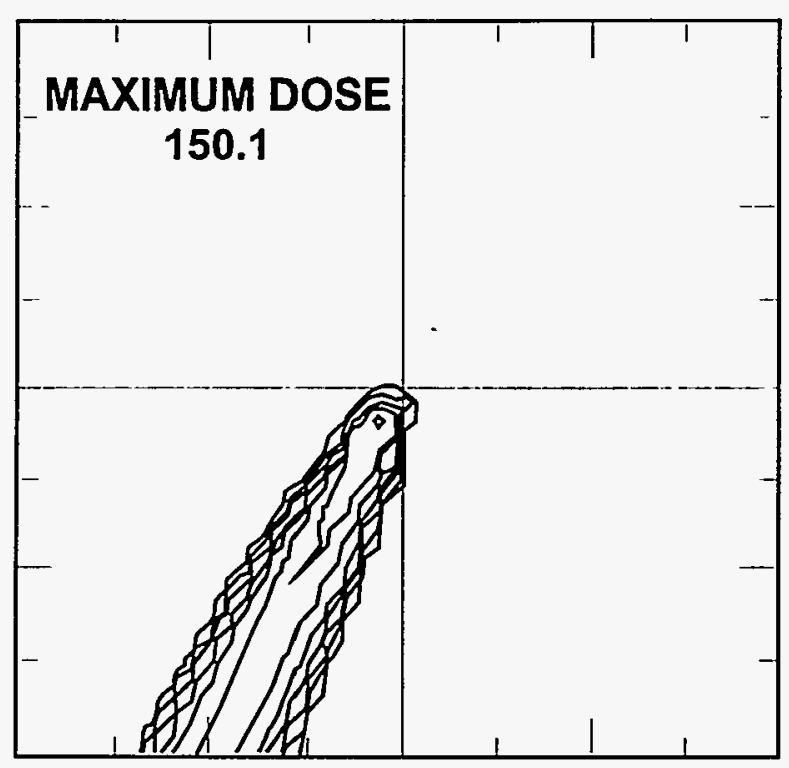

(a)

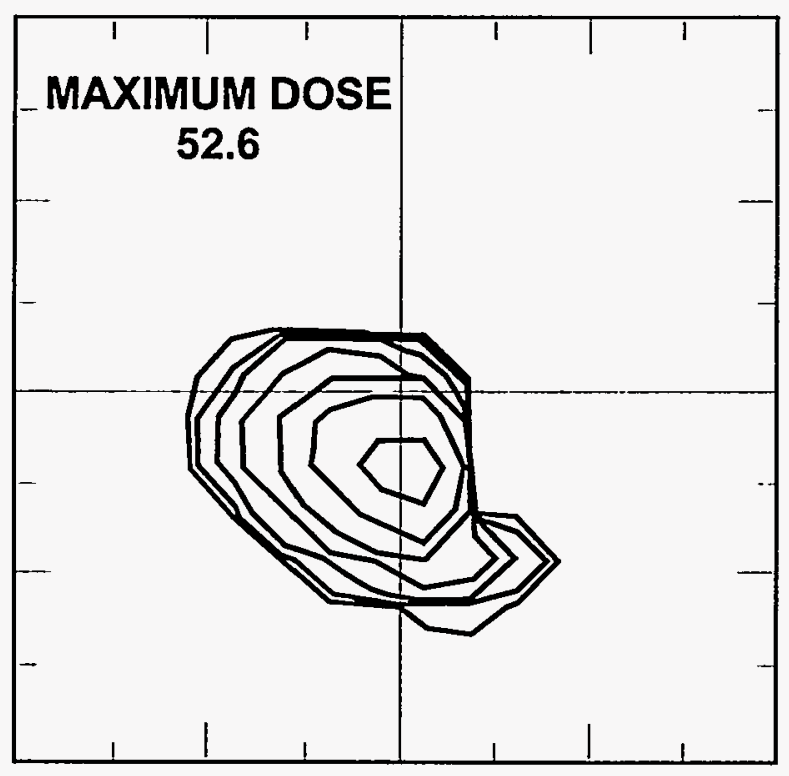

(c)

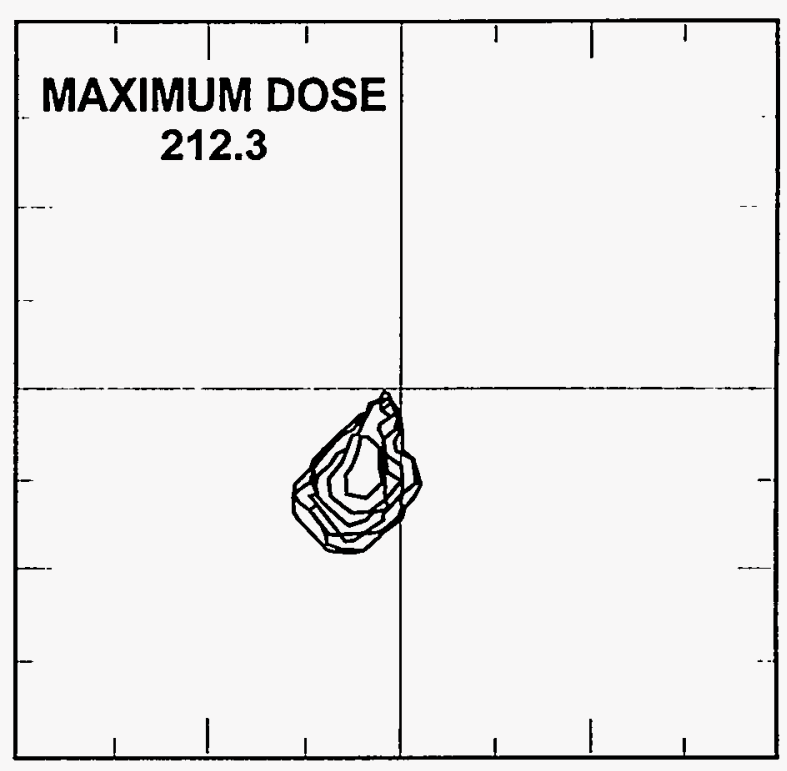

(b)

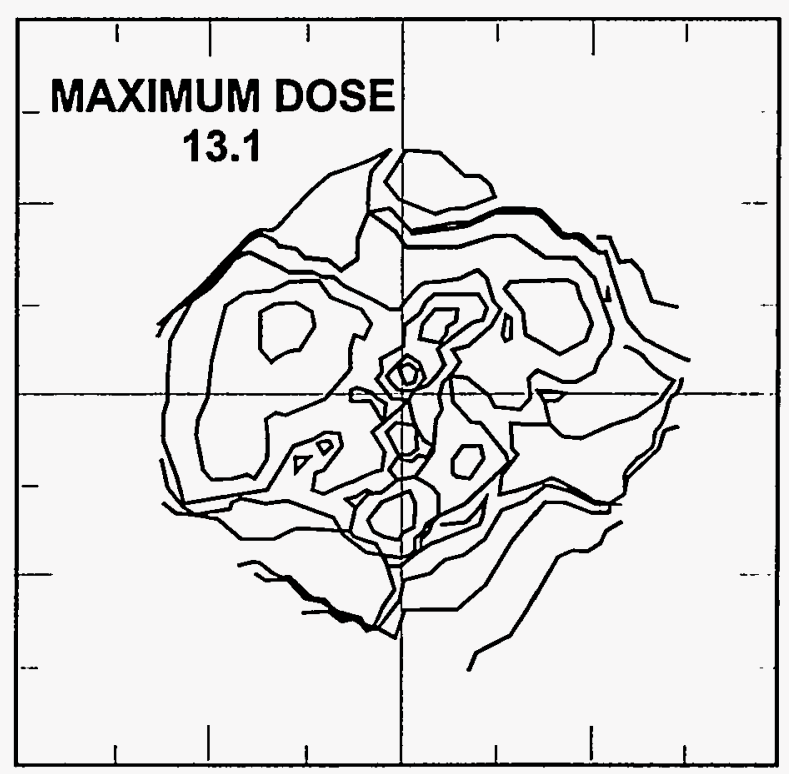

(d)

Figure 5.2-12 One-hour surface doses predicted by (a) Gaussian plume model, (b) puff-trajectory model, (c) complex numerical model, and (d) doses actually observed 


\section{References for Section $\mathbf{5 . 2}$}

1. S. Abrahamson, B.B. Boecker, E.S. Gilbert, and B.R. Scott, "Health Effects Models for Nuclear Power Plant Accident Consequence Analysis, Modifications of Models Resulting from Recent Reports on Health Effects of Ionizing Radiation, Low LET Radiation, Part II: Scientific Bases for Health Effects Models,"NUREG/CR-4214, Rev. 1, Part II Addendum 1, LMF-132, August 1991.

2. NUREG-1150, Table 11.7, Plant 3, exceedance frequency $10^{-6} \mathrm{yr}^{-1}$, mean complementary cumulative distribution function (CCDF), adjusted to one cancer per 2000 person-rem.

3. U.S. Nuclear Regulatory Commission, "RTM-96 Response Technical Manual," Vol. 1, Rev. 4, March 1996, pp. O-6 to 0-9.

4. S. Abrahamson, et al, "Health Effects Models for Nuclear Power Plant Accident Consequence Analysis, Low LET Radiation, Part II: Scientific Bases for Health Effects Models," NUREG/CR-4214, SAND85-7185, Rev. 1, Part II, May 1989, Tables 2.7 and 2.8.

5. D. H. Slade, Editor, "Meteorology and Atomic Energy--1968," Washington, DC, U.S. Atomic Energy Commission, 1968.

6. U.S. Nuclear Regulatory Commission Regulatory Guide 1.23, 1980.

7. "The Chernobyl Papers, Volume I, Doses to the Soviet Population and Early Health Effects Studies," Steven E. Merwin and Michail I. Balonav editors, Research Enterprises, Richland Washington, 1993.

8. YU.A. Izrael, S.M. Vakulovskii, V.N. Vetrov, F.Ya. Rovinskii, and YeD. Stukin, "Chernobyl: Radioactive contamination of the environment. Leningrad: Gidrometeoizdat;" 1990 (in Russian).

9. Z. Jaworowski, and L. Kownacka, "Tropospheric and stratospheric distributions of radioactive iodine and cesium after the Chernobyl event," J. Environ. Radioact. 6:145-150; 1988.

10. YU.A. Izrael, S.M. Vakulovskii, V.N. Vetrov, F.Ya. Rovinskii, and Ye.D. Stukin, "Chernobyl: Radioactive contamination of the environment. Leningrad: Gidrometeoizdat;" 1990 (in Russian).

11. USSR State Committee on Hydrometeorology. Radiation maps in the territory of the European part of the USSR as of December 1990. Densities of area contamination by cesium-137, strontium-90, and plutonium-239, 240. Minsk: SCH; 1991.

12. Balonov, M.I., "Overview of Doses to the Soviet Population from the Chernobyl Accident and the Protective Actions Applied," in The Chernobyl Papers, Volume I, Doses to the Soviet Population and Early Health Effects Studies, Steven E. Merwin and Michail I. Balonav editors, Research Enterprises, Richland Washington, 1993. 


\subsection{Protective Actions}

The public can usually be protected from an uncontrolled release of radiological material only by some form of intervention (e.g. evacuation) that disrupts normal living. Such intervention is termed protective action. This section presents information regarding the appropriate timing and potential effectiveness of various protective actions. Emergency preparedness, that is, the process of preparing to take effective actions to protect the public in the case of a U.S. reactor accident, is the subject of Section 5.4.

\subsubsection{Basic Concepts}

\subsubsection{Early, Intermediate, and Late Phases}

In discussing protective actions, it is convenient to identify three time phases: early, intermediate, and late. Although the time intervals associated with these phases may overlap, different considerations apply within each phase.

The early phase (also referred to as the emergency phase) is the period at the beginning of a reactor accident when immediate decisions for the effective use of protective actions are required. This phase may last from hours to days.

The intermediate phase is the period beginning after the radiological releases have been brought under control and reliable environmental measurements are available to provide a basis for decisions on additional protective actions. It extends until these additional protective actions are terminated. This phase may overlap the early and late phases and last from weeks to many months.

The late phase (also referred to as the recovery phase) begins with recovery actions designed to reduce radiation levels in the environment and ends when all recovery actions have been completed. This period may extend from months to years.

The protective actions available to avoid or reduce radiation dose can be categorized as a function of exposure pathway and incident phase, as shown in Table 5.3-1. Evacuation and sheltering are the principal protective actions available to protect the public from exposure during the early phase. It may also be appropriate to take actions to protect against contamination of milk (primarily by radioactive iodine) or to issue stable iodine to reduce thyroid doses. The use of simple, ad hoc respiratory protection may also be appropriate.

It is necessary to distinguish between evacuation and relocation with regard to incident phases. Evacuation is the urgent removal of people from an area to avoid or reduce high-level, short-term exposure, usually from the plume or deposited activity. Relocation, on the other hand, is the removal or continued exclusion of people (households) from contaminated areas to avoid chronic radiation exposure. Conditions may develop in which some groups who have been evacuated in an emergency may be allowed to return, while others may be converted to relocation status.

Relocation and decontamination are key protective actions for the intermediate and late phases. Decisions would be made during the intermediate phase concerning whether areas from which the public has been relocated should be decontaminated and reoccupied, or condemned and the occupants permanently relocated. Another protective action for the intermediate and late phases is the imposition of restrictions on the use of contaminated food and water. 


\subsubsection{Basic Radiation Protection Objectives}

Protective actions taken in response to a severe accident at a nuclear power plant have the following objectives:

1. To avoid (prevent) doses sufficient to cause early health effects (injuries or deaths) that would be seen at specific organ (e.g., bone marrow or thyroid) doses above 50 rem;

2. to reduce early off-site doses that would otherwise exceed federal protective action guidelines (see Appendix 5A); and

3. to reduce the risk of long-term health effects (e.g., cancers).

These objectives are listed in decreasing order of importance. Initial protective actions should be directed toward meeting the first objective by keeping the acute doses from the passing plume (cloud shine, ground shine, and inhalation doses) below levels that could result in early injuries or deaths. Federal protective action guides (PAG) dose levels are well below the levels that would cause early health effects (see Appendix $5 A)$.

\subsubsection{Early Protective Action Guidance}

Guidance regarding early protective actions has evolved from numerous severe accident studies. This guidance has been incorporated into response procedures and training manuals for the NRC staff, the latest edition of which is Response Technical Manual (RTM)-96.' Figures 5.3-1 and 5.3-2 depict the current strategy. In short, the early protective action guidance says, given a severe core damage accident, people should immediately evacuate areas near the plant (within a 2 - to 3 -mile radius) and remain in shelter elsewhere for the immediate future. Let us now examine the rational for this guidance.

\subsubsection{Timing of Initial Actions}

First, consider the need for the immediate implementation. As discussed in Section 5.1 , core damage and containment failure are both required for a large release. Control room indicators of core damage should be numerous. On the other hand, it would be virtually impossible to predict the occurrence or time of containment failure in most severe accidents. A major release would be very intense with most of the radioactive material being released within 0.5 to $2.0 \mathrm{hr}$ of containment failure. Relying on predictions of containment failure or waiting for indications of containment failure could delay an evacuation during the period when it would be the most effective action for avoiding offsite health effects.

The best way to ensure that protective actions are started before a major release is to initiate the actions as soon as core damage is detected. If the decision to take action awaits dose projections or field monitoring results, the population close to the plant could be exposed to the large radioactive plume. This is one of the primary reasons for establishing emergency action levels that tie the declaration of a General Emergency (see Section 5.4) to clear indications of core damage.

\subsubsection{Evacuation}

Early evacuation of the area near the plant has several benefits in terms of public safety:

1. Cloud shine dose from all or at least part of the plume can be 
avoided (if the evacuation begins before or shortly after the release).

2. Dose from contaminated ground and other surfaces can be avoided.

3. Inhalation of contaminated air can be avoided.

4. The highest-risk areas would be cleared early, thereby permitting emergency response teams to focus on other areas.

Immediate evacuation of people near the plant could well prove to be precautionary because most severe accidents (like the Three Mile Island accident) would not be expected to lead to a major release. On the other hand, core damage accidents are expected to be extremely rare; so that precautionary evacuations would also be rare, and the results of not taking immediate protective actions could be tragic. As illustrated in Section 5.3.2.2, for a severe accident resulting in a large release, evacuation near the plant (within 2 to 3 miles) may be the only action that can prevent early health effects.

\subsubsection{Effectiveness of Evacuation}

A concern is sometimes raised that, once a release from a severe reactor accident starts, an evacuation should not be recommended because the evacuees may run into or be overtaken by the plume. However, as illustrated in Section 5.2.4, plume concentrations decrease exponentially with distance from the source.

As a result, large reductions in doses to individuals may be achieved by evacuation. Evacuation also precludes the possibility of long term exposure to hot spots. In contrast, sheltering in a typical farm house reduces a person's dose by no more than a factor of 2 , and does not preclude long term exposure to hot spots. Consequently, public officials must continue to be concerned about people in shelters.

Studies consistently indicate that evacuation during plume passage does not increase risk over sheltering in a typical residential home. Conversely, delaying evacuation can considerably increase risk. These finding are, for example, consistent with NUREG1150 results that compare the following six protective action scenarios:

1. Normal activity, which assumes that no protective actions are taken during the release but that people are relocated within 6 hours of plume arrival.

2. Home sheltering, which assumes (a) shielding typical of masonry houses or basements of wood frame houses, (b) inhalation protection consistent with such homes, and (c) relocation within 6 hours of plume arrival;

3. Large building shelter, which assumes sheltering in a large building such as an office building, hospital, apartment building, or school, indoor protection for inhalation of radionuclides, and relocation within 6 hours of plume arrival;

4. Radial evacuation at $2.5 \mathrm{miles} / \mathrm{hr}$ starting 1 hour before release;

5. Radial evacuation at $2.5 \mathrm{miles} / \mathrm{hr}$ starting at the time of release;

6. Radial evacuation at $2.5 \mathrm{miles} / \mathrm{hr}$ starting 1 hour after the start of release. 
Figures 5.3-3 and 5.3-4 show the conditional probabilities of exceeding 50 -rem and 200rem red bone marrow doses for the six scenarios assuming an early containment failure at Zion with source term magnitudes varying from low to high. ${ }^{2}$ These figures indicate a large probability of doses exceeding 200 rems (and the associated risk of fatalities) within 1 to 2 miles of the plant. With no protective actions, the probability of doses exceeding 50 rems (and the associated risk of radiation-induced injuries) is significant even 10 miles away. Sheltering in a typical house does not significantly lower these probabilities.

As indicated, evacuation before release (scenario 4) provides the greatest risk reduction. Evacuation at time of release (scenario 5) evacuation 1 hour after release (scenario 6) both result in exceedance probabilities that are lower than or, at large distances, comparable to those for basement sheltering. Therefore, if a large release can occur, it is prudent to consider prompt evacuation.

At 3 miles and beyond, it is possible to avoid doses exceeding 200 rems by sheltering in large buildings even in the case of a large release. People in large buildings such as hospitals would therefore not necessarily have to be immediately evacuated, but could shelter instead. Of course, further reductions in dose are possible by prompt evacuation.

At 10 miles, no protective actions except relocation would be necessary to avoid 200rem doses. Sheltering in large buildings or evacuation prior to release would keep doses below 50 rem.

Calculations also indicate the importance of monitoring ground contamination following plume passage and quickly relocating sheltered individuals away from hot spots.
In calculations like those performed for NUREG-1150, people are typically assumed to relocate if the ground contamination is 1 $\mathrm{rem} / \mathrm{h}$ (about 100,000 times the normal background dose rate).

Few people live close to most nuclear power reactors. Figure 5.3-5 illustrates the number of people within 1 and 5 miles of 111 nuclear power plant sites (actual or proposed in 1979). ${ }^{3}$ Well below 10,000 people live within a 1 to 5 mile radius. In fact, at most sites, fewer than 300 people live within 2 miles of the site. Indeed, the area within a 2- to 3-mile radius encompasses the low-population zone around most reactor sites. There would normally be few impediments to immediate evacuation of the population within a $2-$ to 3 -mile radius.

The basic conclusion is that, even for a large release, large numbers of early fatalities can be prevented if (a) areas near the plant ( 2 to 3 miles) are evacuated before or shortly after the release and (b) prompt monitoring is conducted to locate ground contamination that would result in expeditious relocation of people sheltered outside the evacuation zone.

\subsubsection{Evacuation Risks}

Objections have been raised to evacuation because of fears of panic or injuries during the evacuation. Evacuations of up to a few thousand people from areas up to about several square miles are not uncommon. Evacuations of significant size occur about every week to ten days in the United States. (Keep a mental note every time you hear of an evacuation.)

The historical fatality risk is about $1 / 500,000$ per person during evacuations. This evacuation risk is considerably less than PRA estimates of a $1 / 10$ to $1 / 100$ risk of fatality given a core melt accident with no evacuation. Although the comparison says 
nothing definitive about the risk for any particular core melt accident, it does indicate strongly that, on the average, it would be far less risky for a person to evacuate than to remain within 2 to 3 miles of a nuclear power plant experiencing a severe core damage accident. Conversely, on a predetermined basis, an evacuation should not be recommended unless a core melt accident sequence is actually under way.

The practice of basing emergency plans for nuclear facility accidents on information regarding public behavior during nonnuclear emergencies has been questioned. Although the data base is limited, several nuclear-related incidents involving public response have occurred and can be compared to the nonnuclear experience. Some of these incidents (excluding weapons-related incidents) are presented in Table 5.3-2. The Environmental Protection Agency found no reason to expect that people would react differently to a nuclear accident than they would to a flood, fire, or similar emergency. ${ }^{4}$

The accident that appears to be of the greatest relevance is the one at Three Mile Island Unit 2 (TMI-2), which occurred at 4:00 a.m. on March 28, 1979. By 8:00 a.m., the national television networks were broadcasting the news. A small percentage of the local population left the area during the first two days. On the third day (Friday), the governor of Pennsylvania recommended the evacuation of children and pregnant women. By the end of the weekend, about half of the population within 20 miles had left the area. Throughout this time, the people were subjected to intense stress and (to them) conflicting opinions and advice. Despite these conditions, the evacuations that occurred were orderly.

Some observers have stated that the evacuations represented panic. Conversely, it could be argued that the public's behavior was perfectly understandable considering the intense pressures to which they were subjected (e.g., various authorities expressed diametrically opposed positions, and some authorities even reversed their own positions during the course of the accident). In fact, if the current protective action guidance had been in place at the time of the accident, evacuation of the area near the plant would have been recommended.

\subsubsection{Entrapment Scenarios}

Scenarios can be hypothesized in which evacuation may not be practical. For example, if an ice storm is in progress, if major transportation arteries are blocked, or if a major population center is involved, ordering an evacuation may result in entrapment of persons outside, where they may be more vulnerable than in their original locations (a car is not as good a shelter as a house). If early evacuation is simply not possible, local officials must use common sense in providing the best shelter and/or evacuation possible. Emergency personnel should monitor for ground contamination following a release, and motivate people to leave any highly contaminated areas (i.e., hot spots). It would, most likely, not be necessary for people to move very far from such heavily contaminated areas to significantly reduce their exposures. Expedient shelter of some sort is almost always available.

Entrapment problems are expected to be rare at most reactor sites in the United States, especially rare in conjunction with a severe accident. Fewer than 300 people live within 2 to 3 miles of most nuclear power plants in the United States. Within this distance there are few facilities such as hospitals that would require special attention in the event of an evacuation. At a few reactor sites where these conditions are not met, the emergency planner (and responder) must 
recognize that evacuation would be more difficult. Emergency plans must be prepared and decisions made accordingly.

\subsubsection{Sheltering and Relocation from Hot Spots}

Early sheltering is an appropriate protective action measure

1. for areas where the risk of exceeding the doses required for early health effects is relatively low,

2. for lesser events (e.g., Site Area Emergencies) where a major release is not expected,

3. if outside entrapment problems are likely to occur should an evacuation be attempted.

Table 5.3-3 provides factors that can be used to indicate the relative amount by which exposures may be reduced for various pathways as a result of sheltering. These sheltering factors should be used for comparison purposes only, not for predictive purposes. They can be used to determine the type of structure to recommend if a choice of structures is available. For cloudshine and ground- shine, small farmhouses provide very little protection; but, if a farmhouse has a basement, protection can be improved. Large concrete structures can provide a great deal of protection.

Enclosed structures can offer protection from the inhalation pathway. The degree of inhalation protection provided depends on the "openness" or ventilation rate of the shelter and on how long the plume remains outside. Small dwellings with closed windows and doors ventilate at a rate of about one air turnover per hour. Based on risk assessments, life-threatening releases from U.S. plants would be expected to last less than two hours. Less-severe (in quantity) releases could last much longer. For a one-hour release, a protection factor of about three (two-thirds reduction in dose commitment) can be achieved in such a dwelling. For longer releases, the inhalation protection factor would be lower (assuming that the wind does not shift).

Numerous studies indicate that beyond some distance (typically 2 to 3 miles from the plant) sheltering followed by post-release monitoring and relocation from "hot spots" would be as effective as evacuation for many severe accident scenarios. This might not be the case under certain meteorological conditions, in particular, if the radioactive plume passes through rainfall or if severe inversion conditions trap and confine the plume near the ground. Such conditions cannot be predicted with any useful degree of accuracy, and offsite radiological monitoring after the release must be relied upon to determine when evacuation at greater distances is warranted.

Doses from ground contamination may become very important within a few hours of a major release. Therefore, after implementing initial protective actions near the plant, dose projections and field monitoring should be performed. Dose projections would be used to estimate whether protective actions should be expanded according to the Environmental Protection Agency Protective Action Guides. As discussed in Section 5.2, large uncertainties are associated with dose projections. Therefore, as soon as possible after a release, field monitoring data should be the preferred basis for expanding initial protective actions.

In the event of an actual major release, anyone sheltered in an area of high ground-level contamination (e.g., $>1 \mathrm{R} / \mathrm{hr}$ ) 
would be asked to leave, whether or not an emergency plan calls for it. The predetermined level of $1 \mathrm{R} / \mathrm{hr}$ conforms to the Environmental Protection Agency Protective Action Guide of 1 to 5 rems projected whole-body dose. As noted earlier, evacuation at lower dose rates could be recommended on an ad hoc basis, but for a very severe accident, the $1 \mathrm{R} / \mathrm{hr}$ level may be suitable as an initial predetermined "trip" level.

\subsubsection{Improvised Respiratory Protection}

Improvised respiratory protection, such as placing a towel over the mouth and nose, reduces only the dose associated with inhalation of fine aerosols (less than about 10 microns in diameter). It does not impact the dose received from cloud shine or contaminated ground and other surfaces. As a result, improvised respiratory protection is a secondary protective action (i.e., it may be recommended in conjunction with evacuation or sheltering). Implementation of improvised respiratory protection should never delay implementation of other protective actions such as sheltering or evacuation.

Table 5.3-4 shows the results of experiments conducted using different types of improvised respiratory protection. ${ }^{5}$ Military personnel used various household items for protection and measured their efficiency in removing particles. Some results are remarkable. Use of a tight-fitting heavy towel over the nose and mouth can reduce the inhalation exposure from small particulates by a factor of 10 . A loose-fitting towel can be used to reduce particulate inhalation by a factor of 2 to 5 . Similar reduction factors would apply to babies lightly wrapped in blankets, such as they are for protection from wind and cold. Note, however, that exposure received through inhalation of radioactive gases is not reduced by these techniques. Basically, improvised respiratory protection is a secondary protective action that can be used to provide a nontrivial level of additional protection.

\subsubsection{Use of Potassium Iodide (KI)}

The Food and Drug Administration has recommended that potassium iodide tablets be administered for projected thyroid doses greater than $25 \mathrm{rem}^{5}$ Ingestion of potassium iodide (KI) tablets reduces the dose to the thyroid caused by the intake of radioiodine. It must be understood, however, that use of the thyroid-blocking agent potassium iodide (KI) is not an adequate substitute for prompt evacuation or sheltering by the general population near a plant in response to a severe accident. The immediate risk to the population from a severe reactor accident is bone marrow dose, not the dose to the thyroid from radioiodine.

To be effective, potassium iodide must be taken just before or shortly after exposure to radioiodine (within 1 to $2 \mathrm{hr}$ ). Thus, to be potentially effective, it must be readily available. ${ }^{6}$ Taking the recommended dosage of potassium iodide $(130 \mathrm{mg})$ just before or at the time of exposure could block more than $90 \%$ of radioactive iodine uptake by the thyroid as indicated in Figure 5.3-6. If taken approximately 3 to $4 \mathrm{hr}$ after acute exposure, only about $20 \%$ blocking would occur in some persons. Note that a small percentage of people could react adversely to potassium iodide, but the risk of a severe reaction is very small.

The NRC and the Federal Emergency Management Agency (FEMA) recommend predistribution of potassium iodide to predesignated emergency workers, site personnel, and institutionalized individuals who might find it difficult to evacuate during an emergency. FEMA has stated the 
federal position that predistribution of potassium iodide to the general public should not be required for a state or local emergency plan to be acceptable. ${ }^{7}$

\subsubsection{Early Protective Action Decisions During the TMI-2 Accident}

To highlight some of the points discussed in this section, certain aspects of the assessments of the TMI-2 accident merit discussion. Figure 5.3-7 presents the hourly wind vector as measured by the site meteorological system during the first day of the accident. Actually, these measurements were not available to the NRC until three days later because the plant computer crashed early in the accident. It is evident that wind direction at the site varied dramatically throughout the $12-\mathrm{hr}$ period.

A Site Emergency was declared at 6:56 a.m., followed by a General Emergency at 7:24 a.m. Between 7:30 and 8:00 a.m., the State of Pennsylvania did issue warnings of imminent evacuation to the west of the site. At 8:15 a.m., the evacuation alert was called off when the results of onsite and offsite radiation monitoring showed that there had been no major radiological release. Coincident with this decision, molten material existed in the reactor vessel and containment radiation levels were very high (see Table 2.4-1 and Section 3.5).

If an evacuation to the west of the site had been initiated around 8:00 a.m., local wind conditions would have shifted the potentially affected area to the north by 9:00 a.m., and then to the east by 11:00 a.m. Thus, the wrong people would have been told to evacuate. As the NRC Special Inquiry Group noted later, based on in-plant observations as set forth in the emergency plans and as emphasized in NRC emergency planning guidance in place even at the time (R.G. 1.101), omnidirectional evacuation of the total low-population zone (2.5-mileradius area surrounding the site) would have been warranted no later than 7:30 a.m.

Although not diagnosed, by 9:00 a.m. indications of severe core damage were indisputable. Some of the core thermocouple showed temperatures over $2000^{\circ} \mathrm{F}\left(800^{\circ} \mathrm{F}\right.$ beyond that required for cladding failures, and the containment dome monitor increased from 600 to $6000 \mathrm{R} / \mathrm{hr}$ between 8:20 and 9:00 a.m. However, as indicated, the decision not to take action was made based on field-monitoring results. The NRC Special Inquiry Group found that the state offices should have been advised at 9:00 a.m. that

the core has been badly damaged and has released a substantial amount of radioactivity. The plant is in a condition not previously analyzed for cooling system performance.

The Inquiry Group went on to state:

The difficult question in this situation is whether to advise precautionary evacuation of the nearby population or to advise only an alert for possible evacuation. The recommendation to evacuate is consistent with what we think would then be the case, a prudent doubt that the core-cooling passages were still sufficient for cooldown. In addition, the containment building was now filling with intensely radioactive gas and vapors, leaving the nearby public protected by only one remaining barrier, the containment, a barrier with a known leak rate that needed only internal pressure to drive the leakage. 
Finally, the Inquiry Group stated:

Present emergency plans are
inadequate because they do not provide
a clear requirement to evaluate the
need for protective actions based on
deterioration of plant conditions.

This example illustrates the importance (for core melt accidents) of implementing protective actions in the nearby areas as soon as core damage is detected and without regard for wind direction or detection of actual major releases. These are two of the foundations of current NRC staff emergency planning guidance. Early precautionary evacuation of the immediate area (approximately 2-mile radius) should not be recommended in only "downwind" directions because of the inability to determine where downwind will be when the protective actions are actually implemented or when a significant release occurs. In addition, when core damage is detected, the early recommendation to evacuate should not be based on early real-time dose projections but on the status of the core. Indeed, the predetermined, early, initial evacuation for a severe core damage accident is called "precautionary" because a major release may never actually occur, as was the case at TMI2. On the other hand, no immediate, early evacuation would be warranted for sequences less serious than core-melt accidents.

\subsubsection{Other Protective Actions}

Other protective actions such as decontamination of evacuees, milk contamination control, and reservoir (water) protection may also be part of the emergency response; however, very early implementation of these actions (within 0 to $4 \mathrm{hr}$ of the release) would not be crucial to their effectiveness. They would, however, be important in reducing the number of latent health effects.
For radiation protection purposes, it is assumed that, no matter how low the dose, some percentage of the population will eventually suffer from cancer because of the radiation exposure. As indicated in Section 5.2 , consequence models predict that many of the radiation-induced cancers would occur due to doses received by people tens to hundreds of miles from the plant. This is the result of a great number of people receiving a very low dose. Thus, as a practical matter, emergency-phase protective actions available to reduce these effects are very few. In the early time frame of a response, sheltering to long distances might be advised--much as for an air pollution alert.

If a severe reactor accident occurred during the growing season, crops and pasture within the 50-mile ingestion-pathway emergency planning zone (EPZ) might need to be decontaminated or temporarily quarantined to allow radioactivity to decay. This means that very soon after the accident, surveys of pastures, milk, fruits, and leafy vegetables would need to be conducted, dairy and meat animals would have to moved from contaminated to uncontaminated pastures or fed from uncontaminated stored forage. Contaminated crops would have be prevented from reaching market (entering the food distribution system), and residents of the 50 mile EPZ would have to be carefully warned not to eat contaminated food they had privately grown.

\subsubsection{Protective Actions Following The Chernobyl Accident}

After the Chernobyl accident, plant workers and individuals who helped mitigate the accident were exposed to beta and gamma radiation from the reactor ruins, the core fragments expelled by the explosion, the plume, and the radionuclides deposited on the ground. The majority of acute radiation 
injuries occurred from the doses received during the night of the accident (April 26, 1986), when the reactor staff (not knowing the degree of destruction) tried to restore the reactor to operational mode. Shortly thereafter, firemen responding to the emergency were unprotected from the radiation. The dosimeters they wore were either damaged or incapable of measuring the extremely high dose rates they encountered (up to thousands of rads per hour). Clinical treatment for acute radiation sickness was delivered to 134 individuals; 37 of these cases were life threatening. Of these 37, 28 died within days or weeks. Thermal- and beta-induced skin burns affected more than $50 \%$ of the total body surface area of 26 of the 28 patients who died. Two more persons died at the site as a result of the initial explosions, and one person died of cardiac infarction. Thus, a total of 31 people died during the first three months. ${ }^{8}$

After the initial exposures, protective actions were implemented to reduce doses to the remaining Chernobyl workers, persons who helped mitigate the accident, and inhabitants of contaminated regions. No additional cases of acute radiation sickness were observed. In part, this is due to the protective actions including evacuations that are discussed in the following subsections. It is, however, also a result of the energetic lofting of the release and the winds and rains that existed during the release. These factors resulted in deposition patterns that were not as bad as they might otherwise have been in major population centers like the city of Kiev.

The information regarding protective actions and their effectiveness, which is presented in the following sections, is drawn from an overview which appears in a 1993 book entitled The Chernobyl Papers. ${ }^{9}$

\subsubsection{Workers}

Approximately 600,000 individuals took part in mitigation activities at the reactor and within the $30-\mathrm{km}$ zone surrounding the reactor. These workers were all adults, most of whom were males between the ages of 20 and 45. About half were servicemen who were brought in from all territories of the former Soviet Union.

The effective dose equivalent limit established for individuals working in the $30-\mathrm{km}$ zone was $25 \mathrm{rem}$ in accordance with the Soviet standards of radiation safety. Upon reaching this limit, a worker was suspended from work in the $30-\mathrm{km}$ zone and was required to undergo a medical evaluation. In 1987 this limit was reduced to $10 \mathrm{rem}$, and in 1988 to $5 \mathrm{rem}$ per year.

As time progressed, especially while a protective shell (the "sarcophagus") was built around the destroyed reactor, workers continued to receive doses up to $25 \mathrm{rem}$ and even higher in a few cases from exposure to external beta and gamma radiation. The composition of radionuclides contributing to these exposures varied continuously due to decay. Inhalation of radionuclides also occurred. These included volatile forms of I-131 in May 1986 and resuspended fuel particles in the hot, dry summer of 1986. Doses from ingestion were negligible because uncontaminated food products were made available to the workers.

To decrease beta and gamma radiation levels in the $30-\mathrm{km}$ zone, activities included decontamination of buildings and roads using water and special decontamination solutions, removal of radioactive soil, and covering contaminated sites with up to $1.5 \mathrm{~m}$ of crushed rock and/or concrete. These activities were performed using heavy equipment with highly shielded cabins and remotely operated tools. Additional 
countermeasures included decontamination of roofs of buildings at the Chernobyl site using robotic machinery and the application of water and a fixing polymer to the ground to suppress dust.

Additional worker protection was provided through the use of special clothing and footwear, and both filter and supplied-air respirators. External gamma radiation doses were limited by restricting stay times in high exposure-rate areas and through the use of remotely operated tools. Also, stable iodine was administered to workers through June 1986.

\subsubsection{Evacuees}

To avoid acute radiation sickness, 49,000 inhabitants of the town of Pripyat, located 3 $\mathrm{km}$ from the Chernobyl nuclear power plant, were evacuated on April 27, 1986. Additionally, 11,000 inhabitants of 15 villages in the $10-\mathrm{km}$ zone around the plant were evacuated on May 2 and 3, and 42,000 additional inhabitants of 83 villages in the 30-km zone were evacuated between May 4 and May 7. During June through September 1986, after data on the areas contaminated by long-lived radionuclides were refined, the inhabitants of 57 villages in Belarus, 1 village in the Ukraine, and 4 villages in the Bryansk region of Russia were resettled. No cases of acute radiation sickness were observed in any of the 116,000 evacuated individuals.

Although rumors were rampant, the population of Pripyat was not officially notified of the accident until approximately noon on April 27, at which time they were ordered to prepare to evacuate. Evacuation took place by buses mainly between 1 p.m. and 5 p.m. on April 27. The remainder of the population of the $30-\mathrm{km}$ zone learned about the accident from television on the evening of April 28. Stable iodine was administered to approximately $60 \%$ of the population of Pripyat on April 26 and 27, but $65 \%$ of the population did not undertake any other countermeasures prior to evacuation. Rural residents of the $30-\mathrm{km}$ zone did not significantly change routines, nor did they apply any personal countermeasures prior to evacuation.

The evacuees were subjected to external radiation from the plume and to beta and gamma radiation from radionuclides deposited on the ground before evacuation was completed. Ingestion of radionuclides occurred in a number of Belarus villages (in the southern portion of the Gomel region) because notifications of the accident were late and therefore ineffective in preventing consumption of contaminated foods. Consequently, thyroid doses to children in these villages exceeded a thousand rems.

External exposures and the intake of radionuclides essentially ceased after evacuation. The average and maximum effective dose equivalents from external gamma radiation to inhabitants of Pripyat were $1 \mathrm{rem}$ and $10 \mathrm{rem}$, respectively. The values for the rural population of the $30-\mathrm{km}$ zone were approximately $2 \mathrm{rem}$ and $40 \mathrm{rem}$, respectively. The average thyroid dose to Pripyat inhabitants was approximately $20 \mathrm{rad}$ for both children and adults. Administration of stable iodine is estimated to have decreased thyroid doses in Pypriat evacuees by a factor of 10 .

\subsubsection{Residents of Significantly Contaminated Areas}

About 4 million people were, and many continue to be, subjected to external and internal exposures in the $131,000-\mathrm{km}^{2}$ area, with Cs-137 surface activity levels exceeding $1 \mu \mathrm{Ci} / \mathrm{m}^{2}$. Approximately 270,000 of these individuals resided in the controlled area, which consisted of $10,300 \mathrm{~km}^{2}$ with $\mathrm{Cs}-137$ 
surface activity levels exceeding $16 \mu \mathrm{Ci} / \mathrm{m}^{2}$. For these individuals, external exposures from the plume were insignificant compared to the external exposures from deposited radionuclides. According to available data, less than $10 \%$ of the external doses received during the first year were attributed to the plume. Inhalation doses from the plume and from resuspended radionuclides were also insignificant for these individuals compared to the ingestion of $\mathrm{I}, \mathrm{Cs}$, and $\mathrm{Sr}$ isotopes.

Dose limits were developed for the protection of people who continued to reside in significantly contaminated areas. The adopted limits were 10 rem for the first year after the Chernobyl accident, then 3 rem in the second year and $2.5 \mathrm{rem}$ in each year of 1988 and 1989. Overall, through January 1, 1990 the maximum effective dose equivalent allowed was 13 rem per inhabitant. In 1991 a new criterion for relocation of residents to uncontaminated areas was set: for annual effective dose equivalents greater than 0.5 rem, relocation was required. To ensure that the effective dose equivalent limitations were met and to limit internal doses to critical organs, temporary permissible levels of radionuclide activities in food products and drinking water were instituted. Along with the standards for food products, many other standards were introduced including standards for contamination of various surfaces.

In the early and intermediate phase, protective actions taken for inhabitants of significantly contaminated areas included administration of stable iodine, temporary relocation, delivery of uncontaminated meat and dairy products, decontamination of villages, and measures to decrease radionuclide content in agricultural products. The inhabitants of villages with the highest levels of radioactive contamination were gradually resettled to uncontaminated areas. The most effective protective actions for reducing person-rems were temporary and permanent relocation and the supply of uncontaminated food products. Administration of stable iodine was only effective in Pripyat, where short-term (1.5 day) radioiodine intakes were very high and stable iodine was administered in a timely manner. There were no observations of cases of acute radiation sickness in the population of the controlled areas, although radiation-related thyroid cancers may be observed.

In many towns and villages, numerous countermeasures for protection of the population were performed simultaneously. Temporary resettling of children, monitoring of milk contamination and administration of stable iodine together decreased the collective thyroid dose to the 3 million inhabitants of Kiev by an estimated 11 million person-rem, or approximately $40 \%$.

\subsubsection{Residents of Less Contaminated Areas}

The remainder of the population of the former Soviet Union numbered approximately 280 million in 1991. These individuals resided in territories with Cs- 137 surface activity levels below $0.04 \mathrm{MBq} / \mathrm{m}^{2}$ and were subjected to relatively insignificant exposures from local contamination. An important factor was the distribution throughout the country of meat and dairy products produced in the contaminated area. Although concentra-tions of radionuclides in these products were within permissible levels, the content of $\mathrm{Cs}$ radionuclides in the bodies of inhabitants of the former Soviet Union increased compared to the preaccident levels as a result of the consumption of the products. In many regions both individual and collective population doses from these products were higher than those received from the local deposition of radioactive material. 
Outside the former Soviet Union, protective actions in countries that received fallout from Chernobyl varied. In many countries, contamination levels in milk and other food products were monitored and sale of contaminated produce was banned. In some countries potassium iodide was distributed to children to protect against thyroid cancer.

\subsubsection{Long-Term Health Effects From The Chernobyl Accident}

In April of 1996, almost ten years after the Chernobyl accident, an international conference was held in Vienna to discuss the radiological, environmental, and psychosocial consequences of the Chernobyl accident. $^{8}$ One major conclusion of the conference was that the psychological impact of the accident has been extensive and long-lasting. The mental stress caused by what is and is not known about the accident is real. The population is inclined to mistrust official statements and attribute an increase in any kind of illness to radiation. Yet, at the time of the conference, clear evidence regarding the impact of Chernobyl on the incidence rates of various illnesses was sparse.

There is one notable exception. A large number of child thyroid tumors are clearly attributable to the consumption of milk contaminated with radioiodine. At the time of the conference, over 550 cases of thyroid cancer had been diagnosed in children below the age of 15--about 330 in Belarus, 200 in Ukraine, and 25 in Russia. In Belarus, the number of cases diagnosed between 1990 and 1995 was about 50 times greater than in the United Kingdom. This incidence rate is almost an order-of-magnitude greater than would have been predicted based on preexisting models, and the reason for the discrepancy is not clearly understood. Children may be much more sensitive to radioactive iodine than anticipated, or iodine deficiency may have been a factor, or some genetic predisposition to the disease may have existed in the region. If detected sufficiently early, thyroid cancer can be treated with surgery, iodine-131 therapy, and thyroid hormone replacement. Some 10 to $15 \%$ of those treated develop complications that could result in death at a later date.

Data regarding other health effects is less clear. Studies of the overall incidence of cancer among cleanup workers and residents of contaminated areas were undertaken in Ukraine, Belarus, and Russia. Some of these studies indicated no increase in comparison with the general population whereas others reported increases as large a $11 \%$ for cleanup workers and $3 \%$ for inhabitants of contaminated areas. No consistent increase has been validated for leukemia in any of the three countries. After 10 years, an increase in the incidence of leukemia among the cleanup workers was anticipated based on studies of atomic bomb survivors. It may be that atomic bomb survivor studies are not directly applicable to Chernobyl because the doses to cleanup workers and residents in contaminated areas were delivered over comparatively long time periods.

Because additional thyroid cancers are anticipated, information regarding leukemia incidence rates is inconclusive, and the latency period for many other forms of cancer (in particular solid tumors) exceeds 10 years, it is important that studies of the disease incidence rates continue. Unfortunately, key pieces of information are often missing, such as data on the amount and type of radiation to which individuals were exposed. Also, records of the incidence of disease and causes of death for people in the affected areas before and after the accident often are often deficient. As a result, the long-term health effects of the Chernobyl accident may never be known with great accuracy. But major strides have 
been made in the treatment of children with thyroid cancer, the quality of cancer registries, health studies and research infra- structures, and training of epidemiologists and medical personnel. 


\section{Table 5.3-1 Exposure pathways, nuclear incident phases, and protective actions}

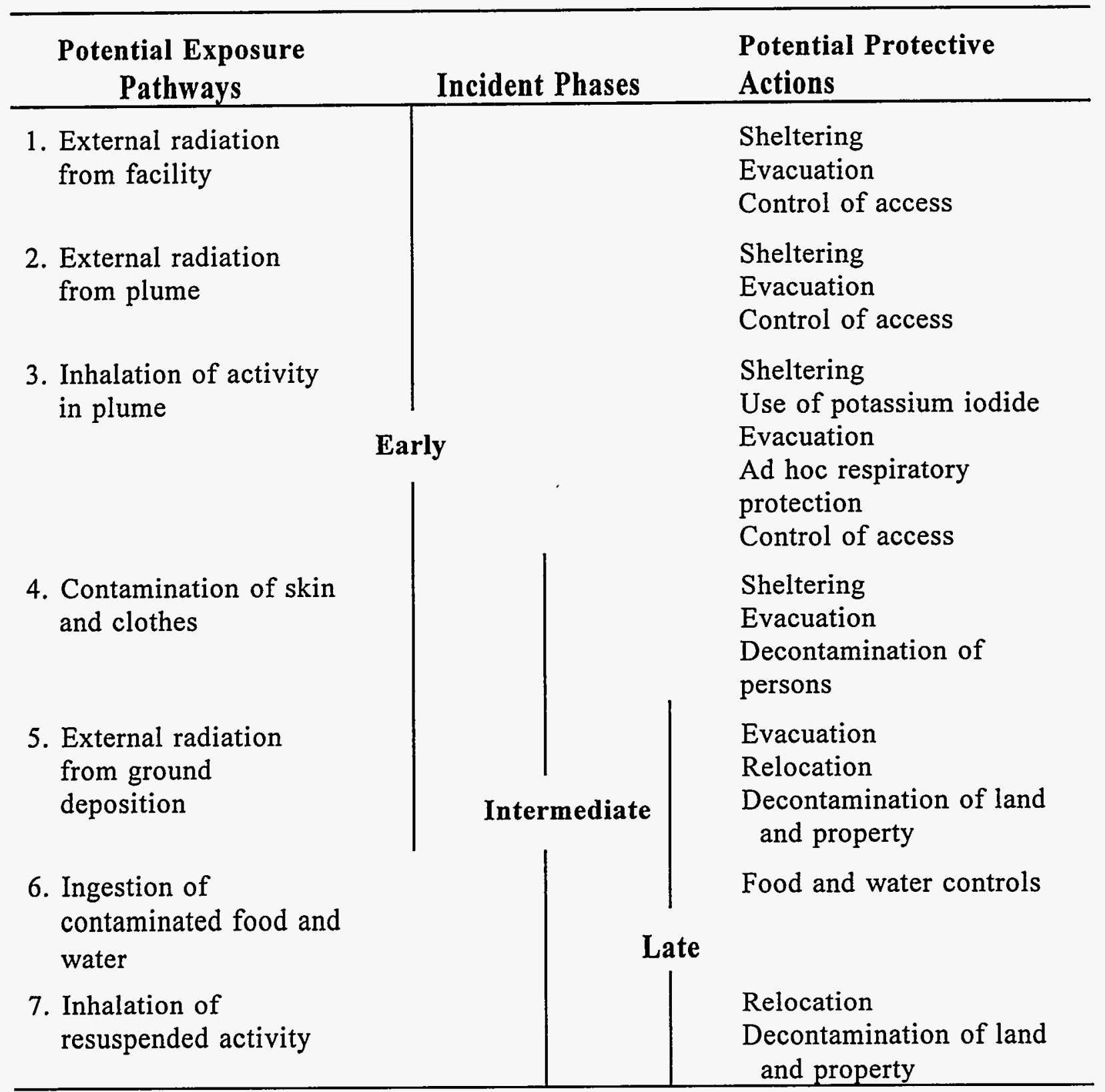

Note: The use of stored animal feed and uncontaminated water to limit the uptake of radionuclides by domestic animals in the food chain can be applicable in any of the phases. 
Table 5.3-2 Public response to nuclear-related incidents

\begin{tabular}{|c|c|c|c|}
\hline Date & Location & Incident & Public reaction \\
\hline 1957 & $\begin{array}{l}\text { Windscale, } \\
\text { England }\end{array}$ & $\begin{array}{l}\text { Accident at a graphite reactor } \\
\text { caused the release of } 20,000 \mathrm{Ci} \text { of } \\
\text { radioiodine }\end{array}$ & Typical, no panic \\
\hline 1977 & $\begin{array}{l}\text { Ft. St. } \\
\text { Vrain, } \\
\text { Colo. }\end{array}$ & $\begin{array}{l}\text { Erroneous reports of a release of } \\
20 \mathrm{Ci} / \mathrm{sec} \text { from a nuclear power } \\
\text { reactor }\end{array}$ & $\begin{array}{l}\text { Normal, no panic despite } \\
\text { blizzard conditions }\end{array}$ \\
\hline 1978 & $\begin{array}{l}\text { Rocky } \\
\text { Flats, Colo. }\end{array}$ & Major fire at a plutonium plant & $\begin{array}{l}\text { Normal, no panic or } \\
\text { widespread flight }\end{array}$ \\
\hline 1980 & $\begin{array}{l}\text { Crystal } \\
\text { River, Fla. }\end{array}$ & $\begin{array}{l}20,000 \text { gal of primary water was } \\
\text { spilled into the containment }\end{array}$ & $\begin{array}{l}\text { Normal, no panic or } \\
\text { widespread flight }\end{array}$ \\
\hline 1979 & $\begin{array}{l}\text { Three Mile } \\
\text { Island, } \mathrm{Pa}\end{array}$ & Nuclear power plant accident & $\begin{array}{l}\text { Half of population within } 20 \\
\text { miles evacuated within } 5 \\
\text { days }\end{array}$ \\
\hline 1982 & $\begin{array}{l}\text { Rochester, } \\
\text { N.Y. }\end{array}$ & $\begin{array}{l}\text { Primary coolant released to the } \\
\text { atmosphere from R.E. Ginna } \\
\text { nuclear power plant }\end{array}$ & $\begin{array}{l}\text { Normal, no panic or } \\
\text { widespread flight }\end{array}$ \\
\hline 1981 & $\begin{array}{l}\text { Indian } \\
\text { Point, N.Y. }\end{array}$ & $\begin{array}{l}\text { Power transformer exploded when } \\
\text { lightning struck a nuclear power } \\
\text { station }\end{array}$ & Small-scale evacuation \\
\hline
\end{tabular}


Table 5.3-3. Factors by which radionuclide exposure may be reduced by sheltering for different types of shelters and pathways of exposure

Type of shelter

Cloud shine Ground shine Inhalation

\begin{tabular}{c|c|c|c}
\hline $\begin{array}{c}\text { Small, frame building } \\
\text { Without basement }\end{array}$ & 1 & 2 & $2^{\mathrm{a}}$ \\
With basement & 3 & $5-10$ & $3^{\mathrm{a}}$ \\
\hline Multiple-story concrete structure & 5 & 10 & 5 \\
\hline
\end{tabular}

"Puff release only. 
Table 5.3-4. Respiratory protection provided by common household and personal items against aerosols of 1 - to 5 - $\mu \mathrm{m}$ particle size

\begin{tabular}{lcc}
\hline \multicolumn{1}{c}{ Item } & $\begin{array}{c}\text { Number of } \\
\text { thicknesses }\end{array}$ & $\begin{array}{c}\text { Geometric mean } \\
\text { efficiency (\%) }\end{array}$ \\
\hline Toilet paper & 3 & 91 \\
Handkerchief, man's cotton & Crumpled & 88 \\
Bath towel, turkish & 2 & 85 \\
Bath towel, turkish & 1 & 74 \\
Bed sheet, muslin & 1 & 72 \\
Handkerchief, man's cotton & 1 & 27 \\
\hline
\end{tabular}




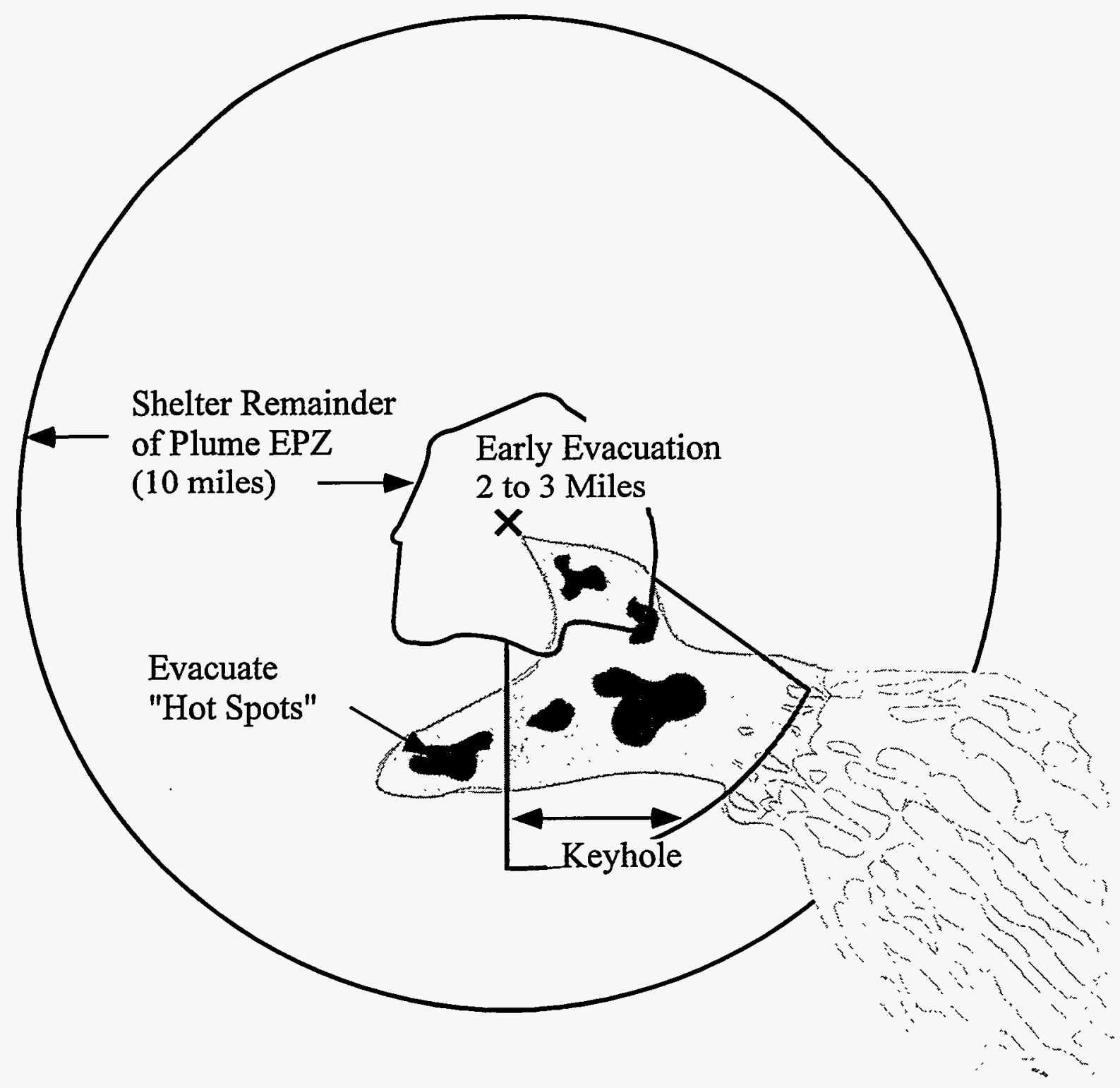

Figure 5.3-1 Early protective actions for core melt accidents 


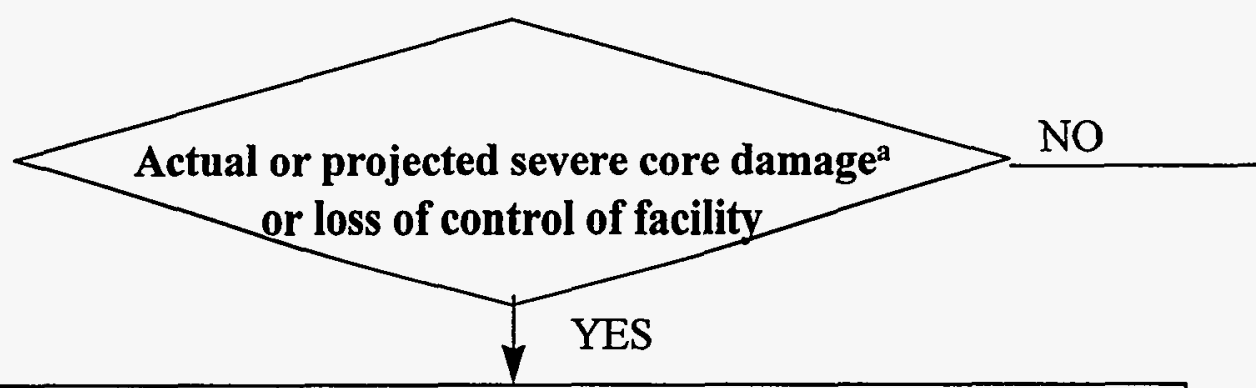

\section{Evacuate a 2 mile radius and 5 mile downwind unless conditions make evacuation dangerous and advise remainder of plume EPZ to go indoors and to monitor EBS broadcast}

(See notes b, c, d, e)

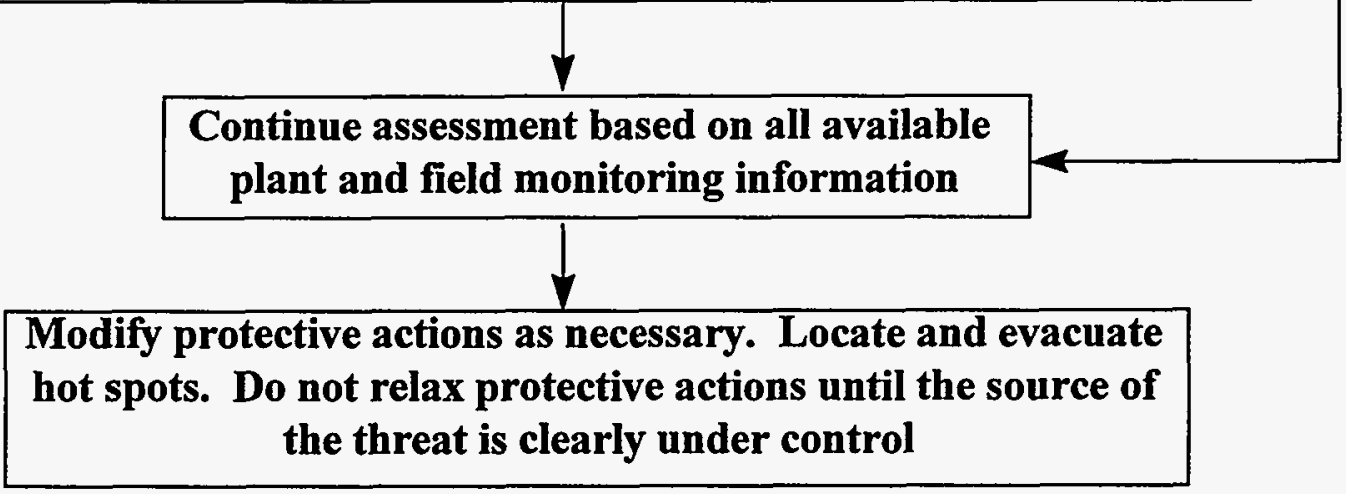

- Severe core damage is indicated by (1) loss of critical functions required for core protection (e.g., loss of injection combined with loss of cooling accident); (2) high core temperatures (PWR) or partially uncovered core (BWR); or (3) very high radiation levels in area or process monitors.

B Distances are approximate - actual distances will be determine by the size of the preplanned sub-areas, which are based on geopolitical boundaries.

c If there are very dangerous travel conditions, initially shelter rather than evacuate the population until condition improve.

D Transit-dependent persons should be advised to remain indoors until transportation resources arrive, if possible.

E Shelter may be the appropriate action for controlled releases of radioactive material from the containment if there is assurance that the release is short term (puff release) and the area near the plant cannot evacuated before plume arrives.

Figure 5.3-2 Protective action flow chart for severe core damage or loss or control facility 


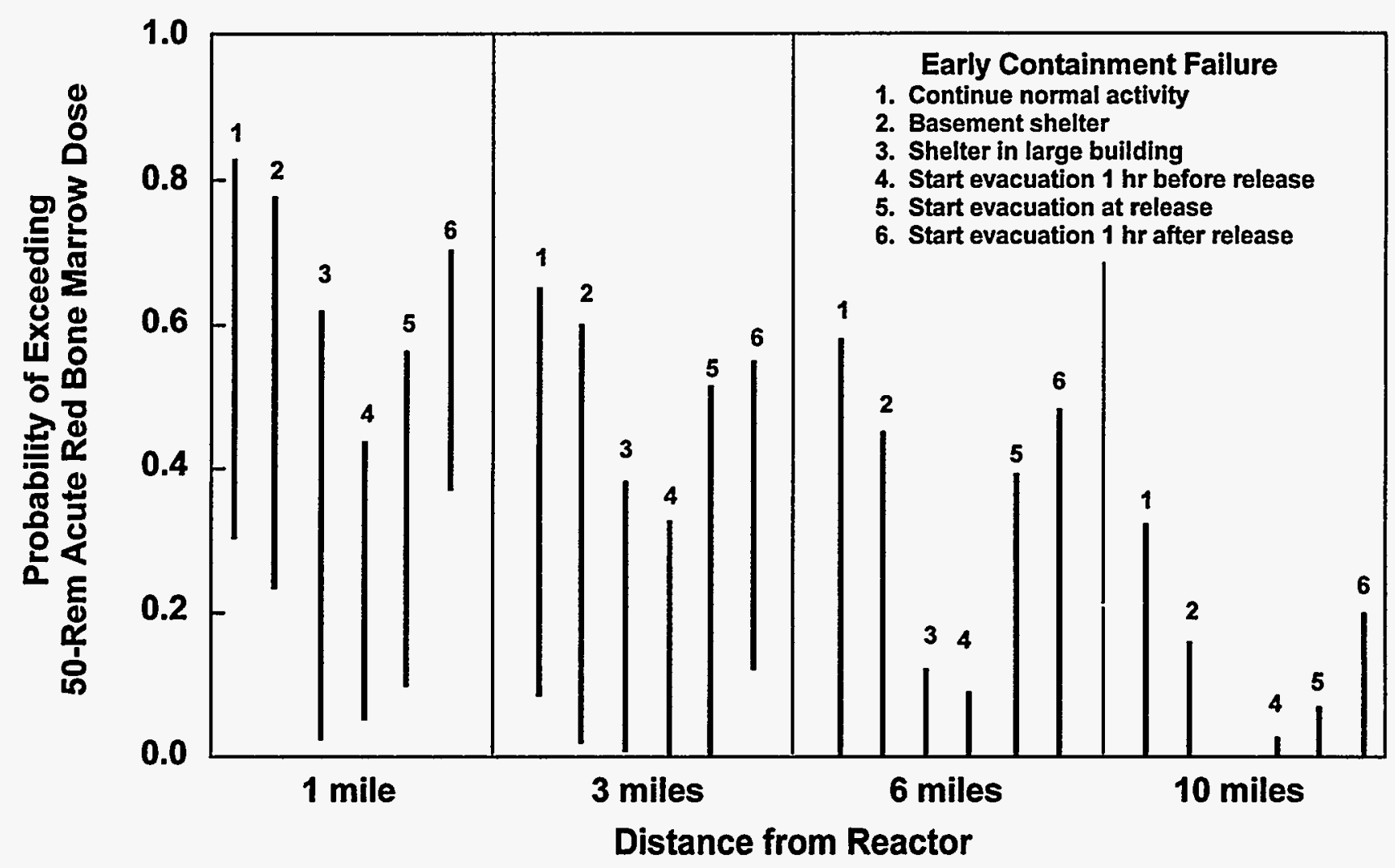

Figure 5.3-3 Relative effectiveness of early protective actions given early containment failure (Source: NUREG-1150, Figure 13.5) 


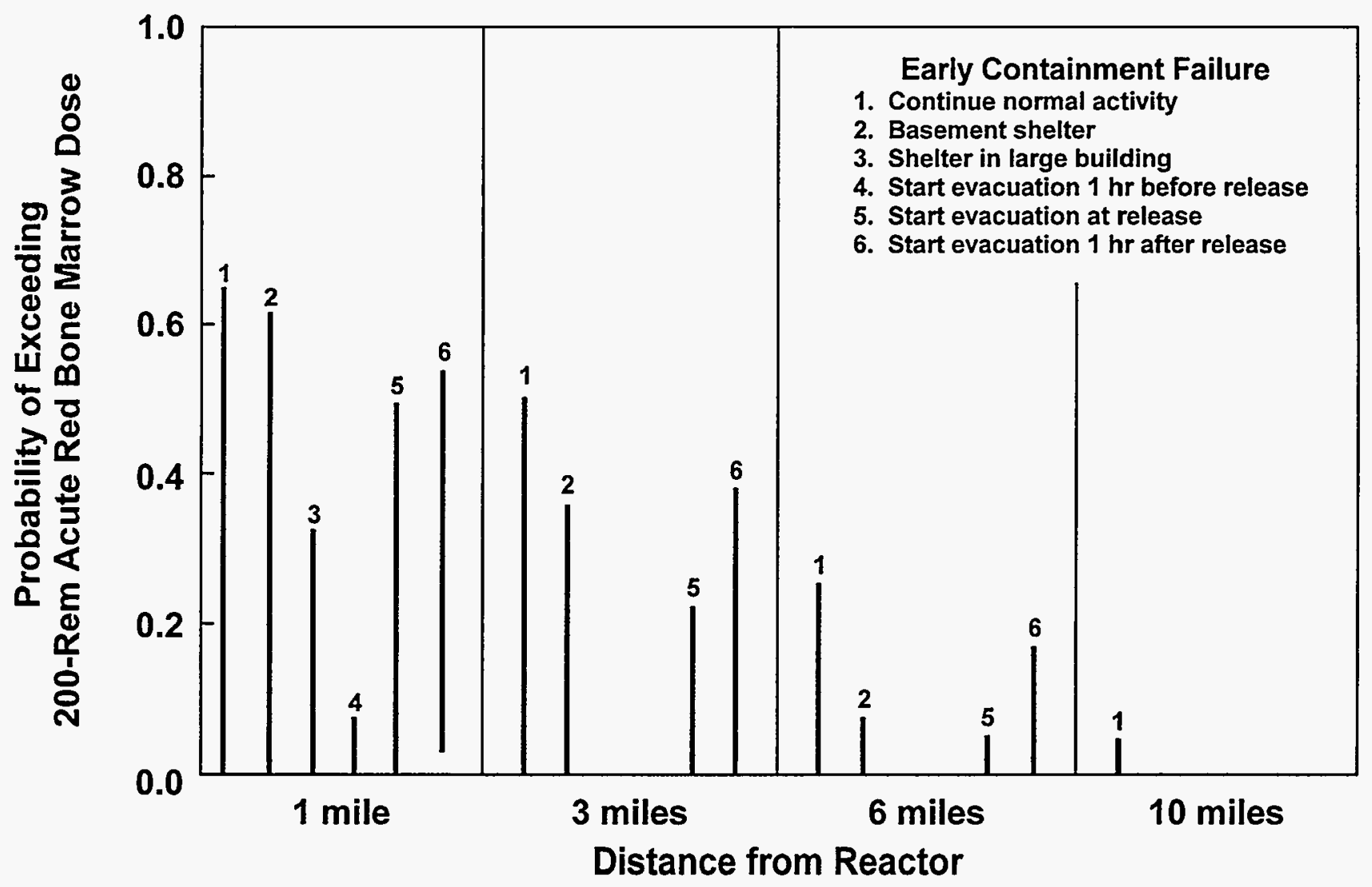

Figure 5.3-4 Relative effectiveness of emergency response actions assuming early containment failure with high and low source terms 


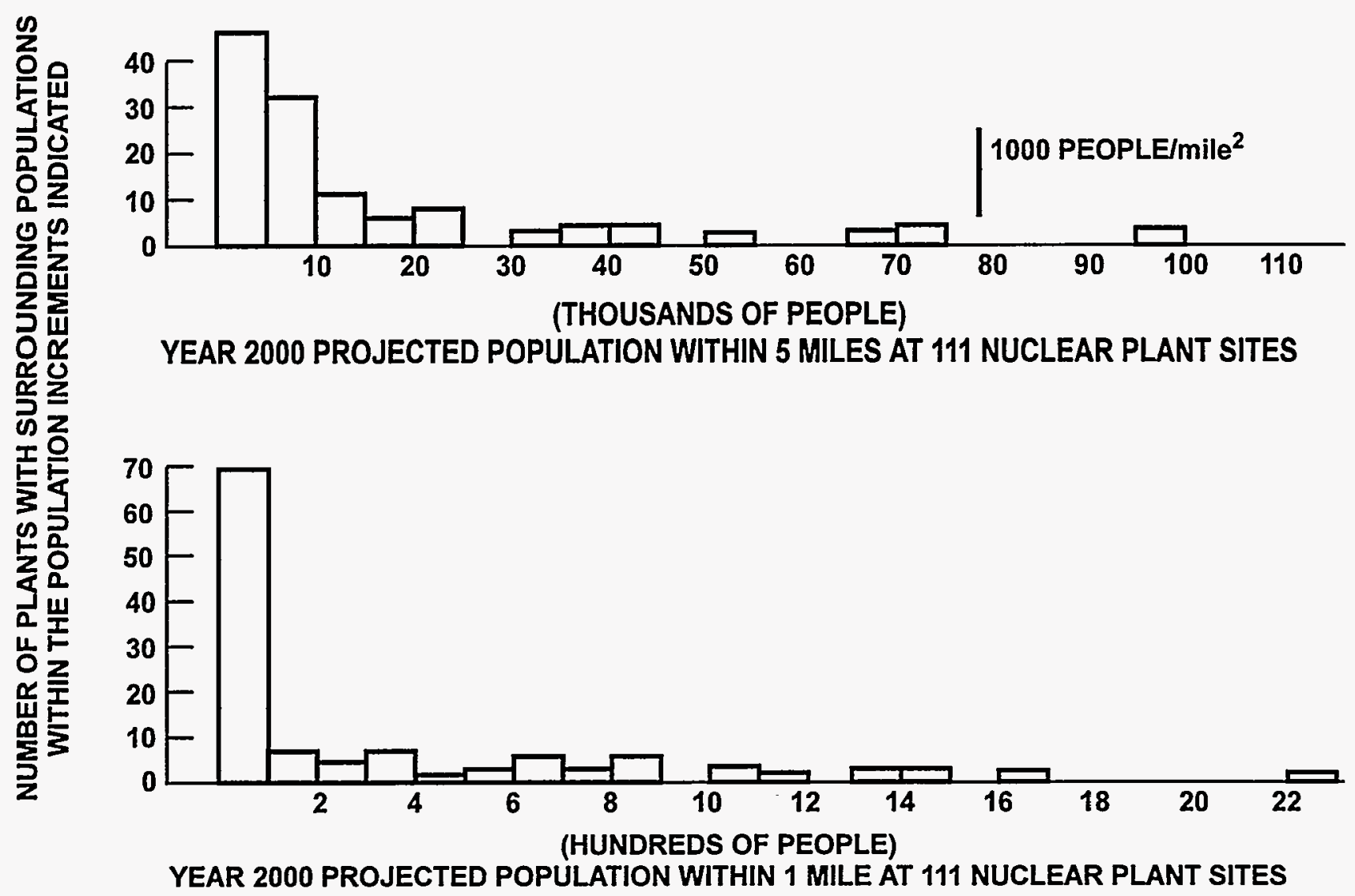

Figure 5.3-5 Number of people within 1 and 5 miles of 111 nuclear power plants, actual or proposed in 1979 


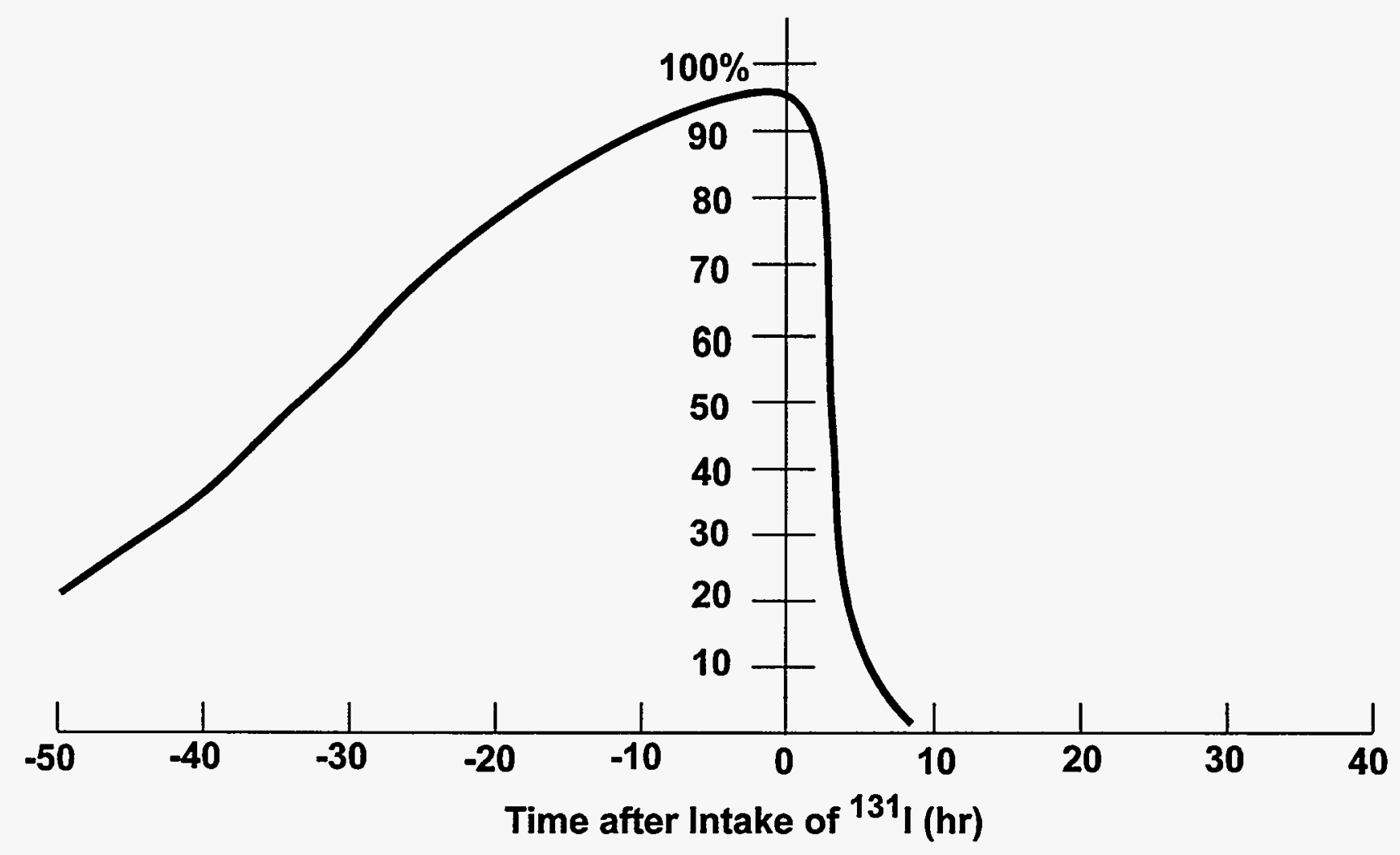

Figure 5.3-6 Percent of thyroid blocking afforded by $100 \mathrm{mg}$ of stable iodine (130 mg of potassium iodide) as a function of time of administration before or after a $1-\mu \mathrm{Ci}$ intake of ${ }^{131} \mathrm{I}$ 


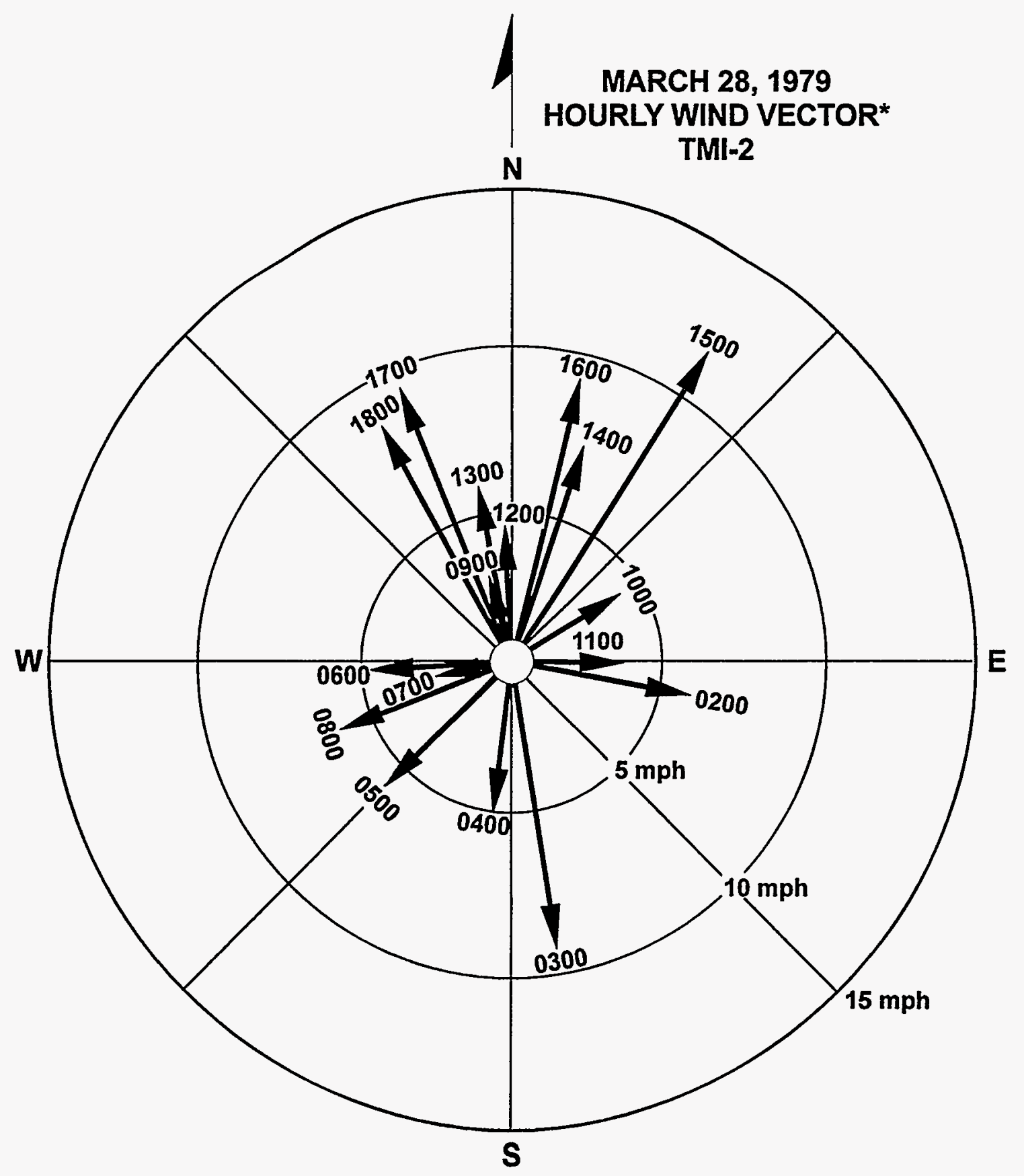

*Arrows indicate direction toward which the on-site wind was blowing at the local time indicated. Circles represent varying wind speeds.

Figure 3.5-7 Hourly wind vector at Three Mile Island on March 28, 1979 


\section{References for Section $\mathbf{5 . 3}$}

1. T. McKenna, et al., "RTM-96 Response Technical Manual," NUREG/BR-0150, Vol. 1, Rev. 4, March 1996, Figure G-1.

2. U.S. Nuclear Regulatory Commission, "Severe Accident Risks: An Assessment for Five U.S. Nuclear Power Plants," NUREG-1150, p. 13-12, December 1990.

3. U.S Nuclear Regulatory Commission, "Demographic Statistics Pertaining to Nuclear Power Reactor Sites," NUREG0348, October 1979.

4. J. M. Hans, Jr. and T. C. Sell, "Evacuation Risks--An Evaluation," Environmental Protection Agency report EPA-520/6-74-002, Office of Radiation Research, National Environmental Research Center, Las Vegas, Nevada, June 1974.

5. J. A. Martin, Jr., et al., "Pilot Program: NRC Severe Reactor Accident Incident Response Training Manual, Public Protective Actions -- Predetermined Criteria and Initial Actions," NUREG1210, Volume 4, 1987.
6. J. A. Martin, "Potassium Iodide: Predistribution or Not? The Real Emergency Preparedness Issue," Health Physics, 49(2):287-289, August 1985.

7. U.S. Food and Drug Administration, "Radioactive Contamination of Human and Animal Feeds and Potassium Iodide as a Blocking Agent in a Radiation Emergency," Federal Register, 43:242, Part VII, December 15, 1978.

8. A. Kaul, H. Landfermann, and $M$. Thieme, "One Decade After Chernobyl: Summing Up the Consequences," Health Physics, Vol. 71, No. 5 (November 1996) 634-640.

9. M. I. Balonov, "Overview of Doses to the Soviet Population from the Chernobyl Accident and the Protective Actions Applied," in The Chernobyl Papers, Vol. I, Doses to the Soviet Population and Early Health Effects Studies, Steven E. Merwin and Michail I. Balonov editors, Research Enter-prises Publishing Segment, Richland, WA, 1993. 


\subsection{Emergency Preparedness}

Preparations for potential nuclear power plant emergencies are extensive. The discussion in this section is limited to those aspects of preparedness that affect the NRC's role of monitoring protective actions. This includes organizational responsibilities, emergency detection and classification, Emergency Planning Zones, licensee response centers, and the response of state and local organizations.

\subsubsection{Regulatory Basis}

Licensees have developed plans and procedures for emergency response in accordance the requirements and guidelines presented in the following documents:

1. Title 10, Code of Federal Regulations (CFR) Pt. 50.47 and Appendix E, which contain the basic requirements for emergency preparedness.

2. NUREG-0654 [Regulatory Guide (R.G.) 1.101, rev. 2], ${ }^{1}$ which contains the criteria to be used in developing and assessing an emergency plan.

3. NUREG-0396, ${ }^{2}$ NUREG- $1131,{ }^{3}$ and Information Notice $83-28,{ }^{4}$ which discuss the foundation for the current emergency preparedness concepts.

4. NUREG-0737, Supplement $1,{ }^{5}$ which clarifies the requirements for the emergency organization and emergency centers.

5. NUREG-1210 and RTM-96,, 67 which update the guidance in NUREG-0654 and Information
Notice 83-28 based on results of severe accident research and experience gained in emergency preparedness exercises.

The licensee emergency plans and procedures are available at NRC Headquarters (HQ) and at the regional offices for each operating reactor.

\subsubsection{Roles in an Emergency}

\subsubsection{Role of Licensee}

In the event of an emergency, the primary responsibilities of the licensee are to protect the core, to prevent or limit offsite consequences, and to notify predesignated state and local officials promptly (within 15 minutes) of the emergency declaration.

The licensee's first priority is to protect the core by maintaining the following critical safety functions:

1. making the core subcritical and keeping it there,

2. keeping the water flowing through the core,

3. keeping the core covered with water,

4. providing makeup for water boiled off, and

5. removing decay heat from the core to an outside heat sink.

The licensee must also take action to prevent or limit offsite consequences by

1. maintaining reactor containment and the Engineered Safety Feature (ESF) systems, 
2. controlling radionuclide releases,

3. recommending appropriate protective actions to offsite officials.

Licensees have developed Emergency Operating Procedures for use by the control room staff in responding to emergency conditions. These Emergency Operating Procedures are discussed in Section 5.4.3.1.

In parallel with attempts to correct the problem, the licensee must notify offsite officials of an emergency declaration promptly (within $15 \mathrm{~min}$ ). The licensee recommends initial protective actions to offsite officials because the licensee has the best early understanding of core and containment conditions. Furthermore, if an actual offsite radionuclide release occurs, the licensee is responsible for monitoring that release to ensure that actions recommended off site are appropriate (i.e., that initial protective action recommendations/decisions continue to be valid based on current, actual monitoring data). Section 5.3 discusses role and efficacy of specific protective actions.

\subsubsection{Role of State and Local Agencies}

State and local agencies are charged with protecting the public from the offsite consequences that might result from a power plant accident. These organizations have the ultimate responsibility for notifying the public to take protective actions in the event of a severe accident. State and local officials base their decisions on the recommendations of the licensee. The licensee cannot order an evacuation of areas surrounding the plant; the licensee can only make such a recommendation to the appropriate offsite officials. Those officials must make the decision to notify the public to implement any protective actions. The response of state and local organizations is discussed in Section 5.4.6.

\subsubsection{Role of the NRC}

The NRC role should be one of monitoring the licensee's actions and providing assistance to the licensee. It is important that the NRC response personnel understand that extensive preplanning has been completed to assist in early decision making. When prompt protective action is dictated by plant conditions in a serious accident, it is not appropriate for the licensee or the responsible state or local agency to seek NRC concurrence prior to initiating the action. The NRC should intervene only if there is a serious lack of appropriate action.

\subsubsection{Emergency Detection and Classification}

\subsubsection{Emergency Operating Procedures}

Prior to the accident at Three Mile Island, plant emergency operating procedures were "event-oriented." They described the steps which the operator should take given the occurrence of certain preselected, pre-analyzed events. These procedures were typically limited to transient events or loss-of-coolant events followed by successful operation of all safety systems designed to respond to these events.

Since the Three Mile Island accident, considerable effort has been devoted to the development of "symptom-based" procedures to replace (or at least significantly augment) the event-specific procedures. The basic premise underlying these symptom-based procedures is that there is a limited set of critical safety functions (CSFs), which, if successfully performed by either automatic plant response or manual action, result in a "safe" condition for the plant. The basic goal of the plant safety systems and the 
ultimate goal of operator actions is to ensure the performance of these critical safety functions. Symptom-based operating procedures relate critical safety function performance to specific plant/control room instruments.

The attractiveness of the "critical safety functions" concept evolves from the implication that the operator need only monitor a relatively few pieces of information to ascertain the safety of the plant. While there are a limited number of critical functions (or parameters) which indicate the performance of these functions, there are virtually an unlimited number of events (with a wide variety of symptoms) that can affect the performance of these functions. The operator can carry out his duties by focusing on these critical functions without regard to the specific events that have occurred.

It is important to note that, in general, the Emergency Operating Procedures address actions that lead up to but do not include actions to be taken after core damage. Therefore, the operators may not have procedures to help them once the core has been damaged. However, as a result of shortcomings identified in the Three Mile Island accident, licensees have installed additional instrumentation to detect inadequate core cooling, developed core condition assessment procedures, and conducted training on core condition assessment. These assessments are based on the relationship of various plant instruments (e.g., containment radiation monitor, reactor water level indicator, core thermocouples, etc.). These relationships must be used with caution, but they do provide gross indicators of the extent of core damage.

\subsubsection{Emergency Action Levels}

Licensees have established Emergency Action Levels based on control room instrument readings (e.g., $1000 \mathrm{R} / \mathrm{h}$ containment monitor reading or $2000^{\circ} \mathrm{F}$ thermocouple) that indicate the scope of an emergency. NRC guidance requires that Emergency Action Levels be established for a full range of events from situations that indicate just a potential problem to actual core damage (General Emergency).

Emergency Action Levels are extremely important. They are trigger levels for the declaration of emergencies and the initiation of predetermined activities that lead to immediate, early actions (e.g., activation of organization, notifications, and protective actions).

Each licensee's emergency action plan contains a list of Emergency Action Levels which are used by the operators in assessing the level of response needed. Most licensees originally established their Emergency Action Levels for each of the 60 example initiating conditions provided in NUREG0654. In many cases, this results in a very long list of diagnostic control room parameters, as can be seen from the sample shown in Table 5.4-1. Some licensees have streamlined this approach by using flow charts and other visual aids. A newer symptomatic EAL classification scheme has been developed by NUMARC and adopted many licensees. In the NUMARC methodology, generic recognition categories replace individual analyses of multiple NUREG-0654 initiating conditions.

Table 5.4-2 shows several examples of the timing of boiling water reactor (BWR) core 
damage accidents. These examples illustrate that core damage could occur within a few minutes or many hours. These are only examples to show what might be typical of the timing during an event and to demonstrate how the ability to take early action based on the exceeding of Emergency Action Levels could provide sufficient time to implement protective actions.

\subsubsection{Emergency Classification System}

Four classes of emergencies (Unusual Event, Alert, Site Area Emergency, and General Emergency) have been established by NRC regulations. The class of emergency that is declared is based on conditions that trigger the Emergency Action Levels (EALs). Typically, licensees have established for each emergency class specific Emergency Plan Implementation Procedures (EPIPs) that are to be implemented by the control room staff. The importance of correct classification cannot be overemphasized. The event classification initiates all appropriate actions for that class. Both over- and under-reaction could have serious adverse consequences. The classification procedures (i.e., Emergency Action Levels) for specific nuclear power plants are included in the emergency plans, which are located in the Region Incident Response Centers (IRCs) and the Headquarters Operations Center.

Each class requires specific initial actions. The classes and the appropriate initial actions are discussed in more detail in the following subsections.

\subsection{Unusual Event}

The rationale for establishing notification of an "Unusual Event" as an emergency class is to provide early and prompt notification of minor events that could possibly lead to more serious conditions. The purpose of offsite notification is to

1. ensure that the first step in any response later found to be necessary has been carried out,

2. bring the operating staff to a state of readiness,

3. provide systematic handling of unusual events information and decision making, and

4. control rumors.

\subsection{Alert}

An alert is declared if events are in progress or have occurred that involve an actual (or potential) substantial degradation of the level of safety at the plant. Any radiological releases are expected to be limited, so that resulting exposures would be small fractions of the U.S. Environmental Protection Agency (EPA) Protective Action Guides.

The purpose of an alert is to

1. ensure that the onsite Technical Support Center is activated so that licensee emergency personnel are readily available to respond,

2. provide offsite authorities with information on the current status of the event, and

3. provide assistance to the control room staff.

\subsection{Site Area Emergency}

A site area emergency is declared if events are in progress or have occurred that involve actual or likely major failures of plant functions needed for protection of the public. 
Radiological releases, if any, are not expected to result in doses exceeding Environmental Protection Agency Protective Action Guide levels, except possibly near the site boundary.

The purpose of the Site Area Emergency declaration is to

1. ensure that all emergency response centers are manned,

2. ensure that radiological monitoring teams are dispatched,

3. ensure that personnel required to aid in the evacuation of near-site areas are at duty stations should the situation become more serious,

4. provide consultation with offsite authorities,

5. provide updates for the public through offsite authorities, and

6. ensure that nonessential personnel are evacuated.

\subsection{General Emergency}

A general emergency is declared if events are in progress or have occurred that involve actual or imminent substantial core degradation or melting. Risks of exceeding Environmental Protection Agency Protection Action Guide exposure levels in more than the immediate area are considerably elevated. This is a very special case. A General Emergency indicates that plant conditions are well beyond design and early protective actions are warranted.

The purpose of the General Emergency declaration is to
1. initiate predetermined protective action notification to the public, and

2. bring the full available resources of government and industry to bear on the situation.

\subsection{Class Summaries and NUMARC Recognition Categories}

Summary descriptions of the four emergency classes are provided in Table 5.4-3. A summary of emergency classification actions for the three major classes is presented in Table 5.4-4. The number of emergencies typically reported to the NRC in a year is 200 unusual events, 10 alerts, and 1 or 2 site area emergencies. No general emergencies have been declared since TMI-2.

Table 5.4-5 displays the relationship between the four emergency classes and the NUMARC recognition classes. By matching the observed plant condition with the recognition category descriptions on the left, the applicable emergency class can be determined. If the recognition category is "Fission Product Barriers Failure or Challenge," plant-specific measurable values indicating loss or potential loss of the cladding, reactor coolant system, and containment barriers are developed by the licensee.

\subsubsection{Protective Action Recommendations}

As discussed earlier, within $15 \mathrm{~min}$ of identifying a situation requiring urgent action (General Emergency), the licensee must recommend protective actions to offsite officials. For situations requiring urgent actions, recommended protective actions should have been predetermined based on discussions between the licensee and offsite 
officials considering plant and local conditions.

It is important to note that applications of protective actions are site-specific. For example, one plan may call for initial evacuation out to 5 miles, while another calls for initial evacuation out to 3 miles, but the basic concept of prompt evacuation of the area near the plant for a severe core damage accident is met.

No predetermined actions are established for site area emergencies and lesser events. The specific actions for these lesser events would be based on projected plant conditions, offsite dose projections, and monitoring conducted at the time.

\subsubsection{Emergency Response Centers}

\subsubsection{Control Room}

Authority to take action in the event of an emergency must reside in the plant control room until the Technical Support Center (see Section 5.4.4.2) or the Emergency Operations Facility (see Section 5.4.4.4) is activated. This includes the authority to declare emergencies, to notify offsite officials within 15 minutes of general emergency declaration, and to provide any appropriate protective action recommendations. The NRC must be notified after the appropriate state and local officials are notified and no later than one hour after declaring the emergency.

Upon declaration of an emergency, most sites designate an onsite Emergency Director, who is in charge of the plant's total response. During night and weekend hours, this typically is the Shift Supervisor. Once the appropriate augmentation staff arrive following declaration of an emergency, this responsibility (and title) normally transfers to the Technical Support Center and then to the Emergency Operations Facility.

\subsubsection{Technical Support Center}

There were indications from the events at Three Mile Island that numerous personnel in the control room acted to congest and confuse the reactor operators' control room activities. Review of this accident also shows that there existed a lack of reliable technical data and other records on which to base accident recovery decisions. As a result, today licensees are required to establish Technical Support Centers whose staff have access to plant technical information and who are responsible for engineering support of reactor operations during an accident. Personnel in the Technical Support Center must be able both to assist the control room when needed and to diagnose and mitigate an event. Until the Emergency Operations Facility is activated, the Technical Support Center will also perform the functions of the Emergency Operations Facility. The Technical Support Center is located close to the control room inside a protected and shielded area to allow fast access for face-to-face discussions with control room personnel.

\subsubsection{Operations Support Center}

The establishment of an Operations Support Center was introduced to help relieve the influx of shift/operational support personnel in the control room. The function of the Operations Support Center is to provide a place to which shift personnel report to receive further instructions from the operations staff. The Operations Support Center can be a locker room with capability for reliable communications with supervisory and decision-making personnel. 


\subsubsection{Emergency Operations Facility}

Personnel with primary responsibility for the licensee's response to a severe accident situation are located in the Emergency Operations Facility once it is activated. The Emergency Operations Facility is an offsite facility, which is usually near the site, with hardening/shielding or a backup facility if necessary. Figure 5.4-1 depicts the relative locations of the licensee emergency response centers.

The Emergency Operations Facility is generally where protective action recommendations would be formulated and where the Emergency Director would be located. Space is also provided for state and local agencies. The Emergency Operations Facility enables effective coordination of onsite actions with those off site, and provides a central location from which to direct all offsite actions by the licensee (e.g., monitoring, sampling, and dose assessment).

\subsubsection{Flow of Authority and Responsibility}

The responsibility and authority for licensee actions during a severe nuclear power plant accident start in the control room and then flow out as people arrive to man the Technical Support Center and the Emergency Operations Facility. The licensee will typically start transferring functions/ responsibilities/authorities out of the control room as soon as possible so that control room personnel can concentrate on bringing the situation under control. Staffing the Technical Support Center would typically require about 30 minutes. About one hour would be required to staff the Emergency Operations Facility. NRC staff initially attempting to contact licensee personnel must be aware of how long the accident has been under way to determine where their contacts should be made. The Emergency
Network System (ENS) and Health Physics Network (HPN) lines can be used to determine where the appropriate licensee representative is located.

\subsubsection{Emergency Planning Zones}

Plume and ingestion Emergency Planning Zones have been established around each nuclear reactor plant site. These Emergency Planning Zones were established so that the public can be notified to implement appropriate protective actions in an efficient and a timely manner in the event of a real emergency.

\subsubsection{Plume Exposure Emergency Planning Zone}

The plume exposure Emergency Planning Zone is that area requiring possible immediate action to reduce risk to the public in the event of an accident. It is an area approximately 10 miles in radius around the power plant. This size is based primarily on the following considerations:

1. Projected doses from the traditional design basis accidents would not exceed Environmental Protection Agency Protective Action Guide (PAG) levels outside the zone.

2. Projected doses from most core melt sequences would not exceed Protective Action Guide upper levels outside the zone.

3. For the worst-case core-melt sequences, immediate lifethreatening doses would generally not occur outside the zone. (For most hypothesized severe accidents, life- 
threatening doses are not predicted beyond 2 to 3 miles from the plant.)

4. Detailed planning within 10 miles provides a substantial base for expansion of response efforts in the event that this proves necessary.

It is unlikely that any immediate protective actions would be required beyond the plume exposure pathway Emergency Planning Zone. The zone is sufficiently large that protective actions within it provide for substantial reduction in early health effects (injuries or deaths) in the event of a worst-case core melt accident.

The boundaries of the plume Emergency Planning Zone take into account local features such as roads, rivers, lakes, peninsula, etc. that may extend the zone beyond 10 miles. The boundaries are selected to assure the existence of adequate evacuation routes as illustrated in Figures 5.4-2 and 5.4-3.

Extensive provisions are made for action within the Emergency Planning Zone. These include:

1. provisions for prompt decision making on protective actions for the public by all responsible parties,

2. development of evacuation plans,

3. provisions for informing the public of emergency plans and procedures (i.e., a public education program),

4. provisions for promptly (within 15 min of the time that state and local officials are notified) alerting and informing the public of the actions to be taken (e.g., siren system and radio messages),

5. provisions for maintaining $24-\mathrm{hr}$ communication between the licensee and state and local officials,

6. provisions for radiological monitoring in the event of an offsite radioactivity release, and

7. provisions for activating and maintaining emergency operations centers.

\subsubsection{Ingestion Pathway Emergency Planning Zone}

The ingestion pathway Emergency Planning Zone is the area in which plans exist for protecting the public from the consumption of food contaminated with radioactive material and for which there is considerable time (hours to days) for action to reduce risks. Thus, the level of preparation is much less in this Emergency Planning Zone than it is in the plume exposure pathway Emergency Planning Zone. Also, the preparations that are made for this Emergency Planning Zone are typically effected at the state level rather than at the local level.

In this Emergency Planning Zone, the concern is for the interdiction of foodstuffs rather than the avoidance of exposure to the plume itself. Protective actions within this zone would generally include the restriction of grazing animals to stored feed and restrictions on crop consumption and water usage. The area of this Emergency Planning Zone generally encompasses a 50 -mile radius around the plant site. The size of the ingestion exposure Emergency Planning Zone (about 50 miles in radius, which also includes the 10 -mile radius plume exposure 
Emergency Planning Zone) was selected for the following reasons:

1. The downwind range within which contamination will generally not exceed the Protective Action Guides is limited to about 50 miles from a power plant because of wind shifts during the release and travel periods.

2. There may be conversion of atmospheric iodine (i.e., iodine suspended in the atmosphere for long time periods) to chemical forms that do not readily enter the ingestion pathway.

3. Much of any particulate material in a radioactive plume would be deposited on the ground within about 50 miles of the facility.

4. The likelihood of exceeding ingestion pathway Protective Action Guide levels at 50 miles is comparable to the likelihood of exceeding plume exposure pathway Protective Action Guide levels at 10 miles.

Except for the most severe accidents, immediate action is not critical for food and agricultural produce because of the additional time involved when compared to the time frame associated with the plume exposure Emergency Planning Zone. Preplanned actions for the ingestion pathway Emergency Planning Zone ordinarily will be implemented by local agencies at the direction of state agencies.

\subsubsection{Response of State and Local Organ- zations}

\subsubsection{Emergency Response Plans}

States and local agencies have formulated written emergency response plans in response to NRC and Federal Emergency Management Agency (FEMA) requirements. These documents (1) describe the procedures that state and local officials will follow in the event of a nuclear power plant emergency and (2) list the responsibilities of each state and local agency involved. In most states, the authority to recommend protective actions to the public resides with local not state authorities.

\subsubsection{Public Notification}

The licensee must notify offsite state and local organizations responsible for implementing protective actions within 15 minutes of the declaration of an emergency. This permits offsite officials to make prompt protective action decisions, to provide an alerting signal (e.g., a siren), and to follow the signal by a message via the local radio station as to what actions the public should take. State and local officials have predetermined the criteria that they will use to make protective action decisions. These criteria should have been coordinated with the recommendations made to local agencies by the licensee.

In most cases, the specific protective action criteria for severe core damage accidents have been developed after consideration of plant and local conditions. For example, the areas planned to be evacuated may be confined to a valley around the site, or the specific evacuation sector boundaries may be determined by local roads. This delineation is done so that the local population can understand the evacuation instructions. 
As discussed in Sections 5.2.6 and 5.4.3, current NRC guidance calls for prompt offsite protective actions on detection of actual or imminent core damage (before dose assessment). Earlier guidance caused many state and local agencies to rely primarily on projected dose assessments. The currently envisioned role for dose assessment during an emergency is discussed in Section 5.2.8.

A flow chart showing the typical steps from detection of an event in the power plant control room (CR) to notification of the public is shown in Figure 5.4-4. Note that the offsite officials generally make decisions based on licensee recommendations, which are, in turn, based on criteria discussed and agreed to in advance. However, conditions that exist off-site (e.g., ice storm, blocked highway, bridge out, etc.) might alter implementation of the licensee's recommendation.

\subsubsection{Evacuation Time Estimates}

Licensees are required to develop evacuation time estimates for the plume-exposure Emergency Planning Zone (10-mile radius). These estimates are based on various models and must be used with caution. These models have not been validated against evacuations and are subject to large uncertainties.

Often, the evacuation time estimates are dominated by assumptions of how long it will take to notify people and for them to get ready to leave. Sometimes it is assumed that it will take an hour or more for preevacuation preparation. Actual experience has shown, however, that, if people are told and motivated to "go now," most will follow instructions and most will evacuate very rapidly. Except for special cases where there is a large population near the site (i.e., Zion and Indian Point) or where there is some special population (e.g., hospital patients), it should be possible to evacuate the area near the site in 1 hour or less. Because of the NRC's siting criteria, there is a limited population ( $<300$ people) within 2 miles of most sites. In these cases, the capacity of the local roads will be great enough so as not to delay an evacuation.

\subsubsection{Dose Projections and Field Monitoring}

Dose projection models used by offsite officials are generally similar to those used by the licensee and have the same limitations as other dose models. The only source of release estimates is from the licensee. Therefore, while offsite officials can confirm (check) licensee transport calculations, they must rely on the licensee's release estimates. Because of the complex processes involved in a core melt scenario, the source term (release) estimate would be highly uncertain early in an event. Offsite monitoring capabilities vary markedly, from excellent to marginal depending on the state's emphasis on developing an independent capability. In some situations, offsite officials rely on the licensee or the responding federal agencies (e.g., DOE, EPA, and NRC) for monitoring information.

\subsubsection{Location of Authority and Responsibility}

During the initial phase of the event, the specific location of the local offsite officials with the authority and responsibility to take action varies. The communications system between the licensee and offsite officials should accommodate this need. This is very site- and/or state-specific. In some cases, there are duty officers and 24-hr manned centers, and in others there are local police stations. Once the local emergency organization has been activated, it will establish a local Operations Center. It should be noted that at some sites there are 
several ( 2 to 20 ) local governments within the plume Emergency Planning Zone and that each might have a center.

At the state level, there are typically two levels of activity of interest: (1) an organization that is responsible for conducting technical assessments (e.g., dose assessment) of the situation and (2) decision makers (e.g., governor). These functions may be performed at two separate locations (centers). The NRC must coordinate its contact with offsite officials to avoid considerable confusion resulting from carrying out discussions with both groups. The licensee or state emergency plans should be consulted to determine the specific emergency organization's locations. 
Table 5.4-1 Sample initiating condition and examples of accompanying Emergency Action Levels

\begin{tabular}{|c|c|}
\hline Initiating condition No. 1 & Emergency Action Levels \\
\hline \multirow{4}{*}{$\begin{array}{l}\text { Known loss of coolant } \\
\text { accident (LOCA) greater } \\
\text { than makeup pump } \\
\text { capacity }\end{array}$} & $\begin{array}{l}\text { Low reactor water level (-134 in.) on level/pressure } \\
\text { recorder } 1 \mathrm{~B} 21-\mathrm{R} 623 \mathrm{~B} \text { panel } 1 \mathrm{H} 12-\mathrm{P} 601\end{array}$ \\
\hline & or \\
\hline & $\begin{array}{l}\text { High drywell pressure }(+1.8 \mathrm{lb}) \text { on pressure indicators } \\
\text { CM010 and/or CM021, panel } 1 \mathrm{PM} 06 \mathrm{~J} \\
\text { with }\end{array}$ \\
\hline & $\begin{array}{l}\text { Water level below (and failure to return to) top of active } \\
\text { fuel as indicated on fuel zone level indicator } 1 \mathrm{~B} 21- \\
\mathrm{R} 6210 \text {, panel } 1 \mathrm{H} 13-\mathrm{P} 601 \text { ( }-150 \mathrm{in} .+50 \text { in. range with " } 0 \text { " } \\
\text { corresponding to top of active fuel), following a time } \\
\text { delay of } 3 \mathrm{~min}\end{array}$ \\
\hline
\end{tabular}

\section{Table 5.4-2 Example of timing for BWR general emergency sequences}

\begin{tabular}{l|c|c|c|c}
\hline \multirow{2}{*}{} & \multicolumn{4}{|c}{ Timing of event (hr) } \\
\cline { 2 - 5 } & $\mathrm{TW}^{\mathrm{a}}$ & $\mathrm{TQUV}^{\mathrm{b}}$ & $\mathrm{AE}^{\mathrm{c}}$ & $\mathrm{S}_{2} \mathrm{~J}^{\mathrm{d}}$ \\
\hline Unusual event & 0.017 & & & \\
\hline Alert & 0.33 & & & 0.17 \\
\hline Site Area Emergency & 1 & & & 0.5 \\
\hline $\begin{array}{l}\text { General Emergency (protective actions } \\
\text { recommended) }\end{array}$ & 1 to 3 & 0.17 & 0.17 & $3+$ \\
\hline Core damage & 18 & 1 & 0.17 & 29 \\
\hline Containment failure & & & & \\
\hline$\quad$ Leak & 16 & 3 & 0.25 & \\
\hline$\quad$ Major & 21 & 5 & 3 & 20 \\
\hline \multicolumn{7}{|c|}{} \\
\hline
\end{tabular}

aReactor shutdown followed by loss of decay heat removal.

${ }^{b}$ Reactor shutdown followed by loss of ability to provide coolant water.

${ }^{c}$ Large loss of coolant and failure of system to replace water.

${ }^{d}$ Small loss of coolant and loss of long-term heat removal.

'Assuming isolation. 


\section{Table 5.4-3 Emergency class descriptions}

\begin{tabular}{l|l|l}
\hline \multicolumn{1}{c|}{ Class $^{\mathrm{a}}$} & \multicolumn{1}{c}{ Core status } & \multicolumn{1}{c}{ Radiation } \\
\hline Unusual Event & No threat to irradiated fuel & $\begin{array}{l}\text { No release above technical } \\
\text { specification (or annual limits) }\end{array}$ \\
\hline Alert & $\begin{array}{l}\text { Actual (or potential for) } \\
\text { substantial degradation of } \\
\text { safety }\end{array}$ & $\begin{array}{l}\text { Release is small fraction of } \\
\text { EPA Protection Action } \\
\text { Guidelines (PAGs) beyond the } \\
\text { site boundary }\end{array}$ \\
\hline $\begin{array}{l}\text { Site Area } \\
\text { Emergency }\end{array}$ & $\begin{array}{l}\text { Major failures of functions } \\
\text { needed for public protection }\end{array}$ & $\begin{array}{l}\text { Release is less than EPA PAGs } \\
\text { beyond the site boundary }\end{array}$ \\
\hline $\begin{array}{l}\text { General } \\
\text { Emergency }\end{array}$ & $\begin{array}{l}\text { Actual or imminent core } \\
\text { degradation }\end{array}$ & $\begin{array}{l}\text { Dose may exceed EPA PAGs } \\
\text { beyond the site boundary }\end{array}$ \\
\hline
\end{tabular}

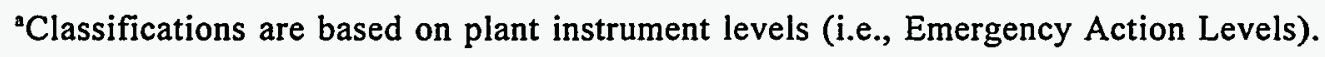




\section{Table 5.4-4 Emergency class response}

\begin{tabular}{|c|c|c|}
\hline Class $^{\mathrm{a}}$ & Plant action & Local and state agency action \\
\hline $\begin{array}{l}\text { Unusual } \\
\text { event }\end{array}$ & Provide notification & Be aware \\
\hline \multirow[t]{2}{*}{ Alert } & $\begin{array}{l}\text { Mobilize plant resources; man } \\
\text { centers (help for control room) }\end{array}$ & \multirow[t]{2}{*}{ Stand $b^{a}$} \\
\hline & $\begin{array}{c}\text { Activate Technical Support Center } \\
\text { (TSC) }\end{array}$ & \\
\hline \multirow[t]{3}{*}{$\begin{array}{l}\text { Site Area } \\
\text { Emergency }\end{array}$} & $\begin{array}{l}\text { Full mobilization; nonessential site } \\
\text { personnel evacuate }\end{array}$ & $\begin{array}{c}\text { Mobilize; Man emergency } \\
\text { centers and dispatch Monitoring } \\
\text { Team } \\
\end{array}$ \\
\hline & $\begin{array}{c}\text { Activate TSC, Operations Support } \\
\text { Center, and Emergency Operations } \\
\text { Facility }\end{array}$ & $\begin{array}{c}\text { Inform public, activate warning } \\
\text { system }\end{array}$ \\
\hline & $\begin{array}{l}\text { Dispatch monitoring team } \\
\text { Provide dose assessments }\end{array}$ & $\begin{array}{c}\text { Take protective actions in } \\
\text { accordance with PAGs or on an } \\
\text { ad hoc basis }\end{array}$ \\
\hline \multirow[t]{2}{*}{$\begin{array}{c}\text { General } \\
\text { Emergency }\end{array}$} & $\begin{array}{l}\text { Full mobilization; recommend } \\
\text { predetermined protective actions } \\
\text { (within } 15 \mathrm{~min} \text { ) after declaring } \\
\text { emergency }\end{array}$ & $\begin{array}{l}\text { Recommend predetermined } \\
\text { protective actions to the public } \\
\text { based on plant conditions }\end{array}$ \\
\hline & & $\begin{array}{l}\text { Precautionary evacuation } \\
\qquad(2 \text { to } 5 \text { miles })\end{array}$ \\
\hline
\end{tabular}

${ }^{3}$ The NRC will typically begin staffing its response centers at the Alert level and may be expected to go to "stand by" or "initial activation." 
Table 5.4-5 Emergency Class vs. Recognition Categories

\begin{tabular}{|c|c|c|c|c|}
\hline \multirow[b]{2}{*}{$\begin{array}{l}\text { Emergency } \\
\text { Class }\end{array}$} & \multicolumn{4}{|c|}{ Recognition Categories } \\
\hline & $\begin{array}{c}\text { Abnormal Rad Level or } \\
\text { Effluents } \\
\text { (All Op Modes) } \\
\end{array}$ & $\begin{array}{l}\text { Fission Product Barriers } \\
\text { Failure or Challenge } \\
\text { (PWR Op) }\end{array}$ & $\begin{array}{l}\text { Hazards/Other Conditions } \\
\text { Affecting Plant Safety (All } \\
\text { Op Models) }\end{array}$ & $\begin{array}{l}\text { System Malfunctions (Various Op } \\
\text { Modes - See NUMARC/NESP-007) }\end{array}$ \\
\hline NOUE & $\begin{array}{l}\text { Unplanned Gas or Liq. Release to } \\
\text { Environment }>2 X \text { TS for } \\
\geq 60 \text { min. } \\
\text { Unexpected Increase in Plant } \\
\text { Radiation } \\
\text { or Airbome Levels }\end{array}$ & $\begin{array}{l}\text { Any Loss or Potential Loss of } \\
\text { Containment. }\end{array}$ & $\begin{array}{l}\text { Natural \& Destructive Phenomena in } \\
\text { the Protected Area. } \\
\text { Fire in the P.A. Not Out W/ } 15 \text { Min } \\
\text { of Detection. } \\
\text { Release of Toxic or Flam. Gas } \\
\text { Detrimental to Plt Safe Ops. } \\
\text { Confirmed Security Event w/Potential } \\
\text { Degradation Safe Op. of Plt. } \\
\text { Other Conditions Warrant Declaration } \\
\text { by ED. }\end{array}$ & $\begin{array}{l}\text { Loss of Offsite Pwr to Essential Busses for } \\
>15 \text { min. } \\
\text { Inability to Reach Req'd S/D within T/S Limits. } \\
\text { Unplanned Loss of Safety Sys. Annunciators for } \\
>15 \text { min. } \\
\text { Fuel Clad Degradation. } \\
\text { RCS Leakage. } \\
\text { Unplanned Loss of All Communication } \\
\text { Capability. } \\
\text { Unplanned Loss Essen. DC Pwr. During Cold } \\
\text { S/D } \\
\text { or Refueling. } \\
\end{array}$ \\
\hline Alert & $\begin{array}{l}\text { Unplanned Gas or Liq. Release to } \\
\text { Environment }>200 \text { X TS for } \geq 15 \\
\text { min. } \\
\text { Major Damage to Irradiated Fuel } \\
\text { Loss of Water Level Uncovers Fuel } \\
\text { Outside RV. } \\
\text { Increase in Plt Rad or Airborne Levels } \\
\text { Impedes Sys Ops or Ability to } \\
\text { Maintain cold S/D. }\end{array}$ & $\begin{array}{l}\text { Any Loss or Potential Loss of } \\
\text { Either Fuel Clad or RCS. }\end{array}$ & $\begin{array}{l}\text { Natural \& Destructive Phenomena in } \\
\text { Plt Vital Areas. } \\
\text { Safety Sys Req'd for Safe S/D } \\
\text { Affected by Fire or Explosion. } \\
\text { Release of Toxic//Flammable Gas } \\
\text { Jeopardizes Sys Op, Safe S/D. } \\
\text { Security Event in P.A. } \\
\text { Control Room Evac Initiated. } \\
\text { Ohter Conditions Warrant Declaration } \\
\text { by ED. }\end{array}$ & $\begin{array}{l}\text { Loss of All On/Offsite AC to Essential Busses, } \\
\text { Cold S/D, Refueling. } \\
\text { Failure RPS to Scram \& Manual Scram } \\
\text { Successful. } \\
\text { Inability to Maintain Cold S/D. } \\
\text { Unplanned Loss All Safety Sys Annun., Transient } \\
\text { in Progress. } \\
\text { AC pwr Loss, Only One Source Feed Essen. } \\
\text { Busses, > } 15 \text { min. }\end{array}$ \\
\hline SAE & $\begin{array}{l}\text { Site Boundary Dose (actual or } \\
\text { projected) Exceds } 100 \mathrm{mRem} \text { W.B. } \\
\text { or } 500 \mathrm{mRem} \\
\text { Child Thyroid. }\end{array}$ & $\begin{array}{l}\text { Loss of Fuel Clad and RCS. } \\
\text { Potential Loss of Fuel Clad and } \\
\text { RCS. } \\
\text { Potential Loss of Fuel Clad or } \\
\text { RCS + Loss of Any Additional } \\
\text { Barrier. }\end{array}$ & $\begin{array}{l}\text { Security Event, PIt Vital Area. } \\
\text { CR Evac Initiated, Plt Control Cannot } \\
\text { Be Established. } \\
\text { Other Conditions Warrant Declaration } \\
\text { by ED. }\end{array}$ & $\begin{array}{l}\text { Loss of All AC pwr. } \\
\text { Failure EPS to Scram \& Manual Scram } \\
\text { Unsuccessful. } \\
\text { Loss of All Vital DC pwr. } \\
\text { Loss of Functions Req'd to Maintain Hot S/D. } \\
\text { Loss of RV Water Level Req'd to Cover Fuel. } \\
\text { Inability to Monitor Significant Transient in } \\
\text { Progress. }\end{array}$ \\
\hline GE & $\begin{array}{l}\text { Site Boundary Dose (actual or } \\
\text { imminent) Exceeds I Rem W.B. or } 5 \\
\text { Rem Child } \\
\text { Thyroid for Actual/Proj. Duration } \\
\text { Release, Actual Meteorology. }\end{array}$ & $\begin{array}{l}\text { Loss of Any Two Barriers and } \\
\text { Potential Loss of Third Barrier. } \\
\text { Any core melt sequence }\end{array}$ & $\begin{array}{l}\text { Security Event, Cannot. } \\
\text { Reach/Maintain Cold S/D. } \\
\text { Other Conditions Warrant Declaration } \\
\text { by ED. }\end{array}$ & $\begin{array}{l}\text { Prolonged Loss of AC pwr. } \\
\text { Failure RPS to Scram \& Manual Scram } \\
\text { Unsuccessful \& Extreme Challenge to Core } \\
\text { Cooling. }\end{array}$ \\
\hline
\end{tabular}

\section{Environment $>200 \times$ TS for $\geq 15$}

Major Damage to Irradiated Fuel

Level Uncovers Fuel

Impedes Sys Ops or Ability to

Site Boundary Dose (actual or

Exceds $100 \mathrm{mRem}$ W.B.

or 500 mRem

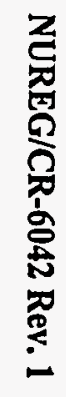

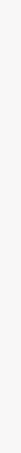




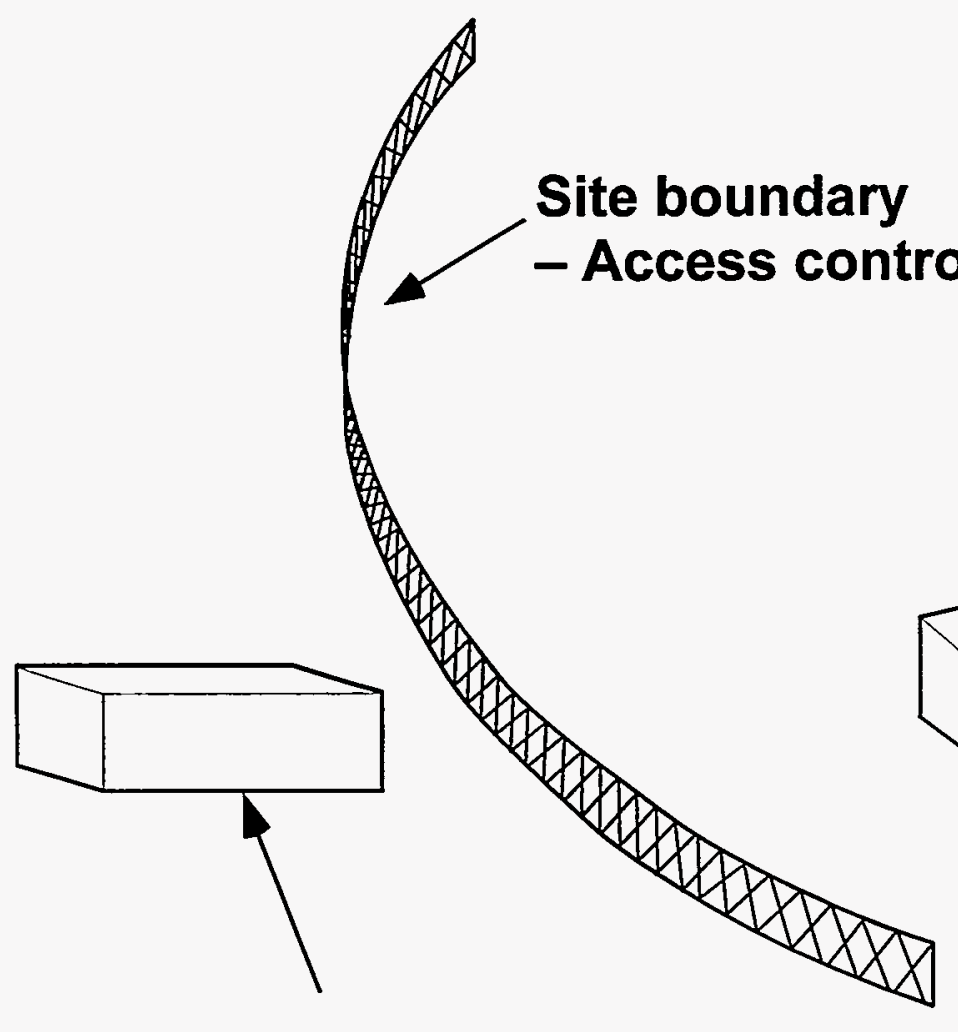

Emergency Operations Facility

- Total licensee response

- Interface with off-site officials

- Off-site monitoring

- Protective action decision making
Technical Support

\section{Center}

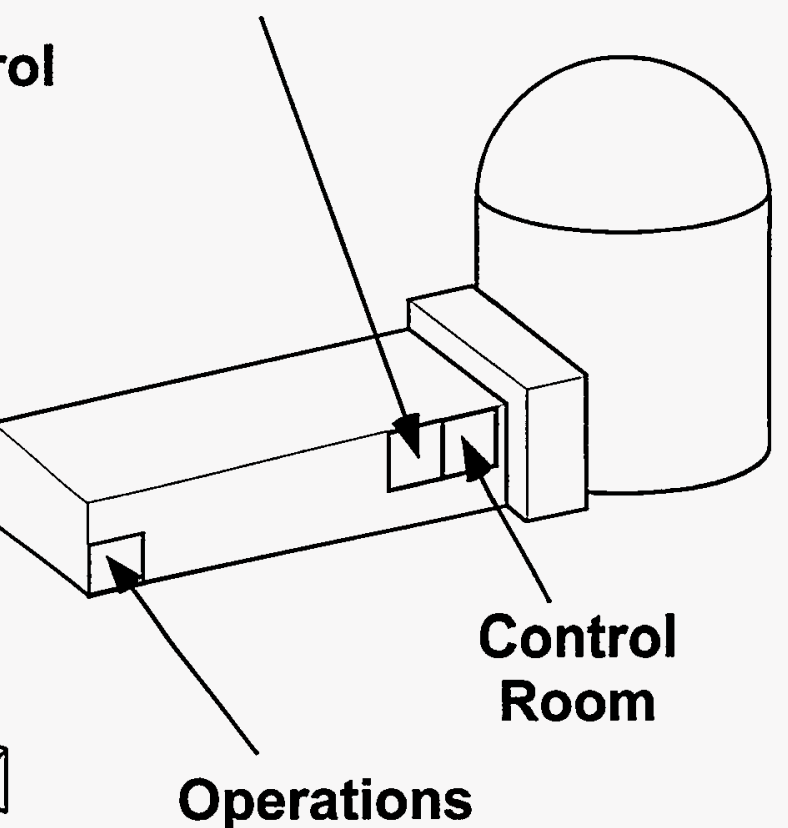

Center

Figure 5.4-1 Relative locations of licensee emergency response centers 


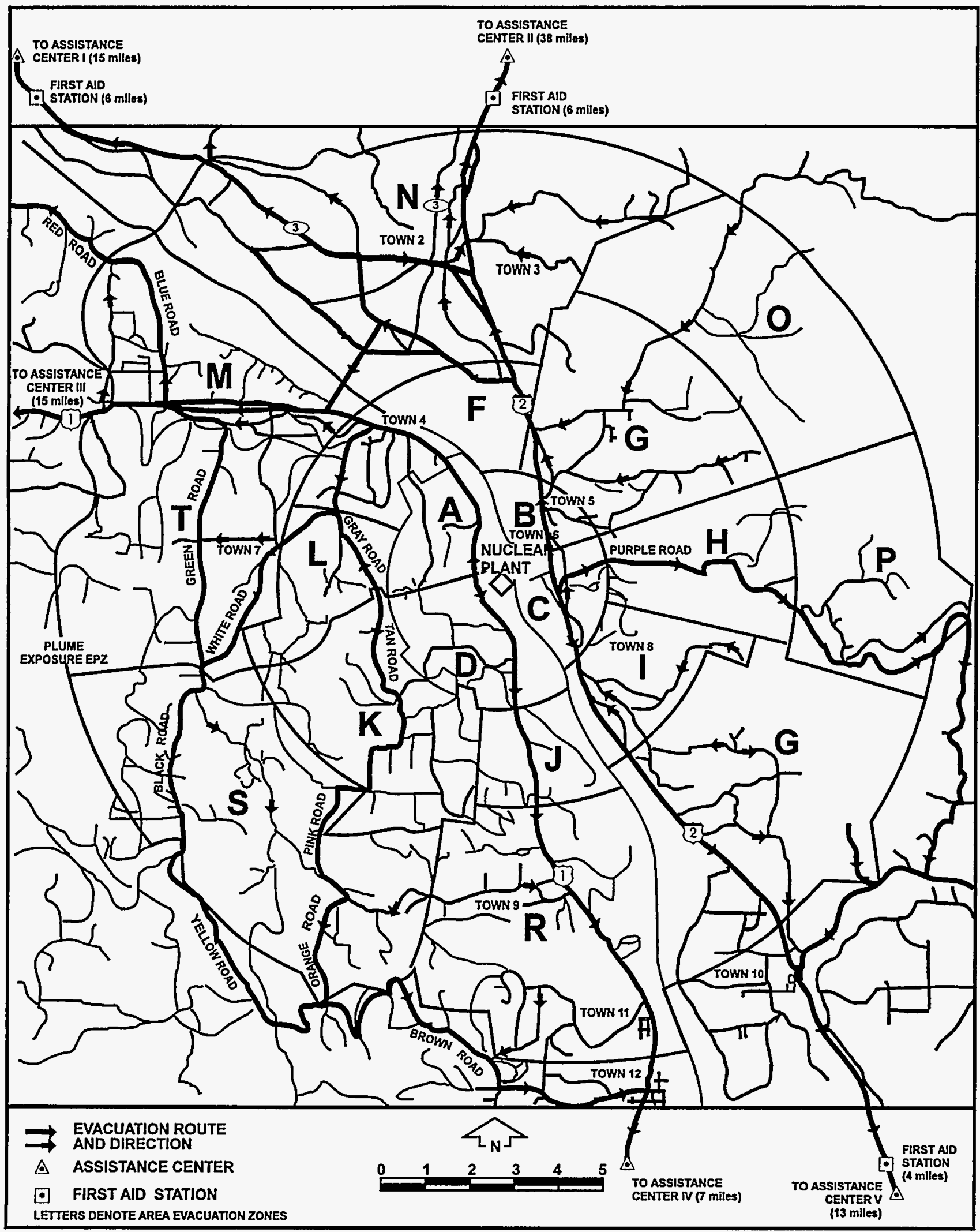

Figure 5.4-2 Example of a plume emergency planning zone with boundaries and evacuation routes determined by roads 


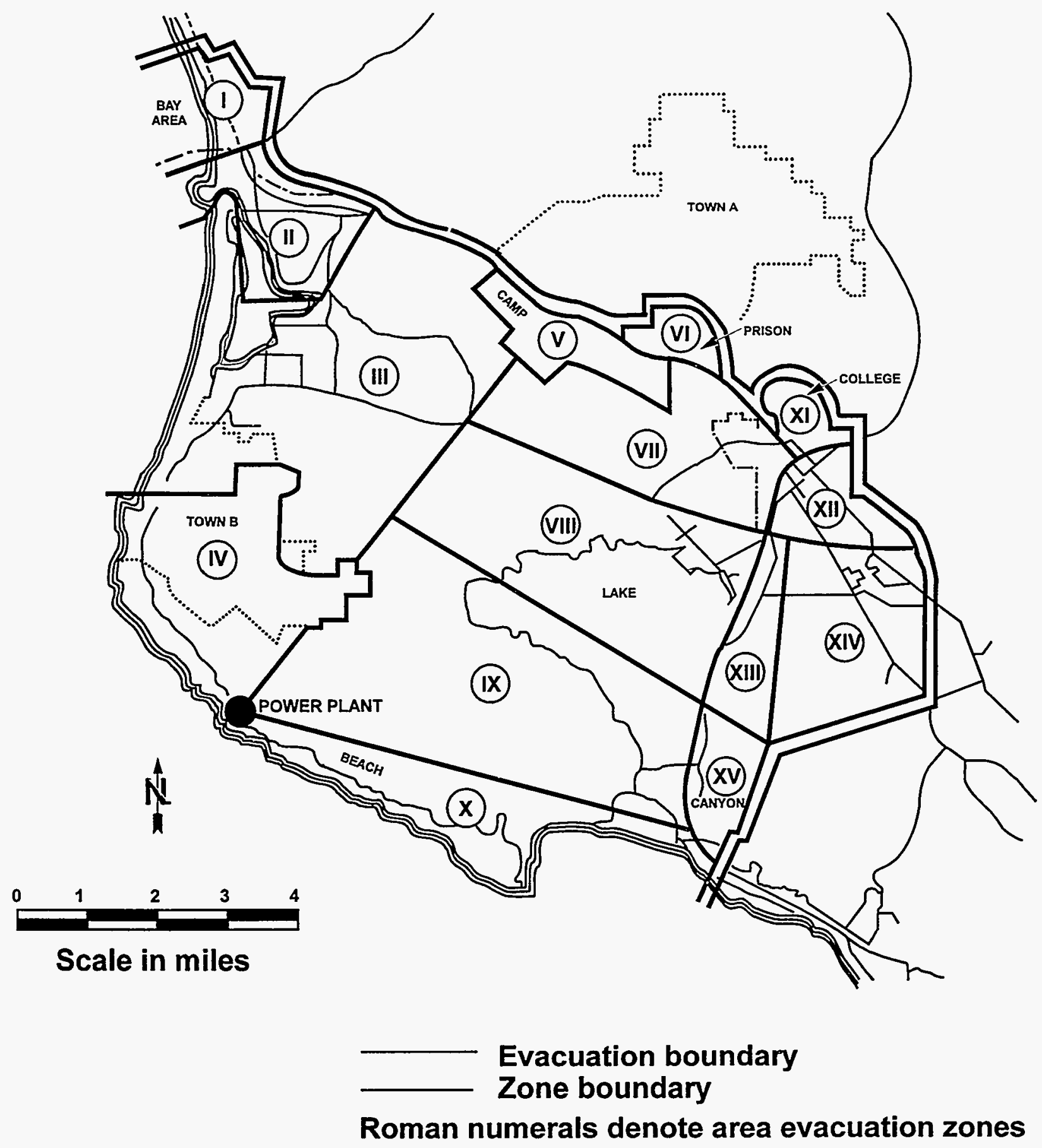

Figure 5.4-3 Example of a plume emergency planning zone (boundaries are determined by natural features) 


\section{EVENT DETECTED BY CONTROL ROOM STAFF}

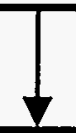

EVENT IS CLASSIFIED, AND EMERGENCY IS DECLARED

OFF-SITE OFFICIALS NOTIFIED ABOUT RECOMMENDATIONS OF PROTECTIVE ACTION

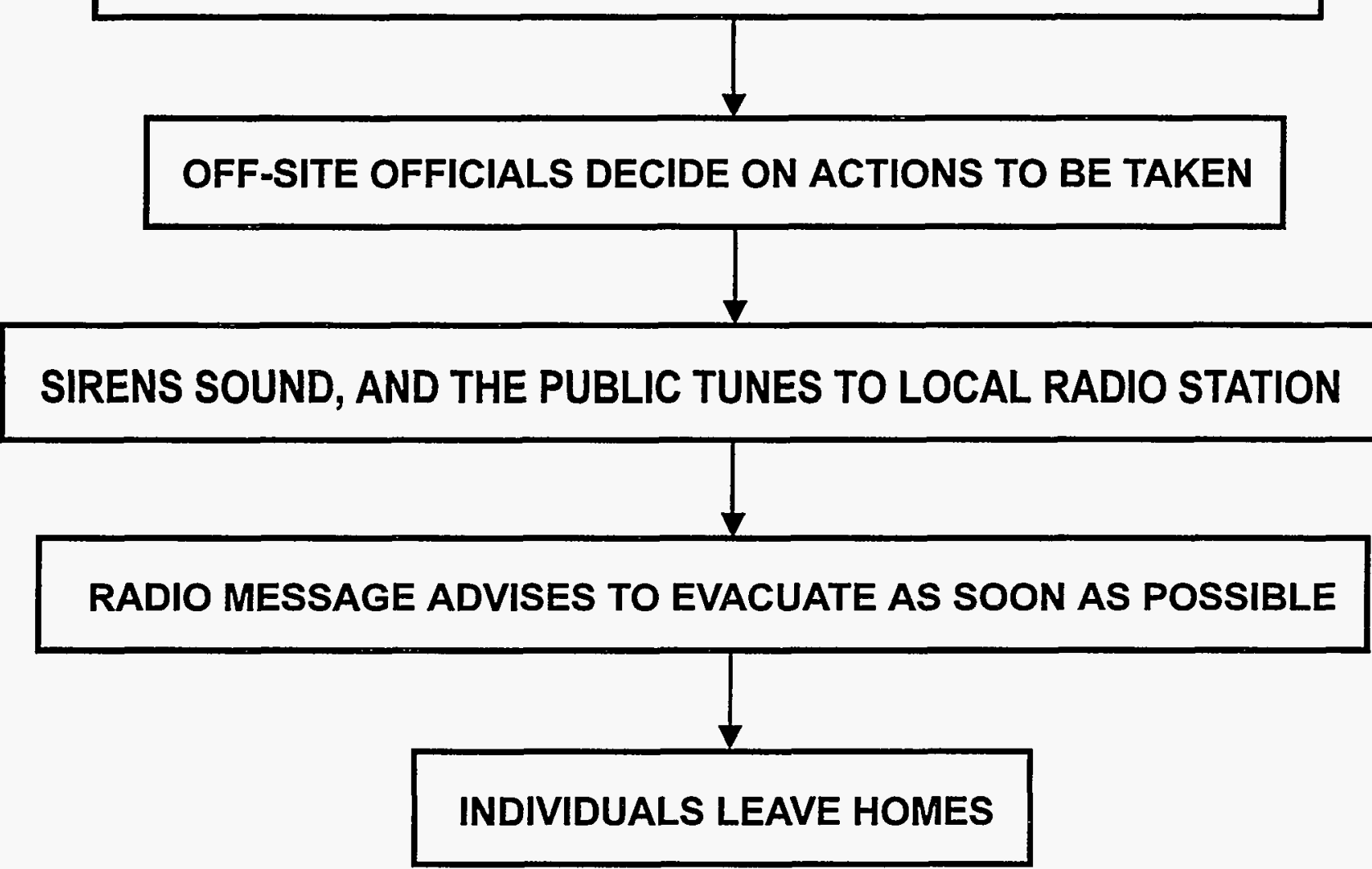

Figure 5.4-4 Flowchart showing steps from detection of a general emergency event in the control room to public evacuation 


\section{References for Section 5.4}

1. U.S. Nuclear Regulatory Commission and Federal Emergency Management Agency, "Criteria for Preparation and Evaluation of Radiological Emergency Response Plans and Preparedness in Support of Nuclear Power Plants," NUREG-0654, FEMA-REP-1, Rev. 1, November 1980.

2. H. E. Collins, B. K. Grimes, and F. Galpin, "Planning Basis for the Development of State and Local Government Radiological Emergency Response Plans in Support of Light Water Nuclear Power Plants," NUREG0396/EPA 520/1-78-016, 1978.

3. D. C. Aldrich, P. McGrath, and N. C. Rasmussen, "Examination of Offsite Radiological Emergency Protective Measures for Nuclear Reactor Accidents Involving Core Melt," NUREG/CR-1131, SAND78-0454, 1978.
4. U.S. Nuclear Regulatory Commission Information Notice (IN) 83-28, "Criteria for Protective Action Recommendations for General Emergencies," May 1983.

5. U.S. Nuclear Regulatory Commission, "Clarification of TMI Action Plan Requirements: Requirements for Emergency Response Capability," NUREG-0737, Supp. 1, No. 1, Washington, D.C., January 1983.

6. T. J. McKenna, et al., "Pilot Program: NRC Severe Reactor Accident Incident Response Training Manual," NUREG-1210, Volumes 15, December, 1990.

7. U.S. Nuclear Regulatory Commission, "RTM96, Response Technical Manual," NUREG/BR-0150, Revision 4, March 1996. 


\section{Appendix 5A Protective Action Guides}

A Protective Action Guide (PAG) is the projected dose to reference man, or other defined individual, from an unplanned release of radioactive material at which a specific protective action to reduce or avoid that dose is recommended. The Environmental Protection Agency (EPA) and Food and Drug Administration (FDA) have established PAGs that are applicable to severe reactor accidents. These PAGs must be considered in licensees emergency plans and decisions as discussed in Sections 5.3 and 5.4.

Protective actions whose implementation early in an accident (before or shortly after an accidental release of radionuclides to the environment) would be crucial to their effectiveness include evacuation, sheltering, improvised respiratory protection, and the use of potassium iodide to block iodine uptake by the thyroid. These protective actions are discussed in Section 5.3. The Environmental Protection Agency has established PAGs for early protective actions. The EPA PAG levels are low enough to meet the secondary radiation protection objective of reducing doses. At the PAG levels, no health effects would be detectable, even for sensitive populations such as pregnant women.

There are currently two different sets of Environmental Protection Agency PAGs in use for early protective actions. The older PAGs, which were promulgated in 1980 , are summarized in Table 5A-1. The newer
PAGs were published in 1991 and are summarized in Table 5A-2. Reactor licensees continue to use the older PAGs until they revise their Emergency Plans to adopt new PAGs.

As indicated in Table 5A-1, the 1980 PAGs are based on the external gamma dose from plume exposure and the committed dose to the thyroid from inhalation. The 1991 PAGs are replace projected whole body dose with the sum of the effective dose equivalent resulting from external exposure to the plume and the effective dose equivalent from inhalation. For reactor accidents, the change from the 1980 PAGs to the 1991 PAGs should not have any impact on protective action decisions because the thyroid dose is the controlling factor and the PAG levels for projected thyroid dose does not change.

It is important to emphasize that protective action guides are based on projected doses-future doses that can be avoided by the specific protective action being considered. Doses incurred prior to initiation of the protective action should not normally be included. Similarly, in considering early protective actions such as evacuation or sheltering, doses that could be avoided by a intermediate or long term protective actions such as control of contaminated food and water are excluded.

The Food and Drug Administration has established protective action guides for intermediate and late phase food and agricultural exposure pathways. These are summarized in Table 5A-3. 
Table 5A-1 Environmental Protection Agency recommended protective actions $^{a}$ to reduce whole-body and thyroid dose from exposure to a gaseous plume

\begin{tabular}{|c|c|c|c|}
\hline \multicolumn{2}{|c|}{$\begin{array}{c}\text { Projected Dose (rem) to } \\
\text { the Population }\end{array}$} & Recommended actions $^{b}$ & Comments \\
\hline $\begin{array}{l}\text { Whole Bodyc } \\
\text { Thyroid }\end{array}$ & $\begin{array}{l}<1 \\
<5\end{array}$ & $\begin{array}{l}\text { No planned protective actions } \\
\text { State may issue an advisory to } \\
\text { seek shelter and await further } \\
\text { instructions. } \\
\text { Monitor environmental radiation } \\
\text { levels. }\end{array}$ & $\begin{array}{l}\text { Previously } \\
\text { recommended } \\
\text { protective actions } \\
\text { may be considered } \\
\text { or terminated. }\end{array}$ \\
\hline $\begin{array}{l}\text { Whole Body } \\
\text { Thyroid }\end{array}$ & $\begin{array}{l}1 \text { to }<5 \\
5 \text { to }<25\end{array}$ & $\begin{array}{l}\text { Seek shelter as a minimum. } \\
\text { Consider evacuation. Evacuate } \\
\text { unless constraints make it } \\
\text { impractical. } \\
\text { Monitor environmental radiation } \\
\text { levels. } \\
\text { Control access. }\end{array}$ & $\begin{array}{l}\text { If constraints exist, } \\
\text { special } \\
\text { consideration } \\
\text { should be given } \\
\text { for evacuation of } \\
\text { children and } \\
\text { pregnant women. }\end{array}$ \\
\hline $\begin{array}{l}\text { Whole Body } \\
\text { Thyroid }\end{array}$ & $\begin{array}{l}5 \text { and above } \\
25 \text { and } \\
\text { above }\end{array}$ & $\begin{array}{l}\text { Conduct mandatory evacuation. } \\
\text { Monitor environmental radiation } \\
\text { levels and adjust area for } \\
\text { mandatory evacuation based on } \\
\text { these levels. } \\
\text { Control access. }\end{array}$ & $\begin{array}{l}\text { Seeking shelter } \\
\text { would be an } \\
\text { alternative if } \\
\text { evacuation were } \\
\text { not immediately } \\
\text { possible. }\end{array}$ \\
\hline
\end{tabular}

${ }^{2}$ EPA Manual of Protective Action Guides and Protective Actions for Nuclear Incidents, 1980.

${ }^{b}$ These actions are recommended for planning purposes. Protective action decisions at the time of the incident must take existing conditions into consideration.

'Effective dose from external sources (cloud and ground) is approximately equal to whole body dose.

${ }^{\mathrm{d}}$ At the time of the incident, officials may implement low-impact protective actions in keeping with the principle of maintaining radiation exposures as low as reasonably achievable. 


\section{Table 5A-2 Environmental Protection Agency recommended protective actions $^{a}$ to reduce external gamma dose from plume exposure and committed dose to the thyroid from inhalation}

\begin{tabular}{c|c|c}
\hline $\begin{array}{c}\text { Projected Dose to the } \\
\text { Population }\end{array}$ & Recommended actions & \multicolumn{1}{c}{ Comments } \\
\hline $1-5 \mathrm{rem}^{\mathrm{c}}$ & $\begin{array}{c}\text { Evacuation }^{\mathrm{d}} \\
\text { (or sheltering) }\end{array}$ & $\begin{array}{l}\text { Evacuation (or for } \\
\text { some situations, } \\
\text { sheltering }{ }^{\mathrm{b}} \text { should } \\
\text { normally be initiated at } \\
\text { one rem. }\end{array}$ \\
\hline $25 \mathrm{rem}^{\mathrm{d}}$ & Administration of stable iodine & $\begin{array}{l}\text { Requires approval of } \\
\text { state medical officials. }\end{array}$ \\
\hline
\end{tabular}

- U.S. Environmental Protection Agency, Manual of Protective Action Guides and Protective Actions for Nuclear Incidents, EPA 400-R-92-001, October 1991.

b Sheltering may be the preferred protective action when it will provide protection equal to or greater than evacuation, based on consideration of factors such as source term characteristics, and temporal or other site-specific conditions.

c The sum of the effective dose equivalent resulting from exposure to external sources and the committed effective dose equivalent incurred from all significant inhalation pathways during the early phase.

Committed dose equivalents to the thyroid and to the skin may be 5 and 50 times larger, respectively.

d Committed dose equivalent to the thyroid from radioiodine.

\section{Table 5A-3 Food and Drug Administration protective action guides}

\begin{tabular}{|c|c|c|}
\hline Organ & FDA PAG dose (rem) & Protective Action \\
\hline Whole body (bone) & $0.5-5$ & \multirow{3}{*}{$\begin{array}{l}\text { At lower projected dose, use of } \\
\text { grazing land should be } \\
\text { restricted. At higher projected } \\
\text { dose, contaminated milk should } \\
\text { be impounded. }\end{array}$} \\
\hline Thyroid & $1.5-15$ & \\
\hline Other body organs & $0.5-5$ & \\
\hline
\end{tabular}


10 CFR 100, 1.2-6, 1.2-6, 1.3-3, 1.4-1

10 CFR 140, 1.2-4

10 CFR 50

Appendix A, 1.3-5

Appendix B, 1.3-7

Appendix $\mathrm{J}, 4.1-5$

Appendix K, 1.3-13, 1.4-3, 1.5-1

Appendix R, 1.3-9

Section 50.46, 1.3-13

Section 50.61, 1.3-2

10 CFR 51, 1.3-11

accident

impacts off site, 5.0-2

initiation, 3.1-3

initiating events (initiators), 1.1-4, 1.4-1

management, 1.1-4

prevention, 1.1-3, 1.1-3, 1.3-1

progression in the reactor vessel, 3.0-1

at low power and shutdown, 1.A-7

acute health effects, 5.2-2

adequate protection, 1.2-1, 1.2-5

administratively confidential, 1.2-4

Advisory Committee on Reactor Safeguards

(ACRS), 1.1-2, 1.2-2, 1.2-3, 1.2-8, 1.2-9,

$1.3-1,1.3-3,1.3-4,1.5-4$,

aerosol generation, $4.4-2$

alert, 5.4-5

alpha mode containment failure, 3.6-4

American Federation of Labor--Congress of

Industrial Organization, 1.2-5

American National Standards Institute, 1.3-8

American Physical Society, 1.5-3

American Society for Testing and Materials,

1.3-1

anticipated transients without scram

(ATWS), 2.4-1, 2.B-1

importance to $\mathrm{CDF}, 2.5-24$

rule, 2.4-5, 2.B-10

antitrust laws, 1.2-1

Athens, Alabama, 1.6-3, 1.6-3

Atmospheric Release Advisory Capability

(ARAC) program, 5.2-8

Atomic Energy Act of 1946, 1.01-1, 1.1-2, 1.2-1

Atomic Energy Act of 1954, 1.2-1, 1.2-5, 1.3-14

Atomic Energy Commission (AEC), 1.1-2

Atomic Safety and Licensing Board, 1.2-2, 1.3-7

authority and responsibility, 5.4-11 automatic depressurization system (ADS), 3.7-5

auxiliary feedwater system, 1.3-10

Backfit Rule, 2.4-8

beyond-design-basis accidents, 1.0-2, 1.3-9, 1.5-1, 4.2-1

Big Rock Point, 4.1-1

boiloff of water in core region, 3.2-2

bottom head failure, 3.7-24

bottom head penetrations, 3.7-21

Brookhaven National Laboratory (BNL),

1.2-4, 1.3-2

Browns Ferry 3, 2.4-3, 2.B-4

fire, $1.0-2,1.6-1$

Browns Ferry Nuclear Power Plant, 1.3-8

BWR

ATWS behavior, 2.B-13

bottom head failure modes, 3.7-21

containment venting, 5.1-7

facilities, 3.7-2

features, 3.7-3

Mark I containments, 4.1-2

Mark I liner failure, 4.7-2

Mark II containments, 4.1-3

Mark III containments, 4.1-3

cable-spreading room, 1.6-2

Calvert Cliffs, 1.3-11

Cardox, 1.6-2

centers of population, 1.2-3

chemical reactions, $1.4-3$

Chernobyl, 1.0-1, 2.3-1

long-term health effects, 5.3-14

source term, 5.1-9

Chicago, 1.2-2

China syndrome, 1.3-1-1.3-4, 2.4-2, 4.4-1

chronic (latent) effects, 5.2-2

cladding, 1.1-5, 1.2-7, 1.4-3

damage, 3.3-3

oxidation, 3.3-1

class summaries and NUMARC recognition categories, 5.4-6

$\mathrm{CO} 2,1.6-2$

coarse mixing, 3.6-1

cold war, 1.2-1

combustible gases, 4.4-2

common-mode failures, 1.3-6, 1.6-1 
common cause failures, 1.A-12

Commonwealth Edison, 1.2-2

condensate booster pumps, 1.6-5

condensate pumps, 1.6-6

conditional containment failure probability

(CCFP), 4.2-3

Connecticut Yankee, 1.2-9

Consolidated Edison, 1.2-2

construction permit, 1.2-1, 1.2-2, 1.2-4

containment, 1.1-2-1.1-5, 1.2-2, 1.2-3, 1.2-5,

1.2-7, 1.2-9

air-cleaning systems, 1.2-8

breached, 1.5-1

bypass, $1.5-1,2.5-26$

challenges, $4.2-1$

design bases, 4.1-1

design criteria, 4.1-4

early failures perspectives, $2.5-26$

failure, 1.2-5, 1.5-3, 4.2-3

frequency (CFF), 4.2-3

modes, 4.1-6

probabilities, $4.5-3$

heat removal, 1.2-8, 4.1-6

integrity, 1.3-3

late failures perspectives, $2.5-26$

leakage, 4.1-5, 4.1-5

sprays, 1.1-4, 1.2-8, 5.1-6

types, 4.1-1

venting, 4.2-5

control air, 1.6-5

control rod drive, $1.6-6$

control room , 5.4-7

core, 1.2-6

-concrete interactions , 4.4-1

catcher, 1.3-3

cooling task force (CCTF), 1.3-4, 1.3-4

damage

due to oxidation, 3.3-3

frequency (CDF), 2.5-14, 2.6-5

inventories, 1.0-1

melt accidents, 1.5-3

meltdown, 1.2-4, 1.3-3, 1.3-4

melting, 1.5-1

plate structure, 3.7-15

uncovering and heatup , 3.2-2

credit for engineered safety features, 1.2-8

crosstie, 1.6-6 current licensing basis (CLB), 2.6-4

Davis-Besse, 1.3-10, 2.A-1

debris

coolability, 3.5-6

interactions with lower plenum water, 3.7-19

movement past the BWR core plate, 3.7-15

on TMI-2 lower head, 3.5-3

pours from vessel, $4.7-3$

spreading, 4.7-6

Decatur, Alabama, 1.6-1

decay heat, 1.4-2, 1.4-3, 1.6-5

defense-in-depth, 1.1-3-1.1-4, 2.6-4, 2.6-6

Department of Defense, 1.5-2

depressurize the reactor, 1.6-5

design-basis

accident (DBA), 1.0-2, 1.2-71.4-1

analysis conservatisms , 1.4-3

perspectives, $1.4-1$

design

criteria, 1.2-3

features, $3.1-3$

Detroit Edison, 1.2-2, 1.2-3

Detroit, 1.2-2

direct containment heating (DCH), 4.5-1

resolution, 4.5-3

dispersion of effluents, 5.2-5

dispersion of the Chernobyl release, 5.2-9

Division of Naval Reactors of the AEC, 1.1-3

dose

pathways, 5.2-3

projections and field monitoring, 5.4-11

versus distance, 5.2-7

doses, 5.2-2

double-ended guillotine break, 1.4-2

Dresden 1, 1.2-2, 1.2-3

Dresden 2, 1.2-9, 1.3-4

Dresden 3 BWR, 1.3-3

dry-chemical fire extinguishers, 1.6-3

drywell-wetwell configuration, 5.1-5

drywell flooding, 4.7-10

Duquesne Light Company, 1.1-3

early protective action decisions during the

TMI-2 accident, 5.3-9

earthquakes, 1.3-8 
emergency core cooling system, 1.2-9, 1.3-5, 1.4-3

acceptance criteria , 1.0-2, 1.4-4

rulemaking, 1.3-12

effects of neutron radiation, 1.3-1

Electric Power Research Institute (EPRI), 2.2-3

emergency

action levels, 5.4-4

classification system , 5.4-5

detection and classification, 5.4-3

operating procedures, 5.4-3

operations facility, 5.4-8

plan implementation procedures (EPIPs), 5.4-5

plans, 1.1-4

preparedness, 5.4-2

procedure guidelines, $2 . \mathrm{B}-18$

response

centers, 5.4-7

improvements, 2.2-5

plans, 5.4-10

Energy Reorganization Act of 1974, 1.0-2, $1.3-13$

Energy Research and Development

Administration (ERDA), 1.3-14

engineered safety features (ESFs), 1.2-6, 1.2-9, 1.4-4

Enrico Fermi, 1.2-2, 1.2-3

entrapment scenarios, 5.3-6

environmental and dynamic effects, 1.3-9

Epler, E. P., 2.4-2

Ergen, William, 1.3-4

errors of commission, 1.A-15

eutectic formation and relocation, 3.7-12

evacuation, 1.1-4, 5.3-3

risks, 5.3-5

time estimates, 5.4-11

event trees, 1.5-2, 1.A-10

ex-vessel steam explosions, $4.5-1$

exclusion area, 1.1-2, 1.1-4-1.1-5, 1.2-7

exclusion distance, 1.1-2

explicitly dependent events, 1 .A-12

external events, 1.A-4, 1.A-16

external water cooling, 3.7-24

failure of the reactor pressure vessel, 1.3-1

fan coolers, 1.1-4 fast breeder reactor, 1.2-3

fault trees, $1.5-2,1 . \mathrm{A}-10,1 . \mathrm{A}-16$

FCI scenarios, 3.6-3

Federal Emergency Management Agency

(FEMA), 2.2-5

filters, 4.4-2

final criteria, 1.3-12

fire analyses, 1.A-16

fire protection, 1.3-8

fires, 1.3-8

fission products, 1.2-7

release, $1.2-6$

floods, 1.3-8

flow blockage, 3.4-2

flow of authority and responsibility, 5.4-8

Foster Wheeler Corporation, 1.3-1

fuel liquefaction, 3.4-1

fuel pellets, 1.1-5

fully and currently informed, 1.2-4

gas evolution, 4.5-2

gas generation, 4.4-2

Gaussian plume model, 5.2-6

general design criteria, 1.0-2, 1.3-4, 1.3-10

General Electric, 1.3-3

general emergency, 5.4-6

Generic Letter 88-20 objectives, 2.5-13

hazards of nuclear power, 1.0-1

health effects, 5.2-2

hearings, 1.2-5

heroic acts, 1.A-15

high pressure coolant injection (HPCI), 1.6-5

high pressure melt ejection (HPME), 4.5-2

high temperature reactor experiment (HTRE-3), 2.4-2

history, 1.0-1

hotspot in TMI-2 lower head, 3.5-4

human-caused external initiators, 1.A-7

human factors, 1.A-15

hurricanes, 1.3-8

hydrogen, 1.2-7, 1.4-3

hydrogen bomb, 1.2-1

hydrogen combustion pressures and

temperatures, 4.A-2 
Ice condenser, 5.1-6

containments, 4.1-2

Idaho National Engineering Laboratory (INEL), 1.3-12

implementation and monitoring program, 2.6-9

in-vessel fuel-coolant interactions, 3.6-1

indemnity legislation, 1.2-4

independent barrier, 1.2-5

independent versus dependent failures, 1.A-11

Indian Point 1, 1.2-2-1.2-3, 1.3-2-1.3-3

individual plant examination (IPE), 2.2-7

industry degraded core rulemaking (IDCOR),

2.2-7

ingestion pathway emergency planning zone,

5.4-9

initial heatup of uncovered fuel, 3.2-4

inspectors , 2.2-2

Institute of Nuclear Power Operations (INPO),

2.2-3

interfacing system LOCA importance to CDF,

2.5-24

interim acceptance criteria, 1.3-12

internal flood importance to CDF, 2.5-24

internal initiating events, 1.A-4

intervention petitions, $1.2-5$

IPE, 4.2-4

jet breakup, 4.5-2

Joint Committee on Atomic Energy (JCAE),

$$
1.1-2,1.2-4-1.2-5
$$

Knolls Atomic Power Laboratory (KAPL), 1.1-3 labor unions, 1.2-5

large dry containments, 4.1-1

large early release frequency (LERF), 2.6-5

leak rate, 1.2-9, 1.4-4

from the containment, 1.2-6

Levine, Saul, 1.5-2-1.5-2

Lewis, Harold, 1.5-3

Libby, 1.2-3

liquefaction, 3.4-1

long-term health effects from the Chernobyl accident, 5.3-14

loss of coolant accident (LOCA), 1.2-7, 1.4-2

importance to $\mathrm{CDF}, 2.5-24$

low population zone, 1.1-4-1.1-5, 1.2-7

lower head Failure, 3.5-4
Modes Analyzed for TMI-2, 3.5-5

lower plenum dryout, 3.7-20

Lyons, Kansas, 1.3-14

main-steam-line isolation valves, $1.6-6$

Manhattan Project, 1.1-2

manual rod insertion, 2.B-16

Mark I containment

design, 4.7-3

failure, $4.7-8$

liner failure study, $4.7-4$

maximum credible accident, 1.2-6

melt

discharge from vessel, 3.6-6

ejection, 4.5-1

flow scenarios, 3.5-2

meltdown accident, 1.2-5, 1.2-6

melting, 3.4-1

metal-water reactions, $1.2-7,1.3-5$

meteorological conditions, 1.2-6, 1.4-4, 1.4-5, 1.5-1

meteorology, 5.2-4

metropolitan siting, 1.2-9

molten pours onto the lower head, 3.5-1

motor-operated valves, $1.3-10$

multi-unit sites, 1.3-10

multiple

barriers, 1.1-4

failures, 1.0-2

versus single failures, 1.A-9

Murray, Thomas, 1.2-4, 1.2-4

National Aeronautics and Space Administration (NASA), 1.3-7, 1.5-2

National Environmental Policy Act (NEPA), 1.3-11

National Environmental Policy Act of 1969, 1.0-1

natural circulation during core degradation, $3.3-4$

during Stage 4, 3.4-5

naturally occurring events, $1 . \mathrm{A}-7$

Navy, 1.1-3

code, 1.3-1

net positive suction head (NPSH), 1.3-6, 4.2-1

New York City, 1.2-2, 1.2-9

nil ductility transition, 1.3-1 
Nine Mile Point, 1.2-9

Nixon, 1.3-11, 1.3-14

notice of a proposed rule, 1.2-6

notice of violation of NRC requirements, 1.6-4

Nuclear Regulatory Commission (NRC), 1.0-1,

1.3-14

commissioners, $1.5-4$

Office of Inspection and Enforcement, 1.6-4

restructuring, 2.2-2

nuclear-powered submarines, 1.1-3

Nuclear Safety Analysis Center (NSAC), 2.2-3

nuclear safety, 1.6-1

Nuclear Utility Management and Resources

Council (NUMARC), 2.2-3

NUREG-0460, 2.4-3

NUREG-1150, 2.2-6, 4.2-4, 4.5-3

Oak Ridge National Laboratory (ORNL), 1.3-4

Office for Analysis and Evaluation of

Operational Data, 2.2-2

offsite dispersion, 5.2-2

offsite health effects, $5.1-3$

operating license, 1.2-1, 1.2-2, 1.2-4

Operations Support Center, 5.4-7

operator training and licensing, 2.2-4

oxidation front, 3.3-1

Oyster Creek, 1.2-9

passive component failures, $1 . \mathrm{A}-14$

Pastore, 1.5-1

peaceful uses of nuclear energy, 1.2-1

peak cladding temperature, $1.4-3$

pipe whipping, 1.3-10

Piqua, Ohio, 1.2-3

plant-internal fires, 1.A-5

plant operating experience, $1.2-3$

plume concentrations, $5.2-5$

plume exposure emergency planning zone, 5.4-8

polyurethane, 1.6-1

population center distance, 1.2-8

potassium iodide (KI), 5.3-8

Power Reactor Development Company (PRDC),

1.2-3

PRA Policy Statement, 2.6-1

PRDC

construction permit, $1.2-5$ financial qualifications, 1.2-5

President's Commission, 2.2-1

pressure-suppression pool, 1.6-5.

pressure rise in containment, 4.5-2

pressurized thermal shock (PTS), 1.3-2

Price-Anderson Act, 1.0-1, 1.2-4, 1.3-2

probabilistic risk assessment (PRA), 1.5-2

probability, 1.2-4

estimates, 1.2-5

protective action, 5.3-2

guidance, 5.3-3

guides, 5.4-5

recommendations, 5.4-6

following the Chernobyl accident, 5.3-10

public

hearing, 1.2-1

notification, $5.4-10$

report, $1.2-4$

publicly available, 1.2-2

publicly document, 1.2-2

qualification of reactor operators, 1.2-2

qualitative safety goals, 2.4-12

quality assurance, 1.3-7

quantitative safety goals, 2.4-12

radiation

dose, $1.2-8,5.2-2$

inversion, 5.2-4

protection objectives, $5.3-3$

sickness, 5.2-3

radioactive waste disposal, 1.3-14

radionuclide inventories, 5.1-2

radionuclide release, 1.1-4, 4.2-3, 1.5-1

Rasmussen, Norman C., 1.5-2, 1.5-2

Ravenswood, 1.2-9

RBMK reactors, 2.3-1

reaction kinetics, 3.3-1

Reactor Cavity, 4.5-1

flooding, 5.1-6

reactor core-isolation cooling, 1.6-5-1.6-6

reactor pressure vessel

integrity, 1.3-1

rupture, $1.5-1$

reactor protection system (RPS), 2.4-1, 2.B-1

Reactor Safeguards Committee, 1.1-2, 1.1-3

Reactor Safety Study, 1.0-2, 1.5-1, 1.5-2 
reactor site criteria, $1.2-8$

reactor siting, 1.2-3

reactor trip system (RTS), 2.B-1

reactor vessel, 1.1-5

cavities, 1.3-2

depressurization, 3.7-5

failure, 1.3-2

irradiation surveillance, $1.3-1$

repressurization, 3.7-8

realism rule, 2.2-6

recirculation pump trip, 2.B-15

recriticality concerns, $3.7-10$

reflooding, 3.1-4

during stage $3,3.3-4$

during stage 4 at TMI-2, 3.4-3

Regulatory Guide 1.120, 1.3-9

Regulatory Guide 1.70, 1.4-1

regulatory guides, 1.3-6

regulatory staff, 1.2-2

release, $1.2-5,1.2-7$

releases of radioactive fission products, 1.4-4

remote siting, 1.1-3

respiratory protection, 5.3-8

Response Technical Manual (RTM)-96, 5.3-3

review, 1.2-4

revised LWR source term, 5.1-8

revised rule, 1.3-13

rights of state, 1.2-1

risk, $1.5-2$

Assessment Review Group, 1.5-3

risk-informed regulation, 2.6-1

Influences, 2.4-1

Rogovin Committee, 2.2-1

role

of licensee, 5.4-2

of state and local Agencies, 5.4-3

of the NRC, 5.4-3

roles in an emergency, 5.4-2

rule of thumb, 1.1-2, 1.2-2

rulemaking hearings, $1.3-12$

rules on radiation protection, 1.2-2

rupture of the reactor pressure vessel, 1.2-5

sabotage not treated in PRA, 1.A-8

safe shutdown earthquake, 1.5-1

safeguarding of fissionable materials, 1.2-2

Safety Analysis Report, 1.4-1 - 1.4-2, 1.5-1
Safety Goal Policy, 2.4-11

backfitting, 2.4-14

safety goals, 2.4-1, 2.6-2

safety

margins, 2.6-7

parameter display systems (SPDS), 2.2-4

strategies, 1.1-2

systems, 1.1-3, 1.1-4

Salem 1, 2.4-4, 2.B-6

San Onofre 1, 1.2-9, 1.2-9

Schlesinger, James R., 1.3-11, 1.3-13

Scott, R. L., 1.6-1

Seabrook, 2.2-5

Section 182(a) of the Act, 1.2-1

seiches, 1.3-8

seismic events, 1.A-5

severe accident, 1.0-2, 1.2-4, 1.5-1

perspectives, $2.0-1$

policy, 2.2-7

research, 2.2-6

stages, 3.1-1

sharing of structures, systems, and components, $1.3-10$

shell failure, 4.7-3

sheltering, 1.1-4

and relocation, 5.3-7

Shippingport, $1.1-3,1.1-3,1.2-3,1.3-4$

Shoreham, 2.2-5

single failure criteria, 1.4-2, 1.5-1

single failures, 1.3-5

site area emergency, 5.4-5

site criteria, 1.0-2, 1.2-3, 1.2-6

siting, 1.1-2

-basis accident, 1.2-7, 1.3-3, 1.4-2

guidelines, 1.2-9

regulation, 1.4-1

sneak circuits, 1.A-14

sodium, 1.1-3

source term, 5.1-2

characteristics, 5.1-2

monitoring, 5.1-10

uncertainty, 5.1-7

spontaneous ignition, 4.4-2

SRV operation, 3.7-9

stainless steel, 1.2-7

standard format and content of safety analysis

reports, 1.4-1 
standard review plan for the review of safety analysis reports, 1.4-1 standard review plan, 1.3-8

Standby Liquid Control System (SLCS),

2.B-16, 1.6-6

state and local organizations, 5.4-10

station blackout, 1.3-10, 2.5-24

station blackout rule, 2.4-6

statutory body, 1.2-4

steam

cooling, 3.7-6

explosion, 3.6-1, 4.5-2

stages of, 3.6-1

Strauss, Lewis L. , 1.2-3

subatmospheric containments, 4.1-1

submarine intermediate reactor, 1.1-2

subsidiary safety goal, 4.2-4

subtle failures, 1.A-14

suppression pools, 1.1-4, 1.2-8, 5.1-4

systematic assessment of licensee performance

(SALP), 2.2-2

Technical Information Document (TID) 14844,

1.2-7

Technical Support Center, 5.4-7

Tennessee Valley Authority (TVA), 1.6-1, 1.6-3

Three Mile Island (TMI), 1.0-1, 1.2-7, 1.5-4,

2.1-1

action plan, 2.2-4

implications, 2.2-1

molten pour, 3.5-1

tornadoes, 1.3-4, 1.3-8

torque switches, 1.3-10

transients importance to $\mathrm{CDF}, 2.5-24$

triggering, 3.6-1

tsunami, 1.3-8

two-step licensing, 1.2-2, 1.2-5

two-step procedure for granting licenses, 1.2-1

U.S. Court of Appeals, 1.2-5

U.S. Supreme Court, 1.2-5

U.S.S. Nautilus, 1.1-3

uncertainties, 2.6-4

in dose projections, 5.2-8

in risk estimates, 1.A-16

uncontained meltdown, 1.2-8

undue risk, $1.2-1,1.2-2,1.2-6$ unusual event, 5.4-5

vessel breach by an in-vessel steam explosion, 3.6-5

vessel failure, $4.5-1$

Vietnam war, 1.3-14

volatile fission products, $1.1-5$

vulnerability of BWRs, $2.5-13-2.5-14$

WASH-3, 1.1-2

WASH-740, 1.2-4-1.2-8, 1.3-2-1.3-3

WASH-1250, 1.5-1

WASH-1270, 2.4-2

WASH-1400, 1.5-2

Westinghouse, 1.1-3, 1.2-9, 1.3-3

worst case consequences, 1.2-5

Zion, 1.3-2, 1.3-7, 3.2-2

Zircaloy, 1.2-7, 3.3-3

zirconium oxidation energy, 3.3-3 


\begin{tabular}{|c|c|}
\hline $\begin{array}{l}\text { U.S. NUCLEAR REGULATORY COMMISSION } \\
\text { BIBLIOGRAPHIC DATA SHEET } \\
\text { (Soo instructions on the roverso) }\end{array}$ & $\begin{array}{l}\text { 1. REPORT NUMBER. } \\
\text { (Assigned by NRC, Add Vol., Supp., Rev.. } \\
\text { and Addendum Numbers, if any.) } \\
\text { NUREG/CR-6042, Rev. } 1 \\
\text { SAND93-0971 }\end{array}$ \\
\hline \multirow{4}{*}{$\begin{array}{l}\text { 2. TITLE AND SUBTITLE } \\
\text { Perspectives on Reactor Safety }\end{array}$} & \\
\hline & DATE REPORT PUBLISHED \\
\hline & $\begin{array}{ll}\text { November } & 1997 \\
\end{array}$ \\
\hline & $\begin{array}{r}\text { 4. FIN OR GRANT NUMBER } \\
\text { L1914 }\end{array}$ \\
\hline 5. AUTHOR(S) & 6. TYPE OF REPORT \\
\hline $\begin{array}{l}\text { F. E. Haskin/UNM } \\
\text { A. L. Camp/SNL }\end{array}$ & Technical \\
\hline S. A. Hodge/ORNL & 7. PERIOD COVERED (Inelusine Delas) \\
\hline \multicolumn{2}{|c|}{$\begin{array}{l}\text { 8. PERFORMING ORGANIZATION - NAME AND ADDRESS HF NRC, provide Division, Ofico or Rogion, U.S. Nuclear Regulatory Commission, and mailing addross; if contractor, } \\
\text { provide name and mailing addross.) }\end{array}$} \\
\hline 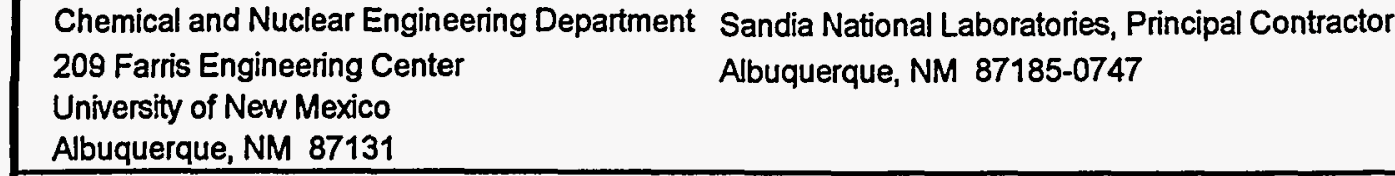 & $\begin{array}{l}\text { Engineering Technology Division } \\
\text { Oak Ridge National Laboratory } \\
\text { Oak Ridge, TN } 37831-8057\end{array}$ \\
\hline \multicolumn{2}{|l|}{$\begin{array}{l}\text { 9. SPONSORING ORGANIZATION - NAME AND ADDRESS (f NRC, type "Same as above"; ff contractor, provide NRC Division, Office or } \\
\text { and melling oddross.) } \\
\text { Technical Training Division } \\
\text { Office for Analysis and Evaluation of Operational Data } \\
\text { U.S. Nuclear Regulatory Commission } \\
\text { Washington, DC 20555-0001 }\end{array}$} \\
\hline \multicolumn{2}{|l|}{ 10. SUPPLEMENTARY NOTES } \\
\hline \multirow{2}{*}{\multicolumn{2}{|c|}{$\begin{array}{l}\text { The U.S. Nuclear Regulatory Commission (NRC) maintains a technical training center at Chattanooga, Tennessee to provide } \\
\text { appropriate training to both new and experienced NRC employees. This document describes a one-week course in reactor safety } \\
\text { concepts. The course consists of five modules: (1) the development of safety concepts; (2) severe accident perspectives; } \\
\text { (3) accident progression in the reactor vessel; (4) containment characteristics and design bases; and (5) source terms and offsite } \\
\text { consequences. The course text is accompanied by slides and videos during the actual presentation of the course. }\end{array}$}} \\
\hline & \\
\hline \multirow[t]{6}{*}{$\begin{array}{l}\text { 12. KEY WORDSIDESCRIPTORS (List words or phrases that will assist researchers in loceting the report.) } \\
\text { reactor safety, Technical Training Center }\end{array}$} & $\begin{array}{c}\text { 13. AVAILABILTY STATEMENT } \\
\text { unlimited }\end{array}$ \\
\hline & 14. SECURTTY CLASSIFICATION \\
\hline & $\begin{array}{l}\text { This Poge) } \\
\text { unclassified }\end{array}$ \\
\hline & $\begin{array}{l}\text { (This Report) } \\
\text { unclassified }\end{array}$ \\
\hline & 15. NUMBER OF PAGES \\
\hline & 16. PRICE \\
\hline
\end{tabular}

